\title{
Wilson-Leonard An 11,000-year Archeological Record of Hunter- Gatherers in Central Texas Volume III: Artifacts and Special Artifact Studies
}

Michael B. Collins

Texas Archeological Research Laboratory

Curt W. Beck

Texas Archeological Research Laboratory

Jonathan Bingham

Texas Archeological Research Laboratory

Boyce N. Driskell

Texas Archeological Research Laboratory

Pamela Headrick

Texas Archeological Research Laboratory

See next page for additional authors

Follow this and additional works at: https://scholarworks.sfasu.edu/ita

Part of the American Material Culture Commons, Archaeological Anthropology Commons, Environmental Studies Commons, Other American Studies Commons, Other Arts and Humanities Commons, Other History of Art, Architecture, and Archaeology Commons, and the United States History Commons

Tell us how this article helped you.

This Article is brought to you for free and open access by the Center for Regional Heritage Research at SFA ScholarWorks. It has been accepted for inclusion in Index of Texas Archaeology: Open Access Gray Literature from the Lone Star State by an authorized editor of SFA ScholarWorks. For more information, please contact cdsscholarworks@sfasu.edu. 


\section{Wilson-Leonard An 11,000-year Archeological Record of Hunter-Gatherers in Central Texas Volume III: Artifacts and Special Artifact Studies}

\section{Authors}

Michael B. Collins, Curt W. Beck, Jonathan Bingham, Boyce N. Driskell, Pamela Headrick, Dale B. Hudler, W. Jeffrey Hurst, Marvin Kay, Marilyn A. Masson, Sean R. Nash, Leslie C. Shaw, Edith C. Stout, and Lauren

A. Sullivan

\section{Creative Commons License}

\section{(c) (1) $\Theta(\Theta$}

This work is licensed under a Creative Commons Attribution-NonCommercial-No Derivative Works 4.0 International License. 


\title{
WILSON-LEONARD
}

\section{An 11,000-year Archeological Record of Hunter-Gatherers in Central Texas}

\section{Volume III: Artifacts and Special Artifact Studies}

\author{
Assembled and Edited by Michael B. Collins
}

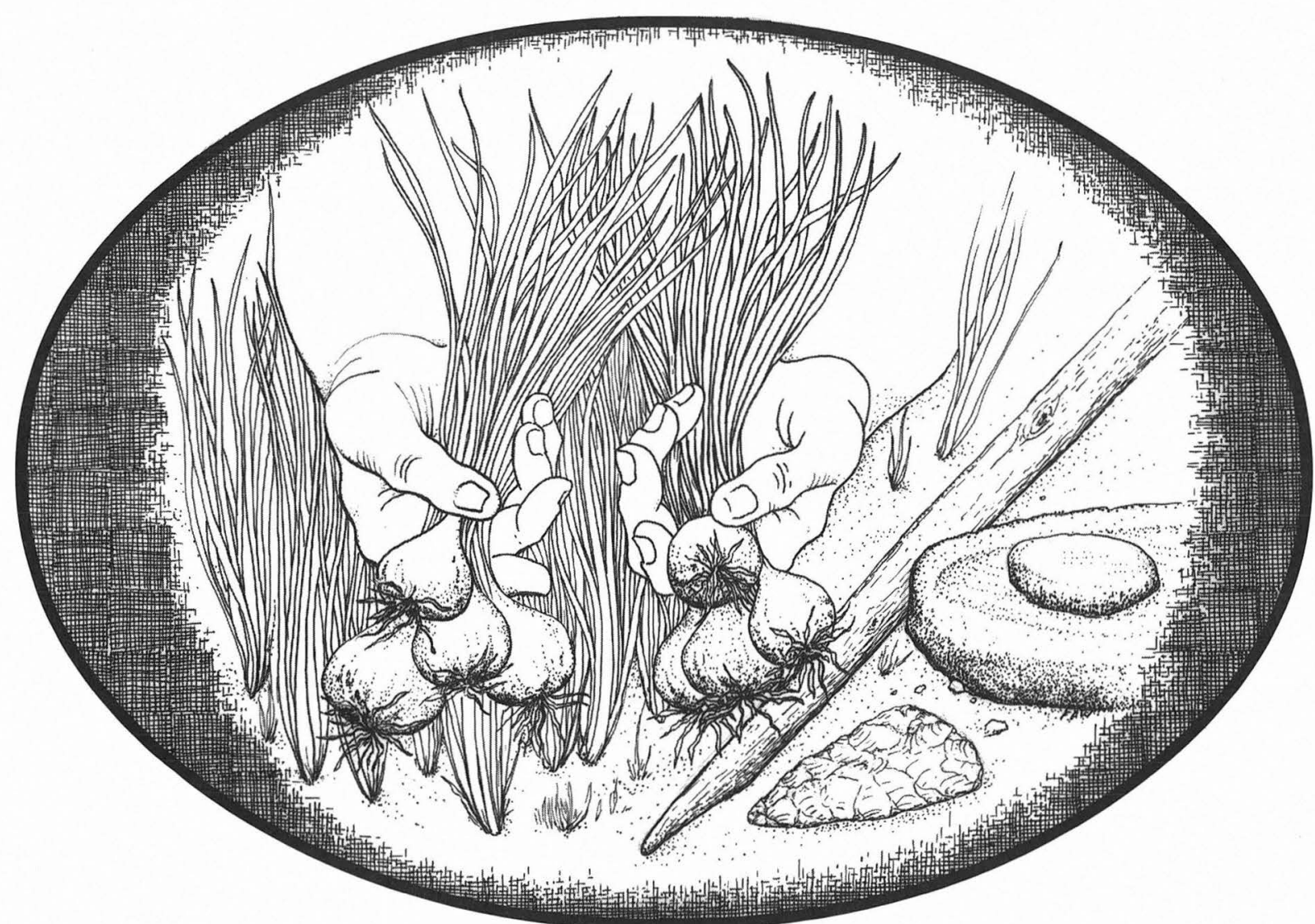

Studies in Archeology 31

Texas Archeological Research Laboratory

The University of Texas at Austin
Archeology Studies Program, Report 10

Texas Department of Transportation Environmental Affairs Division 


\title{
WILSON-LEONARD
}

\section{An 11,000-year Archeological Record of Hunter-Gatherers in Central Texas}

\section{Volume III: Artifacts and Special Artifact Studies}

\author{
assembled and edited by \\ Michael B. Collins \\ with contributions by \\ Curt W. Beck \\ Jonathan Bingham \\ Michael B. Collins \\ Boyce N. Driskell \\ Pamela Headrick \\ Dale B. Hudler \\ W. Jeffrey Hurst \\ Marvin Kay \\ Marilyn A. Masson \\ Sean R. Nash \\ Leslie C. Shaw \\ Edith C. Stout \\ Lauren A. Sullivan
}

Principal Investigator: Nancy Kenmotsu Frank Weir(1982-1988)

Texas Antiquities Committee Permit No. 300

Studies in Archeology 31

Texas Archeological Research Laboratory

The University of Texas at Austin

Archeology Studies Program, Report 10

Texas Department of Transportation

Environmental Affairs Division 
Cover drawing by Frank Weir

The University of Texas at Austin Texas Archeological Research Laboratory J. J. Pickle Research Campus 5

Austin, Texas 78712-1100

Printed 1998, on acid-free, 60-pound paper

ISBN 1-887072-27-6(Volume III)

ISBN 1-887072-24-1 (5-Volume Set) 


\section{TABLE OF CONTENTS \\ Volume III}

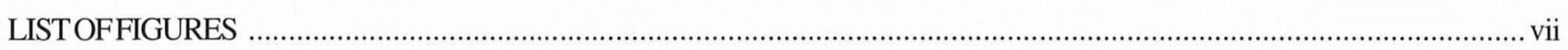

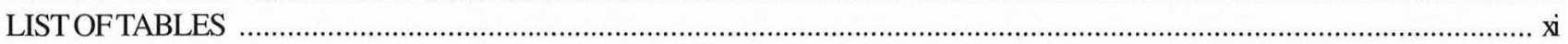

\section{CHAPTER 19: ANALYSIS OFDEBITAGE}

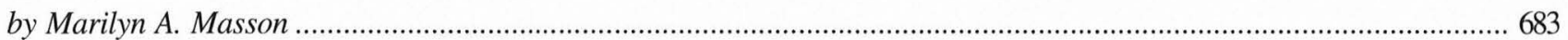

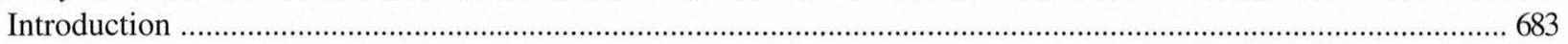

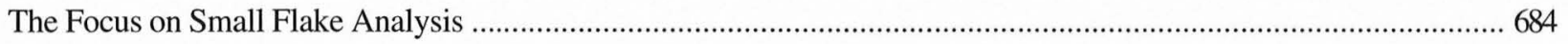

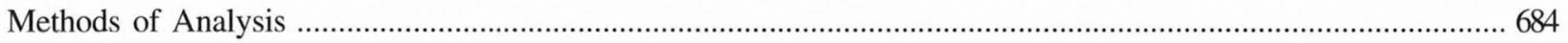

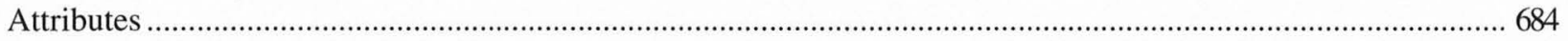

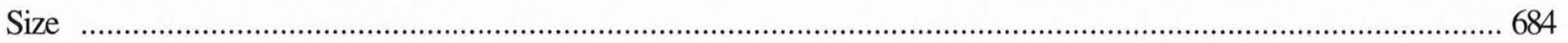

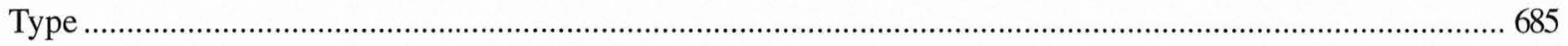

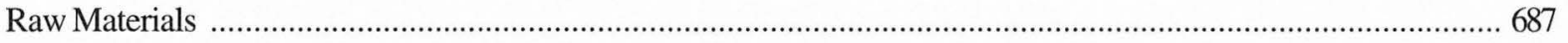

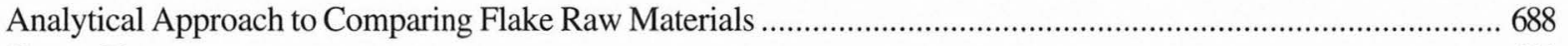

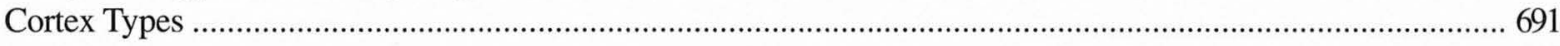

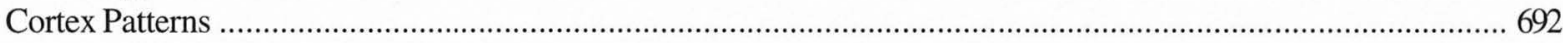

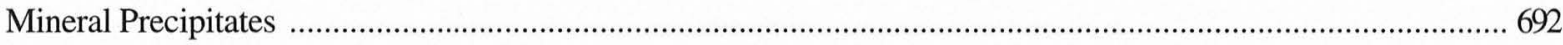

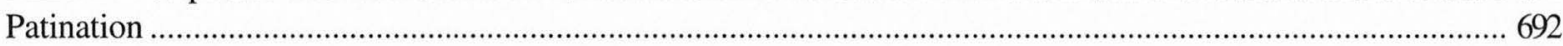

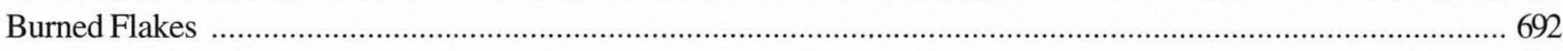

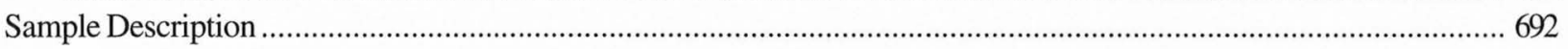

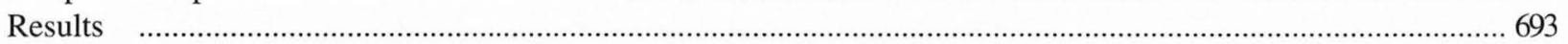

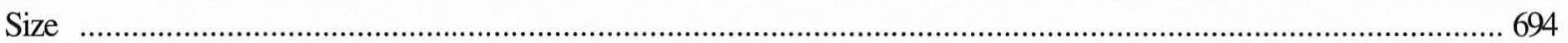

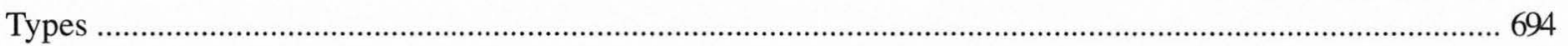

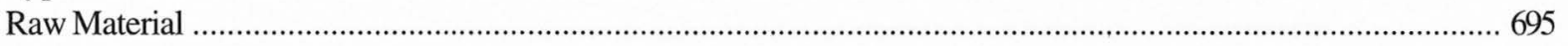

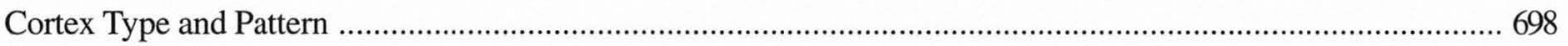

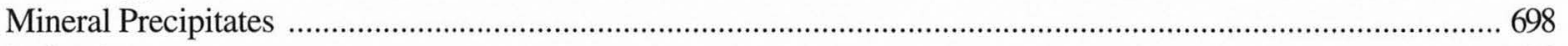

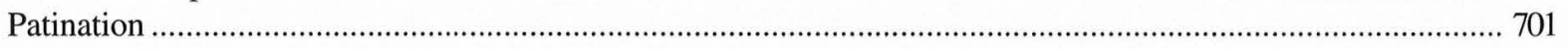

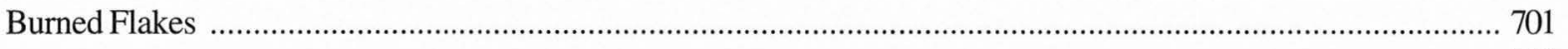

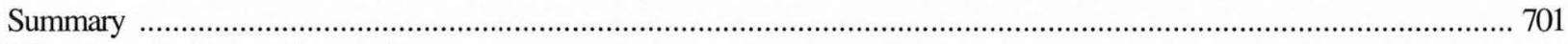

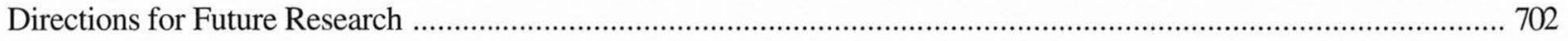

\section{CHAPTER 20: GROUND ANDOTHER NONCHIPPEDSTONE ARTIFACTS}

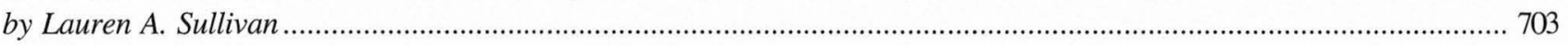

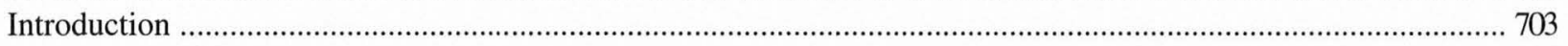

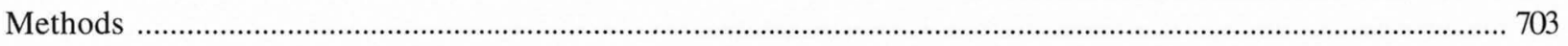

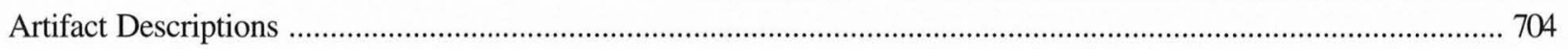

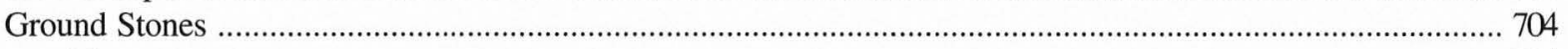

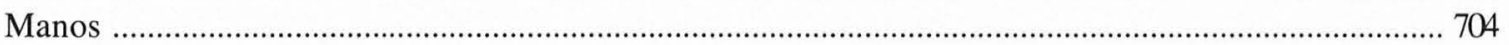

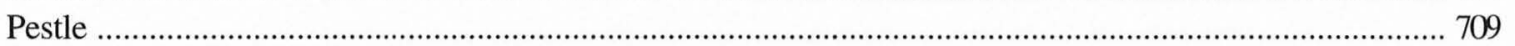

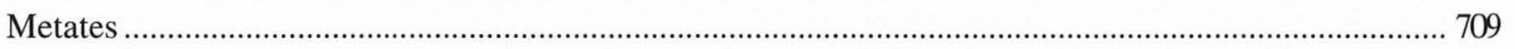

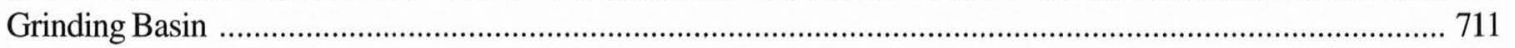

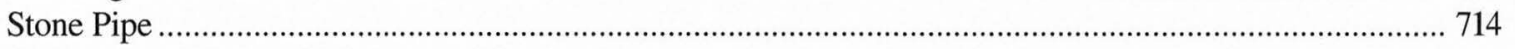

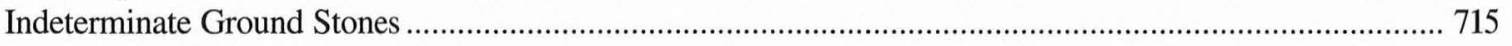

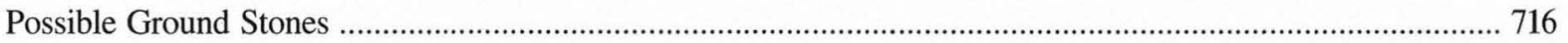

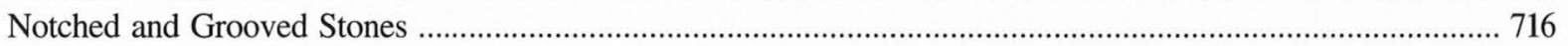

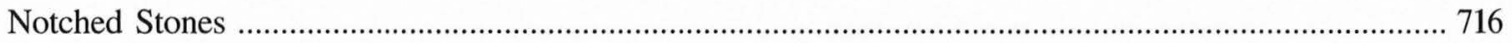

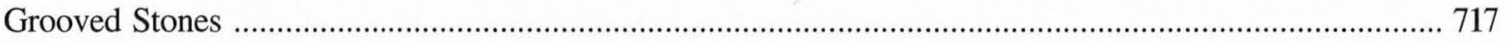

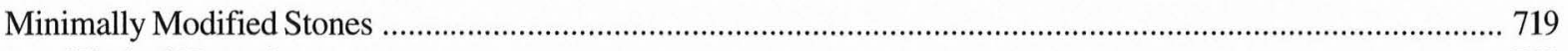

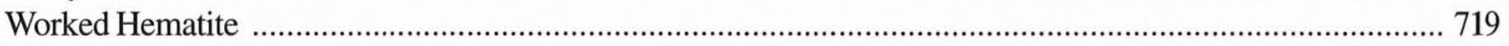

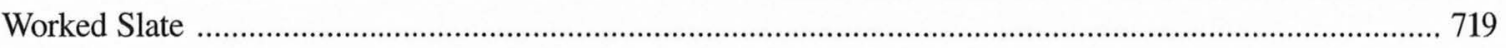

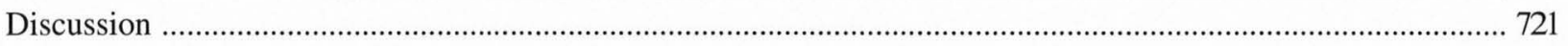


CHAPTER 21: MODIFIED BONEAND SHELL

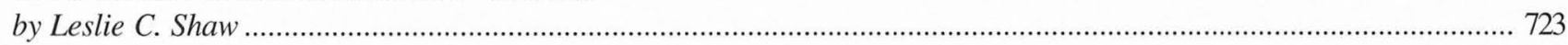

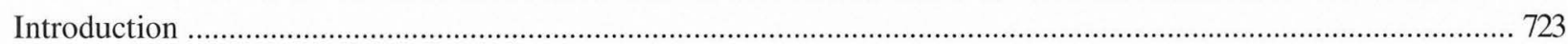

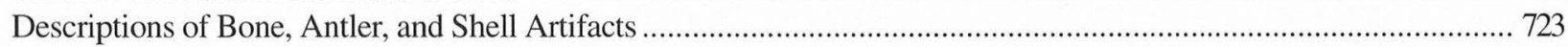

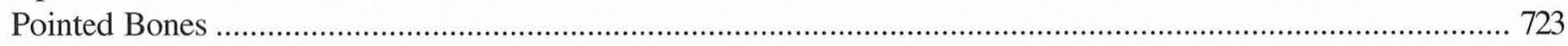

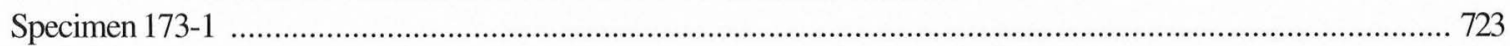

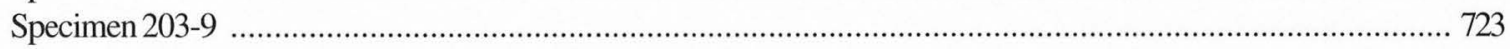

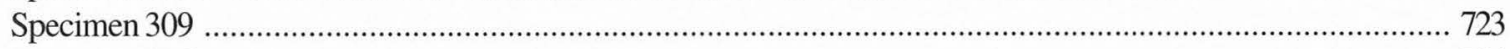

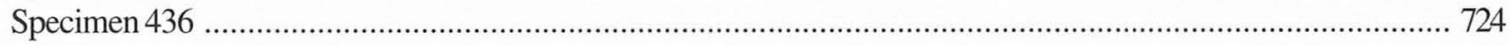

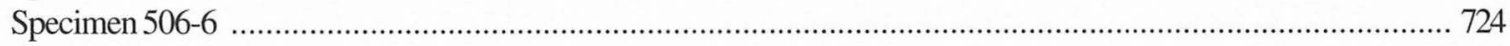

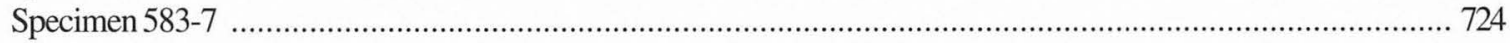

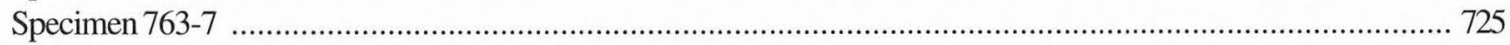

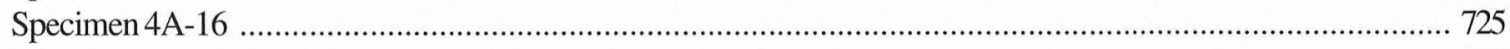

Specimen 5B-10 ……

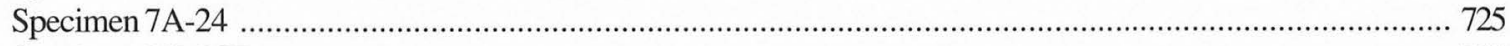

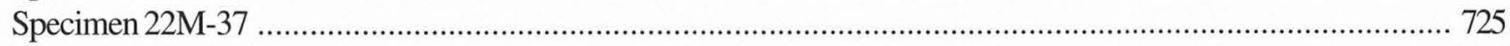

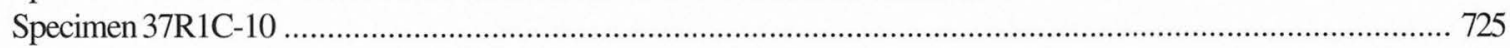

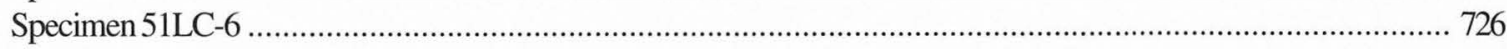

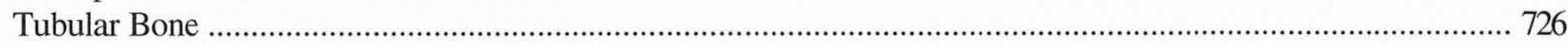

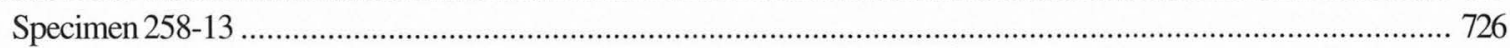

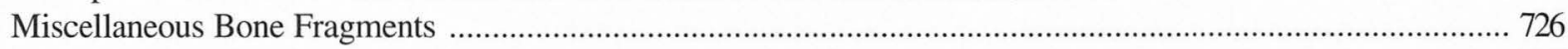

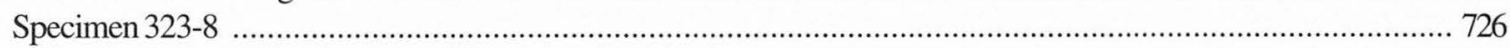

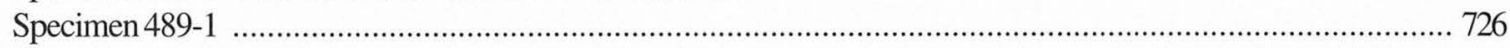

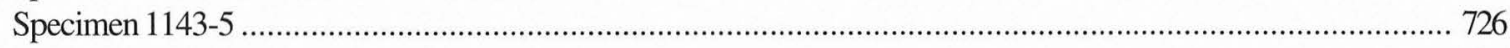

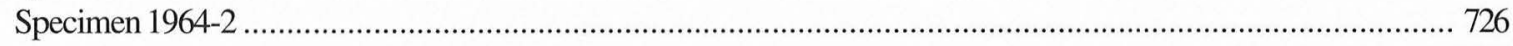

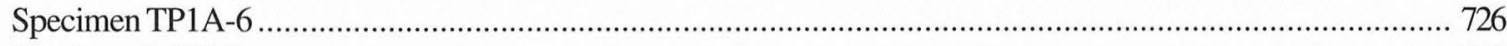

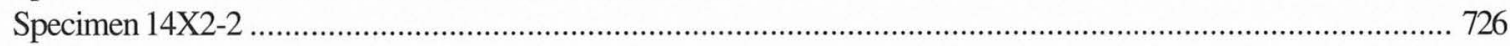

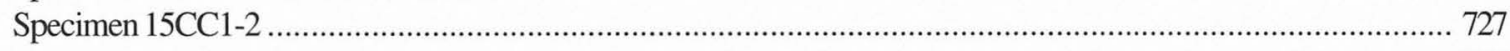

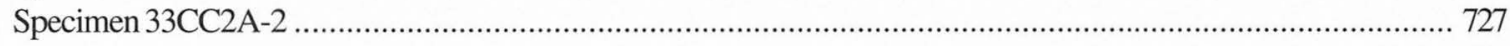

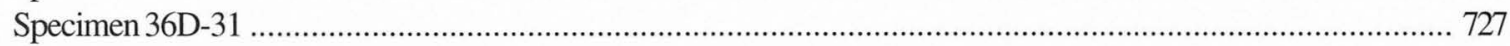

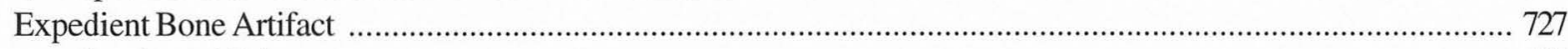

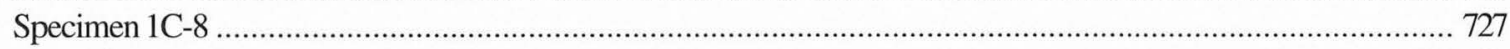

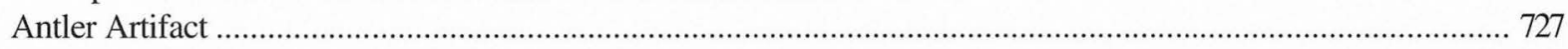

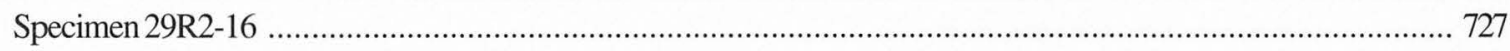

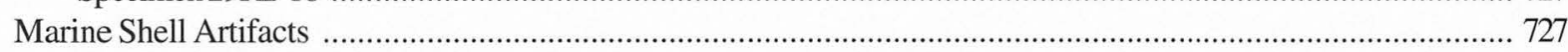

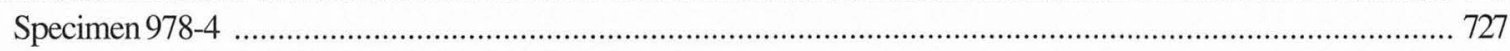

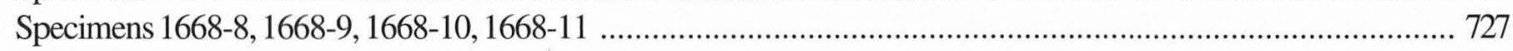

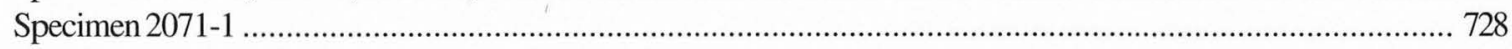

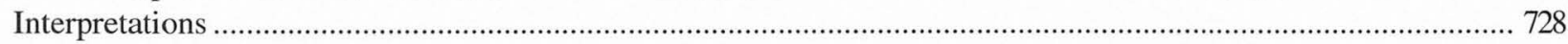

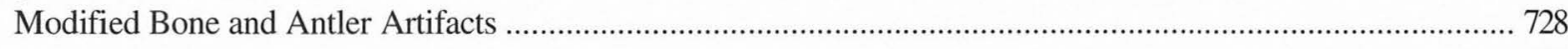

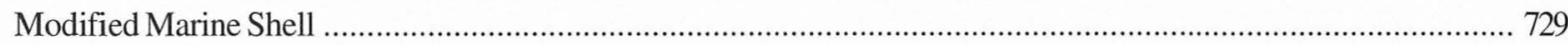

CHAPTER 22: MICROWEAR ANALYSIS OF CHIPPED STONE ARTIFACTS

by Marvin Kay, Dale B. Hudler, Boyce N. Driskell, and Michael B. Collins ........................................................... 731

Introduction

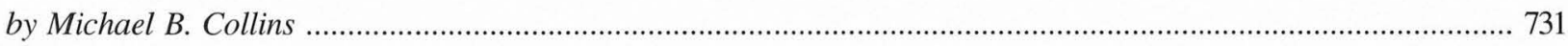

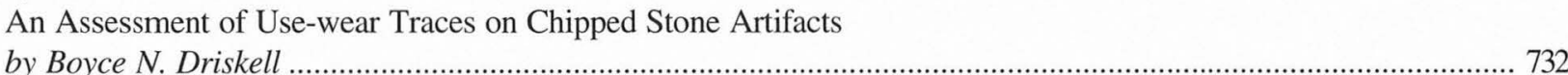

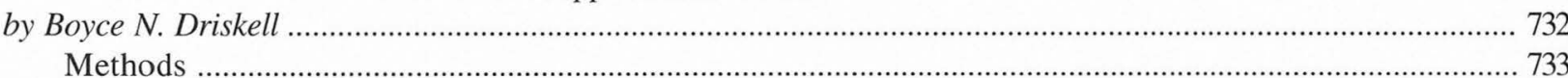

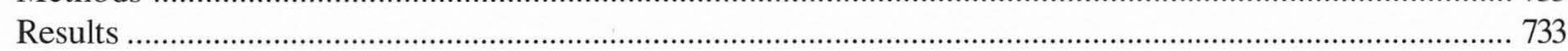

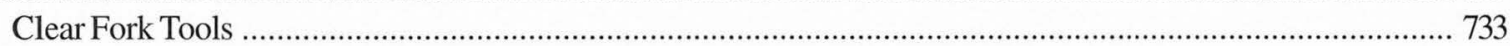

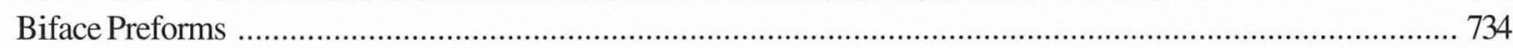

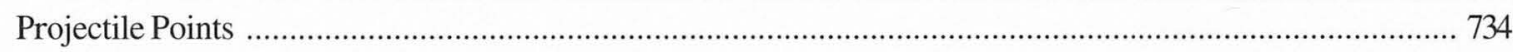

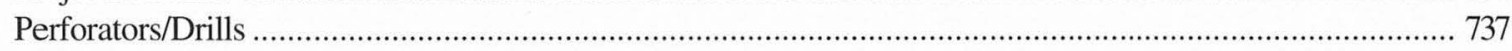

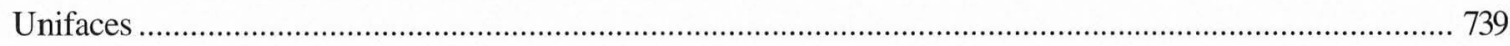




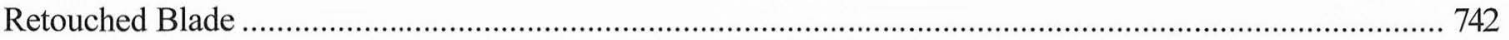

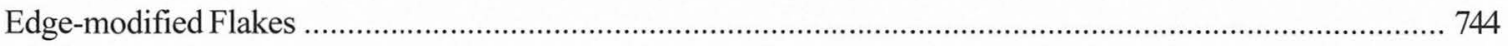

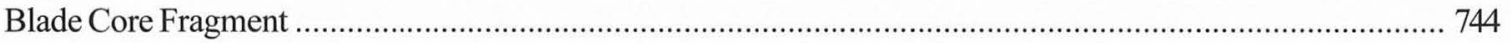

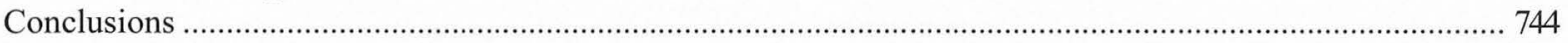

Scratchin' the Surface: Stone Artifact Microwear Evaluation

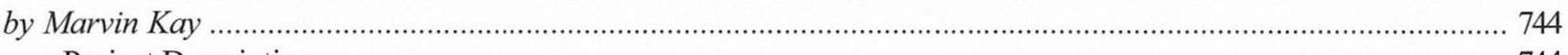

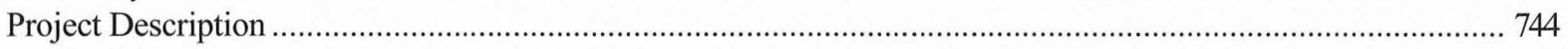

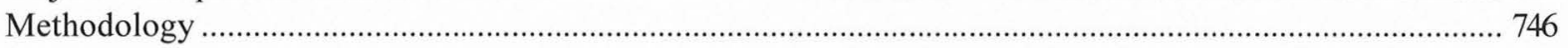

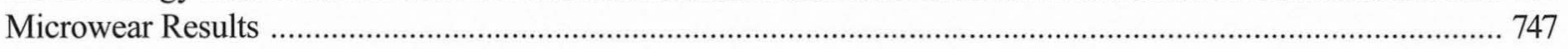

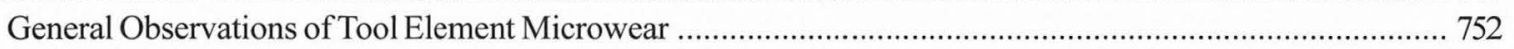

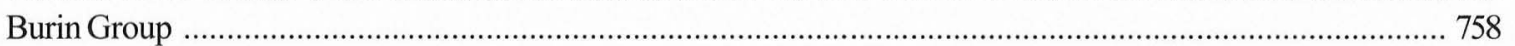

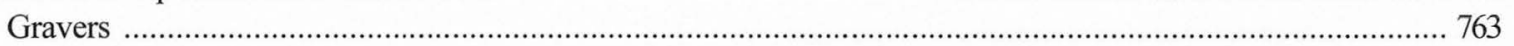

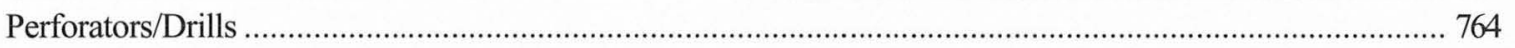

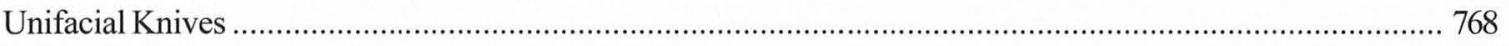

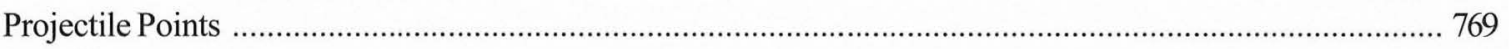

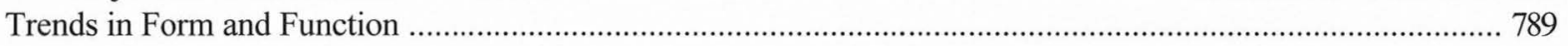

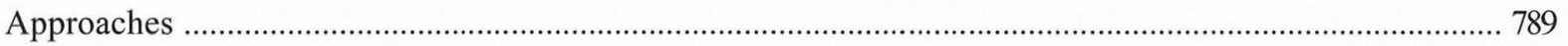

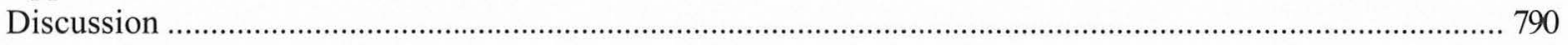

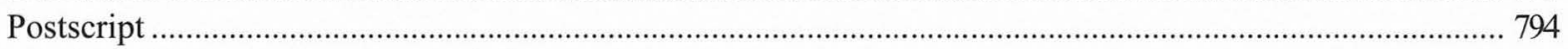

Clear Fork Tool Function: An Approach Centered on Use-Wear

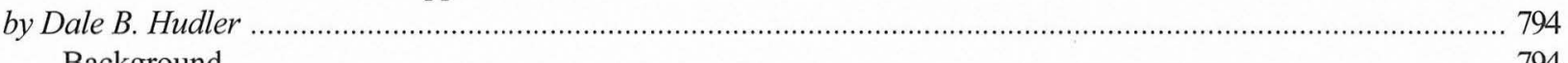

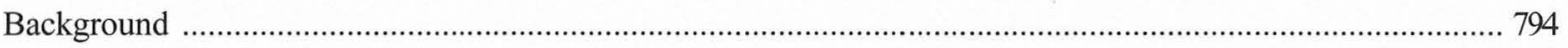

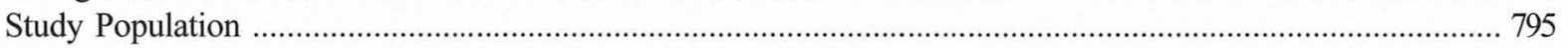

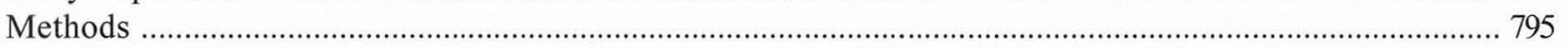

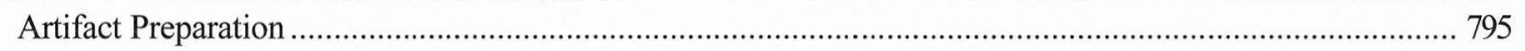

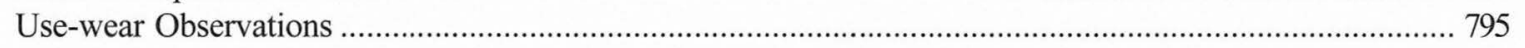

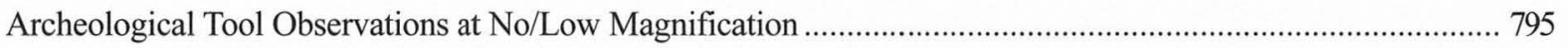

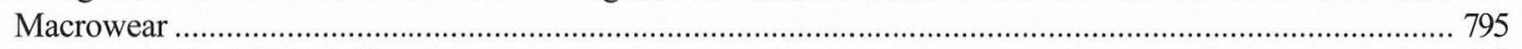

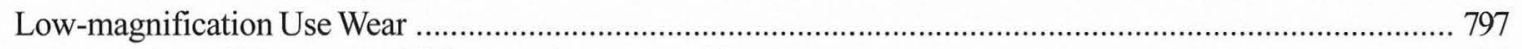

Interpretation of Use-wear Visible at No/Low Magnification ................................................................ 798

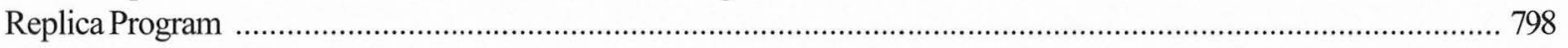

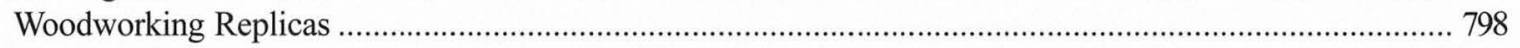

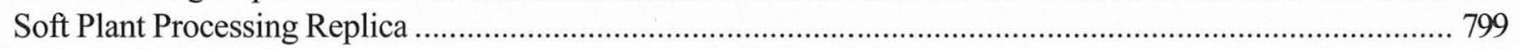

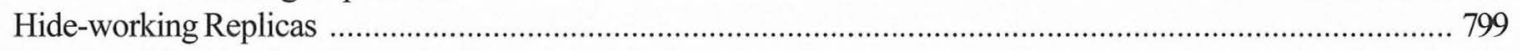

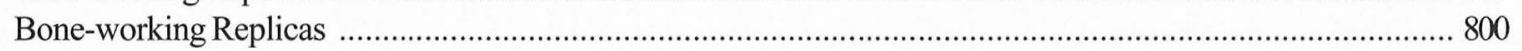

Summary of Replica Use-wear Analysis ............................................................................................. 800

Archeological Tool Use-wear Observations at High Magnification .............................................................. 801

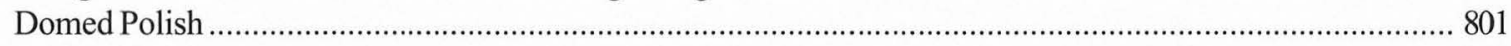

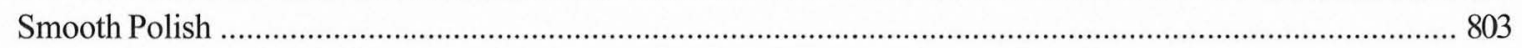

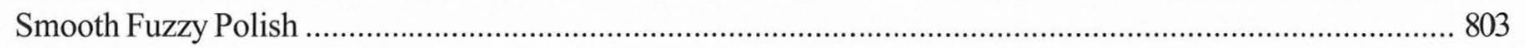

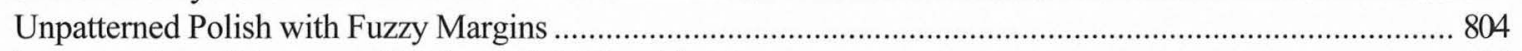

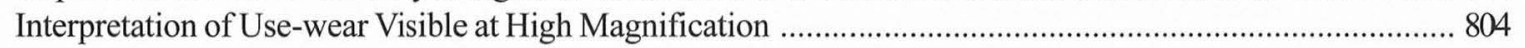

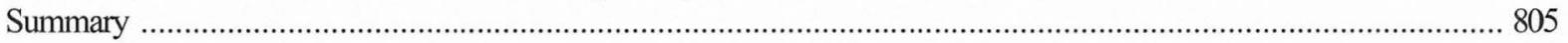

\section{CHAPTER 23: ANALYSES OF RESIDUES ONARTIFACTS}

by W. Jeffrey Hurst, Curt W. Beck, Edith C. Stout, Jonathan Bingham, and Michael B. Collins ................................. 807

Introduction

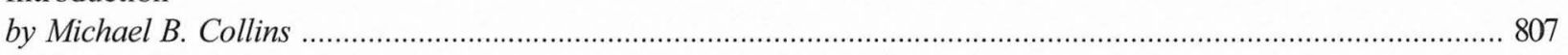

Analysis of Organic Residues by Gas Chromatography-Mass Spectrometry

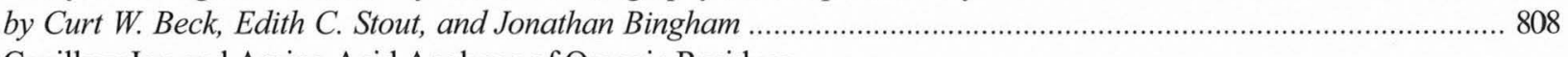

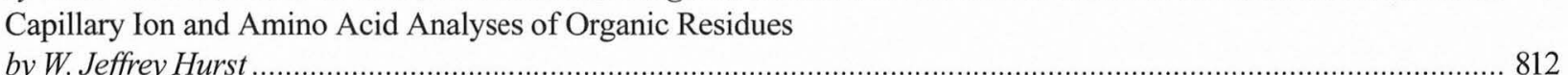

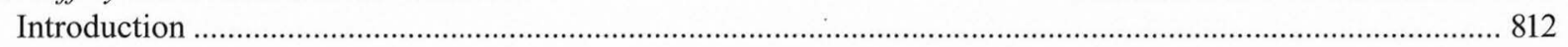

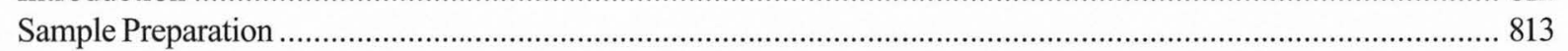

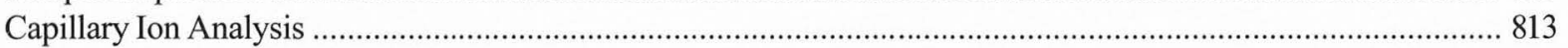

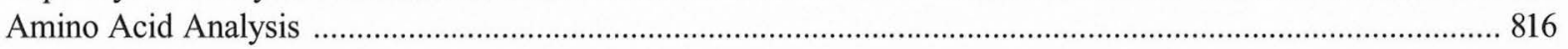




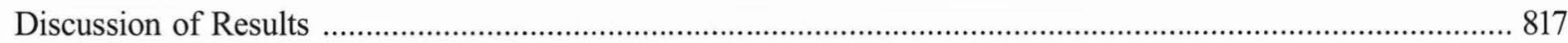

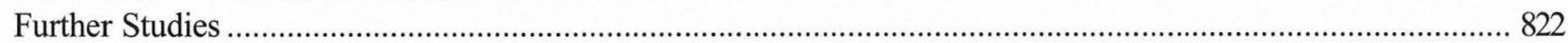

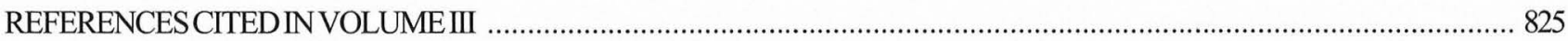

APPENDIX 1: UNMODIFIED NONLOCALRAWMATERIALS

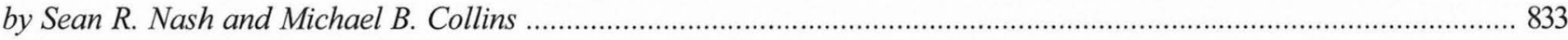

APPENDIX2: BURNEDCLAY

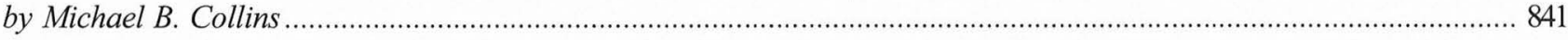

APPENDIX 3: HISTORICARTIFACTS

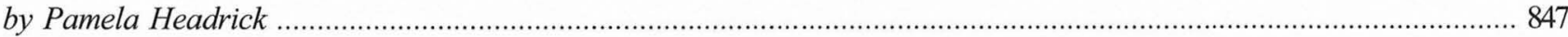

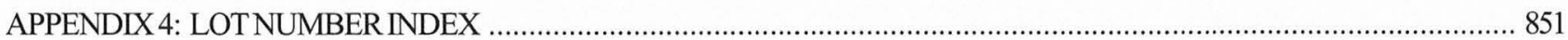

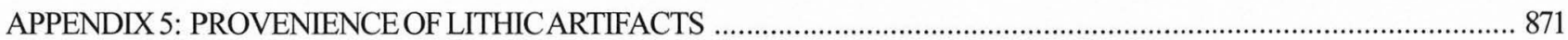




\section{LIST OF FIGURES}

Volume III

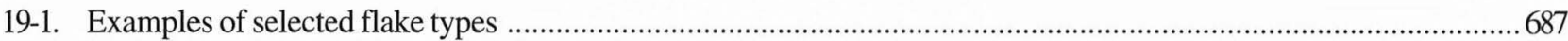

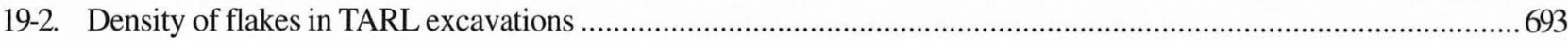

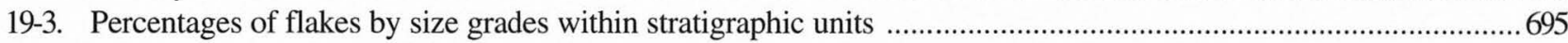

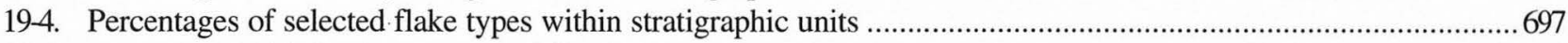

19-5. Percentages of flakes by raw materials within stratigraphic units ................................................................... 700

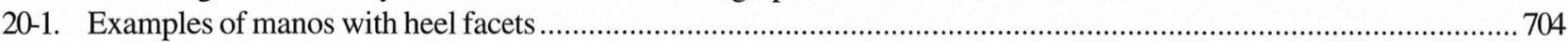

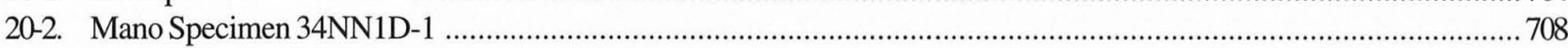

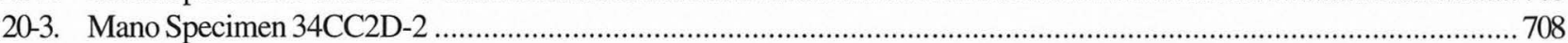

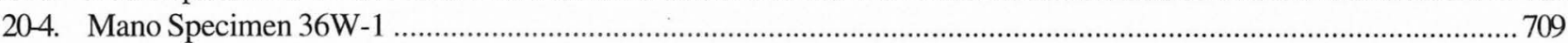

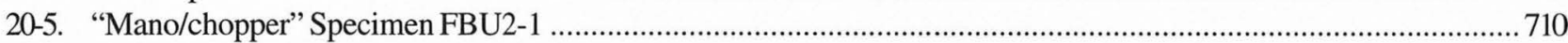

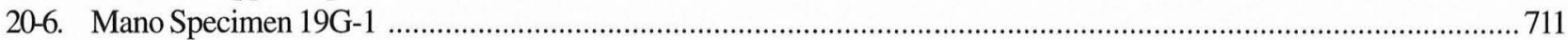

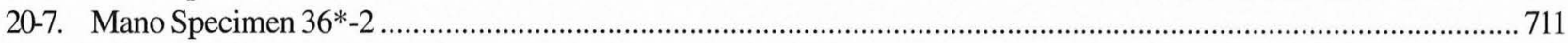

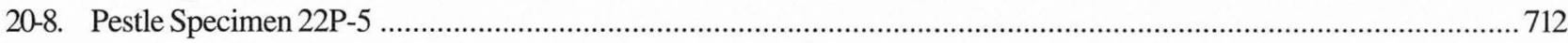

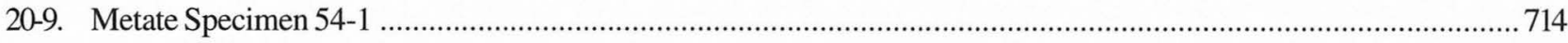

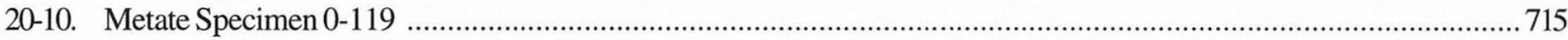

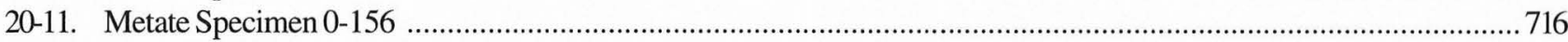

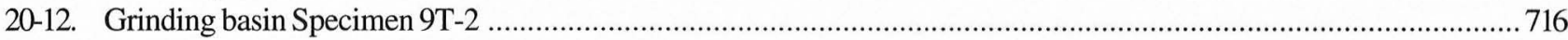

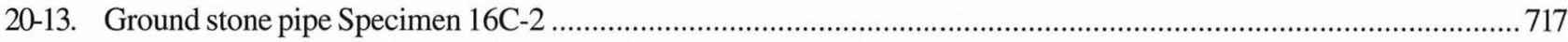

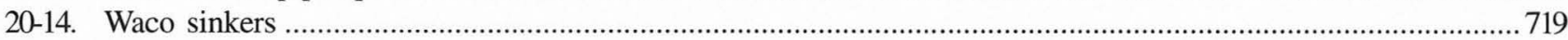

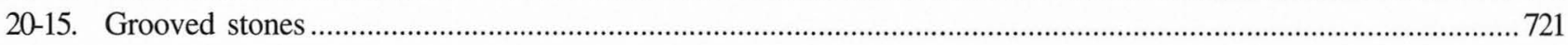

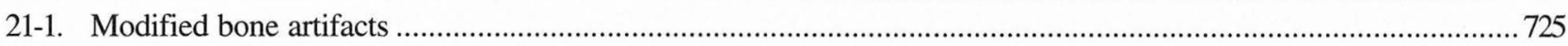

21-2. Tubular bone artifact fragments with incised crosshatched design .................................................................727

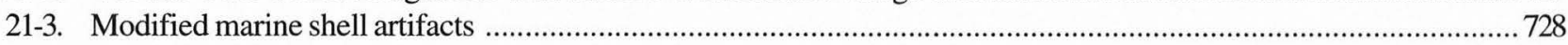

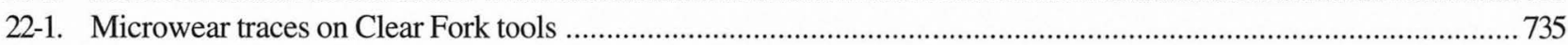

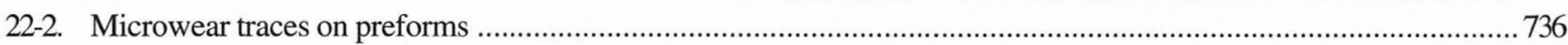

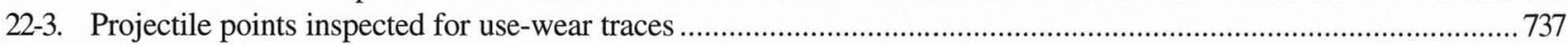

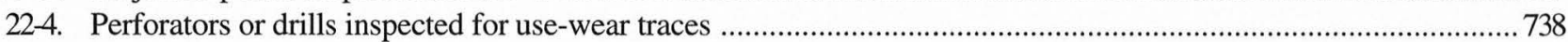

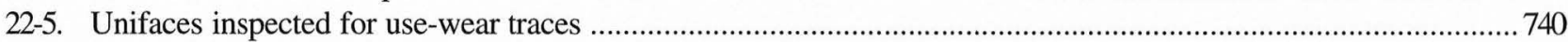

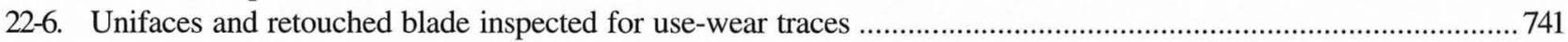

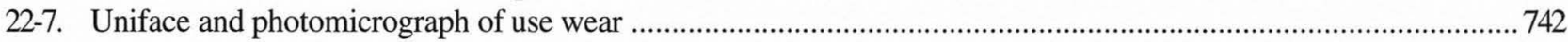

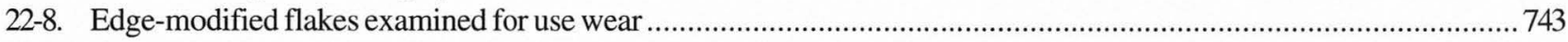

22-9. Graph showing average weight of unused artifacts (NT) and

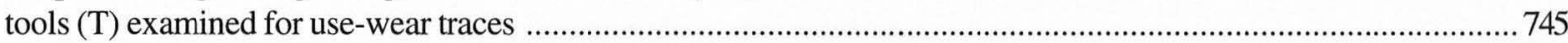

22-10. Postdepositional or other taphonomic wear traces on Wilson-Leonard artifacts ..................................................748

22-11. Intermediate developed abrasive microwear on dihedral angle burin ..............................................................756

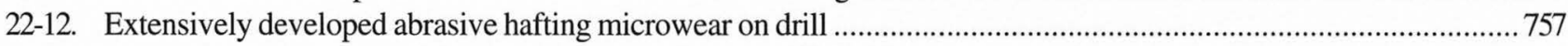

22-13. Invasive arris rounding and striae dur to abrasion on unifacial backed knife ................................................... 757

22-14. Depositional or additive polish on St. Mary's Hall point recycled as knife ...................................................... 758

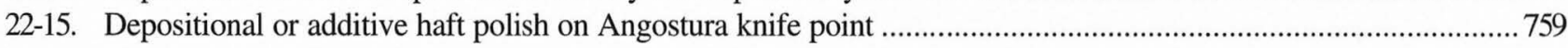

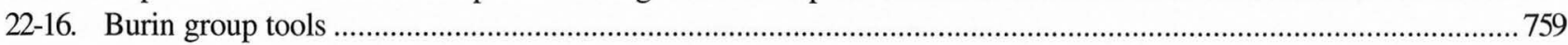

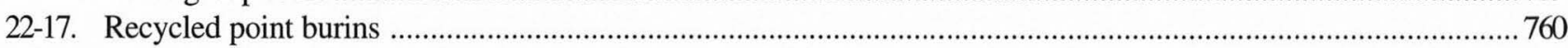

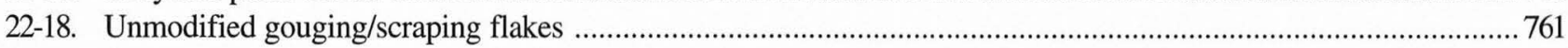

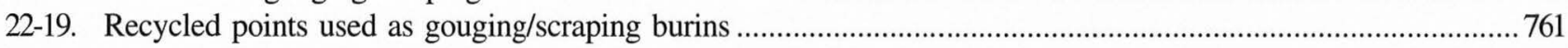

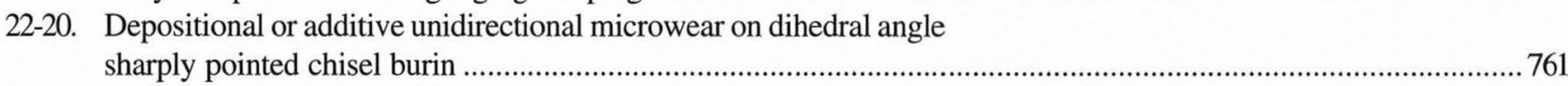

22-21. Ordered sequence of additive microwear on dihedral angle sharply pointed chisel burin .................................. 762

22-22. Additive rotary microwear on recycled Golondrina-Barber point as dihedral angle burin ..................................... 762

22-23. Microwear on flake tool gouging/scraping burin and blunt point burin ...........................................................763

22-24. Additive microwear showing a two-motion rocking stroke on radially fractured biface blunt

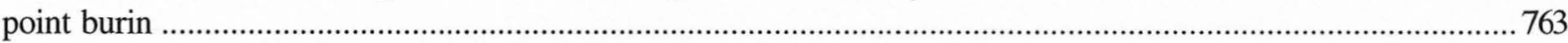

22-25. Additive microwear on gouging/scraping dihedral angle burin ........................................................................763

22-26. Additive microwear on gouging/scraping burin fashioned from broken parallel-sided lanceolate 
22-27. Additive microwear on gouging/scraping burin fashioned from

a broken Golondrina-Barber point

22-28. Additive microwear on gouging/scraping burin fashioned from obtusely

angled broken edge.

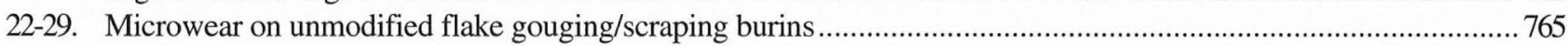

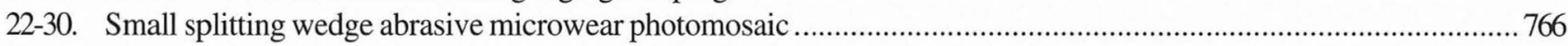

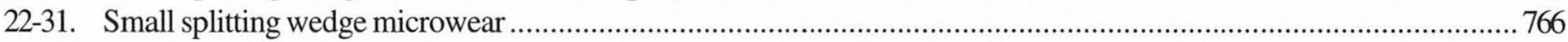

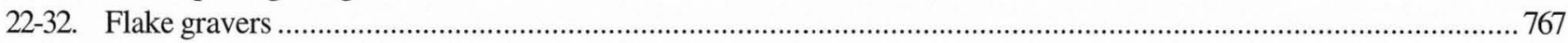

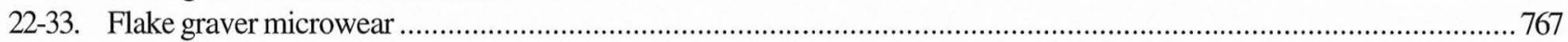

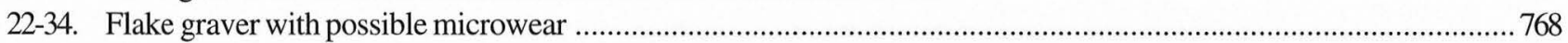

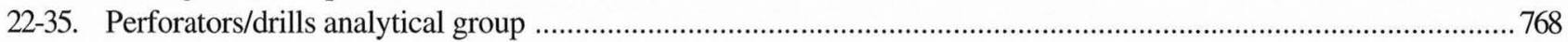

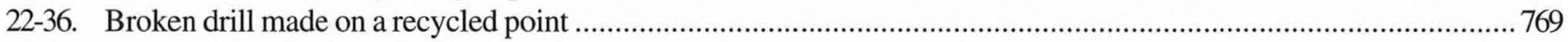

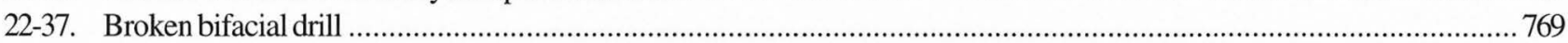

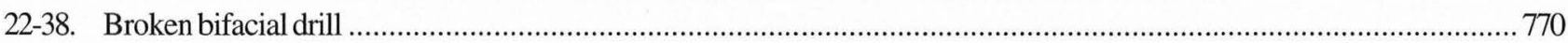

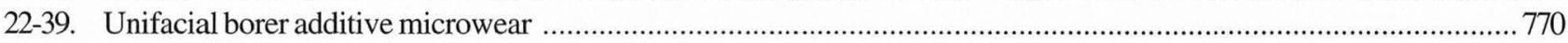

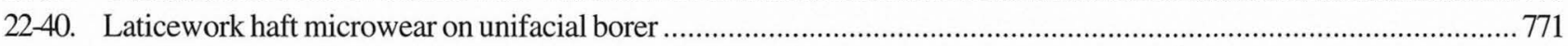

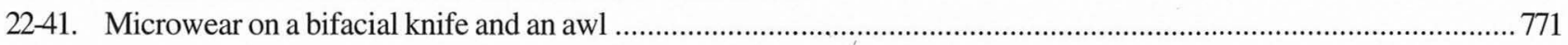

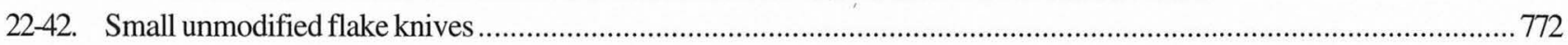

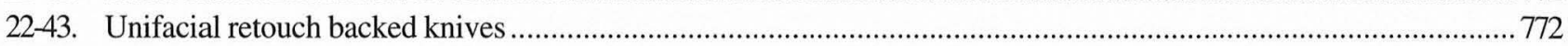

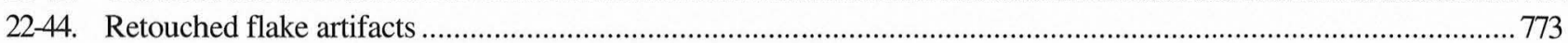

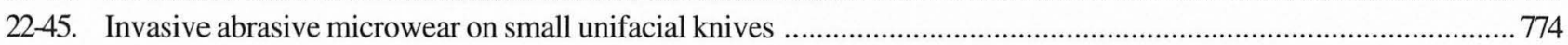

22-46. Abrasive microwear on retouched edge of backed unifacial knife ..........................................................................774

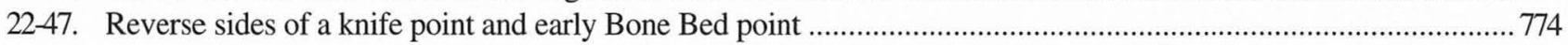

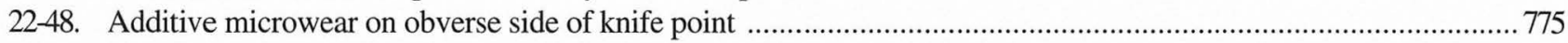

22-49. Additive microwear on obverse side of early Bone Bed point .......................................................................776

22-50. Discarded Wilson and Wilson-like projectile points recycled as knives ................................................................ 777

22-51. Wilson additive microwear showing sequential use as projectile point then knife ...............................................777

22-52. Recycled and probably discarded Wilson points ....................................................................................... 778

22-53. Wilson additive microwear showing sequential use as a knife then as a

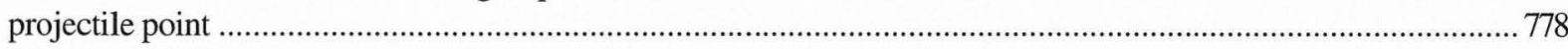

22-54. Complex additive microwear on haft element for extensively resharpened

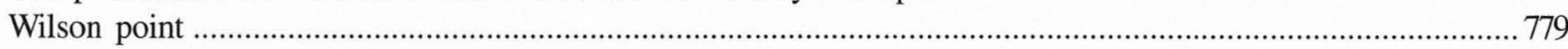

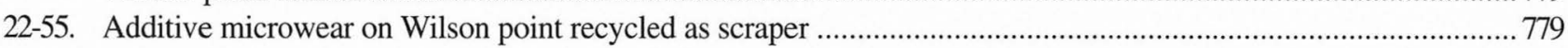

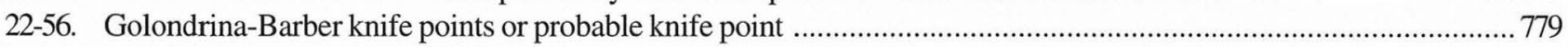

22-57. Golondrina-Barber additive microwear showing sequence of knife then

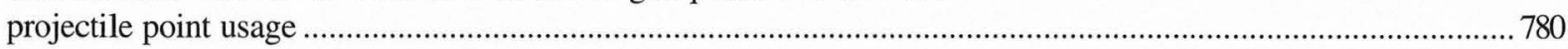

22-58. Golondrina-Barber additive microwear for which projectile point-knife sequence could not be established .............780

22-59. Parallel-sided lanceolate knives and St. Mary's Hall projectile points ................................................................. 781

22-60. Parallel-sided lanceolate knife with additive microwear and repair after breakage ............................................... 781

22-61. St. Mary's Hall haft microwear showing secondary effects of sequential use ........................................................ 782

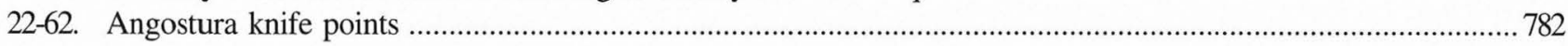

22-63. Angostura knife point invasive additive use-wear ..................................................................................... 783

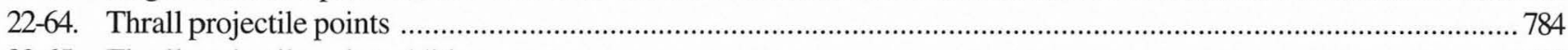

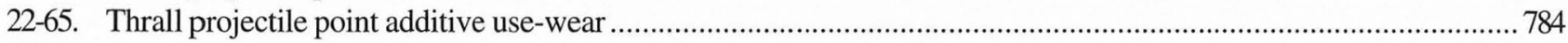

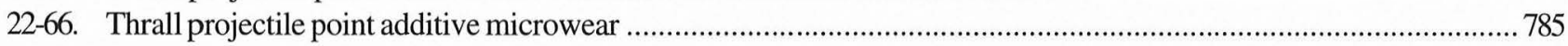

22-67. Thrall projectile point additive microwear showing haft striae

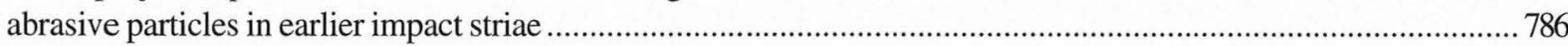

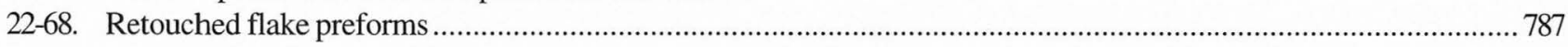

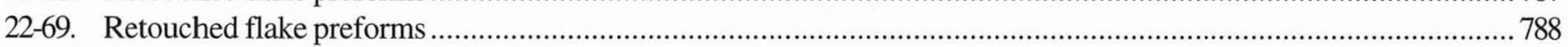

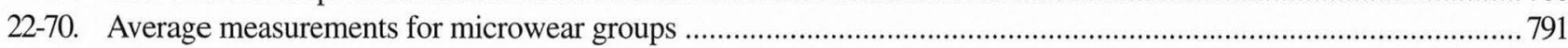

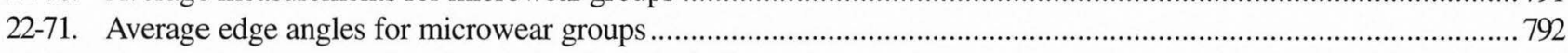

22-72. Trends in average blade edge angles for Paleoindian points ......................................................................... 793

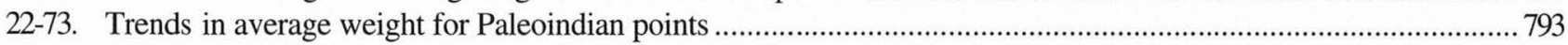

22-74. Trends in average proportional ratios for Paleoindian projectile points ............................................................... 793

22-75. Trends in average proportional ratios for Paleoindian knife points ...................................................................... 793 


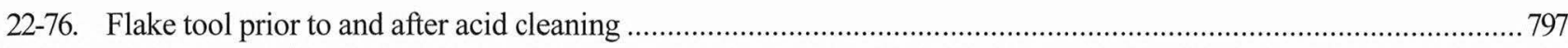

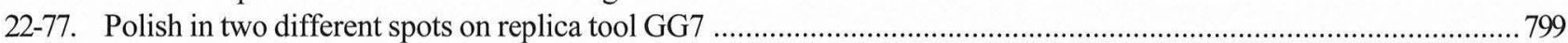

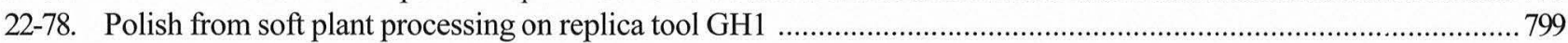

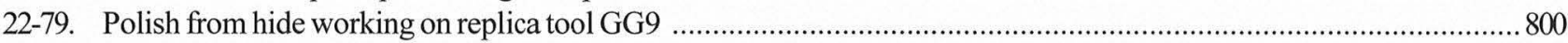

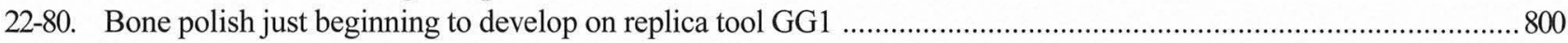

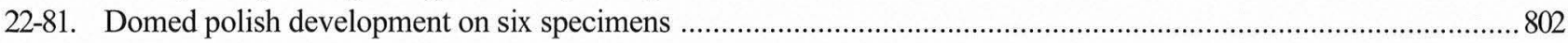

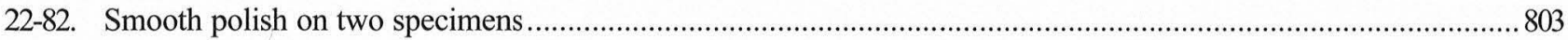

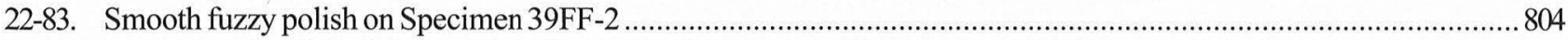

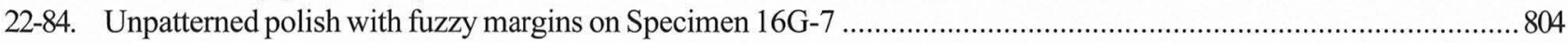

23-1. Total ion chromatograms, Specimens OR379, OR388, OR741, and OR396 …............................................. 809

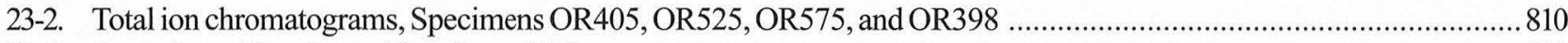

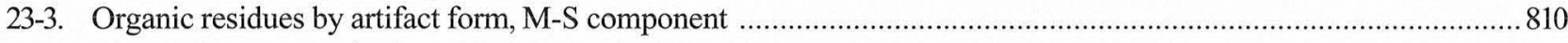

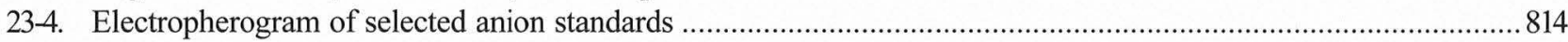

23-5. Electropherogram of artifact Specimens OR41, OR372, OR540, and 9T-2 ……............................................... 814

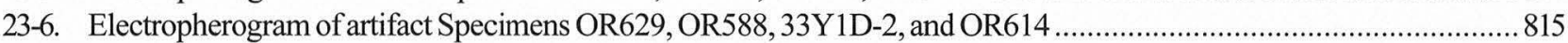

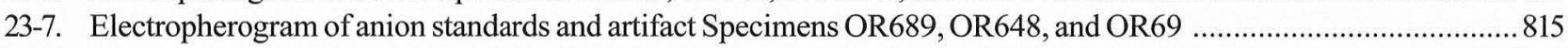

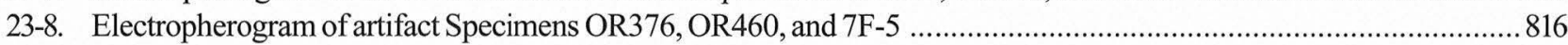

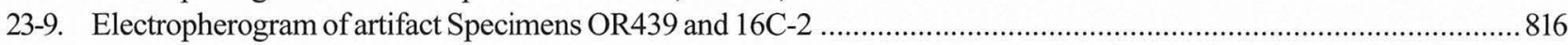

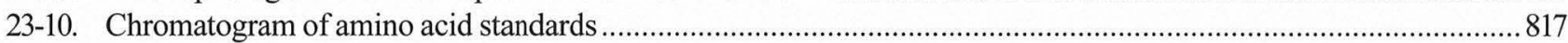

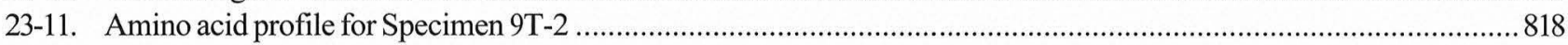

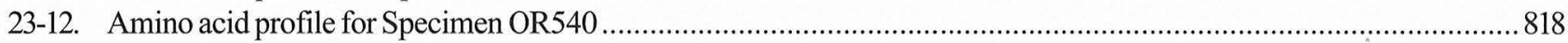

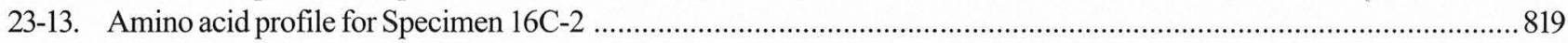

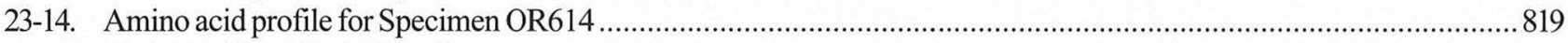

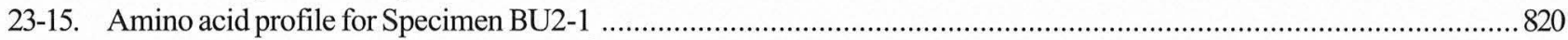

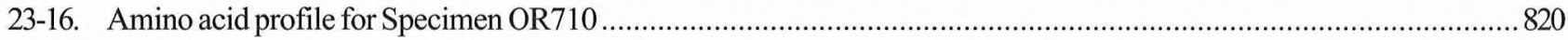




\section{LIST OFTABLES \\ Volume III}

19-1. Flake types and their principal attributes

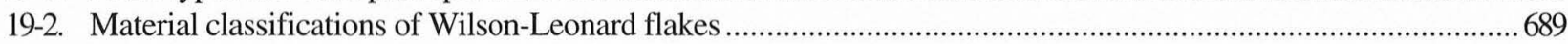

19-3. Percentages of flakes by screen size for each stratigraphic unit .................................................................694

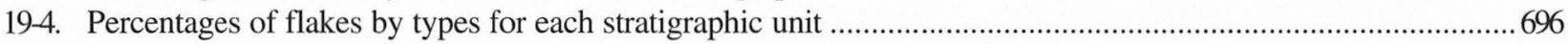

19-5. Percentages of flakes by raw materials for each stratigraphic unit .....................................................................69

19-6. Percentages of flakes by categories of fluorescence for each stratigraphic unit .................................................69

19-7. Percentages of flakes by cortex type and by cortex pattern for each stratigraphic unit .......................................700

19-8. Mineral precipitation, patina, and burning in percentages ........................................................................... 701

20-1. Attributes and distribution of manos, mano fragments, and mano/hammerstones ...........................................706

20-2. Attributes and distribution of metates and metate fragments ............................................................................ 713

20-3. Attributes and distribution of indeterminate ground stones ....................................................................... 717

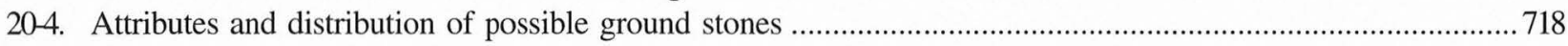

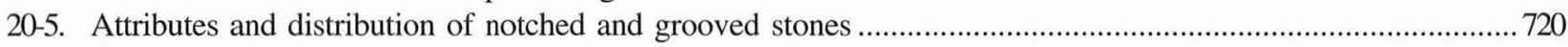

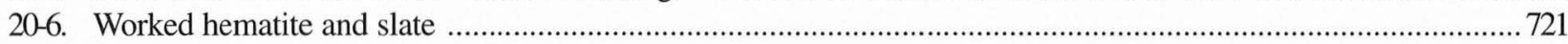

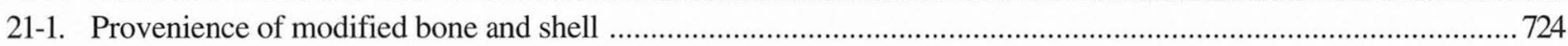

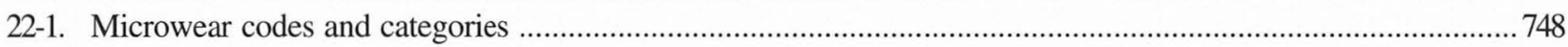

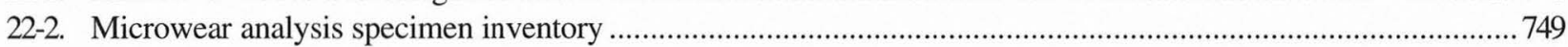

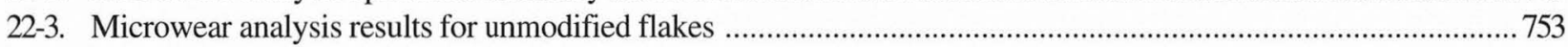

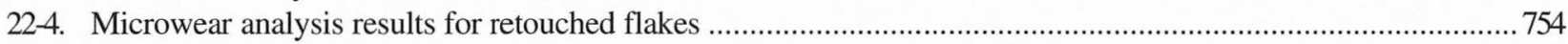

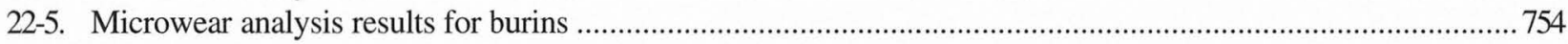

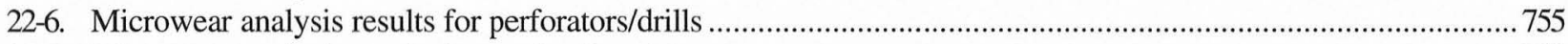

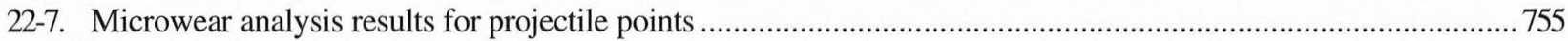

22-8. Inventory of Clear Fork tools examined for microwear ................................................................................ 796

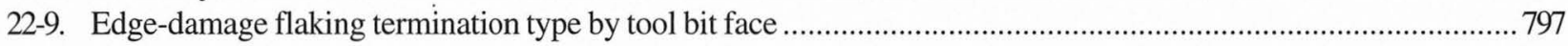

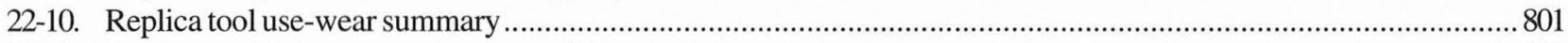

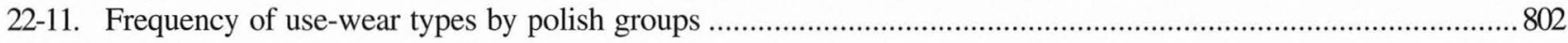

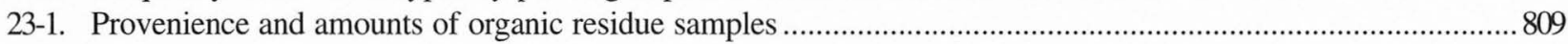

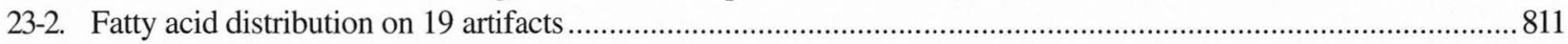

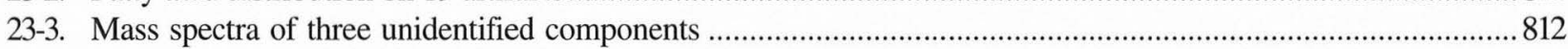

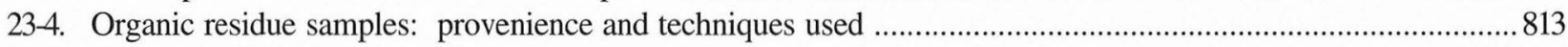

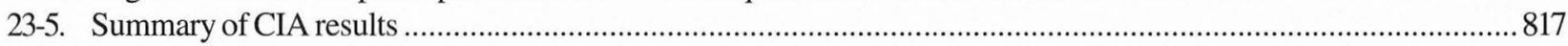

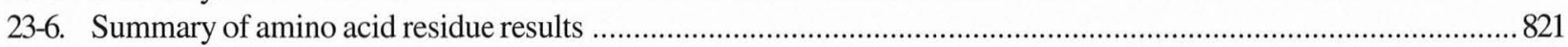

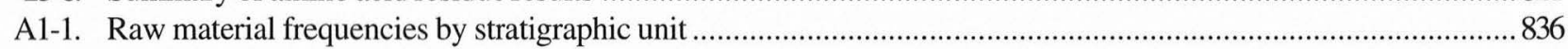

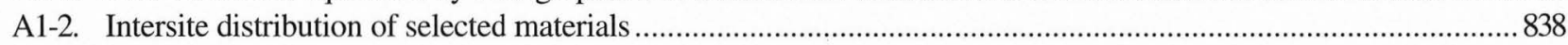

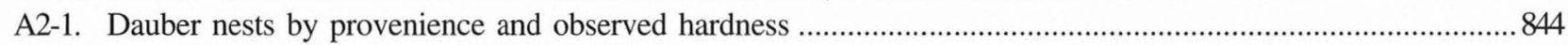

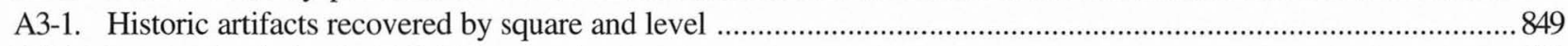

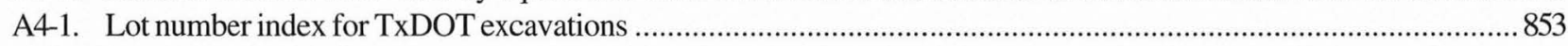

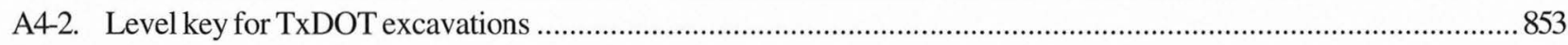

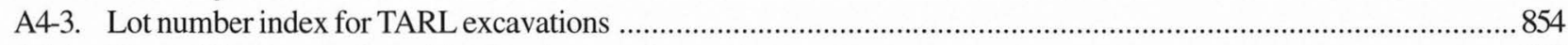

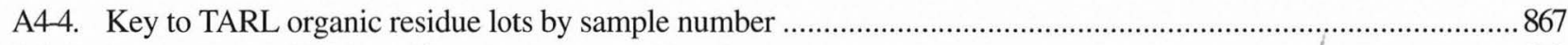

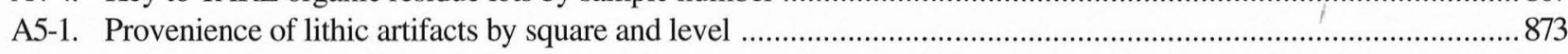




\section{Chapter 19}

\section{ANALYSIS OF DEBITAGE}

by Marilyn A. Masson

\section{INTRODUCTION}

Due to the large number of flakes present at most archeological sites, their analysis represents a costly and timeconsuming undertaking for archeological projects of finite resources. Previous conscientious efforts at quantifying and describing large samples of flakes have been criticized for their lack of interpretive value and high cost (Black 1993), and this class of data is often underanalyzed in favor of lithic artifacts that are more chronologically or functionally diagnostic. Debitage analysts themselves (Ahler 1989; Nash 1980:377; Shott 1994) have criticized the high costs and low benefits of individual flake analysis and measurement, which can result in such predictable inferences as "flake size is related to core size." However, it does not follow from shortcomings in the history of flake analysis that flakes should not be studied. Rather, approaches must be designed that strive to gather information relevant to the anthropology of prehistory; the essential requirement is good context (Collins 1993). Shying away from flake analysis may be convenient but can result in an unfortunate loss of valuable information. After all, debitage often represents the most comprehensive and abundant class of artifacts found at many archeological sites (Shott 1994:71), and the linkages between debitage attributes and knapping behavior are well established (Bradley 1975; Collins 1975; Crabtree 1972; Muto 1971; Newcomer 1971; Shafer 1969; Speth 1972).

Flaking debris from culturally meaningful contexts is the most fruitful for analysis. Brief intervals of activity are represented by the debitage from sites such as Yellow Hawk (Mallouf 1989), each of the components at Agate Basin and Sheaman (Bradley 1982), and Hanson (Frison and Bradley 1980), and its careful study reveals details of behavior not obtainable from any other source. In less-constrained assemblages, flaking debris is the source only of moregeneralized information (as, for example, at the Bull Pen site [Ensor and Mueller-Wille 1988]). Two reasonably tightly constrained debitage assemblages are represented at the Wilson-Leonard site, that of the Wilson component and that of the earliest Paleoindian components. The remainder of the sequence affords moderately constrained cultural contexts that warrant only the generalized level of analysis reported here.

This chapter presents the results of an analysis performed on a sample of 37,933 flakes recovered in the TARL excavations at the Wilson-Leonard site. The objective was to discern general trends in choices of raw materials, on-site activities of manufacturing and refurbishing, technological variation, as well as postdepositional modification of debitage from cultural and natural processes. To insure more-precise temporal control, samples were drawn and interpretations reported only in terms of natural stratigraphic contexts rather than from the cultural constructs that embody additional interpretive iterations. The comparative purpose of this analysis dictates that each sector of the sample be treated in the same manner, and those geologic units containing the Wilson and early Paleoindian components are so treated. Additional behavioral interpretations of debitage from the Wilson and early Paleoindian cultural components are presented in Chapters 8 and 7, respectively. Results of the debitage analysis are integrated with data on the other classes of chipped stone artifacts (cores, unifaces, edge-modified flakes, bifaces, projectile points, etc.) from a technological perspective in Chapters 7-10.

It should be noted that the term "debitage" is employed here in the Americanized sense to refer to flaking debris rather than in the French usage which denotes the act of flaking (Marois et al. 1997:31-32). In the pages that follow are presented the following topics: (1) discussion of the small sizes of most of the flakes analyzed; (2) methods of analysis; (3) detailed description of the attributes studied; (4) discussion of the sample; (5) presentation of the results; and (6) some suggestions for the direction of future studies. 


\section{THE FOCUS ON SMALL FLAKE ANALYSIS}

Small flakes (generally less than 1 inch $[2.5 \mathrm{~cm}]$ in maximum dimension) prevail in this sample as a result of two procedures that were followed in the TARL field and laboratory phases of this project. First, in the field, virtually all large objects found in place were extracted untouched and sealed up for organic residue analysis (the OR sample); many of these OR objects are flakes. Second, in the laboratory, a distinction was made between "modified" and "unmodified" flakes based on visibly evident presence or absence of edge modification; a majority of larger flakes had modified edges and were analyzed as tools (see Chapter 17). In addition, a portion of small flakes exhibit microscopic evidence for use wear (see Chapter 22).

The finding of use wear on small flakes carries important implications for the frequent analytical disregard of smallsized flaking debris in the archeological record of Texas and beyond. It is common for flakes to be separated from "tools" in the categorization and investigation of artifactual remains (Shott 1994:70). The microscopic evidence for frequent utilization of Wilson-Leonard flakes, which would not have been observed macroscopically, implies that traditional distinctions made between flakes and tools may result in substantial underrepresentation of tools.

Small flakes are subject to far less movement in the cultural system than are larger flakes. Small flakes tend to remain at the locus of knapping whereas larger flakes are subject to removal for use. Thus, among materials recovered in the excavated area of the Wilson-Leonard site, small flakes can more confidently be inferred to represent on-site knapping than can large flakes, which may have been detached elsewhere and brought to the site as tools. Conversely, those larger flakes that were actually detached in the excavated area could reasonably be expected to have been taken away as tools and, therefore, not show up in the recovered assemblages. These advantages to analyzing small flakes are somewhat offset by the fact that larger flakes often are more expressive of distinctions in knapping behavior than are small flakes.

The focus on small flakes in this chapter is also due to the use of 1/8-inch screens in TARL excavations (see Chapter 5). Use of small-mesh screens resulted in the collection of larger numbers of flakes smaller than would have been recovered using only the more-traditional (1/4 inch) screen size. As a result of this collection strategy, over half of the sample of "unmodifed" flakes examined in this analysis are smaller than $1 / 4$ inch.

\section{METHODSOF ANALYSIS}

This study, then, is concerned with almost 40,000 flakes that (1) are from secure geologic contexts, (2) were collected on 1/8-inch screens, (3) do not exhibit macroscopic modifications, and (4) are not set aside for residue analysis. Flakes and flake fragments with platforms ("flakes") were analyzed. Flake fragments and other small pieces of chert lacking platforms ("shatter") were not analyzed. These aspects of the sample are consistent throughout the site sequence and, therefore, provide a valid, though obviously limited, basis of comparison.

The flake analysis was designed to collect as much information on procurement, technology, use, and postdepositional impacts as possible. The direct measurement of flakes was avoided, as this is a time-consuming process of negligible contribution to the issues under investigation. Flake size, the first variable recorded in the analytical procedure, was determined through quantifying debris in standardized geologic sorting screens of progressive sizes. Cortex pattern was recorded according to categories of $100 \%, 1-99 \%$, or $0 \%$ on the dorsal surface. Presence/absence observations were made on carbonate, patina, and heat alteration.

Additional attributes reflect qualitative observations of significance to project research problems; these include flake type, flake raw material, and cortex type. The approach designed in this study is in many ways specific to the needs and interests of the Wilson-Leonard site investigations and is philosophically in line with Shott's (1994:69) observation that "the best approaches (to flake analysis) assume rather than demonstrate a relationship between behavior and formal variation." The analytical procedures and criteria for each of these variables are discussed below.

\section{ATTRIBUTES}

\section{Size}

Flake sizes were determined by screening each bag through geological screens of 1/8-inch, 1/4-inch, 1/2-inch, and 1-inch sizes (note that these standard English-system screen-size designations have been maintained in this chapter; their metric equivalents would be $0.32 \mathrm{~cm}, 0.64 \mathrm{~cm}, 1.28$ $\mathrm{cm}$, and $2.56 \mathrm{~cm}$, respectively). This approach was patterned after Stahle and Dunn (1982) and Ahler (1989) in order to facilitate comparisons. Platform-bearing flakes were then sorted from those without platforms, following Shafer (1979). The latter were counted, weighed, and recorded as "shatter." The shatter was not analyzed to avoid recording attributes (material, cortex, etc.) of the same flake more than once. This approach had its price, particularly in the Paleoindian levels, when it was clear that some individual pieces of "shatter" represented raw materials distinct from those observed among the platform-bearing flakes.

The four screen fractions of platform-bearing flakes were bagged separately and labeled according to fraction. Shatter was returned loose to the original lot bag, and the four screened fraction bags were folded and placed into the original bag as well. In this manner, the entire debitage sample was kept together for each lot number, and time-consuming 
labeling and handling of fractions was avoided.

For analysis, flakes of each screen size were laid out, one screen size at a time, according to typological classification. "Types" were laid out according to raw material at the same time as they were classified. Cortex, patina, carbonate, and heat observations were recorded last, as they occurred in low frequencies. Flakes were placed in rows of even numbers for easy counting. Data were entered directly into a Paradox spreadsheet, with one record per flake. Data entry was expedient as it was possible to enter multiple records at once for flakes with identical attributes.

Flakes were examined under long- and short-wave ultraviolet light to identify those that did not fluoresce. The identification of Edwards Plateau chert can be assisted by its property of fluorescence under such a light (Hofman et al. 1991). Raw materials that do not fluoresce can thus be tentatively identifed as deriving from non-Edwards sources or as having been severely heat altered. This observation is primarily true for cherts that have not been subjected to heat alteration or cherts of dark color. Some black cherts of the Edwards Plateau, such as Owl Creek Black, do not fluoresce. This characteristic of Owl Creek Black was originally noted by Charles Frederick (personal communication 1994) and was confirmed empirically in this study. Other black Edwards cherts do fluoresce, however.

\section{Type}

Flake types identified in this analysis (Table 19-1) represent qualitative categories designed to measure variability in lithic technology over time. Initially, 26 types were tentatively defined; of these, 12 proved to be too infrequent to be meaningful or were found to represent indistinct points along a continuum. These types were deleted from the analysis by combining closely similar groups. The original code numbers assigned to the 14 retained types have not been changed. Few highly diagnostic flake types specific to any period of time were found. Descriptions of flake types and meaningful fluctuations among basic categories are examined below; examples of selected flake types are illustrated in Figure 19-1.

The most frequently identified types are normal flakes, dorsal-troughed flakes, exploded-bulb flakes (Figure 19-1a), parallel "pressure" flakes (Figure 19-1b), and bifacial edge trimming or resharpening flakes (thin [Figure 19-1c] and thick [Figure 19-1d]). Normal flakes were highly variable, and this category represents a residual classification of "other" flakes lacking diagnostic attributes assignable to the types listed above. Flakes classified as normal include many that probably are related to primary reduction activities, due to their irregular proportions.

Dorsal-troughed flakes were liberally defined for this analysis and include any flake with a single concave flake scar that extended from the platform across the dorsal surface of the flake. They broadly resemble sequent flakes but do not derive from the same technology. Sequent flakes, as originally defined, refer to a specific technology for the removal of a series of nearly identical flakes off of an edge (e.g., Collins 1974). Sequent flake removal generally refers to larger flakes, such as those that were removed from samples analyzed here due to their edge-modified status (see Chapter 17). For small flake analysis, dorsal-troughed flakes were defined by their pronounced dorsal concavity created by a proximal-to-distal scar. In this analysis, very small dorsaltroughed flakes are found in the 1/8-inch category. They are thought to be closely related to other edge thinning/sharpening flakes and parallel-edged flakes.

Exploded-bulb flakes identified in this analysis are all very small in size (falling through $1 / 4$-inch mesh and trapped in the 1/8-inch fraction). As defined in this study, they exhibit a negative bulb concavity on the dorsal surface and a pronounced convex ventral surface with an extremely prominent bulb that is crescent shaped in cross section. Superficially, they resemble notching flakes (Austin 1986), but they did not always have an indentation on the platform as described by Titmus (1985:251). They are almost round and are of nearly equal length and width dimensions. These flakes resemble the negative impressions that are left by the terminal flake in the notch of deeply notched bifacial artifacts. The definition of exploded-bulb flakes in this analysis may include flakes that originated from a variety of late-stage processes of lithic reduction as well as from notching activities.

Parallel-edged flakes were originally considered in this analysis as late-stage pressure flakes due to their thin cross section, small bulb of percussion, and small platform area. However, flintknapping experimentation by Collins (summer 1994) using a hard-hammer percussor created many flakes of this nature as well. Parallel-edged flakes are still thought to represent final-stage tool shaping or resharpening activities, but flintknappers of skill can apparently remove them with either hard- or soft-hammer implements.

Bifacial edge-trimming or resharpening flakes (thin and thick) are common in the assemblages. The thin group is most often leaf shaped, with tapering proximal and distal ends and length about twice the dimension of the width. The dorsal surface exhibits multiple shallow scars from wellexecuted flaking. These flakes are thin overall and exhibit gradual and symmetric proximal-distal ventral curvature. Thick bifacial edge-trimming flakes are thicker especially toward the proximal end on the dorsal side behind the platform. They are often wider than they are long but exhibit the same well-developed dorsal scarring. These flakes may represent earlier stages of bifacial reduction or the manufacture/resharpening of bulkier tool forms such as choppers.

Other flake types are absent or infrequent, including channel, bifacial thinning (Figure 19-1g), leg-assisted pressure, and edge collapse. Blade and "flake blades" (Figure 19-1i) are also uncommon. Channel flakes were not identified in the TARL sample of analyzed flakes. 
TABLE 19-1

Flake Types and Their Principal Attributes

\begin{tabular}{|c|c|}
\hline Type & Attributes \\
\hline Normal & $\begin{array}{l}\text { Platform-bearing flakes of irregular dimensions that could not be further classified; often thick, many } \\
\text { may be related to primary reduction. }\end{array}$ \\
\hline Biface thinning & $\begin{array}{l}\text { Thin, outflaring with feather termination; slight ventral concavity; moderate bulb; narrow platform; } \\
\text { well-developed dorsal scarring. }\end{array}$ \\
\hline Dorsal troughed & $\begin{array}{l}\text { Dorsal surface dominated by a single large flake scar originating at the platform; somewhat resembles } \\
\text { sequent flakes. }\end{array}$ \\
\hline Exploded bulb & $\begin{array}{l}\text { Generally circular in shape due to extreme bulb protuberance and resultant dorsal concavity; ventral } \\
\text { surface is highly convex; flakes usually }<1 / 4 \text { inch in diameter. Superficially resemble notching flakes. }\end{array}$ \\
\hline Parallel edged & $\begin{array}{l}\text { Small and rectangular in shape with parallel lateral edges and thin cross section; well-developed dorsal } \\
\text { scarring; generally }<1 / 4 \text { inch in size. Resembles biface thinning and smaller version of thin edge } \\
\text { trimming flakes. }\end{array}$ \\
\hline Thin edge trimming & $\begin{array}{l}\text { Moderate sized, leaf shaped with feather termination; cross section is thin. Well-developed dorsal flake } \\
\text { scars may be present; resembles small biface-thinning flake. }\end{array}$ \\
\hline Thick edge trimming & $\begin{array}{l}\text { Thick cross section and short length often nearly equal to width; likely related to late stage } \\
\text { manufacturing, thick biface trimming. }\end{array}$ \\
\hline Flake blade & $\begin{array}{l}\text { Length greater ( } 2 X \text { or more) than width; thin, sometimes with well-developed parallel longitudinal } \\
\text { dorsal ridges, slight ventral concavity. }\end{array}$ \\
\hline Microflake & Small, lacks dorsal scarring but has platform; possibly related to notching process and/or fine trimming. \\
\hline Edge bite flake & Includes both faces of biface lateral edge section as the platform; product of manufacturing error. \\
\hline Core fragment & $\begin{array}{l}\text { Larger sections or "chunks" bearing scars of flake removal; includes core tablets, or sections removed } \\
\text { to rejuvenate platform of unidirectional cores. }\end{array}$ \\
\hline Leg-assisted pressure & Elongate, tongue-like, parallel-sided flakes that are straight in cross section. \\
\hline Manufacturing error & Aberrant with declivities or other indicators of unsuccessful removal; variable. \\
\hline Unifacial resharpening & Exhibits remnants of a unifacially edge-modified margin that has been removed to rejuvenate the tool. \\
\hline
\end{tabular}

Core tablets, core platform preparation flakes, and various core fragments were noted in passing, but they do not represent a quantitatively viable sample as most core fragments were removed from the debitage samples prior to the analysis. A comprehensive analysis of core technology is provided elsewhere in this report (see Chapter 18).

Most bifacial thinning flakes were also removed prior to flake analysis, as they were visibly modified (see Chapter 17). Leg-assisted pressure flakes (Figure 19-1f), as defined by Weber (1994), include elongate, tongue-like, parallel-sided, straight in cross-section flakes that are particularly associated with Bell-Andice manufacture. However, flakes of this description are present in low numbers throughout all analysis units.

Edge-bite or edge-collapse flakes (Collins 1974) are simply those in which both surfaces of the lateral edge of the biface were removed as the platform and are thought to be a manufacturing error (Figure 19-1h). Blades also are noted in many analysis units in low numbers, including "true blades" with dorsal scars from previous blade removals and "flake blades" which exhibit other varieties of dorsal scarring (Figure 19-1i). Unifacial resharpening flakes (Figure 19-1e) are not present in large numbers; the various technologies involved in the unifacial rejuvenation process are discussed in Chapter 17. These infrequent forms are lumped together in the analysis below due to their low number and lack of evidence in most samples of a true blade technology, with the exception of the lowest component (see Chapter 7). Blades were not recovered in abundance in any deposit at the site, and only a few fragments of blade cores were found. Many blades identified in this analysis were microblades of around $2 \mathrm{~cm}$ in length.

Due to the low numbers and sampling issues described above for infrequent flake types, the discussion of flake classification results below focuses on commonly identified types. Any other patterns of significance are mentioned as merited. 


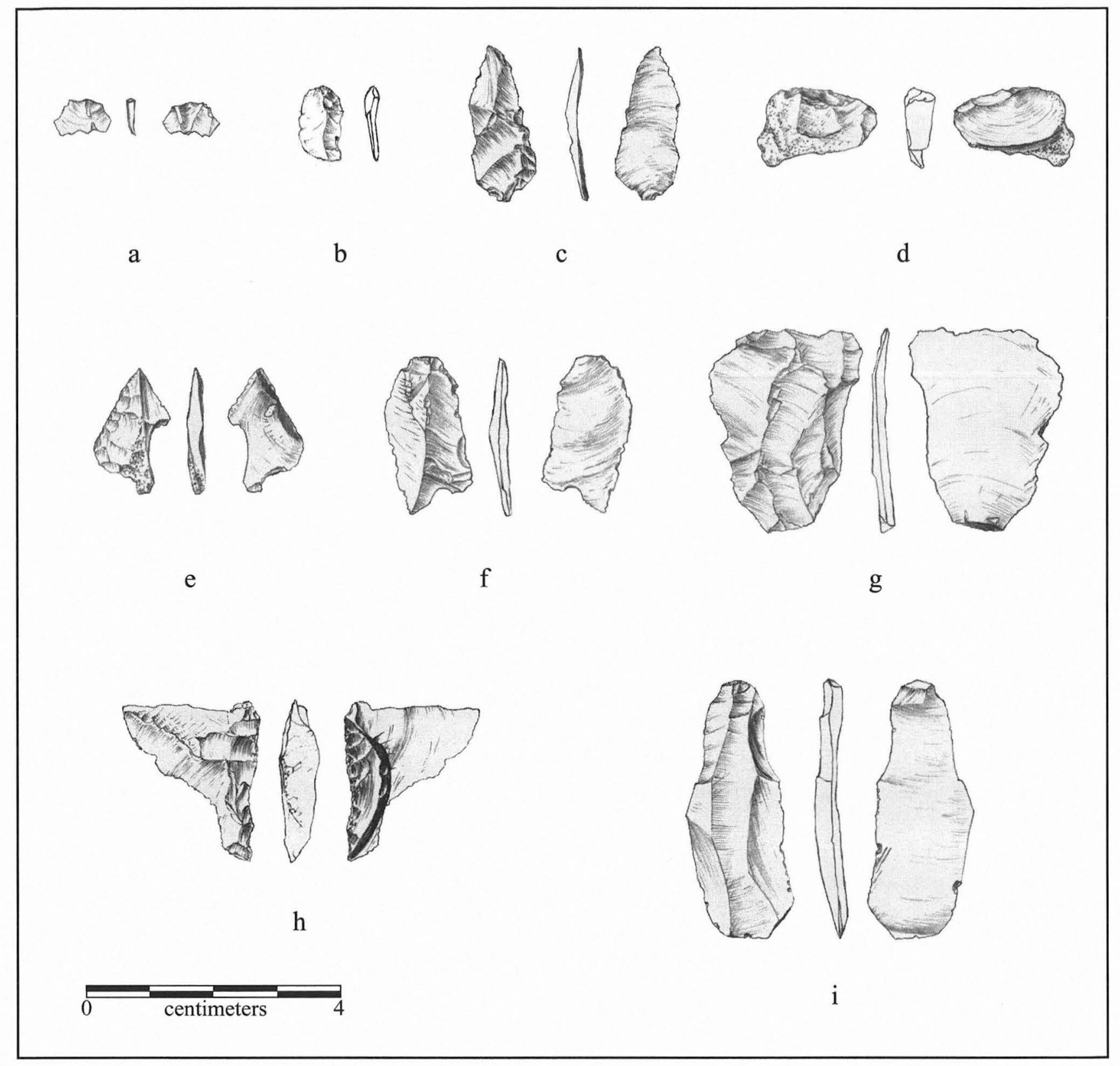

FIGURE 19-1. Examples of selected flake types. (a) exploded bulb; (b) parallel-edged; (c) thin edge trimming; (d) thick edge trimming; (e) unifacial resharpening; (f) leg-assisted pressure; (g) biface thinning; (h) edge bite; (i) flake blade.

\section{Raw Materials}

Most material types classified in this analysis are based on flakes and projectile points from the site. These are constellations of variables relating to color, texture, cortex, and other visible attributes and do not necessarily correspond to geologic patterns of occurrence (Banks 1990). Flake raw materials were initially sorted using a selected sample of large flakes from TxDOT excavations. Great difficulty was encountered separating the colors of local "Georgetown" gray, brown, and tan cherts, as combinations of these colors can be exhibited on single large flakes. However, consulta- tion with Glenn Goode, who donated examples of local chert samples he has collected from localities in or near north Austin, Round Rock, and other parts of Williamson County (as well as most other chert sources in the state), clarified some of the distinctions ultimately recorded in this analysis. Further consultation was undertaken with Charles Frederick, who collected chert samples from across the Edwards Plateau (Frederick and Ringstaff 1994) and donated comparative examples of cherts from Fort Hood to the project.

The origin of many types of nonlocal Edwards cherts is unknown, as orange, honey, and various brown translucent cherts were not recognized in Frederick's roadside collection 
from across the Plateau. The origins of a few nonlocal Edwards cherts are known, such as the excellent-quality "root beer" chert that Goode identifies from Kimble County. Low numbers of cherts like those from Fort Hood were identified at the Wilson-Leonard site. Such types include the moderate- to coarse-grained mustard colored cherts and the wellknown Owl Creek Black (Frederick and Ringstaff 1994). Some of the coarse grays identified at Wilson-Leonard might also be from the vicinity of Fort Hood (resembling those shown in Trierweiler 1994:Appendix C, Plate 2, center row), but this is difficult to ascertain from a sample of one or two flakes. However, comparable cherts can be obtained within walking distance from the Wilson-Leonard site, such as the moderate- to coarse-grained Walnut Creek tan and the MacNeil black cherts (Glenn Goode, personal communication 1994).

According to Goode, the MacNeil limestone quarry is 3 miles south of Round Rock and extends north almost to RR 620 . The chert colors grade from bluish black to jet black (coded as 2b) to cloudier gray and can have gray, brown, or white inclusions (coded as type 30 in this analysis). The chert occurs in patches of flat cobbles about 10-20 feet below the surface. Goode notes that access to it would be difficult except for erosional opportunities. He observes that Sam Bass Black chert occurs north of RR 1431, north of Brushy Creek very near the Wilson-Leonard site. It occurs at or near the surface and would have been easily accessible. Both types of black chert were observed at the site. The Sam Bass Black chert is translucent and can have banded impurities. This type was classified as $2 \mathrm{a}$ in this analysis.

Goode notes two coarser-grained varieties that include New Parmer tan and Walnut Creek (at Parmer Lane). These yellow/tan cherts correspond to types $1 \mathrm{~b}$ and 5 in this analysis. Goode notes that finer grades of this chert appear to the north toward the Gault site area. Type $1 \mathrm{~b}$ appears in gradations of fine to coarse in the flake samples, but more frequently it was used for the manufacture of heavier bifacial tools (see Chapter 16). In addition to gradations that took place in the ground, $1 \mathrm{~b}$ appears to become more fine grained when subjected to heating or possibly to long-term soil moisture conditions at the site. Its raw form near the site, however, leans more toward coarse rather than fine, and it is analyzed here as a medium- to coarse-grained chert.

Georgetown blacks and grays occur, according to Goode, near and below the surface. They have been spotted north of RR 1431 in the Texas Crushed Stone quarry. These cherts are classified as 1c (dark gray), 1 (gray), 2a (black translucent), and $2 \mathrm{~b}$ (jet black) in this analysis. The local blacks are not identified to quarry sites in this analysis due to the difficulty of doing this accurately with one flake at a time. Instead, they are subsumed under the $2 \mathrm{a}$ and $2 \mathrm{~b}$ categories.

Even greater difficulty was encountered in classifying "exotic" chert forms, including both ultraviolet fluorescent Edwards and nonfluorescent non-Edwards. The primary problem was that a single flake had to be used to define a new material type, and the analysis was inhibited by the inability to determine variability within raw material sources. This difficulty has been partially overcome in the interpretation of results below, in which all "honey"-colored cherts (for example) are tabulated together as well as being listed separately. Analyzing the cores was not helpful in identifying exotic raw materials, as most of the cores were made either of high-quality or coarse-grained local cherts. Occasionally, projectile points and bifaces were found (see Chapters 13 and 16) that were made of materials not represented in over 100 material types classified among the flakes. In this event, additional raw material classifications were added. All of this is compounded in some raw materials that seem to have changed color over time through postdepositional processes.

As a result of detailed recording of flake materials, several general patterns can be observed. The "Georgetown" chert group (including Round Rock, MacNeil, etc.) has long been considered one of the finest chert sources in the world. Due to the exceptional quality of this chert, it understandably dominates Wilson-Leonard assemblages of all periods and probably represented a resource that populations in this area exchanged with other groups.

Chert from the north Austin and neighboring areas enjoys international reknown. Francois Bordes (personal communication to Michael B. Collins 1973) claimed that the "Georgetown" chert was of such fine quality that it did not need to be heat treated, and evidence from this analysis and others suggests that it was generally not intentionally heated prior to flintknapping (with a few exceptions). Raw materials identified from the Wilson-Leonard site flakes are listed in Table 19-2. Most (but not all) heating appears fortuitous and postdepositional. Among this group of cherts (Types 1 and 2 ), Types 1a, 1c, 1, 2a, and $2 \mathrm{~b}$ are finer grained and were used in the manufacture of thinner tools with more-acute edge angles (e.g., see Chapter 13). Pink fluorescent types are occasionally thought to be heat affected versions of Type 1 . Types $1 \mathrm{~b}$ and 5 , of a coarser grain, commonly were used to make thicker bifacial tools (e.g., Clear Fork tools) with larger edge angles that probably suffered heavier impacts (see Chapter 15). Other less common but regularly occurring cherts are the orange group, the brown group, and the honey group. The chert-type reference collection used in this study is housed at TARL.

\section{Analytical Approach to Comparing Flake Raw Materials}

In addition to color and texture of raw materials, the classification attempts to distinguish raw material sources on a very broad scale, including highly local (Edwards) cherts, nonlocal types of Edwards cherts, and non-Edwards cherts. The degree of use of each of these categories may be related to the amount of group mobility or to networks of exchange. Although it is often possible to ascertain where materials originated and at what stage of reduction they 
TABLE $19-2$

Material Classifications of Wilson-Leonard Flakes

\begin{tabular}{|c|c|c|}
\hline Numeric Code & Fluorescent Property & Description \\
\hline \multicolumn{3}{|c|}{ Highly Local Cherts } \\
\hline 1 & fluorescent & |fine-grained gray/brown waxy \\
\hline $1 \mathrm{a}, 31$ & fluorescent & fine-grained gray/brown with amber tones \\
\hline $1 b$ & fluorescent & fine-grained brown/tan/cream \\
\hline $1 \mathrm{c}$ & fluorescent & fine-grained dark gray/brown, grades into $2 \mathrm{a}$ \\
\hline 2 & fluorescent & fine-grained gray/dark gray \\
\hline $2 \mathrm{a}$ & fluoresces weakly or not at all & fine-grained very dark gray/translucent black \\
\hline $2 b, 26 a, b$ & fluoresces weakly or not at all & fine-grained jet black, waxy, not translucent \\
\hline 19 & fluorescent & fine-grained type 1 with cortex-related patina \\
\hline 30 & fluorescent & $\begin{array}{l}\text { fine-grained gray speckled translucent, resembles MacNeil quarry blue/gray cherts } \\
\text { in Wilson-Leonard chert collection }\end{array}$ \\
\hline 33 & nonfluorescent & fine-grained black with glass-like patina, burned \\
\hline 62,86 & fluorescent & fine-grained brown mauve \\
\hline 63 & fluorescent & fine-grained brown translucent, stream worn cortex \\
\hline
\end{tabular}

Nonlocal Central Texas Edwards Plateau Cherts

\begin{tabular}{|c|c|c|}
\hline 3 & fluorescent & $\begin{array}{l}\text { fine-grained "root beer" brown/maroon, from western Gillespie, Kimble, and } \\
\text { Menard counties (Glenn Goode, personal communication) }\end{array}$ \\
\hline 4 & fluorescent & fine-grained tan/green waxy \\
\hline 5 & fluorescent & coarse-grained mustard or tan/cream \\
\hline 6 & fluorescent & fine-grained purple/green with faint impurities, resembles Gault site chert \\
\hline 7 & fluorescent & medium-grained brown/yellow \\
\hline 9 & fluorescent & $\begin{array}{l}\text { medium-grained brown/gray with marked impurities, resembles Colorado River } \\
\text { cherts (Glenn Goode, personal communication) }\end{array}$ \\
\hline 15 & fluorescent & green-brown translucent \\
\hline 25 & fluorescent & fine-grained opaque pink with interior cortical bands \\
\hline $35 \mathrm{a}$ & fluorescent & medium-grained speckled yellow \\
\hline $35 b$ & fluorescent & fine-grained opaque white with interior cortical bands \\
\hline 41 & nonfluorescent & fine-grained burned orange \\
\hline $41 b$ & fluorescent & fine-grained burned orange \\
\hline 42 & nonfluorescent & fine-grained orange pink \\
\hline $43,43 b$ & fluorescent & fine-grained orange marbled \\
\hline $47 \mathrm{a}$ & fluorescent & fine-grained orange pink banded \\
\hline $47 b$ & fluorescent & fine-grained orange pink swirled \\
\hline $47 \mathrm{c}$ & fluorescent & fine-grained orange pink plain \\
\hline 48 & fluoresces weakly or not at all & $\begin{array}{l}\text { fine-grained black with white speckles, resembles "Owl Creek Black" cherts } \\
\text { identified at Fort Hood }\end{array}$ \\
\hline 105 & fluorescent & $\begin{array}{l}\text { medium-grained mustard, nontranslucent, resembles cherts identified at Fort Hood } \\
\text { (Charles Frederick, personal communication) }\end{array}$ \\
\hline
\end{tabular}

\section{Nonlocal Edwards Cherts with Speckled Impurities}

\begin{tabular}{l|l}
54 & fluorescent \\
55 & fluorescent \\
83 & fluorescent \\
90 & fluorescent \\
92 & fluorescent \\
93 & fluorescent \\
94 & fluorescent \\
110 & fluorescent
\end{tabular}
coarse-grained orange with black flecks, semitranslucent coarse-grained tan with black flecks, semitranslucent medium-grained white speckled (Williams point 14D-1 only) fine-grained mud brown with cream-colored impurities (Wilson point 28Y2D-2) fine-grained gray with splotchy impurities
fine-grained "trout" green speckled with red tinges (St. Mary's Hall point 28W2C-1) fine-grained waxy speckled (Angostura point 25R1-1) medium-grained white with black speckles

\section{Nonlocal Edwards Pink Types}

\begin{tabular}{l|l}
$57,59,60$ & fluorescent \\
65 & fluorescent \\
66 & fluorescent \\
69 & fluoresces weakly \\
73 & fluorescent \\
$73 \mathrm{~b}$ & nonfluorescent \\
112 & fluorescent \\
\hline
\end{tabular}

fine-grained cloudy pink with or without red flecks

fine-grained clear pink/orange with red specks, "salmon" color

fine-grained pink/blue/gray with dark splotches

fine-grained mottled pink

fine-grained pink/gray mottled with maroon bands

fine-grained pink/gray mottled with maroon bands

fine-grained pink patinated with black speckles 
Table 19-2, continued

\begin{tabular}{|c|c|c|}
\hline Numeric Code & Fluorescent Property & Description \\
\hline $\begin{array}{l}80 \\
80 b\end{array}$ & $\begin{array}{l}\text { fluorescent } \\
\text { fluorescent }\end{array}$ & $\begin{array}{l}\text { coarse-grained mustard color with black flecks } \\
\text { fine-grained mustard color with black flecks }\end{array}$ \\
\hline \multicolumn{3}{|c|}{ Nonlocal and Non-Edwards Gray Types } \\
\hline $\begin{array}{l}37 \\
38 \\
39 \\
44 \\
51 a \\
51 b \\
84 \\
85 \\
95 \\
109 \\
120 \\
121\end{array}$ & $\begin{array}{l}\text { nonfluorescent } \\
\text { nonfluorescent } \\
\text { nonfluorescent } \\
\text { fluorescent } \\
\text { nonfluorescent } \\
\text { fluorescent } \\
\text { fluorescent } \\
\text { fluorescent } \\
\text { fluorescent } \\
\text { nonfluorescent } \\
\text { fluorescent } \\
\text { fluorescent }\end{array}$ & $\begin{array}{l}\text { coarse-grained light blue gray } \\
\text { coarse-grained gray with white flecks } \\
\text { coarse-grained gray slate-like chert with mottling } \\
\text { coarse-grained light blue gray } \\
\text { medium-grained metallic gray } \\
\text { medium-grained blue metallic gray } \\
\text { fine-grained waxy gray with impurities } \\
\text { fine-grained white and orange with rust speckles } \\
\text { coarse-grained creamy gray with conglomerate inclusions (Nolan point 22H-2) } \\
\text { fine-grained gray conglomerate } \\
\text { fine-grained gray with large white blotches } \\
\text { fine-grained gray speckled, looks like } 25 \text { but gray, not yellow }\end{array}$ \\
\hline
\end{tabular}

\section{Nonlocal and Non-Edwards Honey-colored Types (Waxy)}

\begin{tabular}{l|l}
$22,52 \mathrm{~b}, 58,64$ & fluorescent \\
$52 \mathrm{a}, 64 \mathrm{~b}$ & nonfluorescent \\
28 & nonfluorescent \\
20,23 & fluorescent \\
$20 \mathrm{~b}$ & nonfluorescent \\
$20 \mathrm{c}$ & nonfluorescent \\
71 & fluorescent \\
72 & fluorescent \\
119 & fluorescent \\
\hline
\end{tabular}

fine-grained honey translucent

fine-grained honey translucent

fine-grained honey-red translucent

fine-grained mustard yellow

fine-grained mustard yellow

fine-grained mustard yellow with many impurities, grades from speckled to

nontranslucent tan

fine-grained honey with red band

fine-grained amber with red streak inclusions

fine-grained red translucent

\section{Nonlocal Edwards White Types}

\begin{tabular}{l|l|l}
29 & $\begin{array}{l}\text { fluorescent } \\
\text { fluorescent }\end{array}$ & $\begin{array}{l}\text { fine-grained milky, nontranslucent white } \\
\text { fine-grained milky, nontranslucent white with yellow veins (Hoxie point } \\
28 \mathrm{~S} 1-1)\end{array}$ \\
\hline
\end{tabular}

\begin{tabular}{l|l}
\hline Nonlocal and Non-Edwards Miscella \\
11 & nonfluorescent \\
12 & nonfluorescent \\
13 & nonfluorescent \\
61 & nonfluorescent \\
$74 \mathrm{a}$ & fluorescent \\
$74 \mathrm{~b}$ & fluorescent \\
87 & fluorescent \\
$116 \mathrm{a}$ & nonfluorescent \\
$116 \mathrm{~b}$ & nonfluorescent \\
$116 \mathrm{c}$ & nonfluorescent \\
\hline
\end{tabular}

Nonlocal and Non-Edwards Unusual Patinated Types

\begin{tabular}{l|l|l}
8 & fluorescent & medium-grained chalky patinated \\
10 & nonfluorescent & fine-grained pink mottled patinated \\
24 & fluorescent & foarse-grained red speckled patinated \\
53 & fluorescent & fine-grained blue-hued patinated \\
118 & fluorescent & fine-grained yellow patinated
\end{tabular}

\section{Quartzite or Quartz}

\begin{tabular}{l|l}
14 & nonfluorescent \\
$14 \mathrm{~b}$ & nonfluorescent \\
21 & fluorescent \\
45 & nonfluorescent \\
68 & fluorescent \\
76 & nonfluorescent \\
\hline
\end{tabular}

coarse-grained tan brown with marbled streaks

coarse-grained tan brown without marbling

coarse-grained dark gray

coarse-grained rust

coarse-grained honey, light

coarse-grained honey, dark

coarse-grained mauve with marble-like polish

coarse-grained yellow, stream-worn cortex

coarse-grained reddish tan, heated or burned version of $116 \mathrm{a}$

coarse-grained dark mauve, heated or burned version of $116 \mathrm{a}$ medium-grained chalky patinated
fine-grained pink mottled patinated
coarse-grained red speckled patinated
fine-grained blue-hued patinated
fine-grained yellow patinated

coarse-grained red quartzite

coarse-grained green quartzite

coarse-grained marbled quartz, resembles Alibates in coloring but reflects

differently (observed on one point only)

fine-grained translucent quartz crystal

medium-grained light gray quartz blend

medium-grained marbled quartzite blend 
Table 19-2, continued

\begin{tabular}{l|l|l}
\hline Numeric Code & Fluorescent Property & Description \\
\hline 79 & fluorescent & coarse-grained white quartz \\
89 & fluorescent & medium-grained gray quartz \\
108 & fluorescent & medium-grained greenish quartz \\
113 & nonfluorescent & medium-grained pink quartz crystal \\
125 & fluorescent & coarse-grained white \\
\hline
\end{tabular}

Nonlocal and Non-Edwards Rare Types

\begin{tabular}{|c|c|c|}
\hline 18 & nonfluorescent & limestone \\
\hline 36 & nonfluorescent & fine-grained dark brown/black translucent \\
\hline 40 & nonfluorescent & fine-grained chestnut translucent \\
\hline $40 \mathrm{~b}$ & fluorescent & fine-grained chestnut translucent \\
\hline 46 & fluorescent & fine-grained gray banded translucent \\
\hline 49 & nonfluorescent & fine-grained brown translucent \\
\hline 50 & nonfluorescent & fine-grained brown with red streaks, nontranslucent \\
\hline 56 & fluorescent & mudstone \\
\hline 67 & nonfluorescent & fine-grained burned orange nontranslucent, stream-worn cortex \\
\hline 70 & fluorescent & fine-grained brown banded \\
\hline 75 & fluorescent & fine-grained black and white banded, only white part reflective \\
\hline 77 & fluorescent & fine-grained milky orange \\
\hline 78 & fluorescent & fine-grained cloudy "peach" orange \\
\hline 81 & nonfluorescent & medium-grained orange \\
\hline 82 & nonfluorescent & fine-grained "coffee" black \\
\hline 88 & nonfluorescent & medium-grained muddy orange \\
\hline $88 \mathrm{~b}$ & fluorescent & medium-grained muddy orange \\
\hline 91 & nonfluorescent & medium-grained rusty black \\
\hline 96 & fluorescent? & medium-grained "liver" brown with black inclusions (Bulverde point 16E-3) \\
\hline 97 & fluorescent & fine-grained purple nontranslucent \\
\hline 98 & fluorescent & fine-grained yellowish white swirled chalcedony, semitranslucent \\
\hline 99 & fluorescent & coarse-grained tan \\
\hline 100 & nonfluorescent & coarse-grained rust \\
\hline 101 & fluorescent & fine-grained gray with blue areas, patinated \\
\hline 102 & fluorescent & fine-grained slate-like brown/mauve, homogeneous, nontranslucent \\
\hline 103 & fluorescent & fine-grained marble-like patinated white \\
\hline 104 & fluorescent & coarse-grained pink \\
\hline 106 & nonfluorescent & green and red banded \\
\hline 107 & nonfluorescent & medium-grained mottled brick \\
\hline 111 & fluorescent & coarse-grained peach/gray \\
\hline 114 & fluorescent & fine-grained orange/pink haze with orange cortex, resembles types $42,43,47$ \\
\hline 115 & fluorescent & fine-grained cream with orange flecks \\
\hline 116 & fluorescent & fine-grained peach chalcedony (see thin uniface 34EE1C-2) \\
\hline 117 & fluorescent & medium-grained brown/gray mottled with rust spots \\
\hline 126 & fluorescent & fine-grained petrified wood, reddish brown (see thin uniface $32 \mathrm{HH} 2 \mathrm{~B}-2$ ) \\
\hline 127 & nonfluorescent & coarse-grained olive drab, looks like 39 but olive colored (see core 20S-6) \\
\hline
\end{tabular}

were generally brought to the site, it has proven difficult to infer whether acquisition was by members of the local group or through exchange with other groups (Meltzer 1989).

Table 19-2 lists the fluorescent and nonfluorescent raw materials recognized through the flake and, in a few cases, the tool analyses. As noted above, certain postdepositional processes, such as burning, may have skewed fluorescent properties of particular specimens, and in such cases, the assignment of a local versus non-Edwards classification is more difficult.

Material types are also evaluated according to their grain. The frequency of fine-grained materials versus coarsegrained materials is compared in the subsequent analysis to determine the relationship of raw materials to other aspects of the technology. Dial (see Chapter15) has noted that coarser materials were used to make Clear Fork and other heavy bifacial tools, while finer materials are chiefly reserved for thin hafted bifaces (probably used as projectile points and knives). The following analysis of flakes according to this fine/coarse dichotomy is designed to complement the tool analysis.

\section{Cortex Types}

Classifications of cortex types include nodular, upland residual, stream battered, and undetermined. Nodular cortex 
was identified by its soft, white, relatively unweathered appearance. It possibly represents chert sources that were quarried from buried contexts (such as cutbanks) or sources that were only recently exposed to the elements. Uplandresidual cortex was defined in this analysis as that which exhibits a weathered appearance, consists of eroded white desilicified rind with red or brown stains, and is thought to have been acquired from open exposures. Stream-battered cortex has a heavily damaged and often a lustrous surface. The soft white desilicified rind is no longer present, and the cortex is usually stained brown. Many flakes with cortex were classified as undetermined, due to their small size and the even smaller patch of cortex exhibited on them. Distinguishing upland residual from nodular was particularly difficult for eroded cortex on small flakes and was not attempted.

\section{Cortex Patterns}

Cortex was recorded as a percentage of occurrence as well as by location-edge cortex and platform cortex, which may represent specific strategies of core reduction. The use of $0 \%, 1-99 \%$, and $100 \%$ increments was useful (following Muto 1971), as many platform-bearing flakes were broken and lacked the distal half. These classifications did not require guessing what percentage would have covered the missing end of the flake. Although there are many different variations on quantifying the amount of dorsal cortex in debitage analysis (Masson 1989:46), Muto's (1971) scheme assumes that flakes completely covered in dorsal cortex are most likely to be related to primary production. As finished tools can still have cortex on them, arbitrary divisions between $1 \%$ and $99 \%$ cortex to assess stage of production may be misleading.

\section{Mineral Precipitates}

A considerable number of artifacts (including chipped stone tools, flakes, and ground stones) from the WilsonLeonard site had mineral precipitates adhering to them. The occurrence of significant precipitates on flakes was recorded in this study. On some, only a thin veneer or a spot or two of precipitates were observed, and these were not recorded. Recorded precipitates were those exhibiting a thick veneer or a sizable patch on the dorsal or ventral surface of the flake. The location of precipitates was not recorded nor were distinctive patterns. It is thought that these precipitates may be related to flake use or to depositional context.

\section{Patination}

Patinated flakes are relatively rare in the debitage collection from the Wilson-Leonard site, and their frequency does not correlate with stratigraphic age. Patinated flakes are most common in Unit II. They are less frequent in the early Paleoindian levels than in the Late Archaic deposits.
This pattern may be related to rate of deposition, and the rapid aggradation that occurred in Unit I stratigraphy (see Chapter 6) may have prevented flakes from undergoing the patination process. Many flakes exhibit a thin, spotty patina related to proximity to cortex. These flakes were recorded as material Type 19, described above. Flakes with distinctive, thick, well-formed patina are rare and are likely to be of nonlocal materials. For tabulating patina, cortex patina (Type 19) was not included. Experiments by Frederick et al. (1994:38) on cherts from Fort Hood have determined that patina is related to variables of soil chemistry or surface exposure and does not always correspond to artifact age.

\section{Burned Flakes}

Many flakes at the site were heated, but few were visibly burned. Heat alteration of flakes recorded in this analysis refers to burned flakes, which exhibit signs such as crackling, crazing, potlidding, or distinctive discoloration such as red or black. The term "heating" is used in the analysis to mean that flakes most likely were inadvertently exposed directly to heat either during use or through proximity after discard, and these were not tabulated as burned.

Most flakes at the site exhibit no evidence for intentional heat treatment to enhance flintknapping attributes. A significant amount of local materials may have been inadvertently exposed to heat, as waxy green (material Type 4 ) or gray (material Type 1) turn pink when heated. Such heating must have occurred at relatively low temperatures or under buffering conditions, as signs of burning (such as crazing or potlidding) are not present.

Heated flakes (and projectile points, see Chapter 13) were often affected in only a portion of their surface area, which facilitated the identification of the original color and the changes brought by heat alteration. However, the effects of heating are thought to have complicated the material type identifications described above. Heating also alters the fluorescent properties of local cherts, eliminating it entirely in cases of extensive heating. Thus, identification of "nonlocal" based on lack of fluorescence can be misleading if an artifact was heated but is not visibly burned. Material classification attempted to compensate for this pitfall through the creation of heat-altered categories such as pink chert.

Causes for burning are not known with any certainty. At any time fires are burning, flakes could get into the fire through either intentional or unintentional human actions. Alternatively, wherever a fire was built, it may have heated flakes at or near the surface in the fireplace. Once subjected to heat, such flakes could be dispersed when hearths were cleaned out or disturbed.

\section{SAMPLEDESCRIPTION}

A sample of 37,933 flakes with platforms was analyzed. These flakes were collected from the TARL excavations in 1/8- 
inch screens as described above. As stratigraphic Units I and II (and their contact zones) consist of archeological deposits that were less dense than Unit III (Figure 19-2), all of the platform-bearing flakes of Units I and II were analyzed. Of 5,813 flakes and chips recovered in Unit I, all 1,938 (33.3\%) platform-bearing flakes were analyzed. Of 41,492 flakes and chips recovered in Unit II, the entire sample of 13,411 (32.3\%) platform-bearing flakes was also analyzed. The much larger number of flakes and chips in Unit III made it necessary to analyze a subset of the debitage from this deposit. Of 139,551 flakes and chips recovered in Unit III, $22,584(16.2 \%)$ flakes with platforms were analyzed.

The proportion of platform-bearing flakes to chips was consistent in each of these stratigraphic units and their contact zones. The percent of broken flakes is reflected in the amount of shatter versus platform bearing flakes found within each stratigraphic unit. A remarkable degree of consistency was observed among the units, which generally had around $70 \%$ shatter (distal flake ends, chips, chunks) and 30\% flakes with platforms (proximal ends and complete) in the samples examined. In Units I (33.3\%), II (32.3\%), and III (31.4\%), just over $30 \%$ of the debitage consisted of flakes with platforms. This observation suggests that taphonomic processes affecting these flake assemblages were not significantly altering the number of platform-bearing flakes among different depositional units.
Flakes analyzed from Unit III included those from TARL Squares 12 and 20 (1/8-inch fraction from the Vertebrate Paleontology columns) in addition to samples of flakes from other areas in the TARL excavations (see percentages listed below). The analysis resulted in the examination of $11.3 \%$ $(\mathrm{n}=5,708)$ flakes with platforms from Unit IIIa (of a flake and chip sample of 50,672), 18.4\% ( $n=3,001)$ platform flakes from Unit IIIa/b (of 16,353 flakes and chips), $13.7 \%$ ( $n=3,588$ ) platform flakes from Unit IIIb (of 26,187 flakes and chips), 41.8\% $(\mathrm{n}=7,884)$ of Unit IIIb/c platform flakes (of 18,865 flakes and chips), and $8.7 \%(n=2,403)$ platform flakes from Unit IIIc (of 27,474 flakes and chips). Totals given for flakes and chips by Unit III analysis units include only those in units and levels selected for analysis.

\section{RESULTS}

The results of flake analysis presented below are organized according to the attributes of size, type, raw material, cortex type and pattern, mineral precipitates, and heat alteration. The analysis of each variable is diachronic, emphasizing patterning in stratigraphic Units I, II, and III and the several transitional deposits. The summary discussion at the end of this chapter comments on relationships among variables within the analysis units and their interpretive potential for procurement, technological, and depositional patterns.

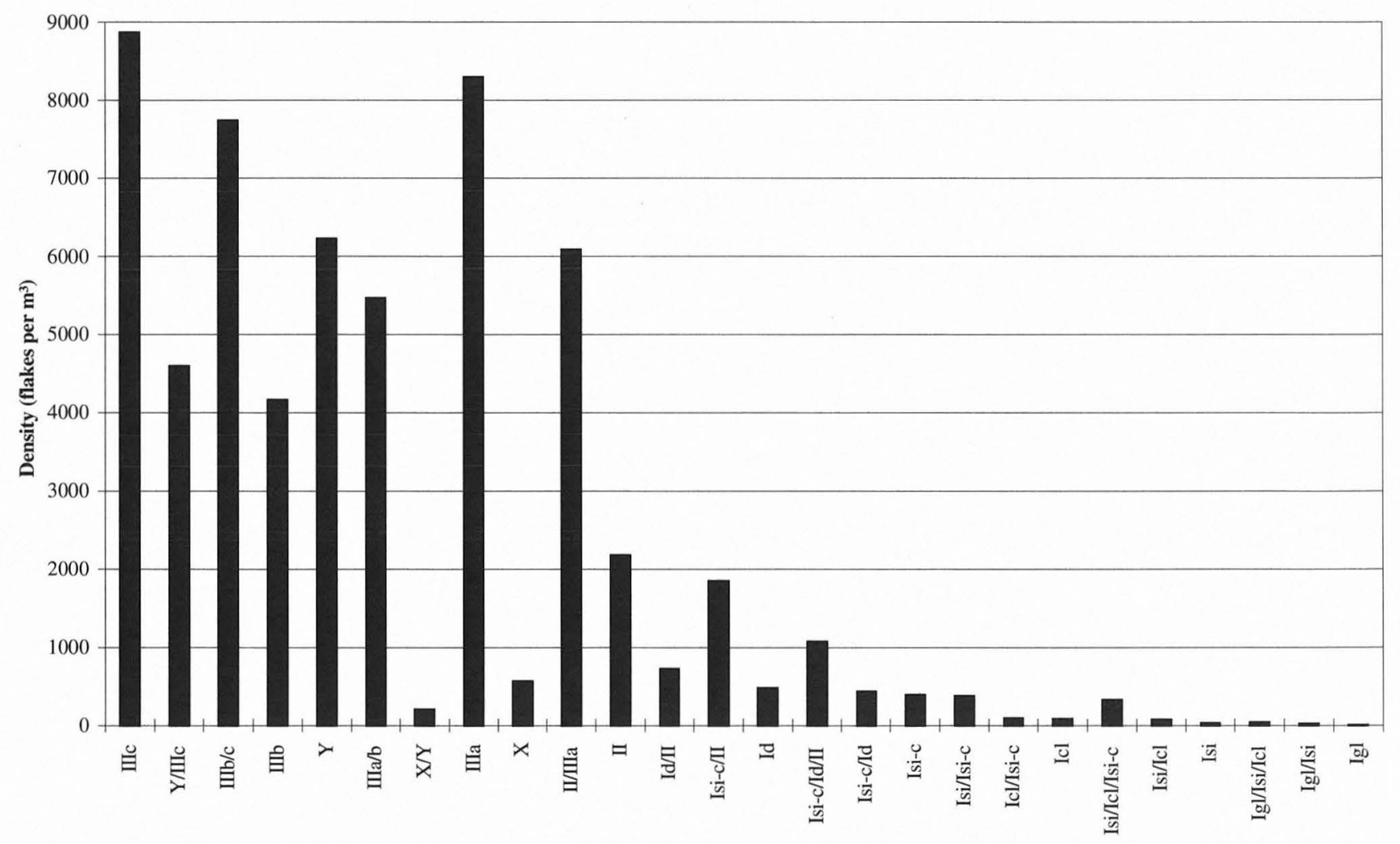

Stratigraphic Unit

FIGURE 19-2. Density of flakes in TARL excavations. 
There are significant differences in the absolute numbers of flakes recovered from Units I, II, and III and their various transitional proveniences; also, density of flakes (all flakes divided by total volume excavated per stratigraphic provenience) increases dramatically in Unit III (see Figure 19-2). These data reflect the relative contribution of natural to cultural depositional rates in the formation of this site. In regard to the interpretive discussion that follows, the reader is reminded that $100 \%$ of the flakes and flake fragments with platforms recovered from Unit I were analyzed, which means that the small counts for some categories are somewhat more significant than they would be if drawn as a sample from a larger collection.

\section{Size}

Throughout the sequence, this data set is dominated by $1 / 8$-inch flakes, followed by $1 / 4$-inch flakes (Table 19-3). The 1/2-inch and especially the 1-inch size categories are comparatively infrequent. Except in Unit Isi-c where they constitute more than $60 \%$ of the flakes, $1 / 8$-inch flakes in Unit I generally amount to around 50-55\%. In Unit II and its transitional zones, these small flakes make up about 53-57\% of the samples. Their proportions are highest in Unit III, ranging from ca. 64-71\%. It is not clear what may account for this trend of increasing numbers of small flakes over time, but more common on-site edge trimming or refurbishing may be indicated.

Frequencies of 1/4-inch flakes range from a high of $40.0 \%$ in Unit Id to a low of $22.1 \%$ in transitional Unit IIIb/ c, but no trends are apparent. Flakes in the $1 / 2$-inch category show their highest frequencies of occurrence $(12.3 \%$ to $16.7 \%$ ) in the lower facies of Unit I (Icl, Isi, and Igl and their transitional zones). There are too few flakes in the 1- inch size category for meaningful interpretation.

In summary, flakes of the $1 / 2$-inch and 1 -inch dimensions are generally present in constant proportions through most of the units observed (Figure 19-3). Unit Isi-c exhibits a notable increase in 1/8-inch flakes relative to 1/4-inch flakes that distinguishes it from other Paleoindian contexts and makes it comparable to Unit IIIa. This is of particular interest given the "Archaic" character of the Wilson component found in Unit Isi-c. In general, small flake size frequencies increase over time, expressed primarily as a changing ratio of 1/4-inch to 1/8-inch flakes (see Figure 19-3).

\section{Types}

Fourteen types of flakes are of primary concern in this analysis (Table 19-4). These are dominated throughout the sequence by "normal" flakes which occur in frequencies from a low of $44.4 \%$ in the lower transitional zones of Unit II to a high of $67.5 \%$ in Unit Id. There is a fairly consistent frequency of normal flakes in the Unit III subdivisions, ranging from ca. $51 \%$ to $57 \%$. Lower in the sequence in Units II and I, the proportion of normal flakes ranges from near $44 \%$ to near $68 \%$ without showing any clear trends. Biface thinning flakes are noticeably infrequent in this data set primarily because they generally have been removed from the sample because of evidence for modification.

The most distinctive trend is among dorsal-troughed flakes that are comparatively frequent (from $10 \%$ to $15 \%$ ) below Unit Isi-c, a little less frequent (from 5\% to 9\%) in the upper part of Unit I and the lower contact of Unit II, and consistently less frequent than $5.6 \%$ in Units II and III. The significance of this trend is not known since the behavioral correlates of such flakes are unclear.

TABLE 19-3

Percentages of Flakes by Screen Size for Each Stratigraphic Unit

\begin{tabular}{|c|c|c|c|c|c|}
\hline \multirow[b]{2}{*}{ Stratigraphic Context } & \multicolumn{4}{|c|}{ Screen Size } & \multirow[b]{2}{*}{ Total No. Analyzed } \\
\hline & 1/8-inch $(\%)$ & 1/4-inch $(\%)$ & 1/2-inch (\%) & 1-inch (\%) & \\
\hline IIIc & 68.8 & 24.3 & 6.0 & 0.9 & 2,403 \\
\hline $\mathrm{IIIb} / \mathrm{c}$ & 70.0 & 22.1 & 7.2 & 0.7 & 7,884 \\
\hline IIIb & 63.7 & 25.2 & 9.8 & 1.3 & 3,588 \\
\hline $\mathrm{IIIa} / \mathrm{b}$ & 57.7 & 31.2 & 10.0 & 1.2 & 3,001 \\
\hline IIIa & 71.0 & 22.7 & 5.9 & 0.4 & 5,708 \\
\hline II/IIIa & 57.0 & 32.0 & 9.8 & 1.3 & 7,048 \\
\hline II & 52.9 & 35.7 & 10.3 & 1.2 & 4,918 \\
\hline Id/II, Isi-c/II & 56.4 & 34.1 & 8.1 & 1.4 & 1,445 \\
\hline Id & 50.0 & 40.0 & 10.0 & 0.0 & 80 \\
\hline Isi-c/Id & 53.0 & 35.8 & 9.0 & 2.2 & 321 \\
\hline Isi-c & 61.1 & 27.4 & 10.5 & 1.0 & 679 \\
\hline Isi-c/Icl/Isi & 51.8 & 36.6 & 10.4 & 1.2 & 508 \\
\hline Icl & 47.8 & 33.3 & 16.7 & 2.2 & 90 \\
\hline Isi/Icl & 50.9 & 35.8 & 12.3 & 0.9 & 106 \\
\hline Isi & 52.8 & 32.6 & 13.5 & 1.1 & 89 \\
\hline Igl\&Igl/Isi/Icl & 55.4 & 29.2 & 15.4 & 0.0 & 65 \\
\hline
\end{tabular}




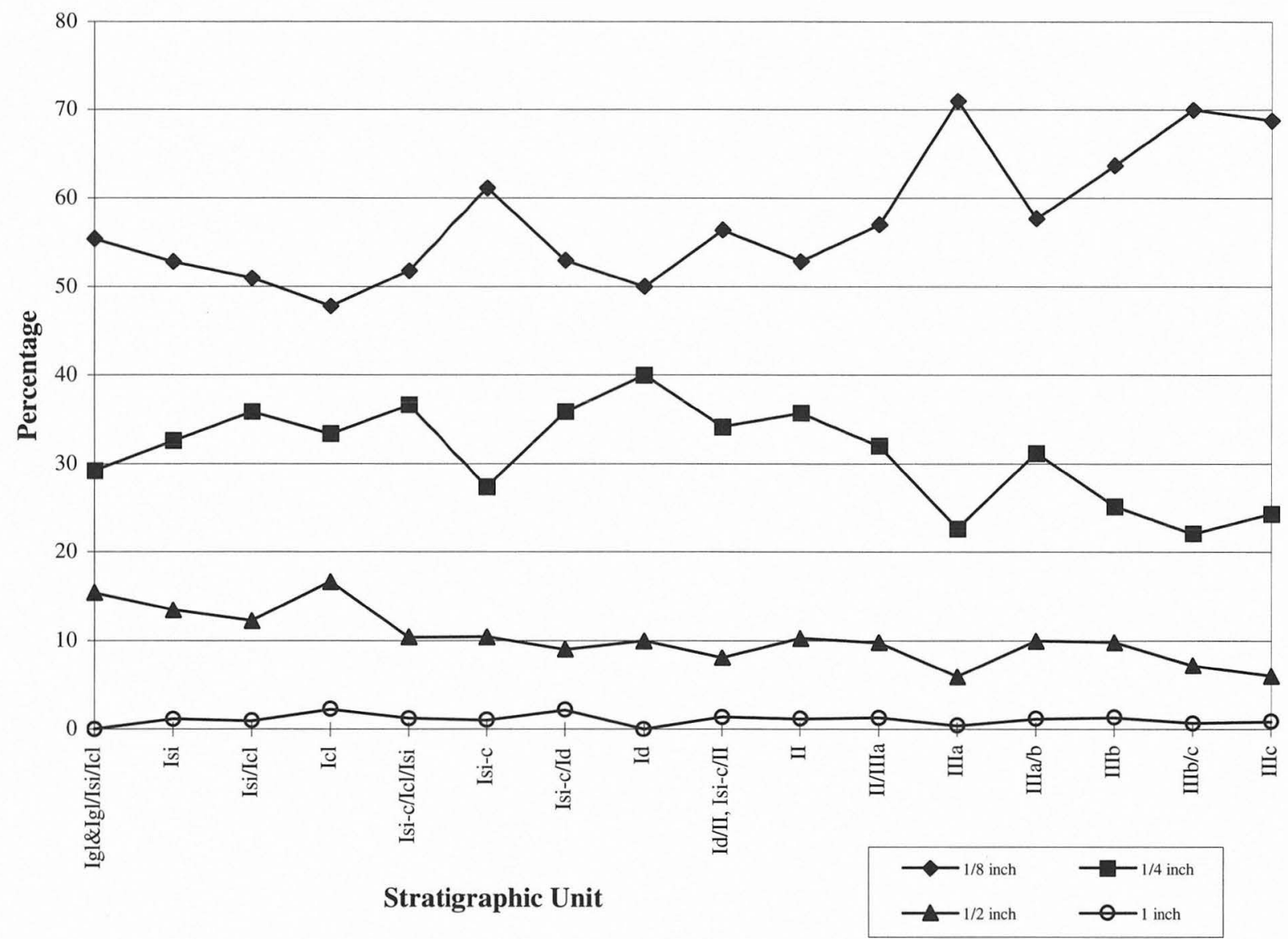

FIGURE 19-3. Percentages of flakes by size grades within stratigraphic units.

Proportions of thin edge-trimming flakes in the samples do not vary greatly throughout the sequence but are most frequent in Unit Isi-c and least frequent in Unit Id and all of Unit III. Thick edge-trimming flakes are infrequent in all of the analysis units, but are slightly more common in Isi-c and Id. The production and maintenance of thin edge-trimmed tools is inferred from these flakes.

It was anticpated that exploded-bulb flakes might include a significant number of notching flakes and that they might correspond to notching technologies (especially with Bell/Andice bifaces) later in the site's history. In general, however, these are present in such low percentages that such comparisons are rendered invalid. Likewise none of the rest of the flake types occurs in sufficient frequencies to indicate meaningful patterns.

A comparative chart of selected flake types demonstrates certain patterns (Figure 19-4). Dorsal-troughed and parallel-edged flakes are significant only in lower units of the site. In general, these categories and thick edge-trimming flakes are in such low frequencies that they do not inform on technological variation at the site. Paralleledged flakes were quantified with the expectation that they would correlate to Paleoindian removal of such flakes in the production of lanceolate bifaces. Although in low percentages, the higher occurrence of parallel-edged flakes in Paleoindian levels seems to confirm this expectation.

Changing proportions of normal flakes to thin edgetrimming flakes (see Figure 19-4) may also represent significant inter-unit technological variation. Normal flakes represent an informal, nonstandardized technology that is more closely related to earlier manufacturing stages than late-stage thin edge-trimming flakes. With this assumption in mind, Figure 19-4 suggests that increased on-site earlystage manufacturing debris is recovered in transitional units immediately below Unit Isi-c and in Id. As these units do not represent well-isolated cultural components, the interpretation of this pattern is problematic. However, the debitage present in these deposits generally derives from Late Paleoindian occupations. On a broad level, it is thus possible to say that more normal flakes are found at the upper extreme of Unit I compared to subsequent recoveries from Units II and III.

\section{Raw Material}

Raw materials show some significant variation over time at the site (Table 19-5). Highly local, fine-grained Edwards chert makes up almost $72 \%$ of the material in Unit Isi, but only $48 \%$ in Igl and its transitional zones and less 
TABLE 19-4

Percentages of Flakes by Types for Each Stratigraphic Unit

\begin{tabular}{|c|c|c|c|c|c|c|c|c|c|c|c|c|c|c|c|}
\hline \multirow[b]{2}{*}{$\begin{array}{l}\text { Stratigraphic } \\
\text { Unit }\end{array}$} & \multicolumn{14}{|c|}{ Flake Types } & \multirow[b]{2}{*}{$\begin{array}{l}\text { Total No. } \\
\text { Analyzed }\end{array}$} \\
\hline & $\begin{array}{l}\text { Normal } \\
\text { Flake }\end{array}$ & \begin{tabular}{|l} 
Biface \\
Thinning \\
Flake
\end{tabular} & $\begin{array}{l}\text { Dorsal } \\
\text { Trough }\end{array}$ & $\begin{array}{l}\text { Exploded } \\
\text { Bulb }\end{array}$ & \begin{tabular}{|l} 
Parallel- \\
edged \\
Pressure \\
Flake
\end{tabular} & $\begin{array}{l}\text { Thin Edge- } \\
\text { trimming } \\
\text { Flake }\end{array}$ & $\begin{array}{l}\text { Thick Edge } \\
\text { trimming } \\
\text { Flake }\end{array}$ & $\begin{array}{l}\text { Flake } \\
\text { Blade }\end{array}$ & $\begin{array}{l}\text { Edge Bite } \\
\text { Flake }\end{array}$ & \begin{tabular}{|l} 
Core \\
Fragment
\end{tabular} & $\begin{array}{l}\text { Microflake } \\
\text { (normal) }\end{array}$ & $\begin{array}{l}\text { Leg- } \\
\text { assisted } \\
\text { Pressure } \\
\text { flake }\end{array}$ & $\begin{array}{l}\text { Manu- } \\
\text { facturing } \\
\text { Error }\end{array}$ & $\begin{array}{l}\text { Unifacial } \\
\text { Resharp- } \\
\text { ening } \\
\text { Flake }\end{array}$ & \\
\hline IIIc & 53.5 & 2.0 & 3.1 & 2.2 & 6.8 & 22.9 & 1.5 & 0.5 & 0.2 & 0.3 & 6.7 & 0.0 & 0.1 & 0.2 & 5,708 \\
\hline $\mathrm{IIIb} / \mathrm{c}$ & 51.1 & 1.8 & 2.6 & 1.8 & 7.0 & 22.8 & 2.1 & 0.5 & 0.2 & 0.2 & 9.9 & 0.0 & 0.1 & 0.1 & 3,001 \\
\hline IIIb & 53.0 & 2.1 & 3.8 & 2.2 & 6.6 & 25.2 & 1.7 & 0.6 & 0.1 & 0.2 & 4.3 & 0.1 & 0.0 & 0.0 & 3,588 \\
\hline $\mathrm{III} / \mathrm{b}$ & 56.5 & 2.2 & 4.4 & 1.3 & 7.0 & 21.2 & 2.1 & 0.5 & 0.3 & 0.1 & 4.2 & 0.0 & 0.0 & 0.1 & 7,884 \\
\hline IIIa & 54.4 & 1.6 & 5.4 & 1.5 & 6.6 & 20.0 & 2.1 & 0.2 & 0.2 & 0.1 & 7.5 & 0.1 & 0.0 & 0.1 & 2,403 \\
\hline II/IIIa & 47.9 & 1.9 & 5.6 & 2.1 & 5.4 & 27.2 & 2.5 & 0.3 & 0.1 & 0.0 & 6.6 & 0.2 & 0.1 & 0.0 & 7,048 \\
\hline II & 48.4 & 2.4 & 5.5 & 1.4 & 6.5 & 28.8 & 2.5 & 0.2 & 0.3 & 0.0 & 4.4 & 0.1 & 0.0 & 0.0 & 4,918 \\
\hline Id/II, Isi-c/II & 44.4 & 1.3 & 6.3 & 2.0 & 6.3 & 30.6 & 2.4 & 0.3 & 0.0 & 0.1 & 6.3 & 0.1 & 0.0 & 0.0 & 1,445 \\
\hline Id & 67.5 & 0.0 & 8.8 & 0.0 & 3.8 & 16.3 & 3.8 & 0.0 & 0.0 & 0.0 & 0.0 & 0.0 & 0.0 & 0.0 & 80 \\
\hline Isi-c/Id & 49.8 & 1.6 & 7.2 & 0.6 & 6.9 & 28.3 & 3.7 & 0.6 & 0.9 & 0.0 & 0.0 & 0.0 & 0.3 & 0.0 & 321 \\
\hline Isi-c & 45.4 & 1.8 & 5.4 & 1.8 & 6.0 & 33.0 & 2.5 & 0.6 & 0.1 & 0.0 & 3.1 & 0.1 & 0.1 & 0.0 & 679 \\
\hline Isi-c/Icl/Isi & 57.1 & 1.6 & 10.4 & 0.8 & 3.3 & 23.6 & 1.6 & 0.8 & 0.4 & 0.0 & 0.0 & 0.0 & 0.4 & 0.0 & 508 \\
\hline Icl & 45.6 & 3.3 & 15.6 & 3.3 & 7.8 & 23.3 & 1.1 & 0.0 & 0.0 & 0.0 & 0.0 & 0.0 & 0.0 & 0.0 & 90 \\
\hline Isi/Icl & 45.3 & 5.7 & 11.3 & 0.0 & 8.5 & 27.4 & 0.0 & 0.0 & 0.0 & 0.0 & 0.0 & 0.0 & 0.9 & 0.9 & 106 \\
\hline Isi & 55.1 & 3.4 & 10.1 & 0.0 & 2.2 & 27.0 & 0.0 & 0.0 & 0.0 & 1.1 & 1.1 & 0.0 & 0.0 & 0.0 & 89 \\
\hline Igl\&Igl/Isi/Icl & 52.3 & 0.0 & 12.3 & 1.5 & 1.5 & 32.3 & 0.0 & 0.0 & 0.0 & 0.0 & 0.0 & 0.0 & 0.0 & 0.0 & 65 \\
\hline
\end{tabular}




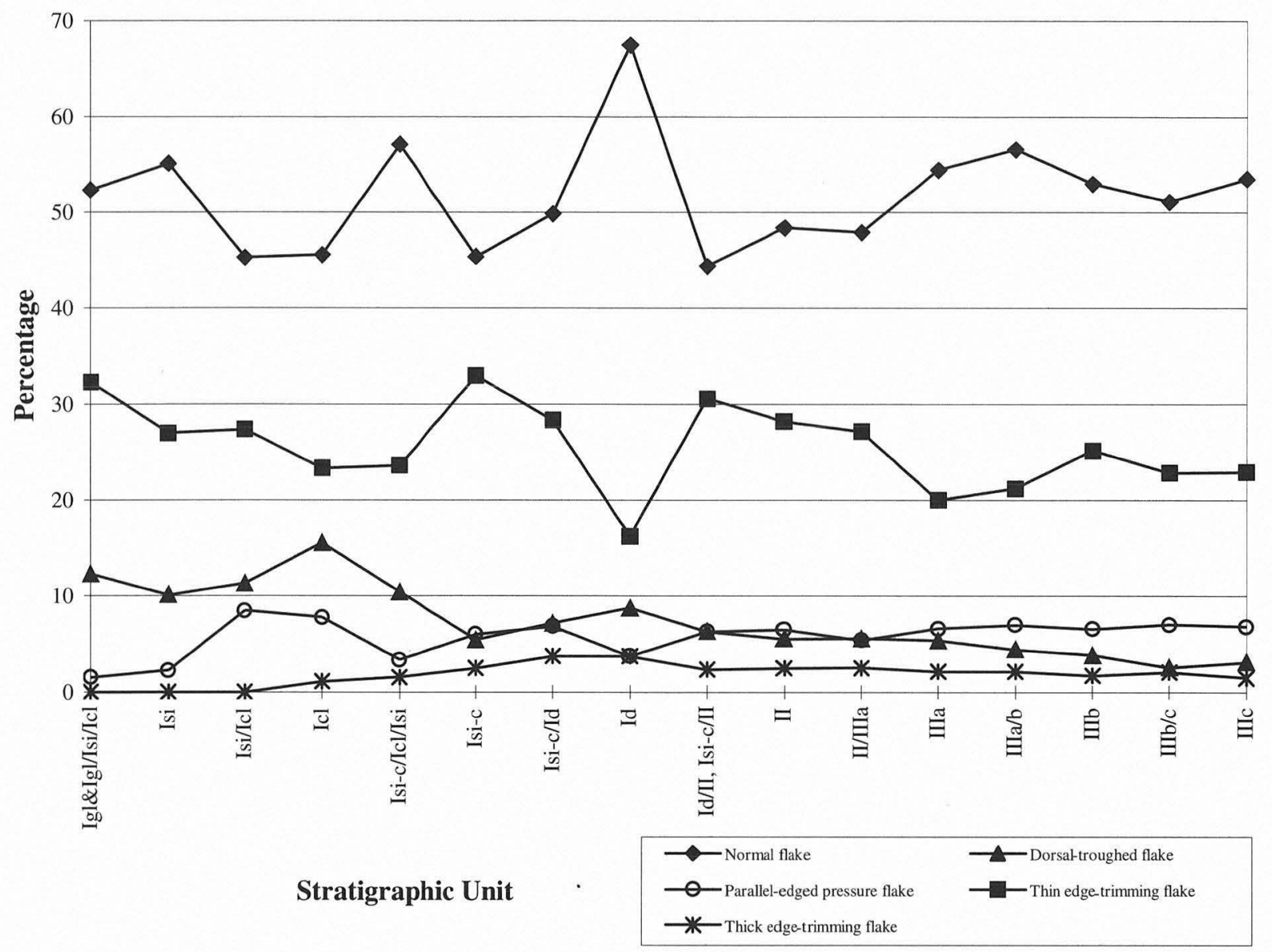

FIGURE 19-4. Percentages of selected flake types within stratigraphic units.

than $57 \%$ in Icl and the Isi/Icl transitional zone. Throughout the remainder of the sequence, this material makes up anywhere from $70-77 \%$ of each sample. The other finegrained Edwards varieties are fairly frequent in the lower part of Unit I (from 18-37\%) and in Unit Id (20\%) but elsewhere are consistently less than $11 \%$ (and even less than $8 \%$ in all but the deposits above IIIa). Low sample sizes are thought to account for greater variability in some Unit I deposits. Highly local, medium-grained and coarse-grained Edwards cherts are low in frequency in Unit I (from 1.1$8.4 \%)$, moderate in frequency in Unit II (9.8\%), and slightly more frequent in Unit III (ca. 12-15\%). When frequencies of all fine-grained cherts are compared to those of all coarsegrained cherts, an increased abundance of the coarser cherts as a whole shows up in Units IIIa, IIIa/b, and IIIb. This pattern may be related to the occurrence of bifacial Clear Fork tools of coarse material which peaks in Unit IIIa (see Chapter 15).

One factor that is difficult to assess is the extent to which groundwater staining may have altered the appearance of some highly local Edwards chert types in Unit I creating some spurious "types" that have been tabulated as "other fine-grained Edwards cherts" in this analysis. Quartzite flakes appear in very small numbers in Unit II and its two transitional zones whereas quartz flakes-also very infrequent-are most noticeable in Icl and Isi-c with its transitional zones. Three quartz flakes were noted in Unit II and one in Unit IIIc.

In their response to ultraviolet irradiation (Table 19-6), the cherts show patterns somewhat different from those based on observations made in normal light, probably due to the effects of staining or burning. Because of the staining problem just mentioned and the inherently more-subjective nature of observing chert colors and textures, fluorescence may be taken as the more reliable indicator of Edwards chert in most cases. Overall, fluorescent cherts exceeded $97 \%$ of every sample from Unit Id upward and from Unit Icl. They were also somewhat frequent in Igl and its transitional zones (92.2\%), Isi (95.3\%), and transitional zone Isi-c/Icl/Isi (91.8\%). In contrast, three analysis units showed lower total occurrences of fluorescence; Isi-c/Id (89.0\%), Isi-c (89.8\%), and Isi/Icl (87.9\%). Fluorescent local tan chert accounted for more than $83 \%$ of the sample in all of Units II and III, but varied in frequency from ca. 54-82\% in the facies of Unit I. Green chert is less than about $3 \%$ of all samples except the following: $\operatorname{Id}(7.5 \%)$, Icl (14.4\%), Isi/ Icl $(7.5 \%)$, Isi (11.2\%), and Igl and its transitional zones $(7.7 \%)$. The fluorescent variety referred to as "mustard or 
TABLE 19-5

Percentages of Flakes by Raw Materials for Each Stratigraphic Unit

\begin{tabular}{|c|c|c|c|c|c|c|}
\hline Stratigraphic Unit & $\begin{array}{l}\text { Total of Fine } \\
\text { Cherts }\end{array}$ & $\begin{array}{l}\text { Highly Local } \\
\text { Edwards, Coarse }\end{array}$ & $\begin{array}{l}\text { Non-Edwards } \\
\text { Coarse }\end{array}$ & $\begin{array}{l}\text { Total of Coarse } \\
\text { Cherts }\end{array}$ & $\begin{array}{l}\text { Quartz and } \\
\text { Quartzites }\end{array}$ & $\begin{array}{l}\text { Total No. } \\
\text { Analyzed }\end{array}$ \\
\hline IIIc & 85.3 & 14.2 & 0.5 & 14.7 & 0.1 & 2,403 \\
\hline $\mathrm{IIIb} / \mathrm{c}$ & 85.9 & 13.2 & 0.9 & 14.1 & 0.0 & 7,884 \\
\hline IIIlb & 83.1 & 15.9 & 1.0 & 16.9 & 0.0 & 3,588 \\
\hline $\mathrm{III} a / b$ & 86.4 & 13.1 & 0.5 & 13.6 & 0.0 & 3,001 \\
\hline IIIa & 87.0 & 12.1 & 0.9 & 13.0 & 0.0 & 5,708 \\
\hline II/IIIa & 87.5 & 11.4 & 1.1 & 12.5 & 0.1 & 7,048 \\
\hline II & 89.6 & 9.8 & 0.6 & 10.4 & 0.2 & 4,918 \\
\hline Id/II, Isi-c/II & 89.4 & 9.9 & 0.7 & 10.6 & 0.1 & 1,445 \\
\hline Id & 92.4 & 6.3 & 1.3 & 7.6 & 0.0 & 80 \\
\hline Isi-c/Id & 89.1 & 8.4 & 2.5 & 10.9 & 0.3 & 321 \\
\hline Isi-c & 90.9 & 8.4 & 0.7 & 9.1 & 0.4 & 679 \\
\hline Isi-c/Icl/Isi & 92.5 & 7.1 & 0.4 & 7.5 & 0.2 & 508 \\
\hline Icl & 94.5 & 4.4 & 1.1 & 5.5 & 1.1 & 90 \\
\hline Isi/Icl & 93.4 & 5.7 & 0.9 & 6.6 & 0.0 & 106 \\
\hline Isi & 98.9 & 1.1 & 0.0 & 1.1 & 0.0 & 89 \\
\hline Igl\&Igl/Isi/Icl & 93.8 & 6.2 & 0.0 & 6.2 & 1.5 & 65 \\
\hline
\end{tabular}

honey" is very infrequent from Unit Id upward (consistently $1.2 \%$ or less); it is modestly frequent in Isi (5.6\%), Isi$\mathrm{c} / \mathrm{Icl} / \mathrm{Isi}(4.5 \%)$, and Isi-c (4.6\%); and it is relatively frequent in Igl and its transitional zones (26.2\%), Isi/Icl (14.2\%), and Icl $(20.0 \%)$. Fluorescent nonlocal gray does not occur in Unit I but appears fairly consistently in very low frequencies throughout Units II and III (none in Unit IIIa/b). One flake of fluorescent white chert was noted in Unit Icl and in Unit Id, but this material is otherwise absent from Unit I; it ranges from 2.2 to $6.6 \%$ in the samples from Units II and III. Fluorescent yellow is found only in Units II and III, and then in frequencies of less than $0.5 \%$.

Generally the nonfluorescent cherts occur in such low frequencies that patterns are not discernible, but the orange variety and the brown variety each has a slight spike in Isi/ Icl. "Other" varieties are more common in Unit I than in either Unit II or Unit III. This finding makes sense considering the high quality of locally available cherts. The relationship between fluorescent cherts and settlement/mobility or range of procurement/exchange is unclear. Conceivably, nonlocal Edwards raw materials could have been obtained from sources as remote as, or more remote than, some of those nonfluorescing non-Edwards materials. Much further work is needed to more specifically identify raw material source areas.

In summary, the only dramatic fluctuations observed in raw materials occur in Unit I deposits that have low sample sizes, such as Isi/Icl, Icl, and Id (Figure 19-5). The remainder of the units exhibit a high usage of fine, locally available raw materials with a slight increase in coarse-grained chert over time in Unit III.

\section{Cortex Type and Pattern}

Cortex type could be determined on relatively few of the total flakes examined (usually less than about 5\%), and in most cases, even when the specimens with indeterminate cortex are included, the occurrences are less than about $12 \%$ (Table 19-7). Nodular cortex is more common in all of Unit I than in Units II or III, having its highest frequency $(10.1 \%)$ in Unit Isi. Upland-residual cortex occurs in low frequencies throughout the sequence and is equal to or higher than percentages of nodular cortex in Units Icl/Isi/Isi-c and higher through Unit IIIc. In fact, upland residual cortex is the dominant cortex form observed in Units II and III.

Cortex pattern is heavily dominated by flakes lacking any cortex (from $77.5 \%$ to $93.8 \%$ ) (see Table 19-7). Noncortex flakes are slightly more characteristic of Units II and III than they are of Unit I. Primary cortex flakes, those with 100\% cortex coverage, are infrequent in the entire sequence, reaching highs of $3.8 \%$ in Unit Id and $3.4 \%$ in Unit Isi. Flakes with cortex platforms or edges are not common at WilsonLeonard.

\section{Mineral Precipitates}

Mineral precipitates are infrequent in Unit IIIa and in the transitional zone, II/IIIa (Table 19-8). Flakes with adhering mineral precipitates are comparatively frequent from Unit II downward through transitional Icl/Isi/Isi-c except in Units Icl and Isi/Icl. The frequency is also fairly high in Units Isi, Igl, and the Igl transitional units. Since these precipitates developed after the flakes were deposited, they 
TABLE 19-6

Percentages of Flakes by Categories of Fluorescence for Each Stratigraphic Unit

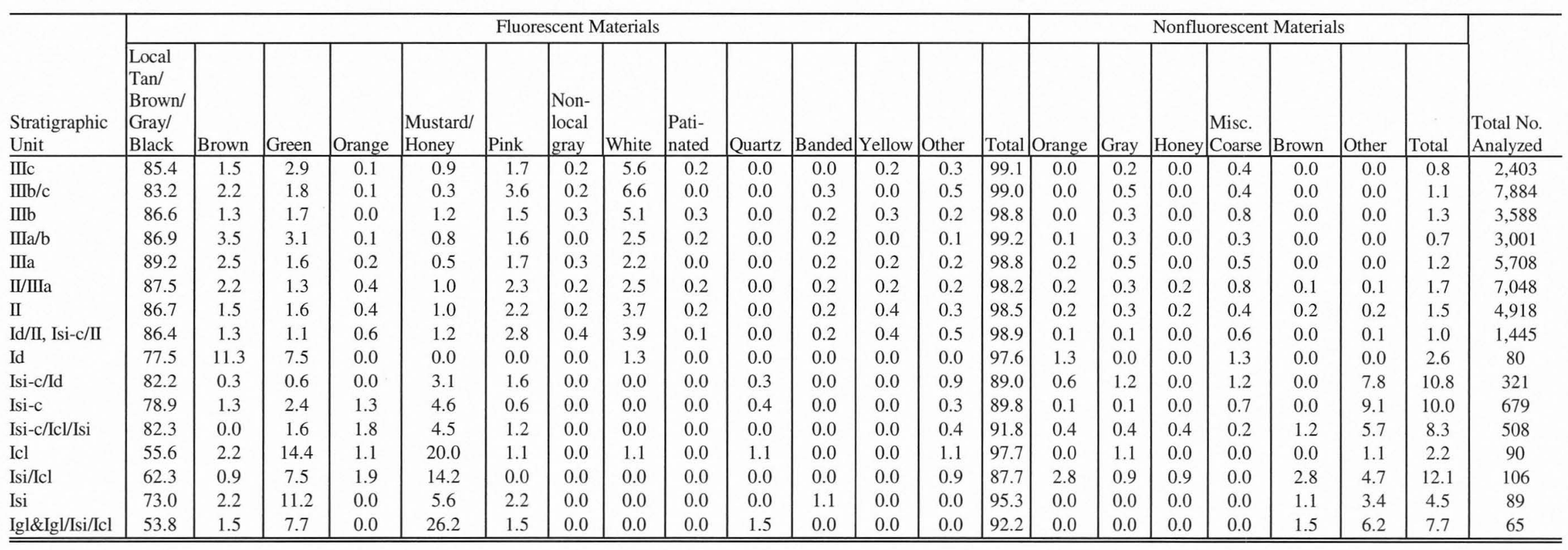




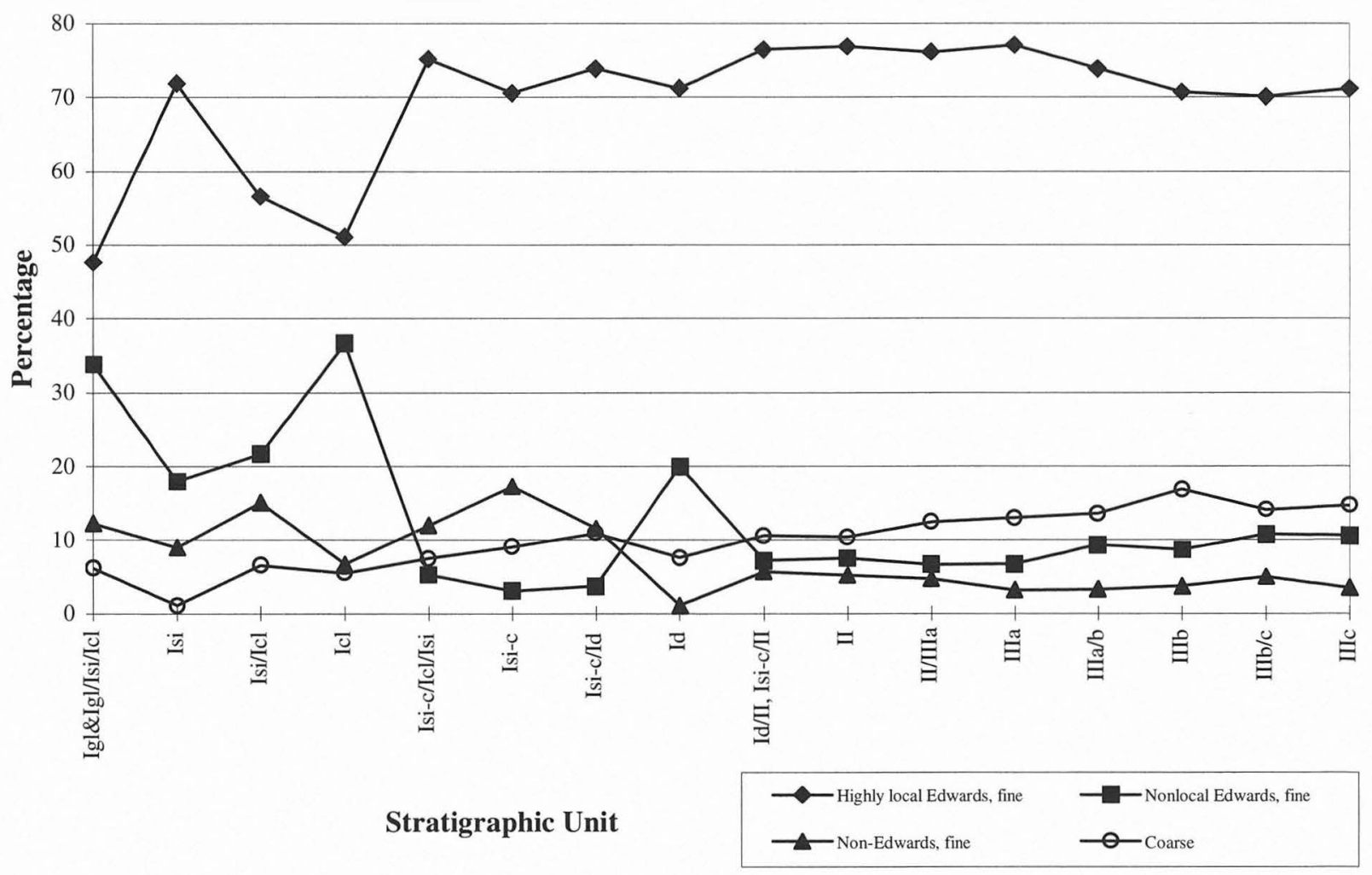

FIGURE 19-5. Percentages of flakes by raw materials within stratigraphic units.

TABLE 19-7

Percentages of Flakes by Cortex Type and by Cortex Pattern for Each Stratigraphic Unit

\begin{tabular}{l|c|c|c|c|c|c|c|c|c|c|c}
\hline \multirow{2}{*}{$\begin{array}{l}\text { Stratigraphic } \\
\text { Unit }\end{array}$} & \multicolumn{9}{|c|}{ Cortex Type } & \multicolumn{5}{c|}{ Cortex Pattern } \\
\cline { 2 - 11 } & Nodular & $\begin{array}{l}\text { Upland } \\
\text { Residual }\end{array}$ & $\begin{array}{l}\text { Stream- } \\
\text { battered }\end{array}$ & $\begin{array}{l}\text { Undeter- } \\
\text { mined }\end{array}$ & $\begin{array}{l}\text { Total No. } \\
\text { Analyzed }\end{array}$ & $\begin{array}{l}\text { No } \\
\text { Cortex }\end{array}$ & $\begin{array}{l}1- \\
99 \%\end{array}$ & $100 \%$ & Edge & Platform & $\begin{array}{l}\text { Total No. } \\
\text { Analyzed }\end{array}$ \\
\hline IIIc & 1.5 & 2.8 & 0.5 & 7.4 & 293 & 87.8 & 6.6 & 0.7 & 2.4 & 2.5 & 2,403 \\
IIIb/c & 0.8 & 3.4 & 0.5 & 6.3 & 864 & 89.0 & 6.1 & 0.7 & 2.1 & 2.0 & 7,884 \\
IIIb & 0.6 & 3.7 & 0.4 & 4.5 & 332 & 90.7 & 5.1 & 0.7 & 1.8 & 1.7 & 3,588 \\
IIIa/b & 0.5 & 5.0 & 0.3 & 3.6 & 282 & 90.6 & 5.2 & 0.8 & 1.7 & 1.7 & 3,001 \\
IIIa & 0.5 & 4.5 & 0.3 & 3.2 & 482 & 91.6 & 4.8 & 0.7 & 1.5 & 1.5 & 5,708 \\
II/IIIa & 1.2 & 4.8 & 0.2 & 3.2 & 664 & 90.7 & 4.6 & 0.7 & 2.6 & 1.4 & 7,048 \\
II & 1.1 & 5.5 & 0.4 & 2.9 & 488 & 90.1 & 5.3 & 0.8 & 1.9 & 1.9 & 4,918 \\
Id/II, Isi-c/II & 0.7 & 4.2 & 0.0 & 3.0 & 115 & 92.0 & 4.4 & 0.6 & 1.5 & 1.4 & 1,445 \\
Id & 2.5 & 1.3 & 0.0 & 1.3 & 4 & 93.8 & 1.3 & 3.8 & 0.0 & 1.3 & 80 \\
Isi-c/Id & 2.5 & 5.3 & 0.6 & 3.4 & 38 & 88.2 & 6.9 & 1.6 & 1.6 & 1.9 & 321 \\
Isi-c & 2.7 & 3.7 & 0.6 & 4.6 & 78 & 88.5 & 6.2 & 0.7 & 3.4 & 1.2 & 679 \\
Icl/Isi/Isi-c & 3.5 & 3.5 & 0.2 & 3.5 & 55 & 89.2 & 6.5 & 0.4 & 2.4 & 1.6 & 508 \\
Icl & 4.4 & 1.1 & 0.0 & 12.2 & 16 & 82.2 & 8.9 & 2.2 & 2.2 & 4.4 & 90 \\
Isi/Icl & 4.7 & 0.9 & 0.9 & 3.8 & 11 & 88.7 & 6.6 & 0.9 & 0.9 & 2.8 & 106 \\
Isi & 10.1 & 2.2 & 0.0 & 10.1 & 20 & 77.5 & 13.5 & 3.4 & 3.4 & 2.2 & 89 \\
Igl\&Igl/Isi/Icl & 3.1 & 0.0 & 0.0 & 9.2 & 8 & 87.7 & 7.7 & 1.5 & 1.5 & 1.5 & 65 \\
\hline \hline
\end{tabular}

primarily reflect pedogenic processes; however, in the case of some artifact classes, there is evidence that cultural processes are also at work (in the Late Archaic midden at the Mustang Branch site, heavy chopping tools showed disproportionately high frequencies of adhering precipitates
[Collins 1994:142-143], and a similar occurrence is seen at Wilson-Leonard [see Chapter 18]). The generally small flakes in this study would not be expected to have userelated precipitates unless they had been detached in resharpening tools affected by use. Such an interpretation 
TABLE $19-8$

Mineral Precipitation, Patina, and Burning in Percentages

\begin{tabular}{|c|c|c|c|c|c|}
\hline Stratigraphic Unit & $\begin{array}{l}\text { Mineral Precipitates } \\
\text { Present }\end{array}$ & Patina Present & \begin{tabular}{|l} 
Differentially \\
Patinated \\
\end{tabular} & Burning Present & Total No. Analyzed \\
\hline$\overline{\text { IIIC }}$ & 1.3 & 2.1 & 0.0 & 15.7 & 2,403 \\
\hline $\mathrm{IIIb} / \mathrm{c}$ & 7.6 & 1.1 & 0.0 & 15.7 & 7,884 \\
\hline IIIb & 2.5 & 0.9 & 0.0 & 6.2 & 3,588 \\
\hline IIIa/b & 3.0 & 0.4 & 0.0 & 7.1 & 3,001 \\
\hline IIIa & 1.8 & 0.7 & 0.0 & 0.8 & 5,708 \\
\hline II/IIIa & 5.1 & 1.3 & 0.0 & 4.4 & 7,048 \\
\hline II & 8.9 & 3.2 & 0.0 & 2.9 & 4,918 \\
\hline Id/II, Isi-c/II & 11.3 & 2.4 & 0.0 & 2.4 & 1,445 \\
\hline Id & 18.8 & 0.0 & 0.0 & 6.3 & 80 \\
\hline Isi-c/Id & 20.2 & 0.9 & 0.0 & 5.6 & 321 \\
\hline Isi-c & 9.1 & 0.7 & 0.1 & 4.0 & 679 \\
\hline Icl/Isi/Isi-c & 11.8 & 0.2 & 0.0 & 5.5 & 508 \\
\hline Icl & 2.2 & 0.0 & 1.1 & 11.1 & 90 \\
\hline Isi/Icl & 5.7 & 0.0 & 0.9 & 6.6 & 106 \\
\hline Isi & 12.4 & 1.1 & 1.1 & 5.6 & 89 \\
\hline Igl\&Igl/Isi/Icl & 12.3 & 1.5 & 0.0 & 1.5 & 65 \\
\hline
\end{tabular}

would be in accord with the high percentages of mineral precipitates in this data set occurring in units (Igl and Igl/ Isi/Icl and Isi) where elevated occurrences of mineral precipitation would not be predicted on geologic grounds.

This is a phenomenon in need of comprehensive investigation. Mineral precipitates adhering to many of the heavy chopping tools at Wilson-Leonard and at the Mustang Branch site (Collins 1994) are concentrated well back from the edges of the tools, which might reflect removal in edge sharpening. Chemical analysis of the precipitates and the tool surfaces beneath them in conjunction with use-wear study needs to be integrated with closer technological consideration of the evidence for resharpening.

\section{Patination}

Patination occurs in low frequencies throughout much of the Wilson-Leonard sequence, with a slight peak in Unit II and its transitional zones (see Table 19-8). Differential patination occurs only in Unit I and in very low frequencies even there. This low frequency of patinated flakes agrees with the overall site formational history, that is one of aggradation prevailing over erosion or surface stability throughout most of the last 11,500 or so years. The low number of differentially patinated flakes also agrees with the findings among other artifact classes that for the most part, knappers at this site were not picking up old chipped stone pieces after long periods of abandonment and reworking them. These are presumed to have been picked up elsewhere and brought to Wilson-Leonard, because natural rates of deposition at the site have kept patination to a minimum.

\section{Burned Flakes}

Flakes exposed to sufficient heat to be visibly altered occur throughout the sequence in low to moderate but varying frequencies (see Table 19-8). Moderately high frequencies are seen in Units Isi/Icl, Icl, Id, IIIa/b, IIIb, IIIb/c, and IIIc. That the highest frequencies occur in IIIb/c and IIIc is consistent with the presence of extensive formation of burned rock features (including middens) in this unit. The high frequency in Unit Icl is unexpected, but being based on only 90 flakes, it may not be entirely representative of either natural or cultural exposure of flakes to heat.

\section{SUMMARY}

This analysis includes flakes smaller than $1 / 2$-inch. Most flakes greater than this size were utilized at the Wilson-Leonard site and are analyzed as tools (see Chapter 17). Generally, the proportion of small (1/8-inch) flakes to 1/4-inch flakes increases over time at the site. This pattern may relate to increased longevity of occupation over time and the occurrence of more late-stage manufacturing or refurbishing activities responsible for the small debitage.

Comparisons of flake types suggest that much of the lithic reduction detectable at the site was late-stage bifacial thinning. Thin edge-trimming, dorsal troughed, and paralleledged flakes are present in greatest numbers of all technologically sensitive flake types, and these are thought to represent various aspects of bifacial edge trimming. Normal flakes, which are less technologically diagnostic and represent a greater variety of activities, are the most common 
flake form among samples large enough to merit comparisons. Their constant presence attests to primary and secondary stage reduction activities occurring to some degree throughout the site's depositional history. Among units with large sample sizes, the proportion of normal to edge-trimming flakes does not vary significantly.

Raw material analysis demonstrates the significant exploitation and reliance upon highly local, fine-grained cherts throughout the site's history. A slight increase in coarsegrained materials is seen over time, a pattern echoed in observations among lithic tool classes. When units of sizable sample numbers are compared, it is noteworthy that Paleoindian units do not exhibit greater diversity in raw material exploitation given the expectation that such groups might have practiced greater settlement mobility. However, considering the subjective assumption that highly local Edwards cherts represent one of the most superior natural resources for tools on this part of the continent, it is less surprising that Paleoindian as well as Archaic assemblages in this area are dominated by these raw materials. Regardless of mobility pattern, cherts highly local to the site were rightfully accorded high value.

Other attributes recorded for small flakes were found in low percentages. Cortex data indicate that nodular cobbles were preferred in lower Unit I, but upland residual cortex dominates for subsequent units. A slight change in exploitation preferences or in resource availability may be hinted at by this observation, but numbers and percentages are too low for definative conclusions. Also, small, late-stage flakes are not the best indicators of cortex patterns. Mineral precipitates occur in levels up to $20 \%$ in some units. The cultural or pedogenic origin of these occurrences is at present poorly understood. Patina occurs in frequencies too low to support conclusive interpretations. Burning increases in apparent association with the large oven and midden features in Units IIIb/c and IIIc.

This study suggests that analyses of small flakes complement the examination of other aspects of the lithic technology. In particular, flake size, flake type, and raw material have proved informative in regard to technological behavior at this site.

\section{DIRECTIONS FOR FUTURE RESEARCH}

Chipped lithic artifacts from the Wilson-Leonard site have been studied as distinct categories-projectile points, bifaces, unifaces, edge-modified flakes, cores, and the unmodified flakes discussed in this chapter. Technological information recovered as part, but never the primary part, of the analysis of each of these categories is extracted and synthesized elsewhere (see Chapters 7-10). Of the several alternative ways in which this project could have been orga- nized, this was selected for a variety of reasons (see Chapter 2 ), and, as is often the case, there were costs as well as benefits to doing the analyses of the various lithic categories separately. At the outset of this chapter, the advantages of examining the small, supposedly unmodified flakes were considered. One of the costs is also significant and is discussed here.

Further analysis of Wilson-Leonard debitage would benefit from an integrated examination of a larger sample of large flakes, even those that are also considered to be "tools." Small flakes examined in this study provide several advantageous perspectives on the site. Advantages include, for the $1 / 8$-inch category, the reduced chance that they were transported out of the knapping context for use as tools. However, this light-weight fraction may also be more susceptible to inadvertent movement by human or other causes. Based on this analysis, a substantial degree of homogeneity is observed among flakes of the 1/8-inch-size category as they are primarily related to late-stage edge sharpening or resharpening. Larger flakes (1/2 inch and larger) are likely to be more heterogeneous, related to primary, secondary, and tertiary stages of manufacture. At this site, most large flakes were classified as modified and thus analyzed in a separate study (see Chapter 17). As such, they have not gone undocumented but are analyzed primarily from their position in the tool-use trajectory at the site rather than the tool-manufacture trajectory.

Equally important is the fact that much that is here considered debitage may, upon microscopic examination, be found to have been used as tools. In effect, this analysis of "debitage" was carried out lacking the information on those flakes considered on macroscopic evidence to be tools but probably including an unknown number of flakes that were used as tools but could be identified as such only under high magnification (cf. Chapter 22).

These conditions suggest that all flakes should be analyzed first as the products and byproducts of knapping and then resorted into tool and debitage categories on macroscopic as well as microscopic criteria. The flake tools would then be subjected to a second level of analysis.

Despite these strengths and weaknesses of examining the smaller debitage at the expense of larger materials, this study does provide a new perspective on the analytical potential of small-sized flakes from hunter-gatherer sites. It is clear that this category of artifacts yields valuable information that contributes to major research questions under investigation. A research design focused solely on large flakes recovered in 1/4-inch screens represents the examination of an incomplete data set. Artful analyses to come will combine creative sampling and laboratory logistical designs with wellplanned research objectives to more completely recover the information from site flake assemblages. 


\section{Chapter 20}

\section{GROUND AND OTHER NONCHIPPED STONE ARTIFACTS}

by Lauren A. Sullivan

\section{INTRODUCTION}

The lithic artifacts from the Wilson-Leonard site not classified as chipped stones are discussed in this chapter. These were manufactured or modified by a variety of methods such as grinding, pecking, polishing, grooving, notching, and battering and include 81 specimens classified as ground stones, 23 as possible ground stones, 9 as notched and/or grooved stones, and 30 as minimally modified stones. These specimens were recovered from contexts spanning the Paleoindian through Late Prehistoric periods.

\section{METHODS}

Each of the nonchipped stone artifacts was grouped according to form into one of the categories of ground stones, possible ground stones, notched and/or grooved stones, and minimally modified stones. All but the minimally modified stones were codified according to the following attributes: completeness, metric measurements, raw material, form (overall and cross section), number of use surfaces, surface modification, and mineral precipitates.

Completeness of each artifact was recorded as complete, end missing, edge missing, corner fragment, end only, edge only, medial fragment, medial break, indeterminate fragment, or other. Length, width, and thickness measurements (to the nearest tenth of a $\mathrm{mm}$ ) were taken of the whole artifacts with sliding calipers. In the case of fragments, only dimensions that were fully represented were measured. Weight was measured to the nearest tenth gram with a triple beam balance. The raw material of each item was recorded as specifically as possible. All identifications were made macroscopically but hydrochloric acid was used in cases of questionable limestone identification. Overall form of each specimen was recorded as oval, round, rectangular, angular, square, irregular, or indeterminate, and cross-section shape was denoted as biconvex, biconcave, biplano, planoconvex, convex-concave, or irregular. In addition, when form was indeterminate from the fragment recovered, its shape was so classified.

The following attributes were noted as present or absent: unifacial or bifacial grinding, polish, battering, pecking, striations, heel facets, grooving, notching, mineral precipitates, and heat alteration. Neither the extent nor the location of any of these attributes was noted except that the unifacial or bifacial attribute was identified by the number of surfaces altered (ground) in preparation or use. Polish was identified as the smoothed, glossy areas on the surface of some artifacts, while pecking appears as a coarse or pitted surface. Striations refer to fine lines macroscopically visible on the surface of many of the ground stone artifacts. In order to confirm their presence or absence, a hand lens or a low-power microscope was used.

Heel facets, the wedge shapes produced when uneven pressure was applied to handheld grinding implements, were identified in varying stages of development on the manos and mano fragments (Figure 20-1). Many of the specimens lack clear evidence of these features, however, a slight rounding on the edges of some of the grinding surfaces showed where heel facets perhaps had begun to develop. On the specimens where two heel facets were observed, the mano was presumably turned end-over-end in order to use the opposite grinding surface creating a wedge-shaped tool (Johnson 1991:74; Morris 1990:186, 191).

Grooves and notches are intentional modification or abrading of the edge of a stone tool. Grooves refer to long narrow furrows or depressions, while notches are shorter, $\mathrm{V}$-shaped cuts or indentations. In this collection, notches and grooves do not co-occur on any artifacts.

Whether or not a specimen was heat altered was determined by color or texture changes in the raw material as observed by project geologist Gene Mear. The presence of mineral precipitates was determined by visual inspection as such deposits are macroscopically visible. 


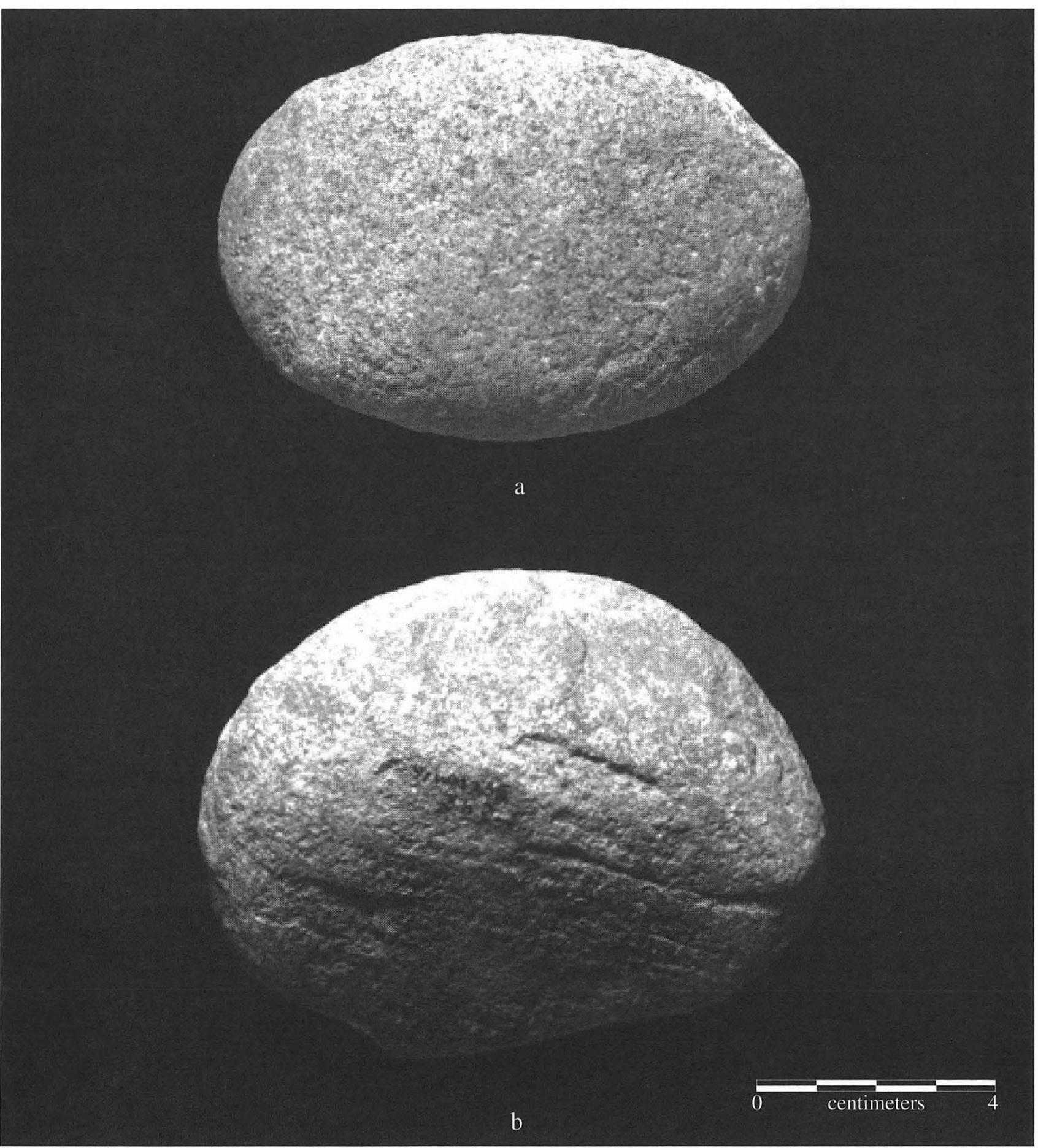

FIGURE 20-1. Examples of manos with heel facets. (a) Specimen 101-1; (b) Specimen 36*-1.

\section{ARTIFACT DESCRIPTIONS}

\section{Ground Stones}

\section{Manos}

Manos are defined as the handheld grinding implements used in association with metates to grind plant and occa- sionally inorganic materials. It has also been suggested that these stones may have been used in hide processing (Adams 1988:307; Clark and Kurashina 1981:305; Collins 1973:91). There are 51 specimens from the Wilson-Leonard site in this category. Of these, 5 are from Paleoindian contexts, 3 are from Late Paleoindian/Early Archaic contexts, 31 are assignable to the Archaic period, 2 are associated with the Late Archaic/Late Prehistoric, 1 is clearly from Late Prehistoric 
context, and 9 are not assignable. This group comprises 43 bifacial and 5 unifacial tools with the remaining 3 undetermined due to their fragmentary or precipitate-covered condition. Attributes are summarized in Table 20-1. Specimens with battering were placed in this category because they were primarily used as manos. The light battering on these specimens was observed along their edges. Two artifacts with heavy battering were classified as mano/hammerstones.

Of the items classified as manos, $17(33 \%)$ are complete, and $34(68 \%)$ are fragmentary. The weights of the complete manos range from 279.7 to $1,195.6 \mathrm{~g}$ (mean=607.8 $\mathrm{g}$ ), lengths from 72.2 to $136.6 \mathrm{~mm}$ (mean=108.7 $\mathrm{mm}$ ), widths from 48.9 to $143.4 \mathrm{~mm}$ (mean=78.2), and thickness from 23.8 to $64.8 \mathrm{~mm}$ (mean=44.2) (see Table 20-1). Their overall shapes are oval, round, and irregular. Two manos were used also as hammerstones and a third (found in Burial 2) was used as a chopper. Sixty-seven percent of the manos recovered from the site were manufactured from sandstone and granite, and the remaining $33 \%$ were made variously of bull quartz, limestone, and quartzite (see Table 20-1). Mineral precipitates were observed on $89 \%$ (8:9) of the manos recovered from Early Archaic contexts as well as on 2 of the 3 Early Archaic/ Late Paleoindian manos and 3 of the 5 Paleoindian specimens. Such deposits were noted on only $22 \%$ (2:9) of those assignable to the Late Archaic. Seventy-three percent ( $n=37)$ of the manos were recovered from the Valley Floor with only $25 \%(n=13)$ coming from the Valley Margin, possibly indicating that the Valley Floor was the primary activity area for plant processing but also perhaps reflecting where manos (as site appliances) were left for future use.

The examination of wear patterns on the manos provides some significant information on their use. During the Paleoindian period, variable attributes imply that manos may have been used as multifunctional, nonspecialized tools. Specimen 34NN1D-1, a limestone mano that also shows evidence of having been used as a hammerstone, is associated with the bison bone bed and could have been used to crack open bison bones in order to obtain marrow as well as in plant processing (Brain 1981:15; Jodry 1987:196) (Figure 20-2). Specimen 34CC2D-2 is a small artifact made from limonitic sandstone. It shows signs of polish, light striations, battering, and possesses an unidentified black stain (Figure 20-3). Specimen OR614 appears to have been shaped; however, the artifact is almost completely covered in mineral precipitates which obscures any evidence of wear. This layer was not removed as it may encapsulate organic residues. The specimen was subjected to chemical residue analyses with the result that 10 amino acids and a chloride were identified on this mano. Specimen $36 \mathrm{~W}-1$ is a complete bifacial granite mano with evidence of pecking and faint striations. One face of this artifact is very smooth, and the beginning of a heel facet was observed suggesting intensive use (Figure 20-4).

Several specimens were found with deeply pecked surfaces, others with this pecked surface partially worn away, and others with a smooth, polished surface. The smooth surfaces may have been used to further reduce the size of coarse particles produced by the rougher, pitted surfaces (Johnson 1991:66). Several grinding stones recovered from the Wilson-Leonard site have both rough and smooth facets, on opposite faces, suggesting that they were turned over from one stage of grinding to the next (see Figure 20-1).

Eight Wilson-Leonard specimens are noted as having "heel facets" (see Figure 20-1). These are neither as flat nor as well defined as those occurring commonly in agricultural contexts (as for example in the American Southwest; Morris 1990) but resemble some of the thicker ones from the Early Archaic Sleeper site (Johnson 1991:69-76). Heel facets at Wilson-Leonard occur in Late Archaic $(\mathrm{n}=1)$, Middle Archaic $(n=2)$, Early Archaic $(n=1)$, Paleoindian $(n=1)$, unassigned $(n=2)$, and Archaic $(n=1)$ contexts.

One of the more interesting manos recovered was associated with Late Paleoindian-age Burial 2 (Figure 20-5). It is a complete ground stone tool (FBU2-1), originally discoidal and manufactured from sandstone with quartz grains and pink feldspar. It apparently was used as a mano and subsequently flaked along one edge into a chopper, resulting in a shape best described as a truncated disc. This tool is pecked, bifacially ground, and has striations on both slightly convex faces providing evidence for its use as a mano. On the more-convex face, there are patches of pecking as well as linear striations oriented in at least three directions. On the less-convex face, there are also linear striations visible in multiple directions; however, these striations are fainter than those on the other face of the specimen. This tool has an acute bifacially flaked edge that resembles a chopper and shows evidence of crushing, battering, and microflaking, presumably as a result of use. The flake scars are fresher in appearance than the rest of the stone's surfaces. The rounded, unflaked edges of the tool show signs of light battering; however, it cannot be determined if these are cultural in origin. Chemical analysis discerned residues of chloride, nitrate, phosphate, and 11 amino acids on this mano/chopper.

In contrast, the types of wear patterns observed on Archaic specimens are based on a larger sample and suggest a more-specialized use for each tool. In this case, a single, dominant wear type is found on each tool, including those that exhibit more than one wear type. Specimen 19G-1, for example, is a complete bifacially ground mano of bull quartz with three heel facets (Figure 20-6). Polish, battering, mineral precipitates, and pecking were also observed on this artifact. An increase in the diversity of overall mano shape is also observed in the Archaic, unlike in the earlier stratigraphic units where the assemblages are dominated by a single form (oval) (see Table 20-1). Polish is the primary wear type observed at this time. It has been noted that fragile grass seeds would require a lighter grinding process, so a controlled motion (which leaves a polish) by a smaller mano would probably have been employed (Kraybill 1977:493). 
TABLE 20-1

Attributes and Distribution of Manos, Mano Fragments, and Mano/Hammerstones

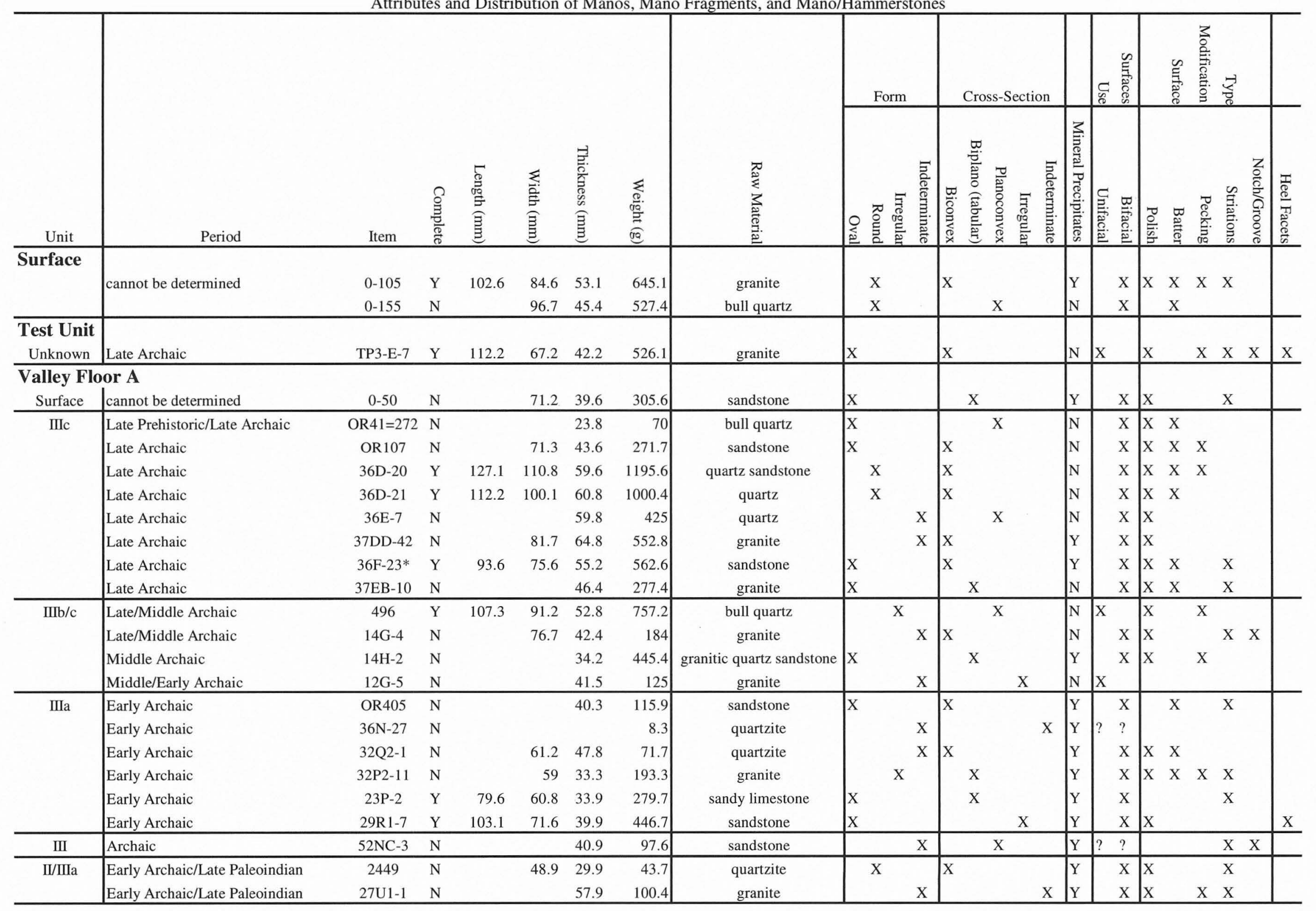




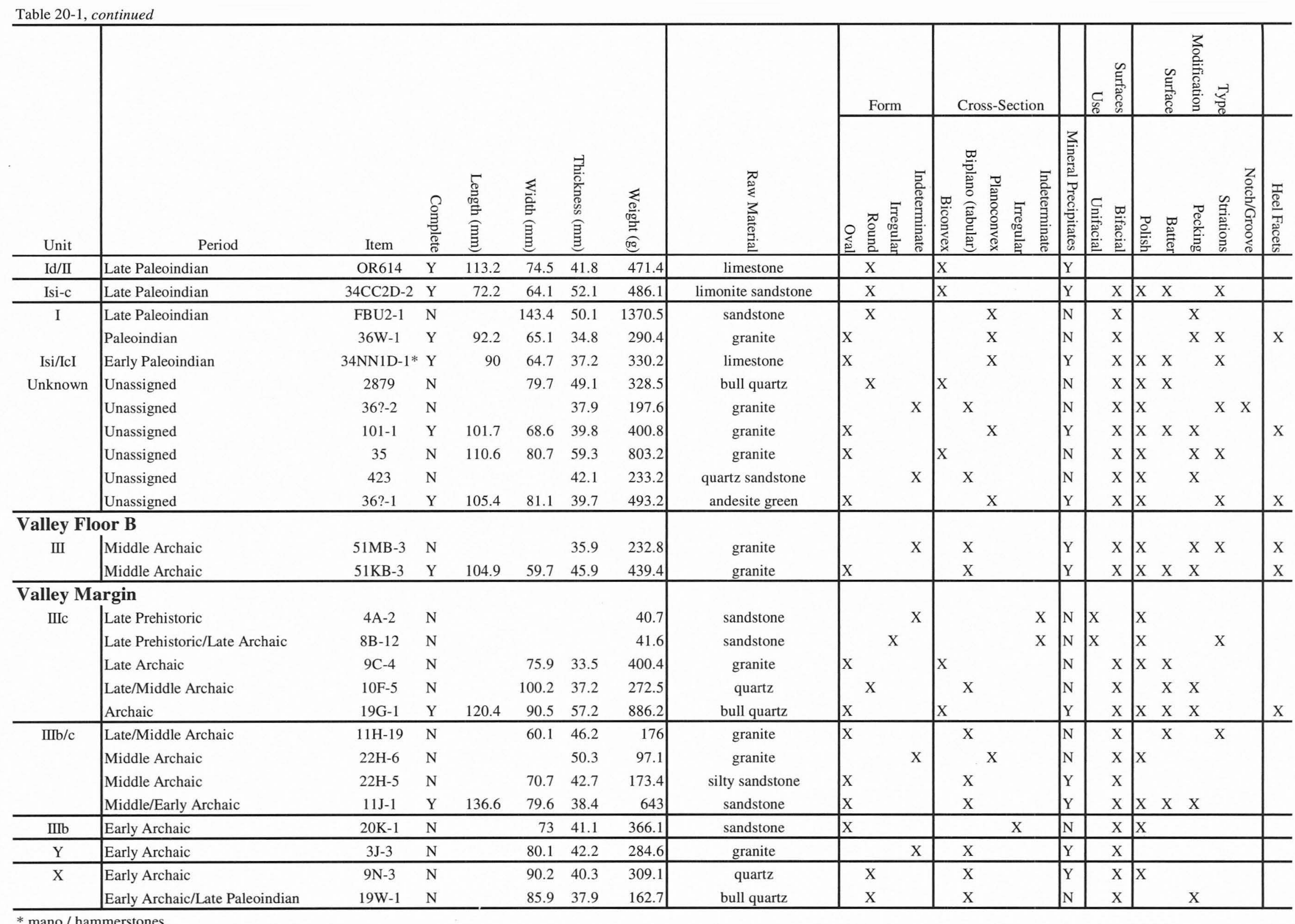




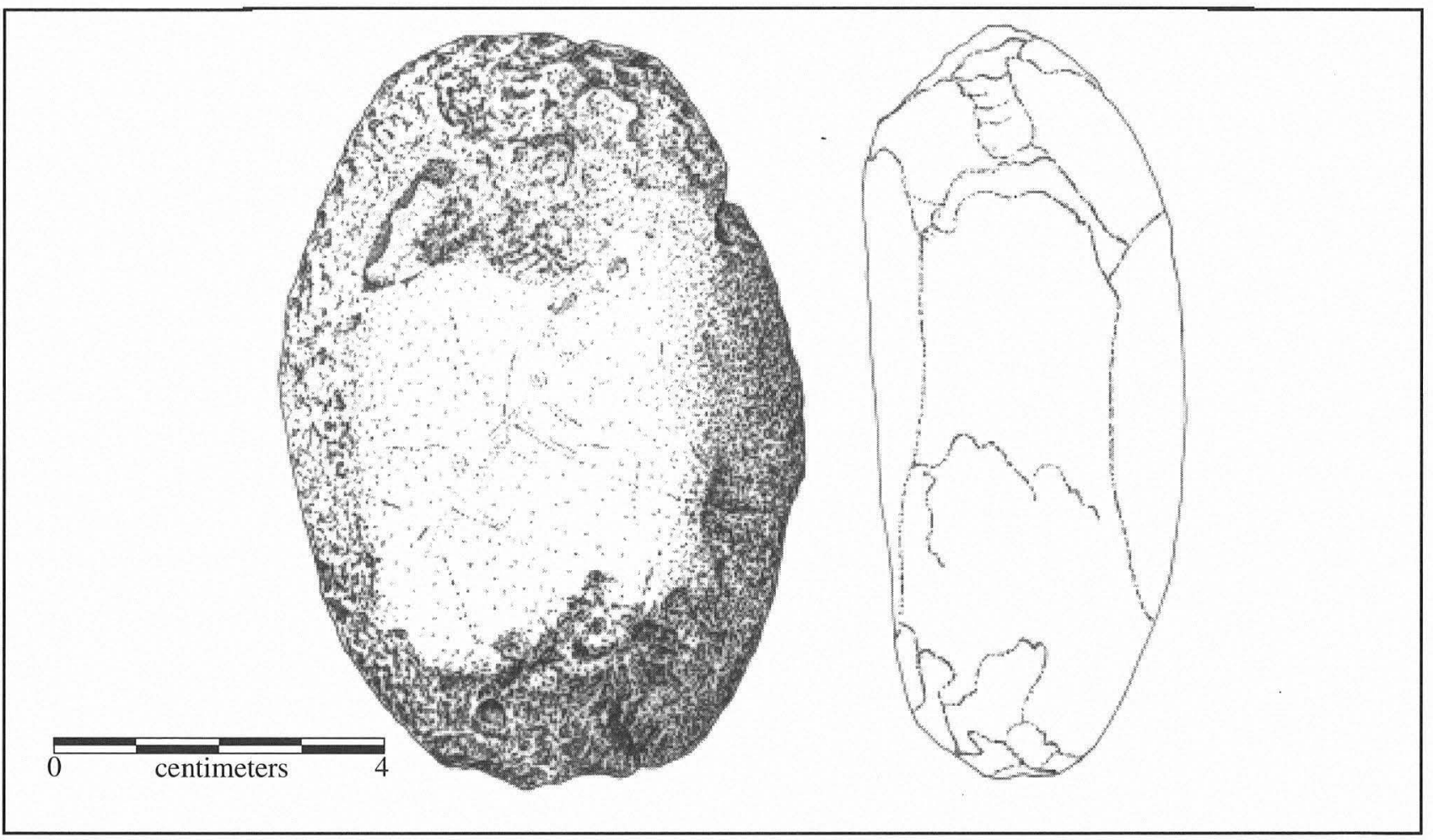

Figure 20-2. Mano Specimen 34NN1D-1.

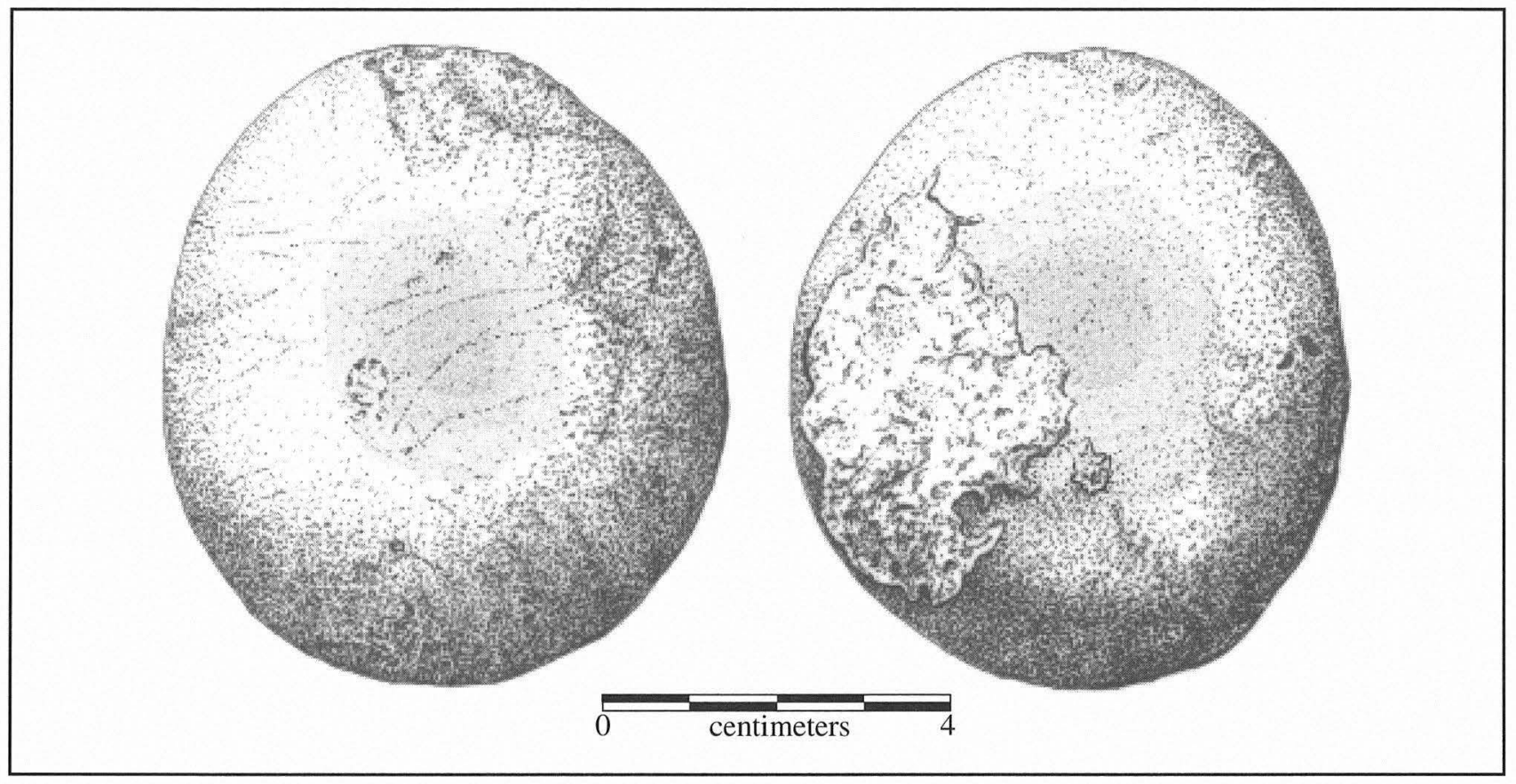

FIGURE 20-3. Mano Specimen 34CC2D-2.

Carbonized grass seeds were recovered from a burned rock feature (Feature 209) from a Middle Archaic context.

Three out of the five specimens recovered from the Paleoindian contexts are primarily complete. In the Archaic, the proportion of functionally complete manos to unusable portions $(10: 21)$ is lower. The majority of mano specimens with heel facets (five of eight) are from the Archaic indicating that some ground stone tools probably were used intensively throughout the Archaic, as this type of wear indicates prolonged use (Johnson 1991; Mauldin 1993:322). Once a stone is so worn that it can no longer be used as a grinding tool, there are other tasks for which it may be adapted such 


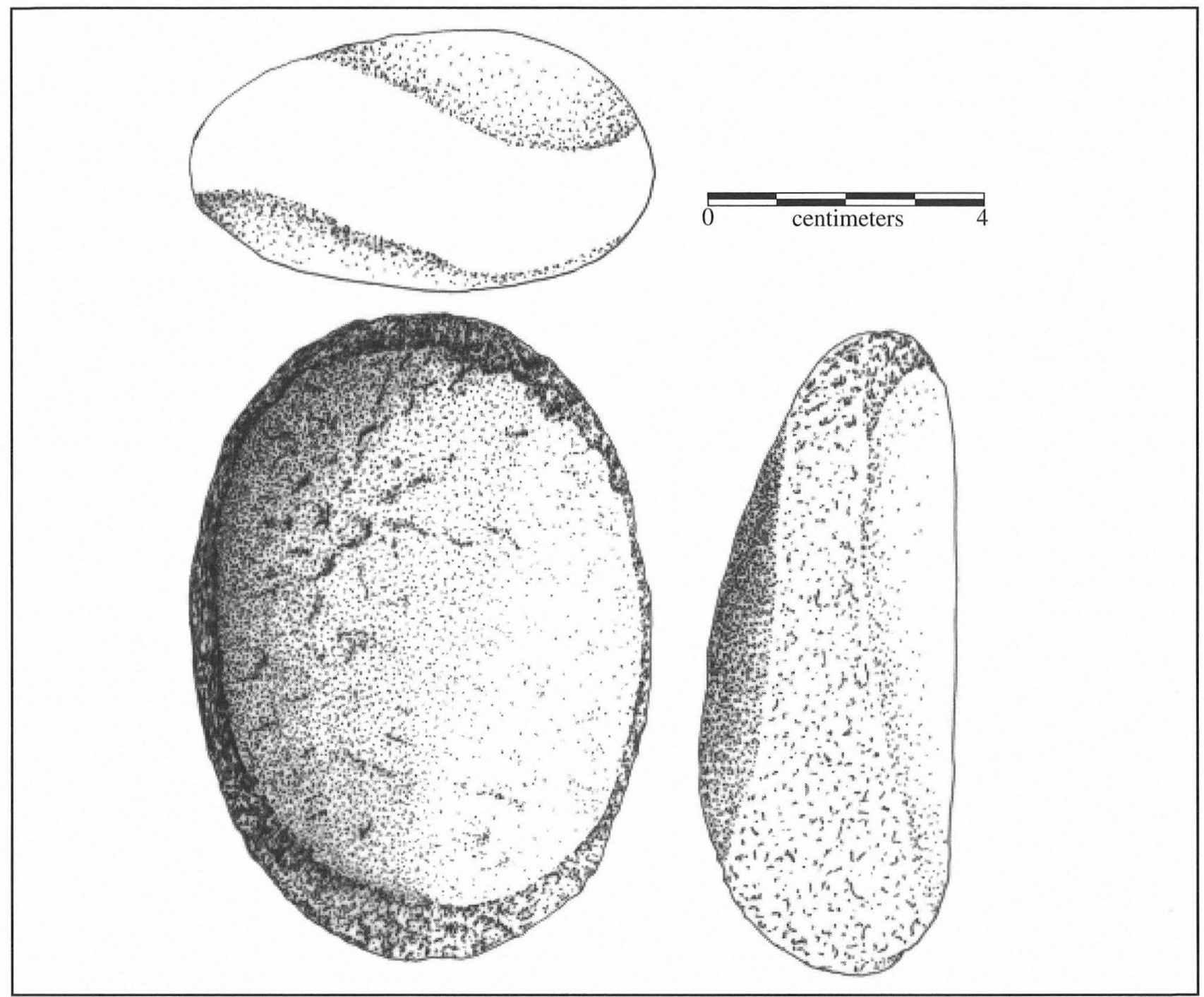

FIGURE 20-4. Mano Specimen 36W-1.

as skinning, abrading, and as architectural elements as documented in the Southwest (Kraybill 1977:491; Leneave 1995:499; Schlanger 1991:463). Specimen $36 *-2$ is a bifacially ground corner fragment of a mano with a groove suggesting its use as an abrader (Figure 20-7). These abraders may have been used in shaft straightening or in shaping, smoothing, or sharpening bone awls, pins, shell, wood, or stone tools (House et al. 1971:4; Leneave 1995:499; Watt 1944:7). One Late Prehistoric/Late Archaic mano fragment (272=OR41) tested for chemical residues yielded negative results for organic compounds and positive tests for chloride, nitrate, phosphate, and carbonate ions. Two Early Archaic mano fragments ( $9 \mathrm{~N}-3$ and OR405) were subjected to chemical residue analyses. Specimen 9 N3 revealed only the presence of carbonate, which probably is pedogenic in origin. The other (OR405), however, tested positive for multiple fatty acids including $\mathrm{C}_{15}$ acid which may derive from contact with bark or leaves of the prickly ash, a known medicinal plant.

\section{Pestle}

Pestles were often used in conjunction with stone or wooden mortars in pounding seeds, nuts, and roots and in other plant processing (Kraybill 1977:489, 497; Turner and Hester 1993:307). One pestle (22P-5) was found at the Wilson-Leonard site in Unit II/IIIa in the Valley Margin (Figure 20-8). It is a complete specimen made of pecked and smoothed limestone measuring $163 \mathrm{~mm}$ in length by $57 \mathrm{~mm}$ in maximum diameter. It weighed $949.1 \mathrm{~g}$. Its almost cylindrical shape is slightly rounded and smoothed with light striations on one end and abraded to a dull, smooth point on the other. The sides are pecked. The pestle was found in a burned rock cluster recorded as Feature 107 (see Chapter 26).

\section{Metates}

These tools, presumably used in conjunction with manos, are defined as the stones that served as the surface 


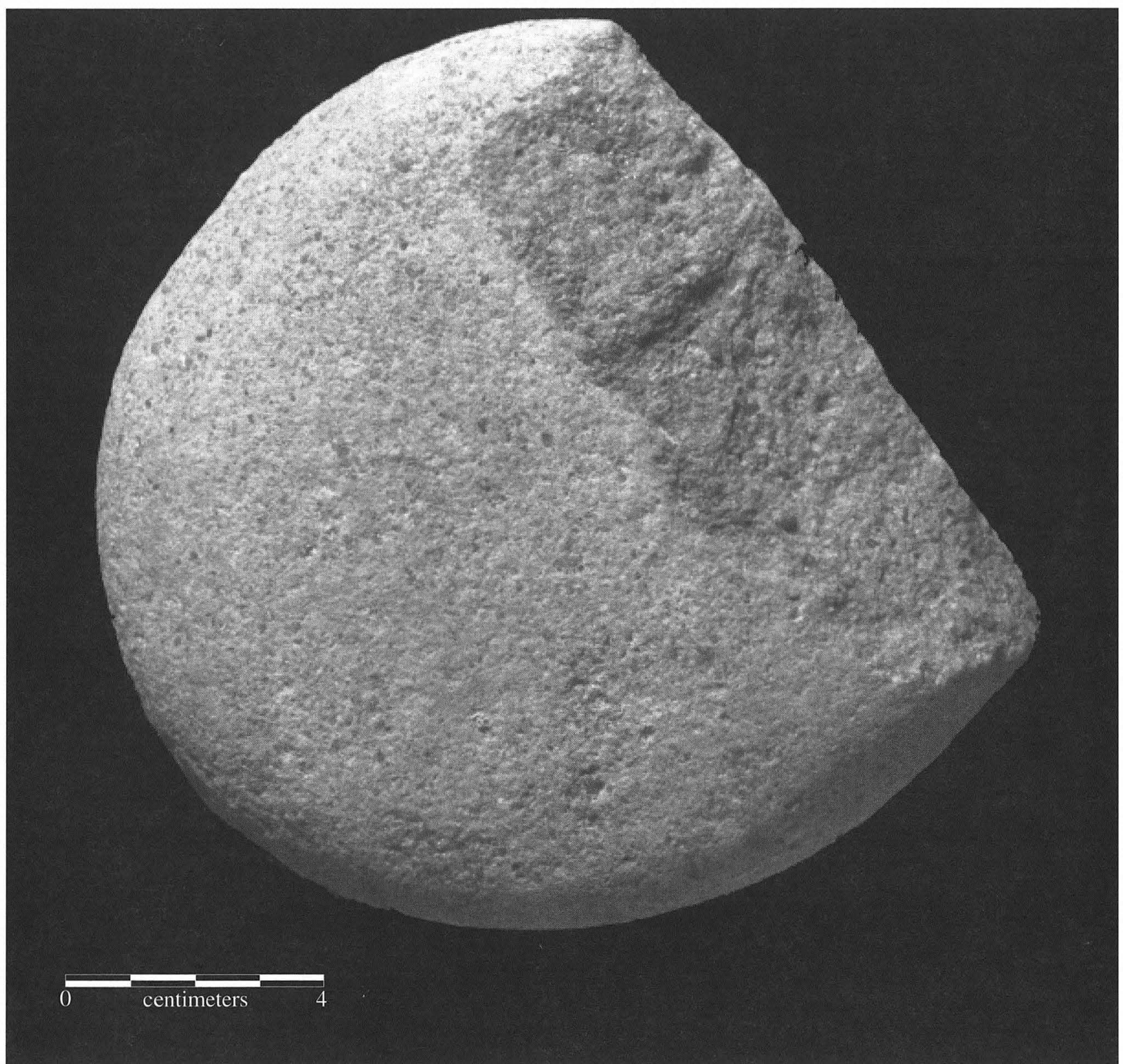

FIGURE 20-5. "Mano/chopper" Specimen FBU2-1.

upon which grinding took place. This group is comprised of 12 that are bifacially and 10 that are unifacially ground; 1 fragment is undetermined (Table 20-2). All but 2 are made from sandstone; 1 is manufactured from limestone and 1 from siltstone. Twenty-one of the 23 specimens in this category are only fragments. The exceptions, Specimens 0-119 and 54-1, are complete oval metates. Unfortunately, the provenience of both is unknown. Specimen $54 *_{-} 1$ is bifacially ground and has mineral precipitates around its circumference. It has a worn, polished facet or slightly concave area on one side. The other side appears rougher (Figure 20-9). Specimen 0-119 is unifacially ground, with a very smooth surface; polish and faint striations are visible toward its edges (Figure 20-10). Mineral precipitates were observed on all $(\mathrm{n}=5)$ of the metate fragments recovered from Early Archaic contexts but on only 40\% (2 of 5) of the fragments from Late Archaic contexts. Nine of the metate specimens were recovered from the Valley Floor, 11 were recovered from the Valley Margin, and 3 were from indeterminate contexts.

The original size and shape of the metates represented by fragments cannot be estimated. Most are tabular in cross section. Thicknesses of the measurable fragments range from 15.5 to $59.6 \mathrm{~mm}$ (mean=29.4).

At Wilson-Leonard, the earliest occurrence of metates was in the Early Archaic levels, where a dramatic increase in the density and size of burned rock features also occurred, supporting the idea that plant processing intensified at this 


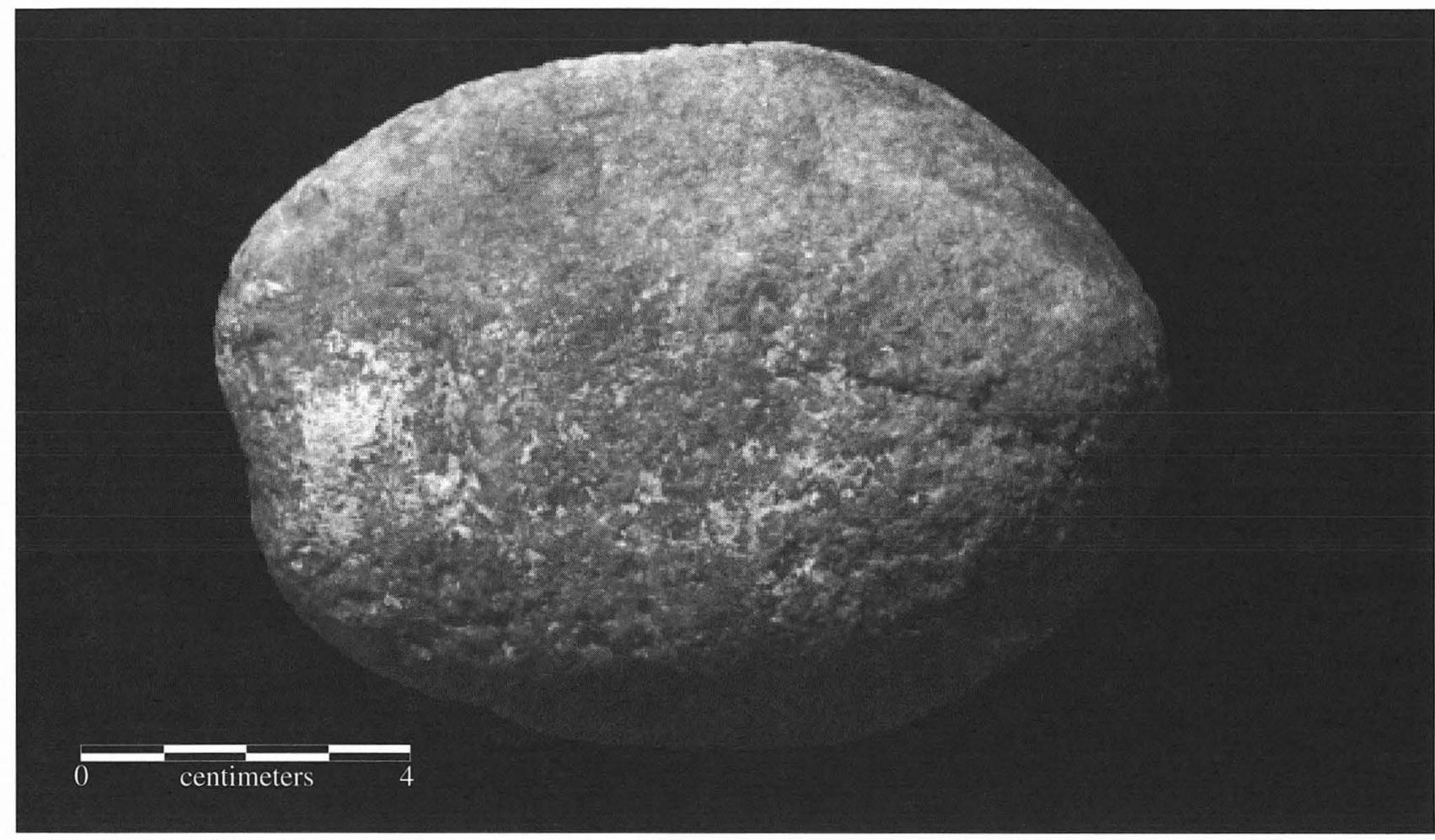

FIGURE 20-6. Mano Specimen 19G-1.

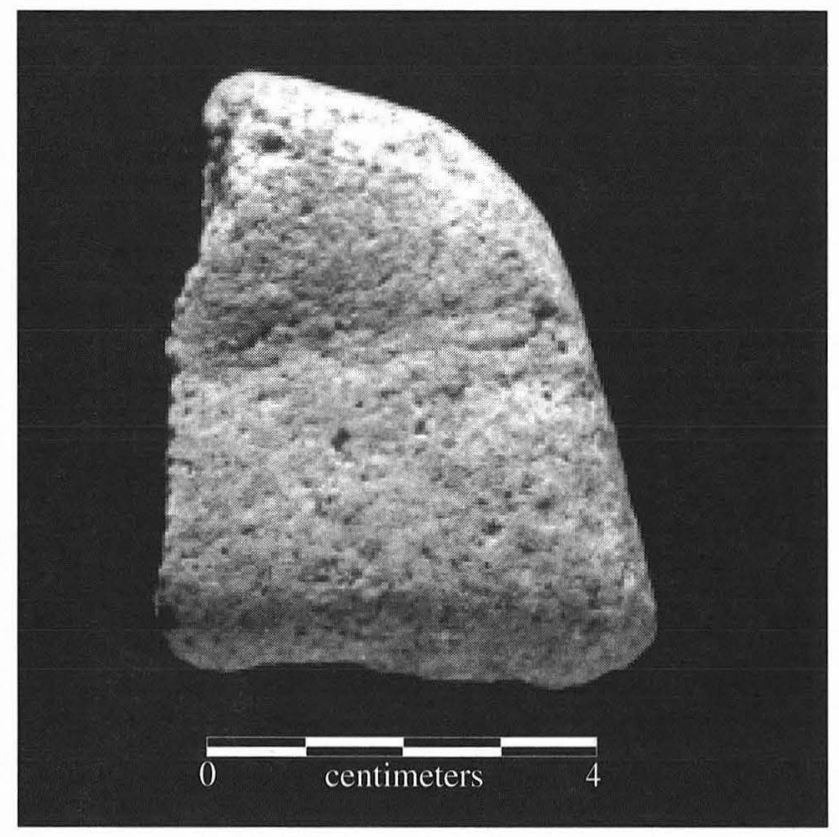

FIGURE 20-7. Mano Specimen 36*-2.

time (see Table 20-2). The appearance of these grinding tools may suggest a subsistence strategy shift toward hard-seeded grain as a significant food supply (Carter 1977:693). Comparisons of the metate weight and size between stratigraphic units are not useful in this analysis because most are fragments and the only complete ones are from mixed stratigraphic contexts.
The wear types observed on the metate fragments provide more useful information. Facets refer to the oval depressions that are worn into the surface of a slab by the grinding motion of a mano and are one of the measures used in determining the degree of utilization of metates or grinding slabs (Leneave 1995:488). The best example of this type of wear is observed on Specimen 0-156. This metate fragment is bifacially ground and heavily polished with one very noticeable concave worn area (Figure 20-11). The majority of the metate fragments were polished, supporting the idea that processing grasses became important during the Archaic as observed in the mano data. Unifacially ground metate fragments dominate in the Valley Margin with a more-even distribution between unifacially and bifacially ground specimens found in the Valley Floor. Striations are most common in the Early Archaic appearing on two of the five metates. Specimen 7F-5, associated with Burial 1, is a large bifacially ground limestone metate fragment with faint striations; chloride, phosphate, and carbonate residues were identified on this piece.

\section{Grinding Basin}

This category is represented by one complete specimen (9T-2) made of bifacially ground quartzite recovered from an Early Archaic/Late Paleoindian context (Figure 20-12). It is considered in a category separate from the metates because of its small size. On the concave face, there are deep striations and grooves going in multiple directions as well 

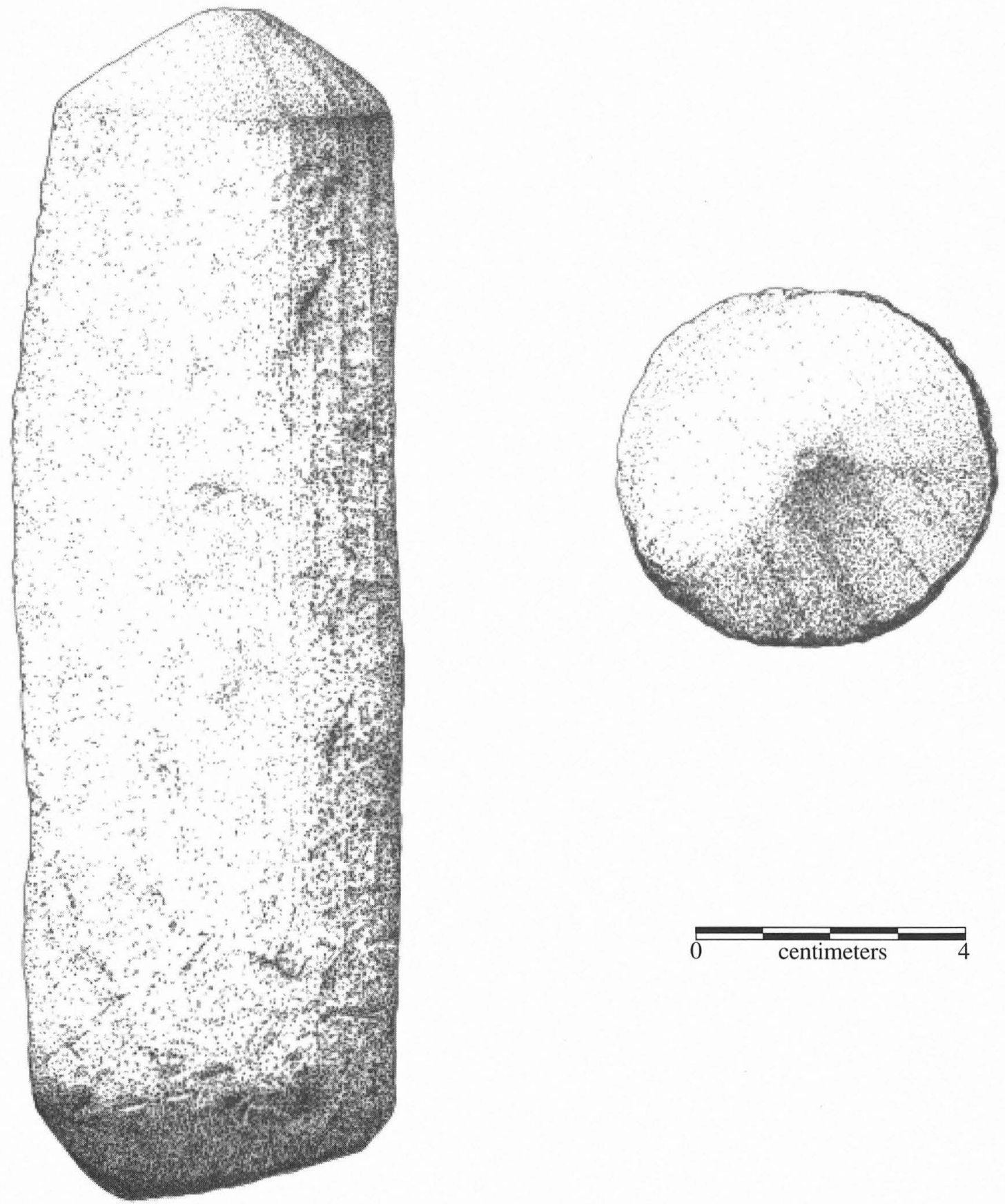

Figure 20-8. Pestle Specimen 22P-5.

as a light polish. The other face has fainter striations that are also oriented in multiple directions. This specimen is oval shaped and measures $67.1 \mathrm{~mm}$ in length, $51.9 \mathrm{~mm}$ in width, and $14.0 \mathrm{~mm}$ in thickness. It weighs $106.1 \mathrm{~g}$. No mineral precipitates were noted on its surface, however, chemical residue analysis detected the presence of chloride and carbonate ions. Organic residues identified on this specimen in- cluded 13 amino acids with an indication that it may have been in contact with acorns.

In spite of the possible presence of acorn residue, this item does not seem large enough to process a significant amount of plant food. Perhaps it was intended or used as a basin to process nonfood materials, such as mineral pigments or plant products used medicinally or otherwise (Black 
TABLE 20-2

Attributes and Distribution of Metates and Metate Fragments

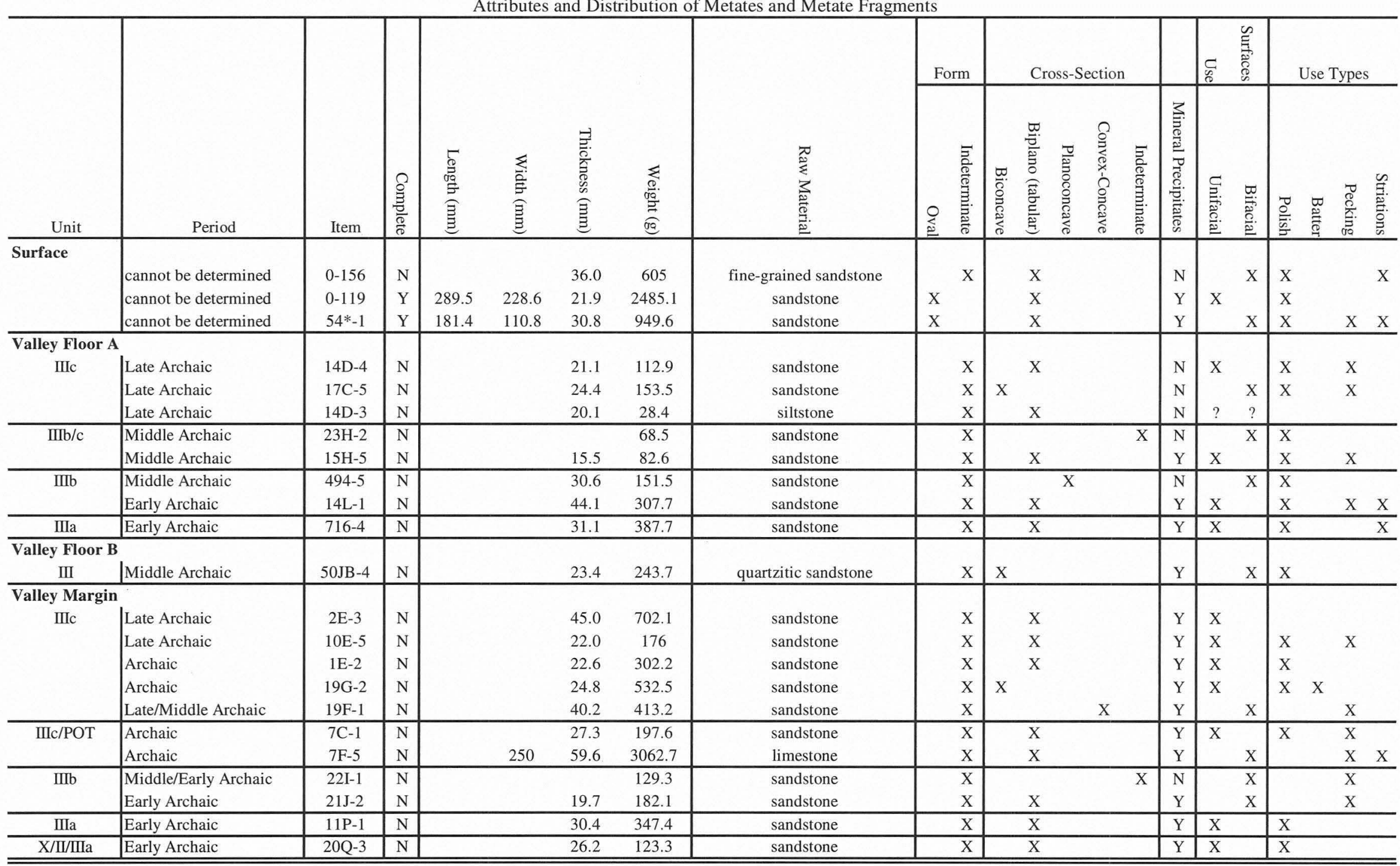




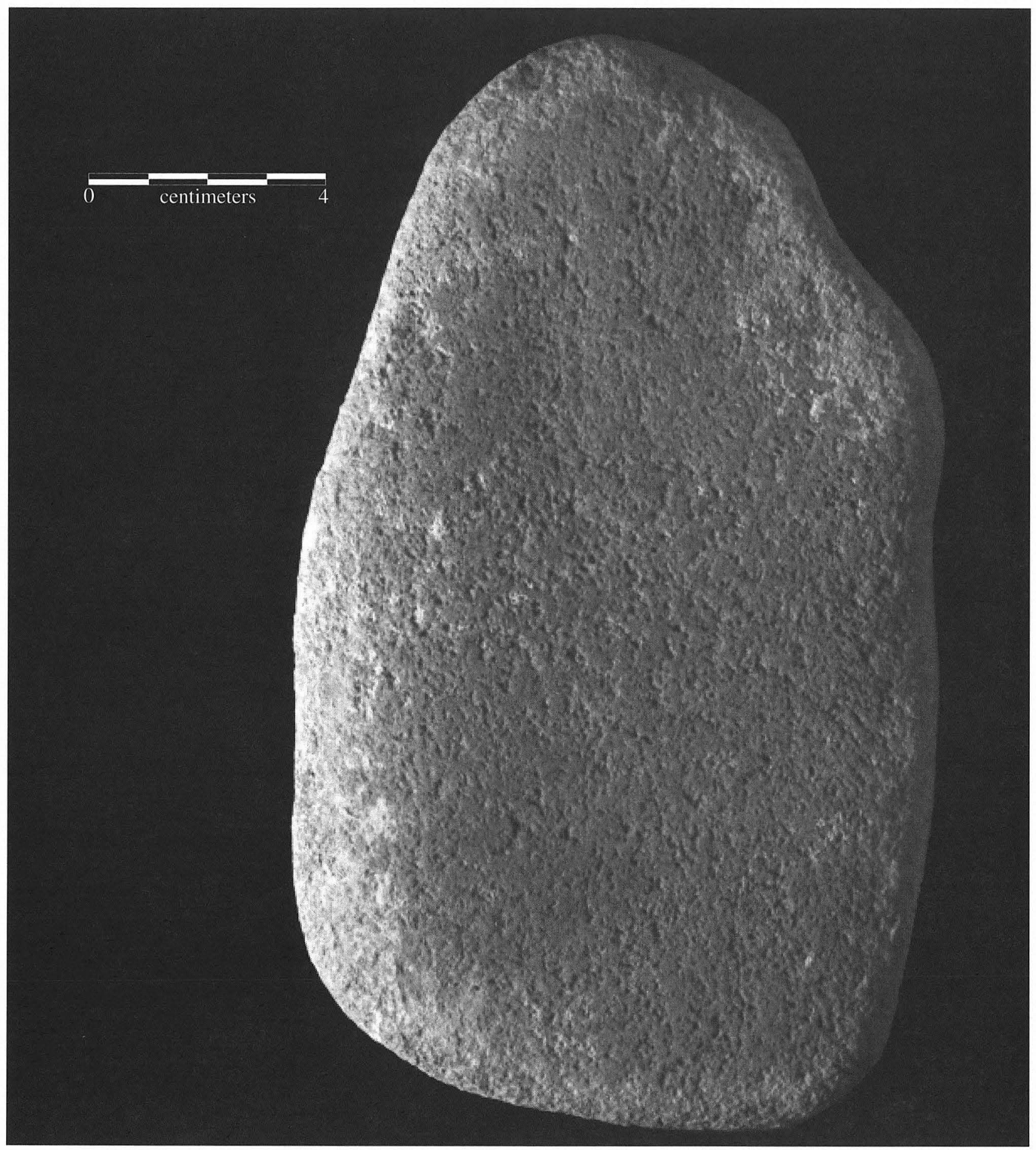

Figure 20-9. Metate Specimen 54-1.

and McGraw 1985:170; Carter 1977:696; Frison and Stanford 1982:69; Logan and Fratt 1993; Schlanger 1991:461; Stahl 1989:174).

\section{Stone Pipe}

A fragmentary cylindrical stone object (16C-2) inferred to have been a pipe or cloud blower was recovered from Unit
IIIc. The present piece seems to be the medial section of a stone tube $74 \mathrm{~mm}$ in outside diameter (Figure 20-13). The diameter of the inside opening tapers very slightly from $30 \mathrm{~mm}$ to $25 \mathrm{~mm}$ in the approximately $60 \mathrm{~mm}$ length of this fragment. Walls of the pipe range from about 24 to $27 \mathrm{~mm}$ in thickness. The exterior of the pipe is smooth but slight striations are visible in patches. This specimen is made of travertine (which is soft when taken from an outcrop and can easily be carved 


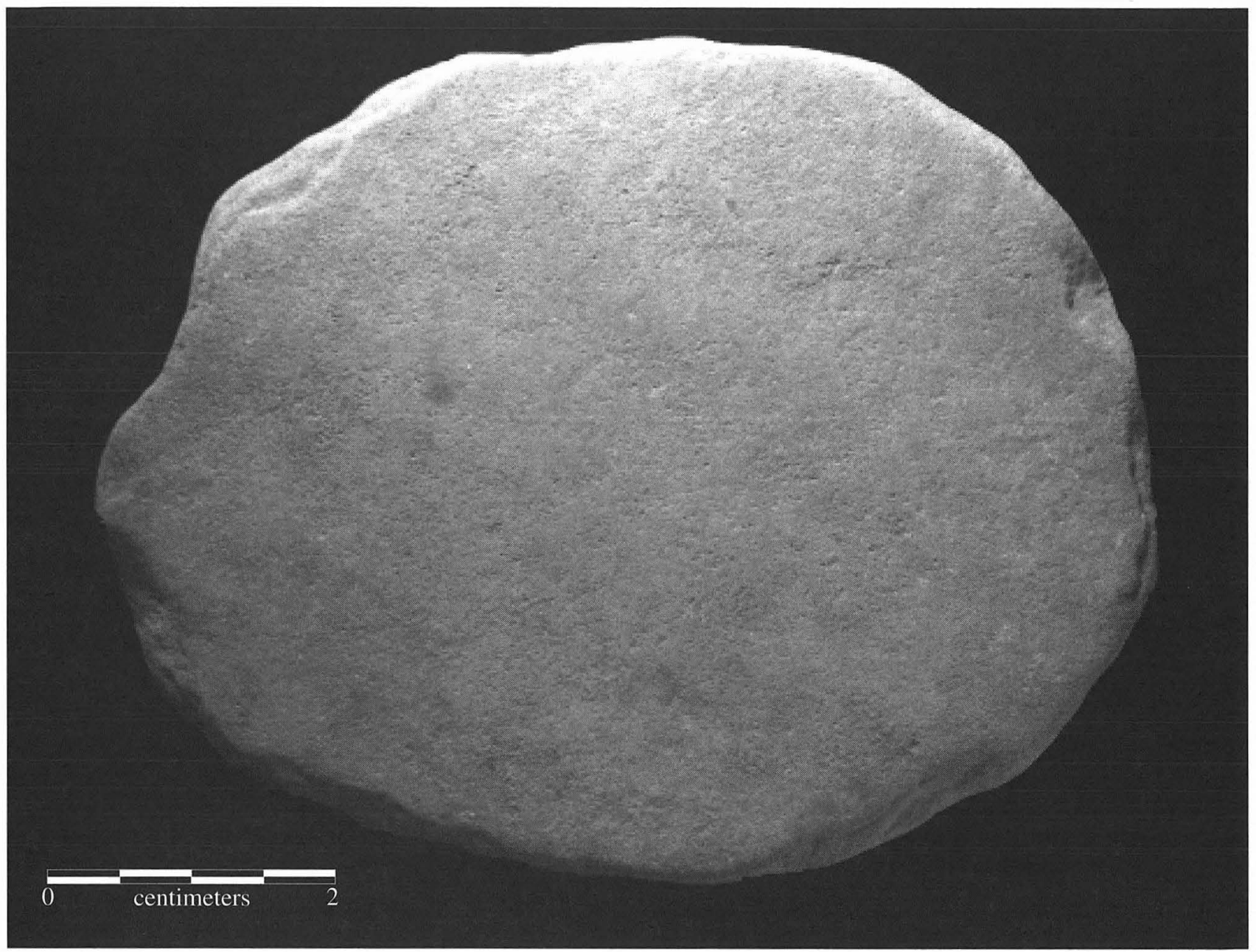

FIGURE 20-10. Metate Specimen 0-119.

with sharpened stone tools) and appears to have been shaped by carving and scraping the exterior. The tubular opening exhibits longitudinal grooves and striations that indicate gouging and reaming rather than drilling as the techniques of manufacture. This fragment is referred to as a pipe even though the definitive constriction seen on complete specimens is missing.

These pipes are typically associated with the Archaic period and have been recovered throughout Texas, but seem to occur most frequently in South Texas on the Coastal Plain and in the Lower Rio Grande Valley (Boyd et al. 1997:403; Jackson 1940:99; Leneave 1995:503). The majority are made of sandstone with only two limestone specimens documented (Leneave 1995:503). Ethnographic accounts and archeological evidence suggest that the exteriors of these pipes were constructed by pecking and grinding. Typically, a hole was then drilled longitudinally through the center of the cylindrical object from both ends; generally these are conical holes with one considerably longer than the other, leaving a characteristic constriction near one end (Leneave 1995:505).

There have been diverse functions discussed for these stone tubes including their use as ordinary smoking pipes, cloud blower pipes, fire carriers, shaft straighteners, enema syringes, and medicine tubes (Jackson 1940:121). Many ethnographic accounts describe pipe smoking as part of a daily routine (Leneave 1995:519). However, the small number of these reported in Texas (only some 81 specimens; Leneave 1995:503) suggests more-restricted use, such as that of a cloud blower in a ceremonial context or a medicine tube used by shaman in curing disease (Jackson 1940:121; Leneave 1995:503, 519). Although this specimen was analyzed for organic residue, the results were not conclusive beyond detecting the presence of chloride, phosphate, and carbonate ions along with nine amino acids.

\section{Indeterminate Ground Stones}

Four fragments of stone that definitely had been ground but could not be further classified by morphological type were placed into this category (Table 20-3). These show at least one smooth or ground surface suggesting that they were once part of a ground stone tool. The two Late Prehistoric specimens (14A-1 and 12A-12) refit and 


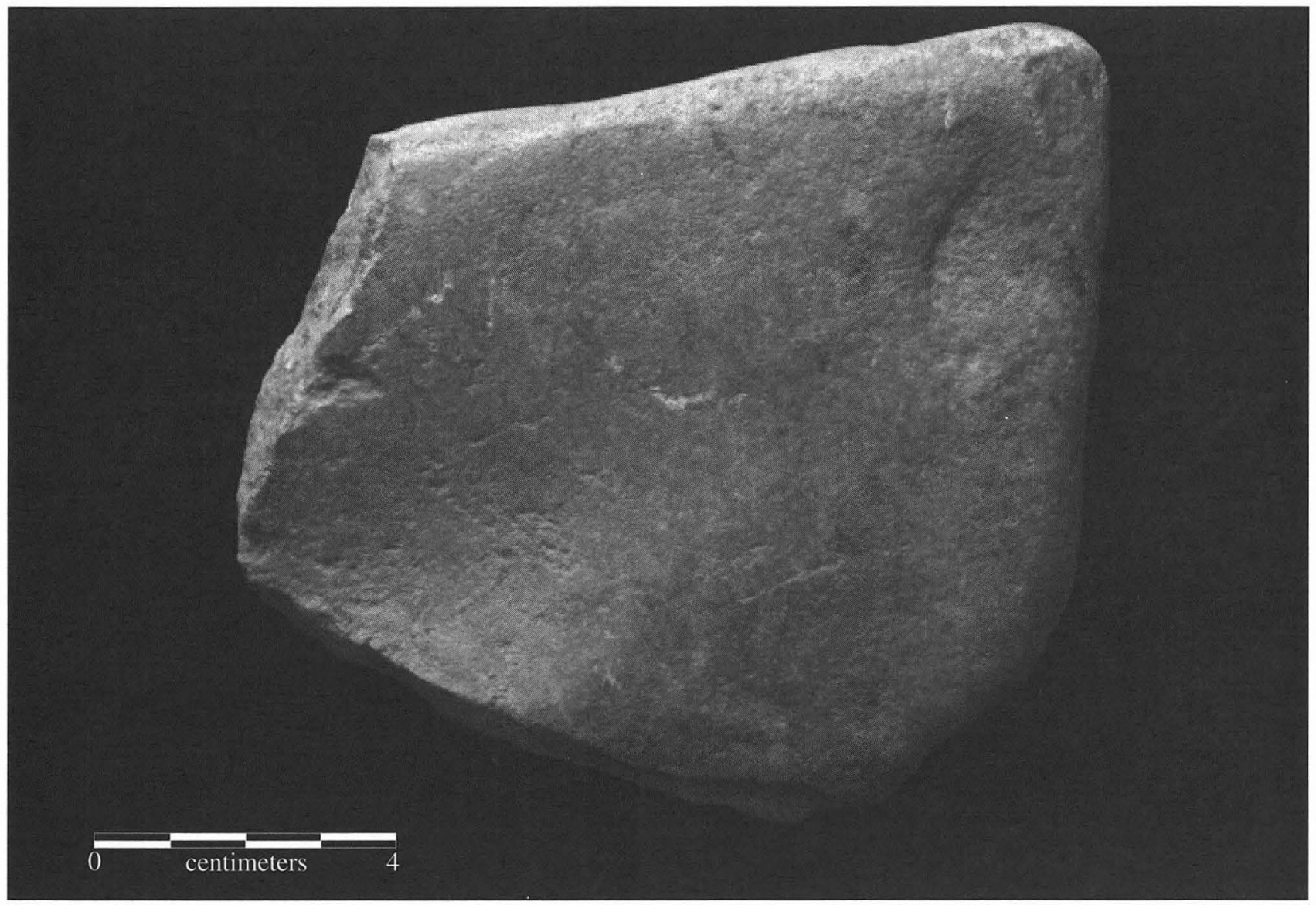

FiguRE 20-11. Metate Specimen 0-156.

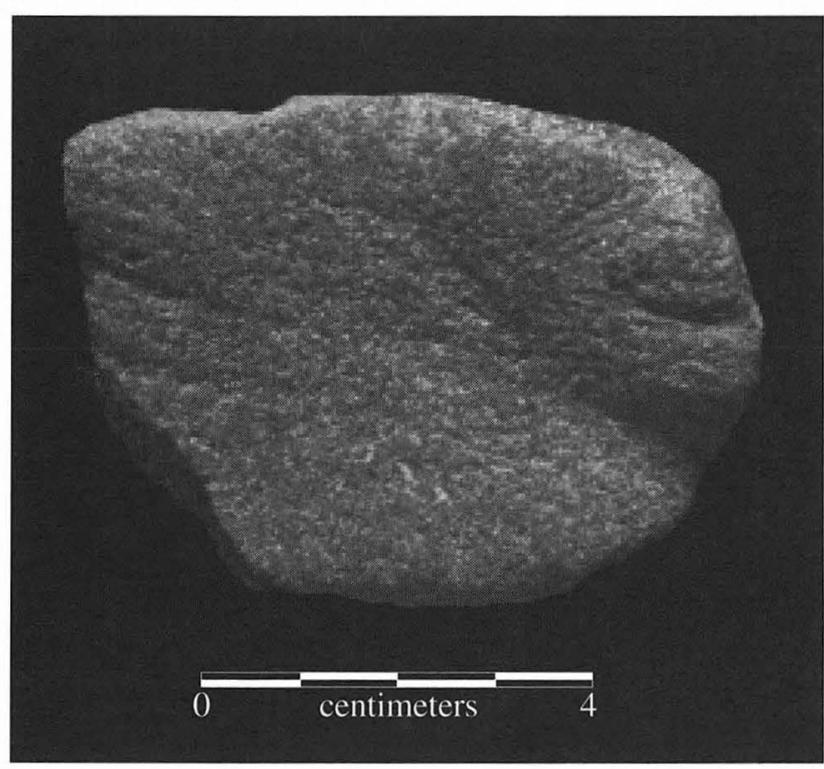

FIGURE 20-12. Grinding basin Specimen 9T-2.

both show signs of polish. One Late Archaic specimen (12A-12) from this group was tested for chemical residues, yielding only nitrate and carbonate ions and no organic traces.

\section{Possible Ground Stones}

Twenty-three fragments that lacked definitive evidence of grinding are considered possible ground stones. This group was subdivided into possible tool types in some cases. Seventeen of the fragments are classified as possible manos and mano fragments. One piece of sandstone is a possible metate fragment from a Middle Archaic context. Possible polish is the primary wear type observed on these 23 specimens. Table 20-4 presents a list of specimen numbers with their attributes. A single specimen (33Y1D-2) from this group was analyzed for chemical residue; phosphate and carbonate ions (probably of pedogenic origin) but no organic traces were detected.

\section{Notched and Grooved Stones}

\section{Notched Stones}

Notched stones of the form recovered from the Wilson-Leonard site are commonly thought to have functioned as weights for fishing nets and are referred to as "Waco sinkers" in the regional literature (Leneave 1995:502; Turner and Hester 1993:316; Watt 1939). Their use as bolas, parts of snares, or as weights on hunting nets has also been 


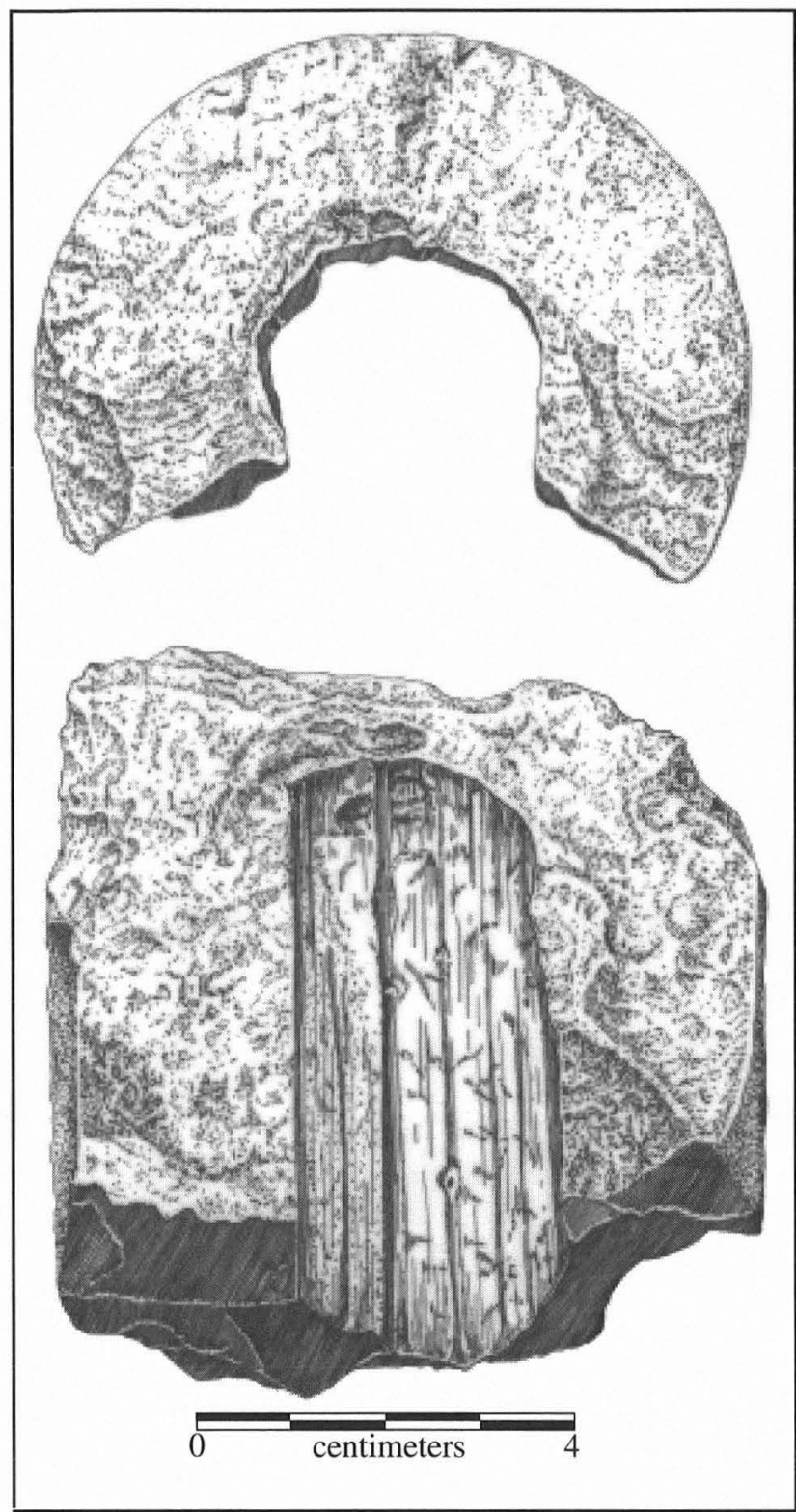

FIGURE 20-13. Ground stone pipe Specimen 16C-2. suggested (Boyd and Shafer 1997). These are generally small ovoid or subspherical pebbles that are notched on each end (Figure 20-14). Six of the seven (37T2A-1, 26R1-19, 0-211, 22Q-4, 17Y2-1, 36P-2) recovered from the Wilson-Leonard site are notched on both ends; 22Q-5 is notched on one end and battered or broken on the other. Their weights range from 8.9 to $66.6 \mathrm{~g}($ mean $=36.4 \mathrm{~g})$; lengths range from 27.6 to $64.0 \mathrm{~mm}$ (mean $=41.8 \mathrm{~mm})$; widths range from 24.0 to $38.0 \mathrm{~mm}$ (mean $=32.9 \mathrm{~mm})$; and thickness from 8.3 to $30.1 \mathrm{~mm}($ mean $=$ $18.1 \mathrm{~mm}$ ) (Table 20-4). They were manufactured from chert, limestone and sandstone. The majority (71\%) were associated with Units II and IIIa, where Late Paleoindian and Early Archaic materials prevail.

Although the presence of sinkers provides possible evidence of fishing when netting fibers are not preserved (Cleland 1982:769-771; Peterson et al. 1984:202), there are some cases where they have been recovered still attached to preserved net fragments (Ritchie 1969:186). Boyd and Shafer (1997) suggest that these stones were used in hunting in upland prairie contexts. These stones also could have been used as "spacers" in the manufacturing of the nets themselves (Watt 1939:54).

\section{Grooved Stones}

These stones are small and round with grooves that extend around the greatest circumference (Figure 20-15). Only two specimens were recovered from the Wilson Leonard site (34V1B-1 and 30Q1-1) (see Table 20-5). Specimen 34V1B-1, associated with Unit II, is oval, made of roughly shaped limestone, and its groove is shallow. Specimen 30Q1-1, associated with Unit IIIa, is made of ground limestone with a V-shaped groove that extends around the maximum circumference of the specimen. Striations are macroscopically visible within the groove. In Watt's (1939:30) study of Waco sinkers, artifacts such as these are included in his Type No. 11 but are not considered to be sinkers. A similar item classified as grooved limestone was recovered from the Hopewell School site, a Late Archaic campsite in the Brazos River

TABLE 20-3

Attributes and Distribution of Indeterminate Ground Stones

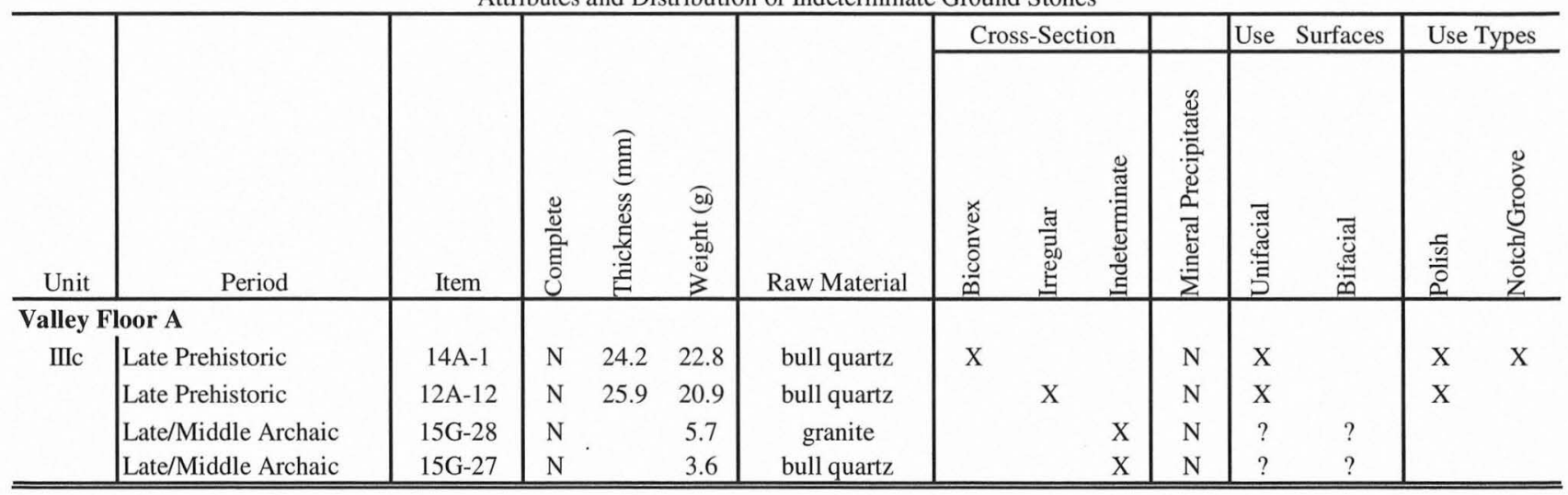


TABLE 20-4

Attributes and Distribution of Possible Ground Stones

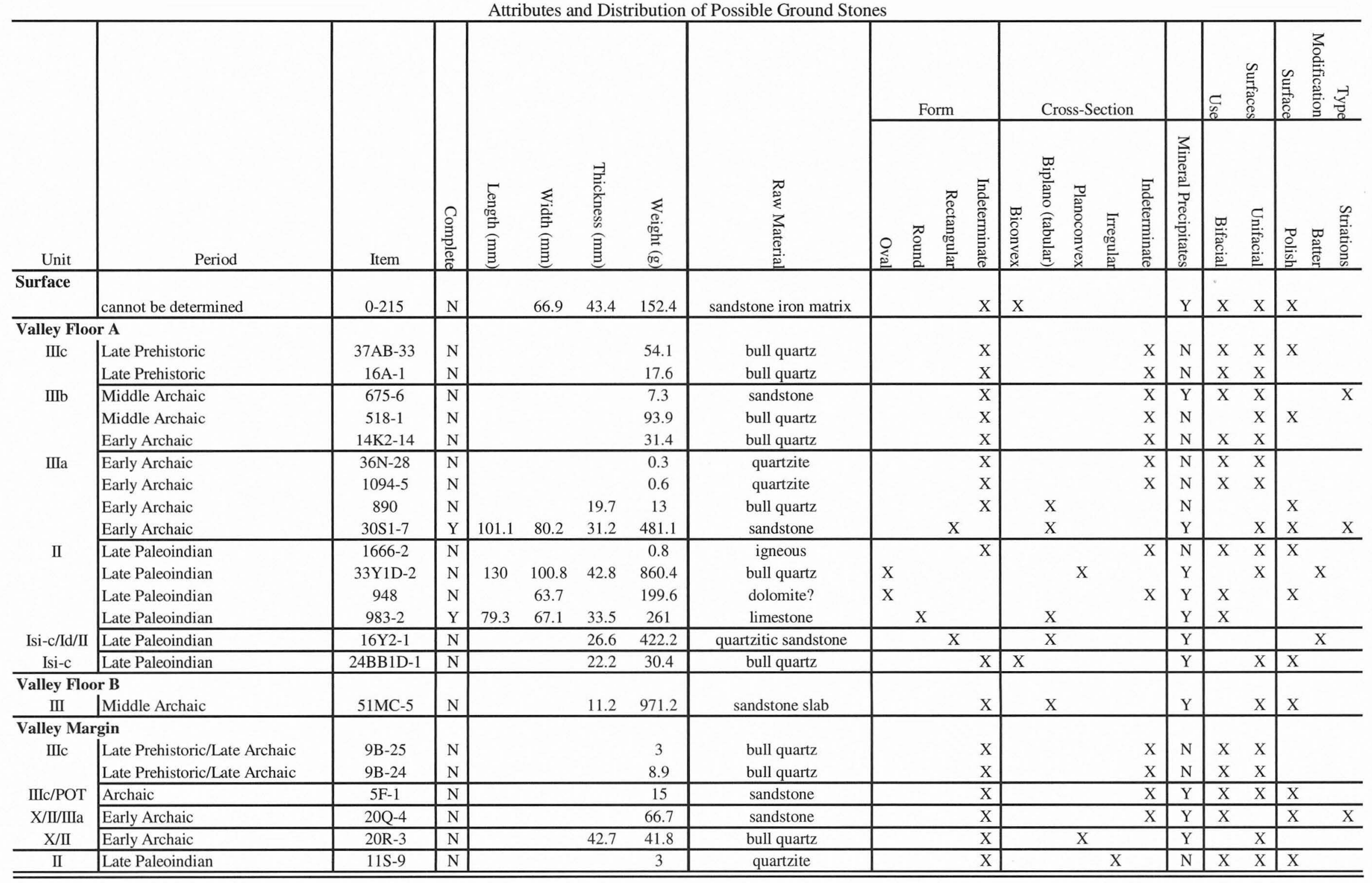




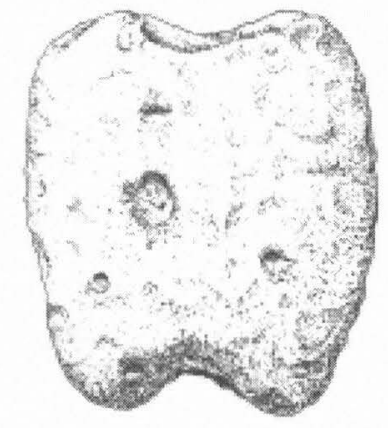

a

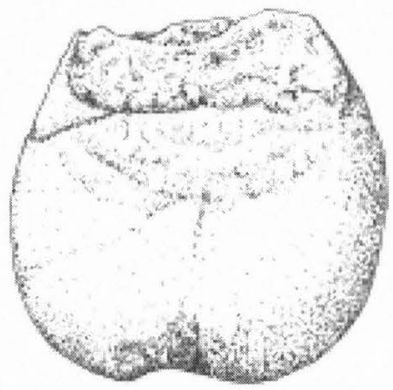

b

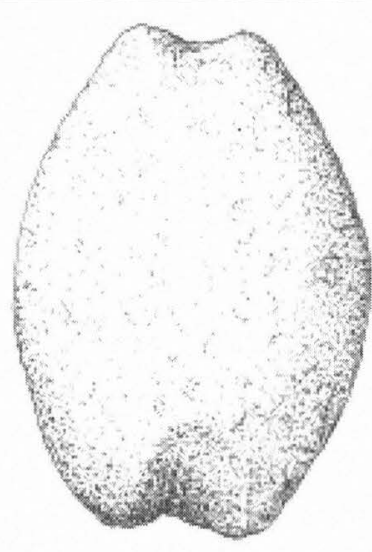

$\mathrm{c}$

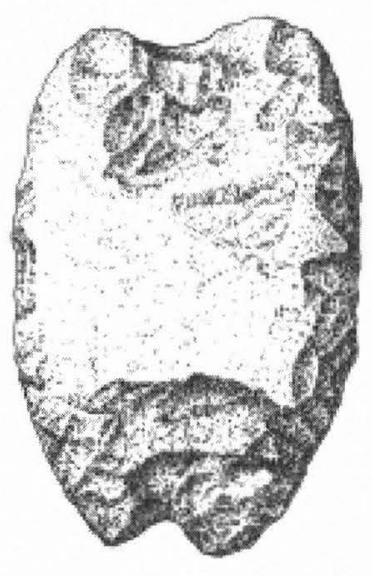

d

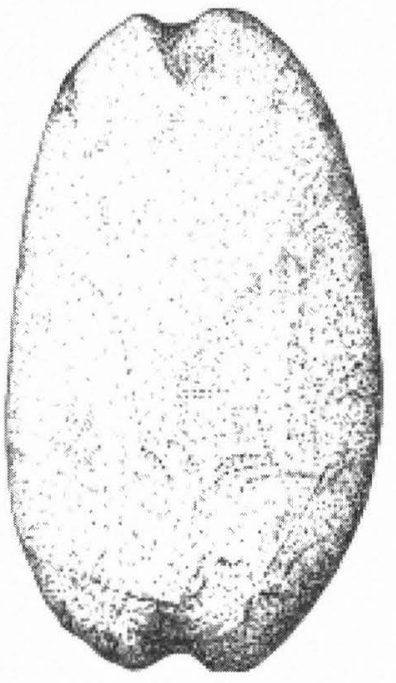

$\mathrm{e}$

FIGURE 20-14. Waco sinkers. (a) Specimen 0-211; (b) Specimen 22Q5; (c) Specimen 17Y2-1; (d) Specimen 37T2-A-1; (e) Specimen $22 \mathrm{Q}-4$.

Valley (Gallagher and Bearden 1976:46). The most directly comparable specimens in form and age (Early Archaic) are one each from the Devil's Mouth and Devil's Rockshelter sites in the Lower Pecos Region (Johnson 1964; Prewitt 1966).

\section{Minimally Modified Stones}

\section{Worked Hematite}

Hematite specimens $(\mathrm{N}=28)$ placed into this category were identified by modifications that include gouges, striations, grooves, ground facets, and polish (Table 20-6). This group represents a minimum number of worked hematite specimens from the site due to the fact that hematite is very soft and tends to disintegrate in the ground. The hematite pieces recovered range from orange to maroon in color and were probably used as a source for pigment (Black and McGraw 1985:183; Highley 1995:521), but other applications of powdered ocher, such as a catalyst in the making of adhesives must also be considered (Allain and Rigaud 1989). Red pigment has numerous documented uses that include body painting, pottery decoration, rock art painting, medicinal uses, and the decoration of human hair (Highley 1995:521). Thirty-nine percent of the worked hematite specimens (11 of 28) were recovered from Unit IIIa suggesting that the importance of hematite use increased during the Early Archaic, if this is not preservation bias.

\section{Worked Slate}

Two small pieces of slate were placed into this group. Specimen 20 N-4 is modified bifacially with faint striations on 
TABLE 20-5

Attributes and Distribution of Notched and Grooved Stone

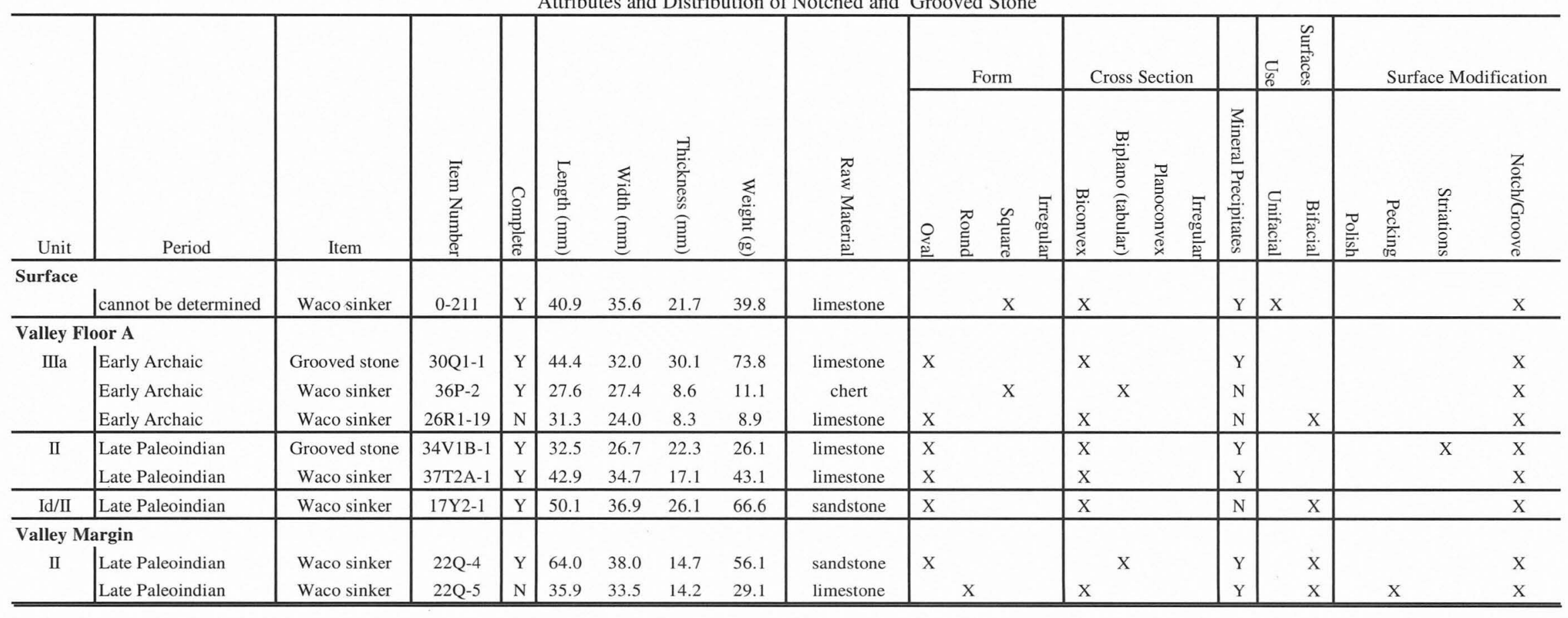




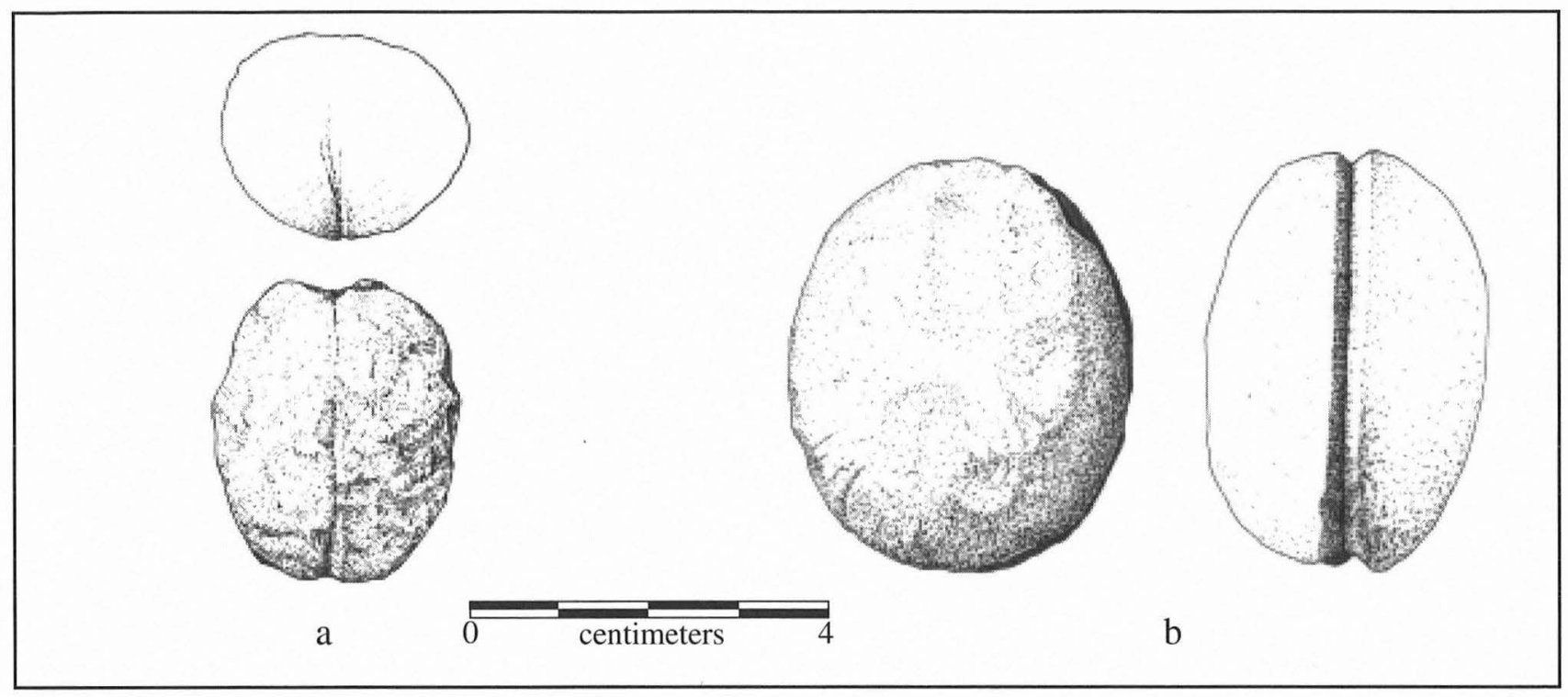

FIGURE 20-15. Grooved stones. (a) Specimen 34V1B-1; (b) Specimen 30Q1-1.

TABLE 20-6

Worked Hematite and Slate

\begin{tabular}{c|c|c}
\hline Unit & Hematite & Slate \\
\hline Valley Floor A & 1 & \\
IIIb/c & 1 & 1 \\
IIIb & 1 & \\
IIIa/b & 11 & \\
IIIa & 2 & \\
III & 3 & \\
II/IIIa & 1 & \\
II & 1 & \\
Isi-c/Id & 2 & \\
Isi-c & 1 & \\
IcI & 1 & \\
IgI/Isi & 1 & \\
Valley Margin & 2 & \\
IIIc & & \\
X/IIIa/b & & \\
X & & \\
\hline
\end{tabular}

one side as well as a small patch of striations on the other side. The overall flatness and smoothness of this gray slate piece could be due to stream rolling. Specimen 22L-20 is triangular in shape suggesting some cultural modification; however, there are no unequivocal signs of human modification.

\section{DISCUSSION}

Ground stone was recovered from Early Paleoindian to Late Prehistoric contexts at the Wilson-Leonard site. Although the presence of ground stone artifacts has generally been interpreted as evidence of plant processing, the low number $(\mathrm{N}=113)$ of these artifacts recovered from the site does not necessarily imply that little plant processing was performed (Black and McGraw 1985:170; Hester 1971a:121; Kraybill 1977:485; Prewitt 1981a; Stahl 1989:174). The use of perishable materials in plant processing has been documented (Stahl 1989:175) with the recovery of a wooden mortar and pestle at a site in Val Verde County, Texas (Hester and Collins 1968), and a wooden mortar found in a cave in Terrell County (Prewitt 1981b).

Sixty-four percent of the ground stone specimens were recovered from the Valley Floor (68 from Valley Floor A and 4 from Valley Floor B), 30\% from the Valley Margin, with the remaining $6 \%$ from indeterminate contexts. The highest percentage $(22 \%)$ of ground stone artifacts were recovered from Early Archaic contexts, with the lowest percentage $(.02 \%)$ associated with the Early Paleoindian period. Sixty percent of all the ground stone specimens date to the Archaic period. The quantity and variety of the Archaic tools indicates the extensive use of ground stone implements at this time as well as an increase in the diversity of the tool kit from Paleoindian times. The notched stones recovered from Late Paleoindian/Early Archaic contexts point to the importance of fish as a resource during these times. The number of artifacts and the different signs of wear observed on these artifacts suggests that by the end of the Early Archaic, plant processing was firmly in place. Specifically, the polish observed on the manos and metates implies that the processing of grasses had become important. 


\section{Chapter 21}

\section{MODIFIED BONE AND SHELL}

by Leslie C. Shaw

\section{INTRODUCTION}

The excavations at the Wilson-Leonard site recovered a small sample of modified bone, antler, and marine shell from a variety of contexts. A total of 24 modified bone and antler artifacts was found, and 1 possibly utilized bone fragment was also identified. The low number of modified bones from this site is probably due in large part to the generally poor organic preservation conditions at the site. Heavy surface weathering reduces the likelihood that modified bone can be recognized. In Texas sites with good bone preservation, bone artifacts often make up a large part of the artifact inventory for both Archaic and Late Prehistoric periods; some Paleoindian assemblages also contain bone artifacts. It is likely that the bone and antler specimens recovered from Wilson-Leonard represent only a few of the actual number of artifacts of these materials used for tools and ornaments at the site.

The marine shells from Wilson-Leonard include two marine gastropod species that can be found along the Texas coast. These shells were minimally modified to create a hole to allow for stringing. The recovery of modified marine shell at this interior location is particularly relevant to the discussion of either long-distance trade with coastal populations or travel to that region.

This chapter begins by providing a detailed descriptive accounting of the modified bone, antler, and marine shell assemblage from the Wilson-Leonard site. This is done to encourage comparative study of these specimens with artifacts from other localities. The small sample size from Wilson-Leonard limits the development of functional and stylistic interpretations of this assemblage in isolation, but it can provide useful data if viewed in broader regional and temporal contexts. The bone and antler artifacts are grouped in categories following those developed by Hall (1981) for the analysis of the large sample recovered from sites in the lower Brazos River valley. The categories represented in the
Wilson-Leonard assemblage include pointed bone $(\mathrm{N}=13)$, tubular bone $(\mathrm{N}=1)$, modified antler $(\mathrm{N}=1)$, fragmentary modified bone ( $\mathrm{N}=9$ ), and an expedient bone fragment $(\mathrm{N}=1)$. All of the marine shells $(\mathrm{N}=6)$ are similar in their type of modification and probable use. Full provenience of bone and shell artifacts is provided in Table 21-1.

\section{DESCRIPTIONS OF BONE, ANTLER, ANDSHELL ARTIFACTS}

\section{Pointed Bones (Figure 21-1a-f)}

\section{Specimen 173-1}

Measurements: length $=8 \mathrm{~mm}$; width $=2 \mathrm{~mm}$; weight $=<0.1 \mathrm{~g}$ Description: This small artifact fragment is the pointed end of a tool, possibly a needle or small awl. The artifact is burned and has polish on the surfaces around the tip. There is a very small, old flake removed from the pointed end which is probably from use. The opposite end has an old break. It cannot be determined which type of animal this bone tool was made from, but the density suggests it is from a mammal.

\section{Specimen 203-9 (see Figure 21-1c)}

Measurements: length $=8 \mathrm{~mm}$; width $=2 \mathrm{~mm}$; weight $=<0.1 \mathrm{~g}$ Description: This artifact is a small pointed end of a tool. The artifact has polish on the pointed end and an old break on the opposite end. It is too small to determine the animal species the bone is from, but the denseness suggests it is from a mammal.

\section{Specimen 309 (see Figure 21-1a)}

Measurements: length $=40 \mathrm{~mm}$; width $=8 \mathrm{~mm}$; weight $=1.0 \mathrm{~g}$ Description: This fragment includes the pointed or working 
TABLE 21-1

Provenience of Modified Bone and Shell

\begin{tabular}{|c|c|c|c|c|c|c|}
\hline Item & Strat. Unit & Square & Level & Feature & Archeological Chronology & Category \\
\hline TP1A-6 & IIIc & Test Pit $1 \mathrm{~A}$ & 1 & & Late Prehistoric & Miscellaneous bone fragment \\
\hline $4 \mathrm{~A}-16$ & IIIIc & E22/S98 & 1 & & Late Prehistoric & Pointed bone \\
\hline $5 B-10$ & IIIc/pot & E20/S96 & 2 & BRM 1 & Late Prehistoric or Archaic & Pointed bone \\
\hline $7 \mathrm{~A}-24$ & IIIc/pot & E20/S92 & 1 & & Late Prehistoric or Archaic & Pointed bone \\
\hline $1 \mathrm{C}-8$ & IIIc & $\mathrm{E} 20 / \mathrm{S} 100$ & 3 & BRM 1 & Late Archaic & Expedient bone tool \\
\hline $36 \mathrm{D}-31$ & IIIc & $\mathrm{E} 40 / \mathrm{S} 70$ & 4 & 120 & Late Archaic & Miscellaneous bone fragment \\
\hline $51 \mathrm{LC}-6$ & III & $\mathrm{E} 2 / \mathrm{N} 8$ & 12 & & Archaic (undifferentiated) & Pointed bone \\
\hline $22 \mathrm{M}-37$ & $\mathrm{IIIa} / \mathrm{b}$ & $\mathrm{E} 22 / \mathrm{S} 82$ & 13 & & Early Archaic & Pointed bone \\
\hline $37 \mathrm{R} 1 \mathrm{C}-10$ & IIIa & E28/S78 & $18 \mathrm{~A}$ & & Early Archaic & Pointed bone \\
\hline 29R2-16 & IIIa & E24/S76 & $18 \mathrm{~B}$ & & Early Archaic & Antler \\
\hline $14 \times 2-2$ & Isi-c/Id & E20/S78 & $24 B$ & & Late Paleoindian & Miscellaneous bone fragment \\
\hline $15 \mathrm{CC} 1-2$ & Isi/Icl/Isi-c & E20/S76 & $29 \mathrm{~A}$ & & Paleoindian (undifferentiated) & Miscellaneous bone fragment \\
\hline $33 \mathrm{CC} 2 \mathrm{~A}-2$ & Isi-c & E26/S76 & $29 B$ & & Late Paleoindian & Miscellaneous bone fragment \\
\hline $258-13$ & IIIc & 17 & 4 & & Late Prehistoric or Late Archaic & Tubular bone \\
\hline 309 & IIIC & 17 & 4 & & Late Prehistoric or Late Archaic & Pointed bone \\
\hline $203-9$ & IIIC & 20 & 7 & & Late Archaic & Pointed bone \\
\hline $323-8$ & $\mathrm{IIIb} / \mathrm{c}$ & 11 & 5 & & Late Archaic & Miscellaneous bone fragment \\
\hline $506-6$ & $\mathrm{IIIb} / \mathrm{c}$ & 14 & 8 & & Late Archaic & Pointed bone \\
\hline $489-1$ & IIIb & 20 & 13 & & Middle Archaic & Miscellaneous bone fragment \\
\hline $583-7$ & IIIb & 38 & 14 & & Middle Archaic & Pointed bone \\
\hline $763-7$ & IIIa & 12 & 17 & & Early Archaic & Pointed bone \\
\hline $978-4$ & IIIa & 25 & 24 & & Early Archaic & Modified shell \\
\hline $173-1$ & IIIa & 38 & 21 & 231 & Early Archaic & Pointed bone \\
\hline $1668-8$ & Y & 100 & 11 & & Early Archaic & Modified shell \\
\hline $1668-9$ & Y & 100 & 11 & & Early Archaic & Modified shell \\
\hline $1668-10$ & Y & 100 & 11 & & Early Archaic & Modified shell \\
\hline $1668-11$ & Y & 100 & 11 & & Early Archaic & Modified shell \\
\hline 1964-2 & ІІ/ІІІа & 38 & 25 & & Early Archaic or Late Paleoindian & Miscellaneous bone fragment \\
\hline $1143-5$ & II/IIIa & 49 & 22 & 231 & Early Archaic or Late Paleoindian & Miscellaneous bone fragment \\
\hline 2071-1 & II & 28 & 31 & 254 & Late Paleoindian & Modified shell \\
\hline 436 & Unknown* & 17 & 0 & & Unknown & Pointed bone \\
\hline
\end{tabular}

*Specimen found in wall cleaning; no level recorded.

end of a tool. It is weathered and exhibits some polish around the tip which may be from use. The opposite end has a break that looks more recent than the other weathered surfaces. The artifact was made from a section of a large mammal diaphysis fragment which was shaped along its edges.

\section{Specimen 436}

Measurements: length $=19 \mathrm{~mm}$; width $=6 \mathrm{~mm}$; weight $=0.2 \mathrm{~g}$ Description: This artifact is the pointed end of a tool, with an old break present on the nonpointed end. It has a flat cross-section and exhibits polish on the tip. The tool was made from bone from a medium to large mammal.

\section{Specimen 506-6 (see Figure 21-1b)}

Measurements: length $=33 \mathrm{~mm}$; width $=9 \mathrm{~mm}$; weight $=0.8 \mathrm{~g}$ Description: This tool is fractured on three surfaces, but only the very tip of the working (distal) end is missing. The artifact is a flat piece of long bone with one end shaped into a narrow, rounded tip. The tip is positioned to one side creating an asymmetrical outline shape. The opposite end and one lateral edge have old breaks. Both of the flat surfaces are polished, either from manufacture or use, and a slight burning is also present on these surfaces. This artifact was probably made from bone from a medium to large mammal.

\section{Specimen 583-7}

Measurements: length $=40 \mathrm{~mm}$; width $=4 \mathrm{~mm}$; weight $=0.4 \mathrm{~g}$ Description: This artifact is a fragment of a pointed tool with a lenticular cross-section. The artifact is in two pieces that fit together and the break appears recent. The tip end has polish to about $20 \mathrm{~mm}$ down the midsection, which could be from manufacture and/or use. The break on the opposite end is old. This tool was made from bone from either a medium mammal or large bird. There is a remnant of the natural interior curve of the bone that indicates the size of the animal, but the type could not be determined. 


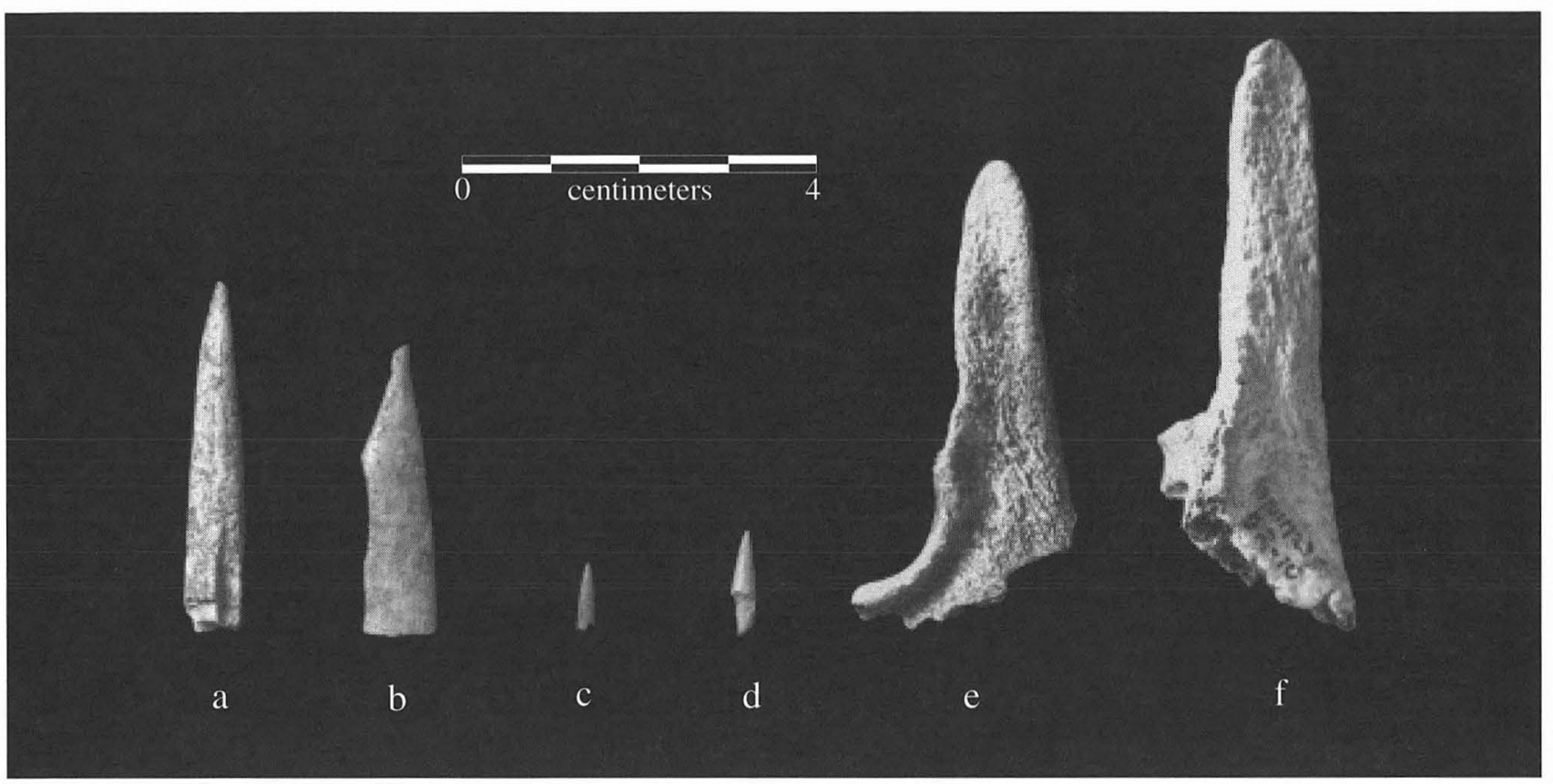

FIGURE 21-1. Modified bone artifacts (pointed tip). Specimen numbers: (a) 309; (b) 506-6; (c) 203-9; (d) 763-7; (e) 7A-24; (f) 5B-10.

Specimen 763-7 (see Figure 21-1d)

Measurements: length $=3 \mathrm{~mm}$; width $=10 \mathrm{~mm}$; weight $=<0.1 \mathrm{~g}$ Description: This small artifact is the pointed end of a tool, possibly a needle or small awl. The pointed end has a slight beveling of surfaces from manufacture, and the opposite end exhibits an old break. The surface of the tool shows polishing that is probably from use. The artifact was made from a dense bone which likely came from a mammal, but the tool is too small for clear species identification.

\section{Specimen 4A-16}

Measurements: length $=20 \mathrm{~mm}$; width $=10 \mathrm{~mm}$; weight $=0.4 \mathrm{~g}$ Description: This fragmentary artifact is the working end of a tool, with the majority of the object missing. The working end is shaped into a rounded point. The tip shows minor indications of either manufacture and/or use. This artifact was made from a large mammal bone and is probably an ulna diaphysis fragment of a large artiodactyl (most likely white-tailed deer).

\section{Specimen 5B-10 (see Figure 21-1f)}

Measurements: length $=64 \mathrm{~mm}$; width $=20 \mathrm{~mm}$; weight $=4.3 \mathrm{~g}$ Description: This artifact was manufactured from the left ulna of an artiodactyl, probably Odocoileus virginianus (white-tailed deer). The bone is missing its proximal articular end, and the distal end utilizes the natural shape of the bone with minimal modification to create a slightly rounded working end. The working end is beveled and has a faint polish, both of which are probably from use. A more noticeable polish is present along one lateral edge of the tool, although much of the artifact surface has heavy weathering.

$$
\text { Specimen 7A-24 (see Figure 21-1e) }
$$

Measurements: length $=65 \mathrm{~mm}$; width $=30 \mathrm{~mm}$; weight $=5.8 \mathrm{~g}$ Description: This specimen is a modified artiodactyl ulna very similar to Specimen 5B-10. The bone used to manufacture the tool is a left ulna from what is probably Odocoileus virginianus (white-tailed deer) based on size. The proximal articular end has broken off, and the surfaces of this portion of the tool are very weathered. The articular surfaces remaining from the proximal end have been shaped to reduce their projection and are smoothed. The distal end of the bone has been rounded with some of this rounding probably from heavy use. There is a faint polish around the working end up to several centimeters from the tip.

\section{Specimen 22M-37}

Measurements: length $=36 \mathrm{~mm}$; width $=9 \mathrm{~mm}$; weight $=1.1 \mathrm{~g}$ Description: This modified bone is the working end of a pointed tool. The end is shaped to a point, but the very weathered and pitted surface does not show traces of manufacture. There are small chips removed from the tip that look like they could have been removed from use. The tool was manufactured from a large mammal bone, probably a longbone diaphysis section.

\section{Specimen 37R1C-10}

Measurements: length $=15 \mathrm{~mm}$; width $=4 \mathrm{~mm}$; weight $=0.1 \mathrm{~g}$ Description: This small artifact is the pointed end of a 
tool. The tip end of this artifact has a small, recent break, and the opposite end has an old break. The white, chalky appearance of this artifact may be due to either heavy burning or weathering. No clear polish from use is evident. It was made from bone from either a medium mammal or large bird.

\section{Specimen 51LC-6}

Measurements: length $=27 \mathrm{~mm}$; width $=11 \mathrm{~mm}$; weight $=1.0 \mathrm{~g}$ Description: This specimen is the working end of a pointed tool. The small break on the tip appears to be old and may have originated from use. The nonbroken areas of the artifact exhibit both striations and polish over much of its surfaces which probably remain from both original manufacture and then use. The very heavy polish directly around the tip is likely from use. This tool has possibly been heat hardened, but it is not clearly burned. This tool was made from a long-bone diaphysis from a large mammal, probably Odocoileus virginianus (white-tailed deer).

\section{Tubular Bone (Figure 21-2)}

\section{Specimen 258-13}

Measurements: length $=9 \mathrm{~mm}$; width $=26 \mathrm{~mm}$ (largest piece); weight $=0.7 \mathrm{~g}$

Description: The bone artifact represented by Lot 258 is a fragmented bone tube with a cross-hatched, incised design. The 12 pieces of this artifact are weathered and, although some of the pieces fit together, the artifact is incomplete even if all the pieces are considered. The tube is made from a thin-walled long-bone shaft which is probably from a large bird. The decoration is incised into the bone in a spiraling motif, with two fields of cross-hatching preserved on the fragments recovered. There is no indication of burning or use wear on the artifact.

\section{Miscellaneous Bone Fragments}

\section{Specimen 323-8}

Measurements: length $=16 \mathrm{~mm}$; width $=4 \mathrm{~mm}$; weight $=0.1 \mathrm{~g}$ Description: This artifact is a midsection fragment of what may have been a pointed tool. It has old breaks on both ends and along one edge, leaving only one original edge. This original edge is smoothed and polished as are the two flat surfaces of the tool. The artifact is weathered but not burned. It was made from bone from a medium to large mammal.

\section{Specimen 489-1}

Measurements: length $=31 \mathrm{~mm}$; width $=9 \mathrm{~mm}$; weight $=0.5 \mathrm{~g}$ Description: This example of modified bone includes two pieces that fit together and represent the midsection of a tool. Both the proximal and distal (working) ends are missing. The tool was made from a diaphysis fragment of a large mammal and was shaped and rounded on both lateral edges. It also has polish on both flat surfaces which is probably from tool shaping during manufacture. Both ends have old breaks, with the narrower end showing possible use after the break occurred. It cannot be determined if the working end was originally pointed or spatulate.

\section{Specimen 1143-5}

Measurements: length $=9 \mathrm{~mm}$; width $=7 \mathrm{~mm}$; weight $=0.2 \mathrm{~g}$ Description: This small bone fragment is probably the midsection of a tool. It has old breaks on both ends, with one break removing most of one edge. The opposite edge has been shaped, and striations that are probably from manufacture are present on both flat surfaces of the tool. The artifact is burned. The density of the bone suggests it is from a medium to large mammal.

\section{Specimen 1964-2}

Measurements: length $=11 \mathrm{~mm}$; width $=6 \mathrm{~mm}$; weight $=0.2 \mathrm{~g}$ Description: This artifact is probably the midsection of a tool with a pointed or spatulate end. Old breaks are present on both ends, and the lateral edges are shaped and rounded. The flat surfaces are smoothed and polished which probably occurred during manufacture. The artifact is completely burned. The bone is dense and there is a slight remnant of an interior curve which suggests that it was made from bone from a medium-sized mammal.

\section{Specimen TP1A-6}

Measurements: length $=14 \mathrm{~mm}$; width $=8 \mathrm{~mm}$; weight $=0.5 \mathrm{~g}$ Description: This specimen of modified bone is probably a midsection fragment of a pointed or blunt-end tool. The fragment has a roughly triangular cross-section and has striations and polish, which likely relate to manufacture, on the original surfaces. This artifact is heavily burned and the angular broken edges suggest the tool was fractured by fire. It was made from a large mammal diaphysis fragment.

\section{Specimen 14X2-2}

Measurements: length $=15 \mathrm{~mm}$; width $=7 \mathrm{~mm}$; weight $=0.2 \mathrm{~g}$ Description: This artifact is probably a midsection of a pointed or spatulate tool. The specimen has breaks on two ends and exhibits some minor burning. Striations on the surface may remain from the original shaping of the tool. It also has a heavy polish on the unbroken surfaces, including the sides. This heavy polish may indicate its use as a needle or awl for basketry or other soft fiber. The artifact was made from a flat bone, probably a scapula fragment or rib from a large mammal. 


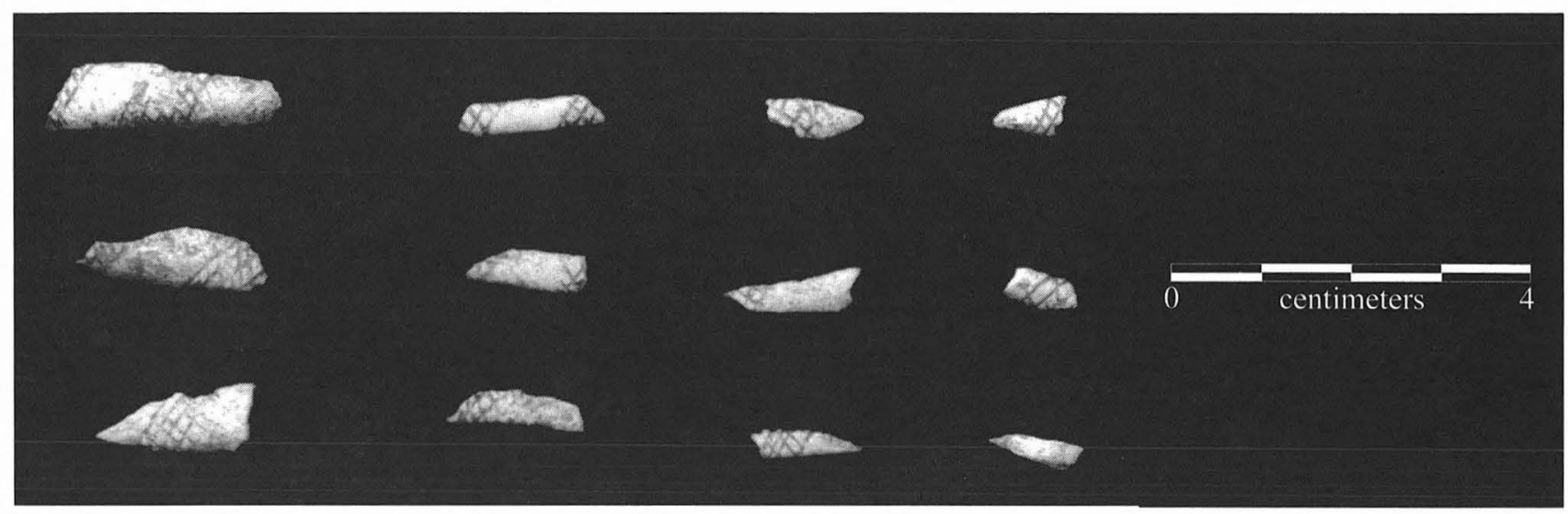

FIgURE 21-2. Tubular bone artifact fragments with incised crosshatched design, Specimen 258-13.

\section{Specimen 15CC1-2}

Measurements: length $=15 \mathrm{~mm}$; width $=5 \mathrm{~mm}$; weight $=0.2 \mathrm{~g}$ Description: This shaped bone fragment has breaks on three sides, leaving little evidence of the original shape of the artifact. The remaining edge is rounded and has striations and polish, probably from manufacture. The specimen is also heavily burned. Its inner curvature suggests it was made from a long-bone diaphysis fragment of a medium- to large-sized mammal.

\section{Specimen 33CC2A-2}

Measurements: length $=14 \mathrm{~mm}$; width $=10 \mathrm{~mm}$; weight $=0.6 \mathrm{~g}$ Description: This artifact fragment is probably the nonworking end of a tool, with its pointed or spatuate working end missing. This object has been shaped into a rounded beveled end. This beveled end has striations that probably remain from manufacture. The specimen is heavily burned. It was manufactured from a large mammal diaphysis section.

\section{Specimen 36D-31}

Measurements: length $=23 \mathrm{~mm}$; width $=5 \mathrm{~mm}$; weight $=0.5 \mathrm{~g}$ Description: This midsection of an artifact is possibly from a thin awl or needle. The artifact has been heavily burned, and the angular breaks on each end suggest that it was fractured in a fire. There are striations on the surface which probably remain from shaping during manufacture. The density of the bone suggests it is from a medium to large mammal.

\section{Expedient Bone Artifact}

\section{Specimen 1C-8}

Measurements: length $=55 \mathrm{~mm}$; width $=16 \mathrm{~mm}$; weight $=5.8 \mathrm{~g}$ Description: This bone is a possible expedient tool with no postbreak modification. The rounded end was created by spiral fracture of the bone and slight rounding of the end may have occurred from use. There is no clear polish on the rounded end. The bone is a diaphysis fragment of a long bone from an artiodactyl, probably Odocoileus virginianus (white-tailed deer).

\section{Antler Artifact}

\section{Specimen 29R2-16}

Measurements: length $=18 \mathrm{~mm}$; width $=10 \mathrm{~mm}$; weight $=0.9 \mathrm{~g}$ Description: This specimen was identified as a modified piece of antler, likely from deer. It is fragmentary and includes only the tip or pointed end of a tool. The almost conical cross-section suggests it may be a fragment of a projectile or a heavy-duty punch. The small fragment missing from the tip appears to be from a fresh break while the opposite end has an old, angular break. The pointed end exhibits some minor polish and there is burning or scorching along one side.

\section{Marine Shell Artifacts (Figure 21-3)}

\section{Specimen 978-4 (see Figure 21-3a)}

Measurements: length $=9 \mathrm{~mm}$; width $=8 \mathrm{~mm}$; weight $=0.3 \mathrm{~g}$ Description: This single modified shell is of the genus of marine gastropod Neritina sp., probably the olive nerite $(N$. reclivata). This specimen is complete except for the area that was ground to create a hole in the shell, probably for stringing. The hole was abraded in the doral surface of the shell, opposite from the natural opening.

\section{Specimens 1668-8, 1668-9, 1668-10, 1668-11 (see Figures 21-3b-e)}

Measurements: length $=10-12 \mathrm{~mm}$; width $=6-7 \mathrm{~mm}$; no weights; dirt inside shells would bias weight

Description: These specimen lots include four examples of modified marine shell that are all of the species Prunum 


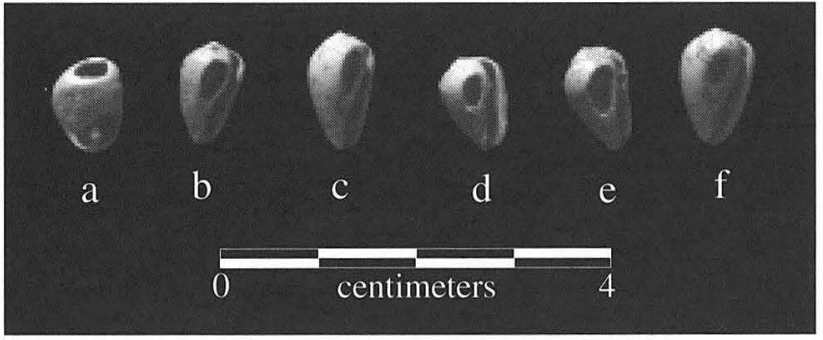

FiguRE 21-3. Modified marine shell artifacts. Specimen numbers: (a) $978-4$; (b) $1668-8$; (c) $1668-9$; (d) $1668-10$; (e) 1668-11; (f) 2071-1.

apicina (marginella). These shells are complete except for the areas abraded to create holes. The abrasion was done on the ventral surfaces, opposite from the natural openings.

\section{Specimen 2071-1 (see Figure 21-3f)}

Measurements: length $=12 \mathrm{~mm}$; width $=7 \mathrm{~mm}$; weight $=0.4 \mathrm{~g}$ Description: This marine shell is very similar to Specimens $1668-8,1668-9,1668-10$, and 1668-11. It is of the marine gastropod Prunum apicina (marginella) and is complete except for the area abraded to create a hole. The hole was abraded on the dorsal surface of the shell like the other examples from the site.

\section{INTERPRETATIONS}

\section{Modified Bone and Antler Artifacts}

The sample of modified bone from the Wilson-Leonard site can be divided into three general categories based primarily on shape, with the one antler artifact considered as a fourth category. Of the 23 examples of modified bone, 13 are fragments of the working end of a pointed tool. One fragmentary tubular bone artifact was found, and it is the only specimen with an incised decoration. The fragmentary modified bone sample includes 7 examples identified as pieces of tool midsections, 1 of which is interpreted as the proximal (or nonworking) end of an artifact, and 1 fragment of unknown tool portion. The 1 example of a possibly utilized but not modified bone is included to emphasize the potential for the expedient use of bone which is likely underidentified in the archeological assemblage.

The 13 bone artifacts with a working end shaped into a pointed end could be subdivided into several forms based on the typology developed by Hall (1981). Pointed bone artifacts have often been called awls in the archeological literature and include tools that might have been used for hide working, basketry, sewing, net making, or other production tasks using relatively soft materials. Their use as hairpins and clothes fasteners has also been suggested. Little work has been directed to identifying use wear on bone artifacts, so the interpretations of function remain gen- eral. Hall (1989) has argued, using ethnographic sources from Texas and the Southwest, that there may be functional differences within the pointed tool category between those that are markedly pointed and those with more rounded ends. $\mathrm{He}$ argues that the rounded-end tools, which often have a hole near the proximal end and an incised design, could have been used in personal hygiene as head scratchers/ louse crushers and/or as sweat scrapers, while the pointed tools may have been used as awls.

The examples from the Wilson Leonard site (e.g., see Figure 21-1a) are primarily the sharp-tipped awl type as opposed to the rounded-end type discussed by Hall (1989). They match most closely the subcategories of pointed tools defined by Hall (1981) for the Ernest Witte site as Forms 6 and 7, which are long, slender tools made from large mammal long-bone segments. No incised designs were noted on the examples from the Wilson-Leonard site, although only one proximal tool end (Specimen 33CC2A-2), the area where design is most often incised, was recovered. The seven modified bone fragments that were thought to be tool midsections could have originated from both the pointed and rounded-end types of artifacts.

There is one example of a pointed-tip artifact that stands out from the general category of pointed end tools (Specimen 506-6; see Figure 21-1b). This piece of mammal bone has a broad midsection, similar to the awls from the site, but the working end has been carefully shaped to create a fine tip with a round cross-section. The tip is positioned off-center to the midsection. The end of the tip is missing but would probably look like three other specimens recovered from the site, Specimens 173-1, 203-9, and 763-7. These three small fragments have fine tips as working ends and a round cross-section. Although in their fragmentary condition they might be classified as needle tips, it is equally plausible that they are broken tips from a tool like Specimen 506-6. This tool is most similar to Hall's (1981) Form 11 , which includes several fine-tipped tools made from large mammal long bones from the Ernest Witte site. A similar example is known from 41LK201 in southern Texas (Highley 1986). This fine-tipped tool may have had a special and specific function apart from the general awls. Further research into this tool type at other sites may help define a distinct bone tool category.

The modified bone assemblage includes two examples of modified deer ulnae (Specimens 5B-10 and 7A-24), a tool type that is widespread in Texas (e.g., Hall 1981; Harrell 1983; Schuetz 1961). The Wilson-Leonard examples are both missing the proximal ends, with old breaks in the area of the epiphyseal suture. The distal ends have been shaped so that the naturally constricting diaphysis has a rounded working end. The specimen designated as 5B-10 has a slightly beveled end with slight polish and more prominent polish along one side of the midsection. The second example, Specimen 7A-24, has a more rounded end with faint polish evident near the tip. One possible working end of an ulna 
tool was also recovered (Specimen 4A-16), but only $20 \mathrm{~mm}$ of the tool remain. This type of tool has been argued to have been used as a pressure flaker in flintknapping. Harrell (1983) conducted use-wear experiments to evaluate this interpretation and concluded that use as pressure flakers was probably the correct function of most of these tools, although two examples in her study did not fit the pattern created by use in pressure flaking, with a finer polish remaining on the modified end. This opens the possibility that this tool type was not used exclusively in flintknapping. The three examples from Wilson-Leonard (including Specimen 4A-16) have some surface weathering that obscures some of the use wear on the ends. The beveling on Specimen 5B-10 may have been created by use in pressure flaking, but the polish seen on the midsections of both tools suggests they may have had other uses.

One fragmentary bone tube (Specimen 258-13) was recovered from a Late Archaic or Late Prehistoric context. This tube is in 12 fragments and even if reconstructed, probably does not represent the complete artifact. The specimen was manufactured by using the natural tube created by a longbone diaphysis with the epiphyseal ends removed. The bone is thin and is probably from a large bird or mediumsized mammal (e.g., rabbit). The tube was decorated with an incised cross-hatch pattern that seems to have spiraled around the tube. This type of design is similar to the geometric patterns seen on pointed and blunt-ended tools (e.g., Hall 1981).

One fragment of a tool made from deer antler (Specimen 29R2-16) was recovered from an Early Archaic context. This artifact is probably only a small fragment of the original tool which makes it difficult to interpret function. The conical shape suggests it was not an awl-type tool and may have been part of a projectile or atlatl.

The expedient bone tool included in the bone tool assemblage is a large mammal diaphysis fragment with a rounded end created by a spiral fracture, probably created by the breaking of bone for removal of marrow. There is a very faint polish on the rounded end which suggests the bone was used without modification. Incidents of such use would probably be much higher in conditions of better preservation and if magnification was used to inspect unmodified bone assemblages.

The bone artifacts from the Wilson-Leonard site are predominantly made from the long bones of large mammals. The white-tailed deer (Odocoileus virginianus) was the most common large artiodactyl in Central Texas prehistorically, with occasional occurrences of antelope and possibly mule deer (Brown 1989). Bison may also have been present in moderate numbers but the bone artifacts from WilsonLeonard all appear to be made from thinner bone than that found in bison long bones. The bone tools were made from segments of the long-bone diaphysis, with the shaping done in part with an abrasive, based on the striations seen on a number of the specimens. The grooved, stone abraders found at some Texas sites (Turner and Hester 1993:290) would have been suitable shaping tools.

The bone and antler artifacts from the Wilson-Leonard site were recovered from a variety of temporal and functional contexts. While three of the bone artifacts were found in features (two from Feature 231 and one from Feature 120), most were recovered outside of features. There does not appear to be a distinct clustering of bone tools in any one context that might suggest a specialized activity area. Some of the bone artifacts were burned (40\%), and the angular fractures exhibited on several of these suggest they may have been discarded in a fire. The light scorching found on a few of these, including the antler artifact, could have occurred in the manufacturing process with heating of the tool done to increase hardness.

Bone artifacts were recovered from Paleoindian through Late Prehistoric contexts. The three specimens (Specimens 14X2-2, 15CC1-2, 33CC2A-2) recovered from Paleoindian (Paleoindian-undifferentiated and Late Paleoindian) contexts include two midsection fragments and one proximal (nonworking) end of a tool. These are all burned, which may have encouraged the long-term preservation of these artifacts. Two midsection fragments (Specimens 1143-5, and 1964-2) found in Late Paleoindian/Early Archaic contexts were also heavily burned. Four pointed bone artifacts (Specimens 173-1, 763-7, 22M-37, and 37R1C10) and the one antler artifact (Specimen 29R2-16) came from Early Archaic contexts. The pointed tools are all small fragments of the tip end and only one shows clear burning. The Middle Archaic deposits at the site contained only three bone artifacts, and these include two pointed bone tools (Specimens 583-7 and 51LC-6) and one midsection fragment (TARL Lot 489-1). The largest sample comes from the Late Archaic and Late Archaic/Late Prehistoric contexts, and these include two deer ulna tools (Specimens 5B-10 and 7A-24) and the incised tubular bone artifact (Specimen 258-13). The two specimens from Late Prehistoric contexts include the pointed end of what was probably a deer ulna tool (Specimen 4A-16) and a midsection fragment (Specimen TP1A-6). This temporal distribution of bone and antler artifacts is not particularly noteworthy other than to suggest that bone and antler were both probably important mediums for tool manufacture as early as the Paleoindian period.

\section{Modified Marine Shell}

The marine shells found at the Wilson-Leonard site are all small gastropods that are common along the Texas Gulf Coast. These include five marginella (Prunum apicina) shells and one of the genus Neritina, probably the olive nerite $(N$. reclivata) (Andrews 1992). These shells are all largely complete, with a hole abraded into the shell surface opposite from the natural opening. This technique for creating a hole in small marine gastropod shells has been noted at other 
Texas sites, both on the coast and in the interior (e.g., Campbell 1957; Collins 1968). The small sizes of these beads may contribute to their scarcity because they could pass through the $1 / 4$-inch-mesh screens commonly used by archeologists.

An interesting aspect of the marine shells from WilsonLeonard is the occurrence of two in early context. One specimen (2071-1) is from a Late Paleoindian context (although a rodent disturbance was noted in this square) and a second (Specimen 978-4) is from an Early Archaic context. The four specimens found together (1668-8 to 1668-11) came from
Stratigraphic Unit Y, which is associated with Early Archaic deposits in the Valley Margin.

There are very few examples of marine shells at inland Texas sites dating to these early periods, with one example being the Witte Museum site (41BX323) (Frances Meskill, personal communication 1996). The trading of marine shells into the interior of Texas during later periods has been documented as far as 250 to $320 \mathrm{~km}$ (160 to 200 miles) inland and include primarily ornamental artifacts in contrast to the utilitarian shell tools that are part of the artifact inventory at coastal sites (Hall et al. 1982; Hester 1971b; Steele 1988). 


\section{Chapter 22}

\section{MICROWEAR ANALYSIS OF CHIPPED STONE ARTIFACTS}

by Marvin Kay, Dale B. Hudler, Boyce N. Driskell, and Michael B. Collins

\section{INTRODUCTION \\ by Michael B. Colllins}

Any determination of the uses to which prehistoric stone tools were put may consider several lines of evidence and should seek concordance from as many of these as possible (Collins 1993). Artifact form, context, patterns of breakage, patterns of refurbishment, traces of wear visible macroscopically, traces of wear visible with low-power microscopy, traces of wear visible with high-power microscopy, and identification of adhering residues are all sources of archeological information. The potential value of this information is greatest when it is empowered with ethnographic and experimental analogies.

To our knowledge, no one has conducted a thoroughly comprehensive study of lithic use-wear employing in logical sequence all of the lines of evidence just enumerated for the obvious reason that it entails an enormous effort for each artifact. Paradoxically, inferred use-wear should be based on patterns within an assemblage, meaning many specimens need to be subjected to this time-consuming level of analysis. The assembled lithic studies in this report touch upon all of these lines of evidence to some degree. In the descriptive chapters (13-20), lithic artifacts are assessed for form, contexts, patterns of breakage, patterns of refurbishment, and other attributes that shed light on function. Traces of organic residue were extracted and assayed, as reported in Chapter 23. In this chapter are reported three separate microscopic use-wear studies.

The three separate studies came about partly through historical accident, and consequently, are not as integrated as they might have been. The present analysis and interpretation of the Wilson-Leonard site and its data were conceived in 1990-1991 (Collins et al. 1991). At that time, usewear studies were almost exclusively of two kinds, the "lowpower magnification" approach of Odell and others (Odell 1982) and the more prevalent "high-power, polish" approach of Keeley, Driskell, and others (Driskell 1986; Keeley 1980). Early in this project, Boyce Driskell agreed to conduct a microscopic study of a sample of lithic artifacts for traces of use-wear. The initial small sample examined by Driskell proved not to have well-developed polishes, a finding that did not bode well for behavioral inferences. A symposium on research at Wilson-Leonard held at the 52nd Plains Anthropological Conference in 1994 included a presentation of Driskell's initial findings. Among those present was Marvin Kay who offered to see if the approach he employs in usewear microscopy would be more effective on the WilsonLeonard materials, and subsequently, he examined a small sample. Indeed, the Normarski optical system Kay uses revealed considerable evidence for use-wear on some WilsonLeonard artifacts. Accordingly, Kay then examined a much larger sample. The approaches and results of Driskell's and Kay's studies are reported below.

Dale Hudler, a graduate student at The University of Texas at Austin, began in Fall of 1995 to examine a regional sample of Clear Fork tools for microscopic evidence of usewear. Since the Wilson-Leonard site had yielded numerous Clear Fork and similar tools from comparatively well-dated archeological contexts, Hudler included the Wilson-Leonard sample in his research (Hudler 1997). His Wilson-Leonard findings are reported in this chapter.

It is important to keep in mind that these three studies were conducted entirely independently and that the three authors have different levels of experience and somewhat different perspectives on research of this kind. Logistically, it was not possible to cycle the same artifacts to all three consultants because, although they began sequentially, much of their work was done concurrently, and they held specimens for extended periods of time. Driskell examined 25 specimens; Kay, 122; Hudler, 59. Driskell and Hudler saw 4 of the same artifacts, Driskell and Kay saw 1 artifact in common, and no single artifact was seen by all three analysts. A total of 201 individual artifacts was examined, accounting 
for the 5 viewed in common. This introductory discussion is concerned more with results than with methodology, and it was never intended that these three studies be a test of alternative procedures, although some may read such an interpretation into the results. Had this been a comparison of techniques, it would have been imperative that each analyst independently see the same specimens.

When the aggregate 206 sets of results are arrayed for the 201 individual artifacts examined, several important findings emerge. Driskell found a pervasive, ill-defined polish (his X-polish) that is apparently the product of soil movement. He also found comparatively little in the way of welldeveloped use-wear polish on most of the specimens he examined. This fact along with the interference caused by the pervasive "X-polish" forced Driskell to concentrate on those few specimens on which well-developed polish was observable through the soil polish. In the case of one hafted end scraper, polish attributable to hide working was found, and on two other unifacial pieces, polish suggestive of movement in a bone haft was observed. From these and other limited use-wear traces (noted on a drill, a retouched flake, an edge-modified flake, and an engraved flake) it is apparent that in spite of limitations, there is potentially valuable information to be gained from study of the polish developed on artifacts from this site.

Kay examined almost five times as many specimens as did Driskell and found use-related micropolish and striations on many of them. He also noted the soil polish seen by Driskell. Kay's procedures are particularly well suited to detecting minute striations that show the direction of tool movement relative to the contact material. These striations often occur in superimposed sets that can be interpreted as resulting from sequential episodes of use. In this vein, it clearly emerges that most forms of "projectile points" were also used in other ways, mostly as knives. One of the most important results of Kay's effort is identification of use-wear on small flakes - the "microlithic" tools discussed in Chapter 17. There is concordance between three lines of evidence-microcores, small modified tools, and use-wear on small flakes - to indicate the use of microlithic tools at the Wilson-Leonard site. Kay notes that the presence of usewear on "waste flakes" might be "disconcerting" to some, but for many applications, the best cutting edges are found on the sharp margins of unretouched flakes be they small or large. This result reinforces previous findings that the byproducts of knapping were commonly selected for brief use as tools, a point well summed up by Vaughan (1985:101):

There has really never been any doubt that unretouched flakes and blades were utilized in prehistoric times ... But unretouched stone tools have traditionally been relegated to the fringes of typological studies because the latter are based by necessity on techniques of edge modification by retouch which result in recognized characteristic forms ... At best, unretouched flints are assimi- lated through a typological back door if they bear retouche d'utilisation.

Lithic analysts cannot assume that flakes represent nothing more than waste.

Like Driskell, Kay emphasizes great as-yet-untapped potential for use-wear analyses in the Wilson-Leonard lithic collections. One of the artifact categories that Kay was unable to include in his study is the Clear Fork tools.

Fortunately, Hudler's examination of Clear Fork tools, including 56 from Wilson-Leonard (Hudler 1997:19), was completed at about the time that it became clear that Kay was not going to be able to give these sufficient attention. Hudler examined the remainder of the Wilson-Leonard specimens for a total of 59. His results indicate that these are primarily woodworking tools but that some were used instead, or also, in working other materials.

The one specimen examined by both Driskell and Kay yielded very different results under the two procedures. Userelated polish was not detectable by Driskell, but Kay was able to discern multiple sets of striae and suggest sequential use episodes. The four Clear Fork specimens examined first by Driskell and then by Hudler produced generally comparable results. Both analysts found extensive, weakly developed polish on all of the specimens. Hudler also found polish that he interprets as evidence of woodworking on one of these specimens.

The specialized subfield of use-wear studies is not without its strengths, weaknesses, and controversies. Unresolved issues embedded in the results reported in this chapter include the extent to which polish is additive or subtractive, the extent to which artifacts should be cleaned before microscopic examination, and how much experimental replication is needed for sound inferences. In spite of these, the present results are useful and important, the collections are available for additional future work, and the analytical procedures for assessing the evidence for use-wear continue to improve. Perhaps the large store of replicative evidence amassed by Keeley, Driskell, and others in combination with the high resolution of directionality possible using Kay's techniques should be used in combination toward that end.

\section{ANASSESSMENT OF USE-WEAR TRACES ON CHIPPED STONE ARTIFACTS} by Boyce N. Driskell

At the request of the excavators, an analysis of microscopic use-wear on 25 chipped stone artifacts from the Late Pleistocene and Early Holocene (Paleoindian and Archaic) deposits at the Wilson-Leonard site (41WM235) was conducted by the author at the Office of Archaeological Services, University of Alabama. Artifacts received for microscopic assessment were previously assigned to morphological classes. The author was asked to (1) assess potential for success in analysis of microscopic wear patterns (particularly analysis of use-wear polish) and (2) answer through 
microscopic inspection, where possible, specific queries about artifact function as suggested by gross morphology. Unlike a previous study of use-wear on chipped stone artifacts from Texas (Driskell 1994), the microwear study of specimens in each morphological class was limited to an analysis protocol designed to address these two objectives. While the following discussion of methods describes techniques of analysis used, specific questions about function and the analysis protocol are discussed with each artifact category in the Results section.

\section{Methods}

The collection of 25 artifacts was classified by the excavators into the following morphological classes: Clear Fork tool $(n=4)$, biface preform $(n=4)$, projectile point $(n=4)$, awl or drill $(n=3)$, uniface $(n=3)$, hafted end scraper $(n=1)$, retouched flake $(n=2)$, edge-modified flake $(n=2)$, blade core fragment $(n=1)$, and engraved flake $(n=1)$. Prior to microscopic examination and as necessary during examination, specimens were thoroughly cleaned using a mild, nonabrasive detergent and small brush. In deference to potential presence of organic residues, no chemical cleaning was conducted. Each artifact was then examined according to the analysis protocol established for its morphological class.

Where called for, low-power, stereoscopic examinations were conducted using a Nikon Stereoscopic Zoom Microscope. Magnification varied from $8 \mathrm{X}$ to $40 \mathrm{X}$; about $20 \mathrm{X}$ was normally satisfactory for observation of microflake scar patterns and edge attrition. Patterns of edge damage observed using the stereoscopic microscope were interpreted by reference primarily to patterns described by Odell (Odell and Odell-Vereechken 1980).

Higher magnifications and epi-illumination were achieved through use of a Zeiss Compound Microscope with incident light attachment. Magnifications range from about 100X to 500X; most identifications of polish and linear features were possible at about $200 \mathrm{X}$ to $250 \mathrm{X}$. This incident light microscope is also fitted with a closed-circuit TV camera, monitor, and image digitizer to store and manipulate computerized images. Scans of edges and areas were generally made at about $100 \mathrm{X}$ with areas of interest magnified to about 200X. Notes on polish, striations, or other potential use alterations were made for each specimen and keyed to specific location on outline drawings of the specimen. Methods of analysis and interpretations for microscopic polishes and linear features closely followed those advocated by Keeley (1980) and later, Vaughan (1985) and Driskell (1986). As noted below, microscopic inspection methods were tailored to questions concerning each class of artifacts.

In regard to polish identifications using the incident light microscope, patterns of brightness (polish) result from areas of microtopography that are perpendicular to the axis of the scope. The larger, smoother, and more perpendicular the area, the brighter its appearance in the scope. It should be remembered, however, that neither damage (microscarring, abrasions, edge rounding) nor polishes are necessarily the result of use. Intentionally or otherwise, artifacts are often damaged, abraded, etc. during manufacture, curation, or after disposal.

An important concern for the microwear analyst is to determine which traces are natural or accidental and which are from use. The author takes a conservative approach to polish interpretation. Therefore, in the following discussions, unless polishes are quite well formed and extensive or definitively patterned, they are categorized by several nondefinitive labels. Ridge or edge "ribbons" are thin areas along ridges (or edges) that exhibit brightness under the incident light microscope. All ridges will exhibit some enhanced brightness but wide, consistent, and intensely bright ridge ribbons are more suggestive of use because they result from modifications to the normally sharp directional break of the ridge or edge. The term "generic polish," used below to designate areas of enhanced brightness, are areas without the magnitude of microtopographic modifications or special characteristics associated with recognizable polishes. Generic polishes may result from use but are more likely the result of other causes of damage and abrasion. Finally, the following discussion references "X-polish," a term applied to a generic polish often associated with randomly oriented striations and seen extensively on the entire collection from the Wilson-Leonard site. While called X-polish here, this polish is almost certainly from postdepositional soil abrasion.

\section{Results}

\section{Clear Fork Tools}

Four artifacts from this morphological class were examined (Figure 22-1) to determine if use-wear on the bit of each tool suggested woodworking and if there was any indication of hafting from polish in the area of the butt. Thus, each side of the bit edge was examined for wear traces using the incident light microscope. Also, each edge near the potential hafting area, along with a transect along the medial ridge of each side of the specimen, was examined for wear traces with the incident light microscope. No other areas were examined microscopically.

Specimen 25BB2D-1 is an intact ovoid biface (Side 1 illustrated, Figure 22-1a). The specimen exhibits a dull abrasive but poorly formed polish across most of the edges and surfaces that were inspected. This polish is particularly well formed on the medial ridge of Side 1. Where well formed, striations are easily observed. This polish is most similar to hide polish but is thought to derive from postdepositional movements in the soil. Reasons for this interpretation include (1) the almost ubiquitous presence of this type of polish on the sample of 25 artifacts examined, and (2) the rather random and extensive presence of the polish on edges and ridges of most specimens. Although thought to result 
from soil movements, this type of polish is referred to as $\mathrm{X}$-polish in discussions below. No other polish or use-wear traces were detected on the bit edge (Area A) or in the potential hafting areas (B1, C1) of this specimen.

Specimen 51AA1D-3 is a similar type of artifact (Side 2 illustrated, Figure 22-1b) with quite similar patterns of microscopic polish. X-polish is extensive on the edge of Area A (bit) but is poorly developed. No well-developed polishes were seen on edges in the potential hafting areas $(\mathrm{B} 1, \mathrm{C} 1)$, but one area $(\mathrm{C} 2)$ on Side 2 shows accentuated X-polish development with clearly perceived striations. Interestingly, a flake scar in Area A (Side 1) appears more recent and does not exhibit as much X-polish. No other polish or use-wear traces were observed.

Specimen 15AA2-2 is a fragment (bit end) of an artifact similar to the others in this category (see Figure 22-1c). $\mathrm{X}$-polish was observed on the bit edge (Area A). The area around $\mathrm{A} 1$ is partially coated with plastic (PVA) from labeling. X-polish was also found on areas of the break facet (Area D). No other polish or use-wear traces were observed on the artifact.

Specimen 50BB1D-2 is, conversely, the potential haftable end of an artifact similar to the intact specimens in this category (Side 2 illustrated, Figure 22-1d). X-polish is generally poorly formed but was found extensively along the break facet (Area A) and edges (B1, C1) on the opposite end. This polish was well formed in Area B2, an area on and near the medial ridge of Side 2. In this area, polish exhibited numerous striations or scratches and crazing similar to some stoneon-stone abrasions. Also, well formed X-polish was observed on the corner (Area A1) of the break facet. No other polish or use-wear traces were observed on this specimen.

No polish indicative of use or of hafting was recognized on any of these tools. However, a type of somewhat abrasive, medium-bright polish (referred to as X-polish) was seen extensively. This appears to be postdepositional soil polish (discussed further in the Conclusions below).

\section{Biface Preforms}

Four similar, bifacially worked artifacts, thought to be biface preforms by the excavators, were inspected (Figure 22-2). If present, use-wear would suggest other functions for these artifacts. To address this question, each specimen was subjected to analysis by scanning each bifacial edge at high incidence (that is, viewed edge on). Normally, bifacial edges (which are usually quite strong) will exhibit some polish (viewed edge on) in areas that have been consistently used. Where polish is seen edge on, closer inspection of adjacent faces (sides) is warranted. Break facets were also scanned for any traces of use after breakage.

Specimen $30 \mathrm{HH} 2 \mathrm{C}-1$ is an ovoid biface with one end missing (Figure 22-2a). Considerable rounding of the edge is apparent in Area $\mathrm{C}$. This rounding is probably the result of platform preparation during manufacture. The break facet is undamaged. Polish formation (X-polish) is extensive but uniformly diffuse and poorly formed. The artifact does not appear to have been used.

Specimen 51AA1D-2 is an intact, trianguloid biface (Figure 22-2b). Area $D$ is faceted with sharp, undamaged edges. The edge in Area B is heavily rounded or battered (platform preparation) but good polish is limited to Area B1 which exhibits a small area of X-polish. Metal scrapings (from excavation?) occur at Areas B1 and B2. There is also a small area of better-developed X-polish at Area A2. Otherwise, diffuse $\mathrm{X}$-polish and thin edge ribbons were seen along artifact margins. The specimen does not appear to have been used.

Specimen 35CC2D-1 is an elongated, ovoid biface with one end missing (Figure 22-2c). Intact edges are rounded and battered. The break facet (Area D) exhibits sharp, undamaged edges. Area D1, near the corner of the break facet, exhibits a small area of well-developed X-polish. Otherwise, diffuse X-polish can be seen on most edges as thin, discontinuous ribbons. There is no evidence of use of the artifact.

Specimen 29JJ1D-1/29II2B-1 is an ovoid biface found in two pieces (Figure 22-2d). An additional piece from one end is missing. Edges are fairly sharp with some limited rounding or battering. Small areas of diffuse X-polish were observed along the artifact's edges. No additional polish was noted. There is no evidence of use of this artifact.

In summary, biface preforms examined exhibit no polish or other wear traces indicative of use as a tool in contact work situations. Rounding and rounding/battering of edges are, in all likelihood, the result of platform preparation during manufacture (Sheets 1973). It is reasonable to assume that these artifacts are preforms. All four biface preforms exhibit the so-called X-polish to lesser or greater degrees.

\section{Projectile Points}

Four projectile points (Figure 22-3) were examined for any evidence of use and for evidence of hafting or hafting materials. Like the biface preforms, edges were scanned at high incidence, break facets were scanned, and a medial transect in the hafting area was scanned using the incident light microscope.

Specimen 1070-2 is a small, side-notched projectile point (San Patrice ?) with one shoulder and side missing (Figure 22-3a). No polish or other probable use damage other than diffuse extensive X-polish was seen on the intact edges of the specimen. Area A1 is a small notch, possibly of postdepositional origin. No microscarring or polish was observed associated with this area. A medial scan revealed no polish resulting from hafting.

Specimen 32CC2B-1 is a nearly intact, corner-notched Wilson projectile point with missing distal tip and missing basal corner (Figure 22-3b). Microscopic scans of intact edges revealed no polish other than diffuse, extensive $\mathrm{X}$-polish. The missing tip possibly results from impact. No polish from hafting was found. 


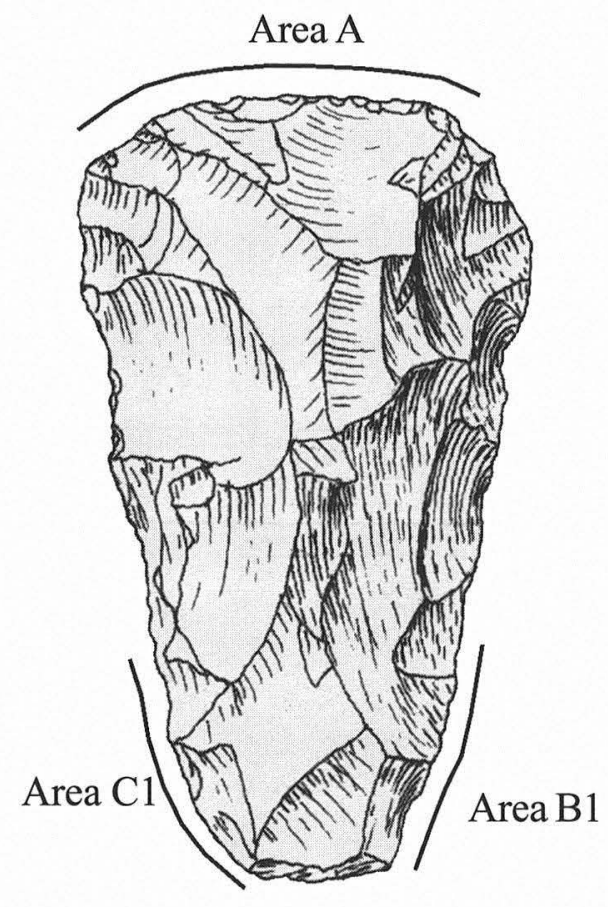

a

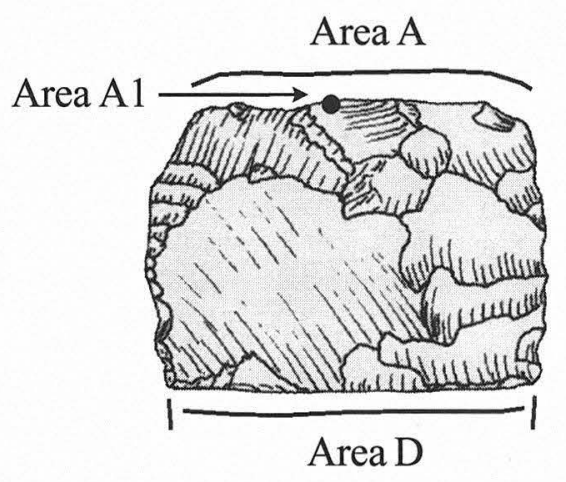

C

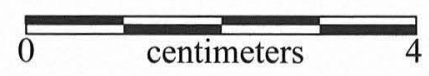

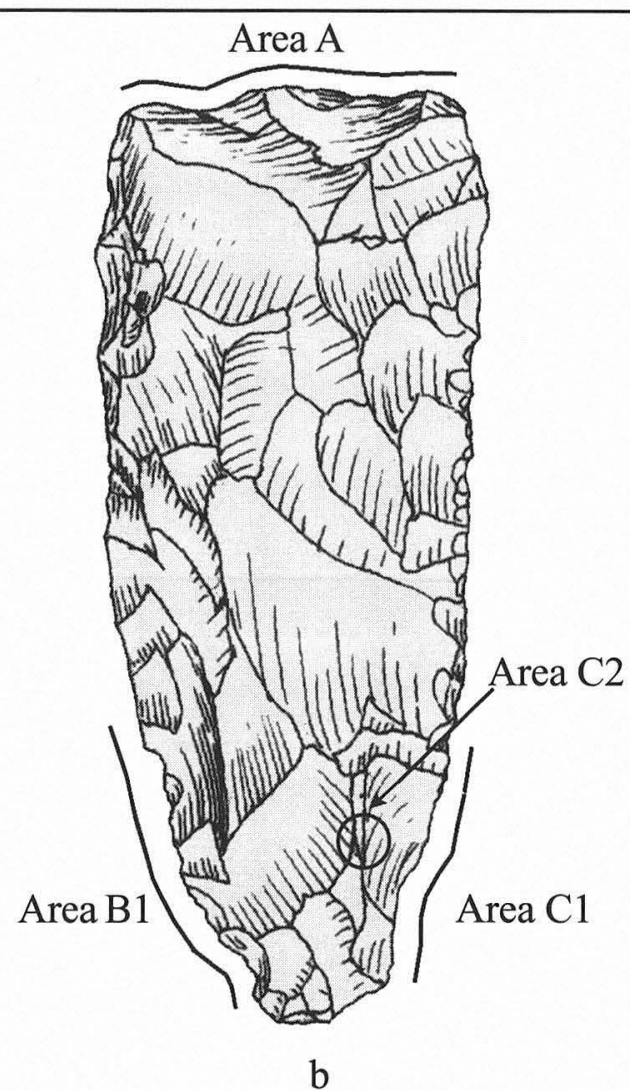

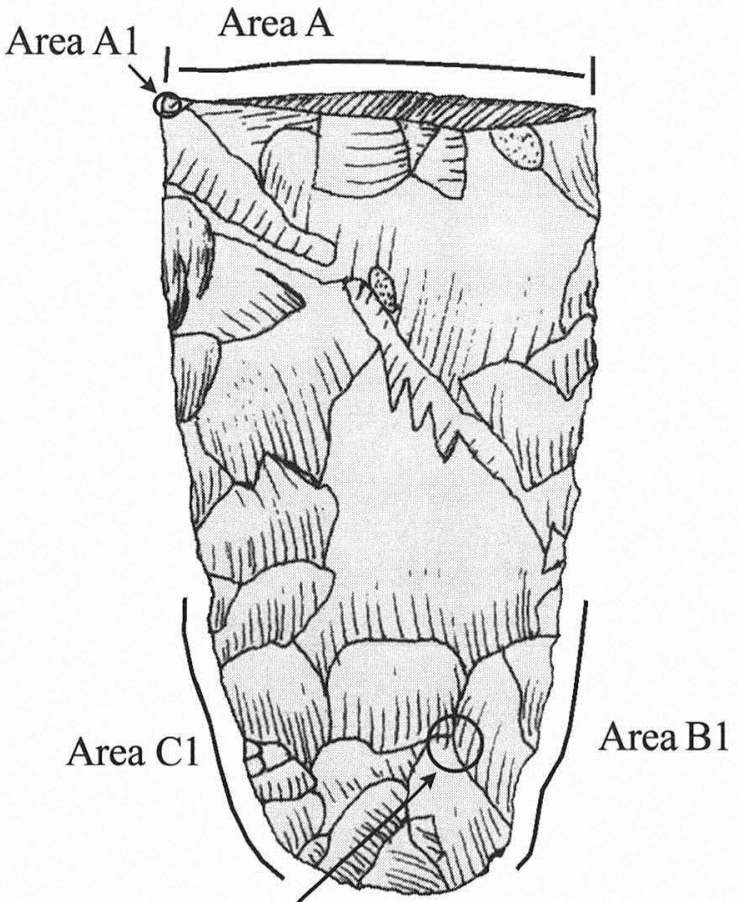

Area B2

d

FiguRE 22-1. Microwear traces on Clear Fork tools from the Wilson-Leonard site. Specimen numbers: (a) 25BB2D-1; (b) 51AA1D-3; (c) 15AA2-2; (d) 50BB1D-2. 

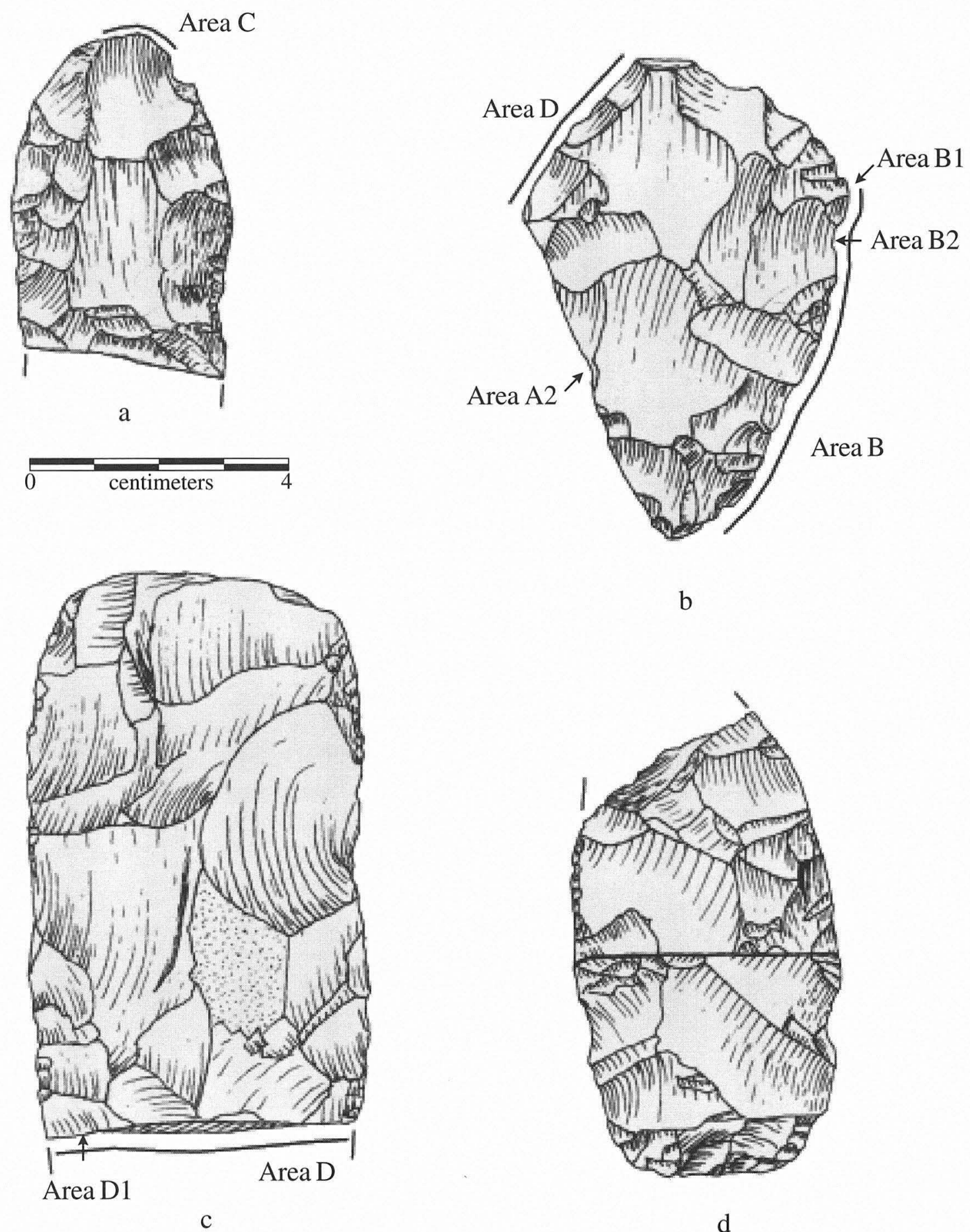

b

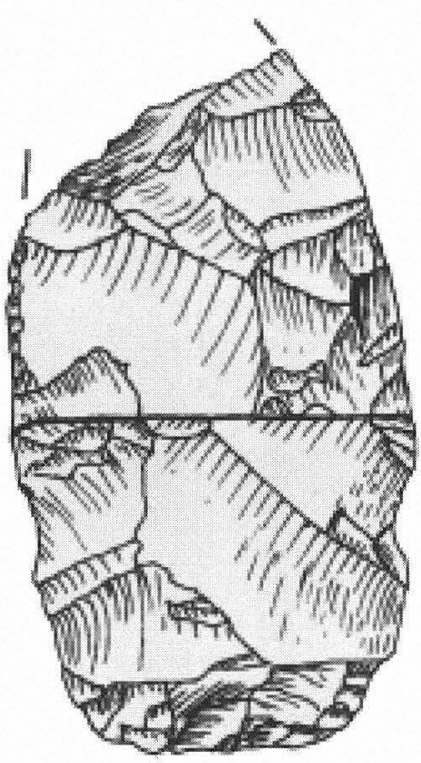

d

FIGURE 22-2.Preforms from the Wilson-Leonard site examined for microwear traces. Specimen numbers: (a) 30HH2C-1; (b) 51AA1D-2; (c) 35CC2D-1; (d) 29JJ1D-1/29II2B-1.

Specimen 34EE1B-1/35EE1A-1 is a corner-notched Wilson projectile point in distal and proximal fragments (Figure 22-3c). Microscopic scans at high incidence on edges identified no polish other than X-polish. Additionally, no polish resulting from hafting was observed.
Specimen 17JJ2/KK1-3 is a small, lanceolate projectile point with recurvate edges, slightly expanded basal area, and incurvate base (Figure 22-3d) ("the Bone Bed Point"). The tip is missing and one side is damaged. This may be the result of impact. High incidence and edge-on microscopic 


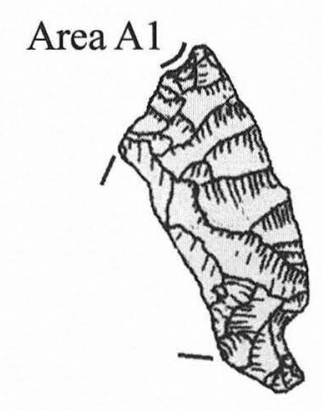

$\mathrm{a}$
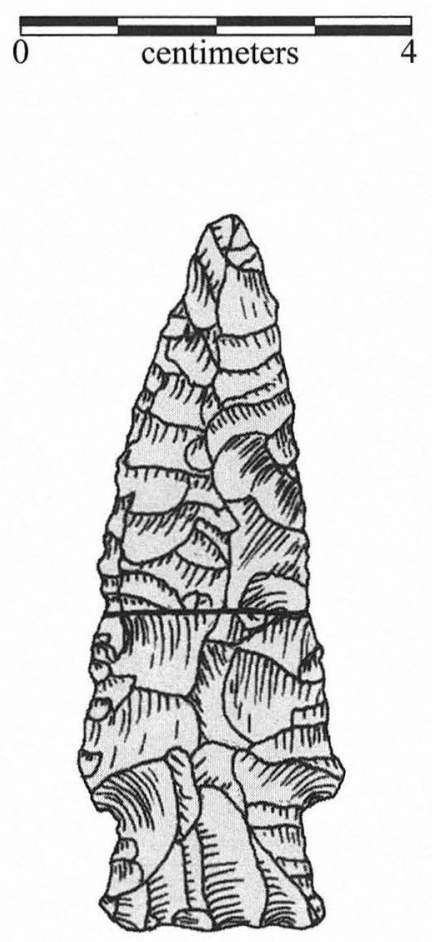

C

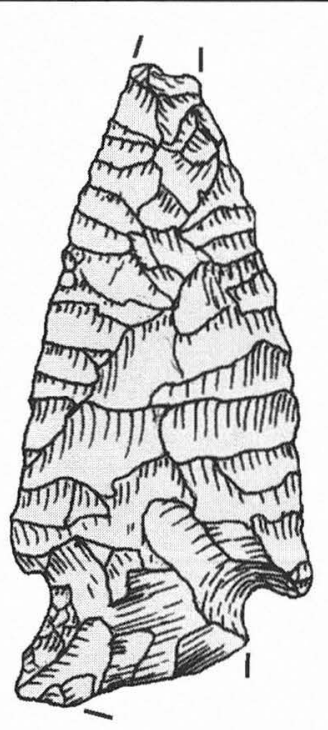

b

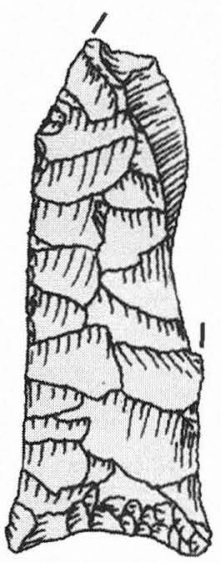

$\mathrm{d}$

FIGURE 22-3. Projectile points from the Wilson-Leonard site inspected for microwear traces. Specimen numbers: (a) 1070-2; (b) 32CC2B1; (c) 34EE1B-1/35EE1A-1; (d) 17JJ2/KK1-3.

scans of intact edges identified no polish other than extensive, diffuse X-polish.

No polish or other alterations were found that suggest use other than probable impact fractures on one specimen and a possible impact fracture on another.

\section{Perforators/Drills}

Three perforators (Figure 22-4) were examined for any evidence of bit use in either rotational or longitudinal actions, and for evidence of hafting. All are bifacially worked. Like other bifaces examined, each edge of the bit area was scanned at high incidence, and a medial transect was scanned on each side near the base using the incident light microscope.

Specimen $25 \mathrm{CC} 1 \mathrm{~A}-1 / 26 \mathrm{Y} 1 \mathrm{C}-2$ is a long chipped stone perforator with a spatulate base (Figure 22-4a). Two fragments, broken in antiquity, are present constituting the entire artifact. High incidence scans of edges along the bit margins revealed little polish development of any kind. Also, there was no good polish seen on the tip. Medial transect 


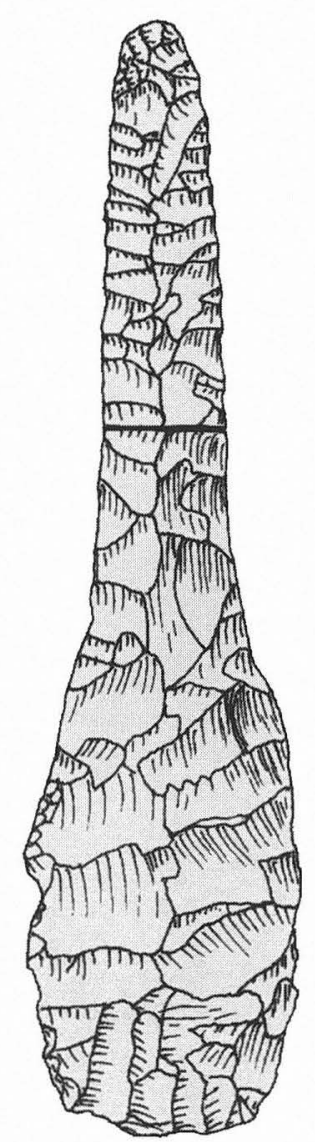

a

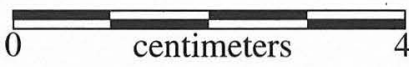

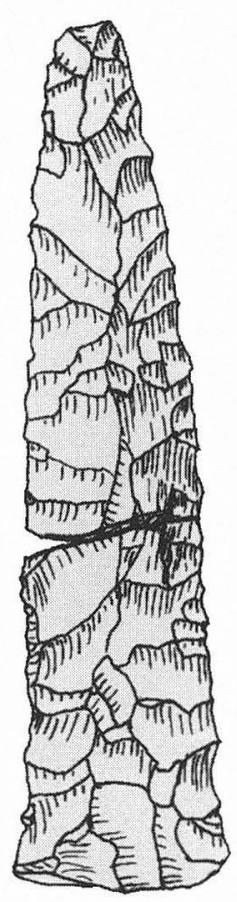

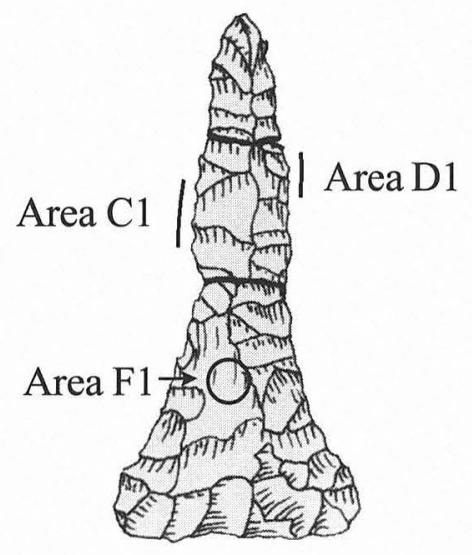

c

b

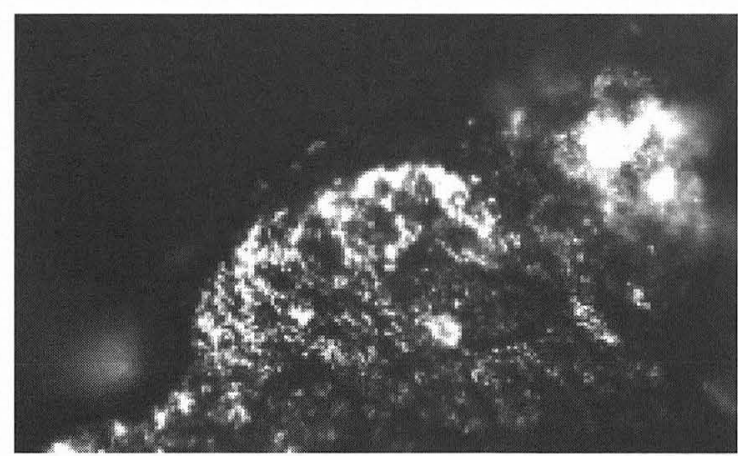

d

FIGURE 22-4. Perforators or drills from the Wilson-Leonard site inspected for microwear traces (a-c) and photomicrograph of polish. Specimen numbers: (a) 25CC1A-1/26Y1C-2; (b) 16AA2-1/31EE1D-1; (c) 1397-1; (d) 1397-1, photomicrograph of Area C1.

scans of both sides of the base revealed moderate development of X-polish on interior ridges and facets, but no evidence of hafting was seen. This artifact was not used substantially as a perforator or drill.

Specimen 16AA2-1/31EE1D-1 is a chipped stone perforator bit in two fragments with the tip and base missing (Figure 22-4b). High incidence scans of edges along the bit margins suggest little polish formation of any kind. The break facet and edges of the missing tip are sharp and exhibit no substantial polish development. Basal medial transect scans of each side of the proximal fragment failed to reveal any polish or other damage from hafting. X-polish was moderately developed on interior ridges, however. This artifact does not appear to have been used.

Specimen 1397-1 is a complete, expanded base, chipped stone drill in three pieces (Figure 22-4c). Stereoscopic exami- 
nation revealed little rounding on or near the tip, which appeared intact. High incidence scans of each edge of the perforator revealed the extensive but moderate accumulation of calcium carbonate on surfaces. In spite of this, several areas were identified where polish is present. The artifact was not subjected to acid treatment to remove calcium carbonate. Area D1 exhibits polish of moderate development, while $\mathrm{C} 1$ is a similarly developed polish in a somewhat larger area. Both of these areas were recognized in edge-on scans. While resembling X-polish and generic polish, each of these areas may represent bone polish in an incipient stage of development. Interestingly, their juxtaposition on the artifact's opposite edges may in itself suggest use. Additionally, narrow ribbons of generic polish on the tip along with striations perpendicular to the perforator axis may have resulted from use. Basal medial transect scans of each side of the base failed to reveal any polish or alterations indicative of hafting. X-polish was well developed at Area F1. In summary, while polish and striations on the specimen may have resulted from postdepositional damage (soil movements, etc.), orientation of striations and location of polish on the shank is suggestive of use. Polish seen at Areas C1 (Figure 22-4d) and D1 are most similar to that produced when working bone or antler.

None of the specimens exhibits good evidence of use although one specimen (1397-1) exhibits polish that may be from bone or antler working. One area on this tool also exhibits clear striations perpendicular to the edge, a pattern consistent with potential use as a drill.

\section{Unifaces}

Unifaces (Figure 22-5) were examined by the author with the goal of defining damaged edge areas, use areas, nature of use, and work materials, where possible. To accomplish this, each artifact was examined under the stereoscopic microscope (at about 20X) to delineate areas of systematic microscarring on edges. Then, these areas were subjected to examination of each face of the edge under incident light microscopy.

Specimen $26 \mathrm{CC} 2 \mathrm{C}-1$ is a thin uniface made on a large flake with unifacial retouch along two edges forming an elongated spur (Figure 22-5a). Stereoscopic examination revealed systematic retouch along Areas A, B and C on Side 2. Many small step fractures and areas of battering suggest hardhammer preparation. Edges are slightly rounded. Incident light microscopy on each side of edges A, B, and C revealed the presence of $\mathrm{X}$-polish with some striations perpendicular to the edge. Area $\mathrm{C} 1$ exhibits a fairly consistent ribbon on Side 1 of rough, bright polish, possibly from working bone or antler (Figure 22-5b). Area C2 (Side 2) also exhibits an areally limited but well-developed polish similar to that of Area C1. A possible interpretation for the observed patterns, also suggested for the artifact discussed next below, is that the spur was prepared and socketed into a haft of bone or antler.
Specimen $16 \mathrm{II} 1 \mathrm{C}-2$ is a thin uniface (Figure 22-5c) with a pronounced medial ridge and a steeply retouched end (Area A). Stereoscopic examination revealed generally undamaged, sharp edges along blade margins with steep and step scarring in Area A as the result of percussion retouch. Incident light microscopy of Area A failed to identify any firm evidence (polish, linear features) for use of this steep edge. Moderate development of X-polish was noted in the area. The artifact was probably never used as a tool, or alternatively, it was systematically resharpened after its last use.

Two of the unifaces examined exhibit polish somewhat suggestive of bone polish. The morphology of these two specimens is such that prominent, edge-retouched protrusions are suitable for hafting (socketing) in a bone or antler handle. Polish placement on each specimen is supportive of this interpretation. Apparently, the remaining specimen was not used. Otherwise, each of the three specimens exhibits extensive X-polish thought to be from soil movement. Also, one specimen was extensively encrusted with calcium carbonate.

A single hafted end scraper was examined (Figure 22-5d). This specimen (24Z1D-3) is a thin uniface with a broadly rounded, steeply retouched end (Area D) and cornernotched base for hafting (A, B, C). Queries for the author included only bit wear presence and type, but the base was also examined for possible indications of hafting and material type. Scans utilizing the incident light microscope in Areas A through C revealed little other than X-polish except in Area A1. Here, polish is better developed, but the material that produced the polish is not known. However, this area (A1) of polish may have resulted from hafting. Notches (B and C) showed little polish.

Area D (Side 2, trailing edge of bit) exhibits especially well-developed areas of polish. A generally wide, continuous ribbon of polish with perpendicular striations is present on the use edge. This polish is particularly pronounced in the Area D2 (edge on and Side 2) (Figure 22-5e). The texture, brightness and placement of this polish is consistent with interpretation of scraping fresh hides. The artifact is a hafted hide scraper. Area D1 (Side 2) is a spot of polish that appears to have resulted from more abrasive work materials (stone on stone?) and may be part of the so-called X-polish ubiquitous to these stone tools.

All edges of two thin unifaces were scanned using the stereoscopic microscope to identify systematically modified edges (Figure 22-6a, b). These edges were then scanned (both sides) for evidence of use wear using incident light microscopy.

Specimen 37Z1D-2 is a thin uniface (see Figure 22-6a) with retouch along Areas A and B on Side 2 only. Retouch in these two areas is overlaid by some microscarring on the same surface (Side 2) suggestive of use of these edges for scraping. Area $\mathrm{C}$ exhibits some irregular retouch or damage, but most of the edge is part of the weathered cortical material on this specimen. Irregular retouch and damage in 


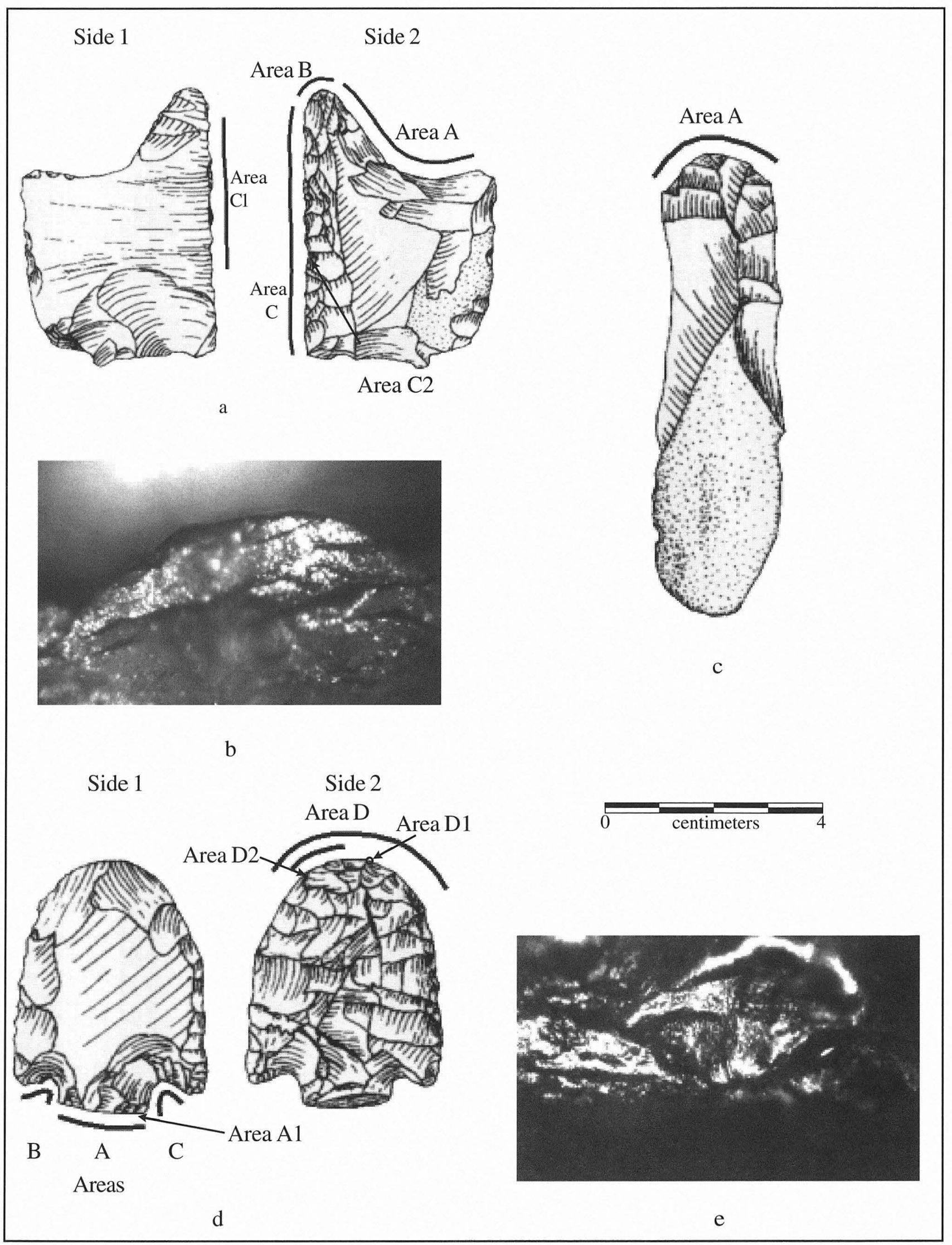

Figure 22-5. Unifaces from the Wilson-Leonard site examined for use wear. Specimen numbers: (a) 26CC2C-1; (b) 26CC2C-1, photomicrograph of Area C1 showing possible bone/antler polish; (c) 16II1C-2; (d) 24Z1D-3; (e) 24Z1D-3, Area D2, Side 2. 


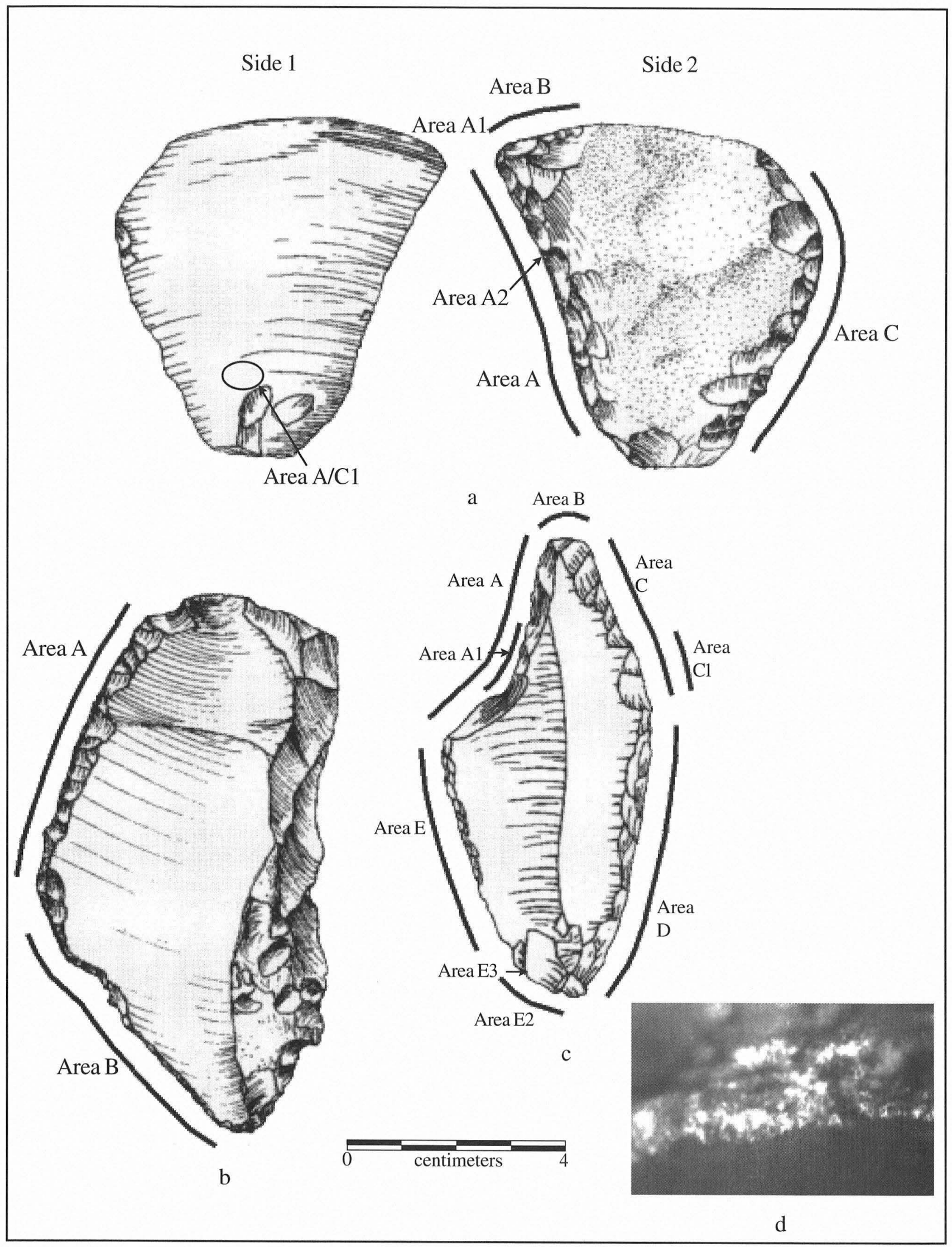

FIGURE 22-6. Unifaces and retouched blade from the Wilson-Leonard site examined for use wear. Specimen numbers: (a) 37Z1D-2; (b) 37QQ1A-1; (c) 14EE2B-2; (d) 14EE2B-2, photomicrograph of Area A1. 
this area may have resulted from intentional attempts to blunt or "back" the artifact. Incident light microscopy of Area A reveals extensive presence of X-polish. Area A1 (Side 2) is a spot of metal(?) scraping while A2 exhibits moderately well-developed X-polish or incipient bone polish on Sides 1 and 2. X-polish was also seen in Area A/C1 on the interior surface, Side 1. It is difficult to interpret this evidence: X-polish is extensive, but some areas of Area A exhibit similar but possibly better-developed polishes that may be from use of the artifact as a scraper. If used, the work duration was probably short. This may be an example of an expedient tool which was picked up, used briefly as a scraper, and discarded.

Specimen 37QQ1A-1 is a thin uniface (see Figure 22-6b) with retouch on Side 2 of Area A and steeply bevelled retouch on Side 2 in Area B. From stereoscopic scans of the edges, it appears that systematic damage or retouch is restricted to Areas A and B. Incident light microscopy of Side 2 at high incidence revealed no polish or other microwear traces other than that thought to be X-polish. The artifact does not appear to have been used in a work action. While polish is extensive, most if not all, appears to be of the type thought to result from postdepositional soil movement (X-polish).

Specimen $30 \mathrm{LL} 1 \mathrm{C}-1$ is a thin uniface made on a flat, cortical flake with geometric incisions in the cortex (Side 1 illustrated, Figure 22-7a). Stereoscopic examination revealed all edges but Area A were steep, undamaged break facets. Area A has been partially retouched on Side 1. Incident light microscopy revealed well-developed areas of hide and fresh hide polish on Side 1 in Area A2 (Figure 22-7b). Area Al is part of the weathered cortex of the exterior of the flake. Area A3 is an area of well-developed hide to fresh hide polish with striations parallel to subparallel to the edge. Area A4 is a well-developed area of similar polish on and near the edge. The whole area of the edge (Area A5) exhibits extensive polish of similar characteristics. This edge exhibits polish indicative of hide scraping and possibly slicing. The material this specimen was used on was probably fresh hides.

\section{Retouched Blade}

Specimen 14EE2B-2 is an elongated flake or blade segment (Figure 22-6c) with unifacial retouch in Areas A, B, and $C$ on Side 2 . The specimen is encrusted with calcium carbonate; it was not subjected to an acid bath prior to analysis. Stereoscopic examination revealed the predominance of step flakes and step-fractured areas near edges in Areas A, B, and C suggesting hard-hammer retouch. Incident light microscopy revealed patterns similar to the previous specimen with diffuse generic polish and ridge ribbons along the edges of Areas A, B, and C and a few small areas of better-developed polish such as A1 (Figure 22-6d).

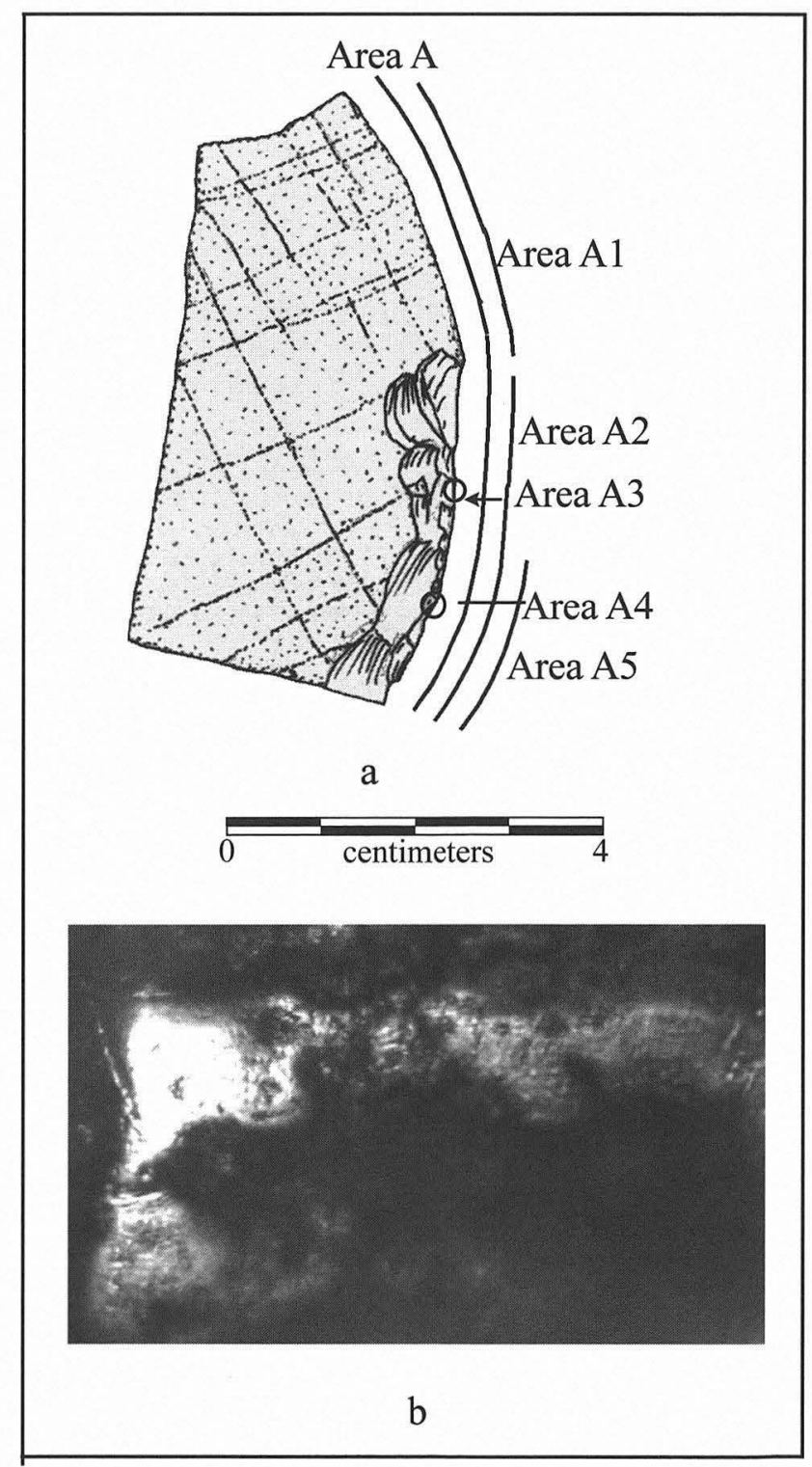

Figure 22-7. Uniface (engraved flake) and photomicrograph of use wear. Specimen number: (a) 30LL1C-1; (b) 30LL1C-1, Area A2, Side 1.

In Area A1 (Side 2), there are numerous spots and short ribbons of bright, rough polish (bone/antler?). Area $\mathrm{C} 1$ is heavily encrusted with calcium carbonate. Area B, like the spur of Specimen 26CC2C-1 above, generally exhibits sharp edges with little polish.

Incident light microscopy of Areas D and $\mathrm{E}$ revealed two spots (E1, Side 2 and E3, both sides) of moderately developed polish. Area E2 (both sides) also exhibits some polish, but most of the area is obscured by calcium carbonate encrustation. The polish is not formed well enough for precise identification. As noted above for Specimen 26CC2C-1, wear patterns from Areas A and C may derive from hafting (socketing) into a bone or antler handle while small amounts of polish seen on the unretouched Area E may derive from some work action. 


\section{Edge-modified Flakes}

Two flakes were examined for similar reasons and in a similar way to the retouched flakes discussed above (Figure 22-8a, b).

Specimen 31MM2B-4 is an elongate flake with thick trianguloid cross section (see Figure 22-8a). Stereoscopic scans of Area A reveal slight, not completely systematic, edge damage. Several half-moon fractures are obvious, but several very thin areas of the edge also remain intact. This evidence alone makes sustained use of this edge unlikely. Similarly, incident light microscopy of Area A revealed only expected X-polish. Area A1 (Side 1) shows more intensely developed polish, but it also is likely the result of natural agency. Edges are generally sharp with little rounding. This specimen has not been used in a work action.

Specimen 32LL1B-3 is an amorphous flake (see Figure 22-8b) with systematic, small scalar flaking along Side 2 of a long, curved edge (Area A). One small section of this edge (Area A3) is bifacially flaked. The opposing edge (B) exhibits irregular flaking on each side. Some edge areas of Area B are quite thin and fragile while Area B2 is more systematically flaked. From stereoscopic inspection alone, Area A would seem to have been used in a scraping or more likely, whittling/cutting action.

Incident light microscopy revealed that in addition to diffuse X-polish along Area B, Area B1 (Side 2) and Area B4 (Side 1) are more intensively developed X-polish spots. Area B3 exhibits very little polish development. Area A exhibits areas of more intensely developed polish. Very little polish development is to be seen in this area on Side 1, but on Side 2, Area A3 exhibits moderately developed spots of polish, possibly X-polish, while Area A4 is an intense, somewhat dull, polish. Also, Area A5 (Side 2) is a dull abraded polish characteristic of dry hide polish (Figure 22-8c). It also exhibits striations parallel to the axis of the edge. This all suggests the involvement of Area A in hide working, possibly slicing or cutting hide or leather. Both specimens exhibit polish thought to be from soil movement at the site. Otherwise, the first specimen shows no additional recognizable polish. The second specimen exhibits areas with more-intensively developed polish that may be from hide working.

\section{Blade Core Fragment}

Specimen $50 \mathrm{KK} 1 / 2 \mathrm{~A}-1$ is an elongate blade-like flake (Figure 22-8d) with little edge damage. This specimen was examined for similar reasons and in a similar way to the retouched flakes and edge-modified flakes discussed above. Area B, under stereoscopic scrutiny, exhibits some systematic microflaking on Side 2. Edges in this area are slightly rounded. Incident light scans of Area B failed to identify polish or use-wear traces other than X-polish thought to result from soil movements (Figure 22-8e). This artifact was not likely used in a work action.

\section{Conclusions}

Results reported here are by no means comprehensive nor definitive. Two problems encountered during analysis diminish potential of polish recognition using the incident light microscope. First, all artifacts exhibit to a lesser or greater degree diffuse, extensive, slightly abrasive, medium-bright polish. This polish, referred to above as X-polish, is similar to bone polish and fresh hide polish in the incipient stages of development and may cause some confusion. Dry hide polish and wood polish, when well developed, should be easily distinguishable, however. Second, some specimens, such as Specimen 14EE2B-2, exhibit extensive encrustations of calcium carbonate. These deposits can be removed with dilute $\mathrm{HCl}$ and do not appear to pose a large problem for future analysis.

In spite of these two obstacles to polish recognition on stone tools from the Wilson-Leonard site, microscopic usewear analysis can provide important data on artifact function. Stereoscopic analysis of microscopic damage including microflake types and orientations remains unimpeded. Calcium carbonate, which obscures edges examined with the incident light microscope, can almost certainly be removed or diminished with acid treatments without damage to the original specimen or its wear traces.

The problem of the pervasive $\mathrm{X}$-polish is a more vexing one. Polish such as that on the bit of the hafted fresh hide scraper (Specimen 2421D-3) is fairly distinguishable from $\mathrm{X}$-polish. Similarly, fairly well-developed bone polish such as that found on two of the uniface scrapers (Specimens 26CC2C-1 and 14EE2B-2) seems distinctive in at least the extent of microtopographic alteration. Other types of polish not yet seen in this analysis may be more distinctive. However, all polishes share visual characteristics to a lesser or greater extent when poorly developed. In essence, presence of the X-polish will no doubt confuse recognition of less than well-developed polish areas. The tendency in analysis will be to disregard these potential use indicators. Only artifacts sustaining considerable use will likely be identified as used tools. Results may therefore by biased toward categories where sustained or heavy use was characteristic such as in the case of the hafted hide scrapers.

\section{SCRATCHIN' THE SURFACE: STONE ARTIFACT MICROWEAREVALUATION} by Marvin Kay

\section{Project Description}

The Wilson-Leonard site collection includes chipped stone artifacts of high quality chert from the nearby Central Texas Edwards Formation. A microwear analysis of a small number of these materials was undertaken using a three-fold analytical strategy. First, the study sought to further assess functional tool categories and concentrate on the Paleoindian 


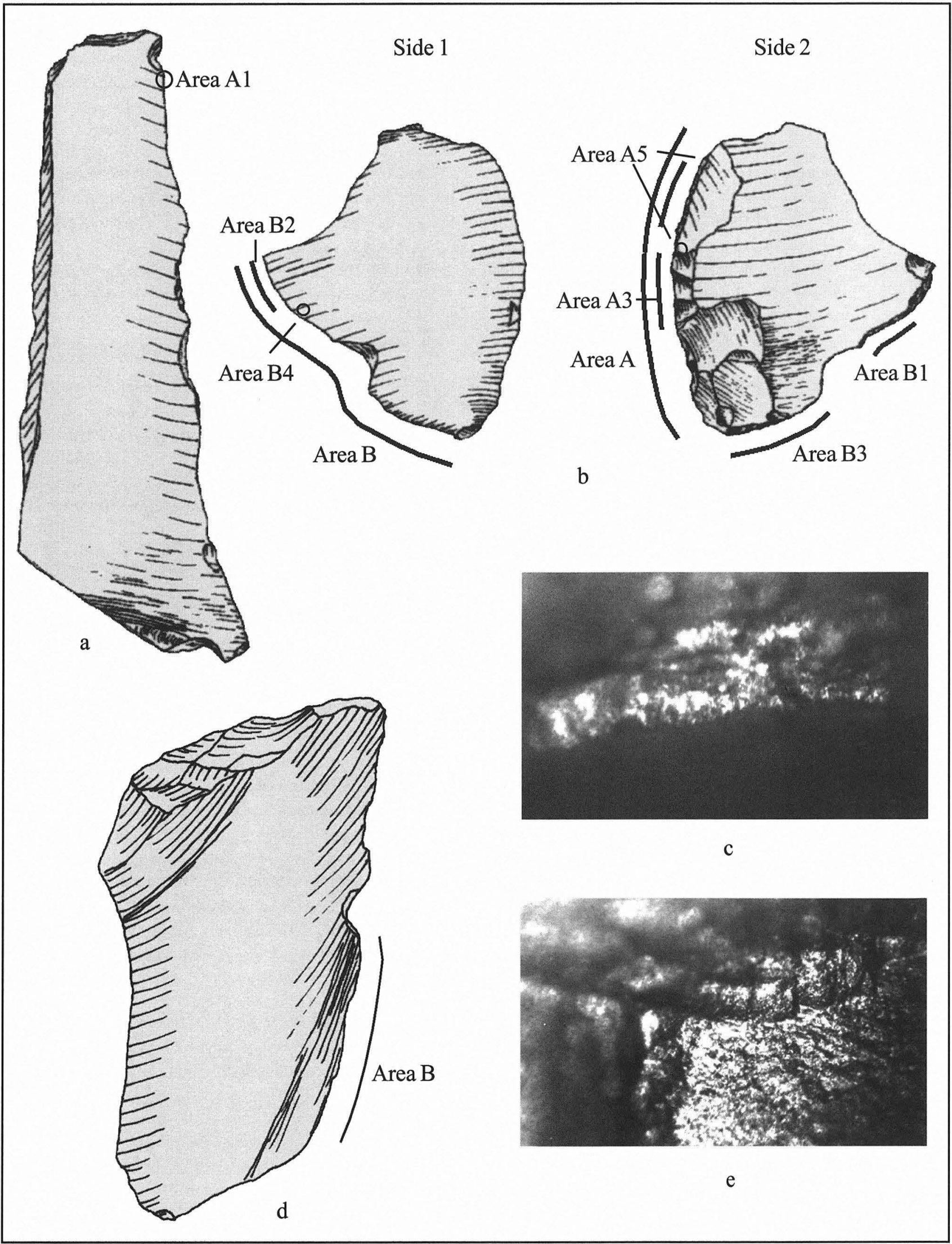

FIGURE 22-8. Edge-modified flakes from the Wilson-Leonard site examined for use wear. Specimen numbers: 31MM2B-4; 32LL1B-3; 32LL1B-3, photomicrograph of Area A5, Side 2; d, 50KK1/2A-1; e, 50KK1/2A-1, photomicrograph of Area B. 
chipped stone points. Second, the study evaluated ad hoc or expedient stone tools that often are misconstrued as lithic debitage. Third, the study attempted to consider postdepositional disturbance and microdamage to artifact surfaces and edges that might contribute to understanding taphonomy, microstratigraphy, and soil fabrics. The first two goals were realized, but the third remains ill-defined.

The number of artifacts analyzed ultimately totaled 299 individual items, divided into 11 technological groups. Of these, 122 artifacts from a subset of 5 technological groupsprojectile points, perforators/drills, burins, retouched flakes, and unmodified flakes - primarily from the lower, Paleoindian strata of the site were actually subjected to a microwear analysis (Figure 22-9). The seemingly unmodified flake category was sent as a more-or-less random sample, and all 52 were subjected to microwear examination. Just slightly less than $29 \%$ of the 69 unifacially retouched flakes were examined. First 11 artifacts were selected randomly and then judgmentally an additional 9 specimens that appeared to be tools, for a total of 20. All specimens of the other examined analytical groups were subjected to the microwear analysis. No more specimens were examined because of time constraints. From a microwear perspective, much more could be done with the collection.

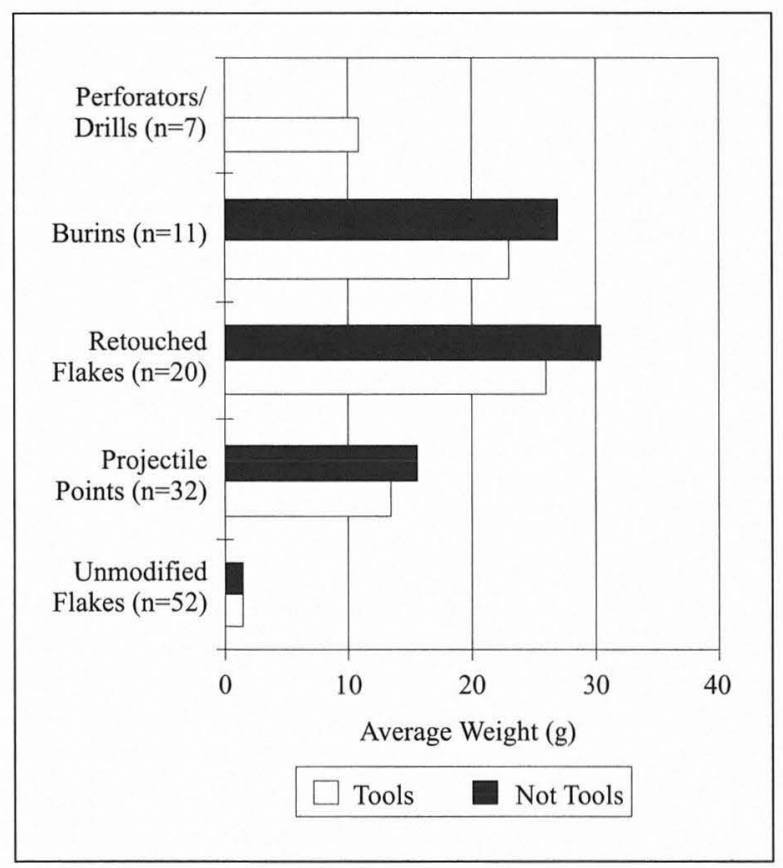

FIGURE 22-9. Analyzed chipped stone artifacts; average weight of unused artifacts (NT) is greater than for tools (T).

The results are of heuristic interest in three prime respects. First, the artifact sample was further subdivided into technofunctional categories based on the presence or absence of microwear. Among other things, microwear presence shows that 15 of the 52 "unmodified" flake group artifacts are unambiguous tools or tool fragments while many intentionally retouched edges of flakes are actually not tool working edges but are blunted for prehension. These results indicate that the concepts of lithic debitage and retouched flakes and how they should be analyzed need to be rethought. Virtually all of the conventionally recognized, "patterned" (or formal) artifacts such as points, drills, or perforators have equally unambiguous microwear traces. These allow not just for functional characterization but also for recognition of use sequences and recycling, or "use history." The projectile points are almost uniform in exhibiting extremely complex use histories; the patterned chipped stone tools were also regularly resharpened or repaired, recycled, and highly curated. Use breakage was common. So also was reuse of a broken edge or surface or continued use of an adjacent tool edge.

Second, the analysis furthered knowledge of micropolishes and other microwear traces: frictional coefficients of use and resistance describe a microwear dichotomy between "surface" and "edge" tools. Many bifaces are classic examples of surface tools in which both bifacially flaked surfaces are invasively in contact with materials worked. While wear traces occur and originate at the working edge, they are both expectable and diagnostic on high flake arrises on tool surfaces. Experimental tool replication studies indicate much of this biface microwear is due to usage in the killing and butchering of game. The radial-fractured tools (Crabtree 1977), a functional subset that crosscuts several Wilson- Leonard technofunctional groups (see also Kay 1995; Root 1994a, 1994b), contrast in being equally classic examples of edge tools whose contact with materials worked is strictly constrained to a tool edge or edges. Experimental tool replication studies show this radial-break tool microwear consistent with usage to engrave, slot, or split medium hard to hard organics such as hard wood, bone, antler, or ivory. Although not prepared as burins, radial-break tools function as chisels or splitting wedges; Wilson-Leonard also has several intentionally prepared dihedral angle burins. Irrespective of manufacture technique, these chisel or wedging tools are formally described as the "burin group."

Finally, striated micropolishes often exhibit unambiguous evidence of remodeling, or what has been referred to as the addition of amorphous silica or a silica gel (Anderson 1980; Keeley 1980; Mansur 1982). Whether or not it truly is a silica gel, the remodeling is undeniable; it is referred to here as a microplating effect. Beyond microplating's significance for defining micropolishes, there would seem to be an as yet unexplored potential for organic residue identification keyed specifically to tool use.

This chapter is more a statement of problems and prospects than the final word on Wilson-Leonard microwear. The microwear methodology and relevant experimental replications are described elsewhere (Kay 1996, 1997) and only the general rationale and relevant particulars of this analysis are presented here. This discussion is followed by ones on general microwear observations, assessments of artifact 
technological groups, and a concluding assessment of design criteria and diachronic technological trends. Not all may be of equal interest and much is technical. For the reader interested in an overview, by all means begin with the illustrated general observations of microwear and thumb to the conclusions before embarking on a cover to cover perusal of the entire chapter.

\section{Methodology}

The particular approach is that developed by Semenov (1964), whose primary impact has been in Russia and the former republics of the Soviet Union, where "traceological" studies of microscopic polishes, striae, and edge damage are used to delineate tool function or use. In the present study, the most crucial information is functionally diagnostic of general classes of stone tools, of contact materials, and the geomorphic or archeological contexts. Specific analytical concerns are: (1) the placement, orientation, and crosscutting relationships among use-wear striae plus their width, depth, and number; (2) for polishes, filling in or "microplating" and the degree of development, texture, area, and placement on a tool surface or edge; and (3) for edge damage, its relationship to other use-wear traces.

The microwear approach used here allows for sequential macroscopic and microscopic observations. It is patterned after Keeley $(1974,1980)$ and Newcomer and Keeley (1979), who are responsible for much of the microwear research in western Europe and America, but eliminates the two-dimensional image problem faced by Keeley (1980:12-14). Although lower magnifications are employed, most helpful is the intermediate magnification range of $100-400 \mathrm{X}$ using a reflected-light differential-interference microscope with polarized light Nomarski optics (Hoffman and Gross 1970). The optical qualities of this microscope are superior to those of most incident light microscopes presently used for microwear studies, but, to my knowledge, have received only minimal attention by microwear analysts in western Europe and America (see Dumont 1982 for a quantified application using a similar microscopy system; Nomarski optics are specifically mentioned also by Petraglia et al. 1996:129). Its Nomarski optics capability is ideally suited to lithic microwear analysis because its color divisions of polarized light allow for three dimensional views of tool surfaces and the ready delineation of striae. Image resolution, or clarity, increases with magnification (in contrast to incident light microscopes but similar to scanning electron microscopes [SEM]) while depth of field decreases. Unlike SEM, the metallic coating of a tool surface is unnecessary. Striae and micropolishes are readily observed, and easy adjustment of the Nomarski optics allows for the best display of wear traces. Micropolishes are optically bright and characteristically undifferentiated. For most archeological specimens, it is also unnecessary to carry out the extensive and potentially destructive chemical cleaning Keeley (1980:11) advocates to ensure the micro- scopic inspection of a tool surface or edge is unimpeded by organic or inorganic residues. No Wilson-Leonard artifact was subjected to chemical cleaning beyond an occasional wipe with a clean cotton ball soaked in methyl alcohol to remove oils from tool surfaces.

The microwear patterns are independent of stone materials and are observable at magnifications greater than 100 diameters. The overall methodology originates from, complements, and provides more specific information about tool use than is available through either macroscopic or low-power magnification $(<100 \mathrm{X})$ microwear studies alone. As an advocate of the latter approach, Odell (1990) notes the low-power magnification examinations are likely to be coarse-grained evaluations of worked material hardness and generally are not suited to the study of complex microflaking on carefully patterned, edge-retouched tools. The analyses reported here take substantially longer to perform and also require more expensive technical equipment than needed for either macroscopic or low-power-magnification microscopic tool use evaluations. The added expense in time and equipment, however, is justified by the results.

Microscopic examinations of edges and tool surfaces attempted to cover the entire area by systematically scanning overlapping transects. As needed, artifacts were reoriented on the microscope stage to facilitate inspection or to enhance microwear for photomicography. Due to the expense, photomicrographs were only selectively taken of areas considered to be either the best example or representative of a range of microwear further noted on individual record sheets for each artifact. The locations of photomicrographs and other microwear observations were plotted carefully on either a to-scale line drawing or an artifact photograph. In either case, the orientation of the photomicrograph to that of the artifact was carefully noted. Illustrated photomicrographs are located appropriately and properly oriented to the artifact. A photographic negative of the $0.1-\mathrm{mm}$ scale bar enlarged to the same size as the photomicrographs was used to measure microwear details and to provide scale for illustrations. For most bifacial artifacts, the microscopic scans were on a single surface, the face opposite the one that previously had been labeled in ink and for which the label had been coated with clear varnish. Occasionally, both faces were examined but this was more the exception than the rule; individual examples are noted as appropriate.

For unifacial artifacts and artifacts of the seemingly unmodified flake category, the microwear examination focused on the ventral surface, which often had been labeled previously in the manner described for bifaces. The rationale for concentrating on the ventral surface of these artifacts was to attempt to eliminate the possible effect of tool use prior to detachment of a flake, which might be apparent on the dorsal surface. (For other studies, I have examined the dorsal surfaces of flakes for possible prior to detachment use-wear, but have done so only after eliminating any that had ventral surface use-wear; in this instance, it was 
simply beyond the scope of the project to attempt a moreexhaustive study of the flakes.) The labeling did make it impossible to thoroughly examine every detail of these flake artifacts, but, on balance, a sufficient coverage was achieved to identify the relevant microwear and trends in tool usage.

Many Wilson-Leonard chipped stone artifacts are formally divisible into blade and haft elements, as described by Binford (1963). Haft wear traces, identifiable on experimental hafted-tool replicates by their location and their often complementary display of secondary effects of tool use-wear (Kay 1996), are readily distinguished for those Wilson-Leonard specimens that meet Binford's criteria. Not all potentially hafted tools, however, have formally discrete haft elements. These pose additional problems for the analysis of haft wear traces that can only be partially resolved: in those instances where wear traces are inconsistent with tool usage and postdepositional damage, they may be taken as potential evidence of either tool hafting or prehension.

Wear traces due to postdepositional or other taphonomic processes also have the potential to mislead. The most common wear traces of this kind for Wilson-Leonard include excavation damage and the streaking of stone surfaces by metal tools, the saltation of abrasive particles across a stone surface by wind, and artifact trampling or postdepositional movement within sediments. Recognition of metal streaks or other metallic residues poses no difficulty, as they are in a nearly unique way optically bright or are macroscopically visible and associated with edge damage. Characteristic of wind-blasted surfaces (Figure 22-10a) are broadly striated areas found on both high and low microtopography; the wind blasted striae often switch directions or have a crossbedded appearance. Artifact trampling or post-depositional movement within sediments is most visible at the lower end of the intermediate magnification range (Figure 22-10b) and often consists of curving, striated bands that randomly intersect. These types of microwear also are generally inconsistent with other wear trace orientation, striation size, and shape; and they were simply discounted or not further considered as putative use-wear.

In addition to the normal repertoire of photomicrographs, a few stereo paired photomicrographs were taken to give a better sense of three-dimensional relationships. The orientation, width, depth, and cross-sectional shape of striae are mainly presented here visually by reference to individual, oriented photomicrographs. A computerized, semi-automatic system to quantify these observations is also being developed and will be used in the future on these photomicrographs.

PARADOX, a relational database management software developed by Borland International, was used to compile basic information about each of the examined artifacts. Complementing a photomicrograph catalog, two primary data files were created. The first essentially is an inventory of the materials as initially received. The second is an assessment of each specimen analyzed. Among the more important information recorded are nominal scale observations for microwear category and use history. As presented in Table $22-1$, these are largely self-explanatory. Two exceptions are the observations, indeterminate and negative results, whose practical effect is essentially the same but the two observations are conceptually different. Indeterminate refers to ambiguous microwear traces that could be (and probably are) byproducts of either natural abrasion or excavation damage but for which it is impossible to absolutely certify they are not due to tool use; negative results refers to a lack of microwear evidence. Specimens coded with either of these two observations (and also the Table 22-1 M Code values 3-7) were excluded from a tool group. Interval scale measures of mass, size, and working edge angle were taken independently of the microwear assessment and are not biased by it, except in the recording of obtuse angles of radial break tool edges that would not have been recognized in the absence of the microwear analysis. Mass was recorded to the nearest hundredth gram for each of the 299 specimens. The other interval scale measures were taken for all 52 unmodified flakes; the 20 retouched flakes subjected to microwear analysis; all bifacial points and perforators/drills; and of the potential burins, only those confirmed by microwear analysis.

\section{Microwear Results}

Not all of the 122 examined artifacts (Table 22-2) exhibited tool use-wear traces. Fifty-eight specimens (47.54\%) had negative or indeterminate results, the majority being unmodified flakes ( $71.15 \%$ of the 52 , Table $22-3$ ), retouched flakes ( $60 \%$ of the 20 , Table $22-4$ ), and burins ( $72.72 \%$ of the 11, Table 22-5). None of the perforators/drills (Table 22-6) and only 1 of the projectile points (3.13\%, Table $22-7)$ lacked tool use-wear. To a degree, these negative results actually are consistent with expectations, especially as they pertain to the unmodified flakes (originally regarded as lithic debitage only) and the bifacially flaked perforators/drills and projectile points. That almost $30 \%$ of the unmodified flakes proved to be tools or tool fragments, however, is disconcerting because it indicates that a significant proportion of ad hoc, if not expedient, chipped stone tools is likely to be overlooked absent a microwear analysis. The majority of retouched flakes proved not to be tools but are likely, however, to represent unfinished (or rejected) preforms or blanks for either unifacial or bifacial tools. Graving spurs, a subset of retouched flakes, are all intentionally finished tools and/or exhibit clear and convincing use-wear. Burin-like facets on flakes and cores do not allow for an uncritical classification of true burins, which do exist but require verification through microwear analysis.

Microwear traces of postdepositional movement and excavation damage are present for most morphological groups (see Tables 22-3 through 22-7) but are insufficient to describe stratigraphic trends that would complement the analysis of soil fabrics. "Trampling" damage, which could be a byproduct of movement either during site use or subsequently, is most 


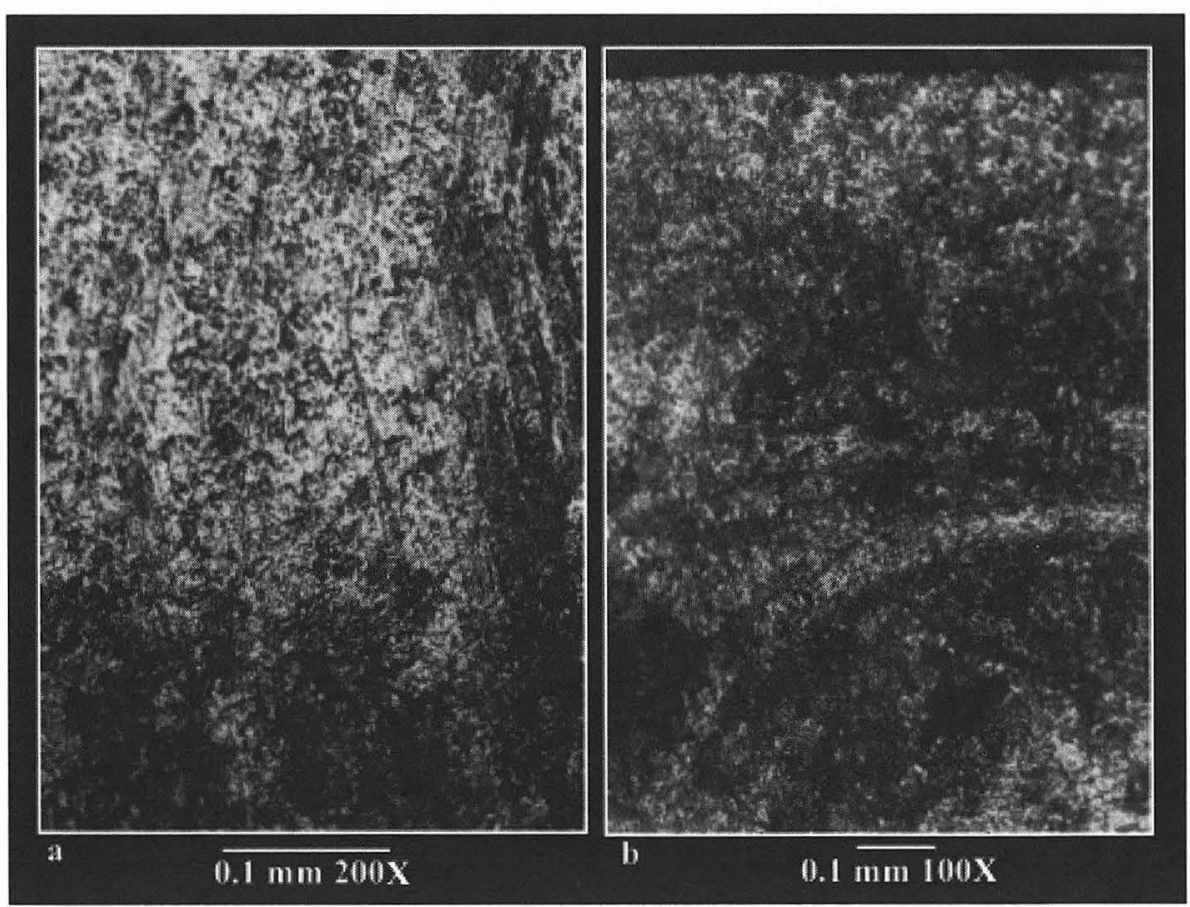

FIGURE 22-10. Postdepositional or other taphonomic wear traces on Wilson-Leonard artifacts.

(a) wind-blasted surface; (b) "trampling" damage or postdepositional movement.

TABLE 22-1

Microwear Codes and Categories

\begin{tabular}{|c|c|c|c|}
\hline UH Code & Use History & M Code & Micro Category \\
\hline $\begin{array}{l}1 \\
2 \\
3 \\
4 \\
5 \\
6 \\
7 \\
8 \\
9 \\
\\
12 \\
13 \\
14 \\
15 \\
17 \\
18 \\
19 \\
20 \\
21 \\
22 \\
23 \\
24 \\
25 \\
26 \\
27\end{array}$ & $\begin{array}{l}\text { Indeterminate } \\
\text { Projectile only } \\
\text { Projectile }->\text { knife } \\
\text { Projectile }->\text { knife }->\text { projectile } \\
\text { Projectile }->\text { knife }->\text { burin } \\
\text { Knife only } \\
\text { Knife }->\text { projectile } \\
\text { Knife }->\text { projectile }->\text { knife } \\
\text { Knife }->\text { radial break tool } \\
\\
\text { Knife }->\text { projectile }->\text { burin } \\
\text { Projectile }<->\text { knife } \\
\text { Projectile }<->\text { knife }->\text { scraper } \\
\text { Projectile }<->\text { knife }->\text { radial break tool } \\
\text { Projectile }<->\text { knife }->\text { repointed } \\
\text { Projectile }<->\text { knife }->\text { drill } \\
\text { Drill } \\
\text { Awl } \\
\text { Burin } \\
\text { Burin/radial break tool } \\
\text { Burin/distal snap tool } \\
\text { Burin flake tool } \\
\text { Unifacial soft cutting tool } \\
\text { Unifacial butchering tool } \\
\text { Graver }\end{array}$ & $\begin{array}{c}1 \\
2 \\
3 \\
4 \\
5 \\
6 \\
7 \\
8 \\
9 \\
10 \\
11\end{array}$ & $\begin{array}{l}\text { Indeterminate } \\
\text { Negative results } \\
\text { Trampling damage } \\
\text { Metal streaks } \\
\text { Stream tumbling? } \\
\text { Bulbar scar striae } \\
\text { Preform? } \\
\text { Butchering } \\
\text { Soft to medium } \\
\text { Medium hard } \\
\text { Recycled }\end{array}$ \\
\hline
\end{tabular}


TABLE 22-2

Microwear Analysis Specimen Inventory

\begin{tabular}{|c|c|c|c|c|c|c|c|c|}
\hline $\begin{array}{l}\text { Specimen } \\
\text { No. }\end{array}$ & Unit & $\begin{array}{l}\text { Item } \\
\text { No. }\end{array}$ & Weight & Description & Group Identification & Use History & Micro Category & \begin{tabular}{|l|} 
Analysts \\
Identification
\end{tabular} \\
\hline 1 & II & 1600 & 0.09 & Parallel-edged flake & Unmodified flakes & & Trampling damage & \\
\hline 2 & II & 1600 & 0.08 & Parallel-edged flake & Unmodified flakes & & Trampling damage & \\
\hline 3 & II & 1600 & 0.1 & Parallel-edged flake & Unmodified flakes & & Indeterminate & \\
\hline 4 & IIIc & 146 & 0.64 & Medial blade & Unmodified flakes & $\begin{array}{l}\text { Unifacial butchering } \\
\text { tool }\end{array}$ & Butchering & \\
\hline 5 & IIIIc & 146 & 3.24 & Medial blade & Unmodified flakes & & Negative results & \\
\hline 6 & IIIc & 146 & 0.22 & Medial blade & Unmodified flakes & & Metal streaks & \\
\hline 7 & IIIb & 532 & 2.25 & Flake blade & Unmodified flakes & & Metal streaks & \\
\hline 8 & $\mathrm{IIIb} / \mathrm{a}$ & 578 & 0.18 & $\begin{array}{l}\text { Microblade } \\
\text { fragment }\end{array}$ & Unmodified flakes & & Metal streaks & \\
\hline 9 & $\mathrm{IIIb} / \mathrm{a}$ & 578 & 0.08 & $\begin{array}{l}\text { Microblade } \\
\text { fragment }\end{array}$ & Unmodified flakes & & Trampling damage & \\
\hline 10 & $\mathrm{IIIb} / \mathrm{a}$ & 578 & 0.33 & $\begin{array}{l}\text { Microblade } \\
\text { fragment }\end{array}$ & Unmodified flakes & Burin flake tool & Medium hard & \\
\hline 11 & $\mathrm{IIIb} / \mathrm{a}$ & 578 & 0.45 & Burin spall & Unmodified flakes & & Negative results & \\
\hline 12 & $\mathrm{IIIc} / \mathrm{b}$ & 1265 & 1.06 & Burin spall & Unmodified flakes & Burin flake tool & Medium hard & \\
\hline 13 & IIIc/b & 1265 & 2.56 & Blade & Unmodified flakes & & Trampling damage & \\
\hline 14 & IIIc/b & 1265 & 0.71 & Blade & Unmodified flakes & & Indeterminate & \\
\hline 15 & $\mathrm{IIIb} / \mathrm{a}$ & 545 & 0.54 & Blade & Unmodified flakes & & Trampling damage & \\
\hline 16 & $\mathrm{IIIc} / \mathrm{b}$ & 497 & 0.27 & Burin spall & Unmodified flakes & $\begin{array}{l}\text { Unifacial butchering } \\
\text { tool }\end{array}$ & Butchering & \\
\hline 17 & $\mathrm{IIIc} / \mathrm{b}$ & 497 & 0.68 & Burin spall & Unmodified flakes & & Negative results & \\
\hline 18 & IIIc/b & 497 & 0.75 & Burin spall & Unmodified flakes & & Negative results & \\
\hline 19 & Icl & 2763 & 1.21 & Unmodified flake & Unmodified flakes & & Metal streaks & \\
\hline 20 & IIIc & 202 & 0.95 & Unmodified flake & Unmodified flakes & & Metal streaks & \\
\hline 21 & Icl & 2633 & 0.4 & Unmodified flake & Unmodified flakes & Burin/distal snap tool & Medium hard & \\
\hline 22 & Icl & 2163 & 1.02 & Unmodified flake & Unmodified flakes & & Metal streaks & \\
\hline 23 & Icl & 2163 & 0.49 & Unmodified flake & Unmodified flakes & & Trampling damage & \\
\hline 24 & Isi-c & 1396 & 1.5 & Unmodified flake & Unmodified flakes & $\begin{array}{l}\text { Burin/radial break } \\
\text { tool }\end{array}$ & Medium hard & \\
\hline 25 & Isi-c & 1396 & 0.88 & Unmodified flake & Unmodified flakes & $\begin{array}{l}\text { Unifacial soft cutting } \\
\text { tool }\end{array}$ & Soft to medium & \\
\hline 26 & Isi-c & 1396 & 1.45 & Unmodified flake & Unmodified flakes & $\begin{array}{l}\text { Burin/radial break } \\
\text { tool }\end{array}$ & Medium hard & \\
\hline 27 & Isi-c & 1428 & 0.57 & Unmodified flake & Unmodified flakes & & Trampling damage & \\
\hline 28 & Isi-c & 1428 & 0.11 & Unmodified flake & Unmodified flakes & & Indeterminate & \\
\hline 29 & Icl & 2758 & 1.57 & Unmodified flake & Unmodified flakes & & Trampling damage & \\
\hline 30 & II & 2017 & 1.21 & Unmodified flake & Unmodified flakes & Burin/distal snap tool & Medium hard & \\
\hline 31 & II & 2035 & 0.82 & Unmodified flake & Unmodified flakes & & Negative results & \\
\hline 32 & II & 1825 & 0.8 & Unmodified flake & Unmodified flakes & Burin/distal snap tool & Medium hard & \\
\hline 33 & Isi-c & 1337 & 1.17 & Unmodified flake & Unmodified flakes & & Metal streaks & \\
\hline 34 & Icl & 2354 & 0.86 & Unmodified flake & Unmodified flakes & & Metal streaks & \\
\hline 35 & Isi-c & 1328 & 1.94 & Unmodified flake & Unmodified flakes & Burin/distal snap tool & Medium hard & \\
\hline 36 & IIIb & 533 & 0.46 & Unmodified flake & Unmodified flakes & & Trampling damage & \\
\hline 37 & IIIa & 661 & 0.16 & Unmodified flake & Unmodified flakes & & Trampling damage & \\
\hline 38 & II & 1822 & 5.1 & Unmodified flake & Unmodified flakes & $\begin{array}{l}\text { Burin/radial break } \\
\text { tool }\end{array}$ & Medium hard & \\
\hline 39 & IIIc/IIIb & 406 & 6.4 & Unmodified flake & Unmodified flakes & & Negative results & \\
\hline 40 & IIIb & 556 & 1.18 & Unmodified flake & Unmodified flakes & & Trampling damage & \\
\hline 41 & IIIb & 541 & 0.28 & Unmodified flake & Unmodified flakes & & Trampling damage & \\
\hline 42 & II & 1803 & 0.79 & Unmodified flake & Unmodified flakes & $\begin{array}{l}\text { Burin/radial break } \\
\text { tool }\end{array}$ & Medium hard & \\
\hline 43 & II & 1803 & 3.81 & Unmodified flake & Unmodified flakes & & Indeterminate & \\
\hline 44 & IIIb/IIIa & 614 & 0.27 & Unmodified flake & Unmodified flakes & $\begin{array}{l}\text { Unifacial soft cutting } \\
\text { tool }\end{array}$ & Soft to medium & \\
\hline 45 & II & 2015 & 1.48 & Unmodified flake & Unmodified flakes & $\begin{array}{l}\text { Burin/radial break } \\
\text { tool }\end{array}$ & Medium hard & \\
\hline
\end{tabular}


Table 22-2, continued

\begin{tabular}{|c|c|c|c|c|c|c|c|c|}
\hline \begin{tabular}{l|} 
Specimen \\
No. \\
\end{tabular} & Unit & Item No. & Weight & Description & Group Identification & Use History & Micro Category & \begin{tabular}{|l|}
$\begin{array}{l}\text { Analysts } \\
\text { Identification }\end{array}$ \\
\end{tabular} \\
\hline 46 & IIII & 274 & 0.47 & Unmodified flake & Unmodified flakes & & Bulbar scar striae & \\
\hline 47 & IIIa & 763 & 0.96 & Unmodified flake & Unmodified flakes & & Trampling damage & \\
\hline 48 & IIIa & 763 & 0.88 & Unmodified flake & Unmodified flakes & & Trampling damage & \\
\hline 49 & IIIa & 763 & 0.45 & Unmodified flake & Unmodified flakes & & Trampling damage & \\
\hline 50 & IIIa & 763 & 0.79 & Unmodified flake & Unmodified flakes & & Metal streaks & \\
\hline 51 & IIIa & 763 & 3.59 & Unmodified flake & Unmodified flakes & & Metal streaks & \\
\hline 52 & IIIa & 763 & 0.49 & Unmodified flake & Unmodified flakes & & Metal streaks & \\
\hline 59 & IIIC & 37DA-7 & 29.78 & $\begin{array}{l}\text { Burin? (nonrandom } \\
\text { sample) }\end{array}$ & Retouched flakes & Burin & Medium hard & Multiple tool \\
\hline 60 & IIIC & 37BD-31 & 13.71 & $\begin{array}{l}16 \% \text { random } \\
\text { sample group }\end{array}$ & Retouched flakes & Graver & Trampling damage & Multiple tool \\
\hline 62 & IIIc & $37 \mathrm{CC}-34$ & 9.91 & $\begin{array}{l}\text { Burin? (nonrandom } \\
\text { sample) }\end{array}$ & Retouched flakes & Burin & Medium hard & Multiple tool \\
\hline 63 & IIIc & 37BD-26 & 25.54 & $\begin{array}{l}16 \% \text { random } \\
\text { sample group }\end{array}$ & Retouched flakes & & Trampling damage & $\begin{array}{l}\text { Edge-modified } \\
\text { flake GR-2 }\end{array}$ \\
\hline 70 & $\mathrm{IIIb}$ & $37 \mathrm{~KB}-2$ & 46.91 & $\begin{array}{l}16 \% \text { random } \\
\text { sample group }\end{array}$ & Retouched flakes & & Metal streaks & Multiple tool \\
\hline 71 & IIIb & 37LA-5 & 9.56 & $\begin{array}{l}16 \% \text { random } \\
\text { sample group }\end{array}$ & Retouched flakes & $\begin{array}{l}\text { Unifacial soft cutting } \\
\text { tool }\end{array}$ & Soft to medium & Thin uniface \\
\hline 78 & IIIa & 33Q2-15 & 27.33 & $\begin{array}{l}16 \% \text { random } \\
\text { sample group }\end{array}$ & Retouched flakes & $\begin{array}{l}\text { Unifacial butchering } \\
\text { tool }\end{array}$ & Butchering & Thin uniface \\
\hline 82 & IIIa & 37Q2D-12 & 2.82 & $\begin{array}{l}16 \% \text { random } \\
\text { sample group }\end{array}$ & Retouched flakes & & Stream tumbling? & Notch GR-2 \\
\hline 86 & $\mathrm{III} / \mathrm{b}$ & $37 \mathrm{O} 2 \mathrm{~A}-2$ & 2.16 & $\begin{array}{l}\text { Graver (nonrandom } \\
\text { sample) }\end{array}$ & Retouched flakes & Graver & Indeterminate & Microspur \\
\hline 87 & II & 28T2D-7 & 1.12 & $\begin{array}{l}\text { Graver (nonrandom } \\
\text { sample) }\end{array}$ & Retouched flakes & Graver & Medium hard & Microspur \\
\hline 88 & IIIa & 24Q1-3 & 3.57 & $\begin{array}{l}\text { Graver (nonrandom } \\
\text { sample) }\end{array}$ & Retouched flakes & Graver & Medium hard & Spur \\
\hline 89 & IIIa & $16 \mathrm{~S} 2-9$ & 4.19 & $\begin{array}{l}\text { Graver (nonrandom } \\
\text { sample) }\end{array}$ & Retouched flakes & Graver & Negative results & $\begin{array}{l}\text { Micro- } \\
\text { denticulate }\end{array}$ \\
\hline 90 & IIIIc & 17D-9 & 97.16 & $\begin{array}{l}16 \% \text { random } \\
\text { sample group }\end{array}$ & Retouched flakes & & Indeterminate & Denticulate \\
\hline 95 & II & $34 \mathrm{U} 2 \mathrm{C}-3$ & 33.43 & $\begin{array}{l}16 \% \text { random } \\
\text { sample group }\end{array}$ & Retouched flakes & $\begin{array}{l}\text { Unifacial butchering } \\
\text { tool }\end{array}$ & Butchering & Thin uniface \\
\hline 104 & II & 29U1C-11 & 5.36 & $\begin{array}{l}16 \% \text { random } \\
\text { sample group }\end{array}$ & Retouched flakes & & Indeterminate & Thin uniface \\
\hline 106 & Isi-c & 37EE1C-1 & 5.67 & $\begin{array}{l}\text { nonrandom sample } \\
\text { group }\end{array}$ & Retouched flakes & & Negative results & Thin uniface \\
\hline 107 & Isi & $15 \mathrm{HH} 1 \mathrm{~A}-1$ & 82.28 & $\begin{array}{l}\text { nonrandom sample } \\
\text { group }\end{array}$ & Retouched flakes & & Trampling damage & $\begin{array}{l}\text { Edge-modified } \\
\text { flake GR-1 }\end{array}$ \\
\hline 108 & Isi & 14FF1B-1 & 22.44 & $\begin{array}{l}\text { nonrandom sample } \\
\text { group }\end{array}$ & Retouched flakes & $\begin{array}{l}\text { Burin/radial break } \\
\text { tool }\end{array}$ & Medium hard & Thin uniface \\
\hline 114 & IIIa & 33Q2-20 & 42.27 & $\begin{array}{l}16 \% \text { random } \\
\text { sample group }\end{array}$ & Retouched flakes & & Indeterminate & Thin uniface \\
\hline 119 & IIIc & $36 \mathrm{E}-23$ & 35.43 & $\begin{array}{l}16 \% \text { random } \\
\text { sample group }\end{array}$ & Retouched flakes & & Preform? & Thin uniface \\
\hline 148 & II & $26 \mathrm{U} 1 \mathrm{~B}-3$ & 9.13 & Awl & Perforators/drills & Awl & Soft to medium & $\begin{array}{l}\text { Perforator, } \\
\text { Group } 4\end{array}$ \\
\hline 149 & II & 32W1B-1 & 6.89 & $\begin{array}{l}\text { Butchering knife, } \\
\text { not awl }\end{array}$ & Perforators/drills & Knife only & Soft to medium & $\begin{array}{l}\text { Perforator, } \\
\text { Group } 2\end{array}$ \\
\hline 150 & $\mathrm{IIIb}$ & $13 \mathrm{~J}-29$ & 6.89 & $\begin{array}{l}\text { Perforator/drill, } \\
\text { recycled }\end{array}$ & Perforators/drills & $\begin{array}{l}\text { Projectile <-> } \\
\text { knife-> drill }\end{array}$ & Recycled & $\begin{array}{l}\text { Perforator, } \\
\text { Group } 3\end{array}$ \\
\hline 151 & IIIc & $14 \mathrm{D}-2$ & 11.5 & $\begin{array}{l}\text { Perforator/drill, } \\
\text { recycled }\end{array}$ & Perforators/drills & $\begin{array}{l}\text { Projectile <-> } \\
\text { knife- }>\text { drill }\end{array}$ & Recycled & $\begin{array}{l}\text { Perforator, } \\
\text { Group } 3\end{array}$ \\
\hline 152 & IIIIa & 26R1-4 & 5.45 & Perforator/drill & Perforators/drills & Drill & Medium hard & $\begin{array}{l}\text { Perforator, } \\
\text { Group } 1\end{array}$ \\
\hline 153 & $\mathrm{IIIa} / \mathrm{II}$ & $30 \mathrm{~T} 1 \mathrm{C}-1$ & 6.37 & Perforator/drill & Perforators/drills & Drill & Medium hard & $\begin{array}{l}\text { Perforator, } \\
\text { unifacial }\end{array}$ \\
\hline
\end{tabular}


Table 22-2, continued

\begin{tabular}{|c|c|c|c|c|c|c|c|c|}
\hline $\begin{array}{l}\text { Specimen } \\
\text { No. }\end{array}$ & Unit & Item No. & Weight & Description & Group Identification & Use History & Micro Category & \begin{tabular}{|l} 
Analysts \\
Identification
\end{tabular} \\
\hline 154 & IIIc & $6 \mathrm{G}-6$ & 28.34 & Drill & Perforators/drills & Drill & Medium hard & $\begin{array}{l}\text { Perforator, } \\
\text { bifacial }\end{array}$ \\
\hline 155 & IIIc & $5 \mathrm{G}-5$ & 7.09 & $\begin{array}{l}\text { Burin facet off } \\
\text { break }\end{array}$ & Burin & & Negative results & Burin, Group 3 \\
\hline 156 & $\mathrm{X}$ & $18 \mathrm{~N}-8$ & 24.98 & Burin facets & Burin & & Indeterminate & Burin, Group 1 \\
\hline 157 & $\mathrm{X}$ & $190-15$ & 18.87 & $\begin{array}{l}\text { Burin facets off } \\
\text { break }\end{array}$ & Burin & & Indeterminate & Burin, Group 4 \\
\hline 158 & IIIa/II & $24 \mathrm{R} 2-5$ & 20 & Burin facets? & Burin & & Indeterminate & Burin, Group 1 \\
\hline 159 & II & 24V1D-2 & 21.13 & $\begin{array}{l}\text { Burin dihedral } \\
\text { facets }\end{array}$ & Burin & & Negative results & Burin, Group 1 \\
\hline 160 & IIIa & $29 \mathrm{R} 2-3$ & 8.38 & $\begin{array}{l}\text { Burin dihedral } \\
\text { angle }\end{array}$ & Burin & Burin & Medium hard & Burin, Group 3 \\
\hline 161 & IIIa & 30R2-13 & 6.87 & $\begin{array}{l}\text { Burin dihedral } \\
\text { angle }\end{array}$ & Burin & Burin & Medium hard & Burin, Group 8 \\
\hline 162 & IIIa & $31 \mathrm{R} 1-4$ & 73.68 & $\begin{array}{l}\text { Prepared Blade } \\
\text { core? }\end{array}$ & Burin & & Negative results & Burin, Group 1 \\
\hline 163 & IIIlb & 37LB-15 & 12.49 & $\begin{array}{l}\text { Burin facets off } \\
\text { break }\end{array}$ & Burin & & Negative results & Burin, Group 3 \\
\hline 164 & IIIa/II & 40R1-1 & 33.05 & $\begin{array}{l}\text { Prepared blade } \\
\text { core? }\end{array}$ & Burin & & Negative results & Burin, Group 3 \\
\hline 165 & IIIC & $50 \mathrm{KA}-6$ & 18.93 & $\begin{array}{l}\text { Radially fractured } \\
\text { biface }\end{array}$ & Burin & $\begin{array}{l}\text { Burin/radial break } \\
\text { tool }\end{array}$ & Medium hard & Burin, Group 3 \\
\hline 169 & IIIa & 11Q-1 & 12.68 & Angostura & $\begin{array}{l}\text { Paleoindian/ } \\
\text { Archaic points }\end{array}$ & $\begin{array}{l}\text { Knife-> projectile-> } \\
\text { knife }\end{array}$ & Recycled & \\
\hline 171 & $\mathrm{III} a / \mathrm{b}$ & $13 \mathrm{~N}-2$ & 22 & Thrall & $\begin{array}{l}\text { Paleoindian/ } \\
\text { Archaic points }\end{array}$ & $\begin{array}{l}\text { Projectile-> knife-> } \\
\text { projectile }\end{array}$ & Recycled & \\
\hline 172 & II/IIIa & 13Q-2 & 19.28 & Golondrina-Barber & $\begin{array}{l}\text { Paleoindian/ } \\
\text { Archaic points }\end{array}$ & $\begin{array}{l}\text { Knife-> projectile-> } \\
\text { burin }\end{array}$ & Recycled & \\
\hline 176 & $\mathrm{Id} / \mathrm{II}$ & $15 \times 1-1$ & 12.84 & Golondrina-Barber & $\begin{array}{l}\text { Paleoindian/ } \\
\text { Archaic points }\end{array}$ & $\begin{array}{l}\text { Projectile or knife<-> } \\
\text { projectile }\end{array}$ & Recycled & \\
\hline 177 & $\mathrm{Id} / \mathrm{II}$ & $15 \times 1-3$ & 2.43 & $\begin{array}{l}\text { Parallel-sided } \\
\text { lanceolate }\end{array}$ & $\begin{array}{l}\text { Paleoindian/ } \\
\text { Archaic points }\end{array}$ & $\begin{array}{l}\text { Projectile<-> knife-> } \\
\text { radial break tool }\end{array}$ & Recycled & $\begin{array}{l}\text { Ground square } \\
\text { stem }\end{array}$ \\
\hline 178 & Isi-c/Id & $15 Y 1-1$ & 17.67 & Golondrina-Barber & $\begin{array}{l}\text { Paleoindian/ } \\
\text { Archaic points }\end{array}$ & Knife-> projectile & Recycled & \\
\hline 181 & IIIa & $16 S 2-1$ & 5.71 & Angostura & $\begin{array}{l}\text { Paleoindian/ } \\
\text { Archaic points }\end{array}$ & $\begin{array}{l}\text { Knife-> projectile-> } \\
\text { knife }\end{array}$ & Recycled & \\
\hline 182 & Isi-c/Id/II & $17 \mathrm{AA} 2-2$ & 7.5 & Wilson & $\begin{array}{l}\text { Paleoindian/ } \\
\text { Archaic points }\end{array}$ & $\begin{array}{l}\text { Projectile <-> } \\
\text { knife-> scraper }\end{array}$ & Recycled & \\
\hline 183 & $\mathrm{X} / \mathrm{IIIb}$ & $19 \mathrm{~N}-1$ & 28.39 & Thrall & $\begin{array}{l}\text { Paleoindian/ } \\
\text { Archaic points }\end{array}$ & $\begin{array}{l}\text { Projectile-> knife-> } \\
\text { projectile }\end{array}$ & Recycled & \\
\hline 185 & $\mathrm{X}$ & $20 \mathrm{~W}-1$ & 8.46 & St. Mary's Hall & $\begin{array}{l}\text { Paleoindian/ } \\
\text { Archaic points }\end{array}$ & Projectile-> knife & Recycled & \\
\hline 186 & $\mathrm{X}$ & $20 X-1$ & 7.4 & Wilson & $\begin{array}{l}\text { Paleoindian/ } \\
\text { Archaic points }\end{array}$ & Projectile $<->$ knife & Recycled & \\
\hline 189 & IIIa & 25R1-1 & 16.04 & Angostura & $\begin{array}{l}\text { Paleoindian/ } \\
\text { Archaic points }\end{array}$ & $\begin{array}{l}\text { Knife-> projectile-> } \\
\text { knife }\end{array}$ & Recycled & \\
\hline 190 & II & $25 \mathrm{U} 2-1$ & 6.73 & St. Mary's Hall & $\begin{array}{l}\text { Paleoindian/ } \\
\text { Archaic points }\end{array}$ & Projectile $<->$ knife & Recycled & \\
\hline 193 & $\mathrm{Id} / \mathrm{II}$ & $26 \times 2 A-1$ & 14.65 & $\begin{array}{l}\text { Parallel-sided } \\
\text { lanceolate }\end{array}$ & $\begin{array}{l}\text { Paleoindian/ } \\
\text { Archaic points }\end{array}$ & $\begin{array}{l}\text { Knife-> projectile-> } \\
\text { knife }\end{array}$ & Recycled & $\begin{array}{l}\text { Parallel side } \\
\text { proximal }\end{array}$ \\
\hline 194 & $\mathrm{Id} / \mathrm{II}$ & $28 \mathrm{Y} 2 \mathrm{C}-1$ & 16.13 & Wilson & $\begin{array}{l}\text { Paleoindian/ } \\
\text { Archaic points }\end{array}$ & Projectile-> knife & Recycled & \\
\hline 195 & $\mathrm{Id} / \mathrm{II}$ & $28 Y 2 D-2$ & 9.55 & Wilson & $\begin{array}{l}\text { Paleoindian/ } \\
\text { Archaic points }\end{array}$ & Projectile-> knife & Recycled & \\
\hline 196 & II & $25 \mathrm{~V} 1 \mathrm{C}-1$ & 15.38 & $\begin{array}{l}\text { Parallel-sided } \\
\text { lanceolate }\end{array}$ & $\begin{array}{l}\text { Paleoindian/ } \\
\text { Archaic points }\end{array}$ & Indeterminate & Trampling damage & $\begin{array}{l}\text { Parallel side, } \\
\text { refit }\end{array}$ \\
\hline 197 & II/IIIa & 29T1C-1 & 13.18 & Angostura & $\begin{array}{l}\text { Paleoindian/ } \\
\text { Archaic points }\end{array}$ & Projectile $<->$ knife & Recycled & \\
\hline 200 & Isi-c & $30 \mathrm{CC} 2 \mathrm{~A}-1$ & 18.98 & Wilson & $\begin{array}{l}\text { Paleo/Archaic } \\
\text { points }\end{array}$ & Knife-> projectile & Recycled & \\
\hline
\end{tabular}


Table 22-2, continued

\begin{tabular}{|c|c|c|c|c|c|c|c|c|}
\hline $\begin{array}{l}\text { Specimen } \\
\text { No. }\end{array}$ & Unit & Item No. & Weight & Description & Group Identification & Use History & Micro Category & \begin{tabular}{|l} 
Analysts \\
Identification
\end{tabular} \\
\hline 201 & IIIa & 31P1-1 & 13.62 & Thrall & $\begin{array}{l}\text { Paleo/Archaic } \\
\text { points }\end{array}$ & $\begin{array}{l}\text { Projectile-> knife-> } \\
\text { projectile }\end{array}$ & Recycled & \\
\hline 202 & IIIa & $31 \mathrm{R} 1-1$ & 19.65 & Thrall & $\begin{array}{l}\text { Paleo/Archaic } \\
\text { points }\end{array}$ & $\begin{array}{l}\text { Projectile }<-> \\
\text { knife-> repointed }\end{array}$ & Recycled & \\
\hline 203 & Isi-c & 32DD1B-1 & 18.08 & Wilson & $\begin{array}{l}\text { Paleo/Archaic } \\
\text { points }\end{array}$ & Projectile-> knife & Recycled & \\
\hline 204 & Isi-c & 33EE1C-1 & 14.7 & Wilson & $\begin{array}{l}\text { Paleo/Archaic } \\
\text { points }\end{array}$ & $\begin{array}{l}\text { Projectile-> knife-> } \\
\text { burin }\end{array}$ & Recycled & \\
\hline 209 & III & 50MA-1 & 11.92 & Wilson-like & $\begin{array}{l}\text { Paleo/Archaic } \\
\text { points }\end{array}$ & Projectile-> knife & Recycled & $\begin{array}{l}\text { Expanding, } \\
\text { Concave D }\end{array}$ \\
\hline 210 & II & $50 \times D-1$ & 3.93 & St. Mary's Hall & $\begin{array}{l}\text { Paleo/Archaic } \\
\text { points }\end{array}$ & Projectile-> knife & Recycled & \\
\hline 211 & $\mathrm{I} / \mathrm{II}$ & 50YA-1 & 7.55 & Golondrina-Barber & $\begin{array}{l}\text { Paleo/Archaic } \\
\text { points }\end{array}$ & Knife-> projectile & Recycled & \\
\hline 212 & $\mathrm{I} / \mathrm{II}$ & 51 Y1B-1 & 20.72 & Golondrina-Barber & $\begin{array}{l}\text { Paleo/Archaic } \\
\text { points }\end{array}$ & $\begin{array}{l}\text { Knife->radial break } \\
\text { tool }\end{array}$ & Recycled & \\
\hline 215 & $\mathrm{X}$ & $7 Q-1$ & 7.09 & St. Mary's Hall & $\begin{array}{l}\text { Paleo/Archaic } \\
\text { points }\end{array}$ & Projectile $<->$ knife & Recycled & \\
\hline 218 & $\mathrm{X}$ & $9 \mathrm{~V}-1$ & 14.71 & Wilson & $\begin{array}{l}\text { Paleo/Archaic } \\
\text { points }\end{array}$ & $\begin{array}{l}\text { Projectile }<-> \\
\text { knife-> repointed }\end{array}$ & Recycled & \\
\hline 222 & II & $26 \mathrm{~V} 2 \mathrm{~B}-2$ & 10.93 & $\begin{array}{l}\text { Parallel-sided } \\
\text { lanceolate }\end{array}$ & $\begin{array}{l}\text { Paleo/Archaic } \\
\text { points }\end{array}$ & $\begin{array}{l}\text { Knife -> projectile-> } \\
\text { burin }\end{array}$ & Recycled & Scottsbluff \\
\hline 305 & Isi-c & OR680 & 17.34 & $\begin{array}{l}\text { Stemmed biface } \\
\text { point }\end{array}$ & $\begin{array}{l}\text { Paleo/Archaic } \\
\text { points }\end{array}$ & Knife only & Soft to medium & $\begin{array}{l}\text { Stemmed } \\
\text { biface }\end{array}$ \\
\hline 306 & Isi/Icl & 17JJ2KK1- & 4.93 & $\begin{array}{l}\text { Early Bone Bed } \\
\text { point }\end{array}$ & $\begin{array}{l}\text { Paleo/Archaic } \\
\text { points }\end{array}$ & $\begin{array}{l}\text { Projectile-> knife -> } \\
\text { burin }\end{array}$ & Recycled & \\
\hline
\end{tabular}

common to what is truly lithic debitage (i.e., 15 or $28.85 \%$ of the unmodified flakes and 3 or $15.00 \%$ of the retouched flakes) but also occurs on projectile points at a lesser rate (4 or $12.5 \%$ of which 3 [specimens $212,222,306$ ] also show unambiguous tool use-wear). Metal streaks, which are probably a byproduct of excavation damage, are most common to the lithic debitage (i.e., 11 or $21.15 \%$ of the unmodified flakes and 1 or $5 \%$ of the retouched flakes). The comparable frequencies and percentages for the unmodified flakes for both wear traces might suggest the most likely source of this microdamage is excavation procedures. Some support for this notion is also seen in the co-occurrence of metal streaks and "trampling" damage found on both tool ( 2 of 7, or $28.57 \%$ ) and nontool elements ( 6 of 25 , or $24 \%$ ). This analysis, however, is simply too limited to determine the source of the "trampling" damage in those instances where it does not co-occur with metal streaks.

A ready and nearly direct correspondence seemingly exists between surface and edge microwear categories and extractive and maintenance tools (Binford and Binford 1966). Edge microwear is typical of the burin group, gravers, and drills-or fabricating or maintenance tools used on bone, antler, and wood. These also include the one awl and Wilson point scraper that exhibit surface microwear but are strictly fabricating tools most likely used on soft wood or animal hide. Surface microwear is typical of bifacial points and unifacial knives. All are piercing, killing, cutting tools-or weapons and extractive tools for game procurement and processing. The analyzed Wilson-Leonard maintenance tools are mostly simpler in design, require fewer manufacturing steps, and conversely, are the easier to maintain. They also are invariably the end product of extractive tool recycling. Tool recycling is more prominent too among the extractive tools. Extractive tools have longer use lives and more complex use histories. The overall production effort and recycling imply a greater value for extractive tools.

Identified tool elements are divided among eight technofunctional groups, or tool types. These include both unifacial and bifacial burins and "radially" fractured tools, or the burin group (22 specimens); flake gravers ( 5 specimens); unifacial knives (7 specimens); and mostly bifacial tools that have complex use histories (33 specimens). Wear traces are first discussed in general terms and then functionally with respect to an inferred gradient of hard to relatively soft contact materials.

\section{General Observations of Tool Element Microwear}

A catalog of Wilson-Leonard microwear observable at the mid-range magnifications should clarify the many subtleties of wear traces and terminology. The prime interest, however, extends to the interpretation of the often complex (or even textbook) microwear images.

Frictional and depositional wear traces create micropolishes but do so by different methods. And some micropolishes are progressive in development. These generally exhibit an initial abrasive phase followed by a layering of added inorganic materials and, possibly, further sequencing 
TABLE 22-3

Microwear Analysis Results for Unmodified Flakes

\begin{tabular}{|c|c|c|}
\hline Specimen & Micro Category & Use History \\
\hline $\begin{array}{ll}\text { Blades: } & \\
& 13 \\
& 14 \\
& 15 \\
\end{array}$ & $\begin{array}{l}\text { Trampling damage } \\
\text { Indeterminate } \\
\text { Trampling damage }\end{array}$ & \\
\hline $\begin{array}{r}\text { Burin Spalls: } \\
11 \\
12 \\
16 \\
17 \\
18 \\
\end{array}$ & $\begin{array}{l}\text { Negative results } \\
\text { Medium hard } \\
\text { Butchering } \\
\text { Negative results } \\
\text { Negative results }\end{array}$ & $\begin{array}{l}\text { Burin flake tool } \\
\text { Unifacial butchering tool }\end{array}$ \\
\hline $\begin{array}{r}\text { Flake Blade: } \\
7 \\
\end{array}$ & Metal streaks & \\
\hline $\begin{array}{c}\text { Medial Blades: } \\
4 \\
5 \\
6 \\
\end{array}$ & $\begin{array}{l}\text { Butchering } \\
\text { Negative results } \\
\text { Metal streaks } \\
\end{array}$ & Unifacial butchering tool \\
\hline $\begin{array}{l}\text { Microblade Fragments: } \\
\qquad \begin{array}{c}8 \\
9 \\
10 \\
\end{array}\end{array}$ & $\begin{array}{l}\text { Metal streaks } \\
\text { Trampling damage } \\
\text { Medium hard }\end{array}$ & Burin flake tool \\
\hline $\begin{array}{c}\text { Parallel-edged Flakes: } \\
1 \\
2 \\
3 \\
\end{array}$ & $\begin{array}{l}\text { Trampling damage } \\
\text { Trampling damage } \\
\text { Indeterminate }\end{array}$ & \\
\hline $\begin{array}{l}\text { Unmodified Flakes: } \\
\qquad \begin{array}{l}19 \\
20 \\
21 \\
22 \\
23 \\
24 \\
25 \\
26 \\
27 \\
28 \\
29 \\
30 \\
31 \\
32 \\
33 \\
34 \\
35 \\
36 \\
37 \\
38 \\
39 \\
40 \\
41 \\
42 \\
43 \\
44 \\
45 \\
46 \\
47 \\
48 \\
49 \\
50 \\
51 \\
52\end{array}\end{array}$ & $\begin{array}{l}\text { Metal streaks } \\
\text { Metal streaks } \\
\text { Medium hard } \\
\text { Metal streaks } \\
\text { Trampling damage } \\
\text { Medium hard } \\
\text { Soft to medium } \\
\text { Medium hard } \\
\text { Trampling damage } \\
\text { Indeterminate } \\
\text { Trampling damage } \\
\text { Medium hard } \\
\text { Negative results } \\
\text { Medium hard } \\
\text { Metal streaks } \\
\text { Metal streaks } \\
\text { Medium hard } \\
\text { Trampling damage } \\
\text { Trampling damage } \\
\text { Medium hard } \\
\text { Negative results } \\
\text { Trampling damage } \\
\text { Trampling damage } \\
\text { Medium hard } \\
\text { Indeterminate } \\
\text { Soft to medium } \\
\text { Medium hard } \\
\text { Bulbar scar striae } \\
\text { Trampling damage } \\
\text { Trampling damage } \\
\text { Trampling damage } \\
\text { Metal streaks } \\
\text { Metal streaks } \\
\text { Metal streaks }\end{array}$ & $\begin{array}{l}\text { Burin/distal snap tool } \\
\text { Burin/radial break tool } \\
\text { Unifacial soft cutting tool } \\
\text { Burin/radial break tool } \\
\text { Burin/distal snap tool } \\
\text { Burin/distal snap tool } \\
\text { Burin/distal snap tool } \\
\text { Burin/radial break tool } \\
\text { Burin/radial break tool } \\
\text { Unifacial soft cutting tool } \\
\text { Burin/radial break tool }\end{array}$ \\
\hline
\end{tabular}


TABLE 22-4

Microwear Analysis Results for Retouched Flakes

\begin{tabular}{|c|c|c|}
\hline Specimen & Micro Category & Use History \\
\hline $\begin{array}{l}\text { 16\% Random Sample Group: } \\
60 \\
63 \\
70 \\
71 \\
78 \\
82 \\
90 \\
95 \\
104 \\
114 \\
119 \\
\end{array}$ & $\begin{array}{l}\text { Trampling damage } \\
\text { Trampling damage } \\
\text { Metal streaks } \\
\text { Soft to medium } \\
\text { Butchering } \\
\text { Stream tumbling? } \\
\text { Indeterminate } \\
\text { Butchering } \\
\text { Indeterminate } \\
\text { Indeterminate } \\
\text { Preform? }\end{array}$ & $\begin{array}{l}\text { Graver } \\
\text { Unifacial soft cutting tool } \\
\text { Unifacial butchering tool } \\
\text { Unifacial butchering tool }\end{array}$ \\
\hline $\begin{array}{l}\text { Burins? (nonrandom sample): } \\
59 \\
62 \\
\end{array}$ & $\begin{array}{l}\text { Medium hard } \\
\text { Medium hard }\end{array}$ & $\begin{array}{l}\text { Burin } \\
\text { Burin }\end{array}$ \\
\hline $\begin{array}{c}\text { Gravers (nonrandom sample): } \\
86 \\
87 \\
88 \\
89 \\
\end{array}$ & $\begin{array}{l}\text { Indeterminate } \\
\text { Medium hard } \\
\text { Medium hard } \\
\text { Negative results } \\
\end{array}$ & $\begin{array}{l}\text { Graver } \\
\text { Graver } \\
\text { Graver } \\
\text { Graver }\end{array}$ \\
\hline $\begin{array}{c}\text { Nonrandom Sample Group: } \\
106 \\
107 \\
108\end{array}$ & $\begin{array}{l}\text { Negative results } \\
\text { Trampling damage } \\
\text { Medium hard }\end{array}$ & Burin/radial break tool \\
\hline
\end{tabular}

TABLE 22-5

Microwear Analysis Results for Burins

\begin{tabular}{l|l|l}
\hline \multicolumn{1}{c|}{ Specimen } & Micro Category & Use History \\
\hline $\begin{array}{c}\text { Burin Dihedral Angle: } \\
160\end{array}$ & $\begin{array}{c}\text { Medium hard } \\
\text { Medium hard }\end{array}$ & $\begin{array}{c}\text { Burin } \\
\text { Burin }\end{array}$ \\
\hline $\begin{array}{c}\text { Burin Dihedral Facets: } \\
159\end{array}$ & Negative results & \\
\hline $\begin{array}{c}\text { Burin Facet Off Break: } \\
155\end{array}$ & Negative results & \\
\hline $\begin{array}{c}\text { Burin Facets: } \\
156\end{array}$ & Indeterminate & \\
\hline $\begin{array}{c}\text { Burin Facets Off Break: } \\
157\end{array}$ & Indeterminate & \\
\hline Burin Facets?: & Negative results & \\
158 & Indeterminate & \\
\hline $\begin{array}{c}\text { Prepared Blade Core(?): } \\
162\end{array}$ & Negative results \\
164 & Negative results & \\
\hline Radially Fractured Biface: & Medium hard & Burin/radial break tool \\
165 & & \\
\hline \hline
\end{tabular}

of use-wear. Before we get to this, the more complex case, we should first examine abrasive microwear.

Use scratches, or striae, are crucial evidence of tool orientation, the identification of material worked, and sequential use, among other things. Abrasive micropolishes invariably are striated and generally are found on the leading edge of a tool surface, or high flake arrises adjacent to unstriated and unpolished lower microtopography. In Figure 22-11, an oriented photomicrograph of a Wilson-Leonard dihedral angle burin working edge, the striae are mostly par- allel to one another, approximately the same in width, and no more than $0.15 \mathrm{~mm}$ in length. But, with one exception, they lack depth or clear cross-sectional shape despite their obvious clarity. The one striation that forms a U-shaped trough left of center in the photomicrograph terminates within the polished area. The black, spherical mass at its distal termination is the abrasive particle that created the striation. That the striation both terminates and has the abrasive particle still within it at the point of termination are unequivocal evidence of the direction of tool use as being opposite the 
TABLE 22-6

Microwear Analysis Results for Perforators/Drills

\begin{tabular}{l|l|c}
\hline \multicolumn{1}{c|}{ Specimen } & Micro Category & Use History \\
\hline Awl: & Soft to medium & Awl \\
\hline $\begin{array}{l}\text { Butchering Knife, not Awl: } \\
149\end{array}$ & Soft to medium & Knife only \\
\hline $\begin{array}{l}\text { Drill: } 154 \\
\text { Perforator/Drill: }\end{array}$ & Medium hard & Drill \\
152 & Medium hard & Drill \\
153 & Medium hard & Drill \\
\hline $\begin{array}{l}\text { Perforator/Drill-recycled: } \\
150\end{array}$ & Recycled & Projectile $<->$ knife $->$ drill \\
151 & Recycled & Projectile $<->$ knife $->$ drill \\
\hline \hline
\end{tabular}

TABLE $22-7$

Microwear Analysis Results for Projectile Points

\begin{tabular}{|c|c|c|}
\hline Specimen & Micro Category & Use History \\
\hline $\begin{array}{r}\text { "Wilson:" } \\
209 \\
\end{array}$ & Recycled & Projectile $\rightarrow$ knife \\
\hline $\begin{array}{r}\text { Angostura: } \\
169 \\
181 \\
189 \\
197 \\
\end{array}$ & $\begin{array}{l}\text { Recycled } \\
\text { Recycled } \\
\text { Recycled } \\
\text { Recycled }\end{array}$ & $\begin{array}{l}\text { Knife }->\text { projectile } \rightarrow \text { knife } \\
\text { Knife }->\text { projectile }->\text { knife } \\
\text { Knife } \rightarrow>\text { projectile }->\text { knife } \\
\text { Projectile }<->\text { knife }\end{array}$ \\
\hline $\begin{array}{c}\text { Late Paleo Point: } \\
305 \\
\end{array}$ & Soft to medium & Knife only \\
\hline $\begin{array}{c}\text { Early Bone Bed Point: } \\
306 \\
\end{array}$ & Recycled & Projectile $->$ knife $->$ burin \\
\hline $\begin{array}{c}\text { Golondrina-Barber: } \\
172 \\
176 \\
178 \\
211 \\
212 \\
\end{array}$ & $\begin{array}{l}\text { Recycled } \\
\text { Recycled } \\
\text { Recycled } \\
\text { Recycled } \\
\text { Recycled } \\
\end{array}$ & $\begin{array}{l}\text { Knife }->\text { projectile }->\text { burin } \\
\text { Projectile or knife }<->\text { projectile } \\
\text { Knife }->\text { projectile } \\
\text { Knife }->\text { projectile } \\
\text { Knife }->\text { radial break tool }\end{array}$ \\
\hline $\begin{array}{c}\text { Parallel-sided Lanceolate: } \\
177 \\
193 \\
196 \\
222 \\
\end{array}$ & $\begin{array}{l}\text { Recycled } \\
\text { Recycled } \\
\text { Trampling damage } \\
\text { Recycled }\end{array}$ & $\begin{array}{l}\text { Projectile }<->\text { knife }->\text { radial break tool } \\
\text { Knife }->\text { projectile }->\text { knife } \\
\text { Indeterminate } \\
\text { Knife }->\text { projectile }->\text { burin }\end{array}$ \\
\hline $\begin{array}{c}\text { St. Mary's Hall: } \\
185 \\
190 \\
210 \\
215 \\
\end{array}$ & $\begin{array}{l}\text { Recycled } \\
\text { Recycled } \\
\text { Recycled } \\
\text { Recycled }\end{array}$ & $\begin{array}{l}\text { Projectile }->\text { knife } \\
\text { Projectile }<->\text { knife } \\
\text { Projectile }->\text { knife } \\
\text { Projectile }<->\text { knife }\end{array}$ \\
\hline $\begin{array}{l}171 \\
183 \\
201 \\
202 \\
\end{array}$ & $\begin{array}{l}\text { Recycled } \\
\text { Recycled } \\
\text { Recycled } \\
\text { Recycled }\end{array}$ & $\begin{array}{l}\text { Projectile }->\text { knife }->\text { projectile } \\
\text { Projectile }->\text { knife }->\text { projectile } \\
\text { Projectile }->\text { knife }->\text { projectile } \\
\text { Projectile }<->\text { knife }->\text { repointed } \\
\end{array}$ \\
\hline $\begin{array}{r}\text { Wilson: } \\
182 \\
186 \\
194 \\
195 \\
200 \\
203 \\
204 \\
218 \\
\end{array}$ & $\begin{array}{l}\text { Recycled } \\
\text { Recycled } \\
\text { Recycled } \\
\text { Recycled } \\
\text { Recycled } \\
\text { Recycled } \\
\text { Recycled } \\
\text { Recycled }\end{array}$ & $\begin{array}{l}\text { Projectile }<->\text { knife }->\text { scraper } \\
\text { Projectile }<->\text { knife } \\
\text { Projectile }->\text { knife } \\
\text { Projectile }->\text { knife } \\
\text { Knife }->\text { projectile } \\
\text { Projectile }->\text { knife } \\
\text { Projectile }->\text { knife }->\text { burin } \\
\text { Projectile }<->\text { knife }->\text { repointed }\end{array}$ \\
\hline
\end{tabular}


point of striation termination. This orientation is also coincident with the longitudinal axis of the burin. The length of this and the similarly oriented striae $(<0.15 \mathrm{~mm})$ is a function of the extent of penetration or of actual contact of the burin edge and the material worked. Their lengths indeed are highly constrained by the worked material, which would have to be both sufficiently hard and unyielding to maintain such a narrow zone of tool contact. That only one striation has an easily described cross-sectional shape simply means their abrasive particles repeatedly removed the troughs of adjacent striae. Not surprisingly, the micropolish surface texture is somewhat grainy or rough, although significantly less so than the adjacent unpolished surface. The one remaining trough would thus be evidence of final tool use. Its abrasive particle would, by definition, have to be as hard or harder than the chert it scratched. The source of the abrasive particle has not been determined, but it could be only one of three things: either from the breakdown of the tool edge, from the material worked, or from adhering grit to either the burin or the worked material. Technically speaking, the striae are mainly vestigial remnants that record information about the extent, direction, and sequencing of burin edge contact with a relatively hard material. Only the one well-defined trough is indicative of potential striae cross-sectional shape and true width. More generally, the larger implication is that striated micropolishes are coincident with tool use and require no additional time to form. As strictly a descriptive analytical convention, I refer to this type of striated micropolish as intermediate developed polish, or IDP.

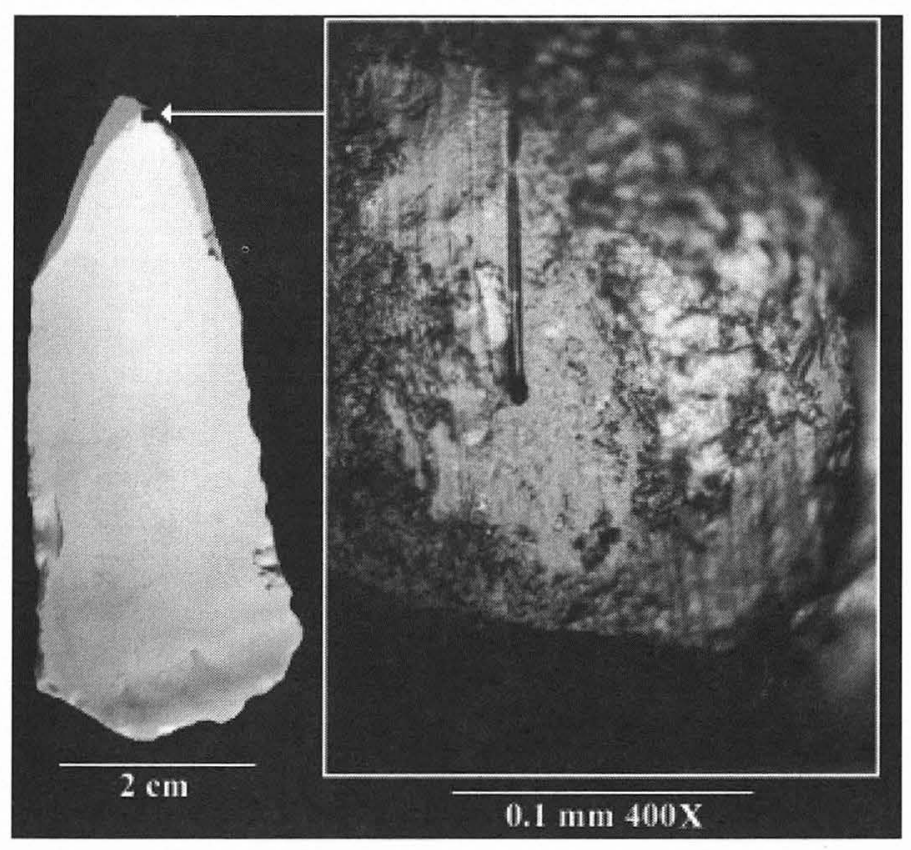

FIGURE 22-11. Intermediate developed (IDP) abrasive microwear on dihedral angle burin, Specimen 37DA-7; note abrasive particle at end of U-shaped striation in left center of photomicrograph and adjacent "vestigial" striae. (All artifact photographs are "smoked" with ammonium chloride. On this and all other oriented photomicrographs, the photomicrograph location is the solid square on the smoked photograph.)
Exhibiting a much smoother surface texture are abrasive micropolishes that, again as strictly a descriptive analytical convention, I refer to as extensive developed polish, or EDP. EDP is reasonably well recognized in the literature, although it is often discounted as microwear (Keeley 1980:28, pls. 8, 10; Vaughan 1985:185-187). Nevertheless, I have documented EDP on experimental tool replicates as byproducts of elephant butchering (Kay 1996), sinew haft bindings of stone projectile points (Kay 1996), and cutting herbaceous plant stems. EDP use-wear is a long-term (or longer term than IDP) byproduct of stone tool contact with soft, pliable materials that either contain or have adhering abrasives. The materials themselves may be either soft plant fibers or animal tissues. A not exhaustive list of examples would include opal phytolith-rich herbaceous plant stems (including sickle gloss [see Keeley 1980:61; Witthoft 1967 for excellent descriptions but with contrasting interpretations of origins]), leaves, bark, meat, hide, sinew, and other soft connective tissues. The contact zone between the stone tool edge or surface and a worked soft material is relatively broad (in comparison to hard contact materials), and EDP characteristics are often well-defined at the lower end (100-200X) of the intermediate magnification range. In addition to the extremely smooth and highly reflective surface texture, among the most conspicuous of EDP characteristics are (1) vestigial striae that lack depth or cross-sectional shape, (2) extensive rounding of tool edge or arrises, and (3) abrasive planing of microtopography.

Relative to the Wilson-Leonard analysis, the fluid appearance, very smooth and highly reflective sickle gloss

type of polish is not seen on any of the artifacts examined. Other EDPs are observed. Figure 22-12 illustrates a representative example, that of a smooth, highly reflective haft binding polish on a bifacially flaked drill (other examples are discussed later) similar to ones seen in experimental replications. In this example, at 100X, there is conspicuous rounding of arrises creating a bilobate microtopography oriented to the primary (horizontal) direction of haft binding. Haft binding direction is also seen (visible at $100 \mathrm{X}$ but more obvious at 200X) in the clearly ordered sequence of vestigial striae that are horizontal and crosscut by vertical striae. These in turn are truncated by diagonally oriented striae. The latter two sets of striae are probably the result of secondary movement of the tool in its haft binding during use.

Abrasive rounding is also readily apparent in Figure 22-13, a flake arris on the ventral surface of a backed retouched flake. Soft hide processing is the most likely cause of the arris rounding.

Additive, or depositional, polishes do exist at Wilson-Leonard. They are, in fact, the more common polish type on the patterned, bifacial tools. These demonstrably consist of the bonding of soluble inorganic material to a stone tool surface. In its most elemental expression, this additive polish forms a microthin layer or layers of an uneven and somewhat grainy texture 


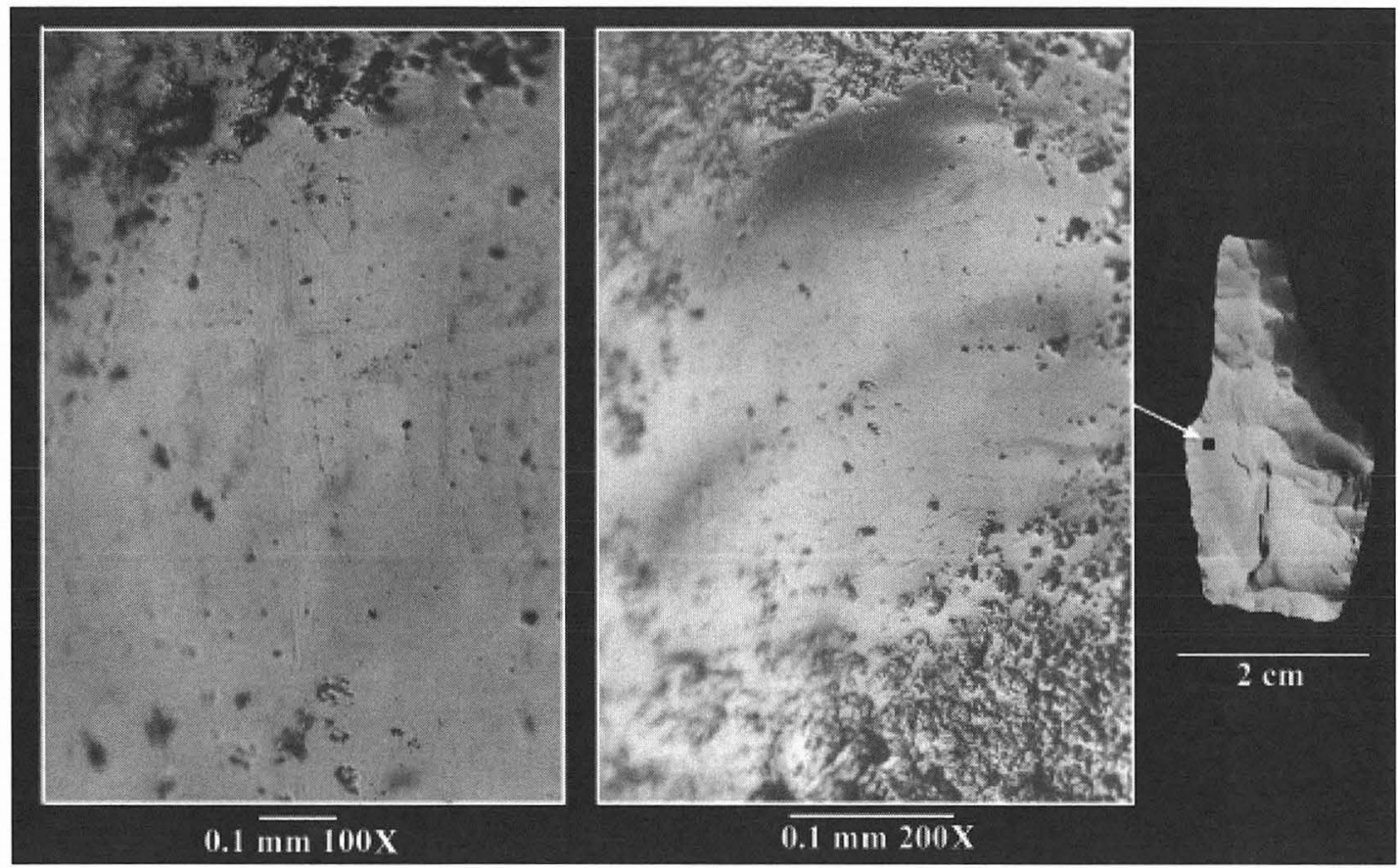

FIGURE 22-12. Extensively developed (EDP) abrasive hafting microwear on drill, Specimen 26R1-4; note bilobate microtopography probably due to soft haft binding and vestigial striae that are a likely secondary effect of tool movement during use.

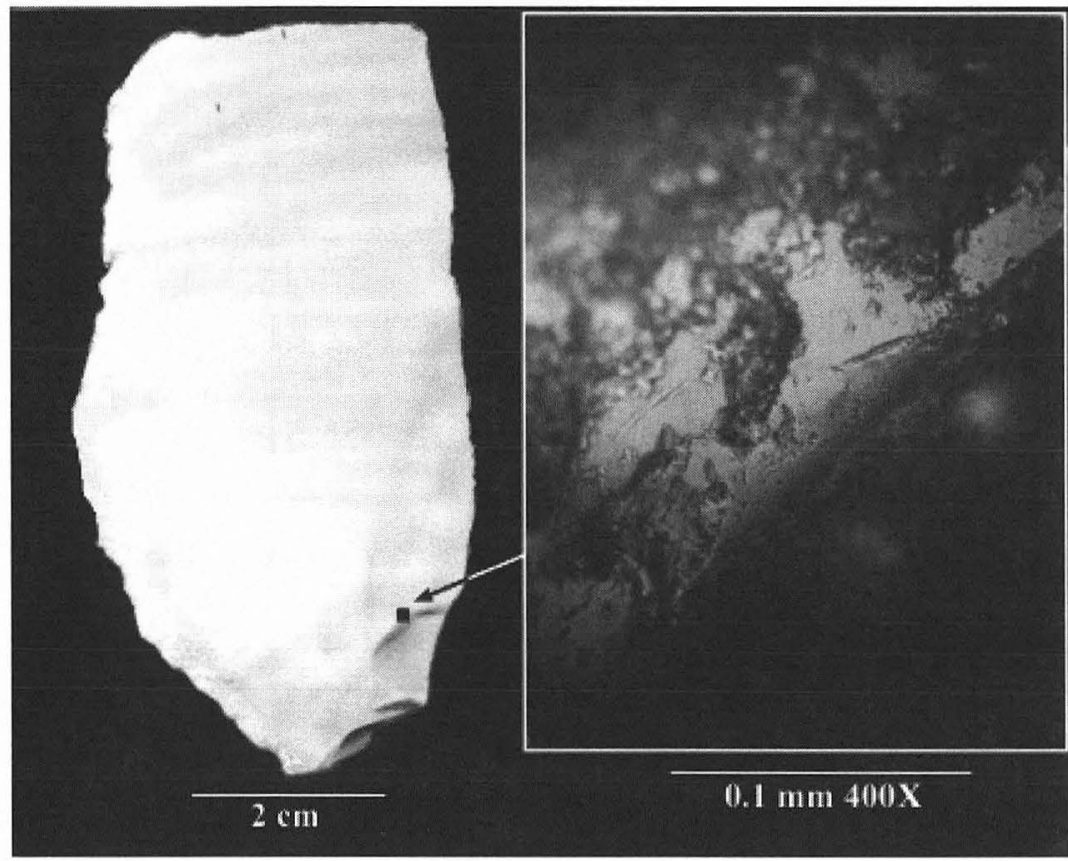

FIGURE 22-13. Invasive EDP arris rounding and striae due to abrasion on unifacial backed knife, Specimen 33Q2-15; compare with Figure 22-12.

that fill in abraded (or striated) polished areas generally on high microtopography. In this sense, most additive polishes are compound and sequential in nature; they present a conceptually more complex palimpsest but in the negative. The soluble inorganic material often crystallizes beyond the polish border, on its trailing side, and appears as extremely bright white filaments anchored to polish edges; thus, when crystallized filaments occur, they are excellent evidence of tool use orientation. Occasionally these crystallized filaments are clearly extruded from the polish and are actually suspended or stick out from a tool surface. There is also no question that this bonding of new inorganic material occurs during 
tool use. Experimental replications (Kay 1996) and archeological examples from Wilson-Leonard and other sites show unambiguously the bonded material is further reworked and striated. In light of the many discussions of silica gels (see Vaughan 1985:12-13 for a well-composed summary and references for the nature of polishes) this description may seem bizarre, yet it is truly the simplest and most basic of descriptions.

Figures 22-14 and 22-15, oriented photomicrographs for respectively a St. Mary's Hall and an Angostura point, should convince even the skeptic. Figure 22-14 Area B comes closest to the general description of additive polishes. A clear microplating, or layering, of soluble material fills in a striae sequence. From experimental replications of projectile point and knife use (Kay 1996), it is possible to confidently identify the striae in functional terms according to their orientation relative to that of the point: vertical projectile point impact striae that originate at and are oriented to the tip are followed by transverse cutting-use striae that originate at the blade edges. The polish border has the bright, recrystallized filaments. The recrystallized filaments are even more distinct at Area A, where they extrude from the trailing edge at the base of the photomicrograph. Note also at Area A, (1) the extensive depositional rounding of the arris, (2) the jagged (desiccation?) crack through the polish, and (3) impact crosscut by butchering striae subsequent to deposition of the inorganic material.

Haft element microwear on the Angostura point (see Figure 22-15) is especially good at showing the filled in hori- zontal striae, the directional spread of the soluble inorganic (lower right to upper left), and subsequent haft wear cutting the microplating. Note also the crystallization of the soluble inorganic at the trailing side in the upper right.

A comparison of the details in Figures 22-14 and 22-15 with the preceding figures makes clearer the differences in the additive and abrasive polishes. Among the differences are: (1) the in-filling of striae, (2) the trailing edge crystallization of the soluble inorganic material, (3) the depositionalas opposed to abrasive-rounding of microtopography (see Figure 22-14a), and (4) a "layer caking" sequence of microwear.

\section{Burin Group}

This diverse group shares variable yet consistent microwear evidence and use histories. Burins were deliberately prepared by the removal of one or more burin spalls that produced burin facets from either flake (Figure 2216a-d) or bifacial point (Figure 22-17) blanks. Epstein's (1963) formal assessment of similar Texas Paleoindian and Archaic point burins, thus, is supported and elaborated upon by this independent analysis. Wilson-Leonard point burins represent a subset of burinated points, not all of which functioned as burins, or ones that have burin facets caused either intentionally or through prior tool use (see Ahler 1971:83 for experimentally produced burin-like facets caused in carcass butchering). In fact, each of the point burins exhibits clear evidence of recycling; burin usage is the final

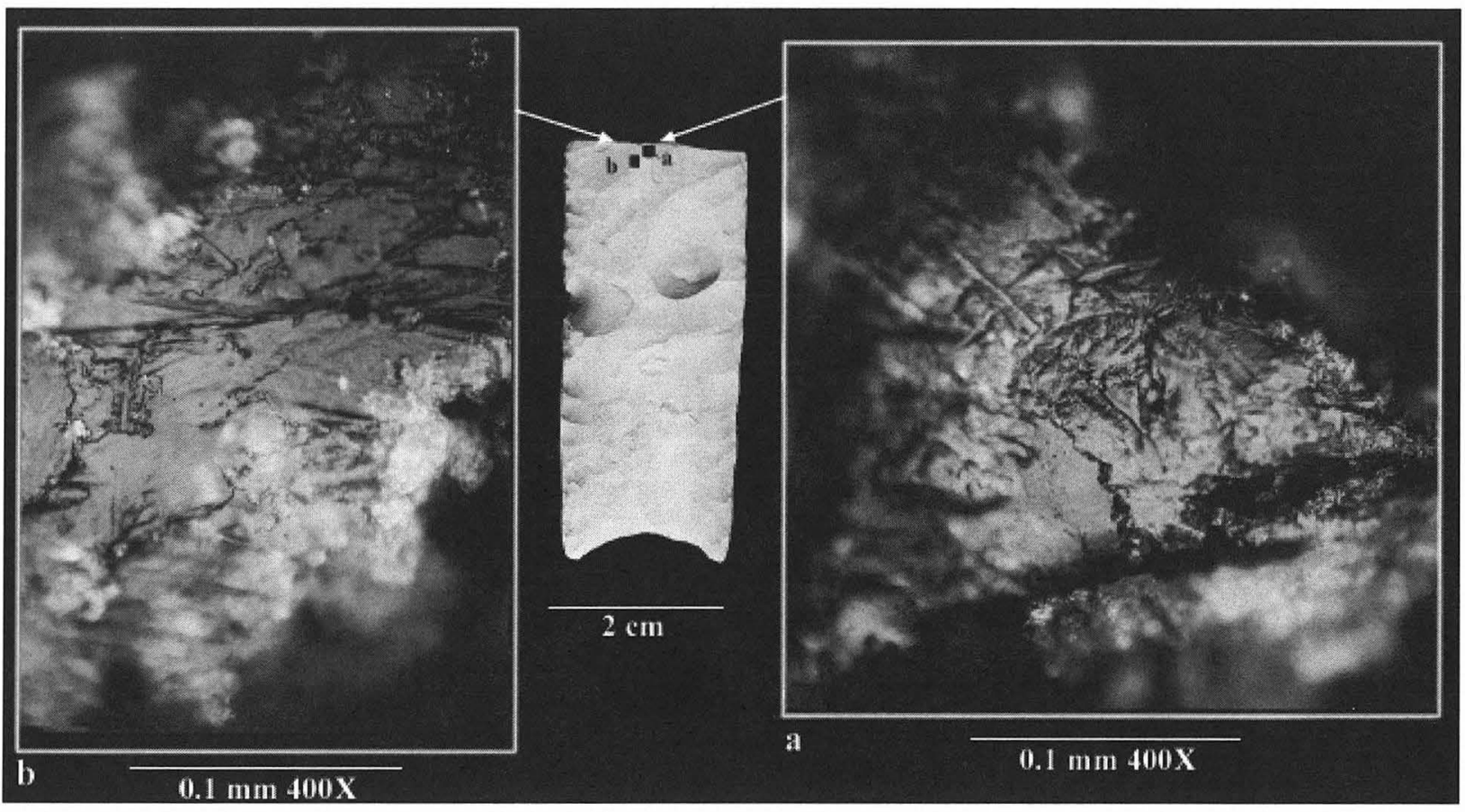

FIGURE 22-14. Depositional, or additive, polish on St. Mary's Hall projectile point recycled as knife, Specimen 20W-1. Note at (a) arris rounding due to deposition, or microplating, desiccation(?) crack and recrystallized filament, and at (b) the microplating and filling in of striae. 


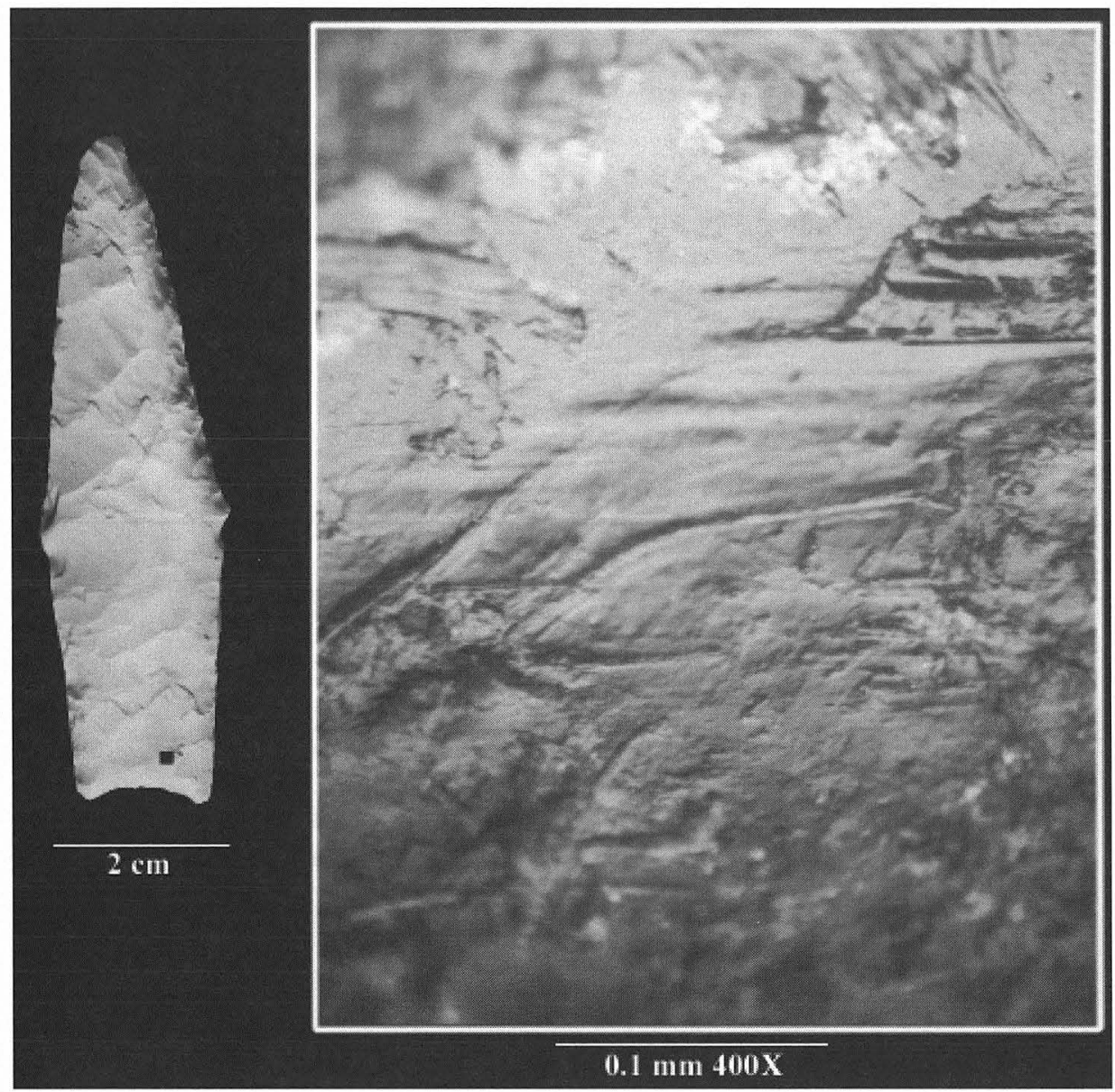

FIGURE 22-15. Depositional, or additive, haft polish on Angostura knife point, Specimen 11Q-1. Note microplating filling in of striae and recrystallization filaments on trailing edge of polish (upper left) and grainy texture of polish.

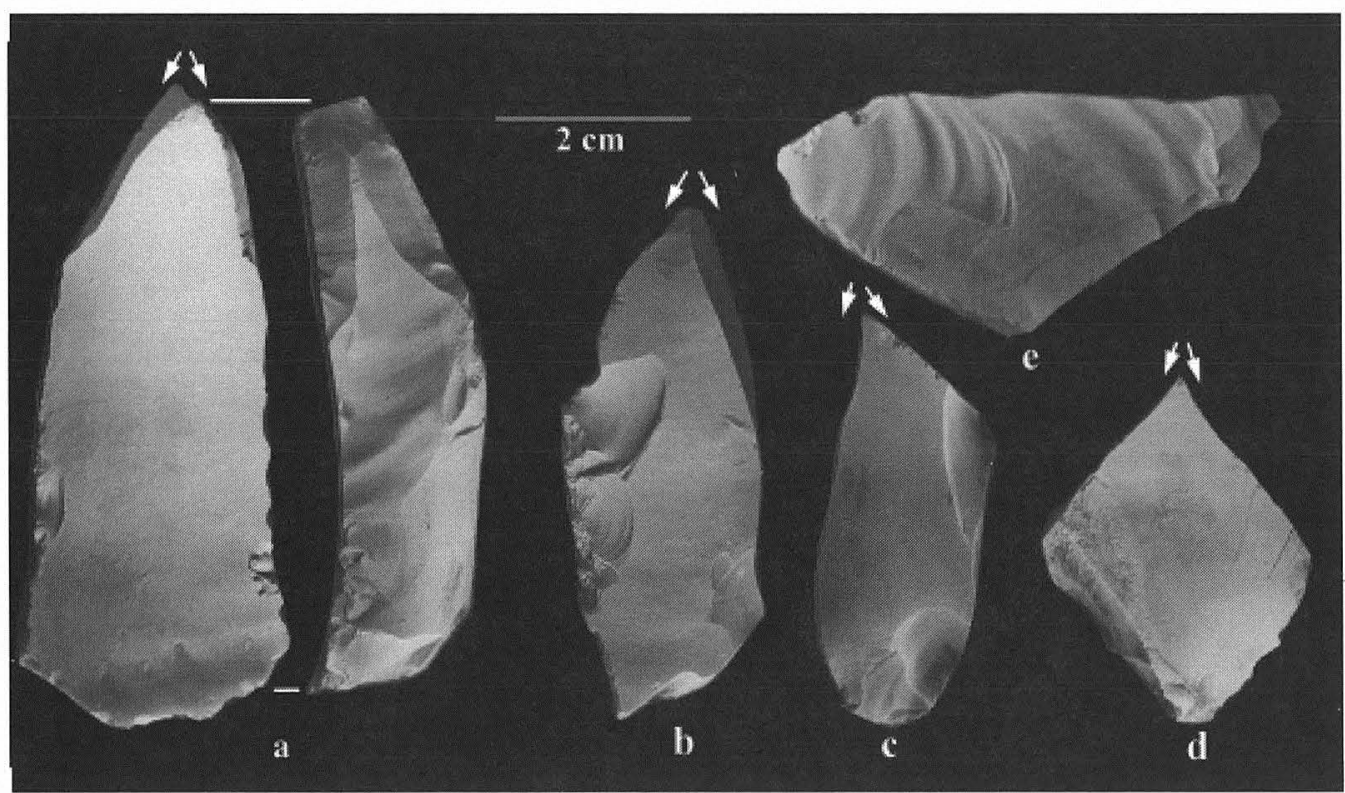

FIGURE 22-16. Burin group tools. (a-d) dihedral angle burins on flakes; (e) radially fractured biface. Specimen numbers: a, 37DA-7; b, 37CC-34; c, 29R2-3; d, 30R2-13; e, 50KA-6. 


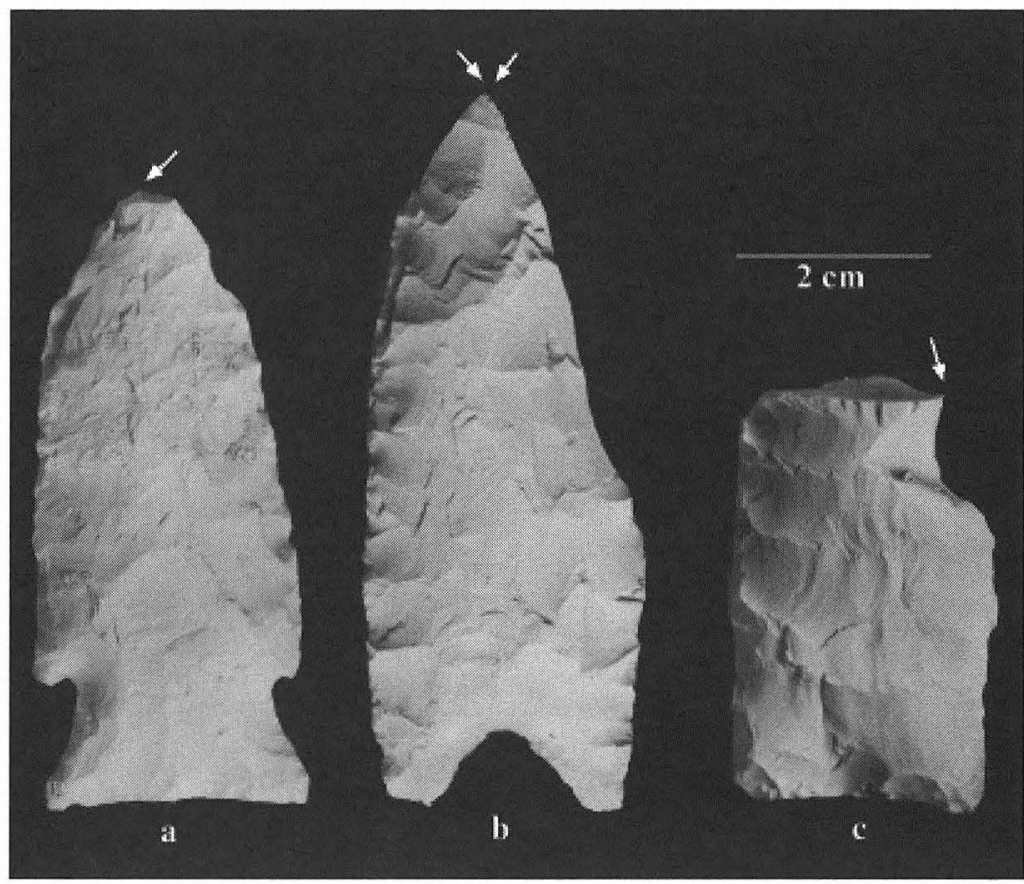

FIGURE 22-17. Recycled point burins. (a) Wilson; (b) Golondrina-Barber; (c) parallelsided lanceolate. Specimen numbers: a, 33EE1C-1; b, 13Q-2; c, 26V2B-2. and mass may have been deciding factors in selection as tools. Three of the four (see Figure 22-16a-c) are either roughly parallel sided or converge to the burin end, as does the fourth in a more dramatic fashion (see Figure 22-16d). Other than the largest which weighs $29.78 \mathrm{~g}$ (and in fact is among the two heaviest of all identified tool elements), the others have more-or-less consistent weights between 6 and $10 \mathrm{~g}$. The eight burinated flakes lacking tool microwear (see Table 22-5) are more divergent in form and variable in weight. As a practical matter, they may have been too cumbersome to be easily held.

Verification of formal and functional burins depends on a microwear assessment, as other superficially similar stone artifacts lack diagnostic wear traces. What then are the diagnostic wear traces? Actually, they are quite variable, often exhibit microplating and the filling in of striae, and are uniformly constrained by material hardness to a very narrow contact zone at the burin edge. The inescapable conclusion is that Wilson-Leonard stage in the recycling process. The point burins differ somewhat from the flake burins, which are all prepared as dihedral angle burins. Only one point burin (Figure 22-17b) in this sample is prepared similarly, the other two have single burin facets struck on a break.

Beyond these formal burins are the chisel-edge tools created by radial fracture, as Crabtree (1977) described, or that take advantage of a potentially unintended obtuse angle break. The latter technically would be ad hoc or expedient tools, whereas those intentionally created by radial fracture would, of course, be deliberately patterned. Important though this distinction is, I could not assess it systematically. I refer to all of these in a generic sense only as functional burins without regard to the possibility for intentional preparation. Prepared or not, a conspicuous selection of blanks having the appropriate mechanical properties for burin usage extends from tiny snapped flakes (Figure 22-18) to medial biface segments (see Figure 22-16e) and the recycling of broken but still serviceable points (Figure 22-19). The prime characteristic each has in common is a relatively thick, obtuse-angled sharp edge.

The point burins presuppose the question of tool hafting. Their form and microwear evidence indicate hafting did occur, but it need not have been coincident with burin usage. The other burins are equivocal for hafting microwear evidence. Although undoubtedly a mechanical advantage would have been conferred, this analysis does not confirm burin hafting even though it did for other tools, described below.

If, as seems likely, the flake dihedral angle burins were unhafted and were handheld, then both their overall shape burins were not used in exactly the same way but comprise subsets, or functional groups. One such group would seem to be aptly named the "sharply pointed chisel burin." A previously described and illustrated dihedral angle burin (see Figure 22-11) is perhaps its archetype and is complemented by another (Figure 22-20) that shows a similar useorientation parallel to the longitudinal axis of the burin facet. These more-or-less symmetrical dihedral angle burins exhibit a primary unidirectional tool use motion that originates at the centrally located point, or tip, of the chisel edge. They would have been pushed parallel to their longitudinal axis into the material worked-perhaps most ideally to initiate a slot or groove. The work force, or momentum of the tool stroke, would have been efficiently concentrated at the wedging tip.

Initial use of another, more-or-less symmetrical dihedral angle burin (Figure 22-21) is actually at an oblique angle to the burin edge. As determined from microplating, subsequent tool use originates at the centrally located point of the chisel edge in a manner nearly identical to the previous examples. It, too, would be classified as a sharply pointed chisel burin.

Another variation but along the lines of a sharply pointed chisel is presented by the point dihedral angle burin (Figure 22-22). At the burin tip the striae are both parallel and oblique to the longitudinal axis of the tool. This suggests a rotary, boring usage much as would be true for a drill or perforator. Use-wear parallels between burins and drills or perforators are often remarkable.

A second chisel burin form is that of a blunt tool point. The two examples occur on a radially fractured biface (see 


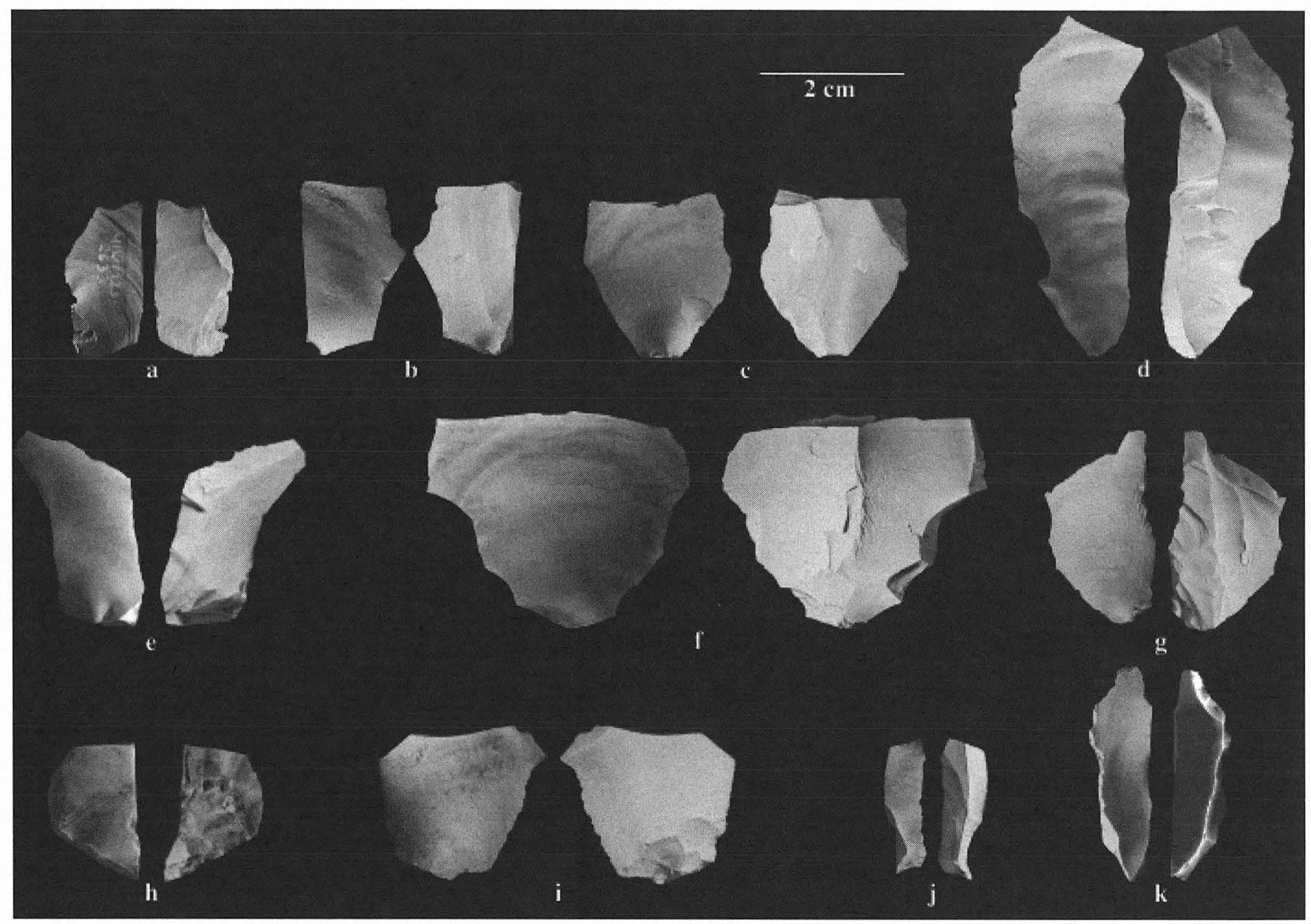

FIGURE 22-18. Unmodified gouging/scraping flakes. (a-g, i, j) wedging; (h) blunt point; (k) buring group tool.

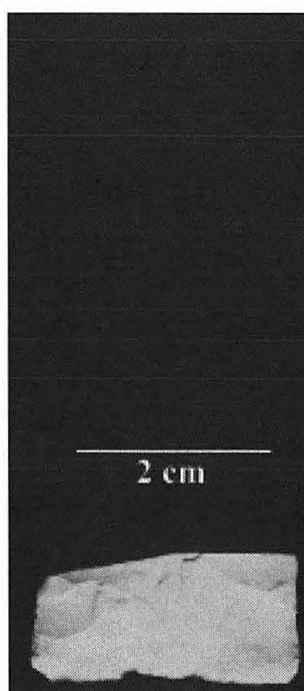

a

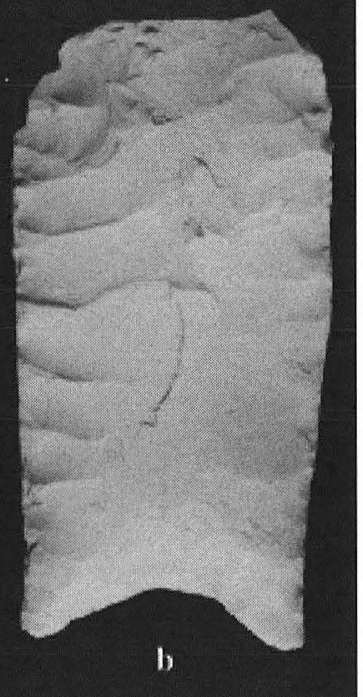

FiguRE 22-19. Recycled point fragments used as gouging/scraping burins. (a) paralel-sided lanceolate, Specimen 15X1-3; (b) Golondrina-Barber, Specimen 51Y1B-1.

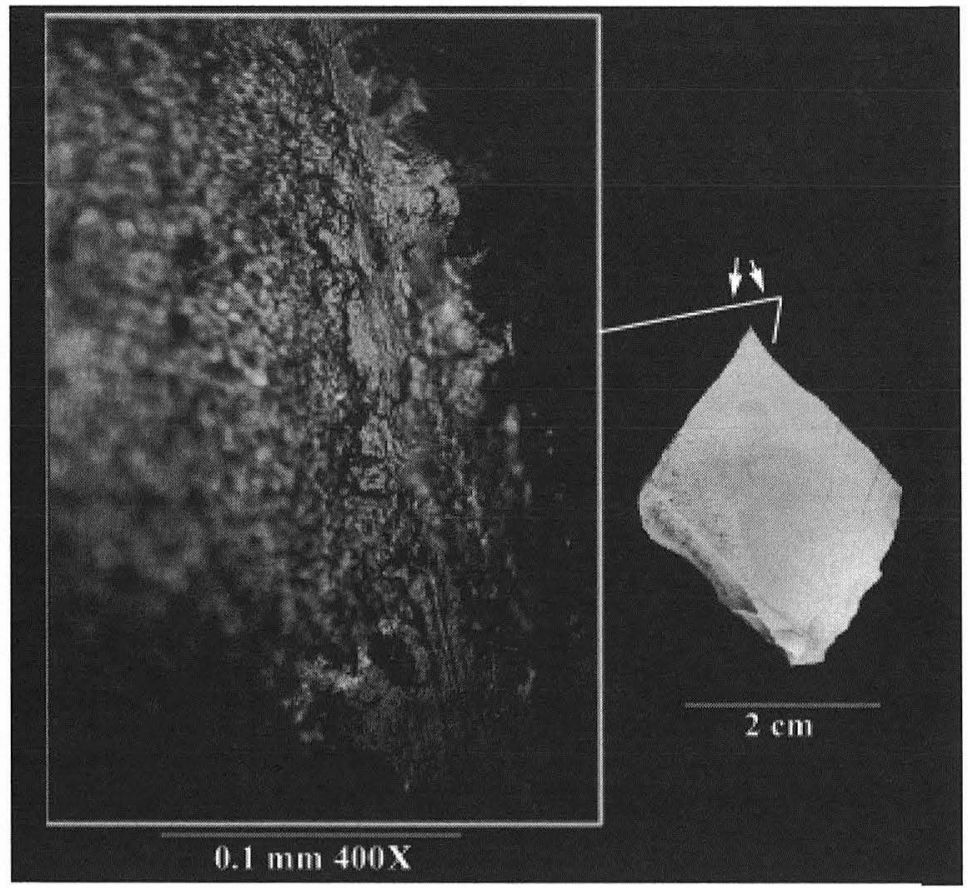

FIGURE 22-20. Depositional, or additive, unidirectional microwear on dihedral angle sharply pointed chisel burin, Specimen 30R2-13; compare with Figure 22-11. 


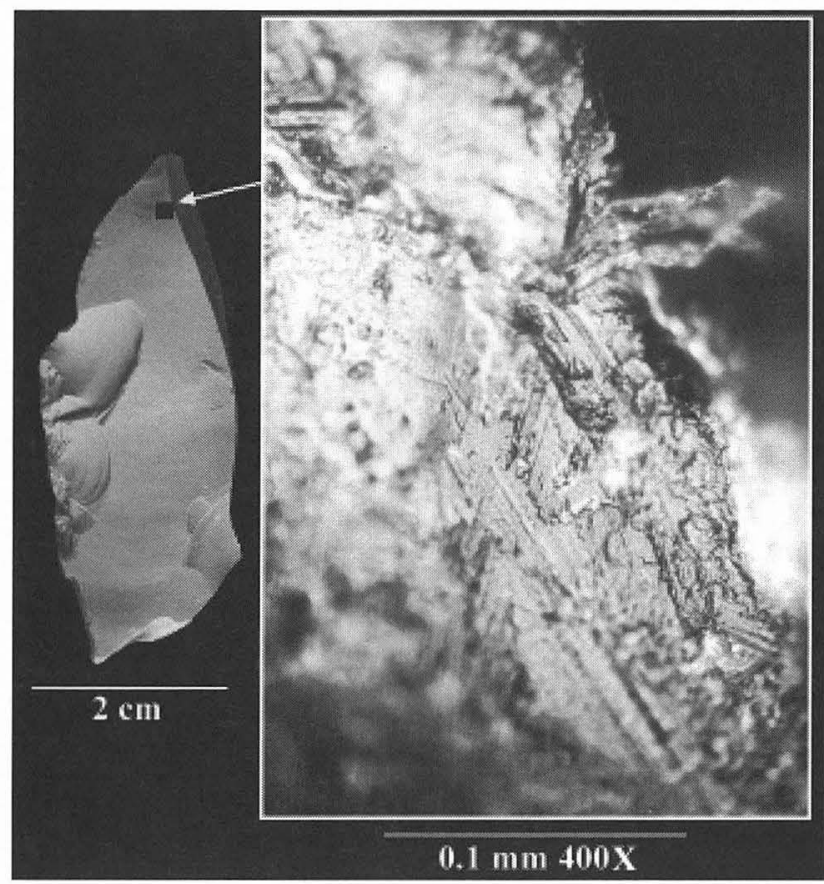

FIGURE 22-21. Ordered sequence of additive microwear on dihedral angle sharply pointed chisel burin, Specimen 37CC-34. Note microplating and recrystallized filament projecting from edge.

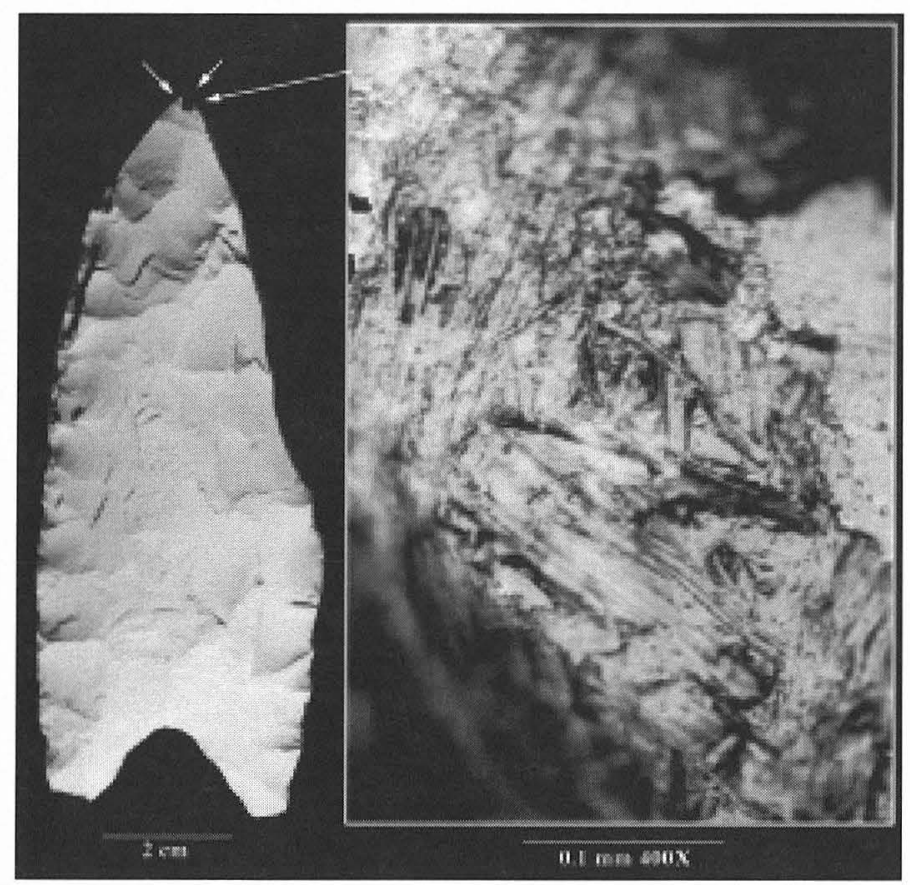

FIGURE 22-22. Additive rotary microwear on recycled Golondrina-Barber point (Specimen 13Q-2) as dihedral angle burin used probably as a boring tool.

Figure 22-16e) and a burin spall (see Figure 22-18k), not on dihedral angle burins. That suggests highly contrastive design criteria in which longitudinal symmetry and central placement of the burin tip play no part. Instead the tools are longitudinally asymmetrical with offset blunt points. Whether intentionally created or simply selected for their requisite design features, the two would have been difficult to hold and use in the manner of the sharply pointed chisel burins. Indeed, the microwear striae are mostly perpendicular to the longitudinal axis of the tools (Figures 22-23b, 22-24). The tools would have been dragged, or rocked, back and forth across a hard surface or an already initiated groove. The tool longitudinal axis would have been nearly perpendicular to the worked surface with force applied both vertically and laterally. In contrast, the sharply pointed chisel burin tips (see Figures 22-20 and 2221) were pushed parallel to $F$ the tool longitudinal axis, or were rotated about this axis (see Figure 22-21).

A further functional permutation is defined by gouging or scraping burins. These are the most common Wilson-Leonard burins and occur on a variety of blank forms (see Figures 22-16c, 22-18a-g and i, and 22-19). These burins exhibit rough longitudinal axis symmetry and are of variable length and thickness. The most conspicuous design element is a relatively wide, obtusely angled burin edge transverse or oblique to the tool's longitudinal axis. The use-wear overall is more-or-less perpendicular to the longitudinal axis of the tool and rockers, or pivots, in a reciprocating two-stroke fashion (Figures 22-25 through 22-27). This microwear must represent a semirotary gouging or scraping along the entire front of the burin edge. Although there is significant variation, an initial "invasive" penetration of the broad burin edge or surface generally occurs at an oblique angle or parallel to the longitudinal axis of the tool. The tool edge is then moved perpendicular to its longitudinal axis, creating striations that parallel the tool edge and are likely a byproduct of a secondary cleaning stroke designed to remove detritus from a groove or slot. This use-wear is shown in Figure 22-28, an intentionally backed flake fragment whose tool edge is opposite the backing. The backing is reasonably interpreted as a way to dull the edge that would have been handheld. Thus, it is further evidence of prehension rather than hafting. Other examples of this gouging or scraping microwear occur on small flake burins (see Figure 22-23a; Figure 22-29) that also exhibit no evidence of hafting.

A final Wilson-Leonard functional burin group is that of a small splitting wedge. This group is represented by a single radially fractured flake specimen (see Figure 22-18h) used before the break as an invasive cutting tool (Figures 22-30, 22-31b). The radially fractured edge (see Figures 22-30, 22-31a) has invasive, striated micropolishes that originate at the edge. The oblique-to-the-edge orientation of the primary striae are diagnostically unidirectional and indicate the tool edge was placed perpendicular to a worked surface or slot. The opposite edge was struck to force the burin edge deeper into the worked material. There are also secondary striae adjacent to and paralleling the tool edge (see Figure 22-31a); these probably represent the 


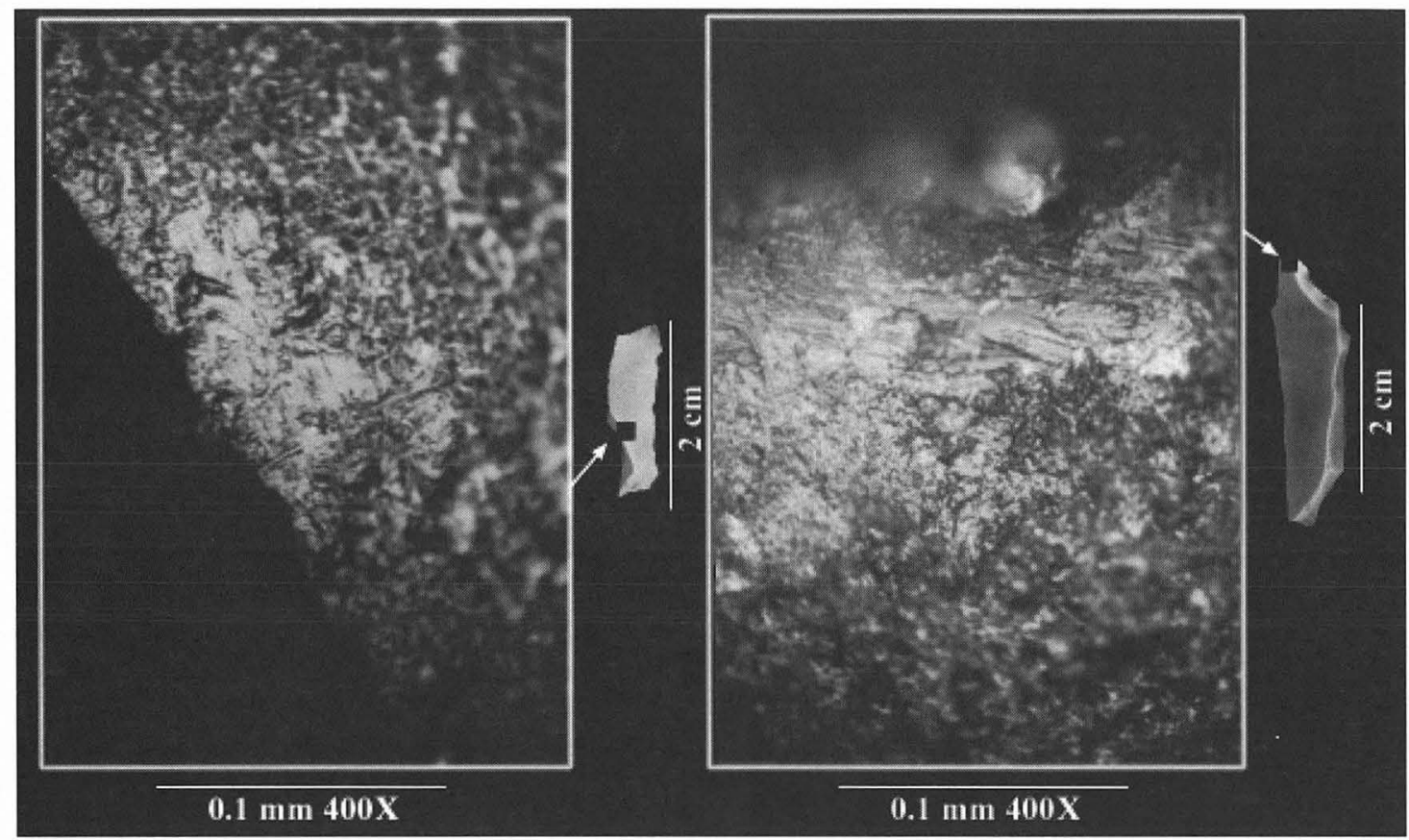

FIGURE 22-23. Microwear on flake tool gouging/scraping burin (a) and blunt tool point burin (b).

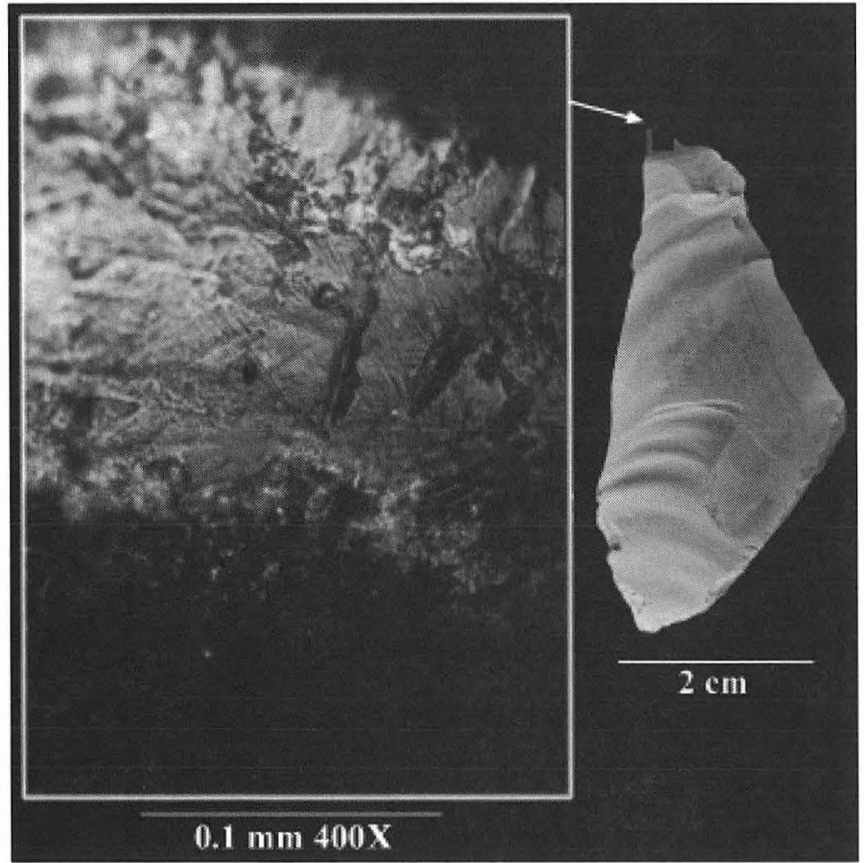

FIGURE 22-24. Additive microwear showing a two-motion rocking stroke on radially fractured biface blunt tool point burin, Specimen 50KA-6; compare with Figure 22-22.

effects of a cleaning stroke to remove detritus much as appears to be the case for the gouging or scraping burins.

\section{Gravers}

A subset of the retouched flakes are five flake gravers (Figure 22-32). All have intentionally prepared graving spurs,

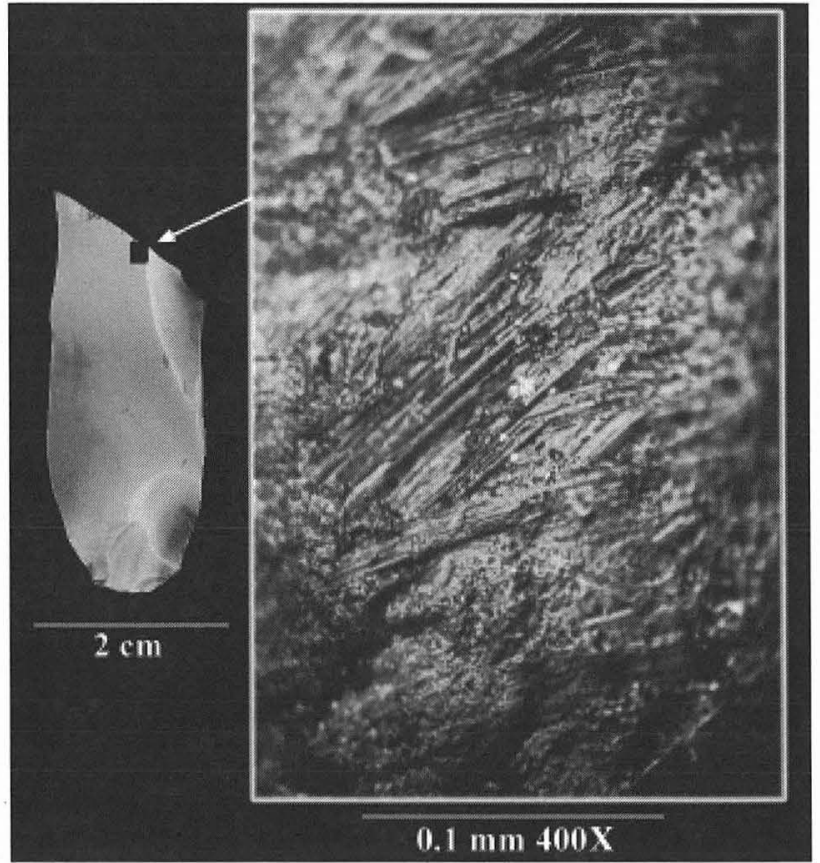

FIGURE 22-25. Additive microwear on gouging/scraping dihedral angle burin, Specimen 29R2-3.

although the number and location vary. Two show unmistakable tool use-wear (see Figure 22-32d, e; Figure 22-33); one other had equivocal wear traces (see Figures 22-32a; Figure 22-34); the remaining two (see Figure 22-32b, c), no use-wear. The graving spurs are mostly delicate, or relatively fragile. It came as something of a surprise that use-wear is consistently restricted to the tip only and does 


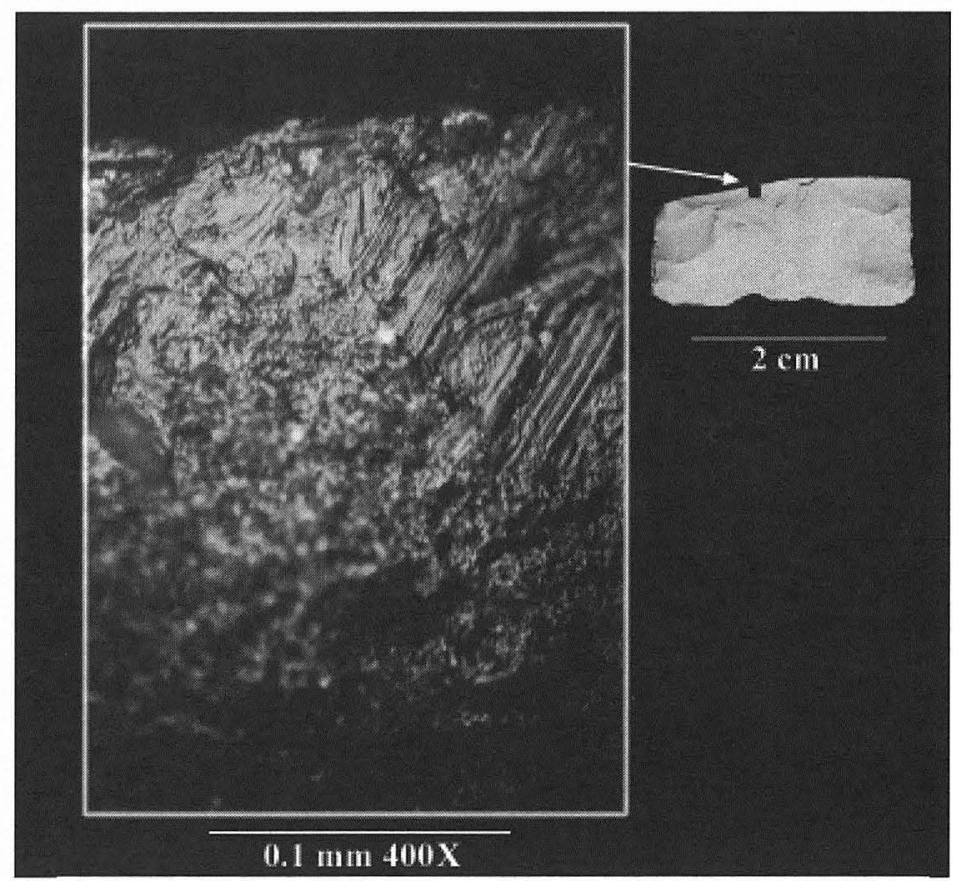

FIGURE 22-26. Additive microwear on gouging/scraping burin fashioned from a broken parallel-sided lanceolate, Specimen 15X1-3.

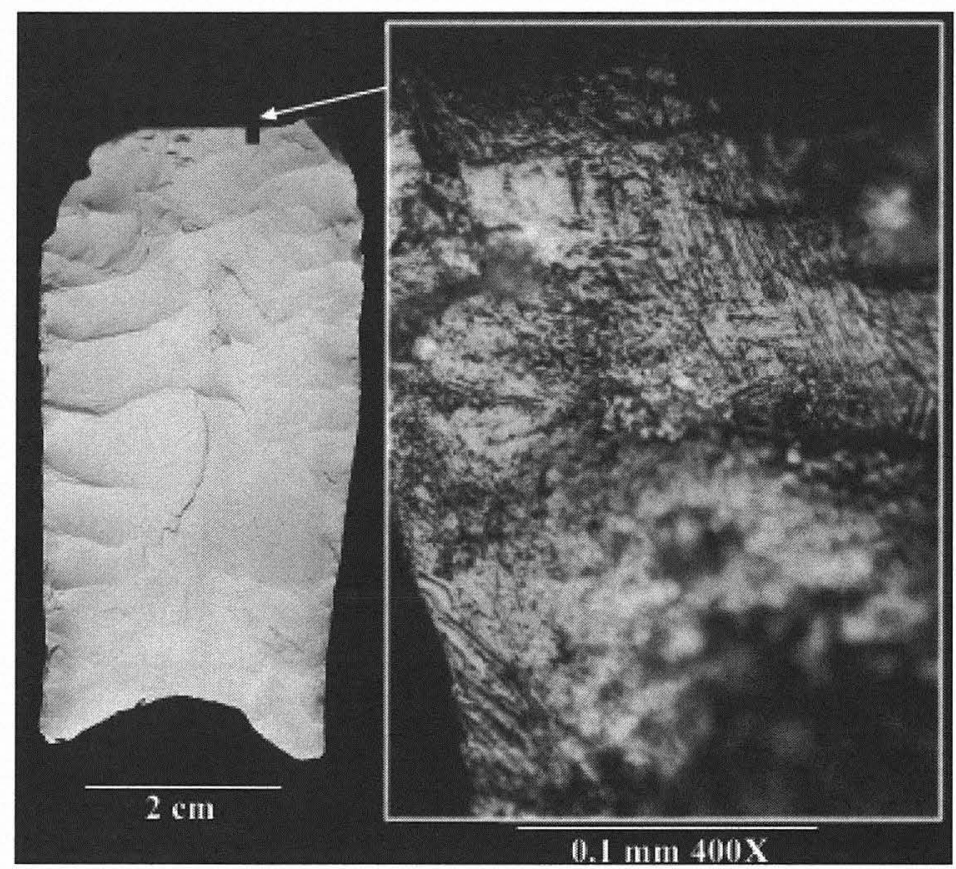

FIGURE 22-27. Additive microwear on gouging/scraping burin fashioned from a broken Golondrina-Barber point, Specimen 51Y1B-1.

not appreciably extend onto the face of the spur. In essence, the use-wear describes the most narrow of contact zones on each graving spur tip. The striated micropolishes are patchy and discontinuous, in part because of use-related microfractures, or flaking, of the tip (see Figure 22-33a). The implication is that in engraving hard materials the spurs failed or broke off. Undoubtedly, much of the microwear evidence normally would be lost. Perhaps the best ex- ample is that of the multispurred graver that shows progressive failure of individual spurs (see Figure 22-32a) but only equivocal microwear (see Figure 22-34).

\section{Perforators/Drills}

Although of similar purpose, a drill and a perforator ideally would contrast in tool motion. Rotary motion applied at the tip would be typical of a drill. A perforator would be plunged into or through a worked material, creating a conical hole by the wedging action of the tip and the tool shaft, and then extracted by pulling back on the tool. Tool forms should differ too. The drill form should allow for rotary contact of its tip with a worked material but ideally not its shaft. A perforator should have almost opposite design elements: because its tip initiates an opening that is further wedged by frictional contact with its shaft, the conical shaft should end in a needle-like tip. Tool extraction, however, might result in almost indistinguishable wear or damage to a drill or perforator shaft.

These distinctions guide the microwear assessment of seven bilaterally symmetrical tools (see Table 22-6). As noted earlier for one (see Figure 2212), all seven have hafting microwear but differ in haft element form. Rotary microwear evidence indicates four served as drills (Figure 22-35c, e-g), of which two (see Figure 22-35e, f) or possibly three (see Figure 22-35g) were recycled from bifacial points. A combination of drill rotary motion and perforator pushing for one, the only uniface (Figure 22-35d), indicates a boring function analogous to that of the sharply pointed chisel burins. The final two lack a drill's rotary tool motion; one (Figure 22-35b) is clearly an awl (or perforator), the other (Figure 22-35a) a knife. The seven tools also display functional differences in inferred worked materials. The five drills or borers were used against relatively but not uniformly hard materials; the other two, contrastive soft materials.

All drills have transversely snapped tips, most likely failure during use. These are all discarded tools. Their wear traces are not in the strict sense on the tip but rather on the drill shaft at varying distances from the broken tip. The drill shafts all taper to the tip, which if only in theory is perhaps inconsistent with optimal engineering design criteria. Evidence of rotary tool motion is nevertheless clear on the drill shafts. The wear traces are diagnostically similar and express a clear order of distance from the tip. The best example of rotary motion is Figure 22-36a, which is somewhat 


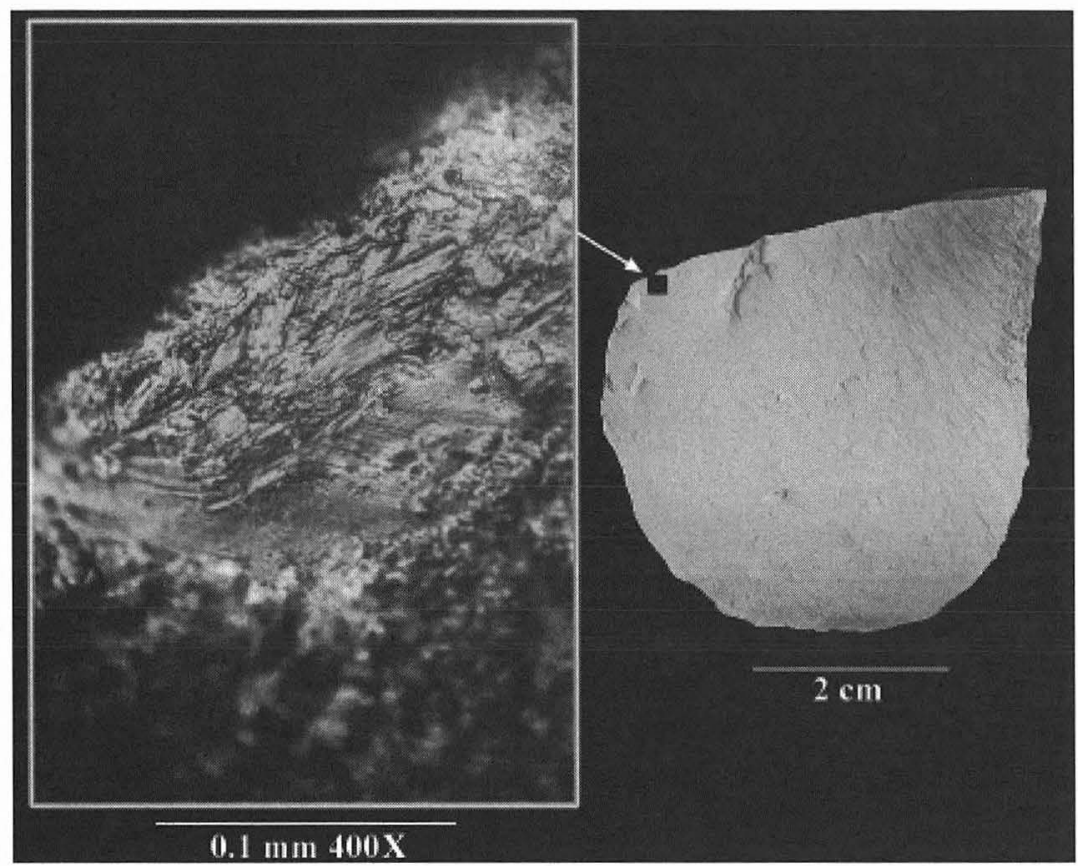

FIGURE 22-28. Additive microwear on gouging/scraping burin fashioned from an obtusely angled broken edge opposite a unifacially retouched, backed edge. The retouch backing was probably to blunt the edge so it might be more easily handheld. Specimen number: 14FF1B-1.

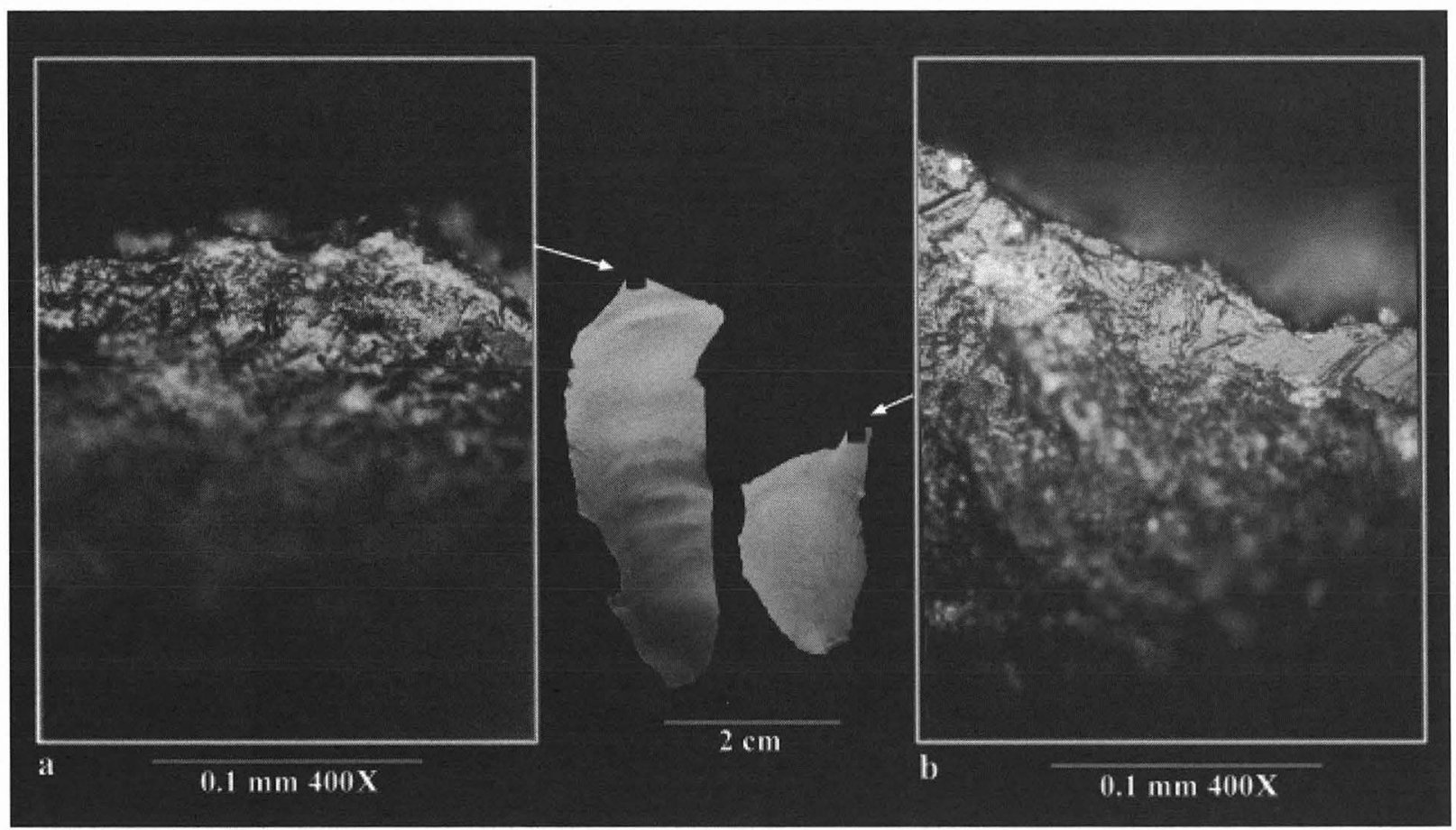

FIGURE 22-29. Microwear on unmodified flake gouging/scraping burins. Lot numbers: (a) 1328; (b) 1825.

back from a broken tip. The striae are essentially perpendicular to the longitudinal axis and crosscut each other, a striation pattern best explained as a byproduct of bidirectional (i.e., back-and-forth) rotary motion given the dia- mond cross-sectional shape of the shaft that tapers to the broken tip. A similar pattern is seen in Figure 22-37a, which is substantially farther back from the tip of another drill, and importantly, has overriding striae oriented parallel to 


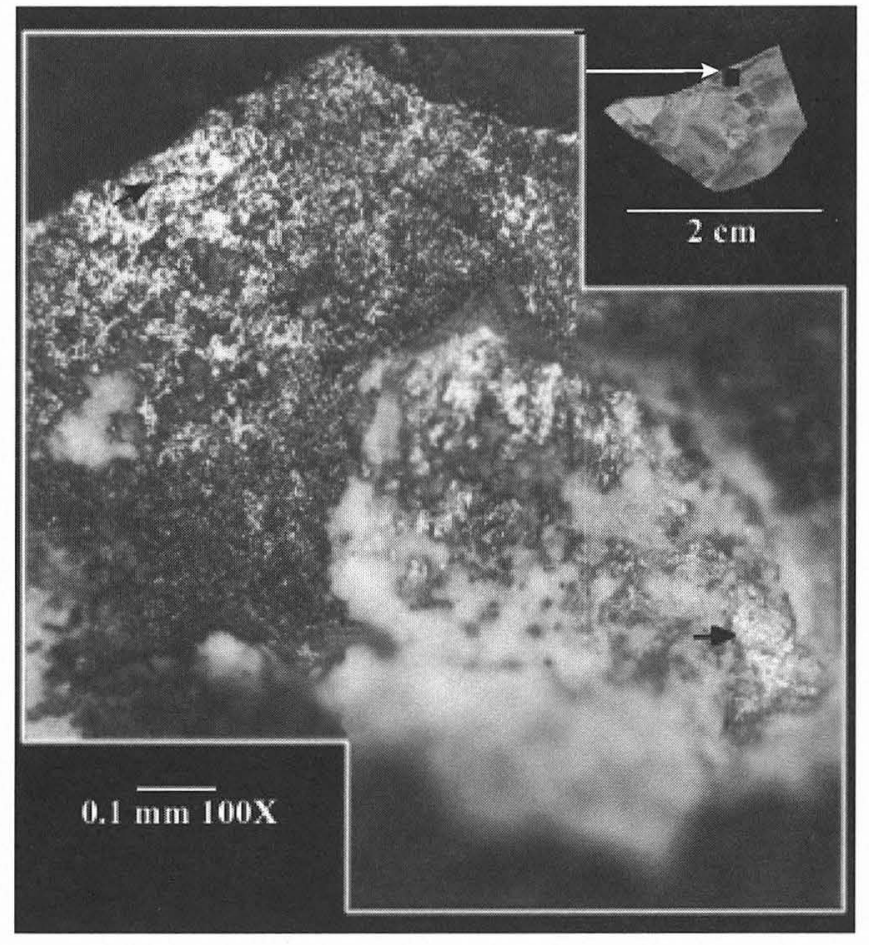

FIGURE 22-30. Small splitting wedge abrasive microwear photomosaic. Upper left arrow points to area enlarged in Figure 22-31a; lower right arrow, to area enlarged in Figure 22-31b. Lot number 1803.

the shaft's longitudinal axis. The latter are likely to be a byproduct of invasive shaft penetration that is further expressed about two-thirds of the way up the shaft from the tip (Figure 22-37b). A third example is that of wear adjacent to a

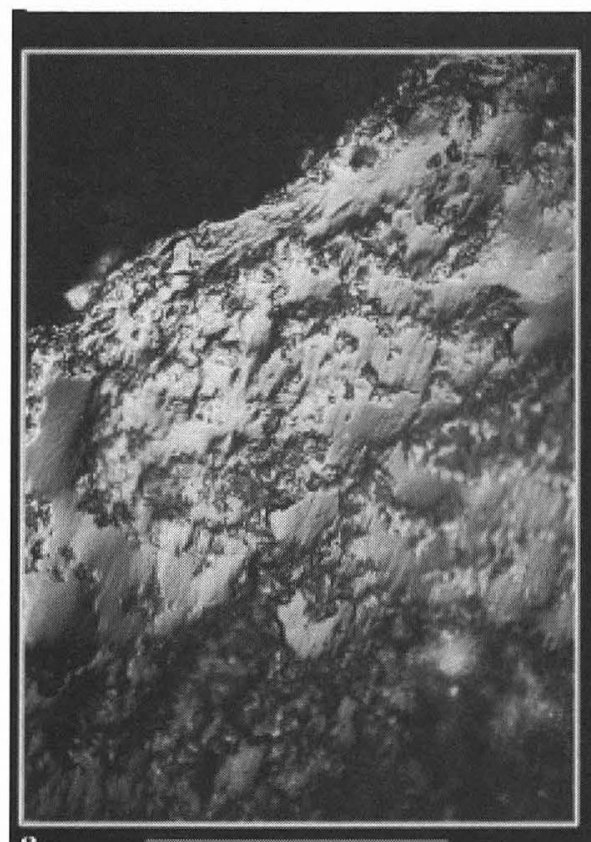

$0.1 \mathrm{~mm} 400 \mathrm{X}$

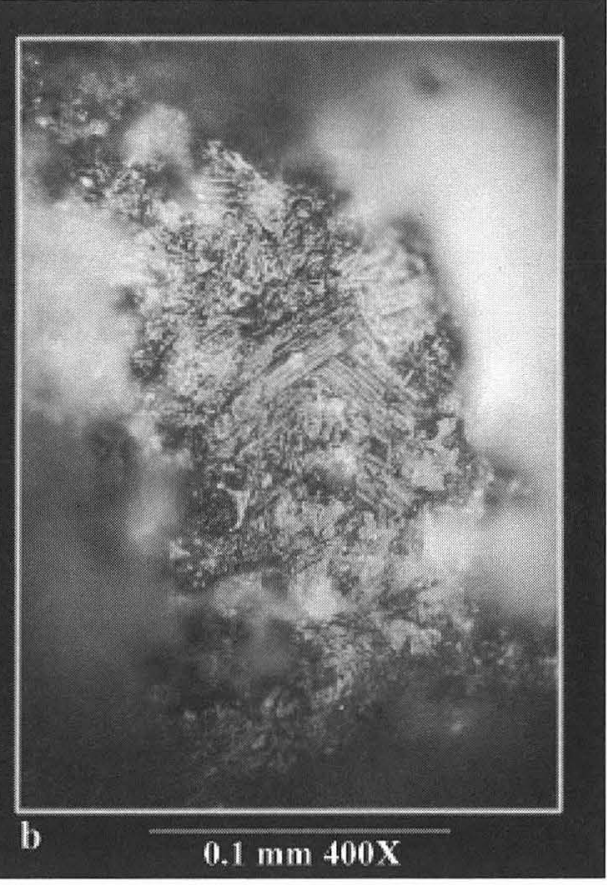

FIGURE 22-31. Small splitting wedge microwear. (a) EDP due to wedging use; (b) previous use as invasive cutting tool (see Figure 22-30 for location). Lot number 1803. broken shaft (Figure 22-38a) in which striae oblique to the shaft's longitudinal axis are overriden by ones that generally parallel or crisscross it (Figure 22-38b). The inference again is of rotary motion coupled with invasive shaft penetration but with the tip somewhat farther away from the break. Undoubtedly, the worked material was either significantly softer for the latter two or the first failed before a deep hole had been bored out.

These overall relations would seem to be borne out by microwear observations of the unifacial tool that, for lack of a better name, is called a borer. The tip is present, and thus it appears not to be a reject. Its microwear (Figure 22-39a, b) shows a clear pattern of striae nearly identical to the drills. The initial striae are perpendicular to the shaft's longitudinal axis and are indicative of rotary motion. Others parallel the shaft's longitudinal axis and have associated abrasive particles (see Figure 22-39a especially) opposite the tip. The tool motion is thus from the tip: the borer was pushed into the worked material, much in the manner of the sharply pointed chisel burins. Not only is the overall sequence of tool motion the same but also the actual appearance of the microwear is almost identical with the sharply pointed chisel burins (see Figure 22-21).

Tool movement within the haft is evident from wear traces also on the drills and the borer. The typical pattern is a latticework of striae (see Figures 22-12, 22-36b; Figure 22-40). One element, striae oriented to the tool's longitudinal axis, is undoubtedly a secondary byproduct of tool use, as noted earlier.

Although superficially similar in form, the final two (and seemingly still serviceable) tools differ in design and usage. The shaft edges of the awl, or perforator, are carefully ground, a deliberate attempt to dull them and enhance frictional drag. The awl shaft has a diamond cross-sectional shape; the sharply edged knife is biconvex. The knife's use-wear originates in a functionally expectable way at its lateral edges but is best expressed along the tool midline (Figure 22-41a). Use striae oriented at an oblique angle to the longitudinal axis converge and intersect. Microplating is common and the tool experienced sustained use. The awl also has use-wear primarily on the tool midline (Figure 22-41b). Use striae orienting parallel to the longitudinal axis are indicative of deep shaft penetration that originated at the awl tip. 


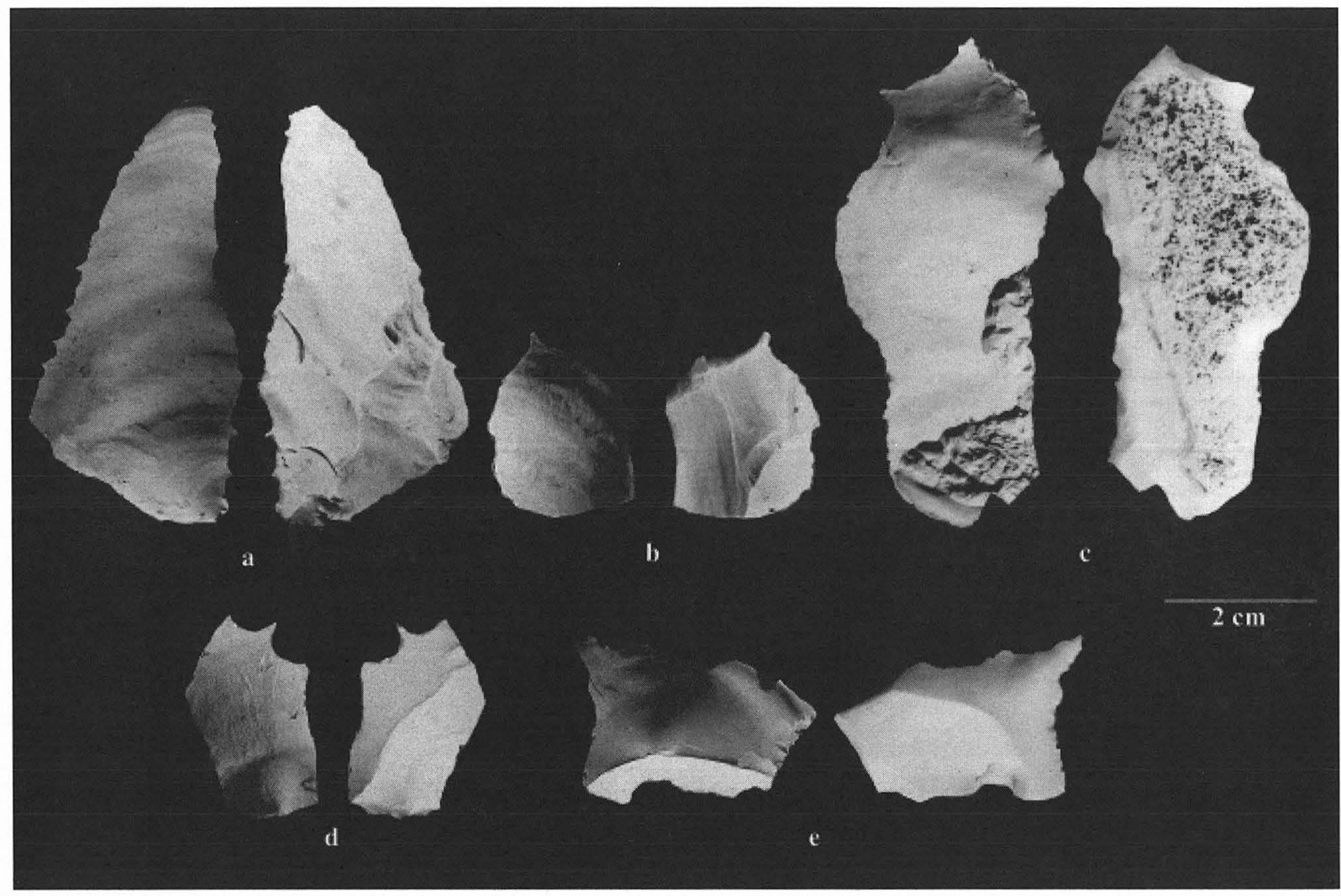

FIGURE 22-32. Flake gravers. Specimen numbers: (a) 16.S2-9; (b) 37DA-2; (c) 37BD-31; (d) 28T2D-7; (e) 24Q1-3.

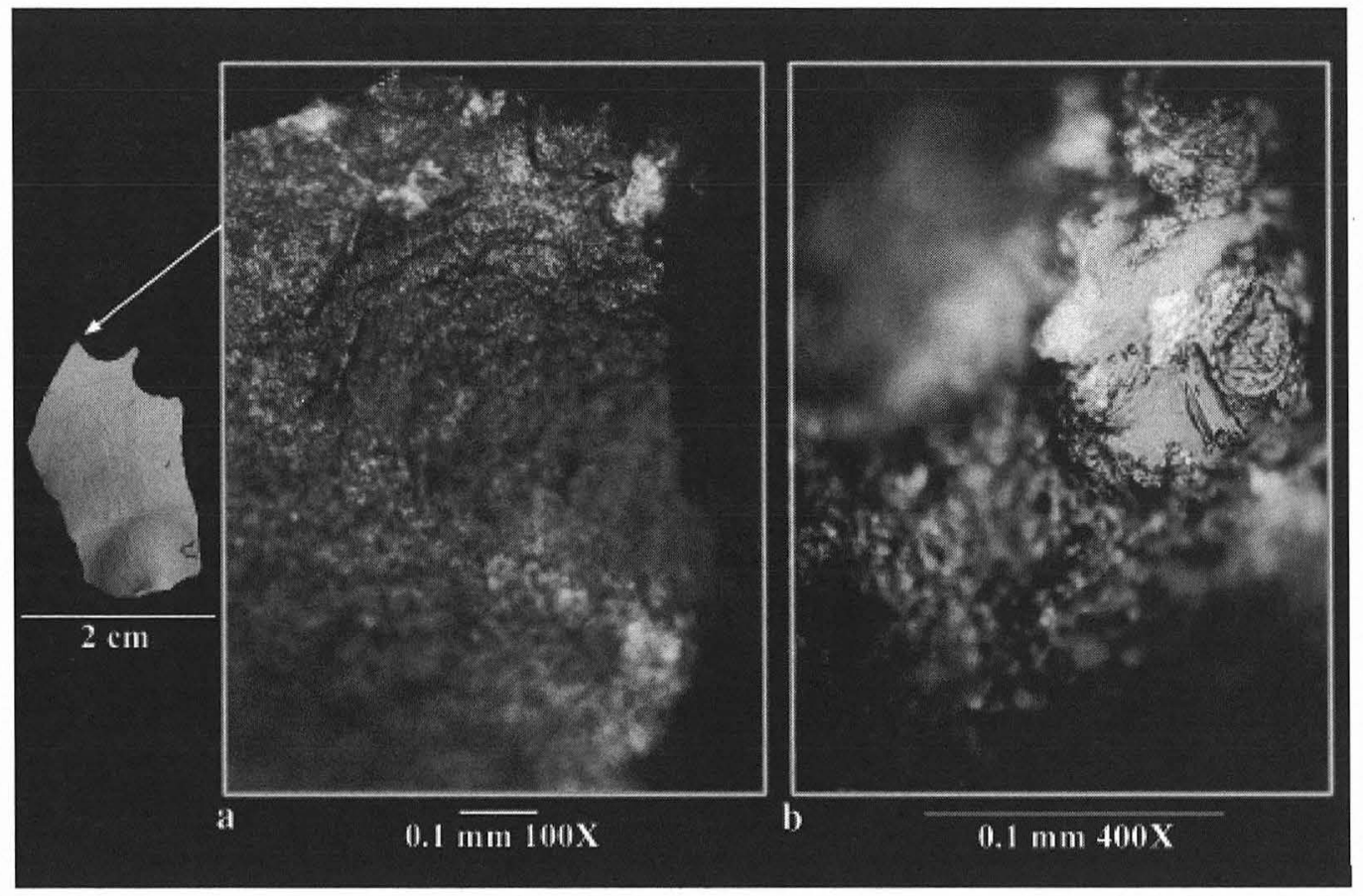

FIGURE 22-33. Flake graver microwear, Specimen 28T2D-7. (a) EDP patches and use miroflaking damage to tip; arrow points to EDP enlarged in (b); (b) microplating and striae with abrasive particles. 


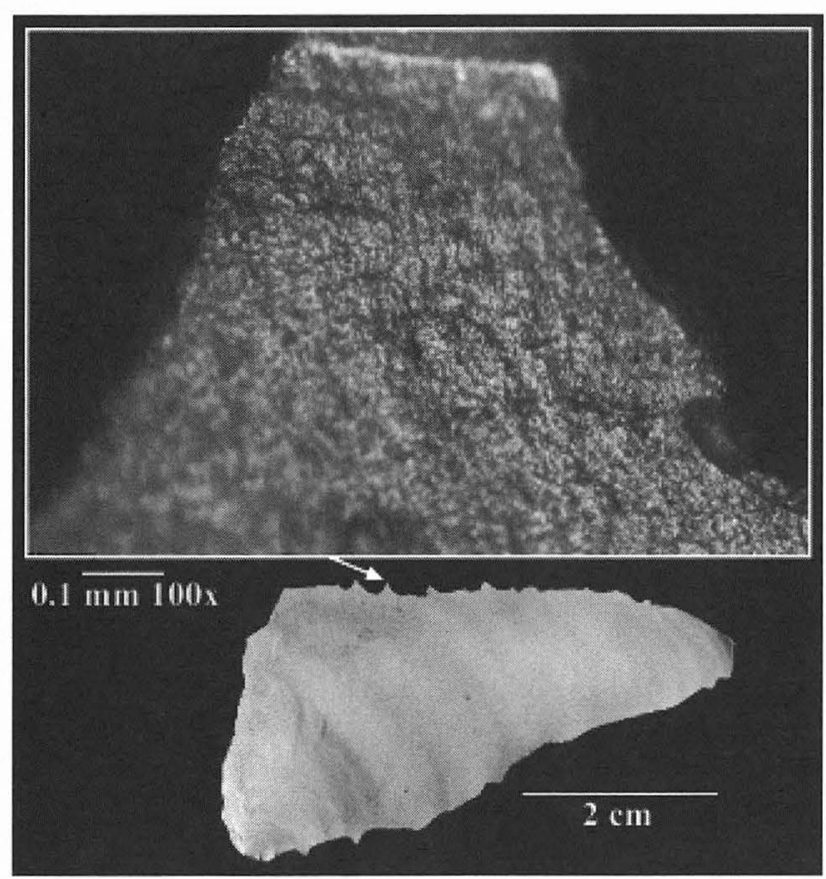

FIGURE 22-34. Flake graver with possible microwear, Specimen 16.S2-9.

\section{Unifacial Knives}

This group of five tools and two tool fragments comes from the unmodified (Figure 22-42) and retouched (Figures 22-43, 22-44b) flakes. Only two (see Figure 22-43) were carefully prepared by backing one of the lateral edges. All appear to have been used primarily on relatively soft materials. Typically, the abrasive microwear is invasive and is accompanied by arris rounding (see Figure 22-13; Figure 22-45). There is no evidence of microplating. The artifacts do not appear to have served as extended use tools, nor to have been hafted; they still appear to be serviceable.

One of the intentionally backed tools was used, if only incidentally, to cut hard material, perhaps bone, as the polish consists of a broad band with striae oriented parallel to the unretouched edge (Figure 22-46). These use-wear details commonly occur in carcass butchering. The overall wear traces for this and the other backed tool indicate the unprepared edge of the two tools was the primary working edge. The backing most likely facilitated holding the tool. The two tools both appear to be similar in function, with use mainly as butchering tools.

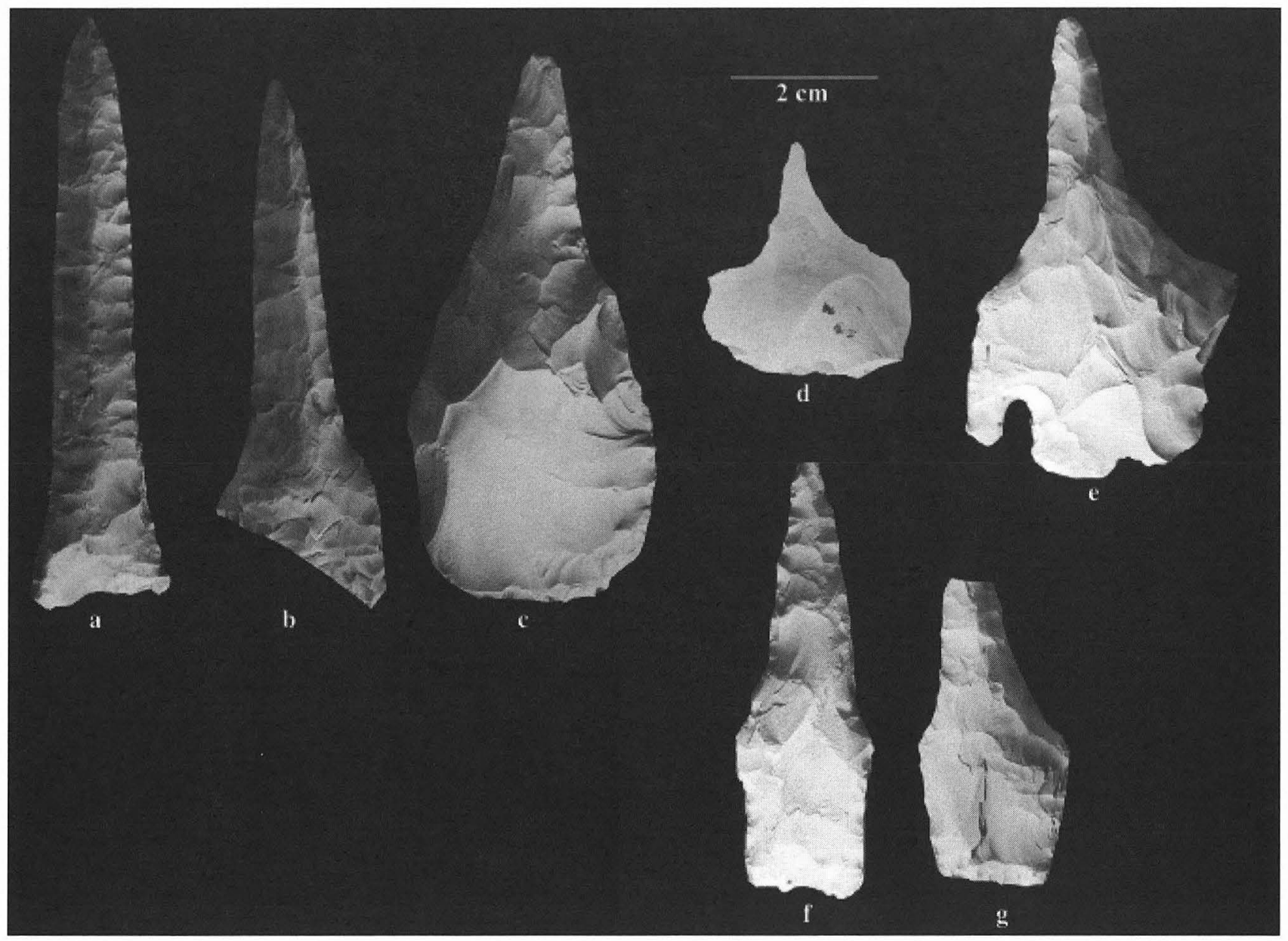

FIGURE 22-35. Perforators/drills analytical group. (a) knife; (b) awl; (c) drill; (d) borer; (e-g) drills. Specimen numbers: (a) 32W1B-1; (b) 26U1B-3; (c) 6G-6; (d) 30T1C-1; (e) 14D-2; (f) 13J-29; (g) 26R1-4. 


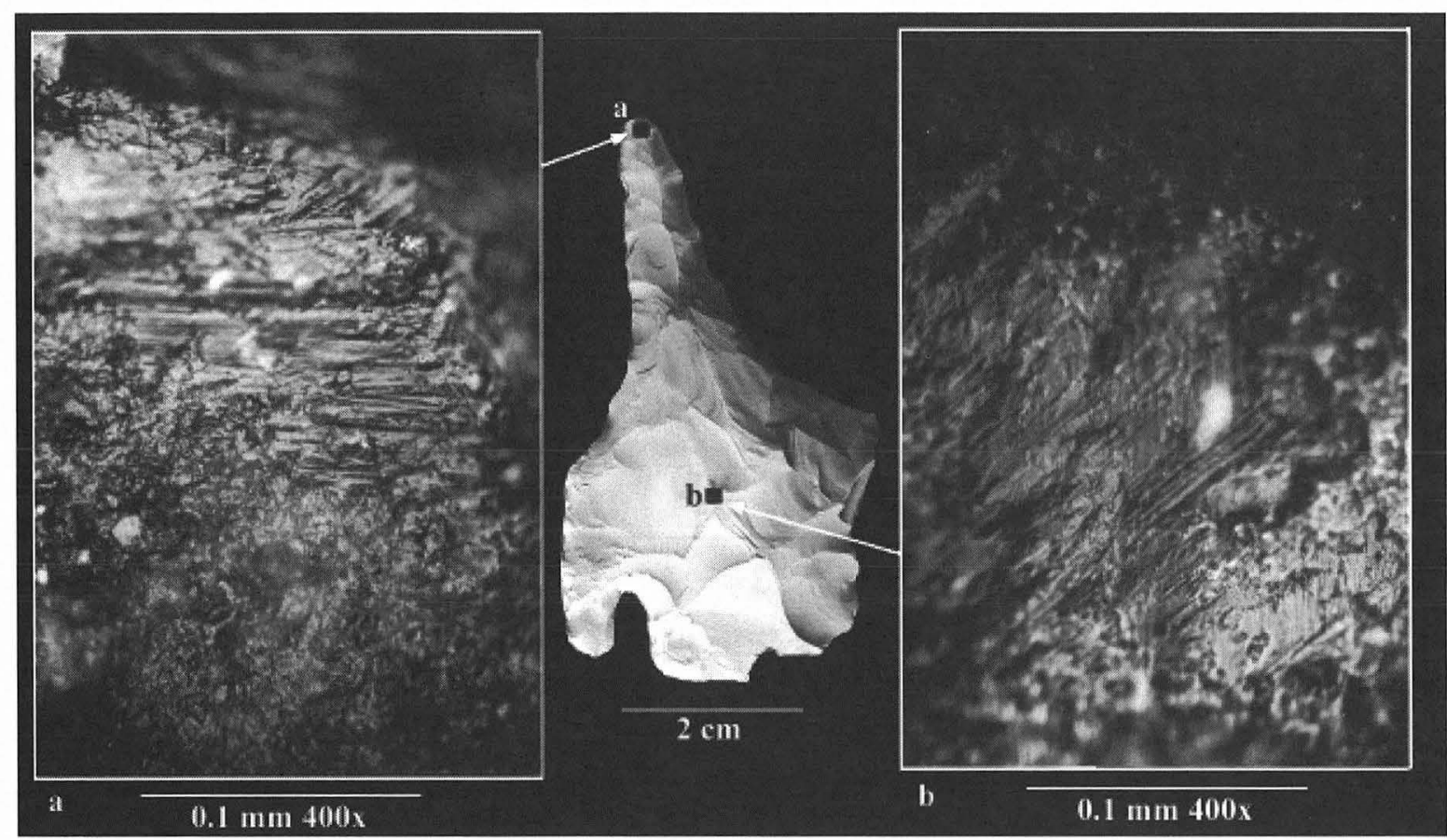

FIGURE 22-36. Broken drill made on a recycled point, Specimen 14D-2. (a) additive rotary microwear, compare with Figure 2223; (b) haft microwear.

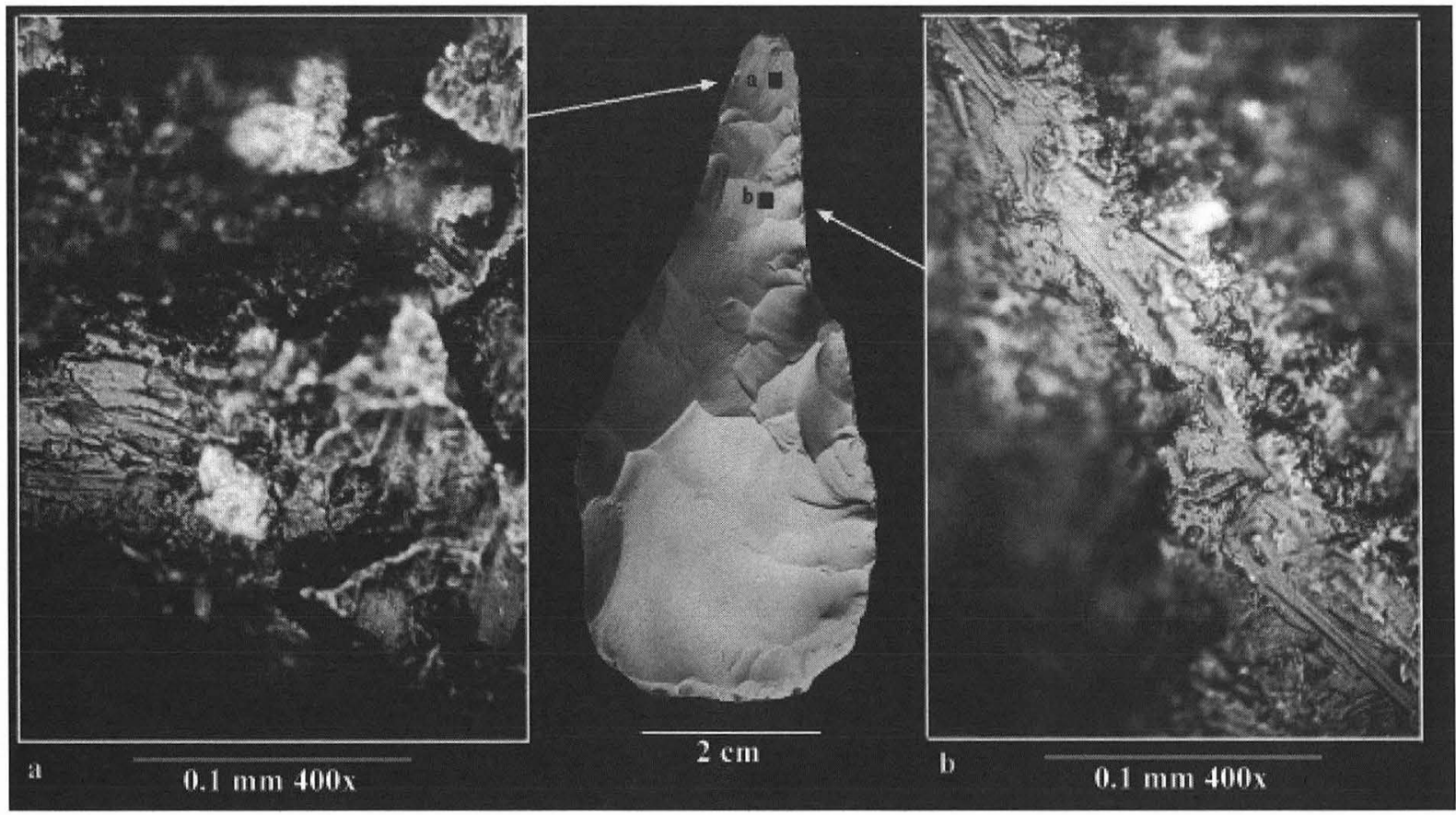

FIGURE 22-37. Broken bifacial drill, Specimen 6G-6. (a) additive rotary microwear; (b) invasive additivemicrowear probably due to removal of shaft from drill hole.

\section{Projectile Points}

The 32 chipped stone points are both stylistically and functionally diverse (see Table 22-7) but generally have carefully ground bases. Unless otherwise noted, the microwear polishes are additive with extensive microplating and evi- dence of use sequencing. Generally speaking, the microwear analysis documents recycling. Most but not all began as projectile points. This summary begins with two points that were difficult to classify typologically: an unusual thin, notched point (Figure 22-47a) found in the Leanne soil and a lanceolate point found in the Bone Bed (or Unit Isi/Icl) 


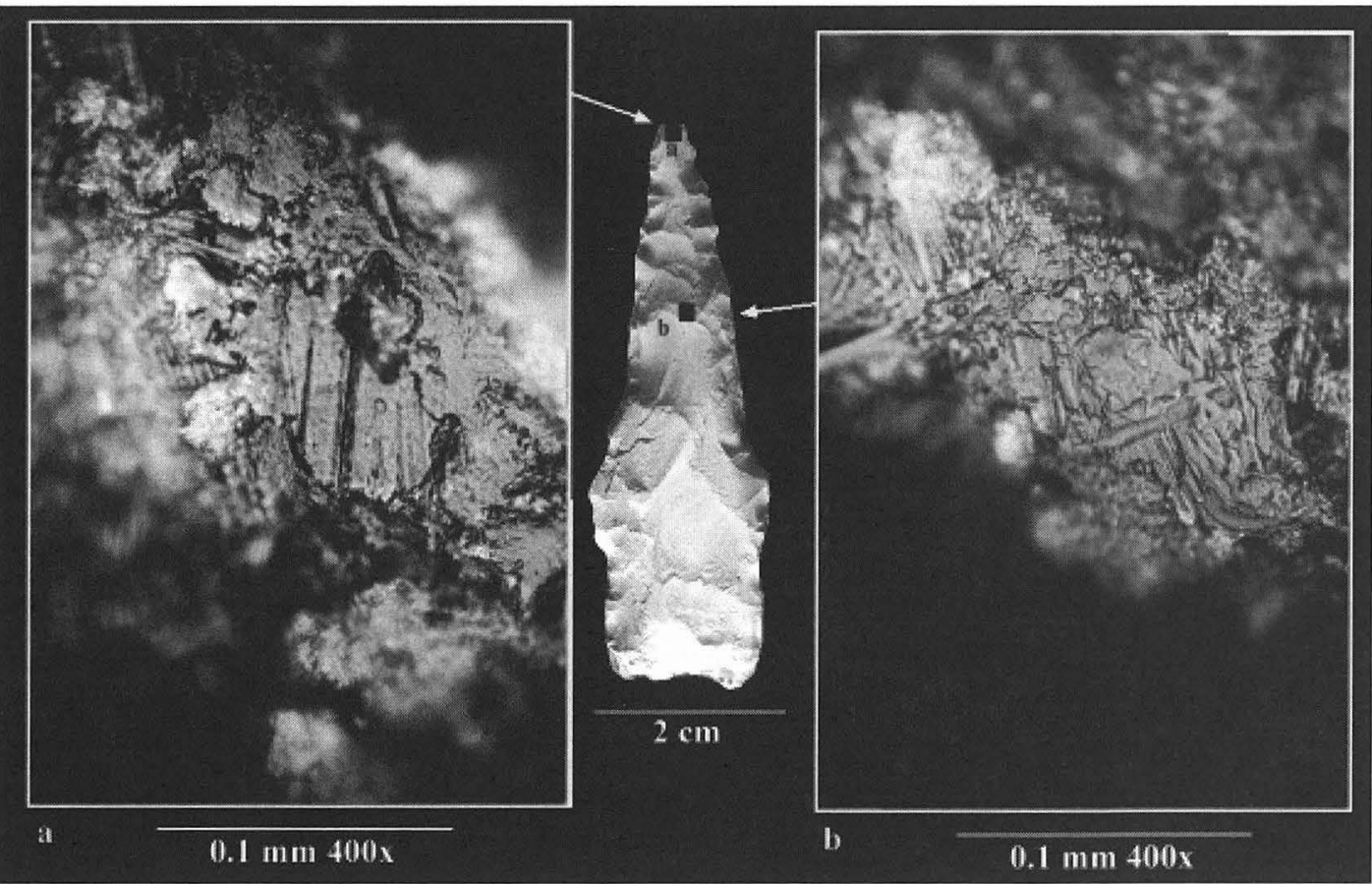

FIGURE 22-38. Broken bifacial drill, Specimen 13J-29. (a) additive rotary microwear; (b) invasive additive microwear probably due to removal of shaft from drill hole, compare with Figure 22-37.

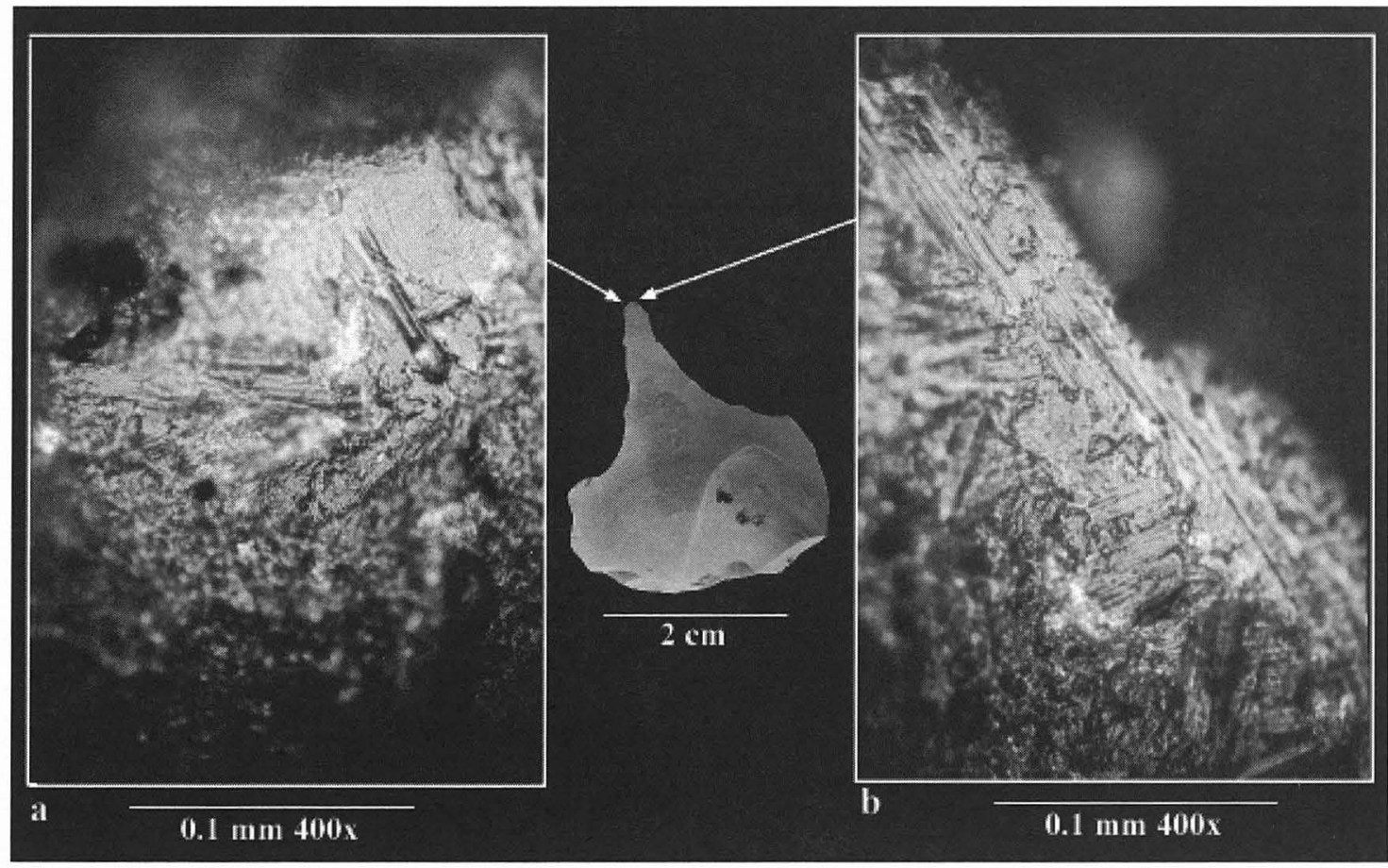

FIGURE 22-39. Unifacial borer additive microwear, Specimen 30T1C-1. (a) note abrasive particle at end of striation; (b) compare with Figure 22-21.

(Figure 22-47b) and then proceeds sequentially to the later, formally named, Late Paleoindian and Early Archaic point types. Based upon the microwear analysis, the latter are placed in a functional rank order in the group illustrations.

\section{LEANNE SOIL AND BONE BED POINTS}

Neither artifact is typologically distinctive and one would be hard pressed to pigeonhole either into an established point type. The thin, notched point, is the more bi- 


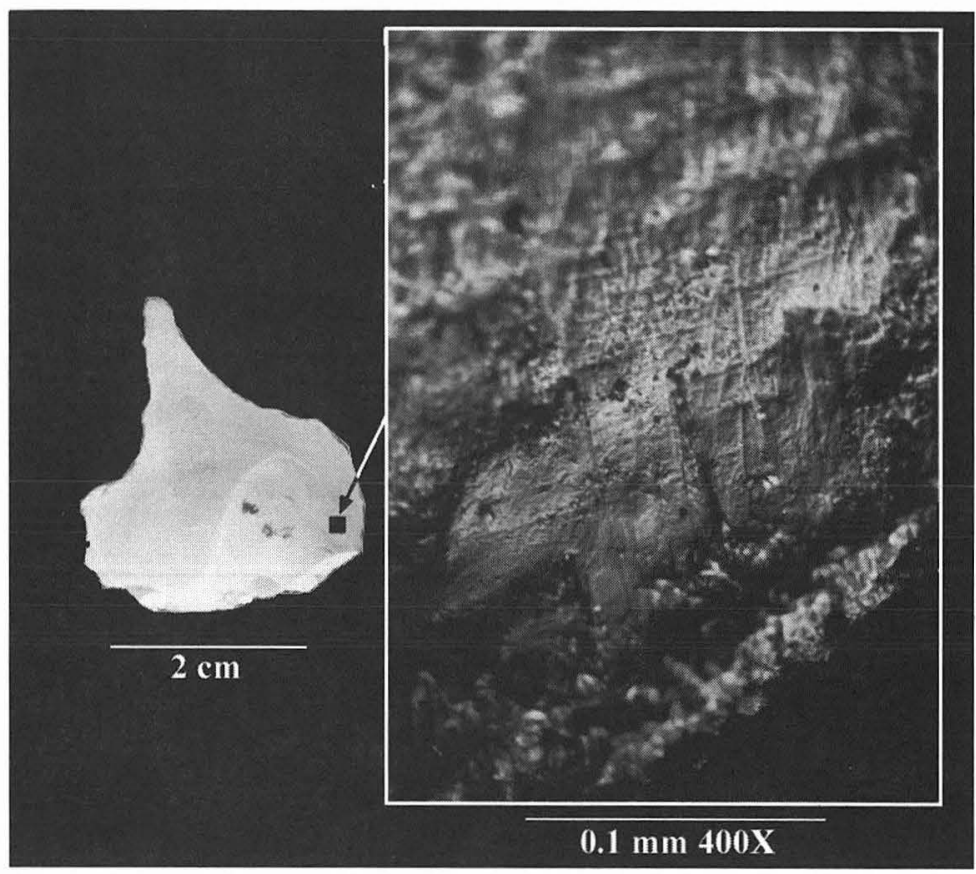

FIGURE 22-40. Laticework haft microwear on unifacial borer, Specimen 30T1C-1.

zarre (see Figure 22-47a). Originally side or corner notched then broken just below the shoulder, it is also notched on one side only above the break. There is no evidence of basal fluting. The artifact's biconvex cross section, high width to thickness ratio ( $>6: 1)$, and pattern of primary flake scars intersecting about the midline are all reminiscent, however, of an early Paleoindian specialized biface technology geared not for weaponry but knives. The most elegant expression of this technol- ogy is the Folsom ultrathin biface (Kay 1995; Root 1994a, 1994b). Potlid fractures, heat crazing, and the dull luster of all flake scars indicate thermal fracture followed manufacture or other optional modifications. There is no microwear evidence, however, associated with the potlid scars and, thus, it is reasonable to assume thermal fracture led to the point's discard. Wear traces originate at the blade edges but are highly invasive and best expressed on the surface of the point; these indicate usage as a knife, most likely a butchering tool. Complementary striation patterns of multiple cutting strokes indicate tool movement both parallel to the blade edges and more-or-less perpendicular to them (Figure 22-48). The area immediately above the notch (see Figure 22-48a) has the exact same perpendicular to the edge striation pattern as a second completely separate area (see Figure 22-48b). But there is no use-wear at the notch edge. Hence, it appears this edge modification occurred after the initial shoulder break and was a further attempt to notch the point. A latticework striation pattern (Figure 22-48c) is similar to haft wear traces noted on the drills and perforators (see Figures 22-12, $22-36 \mathrm{~b}, 22-40$ ). The striations parallel to the longitudinal axis of the point at this location and above the notch on the opposite edge also share the same general orientation. Rehafting after the stem broke is indicated.

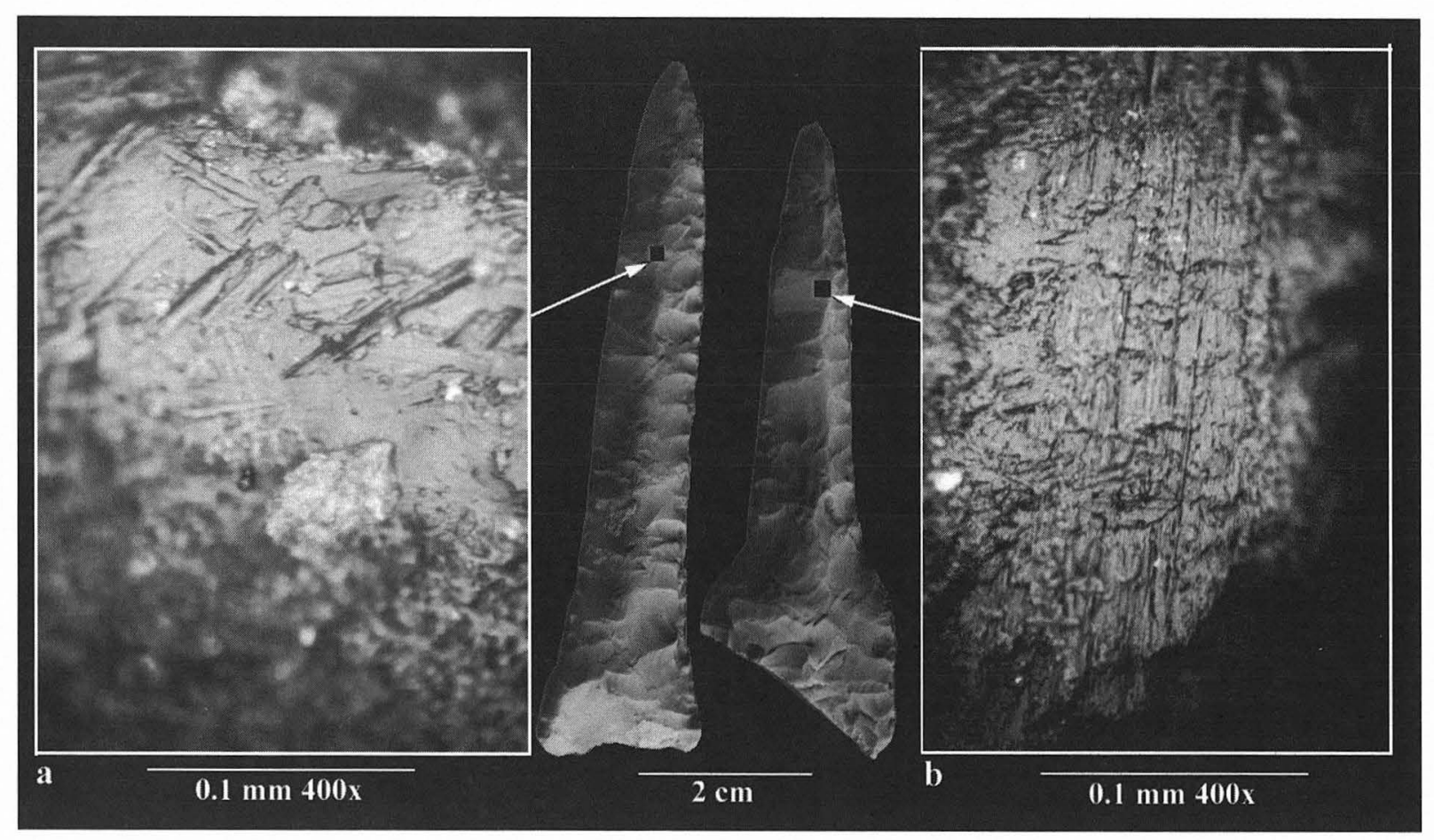

FIGURE 22-41. Microwear on (a) bifacial knife, Specimen 32W1B-1; (b) awl, Specimen 26U1B-3. 


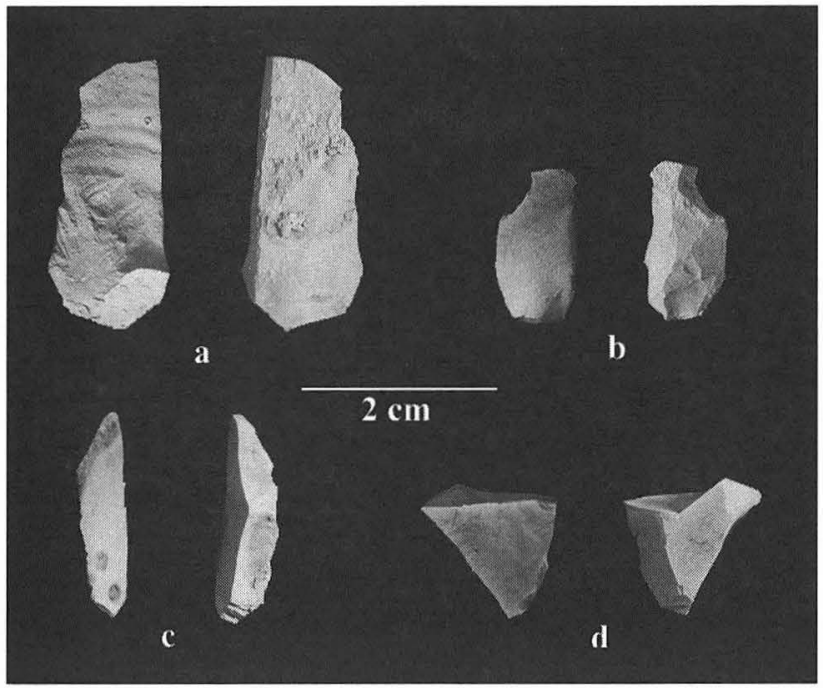

FIGURE 22-42. Small unmodified flake knives.

The Bone Bed point is an extremely thin ( $4.1 \mathrm{~mm}$ maximum thickness) lanceolate with well-executed collateral secondary flaking and a concave base. Lateral and basal edges of the haft element were carefully and extensively ground. Basal fluting was not attempted. The point tip and most of the right blade edge are missing, due at least in part to impact fracturing. The right blade edge may have been deliberately removed, however, by a burin blow to the tip impact break. Deliberately removed or not, the right edge angle is obtuse, consistent with other Wilson-Leonard burins.

Microwear examination clearly shows point recycling. Initial use was as a projectile point that resulted in impact striae about $18^{\circ}$ off the longitudinal axis (Figure 22-49a) and impact breakage: a glancing rather than straight-on blow to the tip is indicated. The tool was then used as a meat knife (Figure 22-49a) and lastly as a burin to cut or saw hard material such as bone, antler, or hardwood (Figure 22-49b). Haft wear traces (Figure 22-49c) include extensive arris rounding and a final series of secondary striae whose orientation is consistent with impact (see Figure 22-49a). At about a $43^{\circ}$ diagonal angle to these are nearly filled-in striae. These may represent an earlier episode of glancing projectile point impact damage.

\section{WILSON AND OTHER EXPANDING STEM POINTS}

Nine stemmed, or corner notched, specimens are included. All are distinctly shouldered and have (or originally had) symmetrical triangular blades. The blade on the largest specimens is over five times as long as the haft element length. A similar point from stratigraphically above the Wilson component lacks the typical haft element grinding and is classified as expanding stem straight base (Figure 22-50d). The nine are functionally subdivided according to wear traces into two main groups. The first are four specimens (Figure 22-50) whose longitudinal sections taper to the base and thicken to a maximum just before plunging to the tip. They show uniform use-wear. Micropolishes have striae oriented to the tool longitudinal axis and originating at the tip crosscut by ones that originate at the blade edges (Figure 22-51). These initially were used as projectile points and then recycled as knives. They have well-maintained blade edges unifacially resharpened and creating an alternating left lateral bevel. The alternating unifacial resharpening is not merely an approach that requires less effort than would

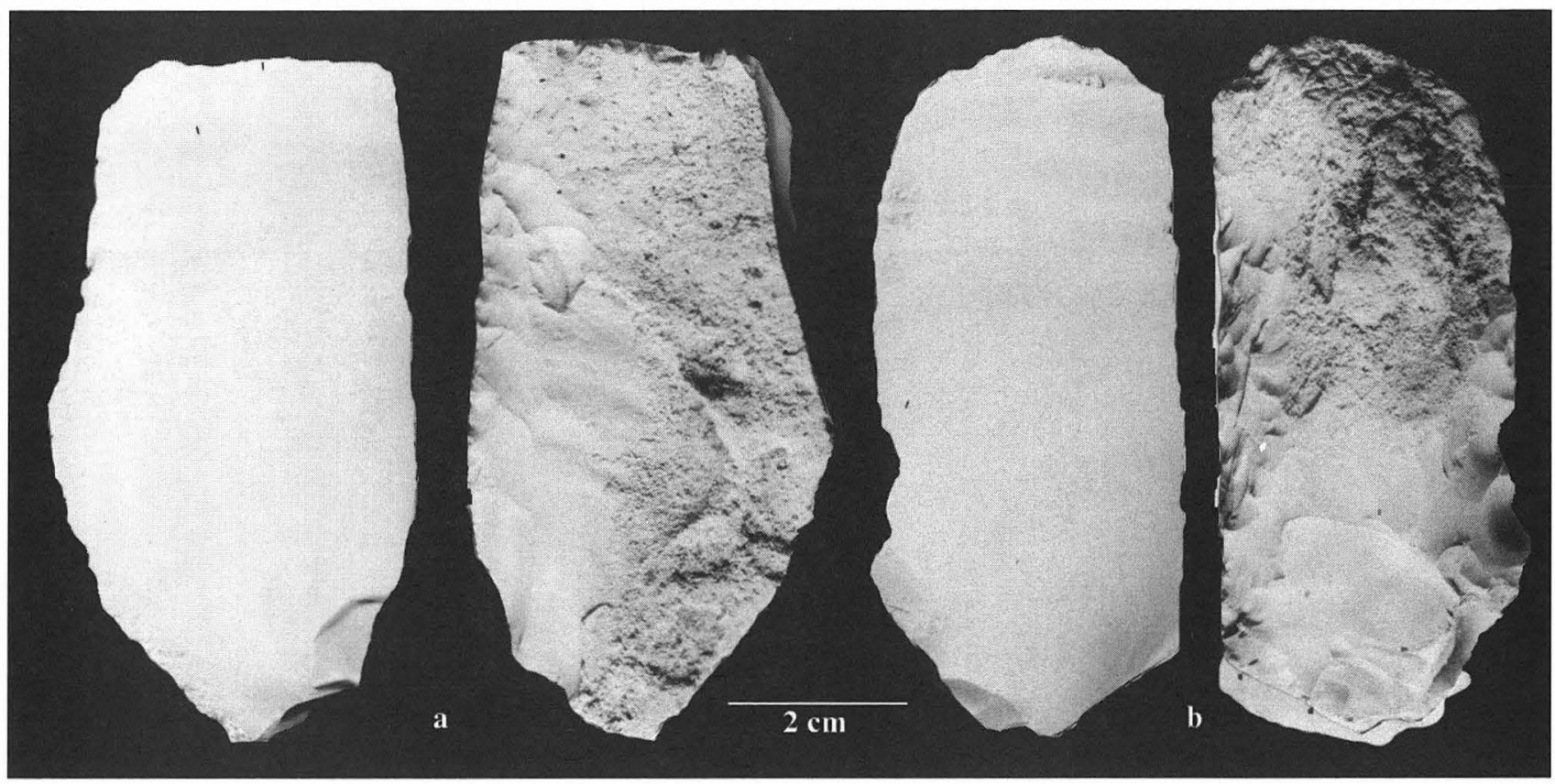

FIGURE 22-43. Unifacial retouch backed knives. Specimen numbers: (a) 33Q2-15; (b) 3462C-3. 


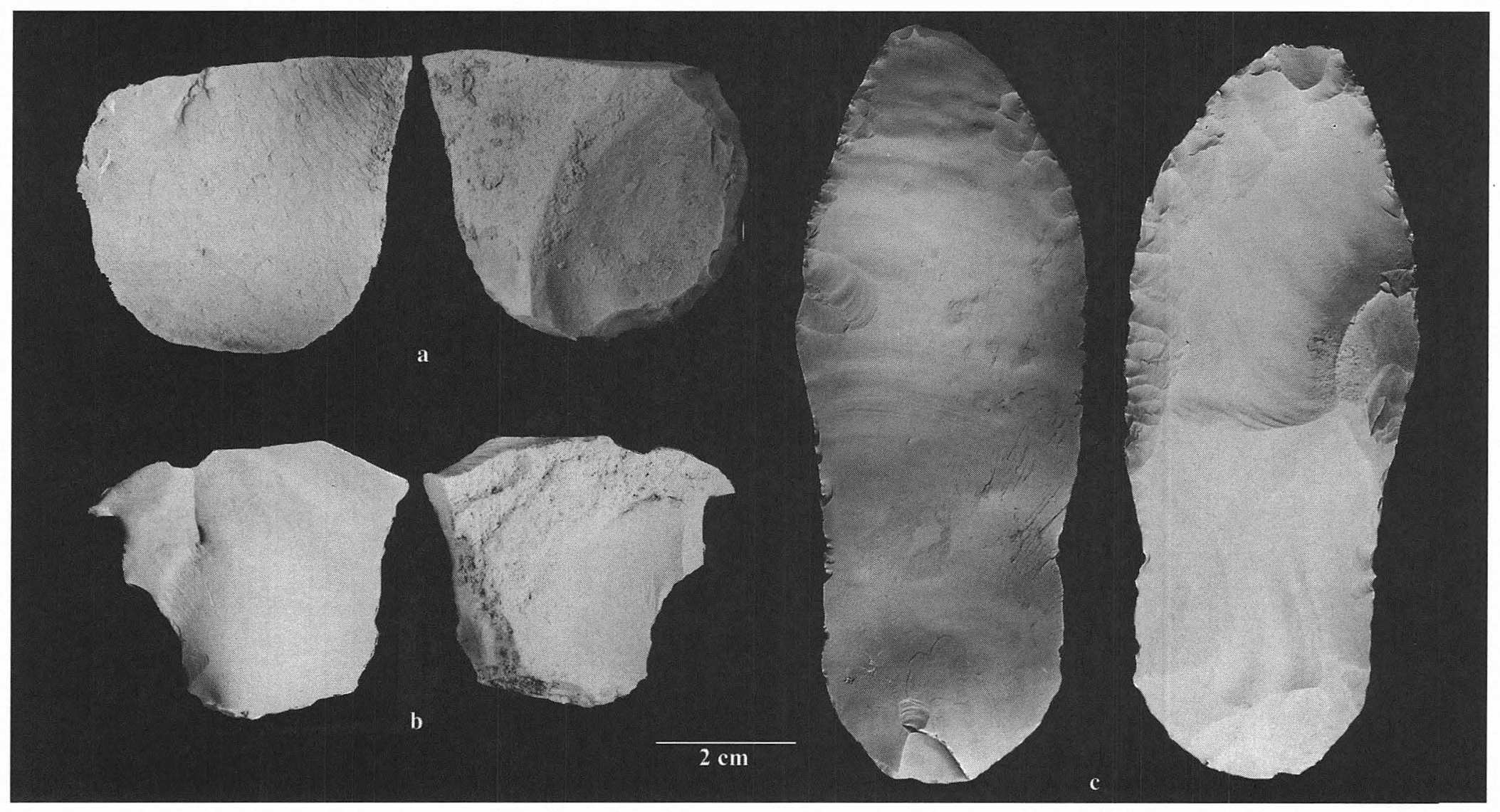

Figure 22-44. Retouched flake artifacts. (a-b) tools (see also Figure 22-28); (c) preform. Specimen numbers: (a) 14FF1B-1; (b) 37LA-5; (c) 36E-23. 


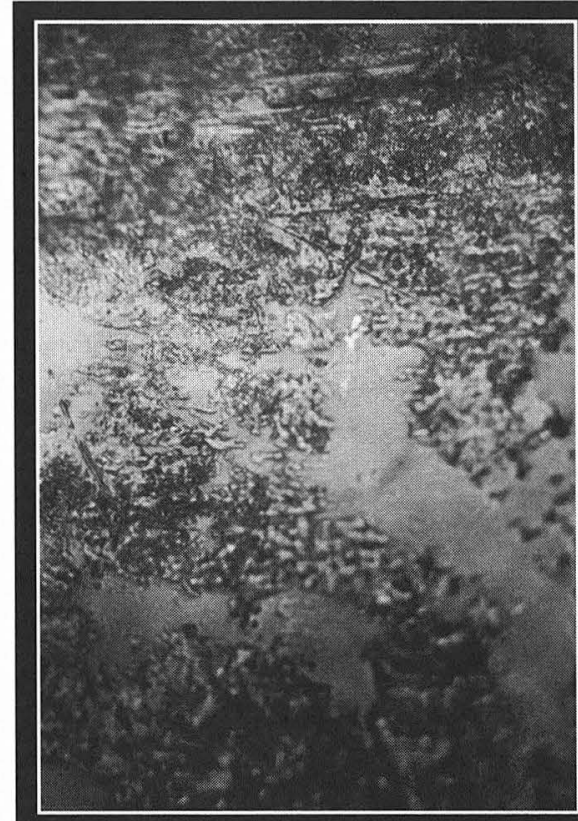

a

$0.1 \mathrm{~mm} 400 \mathrm{X}$

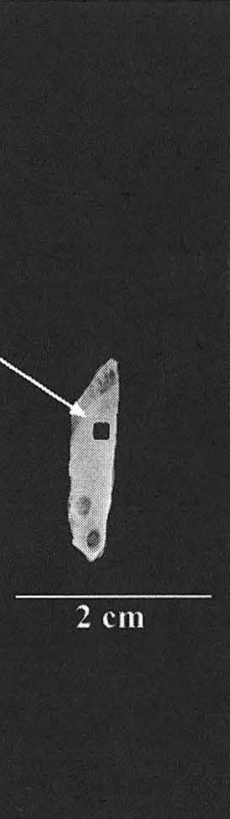

b

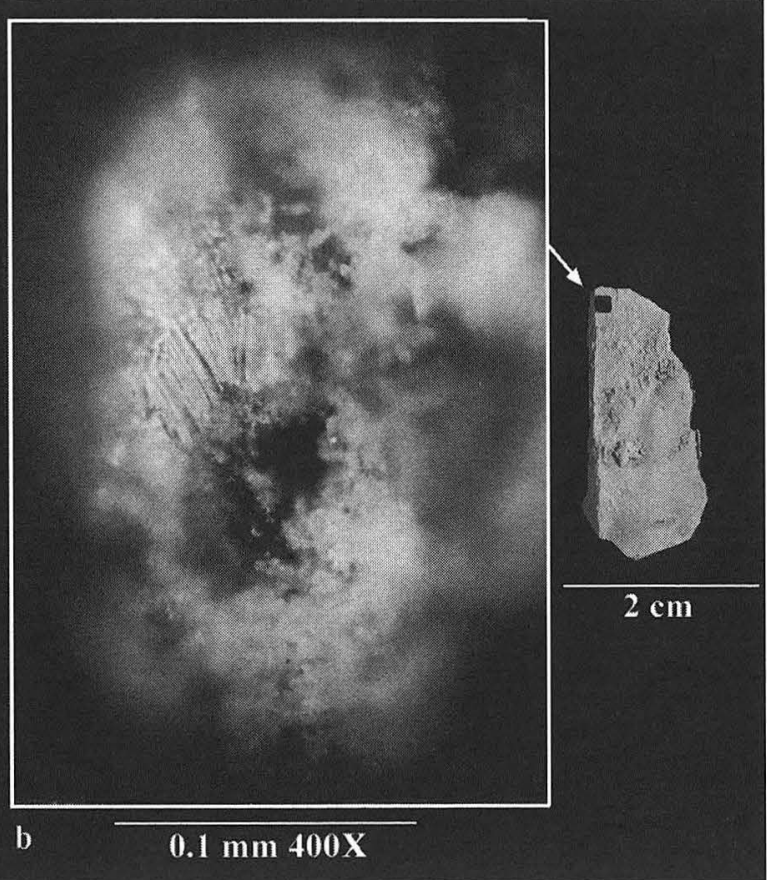

FIGURE 22-45. Invasive abrasive microwear on small unifacial knives.
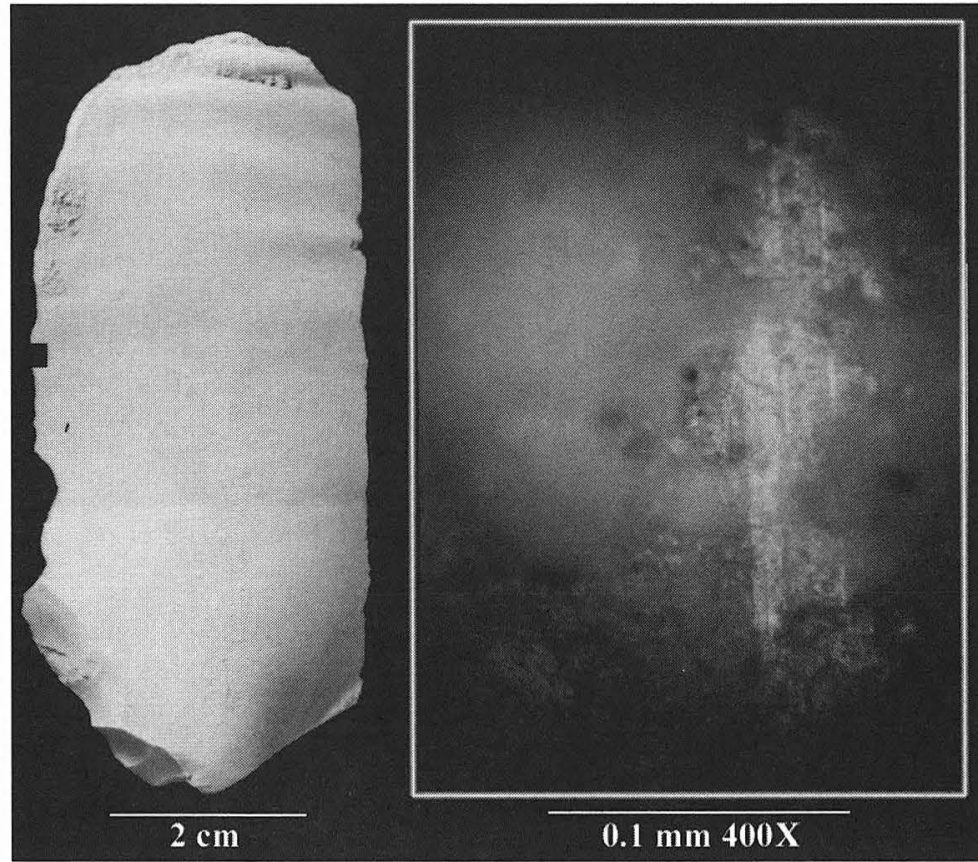

FIGURE 22-46. Abrasive microwear on retouched edge of backed unifacial knife, Specimen 3462C-3.

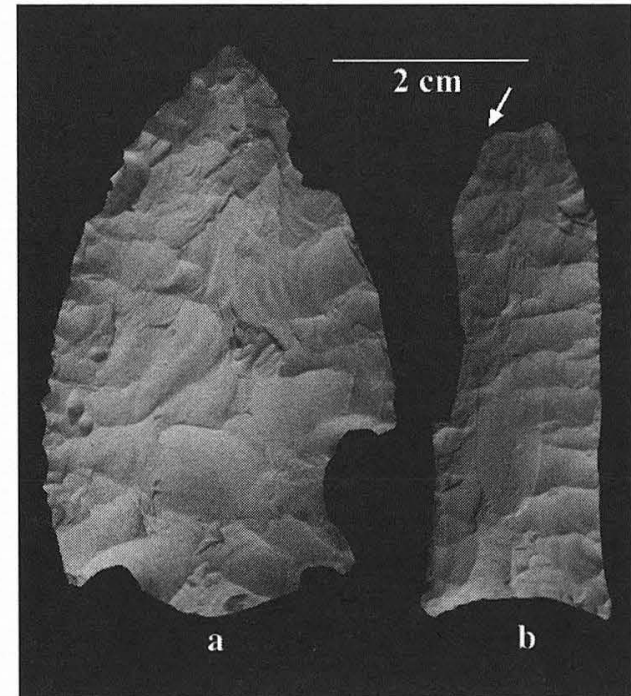

Figure 22-47. Reverse sides of (a) Leanne soil knife point, Specimen OR680; (b) early Bone Bed point, Specimen 17JJ2KK1-3. be true for further bifacial edge maintenance (Sollberger 1971). It also would be less costly in two ways: (1) it would extend the serviceable life of the cutting edge by requiring less of it to be removed when resharpened, and (2) it would result in a reciprocating pattern of use of all potential cutting edges and consequently fewer changes in motor habits to effectively employ the tool.
These points appear to have been rejects (or discards) as opposed to still functional tools. The longest artifact (see Figure 22-50a) has a shoulder removed. The broadest and next in length (see Figure 22-50b) is heat damaged in an identical fashion as the unusual thin, notched point (see Figure 22-47a). Neither of the other two specimens is as wide as the longest, and one has an impact damaged tip (see 


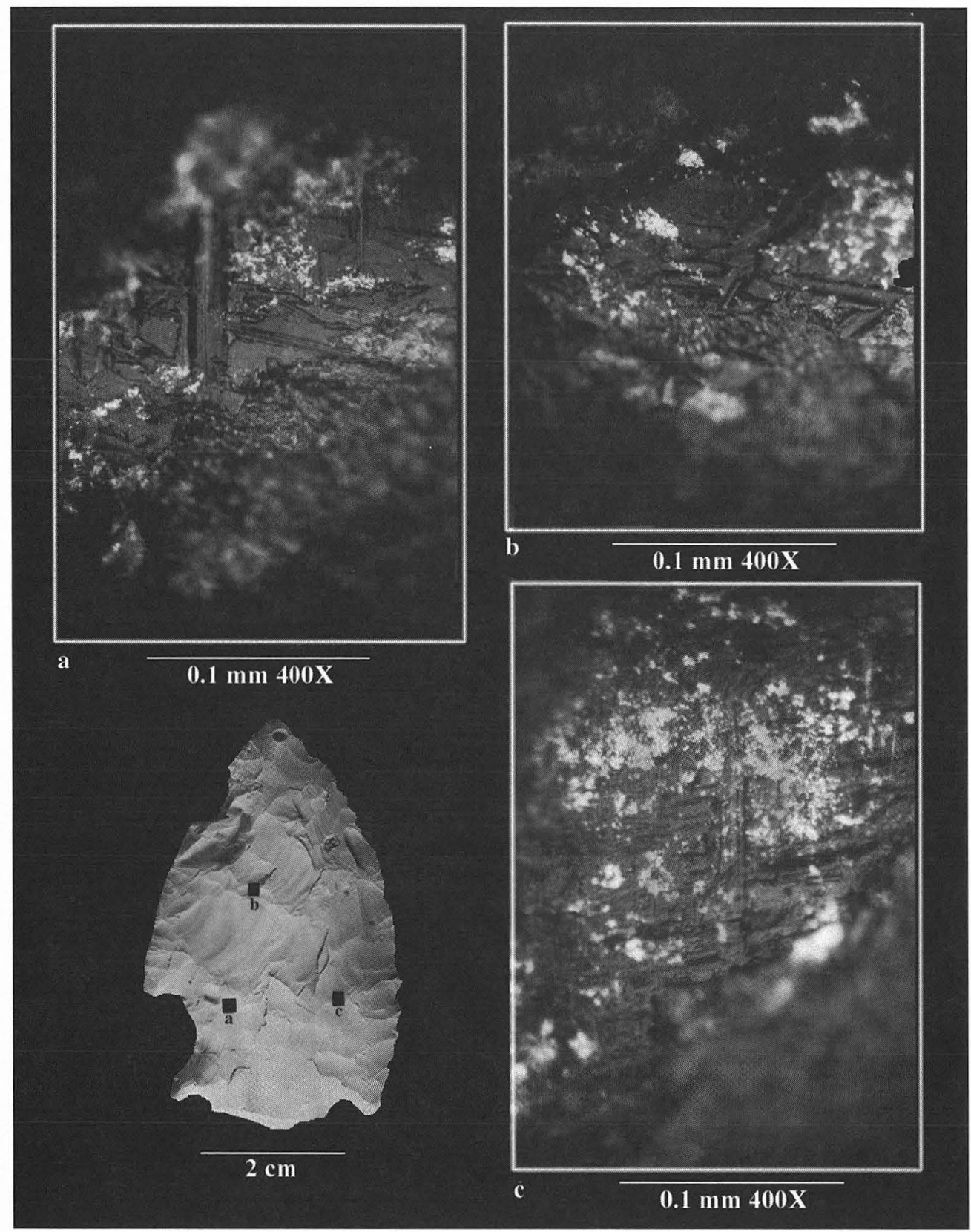

FIGURE 22-48. Additive microwear on obverse side of Leanne soil knife point, Specimen OR680. Specimen was wrapped in aluminum foil, and aluminum residue adheres to the surface in all three photomicrographs. Compare (c) with Figures 22-36 and 22-40.

Figure 22-49c). Continued blade resharpening apparently was not an option for any of the points, either because of thermal fracture or because they were simply too narrow.

The second group includes all other Wilson and expanding stem points. These had more complex use histories. One is a projectile point ultimately recycled as a burin (33EE1C-1) already described; the other four are presented in Figure 22-52. Of the remainder, one (see Figure 22-52d) is virtually identical to the first group, except that it has been repointed. Its basal end has impact scars (on the face extending up the blade element near the right edge), and its maximum thickness is at the midline in the shoulder area, two key bits of evidence of reversing the ends after the tip had broken off. Its maximum blade width is less than that of the thermally fractured point from the first group, and probably it too had reached its limit for successful resharpening. Another has wear traces indicative of initial use as a knife followed by impact striae (Figure 22-53) and is the logical opposite of the first group. Its blade edges differ dramatically in that it was not unifacially resharpened and the right edge is extensively damaged. It appears to have been lost or discarded after tip impact breakage occurred. The 


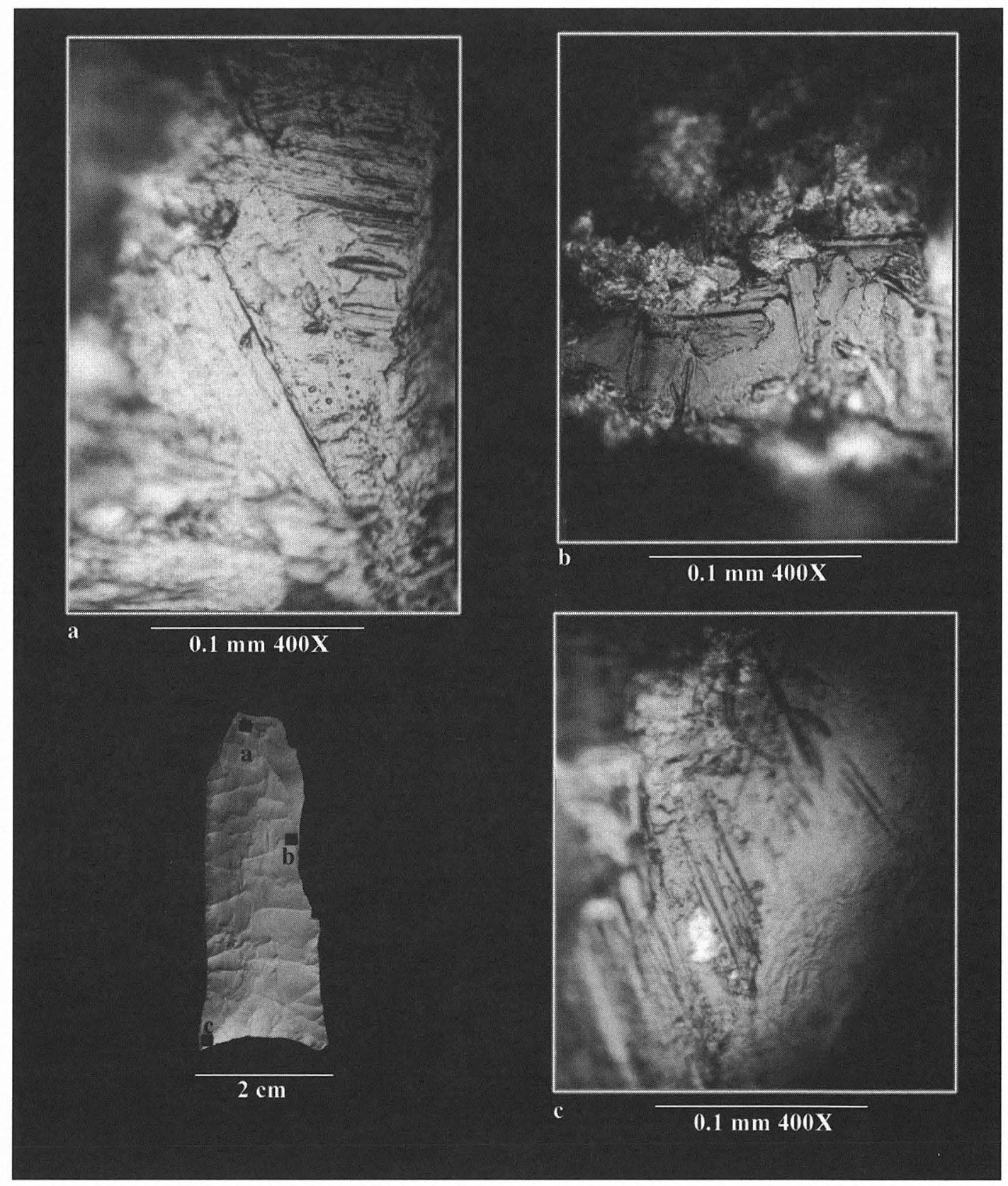

FIGURE 22-49. Additive microwear on obverse side of early Bone Bed point, Specimen 17JJ2KK1-3. Compare (b) with Figure 22-21. Note filled in impact (a) or impact-related (c) striae.

smallest Wilson point contrasts in that its blade element must have been repeatedly resharpened. It also has the most extensive and complex haft wear (Figure 22-54). Usage was as both a projectile and a knife but without any easy way to establish which occurred first. The final Wilson point was resharpened as a scraper. The surface adjacent to but on the opposite side of the scraping edge was also used in a sweeping, back-and-forth lateral scraping motion with force applied perpendicular to the surface (Figure 22-55). The most likely contact material would have been animal skin or hide stretched and held against a hard backing.

\section{GOLONDRINA-BARBER}

The three remaining Golondrina-Barber points (two burins are previously described) differ in design features from the Wilson points. Aside from being true lanceolates, the typical Golondrina-Barber point longitudinal section is more lozenge shaped, or biconvex. Maximum thickness is along the midline in approximately the middle of the point, and it tapers to either end. Blade edges do not exhibit alternate unifacial resharpening. Lateral grinding of the base extends to the point of maximum blade width, or approximately one-third to one-half the total length on these three 


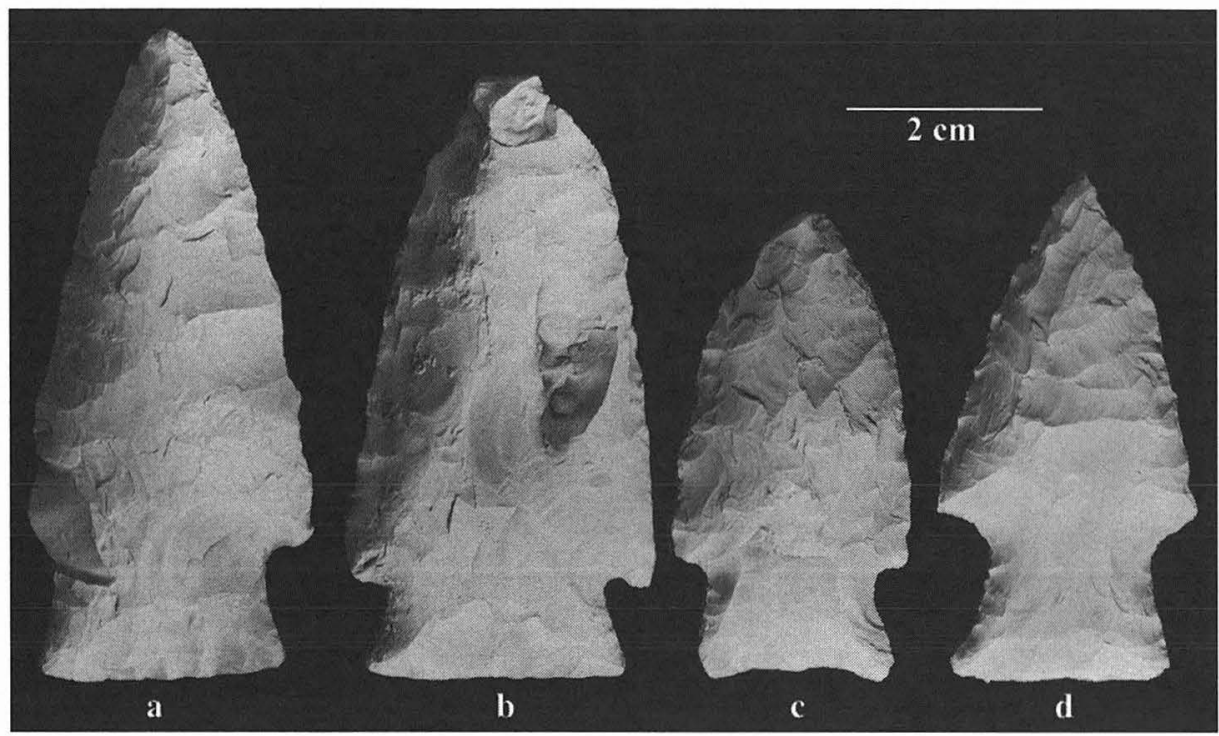

FIGURE 22-50. Discarded Wilson and Wilson-like (d) projectile points recycled as knives. Specimen numbers: (a) 28Y2C-1; (b) 32DD1B-1; (c) 28Y2D-2; (d) 50MA-1.

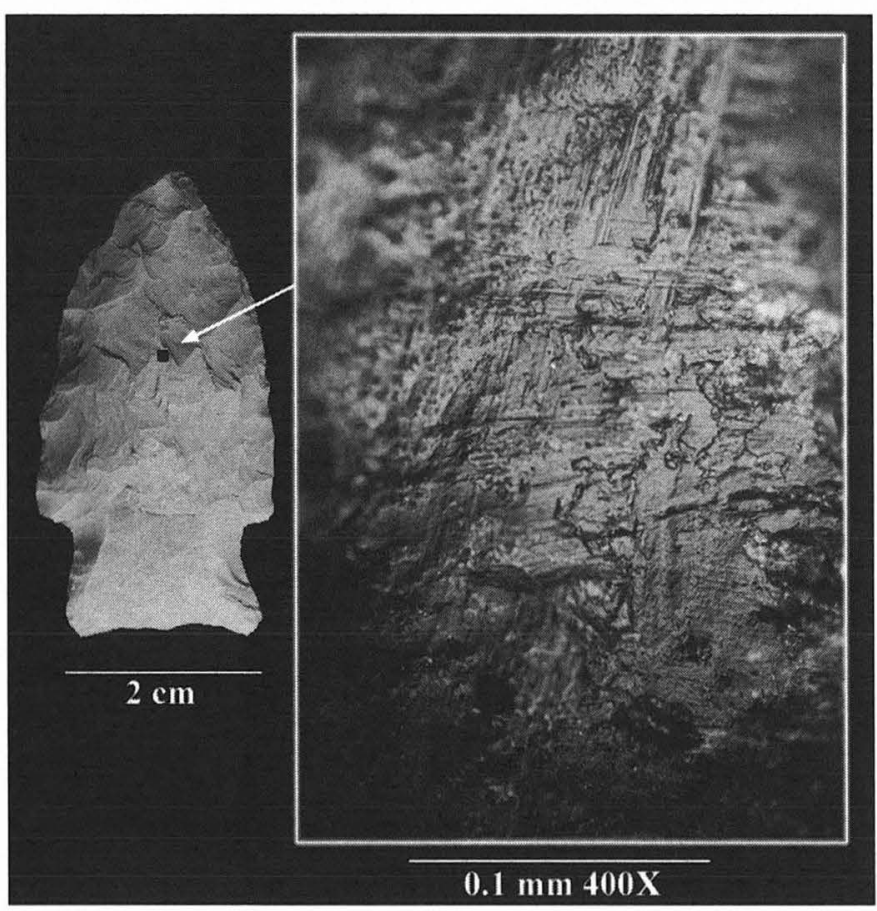

FIGURE 22-51. Wilson additive microwear showing sequential use as a projectile point then knife, Specimen 28Y2D-2. Compare with Figure 22-41b.

specimens. (This is also the case for one [see Figure 22-19b] but not the other [see Figure 22-17b] of the points recycled as burins; the latter appears to have had substantial reworking of blade margins.) Golondrina-Barber contrasts significantly from Wilson in haft to blade element proportions.

Wear traces describe a Golondrina-Barber use-history group that began as knives and ended as projectile points (Figure 22$56 \mathrm{a}, \mathrm{b}$ ) and one (Figure 22-56c) that began either as a projectile point or a knife and ended as a projectile point. The differences in point length are probably due to optional bifacial resharpening of the blade. Each specimen has tip impact damage that should have been easily repaired. They may have been lost as opposed to discarded. The microwear showing initial use as a knife followed by recycling as a projectile point (Figure 22-57) is remarkably similar to one of the Wilson points (see Figure 2253); whereas microplating (Figure 22-58) makes it impossible to judge if another Golondrina-Barber point was a knife or projectile point first-although both uses occurred. Even though the five are but a small sample, the overall impression is still that the Wilson-Leonard Golondrina-Barber point was designed initially as a knife.

\section{PARALLEL-SIDEDLANCEOLATE AND ST. MARY'S HALL}

Parallel-sided and similar in longitudinal section (i.e., relatively thin and almost flat with uniform thickness), these two point types contrast in blade width, thickness, and in basal shape (i.e., the St. Mary's Hall has a concave base). The St. Mary's Hall's haft element would have been longer, as its base is more extensive in its lateral edge grinding. The parallel-sided lanceolate is broader, thicker, and invariably the blade has sustained a transverse fracture. The narrower St. Mary's Hall point typically has an impact fractured tip, although the largest one is transversely fractured. These obvious differences are further borne out by systematic contrasts in microwear that describe alternate - and perhaps equally unsuccessful-use histories. These distinctions, to my way of thinking and as 


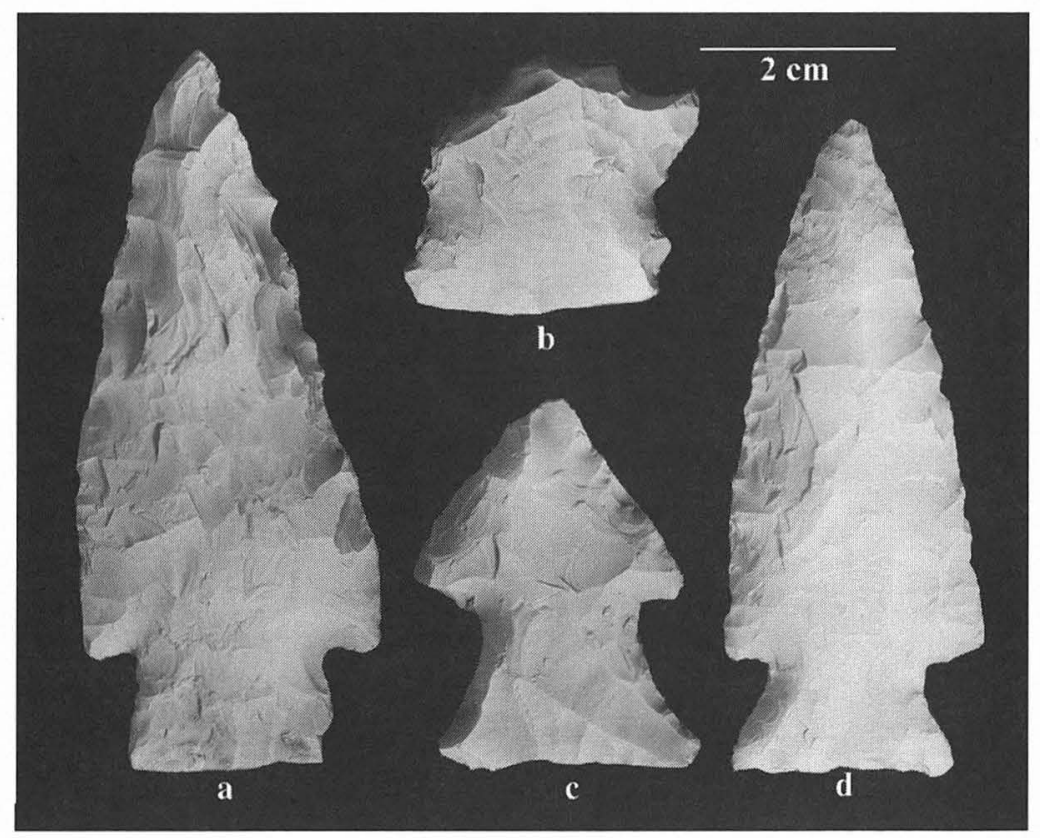

FIGURE 22-52. Recycled and probably discarded Wilson points. (a knife point recycled as a projectile point; (b) recycled as a scraper; (c) extensively resharpened; (d) repointed and reused as a projectile point and then recycled as a knife. Specimen numbers: (a) 30CC2A-1; (b) 17AA2-2; (c) 20X-1; (d) 9V-1.

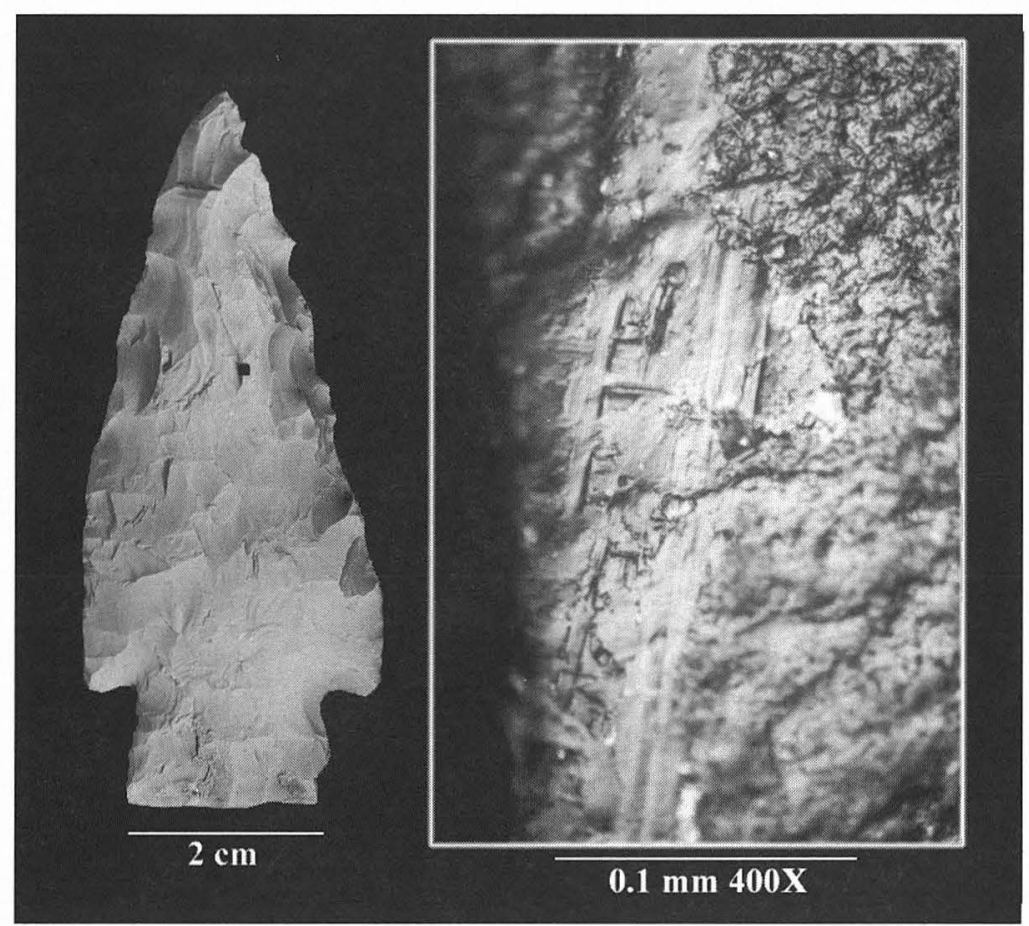

FIGURE 22-53. Wilson additive microwear showing sequential use as a knife point then projectile point, Specimen 30CC2A-1.

Miller (1980) argued for another technological complex, however, do not suggest discretely different point types but use-related contrasts in a single production strategy. The emphasis and initial attempt probably began with the production from flake blanks of relatively large but thin, parallel-sided flat bifaces with a square base. As need or circumstance dictated, these could have been easily transformed either directly into the two point types or from the larger parallel-sided lanceolate into the smaller St. Mary's Hall. 


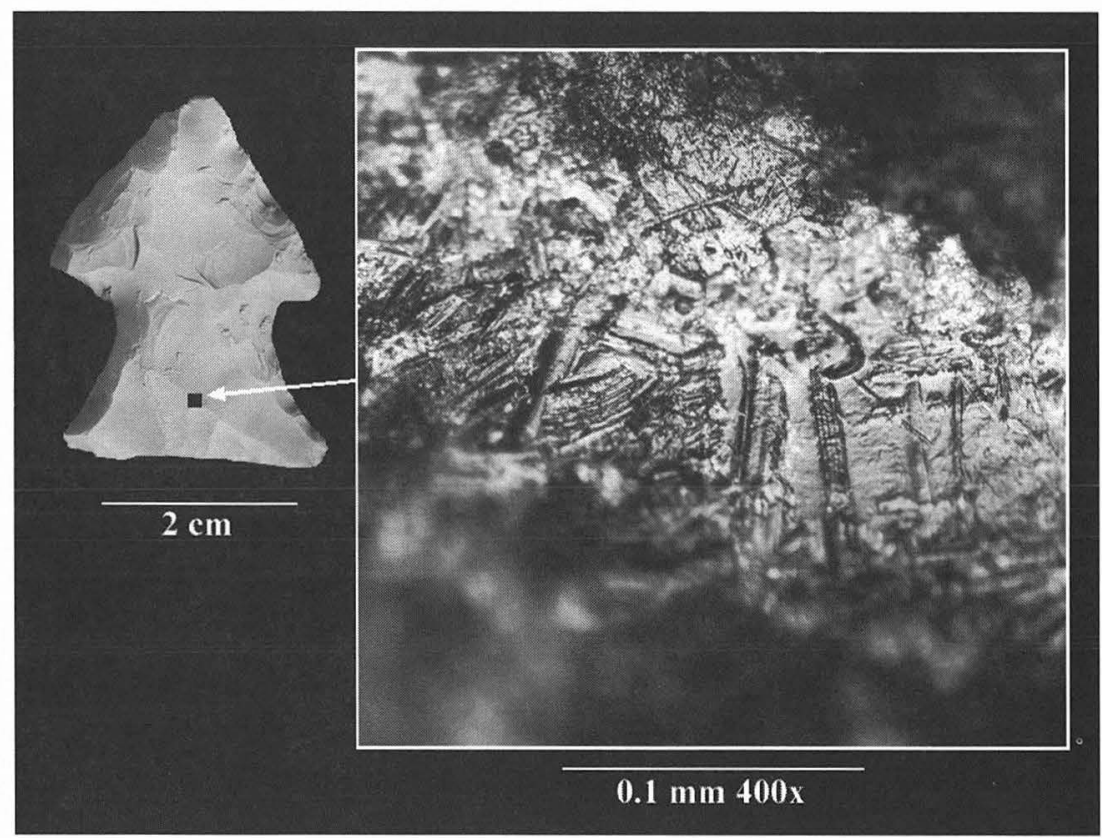

FIGURE 22-54. Complex additive microwear on haft element for extensively resharpened Wilson point, Specimen $20 \mathrm{X}-1$, in which projectile point/knife sequence could not be established.

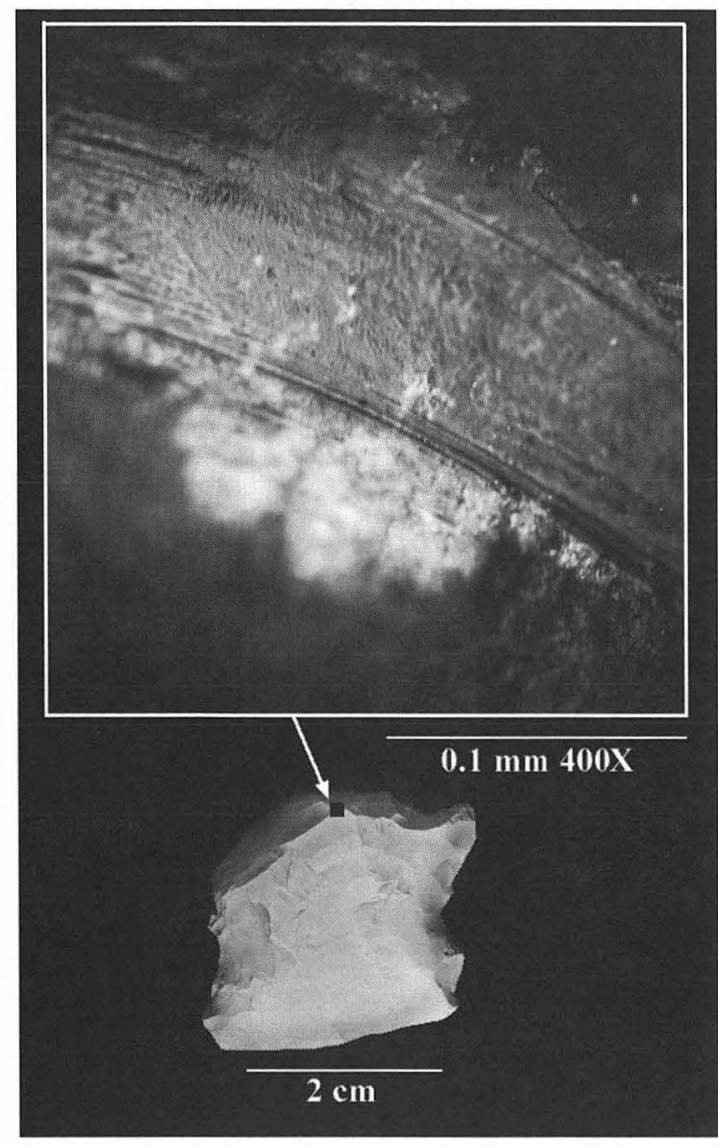

Figure 22-55. Additive microwear on a Wilson point recycled as a scraper, Specimen 17AA2-2. Note the recrystallization of filaments.

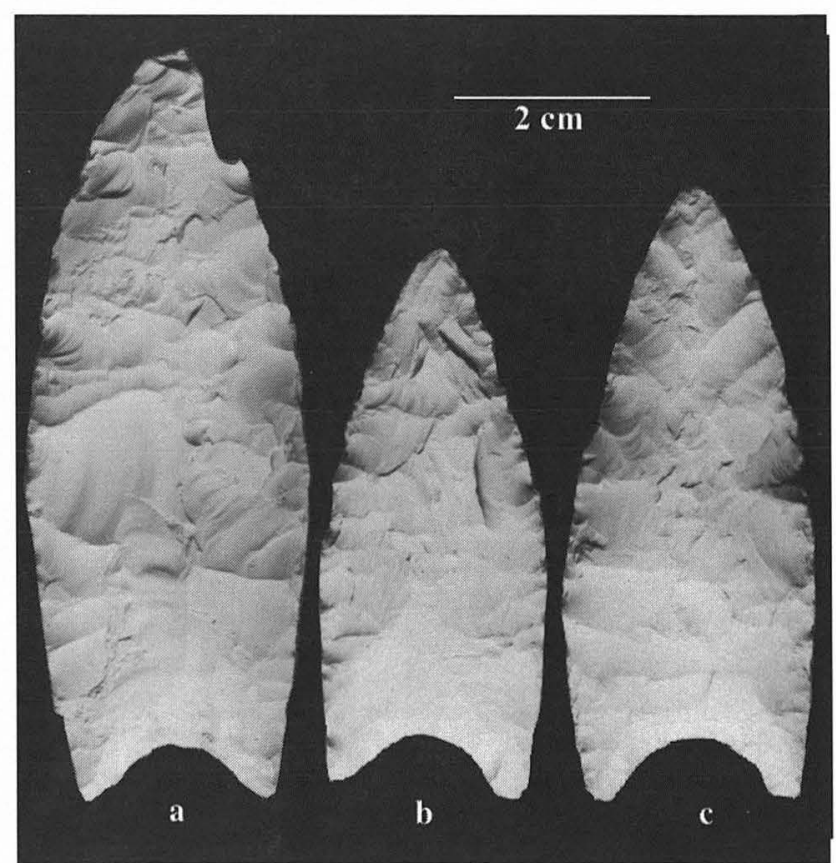

FIGURE 22-56. Golondrina-Barber knife points $(\mathrm{a}, \mathrm{b})$ or probable knife point (c). Specimen numbers: (a) 15Y1-1; (b) 50YA-1; (c) 15X1-1. 


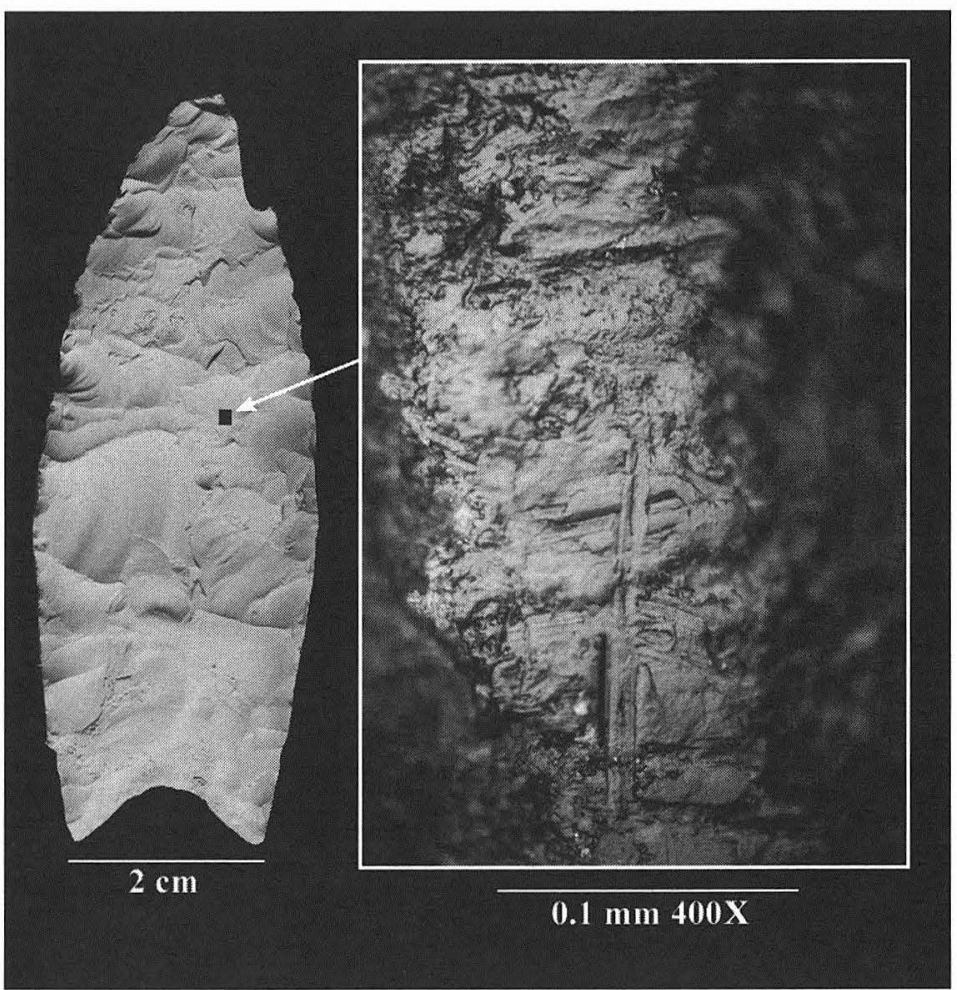

FIGURE 22-57. Golondrina-Barber additive microwear showing sequence of knife point then projectile point usage, Specimen 15Y1-1. Compare with Figure 22-53.

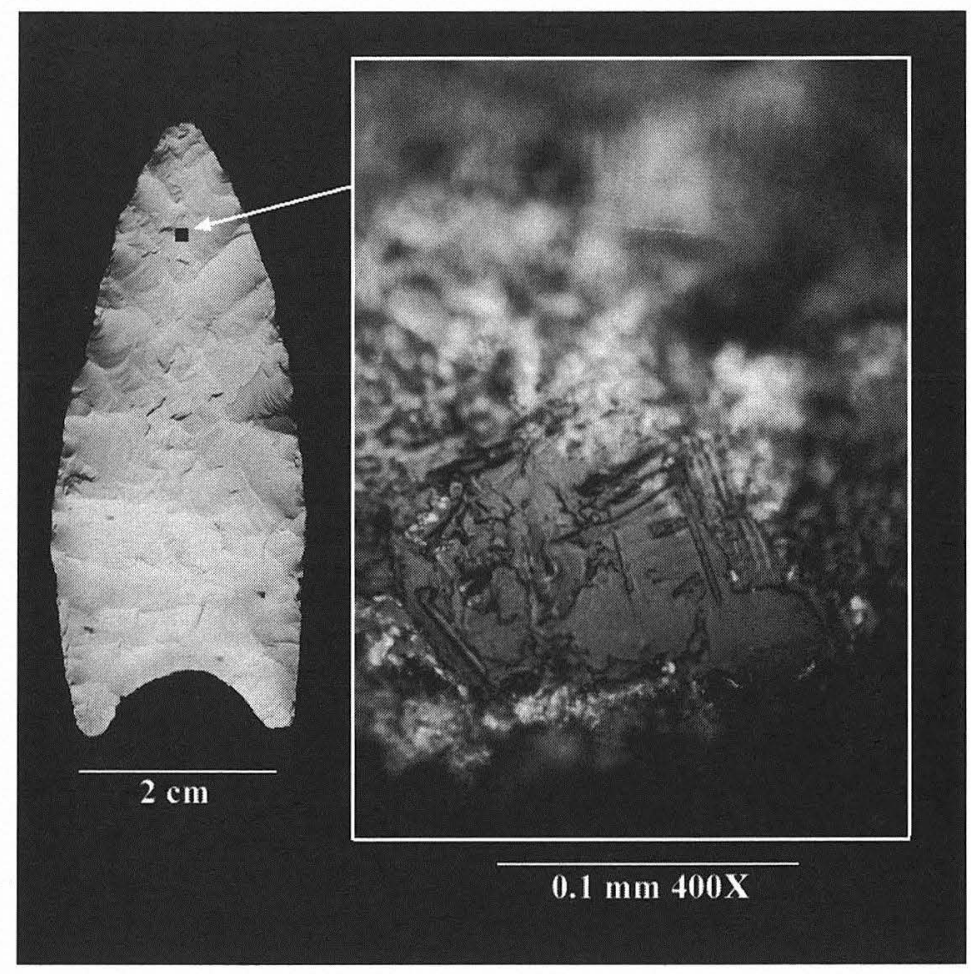

FIGURE 22-58. Golondrina-Barber additive microwear for which projectile point/knife sequence could not be established, Specimen 15X1-1.
Functionally diagnostic are the systemic differences in blade width and edge angle. The parallel-sided lanceolates were designed to be knives, as wear traces demonstrate (Figures 22-59b, 2260 ). Their greater width would have facilitated prolonged bifacial resharpening and maintenance of lateral edge angles that are generally less than $62^{\circ}$. In contrast, the St. Mary's Hall edge angles are generally above $70^{\circ}$. The steeper angle afforded a "tougher" edge for these tools designed as projectile points and only incidentally used as knives (see Figures 22-14, 22-59c; Figure 22-61). Thus, even the largest parallel-sided lanceolate that lacks use-wear (Figure 22-59a) can be characterized as an unused knife on the basis of overall proportions and edge angles. Undoubtedly it was discarded because of thermal fracture prior to use. This logic applies in reverse to the other three smaller but extensively used St. Mary's Hall projectile points with perverse impact fractures (Figure $22-59 \mathrm{~d}, \mathrm{e})$ or an alternate left lateral unifacial bevel (Figure 22-59f): the three appear to be unserviceable discards because blade length and fractures would have made further repair impractical. The polarized blade edge angles for the two lanceolate types describe a functional continuum of no small heuristic potential.

Cutting use-wear often was coincident with a transverse snap, or bending break, of the blade (see Figures 22-14, 22-60, 22-61). Blade edge repair was a paramount concern, if only for the parallelsided lanceolate (as noted for a "burin facet" on the left lateral edge [see Figure 22-60 at "v"]). Even following a transverse snap, the parallel-sided lanceolate continued to function. Due to the extensive damage to the St. Mary's Hall points, this relation is not as clear-cut except as it pertains to the largest specimen whose total length is comparable to the broken but continued to be used parallelsided lanceolates. Used initially as a projectile, this point's characteristic transverse snap, or bending break, came either just prior to or when used as a cutting tool. The break itself, in this instance, was insufficient to cause rejection as the St. Mary's Hall point was being used in essence as a parallelsided lanceolate, thus supporting if not actually proving the transformable nature of the two types. Its massive potlid fractures are indicative of heat-induced material failure likely to have caused the point's discard. The potlid fractures are presumed to be a byproduct of intentional but unsuccessful heat treatment, a retipping preparatory step as opposed to accidental heat damage. Otherwise, it surely would have been repointed and reused as was true for the smaller St. Mary's Hall points. The 


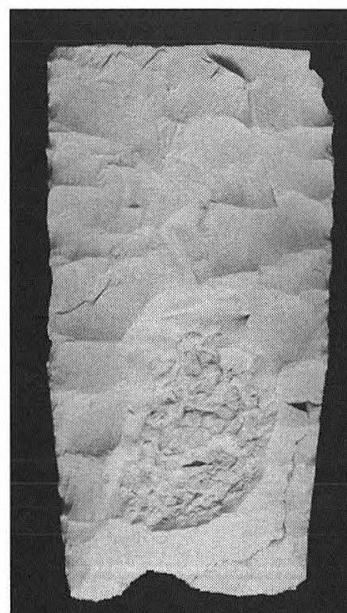

a

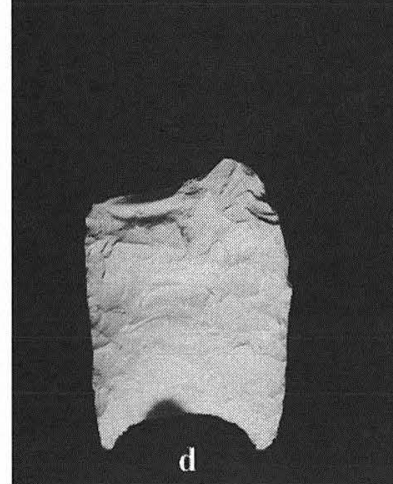

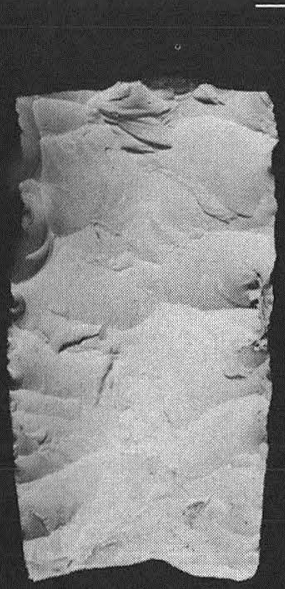

b

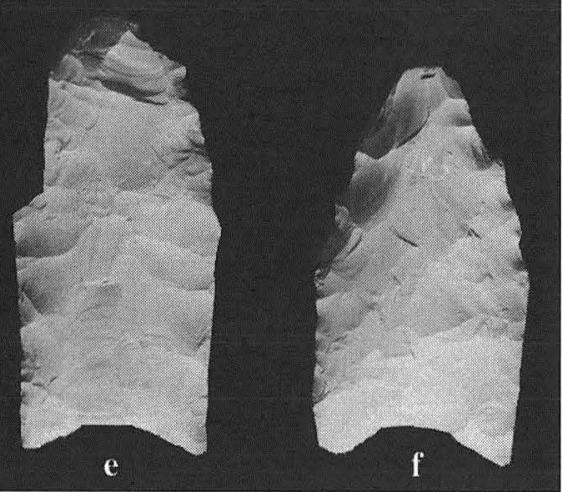

FIGURE 22-59. Parallel-sided lanceolate knives (a, b) and St. Mary's Hall projectile points (c-f). Specimen numbers: (a) 25V1C-1; (b) 26X2A-1; (c) 20W-1; (d) 50XD-1; (e) 25U2-1; (f) 7Q-1.

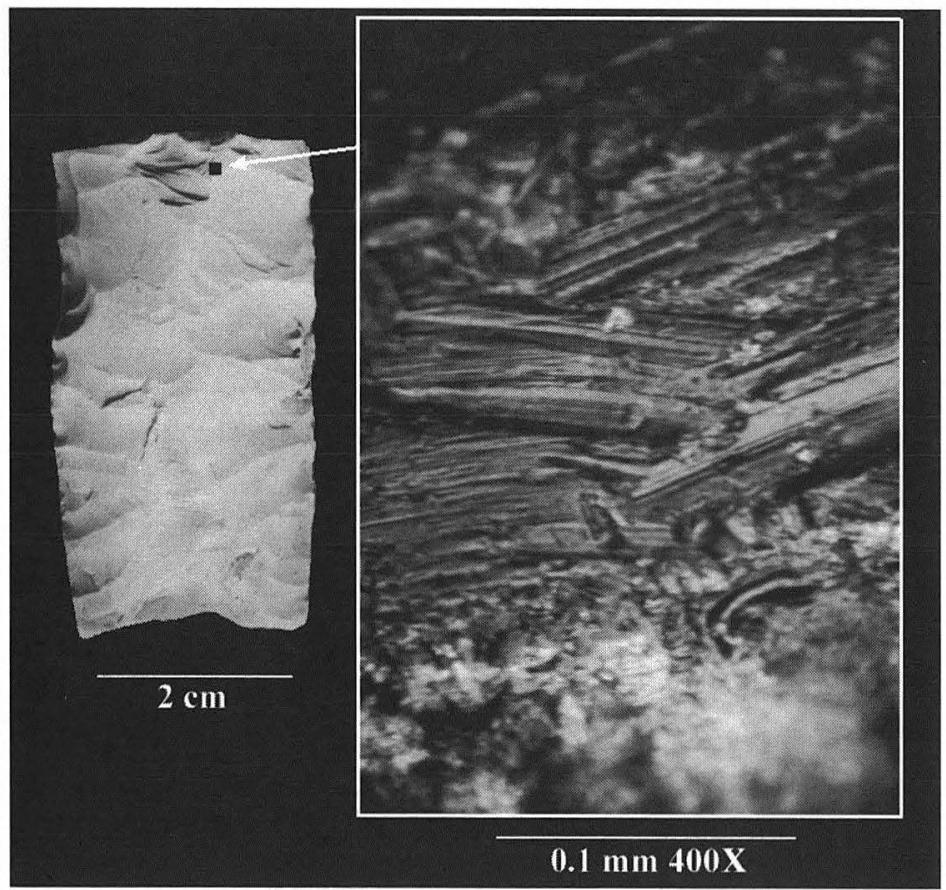

FIGURE 22-60. Parallel-sided lanceolate knife additive microwear with repair of left blade edge following breakage (at "v"), Specimen 26X2A-1. Usage continued after the break. major weakness of either type of point was truly a structural one: its thin, parallel-sided longitudinal section almost ensured the point would be prone to a bending break when, in killing an animal or butchering its carcass, it was accidentally levered against a bone.

\section{ANGOSTURA}

Angostura represents a logical progression in knife technology. The four specimens examined (Figure 22-62) are similar in longitudinal shape to the parallel-sided lanceolate and St. Mary's Hall points but are intermediate in average thickness between the two. They are elliptical, or leaf-shaped lanceolates, as opposed to being parallel sided; the two largest complete specimens (see Figure 22$62 \mathrm{a}, \mathrm{b}$ ) have serrated symmetrical blade edges that converge to the tip. Resharpening on these two specimens followed the material conservative Wilson point approach of alternating unifacial retouch, but contrasts in creating a right lateral bevel. One specimen is asymmetrical in form and was bifacially resharpened (see Figure 22-62d). The blade element of the last specimen (see Figure 22-62c) is missing but its base most closely resembles the two largest specimens. The rounded point tips for all three complete specimens exhibit, at low-power magnification, use-related crushing, or microstep fractures, due to contact with relatively hard materials. The uniformity of tip crushing suggests all three were designed to pry into or to withstand the shock of incidental contact with hard material. Blade use-wear for the three specimens is equally consistent. The basic pattern is that of repeated long-term usage as a cutting tool (Figure 22-63). Substantial microplating and recrystallization unequivocally document that the cutting stroke originated at the resharpened serrated edge. Striae at an oblique angle to the blade edge are invasive and carry over to the midline. Other striae oriented parallel to the longitudinal axis originate at the tip. These are indicative of tip penetration, if not projectile point usage. These striae are consistent with tip crushing and both crosscut the initial cutting use-wear and are followed by further cutting wear traces. Initial usage was as a knife, followed by either usage as a projectile point or by jabbing with the tip (the more likely as discussed below), and then returning to a knife.

In light of the microwear evidence, the original blade form may be reconstructed as a serrated meat knife whose convex edges converged to a rounded tip and with a blade to haft element length ratio of about 3:1. The four specimens (see Figure 


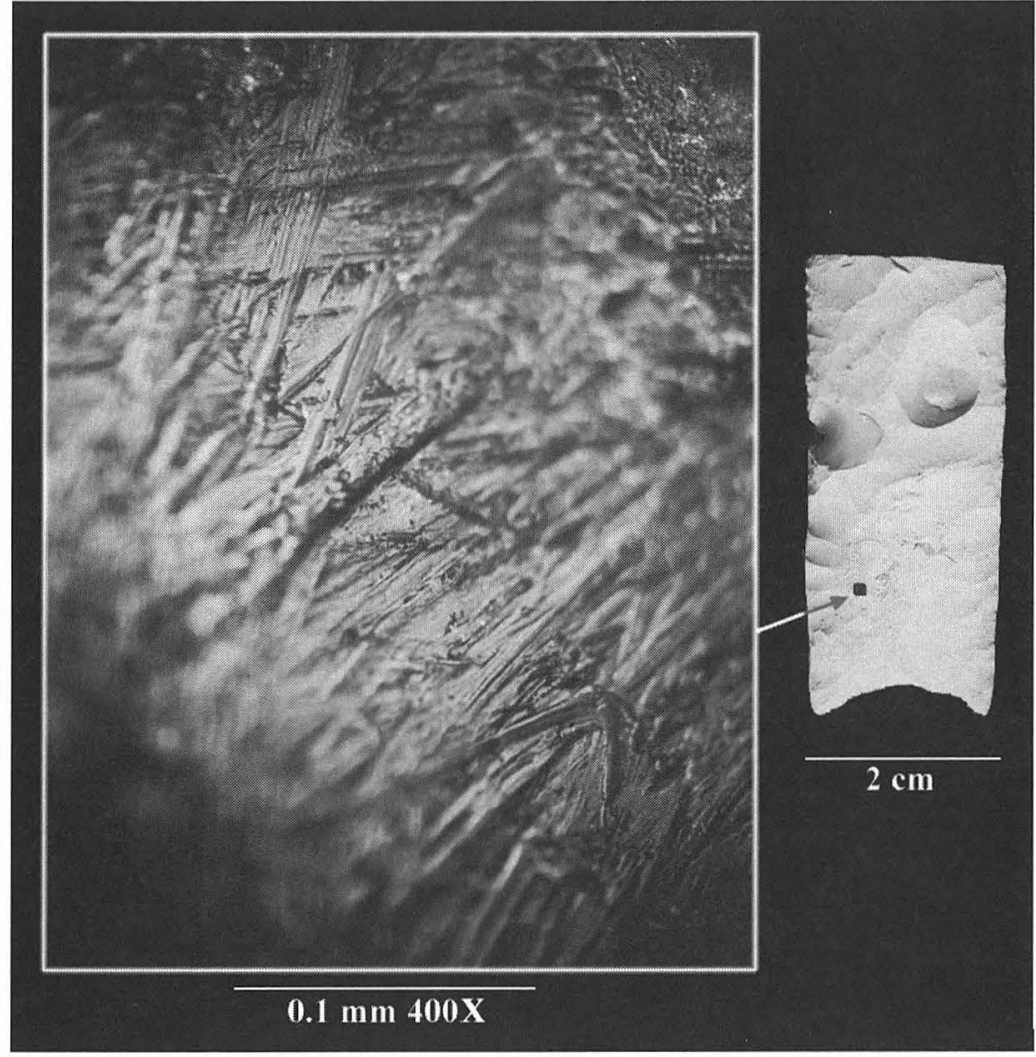

FIGURE 22-61. St. Mary's Hall haft microwear showing secondary effects of sequential use as, first, projectile (the vertically oriented striae overriding the horizontal ones) and then as knife (the crisscrossing obliquely oriented striae overriding the vertically oriented striae), Specimen 20W-1. See also Figure 22-14, which shows the same sequence and indicates usage continued after the break; compare with Figure 22-54.

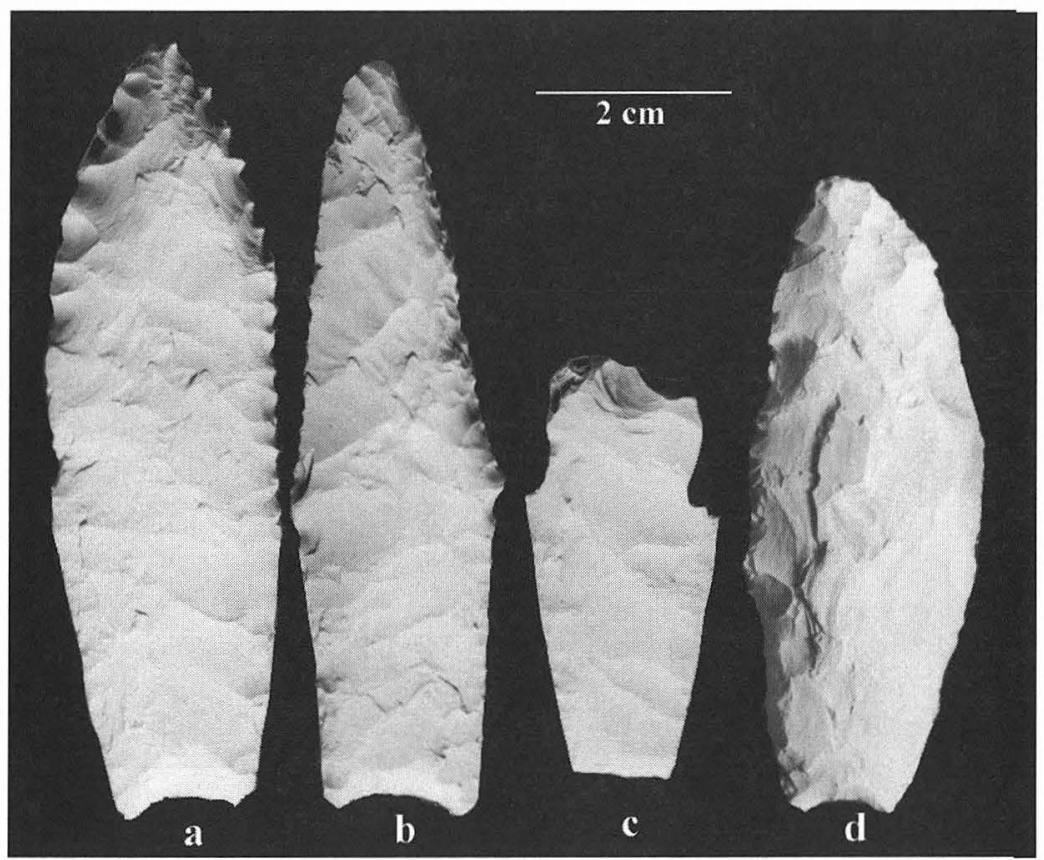

FIGURE 22-62. Angostura knife points. (a, b) appear to be still serviceable and may have been lost; (c, d) unserviceable and probably discarded. Specimen numbers: (a) 25R1-1; (b) 11Q-1; (c) 16.S2-1; (d) 29T1C-1.
22-62) show linear effects of blade use and resharpening: alternate unifacial beveling or blade element asymmetry are clear evidence of resharpening; serrations the relative state of blade maintenance and use. Not by accident is the largest specimen also the one with the most conspicuous blade serrations, or does resharpening result primarily in a reduction in blade width not length. Converging blade edges and tip rounding appear to confer other advantages, most likely to withstand end shock and blade failure resulting from bending breaks so common to the parallel-sided lanceolates. In contrast, the Angostura blade form appears to have been more successful. It better withstood incidental contact with bone in carcass butchering and was less prone to end shock failure. Although the similar longitudinal sections lessened drag per cutting stroke, serrations expanded the cutting surface of the blade edge per unit length, making the cutting stroke more efficient. The alternate unifacial resharpening maintained the serrated, converging-to-tip blade profile without unduly sacrificing essential blade length that ensured cutting efficiency.

The three complete Angostura points express a predictable gradient in blade form and length. Reductions in blade width due to alternating unifacial resharpening accommodated the need to maintain serrations, the converging-to-tip blade edges, tip rounding, and seemingly functional blade to haft element length ratios (2.8:1, $3: 1$, respectively) for the larger two. These two would appear to have been still serviceable. In addition to use-related differences in form and resharpening technique, the third complete specimen contrasts in having a smaller blade to haft element length ratio (2.6:1). Its blade serrations are nearly completely worn off. No further attempt was made to resharpen. It is more likely to have been a reject; its blade to haft element length ratio may express a lower boundary for use as a meat knife for Angostura.

\section{THRALL}

The Thrall point is another leaf-shaped lanceolate with a ground, concave base but differs substantially from Angostura. Thrall points are greater in thickness and lack blade serrations. Longitudinal section is biconvex 


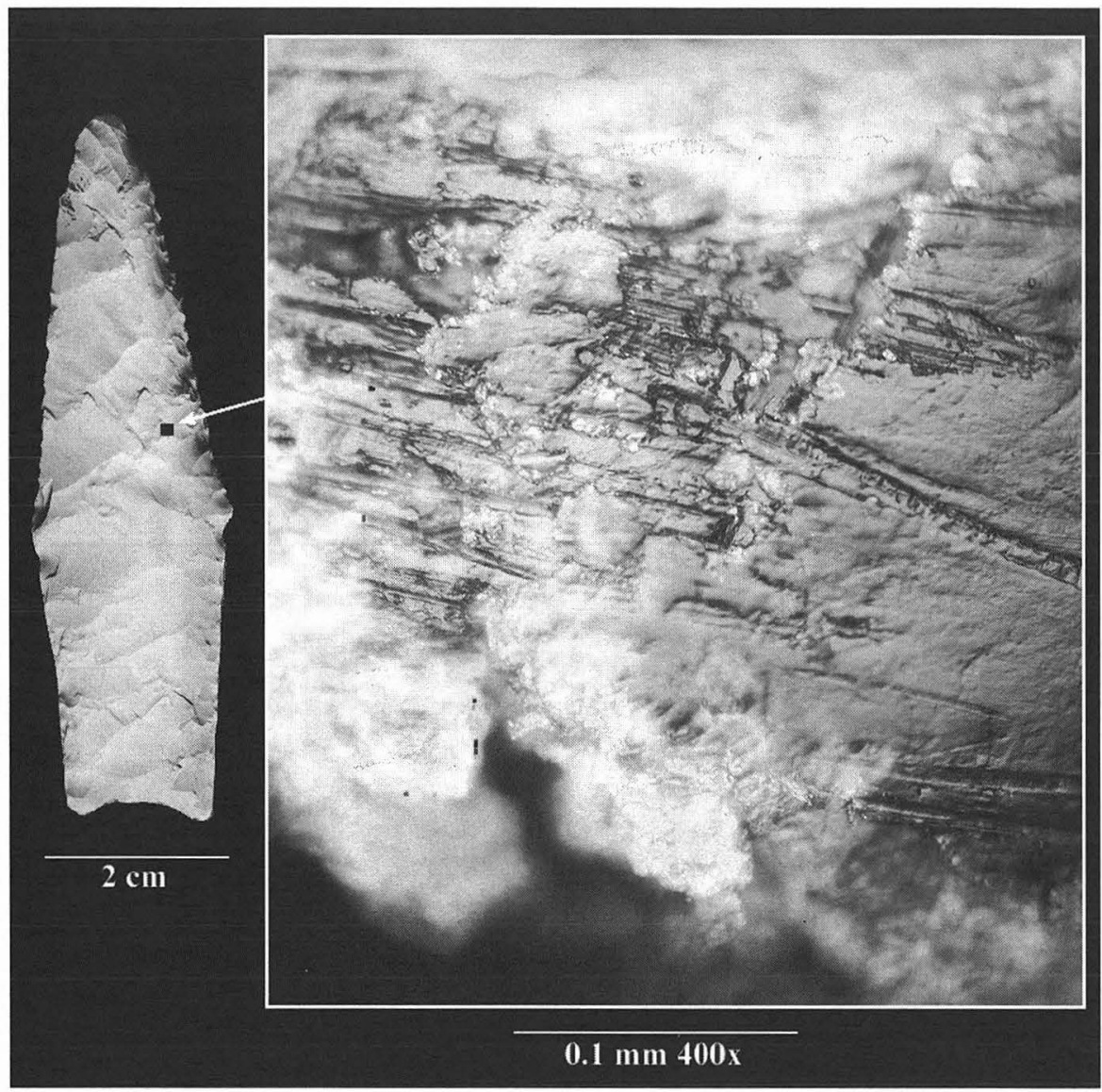

FIGURE 22-63. Angostura knife point invasive additive use-wear with extensive microplating, filling in of striae and recrystallization on trailing side, Specimen 11Q-1. See also Figure 22-15.

and attains maximum thickness coincident with maximum blade width, approximately one-quarter to one-third back from the tip. The proportional relationships of biconvex longitudinal section, maximum width and thickness well forward of the haft/blade element juncture (where Angostura maximum width occurs) suggest a frontally oriented penetrating wedge whose focus is the tip, not the lateral edges per se. This unserrated form, in combination with the impact fractures on each of the four specimens (Figure 22-64), seems to be entirely intentional. Indeed, it is totally consistent with the microwear evidence that suggests one and only one thing: Thrall is the ultimate projectile point technology of the Wilson-Leonard Paleoindian and Early Archaic point complex.

Although projectiles, it would be misleading to suggest they were only that. The extensively microplated microwear for all four tools is uniform in this respect and shows a characteristic cycling of projectile point:knife:projectile point usage. The most elemental of the microwear, however, is exhibited on the smallest (and most likely, most extensively reworked) specimen (Figure 22-65) that consists of the final episode of projectile point usage. The most complex microwear for the entire Wilson-Leonard collection is shown on a second extensively reworked Thrall point (Figure 22-
66) and records a series of projectile point:knife:projectile point episodes.

The impression one receives is that these, the most massive of Wilson-Leonard projectile points were employed in a more-or-less ad hoc fashion as butchering knives following a kill. An impact-damaged tip was repaired along with any needed changes in overall shape, and the tool was again employed as a projectile point. In a strict sense they were not recycled. They appear rather to have had an anticipated, or planned, use as a meat knife as circumstances dictated but without the efficiency imparted by a serrated edge. (However, for a projectile point an unserrated edge would reduce effective blade length and frictional drag; it would be the edge design of choice.) Knife use would have been incidental to its primary function as a projectile point.

The four Thrall points examined comprise two related microwear groups. The first describes a use-maintenance continuum of tip impact breakage and blade resharpening (see Figures 22-64a-c, 22-65, 22-66); the second, the reversal of ends and repointing of a broken blade element (see Figures 22-64d; Figure 22-67). In Figure 22-64, the first group is arranged in the order expectable from repeated resharpening of the broken tips and wear traces. For both groups, however, the overall reduction in blade length is accompanied 


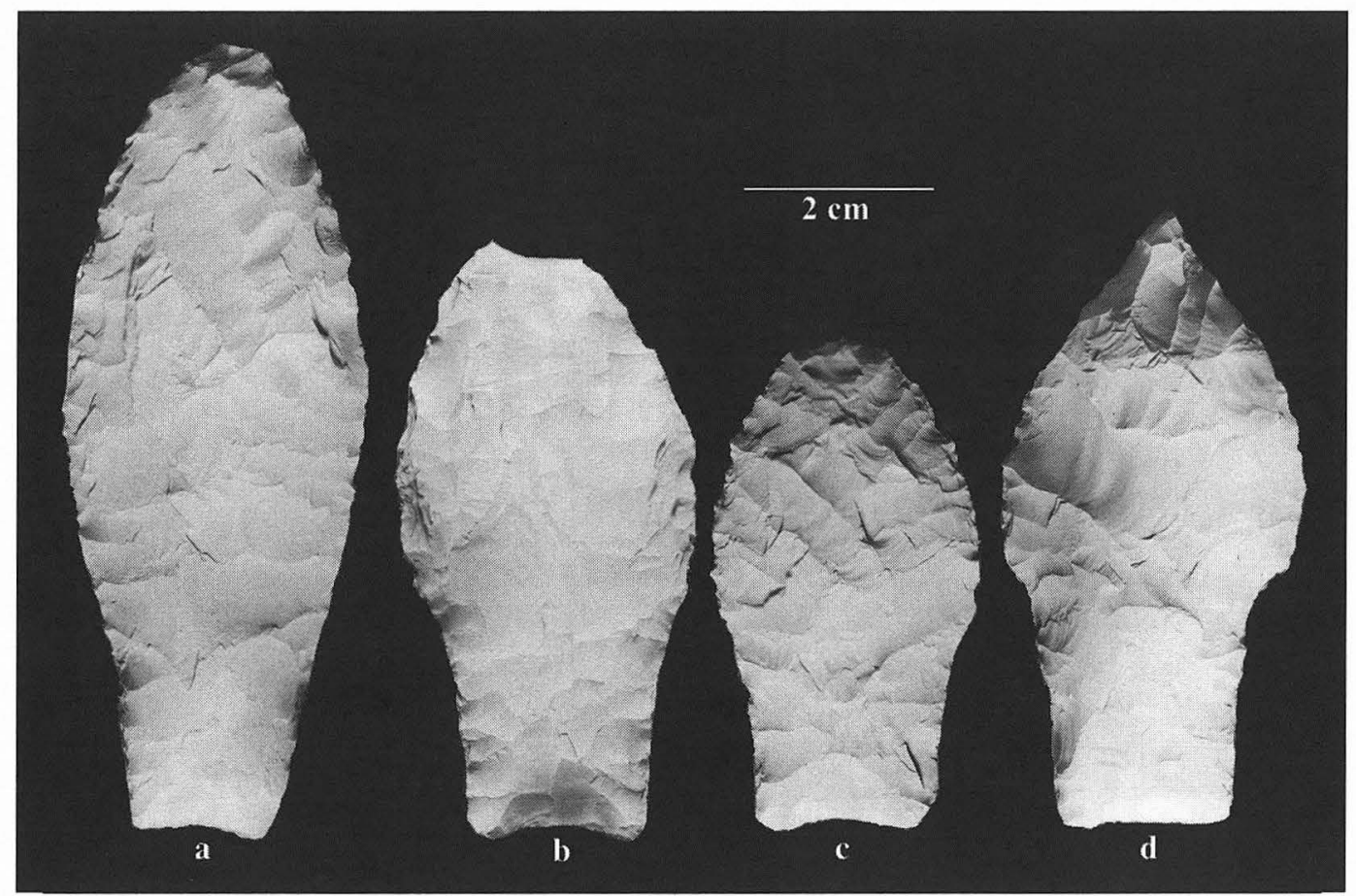

FIGURE 22-64. Thrall projectile points. (a-c) a resharpening sequence; (d) repointed. All appear to still have been repairable following impact fractures. Specimen numbers: (a) 19N-1; (b) 13N-2; (c) 31P1-1; (d) 31R1-1.

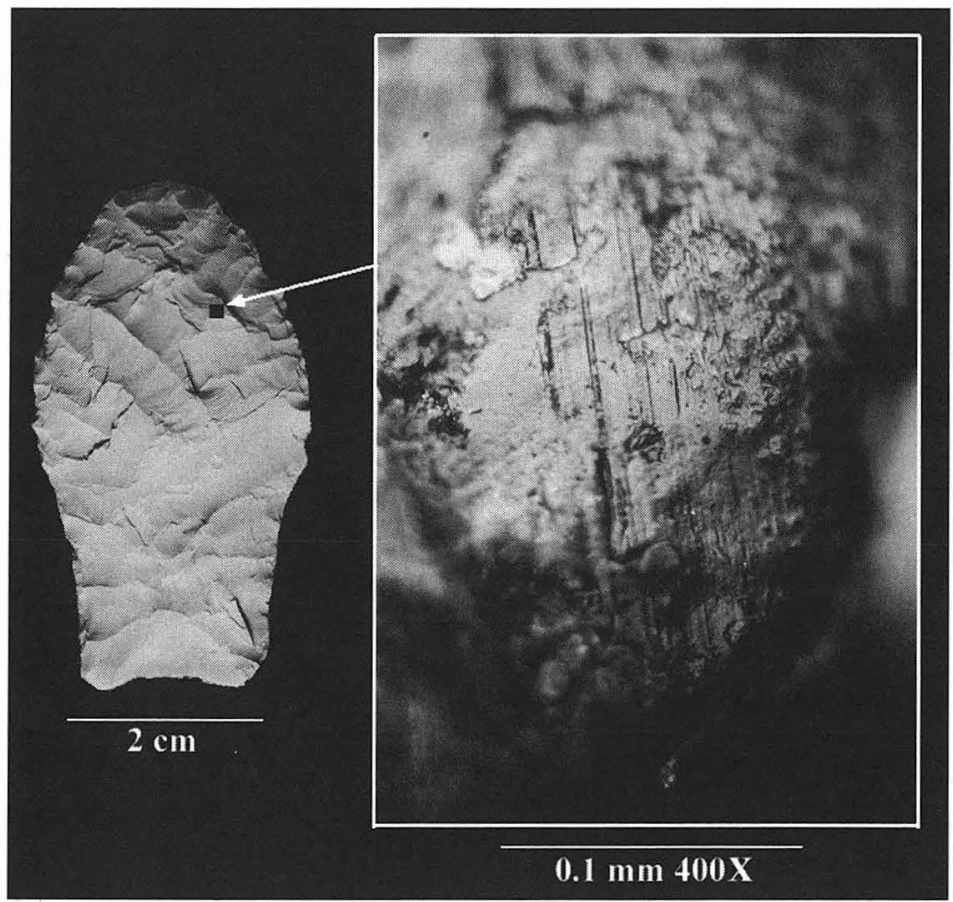

FIGURE 22-65. Thrall projectile point additive use-wear, Specimen 31P1-1. Note the proximally dislodged particle in the center of the photomicrograph that conclusively shows striae originated at the distal, or tip, end.

by a blade/haft element juncture made more distinct by a change in blade edge curvature. Reworking of these tools affected both the blade and haft elements alike. Functional necessities were carefully met for overall shape, thickness, and size.
The base in comparison to the blade is the more consistent and accords a sense of hafting parameters. Its hafting must have been less wide than and centered upon the blade of the projectile point. Although not directly observable, it seems equally likely to have been less than the maximum thickness of the point, to minimize frictional drag on penetration. Extensive lateral grinding of the base suggests mounting in a split as opposed to a socketed foreshaft, as deliberately dulling the edges would reduce the likelihood of cutting the binding lashes.

Hafting microwear (and for Angostura [see Figure 22-15] and even St. Mary's Hall [see Figure 22-61]) is consistent in showing the effects of horizontal binding lashes. Assuming the point was attached to a split foreshaft, the extensive basal grinding and haft binding requirements would seem to be borne out by these wear traces.

The difference in technology afforded by Angostura and Thrall hafting requirements is instructive of a larger puzzle - that of accommodating a similar hafting approach to contrastive tool functions. For Angostura, the handle or split foreshaft would have had to exceed the width and thickness of the blade element. For Thrall, the reverse is more likely the case. Why would such a systematic difference be both appropriate and predictable? The answer must lie in the intended tool 


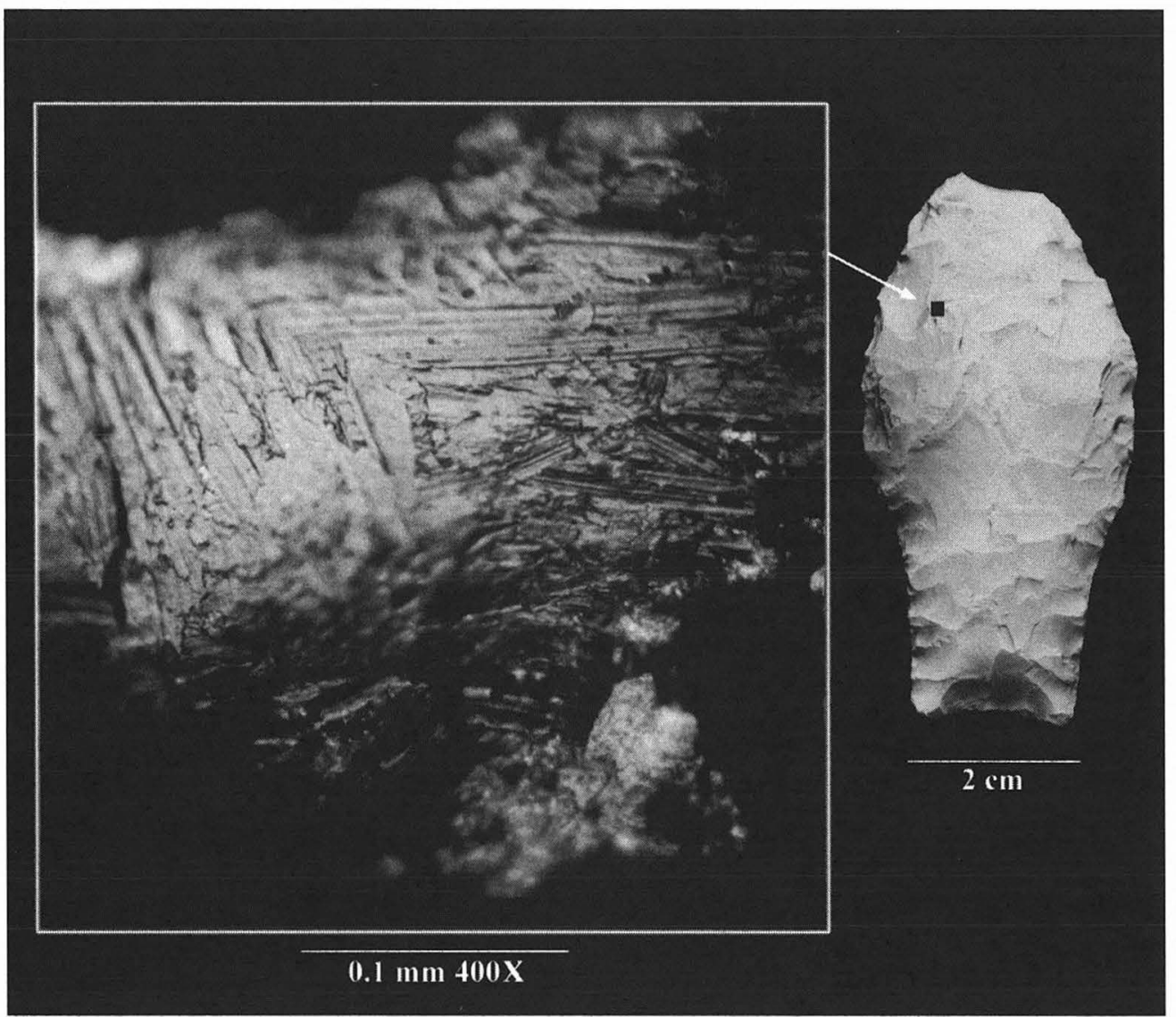

FIGURE 22-66. Thrall projectile point additive microwear with extremely complex sequence of usage as projectile:knife:projectile, Specimen $13 \mathrm{~N}-2$. Note also the many abrasive particles in the striae.

function and the manner in which hafting accommodates the specialized tool form.

For Angostura, a handle as large or larger in width and thickness than its blade would not impede its use as seemingly the ultimate Paleoindian and Early Archaic butchering knife, because the handle would not be intended to penetrate a carcass. Its overall size and shape would be designed instead to enhance the cutting effectiveness of the blade edges and to fit comfortably in the hand.

For Thrall, the foreshaft should exhibit a transverse profile smaller than blade width and thickness so as not to impede penetration of the projectile point. Assuming recovery of damaged but still maintainable points, blade rejuvenation would continue as long as this relation held. (The four Thrall points are all impact damaged. But in considering their use history that is uniformly one of being reworked, it seems that all could have been repaired. The fact they were not suggests the four were probably lost as opposed to being simply discarded.) A variable but finite limit on optional tool maintenance would be contingent not on overall blade length but on proportional differences in width and thickness: further resharpening would have been the expected option whenever blade width and thickness exceeded the maximum transverse sectional parameters of the foreshaft.
The ratio of blade to haft element length that, to judge from the Angostura example, is functionally constrained for a meat knife might also be expected to be more variable as repointing continued on damaged projectiles. Thus, this ratio would not be a practical measure of continued projectile point use life, while a blade width to thickness ratio might truly be instructive.

One could argue, of course, that to base such conclusions on a sample of four tools is simply too large a stretch to be credible. And, in this instance, I make no pretense of trying to satisfy a statistician's ideal for sampling. Interpretations, however, are not inherently marred by small sample size. Indeed, the question is not so much sample size as it is sample variability. Even our small sample is sufficiently variable to judge the central role the foreshaft had in retooling.

The proof comes from the final Thrall point (see Figure 22-64d). Its microwear (see Figure 22-67) shows an unequivocal ordered series of striae, microplating, and recrystallization that does two things. First, it establishes that rehafting came after earlier projectile point tool use. A notable detail among many is the "capture" of abrasive particles that cut hafting striae by an earlier series of impact striae oriented to the tool's longitudinal axis. Given the order established, it is simply inconceivable that these are haft-related secondary 


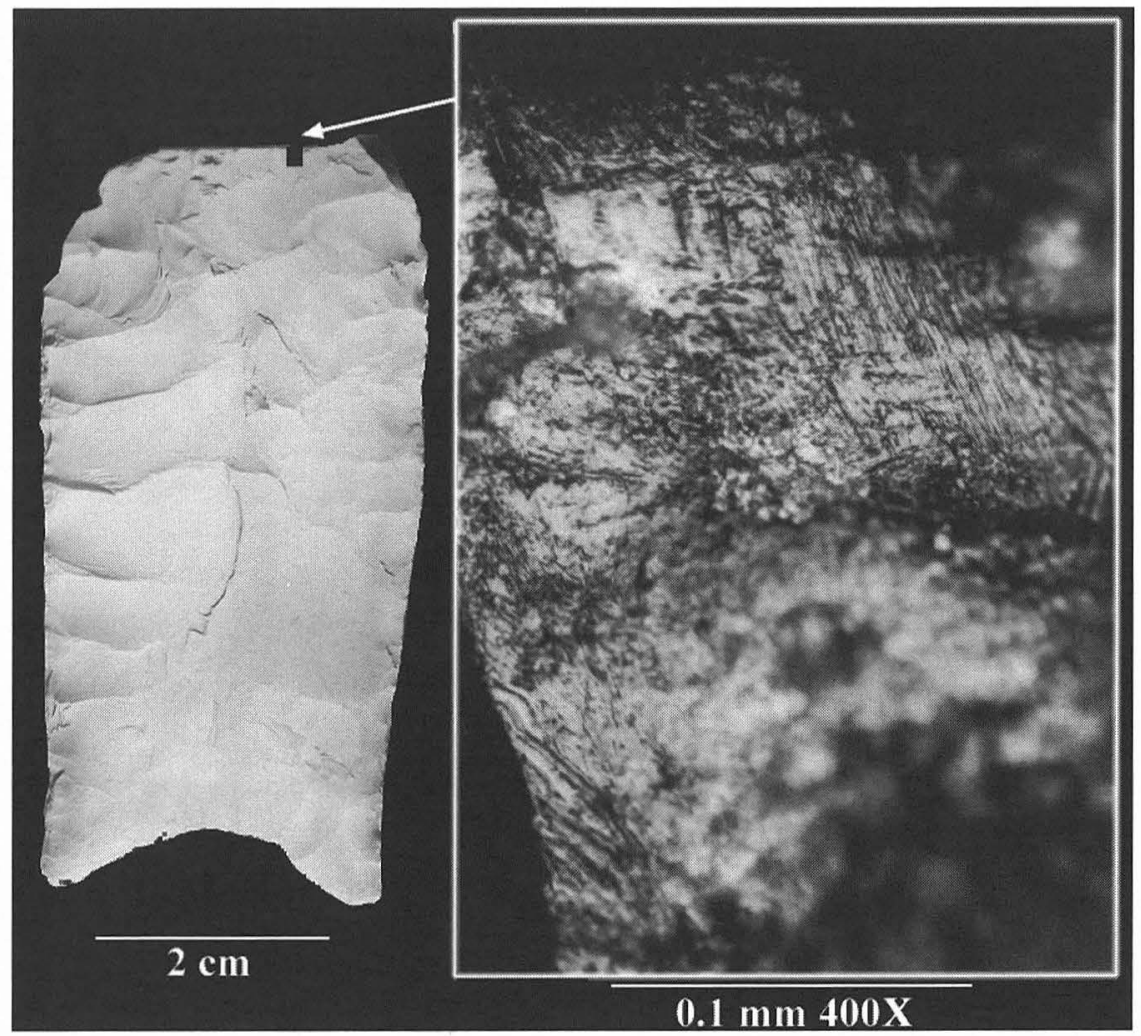

FIGURE 22-67. Thrall projectile point additive microwear showing "capture" of haft striae abrasive particles in earlier impact striae, Specimen 31R1-1. Note also recrystallization on trailing edge of haft wear.

impact striae. Rather, they are primary and document that the basal end originally was the tip end. In sum, there was a reversal of ends and continued use as a projectile point. Second, the recreated haft element is almost identical in size and proportion to the others. These similarities are truly remarkable. They underscore not only the governing proportional relations in blade width and thickness, but also that foreshaft transverse profiles met a narrow range of tolerance in both proportion and actual dimensions. Exactly why remains a mystery. It may relate to the maximum acceptable size of foreshaft materials, the spear's stability in flight and on impact and penetration, the preferences of individual tool makers, or a combination of all these considerations. Admittedly just a guess, but I would not be surprised if all four points were made and used by one person.

Thrall is differentiated from the other projectile points in that (1) its use history began and ended as a projectile point; (2) its blade edges were repaired bifacially, the most efficient way to maintain transverse blade proportions but not blade length; (3) its transverse and longitudinal blade profiles are mutually reinforcing, projecting wedges designed to initiate a broad, lethal wound; (4) its split foreshaft assembly (if not the shaft) most likely was shielded by the broader and thicker blade element and, thereby, did not add to frictional resistance, or drag, on penetration; and (5) the projecting blade wedges assured repeated optional maintenance because maximum blade width and thickness both coincided and were well forward of the haft/blade element juncture but well back of the tip. Thus the penetrating blade wedges could be maintained easily even when substantial reworking of the tip, the base, or both was required.

\section{NONTOOLELEMENTS}

Microwear analysis does distinguish unifacially retouched flake tools or, in the case of flake gravers, tools to be and tool renewal. In addition to flake gravers, nine, however, exhibit no use-wear, and it is instructive to take a closer look at these (see Figure 22-44c; Figures 22-68, 22$69)$. Several are carefully retouched (see Figures $22-44 c$, $22-68 \mathrm{a}, \mathrm{b}, 22-69 \mathrm{a}, \mathrm{b}, \mathrm{d})$ in ways that suggest intentional preparation of a tool blank or preform. The others are less carefully flaked or merely edge damaged but are of approximately the same or larger size. With three exceptions, two of which are carefully retouched (see Figure 22-68b, c) and the third is edge damaged (see Figure 22-68d), the retouched flakes are as large or substantially larger than any of the tool elements. Virtually any of the retouched flakes, carefully patterned or not, could be viewed as a tool blank or preform for many of the bifacial implements. Not analyzed, 


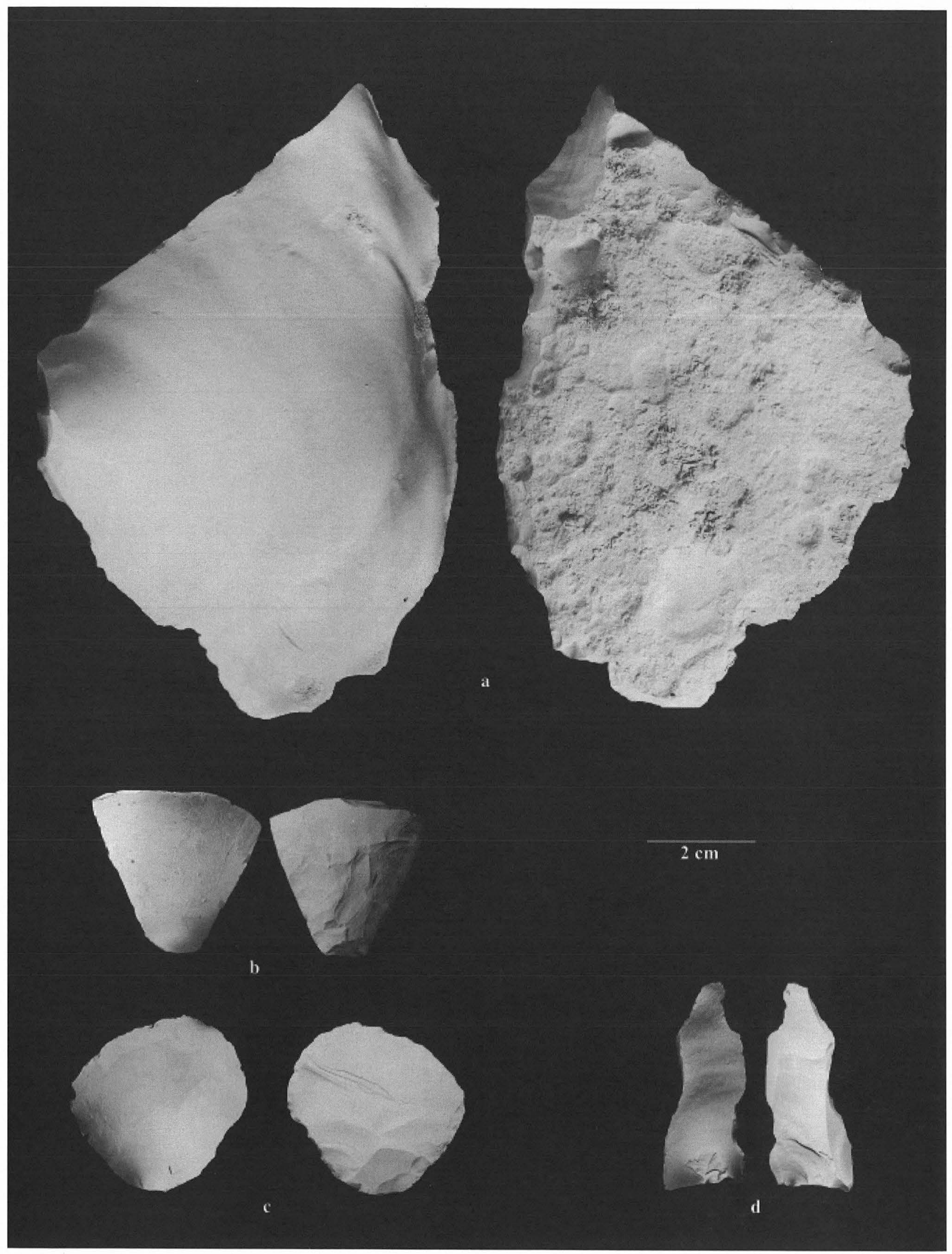

FIGURE 22-68. Retouched flake preforms. Specimen numbers: (a) 15HH1A-1; (b) 37EE1C-1; (c) 29U1C-11; (d) 37Q2D-12. 


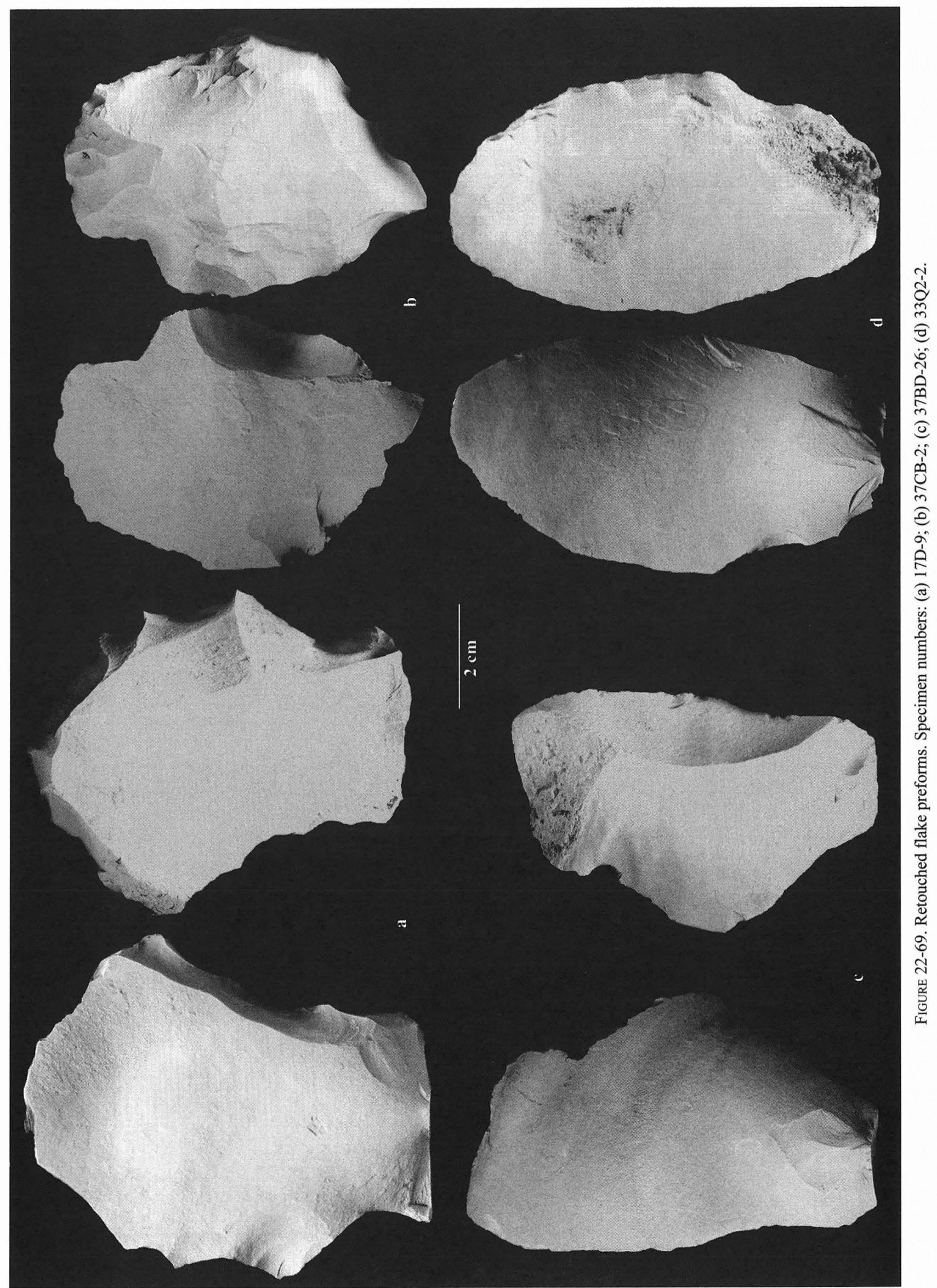


however, are even larger bifaces; some undoubtedly are tools - as would be true for the adzes - but others probably are simply large preforms at a more advanced stage of manufacture. A more comprehensive analysis in which microwear would play a small but important part is needed to differentiate possible core:biface or flake:biface production strategies.

\section{Trends in Form and Function}

In a strictly technological sense, the analyzed artifacts all are utilitarian or byproducts of manufacture or maintenance. They were regularly broken, repaired, recycled, discarded, or lost at the Wilson-Leonard site. These observations are neither startling nor unexpected, if only because in the late-nineteenth century, W. H. Holmes recognized (see Johnson 1993 for an insightful review) chipped stone tool manufacture and use as interrelated, linear subtractive processes, and we have followed his lead ever since. Indeed, the novelty-and an upsetting one at that-would have been if these relations had not held. The value of this study, however, is not in confirming the obvious, at least the obvious to a knowledgeable lithic specialist of whom this project already has several. Nor is it sufficient to simply provide additional details, however attractive and intricate the wear traces may be.

No, its value must lie in an entirely different area, one pursued on a more-or-less individual tool type or group basis so far: it is, of course, that of applying principles of engineering design and least effort to chipped stone tools. Initially pioneered by Semenov and using microwear and tool edge characteristics as evidence, this approach is a mainstay of lithic technological studies (Cotterell and Kamminga 1990; Shott 1989:22-27). Indeed, it is among the most robust analytical conventions available to archeologists, as Braun (1983:111-112) makes clear in speaking about tools and domestic crafts- "where the makers all are the users"-in an elegant if somewhat ironic way:

When pottery making is a domestic craft, we can then assume a selective process. Pottery techniques that produce vessels that are inefficient as tools, require relatively high labor or material costs, or require relatively frequent replacement, will tend to be avoided in favor of techniques that produce more efficient results, at lower costs, with lower frequencies of replacement. Conversely, then, materials and shapes used by domestic potters can be expected to be, if not actually finely attuned to all details of intended vessel performance, at least satisfactory for the demands placed on them [emphasis in original].

To paraphrase Braun, the Wilson-Leonard artifacts are a byproduct of a domestic craft and obviously do express information about the efficiency of tool design in addition to being formally describable as functional tool types (i.e., extractive, maintenance, etc.). The question is, how best to assess the available information?

\section{Approaches}

The Wilson-Leonard sample poses at its worst some insurmountable statistical problems and at best is less than ideal. Analyzed artifact sample sizes are generally small and variable. Missing data are common. For the most part, probabilistic hypothesis testing would be inappropriate and misleading, if not simply unintelligible. These problems serious though they are, however, do not preclude a statistical analysis of trends in tool form and function. But pairwise contingency tests or even more powerful and sophisticated parametric procedures would not be appropriate.

In a classic paper, Spaulding (1982) describes structures in archeological data. Spaulding's (1982:9-10) thesis is to hierarchically model all possible relationships among archeological data, which he regards as characteristically nominal (or categorical) in scale. He argues to expect in some cases a "complex interaction among all those variables such that each combination of two attributes predicts the attribute of the third variable." This hierarchical approach may reveal the underlying structure, or pattern, that would be overlooked by pairwise contingency testing.

Hierarchical modeling has further advantages: in theory, of being independent of sample sizes and, in practice, to be nearly so. So, in demonstrating a statistical approach oriented not to probability but rather to estimation, Spaulding has done us all a favor of no small size.

The power of the technique is expressed readily by graphic triangulations. And, as Spaulding (1982:9) illustrates, a diagram is worth a thousand words. Frankly, without graphs the interrelations of a hierarchical model would be nearly impossible to appreciate. But we are hardly constrained to employ only the cellular models Spaulding uses.

It may seem a violation of Spaulding's assumptions that I choose to crossplot ratio scale data, but in theory and reality it is not. He allows and underscores the utility of ratio scale data to express patterns, and indeed regards them as far superior to patterns of nominal data. Spaulding (1982:5-6) makes a further distinction with which I completely agree:

When we examine a group of artifacts made by the members of a nonindustrial society, we describe them as made of wood, bone, clay, stone, or metal, and as vessels, projectile points, axes, knives, and awls. We do measure and weigh the artifacts, of course, but we do not think of the measurements as descriptions in quite the same sense as the classification 'projectile point.' The measurements are instead raw material for further analysis: we hope to demonstrate an order within or among the measurements that reflects culturally imposed patterning, to show that the projectile points can be described objectively as long or short, for example. In very plain situations, the measurements may be treated directly as nominal classifications; we simply observe that there are long and short categories, and in doing so we make an implicit inference about the perceptions of the artifact makers. 


\section{Discussion}

Tool blank selection at virtually all levels shows a consistent relationship with average measures of mass (see Figure 22-9) and size (Figure 22-70). Even the small, unmodified flakes differ in overall proportions depending on their having been tools or unmodified flakes (see Figure 22-70). This difference extends as well to their average edge angles (Figure 22-71). What distinguishes the "typical" unmodified flake tool is its overall larger size and edge angle from comparable lithic debitage. On average, retouched flake blanks contrast in being larger in mass, size, and edge angle than retouched flake tools and in size and weight but not edge angles for bifacial points (see Figures 22-70, 22-71). These observations are consistent with expectations for the manufacture and use of unifacial and bifacial tools from retouched flake blanks. With resharpening, the edge angles should become steeper and that is exactly the observation. Average tool edge angles also show a progression in steepness that begins at the low end with the unused parallel-sided lanceolate knife point followed by unifacial and bifacial point knives, projectile points, drills, and the awl (see Figure 22-71). Average burin edge angles are obtuse but differ between unifacial or recycled knife point burins and those recycled from projectile points (see Figure 22-71).

What undoubtedly will be of great interest to other researchers is the average trend in tool edge angles, and especially the distinctions between knives and projectile points. These differences, I think, are not merely a function of small samples or other peculiarities of the Wilson-Leonard collection and site. An especially strong bit of supporting evidence is that Wilson-Leonard unifacial and bifacial knives have almost identical edge angles. The difference between the two is not in intended tool function, for which edge angle preparation is critical, but in intended use history; unifacial knives were not regularly recycled, nor do they exhibit progressive use-wear associated with the bifacial knives. In sum, they contrast in projected length of service, not function. Unifacial knives were for short-term use; bifacial knives, long-term. Then too, the Folsom ultrathin biface, a very specialized knife found at Wilson Leonard but not included in this study, has comparable edge angles to both the unifacial and bifacial point knives of between $40^{\circ}$ and $60^{\circ}$ (Kay 1995). Projectile points are steeper. And as seems to be the case for the St. Mary's Hall points, the initial edge design ensured razor sharpness and durability. The idea, however, behind projectile point blade edge razor sharpness and durability is not to improve its cutting tool efficiency. But instead, it is to minimize frictional drag upon penetration while concurrently reducing the likelihood of blade failure. Ideally, resharpening of a projectile point, when needed, would be to the tip not the blade edges, because this would extend its use life. When a projectile point's blade edges fail, there is simply less of the blade available to be resharpened or remodeled.
A comparison of individual bifacial point tools makes even clearer the functional design characteristics. For this purpose, the microwear evidence is used to group the 32 tools into three, first-use functional categories - knife points, projectile points, and initial use as either a projectile or knife point (projectile $<->$ knife); these distinctions have already appeared in the average edge angle trends. The category of initial use as either a projectile or knife point is meaningful as a measure of recycling (see especially the effect of extensive but differential resharpening of the left edge [see Figure 2270]) and continuous functional variation among projectile points. Not all tools share the same use histories, even within a single functional category, but in most cases can be similarly measured, weighed, and counted. The tools also are not in mint condition. The vast majority are spent discards or not further repaired because they were lost or cached; and only one specimen - the heat-fractured parallel-sided lanceolate - appears not to have been used. So the trends are affected as much by use life as they are by the maker's intent. Placing emphasis on first as opposed to continuous or final use has the advantage of highlighting the intended form and when it ceased to be effective.

The Wilson-Leonard Paleoindian complex is reasonably well stratified and dated by radiocarbon. But not all points of each type are from exactly the same context or depositional unit. For this reason, I have arbitrarily divided the Paleoindian and Early Archaic into six relative time units (or periods). Each unit is identified more-or-less with one or more point type. The first two time periods, units 1 and 2 , are represented by but a single point each and, admittedly, do not provide conclusive information about changes in engineering design. Unit 1 is the Leanne soil, and is represented by the unusual thin, notched point (see Figure 22-47a) that is now regarded as part of the Wilson component. It is sufficiently different in design from the other Wilson component specimens as to warrant, in my opinion, being separated from it - if only for purposes of this discussion. Unit 2 is represented by the lanceolate point (see Figure 22-47b) from the Bone Bed, and is the earliest of the projectile point designs considered. Unit 3 (the Wilson component), unit 4 (the Golondrina-Barber component), unit 5 (the parallel-sided lanceolate and St. Mary's Hall component), and unit 6 (the Angostura and Thrall component) form the core of the analysis. The overall time span is from about 11,200 to 8800 B.P. Each time unit is not of equal length, nor does each square exactly with the stratigraphic placement of the point types. (In the case of unit 6, for instance, the Thrall and Angostura points do not co-occur in the same distinct stratum but do represent the Early Archaic, nevertheless.) They do provide a way, however preliminary, to compare changes over time in tool technology.

Average blade edge angles (Figure 22-72) express a refinement of the information previously summarized. Knife points, other than the one Wilson point (unit 3) that had the most widely variable edge angles $\left(60^{\circ}\right.$ and $\left.100^{\circ}\right)$, range from 


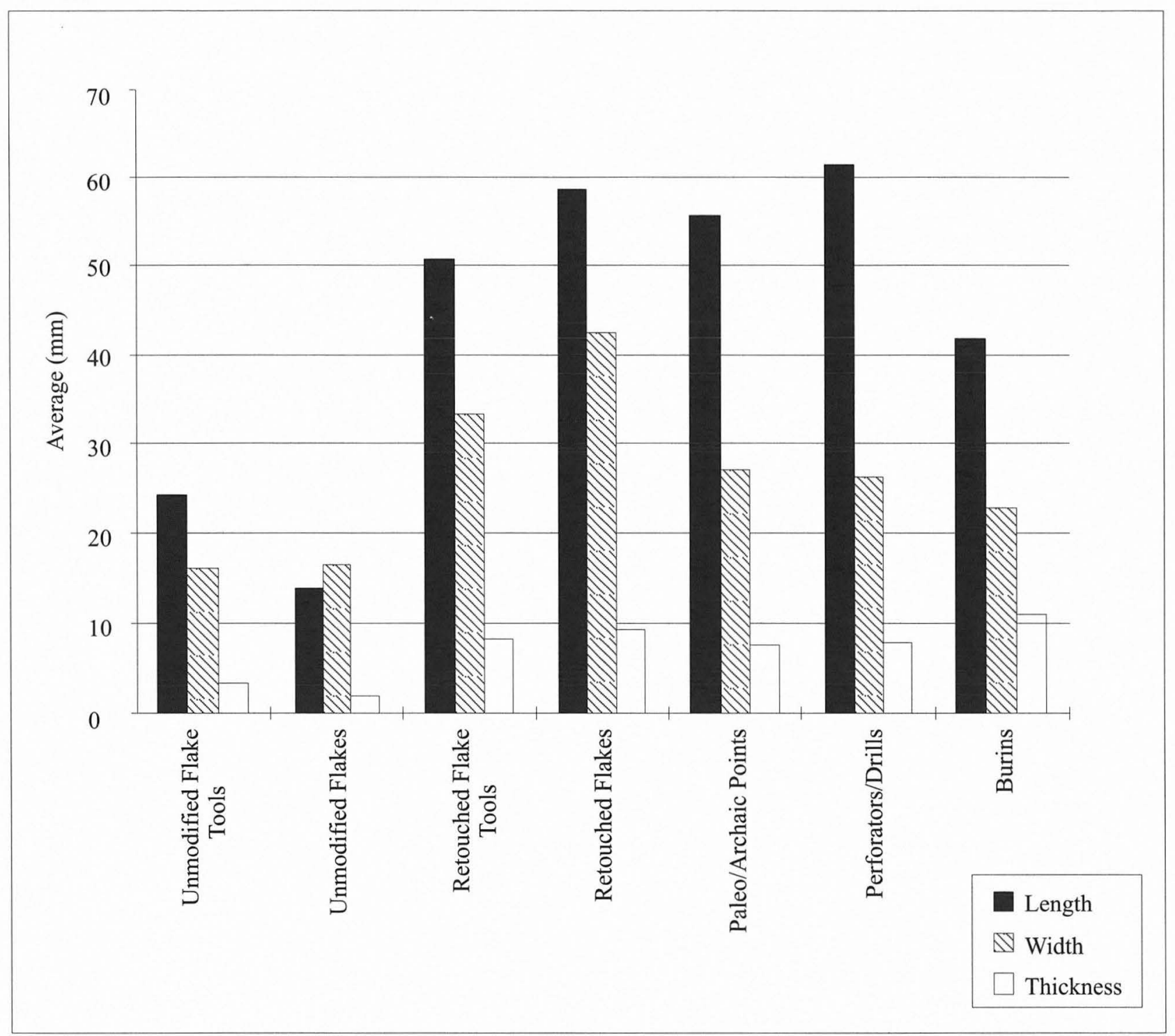

FIGURE 22-70. Average measurements for microwear groups (see Figure 22-9).

about $50^{\circ}$ to $60^{\circ}$ in average edge angle for the mainly discarded specimens from units 1 through 5 . The overall trend is less steep than the edge angles of projectile points.

It undoubtedly would have pleased Spaulding that simple measures of mass have proved to be excellent predictors of tool function. As expressed by average weight, there is a clean separation between the generally heavier knife points and the projectile points (Figure 22-73). The knife points over time show a nearly linear reduction in average weight until they are actually smaller, in unit 6 , than the (Thrall) projectile points.

The projectile points, however, are quite variable and do not exhibit a corresponding smooth change in mass. Instead, the heavily recycled forms prior to unit 6 would seem to represent alternative production strategies in blade and haft proportions (Figure 22-74) rather than one logically leading to the next.
Knife point blade and haft proportions (Figure 22-75) underscore systemic changes most notable following the Wilson component (unit 3). In a functional if not social sense, Golondrina-Barber, parallel-sided lanceolate, and Angostura are related. They show knife point usage increased as blade and haft proportions became more similar. Effective use life increased from Golondrina-Barber to parallel-sided lanceolate to, finally, Angostura while at the same time average mass decreased. Thus, a progressively more efficient use of tool stone occurred. The extension of use life was accomplished by design changes. Principal among them are: (1) a blunted tip that better withstood bending breaks to the blade, (2) alternate unifacial resharpening of the blade that conserved tool stone and concurrently encouraged equal usage of blade edges, (3) serrations that increased the total edge per unit of blade edge length, (4) a symmetrical but convex, converging-to-the-tip blade form that could be resharpened until it 


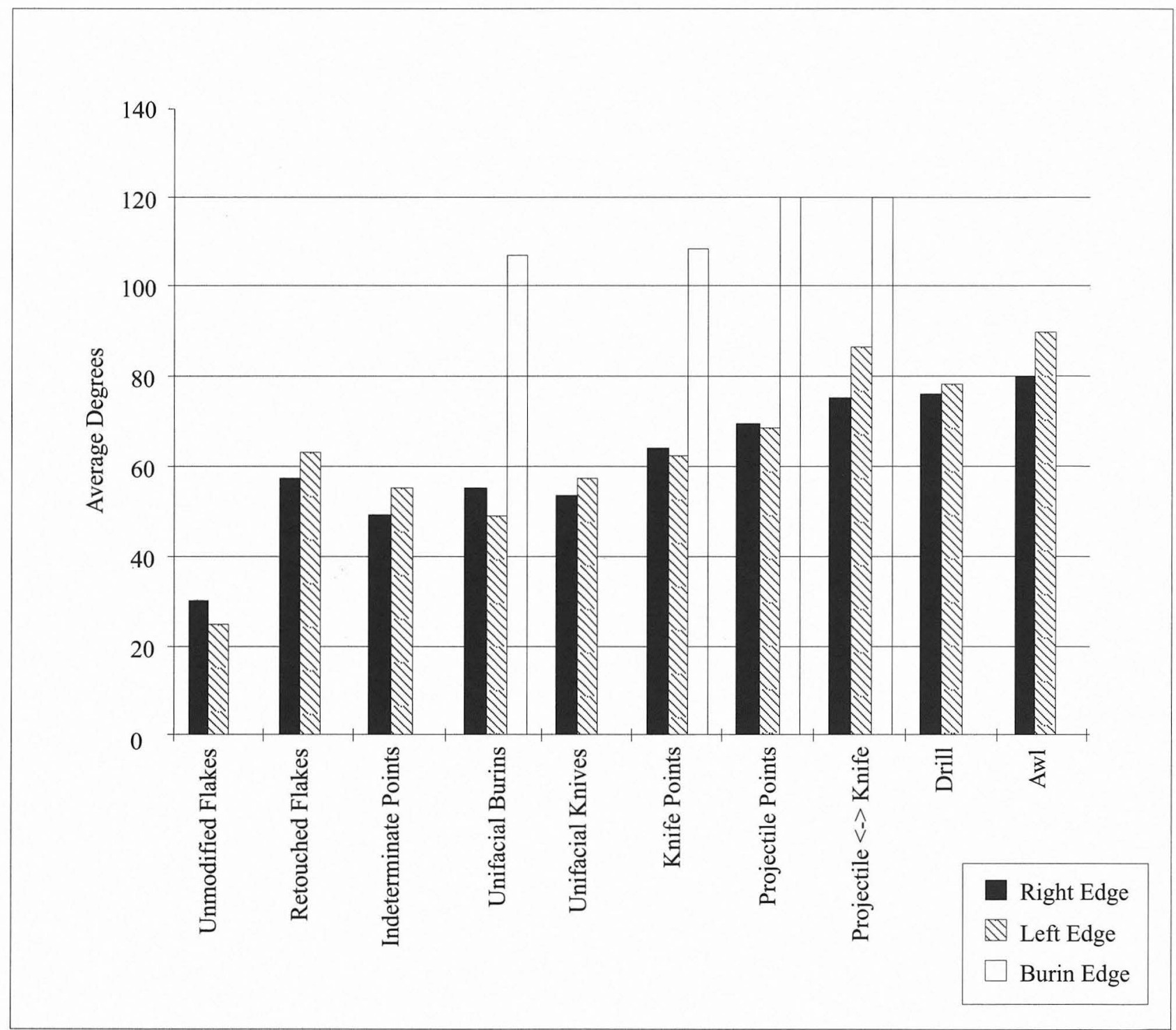

FigURE 22-71. Average edge angles for microwear groups.

became approximately the shape of an isosceles triangle, thereby extending use life, (5) a narrow, parallel-sided longitudinal section that reduced blade element frictional drag, and (6) enhanced overall handling stability as the haft element became about one-third the length of the blade and whose juncture with the blade element expressed the maximum width of the knife point.

In comparison, the earlier Wilson points primarily began and were intended to be projectiles; only one exhibits initial use as a knife. The projectile points were mostly recycled as knives but have much steeper edge angles than the typical knife point. The recycled blade of the Wilson point has many of the design elements of a successful knife. Its serrations and alternate unifacial resharpening are all appropriate measures to conserve tool stone and concurrently increase efficiency of the cutting edge, the triangular form being the successful end product of extended blade use life as it was resharpened. The major limitation of the blade element is its longitudinal section would have increased frictional drag, rather than reducing it. As knives go, the Wilson point, with its exceptionally large blade relative to haft element length, must have been satisfactory if not exceptional. It also illustrates design features not further developed until much later. Thus, the recycling seems quite innovative. As a projectile point, however, it seems to have been less than satisfactory. It was prone to blade and tip breakage on impact. And, when retrieved, it was more likely to be recycled as a knife or other tool form than to be reused as a projectile point.

The starkly disparate trends in knife and projectile point mass and blade and haft proportions after the unit 3 Wilson component merit further comment. It seems odd to the extreme that the same groups of people repeatedly chose alternative tool designs. It must relate to the underlying 


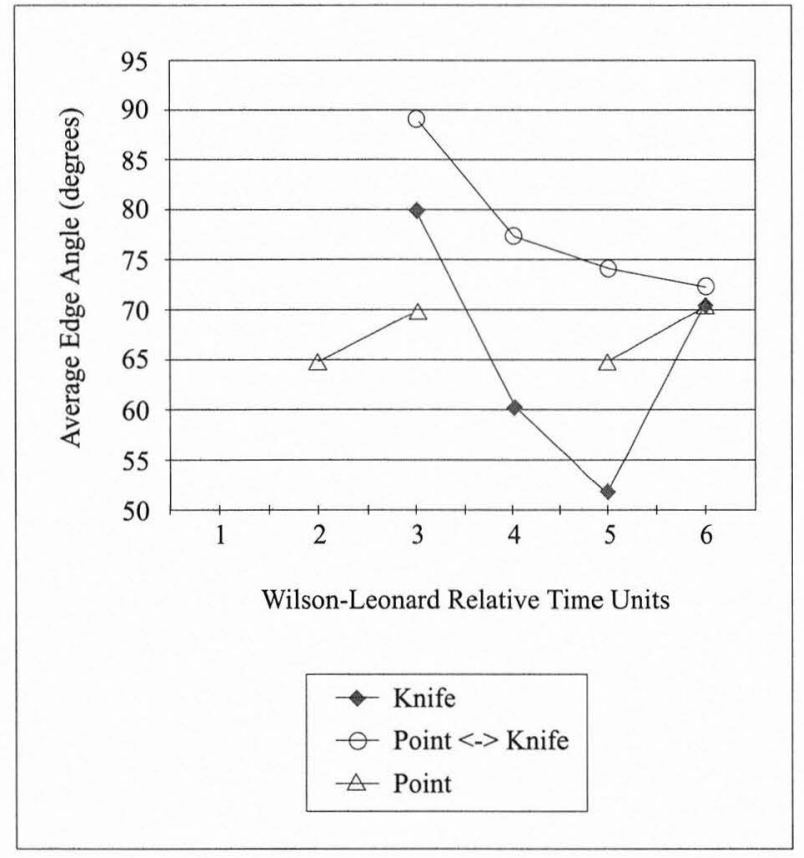

FIGURE 22-72. Trends in average blade edge angles for Paleoindian points.

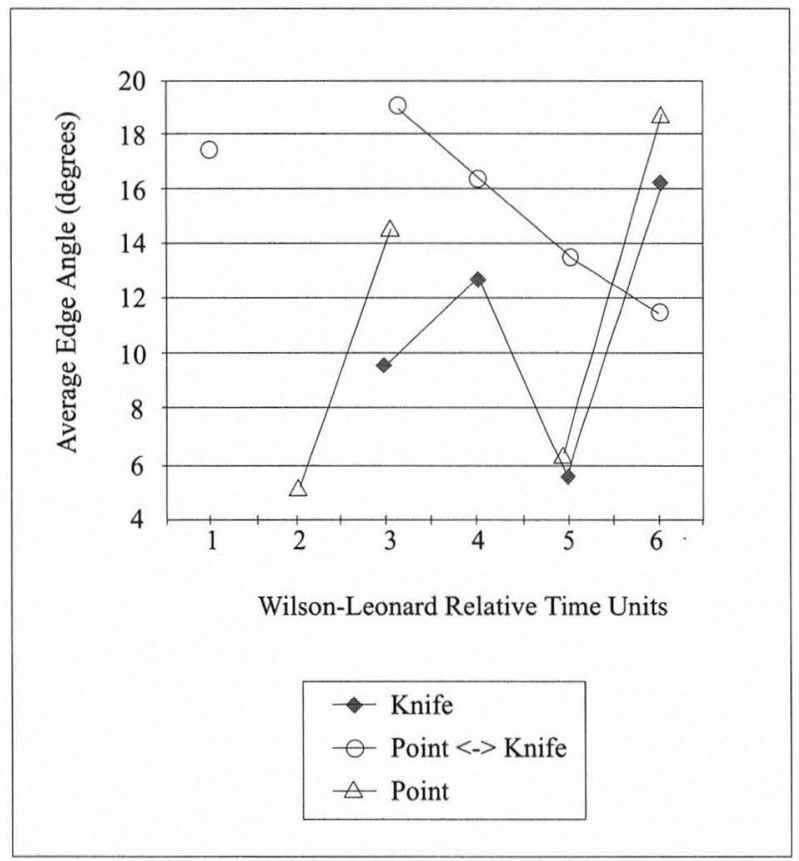

FIGURE 22-73. Trends in average weight $(0.01 \mathrm{~g})$ for Paleoindian points.

structure of the groups, to how tools were used over time, to the availability of tool stone, or to some combination of all these and perhaps to other even less well understood factors. Although speculative, it seems likely that gender differences may be represented in the tool use trends. If this were the case, then the knives were more likely women's tools consistently used in a singular task or group of related

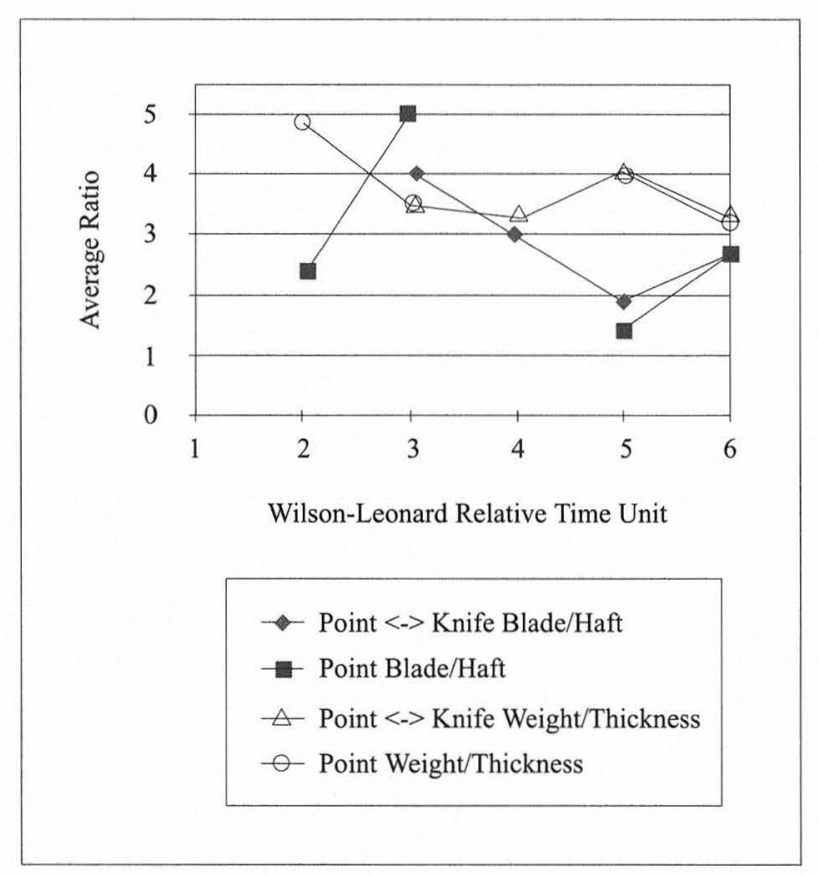

FIGURE 22-74. Trends in average proportional ratios for Paleoindian projectile points.

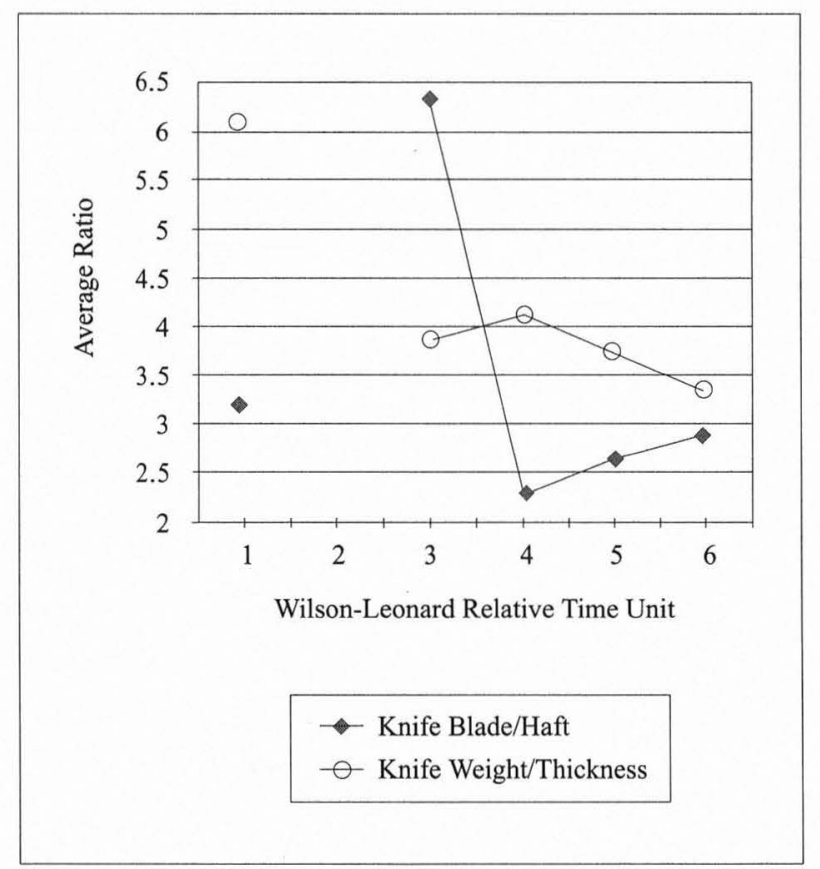

FIGURE 22-75. Trends in average proportional ratios for Paleoindian knife points.

tasks; the dual continuity in users and tasks led to greater tool efficiency and conservation of tool stone. The projectile points were likely to have been men's tools, or weaponry. The microwear demonstrates they would have been used in an ad hoc fashion as a knife following a kill. The projectile points are all similar in this respect. They differ only in their relative ability to be maintained as a projectile 
point. Paradoxically, the Thrall point, the largest of the projectile points, best exemplifies tool stone conservation. Its blade and haft proportions could be maintained more easily and consistently for reuse as a projectile point, whereas none of the earlier ones could. Changes in projectile point form ultimately led to a greater tool efficiency but did so in a vastly different manner to that of the knife points.

\section{Postscript}

In spite of my best intentions, we are left with an imperfect reconstruction that only crudely approximates some qualities of chipped stone tool design. Others have offered ideas that deserve serious consideration. I would like to mention a few here.

Dale B. Hudler notes that part of the engineering design process for a projectile point would be to evaluate the striking power of the weapon and its delivery system. Considerations of mass and velocity versus penetration, the type of prey, its body size, and behavior all would have been factored into the design of specific weapon systems used by prehistoric hunter-gatherers. However difficult these may be to reconstruct or to accurately measure, they must have been of paramount concern in weapon design.

How a projectile point was actually used as part of a specific weapon delivery system is addressed in Chapter 13 . I wish to offer a synopsis of his opinions as they apply to the Thrall projectile point and my reactions to them. His concern is that there is perhaps more than a dichotomy in delivery systems for various projectile point types; that is, between arrows and darts propelled mechanically and spears propelled manually. To this, Collins notes lances are thrust and never propelled. The Thrall point might satisfy the criterion of a lance point, because its broad tip would have been most efficiently employed by thrusting between the rib cage of a prey species, such as bison, rather than propelled. He notes the odds of success in penetrating the rib cage would be significantly greater were it used as a lance tip.

In my opinion, what is most typical of projectile points is that they regularly failed, or were damaged, on impact. Although the St. Mary's Hall is perhaps the most dramatic example, one could make a similar observation for Thrall. The difference between Thrall and the rest is that it appears to have been deliberately designed to be reused as a projectile point after optional maintenance was carried out to retip the point. The others mostly were recycled as knives. What differentiates Thrall in this analysis is its maintainability, or relatively long use life. If it were used as a lance head, it apparently was damaged in spite of any greater control that thrusting might have conferred.

Breaching the rib cage of a large animal by propelling a spear is also perhaps not quite the insurmountable task one might imagine. After some practice, George C. Frison (1986, 1989) had success with hand-propelled and atlatl assisted delivery of Clovis replicate projectile points in deeply pen- etrating the rib cage of already mortally wounded African elephants, in a manner that would have imparted a lethal wound. The atlatl was significant in improving both the range and the penetrating power of the spear. The microwear on these replicate points (see Kay 1996) did not allow for separation of hand or atlatl propelled points, however. And I am unsure that thrusting spears, or lances, would impart distinctive microwear signatures.

There are obvious limitations to any analysis, and this one is no exception. Without further experimentation with replicate weapons systems, we simply cannot know if there is a distinctive lance head microwear. Another area of contention is the identification of gender differences in tool usage, especially of the knife and projectile points. Most hunter-gatherers do have gender as well as age-based divisions in labor, or may employ gender-specific tools. We can never know how appropriate ethnohistoric, ethnographic, and ethnoarcheological studies of hunter-gatherers are for late glacial and early postglacial cultures in the Americas. Yet, we should not give them short shrift, either. The task of archeology is to first identify significant cultural patterning in time and space and then to develop models that attempt to account for variation in the material record. Gender differences may or may not be the best and simplest explanation of the variability seen in tool function trends at Wilson-Leonard, but without voicing the possibility, we shall never develop the appropriate test to find out.

\section{CLEAR FORKTOOL FUNCTION: ANAPPROACH CENTERED ON USE-WEAR}

by Dale B. Hudler

\section{Background}

Several low-magnification use-wear studies of Clear Fork tools were made in the early 1970s. Hester et al. (1973:92) have noted that the characteristic wear on the bit edges of Clear Fork tools is step-flaking and suggested that they were "used in the manner of end scrapers, to dress and smooth wood surfaces." Chandler (1974:18) states:

The most characteristic use wear indicators are distinctive smoothing of the flaked faces and lateral edges with a high percentage of edge nibbling on the bit and lateral edges. The location and direction of striations on the bit edges, supported by limited personal experiments, indicate these tools were probably used in a pushing fashion (i.e., planer gouge) on a hard, unyielding surface, probably wood.

Howard (1973:58) studied the use-wear on 25 Clear Fork tools (both bifacial and unifacial specimens) and concludes:

The study strongly suggests that the Clear Fork gouge was the cutting "bit" of an efficient woodworking tool. The experiments demonstrated that 
the tool was most probably a shaving or planing device. Because of its demonstrated efficiency it was probably used for numerous wood working tasks.

The current study was designed to build on, rather than replicate, these earlier studies. Therefore it focuses on the high-magnification use-wear methods that have come into use since the studies listed above were accomplished. A further reason to re-examine Clear Fork tool function is the questionable status of Clear Fork as a meaningful group. Since the type was defined (Ray 1938:198), these tools have been found to be widespread geographically and to have been in existence for a long period of time (Black and McGraw 1985:139). Additionally, they have a broad range of overlapping morphologies, and some researchers have abandoned Clear Fork as a type (Hall et al. 1982:318-348). These factors suggest that Clear Fork tools might be morphologically similar but with differing functions at different points in time rather than being singlefunction woodworking tools.

\section{Study Population}

Fifty-eight Clear Fork tools from the Wilson-Leonard site were examined in this study (Table 22-8). This group includes all of the lithic artifacts identified as Clear Fork tools (and the subset Brushy Creek bifaces) that were available at the time of the study. Of these, 47 are bifacial, and 11 are unifacial tools. Also included are 9 replica tools used in an experimental use-wear program ( 8 bifacial and 1 unifacial).

\section{Methods}

\section{Artifact Preparation}

The archeological specimens were not cleaned in conjunction with this study. However, most had been cleaned prior to being made available for the study - the TARLexcavated items with water and brush. The experimental tools were cleaned for 10 minutes in an ultrasonic cleaner after use. It should be noted that Keeley cleans both his experimental and his archeological specimens with a mild solution of hydrochloric acid to remove mineral deposits and, if required, with a mild solution of potassium hydroxide to remove organic material (Donahue 1993:164). According to Kimball et al. (1995:7), not cleaning tools via the Keeley method produces erratic results when doing high-magnification polish analysis. However, such cleaning can remove residues and can accelerate patination (Donahue 1993:146). Linear features that appear to be in polish can be removed by acid cleaning (Figure 22-76). This suggests that the linear features are not in the polish but in residues overlying or mixed with the polish. Since it appears that acid cleaning not only destroys residues but can also erase motion indicators as well, a decision was made not to acid clean any tools for this study. One exception was made which is discussed in the high-magnification results section of this paper.

\section{Use-wear Observations}

As a first step, the study population was examined "with the naked eye" to provide a general picture of the large-scale use-wear patterns present. The tools were then examined at 20X magnification (using a Bausch \& Lomb Stereozoom 7 microscope) for edge-damage flaking, edge rounding, striations, and polish (location, extent, and brightness). Edgedamage flake termination shapes were recorded as nominal data (step, hinge, feather), striations were recorded as present/absent, and edge rounding and polish brightness were recorded in ordinal categories. Polish extension was measured to the nearest millimeter. The information collected from these "macro" and low-magnification observations was used to design the experimental use-wear program.

The primary purpose of the experimental program was to confirm that the wear patterns observed at low magnification on the archeological tools was consistent with woodworking and to develop polish on the replicas that could be examined at high-magnification $(200 \mathrm{X}+)$ for comparison with observations of the archeological tools. An Olympus BH-2 compound microscope with incident lighting was used to make these observations (at 200X and 400X). The high-magnification observations focused on searching for additional striations and examining the polish characteristics to see if contact material inferences could be made. Polish characteristics were recorded for the following categories: polish reflectivity, surface texture, surface features, and degree of linkage.

\section{Archeological Tool Observations at No/Low Magnification}

\section{Macrowear}

The most noticeable macrowear in the study group as a whole is snap fractures at the break of partial tool sections. Nineteen of the 80 tools in the collection are partial tools with snap fractures $(24 \%)$. Nine of the partial tools are distal ends, and the bits of these were examined for use-wear. Four (24R2-3, 35U1C-2, 37T1D-3, and 15AA2-2) have use-wear, indicating that the tools were broken after some use and possibly during use. The fifth (38Y-25) has a very sharp bit with no apparent wear, suggesting that it was broken in the last stages of manufacture/hafting or in the late stages of resharpening. The sixth (20W-2) has a very large flake removed from the bit by a blow to the ventral side of the tool (perhaps a failed attempt at resharpening). Not enough is left of the original bit edge to judge whether it has been used or not. The other three (13L-4, 2OP-4, and 743-1) have no visible use-wear. One of these (743-1) appears to be a manufacturing failure. The snap fractures on tools with 
TABLE 22-8

Inventory of Clear Fork Tools Examined for Microwear

\begin{tabular}{|c|c|c|c|c|}
\hline Item & Unit & Square & Analysis Identification & Wear Type \\
\hline $10 \mathrm{~N}-2$ & $\mathrm{X} / \mathrm{III} / \mathrm{b}$ & E20/S86 & Clear Fork uniface & None apparent \\
\hline $10 \mathrm{~S}-3$ & $\mathrm{X} / \mathrm{II}$ & E20/S86 & Clear Fork biface & Domed linear \\
\hline $12 \mathrm{~L}-9$ & IIIb & E20/S82 & Clear Fork biface & Domed linear \\
\hline $12 S-1$ & II & E20/S82 & Clear Fork biface & Smooth \\
\hline $13 \mathrm{~L}-4$ & IIIlb & E20/S80 & Clear Fork biface & None apparent \\
\hline $14 \mathrm{~W} 2-1$ & $\mathrm{Id} / \mathrm{II}$ & E20/S78 & Clear Fork biface & None apparent \\
\hline $15 \mathrm{AA} 2-2$ & Isi-c & E20/S76 & Clear Fork biface & Domed linear \\
\hline 15G-11 & IIIIc & E20/S76 & Clear Fork biface & Domed linear \\
\hline $16 \mathrm{G}-7$ & IIIIc & E20/S74 & Clear Fork uniface & Fuzzy unpatterned \\
\hline $16 \mathrm{R} 2-6$ & IIIa & E20/S74 & Clear Fork biface & None apparent \\
\hline $16 \mathrm{~T} 1-5$ & II/IIIa & E20/S74 & Clear Fork biface & None apparent \\
\hline $17 \mathrm{R} 2-3$ & IIIIa & E20/S72 & Clear Fork biface & None apparent \\
\hline $17 \mathrm{~T} 1-3$ & II/IIIa & E20/S72 & Clear Fork biface & None apparent \\
\hline $17 \mathrm{~T} 1-8$ & III/IIIa & E20/S72 & Clear Fork biface & None apparent \\
\hline $18 \mathrm{~F}-7$ & IIIIc & E22/S90 & Clear Fork uniface & None apparent \\
\hline $18 \mathrm{~J}-10$ & Y/IIIc & E22/S90 & Clear Fork biface & Domed nonlinear \\
\hline $190-17$ & $\mathrm{x}$ & E22/S88 & Clear Fork biface & None apparent \\
\hline $1 \mathrm{~F}-1$ & Y/IIIc & E20/S100 & Clear Fork biface & Smooth \\
\hline $20 I-4$ & $\mathrm{IIIb} / \mathrm{c}$ & E22/S86 & Clear Fork uniface & Domed linear and smooth \\
\hline 20L-11 & IIIIb & E22/S86 & Clear Fork biface & None apparent \\
\hline $20 \mathrm{P}-4$ & $\mathrm{X} / \mathrm{II} / \mathrm{IIIa}$ & E22/S86 & Clear Fork biface & None apparent \\
\hline 20R-10 & $\mathrm{X} / \mathrm{II}$ & E22/S86 & Clear Fork biface, proximal & None apparent \\
\hline $20 \mathrm{~S}-1$ & $\mathrm{X} / \mathrm{II}$ & E22/S86 & Clear Fork biface & None apparent \\
\hline $20 \mathrm{~W}-2$ & $\mathrm{x}$ & E22/S86 & Brushy Creek biface & None apparent \\
\hline $21 \mathrm{~L}-38$ & IIIb & E22/S84 & Clear Fork uniface & Domed nonlinear \\
\hline $22 \mathrm{P}-4$ & II/IIIa & E22/S82 & Clear Fork biface & None apparent \\
\hline $22 \mathrm{Q}-2$ & II & E22/S82 & Clear Fork biface & None apparent \\
\hline $22 \mathrm{Q}-3$ & II & E22/S82 & Clear Fork biface & None apparent \\
\hline $24 \mathrm{R} 2-3$ & II/IIIa & E22/S78 & Clear Fork biface & None apparent \\
\hline 25BB2D-1 & Isi-c & E22/S76 & Clear Fork biface & Fuzzy \\
\hline 25Q2-1 & IIIIa & E22/S76 & Clear Fork biface & Domed linear \\
\hline 29U1C-12 & II & E24/S76 & Brushy Creek biface & None apparent \\
\hline 30Q2-1 & IIIIa & E24/S74 & Clear Fork biface & None apparent \\
\hline 30T1C-3 & II/IIIa & E24/S74 & Clear Fork biface & Domed nonlinear \\
\hline $31 \mathrm{R} 1-2$ & IIIa & E24/S72 & Clear Fork biface, proximal & None apparent \\
\hline $33 Q 2-5$ & IIIIa & E26/S76 & Clear Fork biface & None apparent \\
\hline $33 R 2-9$ & IIIa & E26/S76 & Clear Fork biface & None apparent \\
\hline 34Q2-6 & IIIa & E26/S74 & Clear Fork biface & None apparent \\
\hline $34 \mathrm{X} 2 \mathrm{~A}-1$ & II & E26/S74 & Brushy Creek biface & Smooth \\
\hline $35 \mathrm{U} 1 \mathrm{C}-2$ & II & E26/S72 & Brushy Creek biface & Domed linear \\
\hline $36 \mathrm{O}-11$ & IIIIa & $\mathrm{E} 40 / \mathrm{S} 70$ & Clear Fork biface & None apparent \\
\hline $36 \mathrm{P}-7$ & IIIIa & $\mathrm{E} 40 / \mathrm{S} 70$ & Clear Fork biface & Domed linear \\
\hline 37 GB-9 & IIIIc & E28/S78 & Brushy Creek biface & None apparent \\
\hline 37T1D-3 & II & E28/S78 & Clear Fork biface & None apparent \\
\hline $38 Y-25$ & Isi-c/Id/II & E18/S74 & Clear Fork biface & None apparent \\
\hline
\end{tabular}


Table 22-8, continued

\begin{tabular}{|c|c|c|c|c|}
\hline Item & Unit & Square & Analysis Identification & Wear Type \\
\hline 39FF-2 & Isi/Icl & E18/S76 & Clear Fork biface & Smooth fuzzy \\
\hline $3 \mathrm{D}-7$ & IIIIC & E20/S98 & Clear Fork uniface & None apparent \\
\hline 51AA1D-3 & $\mathrm{I}$ & $\mathrm{E} 2 / \mathrm{N} 8$ & Clear Fork biface & Domed nonlinear \\
\hline $51 \mathrm{WB}-3$ & $\mathrm{II} / \mathrm{III}$ & $\mathrm{E} 2 / \mathrm{N} 8$ & Brushy Creek biface & Fuzzy unpatterned \\
\hline $593-3$ & $\mathrm{IIIa} / \mathrm{b}$ & 38 & Clear Fork uniface & None apparent \\
\hline $5 B-8$ & IIIc (pot) & E20/S96 & Clear Fork uniface & None apparent \\
\hline $743-1$ & IIIIa & 32 & Clear Fork biface & None apparent \\
\hline $7 F-2$ & IIIIc (pot) & E20/S92 & Clear Fork uniface & None apparent \\
\hline $7 \mathrm{~J}-5$ & Y/IIIc & E20/S92 & Clear Fork biface & Domed linear \\
\hline $7 N-3$ & $\mathrm{X} / \mathrm{Y}$ & E20/S92 & Perforator Group 6 & Smooth \\
\hline $9 \mathrm{~J}-7$ & $\mathrm{Y} / \mathrm{IIIb} / \mathrm{c}$ & E20/S88 & Clear Fork uniface & Domed nonlinear \\
\hline 9L-2 & $\mathrm{X} / \mathrm{Y} / \mathrm{IIIb}$ & E20/S88 & Clear Fork uniface & Domed nonlinear and smooth \\
\hline $9 \mathrm{M}-2$ & $\mathrm{X} / \mathrm{IIIb}$ & E20/S88 & Clear Fork uniface & None apparent \\
\hline
\end{tabular}
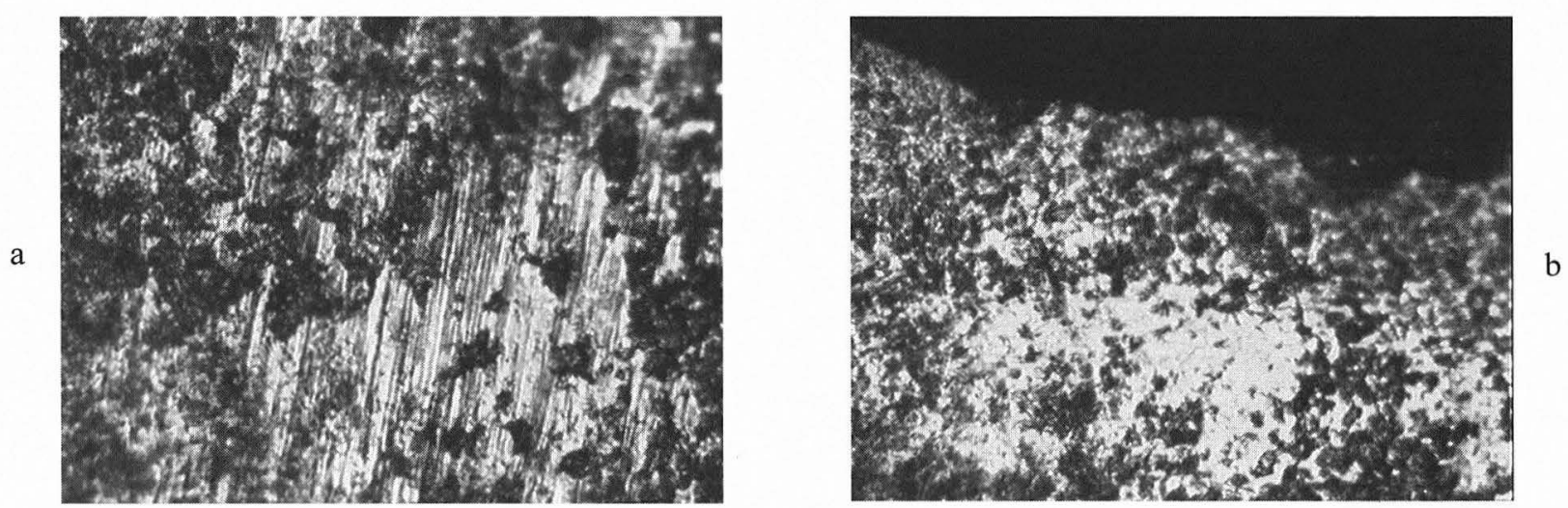

FIGURE 22-76. Flake tool at 200X. (a) prior to acid cleaning; (b) after acid cleaning.

use-wear suggest that they were broken while involved in a task that caused end shock or strong bending forces. Either cause suggests a hard contact material. The possibility exists that the snap fractures occurred while the tools were being "knocked" from the haft, but none of these bits looks exhausted nor is enough known about the hafting of these tools to know if such an operation was necessary.

\section{Low-Magnification Use-wear}

The predominant edge-damage pattern on the tools in the study population is edge-damage flaking with step terminations on the dorsal bit face (Table 22-9). This pattern occurs on 34 of the 58 tools examined. In contrast, only 9 tools have edge-damage flakes with hinge terminations on the dorsal bit face (and 5 of these occur in conjunction with flakes that have step terminations), and no tools have edgedamage flakes with feather terminations.

Ten of the tools in the study population have edgedamage flaking with step terminations, 8 have edge-damage
TABLE 22-9

Edge-damage Flaking Termination Type by Tool Bit Face

\begin{tabular}{l|c|c}
\hline & Dorsal & Ventral \\
\hline Step & 34 & 10 \\
Hinge & 9 & 8 \\
Feather & 0 & 1 \\
\hline \hline
\end{tabular}

flaking with hinge terminations, and only 1 tool has edgedamage flaking with feather terminations on the ventral bit face. Most of the flaking on the ventral bit face occurs in conjunction with edge-damage flaking on the dorsal bit face. This pattern supports the suggestion that many of the tools in the study population were in contact with hard materials. Although the thick bit edge probably encourages flakes with step terminations (as noted by Hurcombe 1992:11), it also probably is true that more force is required to detach any flake from the thick bit edges of these tools than from tools with a thin bit edge.

Edge rounding was noted on seven tools, six being judged as having slight rounding and one as having 
moderate rounding. No striations were noted, but one tool has linear polish patterns perpendicular to the bit, and one has linear polish patterns at a slight angle to perpendicular (both on the ventral tool face). Polish was noted primarily on the ventral bit faces, with four tools having polish extending approximately $10 \mathrm{~mm}$ back on the bit face, two extending approximately $20 \mathrm{~mm}$, and one extending $45 \mathrm{~mm}$.

\section{Intrepretation of Use-wear Visible at No/Low Magnification}

\section{TOOLMOTION}

None of the 58 tools has striations, but 2 have linear polish features perpendicular to the bit edge visible at 20X. An additional 7 have linear polish features approximately perpendicular to the bit edge visible at 200X. These observations indicate a tool motion perpendicular to the bit edge (such as shaving, planing, adzing, etc.) as suggested by Hester et al. (1973:95).

\section{TOOL POSITION RELATIVE TO THE CONTACT MATERIAL}

All of the above-mentioned motion indicators are on the ventral bit face, suggesting that it was the face in primary contact with the worked material. Additionally, polish developed almost exclusively on the ventral bit face, again suggesting that this face was in primary contact with the worked material, although bit morphology may also contribute. The exception is polish on the high flake ridges of the dorsal face on some tools. The extension of polish on the ventral bit face is varied, and seems to correlate more with the morphology of the ventral tool face than anything else. The polish seems to occur on the part of the face that is aligned with the bit face and stops at the point where the tool face turns/becomes unaligned, perhaps due to flake ridges or a curved shape. This suggests a tool positioned at an angle to the contact material such that the ventral face and contact material form an acute angle, such as a plane, chisel, or adze.

\section{CONTACT MATERIAL HARDNESS}

As noted in the macrowear section, the occurrence of tools with snap fractures and the predominance of edgedamage flaking with step terminations all suggest a hard contact material. The distance of polish extension on the tool face does not appear to be an indicator of contact material hardness on these tools, as the polished side appears to have been at an acute angle to the contact material. The fact that polish extension ends in most cases at the point where the polished face becomes unaligned with the bit face, however, suggests contact with a hard, inflexible surface. Addi- tionally, the presence of noticeable edge attrition on seven of the tools suggests a hard contact material.

\section{FORCE OF TOOL MOTION}

While this study did not include looking for haft damage, the presence of what is almost certainly a formal haft element and the evidence for use on hard contact materials suggests that the tools were hafted in some manner in order to generate the force necessary to work the material. The flaking pattern on the bits does not suggest heavy percussion. Only a few tools have the fish-scale-shaped flakes usually associated with percussion tools, and these flakes are not large.

\section{LOW-MAGNIFICATION USE-WEAR SUMMARY}

The use-wear seen on the study population supports the previously cited use-wear studies, suggesting a tool that was used in a planing/adzing motion on a hard contact material such as wood. However, in the design of the use-wear program, it seemed prudent to include some experimental tool use on softer materials that were known to be available to the prehistoric tool users and that could have been "worked" with a tool motion similar to that inferred for the Clear Fork tools. Additionally, the softer materials provide a "control" group for the tools used on harder materials.

\section{Replica Program}

Eight replica Clear Fork tools were hafted and used experimentally in this program. Most of these had very small flakes which terminated with step shapes on the dorsal bit edge. These apparently came from final edge retouch of the bit with a small antler billet. Contact materials used in the program consisted of wood, bone, hide, and soft vegetal material. Only a few wood types were included, as Vaughan (1985:33) has noted that wood type does not seem to affect use-wear polish characteristics but only the speed with which they develop. However, a wide variety of tasks was accomplished with the woodworking tools (chopping, adzing, chiseling, rounding, hollowing). The hide-working experiment followed procedures described by Schutz (1992:334), who reviewed 31 ethnographic accounts of bison hide working from 16 culture groups.

\section{Woodworking Replicas}

\section{GG2(BIFACE)}

This replica was hafted in a short straight haft and used as a chisel. The short haft provided the handhold and striking point for the hammer. The tool was used to chisel wood (live oak) for 15 minutes. The ventral side of the tool was 
placed against the wood surface and thus was in greater contact than the dorsal side. When the bit of the replica was examined at low magnification (20X), edge-damage flaking was visible on the dorsal bit face. These flakes all had steptermination shapes. Polish was visible on the ventral bit edge and extended approximately $3 \mathrm{~mm}$ back on the bit face. This polish was not developed enough to have distinctive characteristics at high magnification.

\section{GG4(BIFACE)}

This replica was hafted in an L-shaped haft and used as an adze. It was used to adze/hollow-out a piece of seasoned live oak for 30 minutes. The ventral side of the tool was in primary contact with the wood. When this tool was examined at low magnification, there were edge-damage flake scars with step-termination shapes on the dorsal bit face and one large flake scar with a hinge-termination shape on the ventral bit face. There was some slight edge rounding of the bit edge in a few areas and moderately bright polish was evident on the ventral bit face. This polish extended 4 to $5 \mathrm{~mm}$ back on the bit face. When examined at high magnification, the polish did not show distinctive characteristics.

\section{GG7(BIFACE)}

This replica was hafted in an L-shaped haft and used as an ax. Although hafted like an adze, the tool was used to chop into wood (live oak) at a steep contact angle (although the strike direction was not quite as vertical to the wood as when using an ax). The tool was used for 45 minutes with the ventral side in greater contact than the dorsal (due to the haft direction/swing plane). When examined at low magnification, edge-damage flaking with step-termination shapes could be seen on both the dorsal and ventral bit face. In addition, several fish-scale-shaped flakes were evident on the ventral bit face. Bright polish was visible extending back 4-5 $\mathrm{mm}$ on to the ventral bit face. When examined at high magnification (200X), this polish had a domed morphology arranged in a linear pattern in some spots (Figure 22-77).

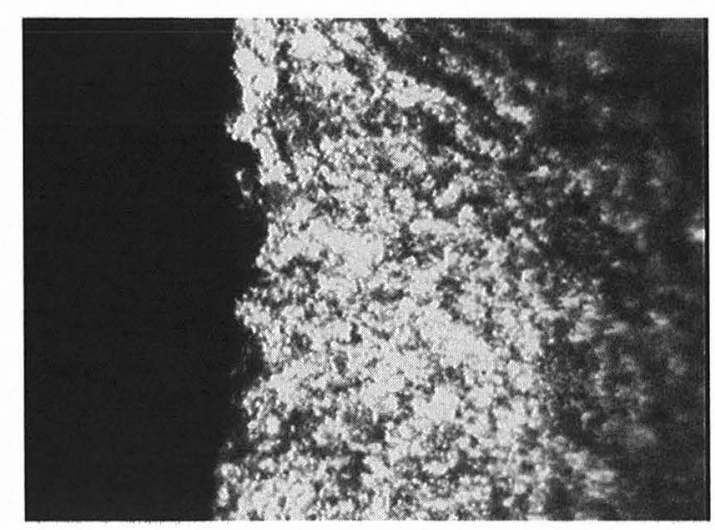

\section{Soft Plant Processing Replica}

The biface used in soft plant processing (GH1) was hafted in an L-shaped haft and was used to decorticate prickly pear pads for 15 minutes. At low magnification (20X), a few edge-damage flakes with step-termination shapes were visible on the dorsal bit face. There was some light rounding of the bit edge, and bright polish extended $5 \mathrm{~mm}$ back on high spots on the ventral bit face. At high magnification, this polish exhibited a vaguely domed surface morphology, but the domes were not very structured. The polish (Figure 2278) was more invasive than that produced by woodworking, and the margins between the polished areas and the unaltered areas were less distinct.

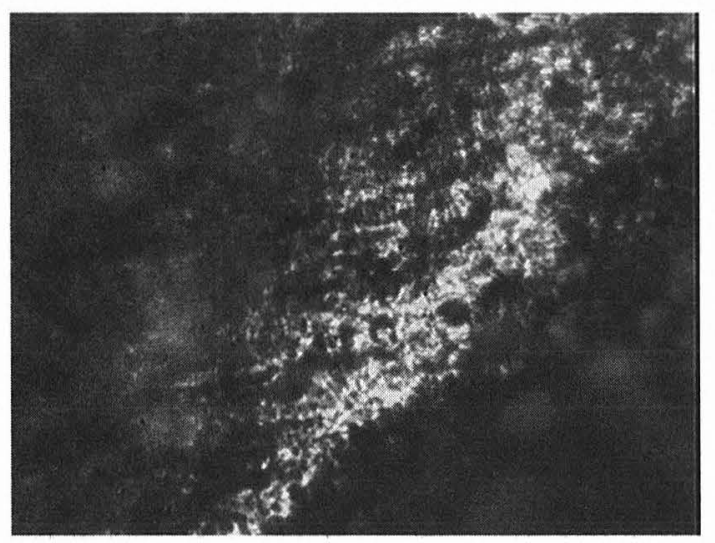

FIGURE 22-78. Polish from soft plant processing on replica tool GH1 (200X).

\section{Hide-working Replicas}

\section{GG9(BIFACE)}

This tool was mounted in an L-shaped haft and used for 30 minutes to deflesh a stretched deer hide and then to dehair the other side for 15 minutes. The ventral side was in primary contact with the hide. No edge-damage flaking was evident at low magnification (20X), but there was moderate edge

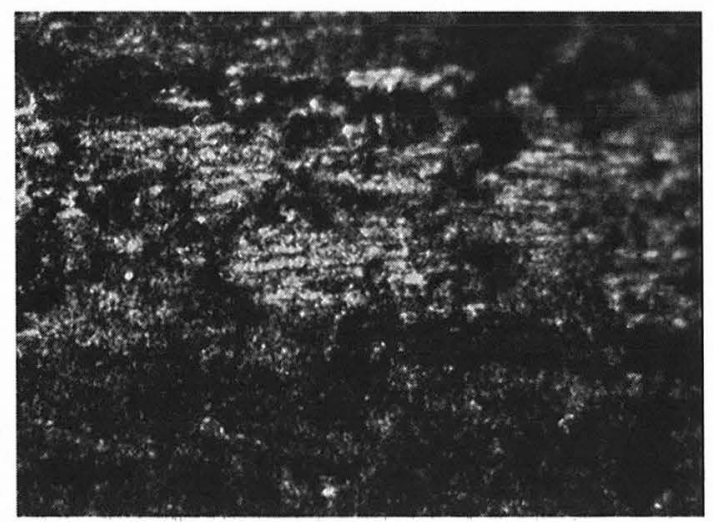

FIGURE 22-77, Polish in two different spots on replica tool GG7 (200X). 
rounding on the corners of the bit. The high ridges of corners also exhibited bright polish that had unclear or fuzzy boundaries between the polished and unpolished tool areas and little structure to the surface morphology when viewed at high magnification (Figure 22-79).

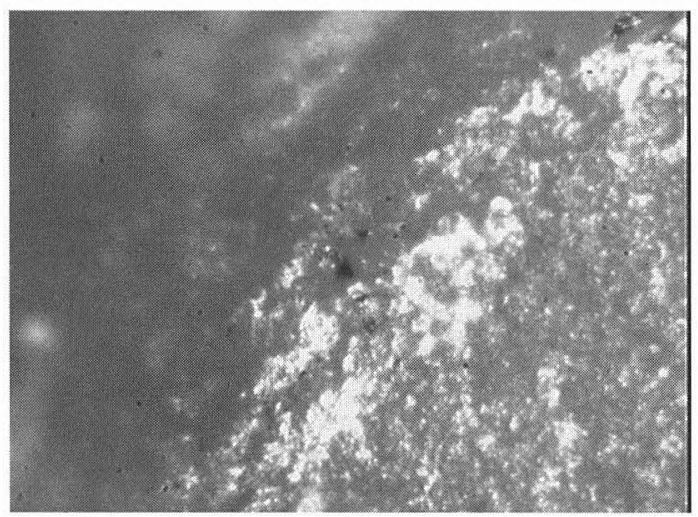

FIGURE 22-79. Polish from hide working on replica tool GG9 (200X).

\section{HH1 (BIFACE)}

This tool was made large enough to be handheld and was used to grain stretched deer hide for 20 minutes. As in the case of the other hide-working tool, no edge-damage flaking was evident at low magnification. Very bright polish extended back 12 to $15 \mathrm{~mm}$ on the ventral face in linear patterns. The polish was similar to that on the other hide-working replica as it had fuzzy edges and lacked structure when viewed at high magnification.

\section{Bone-working Replicas}

\section{GG1 (UNIFACE)}

This tool was mounted in a straight haft and was used to scrape fat and cartilage from a fresh cow bone for 15 minutes. When the bit was examined at low magnification, there was no edge-damage flaking or rounding, but there was noticeable edge attrition. There were only a few spots that had polish on the ventral bit face and this polish lacked distinctive characteristics at high magnification (Figure 2280).

\section{GG2 (BIFACE)}

This tool was mounted in an L-shaped haft and was used to chop/break bone. In fact, the bone proved to be much harder than seasoned oak and the bit began attriting rapidly from large flakes being driven off the bit edge. The tool was only used for four minutes to avoid losing the polish through bit attrition. This tool was relatively wide and thin for a Clear Fork, and probably one of the narrow, thick tools would have done a better job. When examined at

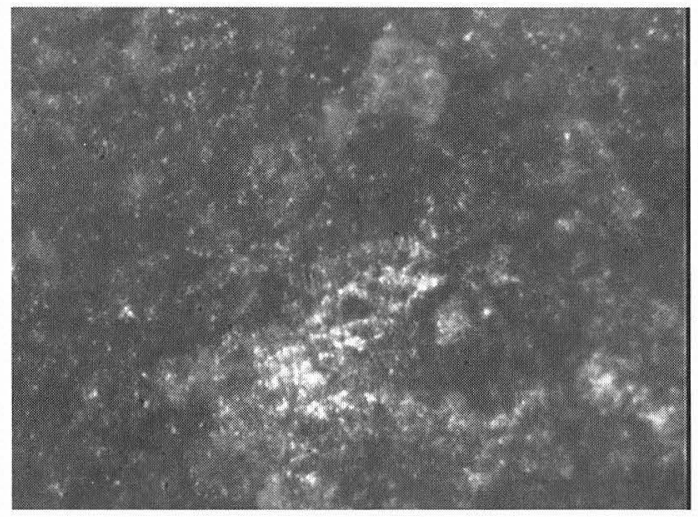

FIGURE 22-80. Bone polish just beginning to develop on replica GG1 (200X).

low magnification, there was noticeable edge crushing and edge-damage flaking with both hinge and feather termination shapes on the dorsal and ventral bit face. Moderately bright polish could be seen extending $4 \mathrm{~mm}$ back on the ventral bit face, however it was not developed enough to have a distinctive surface morphology.

\section{Summary of Replica Use-wear Analysis}

Overall edge-damage flaking generally followed expectations (Table 22-10). Flakes with step-terminations occurred on the dorsal bit edge of most of the woodworking replicas, and the replicas used at steeper contact angles to chop wood and bone had scalar-shaped flakes driven from the bit edge by percussion. The replica used to decorticate prickly pear pads had less edge-damage (a few flakes with step-termination shapes removed from the ventral bit face), and the tools used on hide had no edge-damage flaking. Bit edge rounding was not common on the replicas, as edge-damage flaking continually took off small parts of the edge. One of the hide-working replicas (GG9) did develop moderate edge rounding on both corners of the bit. The replica used to chop bone (GG2) had some edge crushing.

None of the replicas had striations, however linear polish "streaks" that could be seen at low magnification occurred on two tools. All of these linear indicators were perpendicular to the bit and occurred on the ventral side of the bit (which was the side of the tool in primary contact with the worked material).

Polish that could be seen at low magnification developed on all nine of the replicas, and it ranged from moderately bright to very bright. Polish extension was 3 to $5 \mathrm{~mm}$ on the primary contact face of the replica for all contact materials except hide, where it extended $15 \mathrm{~mm}$.

The polish/residue on four of the replicas had distinctive surface morphologies when observed at high magnification (200X). One of the woodworking replicas (GG7) had polish/residue that matched descriptions in Vaughan (1985:33) of domed polish. The domes seemed to have 
TABLE 22-10

Replica Tool Use-wear Summary

\begin{tabular}{|c|c|c|c|c|c|}
\hline Tool No. & Contact Material & Edge Flaking & Edge Rounding & Motion Indicators & Polish Characteristics \\
\hline GG2 & wood & step & none & none & not developed \\
\hline GG4 & wood & step/hinge & slight & none & not developed \\
\hline GG7 & wood & step/cone & none & none & domed \\
\hline GG8 & wood & none & none & perpendicular & not developed \\
\hline GH1 & prickly pear & step & slight & none & vaguely domed \\
\hline GG9 & hide & none & moderate & none & fuzzy \\
\hline HH1 & hide & none & none & perpendicular & fuzzy \\
\hline GG1 & bone & none & attrition & none & not developed \\
\hline GG2 & bone & hinge/feather & crushing & none & not developed \\
\hline
\end{tabular}

structure to their patterning in that they were lined up in the direction of tool use in some cases (see Figure 22-77). The polish/residue on the replica used to decorticate prickly pear pads (GH1) was vaguely domed, but the polish/residue edges were less distinct (see Figure 22-78). The polish/residue on both of the replicas used to work hide had fuzzy margins (Kimball et al. 1995:16) and had little structure (see Figure 2279). The polish/residue on the replica used to chop bone was not very well developed but did show distinct margins and faint linear patterns (see Figure 22-80).

\section{Archeological Tool Use-wear Observations at High Magnification}

Twenty-nine archeological tools from the WilsonLeonard site ( $49 \%$ of the total study population) were selected for high-magnification use-wear study based on the amount of wear and polish visible on the bit at low magnification. Twenty-three are bifaces, and 6 are unifaces. The particular focus of the high-magnification effort was to determine if polish characteristics are visible that support inferences on contact materials. All of the tools were scanned at high magnification, and five polish types - domed, smooth, smooth with fuzzy boundaries, unpatterned with fuzzy boundaries, and generic/not well developed-were defined based on the observations.

Domed polish has a surface morphology apparently made up of small domes that gradually link together and distinct margins between the polished and unaltered surfaces. The domed polish has two variations: domes that formed in linear patterns generally aligned with each other (domed linear), and domed with no linear patterns (domed nonlinear). Smooth polish has a flat surface morphology, frequently with long, narrow linear features. Smooth polish with fuzzy margins has a smooth to gently rolling surface morphology with fuzzy or unclear margins between the polished and unaltered surfaces. Unpatterned polish with fuzzy margins has a definite structure to the surface morphology, but it is variable and has fuzzy or unclear margins between the polished and unaltered surfaces. The generic/not welldeveloped category includes polishes that are not com- pletely developed (like Vaughan's [1985:27] description of smooth-pitted, for example) or possibly polishes that were generated by soil movement (Vaughan's [1985:30] soil sheen).

The presence of four different polishes that have distinct characteristics suggests four different formation processes and perhaps four different contact materials. Thus, the high magnification study group was broken into four categories for the purpose of making tool function/contact material inferences. The use-wear types evident on 22 of the 29 Clear Fork tools examined under high magnification are shown in Table 22-11 by polish group.

\section{Domed Polish}

Fifteen tools were judged to have domed linear or domed nonlinear polish. Both of these polish types closely resemble the polish developed on a replica tool used to work wood (see Figure 22-77). Domed polish also appears to be common on Clear Fork tools from many other sites in Texas. Selected polish images from the replica program, Clear Fork tools from the Wilson-Leonard site, and Clear Fork tools from some other sites in Texas provide an illustration of the varying stages of domed polish development, from just developed to so developed that it is barely identifiable (Figure 22-81). Nine tools from Wilson-Leonard have the domed linear variant: 7J-5, 10S-3, 12L-9, 15AA2-2, 15G-11, 20I-4, 25Q2-1, 35U1C-2, and 36P-7. All are bifaces except 20I-4. One of these tools is a distal end with a snap fracture (15AA2-2) and one has a very worn bit (25Q2-1). Seven have edge-damage flaking, with three tools having flakes with step-termination shapes, three having flakes with both step and hinge termination shapes, and one having flakes with hinge termination shapes. Two have slight edge rounding (15G-11 and 35U1C-2). All have linear motion indicators perpendicular to their bits. One (7J-5) is unique in that the wear patterns are reversed from those of the other tools. The heavy polish is on the dorsal face of the bit rather than the ventral face, and the edge-damage flaking with step-termination shapes is on the ventral bit face rather than the dorsal face, suggesting that this tool was hafted in the opposite direction from the others. The unifacial tool (20I-4) has both domed linear and 
TABLE 22-11

Frequency of Use-wear Types by Polish Groups

\begin{tabular}{|c|c|c|c|c|c|c|c|c|c|c|c|}
\hline & \multirow[b]{2}{*}{ Tools } & \multicolumn{3}{|c|}{ Bit Flaking } & \multicolumn{2}{|c|}{ Bit Rounding } & \multirow[b]{2}{*}{ Bit Very Worn } & \multicolumn{3}{|c|}{ Striae Angle to Bit } & \multirow[b]{2}{*}{ Tool Broken } \\
\hline & & Step & Hinge & Step/hinge & Slight & Moderate & & $90^{\circ}$ & $30^{\circ}$ & Parallel \& $90^{\circ}$ & \\
\hline Domed linear & 9 & 3 & 1 & 3 & 2 & & 1 & 9 & & & 1 \\
\hline Domed non-linear & 6 & 3 & 1 & & 1 & 1 & 1 & & & & \\
\hline Smooth & 4 & 1 & 1 & 1 & & & 1 & & 2 & & \\
\hline Smooth fuzzy & 1 & & & 1 & & & & & & 1 & \\
\hline Unpatterned fuzzy & 2 & 2 & & & & & & & 1 & & \\
\hline
\end{tabular}

a
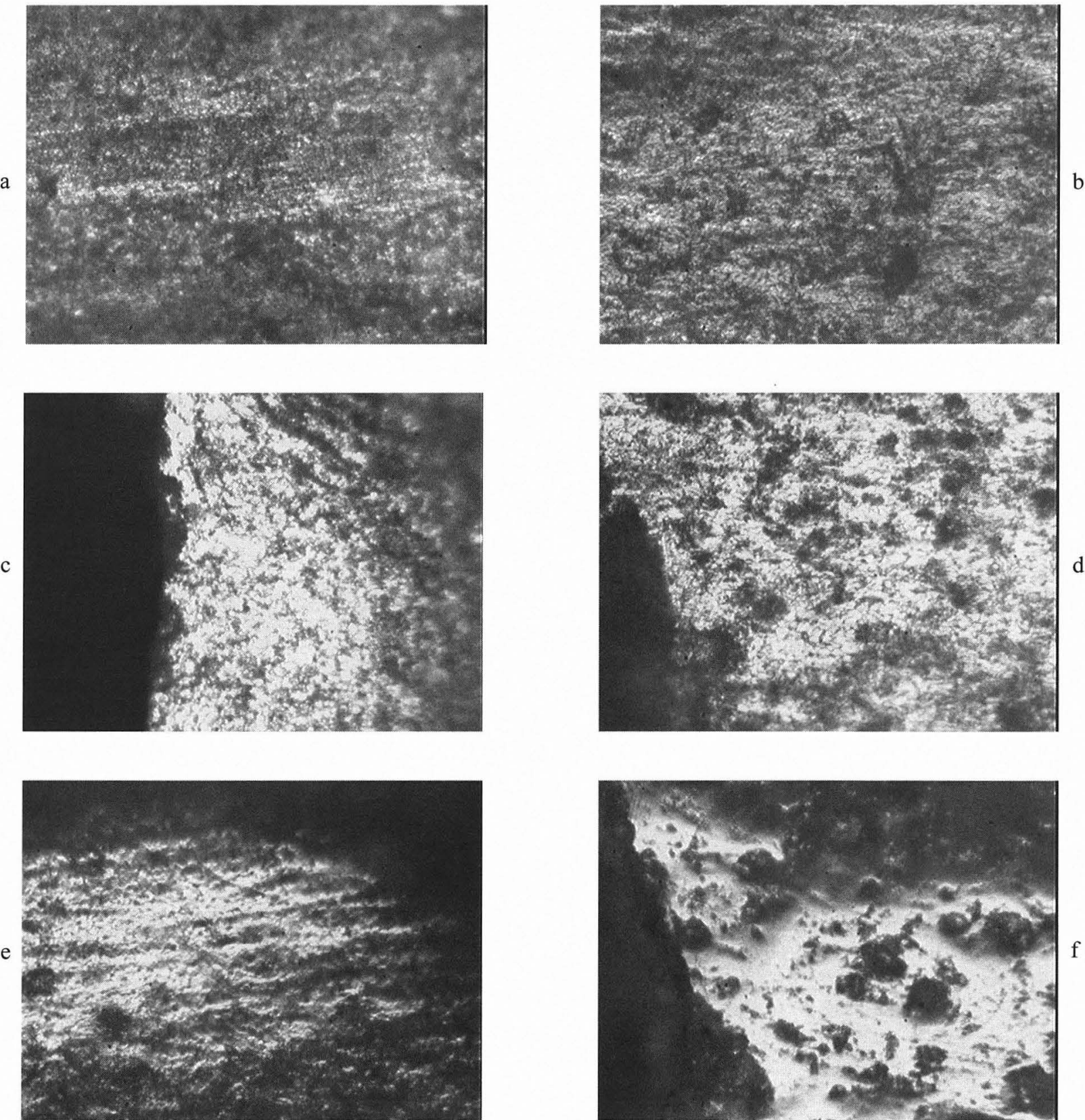

Figure 22-81. Domed polish development at 200X. (a) replica GG7; (b) Clear Fork specimen (198) from the River Spur site (41VT112); (c) replica GG7; (d) Clear Fork specimen (3790) from the Morhiss site (41VT1); (e) Clear Fork specimen (269) from the River Spur site; (f) Clear Fork specimen (12L-9) from the Wilson-Leonard site. 
smooth polish spots on it, suggesting either more than one type of contact material or that the two polish types are related to the same contact material. These tools range in age from Late Paleoindian to Late/Middle Archaic.

Six tools have the domed polish variant that has no linear patterns: 9J-7, 9L-2, 18J-10, 21L-38, 30T1C-3, and 51AA1D-3. Three are bifaces and three are unifaces. One (30T1C-3) has a very worn bit. Four have edge-damage flaking, with three having flakes with step-termination shapes and one having flakes with hinge termination shapes. One of the tools (30T1C-3) has slight edge rounding and one (9J-7) has moderate edge rounding. None has linear motion indicators. One unifacial tool (9L-2) has both domed and smooth polish spots. Note the similarity in edge-damage flaking and rounding patterns in Table 22-11 between the domed and domed linear polish variants. The similarities in wear patterns and polish morphology suggest that these polishes are from the same contact material, but the domed polish is missing the linear alignment because it formed in an area of the tool that was receiving less abrasion from the worked material. Note also that the wear patterns that occur with the domed linear and domed nonlinear polish variants are very close to those of the woodworking replicas. The lack of cone-shaped percussion flakes (which occurred on the replicas used to chop wood) on the archeological tools suggests that they were not used as chopping tools. The tools range in age from Paleoindian to Late/Middle Archaic.

\section{Smooth Polish}

The smooth polish appears to be a mixture of polish and a large amount of residue from the contact material. The polish appears to be additive and has a lot of linear indicators or grooves imbedded in it (Figure 22-82a). Although the polish appears very different from the domed variants, the apparent residue overlying/mixed with it raised the concern that it might be domed polish with residue obscuring it. To determine whether this was the case, a Clear Fork tool that had smooth polish and was from poor context at another site in Texas (41UV2) was cleaned with a $10 \%$ solution of hydrochloric acid for 10 minutes to remove the residues. The polish that remained had clear margins but did not have the same surface morphology as the domed polish (Figure 22$82 \mathrm{~b})$. None of the polish on the replicas matched this polish.

Four tools from the Wilson-Leonard site have smooth polish/residue with linear features: $1 \mathrm{~F}-1,7 \mathrm{~N}-3,12 \mathrm{~S}-1$, and $34 \mathrm{X} 2 \mathrm{~A}-1$. All are bifaces and one $(7 \mathrm{~N}-3)$ has a perforator rather than a haft element opposite the bit. The polish on the latter specimen was on the perforator and not the bit (which did not have well developed polish) so this tool is treated separately later in this section. One (1F-1) of the three tools with polish on the bit has large flakes removed from the bit and looks to have been used on a very hard contact material. A second (12S-1) has large flakes, either from use-wear or some other cause, removed from the ventral bit face. All
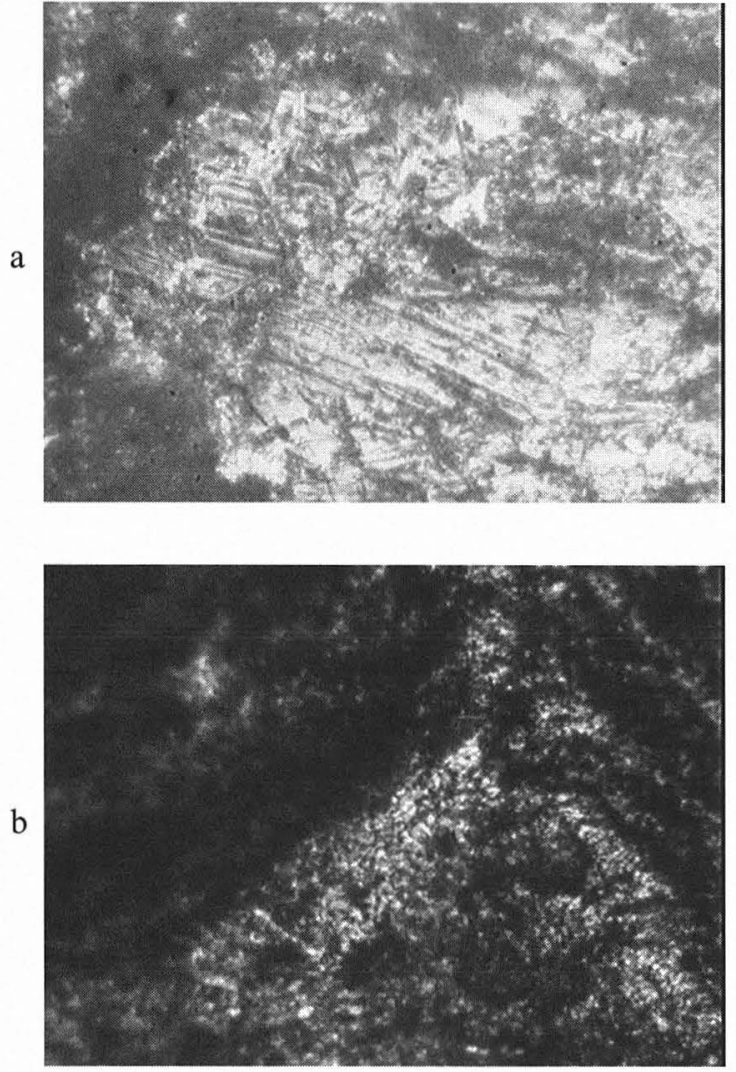

FigurE 22-82. Smooth polish at 200X. (a) Specimen 1F-1; (b) smooth polish after acid cleaning on a Clear Fork specimen from 41UV2.

three have edge-damage flaking, with one having flakes with step-termination shapes, one having flakes with both stepand hinge-termination shapes, and one having flakes with hinge-termination shapes. None of the tools has edge rounding. Two have linear motion indicators running at $30^{\circ}$ angles to the long axis of the tools. The edge-damage patterns on these tools suggest that the contact material was at least as hard and probably harder than that which caused the domed linear and domed nonlinear polishes (judged to probably be wood). The contact material left a lot of residue on the tools, so a hard animal product such as bone or antler is a good candidate. The tools range in age from Late Paleoindian to Archaic undifferentiated.

The perforator (7N-3) has small edge-damage flakes with step-terminations on its lateral edges. A spot of polish on the tip has linear features perpendicular to the long axis of the tool. Another spot near the tip has linear features at $45^{\circ}$ angles to the long axis. Thus this tool appears to have been used to perforate the same kind of material as the three Clear Fork tools in this group were used to work.

\section{Smooth Fuzzy Polish}

One tool (39FF-2) has smooth fuzzy polish. From Paleoindian context, this specimen is a bifacial distal section 
with a snap fracture. The bit has edge-damage flaking with both step- and hinge-termination shapes. There are small, thin polish streaks that run both parallel and generally perpendicular to the bit edge, visible at $20 \mathrm{X}$ on the ventral bit face. A large thin flake has been detached from the ventral bit face after the polish streaks were deposited. This tool has a unique wear pattern and does not resemble any of the replica tools. The fuzzy polish margins (Figure 22-83) suggest an invasive contact material (one that is flexible/yielding enough to wrap around the surface topography).

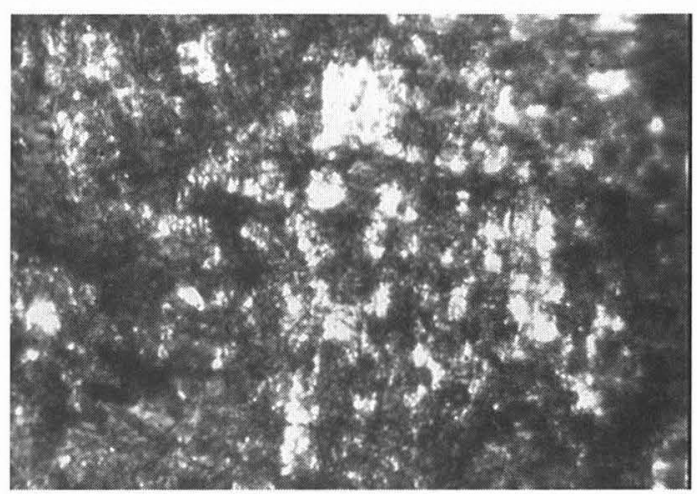

Figure 22-83. Smooth fuzzy polish on Specimen 39FF-2 (200X).

\section{Unpatterned Polish with Fuzzy Margins}

Two tools have this type polish: 16G-7 and 51WB-3. They differ greatly in morphology, although they have the same general wear pattern and polish (both have small edgedamage flakes with step-termination shapes). Specimen 16G-7 is a thin, unifacial tool that appears to have had flakes intentionally removed from the ventral bit face to create a serrated edge. Morphologically, the tool matches descriptions by Schutz (1992:334) of hide defleshers that were mounted on L-shaped hafts and kept very sharp to deflesh bison hides. The fuzzy polish margins (Figure 22-84) suggest a soft or flexible contact material, so this interpretation would fit well with the morphological and ethnographic evidence.

Specimen 51WB-3 is a Brushy Creek biface that appears to have had the bit reshaped by the removal of large flakes (with feather terminations) from the ventral bit face. There are several linear polish features on the ventral face that run at $30^{\circ}$ angles to the long axis of the tool.

\section{Interpretation of Use-wear Visible at High Magnification}

\section{GENERALFUNCTION}

Both bifacial and unifacial Clear Fork tools have been found at the Loma Sandia site (41LK28) in probable Middle Archaic burials. Taylor (1995:404) notes the utilitarian nature of the mortuary inclusions at this site and suggests that they are both the deceased's personal gear and items con-

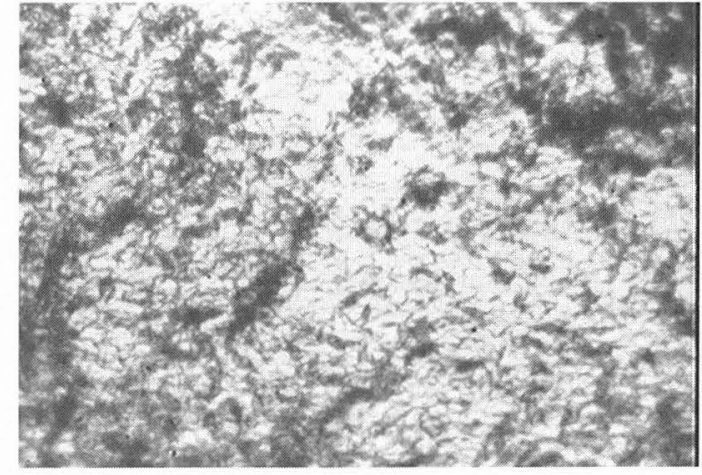

FIGURE 22-84. Unpatterned polish with fuzzy margins on Specimen 16G-7 (200X).

tributed by mourners. It is interesting to note that Clear Fork tools are probably associated with both male and female burials, raising the possibility that both genders accomplished tasks requiring Clear Fork tools. Binford (1979:261) has categorized hunter-gatherer gear based on Nunamuit examples, and it appears from the Loma Sandia context that Clear Fork tools would fall in his "personal gear" category (kept in anticipation of future activities). Keeley (1982:789-799) and Shott (1986:39) feel that evidence of hafting indicates a curated tool, and the Clear Forks were almost certainly hafted to apply the force required to work a hard material. Binford and Binford (1966:249) have also suggested that tools with working edges perpendicular to their longitudinal axis were used for tool manufacturing and maintenance (i.e., machine tools in modern terminology). Both of Binford's suggestions fit well with the groupings of items (which include Clear Fork tools) found in mortuary inclusions at the Loma Sandia site.

\section{SPECIFICFUNCTION}

The 15 tools on which domed polish was observed appear to fit the "classic" definition of Clear Fork tools. Although tool morphology and manufacturing technology vary, with 11 being bifacial and 4 unifacial, the use-wear data suggest that they were used in a planing/adzing motion to manufacture and maintain wooden implements.

Seven tools from the Wilson-Leonard site appear to have been functionally different from the tools with domed polish. The four with smooth polish appear to have been used on a different contact material. From the edge-damage evidence, the material appears to have been harder than that resulting in domed polish (inferred to be wood) and left a lot of residue on the tools. A hard animal product such as bone or antler appears to be a good candidate, and the tool motion appears to have been planing/adzing, but at an angle to the bit.

One tool has a unique wear pattern. Its edge-damage and snap fracture suggest a hard contact material, yet the polish is invasive and appears to from a soft/flexible material, suggesting more than one contact material. Its complex wear pattern seems to indicate a task requiring different tool motions or perhaps multiple uses. 
Two tools with different morphologies and from different cultural contexts have unpatterned polish with fuzzy margins. Ethnographic evidence supports the inference that one was a hide deflesher, while the possible function of the other is unclear.

\section{Summary}

It appears from the evidence at the Wilson-Leonard site that, as expected, many Clear Fork tools were used to manufacture and maintain wooden implements. However, one specimen categorized as a Clear Fork tool is a probable hide deflesher, and four others appear to have been used on hard materials other than wood, perhaps on bone or antler. An additional two tools appear to have been used on other (perhaps softer) contact materials in functions that are as yet unclear. The use-wear data from WilsonLeonard and other Texas sites suggests that Clear Fork tools are morphologically similar tools with differing functions at different points in time and space. 


\section{Chapter 23}

\section{ANALYSES OF RESIDUES ON ARTIFACTS}

by W. Jeffrey Hurst, Curt W. Beck, Edith C. Stout, Jonathan Bingham, and Michael B. Collins

\section{INTRODUCTION}

by Michael B. Collins

Residue analysis is not a mature aspect of archeo-chemistry. The basic premise is that chemico-analytical techniques applied to prehistoric artifacts yield otherwise unobtainable information about materials that have come in contact with those artifacts, but in practice, there is strong disagreement about the methods used and the results obtained over the last dozen years or so (cf. Fiedel 1996). Most archeologists are not sophisticated in their understanding of chemistry, few chemists appreciate the complex histories of artifacts, and there are few hard data on the consequences of artifact residues having remained subject to ongoing chemical processes for centuries or millennia. These conditions have sometimes resulted in unrealistic expectations, questionable procedures, and simplistic interpretations of results. Expectably, and ultimately for the benefit of science, such shortcomings have been severely criticized; unfortunately, there has also been a tendency to overreact and to discredit any and all efforts at identifying and interpreting chemical residues on artifacts. Resolving the controversy and earning a respectable status for valid studies will be a slow and tedious process of educating chemists to the complexities of the archeological record and archeologists to the possibilities and limitations of sound analytical chemistry. And doing so will be hampered by the substantial archeological requirements of chemical residue analysis from research design to finished report, the very high costs of doing the analyses, and the scarcity of chemists who have both the interest and the facilities.

A primary objective of the second season of fieldwork at Wilson-Leonard was to collect a large sample of artifacts in secure contexts for chemical residue analysis. The strategy was to conduct analysis on a modest proportion of those artifacts for the dual purposes of enhancing interpretation of certain kinds of artifacts and attempting to collabo- rate with analytical chemists toward improving the standing of chemical residue analysis. Initially, we envisioned only assaying for organic residues.

During the TARL fieldwork, 753 stone artifacts were exposed in situ, removed, and wrapped in aluminum foil without being touched except by clean metal tools. These were designated as "OR" (organic residue) samples. Twenty of these were submitted without washing to C. W. Beck at Vassar College in 1993 for an assessment of their potential for organic residue analysis. Based on his findings, which encouraged further analyses, it was determined that further descriptive study in the archeological laboratory of OR artifacts could be facilitated by properly cleaning some of the adhering dirt from the remaining 733 specimens. Therefore, in the TARL laboratory (where any necessary handling was done with clean rubber gloves), these 733 artifacts were washed individually in a gentle stream of deionized water, allowed to dry, documented by xerographic image onto a form with provenience and basic descriptive information, and stored for analysis. Sixty-one samples from this latter group were later sent to W. J. Hurst of Hershey Medical Center, Hershey, Pennsylvannia, who intensively assayed 15 of these along with 7 among an additional 10 specimens sent to him from the TxDOT collections. Therefore, 42 specimens have been analyzed at least to some degree for chemical residues, and 718 collected as OR specimens are available for future studies.

The project was fortunate to have the participation of two outstanding senior chemists with interests in the analysis of archeological chemical residues, but finding Drs. Beck and Hurst was a enlightening experience. I contacted dozens of archeochemists in the United States, Canada, and Great Britain and found them all to be either too busy, not interested in the research questions we posed, or lacking in the necessary analytical equipment. Finally, Dr. Beck, at some urging, agreed to conduct a preliminary assessment of a representative sample of the kinds of artifacts we wanted 
analyzed. His findings, reported earlier (Beck and Bingham 1994) and summarized briefly below, indicated the presence of organic compounds in limited quantity and mostly in badly degraded condition. Beck, constrained by the equipment available at his facility, primarily used the gas chromatography-mass spectrometry (GC-MS) approach and suggested that it would be of interest to see if additional procedures might be more productive. He recommended that we find a laboratory with alternative capabilities, which led us circuitously to Dr. Hurst.

In the judgement of Beck, Hurst, and the WilsonLeonard archeological team, the challenge was equally one of exploring analytical procedures and one of identifying and interpreting archeological residues. Therefore, and we believe appropriately given the present immaturity of the field of prehistoric chemical residue analyses, this study has invested its limited resources in intensively assaying a small number of objects with an array of techniques rather than applying a single routine to a larger number. This approach was chosen with the intent of having results with higher levels of confidence on fewer specimens.

Findings made by Beck's team are presented below followed by those of Hurst. Hurst concludes with a suggested analytical protocol for future studies of the Wilson-Leonard or any similar specimens. These two studies confirm the presence of preserved organic and inorganic residues on stones from prehistoric contexts at the site, and it is clear that with ever-increasing effectiveness of techniques for extracting and identifying these residues, much can be learned. This is shown, for example, by the probable identification to genus level a $\mathrm{C}_{15}$ acid residue on six artifacts and by the apparent role of insoluble lipophilic residues in preserving soluble residues on tool surfaces. These results are among those reported below, respectively, by the Vassar team and by Hurst.

\section{ANALYSIS OF ORGANIC RESIDUES ON WILSON-LEONARD ARTIFACTS BY GAS CHROMATOGRAPHY-MASS SPECTROMETRY}

by Curt W. Beck, Edith C. Stout, and Jonathan Bingham

This study examined the organic residues of 20 stone artifacts, including 17 chipped stone objects, a ground stone fragment, and 2 burned rocks, all from the three stratigraphic Units I, II, and III. The artifacts were received in an unwashed state.

In the laboratory, any visible residue was scraped off each artifact, weighed, and dissolved in diethyl ether, an organic solvent. The insoluable (inorganic) portion was removed by filtration, dried, and weighed to calculate the weight of the soluble (organic) portion by difference. The amount of residue obtained ranged from $26 \mathrm{mg}$ to $19 \mathrm{~g}$, and the percentage of ether-soluble organic matter ranged from $0.5 \%$ to $3.4 \%$. In absolute numbers, the ether-soluble organic matter ranged from a low of $0.0006 \mathrm{~g}$ to a high of $0.2911 \mathrm{~g}$ (Table 23-1). The ether solution was then treated with diazomethane to convert free fatty acids to their more volatile methyl esters, concentrated, and subjected to gas chromatography-mass spectrometry (GC-MS) in a Hewlett-Packard Model 5995C/96A GC-MS system equipped with a Model 5997A computer workstation. The column used was a $15 \mathrm{~m}$ RSL-150 poly(dimethylsiloxane) capillary column. The initial oven temperature of $50^{\circ} \mathrm{C}$ was raised at the rate of $5^{\circ} \mathrm{C}$ /minute to $250^{\circ} \mathrm{C}$ and then held constant.

Gas chromatography separates volatile compounds by molecular weight and polarity and displays the components of a mixture as peaks along the elapsed time axis of a total ion chromatogram as seen in Figures 23-1 and 23-2. The more peaks, the greater the number of organic components present. Importantly, there appears to be no correlation between the amount of the organic residue and the number of components detected (Figure 23-3). One of the 20 samples (OR696) contained no volatile organic component; the largest sample (OR379) contained only 1; and 1 of the smaller ones (OR398) contained 54 components in a weight of only $2.6 \mathrm{mg}$ of volatile organics. It must be noted that the analytical techniques employed require two properties to detect a component, those being solubility in ether and volatility at the column temperature. Many potential components in prehistoric food residues, notably proteins and carbohydrates, lack both of these requirements and, therefore, will not be detectable by this method.

Each of the components of the total ion chromatogram is then subjected to mass spectrometry: by bombardment with high-energy electrons, the component molecule is converted to positively charged fragments, the heaviest of which gives the molecular weight of the component and is known as the molecular peak. The last and most difficult step is to deduce the structure of the component from the weight and frequency of the charged fragments. This reconstruction depends heavily on the presence of the molecular peak which, however, is lacking in most of the 548 mass spectra we have obtained by the most common method of ionization, i.e., electron impact at $70 \mathrm{eV}$.

Three components have been positively identified by their mass spectra, including the molecular peaks and their retention times. They are the unbranched, saturated fatty acids myristic acid (tetradecanoic acid), palmitic acid (hexadecanoic acid), and stearic acid (octadecanoic acid), with 14, 16 , and 18 carbon atoms, respectively. Their distribution on the 19 artifacts containing volatile organics is shown in Table 23-2. Myristic acid was found on 8, palmitic acid on 17, and stearic acid on 13. There is no obvious correlation between the occurrence of any of these fatty acids and either artifact type or stratigraphy. Nor does their identification permit a reliable assignment to their specific faunal or floral origin, for all are widely distributed in both animal and plant fats (Gunstone et al. 1994; Hilditch 1956; Karrer et al. 1958-1981).

In addition to these three ubiquitous straight-chain fatty acids with even numbers of carbon atoms, there is a fourth that occurs in six of the samples in such small amounts that 
TABLE 23-1

Provenience and Amounts of Organic Residue Samples

\begin{tabular}{|c|c|c|c|c|c|c|c|}
\hline $\begin{array}{l}\text { OR } \\
\text { Specimen } \\
\text { No. } \\
\end{array}$ & Artifact Category & $\begin{array}{l}\text { Square/ } \\
\text { Level }\end{array}$ & Unit & Associations & $\begin{array}{l}\text { Amount of } \\
\text { Sample (g) }\end{array}$ & $\begin{array}{l}\text { Amount into } \\
\text { Solution }(\mathrm{g})\end{array}$ & $\begin{array}{l}\text { \% Sample } \\
\text { into } \\
\text { Solution }\end{array}$ \\
\hline 89 & Uniface & $16 / 4$ & IIIc & & 0.2607 & 0.0055 & 2.1 \\
\hline 152 & Flake & $13 / 6$ & IIIC & & 0.9699 & 0.0156 & 1.6 \\
\hline 180 & Dart point, Nolan & $11 / 9$ & $\mathrm{IIIb}$ & & 6.1610 & 0.0809 & 1.3 \\
\hline 227 & Biface, Stage 2 & $21 / 12$ & IIIb & & 1.4177 & 0.0167 & 1.2 \\
\hline 379 & Burned rock & $30 / 22 \mathrm{~B}$ & II & Feature 227 & 19.0915 & 0.2911 & 1.5 \\
\hline 388 & Burned rock & $20 / 19$ & IIIa & & 0.2072 & 0.0018 & 0.9 \\
\hline 392 & Flake tool & $30 / 23$ & II & & 0.8691 & 0.0050 & 0.6 \\
\hline 396 & $\begin{array}{l}\text { Dart point, contracting } \\
\text { stem, concave base }\end{array}$ & $27 / 24$ & IIIa & Feature 231 & 0.0481 & 0.0007 & 1.5 \\
\hline 398 & Flake & $27 / 24$ & IIIa & Feature 231 & 0.3027 & 0.0026 & 0.9 \\
\hline 405 & Mano fragment & $20 / 24$ & IIIa & & 8.6048 & 0.1188 & 1.4 \\
\hline 408 & Biface, Stage 2 & $27 / 24$ & IIIa & Feature 231 & 0.3017 & 0.0020 & 0.7 \\
\hline 419 & Perforator & $27 / 24$ & IIIa & Feature 231 & 0.0901 & 0.0018 & 2.0 \\
\hline 485 & Biface, Stage 2 & $100 / 5$ & IIIC & Burned Rock Midden 1 & 0.4456 & 0.0059 & 1.3 \\
\hline 525 & Flake tool & $26 / 31$ & II & & 0.0676 & 0.0018 & 2.7 \\
\hline 567 & Flake tool & $20 / 32$ & II & & 0.1266 & 0.0006 & 0.5 \\
\hline 575 & Perforator & $50 / 27 \mathrm{~A}$ & II & & 0.0845 & 0.0019 & 2.2 \\
\hline 585 & Burin spall & $20 / 34$ & II & & 0.0780 & 0.0015 & 1.9 \\
\hline 598 & Flake & $48 / 33$ & Id & & 1.7477 & 0.0169 & 1.0 \\
\hline 696 & Flake & $59 / 49$ & Isi/Icl & & 0.0264 & 0.0009 & 3.4 \\
\hline 741 & Flake & $53 / 52$ & Isi/Icl & & 0.0734 & 0.0019 & 2.6 \\
\hline
\end{tabular}

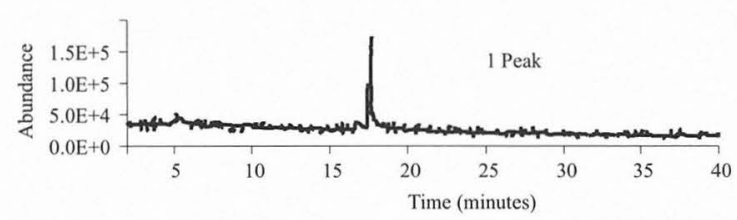

a

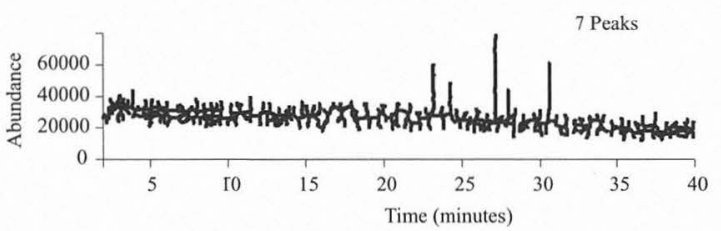

b

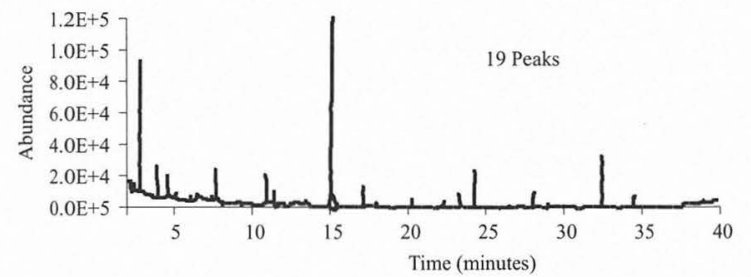

C

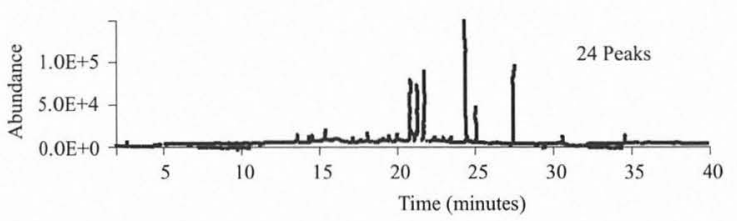

d

FIGURE 23-1. Total ion chromatograms. (a) OR379; (b) OR388; (c) OR741; (d) OR396.

none of its mass spectra fully identify it, because none has a molecular peak. The fragmentation pattern, however, leaves no doubt that this component is a saturated, unbranched fatty acid, and the retention time of 22.4 minutes falls exactly between those of myristic acid $\left(\mathrm{C}_{14}\right)$ and palmitic acid $\left(\mathrm{C}_{16}\right)$. This component can therefore be confidently identified as the $\mathrm{C}_{15}$-acid or pentadecanoic acid. This, like other highmolecular-weight straight-chain fatty acids with odd numbers of carbon atoms, is exceedingly rare and has never been given a common name. Its rarity, however, has the advantage that its presence in the organic residues on the stone implements allows some inferences about the materials used at the Wilson-Leonard site.

Pentadecanoic acid has been reported from only five genera. Two of these are not indigenous to North America: Shorea (southern Asia) and Calendula (Mediterranean to Persia) (Karrer et al. 1958-1981). The most suggestive source is the genus Zanthoxylum 


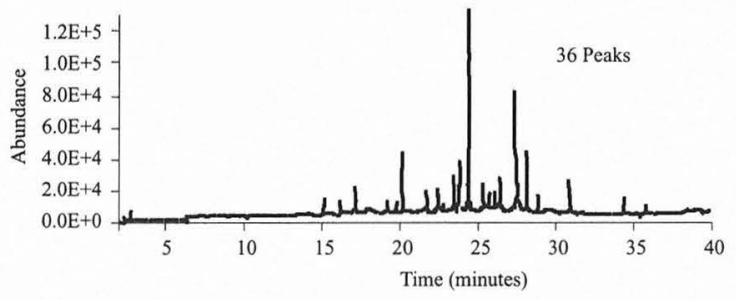

a

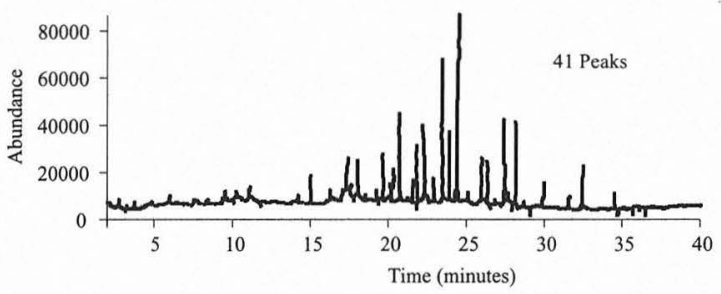

b

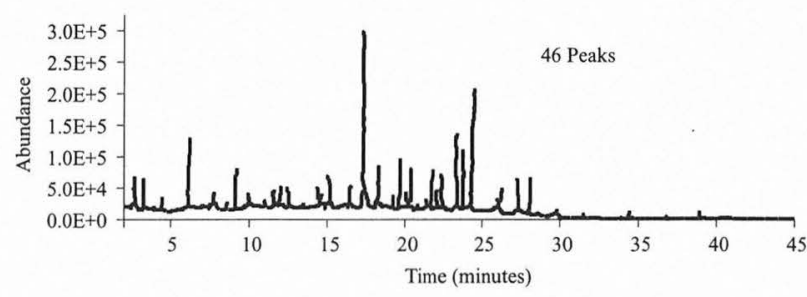

C

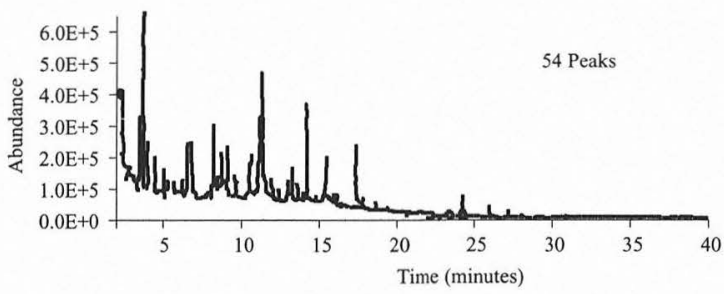

d

FIGURE 23-2. Total ion chromatograms. (a) OR405; (b) OR525; (c) OR575; (d) OR398.

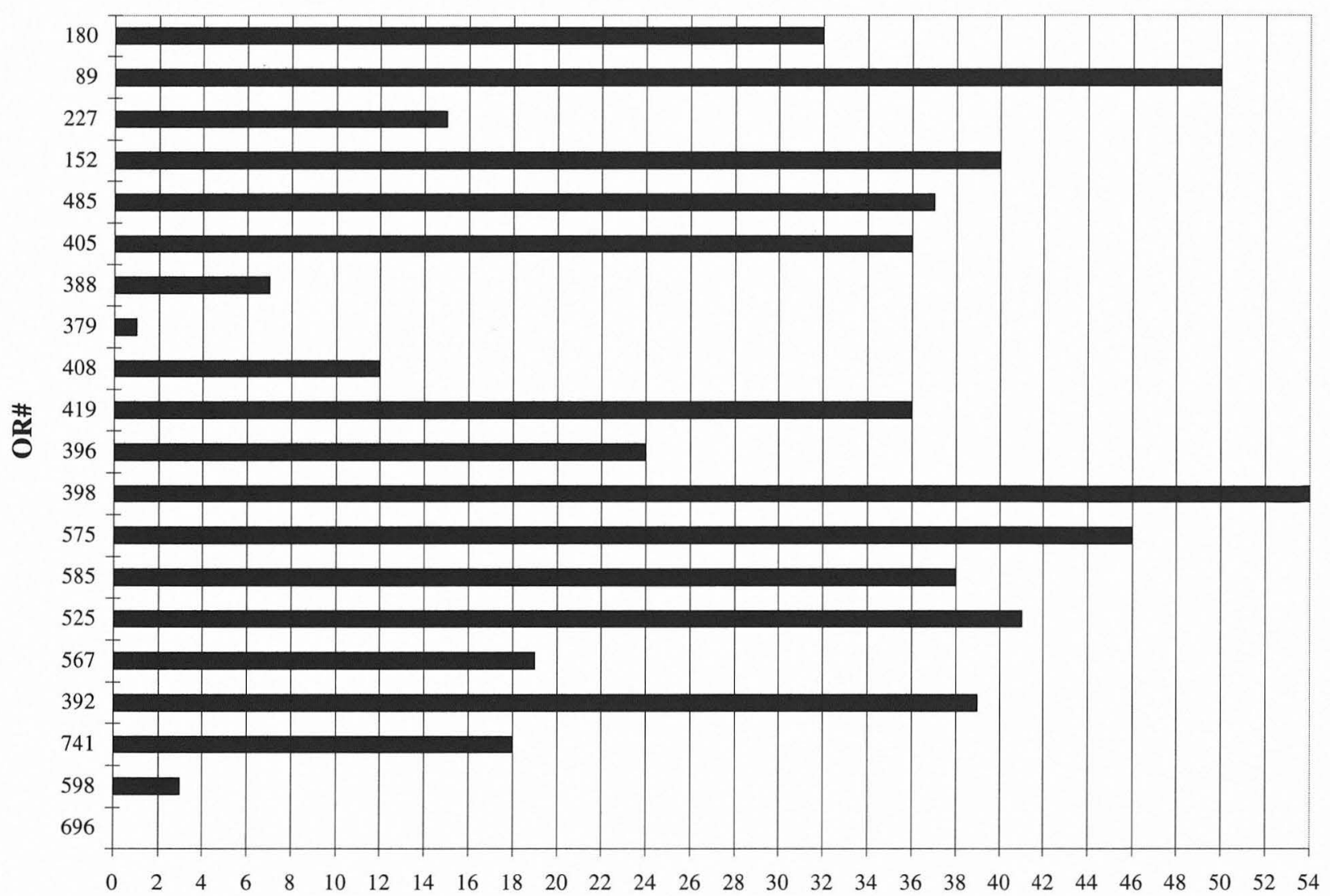

Number of M-S Components

FIGURE 23-3. Organic residues by artifact form, M-S component. 
TABLE 23-2

Fatty Acid Distribution on 19 Artifacts

\begin{tabular}{|c|c|c|c|c|c|c|c|}
\hline & Myristic Acid & $\mathrm{C}_{15}$ Acid & Palmitic Acid & Stearic Acid & Unknown 1 & Unknown 2 & Unknown 3 \\
\hline$\underline{\text { Sample }}$ & $\begin{array}{l}\text { Methyl Ester } \\
\mathrm{RT}=20.4 \\
\mathrm{MW}=242\end{array}$ & $\begin{array}{l}\text { Methyl Ester } \\
\text { RT }=22.5 \\
\text { MW }=256\end{array}$ & $\begin{array}{l}\text { Methyl Ester } \\
\text { RT }=24.5 \\
\text { MW }=270\end{array}$ & $\begin{array}{l}\text { Methyl Ester } \\
\text { RT }=28.2 \\
\mathrm{MW}=298\end{array}$ & $\begin{array}{l}\mathrm{RT}=23.5 \\
\mathrm{MW}=256\end{array}$ & $\begin{array}{l}\mathrm{RT}=27.4 \\
\mathrm{MW}=284\end{array}$ & $\begin{array}{l}\mathrm{RT}=31.0 \\
\mathrm{MW}=312\end{array}$ \\
\hline OR89 & + & & + & + & + & + & + \\
\hline OR152 & & & + & + & + & + & \\
\hline OR180 & & & & & & & \\
\hline OR227 & & & + & & & & + \\
\hline OR379 & & & & & & & \\
\hline OR388 & & & + & + & & & \\
\hline OR392 & + & + & + & + & + & + & + \\
\hline OR396 & + & & + & + & + & + & + \\
\hline OR398 & & & + & + & + & + & \\
\hline OR405 & + & + & + & + & & + & + \\
\hline OR408 & & & + & & + & + & \\
\hline OR419 & & + & + & + & + & + & \\
\hline OR485 & & & + & + & & + & \\
\hline OR525 & + & + & + & + & + & + & \\
\hline OR567 & & & + & & + & + & \\
\hline OR575 & + & + & + & + & + & + & \\
\hline OR585 & + & & + & + & + & + & \\
\hline OR598 & & & + & & & & \\
\hline OR696 & & & & & & & \\
\hline OR741 & + & + & + & + & + & + & \\
\hline
\end{tabular}

(=Xanthoxylum) which includes the prickly-ash also known as "toothache tree" and "tingle-tongue," the bark of which has yielded pentadecanoic acid (Karrer et al. 1958). Both the bark and the leaves are known to have been chewed as a pain killer by Amerindians of the northern United States (Yarnell 1964), and several species (including Z. fagara, Z. clava-herculis, Z. parvum, and Z. hirsutum) occur in Texas (Butterwick 1979; Neck 1988; Vines 1990). Neck (1988) included Z. hirsutum (or Southern Prickly-Ash) on an annotated list of plants he observed living on or near the Wilson-Leonard site in 19871988. Butterwick (1979:85, cited in Neck 1988:21) notes that "the bark of $Z$. hirsutum produces a stimulating tonic that induces sweating and cleanses the blood; the fruit is stimulating, antispasmodic, and antirheumatic (used as a vapor to treat respiratory troubles)." Zanthoxylum, however, is not a unique American source, for pentadecanoic acid has also been isolated from the genus Lonicera (honeysuckle) (Karrer et al. 1977) and from unspecified lichens (Gunstone et al. 1994).

A second group of three constituents is recognizable by their base peak (i.e., their most frequent ion) at $m \backslash z=100$. Their distribution on the artifacts (see Table 232 ) shows that they occur only on objects that also contain saturated fatty acids. As shown in Table 23-3, they yield perfectly identical electron impact (EI) spectra, but these are fragmentary and lack the molecular ion. The identical spectra and the evenly spaced retention times of these compounds make it obvious that they are members of a homologous series, i.e., compounds with closely similar structures differing only by the addition of one or more carbon atoms. Any attempt to determine the structure of these constituents depends on obtaining their molecular weight. This can be done by using a gentler ionization method called chemical ionization (CI) in which electrons of relatively low energy are used in the presence of a reagent gas. We were given access to a Finnigan MAT CI mass spectrometer in the Medical Examiner's Office of Fort Worth, Texas. The spectra obtained with methane as a reagent gas are listed in Table 23-3. While the capillary column and the temperature program were the same as those used in the electron impact (EI) work, the retention times are $0.8-0.9$ minutes shorter, indicating a newer column less depleted of stationary phase. The molecular weights of the three unknown constituents are 256,284 , and 312 , i.e., they have a constant mass difference of 28 or of two methylene $\left(-\mathrm{CH}_{2}-\right)$ groups. All three spectra have prominent $\mathrm{M}+-2$ peaks with intensities of 54 to $72 \%$ and prominent peaks at $\mathrm{mlz}=100$ with intensities of $78-100$. A search of the most comprehensive mass spectral database (McLafferty and Stauffer 1989) shows that no compounds with these characteristics have been reported. For lower molecular weights, there are two examples of fatty acid methyl esters with base peaks of $m l z=100$. These are 5-hydroxy-2-alkenoic acid methyl esters that appear to yield the $\mathrm{mlz}=100$ ion bya McLaffertytype of rearrangement (McLafferty 1966) to the fragment $\left[\mathrm{CH}_{2}-\mathrm{CH}=-\mathrm{C}\left(\mathrm{OCH}_{3}\right)=\mathrm{OH}+\right]$. It is noteworthy that the 5hydroxy-group seems to be a requisite for this fragmentation process, because unsubstituted 2-alkenoic acid 
TABLE 23-3

Mass Spectra of Three Unidentified Components

\begin{tabular}{|c|c|c|c|}
\hline Unknown & $\begin{array}{c}\text { RT } \\
(\min .)\end{array}$ & $\begin{array}{l}\text { Mol } \\
\text { Peak }\end{array}$ & Fragments \\
\hline & & & Electron Impact (EI) Spectra; $70 \mathrm{eV}$ \\
\hline 1 & 23.5 & none & $100(100) 87(3.1) 70(3.3) 69(3.2) 57(4.4) 56(5.8) 55(6.1) 45(3.1) 44(6.1) 43(9.5) 42(7.2) 41(8.1)$ \\
\hline 2 & 27.4 & none & $283(1) 100(100) 87(2.9) 70(3.3) 69(3.3) 57(4.5) 56(5.8) 55(5.5) 44(5.0) 43(10.0) 42(5.8) 41(8.0)$ \\
\hline 3 & 31.0 & none & $\begin{array}{l}100(100) 87(4.7) 70(2.5) 69(1.3) 57(4.8) 56(5.6) 55(6.5) 44(6.3) 43(10.2) 42(5.9) 41(8.4) \\
\text { Chemical Ionization }(\mathrm{Cl}) \text { Spectra; methane }\end{array}$ \\
\hline 1 & 22.6 & $256(100)$ & $254(54) 100(78) 114(8) 109(11) 99(8) 88(10) 81(7)$ \\
\hline 2 & 26.6 & 284(100) & 283(11) 282(72) 125(11) 123(9) 111(13) 109(5) 100(100) 99(10) 97(12) 87(6) 81(6) \\
\hline 3 & 30.2 & $312(74)$ & $311(14) 310(61) 123(2) 109(6) 101(5) 100(100) 99(8) 81(4)$ \\
\hline
\end{tabular}

methyl esters with 8 to 16 carbon atoms do not produce an $m \backslash z=100$ fragment (Mass Spectrometric Data Centre 1986). We are therefore led to the tentative identification of the three constituents as:

Unknown 1: 5-hydroxy-2 tetradecanoic acid methyl ester $\mathrm{C}_{15} \mathrm{H}_{28} \mathrm{O}_{3}, \mathrm{MW}=256$

Unknown 2: 5-hydroxy-2-hexadecanoic acid methyl ester $\mathrm{C}_{17} \mathrm{H}_{32} \mathrm{O}_{3}, \mathrm{MW}=284$

Unknown 3: 5-hydroxy-2-octadecanoic acid methyl ester $\mathrm{C}_{19} \mathrm{H}_{36} \mathrm{O}_{3}, \mathrm{MW}=312$.

A comprehensive computer search of Chemical Abstracts shows that none of these compounds has ever been reported as natural or synthetic products. If the suggested structures are correct, they might be oxidative degradation products of the three positively identified even-numbered saturated fatty acids with which they share the same carbon skeleton.

Three even-numbered saturated fatty acids with carbon-chain lengths of 14,16 , and 18 have been identified, in the form of their methyl esters, by gas chromatographyelectron impact mass spectrometry on all but 3 of 20 WilsonLeonard artifacts. Since they are widely distributed in plants as well as animals, their presence does not allow attribution to specific sources. A fourth saturated acid with 15 carbon atoms is exceedingly rare. Its most likely source is a Zanthoxylum species, i.e., the prickly-ash or "tooth-ache tree" known to have been used by Amerindians; but honeysuckle and lichens are other possible sources. Three homologous compounds have yielded chemical ionization mass spectra that strongly suggest oxidation products of the saturated fatty acids 14,16 , and 18 carbon atoms, but their identification remains tentative.

\section{CAPILLARY ION AND AMINO ACID ANALYSES OFORGANIC RESIDUES}

by W. Jeffrey Hurst

\section{Introduction}

A total of 71 artifacts was submitted for organic residue analysis including 61 from TARL and 10 from TxDOT exca- vations. Due to time constraints, only 22 were analyzed-15 collected as OR samples from the TARL excavations and 7 recovered from TxDOT excavations but not collected for special study (Table 23-4). The studies that were conducted utilized two techniques, capillary ion analysis (CIA) for the determination of inorganic ions and high performance liquid chromatography (HPLC) for the determination of amino acid residues.

Analysis of residues from archeological artifacts has become an active area of analytical chemistry (Evershed 1993; Fielder 1996; Hillman et al. 1993; Lein 1983; Marchbanks 1989; Newman et al. 1993). Many such determinations have focused on lipophilic materials obtained after surface grinding of artifacts and extraction with a standard solvent used for extracting lipids from foodstuffs such as Folch reagent (2:1, chloroform:methanol) (Folch et al. 1957). This work is well documented, and earlier reports for this site have chronicled this data. Evershed (1993) provides an introduction to this subject and an overview of lipid analysis in biomolecular archeology.

Data also have been reported on organic matter and carbonates by Stein (1984) who presented a loss-on-ignition technique for determining carbonate at the Vosburg site in south-central Minnesota. Hillman et al. (1993) report the use of various techniques including SEM Pyrolysis Mass Spectrometry and Infrared Spectroscopy to develop information on charred grains that compared the role of chemical, histological, and morphological criteria. Anderson-Gerfaud (1981) published work on residue analysis of stone plantprocessing tools. Finally, Loy and Wood (1989) report the identification of blood residues on stone tools using immunoassay-based techniques; their study has recently come under scrutiny based on some later findings, and while it may be less accepted, it is included in these introductory paragraphs for completeness.

The citations above outline some earlier work that has been performed on the determination of residues from archeological artifacts. These determinations have focused primarily on the determination of organic residues since they can provide some indication of the possible use of archeological artifacts. The present samples provide an excellent opportunity to evaluate other analytical techniques and 
TABLE 23-4

Organic Residue Samples: Provenience and Techniques Used

\begin{tabular}{|c|c|c|c|c|c|c|c|}
\hline Specimen No. & Artifact Category & Square & Level & Feature & Unit & CIA & HPLC \\
\hline OR41 & Mano fragment & 17 & 4 & & IIIc & $\mathrm{x}$ & $\mathrm{x}$ \\
\hline OR69 & Projectile point, Marcos & 19 & 9 & & $\mathrm{IIIb} / \mathrm{c}$ & $\mathrm{x}$ & $\mathrm{x}$ \\
\hline OR372 & Clear Fork biface & 52 & 22 & 231 & IIIa & $\mathrm{x}$ & $\mathrm{x}$ \\
\hline OR376 & Burned limestone & 27 & 22 & 225 & IIIa & $x$ & $x$ \\
\hline OR439 & Projectile point, Golondrina-Barber & 34 & 22 & 231 & II/IIIa & $\mathrm{x}$ & $\mathrm{x}$ \\
\hline OR460 & Core tool & 35 & 23 & & II/IIIa & $\mathrm{x}$ & $\mathrm{x}$ \\
\hline OR540 & Burned limestone & 48 & 31 & 236 & $\mathrm{Id} / \mathrm{II}$ & $\mathrm{x}$ & $\mathrm{x}$ \\
\hline OR558 & Burned limestone & 28 & 25 & 245 & IIIa & $\mathrm{x}$ & $\mathrm{x}$ \\
\hline OR588 & Projectile point, Angostura & 37 & 27 & & II & $\mathrm{x}$ & $\mathrm{x}$ \\
\hline OR614 & Mano & 49 & 33 & & $\mathrm{Id} / \mathrm{II}$ & $\mathrm{x}$ & $x$ \\
\hline OR629 & Clear Fork biface & 57 & 37 & & Isi-c & $\mathrm{x}$ & $\mathrm{x}$ \\
\hline OR648 & Burin & 101 & 12 & & $\mathrm{Y}$ & $\mathrm{x}$ & $\mathrm{x}$ \\
\hline OR689 & Biface, Stage 2 & 20 & 50 & & Icl & $\mathrm{x}$ & $\mathrm{x}$ \\
\hline OR708 & Flake & 52 & 42 & & Isi-c & $\mathrm{x}$ & $\mathrm{x}$ \\
\hline OR710 & Flake & 52 & 43 & & Isi-c & $\mathrm{x}$ & $\mathrm{x}$ \\
\hline $7 F-5$ & Metate fragment & E20/S92 & 6 & Burial 1 & IIIc/Pot & $\mathrm{x}$ & $\mathrm{x}$ \\
\hline $9 N-3$ & Mano fragment & E20/S 88 & 14 & 12 & $\mathrm{X}$ & $\mathrm{x}$ & $\mathrm{x}$ \\
\hline $9 \mathrm{~T}-2$ & Grinding basin & E20/S 88 & 20 & & $\mathrm{X}$ & $\mathrm{x}$ & $\mathrm{x}$ \\
\hline $12 \mathrm{~A}-12$ & Indeterminate ground stone & $\mathrm{E} 20 / \mathrm{S} 82$ & 1 & & IIIC & $\mathrm{x}$ & $\mathrm{x}$ \\
\hline $16 \mathrm{C}-2$ & Tubular stone pipe & E20/S74 & 3 & & IIIC & $\mathrm{x}$ & $\mathrm{x}$ \\
\hline 33 Y1D-2 & Possible ground stone & $\mathrm{E} 26 / \mathrm{S} 76$ & $25 \mathrm{~A}$ & & II & $\mathrm{x}$ & $\mathrm{x}$ \\
\hline BU2-1 & Ground stone tool & $\mathrm{E} 20 / \mathrm{S} 74$ & $31 \mathrm{~A}$ & Burial 2 & Isi/Icl/Isi-c & $\mathrm{x}$ & $\mathrm{x}$ \\
\hline
\end{tabular}

possibly to determine the presence not only of residue attributable to various lipids but also water-soluble organic residues and inorganic residues. This orthogonal approach allowed for the determination of a variety of compound types which then provided an opportunity for a multidimensional evaluation of a number of artifacts.

\section{Sample Preparation}

All of the samples for this analysis were treated in the same manner. While other researchers performing organic residue analysis have physically removed small amounts of the material (Hillman et al. 1993), samples in this study were subjected to an exhaustive extraction with a modified Folch reagent which obviated the need to physically remove materials from the artifact. The reason for this approach was to maintain the artifacts in their current physical state rather than to destroy the topic layer of materials as had been done in earlier studies. Folch reagent consists of a 2:1 (w:v) mixture of chloroform-methanol. These extractions used a modified Folch reagent consisting of the previous solvent with $0.1 \%$ BHT. Folch reagent is a standard solvent utilized for the extraction of lipids from a variety of materials in an efficient manner. BHT is an antioxidant which was added to limit any additional oxidation of the extracts to that present before extraction since exhaustive extraction can sometimes create analytical artifacts and provide misleading data. The resulting extracts were filtered and reduced in volume in an inert atmosphere to potentially eliminate analytical oxidation byproduct formation. After the solvent was removed, the samples were stored in sealed vessels at $-4^{\circ} \mathrm{C}$ until sub- sequent analysis.

After extraction with the modified Folch reagent, samples were allowed to dry and extracted with approximately 1:20 (w:v) ratio of artifact to distilled water. The container with the artifact and water was placed on a water bath set at $85^{\circ} \mathrm{C}$ for two hours. After cooling to room temperature, aqueous extracts were filtered, placed in glass bottles with Teflon-lined tops, and stored at $-4^{\circ} \mathrm{C}$. The final result of these sample preparations was that each artifact was extracted with the modified Folch reagent to extract the lipophilic components and subsequently treated with water to extract any hydrophilic residues.

\section{Capillary Ion Analysis (CIA)}

Capillary ion analysis (CIA) is a relatively new analytical technique that can be used for the determination of various anions (Danielson and Sherman 1993). The choice of CIA was deliberate since it is sample conservative, utilizing only a few microliters of sample, and has rapid analysis time. Also, literature on the determination of inorganic residues is sparse, and data that were developed would provide another perspective on the analysis of residues from archeological artifacts.

Aqueous extracts of selected samples were analyzed by capillary ion analysis with conductivity detection. Figure 23-4 provides an example electropherogram of an 8-anion standard which includes chloride, bromide, nitrite, nitrate, sulfate, carbonate, fluoride, carbonate, and acetate while Figures 23-5 through 23-9 provide electropherograms from 16 artifacts. The results obtained can be classified as 


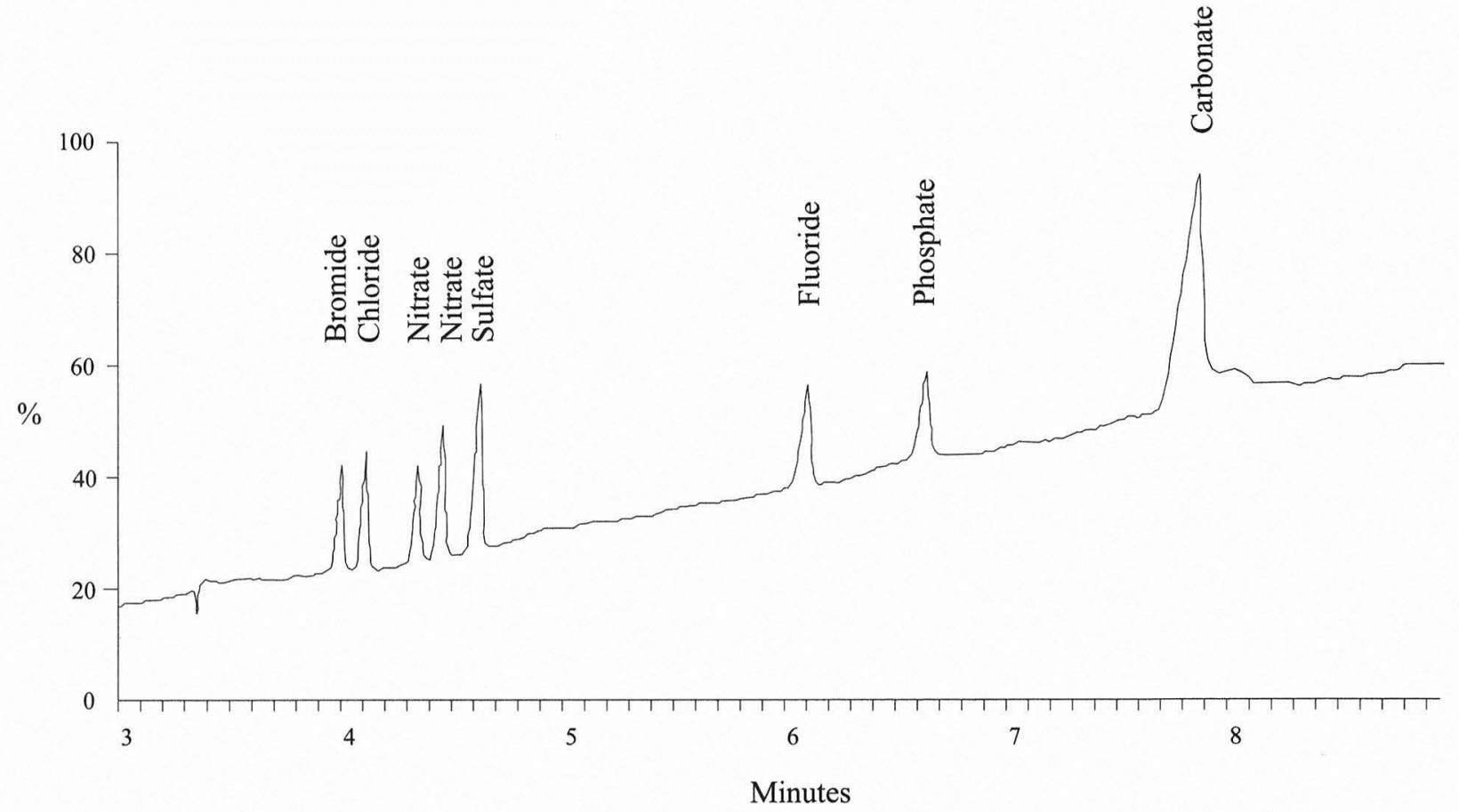

FIGURE 23-4. Electropherogram of selected anion standards.
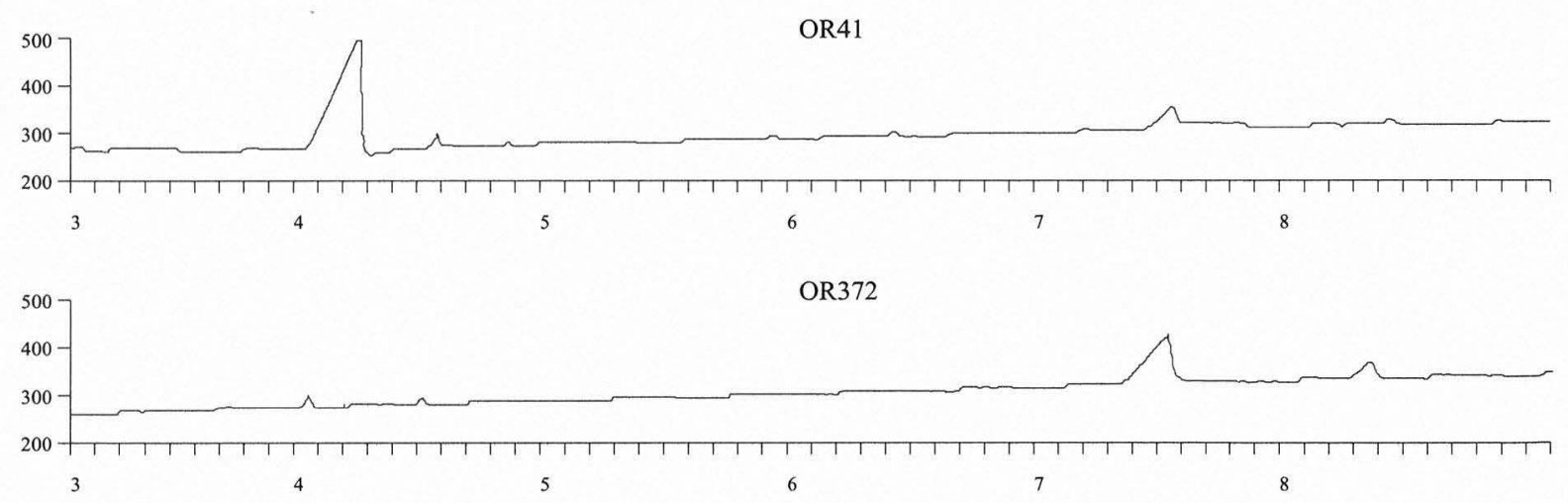

$\mathrm{mV}$
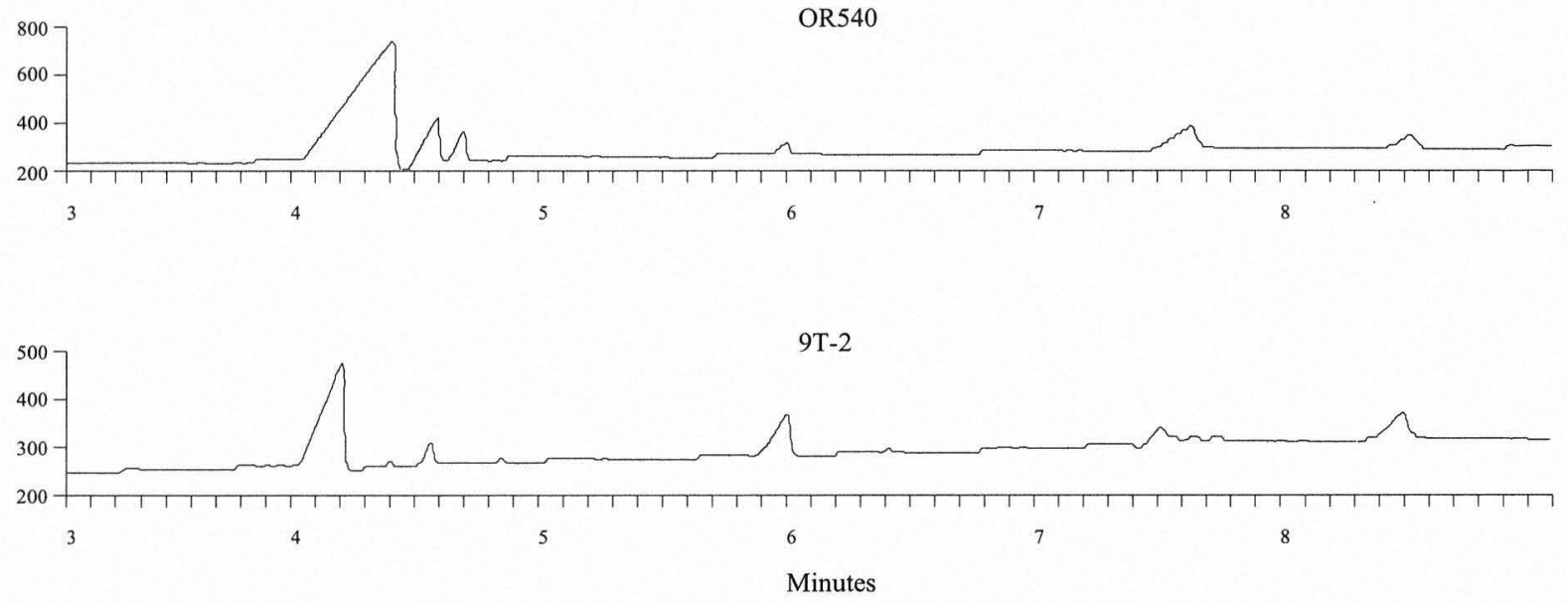

FIGURE 23-5. Electropherogram of artifact Specimens OR41, OR372, OR540, and 9T-2. 


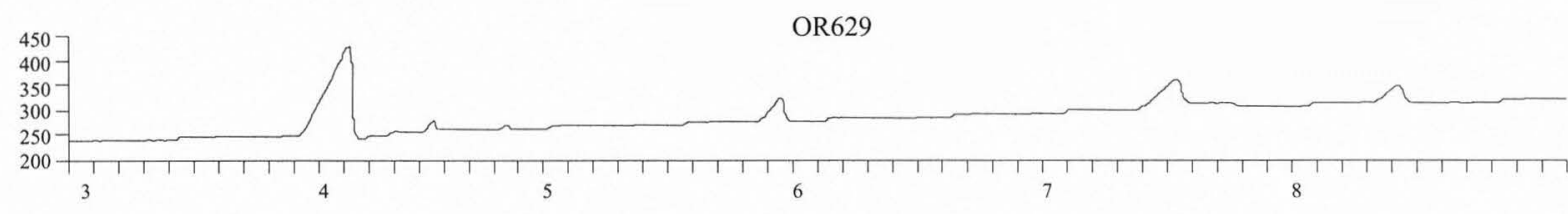

OR588

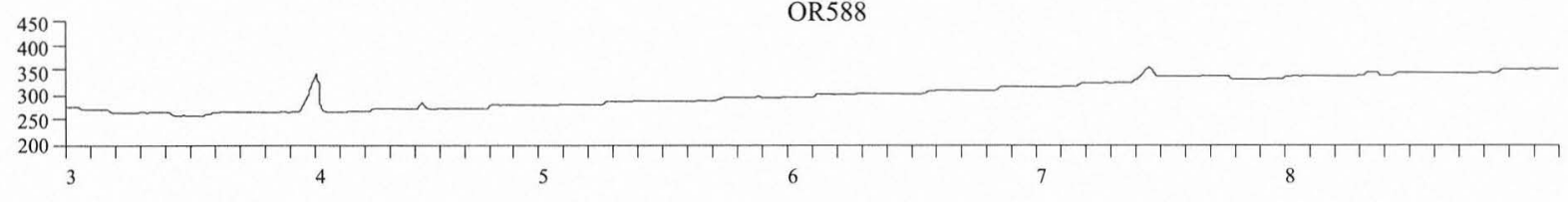

$\mathrm{mV}$
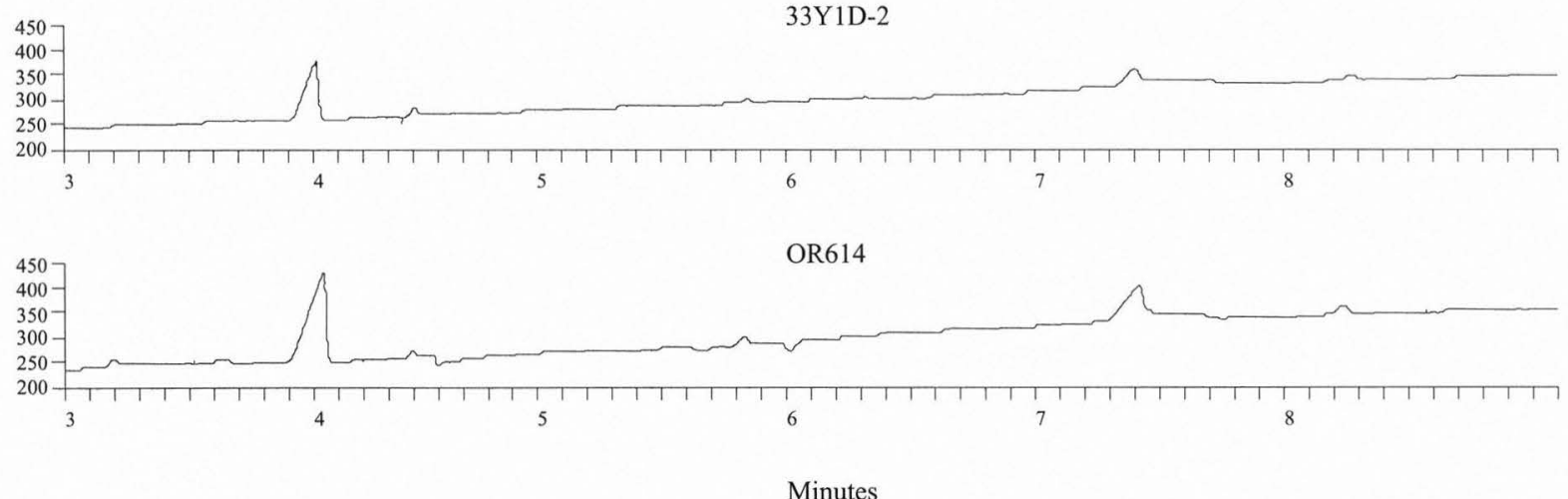

FIGURE 23-6. Electopherogram of artifact Specimens OR629, OR588, 33YID-2, and OR614.
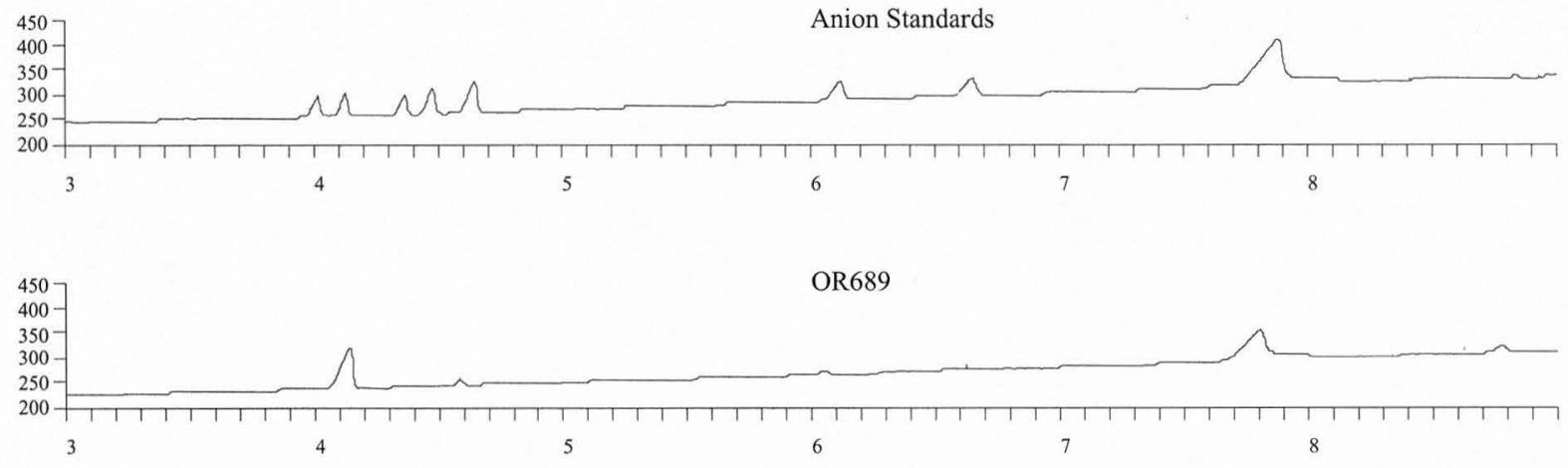

$\mathrm{mV}$
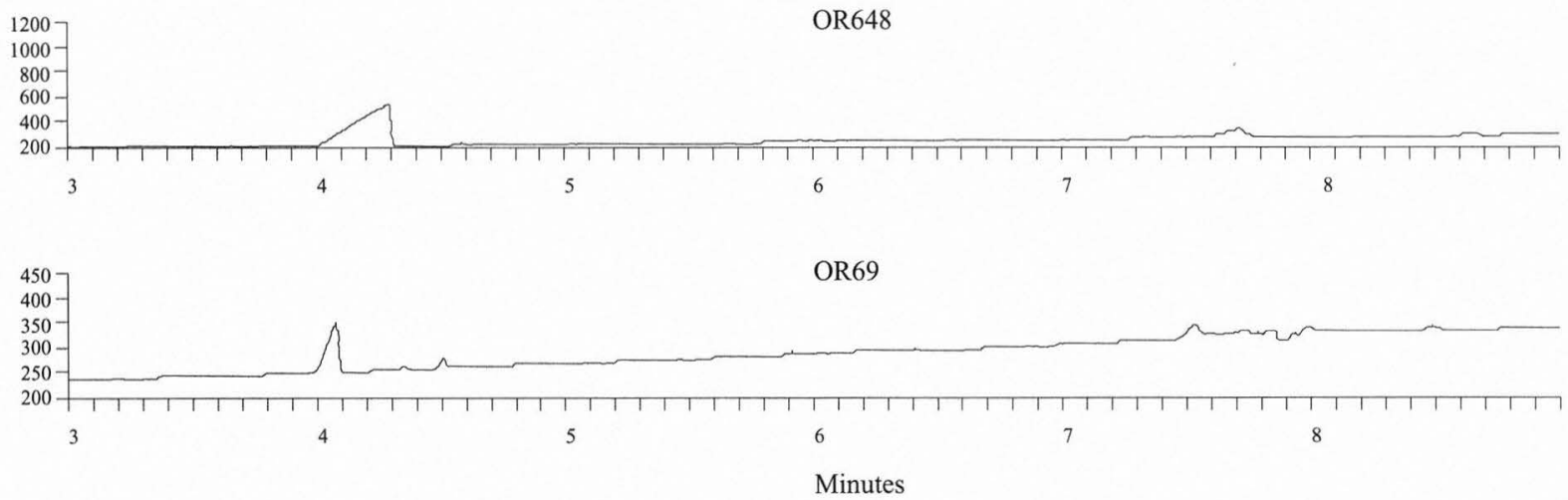

FIGURE 23-7. Electropherogram of anion standards and artifact Specimens OR689, OR648, and OR69. 


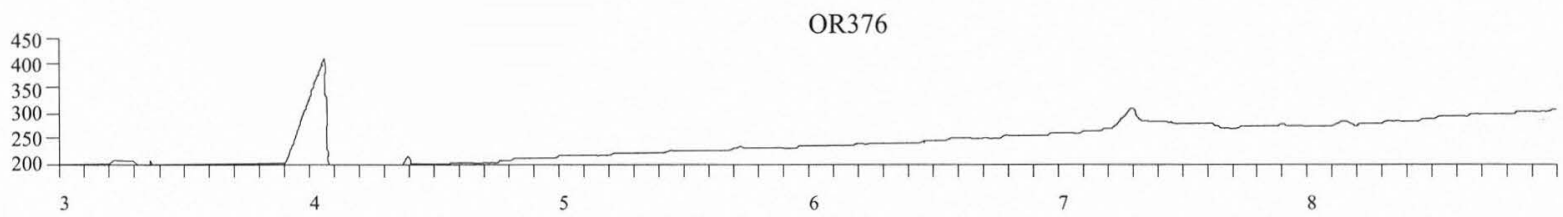

OR460
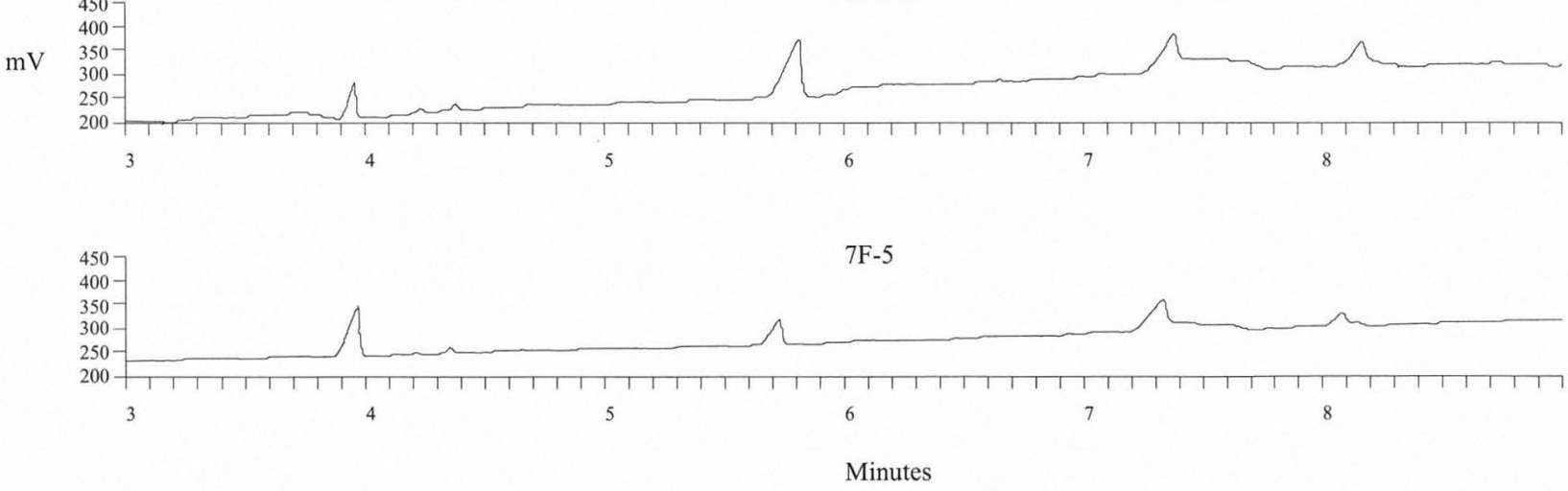

FIGURE 23-8. Electropherogram of artifact Specimens OR376, OR460, and 7F-5.

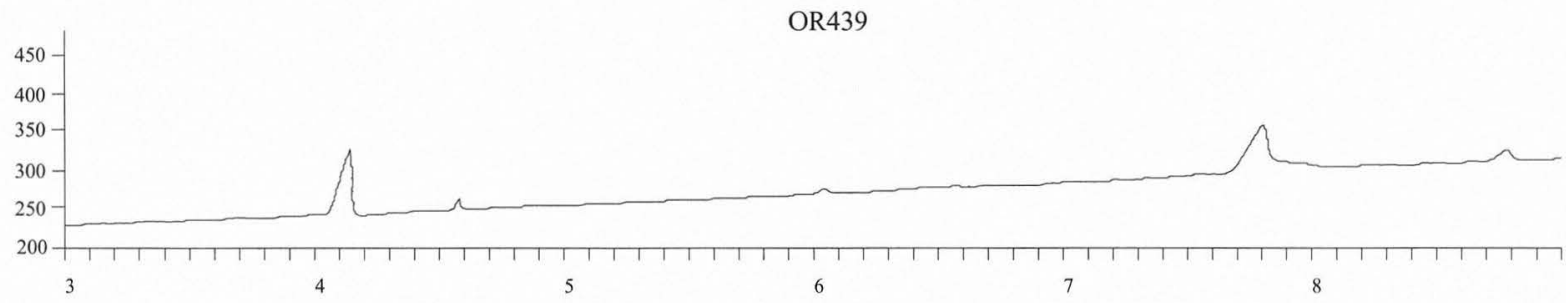

$\mathrm{mV}$

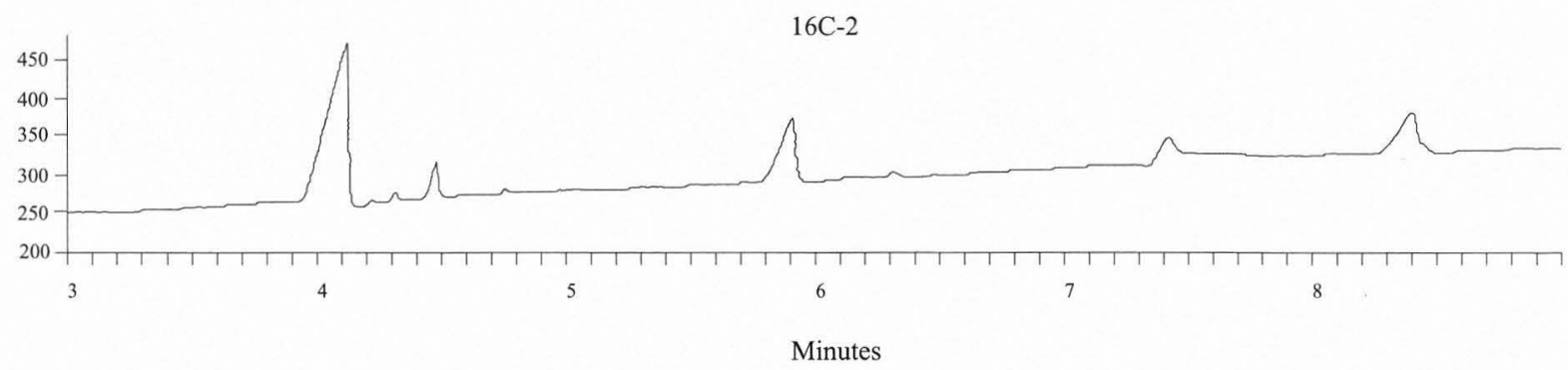

FIGURE 23-9. Electropherogram of artifact Specimens OR439 and 16C-2.

semiquantitative, since an attempt was made to extract all samples with a constant ration of water. The results of these determinations are listed in Table 23-5. The electropherograms that are provided are scaled to the largest peak so some of the smaller peaks, even though they are listed in the table, are not seen due to scaling of the data.

\section{Amino Acid Analysis}

A portion of each aqueous extract was subjected to amino acid analysis after filtering it through a $10,000 \mathrm{Mo}-$ lecular Weight Ultrafiltration (UF) membrane that eliminated any aqueous material with a molecular weight greater than 10 Kilodaltons $(\mathrm{kD})$. These resulting materials were then analyzed by HPLC after the formation of a precolumn orthophthaldehyde (OPA) derivative which is a standard method for the determination of amino acids in biological systems (Hill et al. 1979).

Figure 23-10 provides a chromatogram of the amino acid standard while Figures 23-11 through 23-16 provide sample chromatograms for additional artifacts. The results obtained from the other artifacts can be seen in Table 23-6. The chromatograms that are provided are scaled to the largest peak so some of the smaller peaks, even though 
TABLE 23-5

Summary of CIA Results

\begin{tabular}{|c|c|c|c|c|c|}
\hline Specimen No. & Chloride & Nitrate & Sulfate & Phosphate & Carbonate \\
\hline OR689 & $\mathrm{x}$ & & $\mathrm{x}$ & & $\mathrm{x}$ \\
\hline OR648 & $\mathrm{x}$ & & & & $\mathrm{x}$ \\
\hline OR69 & $\mathrm{x}$ & $\mathrm{x}$ & & & \\
\hline OR41 & $\mathrm{x}$ & $\mathrm{x}$ & & $\mathrm{x}$ & $\mathrm{x}$ \\
\hline OR372 & $\mathrm{x}$ & $\mathrm{x}$ & & & $\mathrm{x}$ \\
\hline OR540 & $\mathrm{x}$ & $\mathrm{x}$ & $\mathrm{x}$ & $\mathrm{x}$ & $\mathrm{x}$ \\
\hline 9T-2 & $\mathrm{x}$ & & & & $\mathrm{x}$ \\
\hline $16 \mathrm{C}-2$ & $\mathrm{x}$ & & & $\mathrm{x}$ & $\mathrm{x}$ \\
\hline OR439 & $\mathrm{x}$ & & & & $\mathrm{x}$ \\
\hline OR629 & $\mathrm{x}$ & $\mathrm{x}$ & & & $\mathrm{x}$ \\
\hline OR588 & $\mathrm{x}$ & & & & $\mathrm{x}$ \\
\hline 33Y1D-2 & & & & $\mathrm{x}$ & $\mathrm{x}$ \\
\hline OR614 & $\mathrm{x}$ & & & & \\
\hline $12 \mathrm{~A}-12$ & & $\mathrm{x}$ & & & $\mathrm{x}$ \\
\hline OR558 & & & & & \\
\hline OR708 & & & & & \\
\hline BU2-1 & $\mathrm{x}$ & $\mathrm{x}$ & & $\mathrm{x}$ & \\
\hline $9 \mathrm{~N} 3$ & & & & & $\mathrm{x}$ \\
\hline OR710 & & & & & \\
\hline OR460 & $\mathrm{x}$ & $\mathrm{x}$ & & & $\mathrm{x}$ \\
\hline $7 F-5$ & $\mathrm{x}$ & & & $\mathrm{x}$ & $\mathrm{x}$ \\
\hline OR376 & $\mathrm{x}$ & & $\mathrm{x}$ & & \\
\hline
\end{tabular}

An " $\mathrm{x}$ " indicates that the anion was present in the artifact while a blank indicates that none of the anions was present in the extract.

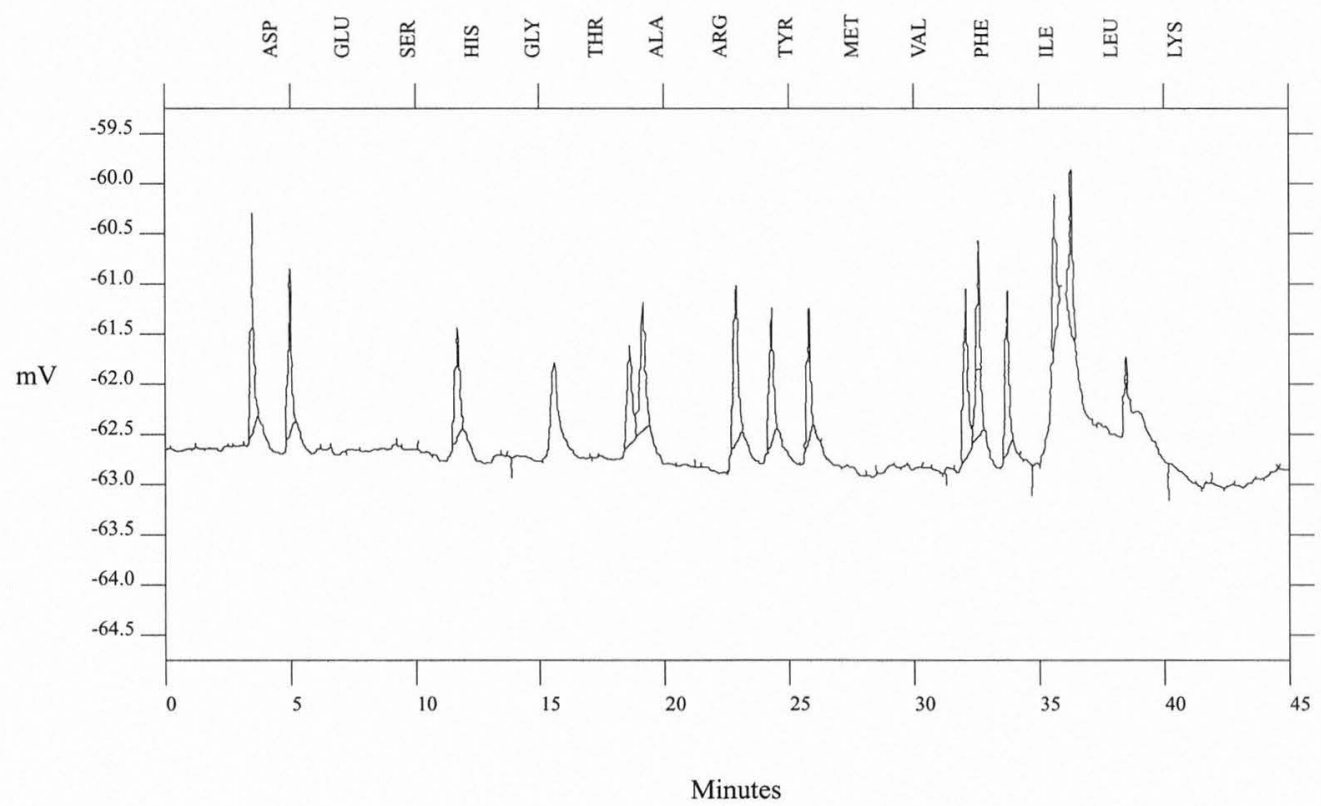

FIGURE 23-10. Chromatogram of amino acid standards.

they are listed in the table, are not seen due to scaling of the data.

\section{Discussion of Results}

The results for the anion analysis were revealing. The column material, chemistries used, and the detector make this technique extremely selective and sensitive, lending a high level of confidence to the results. Most samples analyzed had substantial amounts of chloride with OR540, a burned limestone rock, having an extremely large amount when compared to others. One might readily interpret this to be a pedogenic product with no cultural significance. Most samples contained carbonate likely due to the makeup of the 


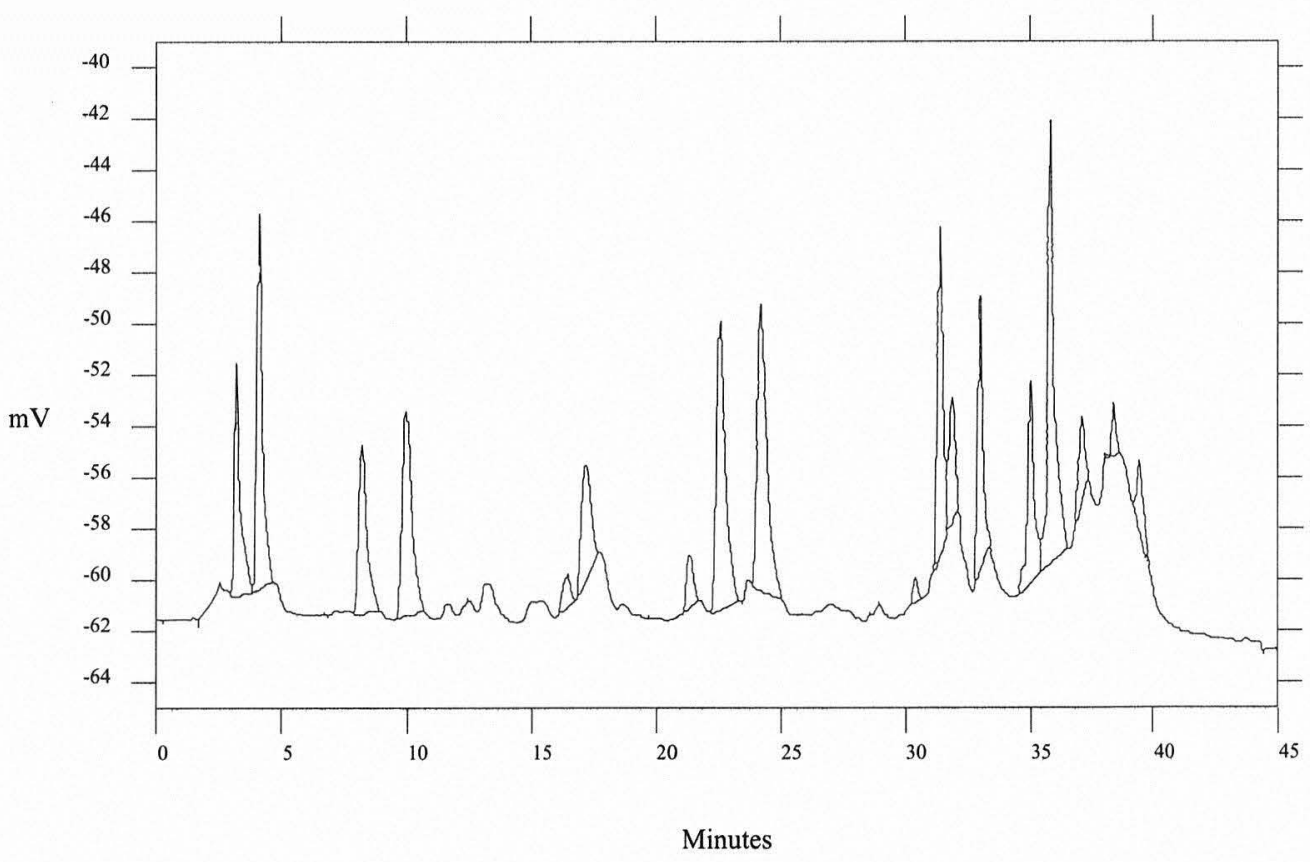

Figure 23-11. Amino acid profile for Specimen 9T-2.

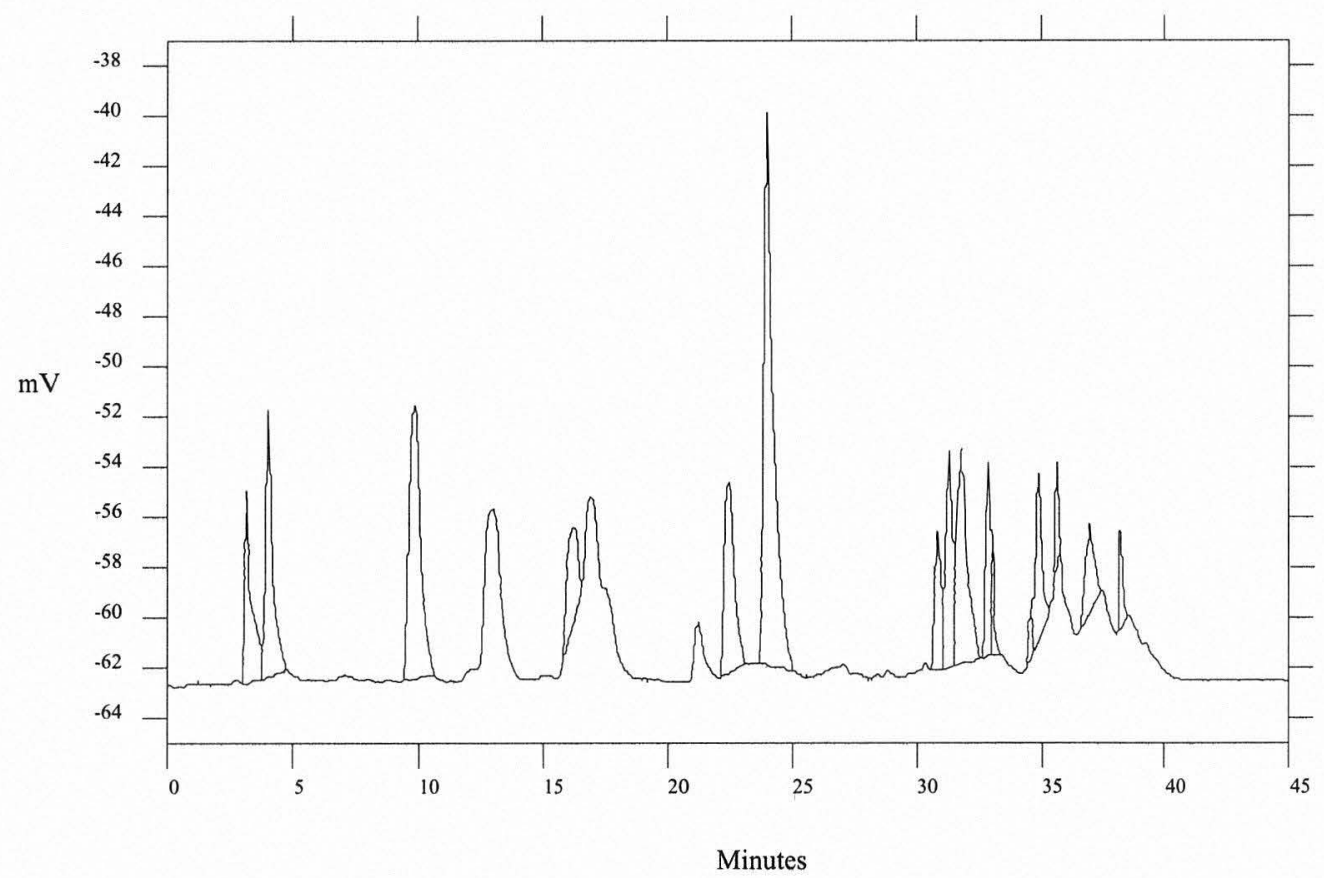

FIGURE 23-12. Amino acid profile for Specimen OR540.

material. The limestone is a carbonate; even those samples not made of limestone could have been enriched by soil carbonate over time. While most samples tended to contain chloride and carbonate, the appearance of the other anions was most intriguing. Eight samples as indicated on Table 23-5 showed evidence of nitrate, which, while possibly attributable to some type of agricultural runoff, may also have accumulated on the artifact during use. For ex- ample, Stein (1984:239-242) notes that "as unused food, refuse from house construction, and the dead decompose, significant amounts of carbon, nitrogen, calcium and phosphorus... are released." Since the disposition of the nitrate was not universal, other than pedogenic sources are suggested.

Phosphate was also seen in six samples as indicated in Table 23-5. In this case, environmental sources for this 


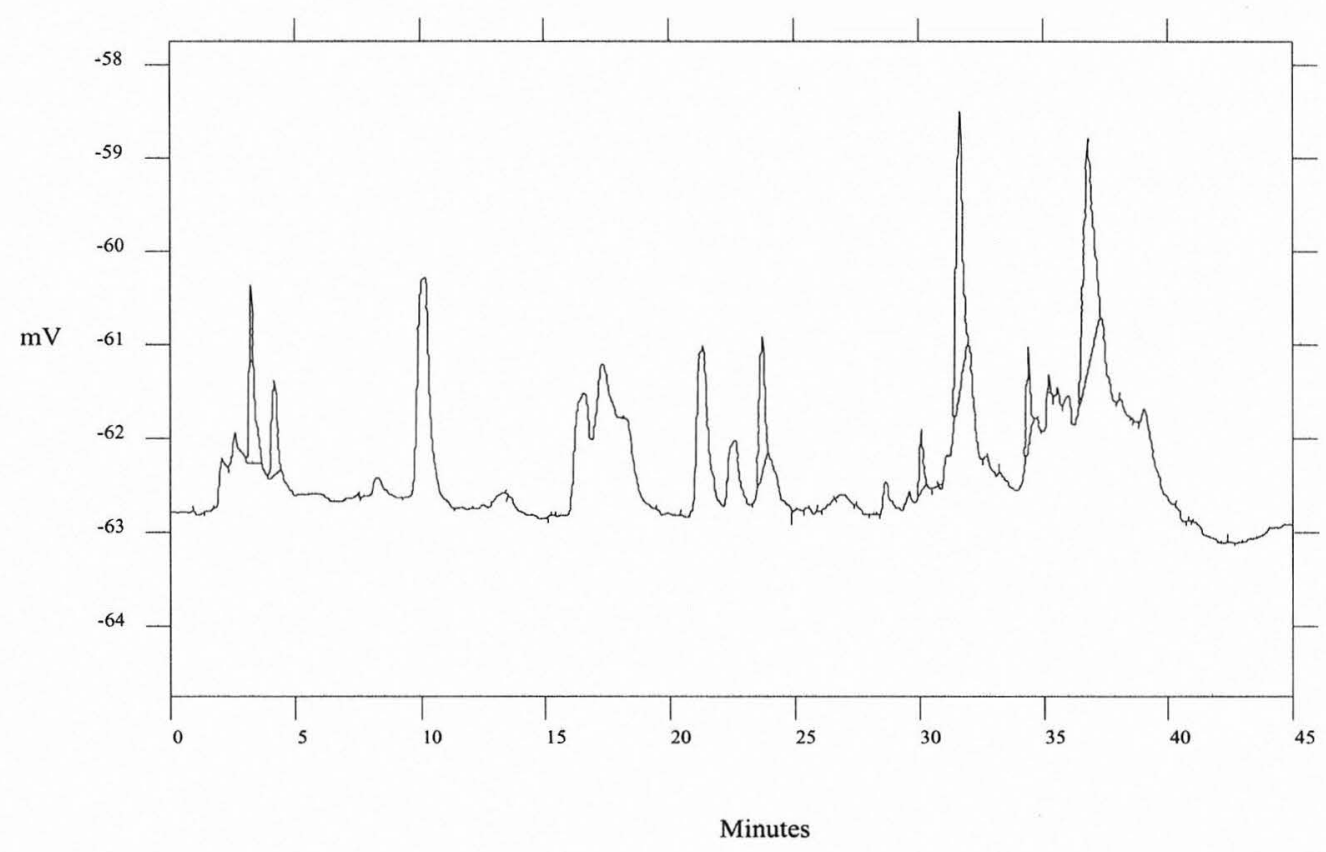

Figure 23-13. Amino acid profile for Specimen 16C-2.

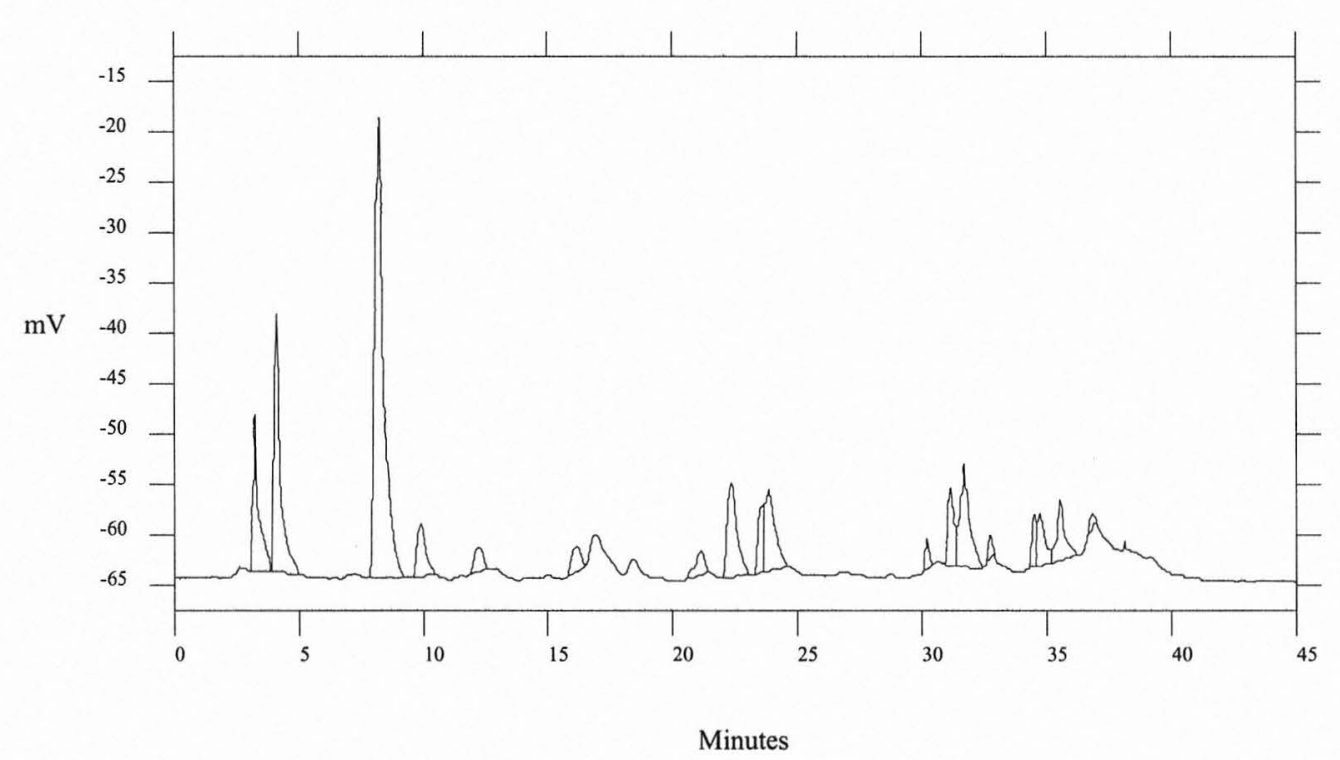

FIGURE 23-14. Amino acid profile for Specimen OR614.

residue are difficult to explain. Phosphate is a component of hydroxyapatite, which is a chemical component of bone and again supports the comments by Stein. Finally, Specimen BU2-1 had a coating of carbonate that was physically removed and then extracted. The primary compounds found were nitrate and phosphate. While phosphate and nitrate are widely used in current farming practices, the fact that these compounds were found after the extraction of an outer lipophilic layer gives support to the conclusion that these are true organic residues rather than some environmental artifact. Also, the fact that these compounds were not universally distributed would seem to give further support to these findings. The ability to detect inorganic in addition to organic residues in archeological artifacts is exciting since it opens other avenues in these determinations.

The final general class of compounds analyzed were amino acids. The OPA method for precolumn derivative formation is well established in the scientific literature as a method for the determination of amino acids with lower limits in the femtomole range, so it is an ideal candidate for evaluating samples containing small amounts of amino 


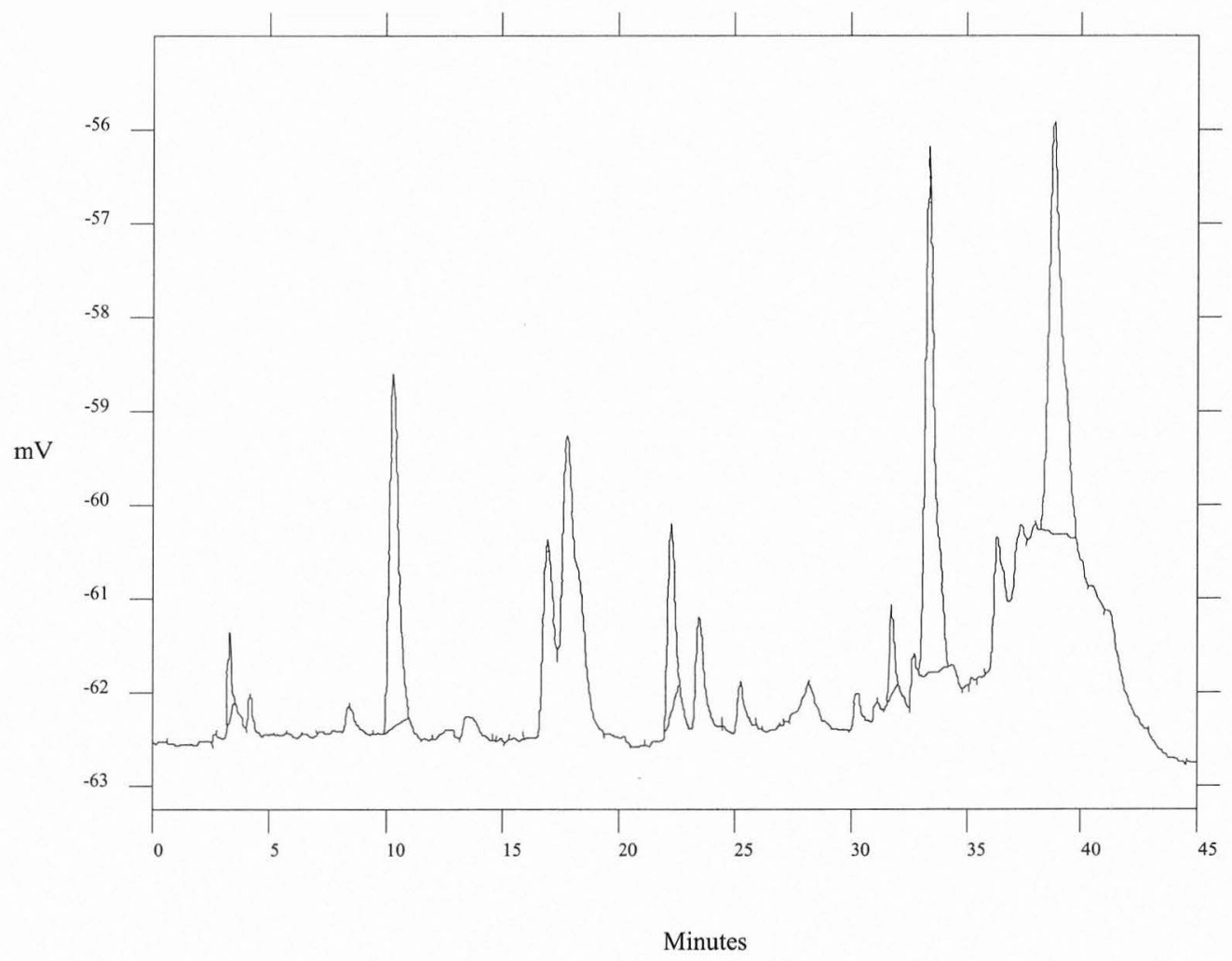

FIGURE 23-15. Amino acid profile for Specimen BU2-1.

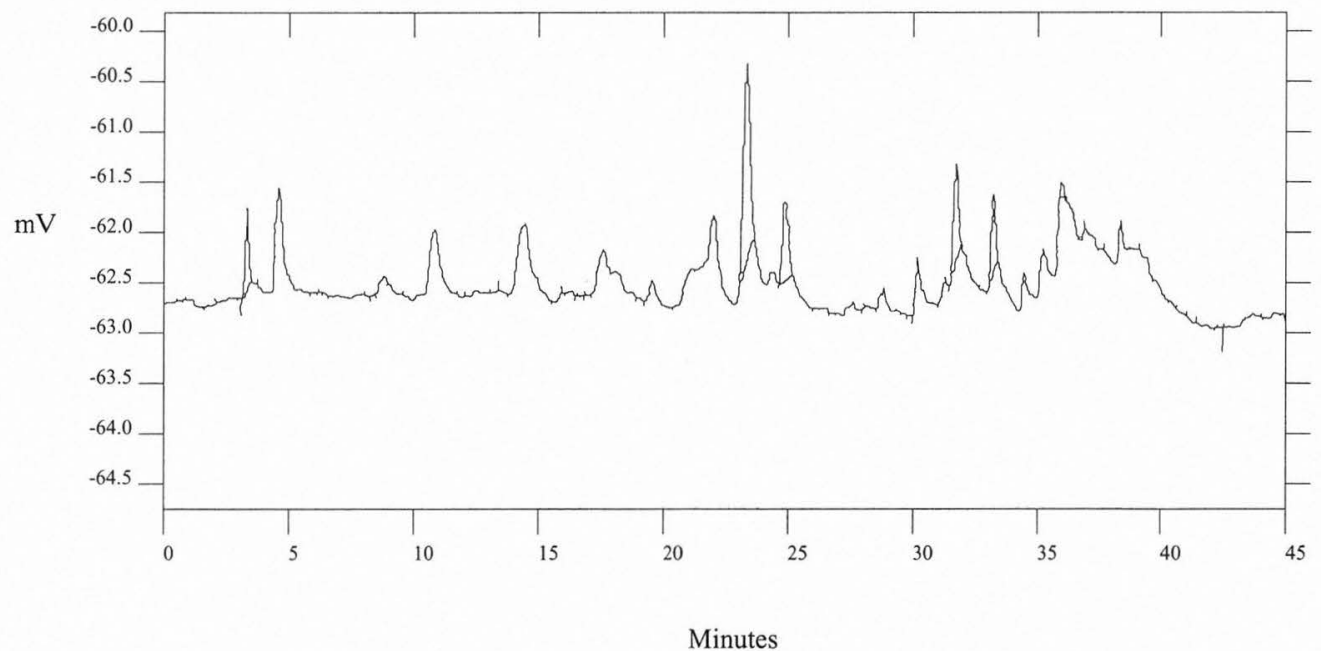

FIGURE 23-16. Amino acid profile for Specimen OR710.

acids. Additionally, it is also very specific giving it a high level of confidence. Eight of the artifacts contained some amino acid residues and six of these had substantial numbers of amino acids. The most encouraging results are from one of the ground stone artifacts, a burned limestone rock, and the pipe. Ground stone Specimen 9T-2, a grinding basin, gave a free amino acid profile very similar to that of an acorn (United States Department of Agriculture 1976) which could be attributable to the live oak acorn indigenous to the region. There were isolated amino acids in other samples but nothing as definitive as that from the ground stone artifact. While none of these results is confirmatory, the sum is intriguing, as in the case of the anion samples. The outer layer provided a protective coating allowing for the extraction and analysis of these compounds. The results from the ground stone specimen support the argument that it was used to grind live oak acorns which might have been used as a food source. 
TABLE 23-6

Summary of Amino Acid Residue Results

\begin{tabular}{|c|c|c|c|c|c|c|c|c|c|c|c|c|c|c|c|}
\hline $\begin{array}{l}\text { Specimen } \\
\text { No. }\end{array}$ & $\begin{array}{l}\text { Aspartic } \\
\text { Acid }\end{array}$ & $\begin{array}{l}\text { Glutamic } \\
\text { Acid }\end{array}$ & Serine & Histidine & Glycine & Tryptophan & Alanine & Arginine & Tyrosine & Methionine & Valine & Phenylalanine & Isoleucine & Leucine & Lysine \\
\hline $\begin{array}{l}\text { OR689 } \\
\text { OR648 } \\
\text { OR69 } \\
\text { OR41 } \\
\text { OR372 }\end{array}$ & & & & & & $x$ & & & & & $\begin{array}{l}\mathrm{x} \\
\mathrm{x}\end{array}$ & & & & \\
\hline OR540 & $\mathrm{x}$ & $\mathrm{x}$ & $\mathrm{x}$ & & & $\mathrm{x}$ & $\mathrm{x}$ & $\mathrm{x}$ & $\mathrm{x}$ & $\mathrm{x}$ & $\mathrm{x}$ & $\mathrm{x}$ & $\mathrm{x}$ & $\mathrm{x}$ & \\
\hline $9 \mathrm{~T}-2$ & $\mathrm{x}$ & $\mathrm{x}$ & $\mathrm{x}$ & $\mathrm{x}$ & $\mathrm{x}$ & & & $\mathrm{x}$ & $\mathrm{x}$ & $\mathrm{x}$ & $\mathrm{x}$ & $\mathrm{x}$ & $\mathrm{x}$ & $\mathrm{x}$ & $\mathrm{x}$ \\
\hline $\begin{array}{l}16 C-2 \\
\text { OR629 }\end{array}$ & $\mathrm{x}$ & $\mathrm{x}$ & $\mathrm{x}$ & & & & $\mathrm{x}$ & $\mathrm{x}$ & $\mathrm{x}$ & & & $\mathrm{x}$ & $\mathrm{x}$ & $\mathrm{x}$ & \\
\hline $\begin{array}{l}\text { OR588 } \\
\text { 33Y1D-2 }\end{array}$ & & & & & & & & & & & & & & & \\
\hline $\begin{array}{l}\text { OR614 } \\
\text { 12A-12 } \\
\text { OR558 } \\
\text { OR708 }\end{array}$ & $\mathrm{x}$ & $\mathrm{x}$ & & & & $\mathrm{x}$ & $\mathrm{x}$ & $\mathrm{x}$ & & $\mathrm{x}$ & $\mathrm{x}$ & $\mathrm{x}$ & $\mathrm{x}$ & $\mathrm{x}$ & \\
\hline $\begin{array}{l}\text { BU2-1 } \\
9 \mathrm{~N}-3\end{array}$ & $\mathrm{x}$ & $\mathrm{x}$ & $\mathrm{x}$ & & $\mathrm{x}$ & $\mathrm{x}$ & $\mathrm{x}$ & $\mathrm{x}$ & $\mathrm{x}$ & & & & $\mathrm{x}$ & $\mathrm{x}$ & $\mathrm{x}$ \\
\hline $\begin{array}{l}\text { OR710 } \\
\text { OR460 } \\
\text { 7F-5 } \\
\text { OR376 }\end{array}$ & $\mathrm{x}$ & $\mathrm{x}$ & $\mathrm{x}$ & $\mathrm{x}$ & $\mathrm{x}$ & & $\mathrm{x}$ & $\mathrm{x}$ & $\mathrm{x}$ & & & $\mathrm{x}$ & $\mathrm{x}$ & & $\mathrm{x}$ \\
\hline
\end{tabular}




\section{Further Studies}

Additional studies should be completed on various lipid fractions that can be obtained from extractions with a focus on acids other than the fatty acids. A focus on the sterols might provide an opportunity to further differentiate among food sources since they and related compounds can provide a wealth of information. For example, an artifact containing phytosterols could then be further fractionated to a particular type of phytosterol and potentially plant type. Additionally, one can effectively prefractionate lipid extracts and determine how much of each of the various sterols was evident and determine additional information about the food sources. While fatty acid data are useful, some members of the class undergo degradation under varying rates and are not included in final calculations, making assignment of a particular fatty acid to a particular food type problematic. The sterol data could provide some supplementary information.

The lipid coating on some samples is a rich source of information and should be further exploited since one might be able to obtain information on a surviving lipoprotein component. Additionally, this layer might contain one of a number of polyaromatic hydrocarbon type compounds that are characteristic products of combustion using a variety of fuel sources. These could provide additional data about food sources or combustion materials (Jones and Fruedenthal 1978).

These studies seem to indicate that the rich lipophilic layer provides a protective coating for the inner layer. This finding encourages more in-depth studies using state-ofthe-art residue analysis techniques to investigate carbohydrates that are characteristic of various food types, amino acids, anions, cations, and potentially even small peptides. With the use of appropriate technologies, only very small sample sizes are required, potentially eliminating the need for a "destructive" sample preparation protocol.

A side-by-side comparison between two complementary techniques would provide some additional support to ensure that the residues obtained were not due to some environmental artifact. Another set of studies also might be conducted to evaluate the effect of various types of "aging" (i.e., high heat or other differing environmental factors) on the fate of some of these residues. The studies described here are important and should be completed but were not within the scope of the current study.

The foregoing effort provided valuable insights that should be considered in future analysis. The following is a proposed protocol for achieving continued improvement in methodology for organic residue analysis. These recommendations are contingent on the artifact being previously unwashed and stored wrapped but not in a plastic bag. If the artifact has been stored in less than ideal conditions, variations in the protocol and resulting analysis may be necessary to ensure appropriate results.
The artifact should first be extracted with the modified Folch reagent described above and the solvent removed in an inert atmosphere. The artifact should be allowed to dry and exhaustively extracted with warm water (approximately $90^{\circ} \mathrm{C}$ ). A minimal amount of water should be used or it should be reduced by lyophilization or some other nondestructive technique. Finally, the artifact can be extracted with a mixed solvent such as methanol/water which can isolate other culturally significant residues. Based on the results obtained in these studies, the outer lipophilic layer seems to provide a protective outer coating for other materials to ensure the recovery of the maximum number and number of compounds.

Lipophilic Fraction (Marini 1993)

Compound Class Analytical Technique

Fatty Acid

Free $\quad G C$ with Flame Ionization Detector, HPLC with Refractive Index, Ultraviolet, or Evaporative Light Scattering Detection

Total GC with Flame Ionization Detector, HPLC with Refractive Index, Ultraviolet or Evapo rative Light Scattering Detection

Triglyceride HPLC with Evaporative Light Scattering Detection

Other Lipids $\quad$ HPLC with Evaporative Light Scattering Detection or Refractive Index Detection

Polyaromatic HPLC with Fluorescence

Hydrocarbons Detection

Ideally, one would subject a portion of this material to an HPLC class separation as outlined by Marini (1993) where the entire fraction can be divided into fatty acids; mono, di, and triglycerides; and sterols, especially cholesterol and phospholipids. These fractions can then be further isolated for individual class members. While obviously more expensive than Thin Layer Chromotography (TLC) fractionation, the data would prove superior.

\section{Water Fractions}

Compound Class Analytical Technique

Anions Capillary Electrophoresis (CE)

(Danielson and Sherman 1993)

Cations Capillary Electrophoresis (CE)

(Danielson and Sherman 1993)

Amino Acids HPLC with Fluorescence Detection

(White and Hart 1993)

Carbohydrates HPLC with Pulsed Amperometric Detection (Scott 1993)

Should an artifact have a particular background or cultural importance, then one could focus on artifact-specific compounds.

Each of the techniques has been chosen to obtain the maximum amount of information for the least amount of sample without destroying the sample. The aim of any analy- 
sis determination of this type is to obtain the most information. In many of these compound classes, the detector of choice would have been mass spectrometry (MS). In the cases of GC, HPLC, and CE there are sufficient MS detector types commercially available to extract large amounts of information. While MS is the ideal detector, it can be prohibitively expensive; other detector types are readily available in most laboratories and would afford nanomole levels of sensitivity.

The reasons for the departure from the method of fatty acid distributions are several. First, since fatty acids are said to degrade at differing rates, the presence or absence of a particular fatty acid might be an analytical or sample preparation bias. While this is not to detract from the excellent work in developing the various $\% \mathrm{~S}$ ratios, this protocol might serve as an alternative. The ability to develop information on triglycerides and sterols would be useful in supplementing other findings related to the lipophilic extract. The inclusion of the polyaromatic hydrocarbons would provide some interesting additional information on possible combustion sources.

The compounds chosen for examination in the water soluble fraction would provide another set of information. Anions have already been discussed above and cations could be examined in similar approaches. Free and total amino acids could provide information about possible plant/animal sources, and depending on the amount and state of extract available, one could examine peptide fractions. Finally, peptides and carbohydrates could also provide important data on the residue sources. 


\section{REFERENCES CITED IN VOLUME III}

Adams, J. L.

1988 Use-Wear Analysis on Manos and Hide-Processing Stones. Journal of Field Archaeology 15 (3):307-315.

1993 Technological Development of Manos and Metates on the Hope Mesas. Kiva 58 (3):331-344.

Ahler, S. A.

1971 Projectile Point Form and Function at Rogers Shelter. Research Series 8. Missouri Archeological Society, Columbia.

1989 Mass Analysis of Flaking Debris: Studying the Forest Rather than the Tree. In Alternative Approaches to Lithic Analysis, edited by D. O. Henry and G. H. Odell, pp. 85-118. Archeological Papers of the American Anthropological Association Number 1.

Allain, J., and A. Rigaud

1989 Colles et mastics au Magdalenien. Actes du Colloque International de Nemours 1987, sous la direction de M. Olive et Y. Taborin, pp. 221-223. Memoirs du Musee de Prehistoire d'Ille de France No. 2.

Anderson, P. C.

1980 A Testimony of Prehistoric Tasks: Diagnostic Residues on Stone Tool Working Edges. World Archaeology 12:181194.

Anderson-Gerfaud, P.C.

1981 Contribution Methodologique a L'analyse de Microtraces d'utilization sur les Outils Prehistoriques. Ph.D. dissertation, University of Bordeaux.

Andrews, J.

1992 A Field Guide to Shells of the Texas Coast. Gulf Publishing Co., Houston.

Austin, R. J.

1986 The Experimental Reproduction and Archaeological Occurrence of Biface Notching Flakes. Lithic Technology 15(3):96-101.

Banks, L. D.

1990 From Mountain Peaks to Alligator Stomachs: A Review of Lithic Sources in the Trans-Mississippi South, the Southern Plains, and Adjacent Southwest. Oklahoma Anthropological Society, Memoir 4.

Bartlett, K.

1933 Pueblo Milling Stones of the Flagstaff Region and their Relation to Others in the Southwest. Museum of Northern Arizona Bulletin 3. Northern Arizona Society of Science and Art, Flagstaff.

Beck, C. W., and J. Bingham

1994 Organic Residues on Stone Artifacts at the Wilson Leonard Site. Paper read at the Plains Anthropological Society Meeting, Lubbock, Texas.
Binford, L. R.

1979 Organization and Formation Processes: Looking at Curated Technologies. Journal of Anthropological Research 35:255-273.

1963 A Proposed Attribute List for the Description and Classification of Projectile Points. In Miscellaneous Studies in Typology and Classification, edited by A. M. White, L. R. Binford, and M. L. Papworth, pp. 193-221. Anthropological Papers 19. Museum of Anthropology, University of Michigan, Ann Arbor.

Binford, L. R., and S. R. Binford

1966 A Preliminary Analysis of Functional Variability in the Mousterian of Levallois Facies. American Anthropologist 68(2):238-295.

Black, S. L.

1993 Nailing the Coffin Shut on the Traditional Approach to Prehistoric Archeology in Texas: An Epitaph and Inquiry into the Afterlife. In Cultural Resource Management News and Views 5(1):16-19.

Black, S. L., and A. J. McGraw

1985 The Panther Springs Creek Site: Cultural Change and Continuity with the Upper Salado Creek Watershed, South-Central Texas. Archaeological Survey Report 100. Center for Archaeological Research, The University of Texas at San Antonio.

Boyd, C. L. and H. J. Shafer

1997 Another Look at the Distribution, Age, and Function of "Waco Sinkers." Bulletin of the Texas Archaeological Society 68:263-271.

Boyd, J. B., D. E. Wilson, T. R. Hester, and T. K. Perttula

1997 Southern Island, A Prehistoric Cemetery Site in the Falcon Reservoir, Tamaulipas, Mexico. Bulletin of the Texas Archeological Society 68:387-425.

Bradley, B. A.

1975 Lithic Reduction Sequences: A Glossary and Discussion. In Lithic Technology: Making and Using Stone Tools, edited by E. Swanson, pp 5-14. Mouton, The Hague.

1982 Flaked Stone Technology and Typology. In The Agate Basin Site, by G. C. Frison and D. J. Stanford, pp. 181208. Academic Press, New York.

Brain, C. K.

1981 The Hunters or the Hunted? An Introduction to African Cave Taphonomy. University of Chicago Press, Chicago.

Braun, D. P.

1983 Pots as Tools. In Archeological Hammers and Theories, edited by J. A. Moore and A. S. Keene, pp. 108-134. Academic Press, New York. 
Brown, D. O.

1989 Prehistoric Subsistence Strategies in Northeastern Central Texas. Bulletin of the Texas Archeological Society 59:201-244.

Butterwick, M.

1979 A Survey of the Flora of Enchanted Rock and Vicinity, Llano and Gillespie Counties, Texas. In Enchanted Rock, D. Kennard, project director, pp. 41-102. Natural Area Survey 14:1-166. Lyndon B. Johnson School of Public Affairs, The University of Texas at Austin.

Campbell, T. N.

1957 Archeological Investigations at the Caplen Site, Galveston County, Texas. Texas Journal of Science 9(4):448-471.

Carter, G. F.

1977 The Metate: An Early Grain-Grinding Implement in the New World. In Origins of Agriculture, edited by C. A. Reed, pp. 693-712. Mouton Publishers, The Hague.

Chandler, C. K.

1974 Use Wear Analysis of "Clear Fork" Tools from the Falcon Reservoir Area, Southern Texas. La Tierra 1(4):15-21.

Clark, J. D., and H. Kurashina

1981 A Study of the Work of a Modern Tanner in Ethiopia and Its Relevance for Archaeological Interpretation. In Modern Material Culture. Academic Press, New York.

Cleland, C. E.

1982 The Inland Shore Fishery of the Northern Great Lakes: Its Development and Importance in Prehistory. American Antiquity 47 (4):761-784.

Collins, M. B.

1968 The Andrews Lake Locality: New Archeological Data from the Southern Llano Estacado, Texas. Master's thesis. Department of Anthropology, The University of Texas at Austin.

1973 The Devil's Hollow Site, A Stratified Archaic Campsite in Central Texas. Bulletin of the Texas Archeological Society 43:77-100.

1974 A Functional Analysis of Lithic Technology among Prehistoric Hunter-gatherers of Southwestern France and Western Texas. Ph.D. dissertation, Department of Anthropology, University of Arizona, Tucson.

1975 Lithic Technology as a Means of Processual Inference. In Lithic Technology: Making and Using Stone Tools, edited by E. Swanson, pp. 15-34. Mouton, The Hague.

1993 Comprehensive Lithic Studies: Context, Technology, Style, Attrition, Breakage, Use-Wear and Organic Residues. Lithic Technology 18(1\&2):87-94.

1994 Late Archaic Evidence in the Project Area. In Archaic and Late Prehistoric Human Ecology in the Middle Onion Creek Valley, Hays County, Texas, by R. A. Ricklis and M. B. Collins, pp. 101-189. Studies in Archeology
19. Texas Archeological Research Laboratory, The University of Texas at Austin.

Collins, M. B., J. Guy, and S. Carpenter

1991 An Evaluation of Documentation from 1981-1984 Investigations at the Wilson-Leonard Site (41WM235) Williamson County, Texas. Technical Series 21. Texas Archeological Research Laboratory, The University of Texas at Austin.

Cotterell, B., and J. Kamminga

1990 Mechanics of Pre-Industrial Technology. Cambridge University Press, New York.

Crabtree, D. E.

1972 An Introduction to Flintworking. Occasional Papers No. 28. Idaho State University Museum, Pocatello.

1977 The Obtuse Angle as a Functional Edge. In Experimental Archeology, edited by D. Ingersoll, J. E. Yellen, and W. MacDonald, pp. 38-51. Columbia University Press, New York.

Danielson, N. D., and J. H. Sherman

1993 Determination of Anions and Cations by HPLC. In Food Analysis by HPLC, edited by L. Nollett, pp. 713-729. Marcel Dekker, New York.

Donahue, R. E.

1993 The Current State of Lithic Microwear Research. In Stories in Stone, edited by N. Ashton and A. David, pp. 156-168. Occasional Paper 4. Lithic Studies Society, St. Hilda's College, Oxford.

Driskell, B. N.

1986 The Chipped Stone Tool Production/Use Cycle: Its Potential in Activity Analysis of Disturbed Sites. BAR International Series 305. British Archaeological Reports, Oxford.

1994 Use-Wear Analysis of Chipped Stone Artifacts from the Barton and Mustang Branch Sites (41HY202 and 41HY209).In Archaic and Late Prehistoric Human Ecology in the Middle Onion Creek Valley, Hays County, Texas, edited by R. A. Ricklis and M. B. Collins, pp. 583-606. Studies in Archeology 19. Texas Archeological Research Laboratory, The University of Texas at Austin.

Dumont, J.

1982 The Quantification of Microwear Traces: A New Use for Interferometry. World Archaeology 14:206-217.

Ensor, H. B., and C. S. Mueller-Wille

1988 Excavations at the Bull Pen Site 41BP280, Colorado River Drainage, Bastrop County, Texas. Contract Reports in Archeology 3. Texas State Department of Highways and Public Transportation, Austin.

Epstein, J. F.

1963 The Burin-Faceted Projectile Point. American Antiquity 29:187-201. 
Evershed, R. P.

1993 Bimolecular Archaeology and Lipids. World Archaeology 25:74-93.

Fiedel, S. J.

1996 Blood for Stones? Some Methodological and Interpretive Problems in Blood Residue Analysis. Journal of Archaeological Science 23:139-147.

Folch, J., M. Lees, and G. H. S. Stanley

1957 A Sample Method for Isolation and Purification of Total Lipids from Animal Tissue. Journal of Biological Chemistry 226:497-501.

Frederick, C. D., and C. Ringstaff

1994 Lithic Resources at Fort Hood: Further Investigations. In Archaeological Investigations on 571 Prehistoric Sites at Fort Hood, Bell and Coryell Counties, Texas, edited by W. N. Trierweiler, pp. 125-179. United States Army Fort Hood Archeological Resource Management Series Research Report No. 31. Mariah and Associates, Austin.

Frederick, C. D., M. D. Glasscock, H. Neff, and C. M. Stevenson 1994 Evaluation of Chert Patination as a Dating Technique: A Case Study from Fort Hood, Texas. United States Army Fort Hood Archeological Resource Management Series Research Report No. 32. Mariah and Associates, Austin.

Frison, G. C.

1986 Mammoth Hunting and Butchering from a Perspective of Africa Elephant Culling. In The Colby Mammoth Site, edited by G. C. Frison and L. C. Todd, pp. 115-134. University of New Mexico Press, Albuquerque.

1989 Experimental Use of Clovis Weaponry and Tools on African Elephants. American Antiquity 54:766-784.

Frison, G. C., and B. Bradley

1980 Folsom Tools and Technology of the Hanson Site, Wyoming. University of New Mexico Press, Albuquerque.

Frison, G. C., and D. J. Stanford

1982 The Agate Basin Site: A Record of the Paleoindian Occupation of the Northwestern High Plains. Academic Press, New York.

Gallagher, J. G., and S. E. Bearden

1976 The Hopewell School Site: A Late Archaic Campsite in the Central Brazos River Valley. Contributions in Anthropology 19. Institute for the Study of Earth and Man, Southern Methodist University, Dallas.

Gunstone, F. D., J. L. Harwood, and F. B. Padley

1994 The Lipid Handbook. 2nd ed. Chapman \& Hall, London.

Hall, G. D.

1981 Allens Creek: A Study in the Cultural Prehistory of the Lower Brazos River Valley, Texas. Research Report 61. Texas Archeological Survey, The University of Texas at Austin.
1989 Long-Bone Implements from Some Prehistoric Sites in Texas: Functional Interpretations Based on Ethnographic Analogy. Bulletin of the Texas Archeological Society 59:157-176.

Hall, G. D., S. L. Black, and C. Graves

1982 Archaeological Investigations at Choke Canyon Reservoir, South Texas: The Phase I Findings. Choke Canyon Series 5. Center for Archaeological Research, The University of Texas at San Antonio.

Harrell, L. L.

1983 A Study of the Bone and Antler Tools from Hog Creek Reservoir, Bosque and Coryell Counties, Texas. Master's thesis. Department of Anthropology, The University of Texas at Austin.

Hester, T. R.

1971a Archeological Investigations at the La Jita Site, Uvalde County, Texas. Bulletin of the Texas Archeological Society 42:51-148.

1971b Marine Shells from Archeological Sites in Southwestern Texas. Texas Journal of Science 22:87-88.

Hester, T. R., and M. B. Collins

1968 A Wooden Mortar and Pestle from Val Verde County, Texas. Bulletin of the Texas Archeological Society 39:18.

Hester, T. R., D. Gilbow, and A. D. Albee

1973 A Functional Analysis of "Clear Fork" Artifacts from the Rio Grande Plain, Texas. American Antiquity 38:9096.

Highley, C. L.

1986 Archaeological Investigations at 41LK201, Choke Canyon Reservoir, Southern Texas. Choke Canyon Series Volume 11. Center for Archaeological Research, The University of Texas at San Antonio.

1995 Miscellaneous Minerals and Materials. In Archeological Investigations at the Loma Sandia Site (41LK28), by A. J. Taylor and C. L. Highley, pp. 519-522. Studies in Archeology 20. Texas Archeological Research Laboratory, The University of Texas at Austin.

Hilditch, T.P.

1956 The Chemical Constitution of Natural Fats. 3rd ed. Wiley, New York.

Hill, D.W., F. H. Walters, T. D. Wilson, and J. D. Stuart

1979 High Performance Liquid Chromatographic Determination of Amino Acids in the Picomole Range. Analytical Chemistry 51:1338-1341.

Hillman, G., S. Wales, F. McLaren, J. Evans, and A. Butler

1993 Identifying Problematic Remains of Ancient Plant Foods; A Comparison of the Role of Chemical, Histological and Morphological Criteria. World Archeology 25:94-117. 
Hoffman, R., and L. Gross

1970 Reflected-Light Differential-Interference Microscopy: Principles, Use and Image Interpretation. Journal of Microscopy 91(3): 149-172.

Hofman, J. L., L. C. Todd, and M. B. Collins

1991 Identification of Central Texas Edwards Chert at the Folsom and Lindenmeier Sites. Plains Anthropologist 36(137):297-308.

House, J. W., T. R. Hester, and T. C. Hill, Jr.

1971 Notes on Incised and Grooved Stones from Southern and Western Texas. Department of Anthropology, University of California, Berkeley.

Howard, C. D.

1973 A Study of the Clear Fork Gouge. Bulletin of the Texas Archeological Society 44:51-60.

Hudler, D.

1997 Determining Clear Fork Tool Function through Use-Wear Analysis: A Discussion of Use-Wear Methods and Clear Fork Tools. Studies in Archeology 25. Texas Archeological Research Laboratory, The University of Texas at Austin.

Hurcombe, L.

1992 Use Wear Analysis and Obsidian: Theory, Experiments and Results. Sheffield Archaeological Monographs 4. University of Sheffield, Sheffield.

Jackson, A. T.

1940 Tubular Pipes and Other Tubes in Texas. Bulletin of the Texas Archeology and Paleontological Society 12:99-134.

Jodry, M. A.

1987 Stewart's Cattle Guard Site: A Folsom Site in Southern Colorado: A Report of the 1981 and 1983 Field Seasons. Unpublished Master's thesis, The University of Texas at Austin.

Johnson, J. K.

1993 North American Biface Production Trajectory Modeling in Historic Perspective. Plains Anthropologist 38:151162.

Johnson, L., Jr.

1964 The Devil's Mouth Site, A Stratified Campsite at Amistad Reservoir, Val Verde County, Texas. Archaeology Series Number 6. Department of Anthropology, The University of Texas at Austin.

1991 Early Archaic Life at the Sleeper Archaeological Site, 41BC65, of the Texas Hill Country, Blanco County, Texas. Publications in Archaeology Report 39. Texas State Department of Highways and Public Transportation Highway Design Division, Austin, Texas.

Jones, P., and R. Freudenthal

1978 Carcinogensis: A Comprehensive Survey, Vol. 3, Polyaromatic Hydrocarbons. Raven Press, New York.
Karrer, W., E. Cherbuliez, C. H. Eugster, and H. Hürlimann

1958 - 1981 Konstitution und Vorkommen der Organischen Pflanzenstoffe. Birkhauser Verlag, Basel.

Kay, M.

1995 Microwear Examination of Lake Ilo Project Folsom Artifacts. Unpublished report on file, Lake Ilo Project Northern Arizona University, Pullman.

1996 Microwear Analysis of Some Clovis and Experimental Chipped Stone Tools. In Stone Tools: Theoretical Insights into Human Behavior, edited by G. H. Odell, pp. 315-344. Plenum Press, New York.

1997 Imprints of Ancient Tool Use at Monte Verde. In Monte Verde: A Late Pleistocene Settlement in Chile, Volume 2, edited by T. D. Dillehay. Smithsonian Institution Press, Washington, D.C.

Keeley, L. H.

1974 Technique and Methodology of Microwear Studies. World Archaeology 5:323-336.

1980 Experimental Determination of Stone Tool Uses: A Microwear Analysis. University of Chicago Press, Chicago.

1982 Hafting and Retooling: Effects on the Archeological Record. American Antiquity 47:798-809.

Kimball, L. R., J. F. Kimball, and P. E. Allen

1995 Microwear Polishes as Viewed through the Atomic Force Microscope. Lithic Technology 20(1):6-28.

Kraybill, N.

1977 Pre-Agricultural Tools for the Preparation of Foods in the Old World. In The Origins of Agriculture, edited by C. A. Reed. Mouton Publishers, The Hague.

Lein, P. M.

1983 Amino Acid Racemization from Paleo-Indian Sites in Florida. Florida Anthropologist 36:106-107.

Leneave, R. J.

1995 Ground Stone. In Archeological Investigations at the Loma Sandia Site (41LK28), by A. J. Taylor and C. L. Highley, pp. 486-519. Studies in Archeology 20. Texas Archeological Research Laboratory, The University of Texas at Austin.

Logan, E. N., and L. Fratt

1993 Pigment Processing at Homol'ovi III: A Preliminary Study. Kiva 58 (3):415-428.

Loy, T. H., and A. R. Wood

1989 Blood Residues at Cayonu Tepsi. Journal of Field Archaeology 16:451-460.

Mallouf, R. J.

1989 A Clovis Quarry Workshop in the Callahan Divide: The Yellow Hawk Site, Taylor County, Texas. Plains Anthropologist 34(124):81-103. 
Mansur, M. E.

1982 Microwear Analysis of Natural and Use Striations: New Clues to the Mechanism of Striation Formation. Studia Prehistorica Belgica 2:213-233.

Marchbanks, M.

1989 Lipid Analysis in Archaeology: An Initial Study of Ceramics and Subsistence at the George C. Davis Site. Unpublished Master's thesis. The University of Texas at Austin.

Marini, D.

1993 HPLC of Lipids. In Food Analysis by HPLC, edited by L. Nollett, pp. 169-240. Marcel Dekker, New York.

Marois, R., E. B. Jelks, M. C. Mineiro Scatamacchia, A. M. Groot de Mahecha, and J. Echeverría Almeida

1997 Multilingual Dictionary of Lithic Technology Terms. Publication 499. Pan American Institute of Geography and History, Mexico D.F. Mexico.

Martin, G.

1996 Keepers of the Oaks. Discovery, August, 45-50.

Mass Spectrometric Data Centre

1986 Eight Peak Index of Mass Spectra. Royal Society of Chemistry, Nottingham.

Masson, M. A.

1989 Lithic Production Changes in Late Classic Maya Workshops at Colha, Belize: A Study of Debitage Variation. Master's Thesis, Department of Anthropology, Florida State University, Tallahassee.

Mauldin, R.

1993 The Relationship Between Ground Stone and Agricultural Intensification in Western New Mexico. Kiva 58(3):317-330.

McLafferty, F. W.

1966 Interpretation of Mass Spectra. Benjamin, New York.

McLafferty, F. W., and D. B. Stauffer

1989 The Wiley/NBS Registry of Mass Spectral Data, CDRom version. Wiley, New York.

McReynolds, R. L.

1983 Two Paleolithic Tools from Coleto Creek, Victoria County, Southern Texas. La Tierra 10(4):26-30.

Meltzer, D. J.

1989 Was Stone Exchanged among Eastern North American Paleo-Indians? In Eastern Paleo-Indian Lithic Resource Use, edited by C. Ellis and J. Lothrop, pp. 11-39. Westview Press, Boulder.

Miller, P. A.

1980 Archaic Lithics from the Coffey Site. In Archaic Prehistory on Prairie-Plains Border, edited by A. E. Johnson, pp. 107-111. Publications in Anthropology 12. University of Kansas, Lawrence.
Morris, D. H.

1990 Changes in Groundstone Following the Introduction of Maize in the American Southwest. Journal of Anthropological Research 46(2):177-194.

Muto, G. R.

1971 Technological Analysis of the Early Stages of Manufacture of Lithic Artifacts. Master's thesis, Department of Anthropology, Washington State University, Pullman.

Nash, M.

1980 An Analysis of a Debitage Collection from Colha, Belize. In The Colha Project, Second Season, 1980 Interim Report, edited by T. R. Hester, J. D. Eaton, and H. J. Shafer, pp. 333-352. Center for Archaeological Research, The University of Texas at San Antonio and Centro Studi e Ricerche Ligabue, Venezia. San Antonio.

Neck, R. W.

1988 Plant Resources in the Vicinity of the Wilson-Leonard Site (41WM235). Ms. on file at the Texas Archeological Research Laboratory, The University of Texas at Austin.

Newcomer, M. H.

1971 Some Quantitative Experiments in Handaxe Manufacture. World Archaeology 3(1):85-93.

Newcomer, M. H., and L. H. Keeley

1979 Testing a Method of Microwear Analysis with Experimental Flint Tools. In Lithic Use-Wear Analysis, edited by B. Hayden, pp. 195-205. Academic Press, New York.

Newman, M. E., R. M. Yohe II, H. Ceri, and M. Sutton

1993 Immunological Protein Residue Analysis on Non-lithic Archeological Materials. Journal of Archaeological Science 20:93-100.

Odell, G. H.

1982 Emerging Directions in the Analysis of Prehistoric Stone Tool Use. Reviews in Anthropology 9:17-33.

1990 Brer Rabbit Seeks True Knowledge. Aun 14:125-134.

Odell, G. H., and F. Odell-Vereechken

1980 Verifying the Reliability of Lithic Use Wear Assessments by "Blind Tests:" The Low-Power Approach. Journal of Field Archaeology 7:87-120.

Peterson, J. B., N. D. Hamilton, J. M. Adovasio, and A. L. McPherron

1984 Netting Technology and the Antiquity of Fish Exploitation in Eastern North America. Midcontinental Journal of Archaeology 9 (2):199-225.

Petraglia, M., D. Knepper, P. Glumac, M. Newman, and C. Sussman 1996 Immunological and Microwear Analysis of Chipped-stone Artifacts from Piedmont Contexts. American Antiquity 61:127-135. 
Prewitt, E.

1966 A Preliminary Report on the Devil's Rockshelter Site, Val Verde County, Texas. Texas Journal of Science 18:206-224.

1981a Cultural Chronology in Central Texas. Bulletin of the Texas Archeological Society 52:65-89.

1981b A Wooden Mortar from the Stockton Plateau of Texas. Journal of Field Archaeology 8(1):111-117.

Ray, C. N.

1938 The Clear Fork Culture Complex. Bulletin of the Texas Archeological and Paleontological Society 10:193-207.

Ritchie, W. A.

1969 The Archaeology of New York State (Revised Edition). The Natural History Press, New York.

Root, M. J.

1994a Analysis of Stone Tools and Flaking Debris. In Archaeology of the Bobtail Wolf Site (32DU955A): 1993-1994 Progress Report, edited by M. J. Root and A. M. Emerson, pp. 147-224. Project Report 26. Center for Northwest Anthropology, Department of Anthropology, Washington State University, Pullman.

1994b Archeological Field and Laboratory Techniques. In Archaeology of the Bobtail Wolf Site (32DU955A): 19931994 Progress Report, edited by M. J. Root and A. M. Emerson, pp. 23-48. Project Report 26. Center for Northwest Anthropology, Department of Anthropology, Washington State University, Pullman.

Schlanger, S. H.

1991 On Manos, Metates, and the History of Site Occupation. American Antiquity 56(3):460-482.

Schuetz, M. K.

1961 An Analysis of Val Verde County Cave Material: Part II. Bulletin of the Texas Archeological Society 31:131-165.

Schutz, J. M.

1992 The Use-Wear Generated by Processing Bison Hides. Plains Anthropologist 141:333-351.

Scott, F. W.

1993 HPLC of Carbohydrates in Foods. In Food Analysis by HPLC, edited by L. Nollett, pp. 259-274. Marcel Dekker, New York.

Semenov, S. A.

1964 Prehistoric Technology. Cory, Adams and Mackay, London.

Shafer, H. J.

1969 Archeological Investigations in the Robert Lee Reservoir Basin, West Central Texas. Papers of the Texas Archeological Salvage Project 17. The University of Texas at Austin.

1979 A Technological Study of Two Maya Lithic Workshops at Colha, Belize. In The Colha Project, 1979: A Collec- tion of Interim Papers, edited by T. R. Hester, pp. 2978. Center for Archaeological Research, The University of Texas at San Antonio.

Sheets, $\mathrm{P}$.

1973 Edge Abrasion during Biface Manufacture. American Antiquity 38:215-218.

Shott, M. J.

1986 Technological Organization and Settlement Mobility: An Ethnographic Examination. Journal of Anthropological Research 42:15-51.

1989 On Tool-Class Use Lives and the Formation of Archeological Assemblages. American Antiquity 54:9-30.

1994 Size and Form in the Analysis of Flake Debris: Review and Recent Approaches. Journal of Archaeological Method and Theory 1(1):69-110.

Sollberger, J. B.

1971 A Technological Study of Beveled Knives. Plains Anthropologist 16:209-218.

Spaulding, A. C.

1982 Structure in Archeological Data: Nominal Data. In Archaeological Typology, edited by R. Whallon and J. A. Brown, pp. 1-20. Center for American Archeology Press, Evanston.

Speth, J. D.

1972 Mechanical Basis of Percussion Flaking. American Antiquity 37:34-60.

Stahl, A. B.

1989 Plant-Food Processing: Implications for Dietary Quality. In Foraging and Farming: The Evolution of Plant Exploitation, edited by D. R. Harris and G. C. Hillman, pp. 171-194. University College, London.

Stahle, D. W., and J. E. Dunn

1982 An Analysis and Application of the Size Distribution of Waste Flakes from the Manufacturing of Bifacial Stone Tools. World Archaeology 14:84-97.

Steele, G. D.

1988 Utilization of Marine Mollusks by Inhabitants of the Texas Coast. Bulletin of the Texas Archeological Society $58: 215-248$

Stein, J.

1984 Organic Matters and Carbonates in Archeological Sites. Journal of Field Archaeology 11:239-242.

Taylor, A. J.

1995 Summary and Consideration of Cultural Features. In Archeological Investigations at the Loma Sandia Site (41LK28): A Prehistoric Cemetery and Campsite in Live Oak County, Texas, by A. J. Taylor and C. L. Highley, pp. 359-404. Studies in Archeology 20. Texas Archeological Research Laboratory, The University of Texas at Austin. 
Titmus, G. L.

1985 Some Aspects of Stone Tool Notching. In Stone Tool Analysis: Essays in Honor or Don E. Crabtree, edited by M. G. Plew, J. C. Woods, and M. G. Pavesic, pp. 243-265. University of New Mexico Press, Albuquerque.

Trierweiler, W. N. (editor)

1994 Archeological Investigations on 571 Prehistoric Sites at Fort Hood, Bell and Coryell Counties, Texas. United States Army Fort Hood Archeological Resource Management Series Research Report No. 31. Mariah and Associates, Austin.

Turner, E. S., and T. R. Hester

1993 A Field Guide to Stone Artifacts of Texas Indians, 2nd ed. Gulf Publishing Co., Houston.

United States Department of Agriculture

1976 USDA Handbook No. 8. United States Department of Agriculture, Washington, D.C.

Vaughan, P. C.

1985 Use-Wear Analysis of Flaked Stone Tools. The University of Arizona Press, Tuscon.

Vines, R. A.

1990 Trees, Shrubs, and Woody Vines of the Southwest. University of Texas Press, Austin.
Watt, F.

1939 The Waco Sinker. Central Texas Archeologist 4. Central Texas Archeologist, Waco, Texas.

1944 Abrading Implements and Cultural Indices in the Central Brazos Valley Area. Central Texas Archeologist 5. Central Texas Archeologist, Waco, Texas.

Weber, C.

1994 A Replication Technique for Andice/Bell Points. In Archaic and Late Prehistoric Human Ecology in the Middle Onion Creek Valley, Hays County, Texas, by R. A. Ricklis and M. B. Collins, pp. 629-651. Studies in Archeology 19. Texas Archeological Research Laboratory, The University of Texas at Austin.

White, J. A., and R. J. Hart

1993 Derivatization Methods for Liquid Chromatographic Separation of Amino Acids. In Food Analysis by HPLC, edited by L. Nollett, pp. 53-73. Marcel Dekker, New York.

Witthoff, J.

1967 Glazed Polish on Flint Tools. American Antiquity 32:383388.

Yarnell, R. A.

1964 Aboriginal Relationships between Culture and Plant Life in the Upper Great Lakes Region. University of Michigan, Ann Arbor. 


\title{
APPENDIX 1: UNMODIFIED LITHIC MATERIALS
}

\author{
by Sean R. Nash and Michael B. Collins
}




\section{INTRODUCTION}

Natural rocks that were, or may have been, introduced to the Wilson-Leonard site through human agency are discussed in this appendix. None of the specimens has discernible cultural modifications, but natural processes cannot account for the presence of some lithologies found at the site (e.g., pieces of granite or sandstone). Some lithologies that occur naturally within the geological setting of the site (e.g., hematite and calcite) are included because other evidence (e.g., their size, concentrations, or condition) suggests possible human introduction which could have been either intentional or unintentional.

Intentional introductions include specific rocks collected in order to be made into tools (e.g., tabular sandstone to be made into metates or hematite for use in pigments or adhesives). Unintentional introductions are those caused incidentally by other human activities. Any number of objects routinely brought to a habitation site might have sand and small pebbles adhering. Woody roots intended as fuel, sticky surfaces of field-dressed game or fish, and even muddy sandals are among the possibilities.

Identifications were made using standard hand specimen geological practices. A hand lens, low-power microscopy, and diluted hydrochloric acid were the only aids employed during analysis.

Some lithologies were grouped according to the size grades of Folk (1980). The term "shatter" has been employed to describe sharp-edged fragments of bull quartz that are less than $32 \mathrm{~mm}$ in greatest dimension; these give minimal indications of the size of the original rock. Each lithologic category is described and discussed below in alphabetical order. This is followed by a distributional analysis of hematite, calcite, and cryptocrystalline quartz pebbles. All specimens are listed by provenience in Table A1-1.

\section{LITHOLOGICCATEGORIES}

Bull quartz refers to massive, macrocrystalline quartz with irregular, interlocking crystals often formed in masses and seams in Town Mountain granite (Barnes 1981a). Two of the three bull quartz pebbles found at the Wilson-Leonard site have rounded edges and appear to have been stream rolled. The third is an angular chunk. The origin of these specimens is presumed to be the Town Mountain or other granitic unit in the Central Mineral Region as this is the only close source. The stream-rolled appearance indicates that two pieces were found as gravel after having been transported by a stream. The stream system draining the Central Mineral Region does not include Brushy Creek, which rules out any possibility that bull quartz pebbles were introduced into the site as natural fluvial deposits. Rather, the closest possible fluvial source is along the Colorado River, which is within about $30 \mathrm{~km}$ of the site. The chunk was probably found or quarried at the outcrop.
Because bull quartz pebbles were imported from a source at least $30 \mathrm{~km}$ away, it is likely that a specific use was anticipated. Several manos made from bull quartz cobbles were found at the site. However, there was no pebble-sized bull quartz recovered with any discernible cultural modifications. In contrast, all the bull quartz cobbles found had been used as manos.

Possibly these pebbles were (1) brought to the site to be used as manos or some other tool and then judged to be inappropriate; (2) introduced unintentionally; or (3) imported for a use that did not require physical modification. The latter could include use as a thermal storage device. The chunk, which is a pebble not exhibiting any stream rolling, has a fourth possibility; it could be the remains of a fractured mano or other object.

Bull quartz shatter found at the Wilson-Leonard site likely represents fragments introduced to the site for one of the reasons listed above. Some pieces retain cortex. Visual inspection of the cortex of the shatter from one lot shows evidence of stream rolling. Visual inspection of the remainder was inconclusive because of the small size of the specimens. Most of the shatter has no cortex, so it is possible that the bull quartz was quarried at the source.

Some could be the remains of shattered manos or hammerstones. Some manos found at Wilson-Leonard are fractured and could have created similar shatter. Heat can also cause bull quartz to shatter. The use of these rocks as thermal storage devices (including boiling stones) could account for both their importation and subsequent shatter. Unintentional exposure to heat could also explain some shatter.

Calcite is a naturally occurring mineral in the geological setting of the Wilson-Leonard site, and excavators noted large amounts of calcite at the site. Mostly crystalline calcite pieces $(\mathrm{N}=132)$ were collected. They range in size from granules to very large pebbles. Some pieces appear stream rolled. Calcite was distributed roughly evenly horizontally and vertically throughout the site (see discussion below).

Chalcedony and jasper are ubiquitous in Central Texas but chalcedony, in pieces large enough to be of cultural utility, is found almost exclusively at massive Edwards limestone outcrops, which are not present in the Brushy Creek drainage above Wilson-Leonard. Jasper has a similar occurrence in the limestone formations, but is more common than chalcedony as pebbles in past and present streams. These small weathered pebbles do occur in Brushy Creek and elsewhere in the region. If jasper pebbles were imported, they could all have been collected in the vicinity of the site, whereas chalcedony specimens may represent longer-distance transport (Barnes 1981b). Some specimens exhibit characteristics associated with stream rolling. The jasper is essentially iron-stained chert. One chalcedony specimen (Lot 1265 ) is a fragment of a geode and was found in association with Burned Rock Midden 1 in stratigraphic Unit IIIc of the Valley Margin. 
TABLE A1-1

Raw Material Frequencies by Stratigraphic Unit

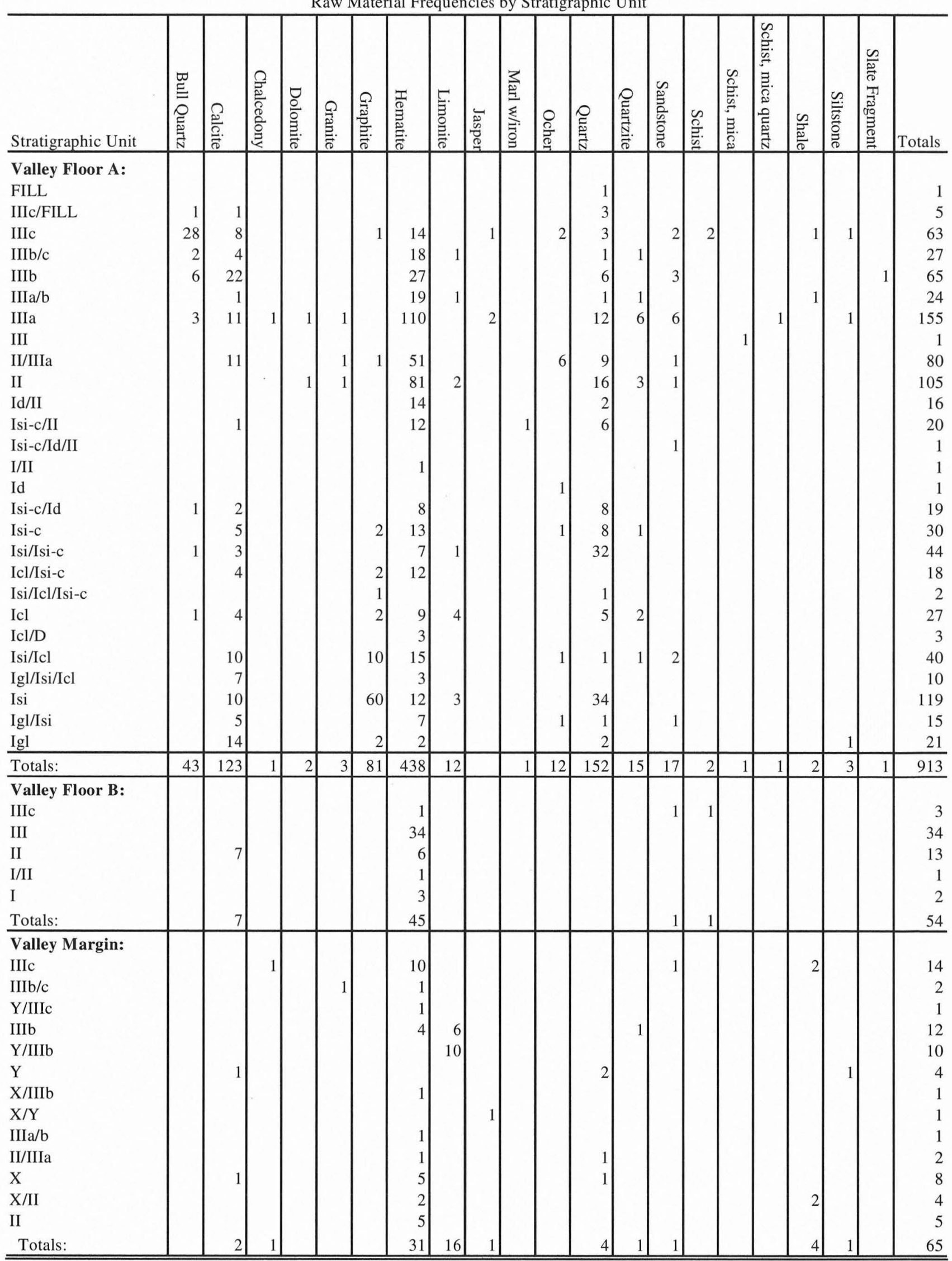


Dolomite is common in Edwards limestone and pieces of it possibly could have been deposited naturally in the Wilson-Leonard site, but more likely they were from nearby outcrops (Barnes 1981b). Two dolomite rocks were recovered. A uniformly gray dolomite cobble was found in stratigraphic Unit II. Because of the disintegration of its surface, any evidence of the rock's usage is lost. It is crystalline and angular.

A very large dolomite pebble was also found. It (Lot $33 \mathrm{R}$ from Unit IIIa) is a coarse-grained rounded rock that resembles some manos also found at the site. It is fine grained and has a pink tinge.

Granite, like bull quartz, occurs naturally in surface exposures in the Central Mineral Region and fluvial deposits downstream from it (Barnes 1981a, 1981b). The Town Mountain Formation is one possible source. For the same reasons discussed for bull quartz, granite is probably a manuport. Four unmodified pebbles were found. The color of the two smaller pieces is pink. The larger pieces are pink with an orange tinge. Two were found in Archaic-age deposits (Units IIIa and IIIb/c), one in Late Paleoindian contexts (Unit II), and one in mixed Late Paleoindian and Early Archaic deposits (Unit II/IIIa transition zone). Granite cobbles were used as hammerstones and manos at the Wilson-Leonard site during the Archaic period. The two small pebbles could represent pieces of manos or hammerstones. The larger pebbles are disintegrating and could not be used as manos or hammerstones in their present condition. It is unknown if these pebbles were brought to the site in this condition or if human agency or natural conditions at the site caused their disintegration. Intentional or unintentional heating could contribute to the disintegration of granite.

Possible explanations for the importation of these larger granite pebbles include (1) that they were brought to the site to be used as manos or other tools and then judged to be inappropriate; (2) after use as manos (or other tools), intentional or unintentional heating destroyed the evidence; (3) they were imported for uses that did not require modification, such as thermal storage devices; or (4) the introduction was unintentional.

Graphite, probably from the Central Mineral Region or its fluvial deposits, was imported to the site during the Paleoindian phase. Both graphite in schist and graphite in quartz were found. Three possible sources for the graphiterich schist are the Precambrian Honey, Packsaddle Schist, and Cap Mountain Schist formations. The Honey Formation is the most likely source (Barnes 1981a).

A total of 81 pieces was found. Seventy-nine specimens ranging in size from granules to large pebbles were found in Unit I below Unit Id; 59 of these were found in Unit Isi. Only 2 specimens were found above Unit I-a granule in Unit II, and a large pebble in Unit IIIc.

Spatially, the bulk of the graphite in schist was in TARL Square 59 (60 pieces) and adjacent squares (10 additional pieces). The concentration in Square 59 suggests that much or all of the material may have originally come to the site as a single piece.

Graphite can be easily removed from its matrix by pulverizing. Thumb pressure can easily crush a pebble of the schist. The resulting graphite powder could be separated out and used for pigment or other purposes.

Ochers, including hematite and limonite, are naturally occurring minerals in the geological setting of the WilsonLeonard site, but disproportional representation of these iron oxides within the site suggests human intervention. The high number of worked ocher pieces also suggests regular importation and use of ochers (see Chapter 20). Only pieces exhibiting no cultural modifications are discussed here. Ochers found at the site varied from yellow and brown (limonite) to orange and red (hematite). Sizes range from granules to very large pebbles. The majority are classified as hematite and are pebble sized, red, and pulverulent.

Over 550 pieces of unmodified ocher were recovered. Of these, 514 were classified as hematite, 28 were classified as limonite, and 12 as ocher, miscellaneous. Ocher has at least three possible cultural uses: in making adhesives, pigments, and medicines (Highley 1995).

Quartz in this presentation refers to stream-rolled cryptocrystalline pebbles that are ubiquitous in Central Texas. Excavators noted sufficiently large numbers $(N=156)$ to suggest that some of the pebbles may have been imported. The sample shows the quartz is evenly distributed throughout the TARL excavations and the TxDOT fine-screened unit (Square 37), and a wide array of colors is represented.

Quartzite does not occur naturally with any frequency within the Brushy Creek drainage, and it is inferred that the 16 unmodified quartzite specimens are manuports. Many possible sources for the quartzite, such as the Hensell Sand Formation with outcrops as close as $25 \mathrm{~km}$ south and $35 \mathrm{~km}$ east of the site contain cobble-sized quartzite nodules (Banks 1990).

Widespread occurrences of upland gravels often called "Uvalde" and "Ogallala" gravels are known sources of quartzite (Banks 1990). Sources in South Texas and the Big Bend area produce purple, green, and red quartzites (Banks 1990) similar to some found at Wilson-Leonard (Lots 31CC, 29HH, 34S, 1677, 912).

Sandstone occurs naturally throughout much of Texas, but it does not occur naturally within the Brushy Creek drainage. The closest sources for sandstone are the Hensell Sand and the Smithwick formations east of Marble Falls (Barnes 1981a). Eocene formations in East Texas, such as the Calvert Bluff Formation, are also possible sources of some sandstone pieces found at the site (Sellards 1958).

Various lithologies are represented in the 19 unmodified sandstone pieces from the Wilson-Leonard site. Sizes range from small pebble to cobble. Colors are gray, brown, buff, yellow, and pink, and most are cemented with calcite or quartz but some are cemented with hematite. Grains of quartz, feldspar, and chert are present in the various sandstones. 
Textures grade from fine to coarse. Some visually resemble Hensell Sand Formation sandstone. Use of sandstone for grinding stones or small abraders is common and may account for their presence at the site.

Schist probably came from the Central Mineral Region or from streams within its drainage and could not have been introduced to the site through natural processes. Included in the sample is mica quartz schist. The Sandy Formation is a likely source for mica quartz schist; other schist sources include Cap Mountain Schist and Packsaddle Schist (Barnes 1981a).

A total of five schist pebbles was found; the mica quartz schist mentioned above, a medium pebble identified as mica schist, and three additional pebbles classified as schist. The three pebbles classified as schist are dark gray. All three are flat and display worn edges consistent with stream transport. No cultural explanation for their presence is apparent.

Shale naturally occurs widely in Texas, but only very soft varieties are present in the upper Brushy Creek valley. Like sandstone, human agency must have been responsible for its introduction into the site. Five medium to very large pebbles were found. All five are dark blue-gray and flat with rounded edges consistent with stream transport.

Siltstone occurs in the same formations (e.g., Del Rio Clay, Smithwick Formation) as sandstone and shale (Barnes 1981b) and must have been imported to the site by humans. One of the five siltstones is tabular and exhibits angular fracturing and oxidized coloring consistent with burning.

One siltstone is a calcareous cobble, one side of which is partially covered with calcium carbonate. The other side is exposed siltstone and has a white chalky appearance. The size and shape of the stone are typical of manos found at the site, but it bears no evidence to this effect. A Waco Sinker found at the site is made from a similar material. At the Wilson-Leonard site, tabular siltstone was used to make metates and a crude uniface (Lot 22H-7).

\section{A NOTE ONDISTRIBUTION OFUNMODIFIEDLITHICMATERIALS}

Different recovery strategies during the TxDOT and TARL excavations directly affected the sample and distributional interpretations. TxDOT archeologists dry-screened sediments with 1/4-inch screens for all squares except one. Square 37 (E28/S78) was water-screened through 1/16-inchmesh screen. TARL crews water-screened all sediments from controlled excavation units through 1/8-inch screen. Additionally, the TxDOT plan did not intentionally save quartz pebbles at any time; TARL policy was to save all quartz pebbles. The result of this is that all but one quartz pebble in the sample came from the TARL excavations.

In evaluating the distribution of unmodified raw materials, three categories - quartz, calcite, and hematite - showed higher frequencies. In order to examine a sample less prone to recovery bias and given the consistent policy on the recovery of these three materials during TARL excavations, only lots from TARL squares were considered (Table A1-2). Additional data from TxDOT fine-screened Square 37 are separately presented in the table to enlarge the hematite sample. The difference in screen size appears to have had neglible affect on the hematite data.

Table A1-2 shows the distribution of hematite, calcite, and quartz in these selected excavation squares. The excavated volume of sediments from each stratigraphic unit is included for comparison along with the calculated density of each material per $\mathrm{m}^{3}$.

As shown, the proportional distributions of quartz and calcite are very similar, and both are similar to the proportion of sediments per stratum. This suggests natural forces are responsible for all or most of the quartz and calcite. The hematite, however, shows a contrasting pattern, which supports the inference that some of the hematite was culturally introduced. The highest density of hematite occurs at the Unit II/IIIa transition zone, comprising Late Paleoindian and Early Archaic deposits.

TABLE A1-2

Intersite Distribution of Selected Materials

\begin{tabular}{|c|c|c|c|c|c|c|c|c|c|c|c|c|}
\hline \multirow[b]{2}{*}{ Unit } & \multirow{2}{*}{$\begin{array}{c}\text { Volume } \\
\text { Excavated }\end{array}$} & \multirow[b]{2}{*}{$\%$} & \multicolumn{2}{|c|}{ Calcite } & \multicolumn{2}{|c|}{ Quartz } & \multicolumn{2}{|c|}{ Hematite } & \multicolumn{2}{|c|}{ Hematite TxDOT } & \multicolumn{2}{|c|}{ Hematite Total } \\
\hline & & & No. & Density & No. & Density & No. & Density & No. & Density & No. & Density \\
\hline I & 44.314 & 68 & 54 & 1.21857 & 95 & 2.14379 & 43 & 0.97034 & 23 & 0.519023 & 66 & 0.9703 \\
\hline I/II & 3.631 & 6 & 1 & 0.27540 & 7 & 1.92784 & 23 & 6.33434 & 3 & 0.826219 & 26 & 6.6097 \\
\hline II & 7.446 & 11 & 5 & 0.67150 & 16 & 2.14880 & 51 & 6.84931 & 7 & 0.940102 & 58 & 6.8493 \\
\hline II/IIIa & 3.481 & 5 & 9 & 2.63311 & 8 & 2.29819 & 33 & 9.48003 & 2 & 0.574548 & 35 & 7.7563 \\
\hline IIIa & 6.116 & 9 & 9 & 1.47155 & 10 & 1.63505 & 39 & 6.37671 & 4 & 0.654022 & 43 & 6.8672 \\
\hline Totals & 64.988 & 99 & 78 & & 136 & & 189 & & 39 & & 228 & \\
\hline
\end{tabular}




\section{REFERENCES CITED}

Banks, L.

1990 From Mountain Tops to Alligator Stomachs: A Review of Lithic Sources in the Trans-Mississippi South, the Southern Plains, and Adjacent Southwest. Memoir 4. Oklahoma Anthropological Society, Norman.

Barnes, V.

1981a Geological Atlas of Texas, Llano Sheet. Bureau of Economic Geology, The University of Texas at Austin.

1981b Geological Atlas of Texas, Austin Sheet. Bureau of Economic Geology, The University of Texas at Austin.

Folk, R. L.

1980 Petrology of Sedimentary Rocks. Hemphill Publishing Company, Austin.
Highley, C. L.

1995 Miscellaneous Materials. In Archeological Investigations at the Loma Sandia Site (41LK28), A Prehistoric Cemetery and Campsite in Live Oak County, Texas, Volume 2, by A. J. Taylor and C. L. Highley, pp. 519521. Studies in Archeology 20. Texas Archeological Research Laboratory, The University of Texas at Austin.

Sellards, E. H. (director)

1958 The Geology of Texas, Volume 1, Stratigraphy by S.A.P. The University of Texas Bulletin 3232. Bureau of Economic Geology, The University of Texas at Austin. 
APPENDIX 2: IMPRESSED CLAY AND MUD DAUBER NESTS

by Michael B. Collins 
Three pieces of clay with preserved impressions, possibly daub, and 41 mud dauber nests were recovered from the Wilson-Leonard site. These are described and discussed briefly below.

\section{IMPRESSED CLAY}

Two very small pieces of fired clay with impressions of small cylindrical objects, inferred to be grass stems, and one larger piece of hardened clay with the impression of a larger rounded object resemble fired daub that is sometimes produced when a wattle and daub structure burns. Alternatively, these could be bits of mud hardened after contact with objects under a wide array of other circumstances.

The first of these is from E40/S70, Level 3 (Unit IIIc). It is fired very hard and has a reddish color. The piece is $9-x-8-x-$ $4 \mathrm{~mm}$ in size and has multiple impressions of straight, cylindrical rods 1 to $2 \mathrm{~mm}$ in diameter on one face.

From E26/S78, Level 19B (Unit II/IIIIa), is a nearly identical piece fired medium hard, reddish tan in color, with grass stem (?) impressions on one face. It is $10-x-9-x-5 \mathrm{~mm}$ in size, and the cylindrical impressions are also between 1 and $2 \mathrm{~mm}$ in diameter.

The third object is an irregular lump of medium hard clay, light gray in color. The hardness suggests that this piece has been heated, but it does not have the appearance of being fired; perhaps it was "baked" in a reducing atmosphere. It is $54-\mathrm{x}-40-\mathrm{x}-26 \mathrm{~mm}$ in maximum dimensions and is characterized by a smooth impression on one face. The impression appears to be of a cylindrical object estimated by extrapolating the preserved arc to have been approximately 80 $\mathrm{mm}$ in diameter. Such an impression could be from a wooden pole or the rounded edge of a rock. Its provenience (E20/ S86, Level 4; Unit IIIc) is shared with numerous hearth stones, and the inference that this is from a rock-lined hearth may be more likely than one suggesting that it is a piece of daub.

These pieces are few, small, dispersed in time and space, and not definitely identifiable as daub. Therefore, they do not independently support any interpretation of daubed architecture.

\section{MUDDAUBER NESTS}

Forty-one whole or fragmentary mud dauber nests were recovered from various areas and stratigraphic units in the site (Table A2-1). The majority are fragmentary, either having been damaged by excavation tools or having broken apart during or after excavation; some may have been fragmentary before excavation, but this is difficult to determine with certainty. All of them are of the same kind of nest, consisting of multichambered clusters in a roughly cylindrical or hemispherical grouping, characteristic of the genus Sceliphron (members of the Sphecidae family of solitary wasps) whose range includes Central Texas (Swann and Papp 1972:562-564).
Most of these are of medium hardness (barely resistant to scratching with the fingernail), a few are harder (completely resistant to scratching with the fingernail), and one is extremely hard (of ceramic-like hardness) (see Table A21). All of these medium, hard, and very hard specimens are yellowish tan to reddish in color and have every indication of having been heated. The remainder are soft enough to be scratched with the fingernail, are dark gray in color, and seem to be minimally altered by heat, if at all. The preservation of these latter is puzzling.

Dauber nests are constructed from damp, clay-rich mud and are moderately hard as soon as they dry. The question that arose in this study from the softer, dark-colored specimens was whether firing is necessary in the preservation of these objects; in other words, could their natural hardness and integrity result in preservation if they were rapidly buried intact? This would be possible only if they escaped the pervasive postdepositional disturbances documented for these deposits (see Chapters 6 and 29), particularly the actions of earthworms. The question becomes, are they too hard for the passage of worms? No answer is proposed from this study.

The presence of mud dauber nests in an open archeological site can be explained in a limited number of ways, since the nests are only built in places sheltered from rain. If humans had no part in their introduction, the most probable explanation is that natural building sites existed in the siteunder tree branches or inside hollow tree trunks or limbs being by far the most likely locations. If nests can be preserved without firing, all that would be required is for such nests to come to rest on the ground and become buried before melting; if firing is necessary, the limb or trunk would have to burn.

Humans might introduce nests inadvertently or purposefully. Inadvertent introduction could occur if nests were on or inside a piece of firewood, a circumstance favoring the firing of the nests. Another unintended way for humans to cause nests to occur in their sites is the building of houses that become artificial shelter for the dauber's nest. If such a structure burns, fired nests result (e.g., Webb 1959:27).

Purposeful introduction most likely would involve the collection of the nests for the purpose of extracting the dauber larvae as food. Wasp larvae being gathered and roasted for food has been recorded ethnographically among, for examples, the Paiute (Fowler 1989:61; Heizer 1954:7) and the Nisenan (Beals 1933:346-347).

At Wilson-Leonard, dauber nests are most common in upper Unit I and in Unit II, archeologically the late Paleoindian components (see Table A2-1). Fewer examples were recovered from the subunits of Unit III. There are no concentrations in the Unit I or Unit III proveniences that suggest the presence of a temporary structure. There are, however, interesting concentrations in Unit II.

The first consists of four nests in Level 22 of Square E28/S78, the fine screen unit (see Table A2-1). Three others were found in adjacent squares E22/S76 and E22/S78, Levels 
TABLE A2-1

Dauber Nests by Provenience and Observed Hardness

\begin{tabular}{|c|c|c|c|c|}
\hline Unit & Square & Level & Hardness & Feature \\
\hline Y/IIIc & $\mathrm{E} 22 / \mathrm{S} 88$ & 9 & Medium hard & 79, Burned Rock Midden 1 \\
\hline IIIc & E20/S76 & 2 & Medium hard & \\
\hline IIIc, disturbed & E20/S96 & 3 & Hard & Burned Rock Midden 1 \\
\hline IIIC & E20/S84 & 3 & Very hard & \\
\hline IIIc & 15 & $4 \mathrm{~A}$ & Hard & \\
\hline IIIc & E20/S90 & 4 & Hard & Burned Rock Midden 1 \\
\hline IIIc & $\mathrm{E} 20 / \mathrm{S} 76$ & 7 & Hard & \\
\hline IIIc & $\mathrm{E} 22 / \mathrm{S} 88$ & 8 & Medium hard & Burned Rock Midden 1 \\
\hline$?$ & T.P.3 & 9 & Medium hard & \\
\hline $\mathrm{IIIb}$ & E20/S82 & 12 & Medium hard & $21 ?$ \\
\hline IIIa & $\mathrm{E} 22 / \mathrm{S} 84$ & 16 & Medium hard & \\
\hline IIIa & 39 & $22 \mathrm{~A}$ & Soft; possibly not burned & 231 \\
\hline IIIa & 26 & 24 & Hard & \\
\hline $\mathrm{X} / \mathrm{Y}$ & $\mathrm{E} 22 / \mathrm{S} 98$ & 11 & Medium hard & \\
\hline $\mathrm{X} / \mathrm{II}$ & E20/S86 & 20 & Medium hard & \\
\hline $\mathrm{X} / \mathrm{II} / \mathrm{IIIa}$ & $\mathrm{E} 22 / \mathrm{S} 86$ & 16 & Medium hard & \\
\hline II/IIIa & $\mathrm{E} 22 / \mathrm{S} 78$ & $19 \mathrm{~A}$ & Hard & \\
\hline II/IIа & $\mathrm{E} 22 / \mathrm{S} 78$ & 19B & Hard & \\
\hline II/IIIa & E24/S76 & $20 \mathrm{~A}$ & Soft; possibly not burned & \\
\hline II & $\mathrm{E} 22 / \mathrm{S} 82$ & 20 & Medium hard & \\
\hline II & E26/S72 & $21 \mathrm{~A}$ & Medium hard & \\
\hline II & E28/S78 & $22 \mathrm{~A}$ & Medium hard & \\
\hline II & $\mathrm{E} 28 / \mathrm{S} 78$ & $22 \mathrm{~B}$ & Soft; possibly not burned & \\
\hline II & $\mathrm{E} 28 / \mathrm{S} 78$ & $22 \mathrm{~B}$ & Medium hard & \\
\hline II & $\mathrm{E} 28 / \mathrm{S} 78$ & 22B & Medium hard & \\
\hline II & $\mathrm{E} 22 / \mathrm{S} 78$ & $22 \mathrm{~A}$ & Soft; possibly not burned & \\
\hline II & E22/S78 & $23 \mathrm{~A}$ & Soft; possibly not burned & \\
\hline II & $\mathrm{E} 22 / \mathrm{S} 76$ & $23 \mathrm{~A}$ & Medium hard & \\
\hline II & E24/S74 & 24B & Soft; possibly not burned & \\
\hline II & E26/S76 & $24 B$ & Medium hard & \\
\hline II & E26/S76 & $25 \mathrm{~A}$ & Medium hard & \\
\hline II & E26/S72 & $26 \mathrm{~A}$ & Medium hard & \\
\hline II & 39 & 34 & Medium hard & \\
\hline I & $\mathrm{E} 2 / \mathrm{N} 8$ & $28 \mathrm{~A}$ & Medium hard & \\
\hline $\mathrm{Id} / \mathrm{II}$ & $\mathrm{E} 28 / \mathrm{S} 78$ & $25 \mathrm{~A}$ & Medium hard & \\
\hline Isi-c/II & 12 & 28 & Soft; possibly not burned & \\
\hline Isi-c/Id & 33 & 34 & Medium hard & \\
\hline Isi-c & E20/S74 & $27 \mathrm{~A}$ & Soft; possibly not burned & \\
\hline Isi-c & E26/S78 & $29 B$ & Medium hard & \\
\hline Isi/Isi-c & E20/S76 & 28B & Medium hard & \\
\hline$\underline{\mathrm{Igl} / \mathrm{Isi}}$ & $\mathrm{E} 22 / \mathrm{S} 72$ & $38 \mathrm{~A}$ & Medium hard & \\
\hline
\end{tabular}

22 and 23 (see Table A2-1). Another possible spatial grouping includes one nest each from the same level of diagonally adjacent squares (E24/S74, Level 24B and E26/S76 Levels
24B and 25A; see Table A2-1). The possible cultural signficance of these distributions is discussed in the interpretive chapters of Volume I. 


\section{REFERENCES CITED}

Beals, Ralph L

1933 Ethnology of the Nisenan. University of California Publications in American Archaeology and Ethnology 31(6):335-414.

Fowler, Catherine S.

1989 Willard Z. Park's Ethnographic Notes on the Northern Paiute of Western Nevada, 1933-1944. University of Utah Anthropological Papers I(114).

Heizer, Robert F.

1954 Notes on the Utah Utes by Edward Palmer, 1866-1877.
Anthropological Papers 17. Department of Anthropology, University of Utah.

Swann, Lester A., and Charles S. Papp

1972 The Common Insects of North America. Harper and Row, New York.

Webb, Clarence $\mathrm{H}$.

1959 The Belcher Mound. A Stratified Caddoan Site in Caddo Parish, Louisiana. Society for American Archaeology, Memoir 16. 
APPENDIX 3: HISTORIC ARTIFACTS

by Pamela Headrick 
During the course of the TxDOT and TARL excavations, 118 artifacts were recovered that were assigned to the Historic period (Table A3-1). It is impossible to assign any of this material to a particular time or ascertain how it came to reside at this site. Generally, the artifacts are ones that would be expected to be discarded in a field (such as a rusted portion of a plow pin) or along a roadway over time. The three shards of purpled glass do indicate a manufacturing date of pre-1920, but their deposition at the site is not indicative of any particular activity. None of the artifacts was identifiable as to manufacturer.

The most conclusive statement that can be made about this small assemblage is that people tend to discard items that have lost their usefulness in places where others have done the same. In other words, areas of refuse seem to be self perpetuating (Schiffer 1987:62).

\section{TABLE A3-1}

Historic Artifacts Recovered by Square and Level

\begin{tabular}{|c|c|c|c|c|c|}
\hline Square & Level & Lot & Item & No. & Description \\
\hline E20/S86 & 6 & $10-\mathrm{F}$ & Ceramic, ironstone & 1 & $\begin{array}{l}\text { Interior and exterior green glaze, probably Fiestaware bowl } \\
\text { from the 1930s-1940s }\end{array}$ \\
\hline 17 & 3 & $194-9$ & Ceramic, stoneware & 1 & White exterior, brown rippled interior, related to Lots 121 and 167 \\
\hline 16 & 1 & 121 & Ceramic, stoneware & 1 & $\begin{array}{l}\text { Brown-green-cream exterior, brown interior glaze, alkaline, } \\
\text { related to Lot } 167\end{array}$ \\
\hline 16 & 2 & 167 & Ceramic, stoneware & 1 & White exterior, brown interior glaze, alkaline, related to Lot 121 \\
\hline 58 & 47 & 2115 & Flagging tape & 1 & \\
\hline 11 & 8 & 508 & Glass, amber & 1 & Probably from modern beer bottle \\
\hline 17 & 1 & 110 & Glass, amber & 1 & Very small shard, probably from beer bottle \\
\hline 100 & 2 & 1206 & Glass, aqua & 1 & Very small triangular shard \\
\hline 16 & 1 & 111 & Glass, aqua & 4 & Burned, from bottle \\
\hline 12 & 1 & 145 & Glass, clear & 2 & From modern bottle \\
\hline 12 & 4 & 202 & Glass, clear & 2 & Modern bottle \\
\hline 12 & 28 & 1209 & Glass, clear & 1 & Very tiny shard \\
\hline 15 & $4 \mathrm{~A}$ & 235 & Glass, clear & 3 & Two pieces may be window glass \\
\hline 18 & 9 & 371 & Glass, clear & 1 & Very small undiagnostic shard \\
\hline 19 & 7 & 230 & Glass, clear & 2 & Inconclusive, probably not window glass \\
\hline 19 & 10 & 487 & Glass, clear & 3 & Modern bottle \\
\hline 20 & 24 & 1016 & Glass, clear & 1 & Clear, very modern \\
\hline 21 & 5 & 175 & Glass, clear & 1 & Very small shard \\
\hline 25 & 31 & 1377 & Glass, clear & 1 & Slightly curved, bottle portion \\
\hline E20/S100 & 1 & $1-\mathrm{A}$ & Glass, clear & 1 & Neck ring from bottle, undiagnostic \\
\hline 17 & 1 & 110 & Glass, clear & 1 & Very small shard from bottle \\
\hline 16 & 1 & 111 & Glass, clear & 6 & Unburned from bottle, rather large \\
\hline 16 & 1 & 111 & Glass, clear & 6 & Large bottle, looks smokey from slight burning \\
\hline 21 & 1 & 154 & Glass, clear & 1 & From bottle, rather large but thin glass \\
\hline 13 & 2 & 163 & Glass, clear & 1 & Maybe window glass \\
\hline 16 & 2 & 167 & Glass, clear & 1 & Portion of scored base "W/\#83 ..." \\
\hline 12 & 2,3 & 146 & Glass, green & 7 & From modern bottle \\
\hline 17 & 1 & 110 & Glass, green & 16 & Base and body shards, fluted or scored base, mold mark to base \\
\hline 16 & 1 & 111 & Glass, green & 5 & From small bottle, burned \\
\hline 21 & 1 & 154 & Glass, green & 1 & From bottle, rather large and thin \\
\hline $\mathrm{E} 20 / \mathrm{S} 100$ & 1 & $1-\mathrm{A}$ & Glass, purpled & 1 & Nondiagnostic slightly purpled shard \\
\hline $\mathrm{E} 20 / \mathrm{S} 86$ & 1 & $10-\mathrm{A}$ & Glass, purpled & 1 & Rim shard, no mold mark evident, pre 1920 \\
\hline E20/S84 & 1 & $11-\mathrm{A}$ & Glass, purpled & 1 & Very small portion of a bottle neck \\
\hline 17 & 9 & 544 & Metal & 1 & Unidentifiable \\
\hline 16 & 1 & 111 & Metal & 1 & Flip top from soda or beer (pre 1980s) \\
\hline 16 & 2 & 167 & Metal & 1 & Chisel \\
\hline 13 & 3 & 176 & Metal & 1 & Copper electrical connector clamp with paper insert intact \\
\hline 16 & 1 & 111 & Metal crown cap & 1 & \\
\hline E20/S96 & 1 & $5-\mathrm{A}$ & Metal plow pin & 1 & Rusted head of pin only \\
\hline 14 & 1 & 112 & Metal wire & 1 & Barbed, rusted \\
\hline 11 & 6 & 405 & Nail & 1 & Large finishing nail \\
\hline 39 & $22 \mathrm{~A}$ & 1156 & Plaster & 2 & \\
\hline 12 & 13 & 661 & Plastic & 1 & Hollow tube, white \\
\hline 46 & 39 & 1925 & Plastic & 1 & Scored like turtle shell, very tiny, beige, see Lot 1723 \\
\hline 38 & 14 & 583 & Plastic & 1 & Small, opaque translucent white \\
\hline$\underline{39}$ & 48 & 2582 & Plastic & 1 & Small, opaque translucent white \\
\hline
\end{tabular}


Table A3-1, continued

\begin{tabular}{l|l|l|l|l|l}
\hline Square & Level & Lot & Item & No. & Description \\
\hline 46 & 36 & 1723 & Plastic & 2 & Very tiny, scored, matches Lot 1925 \\
56 & 44 & 2110 & Plastic & 1 & Very tiny, white plastic, may be from bucket \\
T.P. A & 2 & 105 & Plastic & 1 & Probably Bakelite or plastic \\
11 & 9 & 534 & String & 1 & Looks like dental floss tied in a loop at one end \\
33 & $30 \mathrm{~B} / 31 \mathrm{~B}$ & 1420 & Wire & 1 & Associated with fishing \\
16 & 1 & 111 & Wire mesh & 1 & Screen? \\
14 & 3 & 187 & Wood & 1 & Unmodified chunk \\
26 & 25 & 1094 & Wood & 1 & Sliver \\
30 & $20 \mathrm{~A}$ & 904 & Wood & 1 & Small sliver \\
35 & 44 & 2659 & Wood & 1 & Small knot \\
35 & $26 \mathrm{~A}$ & 1104 & Wood & 1 & Small sliver \\
37 & 14 & 673 & Wood & 2 & One piece looks burned \\
37 & $12 \mathrm{~A}$ & 557 & Wood & 1 & Root fragment \\
46 & 24 & 1097 & Wood & 2 & Twigs \\
46 & 54 & 2619 & Wood & 1 & Large splinter \\
52 & 21 & 910 & Wood & 1 & Small disk \\
53 & 19 & 873 & Wood & 3 & \\
100 & 2 & 1206 & Wood & 2 & Unmodified, small \\
T.P. B & 1 & 297 & Wood & 1 & Unmodified, twig? \\
\hline Total: & \multicolumn{1}{l}{}
\end{tabular}

\section{REFERENCE CITED}

Schiffer, Michael B.

1987 Formation Processes of the Archaeological Record. University of New Mexico Press, Albuquerque. 
APPENDIX 4: LOT NUMBER INDEX 
TABLE A4-1

Lot Number Index for TxDOT Excavations

\begin{tabular}{|c|c|}
\hline Lot & Grid Coordinates \\
\hline 0 & surface \\
\hline 1 & $\mathrm{E} 20 / \mathrm{S} 100$ \\
\hline 2 & E22/S100 \\
\hline 3 & $\mathrm{E} 20 / \mathrm{S} 98$ \\
\hline 4 & $\mathrm{E} 22 / \mathrm{S} 98$ \\
\hline 5 & E20/S96 \\
\hline 6 & E20/S94 \\
\hline 7 & $\mathrm{E} 20 / \mathrm{S} 92$ \\
\hline 8 & $\mathrm{E} 20 / \mathrm{S} 90$ \\
\hline 9 & E20/S88 \\
\hline 10 & E20/S86 \\
\hline 11 & E20/S84 \\
\hline 12 & E20/S82 \\
\hline 13 & E20/S80 \\
\hline 14 & E20/S78 \\
\hline 15 & E20/S76 \\
\hline 16 & E20/S74 \\
\hline 17 & $\mathrm{E} 20 / \mathrm{S} 72$ \\
\hline 18 & $\mathrm{E} 22 / \mathrm{S} 90$ \\
\hline 19 & E22/S88 \\
\hline 20 & E22/S86 \\
\hline 21 & $\mathrm{E} 22 / \mathrm{S} 84$ \\
\hline 22 & $\mathrm{E} 22 / \mathrm{S} 82$ \\
\hline 23 & $\mathrm{E} 22 / \mathrm{S} 80$ \\
\hline 24 & E22/S78 \\
\hline 25 & E22/S76 \\
\hline 26 & E22/S74 \\
\hline 27 & $\mathrm{E} 22 / \mathrm{S} 72$ \\
\hline 28 & $\mathrm{E} 24 / \mathrm{S} 78$ \\
\hline 29 & E24/S76 \\
\hline 30 & E24/S74 \\
\hline 31 & E24/S72 \\
\hline 32 & E26/S78 \\
\hline 33 & E26/S76 \\
\hline 34 & E26/S74 \\
\hline 35 & E26/S72 \\
\hline 36 & $\mathrm{E} 40 / \mathrm{S} 70$ \\
\hline 37 & E28/S78 \\
\hline 38 & E18/S74 \\
\hline 39 & E18/S76 \\
\hline 40 & E18/S84 \\
\hline 43 & E18/S84 \\
\hline 50 & W0/N8 \\
\hline 51 & $\mathrm{E} 2 / \mathrm{N} 8$ \\
\hline 52 & E24/S64 \\
\hline 54 & $\mathrm{E} 24 / \mathrm{S} 60$ \\
\hline 55 & $\mathrm{E} 26 / \mathrm{S} 80$ \\
\hline BU2 & E20/S74 \\
\hline TP1 & TEST PIT 1 \\
\hline TP2 & TEST PIT 2 \\
\hline TP3 & TEST PIT 3 \\
\hline TR? & TRENCH? \\
\hline TR1 & TRENCH 1 \\
\hline TR2 & TRENCH 2 \\
\hline
\end{tabular}

TABLE A4-2

Level Key for TxDOT Excavations

\begin{tabular}{|c|c|}
\hline Letter & Level \\
\hline A & 1 \\
\hline B & 2 \\
\hline $\mathrm{C}$ & 3 \\
\hline $\mathrm{D}$ & 4 \\
\hline $\mathrm{E}$ & 5 \\
\hline F & 6 \\
\hline $\mathrm{G}$ & 7 \\
\hline $\mathrm{H}$ & 8 \\
\hline I & 9 \\
\hline $\mathrm{J}$ & 10 \\
\hline $\mathrm{K}$ & 11 \\
\hline $\mathrm{L}$ & 12 \\
\hline M & 13 \\
\hline $\mathrm{N}$ & 14 \\
\hline $\mathrm{O}$ & 15 \\
\hline $\mathrm{P}$ & 16 \\
\hline $\mathrm{Q}$ & 17 \\
\hline $\mathrm{R}$ & 18 \\
\hline $\mathrm{S}$ & 19 \\
\hline $\mathrm{T}$ & 20 \\
\hline $\mathrm{U}$ & 21 \\
\hline V & 22 \\
\hline W & 23 \\
\hline$X$ & 24 \\
\hline $\mathrm{Y}$ & 25 \\
\hline $\mathrm{Z}$ & 26 \\
\hline $\mathrm{AA}$ & 27 \\
\hline BB & 28 \\
\hline $\mathrm{CC}$ & 29 \\
\hline $\mathrm{DD}$ & 30 \\
\hline $\mathrm{EE}$ & 31 \\
\hline FF & 32 \\
\hline GG & 33 \\
\hline $\mathrm{HH}$ & 34 \\
\hline II & 35 \\
\hline JJ & 36 \\
\hline KK & 37 \\
\hline LL & 38 \\
\hline MM & 39 \\
\hline $\mathrm{NN}$ & 40 \\
\hline OO & 41 \\
\hline PP & 42 \\
\hline QQ & 43 \\
\hline $\mathrm{RR}$ & 44 \\
\hline SS & 45 \\
\hline $\mathrm{TT}$ & 46 \\
\hline UU & 47 \\
\hline VV & 48 \\
\hline WW & 49 \\
\hline $\mathrm{XX}$ & 50 \\
\hline
\end{tabular}


TABLE A4-3

Lot Number Index for TARL Excavations

\begin{tabular}{|c|c|c|c|c|c|c|c|c|}
\hline Lot & Square & Level/Sublevel & Lot & Square & Level/Sublevel & Lot & Square & Level/Sublevel \\
\hline 0 & Surface & & 169 & 11 & 3 & 239 & 19 & 7 \\
\hline 100 & Surface & & 170 & 19 & 1 & 240 & Test & wall \\
\hline 101 & Surface & & 171 & 19 & 6 & 241 & 13 & 4 \\
\hline 102 & Surface & & 172 & wall & & 242 & 20 & 8 \\
\hline 103 & Surface & & 173 & 38 & $21 \mathrm{~A}$ & 243 & 20 & 8 \\
\hline 104 & Test & 1 & 174 & Test & 11 & 244 & 13 & 4 \\
\hline 105 & Test & 2 & 175 & 21 & 5 & 245 & 13 & 4 \\
\hline 106 & Test & 3 & 176 & 13 & 3 & 246 & Test & 14B \\
\hline 107 & Test & 4 & 177 & Test & 9 & 247 & Test & 17 \\
\hline 108 & Surface & & 178 & 13 & 3 & 248 & 20 & 8 \\
\hline 109 & Surface & & 179 & 22 & 4 & 249 & 20 & 8 \\
\hline 110 & 17 & 1 & 180 & 20 & 6 & 250 & 20 & 8 \\
\hline 111 & 16 & 1 & 181 & Test & 8 & 251 & 20 & 8 \\
\hline 112 & 14 & 1 & 182 & 20 & 6 & 252 & 22 & 6 \\
\hline 113 & Test & 5 & 183 & 22 & 5 & 253 & 21 & $6 \mathrm{~B}$ \\
\hline 114 & 11 & 1 & 184 & 22 & 5 & 254 & 21 & $7 \mathrm{~A}$ \\
\hline 115 & 20 & 1 & 185 & 21 & $6 \mathrm{~B}$ & 255 & 20 & 8 \\
\hline 116 & 22 & 1 & 186 & Test & 10 & 256 & 11 & 4 \\
\hline 117 & Surface & & 187 & 14 & 3 & 257 & 11 & 4 \\
\hline 118 & Surface & & 188 & 18 & 8 & 258 & 17 & 4 \\
\hline 119 & 17 & 4 & 189 & 20 & 7 & 259 & 13 & 4 \\
\hline 120 & 16 & 4 & 190 & 20 & 7 & 260 & 21 & $7 \mathrm{~A}$ \\
\hline 121 & 16 & 1 & 191 & 20 & 7 & 261 & Test & $15 \mathrm{~A}$ \\
\hline 122 & 18 & 1 & 192 & Test & 13 & 262 & 19 & $8 \mathrm{~A}$ \\
\hline 123 & Test & 6 & 193 & 14 & 3 & 263 & 19 & $8 \mathrm{~A}$ \\
\hline 124 & Test & 6 & 194 & 17 & 3 & 264 & 17 & 4 \\
\hline 125 & Test & wall & 195 & 18 & 8 & 265 & 17 & 4 \\
\hline 126 & 13 & 1 & 196 & Test & 11 & 266 & 19 & $8 \mathrm{~A}$ \\
\hline 127 & 44 & wall & 197 & 14 & 3 & 267 & 21 & $7 \mathrm{~A}$ \\
\hline 128 & 16 & 4 & 198 & 20 & 7 & 268 & 17 & 4 \\
\hline 129 & 15 & $6 \mathrm{~A}$ & 199 & 12 & 4 & 269 & 17 & 4 \\
\hline 130 & Test & 7 & 200 & 14 & 3 & 270 & Test & 19 \\
\hline 131 & 17 & 1 & 201 & 21 & $6 \mathrm{~B}$ & 271 & Test & $15 \mathrm{~B}$ \\
\hline 132 & Test & 1 & 202 & 12 & 4 & 272 & 17 & 4 \\
\hline 133 & 44 & wall & 203 & 20 & 7 & 273 & 17 & 4 \\
\hline 134 & 23 & wall & 204 & 42 & 18 & 274 & 12 & 5 \\
\hline 135 & Surface & & 205 & 11 & 3 & 275 & 17 & 4 \\
\hline 136 & Test & 2 & 206 & 11 & 3 & 276 & 17 & 4 \\
\hline 137 & 27 & 18 & 207 & 21 & $6 \mathrm{~B}$ & 277 & 12 & 5 \\
\hline 138 & 52 & $15 \mathrm{~B}$ & 208 & 22 & 5 & 278 & 16 & 4 \\
\hline 139 & 52 & $16 \mathrm{~B}$ & 209 & 21 & $6 A-B$ & 279 & Test & 20 \\
\hline 140 & 20 & 1 & 210 & 49 & wall & 280 & 17 & 4 \\
\hline 141 & 22 & 1 & 211 & 22 & 5 & 281 & 17 & 4 \\
\hline 142 & 22 & 1 & 212 & Test & 12 & 282 & 17 & 4 \\
\hline 143 & Test & 3 & 213 & Test & 14 & 283 & 16 & 4 \\
\hline 144 & 11 & 1 & 214 & 20 & 7 & 284 & 16 & 4 \\
\hline 145 & 12 & 1 & 215 & 21 & $6 \mathrm{~B}$ & 285 & Test & $16 \mathrm{~A}$ \\
\hline 146 & 12 & $2-3$ & 216 & 14 & 3 & 286 & 22 & 7 \\
\hline 147 & 14 & 2 & 217 & 15 & 3 & 287 & 19 & $8 \mathrm{~A}$ \\
\hline 148 & Surface & & 218 & 20 & 8 & 288 & Test & $16 \mathrm{~B}$ \\
\hline 149 & 17 & 2 & 219 & 14 & 3 & 289 & 12 & 5 \\
\hline 150 & Test & 8 & 220 & 14 & 3 & 290 & 17 & 4 \\
\hline 151 & 17 & 2 & 221 & 14 & 3 & 291 & 17 & 4 \\
\hline 152 & Test & 4 & 222 & Test & 13 & 292 & 17 & 4 \\
\hline 153 & 19 & 1 & 223 & 15 & 3 & 293 & 17 & 4 \\
\hline 154 & 21 & 1 & 224 & Test & 15 & 294 & 16 & 4 \\
\hline 155 & 19 & 1 & 225 & Test & 12 & 295 & 16 & 4 \\
\hline 156 & 12 & 2 & 226 & 22 & 6 & 296 & 16 & 4 \\
\hline 157 & Test & 5 & 227 & 21 & $6 \mathrm{~B}$ & 297 & Test & 1 \\
\hline 158 & 19 & 1 & 228 & Test & 18 & 298 & 22 & 7 \\
\hline 159 & 18 & 1 & 229 & 14 & 3 & 299 & Test & 21 \\
\hline 160 & Test & 6 & 230 & 19 & 7 & 300 & 17 & 4 \\
\hline 161 & 15 & 2 & 231 & 11 & 4 & 301 & 20 & 8 \\
\hline 162 & 11 & 2 & 232 & Test & $14 \mathrm{~A}$ & 302 & 20 & 8 \\
\hline 163 & 13 & 2 & 233 & 22 & 6 & 303 & Test & $17 \mathrm{~A}$ \\
\hline 164 & Test & 9 & 234 & Test & 16 & 304 & 22 & 7 \\
\hline 165 & Test & 10 & 235 & 15 & $4 \mathrm{~A}$ & 305 & Test & 17B \\
\hline 166 & Test & 7 & 236 & 13 & 4 & 306 & 14 & 4 \\
\hline 167 & 16 & 2 & 237 & 13 & 4 & 307 & Test & 22 \\
\hline 168 & 16 & 3 & 238 & 13 & 4 & 308 & 17 & 4 \\
\hline
\end{tabular}




\begin{tabular}{|c|c|c|c|c|c|c|c|c|}
\hline Lot & Square & Level/Sublevel & Lot & Square & Level/Sublevel & Lot & Square & Level/Sublevel \\
\hline 310 & 17 & 4 & 383 & 21 & $7 \mathrm{~B}$ & 456 & 17 & $7 \mathrm{~A}$ \\
\hline 311 & 17 & 4 & 384 & 11 & 3 & 457 & 16 & $6 \mathrm{~B}$ \\
\hline 312 & 12 & 5 & 385 & 15 & $4 \mathrm{~B}$ & 458 & 21 & 8 \\
\hline 313 & Test & 18 & 386 & 13 & 5 & 459 & 17 & $7 \mathrm{~A}$ \\
\hline 314 & 16 & 4 & 387 & 15 & $5 \mathrm{~A}$ & 460 & 15 & $6 \mathrm{~A}$ \\
\hline 315 & 16 & 4 & 388 & 18 & 9 & 461 & 15 & $6 \mathrm{~A}$ \\
\hline 316 & 16 & 4 & 389 & 20 & $11 \mathrm{~A}$ & 462 & 17 & $8 \mathrm{~A}$ \\
\hline 317 & 16 & 4 & 390 & 17 & 6 & 463 & 21 & 8 \\
\hline 318 & 16 & 4 & 391 & 16 & 5 & 464 & 13 & 6 \\
\hline 319 & 16 & 4 & 392 & 21 & $7 \mathrm{~B}$ & 465 & 14 & $6 \mathrm{~A}$ \\
\hline 320 & 16 & 4 & 393 & 17 & 5 & 466 & 19 & $8 \mathrm{~B}$ \\
\hline 321 & 16 & 4 & 394 & 18 & 9 & 467 & 19 & $9 \mathrm{~B}$ \\
\hline 322 & 14 & 4 & 395 & 16 & 5 & 468 & 15 & $6 \mathrm{~A}$ \\
\hline 323 & 11 & 5 & 396 & 16 & 5 & 469 & 19 & $9 \mathrm{~B}$ \\
\hline 324 & 16 & 4 & 397 & 18 & 9 & 470 & 19 & $9 \mathrm{~B}$ \\
\hline 325 & 16 & 4 & 398 & 15 & $5 \mathrm{~A}$ & 471 & 19 & $8 \mathrm{~B}$ \\
\hline 326 & 21 & $7 \mathrm{~A}$ & 399 & 22 & 8 & 472 & 19 & $9 \mathrm{~B}$ \\
\hline 327 & 13 & 5 & 400 & 13 & 5 & 473 & 20 & $12 \mathrm{~B}$ \\
\hline 328 & 22 & 7 & 401 & 14 & 5 & 474 & 11 & 7 \\
\hline 329 & 19 & $8 \mathrm{~A}$ & 402 & 18 & 9 & 475 & 15 & $6 \mathrm{~B}$ \\
\hline 330 & 19 & $8 \mathrm{~A}$ & 403 & 16 & 5 & 476 & 15 & $6 \mathrm{~A}$ \\
\hline 331 & 22 & 7 & 404 & 22 & $8 \mathrm{~B}$ & 477 & 15 & $6 \mathrm{~A}$ \\
\hline 332 & 20 & 9 & 405 & 11 & 6 & 478 & 15 & $6 \mathrm{~A}$ \\
\hline 333 & 11 & 5 & 406 & 12 & 6 & 479 & 19 & $9 \mathrm{~B}$ \\
\hline 334 & 11 & 5 & 407 & 26 & 18 & 480 & 16 & $7 \mathrm{~A}$ \\
\hline 335 & 11 & 5 & 408 & 14 & $6 \mathrm{~A}$ & 481 & 25 & 17 \\
\hline 336 & 19 & $8 \mathrm{~A}$ & 409 & 11 & 6 & 482 & 11 & 7 \\
\hline 337 & 13 & 5 & 410 & 11 & 6 & 483 & 11 & 7 \\
\hline 338 & Test & 19 & 411 & 19 & $9 \mathrm{~A}$ & 484 & 21 & 8 \\
\hline 339 & 22 & 7 & 412 & 18 & 10 & 485 & 38 & $21 \mathrm{~B}$ \\
\hline 340 & 19 & $8 \mathrm{~A}$ & 413 & 14 & $6 \mathrm{~A}$ & 486 & 15 & 7 \\
\hline 341 & 13 & 5 & 414 & 14 & $6 \mathrm{~A}$ & 487 & 19 & 10 \\
\hline 342 & 0 & & 415 & 16 & 5 & 488 & 14 & 7 \\
\hline 343 & 19 & $8 \mathrm{~A}$ & 416 & 15 & $6 \mathrm{~A}$ & 489 & 20 & $13 \mathrm{~A}$ \\
\hline 344 & 17 & 5 & 417 & 20 & $12 \mathrm{~A}$ & 490 & 13 & 7 \\
\hline 345 & 20 & 9 & 418 & 16 & 5 & 491 & 21 & 9 \\
\hline 346 & 20 & 9 & 419 & 15 & $5 \mathrm{~A}$ & 492 & 48 & 17 \\
\hline 347 & 14 & 4 & 420 . & 14 & $6 \mathrm{~A}$ & 493 & 21 & 9 \\
\hline 348 & Test & 20 & 421 & 14 & $6 \mathrm{~B}$ & 494 & 13 & 8 \\
\hline 349 & 13 & 5 & 422 & 11 & 6 & 495 & 21 & 9 \\
\hline 350 & 17 & 5 & 423 & 0 & & 496 & 19 & 10 \\
\hline 351 & 16 & 4 & 424 & 11 & 6 & 497 & 12 & 7 \\
\hline 352 & 13 & 5 & 425 & 16 & 5 & 498 & 12 & 7 \\
\hline 353 & 19 & $8 \mathrm{~A}$ & 426 & 22 & 8 & 499 & 15 & 3 \\
\hline 354 & 14 & 4 & 427 & 19 & $9 \mathrm{~A}$ & 500 & 15 & 3 \\
\hline 355 & 17 & 5 & 428 & 22 & 8 & 501 & 52 & 24 \\
\hline 356 & 17 & 5 & 429 & 18 & 10 & 502 & 17 & $7 \mathrm{~A}$ \\
\hline 357 & 17 & 5 & 430 & 12 & 6 & 503 & 21 & 9 \\
\hline 358 & 20 & 9 & 431 & 21 & 8 & 504 & 16 & 5 \\
\hline 359 & 19 & $8 \mathrm{~A}$ & 432 & 19 & $9 \mathrm{~A}$ & 505 & 15 & $4 \mathrm{~A}$ \\
\hline 360 & Test & 21 & 433 & 17 & 6 & 506 & 14 & 8 \\
\hline 361 & 20 & 9 & 434 & 17 & 6 & 507 & 15 & 8 \\
\hline 362 & 11 & 5 & 435 & 21 & 8 & 508 & 11 & 8 \\
\hline 363 & 11 & 5 & 436 & 17 & & 509 & 38 & 9 \\
\hline 364 & 11 & 5 & 437 & 17 & 6 & 510 & 20 & $13 \mathrm{~B}$ \\
\hline 365 & 19 & $9 \mathrm{~A}$ & 438 & 21 & $7 \mathrm{~B}$ & 511 & 16 & 8 \\
\hline 366 & 19 & $8 \mathrm{~A}$ & 439 & 20 & $11 \mathrm{~B}$ & 512 & 14 & 9 \\
\hline 367 & 21 & $7 \mathrm{~B}$ & 440 & 20 & $12 \mathrm{~B}$ & 513 & 19 & 11 \\
\hline 368 & 14 & 5 & 441 & 14 & $6 \mathrm{~B}$ & 514 & 16 & $7 \mathrm{~B}$ \\
\hline 369 & Test & 22 & 442 & 21 & 9 & 515 & 38 & 10 \\
\hline 370 & 13 & 5 & 443 & Test & 91.7 & 516 & 19 & 11 \\
\hline 371 & 18 & 9 & 444 & Test & 91.9 & 517 & 19 & 11 \\
\hline 372 & 20 & 10 & 445 & Test & 92.0 & 518 & 13 & 9 \\
\hline 373 & 13 & 5 & 446 & Test & 92.4 & 519 & 38 & 10 \\
\hline 374 & 15 & $4 B$ & 447 & 13 & 6 & 520 & 37 & 10 \\
\hline 375 & 14 & 5 & 448 & 16 & $6 \mathrm{~A}$ & 521 & 22 & $9 \mathrm{~A}$ \\
\hline 376 & 13 & 5 & 449 & 20 & 11-1 & 522 & 21 & 10 \\
\hline 377 & 14 & 5 & 450 & 19 & $9 \mathrm{~B}$ & 523 & 20 & $13 \mathrm{C}$ \\
\hline 378 & 18 & 9 & 451 & 16 & $6 \mathrm{~B}$ & 524 & 22 & $9 \mathrm{~A}$ \\
\hline 379 & 18 & 9 & 452 & 16 & $6 \mathrm{~B}$ & 525 & 11 & 8 \\
\hline 380 & 20 & 10 & 453 & 12 & 5 & 526 & 15 & 9 \\
\hline 381 & 21 & $7 \mathrm{~B}$ & 454 & 17 & $7 \mathrm{~A}$ & 527 & 38 & 11 \\
\hline
\end{tabular}




\begin{tabular}{|c|c|c|c|c|c|c|c|c|}
\hline$\overline{\text { Lot }}$ & Square & Level/Sublevel & Lot & Square & Level/Sublevel & Lot & Square & Level/Sublevel \\
\hline$\overline{528}$ & 20 & $13 \mathrm{~B}$ & 601 & 22 & 11 & 674 & 22 & 13 \\
\hline 529 & 21 & 10 & 602 & 18 & 11 & 675 & 22 & 14 \\
\hline 530 & 16 & 9 & 603 & 20 & 18 & 676 & 17 & 12 \\
\hline 531 & 20 & 14 & 604 & 12 & $11 \mathrm{~B}$ & 677 & 17 & 6 \\
\hline 532 & 37 & 11 & 605 & 26 & 29 & 678 & 27 & 14 \\
\hline 533 & 12 & 8 & 606 & 12 & $11 \mathrm{~B}$ & 679 & 15 & wall \\
\hline 534 & 11 & 9 & 607 & 18 & 12 & 680 & 17 & 12 \\
\hline 535 & 38 & $12 \mathrm{~A}$ & 608 & 14 & 15 & 681 & 12 & wall \\
\hline 536 & 17 & $8 \mathrm{~B}$ & 609 & 16 & $10 \mathrm{~B}$ & 682 & 33 & 16 \\
\hline 537 & 14 & 10 & 610 & 22 & $12 \mathrm{~A}$ & 683 & 32 & 14 \\
\hline 538 & 22 & $10 \mathrm{~A}$ & 611 & 11 & 12 & 684 & 12 & 14 \\
\hline 539 & 11 & 9 & 612 & 37 & $13 \mathrm{~A}$ & 685 & 16 & 13 \\
\hline 540 & 12 & 9 & 613 & 12 & $12 \mathrm{~B}$ & 686 & 30 & 14 \\
\hline 541 & 12 & 9 & 614 & 12 & $12 \mathrm{~A}$ & 687 & 17 & 12 \\
\hline 542 & 15 & 10 & 615 & 14 & 15 & 688 & 33 & 16 \\
\hline 543 & 13 & $10 \mathrm{~A}$ & 616 & 20 & 16B & 689 & 33 & 16 \\
\hline 544 & 17 & 9 & 617 & 21 & 12 & 690 & 17 & 12 \\
\hline 545 & 20 & 15 & 618 & 19 & $9 \mathrm{~A}$ & 691 & 16 & 13 \\
\hline 546 & 20 & 15 & 619 & 19 & $9 \mathrm{~A}$ & 692 & 37 & 15 \\
\hline 547 & 20 & 15 & 620 & 20 & $13 \mathrm{~B}$ & 693 & 34 & 16 \\
\hline 548 & 20 & $13 \mathrm{~B}$ & 621 & 17 & 9 & 694 & 37 & 15 \\
\hline 549 & 15 & 11 & 622 & 17 & 10 & 695 & 33 & $17 \mathrm{~A}$ \\
\hline 550 & 38 & $13 \mathrm{~A}$ & 623 & 37 & $13 \mathrm{~A}$ & 696 & 52 & 14 \\
\hline 551 & 14 & 11 & 624 & 14 & 15 & 697 & 25 & 14 \\
\hline 552 & 11 & 10 & 625 & 17 & 10 & 698 & 27 & 15 \\
\hline 553 & 52 & 24 & 626 & 19 & 12 & 699 & 33 & $17 \mathrm{~B}$ \\
\hline 554 & 16 & $10 \mathrm{~A}$ & 627 & 18 & 12 & 700 & 26 & 15 \\
\hline 555 & 21 & 11 & 628 & 13 & $12 \mathrm{~A}$ & 701 & 28 & 15 \\
\hline 556 & 12 & 10 & 629 & 21 & 14 & 702 & 32 & 15 \\
\hline 557 & 37 & $12 \mathrm{~A}$ & 630 & 18 & 12 & 703 & 17 & 13 \\
\hline 558 & 22 & $9 \mathrm{~B}$ & 631 & 11 & 12 & 704 & 16 & 13 \\
\hline 559 & 47 & 27 & 632 & 37 & $13 \mathrm{~A}$ & 705 & 25 & 14 \\
\hline 560 & 13 & $10 \mathrm{~B}$ & 633 & 13 & $12 \mathrm{~A}$ & 706 & 30 & 14 \\
\hline 561 & 14 & 12 & 634 & 37 & $13 \mathrm{~B}$ & 707 & 0 & \\
\hline 562 & 20 & $16 \mathrm{~A}$ & 635 & 14 & 16 & 708 & 30 & 14 \\
\hline 563 & 13 & $11 \mathrm{~A}$ & 636 & 37 & $13 \mathrm{~B}$ & 709 & 35 & 14 \\
\hline 564 & 11 & 10 & 637 & 11 & 12 & 710 & 20 & 19 \\
\hline 565 & 11 & 10 & 638 & 37 & 13B & 711 & 52 & $15 \mathrm{~A}$ \\
\hline 566 & 22 & $10 \mathrm{~B}$ & 639 & 38 & 16 & 712 & 33 & $17 \mathrm{~B}$ \\
\hline 567 & 20 & 14 & 640 & 15 & 14 & 713 & 12 & 15 \\
\hline 568 & 15 & 12 & 641 & 13 & $12 \mathrm{~B}$ & 714 & 26 & 16 \\
\hline 569 & 21 & 11 & 642 & 15 & 14 & 715 & 27 & 16 \\
\hline 570 & 11 & 11 & 643 & 21 & 14 & 716 & 30 & 15 \\
\hline 571 & 38 & $13 \mathrm{~B}$ & 644 & 22 & 13 & 717 & 32 & 16 \\
\hline 572 & 22 & 11 & 645 & 14 & 16 & 718 & 25 & 14 \\
\hline 573 & 16 & $10 \mathrm{~A}$ & 646 & 17 & 11 & 719 & 25 & 14 \\
\hline 574 & 14 & 13 & 647 & 17 & 11 & 720 & 52 & $15 \mathrm{~A}$ \\
\hline 575 & 11 & 5 & 648 & 21 & 14 & 721 & 35 & wall \\
\hline 576 & 17 & $7 \mathrm{~B}$ & 649 & 21 & 14 & 722 & 39 & $15 \mathrm{~A}$ \\
\hline 577 & 38 & $12 \mathrm{~B}$ & 650 & 22 & $7-10$ & 723 & 38 & 9 \\
\hline 578 & 12 & $11 \mathrm{~A}$ & 651 & 16 & $12 \mathrm{~A}$ & 724 & 25 & 15 \\
\hline 579 & 27 & $29 \mathrm{~A}$ & 652 & 17 & 11 & 725 & 17 & 13 \\
\hline 580 & 16 & $11 \mathrm{~A}$ & 653 & 18 & 13 & 726 & 17 & 13 \\
\hline 581 & 16 & $11 \mathrm{~B}$ & 654 & 19 & 13 & 727 & 39 & $15 \&$ \\
\hline 582 & 20 & 17 & 655 & 13 & 13 & 728 & 25 & 15 \\
\hline 583 & 38 & 14 & 656 & 13 & $12 \mathrm{~A}$ & 729 & 28 & 16 \\
\hline 584 & 21 & 12 & 657 & 27 & & 730 & 39 & $15 \&$ \\
\hline 585 & 38 & 14 & 658 & 11 & 13 & 731 & 30 & 15 \\
\hline 586 & 13 & $11 \mathrm{~B}$ & 659 & 13 & 13 & 732 & 17 & 13 \\
\hline 587 & 21 & 12 & 660 & 15 & $5 \mathrm{~A}$ & 733 & 52 & $15 \mathrm{~A}$ \\
\hline 588 & 37 & $12 \mathrm{~B}$ & 661 & 12 & 13 & 734 & 27 & 16 \\
\hline 589 & 18 & 11 & 662 & 18 & 14 & 735 & 26 & 16 \\
\hline 590 & 14 & 14 & 663 & 19 & $14 \mathrm{~A}$ & 736 & $45^{*}$ & $13-1$ \\
\hline 591 & 11 & 11 & 664 & 17 & 11 & 737 & 34 & 17 \\
\hline 592 & 37 & $13 \mathrm{~A}$ & 665 & 17 & 11 & 738 & 47 & $15-1$ \\
\hline 593 & 38 & 15 & 666 & 22 & 13 & 739 & 25 & 15 \\
\hline 594 & 21 & 13 & 667 & 38 & $17 \mathrm{~A}$ & 740 & 39 & $15 \mathrm{~A}$ \\
\hline 595 & 17 & 10 & 668 & 16 & $12 \mathrm{~B}$ & 741 & 49 & 16 \\
\hline 596 & 15 & 13 & 669 & 16 & $12 \mathrm{~B}$ & 742 & 12 & 16 \\
\hline 597 & 17 & 10 & 670 & 22 & 13 & 743 & 32 & 17 \\
\hline 598 & 21 & 13 & 671 & 22 & $12 \mathrm{~B}$ & 744 & 30 & 16 \\
\hline 599 & 20 & 18 & 672 & 34 & 15 & 745 & 30 & 16 \\
\hline 600 & 15 & 12 & 673 & 37 & 14 & 746 & 52 & $16 \mathrm{~A}$ \\
\hline
\end{tabular}




\begin{tabular}{|c|c|c|c|c|c|c|c|c|}
\hline Lot & Square & Level/Sublevel & Lot & Square & Level/Sublevel & Lot & Square & Level/Sublevel \\
\hline 747 & 30 & 16 & 820 & 30 & 17 & 893 & 37 & 19 \\
\hline 748 & 25 & 16 & 821 & 30 & 17 & 894 & 35 & 20 \\
\hline 749 & 27 & 17 & 822 & 43 & 20 & 895 & 45 & 20 \\
\hline 750 & 34 & 17 & 823 & 25 & 18 & 896 & 39 & 20 \\
\hline 751 & 34 & 17 & 824 & 46 & 19 & 897 & 26 & 22 \\
\hline 752 & 26 & 17 & 825 & 37 & $17 \mathrm{~A}$ & 898 & 47 & $20 \mathrm{~B}$ \\
\hline 753 & 28 & 17 & 826 & 39 & $16 \mathrm{~A}$ & 899 & 53 & 20 \\
\hline 754 & 48 & 17 & 827 & 27 & $29 \mathrm{~A}$ & 900 & 39 & 20 \\
\hline 755 & 32 & 17 & 828 & 35 & $17 \mathrm{~A}$ & 901 & 35 & 20 \\
\hline 756 & 35 & 15 & 829 & 47 & 18 & 902 & 33 & $17 \mathrm{~B}$ \\
\hline 757 & 39 & $15 \mathrm{C}$ & 830 & 30 & $29 \mathrm{~B}$ & 903 & 47 & 21 \\
\hline 758 & 25 & 16 & 831 & 28 & 19 & 904 & 30 & $20 \mathrm{~A}$ \\
\hline 759 & 25 & 16 & 832 & 51 & 17 & 905 & 27 & 21 \\
\hline 760 & 44 & 17 & 833 & 28 & 19 & 906 & 41 & 20 \\
\hline 761 & 49 & 17 & 834 & 39 & $16 \mathrm{~A}$ & 907 & 39 & 20 \\
\hline 762 & 27 & 17 & 835 & 26 & 20 & 908 & 32 & $20 \mathrm{~A}$ \\
\hline 763 & 12 & 17 & 836 & 42 & 20 & 909 & 25 & 21 \\
\hline 764 & 42 & 17 & 837 & 48 & 18 & 910 & 52 & 21 \\
\hline 765 & 30 & 17 & 838 & 45 & 18 & 911 & 46 & $21 \mathrm{~A}$ \\
\hline 766 & 39 & $15 \mathrm{C}$ & 839 & 26 & 20 & 912 & 33 & 19 \\
\hline 767 & 37 & $16 \mathrm{~A}$ & 840 & 26 & 20 & 913 & 30 & $20 \mathrm{~B}$ \\
\hline 768 & 43 & 17 & 841 & 30 & 18 & 914 & 12 & $20 \mathrm{~B}$ \\
\hline 769 & 39 & $15 \mathrm{C}$ & 842 & 37 & $16 \mathrm{~B}$ & 915 & 32 & $20 \mathrm{~B}$ \\
\hline 770 & 52 & $16 \mathrm{~A}$ & 843 & 34 & 18 & 916 & 26 & 22 \\
\hline 771 & 47 & 17 & 844 & 35 & 18 & 917 & 48 & 19 \\
\hline 772 & 32 & 18 & 845 & 34 & $19 \mathrm{~A}$ & 918 & 12 & $20 \mathrm{~B}$ \\
\hline 773 & 46 & 17 & 846 & 37 & 17 & 919 & 38 & 19 \\
\hline 774 & 52 & $15 \mathrm{~B}$ & 847 & 45 & 18 & 920 & 50 & 19 \\
\hline 775 & 52 & $16 \mathrm{~B}$ & 848 & 25 & 19 & 921 & 52 & 21 \\
\hline 776 & 26 & 17 & 849 & 35 & 18 & 922 & 32 & 21 \\
\hline 777 & 28 & 17 & 850 & 52 & 19 & 923 & 41 & 21 \\
\hline 778 & 37 & $16 \mathrm{~A}$ & 851 & 37 & $16 \mathrm{~B}$ & 924 & 25 & 22 \\
\hline 779 & 46 & Over & 852 & 37 & 18 & 925 & 46 & $21 \mathrm{~B}$ \\
\hline 780 & 25 & 16 & 853 & 12 & 19 & 926 & 30 & $20 \mathrm{~B}$ \\
\hline 781 & 28 & $27 \mathrm{~B}$ & 854 & 50 & 17 & 927 & 45 & 21 \\
\hline 782 & 12 & 15 & 855 & 26 & 21 & 928 & 42 & 22 \\
\hline 783 & 17 & 13 & 856 & 42 & 21 & 929 & 12 & 21 \\
\hline 784 & 39 & $15 \mathrm{~B}$ & 857 & 39 & $16 \mathrm{~A}$ & 930 & 47 & 22 \\
\hline 785 & 34 & 18 & 858 & 46 & 19 & 931 & 37 & 20 \\
\hline 786 & 47 & 14 & 859 & 12 & 19 & 932 & 32 & 22 \\
\hline 787 & 0 & & 860 & 52 & 19 & 933 & 30 & $21 \mathrm{~A}$ \\
\hline 788 & 44 & 18 & 861 & 39 & 18 & 934 & 46 & 22 \\
\hline 789 & 28 & 18 & 862 & 30 & 19 & 935 & 12 & 21 \\
\hline 790 & 12 & 18 & 863 & 32 & 19 & 936 & 37 & 20 \\
\hline 791 & 46 & 18 & 864 & 49 & 19 & 937 & 37 & 20 \\
\hline 792 & 35 & 15 & 865 & 27 & 20 & 938 & 26 & 24 \\
\hline 793 & 52 & $15 \mathrm{~B}$ & 866 & 35 & 19 & 939 & 43 & 21 \\
\hline 794 & 52 & $15 \mathrm{~B}$ & 867 & 30 & 19 & 940 & 38 & 19 \\
\hline 795 & 43 & 18 & 868 & 26 & 21 & 941 & 30 & $21 \mathrm{~B}$ \\
\hline 796 & 27 & 19 & 869 & 37 & 18 & 942 & 51 & 19 \\
\hline 797 & 51 & 16 & 870 & 30 & 19 & 943 & 47 & 23 \\
\hline 798 & 27 & 19 & 871 & 25 & 20 & 944 & 43 & 21 \\
\hline 799 & 34 & 18 & 872 & 34 & 19B & 945 & 12 & 22 \\
\hline 800 & 25 & 17 & 873 & 53 & 19 & 946 & 53 & 21 \\
\hline 801 & 34 & 18 & 874 & 39 & 19 & 947 & 42 & 24 \\
\hline 802 & 45 & 17 & 875 & 47 & 19 & 948 & 30 & $21 \mathrm{~B}$ \\
\hline 803 & 35 & 16 & 876 & 46 & $20 \mathrm{~A}-$ & 949 & 46 & 23 \\
\hline 804 & 32 & 18 & 877 & 52 & 20 & 950 & 52 & 22 \\
\hline 805 & 25 & 17 & 878 & 47 & $20 \mathrm{~A}$ & 951 & 32 & 23 \\
\hline 806 & 35 & 16 & 879 & 45 & 19 & 952 & 27 & 22 \\
\hline 807 & 52 & 17 & 880 & 37 & 18 & 953 & 26 & 24 \\
\hline 808 & 35 & 16 & 881 & 34 & $19 \mathrm{~B}$ & 954 & 27 & 22 \\
\hline 809 & 42 & 19 & 882 & 32 & 19 & 955 & 52 & 22 \\
\hline 810 & 26 & 19 & 883 & 47 & 19 & 956 & 52 & 22 \\
\hline 811 & 45 & 17 & 884 & 50 & 18 & 957 & 41 & 22 \\
\hline 812 & 50 & 16 & 885 & 28 & 20 & 958 & 45 & 22 \\
\hline 813 & 35 & 16 & 886 & 39 & 19 & 959 & 27 & 22 \\
\hline 814 & 30 & 18 & 887 & 27 & 21 & 960 & 46 & 23 \\
\hline 815 & 49 & 18 & 888 & 12 & $20 \mathrm{~A}$ & 961 & 27 & 22 \\
\hline 816 & 38 & $17 \mathrm{~B}$ & 889 & 45 & 19 & 962 & 30 & $22 \mathrm{~A}$ \\
\hline 817 & 43 & 19 & 890 & 27 & 21 & 963 & 38 & 20 \\
\hline 818 & 44 & 19 & 891 & 52 & 20 & 964 & 47 & 24 \\
\hline 819 & 52 & 17 & 892 & 12 & $20 \mathrm{~A}$ & 965 & 50 & 20 \\
\hline
\end{tabular}




\begin{tabular}{|c|c|c|c|c|c|c|c|c|}
\hline$\overline{\text { Lot }}$ & Square & Level/Sublevel & Lot & Square & Level/Sublevel & Lot & Square & Level/Sublevel \\
\hline 966 & 35 & 20 & 103 & 30 & 25 & 111 & 38 & $21 \mathrm{~A}$ \\
\hline 967 & 45 & 22 & 103 & 12 & 25 & 111 & 52 & 23 \\
\hline 968 & 37 & 20 & 104 & 25 & 25 & 111 & 46 & 25 \\
\hline 969 & 26 & 24 & 104 & 35 & 22 & 111 & 33 & 24 \\
\hline 970 & 12 & 23 & 104 & 12 & 26 & 111 & 35 & 22 \\
\hline 970 & 12 & 23-2 & 104 & 12 & $26-2$ & 111 & 34 & 21 \\
\hline 971 & 35 & 20 & 104 & 48 & 21 & 111 & 26 & 25 \\
\hline 972 & 44 & 20 & 104 & 44 & 21 & 111 & 28 & 22 \\
\hline 973 & 32 & 24 & 104 & 33 & 23 & 111 & 52 & 23 \\
\hline 974 & 33 & 20 & 104 & 27 & 24 & 111 & 35 & 22 \\
\hline 975 & 50 & 20 & 104 & 35 & 22 & 112 & 35 & 22 \\
\hline 976 & 30 & $22 \mathrm{~A}$ & 104 & 30 & 25 & 112 & 30 & 26 \\
\hline 977 & 52 & 22 & 104 & 51 & 20 & 112 & 52 & 23 \\
\hline 978 & 25 & 24 & 105 & 35 & 22 & 112 & 25 & 26 \\
\hline 979 & 28 & 21 & 105 & 20 & 24 & 112 & 35 & 22 \\
\hline 980 & 33 & 20 & 105 & 27 & 24 & 112 & 50 & 21 \\
\hline 981 & 32 & 24 & 105 & 35 & 22 & 112 & 38 & $21 \mathrm{~B}$ \\
\hline 982 & 12 & 23 & 105 & 44 & 22 & 112 & 34 & 21 \\
\hline 983 & 47 & 25 & 105 & 27 & 24 & 112 & 28 & 22 \\
\hline 984 & 32 & 25 & 105 & 48 & 22 & 112 & 43 & 24 \\
\hline 985 & 34 & 20 & 105 & Test & & 113 & 41 & 25 \\
\hline 986 & 52 & 22 & 105 & 45 & 24 & 113 & 46 & 25 \\
\hline 987 & 34 & 20 & 105 & 51 & 20 & 113 & 49 & 21 \\
\hline 988 & 30 & $22 \mathrm{~B}$ & 106 & 35 & 22 & 113 & 33 & 25 \\
\hline 989 & 34 & 20 & 106 & 32 & 27 & 113 & 46 & 26 \\
\hline 990 & 34 & 20 & 106 & 48 & 27 & 113 & 39 & $21 \mathrm{~A}$ \\
\hline 991 & 48 & 20 & 106 & 38 & 22 & 113 & 37 & 22 \\
\hline 992 & 27 & 22 & 106 & 38 & 22 & 113 & 48 & 24 \\
\hline 993 & 52 & 22 & 106 & 38 & 22 & 113 & 52 & 23 \\
\hline 994 & 12 & 24 & 106 & 30 & 28 & 113 & 38 & $21 \mathrm{~A}$ \\
\hline 995 & 33 & 21 & 106 & 30 & 28 & 114 & 26 & 25 \\
\hline 996 & 35 & 21 & 106 & 39 & $22 \mathrm{~A}$ & 114 & 45 & 27 \\
\hline 997 & 30 & $21 B$ & 106 & 38 & 22 & 114 & 39 & $21 \mathrm{~A}$ \\
\hline 998 & 30 & $22 \mathrm{~B}$ & 107 & 30 & 28 & 114 & 49 & 22 \\
\hline 999 & 41 & 27 & 107 & 49 & 26 & 114 & 20 & $25 \mathrm{~A}$ \\
\hline 100 & 12 & 24 & 107 & 50 & 22 & 114 & 20 & $25 \mathrm{~A}-$ \\
\hline 100 & 35 & 21 & 107 & 42 & 27 & 114 & 20 & $25 \mathrm{~B}$ \\
\hline 100 & 38 & $21 B$ & 107 & 39 & $22 \mathrm{~B}$ & 114 & 38 & $21 \mathrm{~A}$ \\
\hline 100 & 33 & 21 & 107 & 39 & $22 \mathrm{~B}$ & 114 & 37 & 22 \\
\hline 100 & 47 & 26 & 107 & 37 & 22 & 114 & 48 & 24 \\
\hline 100 & 48 & 21 & 107 & 37 & 22 & 114 & 30 & 27 \\
\hline 100 & 43 & 22 & 107 & 39 & $22 \mathrm{~B}$ & 114 & 46 & 26 \\
\hline 100 & 32 & 26 & 107 & 44 & 21 & 115 & 39 & $22 \mathrm{~A}$ \\
\hline 100 & 39 & $21 \mathrm{~A}$ & 108 & 44 & 22 & 115 & 53 & 23 \\
\hline 100 & 45 & 23 & 108 & 27 & 24 & 115 & 41 & 26 \\
\hline 101 & 37 & 21 & 108 & 33 & 23 & 115 & 26 & 26 \\
\hline 101 & 43 & 22 & 108 & 35 & 22 & 115 & 30 & 27 \\
\hline 101 & 20 & 19 & 108 & 20 & 24 & 115 & 45 & 28 \\
\hline 101 & 20 & 19 & 108 & 27 & 24 & 115 & 39 & $22 \mathrm{~A}$ \\
\hline 101 & 39 & $21 \mathrm{~A}$ & 108 & 35 & 22 & 115 & 48 & 25 \\
\hline 101 & 39 & $21 \mathrm{~A}$ & 108 & 12 & 26 & 115 & 46 & $27 \mathrm{~A}$ \\
\hline 101 & 20 & 24 & 108 & 50 & 21 & 115 & 37 & 22 \\
\hline 101 & 37 & 21 & 108 & 46 & 24 & 116 & 51 & 21 \\
\hline 101 & 53 & 22 & 109 & 48 & 22 & 116 & 25 & 26 \\
\hline 101 & 20 & 24 & 109 & 27 & 24 & 116 & 34 & 22 \\
\hline 102 & 12 & 25 & 109 & 45 & 25 & 116 & 46 & $27 \mathrm{~A}$ \\
\hline 102 & 49 & 20 & 109 & 12 & 27 & 116 & 46 & $27 \mathrm{~A}$ \\
\hline 102 & 30 & 23 & 109 & 26 & 25 & 116 & 53 & 23 \\
\hline 102 & 33 & 22 & 109 & 48 & 23 & 116 & 48 & 26 \\
\hline 102 & 30 & 23 & 109 & 42 & 26 & 116 & 20 & $25 \mathrm{~B}$ \\
\hline 102 & 28 & 22 & 109 & 46 & 24 & 116 & 26 & 26 \\
\hline 102 & 37 & 21 & 109 & 52 & 23 & 116 & 26 & 26 \\
\hline 102 & 27 & $24-2$ & 109 & 33 & 24 & 117 & 26 & 26 \\
\hline 102 & 27 & 24 & 110 & 50 & 21 & 117 & 34 & 22 \\
\hline 102 & 30 & 24 & 110 & 38 & $21 \mathrm{~A}$ & 117 & 34 & 22 \\
\hline 103 & 39 & $21 \mathrm{~A}$ & 110 & 27 & 24 & 117 & 39 & $21 \mathrm{~B}$ \\
\hline 103 & 39 & $21 \mathrm{~A}$ & 110 & 32 & $20 \mathrm{~A}$ & 117 & 37 & 22 \\
\hline 103 & 27 & 24 & 110 & 35 & $26 \mathrm{~A}$ & 117 & 34 & 22 \\
\hline 103 & 41 & 24 & 110 & 45 & 26 & 117 & 46 & $28 \mathrm{~B}$ \\
\hline 103 & 51 & 22 & 110 & 16 & $6 \mathrm{~B}$ & 117 & 33 & 26 \\
\hline 103 & 39 & $21 \mathrm{~A}$ & 110 & 35 & 22 & 117 & 34 & 22 \\
\hline 103 & 52 & 24 & 110 & 38 & $21 \mathrm{~A}$ & 117 & 26 & 26 \\
\hline 103 & 30 & 24 & 110 & 27 & 24 & 118 & 26 & 26 \\
\hline
\end{tabular}




\begin{tabular}{|c|c|c|c|c|c|c|c|c|}
\hline Lot & Square & Level/Sublevel & Lot & Square & Level/Sublevel & Lot & Square & Level/Sublevel \\
\hline$\overline{118}$ & 48 & 27 & 125 & 12 & 29 & 132 & 39 & 23 \\
\hline 118 & 26 & 26 & 125 & 12 & 30 & 132 & 12 & 32 \\
\hline 118 & 47 & 27 & 125 & 20 & 27 & 132 & 100 & 5 \\
\hline 118 & 46 & $28 \mathrm{~A}$ & 125 & 20 & 27 & 133 & 32 & 32 \\
\hline 118 & 20 & $25 \mathrm{~B}$ & 125 & 12 & 30 & 133 & 30 & $33 \mathrm{~B}$ \\
\hline 118 & 20 & $25 \mathrm{~B}$ & 125 & 32 & $29 \mathrm{~B}$ & 133 & 39 & 23 \\
\hline 118 & 20 & $25 \mathrm{~B}$ & 126 & 26 & 28 & 133 & 30 & $33 \mathrm{~B}$ \\
\hline 118 & 51 & 22 & 126 & 27 & 25 & 133 & 32 & 32 \\
\hline 118 & 46 & $28 \mathrm{~B}$ & 126 & 41 & 29 & 133 & 25 & 30 \\
\hline 119 & 46 & $27 \mathrm{~B}$ & 126 & 32 & $29 \mathrm{~A}$ & 133 & 48 & $30 \mathrm{~B}$ \\
\hline 119 & 27 & 24 & 126 & 48 & 29 & 133 & 46 & 32 \\
\hline 119 & 38 & 22 & 126 & 100 & 3 & 133 & 32 & 32 \\
\hline 119 & 30 & 29 & 126 & 100 & 3 & 133 & 12 & 32 \\
\hline 119 & 20 & $26 \mathrm{~B}$ & 126 & 34 & $23 \mathrm{~B}$ & 134 & 30 & $34 \mathrm{~A}$ \\
\hline 119 & 20 & 26B & 126 & 26 & 28 & 134 & 37 & 23 \\
\hline 119 & 25 & 27 & 126 & 32 & $29 B$ & 134 & 50 & 23 \\
\hline 119 & 100 & 1 & 127 & 25 & 29 & 134 & 50 & 23 \\
\hline 119 & 33 & 27 & 127 & 26 & 28 & 134 & 12 & 32 \\
\hline 119 & 26 & 27 & 127 & 32 & $29 B$ & 134 & 37 & 23 \\
\hline 120 & 30 & 30 & 127 & 37 & 22 & 134 & 34 & $25 \mathrm{~A}$ \\
\hline 120 & 46 & $28 \mathrm{~A}$ & 127 & 12 & 31 & 134 & 37 & 23 \\
\hline 120 & 25 & 27 & 127 & 52 & 23 & 134 & 30 & $34 \mathrm{~A}$ \\
\hline 120 & 35 & 22 & 127 & 46 & 30 & 134 & 100 & 6 \\
\hline 120 & 35 & 22 & 127 & 39 & $22 \mathrm{~B}$ & 135 & 35 & 24 \\
\hline 120 & 35 & 22 & 127 & 49 & 24 & 135 & 37 & 23 \\
\hline 120 & 100 & 2 & 127 & 52 & 23 & 135 & 51 & 23 \\
\hline 120 & 46 & 29 & 128 & 27 & 26 & 135 & 100 & 6 \\
\hline 120 & 48 & 28 & 128 & 34 & 24 & 135 & 38 & 23 \\
\hline 120 & 12 & 28 & 128 & 52 & 46 & 135 & 30 & 39 \\
\hline 121 & 12 & 28 & 128 & 59 & 44 & 135 & 37 & 23 \\
\hline 121 & 20 & $26 \mathrm{~A}$ & 128 & 28 & 25 & 135 & 33 & $30 \mathrm{~A}$ \\
\hline 121 & 100 & 2 & 128 & 46 & 34 & 135 & 39 & 23 \\
\hline 121 & 32 & $28 \mathrm{~A}$ & 128 & 47 & 29 & 135 & 39 & 23 \\
\hline 121 & 12 & 28 & 128 & 45 & 29 & 136 & 42 & 29 \\
\hline 121 & 33 & 28 & 128 & 46 & 30 & 136 & 30 & $33 B$ \\
\hline 121 & 41 & 28 & 128 & 27 & 26 & 136 & 26 & 29 \\
\hline 121 & 30 & $31 \mathrm{~B}$ & 129 & 46 & $20 \mathrm{~A}$ & 136 & 34 & $25 \mathrm{~A}$ \\
\hline 121 & 47 & 28 & 129 & 32 & 30 & 136 & 33 & 29 \\
\hline 121 & 100 & 2 & 129 & 34 & 24 & 136 & 34 & $25 \mathrm{~A}$ \\
\hline 122 & 100 & 2 & 129 & 25 & 33 & 136 & 34 & $25 \mathrm{~A}$ \\
\hline 122 & 49 & 23 & 129 & 30 & $33 \mathrm{~A}$ & 136 & 30 & $34 \mathrm{~B}$ \\
\hline 122 & 100 & 2 & 129 & 100 & 4 & 136 & 34 & $25 \mathrm{~A}$ \\
\hline 122 & 32 & $28 \mathrm{~A}$ & 129 & 48 & 29 & 136 & 27 & $27 \mathrm{~A}$ \\
\hline 122 & 100 & 2 & 129 & 48 & 29 & 137 & 30 & $33 B$ \\
\hline 122 & 13 & $11 \mathrm{~B}$ & 129 & 48 & 29 & 137 & 34 & $25 \mathrm{~A}$ \\
\hline 122 & 35 & 23 & 129 & 32 & 30 & 137 & 39 & 23 \\
\hline 122 & 12 & 28 & 130 & 35 & 24 & 137 & 100 & 7 \\
\hline 122 & 30 & 31 & 130 & 30 & $33 \mathrm{~B}$ & 137 & 38 & 23 \\
\hline 122 & 32 & $28 \mathrm{~A}$ & 130 & 30 & $33 \mathrm{~B}$ & 137 & 38 & 23 \\
\hline 123 & 20 & $26 \mathrm{~B}$ & 130 & 48 & $30 \mathrm{~A}$ & 137 & 27 & $27 \mathrm{~A}$ \\
\hline 123 & 33 & 29 & 130 & 34 & 24 & 137 & 25 & 31 \\
\hline 123 & 32 & $28 \mathrm{~B}$ & 130 & 32 & 31 & 137 & 26 & 29 \\
\hline 123 & 35 & 23 & 130 & 35 & 24 & 137 & 32 & 33 \\
\hline 123 & 32 & 28B & 130 & 27 & 26 & 138 & 27 & $27 \mathrm{~A}$ \\
\hline 123 & 35 & 23 & 130 & 100 & 5 & 138 & 32 & 33 \\
\hline 123 & 25 & 28 & 130 & 34 & 24 & 138 & 34 & $25 \mathrm{~B}$ \\
\hline 123 & 12 & 29 & 131 & 12 & 31 & 138 & 48 & $31 \mathrm{~A}$ \\
\hline 123 & 20 & $26 \mathrm{~A}$ & 131 & 27 & 26 & 138 & 100 & 7 \\
\hline 123 & 32 & $28 \mathrm{~B}$ & 131 & 35 & 24 & 138 & 30 & $34 \mathrm{~B}$ \\
\hline 124 & 35 & 23 & 131 & $45 *$ & 31 & 138 & 38 & 23 \\
\hline 124 & 20 & $26 \mathrm{~A}$ & 131 & 30 & $33 \mathrm{~A}$ & 138 & 46 & 33 \\
\hline 124 & 32 & $28 \mathrm{~B}$ & 131 & 100 & 5 & 138 & 12 & 33 \\
\hline 124 & 34 & $23 \mathrm{~A}$ & 131 & 25 & 30 & 138 & 20 & 28 \\
\hline 124 & 20 & $26 \mathrm{~A}$ & 131 & 32 & 32 & 139 & 48 & $31 \mathrm{~A}$ \\
\hline 124 & 34 & $23 \mathrm{~A}$ & 131 & 46 & 31 & 139 & 32 & 33 \\
\hline 124 & 100 & 2 & 131 & 43 & 26 & 139 & 25 & 31 \\
\hline 124 & 42 & 28 & 132 & 39 & 23 & 139 & 12 & 33 \\
\hline 124 & 43 & 25 & 132 & 46 & 31 & 139 & 49 & 26 \\
\hline 124 & 30 & 32 & 132 & 46 & 31 & 139 & 27 & $27 \mathrm{~A}$ \\
\hline 125 & 30 & 32 & 132 & 39 & 23 & 139 & 12 & 33 \\
\hline 125 & 20 & 27 & 132 & 28 & 22 & 139 & 12 & $33-3$ \\
\hline 125 & 32 & $29 \mathrm{~A}$ & 132 & 44 & 22 & 139 & 32 & 33 \\
\hline 125 & 32 & $29 \mathrm{~A}$ & 132 & 100 & 5 & 139 & 35 & 25 \\
\hline
\end{tabular}




\begin{tabular}{|c|c|c|c|c|c|c|c|c|}
\hline$\overline{\text { Lot }}$ & Square & Level/Sublevel & Lot & Square & Level/Sublevel & Lot & Square & Level/Sublevel \\
\hline 139 & 43 & 27 & 147 & 49 & 28 & 154 & 48 & 32 \\
\hline 140 & 22 & 14 & 147 & 34 & $27 \mathrm{~B}$ & 154 & 35 & 28 \\
\hline 140 & 32 & 34 & 147 & 37 & $24 \mathrm{~A}$ & 154 & 52 & $25 \mathrm{~A}$ \\
\hline 140 & 100 & 7 & 147 & 20 & 30 & 154 & 52 & $25 \mathrm{~B}$ \\
\hline 140 & 35 & 25 & 147 & 35 & 27 & 154 & 30 & 37 \\
\hline 140 & 33 & $30 \mathrm{~A}$ & 147 & 37 & $24 \mathrm{~A}$ & 155 & 100 & 10 \\
\hline 140 & 43 & 28 & 147 & 35 & 27 & 155 & 34 & 29 \\
\hline 140 & 43 & 28 & 147 & 37 & $24 \mathrm{~A}$ & 155 & 37 & 25 \\
\hline 140 & 33 & $31 \mathrm{~A}$ & 148 & 37 & $24 \mathrm{~A}$ & 155 & 44 & 25 \\
\hline 140 & 33 & $30 \mathrm{~A}$ & 148 & 44 & 24 & 155 & 20 & 31 \\
\hline 140 & 27 & $27 \mathrm{~B}$ & 148 & 32 & 35 & 155 & 20 & 31 \\
\hline 141 & 32 & $28 \mathrm{~B}$ & 148 & 37 & $24 \mathrm{~A}$ & 155 & 48 & 32 \\
\hline 141 & 25 & 32 & 148 & 37 & $24 \mathrm{~A}$ & 155 & 52 & $25 \mathrm{~B}$ \\
\hline 141 & 43 & 28 & 148 & 34 & $27 \mathrm{~B}$ & 155 & 44 & 25 \\
\hline 141 & 48 & $31 \mathrm{~B}$ & 148 & 44 & 24 & 155 & 48 & 32 \\
\hline 141 & 33 & $31 \mathrm{~A}$ & 148 & 30 & 36 & 156 & 100 & 10 \\
\hline 141 & 12 & 33 & 148 & 28 & 24 & 156 & 37 & 25 \\
\hline 141 & 20 & $29 \mathrm{~A}$ & 148 & & & 156 & 35 & 28 \\
\hline 141 & 30 & 35 & 149 & 52 & 24 & 156 & 100 & 10 \\
\hline 141 & 27 & $28 \mathrm{~A}$ & 149 & 35 & 27 & 156 & 35 & 28 \\
\hline 141 & 26 & 30 & 149 & 25 & 33 & 156 & 48 & 33 \\
\hline 142 & 33 & $30 \mathrm{~B}$ & 149 & 30 & 36 & 156 & 39 & 25 \\
\hline 142 & 34 & $26 \mathrm{~A}$ & 149 & 48 & $31 \mathrm{~B}$ & 156 & 44 & 25 \\
\hline 142 & 100 & 8 & 149 & 37 & $24 \mathrm{~A}$ & 156 & 50 & $24 B$ \\
\hline 142 & 100 & 8 & 149 & 48 & $31 \mathrm{~B}$ & 156 & 49 & 30 \\
\hline 142 & 27 & $28 \mathrm{~B}$ & 149 & 48 & $31 \mathrm{~B}$ & 157 & 48 & 32 \\
\hline 142 & 30 & 35 & 149 & 25 & 33 & 157 & 37 & 26 \\
\hline 142 & 30 & 35 & 149 & 37 & $24 \mathrm{~A}$ & 157 & 26 & 29 \\
\hline 142 & 49 & 27 & 150 & 26 & 32 & 157 & 35 & 28 \\
\hline 142 & 12 & 34 & 150 & 100 & 9 & 157 & 33 & 32 \\
\hline 142 & 37 & 23 & 150 & 100 & 9 & 157 & 39 & 25 \\
\hline 143 & 34 & $26 \mathrm{~B}$ & 150 & 49 & 29 & 157 & 27 & $28 \mathrm{~A}$ \\
\hline 143 & 33 & $30 \mathrm{~B}$ & 150 & 28 & 24 & 157 & 28 & 25 \\
\hline 143 & 35 & $26 \mathrm{~B}$ & 150 & 100 & 9 & 157 & 52 & $25 \mathrm{~A}$ \\
\hline 143 & 27 & $28 \mathrm{~B}$ & 150 & 26 & 32 & 157 & 28 & 25 \\
\hline 143 & Unknow & Unkn & 150 & 14 & 8 & 158 & 39 & 25 \\
\hline 143 & 25 & 33 & 150 & 15 & 8 & 158 & 33 & 32 \\
\hline 143 & 33 & $30 \mathrm{~B}$ & 150 & 11 & 8 & 158 & 52 & $25 \mathrm{~B}$ \\
\hline 143 & 33 & $30 \mathrm{~B}$ & 151 & 14 & 9 & 158 & 52 & $25 \mathrm{~B}$ \\
\hline 143 & 26 & 30 & 151 & 38 & 10 & 158 & 27 & $29 \mathrm{~A}$ \\
\hline 143 & 20 & $29 \mathrm{~A}$ & 151 & 15 & 9 & 158 & 25 & 34 \\
\hline 144 & 46 & 35 & 151 & 20 & 14 & 158 & 25 & 34 \\
\hline 144 & 46 & 35 & 151 & 11 & 9 & 158 & 28 & 25 \\
\hline 144 & 34 & $26 \mathrm{~B}$ & 151 & 38 & $12 \mathrm{~A}$ & 158 & 52 & $25 \mathrm{~B}$ \\
\hline 144 & 46 & 35 & 151 & 32 & 35 & 158 & 50 & $24 B$ \\
\hline 144 & 47 & 35 & 151 & 25 & 33 & 159 & 52 & $25 \mathrm{~B}$ \\
\hline 144 & 47 & 35 & 151 & 37 & $24 \mathrm{~A}$ & 159 & 49 & 30 \\
\hline 144 & 34 & $27 \mathrm{~A}$ & 151 & 25 & 33 & 159 & 33 & 32 \\
\hline 144 & 27 & $28 \mathrm{~A}$ & 152 & 37 & $24 \mathrm{~A}$ & 159 & 50 & $24 \mathrm{~A}$ \\
\hline 144 & 35 & $26 \mathrm{~B}$ & 152 & 25 & $33 \mathrm{~A}$ & 159 & 50 & $24 \mathrm{~A}$ \\
\hline 144 & 47 & 35 & 152 & 37 & $24 B$ & 159 & 39 & 25 \\
\hline 145 & 47 & 35 & 152 & 25 & 33 & 159 & 50 & $24 \mathrm{~A}$ \\
\hline 145 & 26 & 31 & 152 & 37 & 25 & 159 & 30 & 38 \\
\hline 145 & 20 & $29 \mathrm{~B}$ & 152 & 33 & $31 \mathrm{~B}$ & 159 & 25 & 34 \\
\hline 145 & 47 & 35 & 152 & 39 & 24 & 159 & 52 & $25 \mathrm{~B}$ \\
\hline 145 & 46 & 35 & 152 & 39 & 24 & 160 & 20 & 32 \\
\hline 145 & 52 & 24 & 152 & 37 & 25 & 160 & 30 & 39 \\
\hline 145 & 27 & $28 \mathrm{~A}$ & 152 & 39 & 24 & 160 & 20 & 32 \\
\hline 145 & 17 & $7 \mathrm{~A}$ & 153 & 25 & $33 \mathrm{~B}$ & 160 & 27 & $29 \mathrm{~A}$ \\
\hline 145 & 27 & $28 \mathrm{~B}$ & 153 & 34 & 28 & 160 & 28 & 25 \\
\hline 145 & 52 & 24 & 153 & 12 & 35 & 160 & 28 & 25 \\
\hline 146 & 53 & 24 & 153 & 33 & $31 \mathrm{~B}$ & 160 & 100 & 10 \\
\hline 146 & 52 & 24 & 153 & 32 & 35 & 160 & 30 & 41 \\
\hline 146 & 52 & 24 & 153 & 33 & $31 \mathrm{~B}$ & 160 & 28 & $27 \mathrm{~A}$ \\
\hline 146 & 35 & 27 & 153 & 33 & $31 \mathrm{~B}$ & 160 & 34 & $31 \mathrm{~B}$ \\
\hline 146 & 52 & 24 & 153 & 20 & 31 & 161 & 27 & $29 \mathrm{~A}-$ \\
\hline 146 & 48 & $31 \mathrm{~B}$ & 153 & 37 & 25 & 161 & 20 & 35 \\
\hline 146 & 34 & $27 \mathrm{~A}$ & 153 & 12 & 35 & 161 & $20 \& 12$ & 35 \\
\hline 146 & 26 & 31 & 154 & 35 & 28 & 161 & 34 & $31 \mathrm{C}$ \\
\hline 146 & 27 & $29 \mathrm{~A}$ & 154 & 37 & 25 & 161 & 35 & $31 \mathrm{~B}$ \\
\hline 146 & 12 & 35 & 154 & 34 & 29 & 161 & 35 & 32 \\
\hline 147 & 44 & 24 & 154 & 53 & 25 & 161 & 12 & 36 \\
\hline 147 & 32 & 35 & 154 & $\mathrm{n} / \mathrm{a}$ & & 161 & 12 & 36 \\
\hline
\end{tabular}




\begin{tabular}{|c|c|c|c|c|c|c|c|c|}
\hline Lot & Square & Level/Sublevel & Lot & Square & Level/Sublevel & Lot & Square & Level/Sublevel \\
\hline 161 & 27 & $30 \mathrm{~A}$ & 169 & 35 & $30 \mathrm{~B}$ & 176 & 37 & 27 \\
\hline 161 & 26 & 35 & 169 & 52 & $28 \mathrm{~A}$ & 176 & 28 & $24-2$ \\
\hline 161 & 25 & 36 & 169 & 32 & 36 & 176 & 49 & $31 \mathrm{~B}$ \\
\hline 162 & $37 / 32$ & $27 \&$ & 169 & 32 & 36 & 176 & 44 & 27 \\
\hline 162 & $37 / 32$ & $27 \&$ & 169 & 32 & 36 & 176 & 27 & 27B- \\
\hline 162 & 49 & $31 \mathrm{~A}$ & 169 & 52 & 31 & 176 & 28 & $27 \mathrm{~A}$ \\
\hline 162 & 27 & $30 \mathrm{~B}$ & 169 & 51 & $28 \mathrm{~A}$ & 176 & 49 & $31 \mathrm{~B}$ \\
\hline 162 & $34 / 49$ & $32 \mathrm{~B}$ & 169 & 34 & $31 \mathrm{~A}$ & 177 & 52 & $25 \mathrm{~B}$ \\
\hline 162 & 28 & $27 \mathrm{~B}$ & 169 & 35 & $30 \mathrm{~A}$ & 177 & 20 & 34 \\
\hline 162 & 50 & 28 & 169 & 35 & $31 \mathrm{~A}$ & 177 & 33 & 34 \\
\hline 162 & 28 & $27 \mathrm{~A}$ & 170 & 52 & $28 \mathrm{~B}$ & 177 & 33 & 34 \\
\hline 162 & 37 & 28 & 170 & 50 & $26 \mathrm{~A}$ & 177 & 28 & $28 \mathrm{~A}$ \\
\hline 162 & 26 & 36 & 170 & 52 & $28 \mathrm{~B}$ & 177 & 28 & $28 \mathrm{~A}$ \\
\hline 163 & 50 & 28 & 170 & 20 & 33 & 177 & 28 & $28 \mathrm{~A}$ \\
\hline 163 & 46 & 37 & 170 & 32 & $37 \mathrm{~B}$ & 177 & 52 & 25 \\
\hline 163 & 46 & 37 & 170 & 50 & $27 \mathrm{~B}$ & 177 & 33 & 34 \\
\hline 163 & 37 & 28 & 170 & 50 & $27 \mathrm{C}$ & 177 & 28 & $28 \mathrm{~B}$ \\
\hline 163 & 25 & 37 & 170 & 53 & 28 & 178 & 52 & 25 \\
\hline 163 & 28 & $27 \mathrm{~B}$ & 170 & 42 & 34 & 178 & 33 & 34 \\
\hline 163 & 28 & $27 \mathrm{~B}$ & 170 & 42 & 35 & 178 & 33 & 34 \\
\hline 163 & 28 & $27 \mathrm{~B}$ & 171 & 42 & 36 & 178 & 33 & 34 \\
\hline 163 & 34 & $32 \mathrm{~B}$ & 171 & 50 & $27 \mathrm{~B}$ & 178 & 20 & 36 \\
\hline 163 & 28 & $28 \mathrm{~A}$ & 171 & 35 & $30 \mathrm{~B}$ & 178 & 49 & $32 \mathrm{~A}$ \\
\hline 164 & 43 & 29 & 171 & 50 & $27 \mathrm{~A}$ & 178 & 34 & $32 \mathrm{~A}$ \\
\hline 164 & 20 & 35 & 171 & 28 & 26 & 178 & 37 & 28 \\
\hline 164 & 33 & 34 & 171 & 25 & 35 & 178 & 28 & $28 \mathrm{~A}$ \\
\hline 164 & 48 & 33 & 171 & 26 & 34 & 178 & 52 & 25 \\
\hline 164 & 43 & 30 & 171 & 28 & 26 & 179 & 27 & 32 \\
\hline 164 & 28 & $28 \mathrm{C}$ & 171 & 34 & $31 \mathrm{~B}$ & 179 & 41 & 37 \\
\hline 164 & 34 & $32 \mathrm{~B}$ & 171 & 46 & 36 & 179 & 20 & 36 \\
\hline 164 & 43 & 29 & 172 & 46 & 36 & 179 & 37 & 29 \\
\hline 164 & 52 & 24 & 172 & 46 & 36 & 179 & 37 & 29 \\
\hline 164 & 35 & 29 & 172 & 34 & $32 \mathrm{~B}$ & 179 & 37 & 29 \\
\hline 165 & 53 & $26 \mathrm{~B}$ & 172 & 46 & 36 & 179 & 27 & 32 \\
\hline 165 & 44 & 26 & 172 & 50 & $27 \mathrm{~A}$ & 179 & 46 & 37 \\
\hline 165 & 53 & $26 \mathrm{~B}$ & 172 & 28 & 26 & 179 & 28 & $28 \mathrm{~B}$ \\
\hline 165 & 45 & 39 & 172 & 28 & 26 & 179 & 20 & 36 \\
\hline 165 & 52 & $26 \mathrm{~B}$ & 172 & 28 & 26 & 180 & 44 & $28 \mathrm{~B}$ \\
\hline 165 & 28 & 26 & 172 & 20 & 34 & 180 & 50 & $30 \mathrm{~B}$ \\
\hline 165 & 20 & 32 & 172 & 35 & $31 \mathrm{~B}$ & 180 & 27 & 32 \\
\hline 165 & 33 & 33 & 173 & 25 & 36 & 180 & 50 & 29 \\
\hline 165 & 28 & 26 & 173 & 25 & 36 & 180 & $34 / 49$ & $32 \mathrm{~B}$ \\
\hline 165 & 26 & 33 & 173 & 35 & $30 \mathrm{~A}$ & 180 & 34 & \\
\hline 166 & 20 & 32 & 173 & 50 & $27 \mathrm{~A}$ & 180 & 32 & 38 \\
\hline 166 & 52 & 27 & 173 & 25 & 36 & 180 & 46 & 37 \\
\hline 166 & 28 & 26 & 173 & 25 & 36 & 180 & 34 & $32 \mathrm{~B}$ \\
\hline 166 & 37 & $24 \mathrm{~A}$ & 173 & 50 & $28 \mathrm{~A}$ & 180 & 27 & 31 \\
\hline 166 & 30 & 39 & 173 & 32 & $37 \mathrm{~B}$ & 181 & 35 & 33 \\
\hline 166 & 33 & 33 & 173 & 32 & $37 \mathrm{~A}$ & 181 & 41 & 38 \\
\hline 166 & 34 & 30 & 173 & 26 & 34 & 181 & 41 & 38 \\
\hline 166 & 26 & 33 & 174 & 30 & 40 & 181 & 20 & 36 \\
\hline 166 & 100 & 11 & 174 & 52 & $28 \mathrm{~A}$ & 181 & 26 & 37 \\
\hline 166 & 53 & $26 \mathrm{~A}$ & 174 & 52 & $28 \mathrm{~B}$ & 181 & 32 & 39 \\
\hline 167 & 50 & $25 \mathrm{~A}$ & 174 & 35 & $31 \mathrm{~A}$ & 181 & 32 & 39 \\
\hline 167 & 50 & $25 B$ & 174 & 52 & $25 \mathrm{~B}$ & 181 & 50 & $30 \mathrm{~A}$ \\
\hline 167 & 28 & 26 & 174 & 50 & $27 \mathrm{~A}$ & 181 & 12 & 37 \\
\hline 167 & 34 & $31 \mathrm{C}$ & 174 & 32 & $37 \mathrm{~A}$ & 181 & 33 & 34 \\
\hline 167 & 34 & $31 \mathrm{~B}$ & 174 & 32 & $37 \mathrm{~A}$ & 182 & 20 & 37 \\
\hline 167 & 34 & $31 \mathrm{~A}$ & 174 & 30 & 41 & 182 & 26 & 37 \\
\hline 167 & 50 & $26 \mathrm{~B}$ & 174 & 30 & 41 & 182 & 37 & 29 \\
\hline 167 & 20 & 33 & 175 & 35 & $31 \mathrm{~A}$ & 182 & 37 & 29 \\
\hline 167 & 52 & $26 \mathrm{~A}$ & 175 & 28 & $27 \mathrm{~A}$ & 182 & 44 & $28 \mathrm{~A}$ \\
\hline 167 & 50 & 26B & 175 & 44 & 27 & 182 & 50 & $30 \mathrm{~B}$ \\
\hline 168 & 34 & $31 \mathrm{C}$ & 175 & 20 & 34 & 182 & 52 & $26 \mathrm{~A}$ \\
\hline 168 & 34 & $31 \mathrm{~A}$ & 175 & 20 & 34 & 182 & 50 & $30 \mathrm{~A}$ \\
\hline 168 & 34 & $31 \mathrm{~A}$ & 175 & 52 & $25 \mathrm{~A}$ & 182 & 52 & $26 \mathrm{C}$ \\
\hline 168 & 53 & 27 & 175 & 34 & $31 \mathrm{C}$ & 182 & 52 & $26 \mathrm{~B}$ \\
\hline 168 & 52 & 27 & 175 & 37 & 27 & 183 & 52 & $26 \mathrm{C}$ \\
\hline 168 & 35 & 29 & 175 & 12 & 36 & 183 & 52 & 26B \\
\hline 168 & 50 & $26 \mathrm{C}$ & 175 & 12 & 36 & 183 & 37 & 30 \\
\hline 168 & 50 & $26 \mathrm{C}$ & 176 & 30 & 41 & 183 & 54 & 46 \\
\hline 168 & 50 & $26 \mathrm{C}$ & 176 & 12 & 36 & 183 & 54 & 47 \\
\hline 168 & 32 & 36 & 176 & 28 & $27 \mathrm{~A}$ & 183 & 27 & 32 \\
\hline
\end{tabular}




\begin{tabular}{|c|c|c|c|c|c|c|c|c|}
\hline Lot & Square & Level/Sublevel & Lot & Square & Level/Sublevel & Lot & Square & Level/Sublevel \\
\hline 183 & 25 & 38 & 190 & 57 & 35 & 198 & 35 & 36 \\
\hline 183 & 30 & 42 & 191 & 39 & 27 & 198 & 58 & 42 \\
\hline 183 & Surface & & 191 & 39 & 27 & 198 & 52 & 30 \\
\hline 183 & 28 & $29 \mathrm{C}$ & 191 & 39 & 27 & 198 & 58 & 42 \\
\hline 184 & 50 & $31 \mathrm{~B}$ & 191 & 39 & 27 & 198 & 28 & 26 \\
\hline 184 & 49 & 33 & 191 & 57 & 36 & 198 & 20 & 40 \\
\hline 184 & 53 & $29 \mathrm{~B}$ & 191 & 55 & 41 & 198 & 28 & 26 \\
\hline 184 & 26 & 39 & 191 & 58 & 40 & 198 & 56 & 40 \\
\hline 184 & 32 & 39 & 191 & 57 & 36 & 199 & 56 & 40 \\
\hline 184 & 46 & 38 & 191 & 56 & 37 & 199 & 57 & 38 \\
\hline 184 & 46 & 38 & 191 & 25 & 39 & 199 & 26 & 40 \\
\hline 184 & 46 & 38 & 192 & 56 & 38 & 199 & 58 & 43 \\
\hline 184 & 34 & 33 & 192 & 55 & 41 & 199 & 27 & 34 \\
\hline 184 & 53 & $29 \mathrm{~A}$ & 192 & 35 & 34 & 199 & 35 & 37 \\
\hline 185 & 34 & 33 & 192 & 37 & 33 & 199 & 20 & 41 \\
\hline 185 & 46 & 38 & 192 & 35 & 34 & 199 & 39 & 30 \\
\hline 185 & 50 & $31 \mathrm{~B}$ & 192 & 46 & 39 & 199 & 56 & 40 \\
\hline 185 & 50 & $31 \mathrm{~A}$ & 192 & 56 & 38 & 199 & 56 & 40 \\
\hline 185 & 49 & 33 & 192 & 58 & 40 & 200 & 56 & 40 \\
\hline 185 & 44 & $29 \mathrm{~A}$ & 192 & 55 & $42 \mathrm{~B}$ & 200 & 35 & 37 \\
\hline 185 & 32 & 40 & 192 & 52 & 29 & 200 & 28 & 26 \\
\hline 185 & 46 & 38 & 193 & 51 & 24 & 200 & 51 & $27 \mathrm{~B}$ \\
\hline 185 & 46 & 38 & 193 & 56 & 38 & 200 & 38 & 27 \\
\hline 185 & 39 & 26 & 193 & 56 & 38 & 200 & 38 & 27 \\
\hline 186 & 37 & 31 & 193 & 35 & 34 & 200 & 51 & $27 \mathrm{~A}$ \\
\hline 186 & 39 & 26 & 193 & 12 & $39 \mathrm{~B}$ & 200 & 51 & $27 \mathrm{~B}$ \\
\hline 186 & 52 & 27 & 193 & 12 & $39 \mathrm{~A}$ & 200 & 28 & 26 \\
\hline 186 & 52 & 27 & 193 & 20 & 39 & 200 & 28 & 26 \\
\hline 186 & 41 & 39 & 193 & 26 & 39 & 201 & 20 & 41 \\
\hline 186 & 41 & 39 & 193 & 55 & 42 & 201 & 20 & 41 \\
\hline 186 & 52 & $29 \mathrm{~B}$ & 193 & 56 & 39 & 201 & 38 & 27 \\
\hline 186 & 52 & $29 \mathrm{~B}$ & 194 & 57 & 37 & 201 & 57 & 38 \\
\hline 186 & 12 & 38 & 194 & 56 & 38 & 201 & 12 & 6 \\
\hline 186 & 30 & 43 & 194 & 35 & 35 & 201 & 27 & 35 \\
\hline 187 & 52 & $27 \mathrm{~B}$ & 194 & 57 & 37 & 201 & 26 & 41 \\
\hline 187 & 57 & 34 & 194 & 57 & 37 & 201 & 52 & 31 \\
\hline 187 & $52 *$ & 29 & 194 & 20 & 39 & 201 & 39 & 31 \\
\hline 187 & 52 & $29 \mathrm{~A}$ & 194 & 20 & 39 & 201 & 26 & 41 \\
\hline 187 & 50 & 32 & 194 & 56 & 39 & 202 & 35 & 38 \\
\hline 187 & 52 & $29 B$ & 194 & 56 & 39 & 202 & 56 & 41 \\
\hline 187 & 33 & 35 & 194 & 39 & 28 & 202 & 57 & 38 \\
\hline 187 & 50 & $32 \mathrm{~B}$ & 195 & 51 & $25 \mathrm{~B}$ & 202 & 39 & 32 \\
\hline 187 & 52 & $27 \mathrm{~A}$ & 195 & 38 & $24 \mathrm{~B}-$ & 202 & 28 & 26 \\
\hline 187 & 26 & 38 & 195 & 38 & $25 \mathrm{~A}$ & 202 & 56 & 41 \\
\hline 188 & 39 & 26 & 195 & 39 & $28-2$ & 202 & 51 & $28 \mathrm{~A}$ \\
\hline 188 & 52 & $29 \mathrm{~B}$ & 195 & 57 & 37 & 202 & 20 & 42 \\
\hline 188 & 57 & 34 & 195 & 51 & 25 & 202 & 58 & 44 \\
\hline 188 & 33 & 35 & 195 & 35 & 35 & 202 & 57 & 39 \\
\hline 188 & 33 & 35 & 195 & 28 & 24 & 203 & 57 & 38 \\
\hline 188 & 37 & 32 & 195 & 52 & 30 & 203 & 39 & 31 \\
\hline 188 & 26 & 38 & 195 & 58 & 41 & 203 & 38 & 28 \\
\hline 188 & 26 & 38 & 196 & 26 & 40 & 203 & 57 & 39 \\
\hline 188 & 20 & 38 & 196 & 38 & $24 \mathrm{~A}$ & 203 & 51 & $28 \mathrm{~B}$ \\
\hline 188 & 33 & 35 & 196 & 56 & 39 & 203 & 39 & 32 \\
\hline 189 & 28 & $29 \mathrm{~A}$ & 196 & 20 & 40 & 203 & 26 & 42 \\
\hline 189 & 25 & 39 & 196 & 38 & $25 \mathrm{~A}$ & 203 & 12 & 41 \\
\hline 189 & 54 & 44 & 196 & 38 & $26 \mathrm{~B}$ & 203 & 51 & $27 \mathrm{~B}$ \\
\hline 189 & 52 & 28 & 196 & 28 & 25 & 203 & 52 & 32 \\
\hline 189 & 28 & $29 \mathrm{~B}$ & 196 & 28 & 25 & 204 & 54 & 49 \\
\hline 189 & 54 & 45 & 196 & 28 & 25 & 204 & 39 & 32 \\
\hline 189 & 50 & $32 \mathrm{~A}$ & 196 & 12 & 40 & 204 & 39 & 32 \\
\hline 189 & 37 & 32 & 197 & 54 & 48 & 204 & 51 & $29 \mathrm{~B}$ \\
\hline 189 & $44 *$ & $29 \mathrm{~B}$ & 197 & 51 & 26 & 204 & 39 & 32 \\
\hline 189 & 28 & $30 \mathrm{~A}$ & 197 & 38 & $26 \mathrm{~A}$ & 204 & 35 & 39 \\
\hline 190 & 20 & $30 \mathrm{~B}$ & 197 & 38 & $26 \mathrm{~A}$ & 204 & 56 & 42 \\
\hline 190 & 39 & 27 & 197 & 39 & $29-3$ & 204 & 55 & $43 \mathrm{~B}$ \\
\hline 190 & 27 & 33 & 197 & 28 & 25 & 204 & 57 & 39 \\
\hline 190 & 56 & 36 & 197 & 35 & 36 & 204 & 28 & 31 \\
\hline 190 & 57 & 35 & 197 & 35 & 36 & 205 & 28 & 31 \\
\hline 190 & 56 & 36 & 197 & 28 & 25 & 205 & 38 & 29 \\
\hline 190 & 56 & 36 & 197 & 56 & 40 & 205 & 26 & 43 \\
\hline 190 & 52 & 28 & 198 & 39 & 29 & 205 & 28 & 31 \\
\hline 190 & 27 & 33 & 198 & 39 & 29 & 205 & 57 & 39 \\
\hline
\end{tabular}




\begin{tabular}{|c|c|c|c|c|c|c|c|c|}
\hline Lot & Square & Level/Sublevel & Lot & Square & Level/Sublevel & Lot & Square & Level/Sublevel \\
\hline 205 & 51 & $30 \mathrm{~B}$ & 212 & 27 & 38 & 220 & 28 & 40 \\
\hline 205 & 35 & 39 & 212 & Unknow & Unkn & 220 & 28 & 40 \\
\hline 205 & 35 & 40 & 213 & 28 & 32 & 220 & 38 & 24 \\
\hline 205 & 57 & 39 & 213 & 20 & 45 & 220 & 27 & 45 \\
\hline 205 & 55 & $43 \mathrm{~B}$ & 213 & 59 & 37 & 220 & 27 & 45 \\
\hline 206 & 51 & $29 B$ & 213 & 35 & 43 & 220 & 27 & 46 \\
\hline 206 & 38 & 29 & 213 & 35 & 43 & 220 & 52 & 39 \\
\hline 206 & 51 & $29 \mathrm{~A}$ & 213 & 52 & 36 & 220 & 52 & 39 \\
\hline 206 & 51 & $30 \mathrm{~A}$ & 213 & 59 & 38 & 220 & 52 & 39 \\
\hline 206 & 51 & $30 \mathrm{~B}$ & 213 & 12 & 44 & 221 & 51 & 24 \\
\hline 206 & 38 & 30 & 213 & 52 & $36 \mathrm{~B}$ & 221 & 52 & 39 \\
\hline 206 & 58 & 45 & 213 & 58 & 48 & 221 & 28 & 42 \\
\hline 206 & 12 & 42 & 214 & 58 & 48 & 221 & 38 & $25 \mathrm{~A}$ \\
\hline 206 & 57 & 39 & 214 & 57 & 46 & 221 & 53 & $38 \mathrm{~B}$ \\
\hline 206 & 51 & $31 \mathrm{~A}$ & 214 & 57 & 46 & 221 & 53 & $38 \mathrm{~B}$ \\
\hline 207 & 51 & $31 \mathrm{~B}$ & 214 & 26 & 46 & 221 & 28 & $42 \mathrm{~B}$ \\
\hline 207 & 28 & $31 \mathrm{~B}$ & 214 & 28 & 32 & 221 & 53 & $38 \mathrm{~B}$ \\
\hline 207 & 51 & $31 \mathrm{~B}$ & 214 & 56 & 45 & 221 & 38 & $25 \mathrm{~B}$ \\
\hline 207 & 28 & $31 \mathrm{~A}$ & 214 & 56 & 45 & 221 & 53 & $39 \mathrm{~B}$ \\
\hline 207 & 35 & 40 & 214 & 101 & 21 & 222 & 53 & $39 \mathrm{~B}$ \\
\hline 207 & 26 & 43 & 214 & 56 & 45 & 222 & 53 & $39 \mathrm{~B}$ \\
\hline 207 & 101 & 12 & 214 & 46 & 43 & 222 & 53 & 39 \\
\hline 207 & 28 & $27 \mathrm{~B}$ & 215 & 59 & 39 & 222 & 53 & $39 \mathrm{~B}$ \\
\hline 207 & 51 & $31 \mathrm{~A}$ & 215 & 58 & 49 & 222 & 52 & 40 \\
\hline 207 & 51 & $31 \mathrm{~B}$ & 215 & 28 & 33 & 222 & 59 & 46 \\
\hline 208 & 52 & 33 & 215 & 43 & & 222 & 59 & 46 \\
\hline 208 & 57 & 40 & 215 & 28 & 33 & 222 & 20 & 52 \\
\hline 208 & 56 & 43 & 215 & 57 & 48 & 222 & 28 & 44 \\
\hline 208 & 101 & 12 & 215 & 56 & 46 & 222 & 35 & 47 \\
\hline 208 & 59 & 34 & 215 & 52 & 37 & 223 & 59 & 49 \\
\hline 208 & 12 & 43 & 215 & 56 & 46 & 223 & 35 & 48 \\
\hline 208 & 28 & 28 & 215 & 58 & 49 & 223 & 28 & 47 \\
\hline 208 & 35 & 41 & 216 & 58 & 49 & 223 & 28 & 47 \\
\hline 208 & 39 & 33 & 216 & 28 & 34 & 223 & 35 & 47 \\
\hline 208 & 58 & 46 & 216 & 20 & 45 & 223 & 35 & 49 \\
\hline 209 & 57 & 40 & 216 & 28 & 49 & 223 & 20 & 53 \\
\hline 209 & 28 & $27 \mathrm{~B}$ & 216 & 12 & 45 & 223 & 28 & 48 \\
\hline 209 & 56 & 43 & 216 & 12 & 6 & 223 & 28 & 48 \\
\hline 209 & 56 & 43 & 216 & 12 & $39 \mathrm{~A}$ & 223 & 28 & 48 \\
\hline 209 & 39 & 33 & 216 & 21 & 7 & 224 & 20 & 53 \\
\hline 209 & 28 & 28 & 216 & 12 & 37 & 224 & 20 & 53 \\
\hline 209 & 101 & 15 & 216 & 12 & 37 & 224 & 28 & 50 \\
\hline 209 & 56 & 43 & 217 & 22 & 11 & 224 & 51 & 26 \\
\hline 209 & 59 & 35 & 217 & 18 & 11 & 224 & 39 & 42 \\
\hline 209 & 20 & 43 & 217 & 12 & $11 \mathrm{~A}$ & 224 & 28 & 51 \\
\hline 210 & 57 & 41 & 217 & 39 & $21 \mathrm{~A}$ & 224 & 28 & 51 \\
\hline 210 & 56 & 43 & 217 & 46 & $28 \mathrm{~A}$ & 224 & 27 & 50 \\
\hline 210 & 28 & 29 & 217 & 49 & 25 & 224 & 27 & 50 \\
\hline 210 & 59 & 35 & 217 & 15 & 10 & 224 & 28 & 52 \\
\hline 210 & 52 & 34 & 217 & 15 & 11 & 225 & 38 & $26 \mathrm{C}$ \\
\hline 210 & 39 & 34 & 217 & 15 & 11 & 225 & 38 & $26 \mathrm{C}$ \\
\hline 210 & 27 & 37 & 217 & 13 & $10 \mathrm{~B}$ & 225 & 28 & 52 \\
\hline 210 & 28 & $30 \mathrm{~A}$ & 218 & 13 & $11 \mathrm{~A}$ & 225 & 20 & 48 \\
\hline 210 & 59 & 36 & 218 & 11 & 11 & 225 & 46 & 47 \\
\hline 210 & 46 & 40 & 218 & 14 & 12 & 225 & 38 & 24 \\
\hline 211 & 56 & 44 & 218 & 22 & $8-10$ & 225 & 12 & 46 \\
\hline 211 & 46 & 41 & 218 & 38 & 15 & 225 & 20 & 46 \\
\hline 211 & 39 & 34 & 218 & 22 & $12 \mathrm{~A}$ & 225 & 39 & 36B- \\
\hline 211 & 101 & 14 & 218 & 22 & $12 \mathrm{~A}$ & 225 & 38 & 24 \\
\hline 211 & 20 & 44 & 218 & 20 & 36 & 226 & 38 & 24 \\
\hline 211 & 58 & 47 & 218 & 28 & 34 & 226 & W of 27 & 43 \\
\hline 211 & 58 & 47 & 218 & 39 & 38 & 226 & 38 & 24 \\
\hline 211 & 46 & $42 \mathrm{~B}$ & 219 & 28 & 33 & 226 & W of 27 & 44 \\
\hline 211 & 35 & 42 & 219 & 28 & 35 & 226 & 39 & $38 \mathrm{~A}$ \\
\hline 211 & 28 & $31 \mathrm{~A}$ & 219 & 39 & 37 & 226 & 27 & 45 \\
\hline 212 & 28 & $30 \mathrm{~B}$ & 219 & 28 & 37 & 226 & 26 & 47 \\
\hline 212 & 28 & $30 \mathrm{~A}$ & 219 & 28 & 37 & 226 & 28 & 36 \\
\hline 212 & 39 & 35 & 219 & 27 & 43 & 226 & 28 & 35 \\
\hline 212 & 28 & $31 \mathrm{~B}$ & 219 & 59 & $42 \mathrm{~B}$ & 226 & 59 & 41 \\
\hline 212 & 28 & $31 \mathrm{~A}$ & 219 & 59 & $42 \mathrm{~B}$ & 227 & 56 & 47 \\
\hline 212 & 54 & 53 & 219 & 59 & $42 \mathrm{~B}$ & 227 & 56 & 49 \\
\hline 212 & 20 & 45 & 219 & 28 & 39 & 227 & 59 & $42 \mathrm{~A}$ \\
\hline 212 & 35 & 42 & 220 & 28 & 39 & 227 & 26 & 48 \\
\hline
\end{tabular}




\begin{tabular}{|c|c|c|c|c|c|c|c|c|}
\hline Lot & Square & Level/Sublevel & Lot & Square & Level/Sublevel & Lot & Square & Level/Sublevel \\
\hline 227 & 28 & 33 & 234 & 53 & 47 & 242 & 12 & 65 \\
\hline 227 & 39 & 36 & 234 & 52 & $46-4$ & 242 & 28 & 48 \\
\hline 227 & 39 & $36 \mathrm{~A}$ & 234 & 53 & 47 & 242 & 52 & $42 \mathrm{~B}$ \\
\hline 227 & 39 & $36 \mathrm{~B}$ & 235 & 0 & & 242 & 20 & 53 \\
\hline 227 & 59 & 40 & 235 & 53 & $39 \mathrm{~B}$ & 242 & 20 & 53 \\
\hline 227 & 56 & 47 & 235 & 53 & $39 \mathrm{~B}$ & 242 & 35 & 50 \\
\hline 228 & 56 & 48 & 235 & 59 & 47 & 242 & 35 & 49 \\
\hline 228 & 42 & 48 & 235 & 20 & 52 & 242 & 35 & 50 \\
\hline 228 & 55 & 47 & 235 & 20 & 52 & 242 & 52 & 43 \\
\hline 228 & 28 & 37 & 235 & 20 & 51 & 242 & 28 & 49 \\
\hline 228 & 27 & 39 & 235 & 20 & 52 & 243 & 20 & 27 \\
\hline 228 & 20 & 49 & 235 & 38 & $25 \mathrm{C}$ & 243 & 39 & 42 \\
\hline 228 & 38 & 24 & 235 & 20 & 52 & 243 & 38 & $25 \mathrm{C}$ \\
\hline 228 & 51 & 24 & 236 & 51 & 25 & 243 & 38 & $26 \mathrm{~B}$ \\
\hline 228 & 39 & $38 \mathrm{~B}$ & 236 & 35 & 47 & 243 & 52 & $42 \mathrm{~B}$ \\
\hline 228 & 59 & $42 B$ & 236 & 55 & 50 & 243 & 27 & 50 \\
\hline 229 & 57 & 49 & 236 & 12 & 52 & 243 & 27 & 50 \\
\hline 229 & 101 & 22 & 236 & 28 & 44 & 243 & 27 & 50 \\
\hline 229 & 51 & 24 & 236 & 28 & 45 & 243 & 27 & 50 \\
\hline 229 & 44 & 41 & 236 & 28 & 45 & 243 & 20 & $54 \mathrm{~B}$ \\
\hline 229 & 28 & 41 & 236 & 59 & 49 & 244 & 38 & $26 \mathrm{C}$ \\
\hline 229 & 56 & 49 & 236 & 28 & 45 & 244 & 54 & 53 \\
\hline 229 & 20 & 49 & 236 & 52 & 41 & 244 & 50 & 20 \\
\hline 229 & 44 & 40 & 237 & 35 & 48 & 244 & 38 & $26 \mathrm{~B}$ \\
\hline 229 & 52 & 38 & 237 & 20 & 52 & 244 & 35 & 53 \\
\hline 229 & 27 & 48 & 237 & 59 & 50 & 244 & 27 & $51 \mathrm{~B}$ \\
\hline 230 & 20 & 47 & 237 & 27 & $51 \mathrm{~B}$ & 244 & Unknow & Unkn \\
\hline 230 & 12 & 47 & 237 & 59 & 43 & 244 & 26 & 51 \\
\hline 230 & 28 & 42 & 237 & 38 & $25 \mathrm{~A}$ & 244 & 35 & 54 \\
\hline 230 & 27 & 49 & 237 & 35 & 46 & 244 & 51 & $27 \mathrm{C}$ \\
\hline 230 & 20 & 52 & 237 & 12 & 53 & 245 & 20 & $55 \mathrm{~A}$ \\
\hline 230 & 27 & 49 & 237 & 28 & 46 & 245 & 27 & $51 \mathrm{~B}$ \\
\hline 230 & 46 & 48 & 237 & 38 & $25 \mathrm{C}$ & 245 & 20 & $55 \mathrm{~A}$ \\
\hline 230 & 12 & 48 & 238 & 35 & 48 & 245 & 27 & $51 \mathrm{~B}$ \\
\hline 230 & 28 & $42 B$ & 238 & 35 & 48 & 245 & 27 & $51 \mathrm{~B}$ \\
\hline 230 & 28 & $42 \mathrm{~A}$ & 238 & 52 & 42 & 245 & 51 & $27 \mathrm{~B}$ \\
\hline 231 & 28 & $42 B$ & 238 & 59 & 51 & 245 & 51 & $27 \mathrm{C}$ \\
\hline 231 & 20 & 53 & 238 & 59 & 51 & 245 & 27 & $51 \mathrm{~B}$ \\
\hline 231 & 12 & 49 & 238 & 59 & 51 & 245 & 52 & 44 \\
\hline 231 & 59 & 44 & 238 & 20 & 53 & 245 & 39 & 41 \\
\hline 231 & 43 & 47 & 238 & 59 & 51 & 246 & 28 & 44 \\
\hline 231 & 38 & 24 & 238 & 59 & 51 & 246 & 27 & $51 \mathrm{~B}$ \\
\hline 231 & 59 & 45 & 238 & 59 & 51 & 246 & 20 & $56 \mathrm{~A}$ \\
\hline 231 & 59 & 45 & 239 & Test & & 246 & 27 & $52 \mathrm{~B}$ \\
\hline 231 & 20 & 50 & 239 & 35 & 48 & 246 & 38 & 30 \\
\hline 231 & 20 & 50 & 239 & Test & & 246 & 38 & $25 \mathrm{~A}$ \\
\hline 232 & 44 & 41 & 239 & 20 & 53 & 246 & 38 & $27 \mathrm{~B}$ \\
\hline 232 & 28 & 25 & 239 & 20 & 53 & 246 & 52 & 45 \\
\hline 232 & 51 & 26 & 239 & 20 & 53 & 246 & 52 & 46 \\
\hline 232 & Test & & 239 & 12 & 54 & 246 & 27 & $52 \mathrm{~B}$ \\
\hline 232 & Test & & 239 & 52 & 42 & 247 & 52 & 46 \\
\hline 232 & Test & & 239 & 52 & 42 & 247 & 20 & $55 \mathrm{~B}$ \\
\hline 232 & 12 & 33 & 239 & 20 & 53 & 247 & 52 & 46 \\
\hline 232 & 12 & 32 & 240 & 20 & 53 & 247 & 52 & 46 \\
\hline 232 & 12 & 30 & 240 & 20 & 53 & 247 & 28 & 47 \\
\hline 232 & 12 & 28 & 240 & 16 & $6 \mathrm{~B}$ & 247 & 20 & 53 \\
\hline 233 & 57 & 38 & 240 & 16 & $6 \mathrm{~B}$ & 247 & 52 & 46 \\
\hline 233 & 57 & 38 & 240 & 20 & $54 \mathrm{~A}$ & 247 & 28 & 52 \\
\hline 233 & 57 & 38 & 240 & 12 & 55 & 247 & 28 & 52 \\
\hline 233 & 57 & 38 & 240 & 52 & $42 \mathrm{~B}$ & 247 & 28 & 52 \\
\hline 233 & 57 & 38 & 240 & 12 & 56 & 248 & 26 & 51 \\
\hline 233 & 57 & 38 & 240 & 12 & 57 & 248 & 26 & 51 \\
\hline 233 & 57 & 38 & 240 & 12 & 58 & 248 & 26 & 51 \\
\hline 233 & 57 & 38 & 241 & 12 & 59 & 248 & 26 & 51 \\
\hline 233 & 28 & 41 & 241 & 20 & $55 \mathrm{~B}$ & 248 & 26 & 51 \\
\hline 233 & 38 & $25 \mathrm{~B}$ & 241 & 12 & 60 & 248 & 26 & 51 \\
\hline 234 & 52 & 46 & 241 & 12 & 61 & 248 & 26 & 51 \\
\hline 234 & 38 & $25 \mathrm{~B}$ & 241 & 12 & 62 & 248 & 52 & 47 \\
\hline 234 & 12 & 50 & 241 & 20 & $56 \mathrm{~B}$ & 248 & 27 & 53 \\
\hline 234 & 20 & 50 & 241 & 12 & 63 & 248 & 51 & $28 \mathrm{~B}$ \\
\hline 234 & 20 & 51 & 241 & 20 & 57 & 249 & 51 & $28 \mathrm{D}$ \\
\hline 234 & 44 & 47 & 241 & 12 & 64 & 249 & 51 & $28 \mathrm{C}$ \\
\hline 234 & 12 & 48 & 241 & 20 & 58 & 249 & 59 & 52 \\
\hline
\end{tabular}




\begin{tabular}{|c|c|c|c|c|c|c|c|c|}
\hline Lot & Square & Level/Sublevel & Lot & Square & Level/Sublevel & Lot & Square & Level/Sublevel \\
\hline 249 & 59 & 52 & 256 & 52 & 50 & 263 & 55 & 50 \\
\hline 249 & 59 & 52 & 256 & 39 & 47 & 264 & 59 & 44 \\
\hline 249 & 59 & 52 & 256 & 59 & 53 & 264 & 56 & 50 \\
\hline 249 & 39 & 45 & 256 & 26 & 53 & 264 & 27 & 36 \\
\hline 249 & 51 & $28 \mathrm{C}$ & 257 & 26 & 53 & 264 & 0 & \\
\hline 249 & 51 & $28 \mathrm{C}$ & 257 & 26 & 53 & 264 & 26 & 55 \\
\hline 249 & 51 & $28 \mathrm{D}$ & 257 & 26 & 53 & 264 & 27 & 57 \\
\hline 250 & 52 & 48 & 257 & 27 & $55 \mathrm{~A}$ & 264 & 57 & 42 \\
\hline 250 & 12 & 69 & 257 & 26 & 53 & 264 & 27 & $56 \mathrm{C}$ \\
\hline 250 & 28 & 53 & 257 & 52 & 51 & 264 & 59 & 55 \\
\hline 250 & 59 & 52 & 257 & 52 & 52 & 264 & 20 & 68 \\
\hline 250 & 51 & $28 \mathrm{~A}$ & 257 & 52 & 52 & 265 & 52 & 54 \\
\hline 250 & 52 & 47 & 257 & 52 & 52 & 265 & 101 & 15 \\
\hline 250 & 27 & 53 & 257 & 52 & 52 & 265 & 27 & 41 \\
\hline 250 & 20 & 59 & 258 & 52 & 52 & 265 & 28 & 38 \\
\hline 250 & 59 & 52 & 258 & 51 & $28 \mathrm{E}$ & 265 & 59 & 55 \\
\hline 250 & 26 & 52 & 258 & 39 & 48 & 265 & 56 & 47 \\
\hline 251 & 26 & 52 & 258 & 35 & 53 & 265 & 56 & 46 \\
\hline 251 & 26 & 52 & 258 & 57 & 53 & 265 & 27 & 58 \\
\hline 251 & 26 & 52 & 258 & 28 & 50 & 265 & 27 & 37 \\
\hline 251 & 27 & $54 \mathrm{~B}$ & 258 & 52 & 52 & 265 & 35 & 44 \\
\hline 251 & 26 & 53 & 258 & 28 & $54 \mathrm{~A}$ & 266 & 26 & 46 \\
\hline 251 & 26 & 53 & 258 & 28 & 52 & 266 & 27 & 59 \\
\hline 251 & 26 & 52 & 258 & 26 & 50 & 266 & 26 & 47 \\
\hline 251 & 52 & 49 & 259 & 39 & 44 & 266 & 27 & 40 \\
\hline 251 & 52 & 49 & 259 & 28 & 51 & 266 & 26 & 58 \\
\hline 251 & 20 & 60 & 259 & 27 & 50 & 266 & 28 & 58 \\
\hline 252 & 38 & $28 \mathrm{~A}$ & 259 & 28 & 48 & 266 & 53 & 52 \\
\hline 252 & 12 & 66 & 259 & 52 & 43 & 266 & 53 & 52 \\
\hline 252 & $38 *$ & $28 \mathrm{~B}$ & 259 & 35 & 50 & 266 & 43 & 51 \\
\hline 252 & 39 & 46 & 259 & 46 & 53 & 266 & 53 & 51 \\
\hline 252 & 52 & 49 & 259 & 28 & 50 & 267 & 53 & 52 \\
\hline 252 & 59 & 53 & 259 & 28 & $54 \mathrm{~B}$ & 267 & 42 & 51 \\
\hline 252 & 27 & $54 \mathrm{~B}$ & 259 & 52 & 53 & 267 & 42 & 51 \\
\hline 252 & 20 & 61 & 260 & 52 & 53 & 267 & 26 & 56 \\
\hline 252 & 12 & 67 & 260 & 46 & 46 & 267 & 26 & 60 \\
\hline 252 & 59 & 53 & 260 & 26 & 49 & 267 & 44 & 51 \\
\hline 253 & 52 & 50 & 260 & 27 & 45 & 267 & 42 & 51 \\
\hline 253 & 52 & 50 & 260 & 58 & 49 & 267 & 27 & 60 \\
\hline 253 & 27 & $54 \mathrm{~A}$ & 260 & 27 & 39 & 267 & 44 & 51 \\
\hline 253 & $38 *$ & $28 \mathrm{~A}$ & 260 & 59 & 38 & 267 & 44 & 51 \\
\hline 253 & 27 & $53 \mathrm{~B}$ & 260 & 57 & 46 & 268 & 28 & 59 \\
\hline 253 & 27 & $51 \mathrm{~B}$ & 260 & 46 & $42 \mathrm{~A}$ & 268 & 43 & 52 \\
\hline 253 & 53 & 41 & 260 & 101 & 20 & 268 & 43 & 52 \\
\hline 253 & 52 & 29 & 261 & 55 & 46 & 268 & 35 & 46 \\
\hline 253 & 27 & $51 \mathrm{~B}$ & 261 & 59 & 37 & 268 & 27 & 39 \\
\hline 253 & 27 & $52 \mathrm{~B}$ & 261 & 56 & 48 & 268 & 44 & 52 \\
\hline 254 & 38 & $27 \mathrm{~A}$ & 261 & 52 & 36 & 268 & 57 & 44 \\
\hline 254 & 57 & $37-3$ & 261 & 55 & 54 & 268 & 28 & 60 \\
\hline 254 & 12 & 51 & 261 & 39 & 43 & 268 & 101 & 18 \\
\hline 254 & 51 & $22-2$ & 261 & 54 & 54 & 268 & Test & \\
\hline 254 & 100 & $6-11$ & 261 & 56 & 54 & 269 & 43 & 52 \\
\hline 254 & 20 & 62 & 261 & 52 & 46 & 269 & 39 & 55 \\
\hline 254 & 12 & 68 & 261 & 46 & 54 & 269 & 35 & 41 \\
\hline 254 & 20 & 63 & 262 & 57 & 54 & 269 & 59 & 39 \\
\hline 254 & 20 & 64 & 262 & 27 & 52 & 269 & 42 & $53 \mathrm{~A}$ \\
\hline 254 & 20 & 65 & 262 & 27 & $52 \mathrm{~A}$ & 269 & 60 & 56 \\
\hline 255 & 20 & 66 & 262 & 56 & 53 & 269 & 43 & $53 \mathrm{~A}$ \\
\hline 255 & 20 & 67 & 262 & 27 & 51 & 269 & 60 & 56 \\
\hline 255 & 20 & 68 & 262 & 27 & $51 \mathrm{~A}$ & 269 & 52 & 58 \\
\hline 255 & 20 & 69 & 262 & 28 & 46 & 269 & 43 & $54 \mathrm{~A}$ \\
\hline 255 & 20 & 70 & 262 & 59 & 50 & 270 & 46 & 45 \\
\hline 255 & 20 & 71 & 262 & 101 & 28 & 270 & 58 & $54 \mathrm{~A}$ \\
\hline 255 & 20 & 72 & 262 & 101 & 26 & 270 & 42 & $54 \mathrm{~A}$ \\
\hline 255 & 20 & 73 & 263 & 28 & 45 & 270 & 58 & 55 \\
\hline 255 & 39 & 46 & 263 & 59 & 49 & 270 & 43 & $54 \mathrm{~A}$ \\
\hline 255 & 52 & 44 & 263 & 59 & 48 & 270 & 42 & $53 \mathrm{~A}$ \\
\hline 256 & 56 & 52 & 263 & 27 & 49 & 270 & 44 & 53 \\
\hline 256 & 55 & 53 & 263 & 59 & 47 & 270 & 43 & $53 \mathrm{~B}$ \\
\hline 256 & 46 & 52 & 263 & 52 & 41 & 270 & 44 & $54 \mathrm{~A}$ \\
\hline 256 & 35 & 54 & 263 & 35 & 47 & 270 & 52 & 57 \\
\hline 256 & 51 & $28 \mathrm{~B}$ & 263 & 46 & 49 & 271 & 0 & \\
\hline 256 & 52 & 49 & 263 & 52 & 40 & 271 & 51 & 26 \\
\hline
\end{tabular}




\begin{tabular}{|c|c|c|c|c|c|c|c|c|}
\hline$\overline{\text { Lot }}$ & Square & Level/Sublevel & Lot & Square & Level/Sublevel & Lot & Square & Level/Sublevel \\
\hline$\overline{271}$ & 12 & & 278 & Unknow & $39-4$ & 285 & 101 & 13 \\
\hline 271 & 35 & & 278 & 35 & 43 & 285 & 53 & 53 \\
\hline 271 & 25 & & 278 & 43 & $56 \mathrm{~A}$ & 286 & 53 & 55 \\
\hline 271 & 35 & & 278 & 53 & 51 & 286 & 26 & $59 \mathrm{~B}$ \\
\hline 271 & 58 & & 278 & 28 & 39 & 286 & 58 & 53 \\
\hline 271 & $25^{*}$ & & 279 & 42 & 55 & 286 & 44 & 52 \\
\hline 271 & Test & & 279 & 44 & 56 & 286 & 53 & 54 \\
\hline 271 & Test & & 279 & 39 & $38 \mathrm{~A}$ & 286 & 52 & 56 \\
\hline 272 & Test & & 279 & 44 & $55 \mathrm{~B}$ & 286 & 52 & 24 \\
\hline 272 & 27 & 53 & 279 & 52 & 37 & 286 & 55 & 52 \\
\hline 272 & 28 & $52-5$ & 279 & 101 & 19 & 286 & 57 & 52 \\
\hline 272 & 28 & 49 & 279 & 46 & 48 & 286 & 52 & 59 \\
\hline 272 & 50 & $27 \mathrm{~B}$ & 279 & 57 & 45 & 287 & 43 & $55 \mathrm{C}$ \\
\hline 272 & 20 & 52 & 279 & 27 & 46 & 287 & 44 & $56 \mathrm{C}$ \\
\hline 272 & Unknow & & 279 & 55 & 48 & 287 & 42 & 57 \\
\hline 272 & 101 & 27 & 280 & 27 & 38 & 287 & 43 & $56 \mathrm{C}$ \\
\hline 272 & 27 & $56 \mathrm{~A}$ & 280 & 52 & 35 & 287 & 43 & $56 \mathrm{~B}$ \\
\hline 272 & 35 & 45 & 280 & 54 & 52 & 287 & 20 & 49 \\
\hline 273 & 38 & wall & 280 & 43 & $55 \mathrm{~B}$ & 287 & Unknow & \\
\hline 273 & 101 & 24 & 280 & 39 & 37 & 287 & 16 & $6 \mathrm{~B}$ \\
\hline 273 & 57 & 49 & 280 & 101 & 16 & 287 & 48 & $30 \mathrm{~B}$ \\
\hline 273 & 59 & 45 & 280 & 39 & 53 & 287 & 0 & \\
\hline 273 & 59 & 54 & 280 & 39 & 52 & 288 & Bore & \\
\hline 273 & 59 & 43 & 280 & 26 & 44 & 288 & $\mathrm{n} / \mathrm{a}$ & \\
\hline 273 & 35 & 52 & 280 & 54 & 51 & 288 & $\mathrm{n} / \mathrm{a}$ & \\
\hline 273 & 39 & 40 & 281 & 28 & 55 & 288 & $\mathrm{n} / \mathrm{a}$ & \\
\hline 273 & 28 & 42 & 281 & 59 & 36 & 288 & 20 & \\
\hline 273 & 35 & 51 & 281 & 27 & 43 & 288 & 20 & \\
\hline 274 & 59 & 46 & 281 & 26 & 56 & 288 & 20 & \\
\hline 274 & 55 & 51 & 281 & 26 & 59 & 288 & 20 & \\
\hline 274 & 26 & $53 \mathrm{~B}$ & 281 & 39 & 51 & 288 & 20 & \\
\hline 274 & 55 & 44 & 281 & 43 & 50 & 288 & 20 & \\
\hline 274 & 46 & 50 & 281 & 58 & 50 & 289 & 20 & \\
\hline 274 & 35 & 49 & 281 & 26 & $57 \mathrm{~A}$ & 289 & 20 & \\
\hline 274 & 57 & 50 & 281 & 26 & 57 & 289 & 20 & \\
\hline 274 & 35 & 48 & 282 & 28 & 57 & 289 & 20 & \\
\hline 274 & 39 & 39 & 282 & 27 & 44 & 289 & 20 & \\
\hline 274 & 52 & 42 & 282 & 58 & 56 & 289 & 20 & \\
\hline 275 & 52 & 53 & 282 & 28 & 37 & 289 & 20 & \\
\hline 275 & 55 & 45 & 282 & 26 & $57 \mathrm{~B}$ & 289 & 20 & \\
\hline 275 & 39 & 42 & 282 & 53 & 50 & 289 & 20 & \\
\hline 275 & 46 & 51 & 282 & 55 & 47 & 289 & 51 & 29 \\
\hline 275 & 53 & $39 \mathrm{~A}$ & 282 & 101 & 17 & 290 & 57 & 46 \\
\hline 275 & 57 & 51 & 282 & 46 & 44 & 300 & 52 & \\
\hline 275 & 53 & 38ID & 282 & 42 & 57 & 300 & 39 & $46-4$ \\
\hline 275 & 101 & 25 & 283 & 53 & 56 & 300 & 39 & 41-4 \\
\hline 275 & 39 & 49 & 283 & 26 & 45 & 300 & 26 & 56 \\
\hline 275 & 28 & 43 & 283 & 57 & 47 & 300 & 27 & 57 \\
\hline 276 & 56 & 51 & 283 & 58 & 46 & 300 & 25 & 35 \\
\hline 276 & 26 & $54 \mathrm{~A}$ & 283 & 39 & 56 & 300 & 25 & 34 \\
\hline 276 & 51 & $27 \mathrm{~A}$ & 283 & 58 & $54 \mathrm{~B}$ & 300 & 20 & $66-6$ \\
\hline 276 & 27 & 48 & 283 & 42 & 56 & 300 & 35 & $39-4$ \\
\hline 276 & 28 & 56 & 283 & 43 & $54 \mathrm{~B}$ & 300 & $17 \& 15$ & $10 \&$ \\
\hline 276 & 28 & 40 & 283 & 43 & 52 & & & \\
\hline 276 & 27 & 47 & 283 & 25 & $39-4$ & & & \\
\hline 276 & 52 & 38 & 284 & 42 & $54 \mathrm{~B}$ & & & \\
\hline 276 & 55 & 49 & 284 & 25 & $39-5$ & & & \\
\hline 276 & 52 & 34 & 284 & 42 & 52 & & & \\
\hline 277 & 27 & $55 \mathrm{C}$ & 284 & 44 & $55 \mathrm{~A}$ & & & \\
\hline 277 & 28 & $54 \mathrm{~B}$ & 284 & 58 & 52 & & & \\
\hline 277 & 52 & 55 & 284 & 58 & $53 \mathrm{~B}$ & & & \\
\hline 277 & 39 & 54 & 284 & 44 & $54 \mathrm{~B}$ & & & \\
\hline 277 & 42 & 50 & 284 & 42 & 51 & & & \\
\hline 277 & 59 & 51 & 284 & 52 & 60 & & & \\
\hline 277 & 28 & 47 & 284 & 42 & $53 \mathrm{~B}$ & & & \\
\hline 277 & 57 & 43 & 285 & 44 & 50 & & & \\
\hline 277 & 58 & 51 & 285 & 27 & 42 & & & \\
\hline 277 & 26 & 55 & 285 & 44 & 51 & & & \\
\hline 278 & 43 & $55 \mathrm{~A}$ & 285 & 43 & 51 & & & \\
\hline 278 & 59 & 56 & 285 & 55 & $43 \mathrm{~A}$ & & & \\
\hline 278 & 39 & 55 & 285 & 44 & 52 & & & \\
\hline 278 & 43 & $56 \mathrm{~B}$ & 285 & 39 & 50 & & & \\
\hline 278 & 38 & $26 \mathrm{~A}$ & 285 & 57 & 48 & & & \\
\hline
\end{tabular}


TABLE A4-4

Key to TARL Organic Residue Lots by Specimen Number

\begin{tabular}{|c|c|c|c|c|c|c|c|}
\hline OR No. & TARL Lot No. & OR No. & TARL Lot No. & OR No. & TARL Lot No. & OR No. & TARL Lot No. \\
\hline OR-001 & 184 & OR-069 & 619 & OR-137 & 1106 & OR-204 & 2180 \\
\hline OR-002 & 207 & OR-070 & 620 & OR-138 & 454 & OR-205 & 574 \\
\hline OR-003 & 199 & OR-071 & 516 & OR-139 & 2402 & OR-206 & 574 \\
\hline OR-004 & 205 & OR-072 & 517 & OR-140 & 456 & OR-207 & 585 \\
\hline OR-005 & 193 & OR-073 & 289 & OR-141 & 457 & OR-208 & 568 \\
\hline OR-006 & 190 & OR-074 & 290 & OR-142 & 416 & OR-209 & 580 \\
\hline OR-007 & 191 & OR-075 & 291 & OR-143 & 459 & OR-210 & 578 \\
\hline OR-008 & 198 & OR-076 & 295 & OR-144 & 1457 & OR-211 & 621 \\
\hline OR-009 & 197 & OR-077 & 296 & OR-145 & 2403 & OR-212 & 580 \\
\hline OR-010 & 178 & OR-078 & 312 & OR-146 & 464 & OR-213 & 2181 \\
\hline OR-011 & 200 & OR-079 & 314 & OR-147 & 465 & OR-214 & 2181 \\
\hline OR-012 & 201 & OR-080 & 315 & OR-148 & 468 & OR-215 & 590 \\
\hline OR-013 & 214 & OR-081 & 316 & OR-149 & 476 & OR-2' 6 & 2184 \\
\hline OR-014 & 215 & OR-082 & 317 & OR-150 & 477 & OR-217 & 548 \\
\hline OR-015 & 216 & OR-083 & 318 & OR-151 & 478 & OR-218 & 529 \\
\hline OR-016 & 219 & OR-084 & 319 & OR-152 & 447 & OR-219 & 1513 \\
\hline OR-018 & 499 & OR-085 & 320 & OR-153 & 482 & OR-220 & 1515 \\
\hline OR-019 & 500 & OR-086 & 321 & OR-154 & 483 & OR-221 & 547 \\
\hline OR-020 & 236 & OR-088 & 322 & OR-155 & 502 & OR-222 & 545 \\
\hline OR-021 & 237 & OR-089 & 325 & OR-156 & 1507 & OR-223 & 567 \\
\hline OR-022 & 239 & OR-090 & 324 & OR-157 & 1509 & OR-224 & 569 \\
\hline OR-023 & 241 & OR-091 & 306 & OR-158 & 494 & OR-225 & 2170 \\
\hline OR-024 & 242 & OR-092 & 333 & OR-159 & 519 & OR-226 & 572 \\
\hline OR-025 & 244 & OR-093 & 334 & OR-160 & 511 & OR-227 & 617 \\
\hline OR-026 & 248 & OR-094 & 335 & OR-161 & 511 & OR-228 & 587 \\
\hline OR-027 & 249 & OR-095 & 337 & OR-162 & 1508 & OR-229 & 601 \\
\hline OR-028 & 252 & OR-096 & 341 & OR-163 & 525 & OR-230 & 602 \\
\hline OR-029 & 257 & OR-097 & 352 & OR-164 & 511 & OR-231 & 598 \\
\hline OR-030 & 256 & OR-098 & 354 & OR-165 & 1511 & OR-232 & 594 \\
\hline OR-031 & 255 & OR-099 & 355 & OR-166 & 1510 & OR-233 & 2185 \\
\hline OR-032 & 505 & OR-100 & 356 & OR-167 & 518 & OR-234 & 2172 \\
\hline OR-033 & 235 & OR-101 & 357 & OR-168 & 518 & OR-235 & 612 \\
\hline OR-034 & 235 & OR-102 & 362 & OR-169 & 518 & OR-236 & 592 \\
\hline OR-035 & 258 & OR-103 & 363 & OR-170 & 518 & OR-237 & 609 \\
\hline OR-036 & 258 & OR-104 & 364 & OR-171 & 530 & OR-238 & 622 \\
\hline OR-037 & 263 & OR-105 & 370 & OR-172 & 530 & OR-239 & 609 \\
\hline OR-038 & 266 & OR-106 & 373 & OR-173 & 1512 & OR-240 & 2186 \\
\hline OR-039 & 268 & OR-107 & 374 & OR-174 & 1512 & OR-241 & 623 \\
\hline OR-040 & 269 & OR-108 & 375 & OR-175 & 532 & OR-242 & 624 \\
\hline OR-041 & 272 & OR-109 & 368 & OR-176 & 533 & OR-243 & 625 \\
\hline OR-042 & 273 & OR-110 & 377 & OR-177 & 533 & OR-244 & 627 \\
\hline OR-043 & 277 & OR-111 & 368 & OR-178 & 540 & OR-245 & 629 \\
\hline OR-044 & 276 & OR-112 & 382 & OR-179 & 541 & OR-246 & 580 \\
\hline OR-045 & 282 & OR-113 & 393 & OR-180 & 539 & OR-247 & 580 \\
\hline OR-046 & 278 & OR-114 & 395 & OR-181 & 2176 & OR-248 & 631 \\
\hline OR-047 & 283 & OR-115 & 398 & OR-182 & 1514 & OR-249 & 632 \\
\hline OR-048 & 284 & OR-116 & 504 & OR-183 & 530 & OR-250 & 633 \\
\hline OR-049 & 298 & OR-117 & 677 & OR-184 & 530 & OR-251 & 2184 \\
\hline OR-050 & 304 & OR-118 & 400 & OR-185 & 541 & OR-252 & 597 \\
\hline OR-051 & 330 & OR-119 & 403 & OR-186 & 542 & OR-253 & 590 \\
\hline OR-052 & 336 & OR-120 & 409 & OR-187 & 541 & OR-254 & 596 \\
\hline OR-053 & 339 & OR-121 & 410 & OR-188 & 543 & OR-255 & 1225 \\
\hline OR-054 & 359 & OR-122 & 413 & OR-189 & 2177 & OR-256 & 596 \\
\hline OR-055 & 361 & OR-123 & 414 & OR-190 & 2178 & OR-257 & 636 \\
\hline OR-056 & 366 & OR-124 & 415 & OR-191 & 556 & OR-258 & 637 \\
\hline OR-057 & 380 & OR-125 & 418 & OR-192 & 556 & OR-259 & 638 \\
\hline OR-058 & 388 & OR-126 & 419 & OR-193 & 556 & OR-260 & 580 \\
\hline OR-059 & 392 & OR-127 & 420 & OR-194 & 554 & OR-261 & 641 \\
\hline OR-060 & 397 & OR-128 & 422 & OR-195 & 551 & OR-262 & 642 \\
\hline OR-061 & 412 & OR-129 & 424 & OR-196 & 2179 & OR-263 & 643 \\
\hline OR-062 & 417 & OR-130 & 425 & OR-197 & 2177 & OR-264 & 645 \\
\hline OR-063 & 469 & OR-131 & 430 & OR-198 & 552 & OR-265 & 648 \\
\hline OR-064 & 470 & OR-132 & 2165 & OR-199 & 552 & OR-266 & 647 \\
\hline OR-065 & 471 & OR-133 & 433 & OR-200 & 564 & OR-267 & 646 \\
\hline OR-066 & 479 & OR-134 & 434 & OR-201 & 565 & OR-268 & 614 \\
\hline OR-067 & 431 & OR-135 & 451 & OR-202 & 556 & OR-269 & 656 \\
\hline OR-068 & 431 & OR-136 & 452 & OR-203 & 2180 & OR-270 & 651 \\
\hline
\end{tabular}




\begin{tabular}{|c|c|c|c|c|c|c|c|}
\hline OR No. & TARL Lot No. & OR No. & TARL Lot No. & OR No. & TARL Lot No. & OR No. & TARL Lot No. \\
\hline OR-271 & 614 & OR-343 & 881 & OR-415 & 1100 & OR-487 & 1338 \\
\hline OR-272 & 614 & OR-344 & 882 & OR-416 & 1101 & OR-488 & 1339 \\
\hline OR-273 & 659 & OR-345 & 883 & OR-417 & 1107 & OR-489 & 1341 \\
\hline OR-274 & 664 & OR-346 & 884 & OR-418 & 1108 & OR-490 & 1342 \\
\hline OR-275 & 666 & OR-347 & 886 & OR-419 & 1109 & OR-491 & 1344 \\
\hline OR-276 & 661 & OR-348 & 891 & OR-420 & 1113 & OR-492 & 1347 \\
\hline OR-277 & 665 & OR-349 & 888 & OR-421 & 1114 & OR-493 & 1350 \\
\hline OR-278 & 670 & OR-350 & 892 & OR -422 & 1116 & OR-494 & 1379 \\
\hline OR-279 & 674 & OR-351 & 900 & OR-423 & 1117 & OR-495 & 1380 \\
\hline OR-280 & 680 & OR-352 & 907 & OR- 424 & 1118 & OR-496 & 1383 \\
\hline OR-281 & 687 & OR -353 & 913 & OR -425 & 1125 & OR-497 & 1386 \\
\hline OR-282 & 688 & OR-354 & 1103 & OR-426 & 1127 & OR-498 & 1392 \\
\hline OR-283 & 689 & OR-355 & 914 & OR-427 & 1131 & OR-499 & 1393 \\
\hline OR-284 & 690 & OR-356 & 935 & OR-428 & 1127 & OR-500 & 1394 \\
\hline OR-285 & 672 & OR-357 & 919 & OR-429 & 1098 & OR-501 & 1356 \\
\hline OR-286 & 691 & OR-358 & 940 & OR-430 & 1136 & OR-502 & 1357 \\
\hline OR-287 & 694 & OR-359 & 944 & OR-431 & 1139 & OR-503 & 1358 \\
\hline OR-288 & 704 & OR-360 & 956 & OR -432 & 1140 & OR-504 & 1359 \\
\hline OR-289 & 700 & OR-361 & 960 & OR-433 & 1147 & OR-505 & 1362 \\
\hline OR-290 & 693 & OR-362 & 959 & OR-434 & 1148 & OR-506 & 1363 \\
\hline OR-291 & 705 & OR-363 & 967 & OR-435 & 1149 & OR-507 & 1364 \\
\hline OR-292 & 706 & OR-364 & 968 & OR-436 & 1163 & OR-508 & 1365 \\
\hline OR-293 & 718 & OR-365 & 969 & OR-437 & 1167 & OR-509 & 1366 \\
\hline OR-294 & 719 & OR-366 & 975 & OR -438 & 1162 & OR-510 & 1367 \\
\hline OR-295 & 720 & OR-367 & 976 & OR-439 & 1178 & OR-511 & 1374 \\
\hline OR-296 & 713 & OR -368 & 977 & OR -440 & 1182 & OR-512 & 1375 \\
\hline OR-297 & 725 & OR-369 & 980 & OR-441 & 1063 & OR-513 & 1395 \\
\hline OR-298 & 726 & OR-370 & 981 & OR-442 & 1066 & OR-514 & 1405 \\
\hline OR-299 & 782 & OR-371 & 982 & OR-443 & 1068 & OR-515 & 1406 \\
\hline OR-300 & 731 & OR -372 & 986 & OR-444 & 1075 & OR-516 & 1407 \\
\hline OR-301 & 731 & OR -373 & 987 & OR-445 & 1077 & OR-517 & 605 \\
\hline OR-302 & 731 & OR-374 & 990 & OR-446 & 1187 & OR-518 & 1418 \\
\hline OR-303 & 732 & OR-375 & 991 & OR-447 & 1191 & OR-519 & 1425 \\
\hline OR-304 & 733 & OR-376 & 992 & OR-448 & 1201 & OR-520 & 1424 \\
\hline OR-305 & 734 & OR -377 & 993 & OR-449 & 1210 & OR-521 & 1436 \\
\hline OR-306 & 735 & OR -378 & 997 & OR- -450 & 1214 & OR-522 & 1437 \\
\hline OR-307 & 783 & OR-379 & 998 & OR-451 & 1219 & OR-523 & 1447 \\
\hline OR-308 & 740 & OR-380 & 1000 & OR-452 & 1222 & OR-524 & 1448 \\
\hline OR-309 & 745 & OR-381 & 1000 & OR-453 & 1223 & OR-525 & 1451 \\
\hline OR-310 & 750 & OR-382 & 1001 & OR-454 & 1227 & OR-526 & 1459 \\
\hline OR-311 & 755 & OR-383 & 1003 & OR-455 & 1228 & OR-527 & 1526 \\
\hline OR-312 & 767 & OR-384 & 991 & OR-456 & 1229 & OR-528 & 1527 \\
\hline OR-313 & 722 & OR-385 & 965 & OR- -457 & 1230 & OR-529 & 1539 \\
\hline OR-314 & 777 & OR-386 & 1010 & OR-458 & 1235 & OR-530 & 1547 \\
\hline OR-315 & 794 & OR-387 & 1011 & OR-459 & 1238 & OR-531 & 1548 \\
\hline OR-316 & 799 & OR-388 & 1012 & OR-460 & 1240 & OR-532 & 1555 \\
\hline OR-317 & 800 & OR-389 & 1013 & OR-461 & 1241 & OR -533 & 1556 \\
\hline OR-318 & 801 & OR-390 & 1014 & OR-462 & 1243 & OR-534 & 1550 \\
\hline OR-319 & 805 & OR-391 & 1014 & OR-463 & 1252 & OR-535 & 1557 \\
\hline OR-320 & 804 & OR-392 & 1024 & OR-464 & 1253 & OR-536 & 1470 \\
\hline OR-321 & 806 & OR-393 & 1026 & OR-465 & 1256 & OR-537 & 1477 \\
\hline OR-322 & 813 & OR-394 & 1021 & OR-466 & 1257 & OR-538 & 1478 \\
\hline OR-323 & 722 & OR-395 & 2173 & OR-467 & 1258 & OR-539 & 1465 \\
\hline OR-324 & 819 & OR-396 & 1028 & OR-468 & 1269 & OR-540 & 1496 \\
\hline OR-325 & 820 & OR -397 & 1031 & OR-469 & 1268 & OR-541 & 1497 \\
\hline OR-326 & 821 & OR-398 & 1032 & OR -470 & 1276 & OR-542 & 1499 \\
\hline OR-327 & 833 & OR-399 & 1021 & OR-471 & 1278 & OR -543 & 1498 \\
\hline OR-328 & 834 & OR -400 & 1037 & OR-472 & 1280 & OR-544 & 1566 \\
\hline OR-329 & 839 & OR-401 & 1039 & OR-473 & 1281 & OR-545 & 1569 \\
\hline OR-330 & 840 & OR-402 & 1043 & OR-474 & 1299 & OR-546 & 1570 \\
\hline OR-331 & 841 & OR-403 & 1044 & OR-475 & 1296 & OR-547 & 1573 \\
\hline OR-332 & 846 & OR -404 & 1050 & OR-476 & 1297 & OR-548 & 1574 \\
\hline OR-333 & 847 & OR-405 & 1051 & OR-477 & 1298 & OR-549 & 1575 \\
\hline OR-334 & 849 & OR-406 & 1052 & OR-478 & 1304 & OR-550 & 1576 \\
\hline OR-335 & 857 & OR-407 & 1054 & OR-479 & 1306 & OR-551 & 1577 \\
\hline OR-336 & 858 & OR-408 & 1055 & OR -480 & 1311 & OR-552 & 1580 \\
\hline OR-337 & 859 & OR-409 & 1083 & OR-481 & 1309 & OR -553 & 1581 \\
\hline OR-338 & 860 & OR-410 & 1086 & OR-482 & 1321 & OR-554 & 1593 \\
\hline OR-339 & 868 & OR-411 & 1087 & OR- 483 & 1322 & OR-555 & 1594 \\
\hline OR-340 & 869 & OR-412 & 1088 & OR-484 & 1327 & OR -556 & 1602 \\
\hline OR-341 & 870 & OR-413 & 1089 & OR-485 & 1326 & OR-557 & 1603 \\
\hline OR-342 & 880 & OR-414 & 1090 & OR-486 & 1330 & OR-558 & 1604 \\
\hline
\end{tabular}




\begin{tabular}{|c|c|c|c|c|c|}
\hline OR No. & TARL Lot No. & OR No. & TARL Lot No. & OR No. & TARL Lot No. \\
\hline OR-559 & 1605 & OR-631 & 1948 & OR-704 & 2385 \\
\hline OR-560 & 1606 & OR-632 & 1955 & OR-705 & 2393 \\
\hline OR-561 & 827 & OR-633 & 1958 & OR-706 & 2474 \\
\hline OR-562 & 579 & OR-634 & 1966 & OR-707 & 2397 \\
\hline OR-563 & 1565 & OR-635 & 1974 & OR-708 & 2398 \\
\hline OR-564 & 1468 & OR-636 & 1976 & OR-709 & 2421 \\
\hline OR-565 & 1284 & OR-637 & 1977 & OR-710 & 2428 \\
\hline OR-566 & 1650 & OR-638 & 1979 & OR-711 & 2429 \\
\hline OR-567 & 1656 & OR-639 & 1988 & OR-712 & 2433 \\
\hline OR-568 & 1657 & OR-640 & 2004 & OR-713 & 2436 \\
\hline OR-569 & 1658 & OR-641 & 2005 & OR-714 & 2438 \\
\hline OR-570 & 1682 & OR- 642 & 2019 & OR-715 & 2444 \\
\hline OR-571 & 1687 & OR-643 & 2022 & OR-716 & 2448 \\
\hline OR-572 & 1686 & OR-644 & 2023 & OR-717 & 2449 \\
\hline OR-573 & 1700 & OR-645 & 1695 & OR-718 & 2458 \\
\hline OR-574 & 2724 & OR-646 & 2049 & OR-719 & 2467 \\
\hline OR-575 & 1713 & OR-647 & 2053 & OR-720 & 2467 \\
\hline OR-576 & 1720 & OR-648 & 2076 & OR-721 & 2468 \\
\hline OR-577 & 1721 & OR-649 & 2081 & OR-722 & 2469 \\
\hline OR-578 & 1729 & OR-650 & 2088 & OR-723 & 2470 \\
\hline OR-579 & 1725 & OR-651 & 2096 & OR-724 & 2471 \\
\hline OR-580 & 1726 & OR-652 & 2093 & OR-725 & 2472 \\
\hline OR-581 & 1731 & OR-653 & 2097 & OR-726 & 2473 \\
\hline OR-582 & 1736 & OR-654 & 2101 & OR-727 & 1282 \\
\hline OR-583 & 1739 & OR-655 & 2119 & OR-728 & 2476 \\
\hline OR-584 & 1752 & OR-656 & 2128 & OR-729 & 2479 \\
\hline OR-585 & 1753 & OR-657 & 2131 & OR-730 & 2480 \\
\hline OR-586 & 1757 & OR-658 & 2136 & OR-731 & 2482 \\
\hline OR-587 & 1758 & OR-659 & 2139 & OR-732 & 2488 \\
\hline OR-588 & 1763 & OR-660 & 2145 & OR-733 & 2498 \\
\hline OR-589 & 1768 & OR-661 & 2154 & OR-734 & 2513 \\
\hline OR-590 & 1608 & OR-662 & 2155 & OR-735 & 2518 \\
\hline OR-591 & 1626 & OR-663 & 2156 & OR-736 & 2520 \\
\hline OR-592 & 1631 & OR-664 & 2157 & OR-737 & 2576 \\
\hline OR-593 & 1633 & OR-665 & 2158 & OR-738 & 2577 \\
\hline OR-594 & 1639 & OR-666 & 2159 & OR-739 & 2599 \\
\hline OR-595 & 1640 & OR-667 & 2284 & OR-740 & 2664 \\
\hline OR-596 & 1641 & OR-668 & 2281 & OR-741 & 2666 \\
\hline OR-597 & 1642 & OR-669 & 2266 & OR-742 & 2669 \\
\hline OR-598 & 1643 & OR-670 & 2279 & OR-743 & 2675 \\
\hline OR-599 & 1774 & OR-671 & 2282 & OR-744 & 2678 \\
\hline OR-600 & 1781 & OR-672 & 2283 & OR-745 & 2679 \\
\hline OR-601 & 1794 & OR-673 & 2280 & OR-746 & 2681 \\
\hline OR-602 & 1799 & OR-674 & 2264 & OR-747 & 2691 \\
\hline OR-603 & 1807 & OR-675 & 2260 & OR-748 & 2694 \\
\hline OR-604 & 1813 & OR-676 & 2259 & OR-749 & 2699 \\
\hline OR-605 & 1814 & OR-677 & 2295 & OR-750 & 2689 \\
\hline OR-606 & 1817 & OR-678 & 2298 & OR-751 & 1843 \\
\hline OR-607 & 1828 & OR-679 & 2296 & OR-752 & 2487 \\
\hline OR-608 & 1829 & OR-680 & 2293 & OR-753 & 2524 \\
\hline OR-609 & 1841 & OR-681 & 2305 & OR-754 & 1232 \\
\hline OR-610 & 1845 & OR-682 & 2374 & & \\
\hline OR-611 & 1846 & OR-683 & 2375 & & \\
\hline OR-612 & 1847 & OR-684 & 2376 & & \\
\hline OR-613 & 1848 & OR-685 & 2313 & & \\
\hline OR-614 & 1854 & OR-686 & 2316 & & \\
\hline OR-615 & 1858 & OR-687 & 2317 & & \\
\hline OR-616 & 1859 & OR-689 & 2318 & & \\
\hline OR-617 & 1861 & OR-690 & 2341 & & \\
\hline OR-618 & 1874 & OR-691 & 2353 & & \\
\hline OR-619 & 1885 & OR-692 & 2357 & & \\
\hline OR-620 & 1886 & OR-693 & 2361 & & \\
\hline OR-621 & 1907 & OR-694 & 2365 & & \\
\hline OR-622 & 1908 & OR-695 & 2366 & & \\
\hline OR-623 & 1911 & OR-696 & 2367 & & \\
\hline OR-624 & 1912 & OR-697 & 2368 & & \\
\hline OR-625 & 1913 & OR-698 & 2369 & & \\
\hline OR-626 & 1914 & OR-699 & 2372 & & \\
\hline OR-627 & 1929 & OR-700 & 2378 & & \\
\hline OR-628 & 1931 & OR-701 & 2379 & & \\
\hline OR-629 & 1940 & OR-702 & 2382 & & \\
\hline OR-630 & 1944 & OR-703 & 2384 & & \\
\hline
\end{tabular}


APPENDIX 5: PROVENIENCE OF LITHIC ARTIFACTS 
Appendix 5: Table 1- TARL Lithics by Provenience

\begin{tabular}{|c|c|c|c|c|c|c|}
\hline Square & Level & Feature & Strata & Item & Analyst Identification & Count \\
\hline Surface & & & & 135 & Arrow point, Sabinal & \\
\hline Surface & & & & 1838 & Arrow point, Scallorn & 1 \\
\hline Surface & & & & $108-8$ & Biface fragment & 1 \\
\hline Surface & & & & $148-3$ & Biface Stage 1 & 1 \\
\hline Surface & & & & OR 103 & Biface Stage 1 & 1 \\
\hline Surface & & & & $108-9$ & Biface Stage 2 & 1 \\
\hline $\begin{array}{l}\text { Surface } \\
\text { Surface }\end{array}$ & & & & $108-1$ & Biface Stage 2 & 1 \\
\hline $\begin{array}{l}\text { Surface } \\
\text { Surface }\end{array}$ & & & & $10 \mathrm{P}-7$ & Biface Stage 2 & 1 \\
\hline $\begin{array}{l}\text { Surface } \\
\text { Surface }\end{array}$ & & & & $148-2$ & $\begin{array}{l}\text { Biface Stage } 3 \\
\text { Burin }\end{array}$ & 1 \\
\hline $\begin{array}{l}\text { Surface } \\
\text { Surface }\end{array}$ & & & & $108-2$ & $\begin{array}{l}\text { Burin } \\
\text { Debitage }\end{array}$ & $\begin{array}{r}1 \\
46\end{array}$ \\
\hline Surface & & & & $108-4$ & $\begin{array}{l}\text { Debitage } \\
\text { Denticulated flake }\end{array}$ & 1 \\
\hline Surface & & & & $148-4$ & Denticulated flake & 1 \\
\hline Surface & & & & $108-6$ & Edge modified flake & 1 \\
\hline Surface & & & & $103-1$ & Edge modified flake & 1 \\
\hline Surface & & & & $148-5$ & Edge modified flake & 1 \\
\hline Surface & & & & $148-6$ & Edge modified flake & 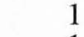 \\
\hline Surface & & & & $102-1$ & Edge modified flake & 1 \\
\hline Surface & & & & $101-1$ & Mano & 1 \\
\hline Surface & & & & 423 & Mano fragment & 1 \\
\hline Surface & & & & 2879 & Mano fragment & 1 \\
\hline Surface & & & & $108-15$ & Projectile point fragment & 1 \\
\hline $\begin{array}{l}\text { Surface } \\
\text { Surface }\end{array}$ & & & & $108-18$ & Projectile point, Bulverde & 1 \\
\hline Surface & & & & $\begin{array}{l}2643-1 \\
108-14\end{array}$ & $\begin{array}{l}\text { Projectile point, Bulverde } \\
\text { Projectile point, Castroville }\end{array}$ & $\begin{array}{l}1 \\
1\end{array}$ \\
\hline Surface & & & & $108-17$ & Projectile point, Castroville & 1 \\
\hline Surface & & & & $148-1$ & Projectile point, Marcos & 1 \\
\hline Surface & & & & $108-13$ & Projectile point, miscellaneous side-notched & 1 \\
\hline Surface & & & & $108-16$ & Projectile point, Pedernales & 1 \\
\hline Surface & & & & $100-1$ & Projectile point, Pedernales & 1 \\
\hline Surface & & & & $108-12$ & Retouched blade & 1 \\
\hline Surface & & & & 108-11 & Thick uniface & 1 \\
\hline Surface & & & & $108-7$ & Thin uniface & 1 \\
\hline Surface & 1 & & & $108-3$ & Thin uniface & 1 \\
\hline 11 & $\begin{array}{l}1 \\
2\end{array}$ & & IIIIc (fill) & & $\begin{array}{l}\text { Debitage } \\
\text { Debitage }\end{array}$ & 60 \\
\hline $\begin{array}{l}11 \\
11\end{array}$ & 3 & & IIIc & $205-4$ & $\begin{array}{l}\text { Debitage } \\
\text { Biface Stage } 1\end{array}$ & 1 \\
\hline 11 & 3 & & IIIc & $\begin{array}{l}205-4 \\
206\end{array}$ & $\begin{array}{l}\text { Biface Stage } 1 \\
\text { Biface Stage } 2\end{array}$ & 1 \\
\hline 11 & 3 & & IIIIc & $169-4$ & Biface Stage 2 & 1 \\
\hline 11 & 3 & & IIIc & $169-1$ & Biface Stage 2 & 1 \\
\hline 11 & 3 & & IIIc & 384 & Biface Stage 2 & 1 \\
\hline 11 & 3 & & IIII & $169-10$ & Burin spall & 1 \\
\hline 11 & 3 & & IIIIC & & Debitage & 620 \\
\hline 11 & 3 & & IIIIc & $169-5$ & Edge modified flake & 1 \\
\hline 11 & $\begin{array}{l}3 \\
3\end{array}$ & & IIIc & $169-9$ & $\begin{array}{l}\text { Edge modified flake } \\
\text { Proiectile point fragment }\end{array}$ & 1 \\
\hline $\begin{array}{l}11 \\
11\end{array}$ & 3 & & $\begin{array}{l}\text { IIIc } \\
\text { IIc }\end{array}$ & $\begin{array}{l}169-2 \\
\text { OR4 }\end{array}$ & $\begin{array}{l}\text { Projectile point fragment } \\
\text { Projectile point, miscellaneous bifurcate }\end{array}$ & 1 \\
\hline 11 & 3 & & IIIc & $169-3$ & $\begin{array}{l}\text { Projectile point, miscellaneous bifurcate } \\
\text { Projectile point, Montell }\end{array}$ & 1 \\
\hline 11 & 4 & & IIIc & $231-4$ & Biface fragment & 1 \\
\hline 11 & 4 & & IIIc & $231-2$ & Burin & 1 \\
\hline 11 & 4 & & IIIc & $231-5$ & Core fragment & 1 \\
\hline 11 & 4 & & IIIIc & & Debitage & 731 \\
\hline 11 & 4 & & IIIIc & $231-3$ & Edge modified flake & 1 \\
\hline 11 & 5 & & $\mathrm{IIIb} / \mathrm{c}$ & $323-3$ & Biface fragment & 1 \\
\hline 11 & 5 & & $\mathrm{IIIb} / \mathrm{c}$ & $323-4$ & Biface Stage 2 & 1 \\
\hline 11 & 5 & & $\mathrm{IIIb} / \mathrm{c}$ & $323-7$ & Biface Stage 3 & 1 \\
\hline 11 & 5 & & $\mathrm{IIIb} / \mathrm{c}$ & $335-10$ & Chert cobble, chunk & 1 \\
\hline 11 & $\begin{array}{l}5 \\
5\end{array}$ & & $\mathrm{IIIb} / \mathrm{c}$ & & Debitage & 611 \\
\hline 11 & $\begin{array}{l}5 \\
5\end{array}$ & & $\mathrm{IIIb} / \mathrm{c}$ & $323-2$ & $\begin{array}{l}\text { Edge modified flake } \\
\text { Edge modified flake }\end{array}$ & 1 \\
\hline 11 & 5 & & $\begin{array}{l}\mathrm{IIlb} / \mathrm{c} \\
\mathrm{IIIb} / \mathrm{c}\end{array}$ & $\begin{array}{l}323-1 \\
\text { OR104 }\end{array}$ & $\begin{array}{l}\text { Edge modified flake } \\
\text { Edge modified flake }\end{array}$ & 1 \\
\hline 11 & 5 & & $\mathrm{IIIJ} / \mathrm{c}$ & $323-5$ & Projectile point fragment & 1 \\
\hline 11 & 5 & & $\mathrm{IIIb} / \mathrm{c}$ & $323-6$ & Projectile point fragment & 1 \\
\hline 11 & 5 & & $\mathrm{IIIb} / \mathrm{c}$ & OR92 & Thick uniface & 1 \\
\hline 11 & 6 & & $\mathrm{IIIb} / \mathrm{c}$ & $405-2$ & Blade & 1 \\
\hline 11 & 6 & & IIIb/c & $405-3$ & Core fragment & r \\
\hline 11 & 6 & & $\mathrm{IIIb} / \mathrm{c}$ & & Debitage & 467 \\
\hline 11 & 6 & & $\mathrm{IIIb} / \mathrm{c}$ & $405-1$ & Edge modified flake & 1 \\
\hline 11 & 6 & & $\mathrm{IIIb} / \mathrm{c}$ & OR129 & Edge modified flake & 1 \\
\hline 11 & $\begin{array}{l}6 \\
7\end{array}$ & & $\mathrm{IIIb} / \mathrm{c}$ & OR128 & Projectile point, Nolan & 1 \\
\hline 11 & $\begin{array}{l}7 \\
7\end{array}$ & & $\begin{array}{l}\text { IIIb } \\
\text { IIIb }\end{array}$ & & Debitage & 445 \\
\hline 11 & 7 & & IIllb & OR153 & Edge modified flake & \\
\hline
\end{tabular}




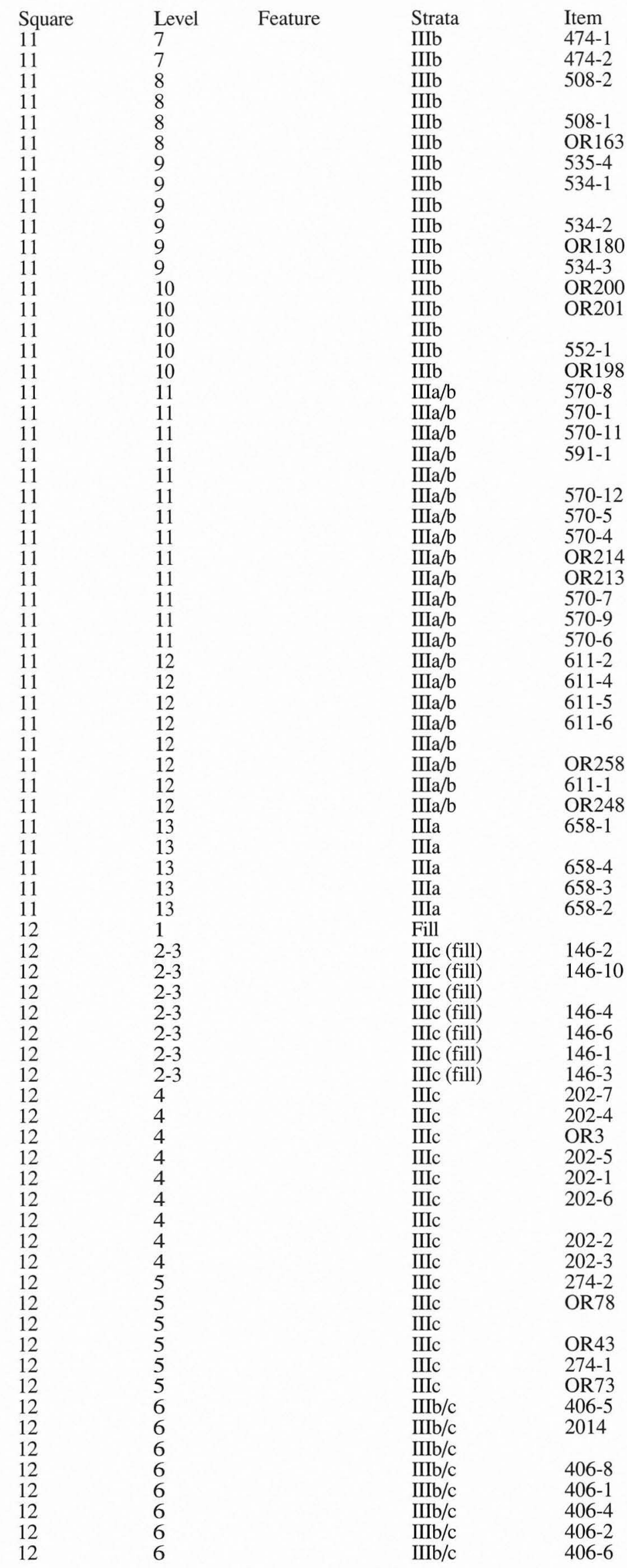

Analyst Identification

Projectile point fragment

Projectile point, expanding concave D

Burin spall

Debitage

Edge modified flake

Projectile point, Nolan

Biface fragment

Biface Stage 3

Debitage

Edge modified flake

Projectile point, Nolan

Worked hematite

Biface Stage 1

Biface Stage 2

Debitage

Projectile point fragment

Tool, unanalyzed

Biface fragment

Bifacial tool Form A

Blade

Core fragment

Debitage

Edge modified flake

Edge modified flake

Edge modified flake

Edge modified flake

Flake, unanalyzed

Retouched blade

Thin uniface fragment

Unifacial multiple tool

Biface fragment

Biface fragment

Burin spall

Burin spall

Debitage

Flake, unanalyzed

Projectile point, expanding concave $\mathrm{C}$

Projectile point, indeterminate

Biface fragment

Debitage

Edge modified flake

Edge modified flake

Thin uniface fragment

Debitage

Arrow point, Scallorn

Biface fragment

Debitage

Edge modified flake

Notched flake

Projectile point, Bulverde-like

Thin uniface fragment

Biface Stage 1

Biface Stage 1

Biface Stage 2

Biface Stage 2

Bifacial tool Form A

Core tool, type 4

Debitage

Projectile point fragment

Projectile point, Ensor

Biface fragment

Biface Stage 2

Debitage

Edge modified flake

Perforator Group 7

Projectile point, Bulverde

Biface fragment

Biface Stage 1

Debitage

Edge modified flake

Projectile point, Castroville

Spurred flake

Thin uniface

Thin uniface fragment 


\begin{tabular}{|c|c|c|c|c|c|c|}
\hline $\begin{array}{l}\text { Square } \\
12\end{array}$ & $\begin{array}{l}\text { Level } \\
7\end{array}$ & Feature & $\begin{array}{l}\text { Strata } \\
\mathrm{IIIb} / \mathrm{c}\end{array}$ & Item & $\begin{array}{l}\text { Analyst Identification } \\
\text { Debitage }\end{array}$ & $\begin{array}{r}\text { Count } \\
308\end{array}$ \\
\hline 12 & 7 & & $\mathrm{IIIb} / \mathrm{c}$ & $497-2$ & Edge modified flake & 1 \\
\hline 12 & 7 & & $\mathrm{IIIb} / \mathrm{c}$ & $497-3$ & Projectile point fragment & \\
\hline 12 & 8 & & IIIb & & Debitage & 316 \\
\hline 12 & 8 & & IIIb & $533-2$ & Edge modified flake & \\
\hline 12 & 8 & & IIIIb & OR177 & Flake, unanalyzed & 1 \\
\hline 12 & 8 & & III b & $533-1$ & Unifacial multiple tool & 1 \\
\hline 12 & 9 & & IIIb & OR 185 & Biface Stage 2 & 1 \\
\hline 12 & 9 & & IIIIb & & Debitage & 454 \\
\hline 12 & 9 & & IIIb & $541-2$ & Edge modified flake & \\
\hline 12 & 9 & & IIIb & $541-1$ & Edge modified flake & 1 \\
\hline 12 & 9 & & IIIb & OR179 & Flake, unanalyzed & 1 \\
\hline 12 & 9 & & IIIb & OR187 & Projectile point, expanding concave $\mathrm{C}$ & 1 \\
\hline 12 & 10 & & IIIb & $556-1$ & Biface Stage 2 & 1 \\
\hline 12 & 10 & & IIIb & & Debitage & 392 \\
\hline 12 & 10 & & IIIb & $556-3$ & Edge modified flake & 1 \\
\hline 12 & 10 & & IIIb & $556-4$ & Flake, Bell/Andice practice? & 1 \\
\hline 12 & 10 & & IIIb & OR202 & Projectile point, expanding concave D & 1 \\
\hline 12 & 10 & & IIIb & OR191 & Projectile point, miscellaneous lanceolate & 1 \\
\hline 12 & 10 & & IIIb & $556-2$ & Spurred flake & 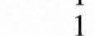 \\
\hline 12 & 10 & & IIIb & OR193 & Tool, unanalyzed & 1 \\
\hline 12 & $11 \mathrm{~A}$ & & IIIa/b & $578-2$ & Chert cobble, chunk & 1 \\
\hline 12 & $11 \mathrm{~A}$ & & IIIa/b & & Debitage & 285 \\
\hline 12 & $11 \mathrm{~A}$ & & $\mathrm{III} / \mathrm{b}$ & OR234 & Flake, unanalyzed & 1 \\
\hline 12 & $11 \mathrm{~A}$ & & $\mathrm{IIIa} / \mathrm{b}$ & OR210 & $\begin{array}{l}\text { Piece esquillee } \\
\text { Pid }\end{array}$ & 1 \\
\hline 12 & $11 \mathrm{~A}$ & & $\mathrm{IIIa} / \mathrm{b}$ & $578-1$ & Projectile point fragment & 1 \\
\hline 12 & $11 \mathrm{~B}$ & Feature 213 & IIIa/b & & Debitage & 1 \\
\hline 12 & $12 \mathrm{~A}$ & & $\mathrm{IIIa} / \mathrm{b}$ & OR268 & Biface Stage 3 & 1 \\
\hline 12 & $12 \mathrm{~A}$ & & IIIa/b & & Debitage & 474 \\
\hline 12 & $12 \mathrm{~A}$ & & $\mathrm{IIIa} / \mathrm{b}$ & OR271 & Flake, unanalyzed & 1 \\
\hline 12 & $12 \mathrm{~A}$ & & $\mathrm{IIIa} / \mathrm{b}$ & OR272 & Flake, unanalyzed & 1 \\
\hline 12 & $12 \mathrm{~A}$ & & IIIa/b & $614-1$ & Projectile point fragment & 1 \\
\hline 12 & $12 \mathrm{~B}$ & Feature 213 & IIIa/b & $613-1$ & Burin spall & 1 \\
\hline 12 & $12 \mathrm{~B}$ & Feature 213 & $\mathrm{III} / \mathrm{b}$ & $613-2$ & Burin spall & 1 \\
\hline 12 & $12 \mathrm{~B}$ & Feature 213 & $\mathrm{IIIa} / \mathrm{b}$ & 613 & Burin spall & 1 \\
\hline 12 & $12 \mathrm{~B}$ & Feature 213 & $\mathrm{III} / \mathrm{b}$ & & Debitage & 36 \\
\hline 12 & 13 & & IIIa & $661-6$ & Biface fragment & . \\
\hline 12 & 13 & & IIIa & $661-1$ & Biface Stage 2 & 1 \\
\hline 12 & 13 & & IIIa & & Debitage & 608 \\
\hline 12 & 13 & & IIIa & $661-2$ & Edge modified flake & 1 \\
\hline 12 & 13 & & IIIa & $661-7$ & Edge modified flake & 1 \\
\hline 12 & 13 & & IIIa & $661-5$ & Edge modified flake & 1 \\
\hline 12 & 13 & & IIIa & $661-3$ & Edge modified flake & 1 \\
\hline 12 & 13 & & IIIa & $661-4$ & Edge modified flake & 1 \\
\hline 12 & 13 & & IIIa & OR276 & Flake, unanalyzed & 1 \\
\hline 12 & 14 & & IIIIa & & Debitage & 864 \\
\hline 12 & 14 & & IIIa & $684-3$ & Projectile point fragment & 1 \\
\hline 12 & 14 & & IIIa & $684-1$ & Thin uniface & 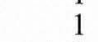 \\
\hline 12 & 15 & & IIIIa & $713-4$ & Biface Stage 3 & 1 \\
\hline 12 & 15 & & IIIa & $713-1$ & Burin spall & 1 \\
\hline 12 & 15 & & IIIa & & Debitage & 778 \\
\hline 12 & 15 & & IIIa & $713-3$ & Edge modified flake & 1 \\
\hline 12 & 15 & & IIIa & OR296 & Flake, unanalyzed & 1 \\
\hline 12 & 15 & & IIIa & OR299 & Flake, unanalyzed & 1 \\
\hline 12 & 15 & & IIIa & $713-2$ & Projectile point fragment & 1 \\
\hline 12 & 16 & & IIIIa & & Debitage & 530 \\
\hline 12 & 16 & & IIIa & $742-1$ & Microspur/microdenticulate & 1 \\
\hline 12 & 16 & & IIIa & $742-2$ & Thin uniface fragment & 1 \\
\hline 12 & 17 & & IIIa & & Debitage & 418 \\
\hline 12 & 17 & & IIIa & $763-2$ & Edge modified flake & 1 \\
\hline 12 & 17 & & IIIIa & $763-6$ & Projectile point fragment & 1 \\
\hline 12 & 18 & & IIIa & & Debitage & 696 \\
\hline 12 & 18 & & IIIa & $790-2$ & Microspur/microdenticulate & 1 \\
\hline 12 & 18 & & IIIa & $790-1$ & Projectile point fragment & 1 \\
\hline 12 & 19 & & IIIa & 853 & Burin spall & 1 \\
\hline 12 & 19 & & IIIa & $853-1$ & Burin spall & 1 \\
\hline 12 & 19 & & IIIIa & & Debitage & 390 \\
\hline 12 & 19 & & IIIa & OR337 & Projectile point, Angostura & 0 \\
\hline 12 & $20 \mathrm{~A}$ & & II/IIIa & & Debitage & 313 \\
\hline 12 & $20 \mathrm{~A}$ & & II/IIIa & $888-4$ & Edge modified flake & 1 \\
\hline 12 & $20 \mathrm{~A}$ & & II/IIIa & $888-3$ & Edge modified flake & 1 \\
\hline 12 & $20 \mathrm{~A}$ & & II/IIIIa & OR349 & Flake, unanalyzed & 1 \\
\hline 12 & $20 \mathrm{~A}$ & & II/IIIa & OR350 & Flake, unanalyzed & 1 \\
\hline 12 & $20 \mathrm{~A}$ & & II/IIIa & $888-5$ & Thin uniface fragment & 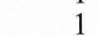 \\
\hline
\end{tabular}




\begin{tabular}{|c|c|c|c|c|c|c|}
\hline Square & Level & Feature & Strata & Item & Analyst Identification & Count \\
\hline 12 & $\begin{array}{l}20 \mathrm{~B} \\
20 \mathrm{~B}\end{array}$ & $\begin{array}{l}\text { Feature } 224 \\
\text { Feature } 224\end{array}$ & $\begin{array}{l}\mathrm{II} / \mathrm{IIIa} \\
\mathrm{II} / \mathrm{III}\end{array}$ & OR355 & $\begin{array}{l}\text { Debitage } \\
\text { Flake, unanalyzed }\end{array}$ & $\begin{array}{r}25 \\
1\end{array}$ \\
\hline 12 & 21 & & II/IIIa & $935-3$ & Biface fragment & 1 \\
\hline 12 & 21 & & II/IIIa & & Debitage & 342 \\
\hline 12 & 21 & & II/IIIa & OR356 & Flake, unanalyzed & 1 \\
\hline 12 & 22 & & II/IIIa & & Debitage & 238 \\
\hline 12 & 23 & & II & & Debitage & 5 \\
\hline 12 & 23 & & II & OR371 & Thin uniface & 1 \\
\hline 12 & $23-24$ & & II & & Debitage & 233 \\
\hline 12 & $23-24$ & & II & $970-2$ & Edge modified flake & 1 \\
\hline 12 & 24 & & II & & Debitage & 139 \\
\hline 12 & 24 & & II & $994-1$ & Edge modified flake & 1 \\
\hline 12 & 24 & & II & OR380 & Flake, unanalyzed & 1 \\
\hline 12 & 24 & & II & OR381 & Flake, unanalyzed & 1 \\
\hline 12 & 25 & & Isi-c/II & OR401 & Biface Stage 2 & 1 \\
\hline 12 & 25 & & Isi-c/II & & Debitage & 117 \\
\hline 12 & 25 & & Isi-c/II & $1020-1$ & Edge modified flake & 1 \\
\hline 12 & 26 & & Isi-c/II & & Debitage & 2 \\
\hline 12 & 26 & & Isi-c/II & OR411 & Projectile point, miscellaneous lanceolate & 1 \\
\hline 12 & $26-27$ & & Isi-c/II & & Debitage & 53 \\
\hline 12 & 27 & & Isi-c/II & & Debitage & 4 \\
\hline 12 & 28 & & Isi-c/II & OR449 & Core, thermal & 1 \\
\hline 12 & 28 & & Isi-c/II & & Debitage & 42 \\
\hline 12 & 28 & & Isi-c/II & OR454 & Flake, unanalyzed & 1 \\
\hline 12 & 28 & & Isi-c/II & OR450 & Flake, unanalyzed & 1 \\
\hline 12 & 29 & & Isi-c/II & & Debitage & 57 \\
\hline 12 & 30 & & Isi-c/II & & Debitage & 95 \\
\hline 12 & 30 & & Isi-c/II & OR467 & Flake, unanalyzed & 1 \\
\hline 12 & 31 & & Isi-c/II & & Debitage & 84 \\
\hline 12 & 31 & & Isi-c/II & $1274-1$ & Thin uniface fragment & 1 \\
\hline 12 & 32 & & Isi-c & & Debitage & 157 \\
\hline 12 & 32 & & Isi-c & OR488 & Edge modified flake & 1 \\
\hline 12 & 32 & & Isi-c & $1328-1$ & Edge modified flake & 1 \\
\hline 12 & 32 & & Isi-c & OR491 & Thick uniface & 1 \\
\hline 12 & 33 & & Isi-c & OR499 & Flake, unanalyzed & 1 \\
\hline 12 & $33-34$ & & Isi-c & $1396-2$ & Core, thermal & 1 \\
\hline 12 & $33-34$ & & Isi-c & & Debitage & 87 \\
\hline 12 & $33-34$ & & Isi-c & $1396-1$ & Edge modified flake & 1 \\
\hline 12 & 34 & & $\begin{array}{l}1 \mathrm{l}-\mathrm{c} \\
\text { Isi-c }\end{array}$ & $1590-1$ & Debitage & 39 \\
\hline 12 & 34 & & Isi-c & $1428-1$ & Edge modified flake & 1 \\
\hline 12 & 34 & & Isi-c & $1428-2$ & Small core hammerstone & 1 \\
\hline 12 & 35 & & Isi//Isi-c & & Debitage & 36 \\
\hline 12 & 35 & & Isi/Isi-c & OR529 & Flake, unanalyzed & 1 \\
\hline 12 & 36 & & Isi//Isi-c & OR587 & Core fragment & 1 \\
\hline 12 & 36 & & Isi/Isi-c & & Debitage & 18 \\
\hline 12 & 37 & & Isi//si-c & & Debitage & 22 \\
\hline 12 & 38 & & Isi/Isi-c & & Debitage & 7 \\
\hline 12 & $39 \mathrm{~A}$ & & Isi//Isi-c & & Debitage & 2 \\
\hline 12 & $39 \mathrm{~B}$ & & Isi/Isi-c & & Debitage & 2 \\
\hline 12 & 40 & & Isi & & Debitage & 5 \\
\hline 12 & 44 & & Isi & & Debitage & 1 \\
\hline 12 & 46 & & Isi & & Debitage & 1 \\
\hline 12 & 48 & & Isi & & Debitage & 1 \\
\hline 12 & Wall & & & $681-5$ & Core fragment & 1 \\
\hline 12 & Wall & & & & Debitage & 16 \\
\hline 12 & Wall & & & $681-3$ & Edge modified flake & 1 \\
\hline 12 & Wall & & & $681-1$ & Thin uniface & 1 \\
\hline 12 & Wall & & & $681-2$ & Thin uniface & 1 \\
\hline 13 & 1 & & Fill & & Debitage & 1 \\
\hline 13 & 2 & & IIII (fill) & $163-2$ & Burin & 1 \\
\hline 13 & 2 & & IIIc (fill) & & Debitage & 58 \\
\hline 13 & 2 & & IIIc (fill) & $163-1$ & Projectile point fragment & 1 \\
\hline 13 & 3 & & IIIc & $176-5$ & Biface & 1 \\
\hline 13 & 3 & & IIII & $176-12$ & Biface fragment & 1 \\
\hline 13 & 3 & & IIII & $176-10$ & Biface Stage 2 & 1 \\
\hline 13 & 3 & & IIIC & $176-4$ & Biface Stage 2 & 1 \\
\hline 13 & 3 & & IIII & $176-1$ & Burin & 1 \\
\hline 13 & 3 & & IIII & $176-3$ & Burin spall & 1 \\
\hline 13 & 3 & & IIII & & Debitage & 483 \\
\hline 13 & 3 & & IIII & $176-2$ & Edge modified flake & 1 \\
\hline 13 & 3 & & IIII & $176-6$ & Edge modified flake & 1 \\
\hline 13 & 3 & & IIII & $176-7$ & Edge modified flake & 1 \\
\hline 13 & 3 & & IIIC & OR10 & Flake, unanalyzed & 1 \\
\hline 13 & 3 & & IIIC & $176-13$ & Projectile point fragment & 1 \\
\hline
\end{tabular}




\begin{tabular}{|c|c|c|c|c|c|c|}
\hline $\begin{array}{l}\text { Square } \\
13\end{array}$ & $\begin{array}{l}\text { Level } \\
4\end{array}$ & Feature & $\begin{array}{l}\text { Strata } \\
\text { IIIc }\end{array}$ & Item & Analyst Identification & Count \\
\hline 13 & 4 & & IIIc & $\begin{array}{l}238 \\
\text { OR23 }\end{array}$ & $\begin{array}{l}\text { Biface fragment } \\
\text { Biface Stage } 2\end{array}$ & 1 \\
\hline 13 & 4 & & IIIc & & Debitage & 41 \\
\hline 13 & 4 & & IIIc & OR25 & Flake, unanalyzed & \\
\hline 13 & 4 & & IIIc & $245-1$ & Unifacial multiple tool & 1 \\
\hline 13 & 5 & & IIIc & $352-8$ & Biface fragment & \\
\hline 13 & 5 & & IIIC & OR96 & Biface Stage 2 & \\
\hline 13 & 5 & & IIIC & OR118 & Core, thermal & 1 \\
\hline 13 & 5 & & IIIIc & & Debitage & 970 \\
\hline 13 & 5 & & IIIIc & $327-4$ & Edge modified flake & 1 \\
\hline 13 & 5 & & IIIc & OR97 & Flake, unanalyzed & 1 \\
\hline 13 & 5 & & IIIC & $327-2$ & Projectile point, Castroville & 1 \\
\hline 13 & 5 & & IIIc & $327-1$ & Projectile point, Jetta & 1 \\
\hline 13 & 5 & & IIIc & $327-3$ & Projectile point, Pedernales & 1 \\
\hline 13 & 6 & & IIIc & $447-5$ & Biface fragment & 1 \\
\hline 13 & 6 & & IIIc & & Debitage & 570 \\
\hline 13 & 6 & & IIIc & $447-4$ & Edge modified flake & J \\
\hline 13 & 6 & & IIII & $447-3$ & Edge modified flake & 1 \\
\hline 13 & 6 & & IIIc & OR146 & Edge modified flake & \\
\hline 13 & 6 & & IIIc & OR152 & Flake, unanalyzed & 1 \\
\hline 13 & 6 & & IIIC & $447-6$ & Projectile point fragment & 1 \\
\hline 13 & 6 & & IIIc & $447-1$ & Projectile point, Montell & 1 \\
\hline 13 & 7 & & $\mathrm{IIIb} / \mathrm{c}$ & & Debitage & 163 \\
\hline 13 & 8 & & IIIb & $494-1$ & Biface Stage 1 & 103 \\
\hline 13 & 8 & & IIIb & & Debitage & 335 \\
\hline 13 & 8 & & IIIb & $494-2$ & Edge modified flake & 1 \\
\hline 13 & 8 & & IIIJ & OR158 & Flake, unanalyzed & 1 \\
\hline 13 & 8 & & IIIb & $494-5$ & Metate fragment & 1 \\
\hline 13 & 8 & & IIIIb & 494-3 & Thick uniface fragment & 1 \\
\hline 13 & 9 & & IIIb & & Debitage & 503 \\
\hline 13 & 9 & & IIIb & $518-6$ & Edge modified flake & 1 \\
\hline 13 & 9 & & $\mathrm{IIIb}$ & $518-7$ & Edge modified flake & 1 \\
\hline 13 & 9 & & IIIb & $518-8$ & Edge modified flake & 1 \\
\hline 13 & 9 & & IIIb & OR170 & Flake, unanalyzed & 1 \\
\hline 13 & 9 & & IIIb & OR168 & Flake, unanalyzed & 1 \\
\hline 13 & 9 & & IIIb & OR169 & Flake, unanalyzed & 1 \\
\hline 13 & 9 & & IIIb & $518-4$ & Notched flake & 1 \\
\hline 13 & 9 & & IIIb & $518-1$ & Possible ground stone & 1 \\
\hline 13 & $10 \mathrm{~A}$ & & IIIb & OR188 & Biface Stage 1 & 1 \\
\hline 13 & $10 \mathrm{~A}$ & & IIIb & & Debitage & 335 \\
\hline 13 & $10 \mathrm{~A}$ & & IIIlb & $543-2$ & Edge modified flake & 1 \\
\hline 13 & $10 \mathrm{~B}$ & Feature 213 & IIIb & & Debitage & 37 \\
\hline 13 & $10 \mathrm{~B}$ & Feature 213 & IIIb & $560-2$ & Unifacial multiple tool & 1 \\
\hline 13 & $11 \mathrm{~A}$ & & IIIb & $563-1$ & Biface fragment & 1 \\
\hline 13 & $11 \mathrm{~A}$ & & IIIb & $563-2$ & Biface fragment & 1 \\
\hline 13 & $11 \mathrm{~A}$ & & IIIb & $563-3$ & Biface fragment & 1 \\
\hline 13 & $11 \mathrm{~A}$ & & IIIIb & & Debitage & 366 \\
\hline 13 & $11 \mathrm{~A}$ & & IIIb & OR203 & Projectile point, Martindale A & 1 \\
\hline 13 & $11 \mathrm{~B}$ & Feature 213 & IIIb & & Debitage & 92 \\
\hline 13 & $11 \mathrm{~B}$ & Feature 213 & IIIb & $586-2$ & Edge modified flake & . \\
\hline 13 & $11 \mathrm{~B}$ & Feature 213 & IIIb & OR255 & Flake, unanalyzed & 1 \\
\hline 13 & $12 \mathrm{~A}$ & & III $/ \mathrm{b}$ & $628-13$ & Biface fragment & 1 \\
\hline 13 & $12 \mathrm{~A}$ & & $\mathrm{IIIa} / \mathrm{b}$ & $628-15$ & Biface fragment & 1 \\
\hline 13 & $12 \mathrm{~A}$ & & $\mathrm{IIIa} / \mathrm{b}$ & $628-14$ & Biface fragment, unanalyzed & 1 \\
\hline 13 & $12 \mathrm{~A}$ & & IIIa/b & OR250 & Biface Stage 2 & 1 \\
\hline 13 & $12 \mathrm{~A}$ & & $\mathrm{IIIa} / \mathrm{b}$ & $628-12$ & Burin spall & 1 \\
\hline 13 & $12 \mathrm{~A}$ & & $\mathrm{IIIa} / \mathrm{b}$ & $628-9$ & Burin spall & 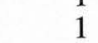 \\
\hline 13 & $12 \mathrm{~A}$ & & III $/ \mathrm{b}$ & $628-6$ & Burin spall & \\
\hline 13 & $12 \mathrm{~A}$ & & IIIa $/ \mathrm{b}$ & $628-2$ & Core, thermal & 1 \\
\hline 13 & $12 \mathrm{~A}$ & & $\mathrm{IIIa} / \mathrm{b}$ & $628-1$ & Core, thermal & 1 \\
\hline 13 & $12 \mathrm{~A}$ & & $\mathrm{IIIa} / \mathrm{b}$ & & Debitage & 608 \\
\hline 13 & $12 \mathrm{~A}$ & & IIIa/b & $628-11$ & Edge modified flake & \\
\hline 13 & $12 \mathrm{~A}$ & & IIIa/b & $628-3$ & Edge modified flake & 1 \\
\hline 13 & $12 \mathrm{~A}$ & & IIIa/b & OR269 & Flake, unanalyzed & 1 \\
\hline 13 & $12 \mathrm{~A}$ & & IIIa/b & $628-7$ & Spurred flake & 1 \\
\hline 13 & $12 \mathrm{~B}$ & Feature 213 & IIIa/b & OR261 & Biface Stage 2 & 1 \\
\hline 13 & 13 & & $\mathrm{IIIa} / \mathrm{b}$ & $655-2$ & Biface fragment & 1 \\
\hline 13 & 13 & & IIIa/b & $655-4$ & Biface fragment & 1 \\
\hline 13 & 13 & & $\mathrm{IIIa} / \mathrm{b}$ & $655-1$ & Biface Stage 2 & \\
\hline 13 & 13 & & $\mathrm{IIIa} / \mathrm{b}$ & $655-5$ & Core tool, type 2 & \\
\hline 13 & 13 & & IIIIa/b & & Debitage & 720 \\
\hline 13 & 13 & & IIIa/b & $655-3$ & Edge modified flake & 1 \\
\hline 13 & 13 & & IIIa/b & OR273 & Projectile point, Uvalde & \\
\hline 14 & 1 & & Fill & & Debitage & \\
\hline
\end{tabular}




\begin{tabular}{|c|c|c|c|c|c|c|}
\hline Square & Level & Feature & Strata & Item & Analyst Identification & Count \\
\hline 14 & 1 & & Fill & $112-1$ & Micro-core, intermediate & 1 \\
\hline 14 & 2 & & IIIc (fill) & $147-2$ & Biface fragment & 1 \\
\hline 14 & 2 & & IIIc (fill) & $147-1$ & Biface fragment & 1 \\
\hline 14 & 2 & & IIIc (fill) & & Debitage & 127 \\
\hline 14 & 2 & & IIIc (fill) & $147-4$ & Edge modified flake & \\
\hline 14 & 3 & & IIIc & OR5 & Arrow point, stemmed & 1 \\
\hline 14 & 3 & & IIIc & $187-2$ & Biface fragment & \\
\hline 14 & 3 & & IIIc & OR9 & Biface Stage 2 & 1 \\
\hline 14 & 3 & & IIIIc & $220-13$ & Core fragment & 1 \\
\hline 14 & 3 & & IIIc & $187-1$ & Core tool, type 1 & 1 \\
\hline 14 & 3 & & IIIc & 221 & Core, thermal & \\
\hline 14 & 3 & & IIIc & & Debitage & 786 \\
\hline 14 & 3 & & IIIIc & OR11 & Edge modified flake & \\
\hline 14 & 3 & & IIIIc & 220 & Projectile point fragment & 1 \\
\hline 14 & 3 & & IIIC & OR15 & Projectile point, Darl & 1 \\
\hline 14 & 3 & & IIIc & OR16 & Retouched blade & \\
\hline 14 & 4 & & IIIc & & Debitage & 752 \\
\hline 14 & 4 & Feature 202 & IIIIc & OR88 & Biface & \\
\hline 14 & 4 & Feature 202 & IIIc & OR91 & Biface Stage 2 & \\
\hline 14 & 4 & Feature 202 & IIIIc & $306-1$ & Core tool, type 1 & 1 \\
\hline 14 & 4 & Feature 202 & IIIc & & Debitage & \\
\hline 14 & 4 & Feature 202 & IIIIc & $306-2$ & Projectile point fragment & 1 \\
\hline 14 & 4 & Feature 202 & IIIIc & $306-3$ & Projectile point, bifurcate stem fragment & 1 \\
\hline 14 & 5 & & IIIIc & OR108 & Arrow point, Scallorn & 1 \\
\hline 14 & 5 & & IIIIc & $368-7$ & Arrow point, Scallorn & 1 \\
\hline 14 & 5 & & IIIc & $368-5$ & Biface fragment & \\
\hline 14 & 5 & & IIIc & $368-4$ & Biface fragment & \\
\hline 14 & 5 & & IIIc & OR110 & Biface Stage 3 & \\
\hline 14 & 5 & & IIIIc & & Debitage & 905 \\
\hline 14 & 5 & & IIIC & $368-1$ & Edge modified flake & \\
\hline 14 & 5 & & IIIc & $368-2$ & Edge modified flake & 1 \\
\hline 14 & 5 & & IIIIc & $368-10$ & Edge modified flake & \\
\hline 14 & 5 & & IIIc & $368-3$ & Edge modified flake & 1 \\
\hline 14 & 5 & & IIIIc & $368-9$ & Projectile point fragment & \\
\hline 14 & 5 & & IIIIc & $368-6$ & Projectile point fragment & \\
\hline 14 & 5 & & IIIc & $368-8$ & Projectile point fragment & 1 \\
\hline 14 & $6 \mathrm{~A}$ & & IIIC & OR147 & Biface Stage 2 & 1 \\
\hline 14 & $6 \mathrm{~A}$ & & IIIIc & $408-8$ & Core fragment & 1 \\
\hline 14 & $6 \mathrm{~A}$ & & IIIC & & Debitage & 903 \\
\hline 14 & $6 \mathrm{~A}$ & & IIIc & $408-2$ & Denticulated flake & 1 \\
\hline 14 & $6 \mathrm{~A}$ & & IIIIc & $408-6$ & Edge modified flake & \\
\hline 14 & $6 \mathrm{~A}$ & & IIIIc & $408-5$ & Edge modified flake & \\
\hline 14 & $6 \mathrm{~A}$ & & IIIc & $408-7$ & Projectile point, Ensor & \\
\hline 14 & $6 \mathrm{~A}$ & & IIIc & $408-1$ & Unifacial multiple tool & \\
\hline 14 & 7 & & $\mathrm{IIIb} / \mathrm{c}$ & & Debitage & 226 \\
\hline 14 & 7 & & $\mathrm{IIIb} / \mathrm{c}$ & $488-1$ & Notched flake & \\
\hline 14 & 8 & & $\mathrm{IIIb} / \mathrm{c}$ & & Debitage & 223 \\
\hline 14 & 8 & & $\mathrm{IIIb} / \mathrm{c}$ & $506-1$ & Edge modified flake & \\
\hline 14 & 8 & & $\mathrm{IIIb} / \mathrm{c}$ & $506-3$ & Edge modified flake, unanalyzed & \\
\hline 14 & 8 & & $\mathrm{IIIb} / \mathrm{c}$ & $506-2$ & Notched flake & \\
\hline 14 & 8 & & $\mathrm{IIIb} / \mathrm{c}$ & OR156 & Projectile point, Bulverde & \\
\hline 14 & 9 & & IIII & & Debitage & 318 \\
\hline 14 & 9 & & IIIb & $512-1$ & Projectile point fragment & \\
\hline 14 & 9 & & IIIb & OR166 & Thick uniface & \\
\hline 14 & 10 & & IIIb & $537-1$ & Biface fragment & \\
\hline 14 & 10 & & IIIb & & Debitage & 167 \\
\hline 14 & 11 & & IIIb & $551-1$ & Biface fragment & \\
\hline 14 & 11 & & IIIJ & & Debitage & 336 \\
\hline 14 & 11 & & IIIb & $551-3$ & Edge modified flake & \\
\hline 14 & 11 & & IIIb & $551-2$ & Projectile point fragment & \\
\hline 14 & 11 & & IIIb & OR195 & Projectile point, Bell/Andice & \\
\hline 14 & 12 & & IIIa/b & $561-4$ & Biface fragment & \\
\hline 14 & 12 & & IIIa/b & & Debitage & 448 \\
\hline 14 & 12 & & IIIa/b & $561-2$ & Edge modified flake & \\
\hline 14 & 12 & & $\mathrm{IIIa} / \mathrm{b}$ & $561-3$ & Thin uniface fragment & \\
\hline 14 & 13 & & IIIa/b & $574-1$ & Biface Stage 1 & \\
\hline 14 & 13 & & $\mathrm{III} a / \mathrm{b}$ & $574-2$ & Biface Stage 2 & \\
\hline 14 & 13 & & $\mathrm{IIIa} / \mathrm{b}$ & $574-3$ & Biface Stage 3 & \\
\hline 14 & 13 & & IIIa/b & & Debitage & 906 \\
\hline 14 & 13 & & $\mathrm{IIIa} / \mathrm{b}$ & $574-5$ & Edge modified flake & \\
\hline 14 & 13 & & IIIa/b & OR206 & Projectile point, Nolan & \\
\hline 14 & 13 & & IIIa/b & OR205 & Thin uniface & \\
\hline 14 & 14 & & IIIa & $590-7$ & Biface fragment & \\
\hline 14 & 14 & & IIIa & $590-2$ & Biface Stage 2 & \\
\hline
\end{tabular}




\begin{tabular}{|c|c|c|c|c|c|c|}
\hline $\begin{array}{l}\text { Square } \\
14\end{array}$ & $\begin{array}{l}\text { Level } \\
14\end{array}$ & Feature & $\begin{array}{l}\text { Strata } \\
\text { IIIa }\end{array}$ & Item & Analyst Identification & $\begin{array}{r}\text { Count } \\
863\end{array}$ \\
\hline 14 & 14 & & IIIa & $590-3$ & $\begin{array}{l}\text { Debitage } \\
\text { Edge modified flake }\end{array}$ & $\begin{array}{r}863 \\
1\end{array}$ \\
\hline 14 & 14 & & IIIa & $590-5$ & Edge modified flake & 1 \\
\hline 14 & 14 & & IIIIa & $590-1$ & Edge modified flake & 1 \\
\hline 14 & 14 & & IIIa & $590-6$ & Projectile point fragment & 1 \\
\hline 14 & 14 & & IIIa & OR253 & Projectile point, expanding concave $\mathrm{E}$ & 1 \\
\hline 14 & 14 & & IIIa & OR215 & Projectile point, square stem & 1 \\
\hline 14 & 15 & & IIIa & $608-2$ & Biface fragment & 1 \\
\hline 14 & 15 & & IIIa & OR242 & Bifacial tool & 1 \\
\hline 14 & 15 & & IIIa & & Debitage & 847 \\
\hline 14 & 15 & & IIIa & $608-4$ & Edge modified flake & 1 \\
\hline 14 & 15 & & IIIa & $608-1$ & Projectile point, miscellaneous lanceolate & 1 \\
\hline 14 & 15 & & IIIa & $608-3$ & Unifacial multiple tool & 1 \\
\hline 14 & 16 & & IIIa & & Debitage & 538 \\
\hline 14 & 16 & & IIIa & $635-1$ & Edge modified flake & 1 \\
\hline 14 & 16 & & IIIa & $635-4$ & Edge modified flake & 1 \\
\hline 14 & 16 & & IIIa & $635-3$ & Notched flake & 1 \\
\hline 14 & 16 & & IIIa & OR264 & Projectile point, concave lanceolate preform & 1 \\
\hline 14 & 16 & & IIIa & $635-6$ & Thin uniface fragment & 1 \\
\hline 15 & 2 & & IIIc (fill) & & Debitage & 27 \\
\hline 15 & 3 & & IIIC & $217-1$ & Arrow point, Scallorn & 1 \\
\hline 15 & 3 & & IIIc & OR19 & Biface Stage 2 & 1 \\
\hline 15 & 3 & & IIIc & OR18 & Biface Stage 2 & $\begin{array}{r}1 \\
1055\end{array}$ \\
\hline 15 & 3 & & IIIc & & Debitage & 1055 \\
\hline 15 & 3 & & IIIc & $217-2$ & Edge modified flake & 1 \\
\hline 15 & 3 & & IIIIc & $217-4$ & Projectile point fragment & 1 \\
\hline 15 & 3 & & IIIIc & $217-5$ & Projectile point fragment & 1 \\
\hline 15 & 3 & & IIIIc & $217-3$ & Projectile point fragment & 1 \\
\hline 15 & $4 \mathrm{~A}$ & & IIIc & OR33 & Biface Stage 1 & 1 \\
\hline 15 & $4 \mathrm{~A}$ & & IIIc & & Debitage & 1079 \\
\hline 15 & $4 \mathrm{~A}$ & & IIIc & $235-3$ & Denticulated flake & \\
\hline 15 & $4 \mathrm{~A}$ & & IIIc & OR34 & Edge modified flake & 1 \\
\hline 15 & $4 \mathrm{~A}$ & & IIIc & $235-1$ & Edge modified flake & 1 \\
\hline 15 & $4 \mathrm{~A}$ & & IIIc & OR32 & Flake, unanalyzed & 1 \\
\hline 15 & $4 \mathrm{~A}$ & & IIIc & $235-2$ & Projectile point fragment & 1 \\
\hline 15 & 4B & & IIIc & $385-1$ & Biface fragment & 1 \\
\hline 15 & 4B & & IIIc & $385-2$ & Biface fragment & 1 \\
\hline 15 & 4B & & IIIIc & & Debitage & 749 \\
\hline $\begin{array}{l}15 \\
15\end{array}$ & $\begin{array}{l}4 \mathrm{~B} \\
4 \mathrm{~B}\end{array}$ & & $\begin{array}{l}\text { IIIc } \\
\text { IIIc }\end{array}$ & $385-4$ & Edge modified flake & 1 \\
\hline $\begin{array}{l}15 \\
15\end{array}$ & $\begin{array}{l}4 \mathrm{~B} \\
4 \mathrm{~B}\end{array}$ & & $\begin{array}{l}\text { IIIc } \\
\text { IIIC }\end{array}$ & $\begin{array}{l}\text { OR107 } \\
385-3\end{array}$ & Mano fragment & 1 \\
\hline $\begin{array}{l}15 \\
15\end{array}$ & $\begin{array}{l}4 \mathrm{~B} \\
4 \mathrm{~B}\end{array}$ & & $\begin{array}{l}\text { IIIc } \\
\text { IIIC }\end{array}$ & $\begin{array}{l}385-3 \\
385-5\end{array}$ & $\begin{array}{l}\text { Unifacial multiple tool } \\
\text { Unifacial multiple tool }\end{array}$ & \\
\hline $\begin{array}{l}15 \\
15\end{array}$ & $5 \mathrm{~A}$ & & $\begin{array}{l}\text { IIIC } \\
\text { IIIc }\end{array}$ & $387-1$ & $\begin{array}{l}\text { Unifacial multiple tool } \\
\text { Burin }\end{array}$ & $\begin{array}{l}1 \\
1\end{array}$ \\
\hline 15 & $5 \mathrm{~A}$ & & IIIc & $387-2$ & $\begin{array}{l}\text { Burın } \\
\text { Burin }\end{array}$ & 1 \\
\hline 15 & $5 \mathrm{~A}$ & & IIIIc & $387-3$ & Burin & 1 \\
\hline 15 & $5 \mathrm{~A}$ & & IIIc & & Debitage & 383 \\
\hline 15 & $6 \mathrm{~A}$ & & IIIIC & $129-8$ & Biface fragment & 1 \\
\hline 15 & $6 \mathrm{~A}$ & & IIIc & OR148 & Blade & 1 \\
\hline 15 & $6 \mathrm{~A}$ & & IIIc & & Debitage & 1082 \\
\hline 15 & $6 \mathrm{~A}$ & & IIIIc & $129-5$ & Edge modified flake & 1 \\
\hline 15 & $6 \mathrm{~A}$ & & IIIc & $129-3$ & Edge modified flake & 1 \\
\hline 15 & $6 \mathrm{~A}$ & & IIIIc & $129-6$ & Edge modified flake & 1 \\
\hline 15 & $6 \mathrm{~A}$ & & IIIc & $129-2$ & Edge modified flake & 1 \\
\hline 15 & $6 \mathrm{~A}$ & & IIIIc & OR142 & Projectile point, Marcos/Marshall & 1 \\
\hline 15 & $6 \mathrm{~A}$ & & IIIc & OR149 & Thin uniface & 1 \\
\hline 15 & $6 \mathrm{~A}$ & & IIIc & $129-1$ & Thin uniface fragment & 1 \\
\hline 15 & $6 \mathrm{~B}$ & Feature 206 & IIIc & & Debitage & 7 \\
\hline 15 & 7 & & $\mathrm{IIIb} / \mathrm{c}$ & $486-1$ & Biface fragment & 1 \\
\hline 15 & 7 & & $\mathrm{IIIb} / \mathrm{c}$ & $486-3$ & Biface Stage 2 & 1 \\
\hline 15 & 7 & & IIIb/c & $486-2$ & Bifacial tool & 1 \\
\hline 15 & 7 & & IIIb/c & & Debitage & 476 \\
\hline 15 & 7 & & $\mathrm{IIIb} / \mathrm{c}$ & $486-4$ & Unifacial multiple tool & 1 \\
\hline 15 & 8 & & $\mathrm{IIIb} / \mathrm{c}$ & & Debitage & 189 \\
\hline 15 & 8 & & $\mathrm{IIIb} / \mathrm{c}$ & $507-1$ & Edge modified flake & 1 \\
\hline 15 & 9 & & IIIb & $526-2$ & Biface fragment & 1 \\
\hline 15 & 9 & & IIIb & $526-1$ & Biface Stage 1 & 1 \\
\hline 15 & 9 & & IIIb & & Debitage & 204 \\
\hline 15 & 10 & & IIIb & OR186 & Biface Stage 2 & 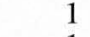 \\
\hline 15 & 10 & & IIIb & $542-1$ & Biface Stage 2 & 1 \\
\hline 15 & 10 & & IIIb & OR181 & Biface Stage 2 & 1 \\
\hline 15 & 10 & & IIIb & & Debitage & 140 \\
\hline 15 & 10 & & IIIb & $542-2$ & Edge modified flake & 1 \\
\hline 15 & 10 & & IIIb & $542-4$ & Edge modified flake & 1 \\
\hline 15 & 10 & & IIIb & $542-5$ & Edge modified flake & 1 \\
\hline
\end{tabular}




\begin{tabular}{|c|c|c|c|c|c|c|}
\hline $\begin{array}{l}\text { Square } \\
15\end{array}$ & $\begin{array}{l}\text { Level } \\
10\end{array}$ & Feature & $\begin{array}{l}\text { Strata } \\
\text { IIIIb }\end{array}$ & Item & $\begin{array}{l}\text { Analyst Identification } \\
\text { Edge modified flake }\end{array}$ & $\begin{array}{r}\text { Count } \\
1\end{array}$ \\
\hline 15 & 10 & & IIIb & $542-6$ & $\begin{array}{l}\text { Edge modified flake } \\
\text { Thin uniface }\end{array}$ & 1 \\
\hline 15 & 11 & & IIIb & $549-3$ & Bifacial tool Form H & 1 \\
\hline 15 & 11 & & IIIIb & OR190 & Core, thermal & 1 \\
\hline 15 & 11 & & IIIb & & Debitage & 441 \\
\hline 15 & 11 & & III b & $549-5$ & Edge modified flake & 1 \\
\hline 15 & 11 & & IIIb & OR189 & Flake, unanalyzed & 1 \\
\hline 15 & 11 & & IIIIb & $549-1$ & Thin uniface & 1 \\
\hline 15 & 11 & & IIIb & OR197 & Tool, unanalyzed & 1 \\
\hline 15 & 12 & & IIIa/b & & Debitage & 375 \\
\hline 15 & 12 & & $\mathrm{IIIa} / \mathrm{b}$ & $568-6$ & Edge modified flake & 1 \\
\hline 15 & 12 & & $\mathrm{III} a / \mathrm{b}$ & $568-3$ & Edge modified flake & 1 \\
\hline 15 & 12 & & $\mathrm{IIIa} / \mathrm{b}$ & $568-8$ & Edge modified flake & 1 \\
\hline 15 & 12 & & $\mathrm{IIIa} / \mathrm{b}$ & $568-4$ & Edge modified flake & 1 \\
\hline 15 & 12 & & $\mathrm{IIIa} / \mathrm{b}$ & $568-5$ & Spurred flake & 1 \\
\hline 15 & 12 & & IIIa/b & $568-2$ & Thin uniface fragment & 1 \\
\hline 15 & 12 & & $\mathrm{IIIa} / \mathrm{b}$ & OR208 & Thin uniface fragment & 1 \\
\hline 15 & 13 & & IIIa/b & & Debitage & 563 \\
\hline 15 & 13 & & IIIa/b & $596-5$ & Edge modified flake & 1 \\
\hline 15 & 13 & & IIIa/b & $596-14$ & Edge modified flake & 1 \\
\hline 15 & 13 & & $\mathrm{IIIa} / \mathrm{b}$ & OR254 & Flake, unanalyzed & 1 \\
\hline 15 & 13 & & $\mathrm{IIIa} / \mathrm{b}$ & OR256 & Flake, unanalyzed & 1 \\
\hline 15 & 13 & & $\mathrm{IIIa} / \mathrm{b}$ & $596-1$ & Projectile point, expanding stem A & 1 \\
\hline 15 & 14 & & IIIa/b & $640-4$ & Biface fragment & 1 \\
\hline 15 & 14 & & IIIIa/b & $640-2$ & Biface Stage 1 & 1 \\
\hline 15 & 14 & & $\mathrm{IIIa} / \mathrm{b}$ & $640-1$ & Biface Stage 2 & 1 \\
\hline 15 & 14 & & $\mathrm{IIIa} / \mathrm{b}$ & OR262 & Bifacial tool & 1 \\
\hline 15 & 14 & & $\mathrm{III} / \mathrm{b}$ & & Debitage & 533 \\
\hline 15 & 14 & & IIIa/b & $640-3$ & Thin uniface fragment & 1 \\
\hline 15 & 14 & & $\mathrm{IIIa} / \mathrm{b}$ & $640-5$ & Unifacial multiple tool & 1 \\
\hline 15 & Wall & & & $679-1$ & Biface Stage 2 & 1 \\
\hline 16 & 1 & & Fill & & Debitage & 17 \\
\hline 16 & 2 & & IIIc (fill) & & Debitage & 38 \\
\hline 16 & 2 & & IIIc (fill) & $167-1$ & Edge modified flake & 1 \\
\hline 16 & 3 & & IIIc & $168-1$ & Arrow point, Scallorn & 1 \\
\hline 16 & 3 & & IIIC & $168-6$ & Biface fragment & 1 \\
\hline 16 & 3 & & IIIc & $168-4$ & Biface Stage 1 & 1 \\
\hline 16 & 3 & & IIIc & $168-10$ & Core, thermal & 1 \\
\hline 16 & 3 & & IIIc & & Debitage & 989 \\
\hline 16 & 3 & & IIIc & $168-3$ & Edge modified flake & 1 \\
\hline 16 & 3 & & IIIc & $168-2$ & Piece esquillee & 1 \\
\hline 16 & 3 & & IIIc & $168-8$ & Spurred flake & 1 \\
\hline 16 & 3 & & IIIc & $168-5$ & Unifacial multiple tool & 1 \\
\hline 16 & 4 & & IIIc & OR80 & Arrow point, Perdiz & 1 \\
\hline 16 & 4 & & IIIc & OR46 & Arrow point, Scallorn & 1 \\
\hline 16 & 4 & & IIIc & OR76 & Arrow point, stemmed & 1 \\
\hline 16 & 4 & & IIIC & $120-2$ & Arrow point, stemmed & 1 \\
\hline 16 & 4 & & IIIc & $120-4$ & Biface fragment & 1 \\
\hline 16 & 4 & & IIIc & $320-7$ & Biface fragment & 1 \\
\hline 16 & 4 & & IIIc & $120-3$ & Biface fragment & 1 \\
\hline 16 & 4 & & IIIc & OR85 & Biface Stage 2 & 1 \\
\hline 16 & 4 & & IIIC & OR47 & Biface Stage 2 & 1 \\
\hline 16 & 4 & & IIIc & OR90 & Biface Stage 2 & 1 \\
\hline 16 & 4 & & IIIc & $120-7$ & Biface Stage 2 & 1 \\
\hline 16 & 4 & & IIIc & $32 \mathrm{O}-3$ & Bifacial tool Form E & 1 \\
\hline 16 & 4 & & IIIc & $120-5$ & Burin & 1 \\
\hline 16 & 4 & & IIIC & $120-1$ & Core fragment & 1 \\
\hline 16 & 4 & & IIII & & Debitage & 2332 \\
\hline 16 & 4 & & IIIc & OR79 & Microspur/microdenticulate & 1 \\
\hline 16 & 4 & & IIIc & $120-6$ & Projectile point fragment & 1 \\
\hline 16 & 4 & & IIIc & OR83 & Projectile point, Marcos & 1 \\
\hline 16 & 4 & & IIIc & OR84 & Projectile point, miscellaneous bifurcate & 1 \\
\hline 16 & 4 & & IIIC & OR48 & Tool, unanalyzed & 1 \\
\hline 16 & 4 & & IIIc & OR89 & Uniface, unanalyzed & 1 \\
\hline 16 & 5 & & IIIc & $391-2$ & Biface fragment & 1 \\
\hline 16 & 5 & & IIIc & OR119 & Biface Stage 3 & 1 \\
\hline 16 & 5 & & IIIc & $391-1$ & Burin spall & 1 \\
\hline 16 & 5 & & IIIC & & Debitage & 933 \\
\hline 16 & 5 & & IIIC & $391-3$ & Projectile point fragment & 1 \\
\hline 16 & 5 & & IIIc & OR114 & Unifacial multiple tool & 1 \\
\hline 16 & $6 \mathrm{~A}$ & & IIIC & $455-1$ & Burin & 1 \\
\hline 16 & $6 \mathrm{~A}$ & & IIII & & Debitage & 978 \\
\hline 16 & $6 \mathrm{~A}$ & & IIIC & $455-2$ & Edge modified flake & 1 \\
\hline 16 & $6 \mathrm{~B}$ & Feature 206 & IIIc & OR139 & Biface Stage 1 & 1 \\
\hline
\end{tabular}




\begin{tabular}{|c|c|c|c|c|c|c|}
\hline Square & Level & Feature & Strata & Item & Analyst Identification & Count \\
\hline 16 & $6 \mathrm{~B}$ & Feature 206 & IIIc & OR145 & Biface Stage 2 & 1 \\
\hline 16 & $6 \mathrm{~B}$ & Feature 206 & IIIc & OR137 & Biface Stage 2 & 1 \\
\hline 16 & $6 \mathrm{~B}$ & Feature 206 & IIIc & $452-1$ & Burin spall & 1 \\
\hline 16 & $6 \mathrm{~B}$ & Feature 206 & IIIc & & Debitage & 7 \\
\hline 16 & $6 \mathrm{~B}$ & Feature 206 & IIIc & OR135 & Edge modified flake & 1 \\
\hline 16 & $6 \mathrm{~B}$ & Feature 206 & IIIc & OR 141 & Projectile point, rectangular stem $\mathrm{C}$ & 1 \\
\hline 16 & $6 \mathrm{~B}$ & Feature 206 & IIIc & $452-2$ & Spurred flake & 1 \\
\hline 16 & $7 \mathrm{~A}$ & & $\mathrm{IIIb} / \mathrm{c}$ & $480-5$ & Biface fragment & 1 \\
\hline 16 & $7 \mathrm{~A}$ & & $\mathrm{IIIb} / \mathrm{c}$ & $480-4$ & Biface Stage 1 & 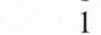 \\
\hline 16 & $7 \mathrm{~A}$ & & $\mathrm{IIIb} / \mathrm{c}$ & $480-3$ & Burin spall & 1 \\
\hline 16 & $7 \mathrm{~A}$ & & $\mathrm{IIIb} / \mathrm{c}$ & & Debitage & 494 \\
\hline 16 & $7 \mathrm{~A}$ & & $\mathrm{IIIb} / \mathrm{c}$ & $480-6$ & Edge modified flake & 1 \\
\hline 16 & $7 \mathrm{~A}$ & & $\mathrm{IIIb} / \mathrm{c}$ & $480-2$ & Projectile point, Marshall & 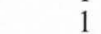 \\
\hline 16 & $7 \mathrm{~A}$ & & $\mathrm{IIIb} / \mathrm{c}$ & $480-7$ & Projectile point, rectangular stem B & 1 \\
\hline 16 & $7 \mathrm{~A}$ & & $\mathrm{IIIb} / \mathrm{c}$ & $480-1$ & Projectile point, Williams & 1 \\
\hline 16 & $7 \mathrm{~B}$ & Feature 208 & $\mathrm{IIIb} / \mathrm{c}$ & & Debitage & 2 \\
\hline 16 & 8 & & $\mathrm{IIIb} / \mathrm{c}$ & $511-4$ & Biface fragment & 1 \\
\hline 16 & 8 & & $\mathrm{IIIb} / \mathrm{c}$ & $511-6$ & Biface Stage 2 & 1 \\
\hline 16 & 8 & & $\mathrm{IIIb} / \mathrm{c}$ & & Debitage & 488 \\
\hline 16 & 8 & & $\mathrm{IIIb} / \mathrm{c}$ & $511-1$ & Edge modified flake & 1 \\
\hline 16 & 8 & & $\mathrm{IIIb} / \mathrm{c}$ & $511-5$ & Projectile point, indeterminate & 1 \\
\hline 16 & 9 & & $\mathrm{IIIb} / \mathrm{c}$ & OR183 & Biface Stage 3 & 1 \\
\hline 16 & 9 & & $\mathrm{IIIb} / \mathrm{c}$ & & Debitage & 684 \\
\hline 16 & 9 & & $\mathrm{IIIb} / \mathrm{c}$ & $530-2$ & Edge modified flake & 1 \\
\hline 16 & 9 & & $\mathrm{IIIb} / \mathrm{c}$ & $530-3$ & Edge modified flake & 1 \\
\hline 16 & 9 & & $\mathrm{IIIb} / \mathrm{c}$ & OR184 & Projectile point, Bell/Andice & 1 \\
\hline 16 & 9 & & $\mathrm{IIIb} / \mathrm{c}$ & $530-1$ & Projectile point, expanding stem A & 1 \\
\hline 16 & $10 \mathrm{~A}$ & & IIIb & OR 194 & Biface Stage 2 & 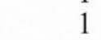 \\
\hline 16 & $10 \mathrm{~B}$ & Feature 214 & IIIb & $609-1$ & Biface fragment & 1 \\
\hline 16 & $10 \mathrm{~B}$ & Feature 214 & IIIb & OR239 & Biface Stage 2 & 1 \\
\hline 16 & $10 \mathrm{~B}$ & Feature 214 & IIIb & & Debitage & 515 \\
\hline 16 & $10 \mathrm{~B}$ & Feature 214 & IIIb & $609-2$ & Edge modified flake & 1 \\
\hline 16 & $10 \mathrm{~B}$ & Feature 214 & IIIb & OR237 & Flake, unanalyzed & 1 \\
\hline 16 & $11 \mathrm{~A}$ & & IIIb & OR260 & Biface Stage 2 & 1 \\
\hline 16 & $11 \mathrm{~A}$ & & IIIb & $580-1$ & Burin spall & 1 \\
\hline 16 & $11 \mathrm{~A}$ & & IIIb & & Debitage & 574 \\
\hline 16 & $11 \mathrm{~A}$ & & IIIb & OR247 & Flake, unanalyzed & - \\
\hline 16 & $11 \mathrm{~A}$ & & IIIb & OR246 & Flake, unanalyzed & 1 \\
\hline 16 & $11 \mathrm{~A}$ & & IIIb & OR209 & Projectile point, Bulverde & 1 \\
\hline 16 & $11 \mathrm{~B}$ & & IIIb & & Debitage & 36 \\
\hline 16 & $12 \mathrm{~A}$ & & IIIb & & Debitage & 735 \\
\hline 16 & $12 \mathrm{~A}$ & & $\mathrm{IIIb}$ & $651-5$ & Edge modified flake & 1 \\
\hline 16 & $12 \mathrm{~A}$ & & IIIb & $651-9$ & Edge modified flake & 1 \\
\hline 16 & $12 \mathrm{~A}$ & & $\mathrm{IIIb}$ & OR270 & Flake, unanalyzed & 1 \\
\hline 16 & $12 \mathrm{~A}$ & & IIIb & $651-2$ & Spurred flake & 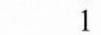 \\
\hline 16 & $12 \mathrm{~A}$ & & IIIb & $651-1$ & Thin uniface fragment & 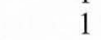 \\
\hline 16 & 13 & & $\mathrm{III} / \mathrm{b}$ & $685-1$ & Biface fragment & 1 \\
\hline 16 & 13 & & IIIa/b & OR288 & Biface Stage 1 & 1 \\
\hline 16 & 13 & & $\mathrm{IIIa} / \mathrm{b}$ & & Debitage & 557 \\
\hline 16 & 13 & & IIIa/b & $685-4$ & Edge modified flake & 1 \\
\hline 16 & 13 & & $\mathrm{III} / \mathrm{b}$ & $685-8$ & Edge modified flake & 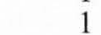 \\
\hline 16 & 13 & & IIIa/b & $685-5$ & Edge modified flake & 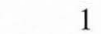 \\
\hline 16 & 13 & & $\mathrm{III} / \mathrm{b}$ & $685-7$ & Edge modified flake & $x$ \\
\hline 16 & 13 & & $\mathrm{IIIa} / \mathrm{b}$ & OR286 & Flake, unanalyzed & 1 \\
\hline 16 & 13 & & $\mathrm{IIIa} / \mathrm{b}$ & $685-2$ & Thin uniface fragment & 1 \\
\hline 16 & 13 & & $\mathrm{IIIa} / \mathrm{b}$ & $685-3$ & Thin uniface fragment & 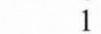 \\
\hline 17 & 1 & & Fill & $110-3$ & Biface fragment & 1 \\
\hline 17 & 1 & & Fill & $110-2$ & Biface fragment & 1 \\
\hline 17 & 1 & & Fill & $110-4$ & Biface Stage 2 & 1 \\
\hline 17 & 1 & & Fill & & Debitage & 14 \\
\hline 17 & 1 & & Fill & $110-1$ & Perforator Group 2 & 1 \\
\hline 17 & 1 & & Fill & $110-5$ & Perforator Group 7 & 1 \\
\hline 17 & 2 & & IIIc (fill) & 151 & Arrow point, stemmed & \\
\hline 17 & 2 & & IIIc (fill) & & Debitage & 1 \\
\hline 17 & 3 & & IIIc & $194-12$ & Biface fragment & 1 \\
\hline 17 & 3 & & IIIC & $194-5$ & Biface Stage 2 & 1 \\
\hline 17 & 3 & & IIIc & $194-6$ & Biface Stage 2 & 1 \\
\hline 17 & 3 & & IIIc & $194-9$ & Core, thermal & 1 \\
\hline 17 & 3 & & IIIc & & Debitage & 1030 \\
\hline 17 & 3 & & IIIc & 194-14 & Edge modified flake & 1 \\
\hline 17 & 3 & & IIII & 194-11 & Edge modified flake & 1 \\
\hline 17 & 3 & & IIIc & $194-10$ & Edge modified flake & \\
\hline 17 & 3 & & IIIc & $194-13$ & Edge modified flake & \\
\hline 17 & 3 & & IIIc & $194-2$ & Projectile point fragment & 1 \\
\hline
\end{tabular}




\begin{tabular}{|c|c|c|c|c|c|c|}
\hline Square & Level & Feature & Strata & Item & Analyst Identification & Count \\
\hline 17 & 3 & & IIIc & $194-1$ & Projectile point fragment & 1 \\
\hline 17 & 3 & & IIIc & 194-3 & Projectile point fragment & 1 \\
\hline 17 & 4 & & IIIc & $258-5$ & Arrow point, Scallorn & 1 \\
\hline 17 & 4 & & IIIc & OR42 & Arrow point, unanalyzed & 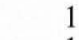 \\
\hline 17 & 4 & & IIIc & $258-10$ & Biface fragment & 1 \\
\hline 17 & 4 & & IIIc & $280-17$ & Biface fragment & 1 \\
\hline 17 & 4 & & IIIc & OR35 & Biface fragment & 1 \\
\hline 17 & 4 & & IIIc & $280-6$ & Biface fragment & 1 \\
\hline 17 & 4 & & IIIc & $280-15$ & Biface fragment & 1 \\
\hline 17 & 4 & & IIIC & OR74 & Biface fragment, unanalyzed & 1 \\
\hline 17 & 4 & & IIIc & OR44 & Biface Stage 2 & 1 \\
\hline 17 & 4 & & IIIIc & OR75 & Biface Stage 3 & 1 \\
\hline 17 & 4 & & IIIC & OR45 & Burin spall & 1 \\
\hline 17 & 4 & & IIIc & $311-1$ & Burin spall & 1 \\
\hline 17 & 4 & & IIIc & $310-5$ & Burin spall & 1 \\
\hline 17 & 4 & & IIIc & & Debitage & 1872 \\
\hline 17 & 4 & & IIIc & $258-9$ & Edge modified flake & 1 \\
\hline 17 & 4 & & IIIc & OR39 & Edge modified flake & 1 \\
\hline 17 & 4 & & IIIC & $258-1$ & Edge modified flake & 1 \\
\hline 17 & 4 & & IIIC & OR41 & Mano fragment & $x$ \\
\hline 17 & 4 & & IIIc & 272 & Mano fragment & 1 \\
\hline 17 & 4 & & IIIc & $308-1$ & Projectile point fragment & 1 \\
\hline 17 & 4 & & IIIC & $281-1$ & Projectile point, miscellaneous side-notched & 1 \\
\hline 17 & 4 & & IIIc & $293-1$ & Spurred flake & 1 \\
\hline 17 & 4 & & IIIC & OR36 & Unifacial multiple tool & 1 \\
\hline 17 & 5 & & IIIc & OR100 & Biface fragment, unanalyzed & 1 \\
\hline 17 & 5 & & IIIc & OR113 & Burin & 1 \\
\hline 17 & 5 & & IIIc & OR99 & Burin & 1 \\
\hline 17 & 5 & & IIIc & & Debitage & 1126 \\
\hline 17 & 5 & & IIIc & OR101 & Edge modified flake & 1 \\
\hline 17 & 6 & & IIIc & OR134 & Biface Stage 1 & 1 \\
\hline 17 & 6 & & IIIc & OR133 & Biface Stage 2 & 1 \\
\hline 17 & 6 & & IIIc & OR117 & Biface Stage 3 & 1 \\
\hline 17 & 6 & & IIIc & & Debitage & 1238 \\
\hline 17 & $7 \mathrm{~A}$ & & $\mathrm{IIIb} / \mathrm{c}$ & $454-7$ & Biface fragment & 1 \\
\hline 17 & $7 \mathrm{~A}$ & & $\mathrm{IIIl} / \mathrm{c}$ & & Debitage & 834 \\
\hline 17 & $7 \mathrm{~A}$ & & $\mathrm{IIIb} / \mathrm{c}$ & $454-6$ & Edge modified flake & 1 \\
\hline 17 & $7 \mathrm{~A}$ & & $\mathrm{IIIb} / \mathrm{c}$ & $454-2$ & Edge modified flake & 1 \\
\hline 17 & $7 \mathrm{~A}$ & & $\mathrm{IIIb} / \mathrm{c}$ & OR144 & Edge modified flake & 1 \\
\hline 17 & $7 \mathrm{~A}$ & & $\mathrm{IIIb} / \mathrm{c}$ & OR155 & Edge modified flake & 1 \\
\hline 17 & $7 \mathrm{~A}$ & & $\mathrm{IIIb} / \mathrm{c}$ & $454-8$ & Edge modified flake & 1 \\
\hline 17 & 7A & & $\mathrm{IIIb} / \mathrm{c}$ & OR143 & Projectile point fragment, unanalyzed & 1 \\
\hline 17 & $7 \mathrm{~A}$ & & $\mathrm{IIIb} / \mathrm{c}$ & $454-1$ & Projectile point, Williams & 1 \\
\hline 17 & 7A & & $\mathrm{IIIb} / \mathrm{c}$ & OR140 & Thick uniface & 1 \\
\hline 17 & $7 \mathrm{~B}$ & Feature 208 & $\mathrm{IIIb} / \mathrm{c}$ & & Debitage & 1 \\
\hline 17 & $8 \mathrm{~A}$ & & $\mathrm{IIIb} / \mathrm{c}$ & & Debitage & 515 \\
\hline 17 & $8 \mathrm{~B}$ & Feature 211 & $\mathrm{IIIb} / \mathrm{c}$ & & Debitage & 21 \\
\hline 17 & 9 & & IIIb & $544-2$ & Bifacial tool Form A & 1 \\
\hline 17 & 9 & & IIIb & & Debitage & 618 \\
\hline 17 & 9 & & IIIb & $544-8$ & Edge modified flake & 1 \\
\hline 17 & 9 & & IIIb & $544-7$ & Edge modified flake & 1 \\
\hline 17 & 9 & & IIIlb & $544-6$ & Edge modified flake & 1 \\
\hline 17 & 9 & & IIIb & $544-1$ & Edge modified flake & 1 \\
\hline 17 & 9 & & IIIb & $544-4$ & Edge modified flake & 1 \\
\hline 17 & 9 & & IIIb & OR211 & Edge modified flake & 1 \\
\hline 17 & 10 & & IIIb & $595-15 b$ & Core, thermal & 1 \\
\hline 17 & 10 & & IIIlb & $595-15 a$ & Core, thermal & 1 \\
\hline 17 & 10 & & IIIb & & Debitage & 660 \\
\hline 17 & 10 & & IIIb & $595-10$ & Denticulated flake & 1 \\
\hline 17 & 10 & & IIIb & OR252 & Flake, unanalyzed & 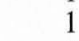 \\
\hline 17 & 10 & & IIIb & $595-5$ & Projectile point fragment & 1 \\
\hline 17 & 10 & & IIIb & $595-12$ & Projectile point fragment & , \\
\hline 17 & 10 & & IIIb & OR238 & Projectile point, Bulverde & 1 \\
\hline 17 & 10 & & IIIb & $595-1$ & Projectile point, Bulverde-like & 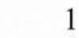 \\
\hline 17 & 10 & & IIIb & $595-2$ & Projectile point, miscellaneous expanding sten & $\mathrm{m}$ \\
\hline 17 & 10 & & IIIb & OR243 & Projectile point, Nolan & 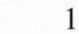 \\
\hline 17 & 11 & & IIIb & $652-1$ & Biface fragment & 1 \\
\hline 17 & 11 & & IIIb & OR267 & Biface Stage 1 & 1 \\
\hline 17 & 11 & & IIIb & OR266 & Biface Stage 2 & 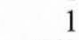 \\
\hline 17 & 11 & & IIIb & & Debitage & 562 \\
\hline 17 & 11 & & IIIb & OR274 & Flake, unanalyzed & . \\
\hline 17 & 11 & & IIIb & OR277 & Flake, unanalyzed & 1 \\
\hline 17 & 11 & & IIIb & $652-3$ & Projectile point, expanding stem A & 1 \\
\hline 17 & 12 & & IIIb & OR281 & Biface Stage 1 & \\
\hline
\end{tabular}




\begin{tabular}{|c|c|c|c|c|c|c|}
\hline Square & Level & Feature & Strata & Item & Analyst Identification & Count \\
\hline 17 & 12 & & IIIb & OR280 & Bifacial tool & \\
\hline 17 & 12 & & IIIb & & Debitage & 754 \\
\hline 17 & 12 & & IIIb & $676-5$ & Edge modified flake & \\
\hline 17 & 12 & & IIIb & $676-2$ & Projectile point fragment & \\
\hline 17 & 12 & & IIIb & OR284 & Projectile point, miscellaneous bifurcate & \\
\hline 17 & 12 & & IIIb & $676-1$ & Projectile point, miscellaneous side-notched & \\
\hline 17 & 12 & & IIIb & $676-3$ & Thin uniface fragment & \\
\hline 17 & 13 & & $\mathrm{IIIa} / \mathrm{b}$ & OR303 & Biface Stage 1 & \\
\hline 17 & 13 & & IIIa/b & OR307 & Bifacial tool & \\
\hline 17 & 13 & & IIIa/b & $703-2$ & Bifacial tool Form E & 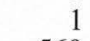 \\
\hline 17 & 13 & & IIIa/b & & Debitage & 569 \\
\hline 17 & 13 & & IIIa/b & OR298 & Flake, unanalyzed & \\
\hline 17 & 13 & & IIIa/b & OR297 & Projectile point, expanding concave B & \\
\hline $17 \& 15$ & $10 \& 13$ & & IIIa/b & & Debitage & \\
\hline $17 \& 15$ & $10 \& 13$ & & IIIa/b & $3009-11 \mathrm{~B}$ & Edge modified flake & \\
\hline $17 \& 15$ & $10 \& 13$ & & IIIa/b & $3009-9 \mathrm{~A}$ & Edge modified flake & \\
\hline $17 \& 15$ & $10 \& 13$ & & IIIa $/ \mathrm{b}$ & $3009-13 B$ & Edge modified flake & \\
\hline $17 \& 15$ & $10 \& 13$ & & IIIa/b & $3009-4 B$ & Edge modified flake & \\
\hline $17 \& 15$ & $10 \& 13$ & & $\mathrm{III} a / \mathrm{b}$ & $3009-3 \mathrm{~A}$ & Edge modified flake & 1 \\
\hline $17 \& 15$ & $10 \& 13$ & & IIIa/b & $3009-8 B$ & Edge modified flake & \\
\hline $17 \& 15$ & $10 \& 13$ & & IIIa/b & $3009-9 B$ & Edge modified flake & \\
\hline $17 \& 15$ & $10 \& 13$ & & $\mathrm{IIIa} / \mathrm{b}$ & $3009-6 B$ & Edge modified flake & 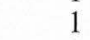 \\
\hline $17 \& 15$ & $10 \& 13$ & & IIIa/b & $3009-8 \mathrm{~A}$ & Edge modified flake & 1 \\
\hline $17 \& 15$ & $10 \& 13$ & & IIIa/b & $3009-7 \mathrm{~A}$ & Unifacial multiple tool & 1 \\
\hline 18 & 1 & & Fill & $159-1$ & Biface fragment & 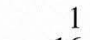 \\
\hline 18 & 1 & & Fill & & Debitage & 16 \\
\hline 18 & 8 & & IIIc (fill) & & Debitage & 67 \\
\hline 18 & 8 & & IIIc (fill) & $195-1$ & Projectile point fragment & \\
\hline 18 & 9 & & $\mathrm{IIIb} / \mathrm{c}$ (fill) & $371-1$ & Biface fragment & \\
\hline 18 & 9 & & $\mathrm{IIIb} / \mathrm{c}$ (fill) & OR60 & Bifacial tool & \\
\hline 18 & 9 & & IIIb/c (fill) & & Debitage & 481 \\
\hline 18 & 9 & & IIIb/c (fill) & $371-5$ & Edge modified flake & \\
\hline 18 & 9 & & $\mathrm{IIIb} / \mathrm{c}$ (fill) & $371-2$ & Edge modified flake & \\
\hline 18 & 9 & & $\mathrm{IIIb} / \mathrm{c}$ (fill) & $371-3$ & Edge modified flake & \\
\hline 18 & 9 & & $\mathrm{IIIb} / \mathrm{c}$ (fill) & 402 & Projectile point fragment & \\
\hline 18 & 9 & & IIIb/c (fill) & 378 & Projectile point, Castroville & \\
\hline 18 & 9 & & IIIb/c (fill) & 379 & Projectile point, expanding concave B & \\
\hline 18 & 9 & & $\mathrm{IIIb} / \mathrm{c}$ (fill) & 388 & Thin uniface & \\
\hline 18 & 9 & & $\mathrm{IIIb} / \mathrm{c}$ (fill) & OR58 & Tool, unanalyzed & \\
\hline 18 & 9 & & $\mathrm{IIIb} / \mathrm{c}$ (fill) & $371-4$ & Unifacial multiple tool & \\
\hline 18 & 10 & & $\mathrm{IIIb} / \mathrm{c}$ & OR61 & Burin & \\
\hline 18 & 10 & & $\mathrm{IIIb} / \mathrm{c}$ & & Debitage & 1329 \\
\hline 18 & 10 & & $\mathrm{IIIb} / \mathrm{c}$ & $412-4$ & Edge modified flake & \\
\hline 18 & 10 & & $\mathrm{IIIb} / \mathrm{c}$ & $412-5$ & Edge modified flake & \\
\hline 18 & 10 & & $\mathrm{IIIb} / \mathrm{c}$ & $412-7$ & Edge modified flake & \\
\hline 18 & 10 & & $\mathrm{IIIb} / \mathrm{c}$ & $412-1$ & Edge modified flake & 1 \\
\hline 18 & 10 & & $\mathrm{IIIb} / \mathrm{c}$ & $412-3$ & Projectile point fragment & \\
\hline 18 & 10 & & $\mathrm{IIIb} / \mathrm{c}$ & $412-6$ & Projectile point fragment & \\
\hline 18 & 11 & & $\mathrm{IIIb} / \mathrm{c}$ & $589-1$ & Biface fragment & \\
\hline 18 & 11 & & $\mathrm{IIIb} / \mathrm{c}$ & & Debitage & 808 \\
\hline 18 & 11 & & $\mathrm{IIIb} / \mathrm{c}$ & 2171-1 & Edge modified flake & \\
\hline 18 & 11 & & $\mathrm{IIIb} / \mathrm{c}$ & $2171-2$ & Micro-core, large & \\
\hline 18 & 11 & & $\mathrm{IIIb} / \mathrm{c}$ & $589-2$ & Projectile point fragment & \\
\hline 18 & 11 & & $\mathrm{IIIb} / \mathrm{c}$ & OR230 & Projectile point, Nolan-like & \\
\hline 18 & 12 & & IIIb & & Debitage & 259 \\
\hline 18 & 12 & & IIIb & $607-2$ & Edge modified flake & \\
\hline 18 & 12 & & IIIb & $607-4$ & Edge modified flake & \\
\hline 18 & 12 & & IIIb & OR244 & Flake, unanalyzed & \\
\hline 18 & 13 & & IIIb & $653-3$ & Biface fragment & \\
\hline 18 & 13 & & $\mathrm{IIIb}$ & $653-6$ & Burin spall & \\
\hline 18 & 13 & & IIIb & & Debitage & 271 \\
\hline 18 & 13 & & IIIb & $653-7$ & Edge modified flake & \\
\hline 18 & 13 & & IIIb & $653-4$ & Edge modified flake & \\
\hline 18 & 13 & & IIIb & $653-8$ & Thick uniface & \\
\hline 18 & 14 & & IIIb & & Debitage & 128 \\
\hline 19 & 1 & & Fill & & Debitage & \\
\hline 19 & 1 & & Fill & 153 & Projectile point, Kinney & \\
\hline 19 & 1 & & Fill & $170-1$ & Thin uniface & \\
\hline 19 & 7 & & IIIc (fill) & OR22 & Biface Stage 1 & \\
\hline 19 & 7 & & IIIc (fill) & & Debitage & 145 \\
\hline 19 & 7 & & IIIc (fill) & $230-3$ & Edge modified flake & \\
\hline 19 & 7 & & IIIc (fill) & $230-1$ & Projectile point fragment & 1 \\
\hline 19 & $8 \mathrm{~A}$ & & $\mathrm{IIIb} / \mathrm{c}$ (fill) & $33 \mathrm{O}-2$ & Biface fragment & \\
\hline 19 & $8 \mathrm{~A}$ & & IIIb/c (fill) & $330-5$ & Biface fragment & \\
\hline
\end{tabular}




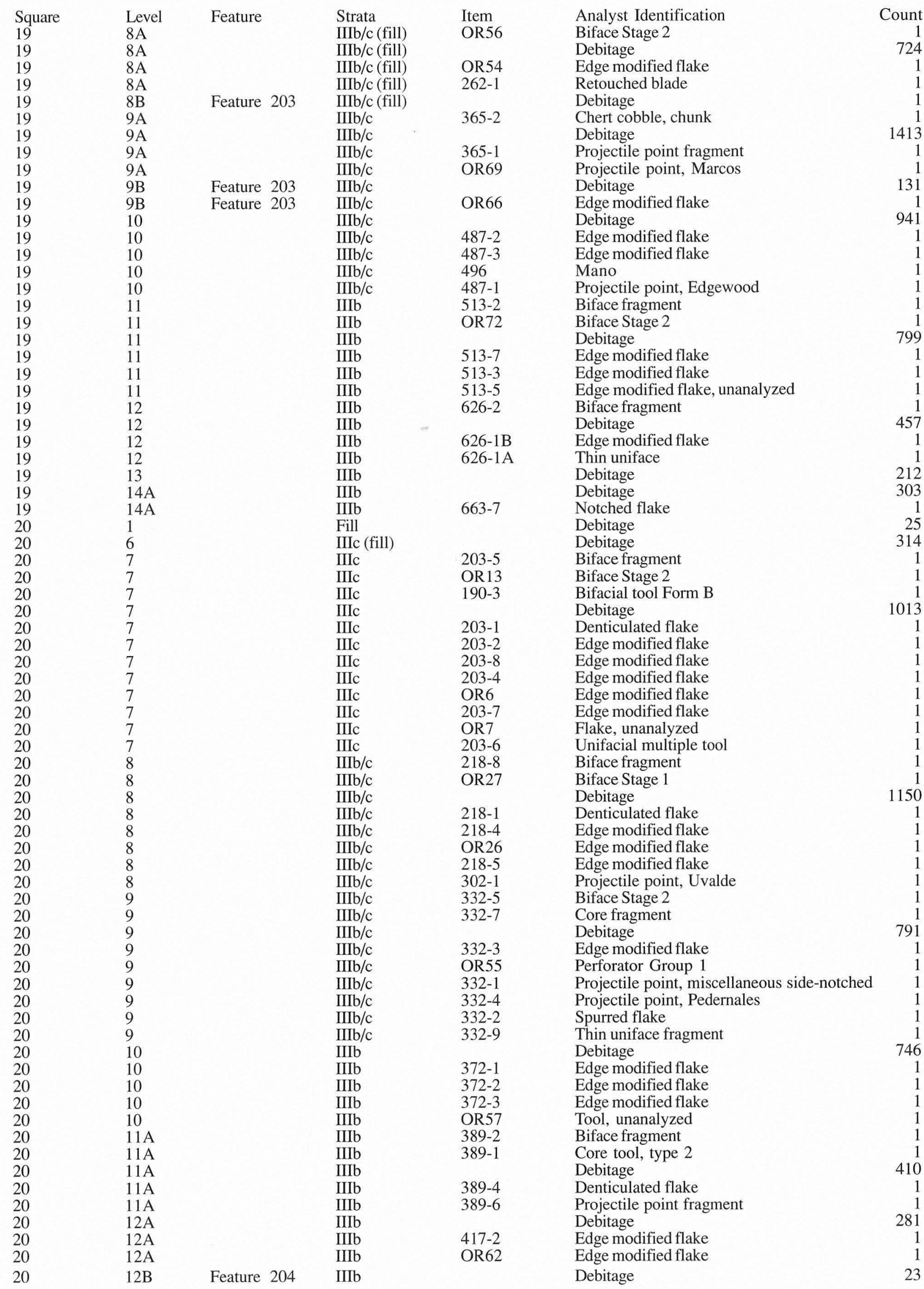




\begin{tabular}{|c|c|c|c|c|c|c|}
\hline Square & Level & Feature & Strata & Item & Analyst Identification & $\begin{array}{r}\text { Count } \\
267\end{array}$ \\
\hline $\begin{array}{l}20 \\
20\end{array}$ & $\begin{array}{l}13 \mathrm{~A} \\
13 \mathrm{~B}\end{array}$ & Feature 209 & $\begin{array}{l}\text { IIIb } \\
\text { IIIb }\end{array}$ & OR217 & $\begin{array}{l}\text { Debitage } \\
\text { Biface Stage 1 }\end{array}$ & $\begin{array}{r}267 \\
1\end{array}$ \\
\hline 20 & $13 \mathrm{~B}$ & Feature 209 & IIIJ & Unzit & Debitage & 22 \\
\hline 20 & $13 \mathrm{C}$ & Feature 209 & IIIb & 523 & Edge modified flake & 1 \\
\hline 20 & 14 & & IIIb & $531-4$ & Burin spall & 1 \\
\hline 20 & 14 & & IIIb & $531-3$ & Core, thermal & 1 \\
\hline 20 & 14 & & IIIb & & Debitage & 173 \\
\hline 20 & 14 & & IIIb & OR219 & Flake, unanalyzed & 1 \\
\hline 20 & 14 & & IIIb & OR223 & Projectile point, Early Triangular & 1 \\
\hline 20 & 15 & & $\mathrm{IIIa} / \mathrm{b}$ & $545-2$ & Biface fragment & 1 \\
\hline 20 & 15 & & IIIa/b & $545-3$ & Biface fragment & 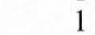 \\
\hline 20 & 15 & & IIIa/b & OR221 & Biface Stage 2 & 1 \\
\hline 20 & 15 & & IIIa/b & OR222 & Biface Stage 2 & 1 \\
\hline 20 & 15 & & IIIa/b & & Debitage & 679 \\
\hline 20 & 15 & & $\mathrm{IIIa} / \mathrm{b}$ & $545-1$ & Spurred flake & 1 \\
\hline 20 & $16 \mathrm{~A}$ & & $\mathrm{IIIa} / \mathrm{b}$ & & Debitage & 317 \\
\hline 20 & $16 \mathrm{~A}$ & & ПIІа/b & $562-1$ & Micro-core, intermediate & 1 \\
\hline 20 & $16 \mathrm{~A}$ & & IIIa/b & $562-2$ & Unifacial multiple tool & 1 \\
\hline 20 & $16 \mathrm{~B}$ & Feature 215 & $\mathrm{IIIa} / \mathrm{b}$ & & Debitage & 51 \\
\hline 20 & 17 & & IIIa & $582-3$ & Biface Stage 2 & \\
\hline 20 & 17 & & IIIa & & Debitage & 215 \\
\hline 20 & 17 & & IIIa & $582-4$ & Edge modified flake & 1 \\
\hline 20 & 17 & & IIIa & $582-1$ & Unifacial multiple tool & 1 \\
\hline 20 & 18 & & IIIa & $599-3$ & Burin spall & 1 \\
\hline 20 & 18 & & IIIa & $599-4$ & Burin spall & 1 \\
\hline 20 & 18 & & IIIa & & Debitage & 497 \\
\hline 20 & 18 & & IIIa & $599-6$ & Projectile point fragment & 1 \\
\hline 20 & 19 & & IIIa & $710-2$ & Biface fragment & 1 \\
\hline 20 & 19 & & IIIa & $710-7$ & Burin spall & 1 \\
\hline 20 & 19 & & IIIa & & Debitage & 773 \\
\hline 20 & 19 & & IIIa & $710-6$ & Edge modified flake & 1 \\
\hline 20 & 19 & & IIIa & $710-8$ & Edge modified flake & 1 \\
\hline 20 & 19 & & IIIa & $710-5$ & Perforator Group 7 & 1 \\
\hline 20 & 19 & & IIIa & OR389 & Rock, unanalyzed & 1 \\
\hline 20 & 19 & & IIIIa & OR388 & Rock, unanalyzed & 1 \\
\hline 20 & 19 & & IIIa & $710-1$ & Unifacial multiple tool & 1 \\
\hline 20 & 24 & & IIIa & & Debitage & 680 \\
\hline 20 & 24 & & IIIa & OR405 & Mano fragment & 1 \\
\hline 20 & 24 & & IIIa & 1016-1B & Notched flake & 1 \\
\hline 20 & 24 & & IIIa & $1016-2 \mathrm{~A}$ & Thin uniface fragment & 1 \\
\hline 20 & 25 & Feature 233 & II/IIIa & & Debitage & 8 \\
\hline 20 & $25 \mathrm{~A}-\mathrm{B}$ & & II/IIIa & & Debitage & 69 \\
\hline 20 & $25 \mathrm{~A}-\mathrm{B}$ & & II/IIIa & $1144-2$ & Edge modified flake & 1 \\
\hline 20 & $25 \mathrm{~A}-\mathrm{B}$ & & II/IIIa & 1144-1 & Edge modified flake & 1 \\
\hline 20 & $25 \mathrm{~B}$ & Feature 233 & II/IIIa & OR437 & Biface Stage 1 & 1 \\
\hline 20 & $25 \mathrm{~B}$ & Feature 233 & II/IIIa & & Debitage & 174 \\
\hline 20 & $25 \mathrm{~B}$ & Feature 233 & II/IIIa & $1185-1$ & Edge modified flake & i \\
\hline 20 & $25 \mathrm{~B}$ & Feature 233 & II/IIIa & OR446 & Flake, unanalyzed & 1 \\
\hline 20 & $26 \mathrm{~A}$ & & II/IIIa & & Debitage & 184 \\
\hline 20 & $26 \mathrm{~A}$ & & II/IIIa & $1244-2$ & Edge modified flake & 1 \\
\hline 20 & $26 \mathrm{~A}$ & & II/IIIa & OR459 & Edge modified flake, unanalyzed & 1 \\
\hline 20 & $26 \mathrm{~A}$ & & II/IIIa & OR461 & Thin uniface & 1 \\
\hline 20 & $26 \mathrm{~B}$ & Feature 233 & II/IIIa & OR457 & Biface Stage 1 & 1 \\
\hline 20 & $26 \mathrm{~B}$ & Feature 233 & II/IIIa & & Debitage & 20 \\
\hline 20 & 27 & & II/IIIa & $2430-1$ & Biface Stage 3 & 1 \\
\hline 20 & 27 & & II/IIIa & & Debitage & 96 \\
\hline 20 & 27 & & II/IIIa & $1251-3$ & Denticulated flake & 1 \\
\hline 20 & 27 & & II/IIIa & OR465 & Flake, unanalyzed & 1 \\
\hline 20 & 27 & & II/IIIa & OR466 & Flake, unanalyzed & \\
\hline 20 & 28 & & II/IIIa & & Debitage & 68 \\
\hline 20 & $29 \mathrm{~A}$ & & II & & Debitage & 133 \\
\hline 20 & 30 & & II & & Debitage & 162 \\
\hline 20 & $30 \mathrm{~B}$ & & II & & Debitage & 25 \\
\hline 20 & 31 & & II & & Debitage & 156 \\
\hline 20 & 31 & & II & $1537-2$ & Edge modified flake & \\
\hline 20 & 31 & & II & OR532 & Flake, unanalyzed & 1 \\
\hline 20 & 31 & & II & $1537-1$ & Projectile point fragment & 1 \\
\hline 20 & 32 & & II & OR556 & Core, unanalyzed & \\
\hline 20 & 32 & & II & & Debitage & 92 \\
\hline 20 & 32 & & II & OR567 & Flake, unanalyzed & \\
\hline 20 & 33 & & II & & Debitage & 161 \\
\hline 20 & 33 & & II & $1677-1$ & Thin uniface fragment & \\
\hline 20 & 34 & & II & OR585 & Burin spall & 1 \\
\hline 20 & 34 & & II & & Debitage & 131 \\
\hline
\end{tabular}




\begin{tabular}{|c|c|c|c|c|c|c|}
\hline $\begin{array}{l}\text { Square } \\
20\end{array}$ & $\begin{array}{l}\text { Level } \\
35\end{array}$ & Feature & $\begin{array}{l}\text { Strata } \\
\text { II }\end{array}$ & Item & $\begin{array}{l}\text { Analyst Identification } \\
\text { Debitage }\end{array}$ & $\begin{array}{r}\text { Count } \\
1\end{array}$ \\
\hline 20 & 35 & & II & OR596 & Rock, unanalyzed & 1 \\
\hline 20 & 36 & & II & & Debitage & 65 \\
\hline 20 & 36 & & II & OR602 & Flake, unanalyzed & 1 \\
\hline 20 & 36 & & II & OR604 & Flake, unanalyzed & 1 \\
\hline 20 & 37 & & II & & Debitage & 24 \\
\hline 20 & 38 & & Isi-c/II & & Debitage & 80 \\
\hline 20 & 39 & & Isi-c & & Debitage & 14 \\
\hline 20 & 40 & & Isi-c & & Debitage & 13 \\
\hline 20 & 41 & & Isi-c & & Debitage & 4 \\
\hline 20 & 42 & & Isi-c & & Debitage & 3 \\
\hline 20 & 43 & & Isi-c & & Debitage & 2 \\
\hline 20 & 44 & & Icl/Isi-c & & Debitage & 4 \\
\hline 20 & 45 & & Icl/Isi-c & OR657 & Core, thermal & 1 \\
\hline 20 & 45 & & $\mathrm{Icl} / \mathrm{Isi}-\mathrm{c}$ & & Debitage & 1 \\
\hline 20 & 46 & & Icl/Isi-c & & Debitage & 1 \\
\hline 20 & 48 & & Icl & & Debitage & 2 \\
\hline 20 & 49 & & Icl & & Debitage & 3 \\
\hline 20 & 49 & & Icl & $2875-1$ & Edge modified flake & 1 \\
\hline 20 & 49 & & Icl & OR679 & Flake, unanalyzed & 1 \\
\hline 20 & 50 & & Icl & OR689 & Biface Stage 2 & 1 \\
\hline 20 & 51 & & Icl & & Debitage & 1 \\
\hline 20 & 52 & & Icl & & Debitage & 2 \\
\hline 20 & 52 & & Icl & OR692 & Flake, unanalyzed & 1 \\
\hline 20 & 52 & & Icl & $2725-1$ & Thin uniface & 1 \\
\hline 20 & 53 & & Isi/Icl & OR705 & Flake, unanalyzed & 1 \\
\hline 20 & $54 \mathrm{~A}$ & & $\mathrm{Igl} / \mathrm{Isi} / \mathrm{Icl}$ & & Debitage & 5 \\
\hline 20 & $54 \mathrm{~B}$ & Feature 261 & Igl/Isi/Icl & & Debitage & 2 \\
\hline 20 & $55 \mathrm{~A}$ & & $\mathrm{Igl} / \mathrm{Isi} / \mathrm{Icl}$ & $2452-1$ & Edge modified flake & 1 \\
\hline 20 & $55 \mathrm{~B}$ & & $\mathrm{Igl} / \mathrm{Isi} / \mathrm{Icl}$ & OR724 & Flake, unanalyzed & 1 \\
\hline $20 \& 12$ & 35 & & II & & Debitage & 152 \\
\hline 21 & 1 & & Fill & & Debitage & 33 \\
\hline 21 & 1 & & Fill & $154-1$ & Edge modified flake & 1 \\
\hline 21 & 1 & & Fill & $154-2$ & Edge modified flake & 1 \\
\hline 21 & 1 & & Fill & $154-3$ & Edge modified flake & 1 \\
\hline 21 & 5 & & IIIc (fill) & $175-5$ & Biface Stage 1 & 1 \\
\hline 21 & 5 & & IIIc (fill) & $175-6$ & Biface Stage 2 & 1 \\
\hline 21 & 5 & & IIIc (fill) & & Debitage & 248 \\
\hline 21 & 5 & & IIIc (fill) & $175-4$ & Edge modified flake & 1 \\
\hline 21 & 5 & & IIIc (fill) & $175-9$ & Edge modified flake & 1 \\
\hline 21 & 5 & & IIIc (fill) & $175-2$ & Edge modified flake & 1 \\
\hline 21 & 5 & & IIIc (fill) & $175-3$ & Edge modified flake & 1 \\
\hline 21 & 5 & & IIIc (fill) & $175-1$ & Unifacial multiple tool & 1 \\
\hline 21 & $6 \mathrm{~A}-\mathrm{B}$ & & IIIc (fill) & $209-1$ & Biface Stage 2 & 1 \\
\hline 21 & $6 \mathrm{~A}-\mathrm{B}$ & & IIIc (fill) & & Debitage & 441 \\
\hline 21 & $6 A-B$ & & IIIc (fill) & $209-4$ & Edge modified flake & 1 \\
\hline 21 & $6 A-B$ & & IIIc (fill) & $209-2$ & Retouched blade & 1 \\
\hline 21 & $6 \mathrm{~B}$ & & IIIc (fill) & $253-1$ & Biface Stage 1 & 1 \\
\hline 21 & $6 \mathrm{~B}$ & Feature 201 & IIIc (fill) & $215-3$ & Biface fragment & 1 \\
\hline 21 & $6 \mathrm{~B}$ & Feature 201 & IIIc (fill) & 185 & Biface fragment & 1 \\
\hline 21 & $6 \mathrm{~B}$ & Feature 201 & IIIc (fill) & OR12 & Biface Stage 2 & 1 \\
\hline 21 & $6 \mathrm{~B}$ & Feature 201 & IIIc (fill) & OR14 & Biface Stage 2 & 1 \\
\hline 21 & $6 \mathrm{~B}$ & Feature 201 & IIIc (fill) & & Debitage & 1 \\
\hline 21 & $6 \mathrm{~B}$ & Feature 201 & IIIc (fill) & $185-11$ & Perforator Unifacial & 1 \\
\hline 21 & 7 & & IIIC & 2167 & Projectile point, Pedernales & 1 \\
\hline 21 & $7 \mathrm{~A}$ & & IIII & $260-1$ & Biface fragment & 1 \\
\hline 21 & $7 \mathrm{~A}$ & & IIIC & $260-4$ & Burin spall & 1 \\
\hline 21 & $7 \mathrm{~A}$ & & IIIc & & Debitage & 334 \\
\hline 21 & $7 \mathrm{~A}$ & & IIIc & $260-13$ & Edge modified flake & 1 \\
\hline 21 & $7 \mathrm{~A}$ & & IIIc & $260-5$ & Edge modified flake & 1 \\
\hline 21 & $7 \mathrm{~A}$ & & IIIc & $260-9$ & Edge modified flake & 1 \\
\hline 21 & $7 \mathrm{~A}$ & & IIIc & $260-8$ & Edge modified flake & 1 \\
\hline 21 & $7 \mathrm{~A}$ & & IIII & $260-14$ & Edge modified flake & 1 \\
\hline 21 & $7 \mathrm{~A}$ & & IIII & $260-1$ & Projectile point, Ensor & 1 \\
\hline 21 & $7 \mathrm{~A}$ & & IIIC & $254-1$ & Projectile point, miscellaneous side-notched & 1 \\
\hline 21 & $7 \mathrm{~B}$ & & IIIc & $367-15$ & Biface fragment & 1 \\
\hline 21 & $7 \mathrm{~B}$ & Feature 201 & IIIc & & Debitage & 776 \\
\hline 21 & 8 & & $\mathrm{IIIb} / \mathrm{c}$ & $431-4$ & Biface fragment & 1 \\
\hline 21 & 8 & & $\mathrm{IIIb} / \mathrm{c}$ & $431-2$ & Biface Stage 1 & 1 \\
\hline 21 & 8 & & $\mathrm{IIIb} / \mathrm{c}$ & & Debitage & 2212 \\
\hline 21 & 8 & & $\mathrm{IIIb} / \mathrm{c}$ & $431-10$ & Edge modified flake & 1 \\
\hline 21 & 8 & & $\mathrm{IIIb} / \mathrm{c}$ & $431-11$ & Edge modified flake & 1 \\
\hline 21 & 8 & & $\mathrm{IIIb} / \mathrm{c}$ & $431-12$ & Edge modified flake & 1 \\
\hline 21 & 8 & & $\mathrm{IIIb} / \mathrm{c}$ & $431-16$ & Edge modified flake & $\hat{1}$ \\
\hline
\end{tabular}




\begin{tabular}{|c|c|c|c|c|c|c|}
\hline Square & Level & Feature & Strata & Item & Analyst Identification & Count \\
\hline 21 & 8 & & IIIb/c & $431-21$ & Edge modified flake & \\
\hline 21 & 8 & & $\mathrm{IIIb} / \mathrm{c}$ & $431-5$ & Edge modified flake & 1 \\
\hline 21 & 8 & & $\mathrm{IIIb} / \mathrm{c}$ & $431-8$ & Edge modified flake & 1 \\
\hline 21 & 8 & & $\mathrm{IIIb} / \mathrm{c}$ & $431-9$ & Edge modified flake & 1 \\
\hline 21 & 8 & & $\mathrm{IIIb} / \mathrm{c}$ & OR67 & Edge modified flake & \\
\hline 21 & 8 & & $\mathrm{IIIb} / \mathrm{c}$ & $431-14$ & Edge modified flake & \\
\hline 21 & 8 & & $\mathrm{IIIb} / \mathrm{c}$ & $431-15$ & Edge modified flake & \\
\hline 21 & 8 & & $\mathrm{IIIb} / \mathrm{c}$ & OR68 & Flake, unanalyzed & \\
\hline 21 & 8 & & $\mathrm{IIIb} / \mathrm{c}$ & $431-3$ & Projectile point fragment & \\
\hline 21 & 8 & & $\mathrm{IIIb} / \mathrm{c}$ & $431-1$ & Projectile point, Castroville & \\
\hline 21 & 8 & & $\mathrm{IIIb} / \mathrm{c}$ & 463 & Projectile point, Marshall & \\
\hline 21 & 8 & & $\mathrm{IIIb} / \mathrm{c}$ & $431-13$ & Unifacial multiple tool & \\
\hline 21 & 9 & & $\mathrm{IIIb} / \mathrm{c}$ & $503-9$ & Biface fragment & 1 \\
\hline 21 & 9 & & $\mathrm{IIIb} / \mathrm{c}$ & $503-7$ & Biface fragment & \\
\hline 21 & 9 & & $\mathrm{IIIb} / \mathrm{c}$ & $503-3$ & Biface Stage 1 & \\
\hline 21 & 9 & & $\mathrm{IIIb} / \mathrm{c}$ & OR493 & Biface Stage 1 & \\
\hline 21 & 9 & & $\mathrm{IIIb} / \mathrm{c}$ & $513-1$ & Burin spall & 1 \\
\hline 21 & 9 & & $\mathrm{IIIb} / \mathrm{c}$ & & Debitage & 970 \\
\hline 21 & 9 & & $\mathrm{IIIb} / \mathrm{c}$ & $503-5$ & Edge modified flake & \\
\hline 21 & 9 & & $\mathrm{IIIb} / \mathrm{c}$ & $503-4$ & Edge modified flake & \\
\hline 21 & 9 & & $\mathrm{IIIb} / \mathrm{c}$ & $503-2$ & Projectile point, Bell/Andice & \\
\hline 21 & 9 & & $\mathrm{IIIb} / \mathrm{c}$ & $503-1$ & Projectile point, Castroville & 1 \\
\hline 21 & 9 & & $\mathrm{IIIb} / \mathrm{c}$ & $503-8$ & Retouched blade & 1 \\
\hline 21 & 10 & & IIIb & $522-1$ & Core fragment & 1 \\
\hline 21 & 10 & & $\mathrm{IIIb}$ & & Debitage & 7 \\
\hline 21 & 10 & & IIIb & $522-2$ & Edge modified flake & \\
\hline 21 & 10 & & $\mathrm{IIIb}$ & OR218 & Flake, unanalyzed & \\
\hline 21 & 10 & & $\mathrm{IIIb}$ & $522-4$ & Projectile point fragment & \\
\hline 21 & 11 & & IIIb & OR224 & Biface Stage 2 & \\
\hline 21 & 11 & & IIIb & & Debitage & 587 \\
\hline 21 & 11 & & IIIb & $555-2$ & Edge modified flake & \\
\hline 21 & 11 & & $\mathrm{IIIb}$ & $555-1$ & Projectile point fragment & \\
\hline 21 & 11 & & IIIb & $555-3$ & Thin uniface & \\
\hline 21 & 12 & & IIIb & $584-1$ & Biface fragment & \\
\hline 21 & 12 & & $\mathrm{IIIb}$ & OR227 & Biface Stage 2 & \\
\hline 21 & 12 & & $\mathrm{IIIb}$ & OR228 & Biface Stage 2 & \\
\hline 21 & 12 & & $\mathrm{IIIb}$ & & Debitage & 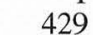 \\
\hline 21 & 12 & & $\mathrm{IIIb}$ & $584-4$ & Thin uniface fragment & \\
\hline 21 & 13 & & IIIb & & Debitage & 217 \\
\hline 21 & 13 & & IIIb & $5 \subset 4-3$ & Edge modified flake & \\
\hline 21 & 13 & & $\mathrm{IIIb}$ & (,R231 & Edge modified flake & \\
\hline 21 & 13 & & $\mathrm{IIIb}$ & $j 94-1$ & Edge modified flake & \\
\hline 21 & 13 & & IIIb & OR232 & Flake, unanalyzed & \\
\hline 21 & 13 & & $\mathrm{IIIb}$ & $594-2$ & Unifacial multiple tool & \\
\hline 21 & 14 & & $\mathrm{IIIb}$ & OR245 & Bifacial tool Form E & 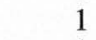 \\
\hline 21 & 14 & & $\mathrm{IIIb}$ & $649-1$ & Burin spall & \\
\hline 21 & 14 & & IIIb & & Debitage & 20 \\
\hline 21 & 14 & & IIIb & $649-2$ & Edge modified flake & \\
\hline 21 & 14 & & IIIb & OR263 & Flake, unanalyzed & \\
\hline 21 & 14 & & IIIb & OR265 & Projectile point, indeterminate & \\
\hline 22 & 1 & & Fill & & Debitage & \\
\hline 22 & 1 & & Fill & $141-2$ & Edge modified flake & \\
\hline 22 & 1 & & Fill & 142 & Projectile point, Bulverde-like & \\
\hline 22 & 1 & & Fill & $141-1$ & Unifacial multiple tool & \\
\hline 22 & 4 & & Fill & & Debitage & \\
\hline 22 & 5 & & IIIc (fill) & $211-1$ & Biface Stage 3 & \\
\hline 22 & 5 & & IIIc (fill) & $208-5$ & Burin & \\
\hline 22 & 5 & & IIIc (fill) & $208-1$ & Burin & \\
\hline 22 & 5 & & IIIc (fill) & & Debitage & 66 \\
\hline 22 & 5 & & IIIc (fill) & $208-4$ & Edge modified flake & \\
\hline 22 & 5 & & IIIc (fill) & $208-6$ & Edge modified flake & \\
\hline 22 & 5 & & IIIc (fill) & $208-2$ & Edge modified flake & \\
\hline 22 & 5 & & IIIc (fill) & $208-3$ & Edge modified flake & \\
\hline 22 & 5 & & IIIc (fill) & $208-7$ & Notched flake & \\
\hline 22 & 5 & & IIII (fill) & $211-2$ & Projectile point fragment & \\
\hline 22 & 5 & & IIIc (fill) & $208-9$ & Unifacial multiple tool & \\
\hline 22 & 6 & & IIIc & & Debitage & 10 \\
\hline 22 & 6 & & IIIc & $226-4$ & Edge modified flake & \\
\hline 22 & 6 & & IIIc & $226-1$ & Notched flake & \\
\hline 22 & 6 & & IIIc & OR28 & Notched flake & \\
\hline 22 & 7 & & IIIc & OR50 & Biface Stage 2 & \\
\hline 22 & 7 & & IIIc & OR53 & Biface Stage 2 & \\
\hline 22 & 7 & & IIIC & & Debitage & 153 \\
\hline 22 & 7 & & IIIc & $286-3$ & Denticulated flake & \\
\hline
\end{tabular}




\begin{tabular}{|c|c|c|c|c|c|c|}
\hline $\begin{array}{l}\text { Square } \\
22\end{array}$ & $\begin{array}{l}\text { Level } \\
7\end{array}$ & Feature & $\begin{array}{l}\text { Strata } \\
\text { IIIc }\end{array}$ & Item & $\begin{array}{l}\text { Analyst Identification } \\
\text { Edoe modified flake }\end{array}$ & $\begin{array}{r}\text { Count } \\
1\end{array}$ \\
\hline 22 & 7 & & IIIIc & $286-8 \mathrm{~B}$ & $\begin{array}{l}\text { Edge modified flake } \\
\text { Edge modified flake }\end{array}$ & 1 \\
\hline 22 & 7 & & IIIc & $286-7$ & Notched flake & 1 \\
\hline 22 & 7 & & IIIc & $286-1$ & Projectile point, miscellaneous side-notched & 1 \\
\hline 22 & 7 & & IIIIc & $286-2$ & Retouched blade & 1 \\
\hline 22 & $7-10$ & & IIIc & & Debitage & 83 \\
\hline 22 & $7-10$ & & IIIC & $650-2$ & Edge modified flake & 1 \\
\hline 22 & 8 & Feature 205 & $\mathrm{IIIb} / \mathrm{c}$ & $399-7$ & Biface fragment & 1 \\
\hline 22 & 8 & Feature 205 & $\mathrm{IIIb} / \mathrm{c}$ & $399-8$ & Biface Stage 2 & 1 \\
\hline 22 & 8 & Feature 205 & $\mathrm{IIIb} / \mathrm{c}$ & $399-12$ & Burin & 1 \\
\hline 22 & 8 & Feature 205 & $\mathrm{IIIb} / \mathrm{c}$ & $399-11$ & Core fragment & 1 \\
\hline 22 & 8 & Feature 205 & $\mathrm{IIIb} / \mathrm{c}$ & & Debitage & 1419 \\
\hline 22 & 8 & Feature 205 & $\mathrm{IIIb} / \mathrm{c}$ & $399-5$ & Edge modified flake & 1 \\
\hline 22 & 8 & Feature 205 & $\mathrm{IIIb} / \mathrm{c}$ & $399-1$ & Projectile point, Montell & 1 \\
\hline 22 & 8 & Feature 205 & $\mathrm{IIIb} / \mathrm{c}$ & 426 & Projectile point, Montell & 1 \\
\hline 22 & 8 & Feature 205 & $\mathrm{IIIb} / \mathrm{c}$ & $399-6$ & Unifacial multiple tool & 1 \\
\hline 22 & $8-10$ & & $\mathrm{IIIb} / \mathrm{c}$ & & Debitage & 85 \\
\hline 22 & $9 \mathrm{~A}$ & & $\mathrm{IIIb} / \mathrm{c}$ & & Debitage & 541 \\
\hline 22 & $9 \mathrm{~B}$ & Feature 210 & $\mathrm{IIIb} / \mathrm{c}$ & & Debitage & 61 \\
\hline 22 & $9 \mathrm{~B}$ & Feature 210 & $\mathrm{IIIb} / \mathrm{c}$ & $558-2$ & Edge modified flake & 1 \\
\hline 22 & $9 \mathrm{~B}$ & Feature 210 & $\mathrm{IIIb} / \mathrm{c}$ & $558-1$ & Projectile point fragment & 1 \\
\hline 22 & $10 \mathrm{~A}$ & & IIIb & $538-4$ & Biface fragment & 1 \\
\hline 22 & $10 \mathrm{~A}$ & & $\mathrm{IIIb}$ & $538-8$ & Burin spall & 1 \\
\hline 22 & $10 \mathrm{~A}$ & & IIIb & & Debitage & 696 \\
\hline 22 & $10 \mathrm{~A}$ & & IIIb & $538-5$ & Edge modified flake & 1 \\
\hline 22 & $10 \mathrm{~A}$ & & IIIb & $538-1$ & Edge modified flake & 1 \\
\hline 22 & $10 \mathrm{~A}$ & & IIIb & $538-3$ & Thin uniface fragment & 1 \\
\hline 22 & $10 \mathrm{~B}$ & Feature 210 & IIIb & & Debitage & 185 \\
\hline 22 & 11 & & IIIIb & OR225 & Biface Stage 2 & 1 \\
\hline 22 & 11 & & IIIb & $572-1$ & Burin spall & 1 \\
\hline 22 & 11 & & IIIb & & Debitage & 692 \\
\hline 22 & 11 & & IIIb & $572-4$ & Edge modified flake & 1 \\
\hline 22 & 11 & & IIIb & $572-3$ & Edge modified flake & 1 \\
\hline 22 & 11 & & IIIb & $572-6$ & Edge modified flake & 1 \\
\hline 22 & 11 & & IIIb & $572-2$ & Edge modified flake & 1 \\
\hline 22 & 11 & & IIIb & OR226 & Flake, unanalyzed & 1 \\
\hline 22 & 11 & & IIIb & OR229 & Projectile point, Lange-like & 1 \\
\hline 22 & $12 \mathrm{~A}$ & & IIIb & & Debitage & 411 \\
\hline 22 & $12 \mathrm{~A}$ & & IIIb & $610-1$ & Edge modified flake & 1 \\
\hline 22 & $12 \mathrm{~A}$ & & IIIb & OR233 & Flake, unanalyzed & 1 \\
\hline 22 & $12 \mathrm{~A}$ & & IIIb & OR240 & Flake, unanalyzed & 1 \\
\hline 22 & 13 & & IIIb & $644-3$ & Biface fragment & 1 \\
\hline 22 & 13 & & IIIb & $644-9$ & Biface fragment & 1 \\
\hline 22 & 13 & & IIIb & $644-2$ & Biface Stage 1 & 1 \\
\hline 22 & 13 & & IIIb & $644-1$ & Biface Stage 3 & 1 \\
\hline 22 & 13 & & IIIb & & Debitage & 238 \\
\hline 22 & 13 & & IIIb & $644-4$ & Edge modified flake & 1 \\
\hline 22 & 13 & & IIIb & $644-7$ & Edge modified flake & 1 \\
\hline 22 & 13 & & IIIlb & $644-5$ & Edge modified flake & 1 \\
\hline 22 & 13 & & IIIb & OR278 & Projectile point, Bell/Andice & 1 \\
\hline 22 & 13 & & IIIIb & OR279 & Projectile point, Bell/Andice & . \\
\hline 22 & 13 & & $\mathrm{IIIb}$ & OR275 & Thick uniface & 1 \\
\hline 22 & 14 & & IIIb & $675-2$ & Biface fragment & 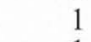 \\
\hline 22 & 14 & & IIIIb & $1400-1$ & Biface Stage 1 & 1 \\
\hline 22 & 14 & & IIIb & & Debitage & 241 \\
\hline 22 & 14 & & IIIb & $675-6$ & Possible ground stone & 1 \\
\hline 22 & 14 & & IIIb & $675-3$ & Projectile point fragment & 1 \\
\hline 23 & Wall & & & 134 & Biface Stage 2 & 1 \\
\hline 25 & 14 & & IIIb & $697-1$ & Biface fragment & 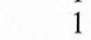 \\
\hline 25 & 14 & & IIIb & OR291 & Biface Stage 2 & 1 \\
\hline 25 & 14 & & IIIb & OR294 & Clear Fork biface & 1 \\
\hline 25 & 14 & & IIIb & & Debitage & 239 \\
\hline 25 & 14 & & IIIb & $697-2$ & Edge modified flake & 1 \\
\hline 25 & 14 & & III & OR293 & Flake, unanalyzed & I \\
\hline 25 & 15 & & IIIb & $739-1$ & Biface fragment & 1 \\
\hline 25 & 15 & & IIIb & $728-1$ & Biface Stage 1 & \\
\hline 25 & 15 & & $\mathrm{IIIb}$ & & Debitage & 515 \\
\hline 25 & 15 & & $\mathrm{IIIb}$ & $724-1$ & Edge modified flake & 1 \\
\hline 25 & 15 & & IIIb & $724-3$ & Edge modified flake & 1 \\
\hline 25 & 15 & & IIIb & $724-5$ & Edge modified flake & 1 \\
\hline 25 & 16 & & III b & $759-1$ & Biface fragment & 1 \\
\hline 25 & 16 & & IIIb & $748-2$ & Burin spall & 1 \\
\hline 25 & 16 & & IIIb & & Debitage & 464 \\
\hline 25 & 16 & & IIIb & $748-3$ & Edge modified flake & 1 \\
\hline
\end{tabular}




\begin{tabular}{|c|c|c|c|c|c|c|}
\hline Square & Level & Feature & Strata & Item & Analyst Identification & Count \\
\hline 25 & 16 & & $\mathrm{IIIb}$ & $748-4$ & Edge modified flake & \\
\hline 25 & 16 & & IIIb & $748-1$ & Edge modified flake & \\
\hline 25 & 16 & & IIIb & $758-1$ & Spurred flake & \\
\hline 25 & 16 & & IIIb & $780-1$ & Thin uniface & \\
\hline 25 & 17 & & IIIb & OR317 & Biface Stage 2 & \\
\hline 25 & 17 & & IIIlb & $481-1$ & Core fragment & \\
\hline 25 & 17 & & IIIb & & Debitage & 1 \\
\hline 25 & 17 & & IIIb & $481-2$ & Edge modified flake & \\
\hline 25 & 17 & & IIIb & OR319 & Perforator Group 7 & \\
\hline 25 & 18 & & IIIb & & Debitage & 16 \\
\hline 25 & 19 & & $\mathrm{IIIa} / \mathrm{b}$ & & Debitage & 17 \\
\hline 25 & 20 & & $\mathrm{IIIa} / \mathrm{b}$ & $871-1$ & Burin & \\
\hline 25 & 20 & & IIIa/b & & Debitage & 2 \\
\hline 25 & 21 & & IIIa & & Debitage & 18 \\
\hline 25 & 21 & & IIIa & $909-1$ & Edge modified flake & \\
\hline 25 & 22 & & IIIa & & Debitage & 342 \\
\hline 25 & 22 & & IIIa & $924-1$ & Projectile point, miscellaneous lanceolate & \\
\hline 25 & 24 & & IIIa & & Debitage & 60 \\
\hline 25 & 24 & & IIIa & $978-2$ & Edge modified flake & \\
\hline 25 & 24 & & IIIa & $978-1$ & Thin uniface fragment & \\
\hline 25 & 25 & & IIIa & $1040-4$ & Bifacial tool Form A & \\
\hline 25 & 25 & & IIIa & & Debitage & 470 \\
\hline 25 & 25 & & IIIa & $1040-3$ & Edge modified flake & \\
\hline 25 & 25 & & IIIa & $1040-6$ & Edge modified flake & \\
\hline 25 & 25 & & IIIa & $1040-8$ & Microspur/microdenticulate & \\
\hline 25 & 25 & & IIIa & $1040-5$ & Spurred flake & \\
\hline 25 & 26 & & II/IIIa & $1161-4$ & Biface fragment & \\
\hline 25 & 26 & & II/IIIa & $1161-2$ & Biface Stage 2 & \\
\hline 25 & 26 & & II/IIIa & $1161-3$ & Burin spall & \\
\hline 25 & 26 & & II/IIIa & & Debitage & 514 \\
\hline 25 & 26 & & II/IIIa & 1161-1 & Edge modified flake & \\
\hline 25 & 27 & & II/IIIa & $1196-3$ & Biface fragment & \\
\hline 25 & 27 & & II/IIIa & $1196-2$ & Chert cobble, unmodified/tested & \\
\hline 25 & 27 & & II/IIIa & & Debitage & \\
\hline 25 & 28 & & II/IIIa & & Debitage & 18 \\
\hline 25 & 29 & & II & & Debitage & \\
\hline 25 & 30 & & II & & Debitage & 129 \\
\hline 25 & 31 & & II & & Debitage & 10 \\
\hline 25 & 31 & & II & OR498 & Projectile point, St. Mary's Hall & \\
\hline 25 & 31 & & II & $1377-1$ & Unifacial multiple tool & \\
\hline 25 & 32 & & II & & Debitage & 139 \\
\hline 25 & 32 & & II & $1411-2$ & Microspur/microdenticulate & \\
\hline 25 & 32 & & II & $1411-3$ & Projectile point fragment & \\
\hline 25 & 33 & & II & & Debitage & 564 \\
\hline 25 & 33 & & II & OR543 & Projectile point, St. Mary's Hall-atypic & \\
\hline 25 & 33 & & II & $1293-2$ & Thin uniface fragment & \\
\hline 25 & 34 & & II & $1598-1$ & Biface fragment & 1 \\
\hline 25 & 34 & & II & & Debitage & 27 \\
\hline 25 & 35 & & II & & Debitage & 12 \\
\hline 25 & 35 & & II & $1715-1$ & Edge modified flake & \\
\hline 25 & 36 & & Isi-c/II & OR581 & Core fragment & 1 \\
\hline 25 & 36 & & Isi-c/II & & Debitage & 78 \\
\hline 25 & 37 & & Isi-c/II & & Debitage & 40 \\
\hline 25 & 37 & & Isi-c/II & $1634-1$ & Edge modified flake, unanalyzed & \\
\hline 25 & 38 & & Isi-c/II & & Debitage & 36 \\
\hline 25 & 39 & & Isi-c & & Debitage & 2 \\
\hline 25 & $39-45$ & & Isi-c & & Debitage & \\
\hline 25 & $39-53$ & & Isi-c & & Debitage & \\
\hline 26 & 15 & & IIIb & OR289 & Clear Fork uniface & \\
\hline 26 & 15 & & $\mathrm{IIIb}$ & & Debitage & 36 \\
\hline 26 & 16 & & $\mathrm{IIIa} / \mathrm{b}$ & & Debitage & \\
\hline 26 & 16 & & IIIa/b & OR306 & Projectile point, Martindale A & \\
\hline 26 & 17 & & $\mathrm{IIIa} / \mathrm{b}$ & & Debitage & 10 \\
\hline 26 & 18 & & $\mathrm{IIIa} / \mathrm{b}$ & & Debitage & 11 \\
\hline 26 & 18 & & IIIa/b & $407-1$ & Microspur/microdenticulate & \\
\hline 26 & 19 & & $\mathrm{IIIa} / \mathrm{b}$ & & Debitage & \\
\hline 26 & 19 & & $\mathrm{IIIa} / \mathrm{b}$ & $810-1$ & Edge modified flake & \\
\hline 26 & 20 & & $\mathrm{IIIa} / \mathrm{b}$ & OR329 & Biface Stage 1 & \\
\hline 26 & 20 & & $\mathrm{IIIa} / \mathrm{b}$ & OR330 & Biface Stage 2 & \\
\hline 26 & 20 & & $\mathrm{IIIa} / \mathrm{b}$ & & Debitage & \\
\hline 26 & 21 & & IIIa & & Debitage & \\
\hline 26 & 21 & & IIIa & $855-1$ & Edge modified flake & \\
\hline 26 & 21 & & IIIa & OR339 & Perforator Group 7 & \\
\hline 26 & 22 & & IIIa & & Debitage & 254 \\
\hline
\end{tabular}




\begin{tabular}{|c|c|c|c|c|c|c|}
\hline Square & Level & Feature & Strata & Item & Analyst Identification & Count \\
\hline 26 & 22 & & IIIa & $897-1$ & Edge modified flake & 531 \\
\hline 26 & 24 & & IIIa & & Debitage & 531 \\
\hline 26 & 24 & & IIIa & $938-1$ & Thin uniface fragment & 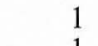 \\
\hline 26 & 24 & & IIIa & OR365 & Thin uniface fragment & 1 \\
\hline 26 & 25 & & IIIa & & Debitage & 761 \\
\hline 26 & 25 & & IIIa & $1094-3$ & Edge modified flake & \\
\hline 26 & 25 & & IIIa & $1094-5$ & Possible ground stone & 1 \\
\hline 26 & 25 & & IIIa & OR432 & Projectile point fragment & \\
\hline 26 & 25 & & IIIa & OR422 & Thin uniface & 1 \\
\hline 26 & 26 & & IIIa & & Debitage & 672 \\
\hline 26 & 26 & & IIIa & OR440 & Flake, unanalyzed & \\
\hline 26 & 26 & & IIIa & 1153-1 & Unifacial multiple tool & 1 \\
\hline 26 & 27 & & II/IIIa & 1199-1 & Burin & 1 \\
\hline 26 & 27 & & II/IIIa & & Debitage & 413 \\
\hline 26 & 28 & & II/IIIa & & Debitage & 134 \\
\hline 26 & 28 & & II/IIIa & OR469 & Flake, unanalyzed & \\
\hline 26 & 29 & & II/IIIa & $1378-1$ & Core fragment & 1 \\
\hline 26 & 29 & & II/IIIa & & Debitage & 184 \\
\hline 26 & 29 & & II/IIIa & OR505 & Flake, unanalyzed & 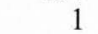 \\
\hline 26 & 29 & & II/IIIa & OR517 & Flake, unanalyzed & 1 \\
\hline 26 & 30 & & II & & Debitage & 168 \\
\hline 26 & 30 & & II & $1419-2$ & Edge modified flake & \\
\hline 26 & 30 & & II & $1419-3$ & Edge modified flake & \\
\hline 26 & 30 & & II & $1419-1$ & Unifacial multiple tool & 1 \\
\hline 26 & 31 & & II & & Debitage & 154 \\
\hline 26 & 31 & & II & $1467-1$ & Edge modified flake & \\
\hline 26 & 31 & & II & OR525 & Flake, unanalyzed & \\
\hline 26 & 32 & & II & $1500-3$ & Biface fragment & \\
\hline 26 & 32 & & II & $1500-5$ & Biface fragment & \\
\hline 26 & 32 & & II & $1500-6$ & Biface fragment & \\
\hline 26 & 32 & & II & $1506-3$ & Biface fragment & 1 \\
\hline 26 & 32 & & II & & Debitage & 162 \\
\hline 26 & 32 & & II & $1500-1$ & Edge modified flake & 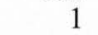 \\
\hline 26 & 33 & & II & $1667-1$ & Biface fragment & \\
\hline 26 & 33 & & II & & Debitage & 150 \\
\hline 26 & 33 & & II & $1667-2$ & Thin uniface fragment & \\
\hline 26 & 34 & & II & OR583 & Biface & 1 \\
\hline 26 & 34 & & II & & Debitage & 170 \\
\hline 26 & 34 & & II & $1716-1$ & Edge modified flake & \\
\hline 26 & 35 & & II & & Debitage & 74 \\
\hline 26 & 36 & & II & $1629-1$ & Arrow point, Scallorn & \\
\hline 26 & 36 & & II & & Debitage & \\
\hline 26 & 37 & & $\mathrm{Id} / \mathrm{II}$ & $1821-1$ & Core, thermal & \\
\hline 26 & 37 & & $\mathrm{Id} / \mathrm{II}$ & & Debitage & 37 \\
\hline 26 & 37 & & $\mathrm{Id} / \mathrm{II}$ & OR605 & Projectile point, San Patrice? & \\
\hline 26 & 38 & & Isi-c/Id/II & OR620 & Biface Stage 2 & \\
\hline 26 & 38 & & Isi-c/Id/II & & Debitage & 57 \\
\hline 26 & 38 & & Isi-c/Id/II & $1879-1$ & Edge modified flake & \\
\hline 26 & 39 & & Isi-c/Id & OR751 & Biface Stage 1 & \\
\hline 26 & 39 & & Isi-c/Id & & Debitage & \\
\hline 26 & 40 & & Isi-c & & Debitage & 9 \\
\hline 26 & 41 & & Isi-c & & Debitage & 24 \\
\hline 26 & 41 & & Isi-c & OR642 & Edge modified flake & \\
\hline 26 & 42 & & Isi-c & & Debitage & 17 \\
\hline 26 & 43 & & Icl/Isi-c & & Debitage & 1 \\
\hline 26 & 44 & & $\mathrm{Icl} / \mathrm{Isi}-\mathrm{c}$ & & Debitage & \\
\hline 26 & 45 & & $\mathrm{Icl} / \mathrm{Isi}-\mathrm{c}$ & & Debitage & \\
\hline 26 & 46 & & $\mathrm{Icl} / \mathrm{Isi}-\mathrm{c}$ & & Debitage & \\
\hline 26 & 47 & & $\mathrm{Icl}$ & & Debitage & \\
\hline 26 & 47 & & Icl & OR669 & Flake, unanalyzed & \\
\hline 26 & 48 & & Icl & & Debitage & $T$ \\
\hline 26 & 49 & & Icl & & Debitage & 10 \\
\hline 26 & 50 & & Isi/Icl & & Debitage & 10 \\
\hline 26 & 51 & & Isi/Icl & & Debitage & 1 \\
\hline 26 & 51 & & Isi/Icl & OR730 & Flake, unanalyzed & \\
\hline 26 & 51 & & $\mathrm{Isi} / \mathrm{Icl}$ & OR731 & Flake, unanalyzed & \\
\hline 26 & 52 & & $\mathrm{Igl} / \mathrm{Isi} / \mathrm{Icl}$ & $2516-1$ & Biface fragment & \\
\hline 26 & 52 & & $\mathrm{Igl} / \mathrm{Isi} / \mathrm{Icl}$ & & Debitage & \\
\hline 26 & 53 & & Igl/Isi/Icl & & Debitage & \\
\hline 26 & $53 \mathrm{~B}$ & & Igl/Isi/Icl & & Debitage & \\
\hline 26 & $54 \mathrm{~A}$ & & $\mathrm{Igl} / \mathrm{Isi}$ & & Debitage & \\
\hline 26 & 55 & & $\mathrm{Ig} / / \mathrm{Isi}$ & & Debitage & 2 \\
\hline 26 & 58 & & Igl & OR740 & Flake, unanalyzed & \\
\hline 26 & 59 & & Igl & & Debitage & \\
\hline
\end{tabular}




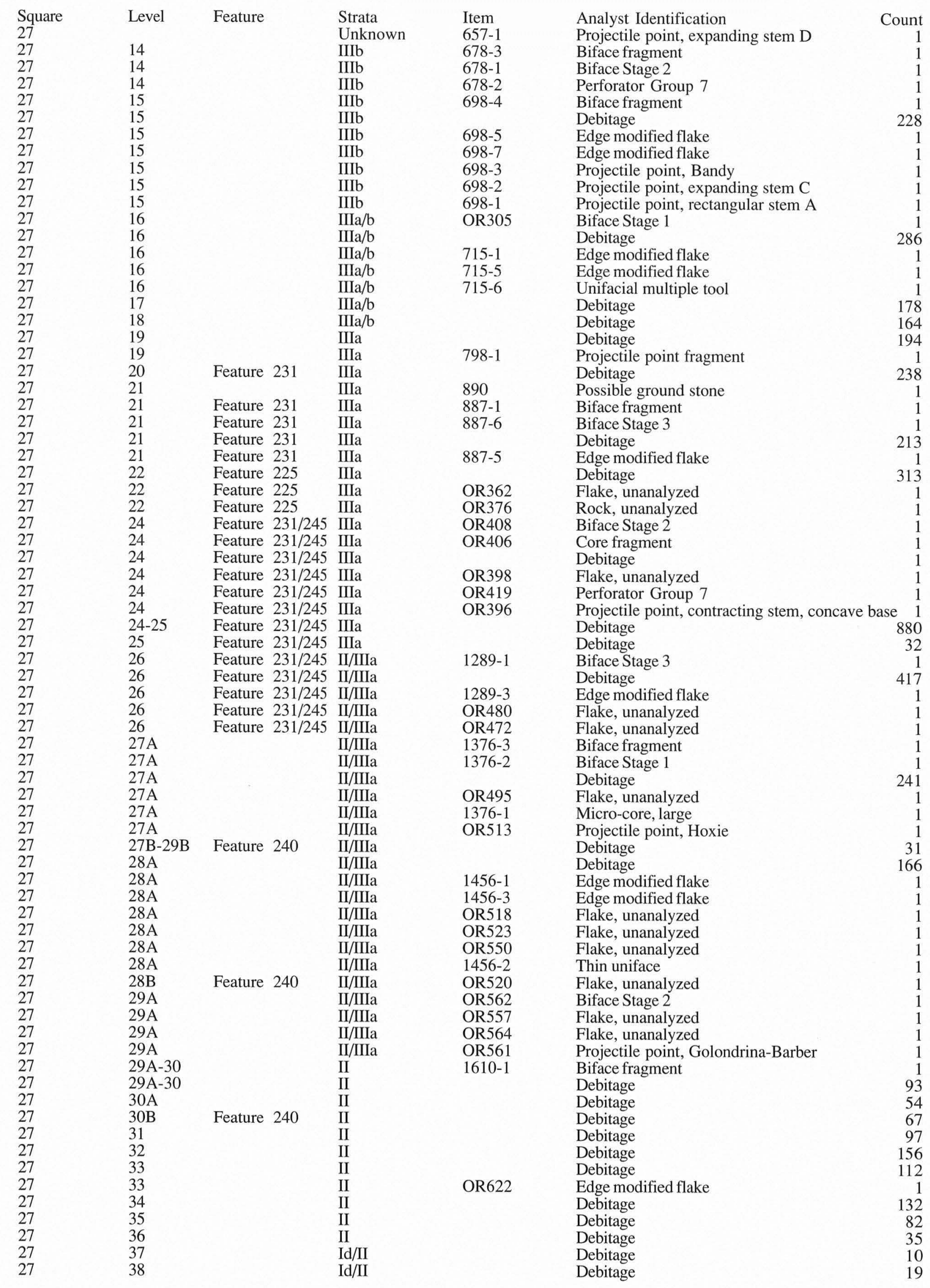




\begin{tabular}{|c|c|c|c|c|c|c|}
\hline Square & Level & Feature & & Strata & Item & Analyst Identification \\
\hline 27 & 38 & & & $\mathrm{Id} / \mathrm{II}$ & OR656 & Flake, unanalyzed \\
\hline 27 & 39 & & & Id & OR667 & Biface Stage 2 \\
\hline 27 & 39 & & & Id & & Debitage \\
\hline 27 & 40 & & & Isi-c/Id & & Debitage \\
\hline 27 & 41 & & & Isi-c & & Debitage \\
\hline 27 & 42 & & & Isi-c & & Debitage \\
\hline 27 & 43 & & & Icl/Isi-c & & Debitage \\
\hline 27 & 44 & & & Icl/Isi-c & & Debitage \\
\hline 27 & 45 & & & Icl & & Debitage \\
\hline 27 & 46 & & & Icl & & Debitage \\
\hline 27 & 47 & & & Icl & & Debitage \\
\hline 27 & 48 & & & $\mathrm{Icl}$ & & Debitage \\
\hline 27 & 49 & & & Icl & & Debitage \\
\hline 27 & 49 & & & Icl & OR681 & Flake, unanalyzed \\
\hline 27 & 50 & & & Isi/Icl & & Debitage \\
\hline 27 & 50 & & & Isi/Icl & OR714 & Flake, unanalyzed \\
\hline 27 & 50 & & & Isi/Icl & OR713 & Flake, unanalyzed \\
\hline 27 & 51 & & & Isi/Icl & & Debitage \\
\hline 27 & $51 \mathrm{~A}$ & & & Isi/Icl & & Debitage \\
\hline 27 & $51 \mathrm{~B}$ & Feature & 262 & Isi/Icl & & Debitage \\
\hline 27 & 52 & & & Isi/Icl & & Debitage \\
\hline 27 & $52 \mathrm{~A}$ & & & Isi/Icl & & Debitage \\
\hline 27 & $52 \mathrm{~B}$ & Feature & 262 & Isi/Icl & OR722 & Biface Stage 2 \\
\hline 27 & 53 & & & $\mathrm{Igl} / \mathrm{Isi} / \mathrm{Icl}$ & & Debitage \\
\hline 27 & 53 & & & $\mathrm{Igl} / \mathrm{Isi} / \mathrm{Icl}$ & OR732 & Flake, unanalyzed \\
\hline 27 & $53 \mathrm{~B}$ & & & $\mathrm{Igl} / \mathrm{Isi} / \mathrm{Icl}$ & & Debitage \\
\hline 27 & $54 \mathrm{~A}$ & & & Igl/Isi/Icl & & Debitage \\
\hline 27 & $54 \mathrm{~B}$ & & & $\mathrm{Igl} / \mathrm{Isi} / \mathrm{Icl}$ & & Debitage \\
\hline 27 & $54 \mathrm{~B}$ & & & Igl/Isi/Icl & OR734 & Projectile point, Clovis distal \\
\hline 27 & 57 & & & Igl & & Debitage \\
\hline 27 & 58 & & & $\mathrm{Igl}$ & & Debitage \\
\hline 27 & 59 & & & Igl & & Debitage \\
\hline 27 & 59 & & & Igl & 2661-1 & Edge modified flake \\
\hline 28 & 15 & & & IIIb & $701-3$ & Biface fragment \\
\hline 28 & 15 & & & IIIb & $701-2$ & Biface Stage 2 \\
\hline 28 & 15 & & & IIIb & $701-4$ & Burin \\
\hline 28 & 15 & & & IIIb & & Debitage \\
\hline 28 & 16 & & & IIIa/b & $729-8$ & Biface fragment \\
\hline 28 & 16 & & & IIIa/b & $729-9$ & Burin spall \\
\hline 28 & 16 & & & IIIa/b & & Debitage \\
\hline 28 & 16 & & & IIIa/b & $729-4$ & Edge modified flake \\
\hline 28 & 16 & & & $\mathrm{IIIa} / \mathrm{b}$ & $729-3$ & Edge modified flake \\
\hline 28 & 16 & & & IIIa/b & $729-1$ & Edge modified flake \\
\hline 28 & 16 & & & IIIa/b & $729-7$ & Thin uniface \\
\hline 28 & 16 & & & IIIa/b & $729-5$ & Thin uniface fragment \\
\hline 28 & 17 & & & IIIa/b & $753-1$ & Biface Stage 2 \\
\hline 28 & 17 & & & $\mathrm{IIIa} / \mathrm{b}$ & & Debitage \\
\hline 28 & 17 & & & IIIa/b & OR314 & Edge modified flake \\
\hline 28 & 18 & & & IIIa/b & & Debitage \\
\hline 28 & 19 & Feature & 231 & IIIa & $831-1$ & Biface Stage 2 \\
\hline 28 & 19 & Feature & 231 & IIIa & & Debitage \\
\hline 28 & 19 & Feature & 231 & IIIa & OR327 & Flake, unanalyzed \\
\hline 28 & 20 & Feature & 231 & IIIa & & Debitage \\
\hline 28 & 21 & Feature & 231 & IIIa & & Debitage \\
\hline 28 & 21 & Feature & 231 & IIIa & $979-4$ & Edge modified flake \\
\hline 28 & 21 & Feature & 231 & IIIa & $979-3$ & Edge modified flake \\
\hline 28 & 21 & Feature & 231 & IIIa & $979-1$ & Edge modified flake \\
\hline 28 & 21 & Feature & 231 & IIIa & $979-2$ & Edge modified flake \\
\hline 28 & 22 & Feature & 231 & IIIa & & Debitage \\
\hline 28 & 22 & Feature & 231 & IIIa & OR423 & Perforator Group 7 \\
\hline 28 & 22 & Feature & 231 & IIIa & $1025-2$ & Unifacial multiple tool \\
\hline 28 & 24 & Feature & 245 & IIIa & & Debitage \\
\hline 28 & 24 & Feature & 245 & IIIa & $1488-1$ & Edge modified flake \\
\hline 28 & $24-27$ & Feature & 245 & IIIa & & Debitage \\
\hline 28 & 25 & Feature & 245 & IIIa & OR558 & Burned limestone, unanalyzed \\
\hline 28 & 25 & Feature & 245 & IIIa & & Debitage \\
\hline 28 & 25 & Feature & 245 & IIIa & $1978-1$ & Edge modified flake \\
\hline 28 & 25 & Feature & 245 & IIIa & OR634 & Flake, unanalyzed \\
\hline 28 & 25 & Feature & 245 & IIIa & OR551 & Flake, unanalyzed \\
\hline 28 & 25 & Feature & 245 & IIIa & OR565 & Rock, unanalyzed \\
\hline 28 & 25 & Feature & 245 & IIIa & OR559 & Rock, unanalyzed \\
\hline 28 & 26 & Feature & 245 & II/IIIa & & Debitage \\
\hline 28 & 26 & Feature & 245 & II/IIIa & OR580 & Flake, unanalyzed \\
\hline 28 & 26 & Feature & 245 & II/IIIa & $2008-1$ & Perforator Unifacial \\
\hline
\end{tabular}

Count<smiles>C=[SiH2]</smiles> 


\begin{tabular}{|c|c|c|c|c|c|c|}
\hline Square & Level & Feature & Strata & Item & Analyst Identification & Count \\
\hline 28 & 26 & Feature 245 & II/IIIa & OR639 & Rock, unanalyzed & 1 \\
\hline 28 & 26 & Feature 245 & $\mathrm{II} / \mathrm{IIIa}$ & OR569 & Rock, unanalyzed & 1 \\
\hline 28 & 26 & Feature 245 & II/IIIa & OR579 & Rock, unanalyzed & 1 \\
\hline 28 & $27 \mathrm{~A}$ & & II/IIIa & $1627-1$ & Biface fragment & \\
\hline 28 & $27 \mathrm{~A}$ & & II/IIIa & OR590 & Biface Stage 2 & 1 \\
\hline 28 & $27 \mathrm{~A}$ & & II/IIIa & & Debitage & 169 \\
\hline 28 & $27 \mathrm{~A}$ & & II/IIIa & $1627-2$ & Edge modified flake & 1 \\
\hline 28 & $27 \mathrm{~A}$ & & II/IIIa & OR589 & Flake, unanalyzed & 1 \\
\hline 28 & $27 \mathrm{~B}$ & Feature 245 & II/IIIa & & Debitage & 195 \\
\hline 28 & $27 \mathrm{~B}$ & Feature 245 & $\mathrm{II} / \mathrm{III} \mathrm{a}$ & $2091-1$ & Edge modified flake & \\
\hline 28 & 28 & & II/IIIa & & Debitage & 140 \\
\hline 28 & 28 & & II/IIIa & $2095-1$ & Edge modified flake & 1 \\
\hline 28 & $28 \mathrm{~A}$ & & II/IIIa & $1788-1$ & Biface fragment & \\
\hline 28 & $28 \mathrm{~A}$ & & II/IIIa & & Debitage & 85 \\
\hline 28 & $28 \mathrm{~A}$ & & $\mathrm{II} / \mathrm{IIIa}$ & OR594 & Flake, unanalyzed & 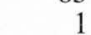 \\
\hline 28 & $28 \mathrm{~A}$ & & II/II & OR599 & Flake, unanalyzed & 1 \\
\hline 28 & $28 \mathrm{~B}$ & & $\mathrm{II} / \mathrm{IIIa}$ & & Debitage & 32 \\
\hline 28 & $28 \mathrm{C}$ & Feature 248 & II/IIIa & & Debitage & 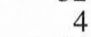 \\
\hline 28 & 29 & & II/IIIa & & Debitage & 33 \\
\hline 28 & $29 \mathrm{~A}$ & & II/IIIa & $1890-3$ & Biface fragment & 1 \\
\hline 28 & $29 \mathrm{~A}$ & & $\mathrm{II} / \mathrm{IIIa}$ & $1890-1$ & Biface fragment, unanalyzed & 1 \\
\hline 28 & $29 \mathrm{~A}$ & & II/IIIa & & Debitage & 59 \\
\hline 28 & $29 \mathrm{~A}$ & & II/IIIa & $1890-2$ & Edge modified flake & \\
\hline 28 & $29 B$ & & II/IIIa & & Debitage & 19 \\
\hline 28 & $30 \mathrm{~A}$ & & $\mathrm{II} / \mathrm{IIIa}$ & & Debitage & 106 \\
\hline 28 & $30 \mathrm{~B}$ & & II/IIIa & & Debitage & 20 \\
\hline 28 & $30 \mathrm{~B}$ & & $\mathrm{II} / \mathrm{IIIa}$ & $2120-1$ & Edge modified flake & 1 \\
\hline 28 & 31 & & II & OR647 & Flake, unanalyzed & 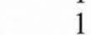 \\
\hline 28 & 31 & & II & OR646 & Projectile point, miscellaneous lanceolate & 1 \\
\hline 28 & $31 \mathrm{~A}$ & & II & & Debitage & 68 \\
\hline 28 & $31 \mathrm{~A}$ & & II & OR655 & Flake, unanalyzed & . \\
\hline 28 & $31 \mathrm{~B}$ & Feature 254 & II & & Debitage & 42 \\
\hline 28 & 32 & & II & & Debitage & 176 \\
\hline 28 & 33 & & II & & Debitage & 100 \\
\hline 28 & 33 & & II & OR661 & Flake, unanalyzed & 1 \\
\hline 28 & 34 & & II & & Debitage & 62 \\
\hline 28 & 35 & & II & & Debitage & 69 \\
\hline 28 & 36 & & $\mathrm{Id} / \mathrm{II}$ & & Debitage & 23 \\
\hline 28 & 37 & & Id & & Debitage & 12 \\
\hline 28 & 37 & & Id & OR672 & Flake, unanalyzed & 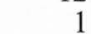 \\
\hline 28 & 38 & & Isi-c/Id & & Debitage & 15 \\
\hline 28 & 38 & & Isi-c/Id & $2653-1$ & Edge modified flake & 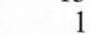 \\
\hline 28 & 39 & & Isi-c/Id & & Debitage & 6 \\
\hline 28 & 40 & & Isi-c & & Debitage & 14 \\
\hline 28 & 41 & & Isi-c & & Debitage & 27 \\
\hline 28 & 42 & & Isi-c & & Debitage & 2 \\
\hline 28 & 43 & & Isi-c & & Debitage & 7 \\
\hline 28 & 44 & & Icl/Isi-c & & Debitage & 11 \\
\hline 28 & 45 & & $\mathrm{Icl} / \mathrm{Isi}-\mathrm{c}$ & & Debitage & 8 \\
\hline 28 & 45 & & Icl/Isi-c & OR697 & Flake, unanalyzed & 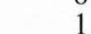 \\
\hline 28 & 45 & & $\mathrm{Icl} / \mathrm{Isi}-\mathrm{c}$ & OR695 & Flake, unanalyzed & 1 \\
\hline 28 & 45 & & Icl/Isi-c & OR694 & Flake, unanalyzed & 1 \\
\hline 28 & 46 & & Icl/Isi-c & & Debitage & 3 \\
\hline 28 & 46 & & $\mathrm{Icl} / \mathrm{Isi}-\mathrm{c}$ & OR700 & Flake, unanalyzed & 1 \\
\hline 28 & 47 & & Icl/Isi-c & & Debitage & 15 \\
\hline 28 & 47 & & $\mathrm{Icl} / \mathrm{Isi}-\mathrm{c}$ & OR706 & Flake, unanalyzed & 1 \\
\hline 28 & 48 & & Icl/Isi-c & & Debitage & 15 \\
\hline 28 & 48 & & Icl/Isi-c & OR709 & Thin uniface & 1 \\
\hline 28 & 49 & & Icl & & Debitage & 21 \\
\hline 28 & 49 & & Icl & OR711 & Flake, unanalyzed & 21 \\
\hline 28 & 50 & & $\mathrm{Isi} / \mathrm{Icl}$ & $2585-1$ & Bifacial tool & 1 \\
\hline 28 & 50 & & Isi/Icl & & Debitage & 6 \\
\hline 28 & 51 & & Isi/Icl & & Debitage & 6 \\
\hline 28 & 52 & & Isi/Icl & & Debitage & 2 \\
\hline 28 & 52 & & Isi/Icl & OR729 & Tool, unanalyzed & 1 \\
\hline 28 & 53 & & Isi/Icl & & Debitage & 6 \\
\hline 28 & $54 \mathrm{~B}$ & & $\mathrm{Ig} 1 / \mathrm{Isi} / \mathrm{Icl}$ & & Debitage & 年 \\
\hline 28 & 55 & & Igl/Isi & & Debitage & 5 \\
\hline 28 & 56 & & Igl & & Debitage & 1 \\
\hline 28 & 57 & & $\mathrm{Igl}$ & & Debitage & 1 \\
\hline 30 & 14 & & IIIIa & $708-1$ & Biface Stage 2 & 1 \\
\hline 30 & 14 & & IIIa & OR292 & Biface Stage 3 & 1 \\
\hline 30 & 14 & & IIIa & & Debitage & 1300 \\
\hline 30 & 14 & & IIIa & $686-7$ & Edge modified flake & 1 \\
\hline
\end{tabular}




\begin{tabular}{|c|c|c|c|c|c|c|}
\hline Square & Level & Feature & Strata & Item & Analyst Identification & Count \\
\hline 30 & & & IIIa & $686-8$ & Edge modified flake & 1 \\
\hline 30 & 14 & & IIIa & $686-2$ & Edge modified flake & 1 \\
\hline 30 & 14 & & IIIa & $686-5$ & Edge modified flake & 1 \\
\hline 30 & 14 & & IIIa & $686-4$ & Notched flake & 1 \\
\hline 30 & 14 & & IIIa & $686-9$ & Thin uniface fragment & 1 \\
\hline 30 & 14 & & IIIIa & $686-1$ & Unifacial multiple tool & 1 \\
\hline 30 & 15 & & IIIa & $716-2$ & Biface Stage 1 & 1 \\
\hline 30 & 15 & & IIIa & $716-3$ & Biface Stage 2 & 1 \\
\hline 30 & 15 & & IIIa & & Debitage & 739 \\
\hline 30 & 15 & & IIIa & $716-1$ & Edge modified flake & 1 \\
\hline 30 & 15 & & IIIIa & OR300 & Flake, unanalyzed & 1 \\
\hline 30 & 15 & & IIIa & OR301 & Flake, unanalyzed & 1 \\
\hline 30 & 15 & & IIIa & OR302 & Flake, unanalyzed & 1 \\
\hline 30 & 15 & & IIIIa & $716-4$ & Metate fragment & 1 \\
\hline 30 & 16 & & IIIa & OR309 & Biface Stage 2 & 1 \\
\hline 30 & 16 & & IIIa & $744-2$ & Burin spall & 1 \\
\hline 30 & 16 & & IIIa & & Debitage & 455 \\
\hline 30 & 17 & & IIIa & $765-3$ & Biface fragment & 1 \\
\hline 30 & 17 & & IIIa & & Debitage & 367 \\
\hline 30 & 17 & & IIIa & OR326 & Flake, unanalyzed & 1 \\
\hline 30 & 17 & & IIIa & OR325 & Flake, unanalyzed & 1 \\
\hline 30 & 17 & & IIIa & $765-1$ & Projectile point fragment & 1 \\
\hline 30 & 18 & & II/IIIa & & Debitage & 509 \\
\hline 30 & 18 & & II/IIIa & $814-1$ & Edge modified flake & 1 \\
\hline 30 & 18 & & II/IIIa & $814-2$ & Edge modified flake & 1 \\
\hline 30 & 18 & & II/IIIa & $814-4$ & Edge modified flake & 1 \\
\hline 30 & 18 & & II/IIIa & OR331 & Flake, unanalyzed & 1 \\
\hline 30 & 19 & & II/IIIa & $862-2$ & Biface fragment & 1 \\
\hline 30 & 19 & & II/IIIa & 867 & Biface Stage 1 & 1 \\
\hline 30 & 19 & & II/IIIa & & Debitage & 438 \\
\hline 30 & 19 & & II/IIIa & $862-1$ & Edge modified flake & 1 \\
\hline 30 & 19 & & II/IIIa & OR341 & Flake, unanalyzed & 1 \\
\hline 30 & $20 \mathrm{~A}$ & & II/IIIa & & Debitage & 374 \\
\hline 30 & $20 \mathrm{~A}$ & & II/IIIa & $904-1$ & Edge modified flake & 1 \\
\hline 30 & $20 \mathrm{~A}$ & & II/IIIa & $904-2$ & Edge modified flake & 1 \\
\hline 30 & $20 \mathrm{~B}$ & Feature 227 & II/IIIa & OR353 & Biface Stage 2 & 1 \\
\hline 30 & $21 \mathrm{~A}$ & & II & & Debitage & 171 \\
\hline 30 & $21 \mathrm{~A}$ & & II & $933-1$ & Microspur/microdenticulate & \\
\hline 30 & $21 \mathrm{~B}$ & Feature 227 & II & & Debitage & 107 \\
\hline 30 & $21 \mathrm{~B}$ & Feature 227 & II & 948 & Possible ground stone & 1 \\
\hline 30 & $21 \mathrm{~B}$ & Feature 227 & II & OR378 & Rock, unanalyzed & 1 \\
\hline 30 & $21 \mathrm{~B}$ & Feature 227 & II & $941-2$ & Thin uniface fragment & 1 \\
\hline 30 & $22 \mathrm{~A}$ & & II & & Debitage & 198 \\
\hline 30 & $22 \mathrm{~A}$ & & II & $962-2$ & Edge modified flake & 1 \\
\hline 30 & $22 \mathrm{~A}$ & & II & OR367 & Flake, unanalyzed & 1 \\
\hline 30 & $22 \mathrm{~B}$ & Feature 227 & II & $988-1$ & Core, thermal & 1 \\
\hline 30 & $22 \mathrm{~B}$ & Feature 227 & II & & Debitage & 82 \\
\hline 30 & $22 B$ & Feature 227 & II & OR379 & Rock, unanalyzed & 1 \\
\hline 30 & 23 & & II & & Debitage & 152 \\
\hline 30 & 23 & & II & OR392 & Flake, unanalyzed & 1 \\
\hline 30 & 24 & & II & & Debitage & 133 \\
\hline 30 & 24 & & II & OR400 & Edge modified flake & 1 \\
\hline 30 & 25 & & II & & Debitage & 45 \\
\hline 30 & 26 & & II & & Debitage & 89 \\
\hline 30 & 26 & & II & 1121-1 & Edge modified flake & 1 \\
\hline 30 & 27 & & II & OR434 & Core, unanalyzed & 1 \\
\hline 30 & 27 & & II & & Debitage & 85 \\
\hline 30 & 28 & & Isi-c/II & & Debitage & 113 \\
\hline 30 & 28 & & Isi-c/II & $1070-2$ & Projectile point, San Patrice? & 1 \\
\hline 30 & 28 & Feature 234 & Isi-c/II & OR442 & Flake, unanalyzed & 1 \\
\hline 30 & $29 B$ & Feature 234 & Isi-c/II & & Debitage & 81 \\
\hline 30 & 30 & Feature 234 & Isi-c/II & & Debitage & 81 \\
\hline 30 & 31 & Feature 234 & Isi-c/II & OR455 & Flake, unanalyzed & 1 \\
\hline 30 & $31 \mathrm{~B}$ & Feature 234 & Isi-c/II & & Debitage & 136 \\
\hline 30 & 32 & & Isi-c & & Debitage & 167 \\
\hline 30 & $33 \mathrm{~A}$ & & Isi-c & & Debitage & 106 \\
\hline 30 & $34 \mathrm{~A}$ & & Isi-c & & Debitage & 191 \\
\hline 30 & $34 \mathrm{~A}$ & & Isi-c & $1348-1$ & Edge modified flake & 1 \\
\hline 30 & $34 \mathrm{~B}$ & Feature 238 & Isi-c & & Debitage & 16 \\
\hline 30 & $34 \mathrm{~B}$ & Feature 238 & Isi-c & OR510 & Flake, unanalyzed & 1 \\
\hline 30 & 35 & & Isi/Isi-c & & Debitage & 42 \\
\hline 30 & 35 & & Isi/Isi-c & $1426-2$ & Edge modified flake & 1 \\
\hline 30 & 35 & & Isi/Isi-c & OR519 & Projectile point, Wilson & 1 \\
\hline 30 & 35 & & Isi/Isi-c & $1426-1$ & Thin uniface fragment & \\
\hline
\end{tabular}




\begin{tabular}{|c|c|c|c|c|c|c|}
\hline Square & Level & Feature & Strata & Item & Analyst Identification & Count \\
\hline 30 & 36 & & Isi/Isi-c & & Debitage & 55 \\
\hline 30 & 37 & & Isi/Isi-c & & Debitage & 21 \\
\hline 30 & 38 & & Isi & & Debitage & 13 \\
\hline 30 & 39 & & Isi & $1601-2$ & Biface fragment & 1 \\
\hline 30 & 39 & & Isi & $1601-4$ & Burin spall & 1 \\
\hline 30 & 39 & & Isi & & Debitage & 10 \\
\hline 30 & 40 & & Isi & & Debitage & 10 \\
\hline 30 & 41 & & Isi & & Debitage & 6 \\
\hline 30 & 42 & & Isi & & Debitage & 23 \\
\hline 30 & 43 & & Isi & & Debitage & 12 \\
\hline 32 & 14 & & IIIa & & Debitage & 682 \\
\hline 32 & 14 & & IIIa & $683-4$ & Edge modified flake & 1 \\
\hline 32 & 14 & & IIIa & $683-5$ & Edge modified flake & 1 \\
\hline 32 & 14 & & IIIa & $683-6$ & Edge modified flake & 1 \\
\hline 32 & 14 & & IIIa & $683-2$ & Unifacial multiple tool & 1 \\
\hline 32 & 15 & & IIIa & $702-2$ & Biface fragment & 1 \\
\hline 32 & 15 & & IIIa & & Debitage & 468 \\
\hline 32 & 15 & & IIIa & $702-3$ & Edge modified flake & 1 \\
\hline 32 & 15 & & IIIa & $702-1$ & Unifacial multiple tool & 1 \\
\hline 32 & 16 & & IIIa & & Debitage & 370 \\
\hline 32 & 16 & & IIIa & $717-1$ & Microspur/microdenticulate & 1 \\
\hline 32 & 17 & & IIIa & $743-1$ & Clear Fork biface & 1 \\
\hline 32 & 17 & & IIIIa & & Debitage & 340 \\
\hline 32 & 17 & & IIIIa & OR311 & Flake, unanalyzed & 1 \\
\hline 32 & 17 & & IIIa & $743-2$ & Worked hematite & 1 \\
\hline 32 & 17 & & IIIa & $743-3$ & Worked hematite & 1 \\
\hline 32 & 18 & & IIIa & $772-1$ & Biface fragment & 1 \\
\hline 32 & 18 & & IIIa & & Debitage & 480 \\
\hline 32 & 18 & & IIIa & OR320 & Flake, unanalyzed & 1 \\
\hline 32 & 19 & & IIIa & $863-3$ & Biface Stage 3 & 1 \\
\hline 32 & 19 & & IIIa & & Debitage & 734 \\
\hline 32 & 19 & & IIIa & $863-2$ & Microspur/microdenticulate & 1 \\
\hline 32 & 19 & & IIIa & $863-1$ & Projectile point fragment & 1 \\
\hline 32 & 19 & & IIIa & OR344 & Projectile point, Hoxie/Gower & 1 \\
\hline 32 & $20 \mathrm{~A}$ & & II/IIIa & OR354 & Bifacial tool Form A & 1 \\
\hline 32 & $20 \mathrm{~A}$ & & II/IIIa & $908-4$ & Blade & 1 \\
\hline 32 & $20 \mathrm{~A}$ & & II/IIIa & $908-1$ & Core, thermal & 1 \\
\hline 32 & $20 \mathrm{~A}$ & & II/IIIa & & Debitage & 675 \\
\hline 32 & $20 \mathrm{~A}$ & & II/IIIa & $908-6$ & Edge modified flake & 1 \\
\hline 32 & $20 \mathrm{~A}$ & & II/IIIa & $908-3$ & Edge modified flake & 1 \\
\hline 32 & $20 \mathrm{~A}$ & & II/IIIa & $908-2$ & Edge modified flake & 1 \\
\hline 32 & $20 \mathrm{~B}$ & & II/IIIa & & Debitage & 87 \\
\hline 32 & $20 \mathrm{~B}$ & & II/IIIa & $915-2$ & Edge modified flake & 1 \\
\hline 32 & 21 & & II/IIIa & & Debitage & 227 \\
\hline 32 & 22 & & II/IIIa & $932-2$ & Biface fragment & 1 \\
\hline 32 & 22 & & II/IIIa & & Debitage & 404 \\
\hline 32 & 22 & & II/IIIa & $932-1$ & Microspur/microdenticulate & 1 \\
\hline 32 & 24 & & II & $973-1$ & Biface fragment & 1 \\
\hline 32 & 24 & & II & & Debitage & 150 \\
\hline 32 & 24 & & II & $973-2$ & Edge modified flake & 1 \\
\hline 32 & 24 & & II & OR370 & Flake, unanalyzed & 1 \\
\hline 32 & 25 & & II & & Debitage & 100 \\
\hline 32 & 26 & & II & & Debitage & 78 \\
\hline 32 & 27 & & II & & Debitage & 104 \\
\hline 32 & $28 \mathrm{~A}$ & & Isi-c/II & OR456 & Burin spall & 1 \\
\hline 32 & $28 \mathrm{~A}$ & & Isi-c/II & & Debitage & 174 \\
\hline 32 & $28 \mathrm{~A}$ & & Isi-c/II & OR453 & Flake, unanalyzed & 1 \\
\hline 32 & $28 \mathrm{~B}$ & Feature 235 & Isi-c/II & OR754 & Burned limestone, unanalyzed & 1 \\
\hline 32 & $29 \mathrm{~A}$ & & Isi-c/II & $1263-1$ & Core, thermal & 1 \\
\hline 32 & $29 \mathrm{~A}$ & & Isi-c/II & & Debitage & 165 \\
\hline 32 & $29 \mathrm{~A}$ & & Isi-c/II & OR464 & Flake, unanalyzed & 1 \\
\hline 32 & $29 \mathrm{~A}$ & & Isi-c/II & OR463 & Flake, unanalyzed & 1 \\
\hline 32 & $29 \mathrm{~B}$ & Feature 235 & Isi-c/II & & Debitage & 97 \\
\hline 32 & $29 \mathrm{~B}$ & Feature 235 & Isi-c/II & OR468 & Flake, unanalyzed & 1 \\
\hline 32 & 30 & & Isi-c/II & & Debitage & 493 \\
\hline 32 & 30 & & Isi-c/II & $1291-3$ & Edge modified flake & 1 \\
\hline 32 & 30 & & Isi-c/II & OR474 & Flake, unanalyzed & 1 \\
\hline 32 & 30 & & Isi-c/II & $1291-1$ & Projectile point, St. Mary's Hall & 1 \\
\hline 32 & 30 & & Isi-c/II & $1291-4$ & Thin uniface fragment & 1 \\
\hline 32 & 31 & & Isi-c/Id/II & & Debitage & 104 \\
\hline 32 & 32 & & Isi-c/Id & OR486 & Core, unanalyzed & 1 \\
\hline 32 & 32 & & Isi-c/Id & & Debitage & 116 \\
\hline 32 & 32 & & Isi-c/Id & $1317-1$ & Edge modified flake & 1 \\
\hline 32 & 32 & & Isi-c/Id & OR487 & Flake, unanalyzed & 1 \\
\hline
\end{tabular}




\begin{tabular}{|c|c|c|c|c|c|c|}
\hline Square & Level & Feature & Strata & Item & Analyst Identification & $\begin{array}{c}\text { Count } \\
122\end{array}$ \\
\hline 32 & 33 & & $\begin{array}{l}\text { IS1-c/ld } \\
\text { Isi-c/Id }\end{array}$ & $1397-2$ & $\begin{array}{l}\text { Debitage } \\
\text { Edge modified flake }\end{array}$ & $\begin{array}{r}122 \\
1\end{array}$ \\
\hline 32 & 33 & & Isi-c/Id & $1397-3$ & Edge modified flake & 1 \\
\hline 32 & 33 & & Isi-c/Id & OR494 & Flake, unanalyzed & 1 \\
\hline 32 & 33 & & Isi-c/Id & $1397-1$ & Perforator Group 2 & 1 \\
\hline 32 & 34 & & Isi-c/Id & & Debitage & 100 \\
\hline 32 & 34 & & Isi-c/Id & $1401-4$ & Edge modified flake & 1 \\
\hline 32 & 34 & & Isi-c/Id & $1401-3$ & Edge modified flake, unanalyzed & 1 \\
\hline 32 & 34 & & Isi-c/Id & $1401-2$ & Thin uniface & 1 \\
\hline 32 & 35 & & Isi/Isi-c & & Debitage & 42 \\
\hline 32 & 36 & & Isi/Isi-c & $1689-1$ & Biface fragment & 1 \\
\hline 32 & 36 & & Isi/Isi-c & & Debitage & 60 \\
\hline 32 & 38 & & Isi/Isi-c & & Debitage & 35 \\
\hline 32 & 38 & & Isi/Isi-c & $1806-1$ & Edge modified flake & . \\
\hline 32 & 39 & & Isi/Isi-c & & Debitage & 61 \\
\hline 32 & 39 & & Isi/Isi-c & 1844-1 & Edge modified flake & 1 \\
\hline 32 & 40 & & Isi/Isi-c & & Debitage & 31 \\
\hline 33 & 16 & & IIIa & $682-1$ & Biface fragment & 1 \\
\hline 33 & 16 & & IIIa & & Debitage & 337 \\
\hline 33 & 16 & & IIIIa & $682-2$ & Edge modified flake & 1 \\
\hline 33 & 16 & & IIIIa & OR283 & Projectile point, bifurcate stem fragment & 1 \\
\hline 33 & 16 & & IIIa & OR282 & Projectile point, miscellaneous expanding stem & n \\
\hline 33 & $17 \mathrm{~A}$ & & IIIa & & Debitage & 94 \\
\hline 33 & $17 \mathrm{~B}$ & Feature 217 & IIIa & & Debitage & 536 \\
\hline 33 & 19 & Feature 231 & IIIa & $912-1$ & Biface fragment & 1 \\
\hline 33 & 19 & Feature 231 & IIIa & & Debitage & 360 \\
\hline 33 & 20 & Feature 231 & IIIa & $974-1$ & Burin spall & 1 \\
\hline 33 & 20 & Feature 231 & IIIa & & Debitage & 570 \\
\hline 33 & 20 & Feature 231 & IIIa & $974-2$ & Edge modified flake & 1 \\
\hline 33 & 20 & Feature 231 & IIIa & OR369 & Flake, unanalyzed & 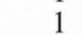 \\
\hline 33 & 21 & & II/IIIa & $995-1$ & Biface Stage 1 & \\
\hline 33 & 21 & & II/IIIa & $995-2$ & Burin spall & 1 \\
\hline 33 & 21 & & II/IIIa & OR383 & Core fragment & 1 \\
\hline 33 & 21 & & II/IIIa & & Debitage & 453 \\
\hline 33 & 21 & & II/IIIa & $995-4$ & Projectile point fragment & 1 \\
\hline 33 & 22 & & II/IIIa & & Debitage & 291 \\
\hline 33 & 22 & & II/IIIa & $1023-2$ & Edge modified flake & 1 \\
\hline 33 & 23 & & II/IIIa & & Debitage & 246 \\
\hline 33 & 24 & & II/IIIa & & Debitage & 183 \\
\hline 33 & 24 & & II/IIIa & OR420 & Flake, unanalyzed & 1 \\
\hline 33 & 25 & & II/IIIa & & Debitage & 180 \\
\hline 33 & 26 & & II/IIIa & $1177-2$ & Biface fragment & 1 \\
\hline 33 & 26 & & II/IIIa & $1177-1$ & Biface fragment & 1 \\
\hline 33 & 26 & & II/IIIa & & Debitage & 107 \\
\hline 33 & 26 & & II/IIIa & $1177-3$ & Edge modified flake & 1 \\
\hline 33 & 27 & & II & & Debitage & 133 \\
\hline 33 & 28 & & II & $1215-1$ & Burin spall & 1 \\
\hline 33 & 28 & & II & & Debitage & 116 \\
\hline 33 & 29 & & II & & Debitage & 54 \\
\hline 33 & 29 & & II & OR507 & Rock, unanalyzed & 1 \\
\hline 33 & $30 \mathrm{~A}$ & & II & & Debitage & 63 \\
\hline 33 & $30 \mathrm{~A}$ & & II & OR502 & Flake, unanalyzed & 1 \\
\hline 33 & $30 \mathrm{~B}$ & Feature 236 & II & & Debitage & 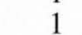 \\
\hline 33 & $30 \mathrm{~B}$ & Feature 236 & II & OR521 & Rock, unanalyzed & 1 \\
\hline 33 & $30 \mathrm{~B}$ & Feature 236 & II & OR522 & Rock, unanalyzed & . \\
\hline 33 & $30 \mathrm{~B} \& 31 \mathrm{~B}$ & Feature 236 & II & & Debitage & 0 \\
\hline 33 & $31 \mathrm{~A}$ & & $\mathrm{Id} / \mathrm{II}$ & & Debitage & 71 \\
\hline 33 & $31 \mathrm{~A}$ & & $\mathrm{Id} / \mathrm{II}$ & OR516 & Flake, unanalyzed & 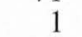 \\
\hline 33 & $31 \mathrm{~B}$ & Feature 236 & $\mathrm{Id} / \mathrm{II}$ & & Debitage & 3 \\
\hline 33 & 32 & & $\mathrm{Id} / \mathrm{II}$ & OR548 & Core fragment & 1 \\
\hline 33 & 32 & & $\mathrm{Id} / \mathrm{II}$ & & Debitage & 173 \\
\hline 33 & 32 & & $\mathrm{Id} / \mathrm{II}$ & OR553 & Flake, unanalyzed & Ne \\
\hline 33 & 33 & & Id & $1665-1$ & Biface fragment & 1 \\
\hline 33 & 33 & & Id & $1665-3$ & Biface fragment & 1 \\
\hline 33 & 33 & & Id & OR568 & Core, thermal & \\
\hline 33 & 33 & & Id & & Debitage & 136 \\
\hline 33 & 33 & & Id & $1665-2$ & Thin uniface fragment & 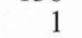 \\
\hline 33 & 34 & & Isi-c/Id & OR600 & Biface fragment, unanalyzed & 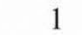 \\
\hline 33 & 34 & & Isi-c/Id & & Debitage & 80 \\
\hline 33 & 34 & & Isi-c/Id & OR597 & Flake, unanalyzed & \\
\hline 33 & 35 & & Isi-c/Id & & Debitage & 99 \\
\hline 34 & & & Unknown & & Debitage & 5 \\
\hline 34 & 15 & & IIIa & $672-5$ & Biface fragment & 1 \\
\hline 34 & 15 & & IIIa & OR285 & Biface Stage 2 & \\
\hline
\end{tabular}




\begin{tabular}{|c|c|c|c|c|c|c|}
\hline Square & Level & Feature & Strata & Item & Analyst Identification & $\begin{array}{r}\text { Count } \\
987\end{array}$ \\
\hline $\begin{array}{l}34 \\
34\end{array}$ & $\begin{array}{l}15 \\
15\end{array}$ & & IIIa & $672-3$ & $\begin{array}{l}\text { Debitage } \\
\text { Fdoe modified flake }\end{array}$ & 987 \\
\hline 34 & 15 & & IIIa & $672-4$ & $\begin{array}{l}\text { Edge modified flake } \\
\text { Edge modified flake }\end{array}$ & \\
\hline 34 & 15 & & IIIa & $672-7$ & Notched flake & \\
\hline 34 & 16 & & IIIa & $693-1$ & Biface fragment & 1 \\
\hline 34 & 16 & & IIIa & & Debitage & 318 \\
\hline 34 & 16 & & IIIa & $693-2$ & Edge modified flake & \\
\hline 34 & 16 & & IIIa & OR290 & Flake, unanalyzed & \\
\hline 34 & 17 & & IIIa & OR310 & Bifacial tool & \\
\hline 34 & 17 & & IIIa & & Debitage & 350 \\
\hline 34 & 18 & & IIIa & $785-1$ & Biface fragment & \\
\hline 34 & 18 & & IIIa & OR316 & Biface Stage 2 & \\
\hline 34 & 18 & & IIIa & OR318 & Burin & \\
\hline 34 & 18 & & IIIa & & Debitage & 37 \\
\hline 34 & $19 \mathrm{~A}$ & & IIIa & & Debitage & 10 \\
\hline 34 & 19B & Feature 223 & IIIa & & Debitage & 37 \\
\hline 34 & 19B & Feature 223 & IIIIa & OR343 & Microspur/microdenticulate & \\
\hline 34 & 19B & Feature 223 & IIIa & $872-4$ & Spurred flake & \\
\hline 34 & 19B & Feature 223 & IIIa & $872-2$ & Thin uniface fragment & \\
\hline 34 & 20 & Feature 231 & IIIa & $985-7$ & Burin spall & \\
\hline 34 & 20 & Feature 231 & IIIa & & Debitage & 595 \\
\hline 34 & 20 & Feature 231 & IIIa & $985-3$ & Edge modified flake & \\
\hline 34 & 20 & Feature 231 & IIIa & $985-5$ & Edge modified flake & \\
\hline 34 & 20 & Feature 231 & IIIa & $985-1$ & Edge modified flake & \\
\hline 34 & 20 & Feature 231 & IIIa & OR373 & Flake, unanalyzed & \\
\hline 34 & 20 & Feature 231 & IIIIa & $985-2$ & Microspur/microdenticulate & \\
\hline 34 & 20 & Feature 231 & IIIa & OR374 & Perforator Group 7 & \\
\hline 34 & 21 & Feature 231 & IIIa & $1115-1$ & Biface Stage 1 & \\
\hline 34 & 21 & Feature 231 & IIIa & OR426 & Biface Stage 2 & \\
\hline 34 & 21 & Feature 231 & IIIIa & & Debitage & 706 \\
\hline 34 & 21 & Feature 231 & IIIa & OR428 & Edge modified flake & \\
\hline 34 & 22 & Feature 231 & II/IIIa & & Debitage & 612 \\
\hline 34 & 22 & Feature 231 & II/IIIa & $1162-2$ & Edge modified flake & \\
\hline 34 & 22 & Feature 231 & II/IIIa & $1162-3$ & Edge modified flake & \\
\hline 34 & 22 & Feature 231 & II/ШІа & $1162-5$ & Edge modified flake & \\
\hline 34 & 22 & Feature 231 & II/IIIa & OR438 & Flake, unanalyzed & \\
\hline 34 & 22 & Feature 231 & II/IIIa & $1162-6$ & Projectile point fragment & \\
\hline 34 & 22 & Feature 231 & II/IIIa & OR439 & Projectile point, Golondrina-Barber & \\
\hline 34 & $23 \mathrm{~A}$ & Feature 231 & II/IIIa & & Debitage & 397 \\
\hline 34 & $23 \mathrm{~A}$ & Feature 231 & II/IIIa & OR462 & Edge modified flake & \\
\hline 34 & 24 & Feature 231 & II/IIIa & OR481 & Core, unidirectional & \\
\hline 34 & 24 & Feature 231 & II/IIIa & & Debitage & 406 \\
\hline 34 & 24 & Feature 231 & II/IIIa & OR478 & Flake, unanalyzed & \\
\hline 34 & 24 & Feature 231 & II/IHa & OR473 & Perforator Unifacial & \\
\hline 34 & $25 \mathrm{~A}$ & & II & & Debitage & 178 \\
\hline 34 & $25 \mathrm{~A}$ & & II & $1346-1$ & Edge modified flake & \\
\hline 34 & $25 \mathrm{~A}$ & & II & OR506 & Flake, unanalyzed & \\
\hline 34 & $25 \mathrm{~A}$ & & II & OR509 & Flake, unanalyzed & \\
\hline 34 & $25 \mathrm{~A}$ & & II & OR508 & Flake, unanalyzed & \\
\hline 34 & $25 \mathrm{~B}$ & Feature 239 & II & & Debitage & 23 \\
\hline 34 & $25 \mathrm{~B}$ & Feature 239 & II & $1382-1$ & Edge modified flake & \\
\hline 34 & $26 \mathrm{~A}$ & & II & & Debitage & \\
\hline 34 & $26 \mathrm{~A}$ & & II & 1421-1 & Spurred flake & \\
\hline 34 & $26 \mathrm{~B}$ & Feature 239 & II & & Debitage & 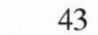 \\
\hline 34 & $27 \mathrm{~A}$ & & II & & Debitage & 155 \\
\hline 34 & $27 \mathrm{~B}$ & Feature 239 & II & & Debitage & 6 \\
\hline 34 & $27 \mathrm{~B}$ & Feature 239 & II & $1473-1$ & Projectile point, Golondrina-Barber & \\
\hline 34 & 28 & & II & & Debitage & 15 \\
\hline 34 & 29 & & II & & Debitage & 18 \\
\hline 34 & 30 & & II & & Debitage & 10 \\
\hline 34 & 30 & & II & $1666-2$ & Possible ground stone & \\
\hline 34 & 30 & & II & $1666-1$ & Projectile point fragment & \\
\hline 34 & $31 \mathrm{~A}$ & & II & & Debitage & \\
\hline 34 & $31 \mathrm{~A}$ & & II & OR570 & Flake, unanalyzed & \\
\hline 34 & $31 \mathrm{~B}$ & Feature 246 & II & & Debitage & \\
\hline 34 & $31 \mathrm{C}$ & Feature 247 & II & & Debitage & 1 \\
\hline 34 & $32 \mathrm{~A}$ & & Id/II & & Debitage & 18 \\
\hline 34 & $32 \mathrm{~A}$ & & $\mathrm{Id} / \mathrm{II}$ & 1786-1 & Edge modified flake & \\
\hline 34 & $32 \mathrm{~B}$ & Feature 246 & $\mathrm{Id} / \mathrm{II}$ & & Debitage & \\
\hline 34 & 33 & & $\mathrm{Id} / \mathrm{II}$ & OR613 & Biface Stage 3 & \\
\hline 34 & 33 & & Id/II & & Debitage & 14 \\
\hline $34 \& 49$ & $32 \mathrm{~B}$ & Feature 246 & $\mathrm{Id} / \mathrm{II}$ & & Debitage & \\
\hline 35 & 14 & & $\mathrm{IIIa} / \mathrm{b}$ & & Debitage & 95 \\
\hline 35 & 14 & & $\mathrm{IIIa} / \mathrm{b}$ & $709-3$ & Edge modified flake & \\
\hline
\end{tabular}




\begin{tabular}{|c|c|c|c|c|c|c|c|}
\hline Square & Level & Feature & & Strata & Item & Analyst Identification & Count \\
\hline 35 & 14 & & & IIIa/b & $709-4$ & Edge modified flake & \\
\hline 35 & 14 & & & IIIa/b & $709-5$ & Notched flake & \\
\hline 35 & 14 & & & $\mathrm{IIIa} / \mathrm{b}$ & $709-1$ & Thin uniface & \\
\hline 35 & 14 & & & IIIa/b & $709-2$ & Thin uniface fragment & \\
\hline 35 & 15 & & & IIIa & & Debitage & 1234 \\
\hline 35 & 15 & & & IIIa & $756-5$ & Edge modified flake & \\
\hline 35 & 15 & & & IIIa & $756-3$ & Edge modified flake & \\
\hline 35 & 15 & & & IIIa & $756-4$ & Edge modified flake & \\
\hline 35 & 15 & & & IIIa & $756-1$ & Projectile point fragment & \\
\hline 35 & 15 & & & IIIa & $756-2$ & Projectile point, concave lanceolate preform & \\
\hline 35 & 16 & & & IIIa & OR321 & Biface Stage 2 & \\
\hline 35 & 16 & & & IIIa & OR322 & Burin & \\
\hline 35 & 16 & & & IIIa & & Debitage & 391 \\
\hline 35 & $17 \mathrm{~A}$ & & & IIIa & $828-14$ & Biface fragment & \\
\hline 35 & $17 \mathrm{~A}$ & & & IIIa & $828-1$ & Biface fragment & 0 \\
\hline 35 & $17 \mathrm{~A}$ & & & IIIa & & Debitage & 398 \\
\hline 35 & 18 & & & IIIIa & OR334 & Clear Fork biface & 1 \\
\hline 35 & 18 & & & IIIa & & Debitage & 548 \\
\hline 35 & 18 & & & IIIa & $844-1$ & Edge modified flake & 1 \\
\hline 35 & 19 & Feature & 231 & IIIa & & Debitage & 442 \\
\hline 35 & 20 & Feature & 231 & IIIa & $894-6$ & Biface fragment & 1 \\
\hline 35 & 20 & Feature & 231 & IIIa & 894-3 & Biface fragment & 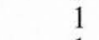 \\
\hline 35 & 20 & Feature & 231 & IIIa & $894-1$ & Biface fragment & 1 \\
\hline 35 & 20 & Feature & 231 & IIIa & & Debitage & 632 \\
\hline 35 & 21 & Feature & 231 & IIIa & OR382 & Biface Stage 2 & 1 \\
\hline 35 & 21 & Feature & 231 & IIIa & & Debitage & 641 \\
\hline 35 & 21 & Feature & 231 & IIIa & $996-2$ & Edge modified flake & \\
\hline 35 & 21 & Feature & 231 & IIIa & $996-5$ & Edge modified flake & 1 \\
\hline 35 & 22 & Feature & 231 & II/IIIa & & Debitage & 833 \\
\hline 35 & 22 & Feature & 231 & II/IIIa & $1041-1$ & Edge modified flake & . \\
\hline 35 & 22 & Feature & 231 & II/IIIa & $1041-3$ & Edge modified flake & \\
\hline 35 & 22 & Feature & 231 & II/IIIa & OR404 & Flake, unanalyzed & \\
\hline 35 & 22 & Feature & 231 & II/IIIa & OR409 & Flake, unanalyzed & \\
\hline 35 & 22 & Feature & 231 & II/IIIa & OR421 & Flake, unanalyzed & \\
\hline 35 & 22 & Feature & 231 & II/IIIa & OR417 & Flake, unanalyzed & \\
\hline 35 & 22 & Feature & 231 & II/IIIa & OR410 & Flake, unanalyzed & \\
\hline 35 & 22 & Feature & 231 & II/IIIa & $1041-9$ & Spurred flake & \\
\hline 35 & 22 & Feature & 231 & II/IIIa & $1041-5$ & Spurred flake & \\
\hline 35 & 22 & Feature & 231 & II/IIIa & $1041-6$ & Spurred flake & \\
\hline 35 & 22 & Feature & 231 & II/IIIa & $1041-8$ & Thin uniface & \\
\hline 35 & 23 & & & II/IIIa & OR460 & Core tool & \\
\hline 35 & 23 & & & II/IIIa & & Debitage & 614 \\
\hline 35 & 23 & & & II/IIIa & $1226-2$ & Edge modified flake & \\
\hline 35 & 23 & & & II/IIIa & $1226-5$ & Edge modified flake & \\
\hline 35 & 23 & & & II/IIIa & OR458 & Flake, unanalyzed & \\
\hline 35 & 23 & & & II/IIIa & $1226-1$ & Thin uniface & \\
\hline 35 & 23 & & & II/IIIa & $1226-4$ & Thin uniface fragment & 1 \\
\hline 35 & 24 & & & II/IIIa & & Debitage & 562 \\
\hline 35 & 24 & & & II/IIIa & $1300-1$ & Edge modified flake & \\
\hline 35 & 24 & & & II/IIIa & OR479 & Flake, unanalyzed & 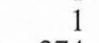 \\
\hline 35 & 25 & & & II & & Debitage & 27 \\
\hline 35 & 25 & & & II & 1398-1 & Edge modified flake & \\
\hline 35 & $26 \mathrm{~A}$ & & & II & & Debitage & 44 \\
\hline 35 & $26 \mathrm{~A}$ & & & II & $1104-1$ & Edge modified flake & \\
\hline 35 & $26 \mathrm{~A}$ & & & II & $1104-2$ & Edge modified flake & \\
\hline 35 & $26 \mathrm{~A}$ & & & II & $1104-3$ & Thin uniface fragment & \\
\hline 35 & $26 \mathrm{~B}$ & Feature & 241 & II & & Debitage & \\
\hline 35 & $26 \mathrm{~B}$ & Feature & 241 & II & OR524 & Rock, unanalyzed & \\
\hline 35 & 27 & & & II & $1476-1$ & Core, thermal & \\
\hline 35 & 27 & & & II & & Debitage & 29 \\
\hline 35 & 27 & & & II & OR538 & Flake, unanalyzed & \\
\hline 35 & 27 & & & II & $1463-1$ & Unifacial multiple tool & \\
\hline 35 & 28 & & & II & & Debitage & 31 \\
\hline 35 & 28 & & & II & $1562-5$ & Edge modified flake & \\
\hline 35 & 28 & & & II & $1562-4$ & Edge modified flake & \\
\hline 35 & 28 & & & II & $1562-2$ & Edge modified flake & \\
\hline 35 & 28 & & & II & OR547 & Flake, unanalyzed & \\
\hline 35 & 28 & & & II & $1562-3$ & Thin uniface fragment & \\
\hline 35 & 28 & & & II & $1562-1$ & Unifacial multiple tool & \\
\hline 35 & 29 & & & II & $1685-3$ & Burin spall & \\
\hline 35 & 29 & & & II & $1685-1$ & Burin spall & \\
\hline 35 & 29 & & & II & & Debitage & 17 \\
\hline 35 & 29 & & & II & $1685-2$ & Spurred flake & \\
\hline 35 & $30 \mathrm{~A}$ & & & II & & Debitage & 146 \\
\hline
\end{tabular}




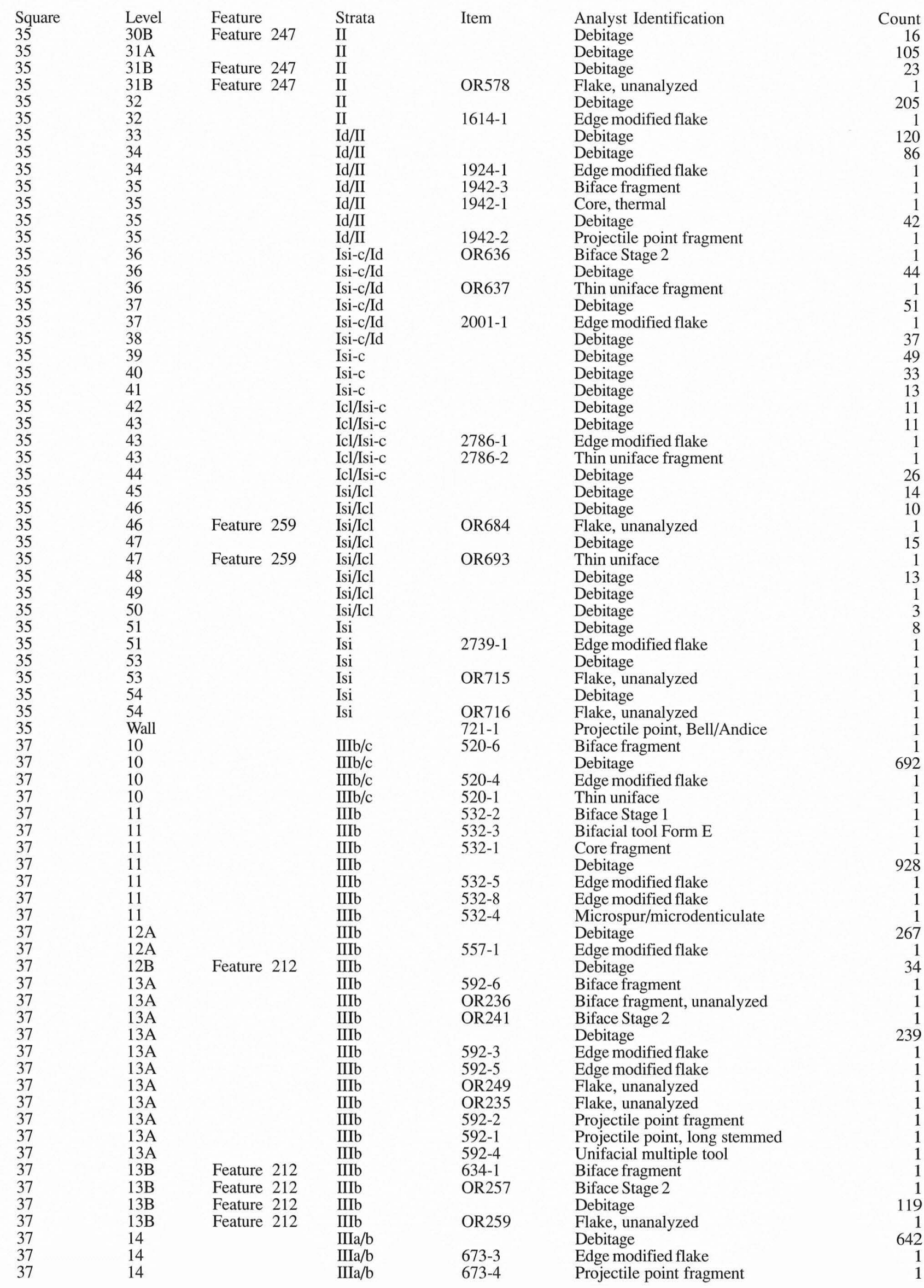




\begin{tabular}{|c|c|}
\hline Square & Level \\
\hline 37 & 15 \\
\hline 37 & 15 \\
\hline 37 & 15 \\
\hline 37 & 15 \\
\hline 37 & 15 \\
\hline 37 & 15 \\
\hline 37 & 15 \\
\hline 37 & 15 \\
\hline 37 & 15 \\
\hline 37 & $16 \mathrm{~A}$ \\
\hline 37 & $16 \mathrm{~A}$ \\
\hline 37 & $16 \mathrm{~B}$ \\
\hline 37 & $16 B \& 17 B$ \\
\hline 37 & 17 \\
\hline 37 & $17 \mathrm{~A}$ \\
\hline 37 & 18 \\
\hline 37 & 18 \\
\hline 37 & 18 \\
\hline 37 & 18 \\
\hline 37 & 19 \\
\hline 37 & 19 \\
\hline 37 & 20 \\
\hline 37 & 20 \\
\hline 37 & 21 \\
\hline 37 & 21 \\
\hline 37 & 21 \\
\hline 37 & 21 \\
\hline 37 & 21 \\
\hline 37 & 21 \\
\hline 37 & 21 \\
\hline 37 & 22 \\
\hline 37 & 22 \\
\hline 37 & 22 \\
\hline 37 & 22 \\
\hline 37 & 22 \\
\hline 37 & 23 \\
\hline 37 & 23 \\
\hline 37 & 23 \\
\hline 37 & 23 \\
\hline 37 & 23 \\
\hline 37 & 23 \\
\hline 37 & $24 \mathrm{~A}$ \\
\hline 37 & $24 \mathrm{~A}$ \\
\hline 37 & $24 \mathrm{~A}$ \\
\hline 37 & $24 \mathrm{~A}$ \\
\hline 37 & $24 \mathrm{~A}$ \\
\hline 37 & $24 \mathrm{~A}$ \\
\hline 37 & $24 \mathrm{~B}$ \\
\hline 37 & 25 \\
\hline 37 & 25 \\
\hline 37 & 26 \\
\hline 37 & 26 \\
\hline 37 & 27 \\
\hline 37 & 27 \\
\hline 37 & 28 \\
\hline 37 & 28 \\
\hline 37 & 28 \\
\hline 37 & 29 \\
\hline 37 & 29 \\
\hline 37 & 29 \\
\hline 37 & 30 \\
\hline 37 & 30 \\
\hline 37 & 31 \\
\hline 37 & 32 \\
\hline 37 & 32 \\
\hline 37 & 33 \\
\hline $37 \& 32$ & $27 \& 37 \mathrm{~A}$ \\
\hline 38 & 9 \\
\hline 38 & 9 \\
\hline 38 & 10 \\
\hline 38 & 10 \\
\hline 38 & 10 \\
\hline 38 & 10 \\
\hline 38 & 10 \\
\hline
\end{tabular}

\begin{tabular}{|c|c|c|c|}
\hline \multirow[t]{12}{*}{ Feature } & Strata & Item & Analyst Identification \\
\hline & IIIa/b & OR287 & Biface Stage 2 \\
\hline & IIIa/b & & Debitage \\
\hline & IIIa/b & $692-5$ & Edge modified flake \\
\hline & $\mathrm{IIIa} / \mathrm{b}$ & $692-8$ & Edge modified flake \\
\hline & $\mathrm{IIIa} / \mathrm{b}$ & $692-7$ & Edge modified flake \\
\hline & $\mathrm{IIIa} / \mathrm{b}$ & $692-3$ & Edge modified flake \\
\hline & IIIa/b & $692-10$ & Projectile point fragment \\
\hline & $\mathrm{IIIa} / \mathrm{b}$ & $692-1$ & Projectile point, Bandy-like \\
\hline & IIIa/b & $692-4$ & Spurred flake \\
\hline & IIIa & & Debitage \\
\hline & IIIa & OR312 & Flake, unanalyzed \\
\hline Feature 222 & IIIa & & Debitage \\
\hline \multirow[t]{7}{*}{ Feature 222} & IIIa & & Debitage \\
\hline & IIIa & OR332 & Thin uniface \\
\hline & IIIa & & Debitage \\
\hline & IIIa & $852-1$ & Biface Stage 2 \\
\hline & IIIa & & Debitage \\
\hline & IIIa & OR342 & Piece esquillee \\
\hline & IIIa & OR340 & Unifacial multiple tool \\
\hline Feature 231 & IIIa & & Debitage \\
\hline Feature 231 & IIIa & 893-1 & Unifacial multiple tool \\
\hline Feature 231 & IIIa & & Debitage \\
\hline Feature 231 & IIIa & OR364 & Flake, unanalyzed \\
\hline Feature 231 & IIIa & $1017-1$ & Biface fragment \\
\hline Feature 231 & IIIa & $1017-2$ & Biface fragment, unanalyzed \\
\hline Feature 231 & IIIa & OR386 & Biface Stage 2 \\
\hline Feature 231 & IIIa & & Debitage \\
\hline Feature 231 & IIIa & $1017-3$ & Projectile point, miscellaneous lanceolate \\
\hline Feature 231 & IIIa & OR393 & Tool, unanalyzed \\
\hline Feature 231 & IIIa & $1017-5$ & Worked hematite \\
\hline Feature 231 & IIIa & $1159-5$ & Biface fragment \\
\hline Feature 231 & IIIa & & Debitage \\
\hline Feature 231 & IIIa & $1159-6$ & Edge modified flake \\
\hline Feature 231 & IIIa & $1159-3$ & Projectile point fragment \\
\hline Feature 231 & IIIa & OR430 & Tool, unanalyzed \\
\hline Feature 231 & IIIa & & Debitage \\
\hline Feature 231 & IIIa & OR489 & Flake, unanalyzed \\
\hline Feature 231 & IIIa & OR492 & Flake, unanalyzed \\
\hline Feature 231 & IIIa & OR501 & Flake, unanalyzed \\
\hline Feature 231 & IIIa & $1429-1$ & Micro-core, intermediate \\
\hline \multirow[t]{7}{*}{ Feature 231} & IIIa & $1345-1$ & Projectile point, Angostura \\
\hline & II/IIIa & $1474-1$ & Biface fragment, unanalyzed \\
\hline & II/IIIa & OR537 & Biface Stage 2 \\
\hline & II/IIIa & & Debitage \\
\hline & II/IIIa & OR542 & Flake, unanalyzed \\
\hline & II/IIIa & $1474-5$ & Notched flake \\
\hline & II/IIIa & $1474-4$ & Spurred flake \\
\hline \multirow[t]{27}{*}{ Feature 231} & II/IIIa & & Debitage \\
\hline & II/IIIa & $1561-1$ & Core, thermal \\
\hline & II/IIIa & & Debitage \\
\hline & II & & Debitage \\
\hline & II & $1571-1$ & Edge modified flake \\
\hline & II & OR586 & Flake, unanalyzed \\
\hline & II & OR588 & Projectile point, Angostura \\
\hline & II & $1787-1$ & Biface fragment \\
\hline & II & & Debitage \\
\hline & II & OR593 & Flake, unanalyzed \\
\hline & II & $1822-1$ & Biface fragment \\
\hline & II & & Debitage \\
\hline & II & OR601 & Flake, unanalyzed \\
\hline & II & & Debitage \\
\hline & II & $1832-1$ & Spurred flake \\
\hline & II & & Debitage \\
\hline & II & & Debitage \\
\hline & II & OR619 & Flake, unanalyzed \\
\hline & II & & Debitage \\
\hline & II & & Debitage \\
\hline & IIIb/c & & Debitage \\
\hline & $\mathrm{IIIb} / \mathrm{c}$ & $723-1$ & Projectile point, Nolan \\
\hline & $\mathrm{IIIb}$ & OR159 & Biface Stage 2 \\
\hline & IIIb & OR 165 & Blade \\
\hline & IIIb & & Debitage \\
\hline & IIIb & $515-4$ & Edge modified flake \\
\hline & IIIb & $515-1$ & Projectile point fragment \\
\hline
\end{tabular}

Coun

941

1

1

1

1

397

1

14

1

239

276

1

333

547

1

1

1
481

1

1

909

1

610

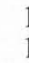

1

1

1

198

198
1

1
19

19
1

185

140

1

1

225

1

112

1

101

136

102

150

199

91

1

410 


\begin{tabular}{|c|c|c|c|c|c|c|}
\hline Square & Level & Feature & Strata & Item & Analyst Identification & Count \\
\hline $\begin{array}{l}38 \\
38\end{array}$ & $\begin{array}{l}11 \\
11\end{array}$ & & IIIb & $\begin{array}{l}527-1 \\
5273\end{array}$ & Biface fragment & \\
\hline 38 & 11 & & $\mathrm{IIIb}$ & $527-3$ & $\begin{array}{l}\text { Burin } \\
\text { Debitage }\end{array}$ & $\begin{array}{r}1 \\
644\end{array}$ \\
\hline 38 & $12 \mathrm{~A}$ & & $\mathrm{IIIb}$ & $535-6$ & Biface fragment & 1 \\
\hline 38 & $12 \mathrm{~A}$ & & IIIIb & $535-5$ & Biface fragment & 1 \\
\hline 38 & $12 \mathrm{~A}$ & & IIIIb & OR220 & Biface Stage 2 & 1 \\
\hline 38 & $12 \mathrm{~A}$ & & IIIb & $535-1$ & Core, thermal & 1 \\
\hline 38 & $12 \mathrm{~A}$ & & IIIIb & & Debitage & 734 \\
\hline 38 & $12 \mathrm{~A}$ & & IIIJ & $535-7$ & Edge modified flake & 1 \\
\hline 38 & $12 \mathrm{~A}$ & & IIIb & $535-9$ & Projectile point fragment & 1 \\
\hline 38 & $12 \mathrm{~A}$ & & IIIb & $535-3$ & Projectile point, expanding stem D & 1 \\
\hline $\begin{array}{l}38 \\
38\end{array}$ & $12 \mathrm{~A}$ & & IIIb & $535-2$ & Projectile point, Nolan & 1 \\
\hline $\begin{array}{l}38 \\
38\end{array}$ & $\begin{array}{l}12 \mathrm{~B} \\
13 \mathrm{~A}\end{array}$ & Feature 212 & IIIb & & Debitage & 3 \\
\hline $\begin{array}{l}38 \\
38\end{array}$ & $\begin{array}{l}13 \mathrm{~A} \\
13 \mathrm{~A}\end{array}$ & & $\begin{array}{l}\text { IIIb } \\
\text { IIIb }\end{array}$ & $\begin{array}{l}550-3 \\
550-2\end{array}$ & $\begin{array}{l}\text { Biface fragment } \\
\text { Biface Stage } 1\end{array}$ & $\begin{array}{l}1 \\
1\end{array}$ \\
\hline 38 & $13 \mathrm{~A}$ & & IIIb & $350-2$ & Debitage & 331 \\
\hline 38 & $13 \mathrm{~B}$ & Feature 212 & IIIJ & & Debitage & 16 \\
\hline 38 & 14 & & IIIb & $583-6$ & Biface fragment & 1 \\
\hline 38 & 14 & & IIIIb & $583-5$ & Biface fragment & \\
\hline 38 & 14 & & IIIIb & & Debitage & 498 \\
\hline 38 & 14 & & IIIlb & $583-1$ & Edge modified flake & 1 \\
\hline 38 & 14 & & IIIlb & $583-2$ & Edge modified flake & 1 \\
\hline 38 & 14 & & IIIIb & $583-4$ & Microspur/microdenticulate & 1 \\
\hline 38 & 14 & & IIIb & OR207 & Projectile point, Nolan & 1 \\
\hline 38 & 14 & & IIIIb & $583-3$ & Thin uniface & 1 \\
\hline 38 & 15 & & IIIa/b & $593-7$ & Biface fragment & 1 \\
\hline 38 & 15 & & IIIa/b & OR216 & Biface Stage 1 & 1 \\
\hline 38 & 15 & & IIIa/b & $593-1$ & Biface Stage 1 & 1 \\
\hline $\begin{array}{l}38 \\
38\end{array}$ & $\begin{array}{l}15 \\
15\end{array}$ & & IIIa/b & OR251 & Biface Stage 2 & \\
\hline $\begin{array}{l}38 \\
38\end{array}$ & $\begin{array}{l}15 \\
15\end{array}$ & & IIIa/b & $593-9$ & Burin & 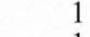 \\
\hline $\begin{array}{l}38 \\
38\end{array}$ & $\begin{array}{l}15 \\
15\end{array}$ & & IIIa/b & $593-3$ & Clear Fork uniface & 1 \\
\hline $\begin{array}{l}38 \\
38\end{array}$ & $\begin{array}{l}15 \\
15\end{array}$ & & IIIa/b & & Debitage & 783 \\
\hline $\begin{array}{l}38 \\
38\end{array}$ & $\begin{array}{l}15 \\
15\end{array}$ & & $\mathrm{IIIa} / \mathrm{b}$ & $593-8$ & Denticulated flake & 1 \\
\hline $\begin{array}{l}38 \\
38\end{array}$ & $\begin{array}{l}15 \\
15\end{array}$ & & IIIa/b & $593-4$ & Edge modified flake & 1 \\
\hline $\begin{array}{l}38 \\
38\end{array}$ & $\begin{array}{l}15 \\
15\end{array}$ & & IIIa/b & $593-5$ & Edge modified flake & 1 \\
\hline $\begin{array}{l}38 \\
38\end{array}$ & $\begin{array}{l}15 \\
15\end{array}$ & & IIIa/b & $593-2$ & Thin uniface fragment & 1 \\
\hline $\begin{array}{l}38 \\
38\end{array}$ & $\begin{array}{l}15 \\
16\end{array}$ & & $\mathrm{IIIa} / \mathrm{b}$ & $593-10$ & Thin uniface fragment & 1 \\
\hline $\begin{array}{l}38 \\
38\end{array}$ & $\begin{array}{l}16 \\
16\end{array}$ & & $\mathrm{IIIT} / \mathrm{b}$ & & Debitage & 497 \\
\hline $\begin{array}{l}38 \\
38\end{array}$ & $\begin{array}{l}16 \\
16\end{array}$ & & IIIa/b & $639-1$ & Denticulated flake & 1 \\
\hline $\begin{array}{l}38 \\
38\end{array}$ & 16 & & IIIa/b & $639-3$ & Edge modified flake & 1 \\
\hline $\begin{array}{l}38 \\
38\end{array}$ & 16 & & IIIa/b & $639-4$ & Edge modified flake & 1 \\
\hline $\begin{array}{l}38 \\
38\end{array}$ & $\begin{array}{l}17 \mathrm{~A} \\
17 \mathrm{~B}\end{array}$ & & IIIa & & Debitage & 318 \\
\hline $\begin{array}{l}38 \\
38\end{array}$ & $17 \mathrm{~B}$ & & IIIa & & Debitage & 42 \\
\hline 38 & 19 & & IIIIa & OR358 & Biface Stage 2 & 1 \\
\hline 38 & 19 & & IIIIa & & Debitage & 343 \\
\hline 38 & 19 & & IIIa & 919-1 & Edge modified flake & 1 \\
\hline 38 & 19 & & IIIa & OR357 & Flake, unanalyzed & \\
\hline 38 & 20 & Feature 231 & IIIa & & Debitage & 495 \\
\hline 38 & 20 & Feature 231 & IIIIa & $963-1$ & Edge modified flake & 1 \\
\hline 38 & $21 \mathrm{~A}$ & Feature 231 & IIIIa & OR416 & Biface Stage 2 & 1 \\
\hline 38 & $21 \mathrm{~A}$ & Feature 231 & IIIa & OR173 & Biface Stage 2 & 1 \\
\hline 38 & $21 \mathrm{~A}$ & Feature 231 & IIIa & OR418 & Biface Stage 2 & \\
\hline 38 & $21 \mathrm{~A}$ & Feature 231 & IIIa & & Debitage & 206 \\
\hline 38 & $21 \mathrm{~A}$ & Feature 231 & ПIIa & OR431 & Thin uniface & 1 \\
\hline 38 & $21 \mathrm{~B}$ & Feature 228 & IIIIa & & Debitage & 69 \\
\hline 38 & 22 & Feature 231 & IIIa & 1064-1 & Biface fragment & \\
\hline 38 & 22 & Feature 231 & IIIa & $1064-3$ & Biface fragment & \\
\hline 38 & 22 & Feature 231 & IIIa & & Debitage & 561 \\
\hline 38 & 22 & Feature 231 & IIIa & OR441 & Flake, unanalyzed & 1 \\
\hline 38 & 22 & Feature 231 & IIIIa & $1064-4$ & Micro-core, small & 1 \\
\hline 38 & 22 & Feature 231 & IIIa & $1064-2$ & Thin uniface fragment & \\
\hline 38 & 23 & Feature 231 & IIIa & & Debitage & 742 \\
\hline 38 & 23 & Feature 231 & IIIIa & OR512 & Flake, unanalyzed & 1 \\
\hline 38 & 23 & Feature 231 & IIIIa & OR511 & Flake, unanalyzed & 1 \\
\hline 38 & 23 & Feature 231 & IIIIa & OR497 & Flake, unanalyzed & \\
\hline 38 & 24 & Feature 231 & II/IIIa & & Debitage & 632 \\
\hline 38 & 24 & Feature 231 & II/IIIa & OR676 & Flake, unanalyzed & \\
\hline 38 & 24 & Feature 231 & II/IIIa & OR675 & Projectile point, Hoxie A & \\
\hline 38 & $24 \mathrm{~A}$ & & П//IIа & & Debitage & 93 \\
\hline 38 & $24 \mathrm{~B}-25 \mathrm{~B}$ & Feature 231 & II/IIIa & & Debitage & 37 \\
\hline 38 & $25 \mathrm{~A}$ & & II/IIIa & & Debitage & 247 \\
\hline 38 & $25 \mathrm{~A}$ & & II/IIIa & OR683 & Flake, unanalyzed & \\
\hline 38 & $25 \mathrm{~B}$ & Feature 231 & II/IIIa & & Debitage & 67 \\
\hline 38 & $25 \mathrm{~B}$ & Feature 231 & II/IIIa & OR690 & Small core hammerstone & \\
\hline
\end{tabular}




\begin{tabular}{|c|c|c|c|c|c|c|}
\hline Square & Level & Feature & & Strata & Item & Analyst Identification \\
\hline 38 & $25 \mathrm{C}$ & Feature & 258 & II/IIIa & $2432-1$ & Core tool, type 2 \\
\hline 38 & $25 \mathrm{C}$ & Feature & 258 & II/IIIa & & Debitage \\
\hline 38 & $25 \mathrm{C}$ & Feature & 258 & II/IIIa & OR701 & Flake, unanalyzed \\
\hline 38 & $26 \mathrm{~A}$ & & & II/IIIa & & Debitage \\
\hline 38 & $26 A$ & Feature & 231 & II/IIIa & & Debitage \\
\hline 38 & $26 \mathrm{~A}$ & Feature & 231 & II/IIIIa & $2784-2$ & Edge modified flake \\
\hline 38 & $26 \mathrm{~B}$ & Feature & 231 & II/IIIa & OR712 & Bifacial tool \\
\hline 38 & $26 \mathrm{~B}$ & Feature & 231 & II/IIIa & & Debitage \\
\hline 38 & 26B & Feature & 231 & II/IIIa & $2443-1$ & Edge modified flake \\
\hline 38 & $26 \mathrm{C}$ & Feature & 258 & II/IIIa & & Debitage \\
\hline 38 & $26 \mathrm{C}$ & Feature & 258 & II/IIIa & $2440-1$ & Microspur/microdenticulate \\
\hline 38 & 27 & & & II & & Debitage \\
\hline 38 & 27 & & & II & OR640 & Flake, unanalyzed \\
\hline 38 & 27 & & & II & OR641 & Projectile point fragment \\
\hline 38 & $27 \mathrm{~A}$ & & & II & & Debitage \\
\hline 38 & 28 & & & II & $2032-1$ & Biface fragment \\
\hline 38 & 28 & & & II & & Debitage \\
\hline 38 & $28 \mathrm{~A}$ & & & II & & Debitage \\
\hline 38 & $28 \mathrm{~A}$ & & & II & OR736 & Flake, unanalyzed \\
\hline 38 & 29 & & & II & & Debitage \\
\hline 38 & 30 & & & II & & Debitage \\
\hline 38 & 30 & & & II & $2065-1$ & Edge modified flake \\
\hline 38 & Wall & & & & $2730-2$ & Bifacial tool Form A \\
\hline 38 & Wall & & & & $2730-3$ & Notched flake \\
\hline 38 & Wall & & & & $2730-1$ & Projectile point, Castroville \\
\hline 39 & $15 \mathrm{~A}$ & & & IIIa/b & & Debitage \\
\hline 39 & $15 \mathrm{~A}$ & & & $\mathrm{IIIa} / \mathrm{b}$ & $722-1$ & Edge modified flake \\
\hline 39 & $15 \mathrm{~A}$ & & & $\mathrm{IIIa} / \mathrm{b}$ & $722-2$ & Edge modified flake \\
\hline 39 & $15 \mathrm{~A}$ & & & IIIa/b & $722-4$ & Edge modified flake \\
\hline 39 & $15 \mathrm{~A}$ & & & IIIa/b & $722-3$ & Edge modified flake \\
\hline 39 & $15 \mathrm{~A}$ & & & IIIa/b & OR313 & Flake, unanalyzed \\
\hline 39 & $15 \mathrm{~A}$ & & & $\mathrm{IIIa} / \mathrm{b}$ & OR323 & Flake, unanalyzed \\
\hline 39 & $15 \mathrm{~A}$ & & & IIIa/b & OR308 & Projectile point, miscellaneous bifurcate \\
\hline 39 & $15 \mathrm{C}$ & Feature & 221 & IIIa/b & & Debitage \\
\hline 39 & $16 \mathrm{~A}$ & & & $\mathrm{IIIa} / \mathrm{b}$ & & Debitage \\
\hline 39 & $16 \mathrm{~A}$ & & & $\mathrm{IIIa} / \mathrm{b}$ & $826-1$ & Edge modified flake \\
\hline 39 & $16 \mathrm{~A}$ & & & IIIa/b & OR328 & Flake, unanalyzed \\
\hline 39 & $16 \mathrm{~A}$ & & & IIIa/b & OR335 & Projectile point, Jetta \\
\hline 39 & 18 & & & $\mathrm{III} / \mathrm{b}$ & & Debitage \\
\hline 39 & 18 & & & $\mathrm{IIIa} / \mathrm{b}$ & $861-1$ & Edge modified flake \\
\hline 39 & 19 & & & $\mathrm{IIIa}$ & & Debitage \\
\hline 39 & 19 & & & IIIa & OR347 & Flake, unanalyzed \\
\hline 39 & 20 & Feature & 231 & IIIa & & Debitage \\
\hline 39 & 20 & Feature & 231 & IIIa & OR351 & Flake, unanalyzed \\
\hline 39 & 20 & Feature & 231 & IIIa & OR352 & Flake, unanalyzed \\
\hline 39 & 20 & Feature & 231 & IIIa & $896-1$ & Micro-core, intermediate \\
\hline 39 & $21 \mathrm{~A}$ & Feature & 231 & IIIa & OR390 & Biface fragment \\
\hline 39 & $21 \mathrm{~A}$ & Feature & 231 & IIIa & OR395 & Burin spall \\
\hline 39 & $21 \mathrm{~A}$ & Feature & 231 & IIIa & & Debitage \\
\hline 39 & $21 \mathrm{~A}$ & Feature & 231 & IIIa & OR397 & Flake, unanalyzed \\
\hline 39 & $21 \mathrm{~A}$ & Feature & 231 & IIIa & OR391 & Flake, unanalyzed \\
\hline 39 & $21 \mathrm{~B}$ & Feature & 230 & IIIa & & Debitage \\
\hline 39 & $22 \mathrm{~A}$ & Feature & 231 & IIIa & & Debitage \\
\hline 39 & $22 \mathrm{~A}$ & Feature & 231 & IIIa & $1156-1$ & Edge modified flake \\
\hline 39 & $22 \mathrm{~A}$ & Feature & 231 & IIIa & $1156-3$ & Spurred flake \\
\hline 39 & $22 \mathrm{~A}$ & Feature & 231 & IIIa & OR443 & Thin uniface \\
\hline 39 & $22 \mathrm{~B}$ & Feature & 230 & IIIa & OR444 & Biface Stage 1 \\
\hline 39 & $22 \mathrm{~B}$ & Feature & 230 & IIIa & & Debitage \\
\hline 39 & 23 & Feature & 231 & IIIa & & Debitage \\
\hline 39 & 23 & Feature & 231 & IIIa & OR504 & Flake, unanalyzed \\
\hline 39 & 23 & Feature & 231 & IIIa & OR484 & Flake, unanalyzed \\
\hline 39 & 23 & Feature & 231 & IIIa & OR503 & Flake, unanalyzed \\
\hline 39 & 24 & Feature & 231 & IIIa & OR528 & Flake, unanalyzed \\
\hline 39 & 24 & Feature & 231 & IIIa & OR527 & Tool, unanalyzed \\
\hline 39 & 24 & Feature & $231 / 245$ & IIIa & & Debitage \\
\hline 39 & 24 & Feature & $231 / 245$ & IIIa & $1529-2$ & Edge modified flake \\
\hline 39 & 25 & Feature & 231 & II/IIIa & OR552 & Bifacial tool \\
\hline 39 & 25 & Feature & 231 & II/IIIa & OR549 & Thin uniface \\
\hline 39 & 25 & Feature & $231 / 245$ & II/IIIa & & Debitage \\
\hline 39 & 25 & Feature & $231 / 245$ & II/IIIa & $1595-1$ & Edge modified flake \\
\hline 39 & 25 & Feature & 245 & $\mathrm{II} / \mathrm{IIIa}$ & OR544 & Flake, unanalyzed \\
\hline 39 & 26 & & & $\mathrm{II} / \mathrm{IIIa}$ & $1880-1$ & Biface fragment \\
\hline 39 & 26 & & & II/IIIa & & Debitage \\
\hline 39 & 26 & & & II/IIIa & OR617 & Rock, unanalyzed \\
\hline
\end{tabular}

Count

1 38
90

1

6 


\begin{tabular}{|c|c|c|c|c|c|c|}
\hline Square & Level & Feature & Strata & Item & Analyst Identification & Count \\
\hline 39 & 26 & & II/IIIa & OR616 & Thick uniface & \\
\hline 39 & 27 & & II & OR624 & Biface Stage 2 & 1 \\
\hline 39 & 27 & & II & & Debitage & 210 \\
\hline 39 & 27 & & II & OR625 & Flake, unanalyzed & 210 \\
\hline 39 & 27 & & II & OR623 & Flake, unanalyzed & 1 \\
\hline 39 & 28 & & II & & Debitage & 160 \\
\hline 39 & 28 & & II & 1949-1 & Edge modified flake & \\
\hline 39 & 28 & & II & $1949-2$ & Spurred flake & 1 \\
\hline 39 & 29 & & II & & Debitage & 116 \\
\hline 39 & $29-30$ & & II & OR635 & Thick uniface & 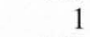 \\
\hline 39 & 30 & & II & & Debitage & 148 \\
\hline 39 & 31 & & II & & Debitage & 178 \\
\hline 39 & 32 & & II & & Debitage & 175 \\
\hline 39 & 32 & & II & OR644 & Flake, unanalyzed & \\
\hline 39 & 33 & & II & OR650 & Biface Stage 1 & 1 \\
\hline 39 & 33 & & II & & Debitage & 74 \\
\hline 39 & 34 & & II & & Debitage & 119 \\
\hline 39 & 35 & & $\mathrm{Id} / \mathrm{II}$ & & Debitage & 130 \\
\hline 39 & $36 \mathrm{~A}$ & & $\mathrm{Id} / \mathrm{II}$ & & Debitage & 59 \\
\hline 39 & $36 \mathrm{~B}$ & & $\mathrm{Id} / \mathrm{II}$ & & Debitage & \\
\hline 39 & 37 & & $\mathrm{Id} / \mathrm{II}$ & & Debitage & 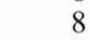 \\
\hline 39 & $38 \mathrm{~A}$ & & Isi-c/Id & & Debitage & \\
\hline 39 & $38 \mathrm{~A}$ & & Isi-c/Id & OR674 & Flake, unanalyzed & \\
\hline 39 & $38 \mathrm{~B}$ & & Isi-c/Id & & Debitage & \\
\hline 39 & 39 & & Isi-c/Id & & Debitage & \\
\hline 39 & 40 & & Isi-c & & Debitage & 6 \\
\hline 39 & 41 & & Isi-c & & Debitage & 13 \\
\hline 39 & 42 & & Isi-c & & Debitage & [ \\
\hline 39 & 43 & & Icl/Isi-c & & Debitage & 15 \\
\hline 39 & 44 & & $\mathrm{Icl} / \mathrm{Isi}-\mathrm{c}$ & & Debitage & 3 \\
\hline 39 & 45 & & Icl/Isi-c & & Debitage & 10 \\
\hline 39 & 46 & & $\mathrm{Icl} / \mathrm{Isi}-\mathrm{c}$ & & Debitage & 6 \\
\hline 39 & 47 & & Icl/Isi-c & & Debitage & 10 \\
\hline 39 & 48 & & Icl & & Debitage & 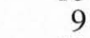 \\
\hline 39 & 49 & & Icl & & Debitage & 11 \\
\hline 39 & 50 & & Icl & & Debitage & 19 \\
\hline 39 & 51 & & Icl & & Debitage & 0 \\
\hline 39 & 52 & & Icl & & Debitage & 5 \\
\hline 39 & 53 & & Isi/Icl & & Debitage & 7 \\
\hline 39 & 54 & & $\mathrm{Igl} / \mathrm{Isi}$ & & Debitage & . \\
\hline 39 & 54 & & Igl/Isi & 2773-1 & Unifacial multiple tool & \\
\hline 39 & 55 & & Igl/Isi & & Debitage & \\
\hline 39 & 55 & & Igl/Isi & OR747 & Tool, unanalyzed & 1 \\
\hline 39 & 56 & & Igl/Isi & & Debitage & 2 \\
\hline 41 & 20 & & IIIa/b & & Debitage & 16 \\
\hline 41 & 21 & & IIIIa & & Debitage & 28 \\
\hline 41 & 22 & & IIIa & & Debitage & 55 \\
\hline 41 & 24 & & IIIa & & Debitage & 85 \\
\hline 41 & 25 & & IIIa & & Debitage & 52 \\
\hline 41 & 26 & & II/IIIa & & Debitage & 60 \\
\hline 41 & 26 & & II/IIIa & $1152-1$ & Edge modified flake & 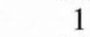 \\
\hline 41 & 27 & & II/IIIa & & Debitage & 24 \\
\hline 41 & 28 & & II/IIIa & & Debitage & 16 \\
\hline 41 & 28 & & II/IIIa & $1216-1$ & Edge modified flake & 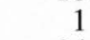 \\
\hline 41 & 29 & & II & & Debitage & 24 \\
\hline 42 & 17 & & IIIa/b & & Debitage & 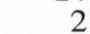 \\
\hline 42 & 18 & & IIIa/b & 204 & Biface fragment & \\
\hline 42 & 18 & & $\mathrm{IIIa} / \mathrm{b}$ & & Debitage & 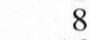 \\
\hline 42 & 20 & & $\mathrm{IIIa} / \mathrm{b}$ & & Debitage & 16 \\
\hline 42 & 21 & & IIIIa & & Debitage & 16 \\
\hline 42 & 22 & & IIIa & & Debitage & 55 \\
\hline 42 & 24 & & IIIa & & Debitage & 25 \\
\hline 42 & 26 & & IIIa & & Debitage & 117 \\
\hline 42 & 26 & & IIIa & 1096-1 & Edge modified flake & \\
\hline 42 & 27 & & ПI/ПIа & & Debitage & 38 \\
\hline 42 & 28 & & II/IIIa & & Debitage & 13 \\
\hline 42 & 29 & & II/IIIa & & Debitage & 19 \\
\hline 42 & 34 & & II & & Debitage & 2 \\
\hline 42 & 35 & & II & & Debitage & \\
\hline 42 & 36 & & II & & Debitage & \\
\hline 42 & 48 & & Icl & OR668 & Flake, unanalyzed & \\
\hline 42 & 50 & & Isi/Icl & & Debitage & \\
\hline 42 & 51 & & Isi/Icl & & Debitage & \\
\hline 42 & 52 & & $\mathrm{Igl} / \mathrm{Isi}$ & & Debitage & t \\
\hline
\end{tabular}




\begin{tabular}{|c|c|c|c|c|c|c|}
\hline Square & Level & Feature & Strata & Item & Analyst Identification & Count \\
\hline $\begin{array}{l}42 \\
42\end{array}$ & 52 & & Igl/Isi & $2842-1$ & Edge modified flake & $\begin{array}{l}1 \\
3\end{array}$ \\
\hline 42 & $\begin{array}{l}53 \mathrm{~A} \\
53 \mathrm{~A}\end{array}$ & & $\begin{array}{l}\mathrm{Ig} / / \mathrm{IS1} \\
\mathrm{Ig} / / \mathrm{Isi}\end{array}$ & OR748 & $\begin{array}{l}\text { Debitage } \\
\text { Flake, unanalyzed }\end{array}$ & $\begin{array}{l}3 \\
1\end{array}$ \\
\hline 42 & $54 \mathrm{~A}$ & & Igl & $2702-1$ & Biface fragment & 1 \\
\hline 42 & $54 \mathrm{~B}$ & & Igl & & Debitage & 3 \\
\hline 42 & 55 & & Igl & & Debitage & 1 \\
\hline 43 & 17 & & IIIa/b & & Debitage & 18 \\
\hline 43 & 18 & & IIIa/b & & Debitage & 26 \\
\hline 43 & 19 & & IIIa & & Debitage & 23 \\
\hline 43 & 20 & Feature 231 & IIIa & & Debitage & 17 \\
\hline 43 & 21 & Feature 231 & IIIIa & & Debitage & 50 \\
\hline 43 & 21 & Feature 231 & IIIa & OR359 & Tool, unanalyzed & \\
\hline 43 & 22 & Feature 231 & IIIa & & Debitage & 158 \\
\hline 43 & 22 & Feature 231 & IIIa & OR387 & Flake, unanalyzed & 1 \\
\hline 43 & 24 & Feature 231 & IIIa & & Debitage & 66 \\
\hline 43 & 24 & Feature 231 & IIIa & $1129-1$ & Edge modified flake & \\
\hline 43 & 25 & Feature 231 & IIIa & & Debitage & 36 \\
\hline 43 & 26 & & II/IIIa & & Debitage & 44 \\
\hline 43 & 27 & & II/IIIa & & Debitage & 68 \\
\hline 43 & 28 & & II/IIIa & & Debitage & 26 \\
\hline 43 & 28 & & II/IIIa & OR514 & Flake, unanalyzed & \\
\hline 43 & 28 & & II/IIIa & OR515 & Flake, unanalyzed & \\
\hline 43 & 29 & & II/IIIa & & Debitage & 25 \\
\hline 43 & 29 & & II/IIIa & $1647-1$ & Edge modified flake & \\
\hline 43 & 29 & & II/IIIa & OR595 & Flake, unanalyzed & \\
\hline 43 & 30 & & II & & Debitage & \\
\hline 43 & 47 & & Icl & & Debitage & \\
\hline 43 & 50 & & Isi/Icl & & Debitage & \\
\hline 43 & 51 & & Isi/Icl & & Debitage & 5 \\
\hline 43 & 52 & & Isi/Icl & & Debitage & 2 \\
\hline 43 & 52 & & Isi/Icl & OR746 & Flake, unanalyzed & \\
\hline 43 & $53 \mathrm{~B}$ & & Igl/Isi/Icl & & Debitage & \\
\hline 43 & $54 \mathrm{~A}$ & & Igl/Isi/Icl & & Debitage & \\
\hline 43 & $54 \mathrm{~A}$ & & Igl/Isi/Icl & OR749 & Flake, unanalyzed & \\
\hline 43 & $54 \mathrm{~B}$ & & Igl/Isi/Icl & & Debitage & \\
\hline 43 & $55 \mathrm{~A}$ & & Igl & & Debitage & \\
\hline 44 & 17 & & IIIa/b & & Debitage & 13 \\
\hline 44 & 18 & & IIIa/b & & Debitage & 10 \\
\hline 44 & 19 & Feature 231 & IIIa & & Debitage & 14 \\
\hline 44 & 20 & Feature 231 & IIIIa & & Debitage & 80 \\
\hline 44 & 21 & Feature 231 & IIIa & & Debitage & 23 \\
\hline 44 & 21 & Feature 231 & IIIIa & OR403 & Projectile point, Hoxie/Gower & \\
\hline 44 & 22 & Feature 231 & IIIIa & OR407 & Biface Stage 2 & \\
\hline 44 & 22 & Feature 231 & IIIa & & Debitage & 55 \\
\hline 44 & 24 & Feature 245 & IIIa & & Debitage & 23 \\
\hline 44 & 24 & Feature 245 & IIIa & OR536 & Tool, unanalyzed & $x$ \\
\hline 44 & 25 & Feature 245 & IIIa & & Debitage & 57 \\
\hline 44 & 26 & Feature 245 & II/IIIa & & Debitage & 63 \\
\hline 44 & 27 & & II/IIIa & & Debitage & 46 \\
\hline 44 & 27 & & II/IIIa & OR584 & Flake, unanalyzed & \\
\hline 44 & $28 \mathrm{~A}$ & & II/IIIa & & Debitage & \\
\hline 44 & $28 \mathrm{~B}$ & Feature 248 & II/IIa & & Debitage & \\
\hline 44 & $29 \mathrm{~A}$ & & II/IIIa & & Debitage & \\
\hline 44 & $29 B$ & Feature 248 & II/IIIa & & Debitage & \\
\hline 44 & 40 & & Unknown & & Debitage & \\
\hline 44 & 41 & & Isi-c & & Debitage & \\
\hline 44 & 41 & & Isi-c & OR680 & Projectile point (stemmed biface) & \\
\hline 44 & 47 & & Unknown & & Debitage & \\
\hline 44 & 50 & & Isi/Icl & & Debitage & \\
\hline 44 & 51 & & Isi/Icl & & Debitage & \\
\hline 44 & 51 & & Isi/Icl & OR743 & Flake, unanalyzed & \\
\hline 44 & 51 & & Isi/Icl & OR744 & Flake, unanalyzed & \\
\hline 44 & 51 & & Isi/Icl & OR745 & Flake, unanalyzed & \\
\hline 44 & 52 & & Isi/Icl & & Debitage & \\
\hline 44 & 53 & & Isi/Icl & & Debitage & \\
\hline 44 & $54 \mathrm{~A}$ & & Igl/Isi/Icl & & Debitage & \\
\hline 44 & $55 \mathrm{~A}$ & & $\operatorname{Igl} / / \operatorname{Isi}$ & & Debitage & \\
\hline 44 & Wall & & & $127-1$ & Biface Stage 2 & \\
\hline 44 & Wall & & & $133-1$ & Thin uniface & \\
\hline 45 & $13-15$ & & IIIa & $736-1$ & Battered cobble & \\
\hline 45 & 17 & & IIIIa & $811-1$ & Biface fragment & \\
\hline 45 & 17 & & IIIa & & Debitage & 1 \\
\hline 45 & 17 & & IIIIa & $802-1$ & Perforator Group 2 & \\
\hline 45 & 18 & & II/IIIa & OR333 & Biface Stage 1 & \\
\hline
\end{tabular}




\begin{tabular}{|c|c|c|c|c|c|c|}
\hline $\begin{array}{l}\text { Square } \\
45\end{array}$ & $\begin{array}{l}\text { Level } \\
18\end{array}$ & Feature & $\begin{array}{l}\text { Strata } \\
\text { II/IIIa }\end{array}$ & Item & $\begin{array}{l}\text { Analyst Identification } \\
\text { Debitage }\end{array}$ & $\begin{array}{r}\text { Count } \\
175\end{array}$ \\
\hline 45 & 19 & & II/IIIIa & $889-1$ & Chert cobble, unmodified/tested & \\
\hline 45 & 19 & & II/IIIIa & & Debitage & 170 \\
\hline 45 & 20 & & II/IIIa & & Debitage & 123 \\
\hline 45 & 20 & & II/IIIa & $895-1$ & Projectile point, Angostura & 1 \\
\hline 45 & 21 & & II & & Debitage & 132 \\
\hline 45 & 22 & & II & OR363 & Biface Stage 2 & 1 \\
\hline 45 & 22 & & II & & Debitage & 87 \\
\hline 45 & 23 & & II & & Debitage & 112 \\
\hline 45 & 24 & & II & & Debitage & 38 \\
\hline 45 & 25 & & II & & Debitage & 46 \\
\hline 45 & 26 & & II & & Debitage & 66 \\
\hline 45 & 27 & & II & & Debitage & 24 \\
\hline 45 & 28 & & II & & Debitage & 33 \\
\hline 45 & 29 & & II & & Debitage & 28 \\
\hline 45 & 31 & & Isi-c/II & 1313 & Projectile point, Golondrina-Barber & 1 \\
\hline 46 & 17 & & IIIa & & Debitage & 300 \\
\hline 46 & 18 & & IIIa & & Debitage & 429 \\
\hline 46 & 18 & & IIIa & $791-1$ & Edge modified flake & 1 \\
\hline 46 & 18 & & IIIa & $791-3$ & Microspur/microdenticulate & 1 \\
\hline 46 & 19 & & II/IIIa & OR336 & Biface Stage 2 & 1 \\
\hline 46 & 19 & & II//IIIa & & Debitage & 500 \\
\hline 46 & 19 & & II/IIIIa & $824-2$ & Thin uniface fragment & 1 \\
\hline 46 & $20 \mathrm{~A}$ & & II/IIIIa & & 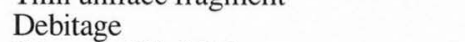 & 296 \\
\hline 46 & $20 \mathrm{~A}$ & & II/IIIIa & $1290-1$ & Edge modified flake & 1 \\
\hline 46 & $20 \mathrm{~A}-\mathrm{B}$ & Feature 226 & II/IIIa & & Debitage & 1 \\
\hline 46 & $21 \mathrm{~A}$ & & II/IIIIa & & Debitage & 202 \\
\hline 46 & $21 \mathrm{~B}$ & Feature 226 & II/IIIa & & Debitage & 32 \\
\hline 46 & 22 & & II/IIIa & 934-1 & Burin & 1 \\
\hline 46 & 22 & & II/IIIa & & Debitage & 74 \\
\hline 46 & 23 & & II/IIIa & OR361 & Biface Stage 2 & 1 \\
\hline 46 & 23 & & II/IIIIa & $949-1$ & Burin spall & 1 \\
\hline 46 & 23 & & II/IIIa & & Debitage & 181 \\
\hline 46 & 24 & & II & & Debitage & 81 \\
\hline 46 & 24 & & II & OR413 & Flake, unanalyzed & 1 \\
\hline 46 & 25 & & II & & Debitage & 167 \\
\hline 46 & 25 & & II & OR427 & Flake, unanalyzed & 1 \\
\hline 46 & 26 & & II & OR435 & Biface Stage 3 & 1 \\
\hline 46 & 26 & & II & & Debitage & 64 \\
\hline 46 & $27 \mathrm{~A}$ & & II & & Debitage & 72 \\
\hline 46 & $27 \mathrm{~A}$ & & II & OR436 & Flake, unanalyzed & 1 \\
\hline 46 & $27 \mathrm{~B}$ & Feature 232 & II & & Debitage & 12 \\
\hline 46 & $28 \mathrm{~A}$ & & II & & Debitage & 65 \\
\hline 46 & $28 \mathrm{~A}$ & & II & OR448 & Flake, unanalyzed & 1 \\
\hline 46 & $28 \mathrm{~B}$ & Feature 232 & II & & Debitage & 1 \\
\hline 46 & 29 & & Isi-c/II & & Debitage & 116 \\
\hline 46 & 30 & & Isi-c/II & & Debitage & 79 \\
\hline 46 & 30 & & Isi-c/II & $1288-1$ & Edge modified flake & 1 \\
\hline 46 & 30 & & Isi-c/II & OR470 & Flake, unanalyzed & 1 \\
\hline 46 & 31 & & Isi-c/II & & Debitage & 66 \\
\hline 46 & 31 & & Isi-c/II & OR483 & Flake, unanalyzed & 1 \\
\hline 46 & 31 & & Isi-c/II & OR482 & Flake, unanalyzed & 1 \\
\hline 46 & 32 & & Isi-c & & Debitage & 159 \\
\hline 46 & 32 & & Isi-c & $1337-1$ & Thin uniface fragment & 1 \\
\hline 46 & 33 & & Isi-c & & Debitage & 82 \\
\hline 46 & 33 & & Isi-c & $1387-1$ & Thin uniface & 1 \\
\hline 46 & 34 & & Isi-c & & Debitage & 43 \\
\hline 46 & 35 & & Isi/Isi-c & & Debitage & 64 \\
\hline 46 & 36 & & Isi/Isi-c & & Debitage & 68 \\
\hline 46 & 36 & & Isi/Isi-c & OR577 & Flake, unanalyzed & 1 \\
\hline 46 & 36 & & Isi/Isi-c & OR576 & Flake, unanalyzed & 1 \\
\hline 46 & 37 & & Isi/Isi-c & OR592 & Biface Stage 2 & 1 \\
\hline 46 & 37 & & Isi/Isi-c & OR603 & Biface Stage 3 & 1 \\
\hline 46 & 37 & & Isi/Isi-c & & Debitage & 48 \\
\hline 46 & 38 & & Isi/Isi-c & & Debitage & 67 \\
\hline 46 & 38 & & Isi/Isi-c & OR612 & Flake, unanalyzed & 1 \\
\hline 46 & 38 & & Isi/Isi-c & OR610 & Flake, unanalyzed & 1 \\
\hline 46 & 38 & & Isi/Isi-c & OR611 & Flake, unanalyzed & 1 \\
\hline 46 & 38 & & Isi/Isi-c & OR615 & Thick uniface & 1 \\
\hline 46 & 39 & & Isi/Isi-c & & Debitage & 43 \\
\hline 46 & 39 & & Isi/Isi-c & $1925-1$ & Edge modified flake & 1 \\
\hline 46 & 40 & & Isi/Isi-c & & Debitage & 49 \\
\hline 46 & 41 & & $\mathrm{Isi} / \mathrm{Isi}-\mathrm{c}$ & & Debitage & 37 \\
\hline 46 & 41 & & Isi/Isi-c & $2111-1$ & Thin uniface fragment & 1 \\
\hline
\end{tabular}




\begin{tabular}{|c|c|c|c|c|c|c|}
\hline Square & Level & Feature & Strata & Item & Analyst Identification & Count \\
\hline & $42 \mathrm{~A}$ & & Isi & & Debitage & 15 \\
\hline 46 & 43 & & Isi & & Debitage & 9 \\
\hline 46 & 44 & & Isi & & Debitage & 2 \\
\hline 46 & 45 & & Isi & & Debitage & 4 \\
\hline 46 & 47 & & Isi & & Debitage & 3 \\
\hline 46 & 48 & & Isi & & Debitage & 1 \\
\hline 46 & 49 & & Isi & & Debitage & 2 \\
\hline 46 & 50 & & Isi & & Debitage & 3 \\
\hline 46 & 51 & & Isi & & Debitage & 2 \\
\hline 46 & 52 & & Isi & & Debitage & 1 \\
\hline 46 & Overbu & & & $779-3$ & Edge modified flake & 1 \\
\hline 46 & Overbu & & & $779-2$ & Microspur/microdenticulate & 1 \\
\hline 46 & Overbı & & & $779-1$ & Projectile point, Castroville & 1 \\
\hline 46 & Overbs & & & $779-4$ & Retouched blade & 1 \\
\hline 47 & 14 & & IIIa & $786-2$ & Biface Stage 3 & 1 \\
\hline 47 & 14 & & IIIa & & Debitage & 93 \\
\hline 47 & 14 & & IIIa & $786-1$ & Microspur/microdenticulate & 1 \\
\hline 47 & $15-16$ & & IIIa & $738-1$ & Projectile point, Angostura & 1 \\
\hline 47 & 18 & & IIIa & $829-3$ & Biface fragment & 1 \\
\hline 47 & 18 & & IIIa & & Debitage & 122 \\
\hline 47 & 18 & & IIIa & $829-2$ & Thin uniface & 1 \\
\hline 47 & 18 & & IIIa & $829-1$ & Unifacial multiple tool & 1 \\
\hline 47 & 19 & & IIIa & OR345 & Clear Fork biface & 1 \\
\hline 47 & 19 & & IIIa & & Debitage & 156 \\
\hline 47 & $20 \mathrm{~A}$ & & II/IIIa & & Debitage & 96 \\
\hline 47 & $20 \mathrm{~B}$ & & II/IIIa & & Debitage & 68 \\
\hline 47 & 21 & & II/IIIa & $903-1$ & Biface Stage 2 & 1 \\
\hline 47 & 21 & & II/IIIa & & Debitage & 113 \\
\hline 47 & 22 & & II/IIIa & & Debitage & 113 \\
\hline 47 & 23 & & II/IIIa & & Debitage & 65 \\
\hline 47 & 24 & & II & & Debitage & 70 \\
\hline 47 & 24 & & II & $964-1$ & Edge modified flake & 1 \\
\hline 47 & 25 & & II & $983-1$ & Biface fragment & 1 \\
\hline 47 & 25 & & II & & Debitage & 48 \\
\hline 47 & 25 & & II & $983-2$ & Possible ground stone & 1 \\
\hline 47 & 26 & & II & & Debitage & 69 \\
\hline 47 & 27 & & II & & Debitage & 35 \\
\hline 47 & 28 & & Isi-c/II & & Debitage & 25 \\
\hline 47 & 29 & & Isi-c/II & & Debitage & 71 \\
\hline 47 & 35 & & Isi/Isi-c & & Debitage & 24 \\
\hline 48 & 17 & & IIIa & $492-1$ & Biface fragment & 1 \\
\hline 48 & 17 & & IIIa & & Debitage & 112 \\
\hline 48 & 18 & Feature 231 & IIIa & $837-1$ & Bifacial tool Form E & 1 \\
\hline 48 & 18 & Feature 231 & IIIa & & Debitage & 106 \\
\hline 48 & 19 & Feature 231 & IIIIa & & Debitage & 158 \\
\hline 48 & 20 & Feature 231 & IIIIa & $991-1$ & Biface fragment & 1 \\
\hline 48 & 20 & Feature 231 & IIIa & OR375 & Biface Stage 2 & 1 \\
\hline 48 & 20 & Feature 231 & IIIa & & Debitage & 213 \\
\hline 48 & 20 & Feature 231 & IIIa & OR384 & Flake, unanalyzed & 1 \\
\hline 48 & 21 & & II/IIIa & & Debitage & 281 \\
\hline 48 & 21 & & II/IIIa & OR402 & Projectile point, Angostura & 1 \\
\hline 48 & 22 & & $\mathrm{II} / \mathrm{IIIa}$ & $1056-1$ & Biface fragment & 1 \\
\hline 48 & 22 & & $\mathrm{II} / \mathrm{IIIa}$ & $1056-2$ & Biface fragment & 1 \\
\hline 48 & 22 & & II/IIIa & & Debitage & 102 \\
\hline 48 & 22 & & II/IIIa & OR414 & Thin uniface & 1 \\
\hline 48 & 23 & & II/IIIa & $1095-1$ & Biface Stage 2 & 1 \\
\hline 48 & 23 & & II/IIIa & & Debitage & 26 \\
\hline 48 & 24 & & $\mathrm{II} / \mathrm{IIIa}$ & OR433 & Biface Stage 2 & 1 \\
\hline 48 & 24 & & II/IIIa & & Debitage & 63 \\
\hline 48 & 25 & & II/IIIa & & Debitage & 48 \\
\hline 48 & 26 & & II/IIIa & & Debitage & 30 \\
\hline 48 & 27 & & II & & Debitage & 32 \\
\hline 48 & 28 & & II & & Debitage & 42 \\
\hline 48 & 29 & Feature 236 & II & & Debitage & 32 \\
\hline 48 & 29 & Feature 236 & II & OR477 & Rock, unanalyzed & 1 \\
\hline 48 & 29 & Feature 236 & II & OR476 & Rock, unanalyzed & 1 \\
\hline 48 & 29 & Feature 236 & II & OR475 & Rock, unanalyzed & 1 \\
\hline 48 & $30 \mathrm{~A}$ & & II & & Debitage & 4 \\
\hline 48 & $30 \mathrm{~B}$ & Feature 236 & II & & Debitage & 3 \\
\hline 48 & $31 \mathrm{~A}$ & & $\mathrm{Id} / \mathrm{II}$ & OR496 & Biface Stage 3 & 1 \\
\hline 48 & $31 \mathrm{~A}$ & & $\mathrm{Id} / \mathrm{II}$ & & Debitage & 19 \\
\hline 48 & $31 \mathrm{~B}$ & Feature 236 & $\mathrm{Id} / \mathrm{II}$ & & Debitage & 1 \\
\hline 48 & $31 \mathrm{~B}$ & Feature 236 & $\mathrm{Id} / \mathrm{II}$ & OR541 & Rock, unanalyzed & 1 \\
\hline 48 & $31 \mathrm{~B}$ & Feature 236 & $\mathrm{Id} / \mathrm{II}$ & OR539 & Rock, unanalyzed & 1 \\
\hline
\end{tabular}




\begin{tabular}{|c|c|c|c|c|c|c|c|}
\hline Square & Level & Feature & & Strata & Item & Analyst Identification & Count \\
\hline 48 & $31 \mathrm{~B}$ & Feature & 236 & $\mathrm{Id} / \mathrm{II}$ & OR540 & Rock, unanalyzed & \\
\hline 48 & 32 & & & $\mathrm{Id} / \mathrm{II}$ & OR533 & Flake, unanalyzed & 1 \\
\hline 48 & 32 & & & $\mathrm{Id} / \mathrm{II}$ & OR546 & Flake, unanalyzed & \\
\hline 48 & 33 & & & Id & OR563 & Edge modified flake & \\
\hline 48 & 33 & & & Id & OR598 & Flake, unanalyzed & \\
\hline 49 & 16 & & & Fill & $741-1$ & Projectile point, expanding concave D & \\
\hline 49 & 17 & & & IIIa & & Debitage & 164 \\
\hline 49 & 17 & & & IIIa & $761-1$ & Edge modified flake & 1 \\
\hline 49 & 18 & & & IIIa & & Debitage & 86 \\
\hline 49 & 19 & Feature & 231 & IIIa & $864-1$ & Biface Stage 2 & \\
\hline 49 & 19 & Feature & 231 & IIIа & $864-2$ & Core, thermal & \\
\hline 49 & 19 & Feature & 231 & IIIa & & Debitage & 168 \\
\hline 49 & 20 & Feature & 231 & IIIa & & Debitage & 127 \\
\hline 49 & 20 & Feature & 231 & IIIa & OR394 & Flake, unanalyzed & \\
\hline 49 & 20 & Feature & 231 & IIIa & OR399 & Flake, unanalyzed & \\
\hline 49 & 21 & Feature & 231 & IIIa & & Debitage & 200 \\
\hline 49 & 22 & Feature & 231 & II/IIIa & & Debitage & 245 \\
\hline 49 & 22 & Feature & 231 & II/IIIa & $1143-1$ & Edge modified flake & 1 \\
\hline 49 & 23 & Feature & 231 & II/IIIa & & Debitage & 224 \\
\hline 49 & 23 & Feature & 231 & II/IIIa & $1221-1$ & Thin uniface fragment & \\
\hline 49 & 24 & Feature & 231 & II/IIIa & & Debitage & 141 \\
\hline 49 & 24 & Feature & 231 & II/IIIa & $1278-1$ & Edge modified flake & \\
\hline 49 & 24 & Feature & 231 & II/IIIa & OR471 & Flake, unanalyzed & 1 \\
\hline 49 & 25 & & & II/IIIa & & Debitage & 88 \\
\hline 49 & 26 & & & II & & Debitage & 53 \\
\hline 49 & 26 & & & II & OR500 & Projectile point, Hoxie/Gower & 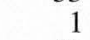 \\
\hline 49 & 27 & & & II & & Debitage & 49 \\
\hline 49 & 28 & & & II & & Debitage & 99 \\
\hline 49 & 29 & & & II & & Debitage & 63 \\
\hline 49 & 30 & & & II & & Debitage & 24 \\
\hline 49 & 30 & & & II & OR545 & Flake, unanalyzed & 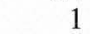 \\
\hline 49 & $31 \mathrm{~A}$ & & & II & & Debitage & 56 \\
\hline 49 & $32 \mathrm{~A}$ & & & $\mathrm{Id} / \mathrm{II}$ & & Debitage & 73 \\
\hline 49 & 33 & & & $\mathrm{Id} / \mathrm{II}$ & OR609 & Flake, unanalyzed & \\
\hline 49 & 33 & & & $\mathrm{Id} / \mathrm{II}$ & OR614 & Mano & 1 \\
\hline 49 & Wall & & & & 210 & Thin uniface & 1 \\
\hline 50 & 16 & & & IIIa & & Debitage & 143 \\
\hline 50 & 17 & & & IIIa & & Debitage & 75 \\
\hline 50 & 18 & & & IIIa & & Debitage & 83 \\
\hline 50 & 18 & & & IIIa & OR346 & Flake, unanalyzed & 1 \\
\hline 50 & 19 & & & IIIa & & Debitage & 269 \\
\hline 50 & 20 & Feature & 231 & IIIa & & Debitage & 212 \\
\hline 50 & 20 & Feature & 231 & IIIa & OR366 & Flake, unanalyzed & \\
\hline 50 & 20 & Feature & 231 & IIIa & OR385 & Perforator Group 7 & \\
\hline 50 & 21 & Feature & 231 & IIIa & & Debitage & 130 \\
\hline 50 & 21 & Feature & 231 & IIIIa & $1088-2$ & Denticulated flake & \\
\hline 50 & 21 & Feature & 231 & IIIa & OR425 & Flake, unanalyzed & \\
\hline 50 & 21 & Feature & 231 & IIIa & OR415 & Flake, unanalyzed & \\
\hline 50 & 21 & Feature & 231 & IIIa & OR412 & Flake, unanalyzed & 1 \\
\hline 50 & 21 & Feature & 231 & IIIa & 1088-1 & Retouched blade & 1 \\
\hline 50 & 22 & Feature & 231 & IIIa & $1072-1$ & Biface fragment & \\
\hline 50 & 22 & Feature & 231 & IIIIa & & Debitage & 268 \\
\hline 50 & 22 & Feature & 231 & IIIa & $1072-3$ & Edge modified flake & \\
\hline 50 & 23 & Feature & 231 & IIIa & & Debitage & 107 \\
\hline 50 & 23 & Feature & 231 & IIIa & OR490 & Flake, unanalyzed & 1 \\
\hline 50 & $24 \mathrm{~A}$ & & & II/IIIa & $1596-1$ & Chert cobble, unmodified/tested & \\
\hline 50 & $24 \mathrm{~A}$ & & & II/IIIa & & Debitage & 7. \\
\hline 50 & $24 \mathrm{~A}$ & & & II/IIIa & OR555 & Flake, unanalyzed & \\
\hline 50 & $24 \mathrm{~A}$ & & & II/IIIa & OR554 & Flake, unanalyzed & \\
\hline 50 & $24 B$ & Feature & 231 & II/IIIa & & Debitage & 45 \\
\hline 50 & $25 \mathrm{~A}$ & & & II/IIIa & & Debitage & 46 \\
\hline 50 & $25 \mathrm{~B}$ & Feature & 231 & II/IIIa & $1671-2$ & Biface fragment & \\
\hline 50 & $25 \mathrm{~B}$ & Feature & 231 & II/IIa & & Debitage & 6 \\
\hline 50 & $26 \mathrm{~A}$ & & & II & & Debitage & 59 \\
\hline 50 & $26 \mathrm{~B}$ & Feature & 231 & II & & Debitage & 9 \\
\hline 50 & $26 \mathrm{C}$ & Feature & 184 & II & OR571 & Flake, unanalyzed & \\
\hline 50 & $26 \mathrm{C}$ & Feature & 184 & II & OR572 & Flake, unanalyzed & \\
\hline 50 & $27 \mathrm{~A}$ & & & II & & Debitage & 77 \\
\hline 50 & $27 \mathrm{~A}$ & & & II & OR575 & Perforator Group 1 & \\
\hline 50 & $27 \mathrm{~B}$ & & & II & & Debitage & \\
\hline 50 & $27 \mathrm{~B}$ & & & II & OR574 & Projectile point, miscellaneous lanceolate & \\
\hline 50 & $27 \mathrm{C}$ & Feature & 184 & II & & Debitage & \\
\hline 50 & 28 & & & II & & Debitage & 136 \\
\hline 50 & 28 & & & II & OR591 & Flake, unanalyzed & \\
\hline
\end{tabular}




\begin{tabular}{|c|c|c|c|c|c|c|}
\hline Square & Level & Feature & & Strata & Item & Analyst Identification \\
\hline & $28 \mathrm{~A}$ & & & II & OR582 & Flake, unanalyzed \\
\hline 50 & 29 & & & II & & Debitage \\
\hline 50 & $30 \mathrm{~A}$ & & & II & & Debitage \\
\hline 50 & $30 \mathrm{~A}$ & & & II & OR606 & Flake, unanalyzed \\
\hline 50 & $30 \mathrm{~B}$ & Feature & 249 & II & & Debitage \\
\hline 50 & $31 \mathrm{~A}$ & & & II & & Debitage \\
\hline 50 & $31 \mathrm{~B}$ & & & II & $1840-1$ & Biface fragment \\
\hline 50 & $31 \mathrm{~B}$ & Feature & 249 & II & & Debitage \\
\hline 50 & 32 & & & II & OR618 & Edge modified flake, unanalyzed \\
\hline 50 & $32 \mathrm{~A}$ & & & II & & Debitage \\
\hline 50 & $32 \mathrm{~B}$ & Feature & 249 & II & & Debitage \\
\hline 51 & 16 & & & $\mathrm{IIIa} / \mathrm{b}$ & & Debitage \\
\hline 51 & 17 & & & IIIa & & Debitage \\
\hline 51 & 19 & & & IIIa & & Debitage \\
\hline 51 & 19 & & & IIIa & $942-1$ & Edge modified flake \\
\hline 51 & 20 & Feature & 231 & IIIIa & & Debitage \\
\hline 51 & 21 & Feature & 231 & IIIa & & Debitage \\
\hline 51 & 21 & Feature & 231 & IIIa & $1160-1$ & Notched flake \\
\hline 51 & 22 & Feature & 231 & IIIa & & Debitage \\
\hline 51 & 22 & Feature & 231 & IIIa & $1034-1$ & Thin uniface fragment \\
\hline 51 & 23 & Feature & 231 & IIIIa & & Debitage \\
\hline 51 & 24 & Feature & 231 & IIIa & & Debitage \\
\hline 51 & 25 & Feature & 231 & IIIa & & Debitage \\
\hline 51 & 25 & Feature & 231 & IIIa & OR632 & Rock, unanalyzed \\
\hline 51 & $25 \mathrm{~B}$ & Feature & 231 & IIIa & & Debitage \\
\hline 51 & 26 & Feature & 231 & II/IIIa & & Debitage \\
\hline 51 & $27 \mathrm{~A}$ & & & II/IIIa & & Debitage \\
\hline 51 & $27 \mathrm{~B}$ & Feature & 249 & II/IIIa & & Debitage \\
\hline 51 & $27 \mathrm{C}$ & Feature & 249 & II/IIIa & 2449 & Mano fragment \\
\hline 51 & $27 \mathrm{C}$ & Feature & 249 & II/IIIa & OR717 & Rock, unanalyzed \\
\hline 51 & $28 \mathrm{~A}$ & & & II/IIIa & & Debitage \\
\hline 51 & $28 \mathrm{~B}$ & Feature & 249 & II/IIIa & & Debitage \\
\hline 51 & $28 \mathrm{C}$ & Feature & 249 & II/IIIa & & Debitage \\
\hline 51 & $28 \mathrm{C}$ & Feature & 249 & II/IIIa & OR733 & Flake, unanalyzed \\
\hline 51 & $28 \mathrm{E}$ & & & II/IIIa & & Debitage \\
\hline 51 & $29 \mathrm{~A}$ & & & $\mathrm{II} / \mathrm{III}$ & & Debitage \\
\hline 51 & $29 B$ & Feature & 249 & II/IIIIa & & Debitage \\
\hline 51 & $30 \mathrm{~A}$ & & & $\mathrm{II} / \mathrm{III}$ & & Debitage \\
\hline 51 & $30 \mathrm{~B}$ & Feature & 249 & II/IIIa & & Debitage \\
\hline 51 & $31 \mathrm{~A}$ & & & II & & Debitage \\
\hline 51 & $31 \mathrm{~B}$ & Feature & 249 & II & & Debitage \\
\hline 52 & 14 & & & Fill & $696-1$ & Biface fragment \\
\hline 52 & 14 & & & Fill & $696-2$ & Thin uniface \\
\hline 52 & $15 \mathrm{~A}$ & & & $\mathrm{IIIa} / \mathrm{b}$ & & Debitage \\
\hline 52 & $15 \mathrm{~A}$ & & & $\mathrm{IIIa} / \mathrm{b}$ & OR304 & Flake, unanalyzed \\
\hline 52 & $15 \mathrm{~A}$ & & & IIIa/b & $711-2$ & Perforator Group 4 \\
\hline 52 & $15 \mathrm{~A}$ & & & IIIa/b & OR295 & Projectile point, expanding concave $\mathrm{C}$ \\
\hline 52 & $15 \mathrm{~A}$ & & & $\mathrm{IIIa} / \mathrm{b}$ & $711-1$ & Unifacial multiple tool \\
\hline 52 & $15 \mathrm{~B}$ & Feature & 220 & $\mathrm{IIIa} / \mathrm{b}$ & OR315 & Biface Stage 1 \\
\hline 52 & $15 \mathrm{~B}$ & Feature & 220 & $\mathrm{IIIa} / \mathrm{b}$ & & Debitage \\
\hline 52 & $16 \mathrm{~A}$ & & & $\mathrm{IIIa} / \mathrm{b}$ & $746-1$ & Bifacial tool Form E \\
\hline 52 & $16 \mathrm{~A}$ & & & $\mathrm{IIIa} / \mathrm{b}$ & & Debitage \\
\hline 52 & $16 \mathrm{~A}$ & & & IIIIa/b & $746-2$ & Projectile point, long stemmed \\
\hline 52 & $16 \mathrm{~B}$ & Feature & 220 & $\mathrm{IIIa} / \mathrm{b}$ & & Debitage \\
\hline 52 & $16 \mathrm{~B}$ & Feature & 220 & $\mathrm{IIIa} / \mathrm{b}$ & $139-1$ & Spurred flake \\
\hline 52 & 17 & & & $\mathrm{IIIa} / \mathrm{b}$ & OR324 & Biface fragment \\
\hline 52 & 17 & & & $\mathrm{IIIa} / \mathrm{b}$ & & Debitage \\
\hline 52 & 19 & - & & IIIa & $850-1$ & Burin \\
\hline 52 & 19 & & & IIIIa & & Debitage \\
\hline 52 & 19 & & & IIIa & OR338 & Flake, unanalyzed \\
\hline 52 & 20 & Feature & 231 & IIIa & OR348 & Biface Stage 1 \\
\hline 52 & 20 & Feature & 231 & IIIIa & $877-1$ & Core fragment \\
\hline 52 & 20 & Feature & 231 & IIIa & & Debitage \\
\hline 52 & 21 & Feature & 231 & IIIa & & Debitage \\
\hline 52 & 22 & Feature & 231 & IIIIa & $950-7$ & Biface fragment \\
\hline 52 & 22 & Feature & 231 & IIIa & OR372 & Clear Fork biface \\
\hline 52 & 22 & Feature & 231 & IIIa & & Debitage \\
\hline 52 & 22 & Feature & 231 & IIIa & OR360 & Flake, unanalyzed \\
\hline 52 & 22 & Feature & 231 & IIIa & OR368 & Flake, unanalyzed \\
\hline 52 & 22 & Feature & 231 & IIIa & OR377 & Flake, unanalyzed \\
\hline 52 & 22 & Feature & 231 & IIIIa & $950-2$ & Microspur/microdenticulate \\
\hline 52 & 23 & Feature & 231 & IIIa & & Debitage \\
\hline 52 & 23 & Feature & 231 & IIIa & OR429 & Flake, unanalyzed \\
\hline 52 & 23 & Feature & 231 & IIIa & OR424 & Projectile point, Hoxie/Gower \\
\hline
\end{tabular}




\begin{tabular}{|c|c|c|c|c|c|c|c|}
\hline $\begin{array}{l}\text { Square } \\
52\end{array}$ & Level & & & Strata & Item & Analyst Identification & Count \\
\hline 52 & 24 & $\begin{array}{l}\text { Feature } \\
\text { Feature }\end{array}$ & $\begin{array}{l}231 \\
231 / 245\end{array}$ & III/IIIa & $\begin{array}{l}1098-1 \\
1648-4\end{array}$ & $\begin{array}{l}\text { Thin uniface fragment } \\
\text { Biface fragment }\end{array}$ & 1 \\
\hline 52 & 24 & Feature & $231 / 245$ & II/IIIa & & Debitage & 401 \\
\hline 52 & 24 & Feature & $231 / 245$ & II/IIIa & $1648-1$ & Edge modified flake & \\
\hline 52 & 24 & Feature & $231 / 245$ & II/IIIa & $1648-2$ & Edge modified flake & \\
\hline 52 & 24 & Feature & $231 / 245$ & II/IIIa & 1464-1 & Microspur/microdenticulate & \\
\hline 52 & 24 & Feature & $231 / 245$ & II/IIIa & $1464-2$ & Notched flake & 1 \\
\hline 52 & 24 & Feature & 245 & II/IIIa & & Debitage & 19 \\
\hline 52 & 24 & Feature & 245 & II/IIIa & OR526 & Flake, unanalyzed & 1 \\
\hline 52 & $25 \mathrm{~A}$ & & & II/IIIa & & Debitage & 40 \\
\hline 52 & $25 \mathrm{~A}$ & & & II/IIIa & OR530 & Flake, unanalyzed & 1 \\
\hline 52 & $25 \mathrm{~B}$ & Feature & $231 / 245$ & II/IIIa & & Debitage & 266 \\
\hline 52 & $25 \mathrm{~B}$ & Feature & 245 & II/IIIa & & Debitage & 58 \\
\hline 52 & $25 \mathrm{~B}$ & Feature & 245 & II/IIIa & $1590-1$ & Edge modified flake & \\
\hline 52 & $25 \mathrm{~B}$ & Feature & 245 & II/IIIa & $1599-1$ & Microspur/microdenticulate & \\
\hline 52 & $25 \mathrm{~B}$ & Feature & 245 & II/IIIa & OR535 & Rock, unanalyzed & \\
\hline 52 & $25 B$ & Feature & 245 & II/IIIa & OR531 & Rock, unanalyzed & 1 \\
\hline 52 & $26 \mathrm{~A}$ & & & II/IIIa & & Debitage & 251 \\
\hline 52 & $26 \mathrm{~A}$ & & & II/IIIa & $1678-1$ & Edge modified flake & 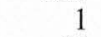 \\
\hline 52 & $26 \mathrm{~B}$ & Feature & 231 & II/IIIa & & Debitage & 45 \\
\hline 52 & $26 \mathrm{~B}$ & Feature & 231 & II/IIIa & OR608 & Flake, unanalyzed & 1 \\
\hline 52 & $26 \mathrm{~B}$ & Feature & 245 & II/IIIa & & Debitage & 36 \\
\hline 52 & $26 \mathrm{C}$ & Feature & 245 & II/IIIa & & Debitage & 71 \\
\hline 52 & $26 \mathrm{C}$ & Feature & 245 & II/IIIa & OR607 & Flake, unanalyzed & \\
\hline 52 & $26 \mathrm{C}$ & Feature & 245 & II/IIIa & $1830-2$ & Perforator Unifacial & \\
\hline 52 & $26 \mathrm{C}$ & Feature & 245 & II/IIIa & $1830-1$ & Projectile point fragment & 1 \\
\hline 52 & 27 & & & II/IIIa & & Debitage & 101 \\
\hline 52 & $27 \mathrm{~A}$ & & & II/IIIa & & Debitage & 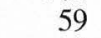 \\
\hline 52 & 27B & & & II/IIIa & & Debitage & \\
\hline 52 & 28 & & & II & & Debitage & 188 \\
\hline 52 & 28 & & & II & OR621 & Flake, unanalyzed & \\
\hline 52 & $28 \mathrm{~A}$ & & & II & & Debitage & 41 \\
\hline 52 & $28 \mathrm{~B}$ & Feature & 248 & II & & Debitage & 23 \\
\hline 52 & $28 \mathrm{~B}$ & Feature & 248 & II & OR573 & Flake, unanalyzed & \\
\hline 52 & 29 & & & II & $2537-2$ & Biface fragment & 1 \\
\hline 52 & 29 & & & II & & Debitage & 107 \\
\hline 52 & 29 & & & II & $2537-1$ & Edge modified flake & \\
\hline 52 & 29 & & & II & OR627 & Flake, unanalyzed & \\
\hline 52 & $29 \mathrm{~A}$ & & & II & & Debitage & 51 \\
\hline 52 & $29 B$ & Feature & 248 & II & & Debitage & 18 \\
\hline 52 & 30 & & & II & & Debitage & 144 \\
\hline 52 & 30 & & & II & OR633 & Flake, unanalyzed & \\
\hline 52 & 30 & & & II & 1984-1 & Thin uniface fragment & \\
\hline 52 & 31 & & & II & $2017-1$ & Biface fragment & \\
\hline 52 & 31 & & & II & & Debitage & 123 \\
\hline 52 & 31 & & & II & OR645 & Flake, unanalyzed & \\
\hline 52 & 32 & & & II & & Debitage & 147 \\
\hline 52 & 32 & & & II & 2039-1 & Edge modified flake & \\
\hline 52 & 32 & & & II & $2039-2$ & Edge modified flake & \\
\hline 52 & 33 & & & II & & Debitage & 161 \\
\hline 52 & 33 & & & II & $2080-1$ & Edge modified flake & \\
\hline 52 & 34 & & & II & & Debitage & 91 \\
\hline 52 & 34 & & & II & $2769-1$ & Edge modified flake & 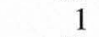 \\
\hline 52 & 35 & & & $\mathrm{Id} / \mathrm{II}$ & & Debitage & 4 \\
\hline 52 & 36 & & & $\mathrm{Id} / \mathrm{II}$ & & Debitage & 3 \\
\hline 52 & 36 & & & Id/II & 2613-1 & Edge modified flake & 1 \\
\hline 52 & $36 \mathrm{~B}$ & & & $\mathrm{Id} / \mathrm{II}$ & & Debitage & 2 \\
\hline 52 & 37 & & & Isi-c/Id & & Debitage & 27 \\
\hline 52 & 37 & & & Isi-c/Id & OR664 & Flake, unanalyzed & \\
\hline 52 & 38 & & & Isi-c/Id & $2767-1$ & Biface Stage 3 & \\
\hline 52 & 38 & & & Isi-c/Id & & Debitage & 17 \\
\hline 52 & 38 & & & Isi-c/Id & OR678 & Flake, unanalyzed & \\
\hline 52 & 39 & & & Isi-c/Id & & Debitage & 1 \\
\hline 52 & 40 & & & Isi-c & & Debitage & \\
\hline 52 & 40 & & & Isi-c & $2638-1$ & Thin uniface fragment & \\
\hline 52 & 41 & & & Isi-c & & Debitage & 3 \\
\hline 52 & 41 & & & Isi-c & OR698 & Flake, unanalyzed & \\
\hline 52 & 42 & & & Isi-c & & Debitage & 1 \\
\hline 52 & 42 & & & Isi-c & OR708 & Flake, unanalyzed & \\
\hline 52 & 42 & & & Isi-c & OR702 & Flake, unanalyzed & \\
\hline 52 & 42 & & & Isi-c & OR707 & Flake, unanalyzed & \\
\hline 52 & 43 & & & Isi-c & & Debitage & 15 \\
\hline 52 & 43 & & & Isi-c & OR710 & Flake, unanalyzed & \\
\hline 52 & 44 & & & Icl/Isi-c & & Debitage & \\
\hline
\end{tabular}




\begin{tabular}{|c|c|c|c|c|c|c|}
\hline Square & Level & Feature & Strata & Item & Analyst Identification & Count \\
\hline 52 & 44 & & $\mathrm{Icl} / \mathrm{Isi}-\mathrm{c}$ & OR718 & Flake, unanalyzed & $\begin{array}{r}1 \\
14\end{array}$ \\
\hline 52 & 45 & & Icl/Isi-c & & Debitage & 14 \\
\hline 52 & 45 & & $\mathrm{Icl} / \mathrm{Isi}-\mathrm{c}$ & OR720 & Flake, unanalyzed & 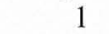 \\
\hline 52 & 45 & & $\mathrm{Icl} / \mathrm{Isi}-\mathrm{c}$ & OR719 & Flake, unanalyzed & 1 \\
\hline 52 & 46 & & $\mathrm{Icl} / \mathrm{Isi}-\mathrm{c}$ & OR727 & Biface Stage 1 & 1 \\
\hline 52 & 46 & & $\mathrm{Icl} / \mathrm{Isi}-\mathrm{c}$ & & Debitage & 20 \\
\hline 52 & 46 & & $\mathrm{Icl} / \mathrm{Isi}-\mathrm{c}$ & OR721 & Flake, unanalyzed & 1 \\
\hline 52 & 46 & & Icl/Isi-c & OR728 & Flake, unanalyzed & 1 \\
\hline 52 & 46 & & Icl/Isi-c & OR723 & Flake, unanalyzed & 1 \\
\hline 52 & 46 & & $\mathrm{Icl} / \mathrm{Isi}-\mathrm{c}$ & OR725 & Flake, unanalyzed & 1 \\
\hline 52 & 46 & & $\mathrm{Icl} / \mathrm{Isi}-\mathrm{c}$ & OR726 & Tool, unanalyzed & 1 \\
\hline 52 & $46-47$ & & Icl/Isi-c & & Debitage & 1 \\
\hline 52 & 47 & & Icl/Isi-c & & Debitage & 37 \\
\hline 52 & 47 & & Icl/Isi-c & OR752 & Flake, unanalyzed & 1 \\
\hline 52 & 48 & & $\mathrm{Icl}$ & & Debitage & 28 \\
\hline 52 & 49 & & Icl & & Debitage & 33 \\
\hline 52 & 49 & & Icl & OR735 & Flake, unanalyzed & 1 \\
\hline 52 & 49 & & Icl & OR753 & Flake, unanalyzed & 1 \\
\hline 52 & 50 & & Isi/Icl & $2531-6$ & Biface fragment & 1 \\
\hline 52 & 50 & & $\mathrm{Isi} / \mathrm{Icl}$ & & Debitage & 16 \\
\hline 52 & 51 & & $\mathrm{Isi} / \mathrm{Icl}$ & & Debitage & 23 \\
\hline 52 & 52 & & Isi/Icl & OR737 & Core, multidirectional & 7 \\
\hline 52 & 52 & & Isi/Icl & & Debitage & 21 \\
\hline 52 & 52 & & $\mathrm{Isi} / \mathrm{Icl}$ & OR738 & Flake, unanalyzed & 1 \\
\hline 52 & 53 & & Isi//Icl & & Debitage & 13 \\
\hline 52 & 53 & & Isi/Icl & OR739 & Flake, unanalyzed & 1 \\
\hline 52 & 54 & & Isi/Icl & & Debitage & 6 \\
\hline 52 & 55 & & $\mathrm{Igl} / \mathrm{Isi}$ & & Debitage & 3 \\
\hline 52 & 56 & & $\mathrm{Igl} / / \mathrm{Isi}$ & & Debitage & 3 \\
\hline 52 & 57 & & $\mathrm{Igl} / \mathrm{Isi}$ & $2709-1$ & Thin uniface & 1 \\
\hline 52 & 58 & & $\mathrm{Igl} / \mathrm{Isi}$ & & Debitage & 2 \\
\hline 53 & 19 & & IIIa & & Debitage & 21 \\
\hline 53 & 20 & Feature 231 & IIIa & & Debitage & 18 \\
\hline 53 & 21 & Feature 231 & IIIa & & Debitage & 21 \\
\hline 53 & 22 & Feature 231 & IIIa & & Debitage & 35 \\
\hline 53 & 23 & Feature 231 & IIIa & & Debitage & 38 \\
\hline 53 & 23 & Feature 231 & IIIa & $1151-1$ & Edge modified flake & 1 \\
\hline 53 & 24 & Feature $231 / 245$ & II/IIIa & & Debitage & 43 \\
\hline 53 & 24 & Feature $231 / 245$ & II/IIIa & $1460-1$ & Edge modified flake & 1 \\
\hline 53 & 25 & & II/IIIIa & & Debitage & 29 \\
\hline 53 & $26 \mathrm{~A}$ & & II/IIIa & & Debitage & 7 \\
\hline 53 & $26 \mathrm{~B}$ & Feature 245 & II/IIIa & OR566 & Biface Stage 2 & 1 \\
\hline 53 & $26 \mathrm{~B}$ & Feature 245 & II/IIIa & & Debitage & 15 \\
\hline 53 & 27 & & II/IIIa & & Debitage & 23 \\
\hline 53 & 28 & Feature 248 & II & & Debitage & 19 \\
\hline 53 & $29 \mathrm{~A}$ & & II & & Debitage & 4 \\
\hline 53 & $29 B$ & Feature 248 & II & & Debitage & 4 \\
\hline 53 & 38ID & & Isi-c/Id & & Debitage & 6 \\
\hline 53 & $39 \mathrm{~A}$ & & Isi-c/Id & & Debitage & 2 \\
\hline 53 & $39 \mathrm{~B}$ & Feature 257 & Isi-c/Id & & Debitage & 1 \\
\hline 53 & 41 & & Isi-c & & Debitage & 1 \\
\hline 53 & 47 & & $\mathrm{Icl} / \mathrm{Isi}-\mathrm{c}$ & & Debitage & 4 \\
\hline 53 & 50 & & Isi/Icl & & Debitage & 2 \\
\hline 53 & 51 & & $\mathrm{Isi} / \mathrm{Icl}$ & & Debitage & 5 \\
\hline 53 & 51 & & Isi/Icl & OR742 & Edge modified flake & 1 \\
\hline 53 & 52 & & Isi/Icl & & Debitage & 9 \\
\hline 53 & 52 & & $\mathrm{Isi} / \mathrm{Icl}$ & OR741 & Flake, unanalyzed & 1 \\
\hline 53 & 53 & & Isi/Icl & & Debitage & 3 \\
\hline 53 & 54 & & Isi/Icl & & Debitage & 8 \\
\hline 53 & 55 & & $\mathrm{Igl} / \mathrm{Isi}$ & & Debitage & 4 \\
\hline 53 & 56 & & Igl/Isi & & Debitage & 3 \\
\hline 54 & 44 & & Isi & & Debitage & 12 \\
\hline 54 & 45 & & Isi & & Debitage & 5 \\
\hline 54 & 46 & & Isi & & Debitage & 13 \\
\hline 54 & 47 & & Isi & & Debitage & 6 \\
\hline 54 & 48 & & Isi & & Debitage & 4 \\
\hline 54 & 54 & & Isi & & Debitage & 1 \\
\hline 55 & 41 & & Isi/Isi-c & & Debitage & 58 \\
\hline 55 & 42 & & Isi/Isi-c & 1938-1 & Biface fragment & 1 \\
\hline 55 & 42 & & Isi/Isi-c & & Debitage & 67 \\
\hline 55 & 42 & & Isi/Isi-c & $1938-2$ & Edge modified flake & 1 \\
\hline 55 & $43 \mathrm{~A}$ & & Isi/Isi-c & & Debitage & 28 \\
\hline 55 & $43 \mathrm{~B}$ & Feature 252 & Isi/Isi-c & & Debitage & 3 \\
\hline 55 & 44 & & Isi & & Debitage & 6 \\
\hline
\end{tabular}




\begin{tabular}{|c|c|c|c|c|c|c|}
\hline Square & Level & Feature & Strata & Item & Analyst Identification & Count \\
\hline & 45 & & Isi & & Debitage & \\
\hline $\begin{array}{l}55 \\
55\end{array}$ & 46 & & Isi & & Debitage & 4 \\
\hline 55 & 47 & & Isi & & Debitage & 1 \\
\hline 55 & 47 & & Isi & OR671 & Flake, unanalyzed & 1 \\
\hline 55 & 48 & & Isi & & Debitage & $T$ \\
\hline 55 & 50 & & Isi & & Debitage & $T$ \\
\hline 55 & 51 & & Isi & & Debitage & \\
\hline 55 & 52 & & Isi & & Debitage & . \\
\hline 55 & 53 & & Isi & & Debitage & 2 \\
\hline 56 & 36 & & Isi-c/Id & & Debitage & 62 \\
\hline 56 & 37 & & Isi-c/Id & & Debitage & 67 \\
\hline 56 & 38 & & Isi-c/Id & & Debitage & 7 \\
\hline 56 & 38 & & Isi-c/Id & OR628 & Flake, unanalyzed & 1 \\
\hline 56 & 39 & & Isi-c & & Debitage & 56 \\
\hline 56 & 39 & & Isi-c & OR631 & Tool, unanalyzed & 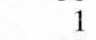 \\
\hline 56 & 40 & & Isi/Isi-c & & Debitage & I \\
\hline 56 & 40 & & Isi/Isi-c & OR638 & Flake, unanalyzed & 7 \\
\hline 56 & 41 & & Isi/Isi-c & & Debitage & 38 \\
\hline 56 & 42 & & Isi/Isi-c & & Debitage & 54 \\
\hline 56 & 43 & & Isi/Isi-c & & Debitage & 60 \\
\hline 56 & 43 & & Isi/Isi-c & OR652 & Flake, unanalyzed & 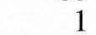 \\
\hline 56 & 43 & & Isi/Isi-c & OR654 & Flake, unanalyzed & 1 \\
\hline 56 & 43 & & Isi/Isi-c & OR653 & Flake, unanalyzed & 1 \\
\hline 56 & 44 & & Isi/Isi-c & & Debitage & 35 \\
\hline 56 & 45 & & Isi/Isi-c & & Debitage & 22 \\
\hline 56 & 45 & & Isi/Isi-c & OR660 & Flake, unanalyzed & 1 \\
\hline 56 & 46 & & Isi & & Debitage & 10 \\
\hline 56 & 46 & & Isi & OR665 & Flake, unanalyzed & 1 \\
\hline 56 & 46 & & Isi & OR663 & Flake, unanalyzed & 1 \\
\hline 56 & 47 & & Isi & & Debitage & 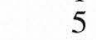 \\
\hline 56 & 47 & & Isi & OR670 & Flake, unanalyzed & 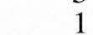 \\
\hline 56 & 48 & & Isi & OR673 & Core, unanalyzed & 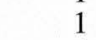 \\
\hline 56 & 48 & & Isi & & Debitage & 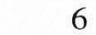 \\
\hline 56 & 49 & & Isi & & Debitage & 0 \\
\hline 56 & 49 & & Isi & OR677 & Flake, unanalyzed & 1 \\
\hline 56 & 50 & & Isi & & Debitage & 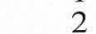 \\
\hline 56 & 51 & & Isi & & Debitage & 3 \\
\hline 56 & 53 & & Isi & & Debitage & 2 \\
\hline 56 & 54 & & Isi & & Debitage & 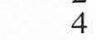 \\
\hline 57 & 34 & & $\mathrm{Id} / \mathrm{II}$ & & Debitage & 69 \\
\hline 57 & 35 & & Id & & Debitage & 74 \\
\hline 57 & 36 & & Isi-c/Id & OR626 & Clear Fork biface & 1 \\
\hline 57 & 36 & & Isi-c/Id & & Debitage & 82 \\
\hline 57 & 37 & & Isi-c & OR629 & Clear Fork biface & 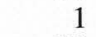 \\
\hline 57 & 37 & & Isi-c & & Debitage & 96 \\
\hline 57 & 37 & & Isi-c & 1954-1 & Edge modified flake & 1 \\
\hline 57 & 37 & & Isi-c & OR630 & Thick uniface fragment & 1 \\
\hline 57 & 38 & & Isi-c & & Debitage & 41 \\
\hline 57 & 38 & & Isi-c & OR643 & Flake, unanalyzed & 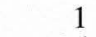 \\
\hline 57 & 39 & & Isi-c & & Debitage & 36 \\
\hline 57 & 40 & . & Isi/Isi-c & OR649 & Biface Stage 2 & 1 \\
\hline 57 & 40 & & Isi/Isi-c & & Debitage & 39 \\
\hline 57 & 41 & & Isi/Icl/Isi-c & & Debitage & 43 \\
\hline 57 & 42 & & Isi/Icl/Isi-c & & Debitage & 16 \\
\hline 57 & 43 & & Isi/Isi-c & & Debitage & 22 \\
\hline 57 & 44 & & Isi/Isi-c & & Debitage & 21 \\
\hline 57 & 45 & & Isi/Isi-c & & Debitage & 15 \\
\hline 57 & 45 & & Isi/Isi-c & $2797-1$ & Thin uniface & 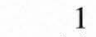 \\
\hline 57 & 46 & & Isi/Isi-c & & Debitage & 14 \\
\hline 57 & 46 & & Isi/Isi-c & $2607-1$ & Edge modified flake & 1 \\
\hline 57 & 47 & & Isi/Isi-c & & Debitage & 16 \\
\hline 57 & 48 & & Isi & & Debitage & \\
\hline 57 & 48 & & Isi & OR662 & Flake, unanalyzed & \\
\hline 57 & 49 & & Isi & & Debitage & \\
\hline 57 & 50 & & Isi & & Debitage & 4 \\
\hline 57 & 52 & & Isi & & Debitage & 10 \\
\hline 57 & 53 & & Isi & & Debitage & \\
\hline 58 & 40 & & Isi-c & & Debitage & \\
\hline 58 & 41 & & Isi-c & & Debitage & 10 \\
\hline 58 & 42 & & Isi-c & & Debitage & \\
\hline 58 & 43 & & Icl/Isi-c & & Debitage & \\
\hline 58 & 44 & & $\mathrm{Icl} / \mathrm{Isi}-\mathrm{c}$ & & Debitage & \\
\hline 58 & 45 & & Icl/Isi-c & & Debitage & 2 \\
\hline 58 & 46 & & Icl/Isi-c & $2833-1$ & Biface fragment & \\
\hline
\end{tabular}




\begin{tabular}{|c|c|c|c|c|c|c|}
\hline Square & Level & Feature & Strata & Item & Analyst Identification & Count \\
\hline 58 & 46 & & Icl/Isi-c & & Debitage & 3 \\
\hline 58 & 47 & & Icl & & Debitage & 6 \\
\hline 58 & 48 & & Isi/Icl & & Debitage & 5 \\
\hline 58 & 48 & & $\mathrm{Isi} / \mathrm{Icl}$ & OR659 & Flake, unanalyzed & 1 \\
\hline 58 & 49 & & Isi/Icl & & Debitage & 3 \\
\hline 58 & 49 & & Isi/Icl & OR666 & Flake, unanalyzed & 1 \\
\hline 58 & 50 & & Isi/Icl & & Debitage & 3 \\
\hline 58 & 51 & & Isi & & Debitage & 6 \\
\hline 58 & 52 & & Isi & & Debitage & 8 \\
\hline 58 & 53 & & Isi & & Debitage & 1 \\
\hline 58 & $54 \mathrm{~A}$ & & $\mathrm{Igl} / \mathrm{Isi}$ & & Debitage & 1 \\
\hline 58 & $54 \mathrm{~B}$ & & $\mathrm{Igl} / \mathrm{Isi}$ & $2835-1$ & Chert cobble, chunk & 1 \\
\hline 58 & 55 & & $\mathrm{Igl} / \mathrm{Isi}$ & & Debitage & 5 \\
\hline 59 & 34 & & $\mathrm{Id} / \mathrm{II}$ & & Debitage & 140 \\
\hline 59 & 35 & & $\mathrm{Id} / \mathrm{II}$ & & Debitage & 64 \\
\hline 59 & 36 & & $\mathrm{Id} / \mathrm{II}$ & & Debitage & 30 \\
\hline 59 & 37 & & Id & & Debitage & 20 \\
\hline 59 & 38 & & Isi-c/Id & & Debitage & 23 \\
\hline 59 & 38 & & Isi-c/Id & $2606-1$ & Edge modified flake, unanalyzed & 1 \\
\hline 59 & 38 & & Isi-c/Id & OR658 & Flake, unanalyzed & 1 \\
\hline 59 & 39 & & Isi-c/Id & & Debitage & 19 \\
\hline 59 & 39 & & Isi-c/Id & 2693-1 & Thin uniface & 1 \\
\hline 59 & 40 & & Isi-c & & Debitage & 34 \\
\hline 59 & 41 & & Isi-c & & Debitage & 23 \\
\hline 59 & $42 \mathrm{~A}$ & & Isi-c & & Debitage & 14 \\
\hline 59 & $42 \mathrm{~B}$ & Feature 255 & Isi-c & & Debitage & 1 \\
\hline 59 & 43 & & Icl/Isi-c & & Debitage & 9 \\
\hline 59 & 43 & & Icl/Isi-c & OR682 & Flake, unanalyzed & 1 \\
\hline 59 & 44 & & $\mathrm{Icl} / \mathrm{Isi}-\mathrm{c}$ & & Debitage & 11 \\
\hline 59 & 44 & & Icl/Isi-c & OR685 & Flake, unanalyzed & 1 \\
\hline 59 & 45 & & Icl/Isi-c & & Debitage & 8 \\
\hline 59 & 45 & & Icl/Isi-c & OR687 & Flake, unanalyzed & 1 \\
\hline 59 & 45 & & $\mathrm{Icl} / \mathrm{Isi}-\mathrm{c}$ & OR686 & Flake, unanalyzed & 1 \\
\hline 59 & 46 & & Icl & & Debitage & 3 \\
\hline 59 & 47 & & Icl & & Debitage & 11 \\
\hline 59 & 47 & & Icl & OR691 & Flake, unanalyzed & 1 \\
\hline 59 & 48 & & Icl & & Debitage & 8 \\
\hline 59 & 49 & & Isi/Icl & & Debitage & 6 \\
\hline 59 & 49 & & Isi/Icl & OR696 & Flake, unanalyzed & 1 \\
\hline 59 & 50 & & Isi/Icl & & Debitage & 9 \\
\hline 59 & 50 & & Isi/Icl & OR699 & Flake, unanalyzed & 1 \\
\hline 59 & 51 & & $\mathrm{Isi} / \mathrm{Icl}$ & & Debitage & 4 \\
\hline 59 & 51 & & Isi/Icl & OR704 & Flake, unanalyzed & 1 \\
\hline 59 & 51 & & Isi/Icl & OR703 & Flake, unanalyzed & 1 \\
\hline 59 & 52 & & Isi & $2503-1$ & Biface fragment & 1 \\
\hline 59 & 52 & & Isi & & Debitage & 12 \\
\hline 59 & 53 & & Isi & & Debitage & 6 \\
\hline 59 & 54 & & Isi & & Debitage & 2 \\
\hline 59 & 55 & & Isi & & Debitage & 3 \\
\hline 59 & 56 & & Isi & & Debitage & 1 \\
\hline 60 & 56 & & $\mathrm{Igl} / \mathrm{Isi}$ & & Debitage & 2 \\
\hline 100 & 1 & & IIIc & $1197-1$ & Biface Stage 2 & 1 \\
\hline 100 & 2 & BRM 1 & IIIIc & $1206-28$ & Arrow point, preform & 1 \\
\hline 100 & 2 & BRM 1 & IIIc & $1206-27$ & Arrow point, Scallorn & 1 \\
\hline 100 & 2 & BRM 1 & IIIC & $1206-34$ & Biface fragment & 1 \\
\hline 100 & 2 & BRM 1 & IIIc & $1206-3$ & Biface Stage 1 & 1 \\
\hline 100 & 2 & BRM 1 & IIIIc & $1206-1$ & Biface Stage 2 & 1 \\
\hline 100 & 2 & BRM 1 & IIIc & 1206 & Biface Stage 2 & 1 \\
\hline 100 & 2 & BRM 1 & IIIIc & OR452 & Bifacial tool & 1 \\
\hline 100 & 2 & BRM 1 & IIIIc & $1206-42$ & Burin spall & 1 \\
\hline 100 & 2 & BRM 1 & IIIc & & Debitage & 2808 \\
\hline 100 & 2 & BRM 1 & IIIc & $1206-10$ & Denticulated flake & 1 \\
\hline 100 & 2 & BRM 1 & IIIC & $1206-37$ & Edge modified flake & 1 \\
\hline 100 & 2 & BRM 1 & IIIC & $1206-11$ & Edge modified flake & 1 \\
\hline 100 & 2 & BRM 1 & IIIC & $1206-12$ & Edge modified flake & 1 \\
\hline 100 & 2 & BRM 1 & IIIc & $1206-14$ & Edge modified flake & 1 \\
\hline 100 & 2 & BRM 1 & IIIc & $1206-23$ & Edge modified flake & 1 \\
\hline 100 & 2 & BRM 1 & IIII & $1206-17$ & Edge modified flake & 1 \\
\hline 100 & 2 & BRM 1 & IIIC & $1206-2$ & Edge modified flake & 1 \\
\hline 100 & 2 & BRM 1 & IIIc & OR451 & Edge modified flake & 1 \\
\hline 100 & 2 & BRM 1 & IIIc & $1206-9$ & Edge modified flake & 1 \\
\hline 100 & 2 & BRM 1 & IIIc & $1206-6$ & Edge modified flake & 1 \\
\hline 100 & 2 & BRM 1 & IIIc & $1206-35$ & Edge modified flake & 1 \\
\hline 100 & 2 & BRM 1 & IIIIc & $1206-4$ & Edge modified flake & 1 \\
\hline
\end{tabular}




\begin{tabular}{|c|c|c|c|c|c|c|}
\hline Square & Level & Feature & Strata & Item & Analyst Identification & Count \\
\hline 100 & 2 & BRM 1 & IIIc & $1206-21$ & Edge modified flake & 1 \\
\hline 100 & 2 & BRM 1 & IIIc & $1206-16$ & Edge modified flake & 1 \\
\hline 100 & 2 & BRM 1 & IIIc & $1206-13$ & Notched flake & 1 \\
\hline 100 & 2 & BRM 1 & IIIC & $1206-5$ & Projectile point fragment & 1 \\
\hline 100 & 2 & BRM 1 & IIIc & $1206-36$ & Projectile point fragment & 1 \\
\hline 100 & 2 & BRM 1 & IIIc & $1206-24$ & Projectile point fragment & 1 \\
\hline 100 & 2 & BRM 1 & IIIc & $1206-25$ & Projectile point fragment & 1 \\
\hline 100 & 2 & BRM 1 & IIIIc & $1206-26$ & Projectile point fragment & 1 \\
\hline 100 & 2 & BRM 1 & IIIc & $1206-29$ & Projectile point fragment & 1 \\
\hline 100 & 2 & BRM 1 & IIIc & $1206-32$ & Projectile point fragment & 1 \\
\hline 100 & 2 & BRM 1 & IIII & $1206-8$ & Projectile point fragment & 1 \\
\hline 100 & 2 & BRM 1 & IIIc & $1206-31$ & Projectile point fragment & 1 \\
\hline 100 & 2 & BRM 1 & IIIIc & $1246-1$ & Projectile point, Nolan & 1 \\
\hline 100 & 2 & BRM 1 & IIIc & $1206-7$ & Thin uniface fragment & 1 \\
\hline 100 & 2 & BRM 1 & IIIIc & $1206-20$ & Thin uniface fragment & 1 \\
\hline 100 & 2 & BRM 1 & IIIIc & $1206-18$ & Unifacial multiple tool & 1 \\
\hline 100 & 3 & BRM 1 & IIII & $1265-7$ & Biface fragment & 1 \\
\hline 100 & 3 & BRM 1 & IIIIc & $1265-10$ & Biface fragment & 1 \\
\hline 100 & 3 & BRM 1 & IIII & $1265-4$ & Biface Stage 2 & 1 \\
\hline 100 & 3 & BRM 1 & IIIc & $1265-13$ & Burin spall & 1 \\
\hline 100 & 3 & BRM 1 & IIIc & $1265-14$ & Burin spall & 1 \\
\hline 100 & 3 & BRM 1 & IIIC & $1265-12$ & Burin spall & 1 \\
\hline 100 & 3 & BRM 1 & IIIc & $1265-15$ & Burin spall & 1 \\
\hline 100 & 3 & BRM 1 & IIIC & & Debitage & 1536 \\
\hline 100 & 3 & BRM 1 & IIIc & $1265-2$ & Edge modified flake & 1 \\
\hline 100 & 3 & BRM 1 & IIIC & $1265-8$ & Edge modified flake & 1 \\
\hline 100 & 3 & BRM 1 & IIIIc & $1265-3$ & Microspur/microdenticulate & 1 \\
\hline 100 & 3 & BRM 1 & IIIIc & $1265-5$ & Projectile point fragment & 1 \\
\hline 100 & 4 & BRM 1 & IIIC & $1295-1$ & Biface fragment & 1 \\
\hline 100 & 4 & BRM 1 & IIIIc & $1295-2$ & Biface Stage 2 & 1 \\
\hline 100 & 4 & BRM 1 & IIIIc & & Debitage & 646 \\
\hline 100 & 4 & BRM 1 & IIIc & $1295-7$ & Denticulated flake & 1 \\
\hline 100 & 4 & BRM 1 & IIIC & $1295-6$ & Projectile point fragment & 1 \\
\hline 100 & 4 & BRM 1 & IIIC & $1295-5$ & Projectile point fragment & 1 \\
\hline 100 & 4 & BRM 1 & IIIIc & $1295-4$ & Thin uniface & 1 \\
\hline 100 & 4 & BRM 1 & IIIIc & $1295-3$ & Thin uniface fragment & 1 \\
\hline 100 & 5 & BRM 1 & IIIc & $1315-6$ & Biface fragment & 1 \\
\hline 100 & 5 & BRM 1 & IIIc & OR485 & Biface Stage 2 & 1 \\
\hline 100 & 5 & BRM 1 & IIIIc & & Debitage & 583 \\
\hline 100 & 5 & BRM 1 & IIIIc & $1315-3$ & Edge modified flake & 1 \\
\hline 100 & 5 & BRM 1 & IIIc & $1315-5$ & Edge modified flake & 1 \\
\hline 100 & 5 & BRM 1 & IIIC & $1315-2$ & Projectile point fragment & 1 \\
\hline 100 & 5 & BRM 1 & IIIIc & $1315-1$ & Projectile point, Marcos & 1 \\
\hline 100 & 5 & BRM 1 & IIIIc & $1315-4$ & Unifacial multiple tool & 1 \\
\hline 100 & 6 & BRM 1 & IIIIc & $1349-1$ & Biface Stage 1 & 1 \\
\hline 100 & 6 & BRM 1 & IIIIc & $1349-7$ & Core, thermal & 1 \\
\hline 100 & 6 & BRM 1 & IIIc & & Debitage & 790 \\
\hline 100 & 6 & BRM 1 & IIIIc & $1349-2$ & Edge modified flake & 1 \\
\hline 100 & 6 & BRM 1 & IIIIC & $1349-8$ & Perforator Group 7 & 1 \\
\hline 100 & 6 & BRM 1 & IIIIc & $1349-4$ & Projectile point, bifurcate stem fragment & 1 \\
\hline 100 & 6 & BRM 1 & IIIC & $1349-5$ & Projectile point, expanding concave B & 1 \\
\hline 100 & 6 & BRM 1 & IIIc & $1349-6$ & Projectile point, Martindale A & 1 \\
\hline 100 & 6 & BRM 1 & IIIIc & $1349-3$ & Thin uniface & 1 \\
\hline 100 & 7 & BRM 1 & IIIIc & & Debitage & 647 \\
\hline 100 & 7 & BRM 1 & IIIIC & $1384-1$ & Edge modified flake & 1 \\
\hline 100 & 8 & BRM 1 & IIIC & $1422-3$ & Biface fragment & 1 \\
\hline 100 & 8 & BRM 1 & IIIIc & $1422-1$ & Burin & 1 \\
\hline 100 & 8 & BRM 1 & IIIIc & & Debitage & 588 \\
\hline 100 & 9 & & $\mathrm{Y} / \mathrm{IIIC}$ & $1505-3$ & Biface fragment & 1 \\
\hline 100 & 9 & & Y/IIIc & $1505-9$ & Biface fragment & 1 \\
\hline 100 & 9 & & Y/IIIc & $1505-2$ & Burin spall & 1 \\
\hline 100 & 9 & & Y/IIIc & $15 \mathrm{O} 2-4$ & Burin spall & 1 \\
\hline 100 & 9 & & $\mathrm{Y} / \mathrm{IIIc}$ & & Debitage & 648 \\
\hline 100 & 9 & & Y/IIIc & $1505-4$ & Edge modified flake & 1 \\
\hline 100 & 9 & & $\mathrm{Y} / \mathrm{IIIC}$ & $1505-8$ & Edge modified flake & 1 \\
\hline 100 & 9 & & Y/IIIc & $1505-5$ & Edge modified flake & 1 \\
\hline 100 & 9 & & $\mathrm{Y} / \mathrm{III} \mathrm{c}$ & $1505-1$ & Projectile point, Marcos & 1 \\
\hline 100 & 10 & & $\mathrm{Y}$ & OR534 & Biface Stage 2 & 1 \\
\hline 100 & 10 & & Y & $1560-5$ & Burin spall & 1 \\
\hline 100 & 10 & & Y & $1560-6$ & Burin spall & 1 \\
\hline 100 & 10 & & Y & & Debitage & 1267 \\
\hline 100 & 10 & & $\mathrm{Y}$ & $1560-3$ & Edge modified flake & 1 \\
\hline 100 & 10 & & Y & $1560-1$ & Micro-core, intermediate & 1 \\
\hline 100 & 10 & & $\mathrm{Y}$ & $1560-4$ & Projectile point, bifurcate stem fragment & 1 \\
\hline
\end{tabular}




\begin{tabular}{|c|c|c|c|c|c|c|}
\hline Square & Level & Feature & Strata & Item & Analyst Identification & Count \\
\hline 100 & 10 & & $\mathrm{Y}$ & OR560 & Projectile point, miscellaneous bifurcate & 1 \\
\hline 100 & 11 & & $\mathrm{Y}$ & $1668-5$ & Biface Stage 2 & 1 \\
\hline 100 & 11 & & $\mathrm{Y}$ & $1668-4$ & Burin spall & 1 \\
\hline 100 & 11 & & Y & $1668-1$ & Chert cobble, unmodified/tested & 1 \\
\hline 100 & 11 & & $\mathrm{Y}$ & & Debitage & 929 \\
\hline 100 & 11 & & $\mathrm{Y}$ & $1668-2$ & Edge modified flake & 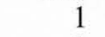 \\
\hline 100 & 11 & & Y & $1668-6$ & Edge modified flake, unanalyzed & 1 \\
\hline 100 & 11 & & $\mathrm{Y}$ & $1668-7$ & Microspur/microdenticulate & 1 \\
\hline 100 & 11 & & $\mathrm{Y}$ & $1668-3$ & Projectile point, Uvalde & 1 \\
\hline 100 & 11 & & $\mathrm{Y}$ & $1668-9$ & Uniface, unanalyzed & 1 \\
\hline 101 & 12 & & $\mathrm{Y}$ & OR648 & Burin & 1 \\
\hline 101 & 12 & & $\mathrm{Y}$ & & Debitage & 732 \\
\hline 101 & 12 & & $\mathrm{Y}$ & 2083-3 & Edge modified flake & 1 \\
\hline 101 & 12 & & $\mathrm{Y}$ & 2083-2 & Thin uniface & 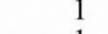 \\
\hline 101 & 12 & & $\mathrm{Y}$ & $2083-1$ & Thin uniface fragment & 1 \\
\hline 101 & 13 & & Y & $2858-7$ & Biface Stage 1 & \\
\hline 101 & 13 & & $\mathrm{Y}$ & & Debitage & 202 \\
\hline 101 & 13 & & $\mathrm{Y}$ & $2858-3$ & Edge modified flake & 1 \\
\hline 101 & 13 & & $\mathrm{Y}$ & $2858-6$ & Edge modified flake & 1 \\
\hline 101 & 13 & & $\mathrm{Y}$ & $2858-1$ & Edge modified flake & 1 \\
\hline 101 & 14 & & $\mathrm{X} / \mathrm{Y}$ & 2113-1 & Biface Stage 1 & 1 \\
\hline 101 & 14 & & $\mathrm{X} / \mathrm{Y}$ & & Debitage & 20 \\
\hline 101 & 15 & & $\mathrm{X}$ & & Debitage & 334 \\
\hline 101 & 15 & & $\mathrm{X}$ & $2651-1$ & Microspur/microdenticulate & \\
\hline 101 & 15 & & $\mathrm{X}$ & OR651 & Thick uniface & x \\
\hline 101 & 16 & & $\mathrm{X}$ & $2805-3$ & Core, thermal & 1 \\
\hline 101 & 16 & & $\mathrm{X}$ & & Debitage & 182 \\
\hline 101 & 16 & & $\mathrm{X}$ & $2805-2$ & Edge modified flake & \\
\hline 101 & 16 & & $\mathrm{X}$ & $2805-4$ & Edge modified flake & 1 \\
\hline 101 & 17 & & $\mathrm{X}$ & $2827-7$ & Core, thermal & 1 \\
\hline 101 & 17 & & $\mathrm{X}$ & & Debitage & 180 \\
\hline 101 & 17 & & $\mathrm{X}$ & $2827-3$ & Notched flake & 1 \\
\hline 101 & 17 & & $\mathrm{X}$ & $2827-1$ & Unifacial multiple tool & 1 \\
\hline 101 & 17 & & $\mathrm{X}$ & $2827-6$ & Unifacial multiple tool & 1 \\
\hline 101 & 18 & & $\mathrm{X}$ & & Debitage & 65 \\
\hline 101 & 19 & & $X$ & & Debitage & 19 \\
\hline 101 & 20 & & $\mathrm{X}$ & & Debitage & 11 \\
\hline 101 & 20 & & $X$ & $2609-1$ & Edge modified flake & 1 \\
\hline 101 & 22 & & $\mathrm{X}$ & & Debitage & 1 \\
\hline Test Unit A & 2 & & Isi & & Debitage & 1 \\
\hline Test Unit A & 3 & & Isi & & Debitage & 5 \\
\hline Test Unit A & 4 & & Isi & & Debitage & 10 \\
\hline Test Unit A & 5 & & Isi & & Debitage & 24 \\
\hline Test Unit A & 6 & & Isi & $124-6$ & Burin spall & 1 \\
\hline Test Unit A & 6 & & Isi & & Debitage & 4 \\
\hline Test Unit A & 7 & & Isi & & Debitage & $?$ \\
\hline Test Unit A & 8 & & Isi & & Debitage & 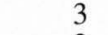 \\
\hline Test Unit A & 13 & & Isi & & Debitage & 2 \\
\hline Test Unit A & 20 & & Igl & & Debitage & 1 \\
\hline Test Unit A & 21 & & $\mathrm{Igl}$ & & Debitage & 5 \\
\hline Test Unit A & 21 & & $\mathrm{Igl}$ & $299-1$ & Unifacial multiple tool & 1 \\
\hline Test Unit A & Wall & & & & Debitage & 1 \\
\hline Test Unit B & & & & OR750 & Biface Stage 1 & 1 \\
\hline Test Unit B & 92.095 & & & OR445 & Bifacial tool Form $\mathrm{G}$ & 1 \\
\hline Test Unit B & 1 & & Isi & & Debitage & 4 \\
\hline Test Unit B & 1 & & Isi & $132-1$ & Edge modified flake & 1 \\
\hline Test Unit B & 2 & & Isi & & Debitage & 2 \\
\hline Test Unit B & 3 & & Igl/Isi & & Debitage & 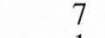 \\
\hline Test Unit B & 4 & & Igl/Isi & & Debitage & 1 \\
\hline Test Unit B & 5 & & $\mathrm{Igl}$ & & Debitage & 1 \\
\hline Test Unit B & 6 & & Igl & & Debitage & 1 \\
\hline Test Unit B & 7 & & Igl & $166-8$ & Microspur/microdenticulate & 1 \\
\hline Test Unit B & 10 & & Igl & & Debitage & 2 \\
\hline Test Unit B & 11 & & Igl & & Debitage & 1 \\
\hline Test Unit B & 13 & & Igl & & Debitage & 1 \\
\hline Test Unit B & 19 & & Igl & 338 & Edge modified flake & 1 \\
\hline Test Unit B & Wall & & Isi & $240-5$ & Biface fragment & 1 \\
\hline Test Unit B & Wall & & Isi & $240-8$ & Biface fragment & 1 \\
\hline Test Unit B & Wall & & Isi & & Debitage & 2 \\
\hline Backfill & & & & $787-5$ & Biface Stage 1 & 1 \\
\hline Backfill & & & & $787-3$ & Biface Stage 2 & 1 \\
\hline Backfill & & & & $787-1$ & Biface Stage 2 & 1 \\
\hline Backfill & & & & $787-4$ & Biface Stage 2 & 1 \\
\hline Backfill & & & & & Debitage & 1 \\
\hline
\end{tabular}




\begin{tabular}{|c|c|c|c|c|c|}
\hline Square & Level & Feature & Strata & Item & Analyst Identification \\
\hline Backfill & & & & $787-2$ & Spurred flake \\
\hline Backfill & & & & $787-6$ & Unifacial multiple tool \\
\hline Baulk & & & & $707-8$ & Biface fragment \\
\hline Baulk & & & & $707-7$ & Biface fragment \\
\hline Baulk & & & & $707-2$ & Biface Stage 1 \\
\hline Baulk & & & & $707-10$ & Biface Stage 2 \\
\hline Baulk & & & & $707-5$ & Biface Stage 2 \\
\hline Baulk & & & & $707-4$ & Biface Stage 2 \\
\hline Baulk & & & & $707-9$ & Biface Stage 2 \\
\hline Baulk & & & & $707-6$ & Biface Stage 2 \\
\hline Baulk & & & & $707-3$ & Biface Stage 2 \\
\hline Baulk & & & & $707-11$ & Bifacial tool Form A \\
\hline Baulk & & & & $707-1$ & Core, multidirectional \\
\hline Baulk & & & & & Debitage \\
\hline Baulk & & & & $707-12$ & Edge modified flake \\
\hline Road & & & & $342-1$ & Projectile point fragment \\
\hline Road & & & & 2350 & Projectile point, Marcos \\
\hline Wall & & & & $172-1$ & Thin uniface fragment \\
\hline Wall & & & & $172-3$ & Thin uniface fragment \\
\hline Wall & & & & $172-2$ & Thin uniface fragment \\
\hline West of 27 & 44 & & & 2263 & Thin uniface fragment \\
\hline Unknown & & & & 2726-1 & Biface Stage 3 \\
\hline Unknown & & & & $2129-1$ & Biface Stage 3 \\
\hline Unknown & & & & 1434 & Projectile point. Bulverde \\
\hline Unknown & $39-45$ & & Unknown & & Debitage \\
\hline
\end{tabular}


Appendix 5: Table 2 - TxDOT Lithics by Provenience

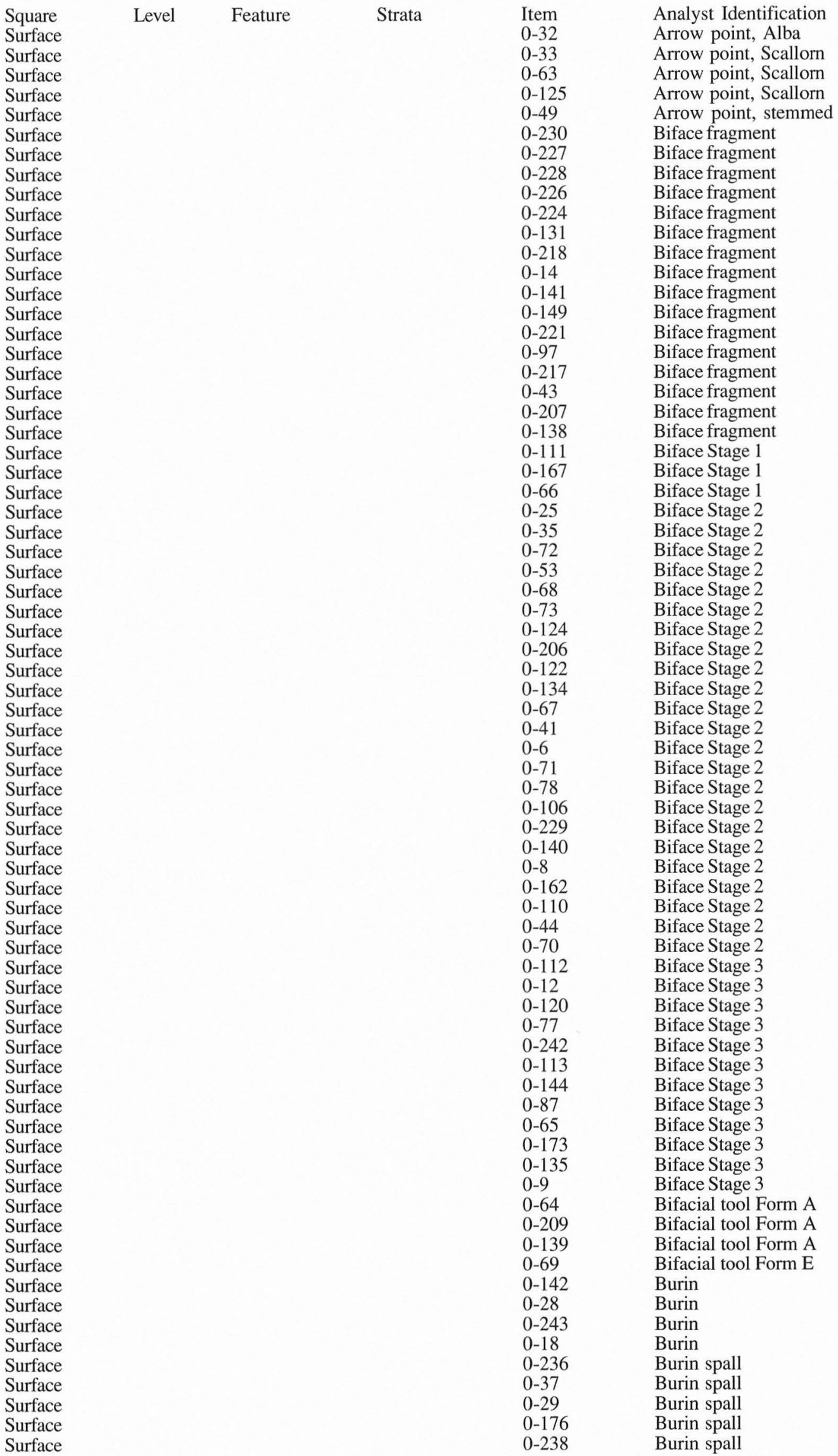

Count

Arrow point, Scallorn

Biface fragment

Biface fragment

Biface fragmen

eragment

Biface fragment

Biface fragment

Biface fragment

Biface Stage

Biface Stage 2

Stage 2

Biface Stage 2

Biface Stage 2

Biface Stage

Biface Stage

Biface Stage

Biface Stage 2

Biface Stage 2

Biface Stage 3

Bifacial tool Form A

Bifacial tool Form E

Burin spall

Burin spal

Burin spall

Burin spall 


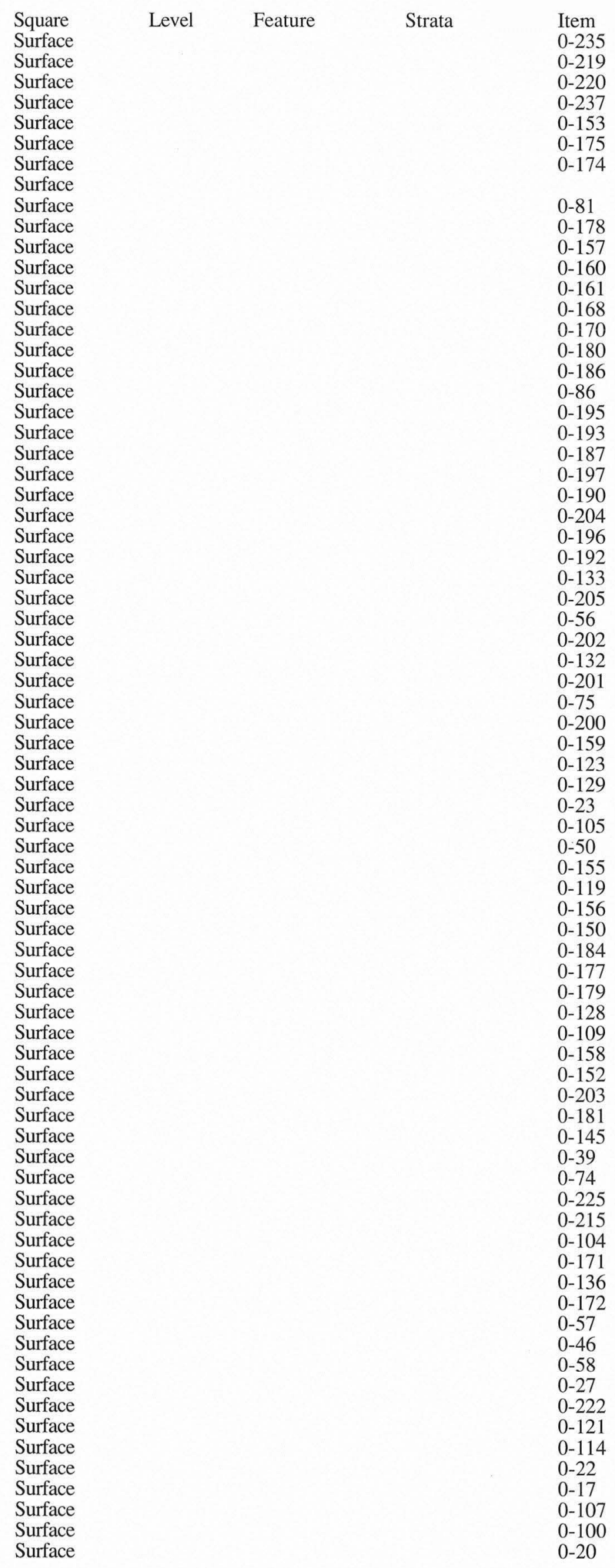

Analyst Identification

Burin spall

Burin spall

Burin spall

Burin spall

Core tool, type 4

Core, thermal

Core, thermal

Debitage

Denticulated flake

Edge modified flake

Edge modified flake

Edge modified flake

Edge modified flake

Edge modified flake

Edge modified flake

Edge modified flake

Edge modified flake

Edge modified flake

Edge modified flake

Edge modified flake

Edge modified flake

Edge modified flake

Edge modified flake

Edge modified flake

Edge modified flake

Edge modified flake

Edge modified flake

Edge modified flake

Edge modified flake

Edge modified flake

Edge modified flake

Edge modified flake

Edge modified flake

Edge modified flake

Edge modified flake

Edge modified flake

Edge modified flake

Edge modified flake

Mano

Mano fragment

Mano fragment

Metate

Metate fragment

Micro-core, intermediate

Microspur/microdenticulate

Microspur/microdenticulate

Microspur/microdenticulate

Microspur/microdenticulate

Notched flake

Notched flake

Notched flake

Notched flake

Notched flake

Perforator Group 1

Perforator Group 1

Perforator Group 7

Perforator Unifacial

Possible ground stone

Projectile point fragment

Projectile point fragment

Projectile point fragment

Projectile point fragment

Projectile point fragment

Projectile point fragment

Projectile point fragment

Projectile point fragment

Projectile point fragment

Projectile point fragment

Projectile point fragment

Projectile point fragment

Projectile point, Angostura

Projectile point, Bandy

Projectile point, beveled narrow stemmed

Projectile point, Bulverde

Count

1

1

1

1 


\begin{tabular}{|c|c|c|c|c|c|c|}
\hline Square & Level & Feature & Strata & Item & Analyst Identification & Count \\
\hline Surface & & & & $0-116$ & Projectile point, Bulverde & 1 \\
\hline Surface & & & & $0-117$ & Projectile point, Bulverde & 1 \\
\hline Surface & & & & $0-99$ & Projectile point, Bulverde & 1 \\
\hline Surface & & & & $0-34$ & Projectile point, Bulverde & 1 \\
\hline Surface & & & & $0-89$ & Projectile point, Bulverde-like & 1 \\
\hline Surface & & & & $0-115$ & Projectile point, Castroville & 1 \\
\hline Surface & & & & $0-118$ & Projectile point, Darl & 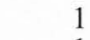 \\
\hline Surface & & & & $0-108$ & Projectile point, Darl & 1 \\
\hline Surface & & & & $0-95$ & Projectile point, Darl & 1 \\
\hline Surface & & & & $0-11$ & Projectile point, Darl & 1 \\
\hline Surface & & & & $0-94$ & Projectile point, Ensor & 1 \\
\hline Surface & & & & $0-59$ & Projectile point, expanding stem A & \\
\hline Surface & & & & $0-60$ & Projectile point, expanding stem C & \\
\hline Surface & & & & $0-98$ & Projectile point, Gower & 1 \\
\hline Surface & & & & $0-31$ & Projectile point, Hoxie & 1 \\
\hline Surface & & & & $0-93$ & Projectile point, indeterminate & 1 \\
\hline Surface & & & & $0-103$ & Projectile point, indeterminate & \\
\hline Surface & & & & $0-38$ & Projectile point, Jetta-like & 1 \\
\hline Surface & & & & $0-88$ & Projectile point, Lange & 1 \\
\hline Surface & & & & $0-15$ & Projectile point, Marcos & 1 \\
\hline Surface & & & & $0-10$ & Projectile point, miscellaneous bifurcate & \\
\hline Surface & & & & $0-96$ & Projectile point, miscellaneous lanceolate & 1 \\
\hline Surface & & & & $0-90$ & Projectile point, miscellaneous side-notched & 1 \\
\hline Surface & & & & $0-137$ & Projectile point, miscellaneous side-notched & 1 \\
\hline Surface & & & & $0-54$ & Projectile point, Montell & 1 \\
\hline Surface & & & & $0-91$ & Projectile point, Nolan & \\
\hline Surface & & & & $0-26$ & Projectile point, Nolan & 1 \\
\hline Surface & & & & $0-101$ & Projectile point, Nolan preform & 1 \\
\hline Surface & & & & $0-146$ & Projectile point, Pedernales & 1 \\
\hline Surface & & & & $0-126$ & Projectile point, Pedernales & \\
\hline Surface & & & & $0-52$ & Projectile point, rectangular stem B & 1 \\
\hline Surface & & & & $0-1$ & Projectile point, St. Mary's Hall & 1 \\
\hline Surface & & & & $0-55$ & Projectile point, Travis-like & 1 \\
\hline Surface & & & & $0-24$ & Projectile point, Uvalde & 1 \\
\hline Surface & & & & $0-208$ & Thick uniface & 1 \\
\hline Surface & & & & $0-210$ & Thick uniface & 1 \\
\hline Surface & & & & $0-169$ & Thick uniface & 1 \\
\hline Surface & & & & $0-85$ & Thin uniface & 1 \\
\hline Surface & & & & $0-83$ & Thin uniface & 1 \\
\hline Surface & & & & $0-198$ & Thin uniface & 1 \\
\hline Surface & & & & $0-79$ & Thin uniface & 1 \\
\hline Surface & & & & $0-48$ & Thin uniface & 1 \\
\hline Surface & & & & $0-40$ & Thin uniface & 1 \\
\hline Surface & & & & $0-84$ & Thin uniface & 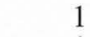 \\
\hline Surface & & & & $0-191$ & Thin uniface fragment & 1 \\
\hline Surface & & & & $0-189$ & Thin uniface fragment & 1 \\
\hline Surface & & & & $0-188$ & Thin uniface fragment & 1 \\
\hline Surface & & & & $0-183$ & Unifacial multiple tool & 1 \\
\hline Surface & & & & $0-36$ & Unifacial multiple tool & 1 \\
\hline Surface & & & & $0-7$ & Unifacial multiple tool & 1 \\
\hline Surface & & & & $0-45$ & Unifacial multiple tool & 1 \\
\hline Surface & & & & $0-13$ & Unifacial multiple tool & 1 \\
\hline Surface & & & & $0-182$ & Unifacial multiple tool & \\
\hline Surface & & & & $0-199$ & Unifacial multiple tool & 1 \\
\hline Surface & & & & $0-80$ & Unifacial multiple tool & 1 \\
\hline Surface & & & & $0-211$ & Waco sinker & \\
\hline W0/N8 & 1 & BRM 2 & IIIc & & Debitage & 54 \\
\hline W0/N8 & 1 & BRM 2 & IIIc & $50 \mathrm{AB}-6$ & Notched flake & 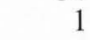 \\
\hline W0/N8 & 1 & BRM 2 & IIIc & $50 \mathrm{AC}-1$ & Projectile point fragment & 1 \\
\hline W0/N8 & 1 & BRM 2 & IIIc & $50 \mathrm{AB}-3$ & Retouched blade & \\
\hline W0/N8 & 1 & BRM 2 & IIIc & $50 \mathrm{AC}-10$ & Uniface, unanalyzed & \\
\hline W0/N8 & 1 & BRM 2 & IIIc & $50 \mathrm{AB}-4$ & Uniface, unanalyzed & \\
\hline W0/N8 & 1 & BRM 2 & IIIc & $50 \mathrm{AB}-7$ & Uniface, unanalyzed & 1 \\
\hline W0/N8 & 1 & BRM 2 & IIIc & $50 \mathrm{AC}-11$ & Uniface, unanalyzed & 1 \\
\hline W0/N8 & 1 & BRM 2 & IIIc & $50 \mathrm{AC}-12$ & Uniface, unanalyzed & \\
\hline W0/N8 & 1 & BRM 2 & IIIc & $50 \mathrm{AC}-13$ & Uniface, unanalyzed & \\
\hline W0/N8 & 1 & BRM 2 & IIIc & $50 \mathrm{AC}-9$ & Uniface, unanalyzed & \\
\hline W0/N8 & 1 & BRM 2 & IIIc & $50 \mathrm{AC}-8$ & Uniface, unanalyzed & \\
\hline WO/N8 & 1 & BRM 2 & IIIc & 50AD-15 & Unifacial multiple tool & \\
\hline W0/N8 & 1 & BRM 2 & IIIc & $50 \mathrm{AA}-2$ & Unifacial multiple tool & \\
\hline W0/N8 & 1 & BRM 2 & IIIc & $50 \mathrm{AB}-5$ & Unifacial multiple tool & \\
\hline W0/N8 & 2 & BRM 2 & IIIc & $50 \mathrm{BB}-5$ & Biface Stage 2 & 1 \\
\hline W0/N8 & 2 & BRM 2 & IIIc & $50 \mathrm{BA}-12$ & Core, thermal & \\
\hline WO/N8 & 2 & BRM 2 & IIIc & & Debitage & 105 \\
\hline
\end{tabular}




\begin{tabular}{|c|c|c|c|c|c|c|}
\hline Square & Level & Feature & Strata & Item & Analyst Identification & Count \\
\hline W0/N8 & 2 & BRM 2 & IIIc & $50 \mathrm{BA}-4$ & Notched flake & 1 \\
\hline W0/N8 & 2 & BRM 2 & IIIc & 50BD-10 & Notched flake & 1 \\
\hline W0/N8 & 2 & BRM 2 & IIIc & $50 \mathrm{BA}-3$ & Uniface, unanalyzed & 1 \\
\hline W0/N8 & 2 & BRM 2 & IIIc & 50BD-11 & Uniface, unanalyzed & 1 \\
\hline $\mathrm{W} 0 / \mathrm{N} 8$ & 2 & BRM 2 & IIIc & $50 \mathrm{BC}-9$ & Uniface, unanalyzed & 1 \\
\hline W0/N8 & 2 & BRM 2 & IIIc & $50 \mathrm{BC}-8$ & Uniface, unanalyzed & 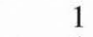 \\
\hline W0/N8 & 2 & BRM 2 & IIIc & $50 \mathrm{BC}-6$ & Uniface, unanalyzed & 1 \\
\hline W0/N8 & 2 & BRM 2 & IIIc & $50 \mathrm{BA}-2$ & Uniface, unanalyzed & 1 \\
\hline W0/N8 & 2 & BRM 2 & IIIc & $50 \mathrm{BC}-7$ & Uniface, unanalyzed & 1 \\
\hline W0/N8 & 2 & BRM 2 & IIIc & $50 \mathrm{BA}-1$ & Unifacial multiple tool & 1 \\
\hline W0/N8 & 3 & BRM 2 & IIIc & 50CD-11 & Biface Stage 2 & 1 \\
\hline W0/N8 & 3 & BRM 2 & IIIIc & $50 \mathrm{CB}-17$ & Core, thermal & 1 \\
\hline W0/N8 & 3 & BRM 2 & IIIc & & Debitage & 94 \\
\hline W0/N8 & 3 & BRM 2 & IIIc & $50 \mathrm{CA}-4$ & Edge modified flake & 1 \\
\hline W0/N8 & 3 & BRM 2 & IIIc & 50CA-1 & Projectile point, rectangular stem C & 1 \\
\hline W0/N8 & 3 & BRM 2 & IIIc & $50 \mathrm{CD}-13$ & Uniface, unanalyzed & 1 \\
\hline W0/N8 & 3 & BRM 2 & IIIc & $50 \mathrm{CA}-3$ & Uniface, unanalyzed & 1 \\
\hline WO/N8 & 3 & BRM 2 & IIIc & $50 \mathrm{CD}-16$ & Uniface, unanalyzed & 1 \\
\hline W0/N8 & 3 & BRM 2 & IIIc & 50CD-14 & Uniface, unanalyzed & 1 \\
\hline W0/N8 & 3 & BRM 2 & IIIc & $50 \mathrm{CD}-12$ & Uniface, unanalyzed & 1 \\
\hline W0/N8 & 3 & BRM 2 & IIIc & $50 \mathrm{CC}-8$ & Uniface, unanalyzed & 1 \\
\hline $\mathrm{W} 0 / \mathrm{N} 8$ & 3 & BRM 2 & IIIc & $50 \mathrm{CC}-10$ & Uniface, unanalyzed & 1 \\
\hline WO/N8 & 3 & BRM 2 & IIIc & $50 \mathrm{CB}-7$ & Uniface, unanalyzed & 1 \\
\hline W0/N8 & 3 & BRM 2 & IIIc & $50 \mathrm{CB}-6$ & Uniface, unanalyzed & 1 \\
\hline W0/N8 & 3 & BRM 2 & IIIIc & $50 \mathrm{CA}-5$ & Uniface, unanalyzed & 1 \\
\hline W0/N8 & 3 & BRM 2 & IIIc & $50 \mathrm{CD}-15$ & Uniface, unanalyzed & 1 \\
\hline W0/N8 & 4 & BRM 2 & IIIc & 50DD-13 & Biface fragment, unanalyzed & 1 \\
\hline W0/N8 & 4 & BRM 2 & IIIc & 50DA-1 & Biface Stage 1 & 1 \\
\hline W0/N8 & 4 & BRM 2 & IIIC & 50DA-2 & Biface Stage 1 & 1 \\
\hline WO/N8 & 4 & BRM 2 & IIIc & 50DD-10 & Biface Stage 2 & 1 \\
\hline WO/N8 & 4 & BRM 2 & IIIc & & Debitage & 85 \\
\hline W0/N8 & 4 & BRM 2 & IIIc & 50DA-3 & Edge modified flake & 1 \\
\hline W0/N8 & 4 & BRM 2 & IIIc & $50 \mathrm{DA}-7$ & Thin uniface & 1 \\
\hline W0/N8 & 4 & BRM 2 & IIIC & $50 \mathrm{DA}-4$ & Uniface, unanalyzed & 1 \\
\hline W0/N8 & 4 & BRM 2 & IIIc & 50DA-5 & Uniface, unanalyzed & 1 \\
\hline WO/N8 & 4 & BRM 2 & IIIc & $50 \mathrm{DA}-6$ & Uniface, unanalyzed & 1 \\
\hline W0/N8 & 4 & BRM 2 & IIIc & 50DC-9 & Uniface, unanalyzed & 1 \\
\hline W0/N8 & 4 & BRM 2 & IIIc & 50DD-11 & Uniface, unanalyzed & 1 \\
\hline WO/N8 & 4 & BRM 2 & IIIc & 50DD-12 & Uniface, unanalyzed & 1 \\
\hline W0/N8 & 5 & BRM 2 & IIIc & $50 \mathrm{~EB}-5$ & Biface Stage 2 & 1 \\
\hline W0/N8 & 5 & BRM 2 & IIIc & $50 \mathrm{EA}-1$ & Biface Stage 2 & 1 \\
\hline W0/N8 & 5 & BRM 2 & IIIc & & Debitage & 81 \\
\hline WO/N8 & 5 & BRM 2 & IIIc & $50 \mathrm{~EB}-6$ & Perforator Group 7 & 1 \\
\hline W0/N8 & 5 & BRM 2 & IIIc & $50 \mathrm{~EB}-7$ & Projectile point, Bulverde & 1 \\
\hline W0/N8 & 5 & BRM 2 & IIIc & $50 \mathrm{EC}-9$ & Uniface, unanalyzed & 1 \\
\hline W0/N8 & 5 & BRM 2 & IIIc & 50EA-3 & Uniface, unanalyzed & 1 \\
\hline W0/N8 & 5 & BRM 2 & IIIc & $50 \mathrm{EA}-2$ & Uniface, unanalyzed & 1 \\
\hline W0/N8 & 5 & BRM 2 & IIIc & $50 \mathrm{EA}-4$ & Uniface, unanalyzed & 1 \\
\hline W0/N8 & 5 & BRM 2 & IIIc & $50 \mathrm{EC}-8$ & Uniface, unanalyzed & 1 \\
\hline W0/N8 & 6 & BRM 2 & IIIc & 50FD-8 & Biface Stage 2 & 1 \\
\hline WO/N8 & 6 & BRM 2 & IIIc & 50FD-9 & Biface Stage 3 & 1 \\
\hline WO/N8 & 6 & BRM 2 & IIIc & $50 \mathrm{FB}-5$ & Biface Stage 3 & 1 \\
\hline W0/N8 & 6 & BRM 2 & IIIc & & Debitage & 125 \\
\hline W0/N8 & 6 & BRM 2 & IIIc & $50 \mathrm{FC}-6$ & Projectile point fragment & 1 \\
\hline W0/N8 & 6 & BRM 2 & IIIc & 50FD-10 & Projectile point, Bulverde & 1 \\
\hline W0/N8 & 6 & BRM 2 & IIIC & 50FB-3 & Projectile point, Nolan & 1 \\
\hline W0/N8 & 6 & BRM 2 & IIIc & $50 \mathrm{FA}-4$ & Projectile point, Nolan & 1 \\
\hline W0/N8 & 6 & BRM 2 & IIIc & $50 \mathrm{FB}-2$ & Projectile point, rectangular stem B & 1 \\
\hline W0/N8 & 6 & BRM 2 & IIIc & $50 \mathrm{FC}-7$ & Uniface, unanalyzed & 1 \\
\hline W0/N8 & 6 & BRM 2 & IIIIc & 50FD-11 & Unifacial multiple tool & 1 \\
\hline W0/N8 & 7 & BRM 2 & IIIC & & Debitage & 163 \\
\hline W0/N8 & 7 & BRM 2 & IIIc & 50GD-13 & Uniface, unanalyzed & 1 \\
\hline W0/N8 & 7 & BRM 2 & IIIc & $50 \mathrm{~GB}-5$ & Uniface, unanalyzed & 1 \\
\hline W0/N8 & 7 & BRM 2 & IIIc & 50GB-4 & Uniface, unanalyzed & 1 \\
\hline WO/N8 & 7 & BRM 2 & IIIc & $50 \mathrm{GA}-1$ & Uniface, unanalyzed & 1 \\
\hline WO/N8 & 7 & BRM 2 & IIIc & $50 \mathrm{~GB}-6$ & Uniface, unanalyzed & 1 \\
\hline W0/N8 & 7 & BRM 2 & IIIc & 50GB-7 & Uniface, unanalyzed & 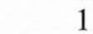 \\
\hline W0/N8 & 7 & BRM 2 & IIIc & 50GD-14 & Uniface, unanalyzed & 1 \\
\hline W0/N8 & 7 & BRM 2 & IIIc & $50 \mathrm{GC}-11$ & Uniface, unanalyzed & 1 \\
\hline W0/N8 & 7 & BRM 2 & IIIc & 50GD-15 & Uniface, unanalyzed & 1 \\
\hline W0/N8 & 7 & BRM 2 & IIIC & $50 \mathrm{GA}-2$ & Uniface, unanalyzed & 1 \\
\hline WO/N8 & 7 & BRM 2 & IIIIc & $50 \mathrm{GC}-12$ & Uniface, unanalyzed & \\
\hline W0/N8 & 7 & BRM 2 & IIIC & $50 \mathrm{~GB}-8$ & Uniface, unanalyzed & \\
\hline W0/N8 & 7 & BRM 2 & IIIc & $50 \mathrm{GC}-10$ & Uniface, unanalyzed & \\
\hline
\end{tabular}




\begin{tabular}{|c|c|c|c|c|c|c|}
\hline Square & Level & Feature & Strata & Item & Analyst Identification & Count \\
\hline W0/N8 & 7 & BRM 2 & IIIc & 50GB-9 & Unifacial multiple tool & \\
\hline W0/N8 & 8 & BRM 2 & IIIC & $50 \mathrm{HC}-10$ & Biface fragment & 1 \\
\hline W0/N8 & 8 & BRM 2 & IIIc & & Debitage & 460 \\
\hline W0/N8 & 8 & BRM 2 & IIIc & $50 \mathrm{HA}-2$ & Projectile point fragment & 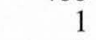 \\
\hline W0/N8 & 8 & BRM 2 & IIIC & $50 \mathrm{HD}-12$ & Projectile point fragment & \\
\hline W0/N8 & 8 & BRM 2 & IIIc & $50 \mathrm{HA}-1$ & Projectile point, Nolan & \\
\hline W0/N8 & 8 & BRM 2 & IIIc & $50 \mathrm{HA}-6$ & Uniface, unanalyzed & 1 \\
\hline W0/N8 & 8 & BRM 2 & IIIC & $50 \mathrm{HA}-3$ & Uniface, unanalyzed & 1 \\
\hline W0/N8 & 8 & BRM 2 & IIII & $50 \mathrm{HB}-7$ & Uniface, unanalyzed & 1 \\
\hline W0/N8 & 8 & BRM 2 & IIIIc & $50 \mathrm{HA}-4$ & Uniface, unanalyzed & 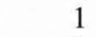 \\
\hline W0/N8 & 8 & BRM 2 & IIII & $50 \mathrm{HD}-11$ & Uniface, unanalyzed & 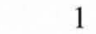 \\
\hline W0/N8 & 8 & BRM 2 & IIIC & 50HD-14 & Uniface, unanalyzed & 1 \\
\hline $\mathrm{W} 0 / \mathrm{N} 8$ & 8 & BRM 2 & IIIC & $50 \mathrm{HB}-8$ & Uniface, unanalyzed & 1 \\
\hline $\mathrm{W} 0 / \mathrm{N} 8$ & 8 & BRM 2 & IIIIc & 50HB-9 & Uniface, unanalyzed & 1 \\
\hline W0/N8 & 9 & & IIIIc & & Debitage & 59 \\
\hline W0/N8 & 9 & & IIII & $50 \mathrm{IC}-12$ & Projectile point fragment & 1 \\
\hline W0/N8 & 9 & & IIIC & $50 \mathrm{IC}-16$ & Uniface, unanalyzed & 1 \\
\hline W0/N8 & 9 & & IIIC & $50 \mathrm{IC}-13$ & Uniface, unanalyzed & 1 \\
\hline W0/N8 & 9 & & IIIc & $50 \mathrm{IC}-15$ & Uniface, unanalyzed & 1 \\
\hline WO/N8 & 9 & BRM 2 & IIIc & 50ID-17 & Biface fragment & 1 \\
\hline W0/N8 & 9 & BRM 2 & IIII & $50 \mathrm{IB}-4$ & Biface Stage 2 & 1 \\
\hline W0/N8 & 9 & BRM 2 & IIIc & 50IA-1 & Biface Stage 3 & 1 \\
\hline W0/N8 & 9 & BRM 2 & IIIC & 50 IB- 6 & Burin & 1 \\
\hline W0/N8 & 9 & BRM 2 & IIIc & & Debitage & 371 \\
\hline W0/N8 & 9 & BRM 2 & IIII & 50IA-2 & Notched flake & 1 \\
\hline W0/N8 & 9 & BRM 2 & IIII & $50 \mathrm{IB}-5$ & Projectile point fragment & 1 \\
\hline W0/N8 & 9 & BRM 2 & IIIc & 50ID-18 & Thin uniface & 1 \\
\hline W0/N8 & 9 & BRM 2 & IIIC & 50 IB- 7 & Thin uniface fragment & 1 \\
\hline WO/N8 & 9 & BRM 2 & IIII & 50 IB- 10 & Uniface, unanalyzed & 1 \\
\hline W0/N8 & 9 & BRM 2 & IIIc & 50IB-9 & Uniface, unanalyzed & 1 \\
\hline W0/N8 & 9 & BRM 2 & IIIIc & 50 IB-11 & Uniface, unanalyzed & 1 \\
\hline $\mathrm{W} 0 / \mathrm{N} 8$ & 9 & BRM 2 & IIIc & 50IB-8 & Uniface, unanalyzed & 1 \\
\hline W0/N8 & 10 & & IIIc & & Debitage & 119 \\
\hline W0/N8 & 10 & & IIIc & $50 \mathrm{JC}-16$ & Thin uniface fragment & 1 \\
\hline W0/N8 & 10 & & IIIc & $50 \mathrm{JC}-17$ & Uniface, unanalyzed & 1 \\
\hline W0/N8 & 10 & & IIIC & $50 \mathrm{JC}-13$ & Uniface, unanalyzed & 1 \\
\hline WO/N8 & 10 & & IIII & $50 \mathrm{JC}-12$ & Unifacial multiple tool & 1 \\
\hline W0/N8 & 10 & BRM 2 & IIIc & 50JB-7 & Biface Stage 1 & 1 \\
\hline W0/N8 & 10 & BRM 2 & IIIc & $50 \mathrm{JA}-1$ & Biface Stage 1 & 1 \\
\hline W0/N8 & 10 & BRM 2 & IIIC & 50JD-20 & Biface Stage 2 & 1 \\
\hline W0/N8 & 10 & BRM 2 & IIIC & 50JD-18 & Biface Stage 2 & 1 \\
\hline W0/N8 & 10 & BRM 2 & IIIC & 50JD-19 & Biface Stage 3 & 1 \\
\hline W0/N8 & 10 & BRM 2 & IIIc & & Debitage & 619 \\
\hline W0/N8 & 10 & BRM 2 & IIIc & $50 \mathrm{JB}-4$ & Metate fragment & 1 \\
\hline W0/N8 & 10 & BRM 2 & IIIc & 50JD-21 & Projectile point fragment & 1 \\
\hline W0/N8 & 10 & BRM 2 & IIIc & $50 \mathrm{JB}-5$ & Projectile point, Bulverde & 1 \\
\hline W0/N8 & 10 & BRM 2 & IIIc & $50 \mathrm{JC}-11$ & Projectile point, expanding concave D & 1 \\
\hline W0/N8 & 10 & BRM 2 & IIIc & $50 \mathrm{JC}-10$ & Projectile point, Travis-like & 1 \\
\hline W0/N8 & 10 & BRM 2 & IIIc & $50 \mathrm{JB}-8$ & Uniface, unanalyzed & 1 \\
\hline W0/N8 & 10 & BRM 2 & IIIc & $50 \mathrm{JA}-2$ & Uniface, unanalyzed & 1 \\
\hline W0/N8 & 10 & BRM 2 & IIIc & 50JD-24 & Uniface, unanalyzed & 1 \\
\hline W0/N8 & 10 & BRM 2 & IIIC & $50 \mathrm{JA}-3$ & Uniface, unanalyzed & 1 \\
\hline W0/N8 & 10 & BRM 2 & IIIC & 50JD-22 & Unifacial multiple tool & 1 \\
\hline W0/N8 & 10 & BRM 2 & IIIc & 50JD-23 & Unifacial multiple tool & 1 \\
\hline W0/N8 & 10 & Feature 195 & IIIc & $50 \mathrm{JC}-9$ & Biface Stage 2 & 1 \\
\hline W0/N8 & 11 & & IIIc & $50 \mathrm{KA}-6$ & Burin & 1 \\
\hline W0/N8 & 11 & & IIIc & & Debitage & 155 \\
\hline W0/N8 & 11 & & IIIC & $50 \mathrm{KA}-5$ & Thin uniface fragment & 1 \\
\hline W0/N8 & 11 & & IIIC & $50 \mathrm{KA}-2$ & Uniface, unanalyzed & 1 \\
\hline W0/N8 & 11 & & IIIc & $50 \mathrm{KA}-4$ & Uniface, unanalyzed & 1 \\
\hline W0/N8 & 11 & & IIIc & $50 \mathrm{KA}-7$ & Uniface, unanalyzed & 1 \\
\hline W0/N8 & 11 & & IIIC & $50 \mathrm{KA}-8$ & Uniface, unanalyzed & 1 \\
\hline W0/N8 & 11 & BRM 2 & IIIC & $50 \mathrm{KC}-16$ & Biface fragment & 1 \\
\hline W0/N8 & 11 & BRM 2 & IIIc & $50 \mathrm{KC}-14$ & Biface Stage 2 & 1 \\
\hline W0/N8 & 11 & BRM 2 & IIIc & $50 \mathrm{~KB}-9$ & Bifacial tool Form A & 1 \\
\hline W0/N8 & 11 & BRM 2 & IIIc & & Debitage & 375 \\
\hline W0/N8 & 11 & BRM 2 & IIIc & $50 \mathrm{KD}-21$ & Notched flake & 1 \\
\hline W0/N8 & 11 & BRM 2 & IIII & $50 \mathrm{~KB}-11$ & Notched flake & 1 \\
\hline W0/N8 & 11 & BRM 2 & IIIc & $50 \mathrm{~KB}-10$ & Uniface, unanalyzed & 1 \\
\hline W0/N8 & 11 & BRM 2 & IIIc & $50 \mathrm{KC}-15$ & Uniface, unanalyzed & 1 \\
\hline W0/N8 & 11 & BRM 2 & IIIc & $50 \mathrm{~KB}-13$ & Uniface, unanalyzed & 1 \\
\hline W0/N8 & 11 & BRM 2 & IIIc & $50 \mathrm{~KB}-12$ & Uniface, unanalyzed & 1 \\
\hline W0/N8 & 11 & BRM 2 & IIIC & $50 \mathrm{KD}-25$ & Uniface, unanalyzed & 1 \\
\hline W0/N8 & 11 & BRM 2 & IIIC & $50 \mathrm{KD}-22$ & Uniface, unanalyzed & 1 \\
\hline
\end{tabular}




\begin{tabular}{|c|c|c|c|c|c|}
\hline Square & Level & Feature & Strata & Item & Analyst Identification \\
\hline W0/N8 & 11 & BRM 2 & IIIc & 50KD-23 & Uniface, unanalyzed \\
\hline W0/N8 & 11 & BRM 2 & IIIc & $50 \mathrm{KD}-24$ & Uniface, unanalyzed \\
\hline W0/N8 & 11 & Feature 194 & IIIc & & Debitage \\
\hline W0/N8 & 11 & Feature 194 & IIIIc & $50 \mathrm{KC}-17$ & Thin uniface \\
\hline W0/N8 & 11 & Feature 194 & IIIc & $50 \mathrm{KC}-18$ & Uniface, unanalyzed \\
\hline W0/N8 & 11 & Feature 194 & IIIc & $50 \mathrm{KC}-19$ & Unifacial multiple tool \\
\hline W0/N8 & 12 & & III & $50 \mathrm{LA}-2$ & Core, thermal \\
\hline W0/N8 & 12 & & III & & Debitage \\
\hline W0/N8 & 12 & & III & 50LD-5 & Projectile point, Bandy \\
\hline W0/N8 & 12 & & III & 50LA-1 & Projectile point, Wells \\
\hline W0/N8 & 12 & & III & $50 \mathrm{LB}-4$ & Uniface, unanalyzed \\
\hline W0/N8 & 12 & & III & 50 LB-3 & Uniface, unanalyzed \\
\hline W0/N8 & 13 & & III & $50 \mathrm{MC}-5$ & Biface fragment \\
\hline W0/N8 & 13 & & III & $50 \mathrm{MC}-9$ & Biface fragment \\
\hline W0/N8 & 13 & & III & 50MD-12 & Biface Stage 2 \\
\hline W0/N8 & 13 & & III & 50MA-2 & Burin spall \\
\hline W0/N8 & 13 & & III & & Debitage \\
\hline WO/N8 & 13 & & III & $50 \mathrm{MC}-10$ & Denticulated flake \\
\hline W0/N8 & 13 & & III & $50 \mathrm{MC}-6$ & Notched flake \\
\hline W0/N8 & 13 & & III & 50MA-1 & Projectile point, expanding stem B \\
\hline W0/N8 & 13 & & III & $50 \mathrm{MC}-7$ & Uniface, unanalyzed \\
\hline W0/N8 & 13 & & III & 50MD-11 & Uniface, unanalyzed \\
\hline W0/N8 & 13 & & III & $50 \mathrm{MA}-3$ & Uniface, unanalyzed \\
\hline W0/N8 & 14 & & III & $50 \mathrm{NB}-2$ & Biface fragment \\
\hline W0/N8 & 14 & & III & & Debitage \\
\hline W0/N8 & 14 & & III & $50 \mathrm{NA}-4$ & Microspur/microdenticulate \\
\hline WO/N8 & 14 & & III & $50 \mathrm{NB}-3$ & Projectile point fragment \\
\hline W0/N8 & 14 & & III & $50 \mathrm{NB}-1$ & Projectile point, Hoxie \\
\hline W0/N8 & 14 & & III & $50 \mathrm{NB}-5$ & Uniface, unanalyzed \\
\hline W0/N8 & 14 & & III & $50 \mathrm{ND}-8$ & Uniface, unanalyzed \\
\hline W0/N8 & 14 & & III & $50 \mathrm{NB}-6$ & Uniface, unanalyzed \\
\hline W0/N8 & 14 & Feature 196 & III & & Debitage \\
\hline W0/N8 & 14 & Feature 196 & III & $50 \mathrm{NC}-7$ & Uniface, unanalyzed \\
\hline W0/N8 & 15 & & III & & Debitage \\
\hline W0/N8 & 15 & & III & 50OD-2 & Projectile point, bifurcate stem fragment \\
\hline W0/N8 & 16 & & III & 50PD-2 & Biface Stage 2 \\
\hline W0/N8 & 16 & & III & $50 \mathrm{PC}-5$ & Core tool, type 2 \\
\hline W0/N8 & 16 & & III & 50PA-3 & Core, thermal \\
\hline W0/N8 & 16 & & III & & Debitage \\
\hline W0/N8 & 16 & & III & 50PB-1 & Projectile point, Gower \\
\hline W0/N8 & 16 & & III & 50PD-6 & Projectile point, long stemmed \\
\hline W0/N8 & 17 & & III & & Debitage \\
\hline W0/N8 & 18 & & III & 50RBD-2 & Chert cobble, unmodified/tested \\
\hline W0/N8 & 18 & & III & & Debitage \\
\hline W0/N8 & 18 & & III & 50RBD-1 & Uniface, unanalyzed \\
\hline W0/N8 & 19 & & III & $50 \mathrm{SB}-2$ & Biface fragment \\
\hline W0/N8 & 19 & & III & 50 SB-6 & Biface fragment \\
\hline W0/N8 & 19 & & III & 50SB-1 & Biface Stage 2 \\
\hline W0/N8 & 19 & & III & & Debitage \\
\hline W0/N8 & 20 & & III & $50 \mathrm{~TB}-2$ & Biface Stage 1 \\
\hline W0/N8 & 20 & & III & 50TA-2 & Core tool, type 5 \\
\hline W0/N8 & 20 & & III & & Debitage \\
\hline W0/N8 & 20 & & III & $50 \mathrm{TC}-3$ & Projectile point, miscellaneous lanceolate \\
\hline W0/N8 & 21 & & III & & Debitage \\
\hline W0/N8 & 21 & & III & $50 \mathrm{UC}-1$ & Notched flake \\
\hline W0/N8 & 22 & & III & & Debitage \\
\hline W0/N8 & 23 & & II/III & 50WC-1 & Biface Stage 2 \\
\hline W0/N8 & 23 & & II/III & 50WD-3 & Biface Stage 2 \\
\hline WO/N8 & 23 & & II/III & $50 \mathrm{WC}-2$ & Burin spall \\
\hline W0/N8 & 23 & & II/III & & Debitage \\
\hline W0/N8 & 24 & & II & $50 \times D-5$ & Biface fragment \\
\hline W0/N8 & 24 & & II & & Debitage \\
\hline W0/N8 & 24 & & II & $50 \times D-1$ & Projectile point, St. Mary's Hall \\
\hline W0/N8 & 24 & & II & $50 \times D-4$ & Uniface, unanalyzed \\
\hline $\mathrm{W} 0 / \mathrm{N} 8$ & 24 & & II & $50 \times A-2$ & Uniface, unanalyzed \\
\hline W0/N8 & 24 & & II & $50 \times B-3$ & Unifacial multiple tool \\
\hline W0/N8 & 25 & & $\mathrm{I} / \mathrm{II}$ & 50YD-2 & Biface Stage 2 \\
\hline W0/N8 & 25 & & $\mathrm{I} / \mathrm{II}$ & & Debitage \\
\hline W0/N8 & 25 & Feature 166 & $\mathrm{I} / \mathrm{II}$ & 50YA-1 & Projectile point, Golondrina-Barber \\
\hline W0/N8 & 26 & & I & $50 \mathrm{ZA}-2$ & Biface fragment \\
\hline W0/N8 & 26 & & I & & Debitage \\
\hline W0/N8 & 26 & & I & 50ZA-1 & Unifacial multiple tool \\
\hline W0/N8 & $26 \mathrm{~A}$ & & I & & Debitage \\
\hline W0/N8 & $26 \mathrm{~B}$ & & I & & Debitage \\
\hline
\end{tabular}

Count

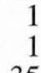




\begin{tabular}{|c|c|c|c|c|c|c|}
\hline Square & Level & Feature & Strata & Item & Analyst Identification & Count \\
\hline W0/N8 & $27 \mathrm{~A}$ & & I & & Debitage & \\
\hline W0/N8 & $27 \mathrm{~B}$ & & I & & Debitage & 75 \\
\hline W0/N8 & $27 \mathrm{~B}$ & & I & 50AA2B-1 & Perforator Group 7 & \\
\hline WO/N8 & $28 \mathrm{~A}$ & & I & 50BB $1 \mathrm{D}-2$ & Clear Fork biface & 1 \\
\hline W0/N8 & $28 \mathrm{~A}$ & & I & & Debitage & 66 \\
\hline Wo/N8 & $28 \mathrm{~A}$ & & I & $50 \mathrm{BB} 1 \mathrm{C}-1$ & Thick uniface & \\
\hline W0/N8 & $28 \mathrm{~B}$ & & I & & Debitage & 35 \\
\hline W0/N8 & $29 \mathrm{~A}$ & & I & & Debitage & 2 \\
\hline W0/N8 & $29 \mathrm{~B}$ & & I & & Debitage & 15 \\
\hline W0/N8 & 30 & & I & 50DDA-1 & Biface Stage 2 & \\
\hline W0/N8 & 30 & & I & & Debitage & 13 \\
\hline W0/N8 & 31 & & I & & Debitage & 2 \\
\hline W0/N8 & $32 \mathrm{~A}-\mathrm{B}$ & & I & & Debitage & 1 \\
\hline W0/N8 & $33 \mathrm{~A}-\mathrm{B}$ & & I & & Debitage & 0 \\
\hline W0/N8 & $34 \mathrm{~A}-\mathrm{B}$ & & I & & Debitage & 4 \\
\hline W0/N8 & $35 \mathrm{~A}-\mathrm{B}$ & & I & & Debitage & 6 \\
\hline W0/N8 & $36 \mathrm{~A}-\mathrm{B}$ & & I & & Debitage & 4 \\
\hline W0/N8 & $37 \mathrm{~A}-\mathrm{B}$ & & I & $50 \mathrm{KK} 1 \& 2 \mathrm{~B}-2$ & Chert cobble, chunk & \\
\hline W0/N8 & $37 \mathrm{~A}-\mathrm{B}$ & & I & $50 \mathrm{KK} 1 \& 2 \mathrm{~A}-1$ & Core, unidirectional & \\
\hline W0/N8 & $37 \mathrm{~A}-\mathrm{B}$ & & I & & Debitage & \\
\hline W0/N8 & $38 \mathrm{~A}-\mathrm{B}$ & & Igl?/I & & Debitage & 7 \\
\hline W0/N8 & $38 \mathrm{~A}-\mathrm{B}$ & & Igl?/I & 50LL1\&2D-1 & Edge modified flake & \\
\hline W0/N8 & $40 \mathrm{~A}-\mathrm{B}$ & & Igl?/I & & Debitage & \\
\hline $\mathrm{E} 2 / \mathrm{N} 8$ & 1 & BRM 2 & IIIIc & $51 \mathrm{AC}-2$ & Biface Stage 2 & \\
\hline $\mathrm{E} 2 / \mathrm{N} 8$ & 1 & BRM 2 & IIIc & $51 \mathrm{AC}-3$ & Bifacial tool Form F & 1 \\
\hline E2/N8 & 1 & BRM 2 & IIIc & & Debitage & 110 \\
\hline E2/N8 & 1 & BRM 2 & IIIc & 51AD-5 & Projectile point, indeterminate & \\
\hline $\mathrm{E} 2 / \mathrm{N} 8$ & 1 & BRM 2 & IIIC & $51 \mathrm{AB}-1$ & Uniface, unanalyzed & \\
\hline $\mathrm{E} 2 / \mathrm{N} 8$ & 2 & & IIIc & $51 \mathrm{BB}-2$ & Biface fragment & \\
\hline $\mathrm{E} 2 / \mathrm{N} 8$ & 2 & BRM 2 & IIIc & $51 \mathrm{BB}-4$ & Biface fragment & \\
\hline E2/N8 & 2 & BRM 2 & IIIc & $51 \mathrm{BB}-3$ & Biface fragment, unanalyzed & \\
\hline $\mathrm{E} 2 / \mathrm{N} 8$ & 2 & BRM 2 & IIIc & $51 \mathrm{BA}-1$ & Biface Stage 2 & \\
\hline E2/N8 & 2 & BRM 2 & IIIc & $51 \mathrm{BB}-5$ & Core, thermal & 1 \\
\hline E2/N8 & 2 & BRM 2 & IIIC & & Debitage & 168 \\
\hline $\mathrm{E} 2 / \mathrm{N} 8$ & 2 & BRM 2 & IIIc & $51 \mathrm{BA}-2$ & Projectile point fragment & \\
\hline E2/N8 & 2 & BRM 2 & IIIC & 51BD-12 & Projectile point, rectangular stem A & \\
\hline $\mathrm{E} 2 / \mathrm{N} 8$ & 2 & BRM 2 & IIIc & $51 \mathrm{BB}-8$ & Thin uniface & \\
\hline E2/N8 & 2 & BRM 2 & IIIC & $51 \mathrm{BB}-6$ & Thin uniface & \\
\hline E2/N8 & 2 & BRM 2 & IIIc & 51BB-11 & Thin uniface fragment & \\
\hline E2/N8 & 2 & BRM 2 & IIIC & 51BD-13 & Uniface, unanalyzed & \\
\hline E2/N8 & 2 & BRM 2 & IIIc & $51 \mathrm{BB}-7$ & Uniface, unanalyzed & \\
\hline $\mathrm{E} 2 / \mathrm{N} 8$ & 2 & BRM 2 & IIIC & $51 \mathrm{BB}-10$ & Unifacial multiple tool & \\
\hline $\mathrm{E} 2 / \mathrm{N} 8$ & 2 & BRM 2 & IIIc & 51BB-9 & Unifacial multiple tool & \\
\hline $\mathrm{E} 2 / \mathrm{N} 8$ & 3 & BRM 2 & IIIc & 51CA-1 & Biface Stage 2 & \\
\hline E2/N8 & 3 & BRM 2 & IIIC & & Debitage & 62 \\
\hline $\mathrm{E} 2 / \mathrm{N} 8$ & 3 & BRM 2 & IIIc & $51 \mathrm{CB}-7$ & Projectile point, Bulverde-like & \\
\hline $\mathrm{E} 2 / \mathrm{N} 8$ & 3 & BRM 2 & IIIc & $51 \mathrm{CD}-13$ & Projectile point, rectangular stem C & \\
\hline $\mathrm{E} 2 / \mathrm{N} 8$ & 3 & BRM 2 & IIIc & 51CD-14 & Uniface, unanalyzed & \\
\hline $\mathrm{E} 2 / \mathrm{N} 8$ & 3 & BRM 2 & IIIc & $51 \mathrm{CA}-6$ & Uniface, unanalyzed & \\
\hline E2/N8 & 3 & BRM 2 & IIIc & 51CA-4 & Uniface, unanalyzed & \\
\hline E2/N8 & 3 & BRM 2 & IIIC & $51 \mathrm{CD}-15$ & Uniface, unanalyzed & \\
\hline E2/N8 & 3 & BRM 2 & IIIc & $51 \mathrm{CC}-12$ & Uniface, unanalyzed & \\
\hline $\mathrm{E} 2 / \mathrm{N} 8$ & 3 & BRM 2 & IIIC & $51 \mathrm{CC}-11$ & Uniface, unanalyzed & \\
\hline E2/N8 & 3 & BRM 2 & IIIC & $51 \mathrm{CC}-10$ & Uniface, unanalyzed & \\
\hline E2/N8 & 3 & BRM 2 & IIIc & $51 \mathrm{CB}-9$ & Uniface, unanalyzed & \\
\hline E2/N8 & 3 & BRM 2 & IIIc & $51 \mathrm{CA}-5$ & Uniface, unanalyzed & \\
\hline E2/N8 & 3 & BRM 2 & IIIC & $51 \mathrm{CA}-3$ & Uniface, unanalyzed & \\
\hline $\mathrm{E} 2 / \mathrm{N} 8$ & 3 & BRM 2 & IIIC & $51 \mathrm{CA}-2$ & Uniface, unanalyzed & \\
\hline $\mathrm{E} 2 / \mathrm{N} 8$ & 4 & BRM 2 & IIIc & $51 \mathrm{DC}-5$ & Biface Stage 2 & \\
\hline E2/N8 & 4 & BRM 2 & IIIc & $51 \mathrm{DB}-4$ & Bifacial tool Form A & \\
\hline $\mathrm{E} 2 / \mathrm{N} 8$ & 4 & BRM 2 & IIIc & & Debitage & 118 \\
\hline $\mathrm{E} 2 / \mathrm{N} 8$ & 4 & BRM 2 & IIII & $51 \mathrm{DB}-2$ & Notched flake & \\
\hline $\mathrm{E} 2 / \mathrm{N} 8$ & 4 & BRM 2 & IIII & $51 \mathrm{DC}-7$ & Thin uniface fragment & \\
\hline $\mathrm{E} 2 / \mathrm{N} 8$ & 4 & BRM 2 & IIII & $51 \mathrm{DD}-8$ & Uniface, unanalyzed & \\
\hline $\mathrm{E} 2 / \mathrm{N} 8$ & 4 & BRM 2 & IIIc & $51 \mathrm{DD}-9$ & Uniface, unanalyzed & \\
\hline $\mathrm{E} 2 / \mathrm{N} 8$ & 4 & BRM 2 & IIIC & 51DA-1 & Uniface, unanalyzed & \\
\hline $\mathrm{E} 2 / \mathrm{N} 8$ & 4 & BRM 2 & IIIC & $51 \mathrm{DC}-6$ & Uniface, unanalyzed & \\
\hline $\mathrm{E} 2 / \mathrm{N} 8$ & 4 & BRM 2 & IIIc & $51 \mathrm{DB}-3$ & Uniface, unanalyzed & \\
\hline $\mathrm{E} 2 / \mathrm{N} 8$ & 5 & BRM 2 & IIIc & $51 \mathrm{EA}-1$ & Biface Stage 2 & \\
\hline $\mathrm{E} 2 / \mathrm{N} 8$ & 5 & BRM 2 & IIIC & $51 \mathrm{~EB}-6$ & Biface Stage 2 & \\
\hline $\mathrm{E} 2 / \mathrm{N} 8$ & 5 & BRM 2 & IIIc & $51 \mathrm{ED}-10$ & Bifacial tool Form A & \\
\hline $\mathrm{E} 2 / \mathrm{N} 8$ & 5 & BRM 2 & IIIC & $51 \mathrm{EA}-4$ & Core, thermal & \\
\hline $\mathrm{E} 2 / \mathrm{N} 8$ & 5 & BRM 2 & IIIc & & Debitage & 90 \\
\hline $\mathrm{E} 2 / \mathrm{N} 8$ & 5 & BRM 2 & IIIc & $51 \mathrm{~EB}-8$ & Uniface, unanalyzed & \\
\hline
\end{tabular}




\begin{tabular}{|c|c|c|c|c|c|c|}
\hline Square & Level & Feature & Strata & Item & Analyst Identification & Count \\
\hline $\mathrm{E} 2 / \mathrm{N} 8$ & 5 & BRM 2 & IIIc & $51 \mathrm{~EB}-7$ & Uniface, unanalyzed & 1 \\
\hline $\mathrm{E} 2 / \mathrm{N} 8$ & 5 & BRM 2 & IIIc & 51EA-2 & Uniface, unanalyzed & 1 \\
\hline $\mathrm{E} 2 / \mathrm{N} 8$ & 5 & BRM 2 & IIIc & $51 \mathrm{EC}-9$ & Uniface, unanalyzed & 1 \\
\hline $\mathrm{E} 2 / \mathrm{N} 8$ & 5 & BRM 2 & IIIc & $51 \mathrm{~EB}-5$ & Unifacial multiple tool & 1 \\
\hline $\mathrm{E} 2 / \mathrm{N} 8$ & 6 & BRM 2 & IIIc & & Debitage & 140 \\
\hline $\mathrm{E} 2 / \mathrm{N} 8$ & 6 & BRM 2 & IIIc & $51 \mathrm{FC}-15$ & Notched flake & 1 \\
\hline $\mathrm{E} 2 / \mathrm{N} 8$ & 6 & BRM 2 & IIIc & $51 \mathrm{FB}-4$ & Projectile point, Bulverde-like & 1 \\
\hline $\mathrm{E} 2 / \mathrm{N} 8$ & 6 & BRM 2 & IIIc & 51FD-16 & Projectile point, Lange & 1 \\
\hline $\mathrm{E} 2 / \mathrm{N} 8$ & 6 & BRM 2 & IIIc & 51FA-1 & Projectile point, Travis & 1 \\
\hline $\mathrm{E} 2 / \mathrm{N} 8$ & 6 & BRM 2 & IIIC & $51 \mathrm{FC}-10$ & Uniface, unanalyzed & 1 \\
\hline $\mathrm{E} 2 / \mathrm{N} 8$ & 6 & BRM 2 & IIIc & $51 \mathrm{FA}-3$ & Uniface, unanalyzed & 1 \\
\hline $\mathrm{E} 2 / \mathrm{N} 8$ & 6 & BRM 2 & IIIc & 51FA-2 & Uniface, unanalyzed & 1 \\
\hline $\mathrm{E} 2 / \mathrm{N} 8$ & 6 & BRM 2 & IIIc & $51 \mathrm{FB}-6$ & Uniface, unanalyzed & 1 \\
\hline $\mathrm{E} 2 / \mathrm{N} 8$ & 6 & BRM 2 & IIIc & $51 \mathrm{FB}-7$ & Uniface, unanalyzed & 1 \\
\hline $\mathrm{E} 2 / \mathrm{N} 8$ & 6 & BRM 2 & IIIC & $51 \mathrm{FC}-11$ & Uniface, unanalyzed & 1 \\
\hline $\mathrm{E} 2 / \mathrm{N} 8$ & 6 & BRM 2 & IIIc & $51 \mathrm{FC}-12$ & Uniface, unanalyzed & 1 \\
\hline $\mathrm{E} 2 / \mathrm{N} 8$ & 6 & BRM 2 & IIIc & $51 \mathrm{FC}-13$ & Uniface, unanalyzed & 1 \\
\hline $\mathrm{E} 2 / \mathrm{N} 8$ & 6 & BRM 2 & IIIc & $51 \mathrm{FC}-9$ & Uniface, unanalyzed & 1 \\
\hline $\mathrm{E} 2 / \mathrm{N} 8$ & 6 & BRM 2 & IIIC & $51 \mathrm{FC}-14$ & Uniface, unanalyzed & 1 \\
\hline $\mathrm{E} 2 / \mathrm{N} 8$ & 7 & BRM 2 & IIIC & $51 \mathrm{~GB}-2$ & Biface Stage 2 & 1 \\
\hline $\mathrm{E} 2 / \mathrm{N} 8$ & 7 & BRM 2 & IIIc & & Debitage & 103 \\
\hline $\mathrm{E} 2 / \mathrm{N} 8$ & 7 & BRM 2 & IIIc & $51 \mathrm{GD}-5$ & Thin uniface & 1 \\
\hline $\mathrm{E} 2 / \mathrm{N} 8$ & 7 & BRM 2 & IIIc & $51 \mathrm{GA}-1$ & Uniface, unanalyzed & 1 \\
\hline $\mathrm{E} 2 / \mathrm{N} 8$ & 7 & BRM 2 & IIIc & $51 \mathrm{~GB}-3$ & Uniface, unanalyzed & 1 \\
\hline $\mathrm{E} 2 / \mathrm{N} 8$ & 7 & BRM 2 & IIIc & $51 \mathrm{GC}-4$ & Uniface, unanalyzed & 1 \\
\hline $\mathrm{E} 2 / \mathrm{N} 8$ & 8 & BRM 2 & IIIc & & Debitage & 113 \\
\hline E2/N8 & 8 & BRM 2 & IIIc & $51 \mathrm{HB}-7$ & Edge modified flake & 1 \\
\hline $\mathrm{E} 2 / \mathrm{N} 8$ & 8 & BRM 2 & IIIc & $51 \mathrm{HD}-13$ & Projectile point fragment & 1 \\
\hline $\mathrm{E} 2 / \mathrm{N} 8$ & 8 & BRM 2 & IIIc & $51 \mathrm{HD}-12$ & Projectile point, Bulverde-like & 1 \\
\hline E2/N8 & 8 & BRM 2 & IIIc & 51HB-6 & Projectile point, Nolan & 1 \\
\hline $\mathrm{E} 2 / \mathrm{N} 8$ & 8 & BRM 2 & IIIC & 51HD-11 & Projectile point, square stem & 1 \\
\hline $\mathrm{E} 2 / \mathrm{N} 8$ & 8 & BRM 2 & IIIc & $51 \mathrm{HD}-14$ & Uniface, unanalyzed & 1 \\
\hline $\mathrm{E} 2 / \mathrm{N} 8$ & 8 & BRM 2 & IIIc & $51 \mathrm{HD}-16$ & Uniface, unanalyzed & 1 \\
\hline $\mathrm{E} 2 / \mathrm{N} 8$ & 8 & BRM 2 & IIII & $51 \mathrm{HB}-9$ & Uniface, unanalyzed & 1 \\
\hline E2/N8 & 8 & BRM 2 & IIIC & $51 \mathrm{HC}-10$ & Uniface, unanalyzed & 1 \\
\hline E2/N8 & 8 & BRM 2 & IIIc & $51 \mathrm{HB}-8$ & Uniface, unanalyzed & 1 \\
\hline $\mathrm{E} 2 / \mathrm{N} 8$ & 8 & BRM 2 & IIIc & $51 \mathrm{HD}-17$ & Uniface, unanalyzed & 1 \\
\hline $\mathrm{E} 2 / \mathrm{N} 8$ & 8 & BRM 2 & IIIc & $51 \mathrm{HA}-4$ & Uniface, unanalyzed & 1 \\
\hline E2/N8 & 8 & BRM 2 & IIIc & 51HD-18 & Uniface, unanalyzed & 1 \\
\hline $\mathrm{E} 2 / \mathrm{N} 8$ & 8 & BRM 2 & IIIc & $51 \mathrm{HA}-3$ & Uniface, unanalyzed & 1 \\
\hline $\mathrm{E} 2 / \mathrm{N} 8$ & 8 & BRM 2 & IIIc & $51 \mathrm{HA}-1$ & Uniface, unanalyzed & 1 \\
\hline $\mathrm{E} 2 / \mathrm{N} 8$ & 8 & BRM 2 & IIIc & $51 \mathrm{HA}-5$ & Uniface, unanalyzed & 1 \\
\hline $\mathrm{E} 2 / \mathrm{N} 8$ & $9 \mathrm{~A}$ & BRM 2 & IIIc & $51 \mathrm{I} 1 \mathrm{~A}-1$ & Biface Stage 2 & 1 \\
\hline $\mathrm{E} 2 / \mathrm{N} 8$ & $9 \mathrm{~A}$ & BRM 2 & IIIc & & Debitage & 167 \\
\hline E2/N8 & $9 \mathrm{~B}$ & BRM 2 & IIIc & & Debitage & 253 \\
\hline $\mathrm{E} 2 / \mathrm{N} 8$ & 10 & & IIIC & $51 \mathrm{JA}-12$ & Worked hematite & 1 \\
\hline E2/N8 & 10 & BRM 2 & IIIc & $51 \mathrm{JB}-6$ & Biface Stage 1 & 1 \\
\hline E2/N8 & 10 & BRM 2 & IIIc & $51 J D-10$ & Biface Stage 3 & 1 \\
\hline $\mathrm{E} 2 / \mathrm{N} 8$ & 10 & BRM 2 & IIIc & $51 \mathrm{JB}-5$ & Biface Stage 3 & 1 \\
\hline E2/N8 & 10 & BRM 2 & IIIc & & Debitage & 347 \\
\hline $\mathrm{E} 2 / \mathrm{N} 8$ & 10 & BRM 2 & IIIC & 51JD-11 & Projectile point fragment & 1 \\
\hline $\mathrm{E} 2 / \mathrm{N} 8$ & 10 & BRM 2 & IIIc & $51 \mathrm{JA}-2$ & Projectile point fragment & 1 \\
\hline $\mathrm{E} 2 / \mathrm{N} 8$ & 10 & BRM 2 & IIIc & $51 \mathrm{JA}-1$ & Projectile point, Early Triangular & 1 \\
\hline $\mathrm{E} 2 / \mathrm{N} 8$ & 10 & BRM 2 & IIIc & $51 \mathrm{JA}-4$ & Projectile point, Nolan & 1 \\
\hline $\mathrm{E} 2 / \mathrm{N} 8$ & 10 & BRM 2 & IIIc & $51 \mathrm{JB}-7$ & Projectile point, rectangular stem B & 1 \\
\hline $\mathrm{E} 2 / \mathrm{N} 8$ & 10 & BRM 2 & IIIc & $51 \mathrm{JB}-8$ & Projectile point, Travis & 1 \\
\hline $\mathrm{E} 2 / \mathrm{N} 8$ & 10 & BRM 2 & IIIc & $51 \mathrm{JC}-9$ & Uniface, unanalyzed & 1 \\
\hline $\mathrm{E} 2 / \mathrm{N} 8$ & 11 & BRM 2 & IIIc & $51 \mathrm{KD}-17$ & Biface fragment & 1 \\
\hline $\mathrm{E} 2 / \mathrm{N} 8$ & 11 & BRM 2 & IIIc & $51 \mathrm{KD}-16$ & Biface Stage 1 & 1 \\
\hline $\mathrm{E} 2 / \mathrm{N} 8$ & 11 & BRM 2 & IIIc & $51 \mathrm{KC}-9$ & Biface Stage 1 & 1 \\
\hline $\mathrm{E} 2 / \mathrm{N} 8$ & 11 & BRM 2 & IIIc & $51 \mathrm{KC}-10$ & Biface Stage 1 & 1 \\
\hline $\mathrm{E} 2 / \mathrm{N} 8$ & 11 & BRM 2 & IIIc & $51 \mathrm{KC}-8$ & Bifacial tool Form J & 1 \\
\hline $\mathrm{E} 2 / \mathrm{N} 8$ & 11 & BRM 2 & IIIc & $51 \mathrm{~KB}-4$ & Burin spall & 1 \\
\hline $\mathrm{E} 2 / \mathrm{N} 8$ & 11 & BRM 2 & IIIc & & Debitage & 615 \\
\hline $\mathrm{E} 2 / \mathrm{N} 8$ & 11 & BRM 2 & IIIc & $51 \mathrm{~KB}-3$ & Mano & 1 \\
\hline $\mathrm{E} 2 / \mathrm{N} 8$ & 11 & BRM 2 & IIIc & $51 \mathrm{KD}-18$ & Projectile point, expanding stem D & 1 \\
\hline $\mathrm{E} 2 / \mathrm{N} 8$ & 11 & BRM 2 & IIIc & $51 \mathrm{KA}-2$ & Projectile point, Nolan & 1 \\
\hline $\mathrm{E} 2 / \mathrm{N} 8$ & 11 & BRM 2 & IIIC & $51 \mathrm{~KB}-6$ & Projectile point, Nolan & 1 \\
\hline $\mathrm{E} 2 / \mathrm{N} 8$ & 11 & BRM 2 & IIIc & $51 \mathrm{KC}-12$ & Uniface, unanalyzed & 1 \\
\hline $\mathrm{E} 2 / \mathrm{N} 8$ & 11 & BRM 2 & IIIc & $51 \mathrm{KC}-11$ & Uniface, unanalyzed & 1 \\
\hline $\mathrm{E} 2 / \mathrm{N} 8$ & 12 & & III & $51 \mathrm{LA}-1$ & Biface Stage 2 & 1 \\
\hline $\mathrm{E} 2 / \mathrm{N} 8$ & 12 & & III & $51 \mathrm{LB}-3$ & Biface Stage 2 & 1 \\
\hline $\mathrm{E} 2 / \mathrm{N} 8$ & 12 & & III & 51LA-2 & Core fragment & 1 \\
\hline $\mathrm{E} 2 / \mathrm{N} 8$ & 12 & & III & & Debitage & 328 \\
\hline
\end{tabular}




\begin{tabular}{|c|c|c|c|c|c|c|}
\hline Square & Level & Feature & Strata & Item & Analyst Identification & Count \\
\hline $\mathrm{E} 2 / \mathrm{N} 8$ & 12 & & III & $51 \mathrm{LD}-5$ & Edge modified flake & 1 \\
\hline $\mathrm{E} 2 / \mathrm{N} 8$ & 12 & & III & $51 \mathrm{LB}-4$ & Uniface, unanalyzed & 1 \\
\hline $\mathrm{E} 2 / \mathrm{N} 8$ & 12 & & III & $51 \mathrm{LB}-7$ & Worked hematite & 1 \\
\hline $\mathrm{E} 2 / \mathrm{N} 8$ & 13 & & III & $51 \mathrm{MD}-8$ & Biface fragment & 1 \\
\hline $\mathrm{E} 2 / \mathrm{N} 8$ & 13 & & III & & Debitage & 376 \\
\hline $\mathrm{E} 2 / \mathrm{N} 8$ & 13 & & III & $51 \mathrm{MB}-3$ & Mano fragment & 1 \\
\hline $\mathrm{E} 2 / \mathrm{N} 8$ & 13 & & III & $51 \mathrm{MC}-5$ & Possible ground stone & 1 \\
\hline $\mathrm{E} 2 / \mathrm{N} 8$ & 13 & & III & $51 \mathrm{MA}-1$ & Projectile point, Bell/Andice & 1 \\
\hline $\mathrm{E} 2 / \mathrm{N} 8$ & 13 & & III & $51 \mathrm{MC}-6$ & Projectile point, square stem & 1 \\
\hline $\mathrm{E} 2 / \mathrm{N} 8$ & 13 & & III & 51MD-9 & Uniface, unanalyzed & 1 \\
\hline $\mathrm{E} 2 / \mathrm{N} 8$ & 13 & & III & $51 \mathrm{MA}-2$ & Uniface, unanalyzed & 1 \\
\hline $\mathrm{E} 2 / \mathrm{N} 8$ & 13 & & III & $51 \mathrm{MB}-4$ & Uniface, unanalyzed & 1 \\
\hline $\mathrm{E} 2 / \mathrm{N} 8$ & 13 & & III & $51 \mathrm{MD}-10$ & Unifacial multiple tool & 1 \\
\hline $\mathrm{E} 2 / \mathrm{N} 8$ & 14 & & III & & Debitage & 334 \\
\hline $\mathrm{E} 2 / \mathrm{N} 8$ & 14 & & III & $51 \mathrm{NA}-1$ & Projectile point, indeterminate & 1 \\
\hline $\mathrm{E} 2 / \mathrm{N} 8$ & 14 & & III & $51 \mathrm{ND}-4$ & Thin uniface & 1 \\
\hline $\mathrm{E} 2 / \mathrm{N} 8$ & 14 & & III & $51 \mathrm{ND}-5$ & Thin uniface & \\
\hline $\mathrm{E} 2 / \mathrm{N} 8$ & 14 & & III & $51 \mathrm{NB}-2$ & Uniface, unanalyzed & 1 \\
\hline $\mathrm{E} 2 / \mathrm{N} 8$ & 14 & Feature 196 & III & & Debitage & 50 \\
\hline $\mathrm{E} 2 / \mathrm{N} 8$ & 14 & Feature 196 & III & $51 \mathrm{ND}-3$ & Projectile point, Bell/Andice & 1 \\
\hline $\mathrm{E} 2 / \mathrm{N} 8$ & 15 & & III & $510 D-2$ & Burin spall & 1 \\
\hline $\mathrm{E} 2 / \mathrm{N} 8$ & 15 & & III & $510 B-1$ & Core fragment & 1 \\
\hline $\mathrm{E} 2 / \mathrm{N} 8$ & 15 & & III & & Debitage & 152 \\
\hline $\mathrm{E} 2 / \mathrm{N} 8$ & 15 & & III & $510 D-3$ & Uniface, unanalyzed & 1 \\
\hline $\mathrm{E} 2 / \mathrm{N} 8$ & 16 & & III & & Debitage & 157 \\
\hline $\mathrm{E} 2 / \mathrm{N} 8$ & 16 & & III & 51PA-3 & Perforator Group 7 & 1 \\
\hline $\mathrm{E} 2 / \mathrm{N} 8$ & 16 & & III & $51 \mathrm{PC}-1$ & Projectile point, miscellaneous lanceolate & \\
\hline E2/N8 & 16 & & III & 51PD-2 & Projectile point, miscellaneous lanceolate & 1 \\
\hline $\mathrm{E} 2 / \mathrm{N} 8$ & 17 & & III & & Debitage & 160 \\
\hline $\mathrm{E} 2 / \mathrm{N} 8$ & 17 & & III & $51 \mathrm{QC}-1$ & Uniface, unanalyzed & 1 \\
\hline $\mathrm{E} 2 / \mathrm{N} 8$ & 17 & & III & 51QD-2 & Unifacial multiple tool & 1 \\
\hline $\mathrm{E} 2 / \mathrm{N} 8$ & 18 & & III & & Debitage & 137 \\
\hline $\mathrm{E} 2 / \mathrm{N} 8$ & 18 & & III & 51RB-1 & Uniface, unanalyzed & 1 \\
\hline $\mathrm{E} 2 / \mathrm{N} 8$ & 19 & & III & $51 \mathrm{SC}-6$ & Biface Stage 1 & 1 \\
\hline $\mathrm{E} 2 / \mathrm{N} 8$ & 19 & & III & 51SA-1 & Burin & 1 \\
\hline $\mathrm{E} 2 / \mathrm{N} 8$ & 19 & & III & $51 \mathrm{SA}-4$ & Burin & 1 \\
\hline $\mathrm{E} 2 / \mathrm{N} 8$ & 19 & & III & & Debitage & 249 \\
\hline $\mathrm{E} 2 / \mathrm{N} 8$ & 19 & & III & $51 \mathrm{SA}-3$ & Micro-core, small & 1 \\
\hline $\mathrm{E} 2 / \mathrm{N} 8$ & 19 & & III & 51SA-2 & Perforator Group 1 & 1 \\
\hline $\mathrm{E} 2 / \mathrm{N} 8$ & 19 & & III & $51 \mathrm{SC}-7$ & Projectile point, expanding concave A & 1 \\
\hline E2/N8 & 19 & & III & 51 SC-9 & Uniface, unanalyzed & 1 \\
\hline $\mathrm{E} 2 / \mathrm{N} 8$ & 19 & & III & $51 \mathrm{SC}-8$ & Uniface, unanalyzed & 1 \\
\hline $\mathrm{E} 2 / \mathrm{N} 8$ & 19 & & III & $51 \mathrm{SB}-5$ & Unifacial multiple tool & 1 \\
\hline $\mathrm{E} 2 / \mathrm{N} 8$ & 20 & & III & $51 \mathrm{TC}-2$ & Biface fragment & 1 \\
\hline $\mathrm{E} 2 / \mathrm{N} 8$ & 20 & & III & $51 \mathrm{TD}-4$ & Biface Stage 2 & 1 \\
\hline $\mathrm{E} 2 / \mathrm{N} 8$ & 20 & & III & $51 \mathrm{TC}-3$ & Burin spall & 1 \\
\hline $\mathrm{E} 2 / \mathrm{N} 8$ & 20 & & III & $51 \mathrm{TD}-5$ & Core tool, type 5 & 1 \\
\hline $\mathrm{E} 2 / \mathrm{N} 8$ & 20 & & III & & Debitage & 267 \\
\hline $\mathrm{E} 2 / \mathrm{N} 8$ & 20 & & III & $51 \mathrm{TD}-6$ & Uniface, unanalyzed & 1 \\
\hline $\mathrm{E} 2 / \mathrm{N} 8$ & 21 & & III & $51 \mathrm{UA}-1$ & Biface fragment & 1 \\
\hline $\mathrm{E} 2 / \mathrm{N} 8$ & 21 & & III & & Debitage & 98 \\
\hline $\mathrm{E} 2 / \mathrm{N} 8$ & 21 & & III & $51 \mathrm{UA}-3$ & Uniface, unanalyzed & 1 \\
\hline $\mathrm{E} 2 / \mathrm{N} 8$ & 22 & & III & $51 \mathrm{VA}-3$ & Burin spall & 1 \\
\hline $\mathrm{E} 2 / \mathrm{N} 8$ & 22 & & III & & Debitage & 86 \\
\hline $\mathrm{E} 2 / \mathrm{N} 8$ & 22 & & III & 51VA-2 & Micro-core, intermediate & 1 \\
\hline $\mathrm{E} 2 / \mathrm{N} 8$ & 22 & & III & 51VA-1 & Perforator Group 5 & 1 \\
\hline $\mathrm{E} 2 / \mathrm{N} 8$ & 23 & & II/III & $51 \mathrm{WB}-3$ & Brushy Creek biface & 1 \\
\hline $\mathrm{E} 2 / \mathrm{N} 8$ & 23 & & II/III & & Debitage & 160 \\
\hline $\mathrm{E} 2 / \mathrm{N} 8$ & 23 & & II/III & 51WB-1 & Projectile point fragment & 1 \\
\hline $\mathrm{E} 2 / \mathrm{N} 8$ & 23 & & II/III & $51 \mathrm{WB}-2$ & Projectile point, miscellaneous lanceolate & 1 \\
\hline $\mathrm{E} 2 / \mathrm{N} 8$ & 24 & & II & & Debitage & 191 \\
\hline $\mathrm{E} 2 / \mathrm{N} 8$ & 24 & & II & $51 \mathrm{XD}-3$ & Thick uniface & 1 \\
\hline $\mathrm{E} 2 / \mathrm{N} 8$ & 24 & & II & $51 \mathrm{XB}-1$ & Thin uniface & 1 \\
\hline $\mathrm{E} 2 / \mathrm{N} 8$ & 25 & Feature 166 & $\mathrm{I} / \mathrm{II}$ & & Debitage & 7 \\
\hline $\mathrm{E} 2 / \mathrm{N} 8$ & $25 \mathrm{~A}$ & & I/II & $51 \mathrm{Y} 1 \mathrm{~B}-2$ & Biface Stage 2 & 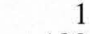 \\
\hline $\mathrm{E} 2 / \mathrm{N} 8$ & $25 \mathrm{~A}$ & & $\mathrm{I} / \mathrm{II}$ & & Debitage & 122 \\
\hline $\mathrm{E} 2 / \mathrm{N} 8$ & $25 \mathrm{~A}$ & & $\mathrm{I} / \mathrm{II}$ & $51 \mathrm{Y} 1 \mathrm{C}-5$ & Unifacial multiple tool & 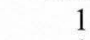 \\
\hline $\mathrm{E} 2 / \mathrm{N} 8$ & $25 \mathrm{~A}$ & Feature 166 & $\mathrm{I} / \mathrm{II}$ & $51 \mathrm{Y} 1 \mathrm{~B}-3$ & Bifacial tool & 1 \\
\hline $\mathrm{E} 2 / \mathrm{N} 8$ & $25 \mathrm{~A}$ & Feature 166 & $\mathrm{I} / \mathrm{II}$ & $51 Y 1 B-1$ & Projectile point, Golondrina-Barber & 1 \\
\hline $\mathrm{E} 2 / \mathrm{N} 8$ & $25 \mathrm{~A}$ & Feature 166 & $\mathrm{I} / \mathrm{II}$ & $51 \mathrm{Y} 1 \mathrm{~B}-4$ & Uniface, unanalyzed & 1 \\
\hline $\mathrm{E} 2 / \mathrm{N} 8$ & $25 \mathrm{~B}$ & & I & & Debitage & 107 \\
\hline $\mathrm{E} 2 / \mathrm{N} 8$ & $25 \mathrm{~B}$ & & I & $51 \mathrm{Y} 2 \mathrm{C}-1$ & Unifacial multiple tool & 1 \\
\hline $\mathrm{E} 2 / \mathrm{N} 8$ & $26 \mathrm{~A}$ & & $\hat{\mathrm{I}}$ & & Debitage & 72 \\
\hline $\mathrm{E} 2 / \mathrm{N} 8$ & $26 \mathrm{~A}$ & Feature 166 & I & & Debitage & 16 \\
\hline
\end{tabular}




\begin{tabular}{|c|c|c|c|c|c|c|}
\hline Square & Level & Feature & Strata & Item & Analyst Identification & Count \\
\hline $\begin{array}{l}\mathrm{E} 2 / \mathrm{N} 8 \\
\mathrm{E} 2 / \mathrm{N} 8\end{array}$ & $\begin{array}{l}26 \mathrm{~B} \\
26 \mathrm{~B}\end{array}$ & & I & $5172 \wedge$ & Debitage & 31 \\
\hline $\begin{array}{l}\mathrm{E} 2 / \mathrm{N} 8 \\
\mathrm{E} 2 / \mathrm{N} 8\end{array}$ & $26 \mathrm{~B}$ & & I & $\begin{array}{l}51 \mathrm{Z} 2 \mathrm{~A}-1 \\
51 \mathrm{Z} 2 \mathrm{C}-4\end{array}$ & $\begin{array}{l}\text { Uniface, unanalyzed } \\
\text { Uniface, unanalyzed }\end{array}$ & \\
\hline $\mathrm{E} 2 / \mathrm{N} 8$ & $26 \mathrm{~B}$ & Feature 166 & I & & Debitage & 4 \\
\hline $\mathrm{E} 2 / \mathrm{N} 8$ & $27 \mathrm{~A}$ & Feature 166 & I & 51AA1D-2 & Biface Stage 2 & \\
\hline $\mathrm{E} 2 / \mathrm{N} 8$ & $27 \mathrm{~A}$ & Feature 166 & I & $51 \mathrm{AA} 1 \mathrm{D}-1$ & Biface Stage 2 & \\
\hline $\mathrm{E} 2 / \mathrm{N} 8$ & $27 \mathrm{~A}$ & Feature 166 & I & $51 \mathrm{AA} 1 \mathrm{D}-3$ & Clear Fork biface & \\
\hline $\mathrm{E} 2 / \mathrm{N} 8$ & $27 \mathrm{~A}$ & Feature 166 & I & & Debitage & \\
\hline $\mathrm{E} 2 / \mathrm{N} 8$ & $27 \mathrm{~B}$ & & I & & Debitage & \\
\hline $\mathrm{E} 2 / \mathrm{N} 8$ & 27B & & I & 51AA2D-1 & Thin uniface & \\
\hline $\mathrm{E} 2 / \mathrm{N} 8$ & $28 \mathrm{~A}$ & & I & & Debitage & \\
\hline $\mathrm{E} 2 / \mathrm{N} 8$ & $28 \mathrm{~A}$ & & I & 51BB1-1 & Uniface, unanalyzed & \\
\hline $\mathrm{E} 2 / \mathrm{N} 8$ & Unknown & & & $51 *-1$ & Burin & \\
\hline $\mathrm{E} 2 / \mathrm{N} 8$ & Unknown & & & & Debitage & \\
\hline E18/S74 & $15 \mathrm{~B}$ & & IIIa & $38 \mathrm{O} 2$ & Biface Stage 2 & \\
\hline E18/S74 & $16 \mathrm{~A}$ & & IIIa & $38 \mathrm{P} 1$ & Bifacial tool & \\
\hline E18/S74 & $19 \mathrm{~A}$ & & IIIa & $38 \mathrm{~S} 1$ & Projectile point, St. Mary's Hall & \\
\hline E18/S74 & 25 & & Isi-c/Id/II & $38 Y-25$ & Clear Fork biface & \\
\hline E18/S76 & 7 & & IIIc & $39 \mathrm{G}$ & Bifacial tool Form A & \\
\hline E18/S76 & 19B & & II/IIIa & $39 \mathrm{~S} 2$ & Biface Stage 2 & \\
\hline E18/S76 & 32 & & Isi/Icl & $39 \mathrm{FF}-1$ & Biface Stage 1 & \\
\hline E18/S76 & 32 & & Isi/Icl & $39 \mathrm{FF}-2$ & Clear Fork biface & \\
\hline E18/S76 & Unknown & & & & Debitage & \\
\hline E18/S84 & 7 & & $\mathrm{IIIb} / \mathrm{c}$ & $40 \mathrm{G}$ & Biface Stage 2 & \\
\hline E18/S84 & 9 & & $\mathrm{IIIb} / \mathrm{c}$ & $40 I$ & Projectile point, Uvalde-like & \\
\hline E18/S84 & 11 & & Unknown & $43 \mathrm{~K}$ & Biface Stage 2 & \\
\hline E18/S84 & 14B & & IIIIa & $40 N 2-1$ & Core, multidirectional & \\
\hline E18/S84 & $18 \mathrm{~A}$ & & II/IIIa & $40 \mathrm{R} 1-2$ & Bifacial tool & \\
\hline E18/S84 & $18 \mathrm{~A}$ & & II/IIIa & $40 \mathrm{R} 1-1$ & Burin & \\
\hline E18/S84 & 19 & & II/IIIa & $40 \mathrm{~S}$ & Thin uniface & \\
\hline E18/S84 & 22 & & $\mathrm{Id} / \mathrm{II}$ & $40 \mathrm{~V}$ & Uniface, unanalyzed & \\
\hline E18/S84 & $22 \mathrm{~B}$ & & $\mathrm{Id} / \mathrm{II}$ & $40 \mathrm{~V} 2$ & Thin uniface & \\
\hline $\mathrm{E} 20 / \mathrm{S} 72$ & 1 & & IIIc & & Debitage & 12 \\
\hline $\mathrm{E} 20 / \mathrm{S} 72$ & 1 & & IIIC & $17 \mathrm{~A}-6$ & Edge modified flake & \\
\hline E20/S72 & 1 & & IIIC & $17 \mathrm{~A}-5$ & Edge modified flake & \\
\hline E20/S72 & 1 & & IIIC & $17 \mathrm{~A}-7$ & Edge modified flake & \\
\hline $\mathrm{E} 20 / \mathrm{S} 72$ & 1 & & IIIC & $17 \mathrm{~A}-2$ & Notched flake & \\
\hline E20/S72 & 1 & & IIIc & $17 \mathrm{~A}-8$ & Thin uniface fragment & \\
\hline E20/S72 & 1 & & IIIc & $17 \mathrm{~A}-3$ & Uniface, unanalyzed & \\
\hline E20/S72 & 1 & & IIIc & $17 \mathrm{~A}-1$ & Unifacial multiple tool & \\
\hline E20/S72 & 2 & & IIIIc & & Debitage & 16 \\
\hline $\mathrm{E} 20 / \mathrm{S} 72$ & 2 & & IIIC & $17 \mathrm{~B}-2$ & Edge modified flake & \\
\hline E20/S72 & 2 & & IIIc & $17 \mathrm{~B}-1$ & Projectile point fragment & \\
\hline E20/S72 & 3 & & IIIc & $17 \mathrm{C}-6$ & Biface fragment & \\
\hline E20/S72 & 3 & & IIIc & $17 \mathrm{C}-7 \mathrm{~A}$ & Biface Stage 2 & \\
\hline E20/S72 & 3 & & IIIc & $17 \mathrm{C}-8$ & Biface Stage 2 & \\
\hline E20/S72 & 3 & & IIIc & $17 \mathrm{C}-7 \mathrm{~B}$ & Biface Stage 3 & \\
\hline E20/S72 & 3 & & IIIc & $17 \mathrm{C}-10$ & Core fragment & \\
\hline $\mathrm{E} 20 / \mathrm{S} 72$ & 3 & & IIIc & & Debitage & 341 \\
\hline E20/S72 & 3 & & IIIc & $17 \mathrm{C}-17$ & Edge modified flake & \\
\hline E20/S72 & 3 & & IIIC & $17 \mathrm{C}-21$ & Edge modified flake & \\
\hline $\mathrm{E} 20 / \mathrm{S} 72$ & 3 & & IIIC & $17 \mathrm{C}-18$ & Edge modified flake & \\
\hline E20/S72 & 3 & & IIIc & $17 \mathrm{C}-16$ & Edge modified flake & \\
\hline E20/S72 & 3 & & IIIc & $17 \mathrm{C}-15$ & Edge modified flake & \\
\hline E20/S72 & 3 & & IIIc & $17 \mathrm{C}-13$ & Edge modified flake & \\
\hline $\mathrm{E} 20 / \mathrm{S} 72$ & 3 & & IIIC & $17 C-19$ & Edge modified flake & \\
\hline E20/S72 & 3 & & IIIc & $17 \mathrm{C}-11$ & Micro-core, intermediate & \\
\hline E20/S72 & 3 & & IIIc & $17 \mathrm{C}-22$ & Notched flake & \\
\hline E20/S72 & 3 & & IIIc & $17 \mathrm{C}-1$ & Projectile point, Ensor & \\
\hline E20/S72 & 3 & & IIIC & $17 \mathrm{C}-3$ & Projectile point, Ensor & \\
\hline E20/S72 & 3 & & IIIc & $17 \mathrm{C}-2$ & Projectile point, Ensor & \\
\hline $\mathrm{E} 20 / \mathrm{S} 72$ & 3 & & IIIc & $17 \mathrm{C}-4$ & Projectile point, Montell & \\
\hline E20/S72 & 3 & & IIIc & $17 \mathrm{C}-20$ & Uniface, unanalyzed & \\
\hline E20/S72 & 3 & & IIIc & $17 \mathrm{C}-12$ & Unifacial multiple tool & \\
\hline E20/S72 & 3 & & IIIc & $17 \mathrm{C}-14$ & Unifacial multiple tool & \\
\hline E20/S72 & 3 & Feature 36 & IIIc & $17 \mathrm{C}-5$ & Metate fragment & \\
\hline E20/S72 & 4 & & IIIc & $17 \mathrm{D}-7$ & Biface Stage 1 & \\
\hline $\mathrm{E} 20 / \mathrm{S} 72$ & 4 & & IIIc & $17 \mathrm{D}-5$ & Biface Stage 3 & \\
\hline E20/S72 & 4 & & IIIc & & Debitage & 465 \\
\hline E20/S72 & 4 & & IIIc & 17D-9 & Denticulated flake & \\
\hline E20/S72 & 4 & & IIIc & $17 \mathrm{D}-8$ & Edge modified flake & \\
\hline E20/S72 & 4 & & IIIc & $17 \mathrm{D}-3$ & Projectile point, Marcos & \\
\hline $\mathrm{E} 20 / \mathrm{S} 72$ & 4 & & IIIc & $17 \mathrm{D}-4$ & Projectile point, Montell & \\
\hline E20/S72 & 4 & & IIIc & $17 \mathrm{D}-2$ & Projectile point, square stem & \\
\hline
\end{tabular}




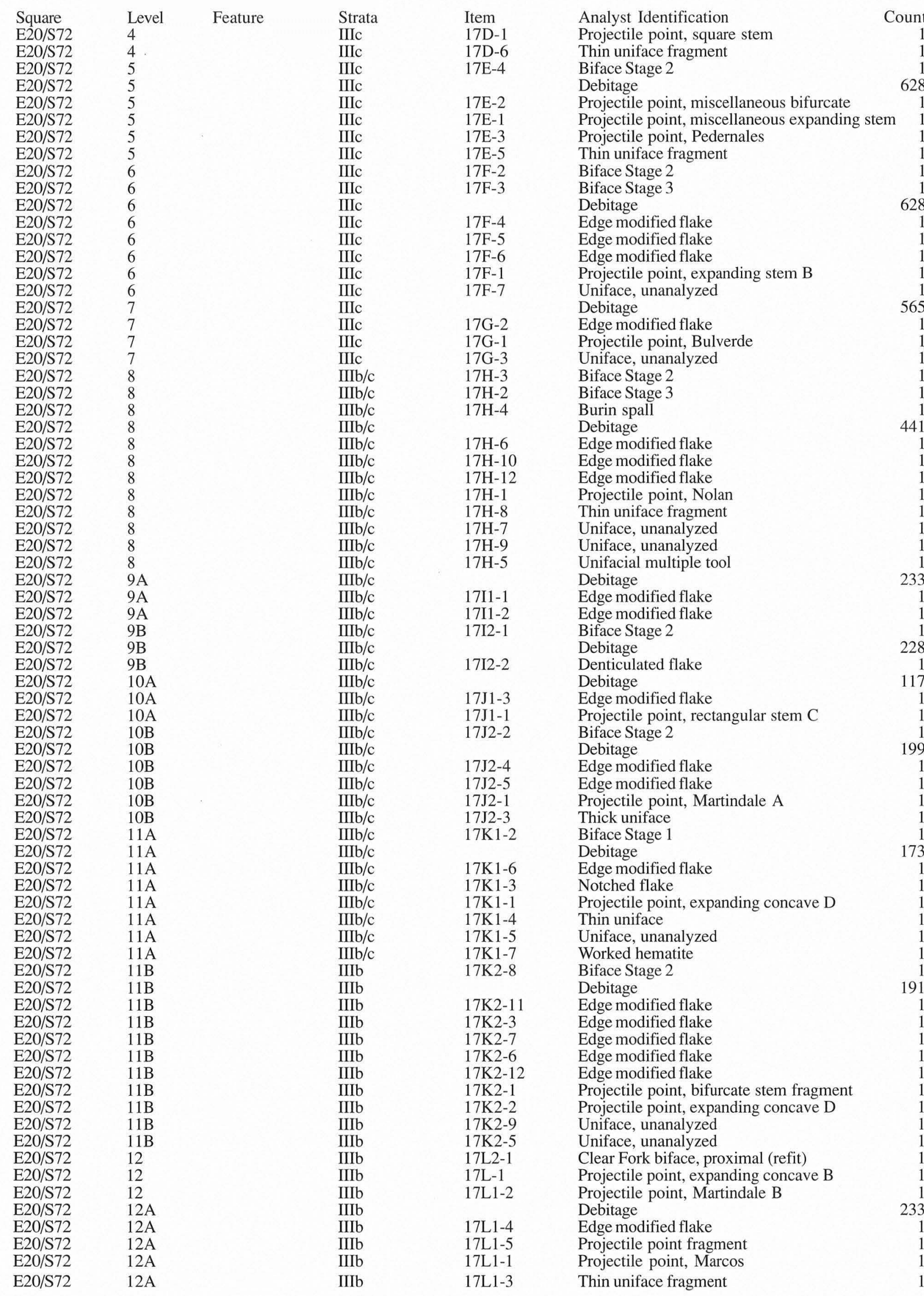




\begin{tabular}{|c|c|c|c|c|c|c|}
\hline Square & Level & Feature & Strata & Item & Analyst Identification & Count \\
\hline E20/S72 & $12 \mathrm{~B}$ & & IIIb & 17L2-3 & Biface Stage 1 & 1 \\
\hline $\mathrm{E} 20 / \mathrm{S} 72$ & $12 B$ & & IIIlb & $17 \mathrm{~L} 2-2$ & Bifacial tool Form J & 1 \\
\hline $\mathrm{E} 20 / \mathrm{S} 72$ & $12 \mathrm{~B}$ & & IIIb & & Debitage & 2581 \\
\hline $\mathrm{E} 20 / \mathrm{S} 72$ & $12 \mathrm{~B}$ & & IIIb & 17L2-6 & Edge modified flake & 1 \\
\hline E20/S72 & $12 B$ & & IIIb & 17L2-4 & Thick uniface & 1 \\
\hline $\mathrm{E} 20 / \mathrm{S} 72$ & $12 \mathrm{~B}$ & & IIIb & 17L2-5 & Thin uniface fragment & 1 \\
\hline $\mathrm{E} 20 / \mathrm{S} 72$ & $13 \mathrm{~A}$ & & IIIb & & Debitage & 260 \\
\hline E20/S72 & $13 \mathrm{~A}$ & & IIIIb & $17 \mathrm{M} 1-5$ & Edge modified flake & 1 \\
\hline $\mathrm{E} 20 / \mathrm{S} 72$ & $13 \mathrm{~A}$ & & $\mathrm{IIIb}$ & $17 \mathrm{M} 1-6$ & Microspur/microdenticulate & 1 \\
\hline E20/S72 & $13 \mathrm{~A}$ & & IIIb & $17 \mathrm{M} 1-2$ & Notched flake & 1 \\
\hline $\mathrm{E} 20 / \mathrm{S} 72$ & $13 \mathrm{~A}$ & & IIIb & $17 \mathrm{M} 1-4$ & Thin uniface & 1 \\
\hline E20/S72 & $13 \mathrm{~A}$ & & IIIb & $17 \mathrm{M} 1-3$ & Unifacial multiple tool & 1 \\
\hline E20/S72 & $13 \mathrm{~B}$ & & IIIb & $17 \mathrm{M} 2-3$ & Biface fragment & 1 \\
\hline E20/S72 & 13B & & IIIb & $17 \mathrm{M} 2-2$ & Burin spall & 1 \\
\hline E20/S72 & $13 \mathrm{~B}$ & & IIIb & & Debitage & 391 \\
\hline E20/S72 & $13 \mathrm{~B}$ & & IIIb & 17M2-1 & Edge modified flake & 1 \\
\hline $\mathrm{E} 20 / \mathrm{S} 72$ & $14 \mathrm{~A}$ & & IIIb & & Debitage & 118 \\
\hline E20/S72 & $14 \mathrm{~A}$ & & IIIb & $17 \mathrm{N1}-1$ & Edge modified flake & 1 \\
\hline E20/S72 & $14 \mathrm{~A}$ & & IIIb & $17 \mathrm{N1}-2$ & Unifacial multiple tool & 1 \\
\hline E20/S72 & 14B & & $\mathrm{IIIa} / \mathrm{b}$ & $17 \mathrm{~N} 2-2$ & Biface Stage 2 & 1 \\
\hline $\mathrm{E} 20 / \mathrm{S} 72$ & 14B & & IIIa/b & & Debitage & 215 \\
\hline E20/S72 & 14B & & IIIa/b & $17 N 2-3$ & Microspur/microdenticulate & 1 \\
\hline $\mathrm{E} 20 / \mathrm{S} 72$ & 14B & & $\mathrm{IIII} / \mathrm{b}$ & $17 \mathrm{~N} 2-1$ & Projectile point, Hoxie A & 1 \\
\hline E20/S72 & $15 \mathrm{~A}$ & & $\mathrm{IIIa} / \mathrm{b}$ & $1701-1$ & Biface Stage 3 & 1 \\
\hline E20/S72 & $15 \mathrm{~A}$ & & IIIa/b & $1701-7$ & Burin spall & 1 \\
\hline $\mathrm{E} 20 / \mathrm{S} 72$ & $15 \mathrm{~A}$ & & $\mathrm{IIIa} / \mathrm{b}$ & & Debitage & 158 \\
\hline $\mathrm{E} 20 / \mathrm{S} 72$ & $15 \mathrm{~A}$ & & IIIa/b & $1701-2$ & Edge modified flake & 1 \\
\hline $\mathrm{E} 20 / \mathrm{S} 72$ & $15 \mathrm{~A}$ & & $\mathrm{IIIa} / \mathrm{b}$ & $1701-4$ & Edge modified flake & 1 \\
\hline $\mathrm{E} 20 / \mathrm{S} 72$ & $15 \mathrm{~B}$ & & IIIa/b & $1702-1$ & Biface Stage 1 & 1 \\
\hline E20/S72 & $15 \mathrm{~B}$ & & $\mathrm{IIIa} / \mathrm{b}$ & & Debitage & 167 \\
\hline $\mathrm{E} 20 / \mathrm{S} 72$ & $15 \mathrm{~B}$ & & $\mathrm{IIIa} / \mathrm{b}$ & $17 \mathrm{O} 2-4$ & Edge modified flake & 1 \\
\hline E20/S72 & $15 B$ & & IIIa/b & $1702-3$ & Unifacial multiple tool & 1 \\
\hline $\mathrm{E} 20 / \mathrm{S} 72$ & $16 \mathrm{~A}$ & & IIIa & $17 \mathrm{Pl}-3$ & Biface Stage 2 & 1 \\
\hline $\mathrm{E} 20 / \mathrm{S} 72$ & $16 \mathrm{~A}$ & & IIIa & $17 \mathrm{P} 1-4$ & Biface Stage 2 & 1 \\
\hline E20/S72 & $16 \mathrm{~A}$ & & IIIa & 17P1-2 & Bifacial tool Form J & 1 \\
\hline $\mathrm{E} 20 / \mathrm{S} 72$ & $16 \mathrm{~A}$ & & IIIa & & Debitage & 267 \\
\hline E20/S72 & $16 \mathrm{~A}$ & & IIIa & 17P1-1 & Projectile point fragment & 1 \\
\hline $\mathrm{E} 20 / \mathrm{S} 72$ & $16 \mathrm{~A}-\mathrm{B}$ & & IIIa & $17 P 1 \& 2-1$ & Biface Stage 2 & 1 \\
\hline E20/S72 & $16 \mathrm{~A}-\mathrm{B}$ & & IIIa & $17 \mathrm{P} 1 \& 2-2$ & Biface Stage 2 & 1 \\
\hline E20/S72 & $16 \mathrm{~B}$ & & IIIa & 17P2-1 & Core, thermal & 1 \\
\hline E20/S72 & $16 \mathrm{~B}$ & & IIIIa & & Debitage & 295 \\
\hline $\mathrm{E} 20 / \mathrm{S} 72$ & $16 \mathrm{~B}$ & & IIIa & $17 \mathrm{P} 2-5$ & Denticulated flake & 1 \\
\hline $\mathrm{E} 20 / \mathrm{S} 72$ & $16 \mathrm{~B}$ & & IIIa & $17 \mathrm{P} 2-3$ & Edge modified flake & 1 \\
\hline $\mathrm{E} 20 / \mathrm{S} 72$ & $16 \mathrm{~B}$ & & IIIa & $17 \mathrm{P} 2-2$ & Edge modified flake & 1 \\
\hline E20/S72 & $16 \mathrm{~B}$ & & IIIa & 17P2-7 & Edge modified flake & 1 \\
\hline E20/S72 & $16 \mathrm{~B}$ & & IIIa & $17 \mathrm{P} 2-6$ & Microspur/microdenticulate & 1 \\
\hline $\mathrm{E} 20 / \mathrm{S} 72$ & $16 \mathrm{~B}$ & & IIIa & $17 \mathrm{P} 2-4$ & Unifacial multiple tool & 1 \\
\hline $\mathrm{E} 20 / \mathrm{S} 72$ & $17 \mathrm{~A}$ & & IIIIa & 17Q1-2 & Burin spall & 1 \\
\hline $\mathrm{E} 20 / \mathrm{S} 72$ & $17 \mathrm{~A}$ & & IIIa & & Debitage & 304 \\
\hline E20/S72 & $17 \mathrm{~A}$ & & IIIIa & 17Q1-4 & Edge modified flake & 1 \\
\hline $\mathrm{E} 20 / \mathrm{S} 72$ & $17 \mathrm{~A}$ & & IIIa & $17 Q 1-6$ & Edge modified flake & 1 \\
\hline $\mathrm{E} 20 / \mathrm{S} 72$ & $17 \mathrm{~A}$ & & IIIa & 17Q1-9 & Edge modified flake & 1 \\
\hline E20/S72 & $17 \mathrm{~A}$ & & IIIa & 17Q1-3 & Microspur/microdenticulate & 1 \\
\hline E20/S72 & $17 \mathrm{~A}$ & & IIIa & 17Q1-1 & Projectile point, Angostura & 1 \\
\hline E20/S72 & $17 \mathrm{~A}$ & & IIIa & $17 Q 1-5$ & Thin uniface fragment & 1 \\
\hline E20/S72 & $17 \mathrm{~A}$ & & IIIa & $17 Q 1-8$ & Uniface, unanalyzed & 1 \\
\hline $\mathrm{E} 20 / \mathrm{S} 72$ & $17 \mathrm{~A}$ & & IIIa & 17Q1-7 & Unifacial multiple tool & 1 \\
\hline $\mathrm{E} 20 / \mathrm{S} 72$ & $17 \mathrm{~B}$ & & IIIa & 17Q2-1 & Burin spall & 1 \\
\hline E20/S72 & $17 \mathrm{~B}$ & & IIIa & & Debitage & 141 \\
\hline $\mathrm{E} 20 / \mathrm{S} 72$ & $17 \mathrm{~B}$ & & IIIa & 17Q2-2 & Thin uniface & 1 \\
\hline $\mathrm{E} 20 / \mathrm{S} 72$ & $17 \mathrm{~B}$ & & IIIa & $17 Q 2-3$ & Thin uniface fragment & 1 \\
\hline E20/S72 & $17 \mathrm{~B}$ & & IIIa & 17Q2-4 & Uniface, unanalyzed & 1 \\
\hline $\mathrm{E} 20 / \mathrm{S} 72$ & $18 \mathrm{~A}$ & & IIIa & $17 \mathrm{R} 1-1$ & Biface Stage 1 & 1 \\
\hline $\mathrm{E} 20 / \mathrm{S} 72$ & $18 \mathrm{~A}$ & & IIIa & 17R1-2 & Biface Stage 2 & 1 \\
\hline E20/S72 & $18 \mathrm{~A}$ & & IIIa & $17 \mathrm{R} 1-3$ & Biface Stage 2 & \\
\hline $\mathrm{E} 20 / \mathrm{S} 72$ & $18 \mathrm{~A}$ & & IIIa & & Debitage & 181 \\
\hline $\mathrm{E} 20 / \mathrm{S} 72$ & $18 \mathrm{~A}$ & & IIIa & 17R1-9 & Edge modified flake & \\
\hline E20/S72 & $18 \mathrm{~A}$ & & IIIa & 17R1-12 & Notched flake & 1 \\
\hline $\mathrm{E} 20 / \mathrm{S} 72$ & $18 \mathrm{~A}$ & & IIIa & $17 \mathrm{R} 1-18$ & Thin uniface & 1 \\
\hline $\mathrm{E} 20 / \mathrm{S} 72$ & $18 \mathrm{~A}$ & & IIIa & $17 \mathrm{R} 1-7$ & Thin uniface & 1 \\
\hline $\mathrm{E} 20 / \mathrm{S} 72$ & $18 \mathrm{~A}$ & & IIIa & $17 \mathrm{R} 1-16$ & Thin uniface & 1 \\
\hline $\mathrm{E} 20 / \mathrm{S} 72$ & $18 \mathrm{~A}$ & & IIIa & $17 \mathrm{R} 1-17$ & Thin uniface fragment & 1 \\
\hline $\mathrm{E} 20 / \mathrm{S} 72$ & $18 \mathrm{~A}$ & & IIIa & 17R1-13 & Uniface, unanalyzed & 1 \\
\hline E20/S72 & $18 \mathrm{~A}$ & & IIIa & $17 \mathrm{R} 1-5$ & Uniface, unanalyzed & 1 \\
\hline
\end{tabular}




\begin{tabular}{|c|c|c|c|c|c|c|}
\hline Square & Level & Feature & Strata & Item & Analyst Identification & Count \\
\hline $\mathrm{E} 20 / \mathrm{S} 72$ & $18 \mathrm{~A}$ & & IIIa & 17R1-19 & Unifacial multiple tool & 1 \\
\hline $\mathrm{E} 20 / \mathrm{S} 72$ & $18 \mathrm{~A}$ & & IIIa & $17 R 1-6$ & Unifacial multiple tool & 1 \\
\hline $\mathrm{E} 20 / \mathrm{S} 72$ & $18 \mathrm{~B}$ & & IIIa & 17R2-1 & Biface Stage 2 & 1 \\
\hline $\mathrm{E} 20 / \mathrm{S} 72$ & $18 \mathrm{~B}$ & & IIIa & 17R2-3 & Clear Fork biface & 1 \\
\hline $\mathrm{E} 20 / \mathrm{S} 72$ & $18 \mathrm{~B}$ & & IIIa & & Debitage & 364 \\
\hline $\mathrm{E} 20 / \mathrm{S} 72$ & $18 \mathrm{~B}$ & & IIIa & 17R2-5 & Microspur/microdenticulate & 1 \\
\hline $\mathrm{E} 20 / \mathrm{S} 72$ & $18 \mathrm{~B}$ & & IIIa & 17R2-2 & Projectile point fragment & 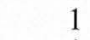 \\
\hline E20/S72 & $18 \mathrm{~B}$ & & IIIa & $17 R 2-4$ & Thin uniface fragment & 1 \\
\hline E20/S72 & $19 \mathrm{~A}$ & & IIIa & 17S1-1 & Burin spall & \\
\hline $\mathrm{E} 20 / \mathrm{S} 72$ & $19 \mathrm{~A}$ & & IIIa & $17 S 1-3$ & Chert cobble, chunk & \\
\hline $\mathrm{E} 20 / \mathrm{S} 72$ & $19 \mathrm{~A}$ & & IIIa & $17 S 1-2$ & Core fragment & 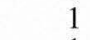 \\
\hline $\mathrm{E} 20 / \mathrm{S} 72$ & $19 \mathrm{~A}$ & & IIIa & $17 S 1-4$ & Core, thermal & 1 \\
\hline E20/S72 & $19 \mathrm{~A}$ & & IIIa & & Debitage & 445 \\
\hline E20/S72 & $19 \mathrm{~A}$ & & IIIa & $17 \mathrm{~S} 1-7$ & Microspur/microdenticulate & \\
\hline $\mathrm{E} 20 / \mathrm{S} 72$ & $19 \mathrm{~A}$ & & IIIa & $17 S 1-5$ & Perforator Group 7 & \\
\hline $\mathrm{E} 20 / \mathrm{S} 72$ & $19 \mathrm{~A}$ & & IIIa & $17 S 1-6$ & Perforator Group 7 & \\
\hline $\mathrm{E} 20 / \mathrm{S} 72$ & $19 \mathrm{~A}$ & & IIIa & $17 \mathrm{~S} 1-10$ & Thin uniface & 1 \\
\hline $\mathrm{E} 20 / \mathrm{S} 72$ & $19 \mathrm{~A}$ & & IIIa & $17 \mathrm{~S} 1-8$ & Thin uniface & \\
\hline E20/S72 & $19 \mathrm{~A}$ & & IIIa & 17S1-9 & Thin uniface fragment & \\
\hline $\mathrm{E} 20 / \mathrm{S} 72$ & $19 \mathrm{~A}$ & & IIIIa & $17 \mathrm{~S} 1-11$ & Worked hematite & 1 \\
\hline E20/S72 & 19B & & IIIa & $17 \mathrm{~S} 2-2$ & Core tool, type 5 & 1 \\
\hline $\mathrm{E} 20 / \mathrm{S} 72$ & $19 \mathrm{~B}$ & & IIIa & & Debitage & 152 \\
\hline $\mathrm{E} 20 / \mathrm{S} 72$ & 19B & & IIIa & $17 S 2-3$ & Edge modified flake & \\
\hline E20/S72 & $19 \mathrm{~B}$ & & IIIa & $17 \mathrm{~S} 2-4$ & Edge modified flake & \\
\hline $\mathrm{E} 20 / \mathrm{S} 72$ & $20 \mathrm{~A}$ & & II/IIIa & 17T1-1 & Biface fragment & \\
\hline $\mathrm{E} 20 / \mathrm{S} 72$ & $20 \mathrm{~A}$ & & II/IIIa & $17 \mathrm{~T} 1-2$ & Bifacial tool Form A & 1 \\
\hline $\mathrm{E} 20 / \mathrm{S} 72$ & $20 \mathrm{~A}$ & & II/IIIa & 17T1-9 & Bifacial tool Form A & \\
\hline E20/S72 & $20 \mathrm{~A}$ & & II/IIIa & $17 \mathrm{~T} 1-5$ & Chert cobble, unmodified/tested & \\
\hline E20/S72 & $20 \mathrm{~A}$ & & II/IIIa & $17 \mathrm{~T} 1-3$ & Clear Fork biface & \\
\hline $\mathrm{E} 20 / \mathrm{S} 72$ & $20 \mathrm{~A}$ & & II/IIIa & $17 \mathrm{~T} 1-8$ & Clear Fork biface & \\
\hline E20/S72 & $20 \mathrm{~A}$ & & II/IIIa & 17T1-4 & Core, thermal & \\
\hline $\mathrm{E} 20 / \mathrm{S} 72$ & $20 \mathrm{~A}$ & & II/IIIa & & Debitage & 219 \\
\hline $\mathrm{E} 20 / \mathrm{S} 72$ & $20 \mathrm{~A}$ & & II/IIIa & $17 \mathrm{~T} 1-12$ & Edge modified flake & 1 \\
\hline $\mathrm{E} 20 / \mathrm{S} 72$ & $20 \mathrm{~A}$ & & II/IIIa & 17T1-7 & Perforator Group 2 & \\
\hline $\mathrm{E} 20 / \mathrm{S} 72$ & $20 \mathrm{~A}$ & & II/IIIa & $17 \mathrm{~T} 1-6$ & Small core hammerstone & \\
\hline $\mathrm{E} 20 / \mathrm{S} 72$ & $20 \mathrm{~A}$ & & II/IIIa & $17 \mathrm{~T} 1-10$ & Thin uniface & \\
\hline E20/S72 & $20 \mathrm{~A}$ & & II/IIIa & 17T1-11 & Unifacial multiple tool & \\
\hline $\mathrm{E} 20 / \mathrm{S} 72$ & $20 \mathrm{~B}$ & & II/IIIa & $17 \mathrm{~T} 2-2$ & Burin spall & \\
\hline $\mathrm{E} 20 / \mathrm{S} 72$ & $20 \mathrm{~B}$ & & II/IIIa & & Debitage & 141 \\
\hline E20/S72 & $20 \mathrm{~B}$ & & II/IIIa & $17 \mathrm{~T} 2-3$ & Edge modified flake & \\
\hline $\mathrm{E} 20 / \mathrm{S} 72$ & $20 \mathrm{~B}$ & & II/IIIa & $17 \mathrm{~T} 2-1$ & Projectile point, miscellaneous lanceolate & \\
\hline E20/S72 & $21 \mathrm{~A}$ & & II & $17 \mathrm{U} 1-3$ & Biface fragment & \\
\hline $\mathrm{E} 20 / \mathrm{S} 72$ & $21 \mathrm{~A}$ & & II & & Debitage & 161 \\
\hline $\mathrm{E} 20 / \mathrm{S} 72$ & $21 \mathrm{~A}$ & & II & 17U1-2 & Micro-core, large & \\
\hline E20/S72 & $21 \mathrm{~A}$ & & II & 17U1-1 & Projectile point, miscellaneous lanceolate & \\
\hline $\mathrm{E} 20 / \mathrm{S} 72$ & $21 \mathrm{~A}$ & & II & $17 \mathrm{U} 1-4$ & Thin uniface fragment & \\
\hline $\mathrm{E} 20 / \mathrm{S} 72$ & $22 \mathrm{~A}$ & & II & & Debitage & 126 \\
\hline $\mathrm{E} 20 / \mathrm{S} 72$ & $22 \mathrm{~A}$ & & II & $17 \mathrm{~V} 1-1$ & Edge modified flake & 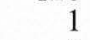 \\
\hline E20/S72 & $22 \mathrm{~A}$ & & II & $17 \mathrm{~V} 1-2$ & Edge modified flake & \\
\hline $\mathrm{E} 20 / \mathrm{S} 72$ & $22 \mathrm{~A}$ & & II & $17 \mathrm{~V} 1-4$ & Projectile point, St. Mary's Hall-atypic & \\
\hline E20/S72 & $22 \mathrm{~A}$ & & II & $17 \mathrm{~V} 1-3$ & Thin uniface & 1 \\
\hline $\mathrm{E} 20 / \mathrm{S} 72$ & $22 \mathrm{~B}$ & & II & $17 \mathrm{~V} 2-2$ & Biface fragment & 1 \\
\hline $\mathrm{E} 20 / \mathrm{S} 72$ & $22 \mathrm{~B}$ & & II & $17 \mathrm{~V} 2-3$ & Biface fragment & \\
\hline $\mathrm{E} 20 / \mathrm{S} 72$ & $22 \mathrm{~B}$ & & II & $17 \mathrm{~V} 2-1$ & Biface fragment & \\
\hline $\mathrm{E} 20 / \mathrm{S} 72$ & $22 \mathrm{~B}$ & & II & $17 \mathrm{~V} 2-4$ & Burin spall & 1 \\
\hline E20/S72 & $22 \mathrm{~B}$ & & II & $17 \mathrm{~V} 2-5$ & Core tool, type 4 & \\
\hline $\mathrm{E} 20 / \mathrm{S} 72$ & 22B & & II & & Debitage & 103 \\
\hline $\mathrm{E} 20 / \mathrm{S} 72$ & $22 \mathrm{~B}$ & & II & $17 \mathrm{~V} 2-7$ & Edge modified flake & \\
\hline $\mathrm{E} 20 / \mathrm{S} 72$ & $22 \mathrm{~B}$ & & II & $17 V 2-6$ & Edge modified flake & \\
\hline $\mathrm{E} 20 / \mathrm{S} 72$ & $23 \mathrm{~A}$ & & II & & Debitage & 80 \\
\hline $\mathrm{E} 20 / \mathrm{S} 72$ & $23 \mathrm{~B}$ & & II & & Debitage & 60 \\
\hline $\mathrm{E} 20 / \mathrm{S} 72$ & $23 \mathrm{~B}$ & & II & 17W2-1 & Projectile point fragment & \\
\hline E20/S72 & $23 \mathrm{~B}$ & & II & $17 W 2-2$ & Projectile point, miscellaneous lanceolate & \\
\hline $\mathrm{E} 20 / \mathrm{S} 72$ & $24 \mathrm{~A}$ & & II & & Debitage & 44 \\
\hline $\mathrm{E} 20 / \mathrm{S} 72$ & $24 \mathrm{~A}$ & & II & $17 \times 1-2$ & Thin uniface & \\
\hline $\mathrm{E} 20 / \mathrm{S} 72$ & $24 \mathrm{~A}$ & & II & $17 \times 1-3$ & Unifacial multiple tool & \\
\hline E20/S72 & $24 \mathrm{~B}$ & & II & & Debitage & 48 \\
\hline $\mathrm{E} 20 / \mathrm{S} 72$ & $25 \mathrm{~A}$ & & $\mathrm{Id} / \mathrm{II}$ & & Debitage & 31 \\
\hline E20/S72 & $25 \mathrm{~A}$ & & $\mathrm{Id} / \mathrm{II}$ & $17 Y 1-2$ & Thin uniface & 1 \\
\hline $\mathrm{E} 20 / \mathrm{S} 72$ & $25 \mathrm{~B}$ & & $\mathrm{Id} / \mathrm{II}$ & $17 Y 2-2$ & Biface Stage 2 & 1 \\
\hline $\mathrm{E} 20 / \mathrm{S} 72$ & $25 \mathrm{~B}$ & & $\mathrm{Id} / \mathrm{II}$ & & Debitage & 37 \\
\hline $\mathrm{E} 20 / \mathrm{S} 72$ & $25 \mathrm{~B}$ & & $\mathrm{Id} / \mathrm{II}$ & $17 Y 2-3$ & Thin uniface fragment & \\
\hline E20/S72 & $25 \mathrm{~B}$ & & $\mathrm{Id} / \mathrm{II}$ & $17 Y 2-1$ & Waco sinker & \\
\hline $\mathrm{E} 20 / \mathrm{S} 72$ & $26 \mathrm{~A}$ & & Isi-c/Id/II & $17 Z 1-2$ & Biface Stage 2 & \\
\hline
\end{tabular}




\begin{tabular}{|c|c|c|c|c|c|c|}
\hline Square & Level & Feature & Strata & Item & Analyst Identification & Count \\
\hline E20/S72 & $26 \mathrm{~A}$ & & Isi-c/Id/II & $17 \mathrm{Z} 1-3$ & Chert cobble, unmodified/tested & \\
\hline E20/S72 & $26 \mathrm{~A}$ & & Isi-c/Id/II & & Debitage & 6 \\
\hline E20/S72 & $26 \mathrm{~A}$ & & Isi-c/Id/II & $17 Z 1-4$ & Unifacial multiple tool & \\
\hline E20/S72 & $26 \mathrm{~B}$ & & Isi-c/Id/II & 17Z2-1 & Core tool, type 5 & \\
\hline $\mathrm{E} 20 / \mathrm{S} 72$ & $26 \mathrm{~B}$ & & Isi-c/Id/II & & Debitage & 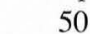 \\
\hline $\mathrm{E} 20 / \mathrm{S} 72$ & $26 B$ & & Isi-c/Id/II & $17 Z 2-2$ & Edge modified flake & \\
\hline E20/S72 & $26 \mathrm{~B}$ & & Isi-c/Id/II & $17 Z 2-3$ & Edge modified flake & \\
\hline $\mathrm{E} 20 / \mathrm{S} 72$ & $27 \mathrm{~A}$ & & Isi-c/Id/II & & Debitage & 5 \\
\hline $\mathrm{E} 20 / \mathrm{S} 72$ & $27 \mathrm{~A}$ & & Isi-c/Id/II & 17AA1-2 & Large core hammerstone & \\
\hline $\mathrm{E} 20 / \mathrm{S} 72$ & $27 \mathrm{~A}$ & & Isi-c/Id/II & $17 \mathrm{AA} 1-3$ & Unifacial multiple tool & \\
\hline $\mathrm{E} 20 / \mathrm{S} 72$ & 27B & & Isi-c/Id/II & & Debitage & 4 \\
\hline E20/S72 & $27 \mathrm{~B}$ & & Isi-c/Id/II & 17AA2-2 & Projectile point, Wilson scraper & \\
\hline $\mathrm{E} 20 / \mathrm{S} 72$ & $27 \mathrm{~B}$ & & Isi-c/Id/II & $17 \mathrm{AA} 2-1$ & Thin uniface & \\
\hline $\mathrm{E} 20 / \mathrm{S} 72$ & $27 \mathrm{~B}$ & & Isi-c/Id/II & $17 \mathrm{AA} 2-3$ & Thin uniface & \\
\hline $\mathrm{E} 20 / \mathrm{S} 72$ & $28 \mathrm{~A}$ & & Isi-c/ld & & Debitage & 4 \\
\hline $\mathrm{E} 20 / \mathrm{S} 72$ & $28 \mathrm{~A}$ & & Isi-c/Id & 17BB 1-1 & Denticulated flake & \\
\hline $\mathrm{E} 20 / \mathrm{S} 72$ & $28 \mathrm{~A}$ & & Isi-c/Id & $17 \mathrm{BB} 1-2$ & Unifacial multiple tool & 1 \\
\hline E20/S72 & $28 \mathrm{~B}$ & & Isi-c & & Debitage & 38 \\
\hline $\mathrm{E} 20 / \mathrm{S} 72$ & $28 \mathrm{~B}$ & & Isi-c & 17BB2-1 & Edge modified flake & \\
\hline $\mathrm{E} 20 / \mathrm{S} 72$ & $29 \mathrm{~A}$ & & Isi-c & & Debitage & 31 \\
\hline E20/S72 & $29 \mathrm{~B}$ & & Isi-c & & Debitage & 36 \\
\hline E20/S72 & $29 B$ & & Isi-c & 17CC2-1 & Edge modified flake & \\
\hline $\mathrm{E} 20 / \mathrm{S} 72$ & $29 B$ & & Isi-c & $17 \mathrm{CC} 2-2$ & Unifacial multiple tool & \\
\hline $\mathrm{E} 20 / \mathrm{S} 72$ & $30 \mathrm{~A}$ & & $\mathrm{Icl} / \mathrm{Isi}-\mathrm{c}$ & 17DD $1-1$ & Biface fragment & \\
\hline E20/S72 & $30 \mathrm{~A}$ & & Icl/Isi-c & & Debitage & 17 \\
\hline $\mathrm{E} 20 / \mathrm{S} 72$ & 31 & & $\mathrm{Isi} / \mathrm{Icl} / \mathrm{Isi}-\mathrm{c}$ & & Debitage & 26 \\
\hline E20/S72 & 31 & & $\mathrm{Isi} / \mathrm{Icl} / \mathrm{Isi}-\mathrm{c}$ & $17 \mathrm{EE}^{*}-2$ & Edge modified flake & \\
\hline $\mathrm{E} 20 / \mathrm{S} 72$ & 31 & & Isi/Icl/Isi-c & $17 \mathrm{EE}^{*}-1$ & Spurred flake & \\
\hline $\mathrm{E} 20 / \mathrm{S} 72$ & 31 & & Isi/Icl/Isi-c & $17 \mathrm{EE}^{*}-3$ & Unifacial multiple tool & \\
\hline $\mathrm{E} 20 / \mathrm{S} 72$ & $34 \mathrm{~A}$ & & $\mathrm{Isi} / \mathrm{Icl} / \mathrm{Isi}-\mathrm{c}$ & & Debitage & 2 \\
\hline E20/S72 & $34 \mathrm{~B}-35 \mathrm{~A}$ & & Isi/Icl & & Debitage & 20 \\
\hline $\mathrm{E} 20 / \mathrm{S} 72$ & $35 \mathrm{~B}-36 \mathrm{~A}$ & & Isi/Icl & & Debitage & 34 \\
\hline $\mathrm{E} 20 / \mathrm{S} 72$ & $36 \mathrm{~B}-37 \mathrm{~A}$ & & $\mathrm{Isi} / \mathrm{Icl}$ & $17 J J 2 K K 1-1$ & Chert cobble, unmodified/tested & \\
\hline $\mathrm{E} 20 / \mathrm{S} 72$ & $36 \mathrm{~B}-37 \mathrm{~A}$ & & Isi/Icl & & Debitage & 44 \\
\hline $\mathrm{E} 20 / \mathrm{S} 72$ & $36 \mathrm{~B}-37 \mathrm{~A}$ & & Isi/Icl & $17 J J 2 K K 1-3$ & Projectile point, bone bed point & \\
\hline $\mathrm{E} 20 / \mathrm{S} 72$ & $36 \mathrm{~B}-37 \mathrm{~A}$ & & Isi/Icl & 17JJ2KK $1-2$ & Spurred flake & $x$ \\
\hline $\mathrm{E} 20 / \mathrm{S} 72$ & $37 \mathrm{~B}-38 \mathrm{~A}$ & & Isi & 17KK2LL1-1 & Core, thermal & 1 \\
\hline E20/S72 & $37 \mathrm{~B}-38 \mathrm{~A}$ & & Isi & & Debitage & 51 \\
\hline $\mathrm{E} 20 / \mathrm{S} 72$ & $37 \mathrm{~B}-38 \mathrm{~A}$ & & Isi & 17KK2LL1-2 & Thin uniface & \\
\hline $\mathrm{E} 20 / \mathrm{S} 72$ & $38 \mathrm{~B}-39 \mathrm{~A}$ & & Isi & & Debitage & 43 \\
\hline $\mathrm{E} 20 / \mathrm{S} 72$ & $39 \mathrm{~B}-40 \mathrm{~A}$ & & $\mathrm{Igl} / \mathrm{Isi}$ & & Debitage & 11 \\
\hline E20/S72 & $40 \mathrm{~B}-41 \mathrm{~A}$ & & $\mathrm{Igl} / \mathrm{Isi}$ & $17 \mathrm{NN} 2 \mathrm{OO} 1-1$ & Biface Stage 2 & \\
\hline $\mathrm{E} 20 / \mathrm{S} 72$ & $40 \mathrm{~B}-41 \mathrm{~A}$ & & $\mathrm{Igl} / \mathrm{Isi}$ & & Debitage & \\
\hline E20/S72 & $40 \mathrm{~B}-41 \mathrm{~A}$ & & Igl/Isi & $17 \mathrm{NN} 2 \mathrm{OO} 1-2$ & Edge modified flake & 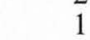 \\
\hline E20/S72 & $41 \mathrm{~B}-42 \mathrm{~A}$ & & Igl & & Debitage & \\
\hline $\mathrm{E} 20 / \mathrm{S} 72$ & $42 \mathrm{~B}-43 \mathrm{~A}$ & & Igl & & Debitage & \\
\hline E20/S72 & $43 \mathrm{~B}-44 \mathrm{~A}$ & & Igl & & Debitage & 11 \\
\hline $\mathrm{E} 20 / \mathrm{S} 72$ & $44 \mathrm{~B}-45 \mathrm{~A}$ & & $\mathrm{Igl}$ & & Debitage & \\
\hline $\mathrm{E} 20 / \mathrm{S} 72$ & $45 \mathrm{~B}-46 \mathrm{~A}$ & & Igl & & Debitage & 1 \\
\hline $\mathrm{E} 20 / \mathrm{S} 72$ & Unknown & Burial 2 & Isi/Icl/Isi-c & & Debitage & 12 \\
\hline $\mathrm{E} 20 / \mathrm{S} 74$ & 1 & & IIIC & $16 \mathrm{~A}-5$ & Arrow point, preform & 12 \\
\hline $\mathrm{E} 20 / \mathrm{S} 74$ & 1 & & IIIc & $16 \mathrm{~A}-9$ & Arrow point, Scallorn/Edwards & \\
\hline $\mathrm{E} 20 / \mathrm{S} 74$ & 1 & & IIIc & $16 \mathrm{~A}-1$ & Biface fragment & \\
\hline E20/S74 & 1 & & IIIc & $16 \mathrm{~A}-7$ & Biface Stage 1 & 1 \\
\hline E20/S74 & 1 & & IIIc & $16 \mathrm{~A}-3$ & Core, thermal & \\
\hline E20/S74 & 1 & & IIIc & & Debitage & 245 \\
\hline E20/S74 & 1 & & IIIc & $16 \mathrm{~A}-10$ & Possible ground stone & \\
\hline $\mathrm{E} 20 / \mathrm{S} 74$ & 1 & & IIIc & $16 \mathrm{~A}-6$ & Projectile point, Darl & \\
\hline $\mathrm{E} 20 / \mathrm{S} 74$ & 2 & & IIIc & & Debitage & 240 \\
\hline E20/S74 & 2 & & IIIc & $16 \mathrm{~B}-2$ & Piece esquillee & \\
\hline E20/S74 & 2 & & IIIc & $16 \mathrm{~B}-1$ & Projectile point, Ensor & \\
\hline E20/S74 & 3 & & IIIc & $16 \mathrm{C}-3$ & Biface fragment & \\
\hline E20/S74 & 3 & & IIIC & $16 \mathrm{C}-4$ & Biface Stage 3 & \\
\hline E20/S74 & 3 & & IIIc & $16 \mathrm{C}-10$ & Burin spall & \\
\hline $\mathrm{E} 20 / \mathrm{S} 74$ & 3 & & IIIc & $16 \mathrm{C}-6$ & Burin spall & \\
\hline E20/S74 & 3 & & IIIc & & Debitage & 430 \\
\hline $\mathrm{E} 20 / \mathrm{S} 74$ & 3 & & IIIc & $16 \mathrm{C}-11$ & Edge modified flake & \\
\hline E20/S74 & 3 & & IIIc & $16 \mathrm{C}-7$ & Edge modified flake & \\
\hline E20/S74 & 3 & & IIIc & $16 \mathrm{C}-8$ & Microspur/microdenticulate & \\
\hline $\mathrm{E} 20 / \mathrm{S} 74$ & 3 & & IIIc & $16 \mathrm{C}-1$ & Projectile point, Ensor & \\
\hline E20/S74 & 3 & & IIIc & $16 \mathrm{C}-2$ & Stone pipe & \\
\hline E20/S74 & 3 & & IIIc & $16 \mathrm{C}-5$ & Thin uniface & \\
\hline E20/S74 & 3 & & IIIc & $16 C-9$ & Thin uniface fragment & \\
\hline E20/S74 & 4 & & IIIc & $16 \mathrm{D}-2$ & Biface Stage 2 & \\
\hline
\end{tabular}




\begin{tabular}{|c|c|c|c|c|c|}
\hline Square & Level & Feature & Strata & Item & Analyst Identification \\
\hline $\mathrm{E} 20 / \mathrm{S} 74$ & 4 & & IIIc & $16 \mathrm{D}-1$ & Burin \\
\hline $\mathrm{E} 20 / \mathrm{S} 74$ & 4 & & IIIc & & Debitage \\
\hline $\mathrm{E} 20 / \mathrm{S} 74$ & 4 & & IIIc & $16 \mathrm{D}-6$ & Edge modified flake \\
\hline E20/S74 & 4 & & IIIc & $16 \mathrm{D}-5$ & Edge modified flake \\
\hline E20/S74 & 4 & & IIIC & $16 \mathrm{D}-4$ & Projectile point fragment \\
\hline E20/S74 & 4 & & IIIc & $16 \mathrm{D}-7$ & Spurred flake \\
\hline $\mathrm{E} 20 / \mathrm{S} 74$ & 4 & & IIIc & $16 \mathrm{D}-3$ & Thick uniface \\
\hline $\mathrm{E} 20 / \mathrm{S} 74$ & 5 & & IIIc & $16 \mathrm{E}-5$ & Biface fragment \\
\hline E20/S74 & 5 & & IIIc & $16 \mathrm{E}-6$ & Biface Stage 3 \\
\hline $\mathrm{E} 20 / \mathrm{S} 74$ & 5 & & IIIc & $16 \mathrm{E}-4$ & Bifacial tool Form $\mathrm{F}$ \\
\hline $\mathrm{E} 20 / \mathrm{S} 74$ & 5 & & IIIc & & Debitage \\
\hline E20/S74 & 5 & & IIIc & $16 \mathrm{E}-7$ & Edge modified flake \\
\hline E20/S74 & 5 & & IIIc & $16 \mathrm{E}-1$ & Projectile point, Bell/Andice \\
\hline $\mathrm{E} 20 / \mathrm{S} 74$ & 5 & & IIIc & $16 \mathrm{E}-3$ & Projectile point, Bulverde-like \\
\hline E20/S74 & 5 & & IIIc & $16 \mathrm{E}-2$ & Projectile point, Castroville \\
\hline E20/S74 & 6 & & IIIC & $16 \mathrm{~F}-2$ & Biface fragment \\
\hline $\mathrm{E} 20 / \mathrm{S} 74$ & 6 & & IIIc & & Debitage \\
\hline E20/S74 & 6 & & IIIc & $16 \mathrm{~F}-3$ & Edge modified flake \\
\hline E20/S74 & 7 & & IIIc & $16 \mathrm{G}-5$ & Biface fragment \\
\hline E20/S74 & 7 & & IIIc & $16 \mathrm{G}-3$ & Biface fragment \\
\hline $\mathrm{E} 20 / \mathrm{S} 74$ & 7 & & IIIc & $16 \mathrm{G}-6$ & Biface Stage 2 \\
\hline E20/S74 & 7 & & IIIc & $16 \mathrm{G}-4$ & Biface Stage 2 \\
\hline E20/S74 & 7 & & IIIc & $16 \mathrm{G}-2$ & Biface Stage 2 \\
\hline E20/S74 & 7 & & IIIc & $16 \mathrm{G}-7$ & Clear Fork uniface \\
\hline $\mathrm{E} 20 / \mathrm{S} 74$ & 7 & & IIIc & & Debitage \\
\hline E20/S74 & 7 & & IIIc & $16 \mathrm{G}-8$ & Denticulated flake \\
\hline E20/S74 & 7 & & IIIC & $16 \mathrm{G}-9$ & Edge modified flake \\
\hline $\mathrm{E} 20 / \mathrm{S} 74$ & 7 & & IIIc & $16 \mathrm{G}-1$ & Projectile point, Montell \\
\hline $\mathrm{E} 20 / \mathrm{S} 74$ & 8 & & $\mathrm{IIIb} / \mathrm{c}$ & $16 \mathrm{H}-9$ & Biface fragment \\
\hline $\mathrm{E} 20 / \mathrm{S} 74$ & 8 & & $\mathrm{IIIb} / \mathrm{c}$ & $16 \mathrm{H}-3$ & Biface Stage 3 \\
\hline E20/S74 & 8 & & $\mathrm{IIIb} / \mathrm{c}$ & $16 \mathrm{H}-5$ & Biface Stage 3 \\
\hline E20/S74 & 8 & & $\mathrm{IIIb} / \mathrm{c}$ & $16 \mathrm{H}-2$ & Clear Fork biface, proximal \\
\hline E20/S74 & 8 & & $\mathrm{IIIb} / \mathrm{c}$ & & Debitage \\
\hline E20/S74 & 8 & & $\mathrm{IIIb} / \mathrm{c}$ & $16 \mathrm{H}-15$ & Edge modified flake \\
\hline $\mathrm{E} 20 / \mathrm{S} 74$ & 8 & & $\mathrm{IIIb} / \mathrm{c}$ & $16 \mathrm{H}-11$ & Edge modified flake \\
\hline E20/S74 & 8 & & $\mathrm{IIIb} / \mathrm{c}$ & $16 \mathrm{H}-13$ & Edge modified flake \\
\hline E20/S74 & 8 & & $\mathrm{IIIb} / \mathrm{c}$ & $16 \mathrm{H}-14$ & Edge modified flake \\
\hline E20/S74 & 8 & & $\mathrm{IIIb} / \mathrm{c}$ & $16 \mathrm{H}-10$ & Edge modified flake \\
\hline E20/S74 & 8 & & $\mathrm{IIIb} / \mathrm{c}$ & $16 \mathrm{H}-7$ & Edge modified flake \\
\hline E20/S74 & 8 & & $\mathrm{IIIb} / \mathrm{c}$ & $16 \mathrm{H}-8$ & Notched flake \\
\hline $\mathrm{E} 20 / \mathrm{S} 74$ & 8 & & $\mathrm{IIIb} / \mathrm{c}$ & $16 \mathrm{H}-1$ & Projectile point, Bell/Andice \\
\hline E20/S74 & 8 & & $\mathrm{IIIb} / \mathrm{c}$ & $16 \mathrm{H}-4$ & Projectile point, Early Triangular \\
\hline $\mathrm{E} 20 / \mathrm{S} 74$ & 8 & & $\mathrm{IIIb} / \mathrm{c}$ & $16 \mathrm{H}-6$ & Projectile point, expanding concave A \\
\hline E20/S74 & 8 & & $\mathrm{IIIb} / \mathrm{c}$ & $16 \mathrm{H}-12$ & Uniface, unanalyzed \\
\hline E20/S74 & $9 \mathrm{~A}$ & & $\mathrm{IIIb} / \mathrm{c}$ & $16 \mathrm{I} 1-6$ & Biface Stage 3 \\
\hline E20/S74 & $9 \mathrm{~A}$ & & $\mathrm{IIIb} / \mathrm{c}$ & $1611-2$ & Bifacial tool Form A \\
\hline $\mathrm{E} 20 / \mathrm{S} 74$ & $9 \mathrm{~A}$ & & $\mathrm{IIIb} / \mathrm{c}$ & $16 \mathrm{I} 1-4$ & Core, thermal \\
\hline E20/S74 & $9 \mathrm{~A}$ & & $\mathrm{IIIb} / \mathrm{c}$ & & Debitage \\
\hline E20/S74 & $9 \mathrm{~A}$ & & $\mathrm{IIIb} / \mathrm{c}$ & $16 \mathrm{I} 1-7$ & Denticulated flake \\
\hline $\mathrm{E} 20 / \mathrm{S} 74$ & $9 \mathrm{~A}$ & & $\mathrm{IIIb} / \mathrm{c}$ & $16 \mathrm{I} 1-8$ & Edge modified flake \\
\hline $\mathrm{E} 20 / \mathrm{S} 74$ & $9 \mathrm{~A}$ & & $\mathrm{IIIb} / \mathrm{c}$ & $16 \mathrm{I} 1-1$ & Projectile point, indeterminate \\
\hline E20/S74 & $9 \mathrm{~A}$ & & $\mathrm{IIIb} / \mathrm{c}$ & $16 \mathrm{I} 1-9$ & Thick uniface \\
\hline E20/S74 & $9 \mathrm{~B}$ & & $\mathrm{IIIb} / \mathrm{c}$ & & Debitage \\
\hline E20/S74 & $10 \mathrm{~A}$ & & $\mathrm{IIIb} / \mathrm{c}$ & $16 \mathrm{~J} 1-4$ & Biface Stage 2 \\
\hline E20/S74 & $10 \mathrm{~A}$ & & $\mathrm{IIIb} / \mathrm{c}$ & $16 \mathrm{~J} 1-2$ & Bifacial tool \\
\hline E20/S74 & $10 \mathrm{~A}$ & & $\mathrm{IIIb} / \mathrm{c}$ & $16 \mathrm{~J} 1-3$ & Bifacial tool Form A \\
\hline $\mathrm{E} 20 / \mathrm{S} 74$ & $10 \mathrm{~A}$ & & $\mathrm{IIIb} / \mathrm{c}$ & & Debitage \\
\hline E20/S74 & $10 \mathrm{~A}$ & & $\mathrm{IIIb} / \mathrm{c}$ & $16 \mathrm{~J} 1-1$ & Projectile point, bifurcate stem fragment \\
\hline $\mathrm{E} 20 / \mathrm{S} 74$ & $10 \mathrm{~B}$ & & $\mathrm{IIIb} / \mathrm{c}$ & $16 \mathrm{~J} 2-3$ & Biface Stage 2 \\
\hline E20/S74 & $10 \mathrm{~B}$ & & $\mathrm{IIIb} / \mathrm{c}$ & $16 \mathrm{~J} 2-2$ & Burin \\
\hline E20/S74 & $10 \mathrm{~B}$ & & $\mathrm{IIIb} / \mathrm{c}$ & & Debitage \\
\hline $\mathrm{E} 20 / \mathrm{S} 74$ & $10 \mathrm{~B}$ & & $\mathrm{IIIb} / \mathrm{c}$ & $16 \mathrm{~J} 2-4$ & Edge modified flake \\
\hline E20/S74 & $10 \mathrm{~B}$ & & $\mathrm{IIIb} / \mathrm{c}$ & $16 \mathrm{~J} 2-1$ & Projectile point, Travis \\
\hline $\mathrm{E} 20 / \mathrm{S} 74$ & $11 \mathrm{~A}$ & & IIIb & & Debitage \\
\hline E20/S74 & $11 \mathrm{~A}$ & & IIIb & $16 \mathrm{~K} 1-8$ & Microspur/microdenticulate \\
\hline $\mathrm{E} 20 / \mathrm{S} 74$ & $11 \mathrm{~A}$ & & IIIb & $16 \mathrm{~K} 1-3$ & Notched flake \\
\hline E20/S74 & $11 \mathrm{~A}$ & & IIIb & $16 \mathrm{~K} 1-2$ & Projectile point fragment \\
\hline $\mathrm{E} 20 / \mathrm{S} 74$ & $11 \mathrm{~A}$ & & IIIb & $16 \mathrm{~K} 1-7$ & Uniface, unanalyzed \\
\hline $\mathrm{E} 20 / \mathrm{S} 74$ & $11 \mathrm{~A}$ & & IIIb & $16 \mathrm{~K} 1-9$ & Uniface, unanalyzed \\
\hline $\mathrm{E} 20 / \mathrm{S} 74$ & $11 \mathrm{~A}$ & & IIIb & $16 \mathrm{~K} 1-6$ & Uniface, unanalyzed \\
\hline E20/S74 & $11 \mathrm{~B}$ & & IIIb & & Debitage \\
\hline E20/S74 & $11 \mathrm{~B}$ & & IIIb & $16 \mathrm{~K} 2-3$ & Edge modified flake \\
\hline E20/S74 & $11 \mathrm{~B}$ & & IIIb & $16 \mathrm{~K} 2-7$ & Edge modified flake \\
\hline $\mathrm{E} 20 / \mathrm{S} 74$ & $11 \mathrm{~B}$ & & IIIb & $16 \mathrm{~K} 2-5$ & Edge modified flake \\
\hline
\end{tabular}




\begin{tabular}{|c|c|c|c|c|c|c|}
\hline Square & Level & Feature & Strata & Item & Analyst Identification & Count \\
\hline E20/S74 & $11 \mathrm{~B}$ & & IIIb & $16 \mathrm{~K} 2-2$ & Projectile point fragment & \\
\hline $\mathrm{E} 20 / \mathrm{S} 74$ & $11 \mathrm{~B}$ & & IIIb & $16 \mathrm{~K} 2-6$ & Thin uniface fragment & \\
\hline $\mathrm{E} 20 / \mathrm{S} 74$ & $11 \mathrm{~B}$ & & IIIb & $16 \mathrm{~K} 2-10$ & Uniface, unanalyzed & \\
\hline $\mathrm{E} 20 / \mathrm{S} 74$ & $11 \mathrm{~B}$ & & IIIb & $16 \mathrm{~K} 2-8$ & Uniface, unanalyzed & \\
\hline E20/S74 & $11 \mathrm{~B}$ & & IIIb & $16 \mathrm{~K} 2-4$ & Unifacial multiple tool & \\
\hline $\mathrm{E} 20 / \mathrm{S} 74$ & $11 \mathrm{~B}$ & & IIIb & $16 \mathrm{~K} 2-9$ & Unifacial multiple tool & \\
\hline $\mathrm{E} 20 / \mathrm{S} 74$ & $11 \mathrm{~B}$ & Feature 46 & IIIb & $16 \mathrm{~K} 2-1$ & Bifacial tool Form B & \\
\hline $\mathrm{E} 20 / \mathrm{S} 74$ & $12 \mathrm{~A}$ & & IIIb & $16 \mathrm{~L} 1-1$ & Biface Stage 2 & \\
\hline E20/S74 & $12 \mathrm{~A}$ & & IIIb & & Debitage & 413 \\
\hline E20/S74 & $12 \mathrm{~A}$ & & IIIb & $16 \mathrm{~L} 1-10$ & Denticulated flake & \\
\hline E20/S74 & $12 \mathrm{~A}$ & & IIIb & $16 \mathrm{~L} 1-3$ & Edge modified flake & \\
\hline E20/S74 & $12 \mathrm{~A}$ & & IIIb & 16L1-4 & Edge modified flake & \\
\hline E20/S74 & $12 \mathrm{~A}$ & & IIIb & $16 L 1-5$ & Notched flake & \\
\hline E20/S74 & $12 \mathrm{~A}$ & & IIIb & $16 \mathrm{~L} 1-2$ & Projectile point, miscellaneous expanding stem & \\
\hline $\mathrm{E} 20 / \mathrm{S} 74$ & $12 \mathrm{~A}$ & & IIIb & $16 \mathrm{~L} 1-11$ & Thin uniface fragment & \\
\hline E20/S74 & $12 \mathrm{~A}$ & & IIIb & $16 \mathrm{~L} 1-6$ & Thin uniface fragment & \\
\hline E20/S74 & $12 \mathrm{~B}$ & & IIIb & $16 \mathrm{~L} 2-1$ & Biface Stage 2 & \\
\hline E20/S74 & $12 \mathrm{~B}$ & & IIIb & $16 \mathrm{~L} 2-3$ & Core, thermal & \\
\hline $\mathrm{E} 20 / \mathrm{S} 74$ & $12 \mathrm{~B}$ & & IIIb & & Debitage & 56 \\
\hline $\mathrm{E} 20 / \mathrm{S} 74$ & $12 \mathrm{~B}$ & & IIIl & $16 \mathrm{~L} 2-6$ & Edge modified flake & \\
\hline E20/S74 & $12 \mathrm{~B}$ & & IIIb & $16 \mathrm{~L} 2-5$ & Edge modified flake & \\
\hline E20/S74 & $12 \mathrm{~B}$ & & IIIb & 16L2-8 & Edge modified flake & \\
\hline E20/S74 & $12 \mathrm{~B}$ & & IIIb & $16 \mathrm{~L} 2-9$ & Edge modified flake & \\
\hline E20/S74 & $12 \mathrm{~B}$ & & IIIb & $16 \mathrm{~L} 2-7$ & Edge modified flake & \\
\hline E20/S74 & $12 \mathrm{~B}$ & & IIIlb & $16 \mathrm{~L} 2-2$ & Small core hammerstone & \\
\hline E20/S74 & $13 \mathrm{~A}$ & & IIIb & $16 \mathrm{M} 1-2$ & Biface fragment & \\
\hline $\mathrm{E} 20 / \mathrm{S} 74$ & $13 \mathrm{~A}$ & & IIIb & & Debitage & 341 \\
\hline E20/S74 & $13 \mathrm{~A}$ & & IIIb & $16 \mathrm{M} 1-4$ & Edge modified flake & \\
\hline $\mathrm{E} 20 / \mathrm{S} 74$ & $13 \mathrm{~A}$ & & IIIb & $16 \mathrm{M} 1-3$ & Edge modified flake & \\
\hline E20/S74 & $13 \mathrm{~A}$ & & IIIb & $16 \mathrm{M1} 1$ & Projectile point, expanding stem C & \\
\hline E20/S74 & $14 \mathrm{~A}$ & & IIIlb & $16 \mathrm{~N} 1-1$ & Burin & \\
\hline E20/S74 & $14 \mathrm{~A}$ & & IIIb & $16 \mathrm{~N} 1-3$ & Burin spall & \\
\hline $\mathrm{E} 20 / \mathrm{S} 74$ & $14 \mathrm{~A}$ & & IIIb & & Debitage & 13 \\
\hline $\mathrm{E} 20 / \mathrm{S} 74$ & $14 \mathrm{~A}$ & & IIIb & $16 \mathrm{~N} 1-2$ & Perforator Group 7 & \\
\hline $\mathrm{E} 20 / \mathrm{S} 74$ & $14 \mathrm{~A}$ & & IIIl & $16 \mathrm{~N} 1-4$ & Thin uniface & \\
\hline $\mathrm{E} 20 / \mathrm{S} 74$ & 14B & & $\mathrm{IIIa} / \mathrm{b}$ & $16 \mathrm{~N} 2-5$ & Biface Stage 1 & \\
\hline E20/S74 & 14B & & $\mathrm{IIIa} / \mathrm{b}$ & & Debitage & 22 \\
\hline E20/S74 & $14 \mathrm{~B}$ & & $\mathrm{IIIa} / \mathrm{b}$ & $16 \mathrm{~N} 2-6$ & Edge modified flake & \\
\hline E20/S74 & 14B & & $\mathrm{IIIa} / \mathrm{b}$ & $16 N 2-4$ & Edge modified flake & \\
\hline E20/S74 & $14 \mathrm{~B}$ & & $\mathrm{IIIa} / \mathrm{b}$ & $16 \mathrm{~N} 2-2$ & Edge modified flake & \\
\hline E20/S74 & $14 \mathrm{~B}$ & & $\mathrm{IIIa} / \mathrm{b}$ & $16 \mathrm{~N} 2-1$ & Projectile point fragment & \\
\hline E20/S74 & 14B & & $\mathrm{IIIa} / \mathrm{b}$ & $16 \mathrm{~N} 2-3$ & Unifacial multiple tool & \\
\hline $\mathrm{E} 20 / \mathrm{S} 74$ & $15 \mathrm{~A}$ & & IIIa/b & $1601-1$ & Biface Stage 2 & \\
\hline E20/S74 & $15 \mathrm{~A}$ & & IIIa $/ \mathrm{b}$ & & Debitage & \\
\hline $\mathrm{E} 20 / \mathrm{S} 74$ & $15 \mathrm{~A}$ & & $\mathrm{IIII} / \mathrm{b}$ & $1601-5$ & Edge modified flake & \\
\hline E20/S74 & $15 \mathrm{~A}$ & & $\mathrm{IIIa} / \mathrm{b}$ & $1601-6$ & Notched flake & \\
\hline E20/S74 & $15 \mathrm{~A}$ & & $\mathrm{III} a / \mathrm{b}$ & $1601-3$ & Projectile point fragment & \\
\hline E20/S74 & $15 \mathrm{~A}$ & & $\mathrm{IIIa} / \mathrm{b}$ & $1601-8$ & Uniface, unanalyzed & \\
\hline E20/S74 & $15 \mathrm{~B}$ & & IIIIa & & Debitage & \\
\hline E20/S74 & $15 \mathrm{~B}$ & & IIIa & $1602-2$ & Edge modified flake & \\
\hline E20/S74 & $15 \mathrm{~B}$ & & IIIa & $1602-5$ & Edge modified flake & \\
\hline E20/S74 & $15 \mathrm{~B}$ & & IIIa & $1602-4$ & Edge modified flake & \\
\hline E20/S74 & $15 \mathrm{~B}$ & & IIIa & $1602-1$ & Spurred flake & \\
\hline $\mathrm{E} 20 / \mathrm{S} 74$ & $15 \mathrm{~B}$ & & IIIa & $1602-3$ & Uniface, unanalyzed & \\
\hline E20/S74 & $15 \mathrm{~B}$ & & IIIa & $1602-6$ & Uniface, unanalyzed & \\
\hline E20/S74 & $15 \mathrm{~B}$ & & IIIa & $1602-8$ & Uniface, unanalyzed & \\
\hline E20/S74 & $16 \mathrm{~A}$ & & IIIa & $16 \mathrm{P} 1-4$ & Biface Stage 1 & \\
\hline E20/S74 & $16 \mathrm{~A}$ & & IIIa & $16 \mathrm{P} 1-1$ & Bifacial tool Form A & \\
\hline E20/S74 & $16 \mathrm{~A}$ & & IIIa & $16 \mathrm{P} 1-6$ & Clear Fork biface, proximal & \\
\hline E20/S74 & $16 \mathrm{~A}$ & & IIIa & & Debitage & \\
\hline E20/S74 & $16 \mathrm{~A}$ & & IIIIa & $16 \mathrm{P} 1-3$ & Edge modified flake & \\
\hline E20/S74 & $16 \mathrm{~A}$ & & IIIa & $16 \mathrm{P} 1-5$ & Unifacial multiple tool & \\
\hline $\mathrm{E} 20 / \mathrm{S} 74$ & $16 \mathrm{~A}$ & & IIIa & $16 \mathrm{P} 1-2$ & Unifacial multiple tool & \\
\hline E20/S74 & $16 \mathrm{~A}-\mathrm{B}$ & & IIIa & & Debitage & \\
\hline $\mathrm{E} 20 / \mathrm{S} 74$ & $16 \mathrm{~A}-\mathrm{B}$ & & IIIa & $16 \mathrm{P} 1 \& 2-1$ & Thick uniface fragment & \\
\hline E20/S74 & $16 \mathrm{~A}-\mathrm{B}$ & & IIIa & $16 \mathrm{P} 1 \& 2-2$ & Thin uniface & \\
\hline E20/S74 & $16 \mathrm{~A}-\mathrm{B}$ & & IIIa & $16 \mathrm{P} 1 \& 2-3$ & Unifacial multiple tool & \\
\hline E20/S74 & $16 \mathrm{~B}$ & & IIIa & $16 \mathrm{P} 2-7$ & Biface fragment & \\
\hline E20/S74 & $16 \mathrm{~B}$ & & IIIa & $16 \mathrm{P} 2-1$ & Biface Stage 2 & \\
\hline E20/S74 & $16 \mathrm{~B}$ & & IIIa & $16 \mathrm{P} 2-2$ & Burin spall & \\
\hline E20/S74 & $16 \mathrm{~B}$ & & IIIa & & Debitage & 353 \\
\hline E20/S74 & $16 \mathrm{~B}$ & & IIIa & $16 \mathrm{P} 2-3$ & Edge modified flake & \\
\hline E20/S74 & $16 \mathrm{~B}$ & & IIIa & $16 P 2-6$ & Edge modified flake & \\
\hline E20/S74 & $16 \mathrm{~B}$ & & IIIa & $16 \mathrm{P} 2-4$ & Microspur/microdenticulate & \\
\hline
\end{tabular}




\begin{tabular}{|c|c|c|c|c|c|}
\hline Square & Level & Feature & Strata & Item & Analyst Identification \\
\hline $\mathrm{E} 20 / \mathrm{S} 74$ & $16 \mathrm{~B}$ & & IIIa & $16 \mathrm{P} 2-5$ & Unifacial multiple tool \\
\hline $\mathrm{E} 20 / \mathrm{S} 74$ & $17 \mathrm{~A}$ & & IIIa & 16Q1-8 & Biface fragment \\
\hline $\mathrm{E} 20 / \mathrm{S} 74$ & $17 \mathrm{~A}$ & & IIIa & $16 Q 1-4$ & Biface Stage 1 \\
\hline $\mathrm{E} 20 / \mathrm{S} 74$ & $17 \mathrm{~A}$ & & IIIa & 16Q1-2 & Biface Stage 1 \\
\hline E20/S74 & $17 \mathrm{~A}$ & & IIIa & 16Q1-1 & Biface Stage 2 \\
\hline $\mathrm{E} 20 / \mathrm{S} 74$ & $17 \mathrm{~A}$ & & IIIa & & Debitage \\
\hline $\mathrm{E} 20 / \mathrm{S} 74$ & $17 \mathrm{~A}$ & & IIIa & 16Q1-3 & Edge modified flake \\
\hline $\mathrm{E} 20 / \mathrm{S} 74$ & $17 \mathrm{~A}$ & & IIIa & $16 \mathrm{Q} 1-6$ & Edge modified flake \\
\hline $\mathrm{E} 20 / \mathrm{S} 74$ & $17 \mathrm{~A}$ & & IIIa & 16Q1-10 & Microspur/microdenticulate \\
\hline $\mathrm{E} 20 / \mathrm{S} 74$ & $17 \mathrm{~A}$ & & IIIa & 16Q1-7 & Spurred flake \\
\hline $\mathrm{E} 20 / \mathrm{S} 74$ & $17 \mathrm{~A}$ & & IIIa & 16Q1-9 & Thin uniface fragment \\
\hline $\mathrm{E} 20 / \mathrm{S} 74$ & $17 \mathrm{~A}$ & & IIIa & $16 \mathrm{Q} 1-5$ & Uniface, unanalyzed \\
\hline $\mathrm{E} 20 / \mathrm{S} 74$ & 17B & & IIIa & & Debitage \\
\hline $\mathrm{E} 20 / \mathrm{S} 74$ & $17 \mathrm{~B}$ & & IIIa & 16Q2-8 & Edge modified flake \\
\hline E20/S74 & $17 \mathrm{~B}$ & & IIIa & $16 Q 2-5$ & Edge modified flake \\
\hline E20/S74 & $17 \mathrm{~B}$ & & IIIa & $16 \mathrm{Q} 2-2$ & Projectile point fragment \\
\hline $\mathrm{E} 20 / \mathrm{S} 74$ & $17 \mathrm{~B}$ & & IIIa & 16Qे2-1 & Projectile point, bifurcate stem fragment \\
\hline $\mathrm{E} 20 / \mathrm{S} 74$ & $17 \mathrm{~B}$ & & IIIa & 16Q2-9 & Thick uniface \\
\hline $\mathrm{E} 20 / \mathrm{S} 74$ & $17 \mathrm{~B}$ & & IIIa & $16 Q 2-10$ & Thin uniface \\
\hline $\mathrm{E} 20 / \mathrm{S} 74$ & $17 \mathrm{~B}$ & & IIIa & 16Q2-4 & Uniface, unanalyzed \\
\hline $\mathrm{E} 20 / \mathrm{S} 74$ & $17 \mathrm{~B}$ & & IIIa & $16 Q 2-7$ & Unifacial multiple tool \\
\hline $\mathrm{E} 20 / \mathrm{S} 74$ & $18 \mathrm{~A}$ & & IIIa & $16 \mathrm{R} 1-2$ & Burin spall \\
\hline E20/S74 & $18 \mathrm{~A}$ & & IIIa & & Debitage \\
\hline E20/S74 & $18 \mathrm{~A}$ & & IIIa & $16 \mathrm{R} 1-5$ & Edge modified flake \\
\hline E20/S74 & $18 \mathrm{~A}$ & & IIIa & $16 \mathrm{R} 1-3$ & Edge modified flake \\
\hline E20/S74 & $18 \mathrm{~A}$ & & IIIa & 16R1-1 & Microspur/microdenticulate \\
\hline $\mathrm{E} 20 / \mathrm{S} 74$ & $18 \mathrm{~A}$ & & IIIa & $16 \mathrm{R} 1-7$ & Microspur/microdenticulate \\
\hline $\mathrm{E} 20 / \mathrm{S} 74$ & $18 \mathrm{~A}$ & & IIIa & $16 \mathrm{R} 1-6$ & Microspur/microdenticulate \\
\hline E20/S74 & $18 \mathrm{~A}$ & & IIIa & $16 \mathrm{R} 1-8$ & Thin uniface \\
\hline E20/S74 & $18 \mathrm{~A}$ & & IIIa & $16 \mathrm{R} 1-4$ & Unifacial multiple tool \\
\hline $\mathrm{E} 20 / \mathrm{S} 74$ & $18 \mathrm{~B}$ & & IIIa & $16 \mathrm{R} 2-4$ & Biface fragment \\
\hline E20/S74 & $18 \mathrm{~B}$ & & IIIa & $16 \mathrm{R} 2-8$ & Bifacial tool Form A \\
\hline E20/S74 & $18 \mathrm{~B}$ & & IIIa & $16 \mathrm{R} 2-3$ & Bifacial tool Form J \\
\hline $\mathrm{E} 20 / \mathrm{S} 74$ & $18 \mathrm{~B}$ & & IIIa & $16 \mathrm{R} 2-5$ & Burin spall \\
\hline E20/S74 & $18 \mathrm{~B}$ & & IIIa & $16 \mathrm{R} 2-6$ & Clear Fork biface \\
\hline E20/S74 & $18 \mathrm{~B}$ & & IIIIa & & Debitage \\
\hline E20/S74 & $18 \mathrm{~B}$ & & IIIa & $16 \mathrm{R} 2-9$ & Denticulated flake \\
\hline E20/S74 & $18 \mathrm{~B}$ & & IIIa & $16 \mathrm{R} 2-10$ & Edge modified flake \\
\hline E20/S74 & $18 \mathrm{~B}$ & & IIIa & $16 \mathrm{R} 2-12$ & Edge modified flake \\
\hline $\mathrm{E} 20 / \mathrm{S} 74$ & $18 \mathrm{~B}$ & & IIIa & $16 \mathrm{R} 2-2$ & Projectile point, Gower/Jetta \\
\hline $\mathrm{E} 20 / \mathrm{S} 74$ & $18 \mathrm{~B}$ & & IIIa & $16 \mathrm{R} 2-1$ & Projectile point, Hoxie \\
\hline E20/S74 & $18 \mathrm{~B}$ & & IIIa & 16R2-11 & Unifacial multiple tool \\
\hline E20/S74 & $18 \mathrm{~B}$ & & IIIa & $16 \mathrm{R} 2-13$ & Unifacial multiple tool \\
\hline $\mathrm{E} 20 / \mathrm{S} 74$ & $19-20$ & & II/IIIa & & Debitage \\
\hline E20/S74 & $19 \mathrm{~A}$ & & IIIa & $16 \mathrm{~S} 1-3$ & Biface Stage 2 \\
\hline $\mathrm{E} 20 / \mathrm{S} 74$ & $19 \mathrm{~A}$ & & IIIa & $16 \mathrm{~S} 1-1$ & Biface Stage 3 \\
\hline $\mathrm{E} 20 / \mathrm{S} 74$ & $19 \mathrm{~A}$ & & IIIa & & Debitage \\
\hline E20/S74 & $19 \mathrm{~A}$ & & IIIa & $16 S 1-2$ & Edge modified flake \\
\hline E20/S74 & 19A & & IIIa & $16 \mathrm{~S} 1-3 \mathrm{a}$ & Spurred flake \\
\hline $\mathrm{E} 20 / \mathrm{S} 74$ & $19 \mathrm{~A}$ & & IIIa & $16 \mathrm{~S} 1-4$ & Thick uniface \\
\hline $\mathrm{E} 20 / \mathrm{S} 74$ & 19B & & IIIa & & Debitage \\
\hline $\mathrm{E} 20 / \mathrm{S} 74$ & $19 \mathrm{~B}$ & & IIIa & $16 S 2-5$ & Edge modified flake \\
\hline $\mathrm{E} 20 / \mathrm{S} 74$ & $19 \mathrm{~B}$ & & IIIa & $16 \mathrm{~S} 2-9$ & Microspur/microdenticulate \\
\hline $\mathrm{E} 20 / \mathrm{S} 74$ & 19B & & IIIa & $16 S 2-1$ & Projectile point, Angostura \\
\hline $\mathrm{E} 20 / \mathrm{S} 74$ & 19B & & IIIa & $16 \mathrm{~S} 2-2$ & Projectile point, St. Mary's Hall \\
\hline E20/S74 & $19 \mathrm{~B}$ & & IIIa & $16 \mathrm{~S} 2-3$ & Uniface, unanalyzed \\
\hline E20/S74 & 19B & & IIIa & $16 S 2-6$ & Uniface, unanalyzed \\
\hline E20/S74 & $19 \mathrm{~B}$ & & IIIa & $16 S 2-4$ & Uniface, unanalyzed \\
\hline E20/S74 & 19B & & IIIa & $16 \mathrm{~S} 2-8$ & Unifacial multiple tool \\
\hline E20/S74 & $20 \mathrm{~A}$ & & II/IIIa & $16 \mathrm{~T} 1-3$ & Biface fragment \\
\hline E20/S74 & $20 \mathrm{~A}$ & & II/IIIa & 16T1-2 & Biface fragment \\
\hline E20/S74 & $20 \mathrm{~A}$ & & II/IIIa & $16 \mathrm{~T} 1-5$ & Clear Fork biface \\
\hline E20/S74 & $20 \mathrm{~A}$ & & II/IIIa & & Debitage \\
\hline E20/S74 & $20 \mathrm{~A}$ & & II/IIIa & $16 \mathrm{~T} 1-6$ & Edge modified flake \\
\hline E20/S74 & $20 \mathrm{~A}$ & & II/IIIa & 16T1-1 & Projectile point, Angostura \\
\hline E20/S74 & $20 \mathrm{~A}$ & & II/IIIa & $16 \mathrm{~T} 1-4$ & Thick uniface \\
\hline E20/S74 & $20 \mathrm{~B}$ & & II/IIIa & $16 \mathrm{~T} 2-2$ & Biface Stage 2 \\
\hline E20/S74 & $20 \mathrm{~B}$ & & II/IIIa & & Debitage \\
\hline $\mathrm{E} 20 / \mathrm{S} 74$ & $20 \mathrm{~B}$ & & II/IIIa & $16 \mathrm{~T} 2-4$ & Edge modified flake \\
\hline E20/S74 & $20 \mathrm{~B}$ & & II/IIIa & $16 \mathrm{~T} 2-3$ & Edge modified flake \\
\hline E20/S74 & $20 \mathrm{~B}$ & & II/IIIa & $16 \mathrm{~T} 2-1$ & Microspur/microdenticulate \\
\hline E20/S74 & $21 \mathrm{~A}$ & & II & & Debitage \\
\hline E20/S74 & $21 \mathrm{~A}$ & & II & $16 \mathrm{U} 1-1$ & Small core hammerstone \\
\hline $\mathrm{E} 20 / \mathrm{S} 74$ & $21 \mathrm{~A}$ & & II & $16 \mathrm{U} 1-3$ & Worked hematite \\
\hline
\end{tabular}

Count

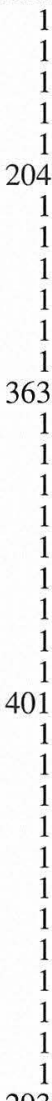

293

1

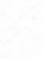

1
1
1
1
39
1
1
178
1
1
1

208

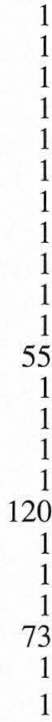




\begin{tabular}{|c|c|c|c|c|c|c|}
\hline Square & Level & Feature & Strata & Item & Analyst Identification & Count \\
\hline E20/S74 & 21B & & II & $16 \mathrm{U} 2-1$ & Bifacial tool Form A & \\
\hline E20/S74 & $21 B$ & & II & & Debitage & 116 \\
\hline $\mathrm{E} 20 / \mathrm{S} 74$ & $22 \mathrm{~A}$ & & II & & Debitage & 98 \\
\hline E20/S74 & $22 \mathrm{~A}$ & & II & $16 \mathrm{~V} 1-2$ & Edge modified flake & \\
\hline E20/S74 & $22 \mathrm{~A}$ & & II & $16 \mathrm{~V} 1-3$ & Edge modified flake & \\
\hline $\mathrm{E} 20 / \mathrm{S} 74$ & $22 \mathrm{~A}$ & & II & 16V1-1 & Unifacial multiple tool & \\
\hline $\mathrm{E} 20 / \mathrm{S} 74$ & $22 \mathrm{~B}$ & & II & & Debitage & 80 \\
\hline E20/S74 & $22 \mathrm{~B}$ & & II & $16 \mathrm{~V} 2-1$ & Thick uniface & \\
\hline E20/S74 & 22B & & II & $16 \mathrm{~V} 2-3$ & Thin uniface fragment & \\
\hline E20/S74 & 22B & & II & $16 \mathrm{~V} 2-2$ & Unifacial multiple tool & 1 \\
\hline E20/S74 & $23 \mathrm{~A}$ & & II & & Debitage & 59 \\
\hline E20/S74 & $23 \mathrm{~A}$ & & II & 16W1-2 & Projectile point fragment & 1 \\
\hline E20/S74 & 23B & & $\mathrm{Id} / \mathrm{II}$ & $16 \mathrm{~W} 2-3$ & Biface Stage 2 & \\
\hline E20/S74 & $23 \mathrm{~B}$ & & $\mathrm{Id} / \mathrm{II}$ & & Debitage & 8 \\
\hline E20/S74 & 24B & & $\mathrm{Id} / \mathrm{II}$ & & Debitage & 43 \\
\hline E20/S74 & $25 \mathrm{~A}$ & & $\mathrm{Id} / \mathrm{II}$ & & Debitage & 47 \\
\hline $\mathrm{E} 20 / \mathrm{S} 74$ & $25 \mathrm{~A}$ & & $\mathrm{Id} / \mathrm{II}$ & $16 Y 1-2$ & Edge modified flake & \\
\hline E20/S74 & $25 \mathrm{~A}$ & & $\mathrm{Id} / \mathrm{II}$ & $16 \mathrm{Y} 1-1$ & Projectile point, parallel side & \\
\hline $\mathrm{E} 20 / \mathrm{S} 74$ & $25 \mathrm{~B}$ & & Isi-c/Id/II & & Debitage & 55 \\
\hline E20/S74 & $25 \mathrm{~B}$ & & Isi-c/Id/II & $16 Y 2-1$ & Possible ground stone & 1 \\
\hline E20/S74 & $26 \mathrm{~A}$ & & Isi-c/Id/II & & Debitage & 38 \\
\hline E20/S74 & $26 \mathrm{~A}$ & & Isi-c/Id/II & $16 \mathrm{Z} 1-1$ & Edge modified flake & 1 \\
\hline E20/S74 & $26 \mathrm{~B}$ & & Isi-c/Id & & Debitage & 45 \\
\hline E20/S74 & $26 \mathrm{~B}$ & & Isi-c/Id & $16 \mathrm{Z} 2-1$ & Thin uniface fragment & 1 \\
\hline E20/S74 & $27 \mathrm{~A}$ & & Isi-c & 16AA1-1 & Biface Stage 2 & 1 \\
\hline E20/S74 & $27 \mathrm{~A}$ & & Isi-c & & Debitage & 35 \\
\hline E20/S74 & $27 \mathrm{~A}$ & & Isi-c & 16AA1-2 & Thick uniface fragment & 1 \\
\hline E20/S74 & $27 \mathrm{~B}$ & & Isi-c & & Debitage & 47 \\
\hline E20/S74 & 27B & & Isi-c & 16AA2-1 & Perforator Group 4 & 1 \\
\hline E20/S74 & $28 \mathrm{~A}$ & & Isi-c & & Debitage & 51 \\
\hline E20/S74 & $28 \mathrm{~A}$ & & Isi-c & 16BB1-1 & Projectile point, miscellaneous lanceolate & 1 \\
\hline E20/S74 & $29 \mathrm{~A}$ & & Isi/Icl/Isi-c & & Debitage & 27 \\
\hline E20/S74 & 29B & & Isi/Icl/Isi-c & $16 \mathrm{CC} 2-1$ & Core fragment & \\
\hline E20/S74 & $29 B$ & & Isi/Icl/Isi-c & & Debitage & 37 \\
\hline E20/S74 & $30 \mathrm{~A}$ & & Isi/Icl/Isi-c & & Debitage & 21 \\
\hline E20/S74 & $30 \mathrm{~A}$ & & Isi/Icl/Isi-c & 16DD1-1 & Edge modified flake & 1 \\
\hline E20/S74 & $31 \mathrm{~A}$ & Burial 2 & Isi/Icl/Isi-c & & Debitage & \\
\hline E20/S74 & $31 \mathrm{~B}$ & Burial 2 & Isi/Icl/Isi-c & & Debitage & $x$ \\
\hline E20/S74 & $32 \mathrm{~A}$ & & Isi/Icl & & Debitage & 3 \\
\hline E20/S74 & $32 \mathrm{~A}$ & Burial 2 & Isi/Icl/Isi-c & & Debitage & 1 \\
\hline E20/S74 & $32 \mathrm{~B}$ & & Isi/Icl & 16FF2B-1 & Biface fragment & \\
\hline E20/S74 & $32 \mathrm{~B}$ & & Isi/Icl & $16 \mathrm{FF} 2 \mathrm{~B}-2$ & Biface fragment & \\
\hline E20/S74 & 32B & & Isi/Icl & & Debitage & 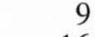 \\
\hline E20/S74 & $33 \mathrm{~A}$ & & Isi/Icl & & Debitage & 16 \\
\hline E20/S74 & $33 \mathrm{~B}$ & & Isi/Icl & & Debitage & 12 \\
\hline E20/S74 & $34 \mathrm{~A}$ & & Isi/Icl & & Debitage & 25 \\
\hline E20/S74 & $34 \mathrm{~A}$ & & Isi/Icl & 16HH1B-1 & Uniface, unanalyzed & \\
\hline E20/S74 & $34 \mathrm{~B}$ & & Isi/Icl & $16 \mathrm{HH} 2 \mathrm{~B}-1$ & Burin spall & 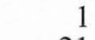 \\
\hline E20/S74 & $34 \mathrm{~B}$ & & $\mathrm{Isi} / \mathrm{Icl}$ & & Debitage & 21 \\
\hline E20/S74 & 34B & & Isi/Icl & $16 \mathrm{HH} 2 \mathrm{D}-3$ & Thick uniface & \\
\hline E20/S74 & $34 \mathrm{~B}$ & & Isi/Icl & $16 \mathrm{HH} 2 \mathrm{C}-2$ & Uniface, unanalyzed & \\
\hline E20/S74 & $35 \mathrm{~A}$ & & Isi & 16II1B-1 & Biface Stage 1 & \\
\hline E20/S74 & $35 \mathrm{~A}$ & & Isi & & Debitage & 21 \\
\hline E20/S74 & $35 \mathrm{~A}$ & & Isi & 16II1D-3 & Edge modified flake & 1 \\
\hline E20/S74 & $35 \mathrm{~A}$ & & Isi & $16111 \mathrm{C}-2$ & Thin uniface & \\
\hline E20/S74 & $35 \mathrm{~B}$ & & Isi & & Debitage & 2 \\
\hline E20/S74 & $35 \mathrm{~B}$ & & Isi & 16II2B-1 & Edge modified flake & 1 \\
\hline E20/S74 & $35 \mathrm{~B}$ & & Isi & $16 \mathrm{II} 2 \mathrm{C}-2$ & Edge modified flake & \\
\hline E20/S74 & $36 \mathrm{~A}$ & & Isi & & Debitage & 11 \\
\hline E20/S74 & $36 \mathrm{~A}$ & & Isi & $16 \mathrm{JJ} 1 \mathrm{~A}-1$ & Edge modified flake & \\
\hline E20/S74 & $36 \mathrm{~B}$ & & Isi & & Debitage & \\
\hline E20/S74 & $36 \mathrm{~B}$ & & Isi & $16 \mathrm{JJ} 2 \mathrm{~A}-1$ & Retouched blade & \\
\hline E20/S74 & $37 \mathrm{~A}$ & & Isi & & Debitage & 2 \\
\hline E20/S74 & Unknown & Burial 2 & Isi/Icl/Isi-c & FBU2-1 & Ground stone tool & \\
\hline E20/S76 & 1 & & IIIc & $15 \mathrm{~A}-3$ & Biface fragment & \\
\hline E20/S76 & 1 & & IIIIc & $15 \mathrm{~A}-2$ & Biface fragment & \\
\hline E20/S76 & 1 & & IIIIc & & Debitage & 299 \\
\hline E20/S76 & 1 & & IIIIc & $15 \mathrm{~A}-5$ & Denticulated flake & \\
\hline E20/S76 & 1 & & IIIIc & $15 \mathrm{~A}-9$ & Edge modified flake & 1 \\
\hline E20/S76 & 1 & & IIIc & $15 \mathrm{~A}-13$ & Edge modified flake & \\
\hline E20/S76 & 1 & & IIIc & $15 \mathrm{~A}-12$ & Edge modified flake & \\
\hline E20/S76 & 1 & & IIIc & $15 \mathrm{~A}-4$ & Edge modified flake & \\
\hline $\begin{array}{l}\text { E20/S76 } \\
\text { E20/S76 }\end{array}$ & 1 & & $\begin{array}{l}\text { IIII } \\
\text { IIIc }\end{array}$ & $\begin{array}{l}15 \mathrm{~A}-8 \\
15 \mathrm{~A}-6\end{array}$ & $\begin{array}{l}\text { Edge modified flake } \\
\text { Edge modified flake }\end{array}$ & \\
\hline
\end{tabular}




\begin{tabular}{|c|c|c|c|c|c|c|}
\hline Square & Level & Feature & Strata & Item & Analyst Identification & Count \\
\hline E20/S76 & 1 & & IIIc & $15 \mathrm{~A}-7$ & Edge modified flake & 1 \\
\hline $\mathrm{E} 20 / \mathrm{S} 76$ & 1 & & IIIC & $15 \mathrm{~A}-1$ & Uniface, unanalyzed & 1 \\
\hline E20/S76 & 1 & & IIIc & $15 \mathrm{~A}-10$ & Uniface, unanalyzed & 1 \\
\hline E20/S76 & 1 & & IIIc & $15 \mathrm{~A}-11$ & Uniface, unanalyzed & 1 \\
\hline E20/S76 & 2 & & IIIc & $15 \mathrm{~B}-8$ & Biface Stage 2 & 1 \\
\hline E20/S76 & 2 & & IIIC & $15 \mathrm{~B}-3$ & Biface Stage 2 & 1 \\
\hline E20/S76 & 2 & & IIIc & & Debitage & 345 \\
\hline E20/S76 & 2 & & IIIC & $15 \mathrm{~B}-6$ & Edge modified flake & 1 \\
\hline E20/S76 & 2 & & IIIc & $15 B-7$ & Edge modified flake & 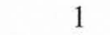 \\
\hline E20/S76 & 2 & & IIIc & $15 \mathrm{~B}-1$ & Edge modified flake & \\
\hline E20/S76 & 2 & & IIII & $15 B-5$ & Notched flake & 1 \\
\hline E20/S76 & 2 & & IIIc & $15 \mathrm{~B}-4$ & Projectile point, Ensor & 1 \\
\hline E20/S76 & 3 & & IIIC & $15 \mathrm{C}-4$ & Biface fragment & 1 \\
\hline E20/S76 & 3 & & IIIc & $15 \mathrm{C}-2$ & Biface fragment & 1 \\
\hline E20/S76 & 3 & & IIIc & $15 \mathrm{C}-1$ & Biface fragment & \\
\hline E20/S76 & 3 & & IIIc & $15 \mathrm{C}-3$ & Biface Stage 2 & \\
\hline E20/S76 & 3 & & IIIC & $15 \mathrm{C}-7$ & Core, multidirectional & $x$ \\
\hline E20/S76 & 3 & & IIIc & $15 \mathrm{C}-6$ & Core, thermal & 1 \\
\hline E20/S76 & 3 & & IIIc & & Debitage & 363 \\
\hline E20/S76 & 3 & & IIIc & $15 \mathrm{C}-8$ & Edge modified flake & 1 \\
\hline E20/S76 & 4 & & IIIc & $15 \mathrm{D}-5$ & Biface Stage 2 & \\
\hline E20/S76 & 4 & & IIIc & $15 \mathrm{D}-4$ & Biface Stage 2 & $x$ \\
\hline E20/S76 & 4 & & IIIc & $15 \mathrm{D}-1$ & Biface Stage 3 & 1 \\
\hline E20/S76 & 4 & & IIIc & $15 \mathrm{D}-7$ & Burin & 1 \\
\hline E20/S76 & 4 & & IIII & & Debitage & 637 \\
\hline E20/S76 & 4 & & IIIc & $15 \mathrm{D}-11$ & Edge modified flake & 1 \\
\hline E20/S76 & 4 & & IIIc & $15 \mathrm{D}-16$ & Edge modified flake & 1 \\
\hline E20/S76 & 4 & & IIIC & $15 \mathrm{D}-8$ & Edge modified flake & 1 \\
\hline E20/S76 & 4 & & IIIC & $15 \mathrm{D}-12$ & Edge modified flake & 1 \\
\hline E20/S76 & 4 & & IIIC & 15D-17 & Edge modified flake & \\
\hline E20/S76 & 4 & & IIIc & $15 \mathrm{D}-2$ & Projectile point, Bulverde & 1 \\
\hline E20/S76 & 4 & & IIIc & $15 \mathrm{D}-3$ & Projectile point, Ensor & \\
\hline E20/S76 & 4 & & IIIC & $15 \mathrm{D}-9$ & Spurred flake & 1 \\
\hline E20/S76 & 4 & & IIIc & $15 \mathrm{D}-6$ & Uniface, unanalyzed & \\
\hline E20/S76 & 4 & & IIIC & $15 \mathrm{D}-15$ & Uniface, unanalyzed & 1 \\
\hline E20/S76 & 4 & & IIIc & $15 \mathrm{D}-10$ & Uniface, unanalyzed & 1 \\
\hline E20/S76 & 4 & & IIIc & $15 \mathrm{D}-18$ & Unifacial multiple tool & \\
\hline E20/S76 & 5 & & IIIc & $15 \mathrm{E}-3$ & Biface fragment & \\
\hline E20/S76 & 5 & & IIIIc & $15 \mathrm{E}-4$ & Biface Stage 1 & 1 \\
\hline E20/S76 & 5 & & IIIc & $15 \mathrm{E}-6$ & Biface Stage 3 & 1 \\
\hline E20/S76 & 5 & & IIIc & $15 \mathrm{E}-2$ & Bifacial tool Form B & \\
\hline E20/S76 & 5 & & IIIc & & Debitage & 481 \\
\hline E20/S76 & 5 & & IIIc & $15 \mathrm{E}-15$ & Edge modified flake & 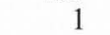 \\
\hline E20/S76 & 5 & & IIII & $15 \mathrm{E}-10$ & Edge modified flake & 1 \\
\hline E20/S76 & 5 & & IIIc & $15 \mathrm{E}-12$ & Edge modified flake & \\
\hline E20/S76 & 5 & & IIIc & $15 \mathrm{E}-19$ & Edge modified flake & \\
\hline E20/S76 & 5 & & IIIc & $15 \mathrm{E}-16$ & Edge modified flake & \\
\hline $\mathrm{E} 20 / \mathrm{S} 76$ & 5 & & IIIc & $15 \mathrm{E}-17$ & Edge modified flake & 1 \\
\hline $\mathrm{E} 20 / \mathrm{S} 76$ & 5 & & IIIc & $15 \mathrm{E}-9$ & Edge modified flake & \\
\hline E20/S76 & 5 & & IIIc & $15 \mathrm{E}-20$ & Edge modified flake & 1 \\
\hline E20/S76 & 5 & & IIIc & $15 \mathrm{E}-1$ & Projectile point fragment & \\
\hline E20/S76 & 5 & & IIIC & $15 \mathrm{E}-7$ & Projectile point fragment & \\
\hline E20/S76 & 5 & & IIIC & $15 \mathrm{E}-5$ & Uniface, unanalyzed & 1 \\
\hline E20/S76 & 5 & & IIIC & $15 \mathrm{E}-21$ & Uniface, unanalyzed & \\
\hline E20/S76 & 5 & & IIIC & $15 \mathrm{E}-18$ & Unifacial multiple tool & \\
\hline E20/S76 & 6 & & IIIc & $15 \mathrm{~F}-4$ & Biface fragment & \\
\hline $\mathrm{E} 20 / \mathrm{S} 76$ & 6 & & IIIc & $15 \mathrm{~F}-7$ & Biface Stage 2 & \\
\hline $\mathrm{E} 20 / \mathrm{S} 76$ & 6 & & IIIC & & Debitage & 625 \\
\hline E20/S76 & 6 & & IIIc & $15 \mathrm{~F}-10$ & Edge modified flake & \\
\hline E20/S76 & 6 & & IIIC & $15 \mathrm{~F}-6$ & Projectile point fragment & \\
\hline $\mathrm{E} 20 / \mathrm{S} 76$ & 6 & & IIIC & $15 \mathrm{~F}-1$ & Projectile point, Bell/Andice & \\
\hline $\mathrm{E} 20 / \mathrm{S} 76$ & 6 & & IIIC & $15 \mathrm{~F}-2$ & Projectile point, Bulverde & 1 \\
\hline E20/S76 & 6 & & IIIc & $15 \mathrm{~F}-3$ & Projectile point, Montell & \\
\hline E20/S76 & 6 & & IIII & $15 \mathrm{~F}-5$ & Projectile point, rectangular stem A & \\
\hline E20/S76 & 6 & & IIIc & $15 \mathrm{~F}-8$ & Uniface, unanalyzed & \\
\hline $\mathrm{E} 20 / \mathrm{S} 76$ & 6 & & IIIC & $15 \mathrm{~F}-9$ & Unifacial multiple tool & 1 \\
\hline E20/S76 & 7 & & IIIc & $15 \mathrm{G}-9$ & Biface fragment & \\
\hline E20/S76 & 7 & & IIIc & $15 \mathrm{G}-10$ & Biface fragment & . \\
\hline E20/S76 & 7 & & IIII & $15 \mathrm{G}-12$ & Biface Stage 2 & \\
\hline E20/S76 & 7 & & IIIC & $15 \mathrm{G}-6$ & Biface Stage 2 & \\
\hline E20/S76 & 7 & & IIIC & $15 \mathrm{G}-7$ & Biface Stage 2 & 1 \\
\hline E20/S76 & 7 & & IIIc & $15 \mathrm{G}-5$ & Biface Stage 2 & \\
\hline E20/S76 & 7 & & IIIC & $15 \mathrm{G}-11$ & Clear Fork biface & 1 \\
\hline E20/S76 & 7 & & IIIc & & Debitage & 53 \\
\hline
\end{tabular}




\begin{tabular}{|c|c|c|c|c|c|c|}
\hline Square & Level & Feature & Strata & Item & Analyst Identification & Count \\
\hline E20/S76 & 7 & & IIIIc & $15 \mathrm{G}-27$ & Indeterminate ground stone & \\
\hline E20/S76 & 7 & & IIIc & $15 \mathrm{G}-28$ & Indeterminate ground stone & 1 \\
\hline E20/S76 & 7 & & IIIc & $15 \mathrm{G}-3$ & Projectile point, Bulverde & 1 \\
\hline E20/S76 & 7 & & IIIc & $15 \mathrm{G}-2$ & Projectile point, Bulverde & 1 \\
\hline $\mathrm{E} 20 / \mathrm{S} 76$ & 7 & & IIIc & $15 \mathrm{G}-4$ & Projectile point, Nolan & 1 \\
\hline $\mathrm{E} 20 / \mathrm{S} 76$ & 7 & & IIIc & $15 \mathrm{G}-1$ & Projectile point, Thrall & 1 \\
\hline E20/S76 & 7 & & IIIc & $15 \mathrm{G}-8$ & Thin uniface fragment & 1 \\
\hline E20/S76 & 8 & & $\mathrm{IIIb} / \mathrm{c}$ & $15 \mathrm{H}-10$ & Biface Stage 2 & 1 \\
\hline E20/S76 & 8 & & $\mathrm{IIIb} / \mathrm{c}$ & $15 \mathrm{H}-4$ & Biface Stage 3 & 1 \\
\hline $\mathrm{E} 20 / \mathrm{S} 76$ & 8 & & $\mathrm{IIIb} / \mathrm{c}$ & & Debitage & 395 \\
\hline E20/S76 & 8 & & $\mathrm{IIIb} / \mathrm{c}$ & $15 \mathrm{H}-11$ & Edge modified flake & 1 \\
\hline E20/S76 & 8 & & IIIb/c & $15 \mathrm{H}-12$ & Edge modified flake & 1 \\
\hline $\mathrm{E} 20 / \mathrm{S} 76$ & 8 & & $\mathrm{IIIb} / \mathrm{c}$ & $15 \mathrm{H}-13$ & Edge modified flake & 1 \\
\hline E20/S76 & 8 & & $\mathrm{IIIb} / \mathrm{c}$ & $15 \mathrm{H}-14$ & Edge modified flake & 1 \\
\hline E20/S76 & 8 & & $\mathrm{IIIb} / \mathrm{c}$ & $15 \mathrm{H}-5$ & Metate fragment & 1 \\
\hline E20/S76 & 8 & & IIIb/c & $15 \mathrm{H}-6$ & Perforator Group 5 & 1 \\
\hline E20/S76 & 8 & & $\mathrm{IIIb} / \mathrm{c}$ & $15 \mathrm{H}-1$ & Projectile point fragment & 1 \\
\hline E20/S76 & 8 & & $\mathrm{IIIb} / \mathrm{c}$ & $15 \mathrm{H}-2$ & Projectile point, expanding concave D & 1 \\
\hline $\mathrm{E} 20 / \mathrm{S} 76$ & 8 & & $\mathrm{IIIb} / \mathrm{c}$ & $15 \mathrm{H}-3$ & Projectile point, Nolan & 1 \\
\hline E20/S76 & 8 & & $\mathrm{IIIb} / \mathrm{c}$ & $15 \mathrm{H}-8$ & Uniface, unanalyzed & 1 \\
\hline E20/S76 & 8 & & $\mathrm{IIIb} / \mathrm{c}$ & $15 \mathrm{H}-9$ & Unifacial multiple tool & 1 \\
\hline E20/S76 & 9A & & $\mathrm{IIIb} / \mathrm{c}$ & $15 \mathrm{I} 1-4$ & Bifacial tool Form B & 1 \\
\hline E20/S76 & $9 \mathrm{~A}$ & & IIIb/c & & Debitage & 180 \\
\hline E20/S76 & $9 \mathrm{~A}$ & & $\mathrm{IIIb} / \mathrm{c}$ & $15 \mathrm{I} 1-9$ & Edge modified flake & 1 \\
\hline E20/S76 & $9 \mathrm{~A}$ & & $\mathrm{IIIb} / \mathrm{c}$ & $15 \mathrm{I} 1-18$ & Edge modified flake & 1 \\
\hline E20/S76 & $9 \mathrm{~A}$ & & $\mathrm{IIIb} / \mathrm{c}$ & $15 \mathrm{I} 1-17$ & Edge modified flake & 1 \\
\hline E20/S76 & $9 \mathrm{~A}$ & & IIIb/c & $15 \mathrm{I} 1-16$ & Edge modified flake & 1 \\
\hline E20/S76 & $9 \mathrm{~A}$ & & $\mathrm{IIIb} / \mathrm{c}$ & $15 \mathrm{I} 1-15$ & Edge modified flake & 1 \\
\hline $\mathrm{E} 20 / \mathrm{S} 76$ & $9 \mathrm{~A}$ & & $\mathrm{IIIb} / \mathrm{c}$ & $15 \mathrm{I} 1-12$ & Edge modified flake & 1 \\
\hline E20/S76 & $9 \mathrm{~A}$ & & IIIb/c & $15 \mathrm{I} 1-8$ & Edge modified flake & 1 \\
\hline E20/S76 & $9 \mathrm{~A}$ & & $\mathrm{IIIl} / \mathrm{c}$ & $15 \mathrm{I} 1-11$ & Edge modified flake & 1 \\
\hline E20/S76 & $9 \mathrm{~A}$ & & $\mathrm{IIIb} / \mathrm{c}$ & $15 \mathrm{I} 1-13$ & Microspur/microdenticulate & 1 \\
\hline E20/S76 & $9 \mathrm{~A}$ & & $\mathrm{IIIb} / \mathrm{c}$ & $15 \mathrm{I} 1-5$ & Projectile point fragment & 1 \\
\hline $\mathrm{E} 20 / \mathrm{S} 76$ & $9 \mathrm{~A}$ & & $\mathrm{IIIb} / \mathrm{c}$ & $15 \mathrm{I} 1-2$ & Projectile point, expanding concave $\mathrm{C}$ & 1 \\
\hline E20/S76 & $9 \mathrm{~A}$ & & IIIb/c & $15 \mathrm{I} 1-1$ & Projectile point, Gower/Jetta & 1 \\
\hline E20/S76 & $9 \mathrm{~A}$ & & $\mathrm{IIIJ} / \mathrm{c}$ & $15 \mathrm{I} 1-6$ & Projectile point, square stem & 1 \\
\hline E20/S76 & $9 \mathrm{~A}$ & & $\mathrm{IIIb} / \mathrm{c}$ & $15 \mathrm{I} 1-3$ & Projectile point, Travis & 1 \\
\hline $\mathrm{E} 20 / \mathrm{S} 76$ & $9 \mathrm{~A}$ & & $\mathrm{IIIb} / \mathrm{c}$ & $15 \mathrm{I} 1-7$ & Spurred flake & 1 \\
\hline E20/S76 & $9 \mathrm{~B}$ & & $\mathrm{IIIb} / \mathrm{c}$ & $15 \mathrm{I} 2-5$ & Biface Stage 2 & 1 \\
\hline E20/S76 & 9B & & $\mathrm{IIIb} / \mathrm{c}$ & $15 \mathrm{I} 2-4$ & Biface Stage 2 & 1 \\
\hline E20/S76 & 9B & & $\mathrm{IIIb} / \mathrm{c}$ & $15 \mathrm{I} 2-6$ & Biface Stage 3 & 1 \\
\hline E20/S76 & $9 B$ & & $\mathrm{IIIb} / \mathrm{c}$ & & Debitage & 190 \\
\hline E20/S76 & $9 \mathrm{~B}$ & & $\mathrm{IIIb} / \mathrm{c}$ & $15 \mathrm{I} 2-8$ & Projectile point fragment & 1 \\
\hline $\mathrm{E} 20 / \mathrm{S} 76$ & $9 \mathrm{~B}$ & & $\mathrm{IIIb} / \mathrm{c}$ & $15 \mathrm{I} 2-3$ & Projectile point, Bulverde-like & 1 \\
\hline E20/S76 & $9 \mathrm{~B}$ & & $\mathrm{IIIb} / \mathrm{c}$ & $15 \mathrm{I} 2-1$ & Projectile point, Marcos & 1 \\
\hline E20/S76 & $9 \mathrm{~B}$ & & $\mathrm{IIIb} / \mathrm{c}$ & $15 \mathrm{I} 2-2$ & Projectile point, Williams & 1 \\
\hline E20/S76 & $10 \mathrm{~A}$ & & $\mathrm{IIIb} / \mathrm{c}$ & $15 \mathrm{~J} 1-1$ & Biface fragment & 1 \\
\hline E20/S76 & $10 \mathrm{~A}$ & & $\mathrm{IIIb} / \mathrm{c}$ & $15 \mathrm{~J} 1-5$ & Biface Stage 1 & 1 \\
\hline E20/S76 & $10 \mathrm{~A}$ & & IIIb/c & $15 \mathrm{~J} 1-2$ & Biface Stage 2 & 1 \\
\hline $\mathrm{E} 20 / \mathrm{S} 76$ & $10 \mathrm{~A}$ & & $\mathrm{IIIb} / \mathrm{c}$ & $15 \mathrm{~J} 1-7$ & Burin & 1 \\
\hline E20/S76 & $10 \mathrm{~A}$ & & $\mathrm{IIIb} / \mathrm{c}$ & & Debitage & 161 \\
\hline E20/S76 & $10 \mathrm{~A}$ & & $\mathrm{IIIb} / \mathrm{c}$ & $15 \mathrm{~J} 1-3$ & Edge modified flake & 1 \\
\hline $\mathrm{E} 20 / \mathrm{S} 76$ & $10 \mathrm{~A}$ & & $\mathrm{IIIb} / \mathrm{c}$ & $15 \mathrm{~J} 1-6$ & Edge modified flake & 1 \\
\hline E20/S76 & $10 \mathrm{~A}$ & & IIIb/c & $15 \mathrm{~J} 1-4$ & Edge modified flake & 1 \\
\hline E20/S76 & $10 \mathrm{~B}$ & & IIIb & $15 J 2-6$ & Biface fragment & 1 \\
\hline E20/S76 & $10 \mathrm{~B}$ & & IIIb & $15 \mathrm{~J} 2-5$ & Bifacial tool Form J & 1 \\
\hline $\mathrm{E} 20 / \mathrm{S} 76$ & $10 \mathrm{~B}$ & & $\mathrm{IIIb}$ & $15 \mathrm{~J} 2-9$ & Burin & 1 \\
\hline $\mathrm{E} 20 / \mathrm{S} 76$ & $10 \mathrm{~B}$ & & $\mathrm{IIIb}$ & $15 \mathrm{~J} 2-11$ & Burin spall & 1 \\
\hline E20/S76 & $10 \mathrm{~B}$ & & IIIb & & Debitage & 248 \\
\hline E20/S76 & $10 \mathrm{~B}$ & & IIIb & $15 \mathrm{~J} 2-13$ & Edge modified flake & 1 \\
\hline E20/S76 & $10 \mathrm{~B}$ & & IIIb & $15 \mathrm{~J} 2-12$ & Edge modified flake & 1 \\
\hline E20/S76 & $10 \mathrm{~B}$ & & $\mathrm{IIIb}$ & $15 \mathrm{~J} 2-7$ & Projectile point fragment & 1 \\
\hline E20/S76 & $10 \mathrm{~B}$ & & IIIb & $15 \mathrm{~J} 2-1$ & Projectile point, Bell/Andice & 1 \\
\hline E20/S76 & 10B & & IIIb & $15 J 2-2$ & Projectile point, Bell/Andice & 1 \\
\hline E20/S76 & $10 \mathrm{~B}$ & & IIIb & $15 \mathrm{~J} 2-3$ & Projectile point, Gower & 1 \\
\hline E20/S76 & $10 \mathrm{~B}$ & & $\mathrm{IIIb}$ & $15 \mathrm{~J} 2-4$ & Projectile point, Nolan & 1 \\
\hline $\mathrm{E} 20 / \mathrm{S} 76$ & $10 \mathrm{~B}$ & & IIIb & $15 \mathrm{~J} 2-14$ & Thin uniface fragment & 1 \\
\hline E20/S76 & $11 \mathrm{~A}$ & & IIIb & $15 \mathrm{~K} 1-1$ & Biface fragment & 1 \\
\hline E20/S76 & $11 \mathrm{~A}$ & & IIIb & & Debitage & 135 \\
\hline E20/S76 & $11 \mathrm{~A}$ & & IIIb & $15 \mathrm{~K} 1-8$ & Edge modified flake & \\
\hline E20/S76 & $11 \mathrm{~A}$ & & IIIb & $15 \mathrm{~K} 1-6$ & Edge modified flake & 1 \\
\hline E20/S76 & $11 \mathrm{~A}$ & & IIIb & $15 \mathrm{~K} 1-7$ & Edge modified flake & 1 \\
\hline E20/S76 & $11 \mathrm{~A}$ & & IIIb & $15 \mathrm{~K} 1-5$ & Uniface, unanalyzed & 1 \\
\hline E20/S76 & $11 \mathrm{~B}$ & & IIIb & $15 \mathrm{~K} 2-2$ & Biface Stage 1 & \\
\hline
\end{tabular}




\begin{tabular}{|c|c|c|c|c|c|c|}
\hline Square & Level & Feature & Strata & Item & Analyst Identification & Count \\
\hline E20/S76 & 11B & & IIIb & $15 \mathrm{~K} 2-3$ & Core, multidirectional & \\
\hline E20/S76 & $11 \mathrm{~B}$ & & $\mathrm{IIIb}$ & & Debitage & 136 \\
\hline E20/S76 & $11 \mathrm{~B}$ & & $\mathrm{IIIb}$ & $15 \mathrm{~K} 2-4$ & Micro-core, small & 1 \\
\hline E20/S76 & $11 \mathrm{~B}$ & & IIIb & $15 \mathrm{~K} 2-1$ & Piece esquillee & 1 \\
\hline E20/S76 & $12 \mathrm{~A}$ & & IIIlb & 15L1-5 & Bifacial tool Form E & \\
\hline E20/S76 & $12 \mathrm{~A}$ & & IIIb & & Debitage & 851 \\
\hline E20/S76 & $12 \mathrm{~A}$ & & IIIb & $15 \mathrm{~L} 1-8$ & Denticulated flake & \\
\hline E20/S76 & $12 \mathrm{~A}$ & & IIIb & 15L1-15 & Edge modified flake & 1 \\
\hline $\mathrm{E} 20 / \mathrm{S} 76$ & $12 \mathrm{~A}$ & & IIIb & 15L1-19 & Edge modified flake & 1 \\
\hline E20/S76 & $12 \mathrm{~A}$ & & IIIIb & 15L1-14 & Edge modified flake & 1 \\
\hline E20/S76 & $12 \mathrm{~A}$ & & IIIb & 15L1-12 & Edge modified flake & \\
\hline E20/S76 & $12 \mathrm{~A}$ & & IIIlb & 15L1-11 & Edge modified flake & \\
\hline E20/S76 & $12 \mathrm{~A}$ & & IIIb & $15 \mathrm{~L} 1-7$ & Projectile point fragment & 1 \\
\hline E20/S76 & $12 \mathrm{~A}$ & & IIIb & 15L1-6 & Projectile point fragment & 1 \\
\hline E20/S76 & $12 \mathrm{~A}$ & & IIIIb & 15L1-1 & Projectile point fragment & 1 \\
\hline E20/S76 & $12 \mathrm{~A}$ & & IIIb & 15L1-3 & Small core hammerstone & \\
\hline E20/S76 & $12 \mathrm{~A}$ & & IIIb & 15L1-2 & Small core hammerstone & \\
\hline E20/S76 & $12 \mathrm{~A}$ & & IIIlb & 15L1-9 & Uniface, unanalyzed & 1 \\
\hline E20/S76 & $12 \mathrm{~A}$ & & IIIIb & $15 \mathrm{~L} 1-16$ & Unifacial multiple tool & 1 \\
\hline E20/S76 & $12 \mathrm{~B}$ & & IIIb & $15 \mathrm{~L} 2-3$ & Biface Stage 2 & \\
\hline E20/S76 & $12 \mathrm{~B}$ & & IIIb & & Debitage & 710 \\
\hline E20/S76 & $12 \mathrm{~B}$ & & IIIIb & $15 \mathrm{~L} 2-1$ & Projectile point, Gower/Jetta & \\
\hline E20/S76 & $12 \mathrm{~B}$ & & IIIb & $15 \mathrm{~L} 2-2$ & Projectile point, Martindale A & 1 \\
\hline E20/S76 & $12 \mathrm{~B}$ & & IIIIb & 15L2-4 & Thin uniface & \\
\hline E20/S76 & $12 \mathrm{~B}$ & & IIIb & $15 \mathrm{~L} 2-5$ & Thin uniface fragment & \\
\hline E20/S76 & $13 \mathrm{~A}$ & & IIIb & $15 \mathrm{M} 1-4$ & Biface Stage 2 & 1 \\
\hline E20/S76 & $13 \mathrm{~A}$ & & IIIb & $15 \mathrm{M} 1-2$ & Biface Stage 2 & 1 \\
\hline E20/S76 & $13 \mathrm{~A}$ & & IIIIb & $15 \mathrm{M} 1-5$ & Burin spall & 1 \\
\hline E20/S76 & $13 \mathrm{~A}$ & & IIIb & & Debitage & 338 \\
\hline E20/S76 & $13 \mathrm{~A}$ & & IIIb & $15 \mathrm{M} 1-6$ & Denticulated flake & 1 \\
\hline E20/S76 & $13 \mathrm{~A}$ & & IIIIb & $15 \mathrm{M} 1-7$ & Edge modified flake & 1 \\
\hline E20/S76 & $13 \mathrm{~A}$ & & IIIIb & $15 \mathrm{M} 1-8$ & Microspur/microdenticulate & 1 \\
\hline E20/S76 & $13 \mathrm{~A}$ & & IIIIb & $15 \mathrm{M} 1-3$ & Projectile point fragment & \\
\hline E20/S76 & $13 \mathrm{~A}$ & & IIIlb & $15 \mathrm{M} 1-1$ & Projectile point, Bell/Andice & \\
\hline E20/S76 & $13 \mathrm{~B}$ & & IIIb & & Debitage & 374 \\
\hline E20/S76 & 13B & & IIIb & $15 \mathrm{M} 2-2$ & Perforator Group 4 & 1 \\
\hline E20/S76 & 13B & & IIIIb & $15 \mathrm{M} 2-1$ & Projectile point fragment & \\
\hline E20/S76 & $14 \mathrm{~A}$ & & IIIa/b & & Debitage & 293 \\
\hline E20/S76 & $14 \mathrm{~A}$ & & IIIa/b & $15 \mathrm{~N} 1-1$ & Edge modified flake & \\
\hline E20/S76 & $14 \mathrm{~A}$ & & IIIa/b & $15 \mathrm{~N} 1-3$ & Edge modified flake & 1 \\
\hline E20/S76 & $14 \mathrm{~A}$ & & IIIa/b & $15 \mathrm{~N} 1-2$ & Unifacial multiple tool & 1 \\
\hline E20/S76 & 14B & & IIIa/b & $15 N 2-7$ & Biface fragment & \\
\hline E20/S76 & 14B & & IIIa/b & & Debitage & 356 \\
\hline E20/S76 & $14 \mathrm{~B}$ & & IIIa/b & $15 \mathrm{~N} 2-1$ & Projectile point, Jetta & \\
\hline E20/S76 & $15 \mathrm{~A}$ & & IIIa & & Debitage & 381 \\
\hline E20/S76 & $15 \mathrm{~A}$ & & IIIa & $1501-1$ & Thin uniface & \\
\hline $\mathrm{E} 20 / \mathrm{S} 76$ & $15 \mathrm{~B}$ & & IIIa & $1502-2$ & Biface fragment & \\
\hline E20/S76 & $15 \mathrm{~B}$ & & IIIa & & Debitage & 444 \\
\hline E20/S76 & $15 \mathrm{~B}$ & & IIIa & $1502-7$ & Edge modified flake & 1 \\
\hline E20/S76 & $15 \mathrm{~B}$ & & IIIIa & $1502-11$ & Edge modified flake & 1 \\
\hline E20/S76 & $15 \mathrm{~B}$ & & IIIa & $1502-10$ & Microspur/microdenticulate & 1 \\
\hline E20/S76 & $15 B$ & & IIIa & $1502-3$ & Projectile point fragment & 1 \\
\hline E20/S76 & $15 \mathrm{~B}$ & & IIIa & $1502-1$ & Projectile point, Thrall & 1 \\
\hline E20/S76 & $15 \mathrm{~B}$ & & IIIIa & $1502-5$ & Thin uniface & 1 \\
\hline E20/S76 & $15 \mathrm{~B}$ & & IIIa & $1502-6$ & Thin uniface & 1 \\
\hline E20/S76 & $15 B$ & & IIIa & $1502-9$ & Uniface, unanalyzed & 1 \\
\hline E20/S76 & $15 \mathrm{~B}$ & & IIIa & $1502-8$ & Unifacial multiple tool & 1 \\
\hline E20/S76 & $16 \mathrm{~A}$ & & IIIa & 15P1-1 & Biface Stage 2 & 1 \\
\hline E20/S76 & $16 \mathrm{~A}$ & & IIIIa & $15 \mathrm{P} 1-3$ & Burin spall & 1 \\
\hline E20/S76 & $16 \mathrm{~A}$ & & IIIa & & Debitage & 459 \\
\hline E20/S76 & $16 \mathrm{~A}$ & & IIIIa & $15 \mathrm{P} 1-5$ & Edge modified flake & \\
\hline E20/S76 & $16 \mathrm{~A}$ & & IIIa & $15 \mathrm{P} 1-4$ & Microspur/microdenticulate & 1 \\
\hline E20/S76 & $16 \mathrm{~A}$ & & IIIIa & 15P1-6 & Thin uniface & \\
\hline $\mathrm{E} 20 / \mathrm{S} 76$ & $16 \mathrm{~B}$ & & IIIa & & Debitage & 296 \\
\hline E20/S76 & $16 \mathrm{~B}$ & & IIIa & $15 \mathrm{P} 2-6$ & Edge modified flake & 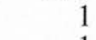 \\
\hline E20/S76 & $16 \mathrm{~B}$ & & IIIIa & $15 P 2-3$ & Edge modified flake & 1 \\
\hline E20/S76 & $16 \mathrm{~B}$ & & IIIa & $15 P 2-5$ & Edge modified flake & 1 \\
\hline E20/S76 & $16 \mathrm{~B}$ & & IIIIa & 15P2-1 & Piece esquillee & 1 \\
\hline E20/S76 & $16 \mathrm{~B}$ & & IIIa & $15 \mathrm{P} 2-7$ & Uniface, unanalyzed & 1 \\
\hline E20/S76 & $17 \mathrm{~B}$ & & IIIa & $15 \mathrm{Q} 2-3$ & Burin spall & \\
\hline E20/S76 & $17 \mathrm{~B}$ & & IIIa & $15 \mathrm{Q} 2-4$ & Burin spall & \\
\hline E20/S76 & 17B & & IIIa & $15 \mathrm{Q} 2-1$ & Burin spall & 1 \\
\hline E20/S76 & $17 \mathrm{~B}$ & & IIIIa & $15 Q 2-2$ & Burin spall & 1 \\
\hline E20/S76 & 17B & & IIIa & $15 \mathrm{Q} 2-12$ & Clear Fork biface, proximal & \\
\hline
\end{tabular}




\begin{tabular}{|c|c|c|c|c|c|c|}
\hline $\begin{array}{l}\text { Square } \\
\text { F20/S76 }\end{array}$ & $\begin{array}{l}\text { Level } \\
17 \mathrm{~B}\end{array}$ & Feature & $\begin{array}{l}\text { Strata } \\
\text { IIIa }\end{array}$ & Item & Analyst Identification & Count \\
\hline $\begin{array}{l}\text { E20/S76 } \\
\text { E20/S76 }\end{array}$ & $17 \mathrm{~B}$ & & IIIa & $\begin{array}{l}15 \mathrm{Q} 2-6 \\
15 \mathrm{Q} 2-7\end{array}$ & $\begin{array}{l}\text { Core tool, type } 5 \\
\text { Core, multidirectional }\end{array}$ & \\
\hline $\mathrm{E} 20 / \mathrm{S} 76$ & 17B & & IIIIa & & Debitage & 531 \\
\hline $\mathrm{E} 20 / \mathrm{S} 76$ & 17B & & IIIa & $15 \mathrm{Q} 2-5$ & Edge modified flake & \\
\hline E20/S76 & $17 \mathrm{~B}$ & & IIIa & $15 \mathrm{Q} 2-14$ & Edge modified flake & 1 \\
\hline E20/S76 & 17B & & IIIa & $15 \mathrm{Q} 2-9$ & Edge modified flake & \\
\hline $\mathrm{E} 20 / \mathrm{S} 76$ & $17 \mathrm{~B}$ & & IIIa & $15 \mathrm{Q} 2-8$ & Microspur/microdenticulate & \\
\hline $\mathrm{E} 20 / \mathrm{S} 76$ & $17 \mathrm{~B}$ & & IIIa & $15 \mathrm{Q} 2-13$ & Thin uniface & \\
\hline E20/S76 & 17B & & IIIa & $15 \mathrm{Q} 2-10$ & Uniface, unanalyzed & \\
\hline E20/S76 & $17 \mathrm{~B}$ & & IIIa & $15 \mathrm{Q} 2-11$ & Uniface, unanalyzed & \\
\hline E20/S76 & $18 \mathrm{~A}$ & & IIIIa & $15 \mathrm{R} 1-5$ & Biface Stage 1 & \\
\hline $\mathrm{E} 20 / \mathrm{S} 76$ & $18 \mathrm{~A}$ & & IIIIa & $15 \mathrm{R} 1-2$ & Biface Stage 2 & \\
\hline $\mathrm{E} 20 / \mathrm{S} 76$ & $18 \mathrm{~A}$ & & IIIIa & $15 \mathrm{R} 1-4$ & Core tool, type 2 & \\
\hline E20/S76 & $18 \mathrm{~A}$ & & IIIIa & $15 \mathrm{R} 1-3$ & Core, thermal & \\
\hline E20/S76 & $18 \mathrm{~A}$ & & IIIIa & & Debitage & 423 \\
\hline E20/S76 & $18 \mathrm{~A}$ & & IIIa & 15R1-7 & Edge modified flake & \\
\hline $\mathrm{E} 20 / \mathrm{S} 76$ & $18 \mathrm{~A}$ & & IIIIa & $15 \mathrm{R} 1-8$ & Edge modified flake & \\
\hline E20/S76 & $18 \mathrm{~A}$ & & IIIIa & $15 \mathrm{R} 1-1$ & Projectile point, miscellaneous lanceolate & \\
\hline E20/S76 & $18 \mathrm{~A}$ & & IIIa & $15 \mathrm{R} 1-6$ & Unifacial multiple tool & \\
\hline E20/S76 & $18 \mathrm{~B}$ & & IIIa & $15 \mathrm{R} 2-3$ & Biface fragment & \\
\hline E20/S76 & $18 \mathrm{~B}$ & & IIIa & $15 \mathrm{R} 2-2$ & Biface fragment & \\
\hline E20/S76 & $18 \mathrm{~B}$ & & IIIIa & $15 \mathrm{R} 2-4$ & Burin spall & \\
\hline $\mathrm{E} 20 / \mathrm{S} 76$ & $18 \mathrm{~B}$ & & IIIa & $15 \mathrm{R} 2-5$ & Core tool, type 5 & \\
\hline E20/S76 & $18 \mathrm{~B}$ & & IIIIa & & Debitage & 430 \\
\hline E20/S76 & $18 \mathrm{~B}$ & & IIIa & $15 R 2-10$ & Edge modified flake & \\
\hline E20/S76 & 18B & & IIIa & $15 \mathrm{R} 2-11$ & Edge modified flake & \\
\hline E20/S76 & $18 \mathrm{~B}$ & & IIIa & $15 \mathrm{R} 2-9$ & Perforator Group 4 & \\
\hline E20/S76 & $18 \mathrm{~B}$ & & IIIIa & $15 \mathrm{R} 2-8$ & Perforator Unifacial & \\
\hline $\mathrm{E} 20 / \mathrm{S} 76$ & $18 \mathrm{~B}$ & & IIIIa & $15 \mathrm{R} 2-1$ & Projectile point, miscellaneous lanceolate & \\
\hline E20/S76 & $18 \mathrm{~B}$ & & IIIa & $15 \mathrm{R} 2-6$ & Thin uniface & \\
\hline E20/S76 & $18 \mathrm{~B}$ & & IIIa & 15R2-7 & Thin uniface fragment & \\
\hline E20/S76 & $18 \mathrm{~B}$ & & IIIa & $15 \mathrm{R} 2-12$ & Uniface, unanalyzed & \\
\hline $\mathrm{E} 20 / \mathrm{S} 76$ & $19 \mathrm{~A}$ & & II/IIIa & $15 \mathrm{~S} 1-1$ & Biface Stage 1 & \\
\hline E20/S76 & $19 \mathrm{~A}$ & & II/IIIIa & & Debitage & 268 \\
\hline $\mathrm{E} 20 / \mathrm{S} 76$ & $19 \mathrm{~B}$ & & II/IIIIa & & Debitage & 439 \\
\hline E20/S76 & 19B & & II/IIIIa & $15 \mathrm{~S} 2-2$ & Denticulated flake & \\
\hline E20/S76 & $19 \mathrm{~B}$ & & II/IIIIa & $15 \mathrm{~S} 2-4$ & Thick uniface & \\
\hline $\mathrm{E} 20 / \mathrm{S} 76$ & $19 \mathrm{~B}$ & & I//IIIa & $15 S 2-1$ & Thin uniface fragment & \\
\hline E20/S76 & $20 \mathrm{~A}$ & & II/IIIIa & & Debitage & 203 \\
\hline $\mathrm{E} 20 / \mathrm{S} 76$ & $20 \mathrm{~A}$ & & II/IIIa & $15 \mathrm{~T} 1-1$ & Denticulated flake & \\
\hline $\mathrm{E} 20 / \mathrm{S} 76$ & $20 \mathrm{~A}$ & & I//IIIa & $15 \mathrm{~T} 1-4$ & Uniface, unanalyzed & 1 \\
\hline E20/S76 & $20 \mathrm{~B}$ & & II & & Debitage & 52 \\
\hline E20/S76 & $20 \mathrm{~B}$ & & II & $15 \mathrm{~T} 2-1$ & Thin uniface & \\
\hline E20/S76 & $21 \mathrm{~A}$ & & II & $15 \mathrm{U} 1-1$ & Burin spall & \\
\hline $\mathrm{E} 20 / \mathrm{S} 76$ & $21 \mathrm{~A}$ & & II & & Debitage & 99 \\
\hline $\mathrm{E} 20 / \mathrm{S} 76$ & $21 \mathrm{~B}$ & & II & & Debitage & 116 \\
\hline E20/S76 & 21B & & II & $15 \mathrm{U} 2-1$ & Projectile point, miscellaneous lanceolate & \\
\hline $\mathrm{E} 20 / \mathrm{S} 76$ & $22 \mathrm{~A}$ & & II & & Debitage & 57 \\
\hline $\mathrm{E} 20 / \mathrm{S} 76$ & $22 \mathrm{~A}$ & & II & 15V1-1 & Projectile point, Wilson & \\
\hline $\mathrm{E} 20 / \mathrm{S} 76$ & $22 \mathrm{~B}$ & & $\mathrm{Id} / \mathrm{II}$ & & Debitage & 66 \\
\hline E20/S76 & $22 \mathrm{~B}$ & & $\mathrm{Id} / \mathrm{II}$ & $15 \mathrm{~V} 2-1$ & Projectile point fragment & \\
\hline E20/S76 & $22 \mathrm{~B}$ & & $\mathrm{Id} / \mathrm{II}$ & $15 \mathrm{~V} 2-2$ & Retouched blade & \\
\hline E20/S76 & $23 \mathrm{~A}$ & & $\mathrm{Id} / \mathrm{II}$ & $15 \mathrm{~W} 1-1$ & Core tool, type 5 & \\
\hline $\mathrm{E} 20 / \mathrm{S} 76$ & $23 \mathrm{~A}$ & & $\mathrm{Id} / \mathrm{II}$ & & Debitage & 53 \\
\hline E20/S76 & $23 \mathrm{~B}$ & & $\mathrm{Id} / \mathrm{II}$ & & Debitage & 100 \\
\hline E20/S76 & $23 \mathrm{~B}$ & & $\mathrm{Id} / \mathrm{II}$ & $15 \mathrm{~W} 2-2$ & Edge modified flake & \\
\hline E20/S76 & $23 \mathrm{~B}$ & & $\mathrm{Id} / \mathrm{II}$ & $15 \mathrm{~W} 2-3$ & Microspur/microdenticulate & \\
\hline $\mathrm{E} 20 / \mathrm{S} 76$ & $24 \mathrm{~A}$ & & $\mathrm{Id} / \mathrm{II}$ & $15 \times 1-4$ & Biface Stage 2 & \\
\hline $\mathrm{E} 20 / \mathrm{S} 76$ & $24 \mathrm{~A}$ & & $\mathrm{Id} / \mathrm{II}$ & & Debitage & 116 \\
\hline $\mathrm{E} 20 / \mathrm{S} 76$ & $24 \mathrm{~A}$ & & $\mathrm{Id} / \mathrm{II}$ & $15 \times 1-5$ & Edge modified flake & \\
\hline $\mathrm{E} 20 / \mathrm{S} 76$ & $24 \mathrm{~A}$ & & $\mathrm{Id} / \mathrm{II}$ & $15 \times 1-1$ & Projectile point, Golondrina-Barber & \\
\hline E20/S76 & $24 \mathrm{~A}$ & & $\mathrm{Id} / \mathrm{II}$ & $15 \times 1-3$ & Projectile point, ground square haft & \\
\hline E20/S76 & $24 \mathrm{~A}$ & & $\mathrm{Id} / \mathrm{II}$ & $15 \times 1-2$ & Thin uniface fragment & \\
\hline E20/S76 & $24 \mathrm{~B}$ & & $\mathrm{Id} / \mathrm{II}$ & & Debitage & 62 \\
\hline $\mathrm{E} 20 / \mathrm{S} 76$ & $24 \mathrm{~B}$ & & $\mathrm{Id} / \mathrm{II}$ & $15 \times 2-1$ & Edge modified flake & \\
\hline E20/S76 & $25 \mathrm{~A}$ & & Isi-c/Id & & Debitage & 30 \\
\hline E20/S76 & $25 \mathrm{~A}$ & & Isi-c/Id & $15 Y 1-2$ & Edge modified flake & \\
\hline $\mathrm{E} 20 / \mathrm{S} 76$ & $25 \mathrm{~A}$ & & Isi-c/Id & $15 Y 1-1$ & Projectile point, Golondrina-Barber & \\
\hline E20/S76 & $25 \mathrm{~B}$ & & Isi-c/Id & $15 Y 2-1$ & Biface Stage 1 & \\
\hline $\mathrm{E} 20 / \mathrm{S} 76$ & $25 \mathrm{~B}$ & & Isi-c/Id & & Debitage & \\
\hline E20/S76 & $25 \mathrm{~B}$ & & Isi-c/Id & $15 Y 2-2$ & Edge modified flake & \\
\hline E20/S76 & $26 \mathrm{~A}$ & & Isi-c & & Debitage & \\
\hline E20/S76 & $26 \mathrm{~A}$ & & Isi-c & $15 Z 1-2$ & Edge modified flake & \\
\hline $\mathrm{E} 20 / \mathrm{S} 76$ & $26 \mathrm{~A}$ & & Isi-c & $15 \mathrm{Z} 1-1$ & Micro-core, large & \\
\hline
\end{tabular}




\begin{tabular}{|c|c|c|c|c|c|c|}
\hline Square & Level & Feature & Strata & Item & Analyst Identification & Count \\
\hline E20/S76 & $26 \mathrm{~B}$ & & Isi-c & $15 Z 2-1$ & Biface Stage 1 & 1 \\
\hline $\mathrm{E} 20 / \mathrm{S} 76$ & $26 \mathrm{~B}$ & & Isi-c & & Debitage & 48 \\
\hline E20/S76 & $26 \mathrm{~B}$ & & Isi-c & $15 Z 2-5$ & Thin uniface & 1 \\
\hline E20/S76 & $26 \mathrm{~B}$ & & Isi-c & $15 Z 2-4$ & Thin uniface fragment & 1 \\
\hline E20/S76 & $27 \mathrm{~A}$ & & Isi-c & 15AA1-1 & Core, multidirectional & 1 \\
\hline $\mathrm{E} 20 / \mathrm{S} 76$ & $27 \mathrm{~A}$ & & Isi-c & & Debitage & 37 \\
\hline E20/S76 & $27 \mathrm{~A}$ & & Isi-c & 15AA1-2 & Thin uniface & 1 \\
\hline E20/S76 & $27 \mathrm{~B}$ & & Isi-c & 15AA2-1 & Biface Stage 2 & 1 \\
\hline E20/S76 & $27 \mathrm{~B}$ & & Isi-c & $15 \mathrm{AA} 2-2$ & Clear Fork biface & 1 \\
\hline E20/S76 & $27 \mathrm{~B}$ & & Isi-c & & Debitage & 38 \\
\hline E20/S76 & $27 \mathrm{~B}$ & & Isi-c & 15AA2-3 & Thin uniface & 1 \\
\hline E20/S76 & $28 \mathrm{~A}$ & & Isi-c & & Debitage & 31 \\
\hline E20/S76 & $28 \mathrm{~A}$ & & Isi-c & 15BB1-1 & Edge modified flake & 1 \\
\hline E20/S76 & $28 \mathrm{~B}$ & & Isi/Isi-c & & Debitage & 48 \\
\hline E20/S76 & $29 \mathrm{~A}$ & & Isi/Icl/Isi-c & & Debitage & 20 \\
\hline E20/S76 & $29 \mathrm{~A}$ & & Isi/Icl/Isi-c & $15 \mathrm{CC} 1-1$ & Unifacial multiple tool & 1 \\
\hline E20/S76 & $29 B$ & & $\mathrm{Isi} / \mathrm{Icl} / \mathrm{Isi}-\mathrm{c}$ & & Debitage & 24 \\
\hline E20/S76 & 29B & & Isi/Icl/Isi-c & $15 \mathrm{CC} 2-1$ & Edge modified flake & 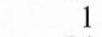 \\
\hline E20/S76 & $30 \mathrm{~A}$ & & Isi/Icl & & Debitage & 24 \\
\hline E20/S76 & $30 \mathrm{~A}$ & & Isi/Icl & 15DD1-1 & Thin uniface & 1 \\
\hline E20/S76 & $30 \mathrm{~B}$ & & Isi/Icl & $15 \mathrm{DD} 2-2$ & Biface fragment & 1 \\
\hline E20/S76 & $32 \mathrm{~A}$ & & Isi/Icl & & Debitage & 30 \\
\hline E20/S76 & $32 \mathrm{~A}-35 \mathrm{~A}$ & Feature 168 & Isi/Icl & & Debitage & 6 \\
\hline E20/S76 & $32 \mathrm{~B}$ & & Isi & & Debitage & 14 \\
\hline E20/S76 & $32 \mathrm{~B}$ & & Isi & $15 \mathrm{FF} 2 \mathrm{D}-1$ & Edge modified flake & 1 \\
\hline E20/S76 & $33 \mathrm{~A}$ & & Isi & & Debitage & 13 \\
\hline E20/S76 & $33 \mathrm{~B}$ & & Isi & & Debitage & 14 \\
\hline E20/S76 & $34 \mathrm{~A}$ & & Isi & & Debitage & 15 \\
\hline $\mathrm{E} 20 / \mathrm{S} 76$ & $34 \mathrm{~A}$ & & Isi & $15 \mathrm{HH} 1 \mathrm{~A}-1$ & Edge modified flake & 1 \\
\hline E20/S76 & $34 \mathrm{~A}$ & & Isi & $15 \mathrm{HH} 1 \mathrm{D}-2$ & Uniface, unanalyzed & 1 \\
\hline E20/S76 & $34 \mathrm{~B}$ & & Isi & & Debitage & 3 \\
\hline E20/S76 & $35 \mathrm{~A}$ & & Isi & & Debitage & 3 \\
\hline $\mathrm{E} 20 / \mathrm{S} 76$ & $35 \mathrm{~B}$ & & Isi & & Debitage & 1 \\
\hline $\mathrm{E} 20 / \mathrm{S} 78$ & 1 & & IIIc & $14 \mathrm{~A}-2$ & Arrow point, tip & 1 \\
\hline E20/S78 & 1 & & IIIc & $14 \mathrm{~A}-4$ & Biface fragment & 1 \\
\hline E20/S78 & 1 & & IIIC & $14 \mathrm{~A}-3$ & Biface fragment & 1 \\
\hline E20/S78 & 1 & & IIII & $14 \mathrm{~A}-20$ & Biface fragment & 1 \\
\hline E20/S78 & 1 & & IIII & $14 \mathrm{~A}-7$ & Core fragment & 1 \\
\hline E20/S78 & 1 & & IIIc & & Debitage & 493 \\
\hline E20/S78 & 1 & & IIIc & 14A-18 & Edge modified flake & 1 \\
\hline E20/S78 & 1 & & IIIc & $14 \mathrm{~A}-17$ & Edge modified flake & \\
\hline E20/S78 & 1 & & IIIc & $14 \mathrm{~A}-13$ & Edge modified flake & 1 \\
\hline E20/S78 & 1 & & IIIc & $14 \mathrm{~A}-12$ & Edge modified flake & \\
\hline E20/S78 & 1 & & IIII & $14 \mathrm{~A}-11$ & Edge modified flake & 1 \\
\hline E20/S78 & 1 & & IIIc & 14A-21 & Edge modified flake & \\
\hline $\mathrm{E} 20 / \mathrm{S} 78$ & 1 & & IIIc & $14 \mathrm{~A}-1$ & Indeterminate ground stone & 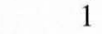 \\
\hline $\mathrm{E} 20 / \mathrm{S} 78$ & 1 & & IIIC & $14 \mathrm{~A}-19$ & Notched flake & 1 \\
\hline E20/S78 & 1 & & IIIc & $14 \mathrm{~A}-8$ & Projectile point fragment & 1 \\
\hline E20/S78 & 1 & & IIII & $14 \mathrm{~A}-16$ & Thin uniface fragment & \\
\hline E20/S78 & 1 & & IIIc & $14 \mathrm{~A}-9$ & Uniface, unanalyzed & 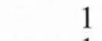 \\
\hline E20/S78 & 1 & & IIIc & $14 \mathrm{~A}-15$ & Uniface, unanalyzed & 1 \\
\hline E20/S78 & 1 & & IIIc & $14 \mathrm{~A}-14$ & Unifacial multiple tool & 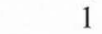 \\
\hline E20/S78 & 2 & & IIIC & 14B-1 & Arrow point, Scallorn/Edwards & \\
\hline E20/S78 & 2 & & IIIc & $14 \mathrm{~B}-3$ & Biface fragment & \\
\hline E20/S78 & 2 & & IIIc & 14B-5 & Biface fragment & 1 \\
\hline E20/S78 & 2 & & IIII & $14 \mathrm{~B}-6$ & Biface Stage 2 & 1 \\
\hline E20/S78 & 2 & & IIIc & $14 \mathrm{~B}-4$ & Biface Stage 2 & 1 \\
\hline E20/S78 & 2 & & IIIc & & Debitage & 267 \\
\hline E20/S78 & 2 & & IIIc & 14B-7 & Edge modified flake & \\
\hline E20/S78 & 2 & & IIIc & 14B-8 & Edge modified flake & 1 \\
\hline E20/S78 & 2 & & IIIc & $14 \mathrm{~B}-2$ & Projectile point fragment & 1 \\
\hline E20/S78 & 3 & & IIIc & $14 \mathrm{C}-3$ & Biface Stage 3 & 1 \\
\hline E20/S78 & 3 & & IIIC & $14 \mathrm{C}-2$ & Biface Stage 3 & \\
\hline E20/S78 & 3 & & IIIIc & & Debitage & 311 \\
\hline E20/S78 & 3 & & IIIc & $14 C-6$ & Edge modified flake & \\
\hline E20/S78 & 3 & & IIIc & $14 C-5$ & Edge modified flake & 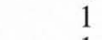 \\
\hline E20/S78 & 3 & & IIIC & $14 C-4$ & Notched flake & 1 \\
\hline E20/S78 & 3 & & IIIc & $14 \mathrm{C}-1$ & Projectile point, Ensor & 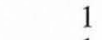 \\
\hline E20/S78 & 4 & & IIIIc & 14D-9 & Biface fragment & 1 \\
\hline E20/S78 & 4 & & IIIc & $14 \mathrm{D}-5$ & Biface Stage 2 & 1 \\
\hline E20/S78 & 4 & & IIIc & $14 \mathrm{D}-8$ & Bifacial tool Form $\mathrm{J}$ & 1 \\
\hline E20/S78 & 4 & & IIIc & $14 \mathrm{D}-6$ & Burin spall & 1 \\
\hline E20/S78 & 4 & & IIIc & & Debitage & 371 \\
\hline E20/S78 & 4 & & IIIc & $14 \mathrm{D}-7$ & Edge modified flake & \\
\hline
\end{tabular}




\begin{tabular}{|c|c|c|c|c|c|c|}
\hline Square & Level & Feature & Strata & Item & Analyst Identification & Count \\
\hline $\mathrm{E} 20 / \mathrm{S} 78$ & 4 & & IIIc & $14 \mathrm{D}-10$ & Edge modified flake & \\
\hline E20/S78 & 4 & & IIIc & 14D-11 & Edge modified flake & \\
\hline E20/S78 & 4 & & IIIc & $14 \mathrm{D}-13$ & Edge modified flake & \\
\hline E20/S78 & 4 & & IIIc & 14D-14 & Edge modified flake & \\
\hline E20/S78 & 4 & & IIIc & $14 \mathrm{D}-12$ & Edge modified flake & \\
\hline E20/S78 & 4 & & IIIC & $14 \mathrm{D}-3$ & Metate fragment & \\
\hline $\mathrm{E} 20 / \mathrm{S} 78$ & 4 & & IIIC & $14 \mathrm{D}-4$ & Metate fragment & \\
\hline E20/S78 & 4 & & IIIc & $14 \mathrm{D}-2$ & Perforator Group 3 & \\
\hline E20/S78 & 4 & & IIIc & 14D-1 & Projectile point, Williams & \\
\hline E20/S78 & 5 & & IIIIc & $14 \mathrm{E}-3$ & Biface fragment & \\
\hline E20/S78 & 5 & & IIIIc & $14 \mathrm{E}-14$ & Biface Stage 1 & \\
\hline $\mathrm{E} 20 / \mathrm{S} 78$ & 5 & & IIIIc & $14 \mathrm{E}-1$ & Biface Stage 2 & \\
\hline E20/S78 & 5 & & IIIc & $14 \mathrm{E}-4$ & $\begin{array}{l}\text { Biface Stage } 3 \\
\text { Debitage }\end{array}$ & 549 \\
\hline E20/S78 & 5 & & IIIc & & $\begin{array}{l}\text { Debitage } \\
\text { Edge modified flake }\end{array}$ & \\
\hline $\begin{array}{l}\text { E20/S78 } \\
\text { E20/S78 }\end{array}$ & $\begin{array}{l}5 \\
5\end{array}$ & & $\begin{array}{l}\text { IIIc } \\
\text { IIIc }\end{array}$ & $\begin{array}{l}14 \mathrm{E}-9 \\
14 \mathrm{E}-6\end{array}$ & $\begin{array}{l}\text { Edge modified flake } \\
\text { Edge modified flake }\end{array}$ & \\
\hline E20/S78 & 5 & & IIIC & $14 \mathrm{E}-7$ & Edge modified flake & \\
\hline E20/S78 & 5 & & IIIc & $14 \mathrm{E}-13$ & Edge modified flake & \\
\hline E20/S78 & 5 & & IIIc & $14 \mathrm{E}-12$ & Edge modified flake & \\
\hline E20/S78 & 5 & & IIIC & $14 \mathrm{E}-11$ & Notched flake & \\
\hline E20/S78 & 5 & & IIIc & $14 \mathrm{E}-5$ & Projectile point fragment & \\
\hline E20/S78 & 5 & & IIIIc & $14 \mathrm{E}-15$ & Thin uniface & \\
\hline E20/S78 & 5 & & IIIc & $14 \mathrm{E}-2$ & Thin uniface & 1 \\
\hline $\mathrm{E} 20 / \mathrm{S} 78$ & 5 & & IIIc & $14 \mathrm{E}-10$ & Unifacial multiple tool & 1 \\
\hline $\mathrm{E} 20 / \mathrm{S} 78$ & 6 & & IIIc & & Debitage & 474 \\
\hline E20/S78 & 6 & & IIIc & $14 \mathrm{~F}-3$ & Edge modified flake & \\
\hline E20/S78 & 6 & & IIIIc & $14 \mathrm{~F}-6$ & Edge modified flake & \\
\hline $\mathrm{E} 20 / \mathrm{S} 78$ & 6 & & IIIc & $14 \mathrm{~F}-2$ & Perforator Group 7 & \\
\hline E20/S78 & 6 & & IIIc & $14 \mathrm{~F}-1$ & Perforator Group 7 & \\
\hline E20/S78 & 6 & & IIIc & $14 \mathrm{~F}-5$ & Projectile point fragment & \\
\hline E20/S78 & 6 & & IIIc & $14 \mathrm{~F}-4$ & Unifacial multiple tool & \\
\hline $\mathrm{E} 20 / \mathrm{S} 78$ & 7 & & $\mathrm{IIIb} / \mathrm{c}$ & 14G-6 & Bifacial tool Form $\mathrm{H}$ & \\
\hline $\mathrm{E} 20 / \mathrm{S} 78$ & 7 & & $\mathrm{IIIb} / \mathrm{c}$ & & Debitage & 247 \\
\hline E20/S78 & 7 & & $\mathrm{IIIb} / \mathrm{c}$ & $14 \mathrm{G}-4$ & Mano fragment & \\
\hline E20/S78 & 7 & & $\mathrm{IIIb} / \mathrm{c}$ & $14 \mathrm{G}-5$ & Projectile point fragment & \\
\hline E20/S78 & 7 & & IIIlb/c & 14G-2 & Projectile point, Martindale B & \\
\hline $\mathrm{E} 20 / \mathrm{S} 78$ & 7 & & $\mathrm{IIIb} / \mathrm{c}$ & 14G-3 & Projectile point, Nolan & \\
\hline $\mathrm{E} 20 / \mathrm{S} 78$ & 7 & & $\mathrm{IIIb} / \mathrm{c}$ & 14G-1 & Projectile point, Uvalde-like & \\
\hline E20/S78 & 8 & & IIIb/c & $14 \mathrm{H}-4$ & Biface Stage 2 & \\
\hline E20/S78 & 8 & & $\mathrm{IIIb} / \mathrm{c}$ & $14 \mathrm{H}-5$ & Biface Stage 2 & \\
\hline E20/S78 & 8 & & $\mathrm{IIIb} / \mathrm{c}$ & $14 \mathrm{H}-3$ & Biface Stage 2 & \\
\hline E20/S78 & 8 & & $\mathrm{IIIb} / \mathrm{c}$ & & Debitage & 315 \\
\hline E20/S78 & 8 & & $\mathrm{IIIb} / \mathrm{c}$ & $14 \mathrm{H}-9$ & Denticulated flake & \\
\hline E20/S78 & 8 & & $\mathrm{IIIb} / \mathrm{c}$ & $14 \mathrm{H}-2$ & Mano fragment & \\
\hline E20/S78 & 8 & & IIIb/c & $14 \mathrm{H}-8$ & Perforator Group 7 & \\
\hline E20/S78 & 8 & & $\mathrm{IIIb} / \mathrm{c}$ & $14 \mathrm{H}-6$ & Projectile point, Early Triangular & \\
\hline E20/S78 & 8 & & $\mathrm{IIIb} / \mathrm{c}$ & $14 \mathrm{H}-7$ & Projectile point, Nolan-like & \\
\hline E20/S78 & 8 & & $\mathrm{IIIb} / \mathrm{c}$ & $14 \mathrm{H}-1$ & Projectile point, Travis & \\
\hline E20/S78 & $9 \mathrm{~A}$ & & $\mathrm{IIIb} / \mathrm{c}$ & $14 \mathrm{I} 1-1$ & Biface Stage 3 & \\
\hline E20/S78 & $9 \mathrm{~A}$ & & IIIlb/c & & Debitage & 173 \\
\hline E20/S78 & $9 \mathrm{~A}$ & & $\mathrm{IIIb} / \mathrm{c}$ & $14 \mathrm{I} 1-2$ & Edge modified flake & \\
\hline E20/S78 & $9 \mathrm{~B}$ & & $\mathrm{IIIb} / \mathrm{c}$ & $14 I 2-3$ & Biface fragment & \\
\hline E20/S78 & $9 \mathrm{~B}$ & & IIIb/c & & Debitage & 206 \\
\hline E20/S78 & $9 \mathrm{~B}$ & & $\mathrm{IIIb} / \mathrm{c}$ & $14 \mathrm{I} 2-4$ & Edge modified flake & \\
\hline E20/S78 & 9B & & $\mathrm{IIIb} / \mathrm{c}$ & 14I2-1 & Thin uniface & \\
\hline E20/S78 & $9 \mathrm{~B}$ & & $\mathrm{IIIb} / \mathrm{c}$ & $14 \mathrm{I} 2-2$ & Thin uniface fragment & \\
\hline $\mathrm{E} 20 / \mathrm{S} 78$ & $9 \mathrm{~B}$ & & $\mathrm{IIIb} / \mathrm{c}$ & $14 \mathrm{I} 2-5$ & Unifacial multiple tool & \\
\hline $\mathrm{E} 20 / \mathrm{S} 78$ & $10 \mathrm{~A}$ & & IIIb & $14 \mathrm{~J} 1-2$ & Biface Stage 3 & \\
\hline E20/S78 & $10 \mathrm{~A}$ & & IIIb & & Debitage & 199 \\
\hline E20/S78 & $10 \mathrm{~A}$ & & IIIb & $14 J 1-1$ & Projectile point, Martindale B & \\
\hline E20/S78 & $10 \mathrm{~A}$ & & IIIb & $14 \mathrm{~J} 1-3$ & Thin uniface & \\
\hline E20/S78 & $10 \mathrm{~A}$ & & IIIb & $14 J 1-4$ & Unifacial multiple tool & \\
\hline E20/S78 & $10 \mathrm{~B}$ & & IIIb & $14 J 2-1$ & Biface fragment & \\
\hline E20/S78 & $10 \mathrm{~B}$ & & IIIlb & $14 J 2-2$ & Biface Stage 3 & \\
\hline $\mathrm{E} 20 / \mathrm{S} 78$ & $10 \mathrm{~B}$ & & IIIb & & Debitage & 184 \\
\hline $\mathrm{E} 20 / \mathrm{S} 78$ & $10 \mathrm{~B}$ & & IIIb & $14 J 2-4$ & Edge modified flake & \\
\hline $\mathrm{E} 20 / \mathrm{S} 78$ & $10 \mathrm{~B}$ & & IIIb & $14 \mathrm{~J} 2-5$ & Edge modified flake & \\
\hline E20/S78 & $10 \mathrm{~B}$ & & IIIb & $14 \mathrm{~J} 2-3$ & Unifacial multiple tool & 1 \\
\hline E20/S78 & $11 \mathrm{~A}$ & & IIIlb & $14 \mathrm{~K} 1-2$ & Biface Stage 2 & \\
\hline $\mathrm{E} 20 / \mathrm{S} 78$ & $11 \mathrm{~A}$ & & IIIb & $14 \mathrm{~K} 1-4$ & Biface Stage 2 & \\
\hline $\mathrm{E} 20 / \mathrm{S} 78$ & $11 \mathrm{~A}$ & & IIIb & $14 \mathrm{~K} 1-3$ & Burin & \\
\hline E20/S78 & $11 \mathrm{~A}$ & & IIIb & & Debitage & 266 \\
\hline E20/S78 & $11 \mathrm{~A}$ & & IHb & $14 \mathrm{~K} 1-7$ & Edge modified flake & \\
\hline E20/S78 & $11 \mathrm{~A}$ & & IIIb & $14 \mathrm{~K} 1-8$ & Projectile point fragment & \\
\hline
\end{tabular}




\begin{tabular}{|c|c|}
\hline Square & Level \\
\hline E20/S78 & $11 \mathrm{~A}$ \\
\hline E20/S78 & $11 \mathrm{~A}$ \\
\hline E20/S78 & $11 \mathrm{~A}$ \\
\hline E20/S78 & $11 \mathrm{~B}$ \\
\hline $\mathrm{E} 20 / \mathrm{S} 78$ & $11 \mathrm{~B}$ \\
\hline E20/S78 & $11 \mathrm{~B}$ \\
\hline E20/S78 & $11 \mathrm{~B}$ \\
\hline E20/S78 & $11 \mathrm{~B}$ \\
\hline E20/S78 & $11 \mathrm{~B}$ \\
\hline E20/S78 & $11 \mathrm{~B}$ \\
\hline E20/S78 & $11 \mathrm{~B}$ \\
\hline E20/S78 & $11 \mathrm{~B}$ \\
\hline E20/S78 & $11 \mathrm{~B}$ \\
\hline E20/S78 & $11 \mathrm{~B}$ \\
\hline E20/S78 & $11 \mathrm{~B}$ \\
\hline E20/S78 & $11 \mathrm{~B}$ \\
\hline E20/S78 & $11 \mathrm{~B}$ \\
\hline E20/S78 & $11 \mathrm{~B}$ \\
\hline E20/S78 & 12 \\
\hline E20/S78 & $12 \mathrm{~A}$ \\
\hline E20/S78 & $12 \mathrm{~A}$ \\
\hline E20/S78 & $12 \mathrm{~A}$ \\
\hline E20/S78 & $12 \mathrm{~A}$ \\
\hline E20/S78 & $12 \mathrm{~A}$ \\
\hline E20/S78 & $12 \mathrm{~A}$ \\
\hline E20/S78 & $12 \mathrm{~A}$ \\
\hline E20/S78 & $12 \mathrm{~A}$ \\
\hline E20/S78 & $12 \mathrm{~A}$ \\
\hline E20/S78 & $12 \mathrm{~A}$ \\
\hline E20/S78 & $12 \mathrm{~A}$ \\
\hline E20/S78 & $12 \mathrm{~A}$ \\
\hline E20/S78 & $12 \mathrm{~A}$ \\
\hline E20/S78 & $12 \mathrm{~A}$ \\
\hline E20/S78 & $12 \mathrm{~A}$ \\
\hline E20/S78 & $12 \mathrm{~A}$ \\
\hline E20/S78 & $12 \mathrm{~A}$ \\
\hline E20/S78 & $12 \mathrm{~A}$ \\
\hline E20/S78 & $12 \mathrm{~A}$ \\
\hline E20/S78 & $12 \mathrm{~A}$ \\
\hline E20/S78 & $12 \mathrm{~A}$ \\
\hline $\mathrm{E} 20 / \mathrm{S} 78$ & $12 \mathrm{~A}$ \\
\hline E20/S78 & $12 \mathrm{~A}-\mathrm{B}$ \\
\hline E20/S78 & $12 \mathrm{~B}$ \\
\hline E20/S78 & $12 \mathrm{~B}$ \\
\hline E20/S78 & $12 \mathrm{~B}$ \\
\hline E20/S78 & $12 \mathrm{~B}$ \\
\hline E20/S78 & $12 \mathrm{~B}$ \\
\hline E20/S78 & $12 \mathrm{~B}$ \\
\hline E20/S78 & $12 \mathrm{~B}$ \\
\hline E20/S78 & $12 \mathrm{~B}$ \\
\hline E20/S78 & $12 \mathrm{~B}$ \\
\hline $\mathrm{E} 20 / \mathrm{S} 78$ & $12 \mathrm{~B}$ \\
\hline E20/S78 & $12 \mathrm{~B}$ \\
\hline E20/S78 & $12 \mathrm{~B}$ \\
\hline E20/S78 & $12 \mathrm{~B}$ \\
\hline E20/S78 & $12 B$ \\
\hline E20/S78 & $12 \mathrm{~B}$ \\
\hline E20/S78 & $12 \mathrm{~B}$ \\
\hline E20/S78 & $13 \mathrm{~A}$ \\
\hline E20/S78 & $13 \mathrm{~A}$ \\
\hline E20/S78 & $13 \mathrm{~A}$ \\
\hline E20/S78 & $13 \mathrm{~A}$ \\
\hline E20/S78 & $13 \mathrm{~A}$ \\
\hline E20/S78 & $13 \mathrm{~A}$ \\
\hline E20/S78 & $13 \mathrm{~A}$ \\
\hline E20/S78 & $13 \mathrm{~B}$ \\
\hline E20/S78 & $13 \mathrm{~B}$ \\
\hline E20/S78 & $13 \mathrm{~B}$ \\
\hline E20/S78 & $13 \mathrm{~B}$ \\
\hline E20/S78 & $13 \mathrm{~B}$ \\
\hline E20/S78 & $13 \mathrm{~B}$ \\
\hline E20/S78 & $13 \mathrm{~B}$ \\
\hline E20/S78 & $13 \mathrm{~B}$ \\
\hline E20/S78 & $14 \mathrm{~A}$ \\
\hline
\end{tabular}

Feature

$\begin{array}{ll}\text { Strata } & \text { Item } \\ \text { IIIb } & 14 \mathrm{~K} 1-1 \\ \text { IIIb } & 14 \mathrm{~K} 1-5 \\ \text { IIIb } & 14 \mathrm{~K} 1-6 \\ \text { IIIb } & 14 \mathrm{~K} 2-1 \\ \text { IIIb } & 14 \mathrm{~K} 2-5 \\ \text { IIIb } & 14 \mathrm{~K} 2-13\end{array}$

$14 \mathrm{~K} 2-7$

14 K2-10

$14 \mathrm{~K} 2-12$

14K2-6

$14 \mathrm{~K} 2-8$

14K2-4

14K2-3

14K2-2

$14 \mathrm{~K} 2-14$

14K2-11

14K2-9

$14 \mathrm{~L}-1$

$14 \mathrm{~L} 1-2$

14L1-5

14L1-4

14L1-20

14L1-6

14L1-18

14L1-10

14L1-17

14L1-14

14L1-12

14L1-3

14L1-16

14L1-8

14L1-7

14L1-1

14L1-13

14L1-19

14L1-15

Feature 50

14L1-21

Feature 50

14L1-22

Feature 50

14L $2-5$

14L2-6

14L2-3

14L2-9.

14L2-10

14L2-7

14L2-8

14L2-4

14L2-1

14L2-2

14L2-11

14L2-13

Feature 50

14L2-12

Feature 50

$14 \mathrm{~L} 2-15$

Feature 50

$14 \mathrm{M} 1-1$

14M1-2

14M1-4

14M1-6

14M1-7

14M1-5

14M2-7

14M2-3

14M2-10

14M2-11

14M2-1

14M2-2

$\begin{array}{ll}\text { IIIa/b } & 14 \mathrm{M} 2-5 \\ \mathrm{III} a / b & 14 \mathrm{~N} 1-2\end{array}$

$\begin{array}{ll}\text { III } a / b & 14 \mathrm{M} 2-5 \\ \mathrm{III} a / b & 14 \mathrm{~N} 1-2\end{array}$

Analyst Identification

Projectile point, Bandy

Projectile point, square stem

Unifacial multiple tool

Biface Stage 2

Biface Stage 2

Core tool, type 1

Debitage

Edge modified flake

Edge modified flake

Edge modified flake

Edge modified flake

Edge modified flake

Edge modified flake

Edge modified flake

Piece esquillee

Possible ground stone

Projectile point fragment

Uniface, unanalyzed

Metate fragment

Biface Stage 2

Biface Stage 2

Biface Stage 2

Burin

Core, multidirectional

Debitage

Edge modified flake

Edge modified flake

Edge modified flake

Edge modified flake

Edge modified flake

Edge modified flake

Edge modified flake

Microspur/microdenticulate

Perforator Group 7

Projectile point, Gower/Uvalde

Spurred flake

Thin uniface

Uniface, unanalyzed

Biface Stage 2

Burin spall

Debitage

Debitage

Burin

Burin spall

Debitage

Edge modified flake

Edge modified flake

Edge modified flake

Edge modified flake

Microspur/microdenticulate

Projectile point fragment

Projectile point, Gower

Uniface, unanalyzed

Unifacial multiple tool

Biface fragment

Biface Stage 3

Debitage

Uniface, unanalyzed

Biface fragment

Burin spall

Debitage

Edge modified flake

Edge modified flake

Projectile point, Gower/Jetta

Thin uniface

Biface fragment

Burin spall

Debitage

Denticulated flake

Edge modified flake

Projectile point fragment

Projectile point, Angostura

Unifacial multiple tool

Bifacial tool Form E

Count

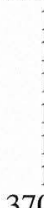

370

(1)

1

1

1

1

1

1

1

617

1

1

1

1

1

69

72

1

621

1

1

1

1

1

17

1

238

1

1

1

1

231

1

1

1 


\begin{tabular}{|c|c|c|c|c|c|c|}
\hline & Level & Feature & Strata & Item & Analyst Identification & Count \\
\hline $\begin{array}{l}\text { E20/S78 } \\
\text { E20/S78 }\end{array}$ & $14 \mathrm{~A}$ & & $\begin{array}{l}\text { IIIa/b } \\
\text { IIIa/b }\end{array}$ & $14 N 1-6$ & $\begin{array}{l}\text { Debitage } \\
\text { Fdoe modified flake }\end{array}$ & $\begin{array}{r}388 \\
1\end{array}$ \\
\hline $\mathrm{E} 20 / \mathrm{S} 78$ & $14 \mathrm{~A}$ & & $\mathrm{IIII} / \mathrm{b}$ & $14 \mathrm{~N} 1-5$ & $\begin{array}{l}\text { Edge modified flake } \\
\text { Edge modified flake }\end{array}$ & 1 \\
\hline E20/S78 & $14 \mathrm{~A}$ & & IIIa/b & $14 N 1-3$ & Edge modified flake & 1 \\
\hline E20/S78 & $14 \mathrm{~A}$ & & IIIa/b & $14 \mathrm{~N} 1-1$ & Projectile point, expanding concave B & 1 \\
\hline E20/S78 & $14 \mathrm{~A}$ & & IIIa/b & $14 \mathrm{~N} 1-4$ & Uniface, unanalyzed & 1 \\
\hline E20/S78 & 14B & & IIIIa & & Debitage & 341 \\
\hline E20/S78 & 14B & & IIIIa & $14 \mathrm{~N} 2-3$ & Edge modified flake & 1 \\
\hline E20/S78 & 14B & & IIIa & $14 \mathrm{~N} 2-4$ & Edge modified flake & 1 \\
\hline E20/S78 & 14B & & IIIa & $14 \mathrm{~N} 2-2$ & Edge modified flake & 1 \\
\hline E20/S78 & $14 \mathrm{~B}$ & & IIIa & $14 \mathrm{~N} 2-1$ & Unifacial multiple tool & 1 \\
\hline $\mathrm{E} 20 / \mathrm{S} 78$ & $15 \mathrm{~A}$ & & IIIa & $1401-2$ & Biface Stage 3 & 1 \\
\hline E20/S78 & $15 \mathrm{~A}$ & & IIIa & & Debitage & 342 \\
\hline $\mathrm{E} 20 / \mathrm{S} 78$ & $15 \mathrm{~A}$ & & IIIa & $1401-3$ & Edge modified flake & 1 \\
\hline E20/S78 & $15 \mathrm{~A}$ & & IIIa & $1401-1$ & Projectile point fragment & 1 \\
\hline E20/S78 & $15 \mathrm{~B}$ & & IIIIa & $1402-1$ & Biface Stage 2 & 1 \\
\hline E20/S78 & $15 \mathrm{~B}$ & & IIIIa & $1402-2$ & Biface Stage 2 & 1 \\
\hline E20/S78 & $15 \mathrm{~B}$ & & IIIIa & & Debitage & 406 \\
\hline E20/S78 & $15 \mathrm{~B}$ & & IIIIa & $14 \mathrm{O} 2-3$ & Edge modified flake & 1 \\
\hline E20/S78 & $15 \mathrm{~B}$ & & IIIa & $1402-4$ & Edge modified flake & 1 \\
\hline E20/S78 & $15 \mathrm{~B}$ & & IIIIa & $1402-5$ & Edge modified flake & 1 \\
\hline E20/S78 & $15 \mathrm{~B}$ & & IIIa & $1402-6$ & Uniface, unanalyzed & 1 \\
\hline E20/S78 & $16 \mathrm{~A}$ & & IIIa & $14 \mathrm{P} 1-2$ & Biface Stage 2 & 1 \\
\hline E20/S78 & $16 \mathrm{~A}$ & & IIIa & & Debitage & 451 \\
\hline E20/S78 & $16 \mathrm{~A}$ & & IIIa & 14P1-7 & Edge modified flake & 1 \\
\hline $\mathrm{E} 20 / \mathrm{S} 78$ & $16 \mathrm{~A}$ & & IIIa & 14P1-6 & Edge modified flake & 1 \\
\hline E20/S78 & $16 \mathrm{~A}$ & & IIIa & 14P1-5 & Edge modified flake & 1 \\
\hline E20/S78 & $16 \mathrm{~A}$ & & IIIa & 14P1-9 & Edge modified flake & 1 \\
\hline E20/S78 & $16 \mathrm{~A}$ & & IIIa & 14P1-1 & Perforator Group 3 & 1 \\
\hline E20/S78 & $16 \mathrm{~A}$ & & IIIIa & 14P1-10 & Perforator Group 7 & 1 \\
\hline E20/S78 & $16 \mathrm{~A}$ & & IIIa & 14P1-11 & Perforator Group 7 & 1 \\
\hline E20/S78 & $16 \mathrm{~A}$ & & IIIa & $14 \mathrm{P} 1-3$ & Perforator Group 7 & 1 \\
\hline E20/S78 & $16 \mathrm{~A}$ & & IIIa & 14P1-8 & Unifacial multiple tool & 1 \\
\hline E20/S78 & $16 \mathrm{~B}$ & & IIIIa & 14P2-1 & Biface fragment & 1 \\
\hline E20/S78 & $16 \mathrm{~B}$ & & IIIIa & $14 \mathrm{P} 2-4$ & Biface fragment & 1 \\
\hline E20/S78 & $16 \mathrm{~B}$ & & IIIa & & Debitage & 273 \\
\hline E20/S78 & $16 \mathrm{~B}$ & & IIIa & $14 \mathrm{P} 2-5$ & Edge modified flake & 1 \\
\hline E20/S78 & $16 \mathrm{~B}$ & & IIIa & 14P2-6 & Microspur/microdenticulate & 1 \\
\hline E20/S78 & $16 \mathrm{~B}$ & & IIIa & 14P2-2 & Projectile point fragment & 1 \\
\hline E20/S78 & $17 \mathrm{~A}$ & & IIIIa & 14Q1-4 & Biface Stage 2 & 1 \\
\hline E20/S78 & $17 \mathrm{~A}$ & & IIIa & 14Q1-1 & Core fragment & 1 \\
\hline E20/S78 & $17 \mathrm{~A}$ & & IIIa & & Debitage & 143 \\
\hline E20/S78 & $17 \mathrm{~A}$ & & IIIIa & 14Q1-2 & Edge modified flake & 1 \\
\hline E20/S78 & $17 \mathrm{~A}$ & & IIIIa & 14Q1-3 & Perforator Unifacial & 1 \\
\hline E20/S78 & 17B & & IIIIa & 14Q2-2 & Biface fragment & 1 \\
\hline E20/S78 & $17 \mathrm{~B}$ & & IIIa & $14 \mathrm{Q} 2-1$ & Biface Stage 2 & 1 \\
\hline E20/S78 & $17 \mathrm{~B}$ & & IIIa & $14 \mathrm{Q} 2-3$ & Core fragment & 1 \\
\hline E20/S78 & $17 \mathrm{~B}$ & & IIIa & & Debitage & 503 \\
\hline E20/S78 & 17B & & IIIa & 14Q2-9 & Edge modified flake & 1 \\
\hline E20/S78 & 17B & & IIIa & $14 \mathrm{Q} 2-7$ & Edge modified flake & 1 \\
\hline E20/S78 & $17 \mathrm{~B}$ & & IIIa & 14Q2-10 & Edge modified flake & 1 \\
\hline E20/S78 & 17B & & IIIa & $14 \mathrm{Q} 2-8$ & Notched flake & 1 \\
\hline E20/S78 & 17B & & IIIa & $14 Q 2-4$ & Perforator Group 7 & 1 \\
\hline E20/S78 & 17B & & IIIa & 14\&15Q2-11 & Projectile point, miscellaneous lanceolate & 1 \\
\hline E20/S78 & 17B & & IIIa & $14 Q 2-5$ & Thin uniface & 1 \\
\hline E20/S78 & $17 \mathrm{~B}$ & & IIIa & 14Q2-6 & Thin uniface & 1 \\
\hline E20/S78 & $18 \mathrm{~A}$ & & II/IIIa & & Debitage & 502 \\
\hline E20/S78 & $18 \mathrm{~A}$ & & II/IIIa & 14R1-1 & Notched flake & 1 \\
\hline E20/S78 & $18 \mathrm{~A}$ & & ІІ/ІІІа & 14R1-2 & Thin uniface & 1 \\
\hline E20/S78 & $18 \mathrm{~B}$ & & II/IIIa & 14R2-1 & Biface Stage 3 & 1 \\
\hline E20/S78 & 18B & & II/IIIa & 14R2-4 & Chert cobble, unmodified/tested & 1 \\
\hline E20/S78 & $18 \mathrm{~B}$ & & II/IIIa & & Debitage & 216 \\
\hline E20/S78 & $18 \mathrm{~B}$ & & II/IIIa & 14R2-3 & Edge modified flake & 1 \\
\hline E20/S78 & $19 \mathrm{~A}$ & & II/IIIa & 14S1-2 & Biface Stage 1 & 1 \\
\hline E20/S78 & $19 \mathrm{~A}$ & & II/IIIa & $14 \mathrm{~S} 1-4$ & Biface Stage 1 & 1 \\
\hline E20/S78 & $19 \mathrm{~A}$ & & II/IIIa & & Debitage & 212 \\
\hline $\mathrm{E} 20 / \mathrm{S} 78$ & $19 \mathrm{~A}$ & & II/IIIa & 14S1-1 & Denticulated flake & 1 \\
\hline E20/S78 & $19 \mathrm{~A}$ & & II/IIIa & $14 \mathrm{~S} 1-3$ & Edge modified flake & 1 \\
\hline E20/S78 & $19 \mathrm{~A}$ & & II/IIIa & $14 \mathrm{~S} 1-5$ & Spurred flake & 1 \\
\hline E20/S78 & $19 \mathrm{~B}$ & & II/IIIa & $14 S 2-1$ & Burin spall & 1 \\
\hline E20/S78 & $19 \mathrm{~B}$ & & II/IIIa & & Debitage & 18 \\
\hline E20/S78 & $20 \mathrm{~A}$ & & II & $14 \mathrm{~T} 1-4$ & Burin spall & 1 \\
\hline E20/S78 & $20 \mathrm{~A}$ & & II & & Debitage & 170 \\
\hline E20/S78 & $20 \mathrm{~A}$ & & II & 14T1-1 & Edge modified flake & 1 \\
\hline
\end{tabular}




\begin{tabular}{|c|c|c|c|c|c|c|}
\hline Square & Level & Feature & Strata & Item & Analyst Identification & Count \\
\hline E20/S78 & $20 \mathrm{~A}$ & & II & $14 \mathrm{~T} 1-3$ & Thick uniface & \\
\hline E20/S78 & $20 \mathrm{~A}$ & & II & 14T1-2 & Unifacial multiple tool & 1 \\
\hline E20/S78 & $20 \mathrm{~B}$ & & II & $14 \mathrm{~T} 2-2$ & Biface Stage 2 & 1 \\
\hline E20/S78 & $20 \mathrm{~B}$ & & II & & Debitage & 168 \\
\hline $\mathrm{E} 20 / \mathrm{S} 78$ & $20 \mathrm{~B}$ & & II & $14 \mathrm{~T} 2-3$ & Edge modified flake & \\
\hline E20/S78 & $20 \mathrm{~B}$ & & II & 14T2-1 & Edge modified flake & r \\
\hline E20/S78 & $21 \mathrm{~A}$ & & II & & Debitage & 36 \\
\hline E20/S78 & $21 \mathrm{~B}$ & & $\mathrm{Id} / \mathrm{II}$ & $14 U 2-2$ & Burin spall & 1 \\
\hline E20/S78 & $21 \mathrm{~B}$ & & $\mathrm{Id} / \mathrm{II}$ & $14 U 2-4$ & Burin spall & 1 \\
\hline $\mathrm{E} 20 / \mathrm{S} 78$ & $21 \mathrm{~B}$ & & $\mathrm{Id} / \mathrm{II}$ & & Debitage & 148 \\
\hline $\mathrm{E} 20 / \mathrm{S} 78$ & $21 \mathrm{~B}$ & & $\mathrm{Id} / \mathrm{II}$ & 14U2-1 & Edge modified flake & \\
\hline E20/S78 & $21 \mathrm{~B}$ & & $\mathrm{Id} / \mathrm{II}$ & $14 U 2-5$ & Perforator Group 7 & 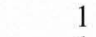 \\
\hline E20/S78 & $21 \mathrm{~B}$ & & $\mathrm{Id} / \mathrm{II}$ & 14U2-7 & Thin uniface & 1 \\
\hline E20/S78 & $22 \mathrm{~A}$ & & $\mathrm{Id} / \mathrm{II}$ & $14 V 1-4$ & Burin spall & 1 \\
\hline E20/S78 & $22 \mathrm{~A}$ & & $\mathrm{Id} / \mathrm{II}$ & 14V1-1 & Burin spall & \\
\hline E20/S78 & $22 \mathrm{~A}$ & & $\mathrm{Id} / \mathrm{II}$ & & Debitage & 122 \\
\hline E20/S78 & $22 \mathrm{~A}$ & & $\mathrm{Id} / \mathrm{II}$ & $14 \mathrm{~V} 1-3$ & Uniface, unanalyzed & 1 \\
\hline E20/S78 & $22 \mathrm{~A}$ & & $\mathrm{Id} / \mathrm{II}$ & $14 \mathrm{~V} 1-2$ & Unifacial multiple tool & 1 \\
\hline E20/S78 & $22 \mathrm{~B}$ & & Id/II & $14 \mathrm{~V} 2-1$ & Core, thermal & \\
\hline E20/S78 & $22 \mathrm{~B}$ & & $\mathrm{Id} / \mathrm{II}$ & & Debitage & 98 \\
\hline E20/S78 & $22 \mathrm{~B}$ & & $\mathrm{Id} / \mathrm{II}$ & $14 V 2-2$ & Denticulated flake & 1 \\
\hline E20/S78 & $23 \mathrm{~A}$ & & $\mathrm{Id} / \mathrm{II}$ & & Debitage & 75 \\
\hline E20/S78 & $23 \mathrm{~A}$ & & $\mathrm{Id} / \mathrm{II}$ & $14 \mathrm{~W} 1-3$ & Edge modified flake & 1 \\
\hline E20/S78 & $23 \mathrm{~B}$ & & $\mathrm{Id} / \mathrm{II}$ & $14 W 2-2$ & Bifacial tool Form A & 1 \\
\hline $\mathrm{E} 20 / \mathrm{S} 78$ & $23 \mathrm{~B}$ & & $\mathrm{Id} / \mathrm{II}$ & 14W2-1 & Clear Fork biface & 1 \\
\hline E20/S78 & $23 \mathrm{~B}$ & & $\mathrm{Id} / \mathrm{II}$ & & Debitage & 89 \\
\hline $\mathrm{E} 20 / \mathrm{S} 78$ & $23 \mathrm{~B}$ & & $\mathrm{Id} / \mathrm{II}$ & $14 W 2-4$ & Notched flake & 1 \\
\hline E20/S78 & $23 \mathrm{~B}$ & & $\mathrm{Id} / \mathrm{II}$ & $14 W 2-3$ & Projectile point fragment & 1 \\
\hline E20/S78 & $23 \mathrm{~B}$ & & $\mathrm{Id} / \mathrm{II}$ & $14 W 2-5$ & Thin uniface & 1 \\
\hline E20/S78 & $24 \mathrm{~A}$ & & Isi-c/Id & & Debitage & 27 \\
\hline E20/S78 & $24 \mathrm{~B}$ & & Isi-c/Id & & Debitage & 56 \\
\hline E20/S78 & $24 B$ & & Isi-c/Id & $14 \times 2-1$ & Thin uniface & 1 \\
\hline E20/S78 & $25 \mathrm{~A}$ & & Isi-c/Id & & Debitage & 61 \\
\hline E20/S78 & $25 \mathrm{~A}$ & & Isi-c/Id & $14 Y 1-2$ & Thick uniface & 1 \\
\hline E20/S78 & $25 \mathrm{~A}$ & & Isi-c/Id & $14 Y 1-1$ & Thin uniface & 1 \\
\hline E20/S78 & $25 \mathrm{~B}$ & & Isi-c/Id & & Debitage & 52 \\
\hline E20/S78 & $25 \mathrm{~B}$ & & Isi-c/Id & $14 Y 2-2$ & Edge modified flake & \\
\hline E20/S78 & $25 B$ & & Isi-c/Id & $14 Y 2-1$ & Edge modified flake & 1 \\
\hline E20/S78 & $25 \mathrm{~B}$ & & Isi-c/Id & $14 Y 2-3$ & Unifacial multiple tool & 1 \\
\hline E20/S78 & $26 \mathrm{~A}$ & & Isi-c & & Debitage & 43 \\
\hline E20/S78 & $26 \mathrm{~B}$ & & Isi-c & & Debitage & 37 \\
\hline E20/S78 & $27 \mathrm{~A}$ & & Isi-c & & Debitage & 47 \\
\hline E20/S78 & 29A-B & & Isi/Isi-c & & Debitage & 22 \\
\hline E20/S78 & $29 \mathrm{~B}$ & & Isi/Isi-c & & Debitage & 19 \\
\hline E20/S78 & $30-34 \mathrm{~A}$ & Feature 169 & Isi/Isi-c & & Debitage & 6 \\
\hline E20/S78 & $30 \mathrm{~A}$ & & Isi/Isi-c & & Debitage & 27 \\
\hline E20/S78 & $30 \mathrm{~A}$ & & Isi/Isi-c & 14DD1A-1 & Edge modified flake & 1 \\
\hline E20/S78 & $30 \mathrm{~B}$ & & Isi/Isi-c & & Debitage & 36 \\
\hline E20/S78 & $31 \mathrm{~A}$ & & Isi/Isi-c & & Debitage & 28 \\
\hline E20/S78 & $31 \mathrm{~B}$ & & Isi & 14EE2B-1 & Core fragment & 1 \\
\hline E20/S78 & $31 \mathrm{~B}$ & & Isi & & Debitage & 27 \\
\hline E20/S78 & $31 \mathrm{~B}$ & & Isi & 14EE2B-2 & Retouched blade & 1 \\
\hline E20/S78 & $32 \mathrm{~A}$ & & Isi & & Debitage & 13 \\
\hline $\mathrm{E} 20 / \mathrm{S} 78$ & $32 \mathrm{~A}$ & & Isi & 14FF1B-1 & Thin uniface & 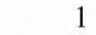 \\
\hline $\mathrm{E} 20 / \mathrm{S} 78$ & $32 \mathrm{~B}$ & & Isi & & Debitage & 10 \\
\hline E20/S78 & $32 \mathrm{~B}$ & & Isi & 14FF2B-1 & Edge modified flake & 1 \\
\hline E20/S78 & $33 \mathrm{~A}$ & & Isi & & Debitage & 1 \\
\hline E20/S78 & $34 \mathrm{~A}$ & & Isi & & Debitage & 5 \\
\hline E20/S78 & $35 \mathrm{~B}$ & & Isi & & Debitage & 1 \\
\hline $\mathrm{E} 20 / \mathrm{S} 78$ & $36 \mathrm{~A}$ & & Isi & & Debitage & 1 \\
\hline E20/S78 & $36 \mathrm{~B}$ & & Isi & & Debitage & 1 \\
\hline E20/S80 & 1 & & IIIc & $13 \mathrm{~A}-3$ & Arrow point, preform & 1 \\
\hline $\mathrm{E} 20 / \mathrm{S} 80$ & 1 & & IIIc & $13 \mathrm{~A}-9$ & Biface Stage 2 & \\
\hline $\mathrm{E} 20 / \mathrm{S} 80$ & 1 & & IIIc & & Debitage & 266 \\
\hline $\mathrm{E} 20 / \mathrm{S} 80$ & 1 & & IIIc & $13 \mathrm{~A}-15$ & Edge modified flake & 1 \\
\hline E20/S80 & 1 & & IIIc & $13 \mathrm{~A}-17$ & Edge modified flake & 1 \\
\hline $\mathrm{E} 20 / \mathrm{S} 80$ & 1 & & IIIc & $13 \mathrm{~A}-18$ & Edge modified flake & 1 \\
\hline $\mathrm{E} 20 / \mathrm{S} 80$ & 1 & & IIIc & $13 \mathrm{~A}-16$ & Edge modified flake & 1 \\
\hline $\mathrm{E} 20 / \mathrm{S} 80$ & 1 & & IIIc & $13 \mathrm{~A}-14$ & Notched flake & 1 \\
\hline $\mathrm{E} 20 / \mathrm{S} 80$ & 1 & & IIIc & $13 \mathrm{~A}-11$ & Projectile point fragment & 1 \\
\hline $\mathrm{E} 20 / \mathrm{S} 80$ & 1 & & IIIc & $13 \mathrm{~A}-7$ & Projectile point fragment & 1 \\
\hline $\mathrm{E} 20 / \mathrm{S} 80$ & 1 & & IIIc & $13 \mathrm{~A}-8$ & Projectile point fragment & 1 \\
\hline $\mathrm{E} 20 / \mathrm{S} 80$ & 1 & & IIIc & $13 \mathrm{~A}-1$ & Projectile point, Edgewood & 1 \\
\hline E20/S80 & 1 & & IIIc & $13 \mathrm{~A}-2$ & Projectile point, Ensor & 1 \\
\hline
\end{tabular}




\begin{tabular}{|c|c|c|c|c|c|c|}
\hline Square & Level & Feature & Strata & Item & Analyst Identification & Count \\
\hline E20/S80 & 1 & & IIIc & $13 \mathrm{~A}-5$ & Projectile point, indeterminate & 1 \\
\hline E20/S80 & 1 & & IIIc & $13 \mathrm{~A}-4$ & Small core hammerstone & 1 \\
\hline E20/S80 & 1 & & IIIc & $13 \mathrm{~A}-13$ & Unifacial multiple tool & 1 \\
\hline E20/S80 & 2 & & IIIc & $13 \mathrm{~B}-1$ & Biface Stage 2 & 1 \\
\hline $\mathrm{E} 20 / \mathrm{S} 80$ & 2 & & IIIc & & Debitage & 125 \\
\hline $\mathrm{E} 20 / \mathrm{S} 80$ & 2 & & IIIc & $13 \mathrm{~B}-2$ & Projectile point fragment & 1 \\
\hline E20/S80 & 3 & & IIIc & $13 \mathrm{C}-3$ & Biface fragment & 1 \\
\hline E20/S80 & 3 & & IIIc & $13 \mathrm{C}-1$ & Biface Stage 3 & 1 \\
\hline E20/S80 & 3 & & IIIc & $13 \mathrm{C}-2$ & Burin & 1 \\
\hline E20/S80 & 3 & & IIIc & $13 \mathrm{C}-4$ & Burin spall & 1 \\
\hline $\mathrm{E} 20 / \mathrm{S} 80$ & 3 & & IIIc & & Debitage & 156 \\
\hline E20/S80 & 3 & & IIIc & $13 \mathrm{C}-8$ & Edge modified flake & 1 \\
\hline E20/S80 & 3 & & IIIc & $13 \mathrm{C}-7$ & Edge modified flake & 1 \\
\hline E20/S80 & 3 & & IIIc & $13 \mathrm{C}-6$ & Edge modified flake & 1 \\
\hline E20/S80 & 3 & & IIIc & $13 \mathrm{C}-5$ & Edge modified flake & 1 \\
\hline E20/S80 & 3 & & IIIc & $13 \mathrm{C}-14$ & Edge modified flake & 1 \\
\hline $\mathrm{E} 20 / \mathrm{S} 80$ & 3 & & IIIc & $13 \mathrm{C}-11$ & Edge modified flake & 1 \\
\hline E20/S80 & 3 & & IIIIc & $13 \mathrm{C}-10$ & Edge modified flake & 1 \\
\hline E20/S80 & 3 & & IIIc & $13 \mathrm{C}-12$ & Thin uniface & 1 \\
\hline E20/S80 & 4 & & IIIc & 13D-6 & Biface Stage 2 & 1 \\
\hline E20/S80 & 4 & & IIIc & $13 \mathrm{D}-4$ & Biface Stage 2 & 1 \\
\hline E20/S80 & 4 & & IIIc & $13 \mathrm{D}-5$ & Bifacial tool Form A & 1 \\
\hline E20/S80 & 4 & & IIIc & $13 \mathrm{D}-3$ & Clear Fork biface, proximal & 1 \\
\hline E20/S80 & 4 & & IIIc & $13 \mathrm{D}-7$ & Core tool, type 4 & 1 \\
\hline E20/S80 & 4 & & IIIc & & Debitage & 425 \\
\hline E20/S80 & 4 & & IIIc & 13D-8 & Large core hammerstone & 1 \\
\hline E20/S80 & 4 & & IIIIc & 13D-1 & Projectile point, Ensor & 1 \\
\hline E20/S80 & 4 & & IIIc & $13 \mathrm{D}-2$ & Projectile point, Hoxie & 1 \\
\hline E20/S80 & 4 & & IIIc & 13D-9 & Unifacial multiple tool & 1 \\
\hline E20/S80 & 5 & & IIIc & $13 \mathrm{E}-2$ & Biface fragment & 1 \\
\hline E20/S80 & 5 & & IIII & $13 \mathrm{E}-5$ & Biface Stage 3 & 1 \\
\hline E20/S80 & 5 & & IIIc & $13 \mathrm{E}-4$ & Biface Stage 3 & 1 \\
\hline E20/S80 & 5 & & IIIc & & Debitage & 116 \\
\hline E20/S80 & 5 & & IIIc & $13 \mathrm{E}-19$ & Edge modified flake & 1 \\
\hline E20/S80 & 5 & & IIIC & $13 \mathrm{E}-8$ & Edge modified flake & 1 \\
\hline E20/S80 & 5 & & IIIc & 13E-11 & Edge modified flake & 1 \\
\hline E20/S80 & 5 & & IIIc & $13 \mathrm{E}-6$ & Edge modified flake & 1 \\
\hline E20/S80 & 5 & & IIIc & $13 \mathrm{E}-10$ & Edge modified flake & 1 \\
\hline $\mathrm{E} 20 / \mathrm{S} 80$ & 5 & & IIIc & $13 \mathrm{E}-16$ & Edge modified flake & 1 \\
\hline E20/S80 & 5 & & IIIc & $13 \mathrm{E}-15$ & Edge modified flake & 1 \\
\hline E20/S80 & 5 & & IIIc & $13 \mathrm{E}-14$ & Edge modified flake & 1 \\
\hline E20/S80 & 5 & & IIIc & $13 \mathrm{E}-12$ & Edge modified flake & 1 \\
\hline E20/S80 & 5 & & IIIc & $13 \mathrm{E}-7$ & Edge modified flake & 1 \\
\hline E20/S80 & 5 & & IIIIc & $13 \mathrm{E}-18$ & Edge modified flake & 1 \\
\hline E20/S80 & 5 & & IIIC & $13 \mathrm{E}-3$ & Projectile point fragment & 1 \\
\hline E20/S80 & 5 & & IIIc & $13 \mathrm{E}-1$ & Projectile point, beveled narrow stemmed & 1 \\
\hline $\mathrm{E} 20 / \mathrm{S} 80$ & 6 & & IIIc & $13 \mathrm{~F}-2$ & Biface Stage 2 & 1 \\
\hline E20/S80 & 6 & & IIIc & & Debitage & 235 \\
\hline $\mathrm{E} 20 / \mathrm{S} 80$ & 6 & & IIIc & $13 \mathrm{~F}-8$ & Edge modified flake & 1 \\
\hline $\mathrm{E} 20 / \mathrm{S} 80$ & 6 & & IIIc & $13 \mathrm{~F}-10$ & Edge modified flake & 1 \\
\hline $\mathrm{E} 20 / \mathrm{S} 80$ & 6 & & IIIc & $13 \mathrm{~F}-6$ & Edge modified flake & 1 \\
\hline E20/S80 & 6 & & IIIc & $13 \mathrm{~F}-9$ & Edge modified flake & 1 \\
\hline E20/S80 & 6 & & IIIc & $13 \mathrm{~F}-12$ & Edge modified flake & 1 \\
\hline E20/S80 & 6 & & IIIc & $13 \mathrm{~F}-5$ & Edge modified flake & 1 \\
\hline $\mathrm{E} 20 / \mathrm{S} 80$ & 6 & & IIIc & $13 \mathrm{~F}-1$ & Projectile point, Bulverde-like & 1 \\
\hline $\mathrm{E} 20 / \mathrm{S} 80$ & 6 & & IIIc & $13 \mathrm{~F}-4$ & Projectile point, Castroville & 1 \\
\hline E20/S80 & 6 & & IIIc & $13 \mathrm{~F}-3$ & Projectile point, miscellaneous bifurcate & 1 \\
\hline E20/S80 & 6 & & IIIc & $13 \mathrm{~F}-7$ & Unifacial multiple tool & 1 \\
\hline E20/S80 & 7 & & $\mathrm{IIIb} / \mathrm{c}$ & $13 \mathrm{G}-2$ & Biface fragment & 1 \\
\hline E20/S80 & 7 & & $\mathrm{IIIb} / \mathrm{c}$ & $13 \mathrm{G}-3$ & Biface Stage 2 & 1 \\
\hline $\mathrm{E} 20 / \mathrm{S} 80$ & 7 & & $\mathrm{IIIb} / \mathrm{c}$ & & Debitage & 170 \\
\hline E20/S80 & 7 & & $\mathrm{IIIb} / \mathrm{c}$ & $13 \mathrm{G}-6$ & Edge modified flake & 1 \\
\hline E20/S80 & 7 & & $\mathrm{IIIb} / \mathrm{c}$ & $13 \mathrm{G}-7$ & Edge modified flake & 1 \\
\hline E20/S80 & 7 & & $\mathrm{IIIb} / \mathrm{c}$ & $13 \mathrm{G}-8$ & Edge modified flake & 1 \\
\hline E20/S80 & 7 & & $\mathrm{IIIb} / \mathrm{c}$ & $13 \mathrm{G}-4$ & Micro-core, intermediate & 1 \\
\hline E20/S80 & 7 & & $\mathrm{IIIb} / \mathrm{c}$ & $13 \mathrm{G}-1$ & Projectile point, Bulverde & 1 \\
\hline $\mathrm{E} 20 / \mathrm{S} 80$ & 7 & & $\mathrm{IIIb} / \mathrm{c}$ & $13 \mathrm{G}-5$ & Projectile point, Pedernales & 1 \\
\hline E20/S80 & 7 & & $\mathrm{IIIb} / \mathrm{c}$ & $13 \mathrm{G}-10$ & Unifacial multiple tool & 1 \\
\hline $\mathrm{E} 20 / \mathrm{S} 80$ & 8 & & $\mathrm{IIIb} / \mathrm{c}$ & $13 \mathrm{H}-5$ & Biface Stage 3 & 1 \\
\hline $\mathrm{E} 20 / \mathrm{S} 80$ & 8 & & $\mathrm{IIIb} / \mathrm{c}$ & $13 \mathrm{H}-1$ & Bifacial tool Form A & 1 \\
\hline E20/S80 & 8 & & $\mathrm{IIIb} / \mathrm{c}$ & $13 \mathrm{H}-2$ & Burin & 1 \\
\hline E20/S80 & 8 & & $\mathrm{IIIb} / \mathrm{c}$ & & Debitage & 153 \\
\hline $\mathrm{E} 20 / \mathrm{S} 80$ & 8 & & $\mathrm{IIIb} / \mathrm{c}$ & $13 \mathrm{H}-4$ & Projectile point fragment & 1 \\
\hline E20/S80 & 8 & & $\mathrm{IIIb} / \mathrm{c}$ & $13 \mathrm{H}-3$ & Projectile point, Wells & 1 \\
\hline
\end{tabular}




\begin{tabular}{|c|c|c|c|c|c|}
\hline Square & Level & Feature & Strata & Item & Analyst Identification \\
\hline $\mathrm{E} 20 / \mathrm{S} 80$ & 9 & & $\mathrm{IIIb} / \mathrm{c}$ & $13 \mathrm{I}-2$ & Biface Stage 1 \\
\hline $\mathrm{E} 20 / \mathrm{S} 80$ & 9 & & $\mathrm{IIIb} / \mathrm{c}$ & $13 \mathrm{I}-3$ & Biface Stage 2 \\
\hline $\mathrm{E} 20 / \mathrm{S} 80$ & 9 & & $\mathrm{IIIb} / \mathrm{c}$ & & Debitage \\
\hline $\mathrm{E} 20 / \mathrm{S} 80$ & 9 & & $\mathrm{IIIb} / \mathrm{c}$ & $13 \mathrm{I}-8$ & Edge modified flake \\
\hline $\mathrm{E} 20 / \mathrm{S} 80$ & 9 & & $\mathrm{IIIb} / \mathrm{c}$ & $13 \mathrm{I}-10$ & Edge modified flake \\
\hline $\mathrm{E} 20 / \mathrm{S} 80$ & 9 & & $\mathrm{IIIb} / \mathrm{c}$ & $13 I-9$ & Edge modified flake \\
\hline $\mathrm{E} 20 / \mathrm{S} 80$ & 9 & & $\mathrm{IIIb} / \mathrm{c}$ & $13 \mathrm{I}-12$ & Edge modified flake \\
\hline $\mathrm{E} 20 / \mathrm{S} 80$ & 9 & & $\mathrm{IIIb} / \mathrm{c}$ & $13 \mathrm{I}-13$ & Edge modified flake \\
\hline E20/S80 & 9 & & $\mathrm{IIIb} / \mathrm{c}$ & $13 \mathrm{I}-4$ & Projectile point, Nolan \\
\hline E20/S80 & 9 & & $\mathrm{IIIb} / \mathrm{c}$ & $13 \mathrm{I}-1$ & Projectile point, Nolan \\
\hline $\mathrm{E} 20 / \mathrm{S} 80$ & 9 & & $\mathrm{IIIb} / \mathrm{c}$ & $13 \mathrm{I}-6$ & Retouched blade \\
\hline $\mathrm{E} 20 / \mathrm{S} 80$ & 9 & & $\mathrm{IIIb} / \mathrm{c}$ & $13 \mathrm{I}-11$ & Uniface, unanalyzed \\
\hline E20/S80 & 9 & & $\mathrm{IIIb} / \mathrm{c}$ & $13 \mathrm{I}-5$ & Unifacial multiple tool \\
\hline E20/S80 & 10 & & IIIb & $13 \mathrm{~J}-15$ & Biface fragment \\
\hline $\mathrm{E} 20 / \mathrm{S} 80$ & 10 & & IIIb & $13 \mathrm{~J}-24$ & Biface fragment \\
\hline $\mathrm{E} 20 / \mathrm{S} 80$ & 10 & & IIIb & $13 \mathrm{~J}-5$ & Biface Stage 2 \\
\hline $\mathrm{E} 20 / \mathrm{S} 80$ & 10 & & IIIb & $13 \mathrm{~J}-3$ & Biface Stage 2 \\
\hline $\mathrm{E} 20 / \mathrm{S} 80$ & 10 & & IIIb & $13 \mathrm{~J}-4$ & Biface Stage 3 \\
\hline E20/S80 & 10 & & IIIb & $13 \mathrm{~J}-11$ & Burin spall \\
\hline E20/S80 & 10 & & IIIb & $13 \mathrm{~J}-8$ & Core tool, type 1 \\
\hline E20/S80 & 10 & & $\mathrm{IIIb}$ & & Debitage \\
\hline E20/S80 & 10 & & IIIb & $13 \mathrm{~J}-21$ & Edge modified flake \\
\hline E20/S80 & 10 & & IIIb & $13 \mathrm{~J}-16$ & Edge modified flake \\
\hline $\mathrm{E} 20 / \mathrm{S} 80$ & 10 & & IIIb & $13 \mathrm{~J}-14$ & Edge modified flake \\
\hline E20/S80 & 10 & & IIIb & $13 \mathrm{~J}-20$ & Edge modified flake \\
\hline E20/S80 & 10 & & IIIb & $13 \mathrm{~J}-19$ & Microspur/microdenticulate \\
\hline E20/S80 & 10 & & IIIb & $13 \mathrm{~J}-23$ & Notched flake \\
\hline E20/S80 & 10 & & IIIb & $13 \mathrm{~J}-29$ & Perforator Group 3 \\
\hline E20/S80 & 10 & & IIIb & $13 \mathrm{~J}-6$ & Perforator Group 7 \\
\hline E20/S80 & 10 & & IIIb & $13 \mathrm{~J}-7$ & Projectile point fragment \\
\hline E20/S80 & 10 & & IIIb & $13 \mathrm{~J}-1$ & Projectile point, Jetta \\
\hline E20/S80 & 10 & & IIIb & $13 \mathrm{~J}-2$ & Projectile point, Martindale A \\
\hline $\mathrm{E} 20 / \mathrm{S} 80$ & 10 & & IIIb & $13 \mathrm{~J}-17$ & Spurred flake \\
\hline E20/S80 & 10 & & IIIb & $13 \mathrm{~J}-26$ & Thick uniface fragment \\
\hline $\mathrm{E} 20 / \mathrm{S} 80$ & 10 & & IIIb & $13 \mathrm{~J}-13$ & Thin uniface \\
\hline E20/S80 & 10 & & IIIb & $13 \mathrm{~J}-22$ & Thin uniface \\
\hline E20/S80 & 10 & & IIIb & $13 \mathrm{~J}-28$ & Thin uniface \\
\hline E20/S80 & 10 & & IIIb & $13 \mathrm{~J}-9$ & Thin uniface fragment \\
\hline E20/S80 & 10 & & IIIb & $13 \mathrm{~J}-27$ & Thin uniface fragment \\
\hline E20/S80 & 10 & & IIIb & $13 \mathrm{~J}-25$ & Uniface, unanalyzed \\
\hline E20/S80 & 10 & & IIIb & $13 \mathrm{~J}-10$ & Unifacial multiple tool \\
\hline E20/S80 & 10 & & IIIb & $13 \mathrm{~J}-18$ & Unifacial multiple tool \\
\hline E20/S80 & 11 & & IIIb & $13 \mathrm{~K}-8$ & Biface Stage 1 \\
\hline E20/S80 & 11 & & IIIb & $13 \mathrm{~K}-9$ & Biface Stage 2 \\
\hline E20/S80 & 11 & & IIIb & $13 \mathrm{~K}-5$ & Biface Stage 2 \\
\hline E20/S80 & 11 & & IIIb & $13 \mathrm{~K}-10$ & Bifacial tool \\
\hline $\mathrm{E} 20 / \mathrm{S} 80$ & 11 & & IIIb & $13 \mathrm{~K}-4$ & Bifacial tool Form A \\
\hline E20/S80 & 11 & & IIIb & $13 \mathrm{~K}-11$ & Bifacial tool Form B \\
\hline E20/S80 & 11 & & IIIb & $13 \mathrm{~K}-2$ & Core, thermal \\
\hline E20/S80 & 11 & & IIIb & & Debitage \\
\hline E20/S80 & 11 & & IIIb & $13 \mathrm{~K}-19$ & Edge modified flake \\
\hline E20/S80 & 11 & & IIIb & $13 \mathrm{~K}-16$ & Edge modified flake \\
\hline E20/S80 & 11 & & IIIb & $13 \mathrm{~K}-14$ & Edge modified flake \\
\hline $\mathrm{E} 20 / \mathrm{S} 80$ & 11 & & $\mathrm{IIIb}$ & $13 \mathrm{~K}-25$ & Edge modified flake \\
\hline E20/S80 & 11 & & IIIb & $13 \mathrm{~K}-27$ & Edge modified flake \\
\hline $\mathrm{E} 20 / \mathrm{S} 80$ & 11 & & IIIb & $13 \mathrm{~K}-20$ & Edge modified flake \\
\hline $\mathrm{E} 20 / \mathrm{S} 80$ & 11 & & IIIb & $13 \mathrm{~K}-24$ & Edge modified flake \\
\hline $\mathrm{E} 20 / \mathrm{S} 80$ & 11 & & IIIb & $13 \mathrm{~K}-12$ & Projectile point fragment \\
\hline E20/S80 & 11 & & IIIb & $13 \mathrm{~K}-13$ & Projectile point fragment \\
\hline E20/S80 & 11 & & IIIb & $13 \mathrm{~K}-28$ & Projectile point fragment \\
\hline E20/S80 & 11 & & IIIb & $13 \mathrm{~K}-1$ & Projectile point, Bell/Andice \\
\hline E20/S80 & 11 & & IIIb & $13 \mathrm{~K}-7$ & Thin uniface \\
\hline E20/S80 & 11 & & IIIb & $13 \mathrm{~K}-26$ & Thin uniface fragment \\
\hline E20/S80 & 11 & & IIIb & $13 \mathrm{~K}-18$ & Uniface, unanalyzed \\
\hline E20/S80 & 11 & & IIIb & $13 \mathrm{~K}-15$ & Unifacial multiple tool \\
\hline $\mathrm{E} 20 / \mathrm{S} 80$ & 11 & & IIIb & $13 \mathrm{~K}-23$ & Unifacial multiple tool \\
\hline E20/S80 & 12 & & IIIb & $13 \mathrm{~L}-1$ & Biface Stage 2 \\
\hline $\mathrm{E} 20 / \mathrm{S} 80$ & 12 & & IIIb & $13 \mathrm{~L}-2$ & Biface Stage 2 \\
\hline E20/S80 & 12 & & $\mathrm{IIIb}$ & $13 \mathrm{~L}-3$ & Biface Stage 3 \\
\hline E20/S80 & 12 & & $\mathrm{IIIb}$ & $13 \mathrm{~L}-4$ & Clear Fork biface \\
\hline E20/S80 & 12 & & IIIb & & Debitage \\
\hline $\mathrm{E} 20 / \mathrm{S} 80$ & 12 & & IIIb & $13 \mathrm{~L}-8$ & Edge modified flake \\
\hline E20/S80 & 12 & & IIIb & $13 \mathrm{~L}-5$ & Edge modified flake \\
\hline E20/S80 & 12 & & $\mathrm{IIIb}$ & $13 \mathrm{~L}-10$ & Microspur/microdenticulate \\
\hline
\end{tabular}




\begin{tabular}{|c|c|c|c|c|c|c|}
\hline Square & Level & Feature & Strata & Item & Analyst Identification & Count \\
\hline $\mathrm{E} 20 / \mathrm{S} 80$ & 12 & & IIIb & $13 \mathrm{~L}-11$ & Microspur/microdenticulate & 1 \\
\hline E20/S80 & 12 & & IIIb & $13 \mathrm{~L}-7$ & Notched flake & 1 \\
\hline E20/S80 & 12 & & IIIb & $13 \mathrm{~L}-9$ & Notched flake & 1 \\
\hline E20/S80 & 12 & & IIIb & $13 \mathrm{~L}-6$ & Spurred flake & 1 \\
\hline E20/S80 & 12 & & $\mathrm{IIIb}$ & $13 \mathrm{~L}-12$ & Unifacial multiple tool & 1 \\
\hline E20/S80 & 13 & & IIIb & $13 \mathrm{M}-7$ & Bifacial tool Form C & 1 \\
\hline E20/S80 & 13 & & IIIb & $13 \mathrm{M}-13$ & Burin & 1 \\
\hline E20/S80 & 13 & & IIIb & $13 \mathrm{M}-6$ & Burin spall & 1 \\
\hline $\mathrm{E} 20 / \mathrm{S} 80$ & 13 & & $\mathrm{IIIb}$ & $13 \mathrm{M}-3$ & Chert cobble, chunk & 1 \\
\hline $\mathrm{E} 20 / \mathrm{S} 80$ & 13 & & $\mathrm{IIIb}$ & $13 \mathrm{M}-2$ & Core fragment & 1 \\
\hline E20/S80 & 13 & & IIIb & $13 \mathrm{M}-1$ & Core tool, type 3 & 1 \\
\hline E20/S80 & 13 & & IIIb & & Debitage & 304 \\
\hline E20/S80 & 13 & & IIIb & $13 \mathrm{M}-10$ & Edge modified flake & 1 \\
\hline $\mathrm{E} 20 / \mathrm{S} 80$ & 13 & & $\mathrm{IIIb}$ & $13 \mathrm{M}-5$ & Projectile point fragment & 1 \\
\hline E20/S80 & 13 & & IIIb & $13 \mathrm{M}-4$ & Projectile point, bifurcate stem fragment & 1 \\
\hline E20/S80 & 13 & & IIIb & $13 \mathrm{M}-12$ & Thin uniface & 1 \\
\hline E20/S80 & 13 & & IIIb & $13 \mathrm{M}-15$ & Thin uniface & 1 \\
\hline E20/S80 & 13 & & IIIb & $13 \mathrm{M}-14$ & Unifacial multiple tool & 1 \\
\hline $\mathrm{E} 20 / \mathrm{S} 80$ & 13 & & IIIb & $13 \mathrm{M}-9$ & Unifacial multiple tool & 1 \\
\hline E20/S80 & 13 & & IIIb & $13 \mathrm{M}-11$ & Unifacial multiple tool & 1 \\
\hline E20/S80 & 14 & & $\mathrm{III} / \mathrm{b}$ & $13 N-3$ & Bifacial tool Form C & 1 \\
\hline E20/S80 & 14 & & $\mathrm{III} / \mathrm{b}$ & $13 \mathrm{~N}-5$ & Burin & 1 \\
\hline E20/S80 & 14 & & $\mathrm{IIIa} / \mathrm{b}$ & & Debitage & 376 \\
\hline E20/S80 & 14 & & $\mathrm{III} / \mathrm{b}$ & $13 \mathrm{~N}-4$ & Piece esquillee & 1 \\
\hline E20/S80 & 14 & & $\mathrm{III} / \mathrm{b}$ & $13 \mathrm{~N}-1$ & Projectile point, Hoxie C & 1 \\
\hline $\mathrm{E} 20 / \mathrm{S} 80$ & 14 & & $\mathrm{IIIa} / \mathrm{b}$ & $13 \mathrm{~N}-2$ & Projectile point, Thrall & 1 \\
\hline E20/S80 & 15 & & IIIa & $130-1$ & Biface Stage 1 & 1 \\
\hline $\mathrm{E} 20 / \mathrm{S} 80$ & 15 & & IIIa & $13 \mathrm{O}-2$ & Biface Stage 2 & 1 \\
\hline $\mathrm{E} 20 / \mathrm{S} 80$ & 15 & & IIIa & & Debitage & 309 \\
\hline E20/S80 & 15 & & IIIa & $130-7$ & Edge modified flake & 1 \\
\hline E20/S80 & 15 & & IIIa & $130-3$ & Projectile point fragment & 1 \\
\hline E20/S80 & 15 & & IIIa & $13 \mathrm{O}-4$ & Projectile point, miscellaneous lanceolate & 1 \\
\hline $\mathrm{E} 20 / \mathrm{S} 80$ & 15 & & IIIa & $130-5$ & Thin uniface & 1 \\
\hline $\mathrm{E} 20 / \mathrm{S} 80$ & 15 & & IIIIa & $130-6$ & Unifacial multiple tool & 1 \\
\hline E20/S80 & 16 & & IIIIa & $13 \mathrm{P}-2$ & Biface fragment & 1 \\
\hline E20/S80 & 16 & & IIIa & $13 \mathrm{P}-4$ & Biface Stage 3 & 1 \\
\hline $\mathrm{E} 20 / \mathrm{S} 80$ & 16 & & IIIa & $13 \mathrm{P}-1$ & Bifacial tool Form D & 1 \\
\hline $\mathrm{E} 20 / \mathrm{S} 80$ & 16 & & IIIa & $13 \mathrm{P}-5$ & Bifacial tool Form $\mathrm{H}$ & 1 \\
\hline E20/S80 & 16 & & IIIa & $13 \mathrm{P}-6$ & Burin spall & 1 \\
\hline $\mathrm{E} 20 / \mathrm{S} 80$ & 16 & & IIIa & & Debitage & 437 \\
\hline E20/S80 & 16 & & IIIa & $13 \mathrm{P}-7$ & Edge modified flake & 1 \\
\hline $\mathrm{E} 20 / \mathrm{S} 80$ & 16 & & IIIa & $13 \mathrm{P}-3$ & Projectile point, Hoxie & 1 \\
\hline E20/S80 & 17 & & II/IIIa & $13 \mathrm{Q}-3$ & Biface fragment & 1 \\
\hline E20/S80 & 17 & & II/IIIa & $13 \mathrm{Q}-4$ & Biface fragment & 1 \\
\hline $\mathrm{E} 20 / \mathrm{S} 80$ & 17 & & II/IIIa & & Debitage & 431 \\
\hline $\mathrm{E} 20 / \mathrm{S} 80$ & 17 & & II/IIIa & 13Q-8 & Edge modified flake & 1 \\
\hline $\mathrm{E} 20 / \mathrm{S} 80$ & 17 & & II/IIIa & $13 \mathrm{Q}-7$ & Edge modified flake & 1 \\
\hline $\mathrm{E} 20 / \mathrm{S} 80$ & 17 & & II/IIIa & $13 Q-6$ & Perforator Group 7 & 1 \\
\hline $\mathrm{E} 20 / \mathrm{S} 80$ & 17 & & II/IIIa & $13 \mathrm{Q}-1$ & Projectile point, Angostura & 1 \\
\hline E20/S80 & 17 & & II/IIIa & $13 Q-2$ & Projectile point, Golondrina-Barber & 1 \\
\hline $\mathrm{E} 20 / \mathrm{S} 80$ & 17 & & II/IIIa & $13 Q-5$ & Projectile point, miscellaneous lanceolate & 1 \\
\hline $\mathrm{E} 20 / \mathrm{S} 80$ & 17 & & II/IIIa & $13 Q-9$ & Thin uniface & 1 \\
\hline E20/S80 & 18 & & II & $13 \mathrm{R}-1$ & Bifacial tool Form E & 1 \\
\hline $\mathrm{E} 20 / \mathrm{S} 80$ & 18 & & II & & Debitage & 137 \\
\hline $\mathrm{E} 20 / \mathrm{S} 80$ & 20 & & II & & Debitage & 114 \\
\hline $\mathrm{E} 20 / \mathrm{S} 80$ & 20 & & II & $13 \mathrm{~T}-1$ & Thin uniface & 1 \\
\hline $\mathrm{E} 20 / \mathrm{S} 80$ & 21 & & II & & Debitage & 136 \\
\hline $\mathrm{E} 20 / \mathrm{S} 80$ & 21 & & II & $13 \mathrm{U}-4$ & Edge modified flake & 1 \\
\hline $\mathrm{E} 20 / \mathrm{S} 80$ & 21 & & II & $13 \mathrm{U}-2$ & Edge modified flake & 1 \\
\hline $\mathrm{E} 20 / \mathrm{S} 80$ & 21 & & II & $13 \mathrm{U}-1$ & Projectile point, Wilson & 1 \\
\hline $\mathrm{E} 20 / \mathrm{S} 80$ & 21 & & II & $13 \mathrm{U}-5$ & Thin uniface & 1 \\
\hline $\mathrm{E} 20 / \mathrm{S} 80$ & 21 & & II & $13 \mathrm{U}-3$ & Thin uniface fragment & 1 \\
\hline E20/S80 & 22 & & $\mathrm{Id} / \mathrm{II}$ & $13 \mathrm{~V}-1$ & Biface Stage 3 & 1 \\
\hline $\mathrm{E} 20 / \mathrm{S} 80$ & 22 & & $\mathrm{Id} / \mathrm{II}$ & $13 \mathrm{~V}-2$ & Core, multidirectional & 1 \\
\hline $\mathrm{E} 20 / \mathrm{S} 80$ & 22 & & $\mathrm{Id} / \mathrm{II}$ & & Debitage & 84 \\
\hline $\mathrm{E} 20 / \mathrm{S} 80$ & 22 & & $\mathrm{Id} / \mathrm{II}$ & $13 \mathrm{~V}-4$ & Edge modified flake & 1 \\
\hline $\mathrm{E} 20 / \mathrm{S} 80$ & 22 & & $\mathrm{Id} / \mathrm{II}$ & $13 \mathrm{~V}-5$ & Thin uniface & 1 \\
\hline E20/S80 & 23 & & Isi-c/Id & $13 \mathrm{~W}-2$ & Biface fragment & 1 \\
\hline $\mathrm{E} 20 / \mathrm{S} 80$ & 23 & & Isi-c/Id & & Debitage & 71 \\
\hline $\mathrm{E} 20 / \mathrm{S} 80$ & 23 & & Isi-c/Id & $13 \mathrm{~W}-1$ & Unifacial multiple tool & 1 \\
\hline $\mathrm{E} 20 / \mathrm{S} 80$ & 23 & & Isi-c/Id & $13 \mathrm{~W}-3$ & Worked hematite & 1 \\
\hline E20/S80 & 24 & & Isi-c & & Debitage & 24 \\
\hline E20/S80 & 25 & & Isi-c & & Debitage & 53 \\
\hline $\mathrm{E} 20 / \mathrm{S} 80$ & 26 & & Isi/Isi-c & $13 \mathrm{AA}-4$ & Biface fragment & 1 \\
\hline
\end{tabular}




\begin{tabular}{|c|c|c|c|c|c|c|}
\hline Square & Level & Feature & Strata & Item & Analyst Identification & $\begin{array}{r}\text { Count } \\
90\end{array}$ \\
\hline E20/S80 & 26 & & Isi/Isi-c & & Debitage & 90 \\
\hline E20/S80 & 26 & & Isi/Isi-c & 13AA-1 & Edge modified flake & 1 \\
\hline $\mathrm{E} 20 / \mathrm{S} 80$ & 26 & & Isi/Isi-c & $13 \mathrm{AA}-3$ & Edge modified flake & 1 \\
\hline $\mathrm{E} 20 / \mathrm{S} 80$ & 26 & & Isi/Isi-c & $13 \mathrm{AA}-5$ & Edge modified flake & 1 \\
\hline $\mathrm{E} 20 / \mathrm{S} 80$ & 26 & & Isi/Isi-c & 13AA-2 & Thin uniface & 1 \\
\hline $\mathrm{E} 20 / \mathrm{S} 80$ & 27 & & Isi & & Debitage & 42 \\
\hline $\mathrm{E} 20 / \mathrm{S} 80$ & 27 & & Isi & 13BB-1 & Thin uniface & 1 \\
\hline E20/S82 & 1 & & IIIc & $12 \mathrm{~A}-10$ & Arrow point, stemmed & 1 \\
\hline E20/S82 & 1 & & IIIC & $12 \mathrm{~A}-2$ & Biface fragment & 1 \\
\hline $\mathrm{E} 20 / \mathrm{S} 82$ & 1 & & IIIc & $12 \mathrm{~A}-1$ & Biface Stage 2 & 1 \\
\hline E20/S82 & 1 & & IIIIc & $12 \mathrm{~A}-3$ & Biface Stage 2 & 1 \\
\hline E20/S82 & 1 & & IIIc & $12 \mathrm{~A}-4$ & Bifacial tool Form B & 1 \\
\hline E20/S82 & 1 & & IIIc & $12 \mathrm{~A}-8$ & Burin spall & 1 \\
\hline E20/S82 & 1 & & IIIc & & Debitage & 770 \\
\hline E20/S82 & 1 & & IIIIc & $12 \mathrm{~A}-7$ & Edge modified flake & 1 \\
\hline $\mathrm{E} 20 / \mathrm{S} 82$ & 1 & & IIIIc & $12 \mathrm{~A}-12$ & Indeterminate ground stone & 1 \\
\hline $\mathrm{E} 20 / \mathrm{S} 82$ & 1 & & IIIc & $12 \mathrm{~A}-11$ & Projectile point fragment & 1 \\
\hline $\mathrm{E} 20 / \mathrm{S} 82$ & 1 & & IIIc & $12 \mathrm{~A}-5$ & Projectile point fragment & 1 \\
\hline E20/S82 & 1 & & IIIIc & $12 \mathrm{~A}-6$ & Projectile point fragment & 1 \\
\hline E20/S82 & 1 & & IIIIc & $12 \mathrm{~A}-9$ & Projectile point, Bulverde & 1 \\
\hline $\mathrm{E} 20 / \mathrm{S} 82$ & 2 & Feature 7 & IIIc & $12 \mathrm{~B}-1$ & Arrow point, stemmed & 1 \\
\hline $\mathrm{E} 20 / \mathrm{S} 82$ & 2 & Feature 7 & IIIc & & Debitage & 330 \\
\hline E20/S82 & 2 & Feature 7 & IIIc & $12 \mathrm{~B}-2$ & Projectile point, miscellaneous side-notched & 1 \\
\hline $\mathrm{E} 20 / \mathrm{S} 82$ & 3 & & IIIIc & & Debitage & 267 \\
\hline $\mathrm{E} 20 / \mathrm{S} 82$ & 3 & & IIIIc & $12 \mathrm{C}-3$ & Projectile point fragment & 1 \\
\hline $\mathrm{E} 20 / \mathrm{S} 82$ & 3 & & IIIc & $12 \mathrm{C}-2$ & Projectile point, miscellaneous bifurcate & 1 \\
\hline $\mathrm{E} 20 / \mathrm{S} 82$ & 3 & & IIIc & $12 \mathrm{C}-1$ & Projectile point, Wells & 1 \\
\hline E20/S82 & 4 & & IIIIc & $12 \mathrm{D}-1$ & Biface fragment & 1 \\
\hline E20/S82 & 4 & & IIIc & & Debitage & 450 \\
\hline E20/S82 & 4 & & IIIc & $12 \mathrm{D}-5$ & Edge modified flake & 1 \\
\hline E20/S82 & 4 & & IIII & $12 \mathrm{D}-3$ & Edge modified flake & 1 \\
\hline E20/S82 & 4 & & IIIc & $12 \mathrm{D}-4$ & Edge modified flake & 1 \\
\hline E20/S82 & 4 & & IIIc & $12 \mathrm{D}-2$ & Projectile point, Fairland & 1 \\
\hline $\mathrm{E} 20 / \mathrm{S} 82$ & 4 & & IIIIc & $12 \mathrm{D}-6$ & Unifacial multiple tool & 1 \\
\hline E20/S82 & 5 & & IIIc & $12 \mathrm{E}-10$ & Biface fragment & 1 \\
\hline E20/S82 & 5 & & IIIc & $12 \mathrm{E}-11$ & Biface fragment & 1 \\
\hline E20/S82 & 5 & & IIIIc & $12 \mathrm{E}-12$ & Biface fragment & 1 \\
\hline $\mathrm{E} 20 / \mathrm{S} 82$ & 5 & & IIIIc & $12 \mathrm{E}-13$ & Biface Stage 2 & 1 \\
\hline E20/S82 & 5 & & IIIc & $12 \mathrm{E}-14$ & Biface Stage 2 & 1 \\
\hline E20/S82 & 5 & & IIIc & & Debitage & 870 \\
\hline E20/S82 & 5 & & IIIc & $12 E-22$ & Edge modified flake & 1 \\
\hline $\mathrm{E} 20 / \mathrm{S} 82$ & 5 & & IIIIc & $12 \mathrm{E}-16$ & Edge modified flake & 1 \\
\hline E20/S82 & 5 & & IIIIc & $12 \mathrm{E}-17$ & Edge modified flake & 1 \\
\hline E20/S82 & 5 & & IIIc & $12 \mathrm{E}-19$ & Edge modified flake & 1 \\
\hline E20/S82 & 5 & & IIIIc & $12 \mathrm{E}-21$ & Edge modified flake & 1 \\
\hline E20/S82 & 5 & & IIIc & $12 \mathrm{E}-6$ & Projectile point, Castroville & 1 \\
\hline E20/S82 & 5 & & IIII & 12E-2 & Projectile point, Ensor & 1 \\
\hline E20/S82 & 5 & & IIIIC & $12 \mathrm{E}-15$ & Projectile point, Marcos & 1 \\
\hline E20/S82 & 5 & & IIIc & $12 \mathrm{E}-4$ & Projectile point, Marcos & 1 \\
\hline E20/S82 & 5 & & IIIc & $12 \mathrm{E}-5$ & Projectile point, Marshall & 1 \\
\hline E20/S82 & 5 & & IIIIc & $12 \mathrm{E}-3$ & Projectile point, Marshall & 1 \\
\hline $\mathrm{E} 20 / \mathrm{S} 82$ & 5 & & IIIIc & $12 \mathrm{E}-7$ & Projectile point, Montell & 1 \\
\hline E20/S82 & 5 & & IIII & $12 \mathrm{E}-8$ & Projectile point, Pedernales & 1 \\
\hline E20/S82 & 5 & & IIII & $12 \mathrm{E}-1$ & Projectile point, Travis-like & 1 \\
\hline E20/S82 & 5 & & IIIIc & 12E-20 & Thin uniface fragment & 1 \\
\hline E20/S82 & 6 & & IIIc & & Debitage & 332 \\
\hline $\mathrm{E} 20 / \mathrm{S} 82$ & 6 & & IIIc & $12 \mathrm{~F}-8$ & Edge modified flake & 1 \\
\hline E20/S82 & 6 & & IIIc & $12 \mathrm{~F}-6$ & Edge modified flake & 1 \\
\hline E20/S82 & 6 & & IIIIc & $12 \mathrm{~F}-5$ & Edge modified flake & 1 \\
\hline E20/S82 & 6 & & IIIc & $12 \mathrm{~F}-1$ & Projectile point, Nolan & 1 \\
\hline E20/S82 & 6 & Feature 14 & IIIc & $12 \mathrm{~F}-3$ & Biface fragment & 1 \\
\hline $\mathrm{E} 20 / \mathrm{S} 82$ & 6 & Feature 14 & IIIc & $12 \mathrm{~F}-4$ & Biface Stage 2 & 1 \\
\hline E20/S82 & 6 & Feature 14 & IIIc & $12 \mathrm{~F}-2$ & Bifacial tool Form A & 1 \\
\hline E20/S82 & 7 & & $\mathrm{IIIb} / \mathrm{c}$ & $12 \mathrm{G}-6$ & Biface Stage 2 & 1 \\
\hline E20/S82 & 7 & & IIIb/c & & Debitage & 557 \\
\hline E20/S82 & 7 & & IIIb/c & $12 \mathrm{G}-8$ & Edge modified flake & 1 \\
\hline E20/S82 & 7 & & $\mathrm{IIIb} / \mathrm{c}$ & $12 \mathrm{G}-7$ & Edge modified flake & 1 \\
\hline E20/S82 & 7 & & $\mathrm{IIIb} / \mathrm{c}$ & $12 \mathrm{G}-5$ & Mano fragment & 1 \\
\hline E20/S82 & 7 & & $\mathrm{IIIb} / \mathrm{c}$ & $12 \mathrm{G}-9$ & Notched flake & 1 \\
\hline E20/S82 & 7 & & $\mathrm{IIIb} / \mathrm{c}$ & $12 \mathrm{G}-4$ & Projectile point fragment & 1 \\
\hline $\mathrm{E} 20 / \mathrm{S} 82$ & 7 & & IIIb/c & $12 \mathrm{G}-1$ & Projectile point, expanding concave B & 1 \\
\hline E20/S82 & 7 & & $\mathrm{IIIb} / \mathrm{c}$ & $12 \mathrm{G}-2$ & Projectile point, miscellaneous bifurcate & 1 \\
\hline E20/S82 & 7 & & $\mathrm{IIIb} / \mathrm{c}$ & $12 \mathrm{G}-3$ & Projectile point, Uvalde & 1 \\
\hline E20/S82 & 8 & & $\mathrm{IIIb} / \mathrm{c}$ & $12 \mathrm{H}-11$ & Biface Stage 1 & 1 \\
\hline
\end{tabular}




\begin{tabular}{|c|c|c|c|c|c|c|}
\hline Square & Level & Feature & Strata & Item & Analyst Identification & Count \\
\hline $\mathrm{E} 20 / \mathrm{S} 82$ & 8 & & $\mathrm{IIIb} / \mathrm{c}$ & $12 \mathrm{H}-2$ & Biface Stage 3 & 1 \\
\hline E20/S82 & 8 & & $\mathrm{IIIb} / \mathrm{c}$ & $12 \mathrm{H}-3$ & Bifacial tool Form E & 1 \\
\hline E20/S82 & 8 & & $\mathrm{IIIb} / \mathrm{c}$ & $12 \mathrm{H}-1$ & Burin & 1 \\
\hline $\mathrm{E} 20 / \mathrm{S} 82$ & 8 & & $\mathrm{IIIb} / \mathrm{c}$ & & Debitage & 395 \\
\hline E20/S82 & 8 & & $\mathrm{IIIb} / \mathrm{c}$ & $12 \mathrm{H}-7$ & Edge modified flake & 1 \\
\hline E20/S82 & 8 & & $\mathrm{IIIb} / \mathrm{c}$ & $12 \mathrm{H}-10$ & Edge modified flake & 1 \\
\hline E20/S82 & 8 & & $\mathrm{IIIb} / \mathrm{c}$ & $12 \mathrm{H}-8$ & Edge modified flake & 1 \\
\hline E20/S82 & 8 & & $\mathrm{IIIb} / \mathrm{c}$ & $12 \mathrm{H}-6$ & Edge modified flake & 1 \\
\hline $\mathrm{E} 20 / \mathrm{S} 82$ & 8 & & $\mathrm{IIIb} / \mathrm{c}$ & $12 \mathrm{H}-9$ & Edge modified flake & 1 \\
\hline E20/S82 & 8 & & $\mathrm{IIIb} / \mathrm{c}$ & $12 \mathrm{H}-5$ & Projectile point fragment & 1 \\
\hline E20/S82 & 8 & & $\mathrm{IIIb} / \mathrm{c}$ & $12 \mathrm{H}-4$ & Projectile point, expanding stem A & 1 \\
\hline E20/S82 & 9 & & $\mathrm{IIIb} / \mathrm{c}$ & $12 \mathrm{I}-10$ & Chert cobble, chunk & 1 \\
\hline E20/S82 & 9 & & $\mathrm{IIIb} / \mathrm{c}$ & & Debitage & 357 \\
\hline E20/S82 & 9 & & $\mathrm{IIIb} / \mathrm{c}$ & $12 \mathrm{I}-6$ & Edge modified flake & 1 \\
\hline E20/S82 & 9 & & $\mathrm{IIIb} / \mathrm{c}$ & $12 \mathrm{I}-5$ & Edge modified flake & 1 \\
\hline E20/S82 & 9 & & $\mathrm{IIIb} / \mathrm{c}$ & $12 \mathrm{I}-3$ & Edge modified flake & 1 \\
\hline E20/S82 & 9 & & $\mathrm{IIIb} / \mathrm{c}$ & $12 \mathrm{I}-1$ & Edge modified flake & 1 \\
\hline E20/S82 & 9 & & $\mathrm{IIIb} / \mathrm{c}$ & $12 \mathrm{I}-4$ & Microspur/microdenticulate & 1 \\
\hline E20/S82 & 9 & & $\mathrm{IIIb} / \mathrm{c}$ & $12 \mathrm{I}-7$ & Notched flake & 1 \\
\hline E20/S82 & 9 & & $\mathrm{IIIb} / \mathrm{c}$ & $12 \mathrm{I}-2$ & Thin uniface & 1 \\
\hline E20/S82 & 9 & & $\mathrm{IIIb} / \mathrm{c}$ & $12 \mathrm{I}-8$ & Thin uniface fragment & 1 \\
\hline E20/S82 & 9 & & $\mathrm{IIIb} / \mathrm{c}$ & $12 \mathrm{I}-9$ & Thin uniface fragment & 1 \\
\hline E20/S82 & 10 & & IIIb & & Debitage & 354 \\
\hline E20/S82 & 10 & & $\mathrm{IIIb}$ & $12 \mathrm{~J}-4$ & Edge modified flake & 1 \\
\hline $\mathrm{E} 20 / \mathrm{S} 82$ & 10 & & $\mathrm{IIIb}$ & $12 \mathrm{~J}-6$ & Edge modified flake & 1 \\
\hline E20/S82 & 10 & & $\mathrm{IIIb}$ & $12 \mathrm{~J}-7$ & Notched flake & 1 \\
\hline E20/S82 & 10 & & $\mathrm{IIIb}$ & $12 \mathrm{~J}-1$ & Projectile point, Bell/Andice & $\hat{1}$ \\
\hline E20/S82 & 10 & & IIIb & $12 \mathrm{~J}-3$ & Retouched blade & 1 \\
\hline E20/S82 & 10 & & $\mathrm{IIIb}$ & $12 \mathrm{~J}-5$ & Thin uniface & 1 \\
\hline E20/S82 & 10 & & $\mathrm{IIIb}$ & $12 \mathrm{~J}-8$ & Thin uniface & 1 \\
\hline E20/S82 & 10 & & $\mathrm{IIIb}$ & $12 \mathrm{~J}-2$ & Thin uniface & 1 \\
\hline $\mathrm{E} 20 / \mathrm{S} 82$ & 11 & & IIIb & & Debitage & 761 \\
\hline E20/S82 & 11 & & IIIb & $12 \mathrm{~K}-1$ & Projectile point, Martindale B & 1 \\
\hline E20/S82 & 11 & & IIIb & $12 \mathrm{~K}-2$ & Projectile point, Uvalde & 1 \\
\hline E20/S82 & 12 & & $\mathrm{IIIb}$ & $12 \mathrm{~L}-6$ & Biface Stage 1 & 1 \\
\hline E20/S82 & 12 & & $\mathrm{IIIb}$ & $12 \mathrm{~L}-18$ & Biface Stage 1 & 1 \\
\hline E20/S82 & 12 & & $\mathrm{IIIb}$ & $12 \mathrm{~L}-3$ & Biface Stage 2 & 1 \\
\hline E20/S82 & 12 & & IIIb & $12 \mathrm{~L}-4$ & Burin spall & 1 \\
\hline E20/S82 & 12 & & IIIb & $12 \mathrm{~L}-12$ & Burin spall & 1 \\
\hline E20/S82 & 12 & & IIIb & $12 \mathrm{~L}-9$ & Clear Fork biface & 1 \\
\hline $\mathrm{E} 20 / \mathrm{S} 82$ & 12 & & $\mathrm{IIIb}$ & $12 \mathrm{~L}-5$ & Core fragment & 1 \\
\hline $\mathrm{E} 20 / \mathrm{S} 82$ & 12 & & IIIb & & Debitage & 895 \\
\hline E20/S82 & 12 & & IIIb & $12 \mathrm{~L}-13$ & Edge modified flake & 1 \\
\hline E20/S82 & 12 & & $\mathrm{IIIb}$ & $12 \mathrm{~L}-11$ & Edge modified flake & 1 \\
\hline E20/S82 & 12 & & $\mathrm{IIIb}$ & $12 \mathrm{~L}-15$ & Edge modified flake & 1 \\
\hline E20/S82 & 12 & & $\mathrm{IIIb}$ & $12 \mathrm{~L}-10$ & Edge modified flake & 1 \\
\hline E20/S82 & 12 & & IIIb & $12 \mathrm{~L}-20$ & Edge modified flake & 1 \\
\hline E20/S82 & 12 & & IIIb & $12 \mathrm{~L}-19$ & Edge modified flake & 1 \\
\hline E20/S82 & 12 & & IIIb & $12 \mathrm{~L}-8$ & Projectile point fragment & 1 \\
\hline E20/S82 & 12 & & IIIb & $12 \mathrm{~L}-1$ & Projectile point, Baker & 1 \\
\hline $\mathrm{E} 20 / \mathrm{S} 82$ & 12 & & IIIb & $12 \mathrm{~L}-7$ & Projectile point, miscellaneous lanceolate & 1 \\
\hline E20/S82 & 12 & & IIIb & $12 \mathrm{~L}-14$ & Thin uniface & 1 \\
\hline $\mathrm{E} 20 / \mathrm{S} 82$ & 13 & & IIIb & $12 \mathrm{M}-13$ & Biface fragment & 1 \\
\hline E20/S82 & 13 & & IIIb & $12 \mathrm{M}-7$ & Biface Stage 2 & 1 \\
\hline E20/S82 & 13 & & IIIb & $12 \mathrm{M}-5$ & Biface Stage 2 & 1 \\
\hline E20/S82 & 13 & & IIIb & $12 \mathrm{M}-4$ & Biface Stage 3 & 1 \\
\hline E20/S82 & 13 & & IIIb & $12 \mathrm{M}-3$ & Bifacial tool Form E & 1 \\
\hline E20/S82 & 13 & & IIIb & $12 \mathrm{M}-1$ & Chert cobble, unmodified/tested & 1 \\
\hline E20/S82 & 13 & & IIIb & $12 \mathrm{M}-6$ & Core fragment & 1 \\
\hline E20/S82 & 13 & & IIIb & & Debitage & 1804 \\
\hline $\mathrm{E} 20 / \mathrm{S} 82$ & 13 & & IIIb & $12 \mathrm{M}-11$ & Projectile point, bifurcate stem fragment & 1 \\
\hline E20/S82 & 13 & & IIIb & $12 \mathrm{M}-10$ & Projectile point, expanding concave B & 1 \\
\hline $\mathrm{E} 20 / \mathrm{S} 82$ & 13 & & IIIb & $12 \mathrm{M}-12$ & Projectile point, miscellaneous lanceolate & 1 \\
\hline E20/S82 & 13 & & IIIb & $12 \mathrm{M}-2$ & Projectile point, miscellaneous lanceolate & 1 \\
\hline E20/S82 & 13 & & $\mathrm{IIIb}$ & $12 \mathrm{M}-8$ & Thin uniface fragment & 1 \\
\hline E20/S82 & 14 & & $\mathrm{III} a / b$ & $12 \mathrm{~N}-10$ & Bifacial tool Form A & 1 \\
\hline $\mathrm{E} 20 / \mathrm{S} 82$ & 14 & & $\mathrm{III} a / \mathrm{b}$ & $12 \mathrm{~N}-8$ & Bifacial tool Form E & 1 \\
\hline $\mathrm{E} 20 / \mathrm{S} 82$ & 14 & & $\mathrm{IIIa} / \mathrm{b}$ & $12 \mathrm{~N}-12$ & Burin spall & 1 \\
\hline E20/S82 & 14 & & IIIa/b & $12 \mathrm{~N}-11$ & Burin spall & 1 \\
\hline E20/S82 & 14 & & $\mathrm{III} / \mathrm{b}$ & $12 \mathrm{~N}-7$ & Clear Fork biface, proximal & 1 \\
\hline E20/S82 & 14 & & $\mathrm{III} a / b$ & & Debitage & 1873 \\
\hline E20/S82 & 14 & & $\mathrm{III} / \mathrm{b}$ & $12 \mathrm{~N}-16$ & Edge modified flake & 1 \\
\hline $\mathrm{E} 20 / \mathrm{S} 82$ & 14 & & $\mathrm{III} / \mathrm{b}$ & $12 \mathrm{~N}-17$ & Edge modified flake & 1 \\
\hline E20/S82 & 14 & & $\mathrm{IIIa} / \mathrm{b}$ & $12 \mathrm{~N}-22$ & Edge modified flake & 1 \\
\hline
\end{tabular}




\begin{tabular}{|c|c|c|c|c|c|c|}
\hline Square & Level & Feature & Strata & Item & Analyst Identification & Count \\
\hline $\mathrm{E} 20 / \mathrm{S} 82$ & 14 & & $\mathrm{IIIa} / \mathrm{b}$ & $12 \mathrm{~N}-24$ & Edge modified flake & 1 \\
\hline $\mathrm{E} 20 / \mathrm{S} 82$ & 14 & & $\mathrm{IIIa} / \mathrm{b}$ & $12 \mathrm{~N}-14$ & Perforator Group 1 & 1 \\
\hline E20/S82 & 14 & & IIIa/b & $12 \mathrm{~N}-1$ & Projectile point fragment & 1 \\
\hline E20/S82 & 14 & & IIIa/b & $12 \mathrm{~N}-13$ & Projectile point, bifurcate stem fragment & 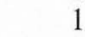 \\
\hline $\mathrm{E} 20 / \mathrm{S} 82$ & 14 & & $\mathrm{IIIa} / \mathrm{b}$ & $12 \mathrm{~N}-5$ & Projectile point, expanding concave $\mathrm{E}$ & 1 \\
\hline $\mathrm{E} 20 / \mathrm{S} 82$ & 14 & & $\mathrm{IIIa} / \mathrm{b}$ & $12 \mathrm{~N}-2$ & Projectile point, expanding stem C & 1 \\
\hline $\mathrm{E} 20 / \mathrm{S} 82$ & 14 & & $\mathrm{IIIa} / \mathrm{b}$ & $12 \mathrm{~N}-3$ & Projectile point, Gower/Jetta & 1 \\
\hline E20/S82 & 14 & & IIIa/b & $12 \mathrm{~N}-4$ & Projectile point, Hoxie & 1 \\
\hline E20/S82 & 14 & & $\mathrm{IIIa} / \mathrm{b}$ & $12 \mathrm{~N}-23$ & Spurred flake & 1 \\
\hline E20/S82 & 14 & & IIIa/b & $12 \mathrm{~N}-15$ & Thin uniface & 1 \\
\hline E20/S82 & 14 & & IIIa/b & $12 \mathrm{~N}-20$ & Thin uniface & 1 \\
\hline E20/S82 & 14 & & IIIa/b & $12 \mathrm{~N}-25$ & Thin uniface & 1 \\
\hline E20/S82 & 14 & & IIIa/b & $12 \mathrm{~N}-21$ & Thin uniface & 1 \\
\hline E20/S82 & 14 & & $\mathrm{III} a / \mathrm{b}$ & $12 \mathrm{~N}-19$ & Thin uniface fragment & 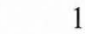 \\
\hline $\mathrm{E} 20 / \mathrm{S} 82$ & 14 & & $\mathrm{IIIa} / \mathrm{b}$ & $12 \mathrm{~N}-18$ & Thin uniface fragment & 1 \\
\hline $\mathrm{E} 20 / \mathrm{S} 82$ & 15 & & IIIa/b & & Debitage & 804 \\
\hline E20/S82 & 15 & & IIIa/b & $120-5$ & Edge modified flake & \\
\hline E20/S82 & 15 & & $\mathrm{IIIa} / \mathrm{b}$ & $12 \mathrm{O}-4$ & Microspur/microdenticulate & 1 \\
\hline E20/S82 & 15 & & IIIa/b & $120-8$ & Projectile point fragment & 1 \\
\hline E20/S82 & 15 & & $\mathrm{IIIa} / \mathrm{b}$ & $120-6$ & Thick uniface & 1 \\
\hline E20/S82 & 15 & & $\mathrm{IIIa} / \mathrm{b}$ & $120-3$ & Thin uniface fragment & 1 \\
\hline E20/S82 & 16 & & IIIa & $12 \mathrm{P}-10$ & Biface fragment & 1 \\
\hline E20/S82 & 16 & & IIIa & $12 \mathrm{P}-2$ & Biface Stage 2 & 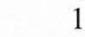 \\
\hline $\mathrm{E} 20 / \mathrm{S} 82$ & 16 & & IIIa & $12 \mathrm{P}-3$ & Biface Stage 3 & 1 \\
\hline E20/S82 & 16 & & IIIa & & Debitage & 589 \\
\hline E20/S82 & 16 & & IIIa & $12 \mathrm{P}-4$ & Denticulated flake & 1 \\
\hline E20/S82 & 16 & & IIIa & $12 \mathrm{P}-12$ & Denticulated flake & 1 \\
\hline E20/S82 & 16 & & IIIa & $12 \mathrm{P}-6$ & Edge modified flake & 1 \\
\hline E20/S82 & 16 & & IIIa & $12 \mathrm{P}-9$ & Edge modified flake & 1 \\
\hline $\mathrm{E} 20 / \mathrm{S} 82$ & 16 & & IIIa & $12 \mathrm{P}-1$ & Micro-core, large & 1 \\
\hline E20/S82 & 16 & & IIIa & $12 \mathrm{P}-11$ & Micro-core, small & 1 \\
\hline $\mathrm{E} 20 / \mathrm{S} 82$ & 16 & & IIIa & $12 \mathrm{P}-5$ & Microspur/microdenticulate & 1 \\
\hline $\mathrm{E} 20 / \mathrm{S} 82$ & 16 & & IIIa & $12 \mathrm{P}-7$ & Notched flake & 1 \\
\hline $\mathrm{E} 20 / \mathrm{S} 82$ & 17 & & II/IIIa & $12 \mathrm{Q}-5$ & Biface Stage 1 & 1 \\
\hline E20/S82 & 17 & & II/IIIa & $12 Q-4$ & Biface Stage 2 & 1 \\
\hline E20/S82 & 17 & & II/IIIa & $12 Q-3$ & Biface Stage 3 & 1 \\
\hline E20/S82 & 17 & & II/IIIa & $12 Q-6$ & Burin spall & 1 \\
\hline $\mathrm{E} 20 / \mathrm{S} 82$ & 17 & & $\mathrm{II} / \mathrm{IIII}$ & & Debitage & 1278 \\
\hline E20/S82 & 17 & & II/IIIa & 12Q-16 & Edge modified flake & 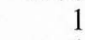 \\
\hline $\mathrm{E} 20 / \mathrm{S} 82$ & 17 & & II/IIIa & $12 \mathrm{Q}-18$ & Edge modified flake & 1 \\
\hline E20/S82 & 17 & & II/IIIa & $12 \mathrm{Q}-15$ & Edge modified flake & 1 \\
\hline $\mathrm{E} 20 / \mathrm{S} 82$ & 17 & & II/IIIa & $12 \mathrm{Q}-13$ & Edge modified flake & 1 \\
\hline $\mathrm{E} 20 / \mathrm{S} 82$ & 17 & & II/IIIa & $12 Q-9$ & Edge modified flake & 1 \\
\hline $\mathrm{E} 20 / \mathrm{S} 82$ & 17 & & II/IIIa & $12 \mathrm{Q}-2$ & Projectile point, Hoxie & 1 \\
\hline $\mathrm{E} 20 / \mathrm{S} 82$ & 17 & & $\mathrm{II} / \mathrm{IIIa}$ & $12 \mathrm{Q}-1$ & Projectile point, Hoxie A & 1 \\
\hline $\mathrm{E} 20 / \mathrm{S} 82$ & 17 & & II/IIIa & $12 \mathrm{Q}-19$ & Retouched blade & 1 \\
\hline E20/S82 & 17 & & II/IIIa & $12 \mathrm{Q}-12$ & Thin uniface & 1 \\
\hline E20/S82 & 17 & & II/IIIa & $12 Q-10$ & Thin uniface & 1 \\
\hline E20/S82 & 17 & & II/IIIa & $12 \mathrm{Q}-20$ & Thin uniface & 1 \\
\hline E20/S82 & 17 & & II/IIIa & $12 \mathrm{Q}-17$ & Thin uniface & 1 \\
\hline E20/S82 & 18 & & II/IIIa & $12 \mathrm{R}-4$ & Biface Stage 2 & 1 \\
\hline $\mathrm{E} 20 / \mathrm{S} 82$ & 18 & & II/IIIa & & Debitage & 434 \\
\hline E20/S82 & 18 & & II/IIIa & $12 \mathrm{R}-9$ & Edge modified flake & 1 \\
\hline E20/S82 & 18 & & II/IIIa & $12 \mathrm{R}-8$ & Perforator Unifacial & 1 \\
\hline E20/S82 & 18 & & II/IIIa & $12 \mathrm{R}-6$ & Projectile point fragment & 1 \\
\hline E20/S82 & 18 & & II/IIIa & $12 \mathrm{R}-1$ & Projectile point, concave lanceolate preform & 1 \\
\hline $\mathrm{E} 20 / \mathrm{S} 82$ & 18 & & II/IIIa & $12 \mathrm{R}-2$ & Projectile point, Hoxie/Gower & 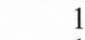 \\
\hline $\mathrm{E} 20 / \mathrm{S} 82$ & 18 & & II/IIIa & $12 \mathrm{R}-5$ & Projectile point, miscellaneous lanceolate & 1 \\
\hline $\mathrm{E} 20 / \mathrm{S} 82$ & 18 & & II/IIIa & $12 \mathrm{R}-7$ & Small core hammerstone & 1 \\
\hline E20/S82 & 18 & & II/IIIa & $12 \mathrm{R}-11$ & Thin uniface & 1 \\
\hline $\mathrm{E} 20 / \mathrm{S} 82$ & 19 & & II & $12 \mathrm{~S}-2$ & Biface Stage 2 & 1 \\
\hline E20/S82 & 19 & & II & $12 \mathrm{~S}-1$ & Clear Fork biface & 1 \\
\hline E20/S82 & 19 & & II & $12 S-4$ & Core, thermal & 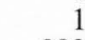 \\
\hline E20/S82 & 19 & & II & & Debitage & 382 \\
\hline E20/S82 & 19 & & II & $12 S-10$ & Denticulated flake & 1 \\
\hline E20/S82 & 19 & & II & $12 \mathrm{~S}-11$ & Edge modified flake & \\
\hline $\mathrm{E} 20 / \mathrm{S} 82$ & 19 & & II & $12 S-8$ & Edge modified flake & 1 \\
\hline E20/S82 & 19 & & II & $12 S-9$ & Microspur/microdenticulate & 1 \\
\hline $\mathrm{E} 20 / \mathrm{S} 82$ & 19 & & II & $12 S-6$ & Projectile point, miscellaneous lanceolate & 1 \\
\hline E20/S82 & 19 & & II & $12 \mathrm{~S}-3$ & Small core hammerstone & 1 \\
\hline E20/S82 & 19 & & II & $12 S-13$ & Thin uniface & 1 \\
\hline E20/S82 & 19 & & II & $12 S-14$ & Thin uniface & \\
\hline E20/S82 & 19 & & II & $12 S-12$ & Thin uniface & \\
\hline E20/S82 & 19 & & II & $12 \mathrm{~S}-7$ & Thin uniface fragment & \\
\hline
\end{tabular}




\begin{tabular}{|c|c|c|c|c|c|c|}
\hline Square & Level & Feature & Strata & Item & Analyst Identification & Count \\
\hline E20/S82 & 20 & & II & $12 \mathrm{~T}-2$ & Biface fragment & \\
\hline E20/S82 & 20 & & II & $12 \mathrm{~T}-3$ & Biface Stage 1 & \\
\hline E20/S82 & 20 & & II & & Debitage & 2. \\
\hline E20/S82 & 20 & & II & $12 \mathrm{~T}-4$ & Thin uniface & \\
\hline E20/S82 & 20 & & II & $12 \mathrm{~T}-1$ & Thin uniface fragment & \\
\hline E20/S82 & 21 & & II & & Debitage & 154 \\
\hline E20/S82 & 21 & & II & $12 \mathrm{U}-1$ & Projectile point, Golondrina-Barber & \\
\hline E20/S82 & 22 & & II & & Debitage & \\
\hline E20/S82 & 23 & & $\mathrm{Id} / \mathrm{II}$ & & Debitage & \\
\hline E20/S82 & 23 & & $\mathrm{Id} / \mathrm{II}$ & $12 \mathrm{~W}-1$ & Thin uniface fragment & \\
\hline E20/S82 & 24 & & Isi-c/Id & & Debitage & 51 \\
\hline E20/S82 & 24 & & Isi-c/Id & $12 \mathrm{X}-1$ & Edge modified flake & \\
\hline E20/S82 & 25 & & Isi-c/Id & $12 \mathrm{Y}-1$ & Thick uniface & \\
\hline E20/S84 & 1 & & IIIc & $11 \mathrm{~A}-1$ & Arrow point, Scallorn & \\
\hline E20/S84 & 1 & & IIIc & $11 \mathrm{~A}-3$ & Arrow point, stemmed & \\
\hline $\begin{array}{l}\mathrm{E} 20 / \mathrm{S} 84 \\
\mathrm{~F} 20 / \mathrm{S} 84\end{array}$ & 1 & & IIIc & $11 \mathrm{~A}-4$ & Arrow point, tip & \\
\hline $\begin{array}{l}\text { E20/S84 } \\
\text { E20/S84 }\end{array}$ & $\begin{array}{l}1 \\
1\end{array}$ & & $\begin{array}{l}\text { IIIc } \\
\text { IIIC }\end{array}$ & $\begin{array}{l}11 \mathrm{~A}-8 \\
11 \mathrm{~A}-7\end{array}$ & $\begin{array}{l}\text { Biface fragment } \\
\text { Biface fraoment }\end{array}$ & \\
\hline $\begin{array}{l}\mathrm{E} 20 / \mathrm{S} 84 \\
\mathrm{E} 20 / \mathrm{S} 84\end{array}$ & 1 & & IIIIc & $11 \mathrm{~A}-12$ & $\begin{array}{l}\text { Biface fragment, unanalyzed } \\
\text { Biface Stage } 1\end{array}$ & \\
\hline E20/S84 & 1 & & IIIc & $11 \mathrm{~A}-10$ & Biface Stage 1 & \\
\hline E20/S84 & 1 & & IIIIc & $11 \mathrm{~A}-11$ & Biface Stage 1 & \\
\hline E20/S84 & 1 & & IIIc & $11 \mathrm{~A}-19$ & Biface Stage 2 & \\
\hline E20/S84 & 1 & & IIIIc & & Debitage & 878 \\
\hline E20/S84 & 1 & & IIIIc & $11 \mathrm{~A}-21$ & Edge modified flake & \\
\hline E20/S84 & 1 & & IIIIc & $11 \mathrm{~A}-5$ & Edge modified flake & \\
\hline E20/S84 & 1 & & IIIIc & $11 \mathrm{~A}-20$ & Edge modified flake & \\
\hline E20/S84 & 1 & & IIIIc & $11 \mathrm{~A}-16$ & Edge modified flake & \\
\hline E20/S84 & 1 & & IIIIc & $11 \mathrm{~A}-17$ & Microspur/microdenticulate & \\
\hline E20/S84 & 1 & & IIIIc & $11 \mathrm{~A}-25$ & Notched flake & \\
\hline E20/S84 & 1 & & IIIIc & $11 \mathrm{~A}-14$ & Projectile point fragment & 1 \\
\hline E20/S84 & 1 & & IIII & $11 \mathrm{~A}-9$ & Projectile point fragment & \\
\hline E20/S84 & 1 & & IIIIc & $11 \mathrm{~A}-15$ & Projectile point fragment & \\
\hline E20/S84 & 1 & & IIIIc & $11 \mathrm{~A}-2$ & Projectile point, Darl & \\
\hline E20/S84 & 1 & & IIIIC & $11 \mathrm{~A}-24$ & Thin uniface & \\
\hline E20/S84 & 1 & & IIIC & $11 \mathrm{~A}-18$ & Thin uniface & 1 \\
\hline E20/S84 & 1 & & IIIc & $11 \mathrm{~A}-22$ & Thin uniface & \\
\hline E20/S84 & 1 & & IIIIc & $11 \mathrm{~A}-6$ & Thin uniface & \\
\hline E20/S84 & 1 & & IIIc & $11 \mathrm{~A}-23$ & Thin uniface & \\
\hline E20/S84 & 2 & & IIIIc & 11B-4 & Arrow point, Scallorn & \\
\hline E20/S84 & 2 & & IIIc & $11 \mathrm{~B}-9$ & Arrow point, tip & \\
\hline E20/S84 & 2 & & IIIIc & 11B-7 & Biface fragment & 1 \\
\hline E20/S84 & 2 & & IIIIc & $11 \mathrm{~B}-5$ & Biface Stage 3 & \\
\hline E20/S84 & 2 & & IIIIc & & Debitage & 40 \\
\hline E20/S84 & 2 & & IIIIc & 11B-11 & Notched flake & \\
\hline E20/S84 & 2 & & IIIc & $11 \mathrm{~B}-8$ & Projectile point fragment & \\
\hline E20/S84 & 2 & & IIIC & 11B-1 & Projectile point, Darl & \\
\hline E20/S84 & 2 & & IIIIc & $11 \mathrm{~B}-3$ & Projectile point, Ensor & \\
\hline E20/S84 & 2 & & IIIc & $11 \mathrm{~B}-2$ & Projectile point, Uvalde-like & \\
\hline E20/S84 & 2 & & IIIc & 11B-12 & Thin uniface & \\
\hline E20/S84 & 2 & & IIIc & $11 \mathrm{~B}-10$ & Thin uniface fragment & 1 \\
\hline E20/S84 & 3 & & IIIIc & $11 \mathrm{C}-3$ & Biface Stage 2 & \\
\hline E20/S84 & 3 & & IIIc & & Debitage & 52 \\
\hline E20/S84 & 3 & & IIIc & $11 \mathrm{C}-1$ & Projectile point, Marcos & \\
\hline E20/S84 & 3 & & IIIc & $11 \mathrm{C}-4$ & Projectile point, Montell & \\
\hline E20/S84 & 3 & & IIIIc & $11 \mathrm{C}-2$ & Projectile point, Pedernales & \\
\hline E20/S84 & 3 & & IIIIc & $11 \mathrm{C}-9$ & Small core hammerstone & \\
\hline E20/S84 & 3 & & IIIc & $11 \mathrm{C}-7$ & Unifacial multiple tool & \\
\hline E20/S84 & 3 & & IIIc & $11 \mathrm{C}-6$ & Unifacial multiple tool & \\
\hline E20/S84 & 4 & & IIIc & $11 \mathrm{D}-7$ & Biface fragment & \\
\hline E20/S84 & 4 & & IIIIc & $11 \mathrm{D}-5$ & Biface Stage 2 & \\
\hline E20/S84 & 4 & & IIIC & $11 \mathrm{D}-6$ & Biface Stage 2 & \\
\hline E20/S84 & 4 & & IIIc & $11 \mathrm{D}-4$ & Biface Stage 3 & \\
\hline E20/S84 & 4 & & IIIC & & Debitage & 50 \\
\hline E20/S84 & 4 & & IIIc & $11 \mathrm{D}-8$ & Denticulated flake & \\
\hline E20/S84 & 4 & & IIIc & $11 \mathrm{D}-10$ & Edge modified flake & \\
\hline E20/S84 & 4 & & IIIIc & $11 \mathrm{D}-9$ & Edge modified flake & \\
\hline E20/S84 & 4 & & IIIIc & 11D-1 & Projectile point, Ensor & \\
\hline E20/S84 & 4 & & IIIc & $11 \mathrm{D}-2$ & Projectile point, Frio & \\
\hline E20/S84 & 4 & & IIIc & $11 \mathrm{D}-3$ & Projectile point, Montell & \\
\hline E20/S84 & 5 & & IIIIc & $11 \mathrm{E}-4$ & Biface fragment & \\
\hline E20/S84 & 5 & & IIIIc & $11 \mathrm{E}-3$ & Biface fragment & \\
\hline E20/S84 & 5 & & IIIC & $11 \mathrm{E}-2$ & Biface fragment & \\
\hline E20/S84 & 5 & & IIIc & & Debitage & 37 \\
\hline E20/S84 & 5 & & IIIc & $11 \mathrm{E}-5$ & Perforator Group 1 & \\
\hline
\end{tabular}




\begin{tabular}{|c|c|c|c|c|c|c|}
\hline Square & Level & Feature & Strata & Item & Analyst Identification & Count \\
\hline $\mathrm{E} 20 / \mathrm{S} 84$ & 5 & & IIIC & $11 \mathrm{E}-7$ & Projectile point fragment & 1 \\
\hline E20/S84 & 5 & & IIIc & $11 \mathrm{E}-6$ & Projectile point, Marcos & 1 \\
\hline E20/S84 & 5 & & IIIC & $11 \mathrm{E}-1$ & Projectile point, rectangular stem $\mathrm{C}$ & 1 \\
\hline $\mathrm{E} 20 / \mathrm{S} 84$ & 5 & & IIIc & $11 \mathrm{E}-8$ & Thin uniface & 1 \\
\hline E20/S84 & 6 & & IIIc & $11 \mathrm{~F}-1$ & Biface fragment & 1 \\
\hline E20/S84 & 6 & & IIIc & $11 \mathrm{~F}-8$ & Biface fragment & 1 \\
\hline $\mathrm{E} 20 / \mathrm{S} 84$ & 6 & & IIIc & $11 \mathrm{~F}-2$ & Core tool, type 3 & 1 \\
\hline E20/S84 & 6 & & IIIc & & Debitage & 470 \\
\hline E20/S84 & 6 & & IIIc & $11 \mathrm{~F}-5$ & Edge modified flake & 1 \\
\hline E20/S84 & 6 & & IIIc & $11 \mathrm{~F}-13$ & Edge modified flake & 1 \\
\hline E20/S84 & 6 & & IIIc & $11 \mathrm{~F}-10$ & Edge modified flake & 1 \\
\hline E20/S84 & 6 & & IIIc & $11 \mathrm{~F}-11$ & Edge modified flake & 1 \\
\hline E20/S84 & 6 & & IIIc & $11 \mathrm{~F}-14$ & Edge modified flake & 1 \\
\hline E20/S84 & 6 & & IIIc & $11 \mathrm{~F}-6$ & Edge modified flake & 1 \\
\hline E20/S84 & 6 & & IIIc & $11 \mathrm{~F}-7$ & Edge modified flake & 1 \\
\hline E20/S84 & 6 & & IIIc & $11 \mathrm{~F}-12$ & Edge modified flake & 1 \\
\hline E20/S84 & 6 & & IIIc & $11 \mathrm{~F}-9$ & Notched flake & 1 \\
\hline E20/S84 & 7 & & IIIc & $11 \mathrm{G}-2$ & Biface fragment & 1 \\
\hline E20/S84 & 7 & & IIIC & $11 \mathrm{G}-3$ & Biface fragment & 1 \\
\hline E20/S 84 & 7 & & IIIc & $11 \mathrm{G}-4$ & Biface Stage 1 & 1 \\
\hline E20/S84 & 7 & & IIIc & $11 \mathrm{G}-1$ & Biface Stage 2 & 1 \\
\hline E20/S84 & 7 & & IIIc & & Debitage & 653 \\
\hline E20/S84 & 7 & & IIIIc & $11 \mathrm{G}-7$ & Perforator Group 2 & 1 \\
\hline $\mathrm{E} 20 / \mathrm{S} 84$ & 7 & & IIIc & $11 \mathrm{G}-6$ & Projectile point, miscellaneous expanding stem & $\mathrm{m}$ \\
\hline E20/S84 & 7 & & IIIc & $11 \mathrm{G}-5$ & Thick uniface & 1 \\
\hline E20/S84 & 8 & & IIIb/c & $11 \mathrm{H}-2$ & Biface fragment & 1 \\
\hline E20/S84 & 8 & & $\mathrm{IIIb} / \mathrm{c}$ & $11 \mathrm{H}-3$ & Biface fragment & 1 \\
\hline E20/S84 & 8 & & $\mathrm{IIIb} / \mathrm{c}$ & $11 \mathrm{H}-6$ & Biface Stage 1 & 1 \\
\hline E20/S84 & 8 & & $\mathrm{IIIb} / \mathrm{c}$ & $11 \mathrm{H}-4$ & Biface Stage 1 & 1 \\
\hline E20/S84 & 8 & & $\mathrm{IIIb} / \mathrm{c}$ & $11 \mathrm{H}-21$ & Biface Stage 1 & 1 \\
\hline E20/S84 & 8 & & $\mathrm{IIIb} / \mathrm{c}$ & $11 \mathrm{H}-5$ & Burin & 1 \\
\hline $\mathrm{E} 20 / \mathrm{S} 84$ & 8 & & $\mathrm{IIIb} / \mathrm{c}$ & $11 \mathrm{H}-7$ & Burin spall & 1 \\
\hline E20/S84 & 8 & & $\mathrm{IIIb} / \mathrm{c}$ & $11 \mathrm{H}-20$ & Core fragment & 1 \\
\hline E20/S84 & 8 & & $\mathrm{IIIb} / \mathrm{c}$ & $11 \mathrm{H}-22$ & Core tool, type 4 & 1 \\
\hline E20/S84 & 8 & & $\mathrm{IIIb} / \mathrm{c}$ & $11 \mathrm{H}-23$ & Core tool, type 4 & 1 \\
\hline E20/S84 & 8 & & $\mathrm{IIIb} / \mathrm{c}$ & & Debitage & 415 \\
\hline E20/S84 & 8 & & $\mathrm{IIIb} / \mathrm{c}$ & $11 \mathrm{H}-11$ & Edge modified flake & 1 \\
\hline E20/S84 & 8 & & $\mathrm{IIIb} / \mathrm{c}$ & $11 \mathrm{H}-9$ & Edge modified flake & 1 \\
\hline E20/S84 & 8 & & $\mathrm{IIIb} / \mathrm{c}$ & $11 \mathrm{H}-10$ & Edge modified flake & 1 \\
\hline E20/S84 & 8 & & IIIb/c & $11 \mathrm{H}-17$ & Edge modified flake & 1 \\
\hline E20/S84 & 8 & & $\mathrm{IIIb} / \mathrm{c}$ & $11 \mathrm{H}-16$ & Edge modified flake & 1 \\
\hline E20/S84 & 8 & & $\mathrm{IIIb} / \mathrm{c}$ & $11 \mathrm{H}-15$ & Edge modified flake & 1 \\
\hline E20/S84 & 8 & & $\mathrm{IIIb} / \mathrm{c}$ & $11 \mathrm{H}-19$ & Mano fragment & 1 \\
\hline E20/S84 & 8 & & $\mathrm{IIIb} / \mathrm{c}$ & $11 \mathrm{H}-14$ & Notched flake & 1 \\
\hline E20/S84 & 8 & & $\mathrm{IIIb} / \mathrm{c}$ & $11 \mathrm{H}-1$ & Projectile point, Thrall & 1 \\
\hline E20/S84 & 8 & & $\mathrm{IIIb} / \mathrm{c}$ & $11 \mathrm{H}-18$ & Thick uniface & 1 \\
\hline E20/S84 & 8 & & $\mathrm{IIIb} / \mathrm{c}$ & $11 \mathrm{H}-8$ & Thick uniface & 1 \\
\hline E20/S84 & 8 & & $\mathrm{IIIb} / \mathrm{c}$ & $11 \mathrm{H}-13$ & Thin uniface & 1 \\
\hline E20/S84 & 9 & & $\mathrm{IIIb} / \mathrm{c}$ & $11 \mathrm{I}-4$ & Biface fragment & 1 \\
\hline E20/S84 & 9 & & $\mathrm{IIIb} / \mathrm{c}$ & $11 \mathrm{I}-3$ & Biface Stage 2 & 1 \\
\hline E20/S84 & 9 & & IIIb/c & $11 \mathrm{I}-2$ & Biface Stage 2 & 1 \\
\hline E20/S84 & 9 & & $\mathrm{IIIb} / \mathrm{c}$ & & Debitage & 235 \\
\hline E20/S84 & 9 & & $\mathrm{IIIb} / \mathrm{c}$ & $11 \mathrm{I}-5$ & Denticulated flake & 1 \\
\hline $\mathrm{E} 20 / \mathrm{S} 84$ & 9 & & $\mathrm{IIIb} / \mathrm{c}$ & $11 \mathrm{I}-1$ & Projectile point, Nolan-like & 1 \\
\hline E20/S84 & 10 & & $\mathrm{IIIb} / \mathrm{c}$ & $11 \mathrm{~J}-4$ & Biface fragment & 1 \\
\hline E20/S84 & 10 & & $\mathrm{IIIb} / \mathrm{c}$ & $11 \mathrm{~J}-7$ & Biface Stage 1 & 1 \\
\hline E20/S84 & 10 & & $\mathrm{IIIb} / \mathrm{c}$ & $11 \mathrm{~J}-12$ & Biface Stage 1 & 1 \\
\hline E20/S84 & 10 & & $\mathrm{IIIb} / \mathrm{c}$ & $11 \mathrm{~J}-2$ & Biface Stage 2 & 1 \\
\hline $\mathrm{E} 20 / \mathrm{S} 84$ & 10 & & $\mathrm{IIIb} / \mathrm{c}$ & $11 \mathrm{~J}-3$ & Biface Stage 2 & 1 \\
\hline E20/S84 & 10 & & IIIb/c & $11 \mathrm{~J}-5$ & Biface Stage 2 & 1 \\
\hline E20/S84 & 10 & & $\mathrm{IIIb} / \mathrm{c}$ & $11 \mathrm{~J}-6$ & Biface Stage 2 & 1 \\
\hline $\mathrm{E} 20 / \mathrm{S} 84$ & 10 & & $\mathrm{IIIb} / \mathrm{c}$ & $11 \mathrm{~J}-8$ & Bifacial tool Form B & 1 \\
\hline E20/S84 & 10 & & $\mathrm{IIIb} / \mathrm{c}$ & & Debitage & 420 \\
\hline E20/S84 & 10 & & $\mathrm{IIIb} / \mathrm{c}$ & $11 \mathrm{~J}-1$ & Mano & 1 \\
\hline E20/S84 & 10 & & $\mathrm{IIIb} / \mathrm{c}$ & $11 \mathrm{~J}-11$ & Microspur/microdenticulate & 1 \\
\hline E20/S84 & 10 & & $\mathrm{IIIb} / \mathrm{c}$ & $11 \mathrm{~J}-9$ & Projectile point, Gary & 1 \\
\hline E20/S84 & 10 & & $\mathrm{IIIb} / \mathrm{c}$ & $11 \mathrm{~J}-10$ & Unifacial multiple tool & 1 \\
\hline E20/S84 & 11 & & IIIb & $11 \mathrm{~K}-8$ & Biface fragment & 1 \\
\hline E20/S84 & 11 & & IIIb & $11 \mathrm{~K}-4$ & Biface Stage 2 & 1 \\
\hline E20/S84 & 11 & & IIIb & $11 \mathrm{~K}-6$ & Burin & 1 \\
\hline E20/S84 & 11 & & IIIb & $11 \mathrm{~K}-7$ & Burin spall & 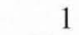 \\
\hline E20/S84 & 11 & & IIIb & & Debitage & 800 \\
\hline $\mathrm{E} 20 / \mathrm{S} 84$ & 11 & & IIIb & $11 \mathrm{~K}-10$ & Microspur/microdenticulate & 1 \\
\hline E20/S84 & 11 & & IIIb & $11 \mathrm{~K}-5$ & Piece esquillee & 1 \\
\hline
\end{tabular}




\begin{tabular}{|c|c|c|c|c|c|c|}
\hline $\begin{array}{l}\text { Square } \\
\text { F20/S84 }\end{array}$ & Level & Feature & Strata & Item & Analyst Identification & Count \\
\hline $\begin{array}{l}\text { E20/S84 } \\
\text { E20/S84 }\end{array}$ & 11 & & IIIb & $\begin{aligned} 11 \mathrm{~K}-9 \\
11 \mathrm{~K}-2\end{aligned}$ & Projectile point fragment & \\
\hline E20/S84 & 11 & & IIIIb & $\begin{array}{l}11 \mathrm{~K}-2 \\
11 \mathrm{~K}-3\end{array}$ & $\begin{array}{l}\text { Projectile point, bifurcate stem fragment } \\
\text { Projectile point, Early Triangular }\end{array}$ & $\begin{array}{l}1 \\
1\end{array}$ \\
\hline E20/S84 & 11 & & $\mathrm{IIIb}$ & $11 \mathrm{~K}-1$ & Projectile point, miscellaneous expanding ster & $\mathrm{m}$ \\
\hline $\mathrm{E} 20 / \mathrm{S} 84$ & 11 & & IIIb & $11 \mathrm{~K}-14$ & Thin uniface & $m$ \\
\hline E20/S84 & 11 & & IIIb & $11 \mathrm{~K}-11$ & Uniface, unanalyzed & 1 \\
\hline E20/S84 & 11 & & IIIIb & $11 \mathrm{~K}-13$ & Uniface, unanalyzed & 1 \\
\hline E20/S84 & 11 & & IIIlb & $11 \mathrm{~K}-12$ & Unifacial multiple tool & 1 \\
\hline E20/S84 & 12 & & IIIb & $11 \mathrm{~L}-5$ & Biface Stage 2 & \\
\hline E20/S84 & 12 & & $\mathrm{IIIb}$ & $11 \mathrm{~L}-3$ & Biface Stage 2 & 1 \\
\hline E20/S84 & 12 & & IIIIb & $11 \mathrm{~L}-4$ & Biface Stage 3 & 1 \\
\hline E20/S84 & 12 & & $\mathrm{IIIb}$ & $11 \mathrm{~L}-13$ & Burin & \\
\hline E20/S84 & 12 & & IIIb & & Debitage & 1380 \\
\hline E20/S84 & 12 & & $\mathrm{IIIb}$ & $11 \mathrm{~L}-12$ & Edge modified flake & 1500 \\
\hline E20/S84 & 12 & & IIIb & $11 \mathrm{~L}-11$ & Edge modified flake & 1 \\
\hline E20/S84 & 12 & & IIIIb & $11 \mathrm{~L}-10$ & Edge modified flake & \\
\hline E20/S84 & 12 & & IIItb & $11 \mathrm{~L}-7$ & Edge modified flake & \\
\hline E20/S84 & 12 & & $\mathrm{IIIb}$ & $11 \mathrm{~L}-6$ & Edge modified flake & \\
\hline E20/S84 & 12 & & IIIJ & $11 \mathrm{~L}-8$ & Edge modified flake & \\
\hline E20/S84 & 12 & & IIIb & $11 \mathrm{~L}-9$ & Microspur/microdenticulate & \\
\hline E20/S84 & 12 & & IIIb & $11 \mathrm{~L}-1$ & Projectile point, expanding concave B & 1 \\
\hline E20/S84 & 12 & & IIIIb & $11 \mathrm{~L}-2$ & Projectile point, expanding concave C & 1 \\
\hline E20/S84 & 13 & & $\mathrm{IIIb}$ & $11 \mathrm{M}-3$ & Biface fragment & \\
\hline E20/S84 & 13 & & IIIIb & $11 \mathrm{M}-9$ & Biface Stage 1 & 1 \\
\hline E20/S84 & 13 & & $\mathrm{IIIb}$ & $11 \mathrm{M}-10$ & Biface Stage 2 & \\
\hline E20/S84 & 13 & & IIIb & $11 \mathrm{M}-4$ & Biface Stage 2 & \\
\hline E20/S84 & 13 & & IIIb & $11 \mathrm{M}-5$ & Biface Stage 2 & 1 \\
\hline E20/S84 & 13 & & IIIIb & $11 \mathrm{M}-6$ & Biface Stage 2 & \\
\hline E20/S84 & 13 & & IIIlb & $11 \mathrm{M}-7$ & Biface Stage 3 & \\
\hline E20/S84 & 13 & & IIIb & & Debitage & 949 \\
\hline E20/S84 & 13 & & IIIb & $11 \mathrm{M}-11$ & Edge modified flake & $7+3$ \\
\hline E20/S84 & 13 & & IIIb & $11 \mathrm{M}-15$ & Edge modified flake & 1 \\
\hline E20/S84 & 13 & & $\mathrm{IIIb}$ & $11 \mathrm{M}-13$ & Notched flake & \\
\hline E20/S84 & 13 & & IIIlb & $11 \mathrm{M}-1$ & Projectile point, Bandy & 1 \\
\hline E20/S84 & 13 & & IIIJ & $11 \mathrm{M}-2$ & Projectile point, contracting stem, concave ba & ase \\
\hline E20/S84 & 13 & & IIIIb & $11 \mathrm{M}-12$ & Thick uniface & \\
\hline E20/S84 & 14 & & IIIIa/b & $11 \mathrm{~N}-1$ & Bifacial tool & 1 \\
\hline E20/S84 & 14 & & IIIa/b & $11 \mathrm{~N}-2$ & Core tool, type 2 & \\
\hline E20/S84 & 14 & & $\mathrm{IIIa} / \mathrm{b}$ & & Debitage & 922 \\
\hline E20/S84 & 14 & & $\mathrm{IIIa} / \mathrm{b}$ & $11 \mathrm{~N}-4$ & Edge modified flake & 22 \\
\hline E20/S84 & 14 & & IIIa/b & $11 \mathrm{~N}-6$ & Edge modified flake & 1 \\
\hline E20/S84 & 14 & & IIIa/b & $11 \mathrm{~N}-3$ & Edge modified flake & 1 \\
\hline E20/S84 & 14 & & $\mathrm{IIIa} / \mathrm{b}$ & $11 \mathrm{~N}-5$ & Microspur/microdenticulate & \\
\hline E20/S84 & 15 & & IIIa/b & $110-6$ & Biface fragment & 1 \\
\hline E20/S84 & 15 & & $\mathrm{IIIa} / \mathrm{b}$ & $110-12$ & Biface fragment & 1 \\
\hline E20/S84 & 15 & & IIIa/b & $110-8$ & Biface Stage 1 & 1 \\
\hline E20/S84 & 15 & & IIIa/b & $110-7$ & Biface Stage 2 & 1 \\
\hline E20/S84 & 15 & & IIIa/b & $110-9$ & Core fragment & 1 \\
\hline E20/S84 & 15 & & $\mathrm{IIIa} / \mathrm{b}$ & & Debitage & 689 \\
\hline E20/S84 & 15 & & IIIIa/b & $110-13$ & Edge modified flake & 99 \\
\hline E20/S84 & 15 & & $\mathrm{IIIa} / \mathrm{b}$ & $110-1$ & Projectile point, Angostura & 1 \\
\hline E20/S84 & 15 & & IIIa/b & $110-3$ & Projectile point, bifurcate stem fragment & 1 \\
\hline E20/S84 & 15 & & $\mathrm{IIIa} / \mathrm{b}$ & $110-2$ & Projectile point, Hoxie C & 1 \\
\hline E20/S84 & 15 & & $\mathrm{IIIa} / \mathrm{b}$ & $110-11$ & Thin uniface & 1 \\
\hline E20/S84 & 15 & & $\mathrm{IIIa} / \mathrm{b}$ & $110-10$ & Thin uniface fragment & \\
\hline E20/S84 & 16 & & IIIIa & $11 \mathrm{P}-7$ & Biface fragment & 1 \\
\hline E20/S84 & 16 & & IIIa & $11 \mathrm{P}-4$ & Biface Stage 1 & 1 \\
\hline E20/S84 & 16 & & IIIa & $11 \mathrm{P}-2$ & Biface Stage 2 & 1 \\
\hline E20/S84 & 16 & & IIIa & $11 \mathrm{P}-6$ & Biface Stage 3 & \\
\hline E20/S84 & 16 & & IIIIa & $11 \mathrm{P}-3$ & Burin & 1 \\
\hline E20/S84 & 16 & & IIIa & $11 \mathrm{P}-10$ & Burin & 1 \\
\hline E20/S84 & 16 & & IIIa & $11 \mathrm{P}-5$ & Burin & 1 \\
\hline $\begin{array}{l}\mathrm{E} 20 / \mathrm{S} 84 \\
\mathrm{E} 20\end{array}$ & 16 & & IIIa & $11 \mathrm{P}-9$ & Burin spall & \\
\hline E20/S84 & 16 & & IIIa & $11 \mathrm{P}-11$ & Burin spall & \\
\hline E20/S84 & 16 & & IIIa & & Debitage & 574 \\
\hline E20/S84 & 16 & & IIIa & $11 \mathrm{P}-12$ & Edge modified flake & \\
\hline E20/S84 & 16 & & IIIa & $11 \mathrm{P}-1$ & Metate fragment & \\
\hline E20/S84 & 16 & & IIIIa & $11 \mathrm{P}-8$ & Unifacial multiple tool & \\
\hline E20/S84 & 17 & & IIIa & $110-4$ & Biface fraoment & \\
\hline E20/S84 & 17 & & IIIa & $11 \mathrm{Q}-2$ & Biface Stage 2 & 1 \\
\hline E20/S84 & 17 & & IIIIa & $11 Q-6$ & Biface Stage 3 & \\
\hline E20/S84 & 17 & & IIIa & & Debitage & 830 \\
\hline E20/S84 & 17 & & IIIa & 11Q-8 & Denticulated flake & 1 \\
\hline E20/S84 & 17 & & IIIIa & $11 \mathrm{Q}-12$ & Edge modified flake & \\
\hline
\end{tabular}




\begin{tabular}{|c|c|c|c|c|c|c|}
\hline Square & Level & Feature & Strata & Item & Analyst Identification & Count \\
\hline $\mathrm{E} 20 / \mathrm{S} 84$ & 17 & & IIIa & 11Q-7 & Microspur/microdenticulate & 1 \\
\hline E20/S84 & 17 & & IIIa & $11 \mathrm{Q}-11$ & Notched flake & 1 \\
\hline E20/S84 & 17 & & IIIa & 11Q-3 & Projectile point fragment & 1 \\
\hline E20/S84 & 17 & & IIIa & 11Q-1 & Projectile point, Angostura & 1 \\
\hline E20/S84 & 17 & & IIIa & 11Q-9 & Thin uniface & 1 \\
\hline E20/S84 & 17 & & IIIa & $11 Q-10$ & Unifacial multiple tool & 1 \\
\hline E20/S84 & 18 & & II/IIIa & $11 \mathrm{R}-2$ & Biface Stage 2 & 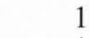 \\
\hline E20/S84 & 18 & & II/IIIa & $11 R-3$ & Biface Stage 2 & 1 \\
\hline E20/S84 & 18 & & II/IIIa & $11 \mathrm{R}-4$ & Clear Fork biface, proximal & 1 \\
\hline E20/S84 & 18 & & II/IIIa & & Debitage & 692 \\
\hline E20/S84 & 18 & & II/IIIa & 11R-7 & Edge modified flake & 1 \\
\hline E20/S84 & 18 & & II/IIIa & 11R-1 & Projectile point, Jetta & 1 \\
\hline E20/S84 & 18 & & II/IIIa & $11 \mathrm{R}-5$ & Thick uniface & 1 \\
\hline E20/S84 & 18 & & II/IIIa & $11 \mathrm{R}-8$ & Thin uniface & 1 \\
\hline E20/S84 & 18 & & II/IIIa & $11 \mathrm{R}-6$ & Thin uniface fragment & 1 \\
\hline E20/S84 & 19 & & II & $11 S-6$ & Bifacial tool Form B & 1 \\
\hline E20/S84 & 19 & & II & $11 \mathrm{~S}-2$ & Burin & 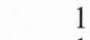 \\
\hline E20/S84 & 19 & & II & $11 \mathrm{~S}-4$ & Burin spall & 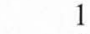 \\
\hline E20/S84 & 19 & & II & $11 S-5$ & Core, thermal & 1 \\
\hline E20/S84 & 19 & & II & & Debitage & 448 \\
\hline E20/S84 & 19 & & II & $11 S-9$ & Possible ground stone & 1 \\
\hline E20/S84 & 19 & & II & 11S-1 & Projectile point, Angostura & 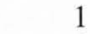 \\
\hline E20/S84 & 19 & & II & $11 \mathrm{~S}-7$ & Thick uniface & 1 \\
\hline E20/S84 & 19 & & II & $11 \mathrm{~S}-3$ & Thin uniface & 1 \\
\hline E20/S84 & 20 & & II & $11 \mathrm{~T}-3$ & Biface fragment & $x$ \\
\hline E20/S84 & 20 & & II & $11 \mathrm{~T}-1$ & Biface Stage 2 & 1 \\
\hline E20/S84 & 20 & & II & $11 \mathrm{~T}-2$ & Biface Stage 2 & 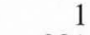 \\
\hline E20/S84 & 20 & & II & & Debitage & 281 \\
\hline E20/S84 & 20 & & II & $11 \mathrm{~T}-4$ & Thin uniface & 1 \\
\hline E20/S84 & 21 & & $\mathrm{X} / \mathrm{II}$ & & Debitage & 206 \\
\hline E20/S84 & 22 & & $\mathrm{X} / \mathrm{II}$ & $11 \mathrm{~V}-3$ & Core, multidirectional & 1 \\
\hline $\mathrm{E} 20 / \mathrm{S} 84$ & 22 & & $\mathrm{X} / \mathrm{II}$ & & Debitage & 105 \\
\hline E20/S84 & 22 & & $\mathrm{X} / \mathrm{II}$ & $11 \mathrm{~V}-2$ & Edge modified flake & 1 \\
\hline E20/S84 & 22 & & $\mathrm{X} / \mathrm{II}$ & $11 \mathrm{~V}-1$ & Thin uniface fragment & 1 \\
\hline E20/S84 & 23 & & $\mathrm{X} / \mathrm{Id} / \mathrm{II}$ & & Debitage & 40 \\
\hline E20/S84 & 23 & & $\mathrm{X} / \mathrm{Id} / \mathrm{II}$ & $11 \mathrm{~W}-1$ & Unifacial multiple tool & 1 \\
\hline E20/S86 & 1 & & IIIc & $10 \mathrm{~A}-9$ & Arrow point, medial & 1 \\
\hline E20/S86 & 1 & & IIIc & $10 A-6$ & Biface fragment & It \\
\hline E20/S86 & 1 & & IIIc & $10 \mathrm{~A}-7$ & Biface Stage 2 & 1 \\
\hline E20/S86 & 1 & & IIIC & $10 \mathrm{~A}-5$ & Burin & 1 \\
\hline E20/S86 & 1 & & IIIC & & Debitage & 1201 \\
\hline E20/S86 & 1 & & IIIc & $10 \mathrm{~A}-12$ & Notched flake & 1 \\
\hline E20/S86 & 1 & & IIIc & $10 \mathrm{~A}-13$ & Notched flake & 1 \\
\hline E20/S86 & 1 & & IIIc & $10 \mathrm{~A}-10$ & Notched flake & 1 \\
\hline $\mathrm{E} 20 / \mathrm{S} 86$ & 1 & & IIIC & $10 \mathrm{~A}-14$ & Notched flake & 1 \\
\hline E20/S86 & 1 & & IIIc & 10A-1 & Projectile point fragment & 1 \\
\hline E20/S86 & 1 & & IIIc & $10 \mathrm{~A}-2$ & Projectile point, Darl & 1 \\
\hline E20/S86 & 1 & & IIIc & $10 \mathrm{~A}-11$ & Spurred flake & 1 \\
\hline E20/S86 & 2 & & IIIc & $10 \mathrm{~B}-1$ & Arrow point, Scallorn & 1 \\
\hline $\mathrm{E} 20 / \mathrm{S} 86$ & 2 & & IIIc & 10B-2 & Arrow point, Scallorn & 1 \\
\hline E20/S86 & 2 & & IIIC & 10B-27 & Biface fragment & 1 \\
\hline E20/S86 & 2 & & IIIc & 10B-10 & Biface fragment & 1 \\
\hline E20/S86 & 2 & & IIIC & 10B-13 & Biface fragment & 1 \\
\hline E20/S86 & 2 & & IIIc & $10 \mathrm{~B}-32$ & Biface Stage 2 & 1 \\
\hline E20/S86 & 2 & & IIIc & 10B-31 & Biface Stage 2 & 1 \\
\hline E20/S86 & 2 & & IIIc & $10 \mathrm{~B}-26$ & Biface Stage 2 & 1 \\
\hline E20/S86 & 2 & & IIIc & 10B-12 & Biface Stage 2 & 1 \\
\hline $\mathrm{E} 20 / \mathrm{S} 86$ & 2 & & IIIc & $10 \mathrm{~B}-15$ & Biface Stage 3 & 1 \\
\hline E20/S86 & 2 & & IIIc & $10 \mathrm{~B}-30$ & Biface Stage 3 & 1 \\
\hline E20/S86 & 2 & & IIIc & 10B-23 & Burin & 1 \\
\hline E20/S86 & 2 & & IIIC & & Debitage & 2037 \\
\hline E20/S86 & 2 & & IIIc & 10B-24 & Edge modified flake & 1 \\
\hline E20/S86 & 2 & & IIIc & $10 \mathrm{~B}-20$ & Edge modified flake & , \\
\hline E20/S86 & 2 & & IIIc & 10B-29 & Edge modified flake & 1 \\
\hline E20/S86 & 2 & & IIIc & 10B-19 & Piece esquillee & 1 \\
\hline E20/S86 & 2 & & IIIc & 10B-18 & Projectile point fragment & 1 \\
\hline $\mathrm{E} 20 / \mathrm{S} 86$ & 2 & & IIIc & 10B-17 & Projectile point fragment & 1 \\
\hline E20/S86 & 2 & & IIIc & $10 \mathrm{~B}-4$ & Projectile point, Darl & 1 \\
\hline E20/S86 & 2 & & IIIc & $10 \mathrm{~B}-5$ & Projectile point, Darl & 1 \\
\hline E20/S86 & 2 & & IIIc & $10 \mathrm{~B}-3$ & Projectile point, Darl & 1 \\
\hline E20/S86 & 2 & & IIIc & 10B-6 & Projectile point, Ensor & 1 \\
\hline $\mathrm{E} 20 / \mathrm{S} 86$ & 2 & & IIIc & $10 \mathrm{~B}-7$ & Projectile point, Ensor & 1 \\
\hline E20/S86 & 2 & & IIIc & 10B-16 & Projectile point, indeterminate & 1 \\
\hline $\mathrm{E} 20 / \mathrm{S} 86$ & 2 & & IIIc & $10 \mathrm{~B}-8$ & Projectile point, miscellaneous bifurcate & 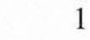 \\
\hline
\end{tabular}




\begin{tabular}{|c|c|c|c|c|c|c|}
\hline Square & Level & Feature & Strata & Item & Analyst Identification & Coun \\
\hline E20/S86 & 2 & & IIIc & 10B-22 & Thin uniface & \\
\hline E20/S86 & 2 & & IIIc & $10 \mathrm{~B}-25$ & Thin uniface fragment & \\
\hline E20/S86 & 2 & & IIIIc & 10B-28 & Thin uniface fragment & \\
\hline E20/S86 & 3 & & IIIC & $10 \mathrm{C}-1$ & Arrow point, Scallorn & \\
\hline E20/S86 & 3 & & IIIc & $10 \mathrm{C}-6$ & Biface fragment & \\
\hline E20/S86 & 3 & & IIIc & $10 \mathrm{C}-5$ & Biface Stage 1 & \\
\hline $\mathrm{E} 20 / \mathrm{S} 86$ & 3 & & IIIIc & $10 \mathrm{C}-7$ & Biface Stage 2 & \\
\hline E20/S86 & 3 & & IIII & $10 \mathrm{C}-8$ & Biface Stage 3 & \\
\hline E20/S86 & 3 & & IIIc & $10 \mathrm{C}-9$ & Bifacial tool Form B & \\
\hline E20/S86 & 3 & & IIIc & $10 \mathrm{C}-16$ & Burin & \\
\hline E20/S86 & 3 & & IIIc & & Debitage & 92 \\
\hline E20/S86 & 3 & & IIIIc & $10 \mathrm{C}-10$ & Edge modified flake & \\
\hline E20/S86 & 3 & & IIIc & $10 \mathrm{C}-11$ & Edge modified flake & \\
\hline E20/S86 & 3 & & IIIIc & $10 \mathrm{C}-14$ & Edge modified flake & \\
\hline E20/S86 & 3 & & IIIC & $10 \mathrm{C}-15$ & Edge modified flake & \\
\hline E20/S86 & 3 & & IIIIc & $10 \mathrm{C}-2$ & Projectile point, Darl & \\
\hline E20/S86 & 3 & & IIIc & $10 \mathrm{C}-3$ & Projectile point, expanding concave B & \\
\hline E20/S86 & 3 & & IIIc & $10 \mathrm{C}-4$ & Projectile point, miscellaneous lanceolate & \\
\hline E20/S86 & 3 & & IIIc & $10 \mathrm{C}-13$ & Thin uniface & \\
\hline E20/S86 & 3 & & IIIc & $10 \mathrm{C}-12$ & Unifacial multiple tool & \\
\hline E20/S86 & 4 & & IIIIc & 10D-6 & Biface Stage 2 & \\
\hline E20/S86 & 4 & & IIIc & $10 \mathrm{D}-5$ & Biface Stage 2 & \\
\hline E20/S86 & 4 & & IIIc & 10D-3B & Biface Stage 2 & \\
\hline E20/S86 & 4 & & IIIc & $10 \mathrm{D}-15$ & Biface Stage 3 & \\
\hline E20/S86 & 4 & & IIIc & 10D-1 & Bifacial tool Form A & \\
\hline E20/S86 & 4 & & IIIIc & $10 \mathrm{D}-3 \mathrm{~A}$ & Bifacial tool Form B & \\
\hline E20/S86 & 4 & & IIIc & $10 \mathrm{D}-7$ & Core tool, type 1 & \\
\hline E20/S86 & 4 & & IIIC & 10D-18 & Core tool, type 5 & \\
\hline E20/S86 & 4 & & IIIc & & Debitage & 551 \\
\hline E20/S86 & 4 & & IIIIc & 10D-12 & Edge modified flake & \\
\hline E20/S86 & 4 & & IIIc & 10D-9 & Edge modified flake & \\
\hline $\mathrm{E} 20 / \mathrm{S} 86$ & 4 & & IIIc & $10 \mathrm{D}-10$ & Edge modified flake & \\
\hline $\mathrm{E} 20 / \mathrm{S} 86$ & 4 & & IIIc & $10 \mathrm{D}-14$ & Edge modified flake & \\
\hline E20/S86 & 4 & & IIIC & 10D-11 & Edge modified flake & \\
\hline E20/S86 & 4 & & IIIIc & 10D-2 & Projectile point, Montell & \\
\hline E20/S86 & 4 & & IIIc & $10 \mathrm{D}-4$ & Thin uniface & \\
\hline E20/S86 & 4 & & IIII & $10 \mathrm{D}-16$ & Thin uniface & \\
\hline E20/S86 & 4 & & IIIC & 10D-17 & Thin uniface & \\
\hline E20/S86 & 4 & & IIIc & $10 \mathrm{D}-13$ & Unifacial multiple tool & \\
\hline E20/S86 & 5 & & IIIc & $10 \mathrm{E}-6$ & Biface Stage 2 & \\
\hline $\mathrm{E} 20 / \mathrm{S} 86$ & 5 & & IIIc & & Debitage & 312 \\
\hline E20/S86 & 5 & & IIIc & $10 \mathrm{E}-9$ & Edge modified flake & \\
\hline E20/S86 & 5 & & IIIC & $10 \mathrm{E}-8$ & Edge modified flake & \\
\hline E20/S86 & 5 & & IIIC & $10 \mathrm{E}-7$ & Edge modified flake & \\
\hline E20/S86 & 5 & & IIIC & $10 \mathrm{E}-12$ & Edge modified flake & \\
\hline E20/S86 & 5 & & IIIc & $10 \mathrm{E}-5$ & Metate fragment & \\
\hline $\mathrm{E} 20 / \mathrm{S} 86$ & 5 & & IIIc & $10 \mathrm{E}-10$ & Notched flake & \\
\hline E20/S86 & 5 & Feature 11 & IIIC & $10 \mathrm{E}-1$ & Biface Stage 1 & \\
\hline E20/S86 & 5 & Feature 11 & IIIIc & $10 \mathrm{E}-3$ & Biface Stage 1 & \\
\hline E20/S86 & 5 & Feature 11 & IIIc & $10 \mathrm{E}-2$ & Biface Stage 1 & \\
\hline E20/S86 & 5 & Feature 11 & IIII & $10 \mathrm{E}-4$ & Core, multidirectional & \\
\hline E20/S86 & 6 & & IIIc & $10 \mathrm{~F}-2$ & Biface Stage 2 & \\
\hline $\mathrm{E} 20 / \mathrm{S} 86$ & 6 & & IIIC & & Debitage & 429 \\
\hline E20/S86 & 6 & & IIIC & $10 \mathrm{~F}-4$ & Edge modified flake & \\
\hline E20/S86 & 6 & & IIIC & $10 \mathrm{~F}-3$ & Edge modified flake & \\
\hline E20/S86 & 6 & & IIIc & $10 \mathrm{~F}-5$ & Mano fragment & \\
\hline E20/S86 & 6 & & IIIc & $10 \mathrm{~F}-1$ & Projectile point, Gary & \\
\hline E20/S86 & 7 & BRM 1 & IIIC & 10G-5 & Biface fragment, unanalyzed & \\
\hline E20/S86 & 7 & BRM 1 & IIIc & 10G-2 & Biface Stage 2 & \\
\hline $\mathrm{E} 20 / \mathrm{S} 86$ & 7 & BRM 1 & IIIc & $10 \mathrm{G}-7$ & Chert cobble, unmodified/tested & \\
\hline $\mathrm{E} 20 / \mathrm{S} 86$ & 7 & BRM 1 & IIIc & & Debitage & \\
\hline E20/S86 & 7 & BRM 1 & IIIc & 10G-6 & Edge modified flake & \\
\hline E20/S86 & 7 & BRM 1 & IIIIc & 10G-4 & Edge modified flake & \\
\hline E20/S86 & 7 & BRM 1 & IIIIc & 10G-1 & Projectile point, Bulverde & \\
\hline $\mathrm{E} 20 / \mathrm{S} 86$ & 7 & BRM 1 & IIIc & $10 \mathrm{G}-3$ & Projectile point, rectangular stem A & \\
\hline E20/S86 & 8 & & IIIc & $10 \mathrm{H}-17$ & Biface fragment & \\
\hline E20/S86 & 8 & & IIIc & $10 \mathrm{H}-19$ & Biface Stage 2 & \\
\hline E20/S86 & 8 & & IIIIc & $10 \mathrm{H}-3$ & Bifacial tool Form A & \\
\hline E20/S86 & 8 & & IIIC & $10 \mathrm{H}-18$ & Bifacial tool Form A & \\
\hline E20/S86 & 8 & & IIIc & & Debitage & 337 \\
\hline E20/S86 & 8 & & IIIc & $10 \mathrm{H}-16$ & Denticulated flake & \\
\hline $\mathrm{E} 20 / \mathrm{S} 86$ & 8 & & IIIc & $10 \mathrm{H}-9$ & Edge modified flake & \\
\hline E20/S86 & 8 & & IIIIc & $10 \mathrm{H}-5$ & Edge modified flake & \\
\hline E20/S86 & 8 & & IIIIc & $10 \mathrm{H}-10$ & Edge modified flake & \\
\hline
\end{tabular}




\begin{tabular}{|c|c|c|c|c|c|c|}
\hline Square & Level & Feature & Strata & Item & Analyst Identification & Count \\
\hline E20/S86 & 8 & & IIIc & $10 \mathrm{H}-11$ & Edge modified flake & \\
\hline E20/S86 & 8 & & IIIc & $10 \mathrm{H}-13$ & Edge modified flake & \\
\hline E20/S86 & 8 & & IIIc & $10 \mathrm{H}-4$ & Edge modified flake & 1 \\
\hline E20/S86 & 8 & & IIIc & $10 \mathrm{H}-7$ & Edge modified flake & 1 \\
\hline $\mathrm{E} 20 / \mathrm{S} 86$ & 8 & & IIIc & $10 \mathrm{H}-8$ & Edge modified flake & 1 \\
\hline $\mathrm{E} 20 / \mathrm{S} 86$ & 8 & & IIIc & $10 \mathrm{H}-12$ & Edge modified flake & \\
\hline E20/S86 & 8 & & IIIc & $10 \mathrm{H}-1$ & Projectile point, Nolan & \\
\hline E20/S86 & 8 & . & IIIc & $10 \mathrm{H}-15$ & Thick uniface & \\
\hline E20/S86 & 8 & & IIIc & $10 \mathrm{H}-14$ & Thin uniface & \\
\hline E20/S86 & 9 & & $\mathrm{IIIb} / \mathrm{c}$ & $10 \mathrm{I}-2$ & Biface Stage 2 & 1 \\
\hline E20/S86 & 9 & & $\mathrm{IIIb} / \mathrm{c}$ & 10I-11 & Burin & \\
\hline E20/S86 & 9 & & $\mathrm{IIIb} / \mathrm{c}$ & & Debitage & 31 \\
\hline E20/S86 & 9 & & $\mathrm{IIIb} / \mathrm{c}$ & $10 I-3$ & Edge modified flake & \\
\hline $\mathrm{E} 20 / \mathrm{S} 86$ & 9 & & $\mathrm{IIIb} / \mathrm{c}$ & $10 \mathrm{I}-5$ & Edge modified flake & \\
\hline E20/S86 & 9 & & $\mathrm{IIIb} / \mathrm{c}$ & $10 \mathrm{I}-7$ & Edge modified flake & \\
\hline E20/S86 & 9 & & $\mathrm{IIIb} / \mathrm{c}$ & $10 \mathrm{I}-9$ & Edge modified flake & \\
\hline E20/S86 & 9 & & $\mathrm{IIIb} / \mathrm{c}$ & $10 \mathrm{I}-4$ & Unifacial multiple tool & \\
\hline $\mathrm{E} 20 / \mathrm{S} 86$ & 10 & & $\mathrm{IIIb}$ & $10 \mathrm{~J}-3$ & Biface fragment & \\
\hline $\mathrm{E} 20 / \mathrm{S} 86$ & 10 & & $\mathrm{IIIb}$ & $10 \mathrm{~J}-2$ & Biface Stage 2 & \\
\hline E20/S86 & 10 & & IIIb & $10 \mathrm{~J}-5$ & Biface Stage 3 & \\
\hline E20/S86 & 10 & & IIIb & $10 \mathrm{~J}-4$ & Biface Stage 3 & \\
\hline $\mathrm{E} 20 / \mathrm{S} 86$ & 10 & & IIIb & & Debitage & 87 \\
\hline E20/S86 & 10 & & IIIb & $10 \mathrm{~J}-6$ & Projectile point fragment & \\
\hline E20/S86 & 10 & & IIIb & $10 \mathrm{~J}-1$ & Projectile point, Bulverde-like & \\
\hline E20/S86 & 10 & & IIIb & $10 \mathrm{~J}-7$ & Thin uniface & 1 \\
\hline E20/S86 & $10-12$ & Feature 20 & $\mathrm{IIIb} / \mathrm{c}$ & & Debitage & 20 \\
\hline $\mathrm{E} 20 / \mathrm{S} 86$ & $10-12$ & Feature 20 & $\mathrm{IIIb} / \mathrm{c}$ & $10 \mathrm{I}-10$ & Edge modified flake & \\
\hline $\mathrm{E} 20 / \mathrm{S} 86$ & 11 & & $\mathrm{IIIb}$ & $10 \mathrm{~K}-2$ & Biface Stage 2 & \\
\hline E20/S86 & 11 & & $\mathrm{IIIb}$ & $10 \mathrm{~K}-3$ & Biface Stage 2 & \\
\hline E20/S86 & 11 & & IIIb & $10 \mathrm{~K}-4$ & Biface Stage 2 & \\
\hline E20/S86 & 11 & & IIIb & & Debitage & 6 \\
\hline E20/S86 & 11 & & $\mathrm{IIIb}$ & $10 \mathrm{~K}-5$ & Projectile point, Gower & \\
\hline E20/S86 & 11 & & IIIb & $10 \mathrm{~K}-1$ & Projectile point, Martindale A & \\
\hline E20/S86 & 11 & & IIIb & $10 \mathrm{~K}-6$ & Thin uniface & \\
\hline E20/S86 & 11 & & IIIb & $10 \mathrm{~K}-7$ & Thin uniface & \\
\hline E20/S86 & 12 & & $\mathrm{X} / \mathrm{IIIb}$ & 10L-9 & Biface fragment & \\
\hline E20/S86 & 12 & & $\mathrm{X} / \mathrm{IIIb}$ & $10 \mathrm{~L}-4$ & Biface Stage 1 & 1 \\
\hline E20/S86 & 12 & & $\mathrm{X} / \mathrm{IIIb}$ & $10 \mathrm{~L}-1$ & Biface Stage 2 & \\
\hline E20/S86 & 12 & & $\mathrm{X} / \mathrm{IIIb}$ & $10 \mathrm{~L}-6$ & Biface Stage 2 & \\
\hline E20/S86 & 12 & & $\mathrm{X} / \mathrm{IIIb}$ & $10 \mathrm{~L}-2$ & Biface Stage 3 & \\
\hline E20/S86 & 12 & & $\mathrm{X} / \mathrm{IIIb}$ & $10 \mathrm{~L}-3$ & Biface Stage 3 & \\
\hline E20/S86 & 12 & & X/IIIb & $10 \mathrm{~L}-7$ & Burin spall & \\
\hline E20/S86 & 12 & & $\mathrm{X} / \mathrm{IIIb}$ & & Debitage & 65 \\
\hline E20/S86 & 12 & & $\mathrm{X} / \mathrm{IIIb}$ & 10L-10 & Edge modified flake & \\
\hline $\mathrm{E} 20 / \mathrm{S} 86$ & 12 & & $\mathrm{X} / \mathrm{IIIb}$ & $10 \mathrm{~L}-5$ & Notched flake & \\
\hline E20/S86 & 12 & & $\mathrm{X} / \mathrm{IIIb}$ & $10 \mathrm{~L}-8$ & Thin uniface fragment & \\
\hline $\mathrm{E} 20 / \mathrm{S} 86$ & 13 & & $\mathrm{X} / \mathrm{IIIb}$ & $10 \mathrm{M}-8$ & Biface fragment & \\
\hline $\mathrm{E} 20 / \mathrm{S} 86$ & 13 & & X/IIIb & $10 \mathrm{M}-9$ & Biface fragment & \\
\hline E20/S86 & 13 & & $\mathrm{X} / \mathrm{IIIb}$ & $10 \mathrm{M}-5$ & Biface fragment & \\
\hline E20/S86 & 13 & & $\mathrm{X} / \mathrm{IIIb}$ & $10 \mathrm{M}-6$ & Biface Stage 2 & \\
\hline $\mathrm{E} 20 / \mathrm{S} 86$ & 13 & & $\mathrm{X} / \mathrm{IIIb}$ & $10 \mathrm{M}-3$ & Biface Stage 2 & \\
\hline E20/S86 & 13 & & $\mathrm{X} / \mathrm{IIIb}$ & $10 \mathrm{M}-2$ & Biface Stage 2 & \\
\hline E20/S86 & 13 & & $\mathrm{X} / \mathrm{IIIb}$ & $10 \mathrm{M}-4$ & Bifacial tool Form A & \\
\hline E20/S86 & 13 & & $\mathrm{X} / \mathrm{IIIb}$ & $10 \mathrm{M}-1$ & Bifacial tool Form E & \\
\hline E20/S86 & 13 & & $\mathrm{X} / \mathrm{IIIb}$ & $10 \mathrm{M}-10$ & Burin spall & \\
\hline E20/S86 & 13 & & $\mathrm{X} / \mathrm{IIIb}$ & & Debitage & 81 \\
\hline $\mathrm{E} 20 / \mathrm{S} 86$ & 13 & & $\mathrm{X} / \mathrm{IIIb}$ & $10 \mathrm{M}-7$ & Thin uniface & \\
\hline $\mathrm{E} 20 / \mathrm{S} 86$ & 14 & & $\mathrm{X} / \mathrm{IIIa} / \mathrm{b}$ & $10 \mathrm{~N}-5$ & Biface Stage 2 & \\
\hline E20/S86 & 14 & & $\mathrm{X} / \mathrm{III} / \mathrm{b}$ & $10 \mathrm{~N}-4$ & Biface Stage 3 & \\
\hline E20/S86 & 14 & & $\mathrm{X} / \mathrm{III} / \mathrm{b}$ & $10 \mathrm{~N}-1$ & Bifacial tool Form B & \\
\hline E20/S86 & 14 & & $\mathrm{X} / \mathrm{IIIa} / \mathrm{b}$ & $10 \mathrm{~N}-16$ & Burin spall & \\
\hline E20/S86 & 14 & & $\mathrm{X} / \mathrm{III} / \mathrm{b}$ & $10 \mathrm{~N}-2$ & Clear Fork uniface & \\
\hline E20/S86 & 14 & & $\mathrm{X} / \mathrm{III} / \mathrm{b}$ & & Debitage & 79 \\
\hline E20/S86 & 14 & & $\mathrm{X} / \mathrm{IIIa} / \mathrm{b}$ & $10 \mathrm{~N}-17$ & Edge modified flake & \\
\hline E20/S86 & 14 & & $\mathrm{X} / \mathrm{IIIa} / \mathrm{b}$ & $10 \mathrm{~N}-13$ & Edge modified flake & \\
\hline E20/S86 & 14 & & $\mathrm{X} / \mathrm{IIIa} / \mathrm{b}$ & $10 \mathrm{~N}-14$ & Edge modified flake & \\
\hline E20/S86 & 14 & & $\mathrm{X} / \mathrm{III} / \mathrm{b}$ & $10 \mathrm{~N}-18$ & Micro-core, intermediate & \\
\hline $\mathrm{E} 20 / \mathrm{S} 86$ & 14 & & $\mathrm{X} / \mathrm{III} / \mathrm{b}$ & $10 N-3$ & Perforator Group 7 & \\
\hline E20/S86 & 14 & & $\mathrm{X} / \mathrm{IIIa} / \mathrm{b}$ & $10 \mathrm{~N}-8$ & Thin uniface & \\
\hline E20/S86 & 14 & & $\mathrm{X} / \mathrm{IIIa} / \mathrm{b}$ & $10 \mathrm{~N}-6$ & Thin uniface fragment & \\
\hline E20/S86 & 15 & & X/IIIa & $10 \mathrm{O}-1$ & Biface fragment & \\
\hline E20/S86 & 15 & & X/IIIa & $10 \mathrm{O}-4$ & Biface fragment & \\
\hline E20/S86 & 15 & & $\mathrm{X} / \mathrm{IIIa}$ & & Debitage & 77 \\
\hline E20/S86 & 15 & & X/IIIa & $100-5$ & Edge modified flake & \\
\hline
\end{tabular}




\begin{tabular}{|c|c|c|c|c|c|c|}
\hline Square & Level & Feature & Strata & Item & Analyst Identification & Count \\
\hline E20/S86 & 15 & & X/IIIa & $10 \mathrm{O}-2$ & Perforator Group 7 & 1 \\
\hline E20/S86 & 15 & & X/IIIa & $100-6$ & Thin uniface & 1 \\
\hline E20/S86 & 16 & & $\mathrm{X} / \mathrm{II} / \mathrm{III}$ & $10 \mathrm{P}-14$ & Biface fragment & 1 \\
\hline E20/S86 & 16 & & X/II/IIIa & $10 \mathrm{P}-6$ & Biface fragment & 1 \\
\hline E20/S86 & 16 & & $\mathrm{X} / \mathrm{II} / \mathrm{IIIa}$ & $10 \mathrm{P}-4$ & Biface fragment & 1 \\
\hline E20/S86 & 16 & & X/II/IIIa & $10 \mathrm{P}-2$ & Biface fragment & 1 \\
\hline E20/S86 & 16 & & X/II/IIIa & $10 \mathrm{P}-3$ & Biface Stage 1 & 1 \\
\hline E20/S86 & 16 & & X/II/IIIa & $10 \mathrm{P}-1$ & Biface Stage 3 & 1 \\
\hline E20/S86 & 16 & & $\mathrm{X} / \mathrm{II} / \mathrm{IIIa}$ & $10 P-16$ & Burin & 1 \\
\hline E20/S86 & 16 & & $\mathrm{X} / \mathrm{II} / \mathrm{III}$ & 10P-17 & Core fragment & . \\
\hline E20/S86 & 16 & & X/II/IIIa & & Debitage & 924 \\
\hline E20/S86 & 16 & & X/II/IIIa & $10 \mathrm{P}-10$ & Edge modified flake & 1 \\
\hline E20/S86 & 16 & & X/II/IIIa & $10 \mathrm{P}-11$ & Microspur/microdenticulate & 1 \\
\hline E20/S86 & 16 & & $\mathrm{X} / \mathrm{II} / \mathrm{IIIa}$ & $10 \mathrm{P}-15$ & Piece esquillee & 1 \\
\hline E20/S86 & 16 & & $\mathrm{X} / \mathrm{II} / \mathrm{III}$ & $10 \mathrm{P}-8$ & Projectile point, bifurcate stem fragment & 1 \\
\hline E20/S86 & 16 & & $\mathrm{X} / \mathrm{II} / \mathrm{III} \mathrm{a}$ & $10 \mathrm{P}-12$ & Thin uniface & , \\
\hline E20/S86 & 16 & & X/II/IIIa & $10 \mathrm{P}-13$ & Unifacial multiple tool & 1 \\
\hline $\mathrm{E} 20 / \mathrm{S} 86$ & 17 & & X/II/IIIa & 10Q-5 & Biface Stage 2 & 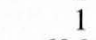 \\
\hline $\mathrm{E} 20 / \mathrm{S} 86$ & 17 & & $\mathrm{X} / \mathrm{II} / \mathrm{III} \mathrm{a}$ & & Debitage & 696 \\
\hline E20/S86 & 17 & & $\mathrm{X} / \mathrm{II} / \mathrm{III}$ & 10Q-6 & Edge modified flake & 1 \\
\hline E20/S86 & 17 & & X/II/IIIa & 10Q-2 & Microspur/microdenticulate & 1 \\
\hline E20/S86 & 17 & & $\mathrm{X} / \mathrm{II} / \mathrm{III}$ & 10Q-1 & Projectile point fragment & 1 \\
\hline E20/S86 & 17 & & $\mathrm{X} / \mathrm{II} / \mathrm{III}$ & 10Q-9 & Projectile point fragment & 1 \\
\hline E20/S86 & 17 & & $\mathrm{X} / \mathrm{II} / \mathrm{III}$ & 10Q-3 & Thin uniface & 1 \\
\hline E20/S86 & 17 & & $\mathrm{X} / \mathrm{II} / \mathrm{III}$ & 10Q-7 & Thin uniface & 1 \\
\hline $\mathrm{E} 20 / \mathrm{S} 86$ & 17 & & $\mathrm{X} / \mathrm{II} / \mathrm{IIIa}$ & 10Q-4 & Unifacial multiple tool & 1 \\
\hline E20/S86 & 17 & Feature 29 & $\mathrm{X} / \mathrm{II} / \mathrm{IIIa}$ & 10Q-8 & Projectile point, Angostura & 1 \\
\hline E20/S86 & 18 & & $\mathrm{X} / \mathrm{II}$ & $10 \mathrm{R}-8$ & Biface Stage 1 & 1 \\
\hline E20/S86 & 18 & & $\mathrm{X} / \mathrm{II}$ & & Debitage & 530 \\
\hline E20/S86 & 18 & & $\mathrm{X} / \mathrm{II}$ & $10 \mathrm{R}-3$ & Edge modified flake & 1 \\
\hline E20/S86 & 18 & & $\mathrm{X} / \mathrm{II}$ & $10 \mathrm{R}-9$ & Edge modified flake & 1 \\
\hline $\mathrm{E} 20 / \mathrm{S} 86$ & 18 & & $\mathrm{X} / \mathrm{II}$ & $10 R-4$ & Microspur/microdenticulate & 1 \\
\hline E20/S86 & 18 & & $\mathrm{X} / \mathrm{II}$ & $10 \mathrm{R}-1$ & Microspur/microdenticulate & 1 \\
\hline E20/S86 & 18 & & $\mathrm{X} / \mathrm{II}$ & $10 \mathrm{R}-10$ & Projectile point, Hoxie A & 1 \\
\hline E20/S86 & 18 & & $\mathrm{X} / \mathrm{II}$ & $10 \mathrm{R}-5$ & Thin uniface & 1 \\
\hline E20/S86 & 19 & & $\mathrm{X} / \mathrm{II}$ & $10 \mathrm{~S}-3$ & Clear Fork biface & 1 \\
\hline E20/S86 & 19 & & $\mathrm{X} / \mathrm{II}$ & & Debitage & 513 \\
\hline E20/S86 & 19 & & $\mathrm{X} / \mathrm{II}$ & $10 S-4$ & Edge modified flake & 1 \\
\hline E20/S86 & 19 & & $\mathrm{X} / \mathrm{II}$ & 10S-7 & Edge modified flake & 1 \\
\hline E20/S86 & 19 & & $\mathrm{X} / \mathrm{II}$ & $10 S-2$ & Edge modified flake & 1 \\
\hline E20/S86 & 19 & & $\mathrm{X} / \mathrm{II}$ & $10 \mathrm{~S}-1$ & Projectile point, Golondrina-Barber & 1 \\
\hline E20/S86 & 19 & & $\mathrm{X} / \mathrm{II}$ & $10 S-6$ & Thin uniface & 1 \\
\hline $\mathrm{E} 20 / \mathrm{S} 86$ & 19 & & $\mathrm{X} / \mathrm{II}$ & $10 \mathrm{~S}-5$ & Thin uniface fragment & 1 \\
\hline $\mathrm{E} 20 / \mathrm{S} 86$ & 20 & & $\mathrm{X} / \mathrm{II}$ & $10 \mathrm{~T}-4$ & Biface Stage 2 & 1 \\
\hline E20/S86 & 20 & & $\mathrm{X} / \mathrm{II}$ & $10 \mathrm{~T}-3$ & Burin spall & 1 \\
\hline E20/S86 & 20 & & $\mathrm{X} / \mathrm{II}$ & $10 \mathrm{~T}-5$ & Core fragment & 1 \\
\hline E20/S86 & 20 & & $\mathrm{X} / \mathrm{II}$ & & Debitage & 325 \\
\hline $\mathrm{E} 20 / \mathrm{S} 86$ & 20 & & $\mathrm{X} / \mathrm{II}$ & $10 \mathrm{~T}-2$ & Projectile point, miscellaneous lanceolate & 1 \\
\hline $\mathrm{E} 20 / \mathrm{S} 86$ & 20 & & $\mathrm{X} / \mathrm{II}$ & $10 \mathrm{~T}-1$ & Thin uniface fragment & 1 \\
\hline $\mathrm{E} 20 / \mathrm{S} 86$ & 21 & & $\mathrm{X}$ & & Debitage & 108 \\
\hline E20/S86 & 22 & & $\mathrm{X}$ & & Debitage & 35 \\
\hline E20/S88 & 1 & & IIIc & $9 A-5$ & Arrow point, Scallorn & 1 \\
\hline E20/S88 & 1 & & IIIc & $9 A-4$ & Arrow point, Scallorn & 1 \\
\hline $\mathrm{E} 20 / \mathrm{S} 88$ & 1 & & IIIc & $9 A-3$ & Arrow point, Scallorn & 1 \\
\hline E20/S88 & 1 & & IIIc & $9 \mathrm{~A}-2$ & Arrow point, stemmed & 1 \\
\hline E20/S88 & 1 & & IIIc & $9 \mathrm{~A}-1$ & Arrow point, stemmed & 1 \\
\hline E20/S88 & 1 & & IIIc & $9 A-9$ & Arrow point, stemmed & 1 \\
\hline E20/S88 & 1 & & IIIc & 9A-19 & Biface fragment & 1 \\
\hline E20/S88 & 1 & & IIIc & $9 \mathrm{~A}-10$ & Biface fragment & 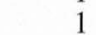 \\
\hline $\mathrm{E} 20 / \mathrm{S} 88$ & 1 & & IIIc & $9 A-26$ & Biface fragment & 1 \\
\hline E20/S88 & 1 & & IIIc & $9 A-21$ & Biface fragment & 1 \\
\hline E20/S88 & 1 & & IIIc & $9 \mathrm{~A}-22$ & Biface fragment & 1 \\
\hline E20/S88 & 1 & & IIIc & $9 A-20$ & Biface fragment & 1 \\
\hline E20/S88 & 1 & & IIIc & $9 A-25$ & Biface Stage 1 & \\
\hline E20/S88 & 1 & & IIIc & $9 A-18$ & Biface Stage 1 & 1 \\
\hline E20/S88 & 1 & & IIIc & $9 A-24$ & Biface Stage 2 & 1 \\
\hline E20/S88 & 1 & & IIIc & $9 A-16$ & Biface Stage 2 & 1 \\
\hline E20/S88 & 1 & & IIIc & $9 \mathrm{~A}-13$ & Biface Stage 2 & 1 \\
\hline E20/S88 & 1 & & IIIc & $9 A-27$ & Bifacial tool Form B & 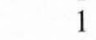 \\
\hline E20/S88 & 1 & & IIIc & $9 \mathrm{~A}-14$ & Burin & \\
\hline E20/S88 & 1 & & IIIc & $9 A-28$ & Burin spall & \\
\hline $\mathrm{E} 20 / \mathrm{S} 88$ & 1 & & IIIc & & Debitage & 832 \\
\hline $\mathrm{E} 20 / \mathrm{S} 88$ & 1 & & IIIc & $9 A-34$ & Edge modified flake & \\
\hline E20/S88 & 1 & & IIIc & $9 \mathrm{~A}-44$ & Edge modified flake & 1 \\
\hline
\end{tabular}




\begin{tabular}{|c|c|c|c|c|}
\hline Square & Level & Feature & Strata & Item \\
\hline E20/S88 & 1 & & IIIc & $9 A-35$ \\
\hline E20/S88 & 1 & & IIIC & $9 \mathrm{~A}-15$ \\
\hline E20/S88 & 1 & & IIIC & $9 A-38$ \\
\hline E20/S88 & 1 & & IIIc & $9 A-43$ \\
\hline E20/S88 & 1 & & IIIc & $9 A-11$ \\
\hline E20/S88 & 1 & & IIIc & $9 A-37$ \\
\hline E20/S88 & 1 & & IIIC & $9 A-39$ \\
\hline E20/S88 & 1 & & IIIC & $9 A-36$ \\
\hline E20/S88 & 1 & & IIIc & $9 \mathrm{~A}-12$ \\
\hline E20/S88 & 1 & & IIIc & $9 A-23$ \\
\hline E20/S88 & 1 & & IIIC & $9 A-6$ \\
\hline E20/S88 & 1 & & IIIc & $9 A-7$ \\
\hline E20/S88 & 1 & & IIIC & $9 \mathrm{~A}-8$ \\
\hline E20/S88 & 1 & & IIIc & $9 A-17$ \\
\hline E20/S88 & 1 & & IIIc & $9 \mathrm{~A}-31$ \\
\hline E20/S88 & 2 & BRM 1 & IIIc & $9 B-5$ \\
\hline E20/S88 & 2 & BRM 1 & IIIC & 9B-7 \\
\hline E20/S88 & 2 & BRM 1 & IIIc & $9 B-8$ \\
\hline E20/S88 & 2 & BRM 1 & IIIc & $9 \mathrm{~B}-9$ \\
\hline E20/S88 & 2 & BRM 1 & IIIc & $9 \mathrm{~B}-1$ \\
\hline E20/S88 & 2 & BRM 1 & IIIc & 9B-6 \\
\hline E20/S88 & 2 & BRM 1 & IIIC & $9 B-14$ \\
\hline E20/S88 & 2 & BRM 1 & IIIC & $9 B-10$ \\
\hline E20/S88 & 2 & BRM 1 & IIIc & $9 \mathrm{~B}-16$ \\
\hline E20/S88 & 2 & BRM 1 & IIIc & $9 B-12$ \\
\hline E20/S88 & 2 & BRM 1 & IIIc & $9 \mathrm{~B}-13$ \\
\hline E20/S88 & 2 & BRM 1 & IIIc & $9 B-20$ \\
\hline E20/S88 & 2 & BRM 1 & IIIc & $9 \mathrm{~B}-11$ \\
\hline E20/S88 & 2 & BRM 1 & IIIC & $9 B-15$ \\
\hline E20/S88 & 2 & BRM 1 & IIIC & $9 B-23$ \\
\hline E20/S88 & 2 & BRM 1 & IIIc & \\
\hline E20/S88 & 2 & BRM 1 & IIIC & $9 B-24$ \\
\hline E20/S88 & 2 & BRM 1 & IIIC & $9 \mathrm{~B}-25$ \\
\hline E20/S88 & 2 & BRM 1 & IIIc & $9 B-17$ \\
\hline E20/S88 & 2 & BRM 1 & IIIc & $9 \mathrm{~B}-19$ \\
\hline E20/S88 & 2 & BRM 1 & IIIc & $9 B-18$ \\
\hline E20/S88 & 2 & BRM 1 & IIIc & $9 \mathrm{~B}-3$ \\
\hline E20/S88 & 2 & BRM 1 & IIIIc & $9 \mathrm{~B}-2$ \\
\hline E20/S88 & 2 & BRM 1 & IIIc & $9 \mathrm{~B}-4$ \\
\hline E20/S88 & 3 & BRM 1 & IIIC & $9 \mathrm{C}-7$ \\
\hline E20/S88 & 3 & BRM 1 & IIIc & $9 \mathrm{C}-8$ \\
\hline E20/S88 & 3 & BRM 1 & IIIIc & $9 \mathrm{C}-6$ \\
\hline E20/S88 & 3 & BRM 1 & IIIc & $9 \mathrm{C}-17$ \\
\hline E20/S88 & 3 & BRM 1 & IIIIc & \\
\hline E20/S88 & 3 & BRM 1 & IIIC & $9 \mathrm{C}-10$ \\
\hline E20/S88 & 3 & BRM 1 & IIIC & $9 \mathrm{C}-14$ \\
\hline E20/S88 & 3 & BRM 1 & IIIc & $9 \mathrm{C}-9$ \\
\hline E20/S88 & 3 & BRM 1 & IIIc & $9 \mathrm{C}-16$ \\
\hline E20/S88 & 3 & BRM 1 & IIIC & $9 C-18$ \\
\hline E20/S88 & 3 & BRM 1 & IIIc & $9 \mathrm{C}-19$ \\
\hline E20/S88 & 3 & BRM 1 & IIIc & $9 \mathrm{C}-12$ \\
\hline E20/S88 & 3 & BRM 1 & IIIc & $9 \mathrm{C}-4$ \\
\hline E20/S88 & 3 & BRM 1 & IIIc & $9 C-25$ \\
\hline E20/S88 & 3 & BRM 1 & IIIc & $9 \mathrm{C}-5$ \\
\hline E20/S88 & 3 & BRM 1 & IIIc & $9 \mathrm{C}-1$ \\
\hline E20/S88 & 3 & BRM 1 & IIIC & $9 \mathrm{C}-2$ \\
\hline E20/S88 & 3 & BRM 1 & IIIc & $9 \mathrm{C}-3$ \\
\hline E20/S88 & 3 & BRM 1 & IIIc & $9 C-11$ \\
\hline E20/S88 & 3 & BRM 1 & IIIc & $9 \mathrm{C}-15$ \\
\hline E20/S88 & 4 & BRM 1 & IIIc & \\
\hline E20/S88 & 4 & BRM 1 & IIIc & $9 \mathrm{D}-3$ \\
\hline E20/S88 & 4 & BRM 1 & IIIc & 9D-1 \\
\hline E20/S88 & 4 & BRM 1 & IIIc & $9 D-2$ \\
\hline E20/S88 & 5 & BRM 1 & IIIc & $9 \mathrm{E}-1$ \\
\hline E20/S88 & 5 & BRM 1 & IIIc & $9 \mathrm{E}-17$ \\
\hline E20/S88 & 5 & BRM 1 & IIIc & $9 \mathrm{E}-2$ \\
\hline E20/S88 & 5 & BRM 1 & IIIC & \\
\hline E20/S88 & 5 & BRM 1 & IIIc & 9E-7 \\
\hline E20/S88 & 5 & BRM 1 & IIIc & $9 \mathrm{E}-12$ \\
\hline E20/S88 & 5 & BRM 1 & IIIc & $9 \mathrm{E}-13$ \\
\hline E20/S88 & 5 & BRM 1 & IIIC & $9 \mathrm{E}-14$ \\
\hline E20/S88 & 5 & BRM 1 & IIIC & $9 \mathrm{E}-16$ \\
\hline E20/S88 & 5 & BRM 1 & IIIc & $9 \mathrm{E}-18$ \\
\hline E20/S88 & 5 & BRM 1 & IIIC & $9 \mathrm{E}-10$ \\
\hline
\end{tabular}

Analyst Identification

Count

Edge modified flake

Edge modified flake

Edge modified flake

Edge modified flake

Edge modified flake

Edge modified flake

Microspur/microdenticulate

Notched flake

Projectile point fragment

Projectile point fragment

Projectile point, Ensor

Projectile point, Frio

Projectile point, Frio

Spurred flake

Unifacial multiple tool

Arrow point, preform

Arrow point, Scallorn

Arrow point, Scallorn

Arrow point, Scallorn

Arrow point, Scallorn

Arrow point, stemmed

Biface Stage 1

Biface Stage 1

Biface Stage 2

Biface Stage 2

Biface Stage 3

Bifacial tool Form A

Bifacial tool Form A

Bifacial tool Form B

Chert cobble, chunk

Debitage

Possible ground stone

Possible ground stone

Projectile point fragment

Projectile point fragment

Projectile point fragment

Projectile point, Darl

Projectile point, Darl

Projectile point, Ensor

Biface fragment

Biface Stage 2

Biface Stage 3

Burin spall

Debitage

Denticulated flake

Denticulated flake

Denticulated flake

Edge modified flake

Edge modified flake

Edge modified flake

Edge modified flake

Mano

Micro-core, small

Projectile point fragment

Projectile point, Darl

Projectile point, Darl

Projectile point, Ensor

Thin uniface fragment

Unifacial multiple tool

Debitage

Edge modified flake

Projectile point, Ensor

Thin uniface

Biface Stage 3

Burin

Core, thermal

Debitage

Edge modified flake

Edge modified flake

Edge modified flake

Edge modified flake

Edge modified flake

Edge modified flake

Edge modified flake 


\begin{tabular}{|c|c|c|c|c|c|c|}
\hline Square & Level & Feature & Strata & Item & Analyst Identification & Count \\
\hline E20/S88 & 5 & BRM 1 & IIIc & $9 \mathrm{E}-6$ & Edge modified flake & 1 \\
\hline E20/S88 & 5 & BRM 1 & IIIC & 9E-19 & Edge modified flake & 1 \\
\hline E20/S88 & 5 & BRM 1 & IIIC & 9E-9 & Edge modified flake & 1 \\
\hline E20/S88 & 5 & BRM 1 & IIIc & $9 \mathrm{E}-3$ & Edge modified flake & 1 \\
\hline E20/S88 & 5 & BRM 1 & IIIc & $9 \mathrm{E}-5$ & Edge modified flake & 1 \\
\hline E20/S88 & 5 & BRM 1 & IIIc & $9 \mathrm{E}-4$ & Micro-core, small & 1 \\
\hline $\mathrm{E} 20 / \mathrm{S} 88$ & 6 & BRM 1 & IIIIc & $9 \mathrm{~F}-4$ & Bifacial tool Form A & 1 \\
\hline E20/S88 & 6 & BRM 1 & IIIc & $9 \mathrm{~F}-3$ & Chert cobble, unmodified/tested & 1 \\
\hline E20/S88 & 6 & BRM 1 & IIIc & $9 \mathrm{~F}-5$ & Core tool, type 2 & 1 \\
\hline $\mathrm{E} 20 / \mathrm{S} 88$ & 6 & BRM 1 & IIIc & & Debitage & 121 \\
\hline $\mathrm{E} 20 / \mathrm{S} 88$ & 6 & BRM 1 & IIIc & $9 \mathrm{~F}-1$ & Projectile point, Bulverde-like & 1 \\
\hline E20/S88 & 6 & BRM 1 & IIIIc & $9 \mathrm{~F}-6$ & Projectile point, indeterminate & 1 \\
\hline E20/S88 & 6 & BRM 1 & IIIIc & $9 \mathrm{~F}-2$ & Projectile point, Nolan & 1 \\
\hline E20/S88 & 7 & BRM 1 & IIIc & $9 \mathrm{G}-4$ & Biface fragment & 1 \\
\hline E20/S88 & 7 & BRM 1 & IIIc & & Debitage & 207 \\
\hline E20/S88 & 7 & BRM 1 & IIIC & $9 \mathrm{G}-3$ & Edge modified flake & 1 \\
\hline E20/S88 & 7 & BRM 1 & IIIc & $9 \mathrm{G}-2$ & Edge modified flake & 1 \\
\hline $\mathrm{E} 20 / \mathrm{S} 88$ & 7 & BRM 1 & IIIc & 9G-1 & Projectile point, Marcos & 1 \\
\hline $\mathrm{E} 20 / \mathrm{S} 88$ & 8 & BRM 1 & IIIc & $9 \mathrm{H}-2$ & Biface Stage 2 & 1 \\
\hline $\mathrm{E} 20 / \mathrm{S} 88$ & 8 & BRM 1 & IIIC & $9 \mathrm{H}-1$ & Bifacial tool Form $\mathrm{H}$ & 1 \\
\hline E20/S88 & 8 & BRM 1 & IIIIc & $9 \mathrm{H}-3$ & Burin & 1 \\
\hline E20/S88 & 8 & BRM 1 & IIIc & & Debitage & 253 \\
\hline $\mathrm{E} 20 / \mathrm{S} 88$ & 8 & BRM 1 & IIIc & $9 \mathrm{H}-7$ & Edge modified flake & 1 \\
\hline E20/S88 & 8 & BRM 1 & IIIC & $9 \mathrm{H}-5$ & Edge modified flake & 1 \\
\hline E20/S88 & 8 & BRM 1 & IIIc & $9 \mathrm{H}-4$ & Edge modified flake & 1 \\
\hline E20/S88 & 8 & BRM 1 & IIIIc & $9 \mathrm{H}-8$ & Thin uniface & 1 \\
\hline $\mathrm{E} 20 / \mathrm{S} 88$ & 8 & BRM 1 & IIIc & $9 \mathrm{H}-6$ & Unifacial multiple tool & 1 \\
\hline $\mathrm{E} 20 / \mathrm{S} 88$ & 9 & BRM 1 & Y/IIIc & $9 \mathrm{I}-7$ & Biface Stage 2 & 1 \\
\hline $\mathrm{E} 20 / \mathrm{S} 88$ & 9 & BRM 1 & $\mathrm{Y} / \mathrm{IIIc}$ & $9 \mathrm{I}-6$ & Biface Stage 2 & 1 \\
\hline E20/S88 & 9 & BRM 1 & Y/IIIc & $9 \mathrm{I}-5$ & Biface Stage 2 & 1 \\
\hline E20/S88 & 9 & BRM 1 & $\mathrm{Y} / \mathrm{IIIc}$ & $9 \mathrm{I}-4$ & Biface Stage 2 & 1 \\
\hline E20/S88 & 9 & BRM 1 & Y/IIIc & $9 \mathrm{I}-3$ & Biface Stage 2 & 1 \\
\hline $\mathrm{E} 20 / \mathrm{S} 88$ & 9 & BRM 1 & Y/IIIc & & Debitage & 283 \\
\hline E20/S88 & 9 & BRM 1 & Y/IIIc & 9I-12 & Denticulated flake & 1 \\
\hline E20/S88 & 9 & BRM 1 & $\mathrm{Y} / \mathrm{IIIC}$ & 9I-9 & Edge modified flake & 1 \\
\hline E20/S88 & 9 & BRM 1 & Y/IIIc & $9 \mathrm{I}-8$ & Edge modified flake & 1 \\
\hline E20/S88 & 9 & BRM 1 & Y/IIIc & 9I-1 & Projectile point, expanding stem B & 1 \\
\hline E20/S88 & 9 & BRM 1 & Y/IIIc & $9 \mathrm{I}-2$ & Projectile point, miscellaneous expanding stem & 1 \\
\hline E20/S88 & 9 & BRM 1 & Y/IIIc & 9I-13 & Thin uniface & 1 \\
\hline E20/S88 & 9 & BRM 1 & Y/IIIc & $9 \mathrm{I}-10$ & Unifacial multiple tool & 1 \\
\hline E20/S88 & 10 & BRM 1 & $\mathrm{Y} / \mathrm{IIIb} / \mathrm{c}$ & $9 \mathrm{~J}-8$ & Biface fragment & 1 \\
\hline E20/S88 & 10 & BRM 1 & $\mathrm{Y} / \mathrm{IIIb} / \mathrm{c}$ & $9 \mathrm{~J}-4$ & Biface fragment & 1 \\
\hline E20/S88 & 10 & BRM 1 & $\mathrm{Y} / \mathrm{IIIb} / \mathrm{c}$ & $9 \mathrm{~J}-3$ & Biface fragment & 1 \\
\hline $\mathrm{E} 20 / \mathrm{S} 88$ & 10 & BRM 1 & $\mathrm{Y} / \mathrm{IIIb} / \mathrm{c}$ & $9 \mathrm{~J}-5$ & Biface Stage 3 & 1 \\
\hline E20/S88 & 10 & BRM 1 & $\mathrm{Y} / \mathrm{IIIb} / \mathrm{c}$ & $9 \mathrm{~J}-7$ & Clear Fork uniface & 1 \\
\hline E20/S88 & 10 & BRM 1 & $\mathrm{Y} / \mathrm{IIIb} / \mathrm{c}$ & $9 \mathrm{~J}-6$ & Core, thermal & 1 \\
\hline E20/S88 & 10 & BRM 1 & $\mathrm{Y} / \mathrm{IIIb} / \mathrm{c}$ & & Debitage & 449 \\
\hline E20/S88 & 10 & BRM 1 & $\mathrm{Y} / \mathrm{IIIb} / \mathrm{c}$ & $9 \mathrm{~J}-2$ & Projectile point, expanding concave $\mathrm{C}$ & 1 \\
\hline E20/S88 & 10 & BRM 1 & $\mathrm{Y} / \mathrm{IIIb} / \mathrm{c}$ & $9 \mathrm{~J}-1$ & Projectile point, Marshall & 1 \\
\hline $\mathrm{E} 20 / \mathrm{S} 88$ & 11 & & $\mathrm{Y} / \mathrm{IIIb}$ & $9 \mathrm{~K}-3$ & Burin spall & 1 \\
\hline E20/S88 & 11 & & $\mathrm{Y} / \mathrm{IIIb}$ & $9 \mathrm{~K}-2$ & Burin spall & 1 \\
\hline E20/S88 & 11 & & Y/IIIb & & Debitage & 302 \\
\hline E20/S88 & 11 & & $\mathrm{Y} / \mathrm{IIIb}$ & $9 \mathrm{~K}-9$ & Edge modified flake & 1 \\
\hline E20/S88 & 11 & & Y/IIIb & $9 \mathrm{~K}-11$ & Edge modified flake & 1 \\
\hline E20/S88 & 11 & & $\mathrm{Y} / \mathrm{IIIb}$ & $9 \mathrm{~K}-7$ & Edge modified flake & 1 \\
\hline E20/S88 & 11 & & $\mathrm{Y} / \mathrm{IIIb}$ & $9 \mathrm{~K}-6$ & Edge modified flake & 1 \\
\hline E20/S88 & 11 & & $\mathrm{Y} / \mathrm{IIIb}$ & $9 \mathrm{~K}-5$ & Edge modified flake & 1 \\
\hline E20/S88 & 11 & & Y/IIIb & $9 \mathrm{~K}-12$ & Edge modified flake & 1 \\
\hline E20/S88 & 11 & & Y/IIIb & $9 \mathrm{~K}-8$ & Edge modified flake & 1 \\
\hline E20/S88 & 11 & & $\mathrm{Y} / \mathrm{IIIb}$ & $9 \mathrm{~K}-4$ & Perforator Group 7 & 1 \\
\hline E20/S88 & 11 & & $\mathrm{Y} / \mathrm{IIIb}$ & $9 \mathrm{~K}-1$ & Projectile point, Thrall & 1 \\
\hline $\mathrm{E} 20 / \mathrm{S} 88$ & 12 & & $\mathrm{X} / \mathrm{Y} / \mathrm{IIIb}$ & $9 \mathrm{~L}-1$ & Biface Stage 1 & 1 \\
\hline E20/S88 & 12 & & $\mathrm{X} / \mathrm{Y} / \mathrm{IIIb}$ & 9L-2 & Clear Fork uniface & 1 \\
\hline E20/S88 & 12 & & $\mathrm{X} / \mathrm{Y} / \mathrm{IIIb}$ & & Debitage & 51 \\
\hline E20/S88 & 12 & & $\mathrm{X} / \mathrm{Y} / \mathrm{IIIb}$ & 9L-3 & Microspur/microdenticulate & 1 \\
\hline E20/S88 & 12 & Feature 8 & $\mathrm{X} / \mathrm{Y} / \mathrm{IIIb}$ & $9 \mathrm{~L}-5$ & Biface fragment & 1 \\
\hline E20/S88 & 12 & Feature 8 & $\mathrm{X} / \mathrm{Y} / \mathrm{IIIb}$ & 9L-6 & Biface Stage 1 & 1 \\
\hline E20/S88 & 12 & Feature 8 & $\mathrm{X} / \mathrm{Y} / \mathrm{IIIb}$ & 9L-4 & Biface Stage 2 & 1 \\
\hline E20/S88 & 12 & Feature 8 & $\mathrm{X} / \mathrm{Y} / \mathrm{IIIb}$ & & Debitage & 276 \\
\hline E20/S88 & 12 & Feature 8 & $\mathrm{X} / \mathrm{Y} / \mathrm{IIIb}$ & 9L-7 & Edge modified flake & 1 \\
\hline E20/S88 & 12 & Feature 8 & $\mathrm{X} / \mathrm{Y} / \mathrm{IIIb}$ & 9L-8 & Edge modified flake & 1 \\
\hline E20/S88 & 13 & Feature 8 & $\mathrm{X} / \mathrm{IIIb}$ & $9 \mathrm{M}-5$ & Biface fragment & 1 \\
\hline E20/S88 & 13 & Feature 8 & $\mathrm{X} / \mathrm{IIIb}$ & $9 \mathrm{M}-3$ & Biface Stage 1 & 1 \\
\hline E20/S88 & 13 & Feature 8 & $\mathrm{X} / \mathrm{IIIb}$ & $9 \mathrm{M}-2$ & Clear Fork uniface & 1 \\
\hline
\end{tabular}




\begin{tabular}{|c|c|c|c|c|c|c|}
\hline Square & Level & Feature & Strata & Item & Analyst Identification & Count \\
\hline $\mathrm{E} 20 / \mathrm{S} 88$ & 13 & Feature 8 & $\mathrm{X} / \mathrm{IIIb}$ & & Debitage & 620 \\
\hline $\mathrm{E} 20 / \mathrm{S} 88$ & 13 & Feature 8 & $\mathrm{X} / \mathrm{IIIb}$ & $9 M-4$ & Edge modified flake & 1 \\
\hline $\mathrm{E} 20 / \mathrm{S} 88$ & 13 & Feature 8 & $\mathrm{X} / \mathrm{IIIb}$ & $9 \mathrm{M}-1$ & Projectile point, miscellaneous bifurcate & 1 \\
\hline $\mathrm{E} 20 / \mathrm{S} 88$ & 14 & & $\mathrm{X}$ & $9 \mathrm{~N}-4$ & Biface Stage 1 & 1 \\
\hline E20/S88 & 14 & & $X$ & & Debitage & 466 \\
\hline $\mathrm{E} 20 / \mathrm{S} 88$ & 14 & & $\mathrm{X}$ & $9 N-5$ & Edge modified flake & 1 \\
\hline $\mathrm{E} 20 / \mathrm{S} 88$ & 14 & . & $\mathrm{X}$ & $9 \mathrm{~N}-1$ & Projectile point, bifurcate stem fragment & 1 \\
\hline $\mathrm{E} 20 / \mathrm{S} 88$ & 14 & & $\mathrm{X}$ & $9 \mathrm{~N}-2$ & Projectile point, Hoxie A & 1 \\
\hline E20/S88 & 14 & & $X$ & $9 \mathrm{~N}-6$ & Thin uniface fragment & 1 \\
\hline $\mathrm{E} 20 / \mathrm{S} 88$ & 14 & Feature 12 & $\mathrm{X}$ & $9 N-3$ & Mano fragment & 1 \\
\hline $\mathrm{E} 20 / \mathrm{S} 88$ & 15 & & $\mathrm{X}$ & $90-5$ & Biface fragment & 1 \\
\hline E20/S88 & 15 & & $\mathrm{X}$ & $90-4$ & Biface Stage 3 & 1 \\
\hline $\mathrm{E} 20 / \mathrm{S} 88$ & 15 & & $\mathrm{X}$ & $90-7$ & Core, thermal & 1 \\
\hline E20/S88 & 15 & & $\mathrm{X}$ & & Debitage & 563 \\
\hline E20/S88 & 15 & & $\mathrm{X}$ & $90-6$ & Edge modified flake & 1 \\
\hline E20/S88 & 15 & & $\mathrm{X}$ & $90-1$ & Projectile point, Baker & 1 \\
\hline $\mathrm{E} 20 / \mathrm{S} 88$ & 15 & & $\mathrm{X}$ & $90-3$ & Projectile point, Golondrina-Barber & 1 \\
\hline E20/S88 & 15 & & $\mathrm{X}$ & $90-2$ & Projectile point, Uvalde-like & 1 \\
\hline E20/S88 & 16 & & $\mathrm{X}$ & $9 \mathrm{P}-1$ & Battered cobble & 1 \\
\hline $\mathrm{E} 20 / \mathrm{S} 88$ & 16 & & $\mathrm{X}$ & $9 \mathrm{P}-3$ & Biface fragment & 1 \\
\hline $\mathrm{E} 20 / \mathrm{S} 88$ & 16 & & $\mathrm{X}$ & $9 \mathrm{P}-2$ & Biface Stage 1 & 1 \\
\hline $\mathrm{E} 20 / \mathrm{S} 88$ & 16 & & $\mathrm{X}$ & & Debitage & 785 \\
\hline E20/S88 & 16 & & $\mathrm{X}$ & 9P-7 & Edge modified flake & 1 \\
\hline $\mathrm{E} 20 / \mathrm{S} 88$ & 16 & & $\mathrm{X}$ & $9 \mathrm{P}-12$ & Edge modified flake & 1 \\
\hline E20/S88 & 16 & & $\mathrm{X}$ & 9P-4 & Projectile point fragment & 1 \\
\hline $\mathrm{E} 20 / \mathrm{S} 88$ & 16 & & $\mathrm{X}$ & $9 \mathrm{P}-5$ & Projectile point, bifurcate stem fragment & 1 \\
\hline E20/S88 & 16 & & $\mathrm{X}$ & 9P-10 & Retouched blade & 1 \\
\hline E20/S88 & 16 & & $\mathrm{X}$ & $9 \mathrm{P}-8$ & Thin uniface & 1 \\
\hline $\mathrm{E} 20 / \mathrm{S} 88$ & 16 & & $\mathrm{X}$ & $9 \mathrm{P}-11$ & Thin uniface fragment & 1 \\
\hline $\mathrm{E} 20 / \mathrm{S} 88$ & 16 & & $\mathrm{X}$ & $9 \mathrm{P}-9$ & Unifacial multiple tool & 1 \\
\hline $\mathrm{E} 20 / \mathrm{S} 88$ & 16 & & $\mathrm{X}$ & $9 \mathrm{P}-6$ & Unifacial multiple tool & 1 \\
\hline $\mathrm{E} 20 / \mathrm{S} 88$ & 17 & & $\mathrm{X}$ & $9 Q-1$ & Biface Stage 3 & 1 \\
\hline $\mathrm{E} 20 / \mathrm{S} 88$ & 17 & & $\mathrm{X}$ & & Debitage & 494 \\
\hline E20/S88 & 18 & & $\mathrm{X}$ & $9 \mathrm{R}-13$ & Biface fragment & 1 \\
\hline E20/S88 & 18 & & $\mathrm{X}$ & $9 \mathrm{R}-5$ & Biface fragment & 1 \\
\hline E20/S88 & 18 & & $\mathrm{X}$ & $9 \mathrm{R}-12$ & Biface Stage 1 & 1 \\
\hline E20/S88 & 18 & & $\mathrm{X}$ & $9 \mathrm{R}-7$ & Biface Stage 2 & 1 \\
\hline E20/S88 & 18 & & $\mathrm{X}$ & $9 \mathrm{R}-1$ & Biface Stage 2 & 1 \\
\hline E20/S88 & 18 & & $\mathrm{X}$ & 9R-9 & Biface Stage 3 & 1 \\
\hline $\mathrm{E} 20 / \mathrm{S} 88$ & 18 & & $\mathrm{X}$ & $9 \mathrm{R}-2$ & Bifacial tool Form A & 1 \\
\hline $\mathrm{E} 20 / \mathrm{S} 88$ & 18 & & $\mathrm{X}$ & $9 \mathrm{R}-3$ & Bifacial tool Form E & 1 \\
\hline $\mathrm{E} 20 / \mathrm{S} 88$ & 18 & & $\mathrm{X}$ & 9R-4 & Burin spall & 1 \\
\hline $\mathrm{E} 20 / \mathrm{S} 88$ & 18 & & $\mathrm{X}$ & & Debitage & 366 \\
\hline $\mathrm{E} 20 / \mathrm{S} 88$ & 18 & & $\mathrm{X}$ & 9R-11 & Edge modified flake & 1 \\
\hline $\mathrm{E} 20 / \mathrm{S} 88$ & 18 & & $\mathrm{X}$ & $9 \mathrm{R}-6$ & Edge modified flake & 1 \\
\hline E20/S88 & 18 & & $\mathrm{X}$ & 9R-8 & Edge modified flake & 1 \\
\hline $\mathrm{E} 20 / \mathrm{S} 88$ & 18 & & $\mathrm{X}$ & $9 \mathrm{R}-10$ & Thin uniface fragment & 1 \\
\hline E20/S88 & 19 & & $\mathrm{X}$ & & Debitage & 199 \\
\hline $\mathrm{E} 20 / \mathrm{S} 88$ & 19 & & $\mathrm{X}$ & $9 \mathrm{~S}-1$ & Edge modified flake & 1 \\
\hline $\mathrm{E} 20 / \mathrm{S} 88$ & 20 & & $\mathrm{X}$ & & Debitage & 173 \\
\hline E20/S88 & 20 & & $\mathrm{X}$ & $9 \mathrm{~T}-4$ & Denticulated flake & 1 \\
\hline $\mathrm{E} 20 / \mathrm{S} 88$ & 20 & & $\mathrm{X}$ & $9 \mathrm{~T}-3$ & Edge modified flake & 1 \\
\hline E20/S88 & 20 & & $\mathrm{X}$ & $9 \mathrm{~T}-2$ & Grinding basin & 1 \\
\hline E20/S88 & 20 & & $\mathrm{X}$ & $9 \mathrm{~T}-1$ & Projectile point, Hoxie & 1 \\
\hline E20/S88 & 20 & & $\mathrm{X}$ & 9T-5 & Thin uniface & 1 \\
\hline E20/S88 & 20 & & $\mathrm{X}$ & $9 \mathrm{~T}-6$ & Thin uniface & 1 \\
\hline E20/S88 & 21 & & $\mathrm{X}$ & $9 \mathrm{U}-3$ & Biface Stage 2 & 1 \\
\hline E20/S88 & 21 & & $\mathrm{X}$ & $9 \mathrm{U}-2$ & Burin & 1 \\
\hline E20/S88 & 21 & & $\mathrm{X}$ & & Debitage & 156 \\
\hline E20/S88 & 21 & & $\mathrm{X}$ & $9 \mathrm{U}-1$ & Projectile point, early bifurcate stem preform & n 1 \\
\hline E20/S88 & 22 & & $\mathrm{X}$ & $9 \mathrm{~V}-3$ & Biface fragment & 1 \\
\hline $\mathrm{E} 20 / \mathrm{S} 88$ & 22 & & $\mathrm{X}$ & $9 \mathrm{~V}-2$ & Biface Stage 1 & 1 \\
\hline E20/S88 & 22 & & $\mathrm{X}$ & $9 \mathrm{~V}-4$ & Chert cobble, chunk & 1 \\
\hline E20/S88 & 22 & & $\mathrm{X}$ & & Debitage & 161 \\
\hline E20/S88 & 22 & & $\mathrm{X}$ & $9 \mathrm{~V}-1$ & Projectile point, Wilson & 1 \\
\hline E20/S90 & 1 & & IIIc & $8 \mathrm{~A}-6$ & Arrow point, medial & 1 \\
\hline $\mathrm{E} 20 / \mathrm{S} 90$ & 1 & & IIIc & $8 \mathrm{~A}-3$ & Arrow point, Scallorn & 1 \\
\hline $\mathrm{E} 20 / \mathrm{S} 90$ & 1 & & IIIc & $8 \mathrm{~A}-2$ & Arrow point, Scallorn & 1 \\
\hline $\mathrm{E} 20 / \mathrm{S} 90$ & 1 & & IIIC & $8 \mathrm{~A}-1$ & Arrow point, Scallorn & 1 \\
\hline $\mathrm{E} 20 / \mathrm{S} 90$ & 1 & & IIIc & $8 A-5$ & Arrow point, Scallorn & 1 \\
\hline E20/S90 & 1 & & IIIc & $8 \mathrm{~A}-4$ & Arrow point, Scallorn & 1 \\
\hline $\mathrm{E} 20 / \mathrm{S} 90$ & 1 & & IIIc & $8 \mathrm{~A}-12$ & Biface fragment & 1 \\
\hline E20/S90 & 1 & & IIIC & 8A-8 & Biface fragment & 1 \\
\hline $\mathrm{E} 20 / \mathrm{S} 90$ & 1 & & IIIc & $8 \mathrm{~A}-10$ & Biface Stage 1 & 1 \\
\hline
\end{tabular}




\begin{tabular}{|c|c|c|c|c|c|c|}
\hline Square & Level & Feature & Strata & Item & Analyst Identification & Count \\
\hline $\mathrm{E} 20 / \mathrm{S} 90$ & 1 & & IIIc & $8 \mathrm{~A}-21$ & Biface Stage 2 & 1 \\
\hline $\mathrm{E} 20 / \mathrm{S} 90$ & 1 & & IIIc & $8 A-11$ & Biface Stage 2 & 1 \\
\hline $\mathrm{E} 20 / \mathrm{S} 90$ & 1 & & IIIc & $8 \mathrm{~A}-17$ & Biface Stage 3 & 1 \\
\hline $\mathrm{E} 20 / \mathrm{S} 90$ & 1 & & IIIc & $8 A-14$ & Biface Stage 3 & 1 \\
\hline E20/S90 & 1 & & IIIC & $8 \mathrm{~A}-19$ & Biface Stage 3 & 1 \\
\hline $\mathrm{E} 20 / \mathrm{S} 90$ & 1 & & IIIIc & $8 \mathrm{~A}-16$ & Bifacial tool & 1 \\
\hline E20/S90 & 1 & & IIIC & $8 \mathrm{~A}-7$ & Bifacial tool Form A & 1 \\
\hline $\mathrm{E} 20 / \mathrm{S} 90$ & 1 & & IIIC & $8 A-32$ & Burin spall & 1 \\
\hline $\mathrm{E} 20 / \mathrm{S} 90$ & 1 & & IIIIc & $8 \mathrm{~A}-47$ & Burin spall & 1 \\
\hline E20/S90 & 1 & & IIIC & & Debitage & 1369 \\
\hline $\mathrm{E} 20 / \mathrm{S} 90$ & 1 & & IIIC & $8 A-38$ & Denticulated flake & 1 \\
\hline $\mathrm{E} 20 / \mathrm{S} 90$ & 1 & & IIIc & $8 A-29$ & Edge modified flake & 1 \\
\hline $\mathrm{E} 20 / \mathrm{S} 90$ & 1 & & IIIc & $8 \mathrm{~A}-31$ & Edge modified flake & 1 \\
\hline $\mathrm{E} 20 / \mathrm{S} 90$ & 1 & & IIIIc & $8 A-39$ & Edge modified flake & 1 \\
\hline $\mathrm{E} 20 / \mathrm{S} 90$ & 1 & & IIIC & $8 A-37$ & Edge modified flake & 1 \\
\hline $\mathrm{E} 20 / \mathrm{S} 90$ & 1 & & IIIC & $8 A-36$ & Edge modified flake & 1 \\
\hline $\mathrm{E} 20 / \mathrm{S} 90$ & 1 & & IIIC & $8 A-42$ & Edge modified flake & 1 \\
\hline E20/S90 & 1 & & IIIC & $8 \mathrm{~A}-23$ & Edge modified flake & 1 \\
\hline $\mathrm{E} 20 / \mathrm{S} 90$ & 1 & & IIIC & $8 \mathrm{~A}-34$ & Edge modified flake & 1 \\
\hline E20/S90 & 1 & & IIII & $8 A-44$ & Notched flake & 1 \\
\hline E20/S90 & 1 & & IIIC & $8 A-40$ & Notched flake & 1 \\
\hline $\mathrm{E} 20 / \mathrm{S} 90$ & 1 & & IIIIc & $8 \mathrm{~A}-25$ & Notched flake & 1 \\
\hline $\mathrm{E} 20 / \mathrm{S} 90$ & 1 & & IIIIc & $8 A-33$ & Notched flake & 1 \\
\hline $\mathrm{E} 20 / \mathrm{S} 90$ & 1 & & IIIc & $8 A-43$ & Notched flake & 1 \\
\hline $\mathrm{E} 20 / \mathrm{S} 90$ & 1 & & IIIc & $8 \mathrm{~A}-20$ & Projectile point fragment & 1 \\
\hline $\mathrm{E} 20 / \mathrm{S} 90$ & 1 & & IIIIc & $8 \mathrm{~A}-18$ & Projectile point fragment & 1 \\
\hline $\mathrm{E} 20 / \mathrm{S} 90$ & 1 & & IIIc & $8 \mathrm{~A}-15$ & Projectile point fragment & 1 \\
\hline E20/S90 & 1 & & IIIIc & $8 \mathrm{~A}-9$ & Projectile point fragment & 1 \\
\hline $\mathrm{E} 20 / \mathrm{S} 90$ & 1 & & IIIc & $8 \mathrm{~A}-27$ & Spurred flake & 1 \\
\hline $\mathrm{E} 20 / \mathrm{S} 90$ & 1 & & IIIc & $8 \mathrm{~A}-48$ & Thin uniface fragment & 1 \\
\hline $\mathrm{E} 20 / \mathrm{S} 90$ & 1 & & IIIc & $8 A-41$ & Thin uniface fragment & 1 \\
\hline E20/S90 & 1 & & IIIc & $8 \mathrm{~A}-24$ & Thin uniface fragment & 1 \\
\hline E20/S90 & 1 & & IIIC & $8 \mathrm{~A}-35$ & Unifacial multiple tool & 1 \\
\hline $\mathrm{E} 20 / \mathrm{S} 90$ & 2 & BRM 1 & IIIc & $8 B-2$ & Arrow point, Scallorn & 1 \\
\hline $\mathrm{E} 20 / \mathrm{S} 90$ & 2 & BRM 1 & IIIc & $8 B-3$ & Arrow point, Scallorn & 1 \\
\hline $\mathrm{E} 20 / \mathrm{S} 90$ & 2 & BRM 1 & IIIc & $8 B-4$ & Arrow point, stemmed & 1 \\
\hline E20/S90 & 2 & BRM 1 & IIIc & $8 B-1$ & Arrow point, stemmed & 1 \\
\hline E20/S90 & 2 & BRM 1 & IIIc & $8 \mathrm{~B}-6$ & Arrow point, tip & 1 \\
\hline E20/S90 & 2 & BRM 1 & IIIc & $8 B-5$ & Arrow point, tip & 1 \\
\hline $\mathrm{E} 20 / \mathrm{S} 90$ & 2 & BRM 1 & IIIc & $8 B-41$ & Biface fragment & 1 \\
\hline $\mathrm{E} 20 / \mathrm{S} 90$ & 2 & BRM 1 & IIIc & $8 B-24$ & Biface fragment & 1 \\
\hline E20/S90 & 2 & BRM 1 & IIIIc & $8 B-36$ & Biface fragment & 1 \\
\hline $\mathrm{E} 20 / \mathrm{S} 90$ & 2 & BRM 1 & IIIC & $8 B-27$ & Biface fragment & 1 \\
\hline E20/S90 & 2 & BRM 1 & IIIc & $8 B-26$ & Biface fragment & 1 \\
\hline E20/S90 & 2 & BRM 1 & IIIc & $8 B-16$ & Biface fragment & 1 \\
\hline $\mathrm{E} 20 / \mathrm{S} 90$ & 2 & BRM 1 & IIIIc & 8B-19 & Biface Stage 2 & 1 \\
\hline E20/S90 & 2 & BRM 1 & IIIIc & $8 B-15$ & Biface Stage 2 & 1 \\
\hline $\mathrm{E} 20 / \mathrm{S} 90$ & 2 & BRM 1 & IIIc & $8 B-20$ & Biface Stage 2 & 1 \\
\hline $\mathrm{E} 20 / \mathrm{S} 90$ & 2 & BRM 1 & IIIc & $8 B-21$ & Biface Stage 2 & 1 \\
\hline $\mathrm{E} 20 / \mathrm{S} 90$ & 2 & BRM 1 & IIIc & $8 \mathrm{~B}-23$ & Biface Stage 2 & 1 \\
\hline E20/S90 & 2 & BRM 1 & IIIIc & $8 B-22$ & Biface Stage 2 & 1 \\
\hline E20/S90 & 2 & BRM 1 & IIIc & $8 B-17$ & Biface Stage 2 & 1 \\
\hline $\mathrm{E} 20 / \mathrm{S} 90$ & 2 & BRM 1 & IIIc & $8 \mathrm{~B}-30$ & Biface Stage 3 & 1 \\
\hline $\mathrm{E} 20 / \mathrm{S} 90$ & 2 & BRM 1 & IIIc & $8 B-25$ & Bifacial tool Form A & 1 \\
\hline $\mathrm{E} 20 / \mathrm{S} 90$ & 2 & BRM 1 & IIIc & $8 B-42$ & Bifacial tool Form J & 1 \\
\hline E20/S90 & 2 & BRM 1 & IIIIc & $8 \mathrm{~B}-28$ & Burin & 1 \\
\hline $\mathrm{E} 20 / \mathrm{S} 90$ & 2 & BRM 1 & IIIc & & Debitage & 1412 \\
\hline E20/S90 & 2 & BRM 1 & IIIC & $8 B-32$ & Edge modified flake & 1 \\
\hline $\mathrm{E} 20 / \mathrm{S} 90$ & 2 & BRM 1 & IIIc & $8 \mathrm{~B}-31$ & Edge modified flake & 1 \\
\hline $\mathrm{E} 20 / \mathrm{S} 90$ & 2 & BRM 1 & IIIc & $8 \mathrm{~B}-33$ & Edge modified flake & 1 \\
\hline E20/S90 & 2 & BRM 1 & IIIIc & 8B-12 & Mano fragment & 1 \\
\hline $\mathrm{E} 20 / \mathrm{S} 90$ & 2 & BRM 1 & IIIc & $8 B-35$ & Notched flake & 1 \\
\hline $\mathrm{E} 20 / \mathrm{S} 90$ & 2 & BRM 1 & IIIC & $8 B-11$ & Perforator Group 3 & 1 \\
\hline $\mathrm{E} 20 / \mathrm{S} 90$ & 2 & BRM 1 & IIIc & $8 B-29$ & Projectile point fragment & 1 \\
\hline $\mathrm{E} 20 / \mathrm{S} 90$ & 2 & BRM 1 & IIIIc & $8 B-14$ & Projectile point fragment & 1 \\
\hline $\mathrm{E} 20 / \mathrm{S} 90$ & 2 & BRM 1 & IIIc & $8 B-7$ & Projectile point, Darl & 1 \\
\hline E20/S90 & 2 & BRM 1 & IIIC & $8 B-9$ & Projectile point, Ensor & 1 \\
\hline $\mathrm{E} 20 / \mathrm{S} 90$ & 2 & BRM 1 & IIIC & 8B-10 & Projectile point, indeterminate & 1 \\
\hline E20/S90 & 2 & BRM 1 & IIIc & $8 \mathrm{~B}-18$ & Projectile point, indeterminate & 1 \\
\hline $\mathrm{E} 20 / \mathrm{S} 90$ & 2 & BRM 1 & IIIc & $8 B-8$ & Projectile point, indeterminate & 1 \\
\hline $\mathrm{E} 20 / \mathrm{S} 90$ & 2 & BRM 1 & IIIc & $8 B-39$ & Thin uniface & 1 \\
\hline $\mathrm{E} 20 / \mathrm{S} 90$ & 2 & BRM 1 & IIIc & $8 B-40$ & Unifacial multiple tool & 1 \\
\hline $\mathrm{E} 20 / \mathrm{S} 90$ & 3 & BRM 1 & IIIc & $8 \mathrm{C}-2$ & Arrow point, preform & 1 \\
\hline $\mathrm{E} 20 / \mathrm{S} 90$ & 3 & BRM 1 & IIIIc & $8 \mathrm{C}-3$ & Biface Stage 2 & 1 \\
\hline
\end{tabular}




\begin{tabular}{|c|c|c|c|c|c|c|}
\hline Square & Level & Feature & Strata & Item & Analyst Identification & Count \\
\hline E20/S 90 & 3 & BRM 1 & IIIc & $8 \mathrm{C}-1$ & Biface Stage 3 & \\
\hline $\mathrm{E} 20 / \mathrm{S} 90$ & 3 & BRM 1 & IIIc & $8 C-4$ & Burin spall & 150 \\
\hline $\mathrm{E} 20 / \mathrm{S} 90$ & 3 & BRM 1 & IIIc & & Debitage & 459 \\
\hline $\mathrm{E} 20 / \mathrm{S} 90$ & 3 & BRM 1 & IIII & $8 C-5$ & Edge modified flake & \\
\hline E20/S90 & 3 & BRM 1 & IIIc & $8 C-6$ & Edge modified flake & \\
\hline $\mathrm{E} 20 / \mathrm{S} 90$ & 3 & BRM 1 & IIIC & $8 \mathrm{C}-7$ & Thin uniface fragment & \\
\hline E20/S90 & 4 & BRM 1 & IIIc & 8D-1 & Biface Stage 1 & \\
\hline $\mathrm{E} 20 / \mathrm{S} 90$ & 4 & BRM 1 & IIIc & $8 \mathrm{D}-2$ & Biface Stage 1 & \\
\hline $\mathrm{E} 20 / \mathrm{S} 90$ & 4 & BRM 1 & IIIc & $8 D-4$ & Burin & \\
\hline E20/S90 & 4 & BRM 1 & IIIc & & Debitage & 251 \\
\hline E20/S90 & 4 & BRM 1 & IIIc & $8 \mathrm{D}-7$ & Edge modified flake & \\
\hline E20/S90 & 4 & BRM 1 & IIIc & $8 \mathrm{D}-8$ & Micro-core, large & \\
\hline $\mathrm{E} 20 / \mathrm{S} 90$ & 4 & BRM 1 & IIIc & $8 D-3$ & Projectile point fragment & \\
\hline $\mathrm{E} 20 / \mathrm{S} 90$ & 4 & BRM 1 & IIIIc & 8D-6 & Thin uniface & \\
\hline $\mathrm{E} 20 / \mathrm{S} 90$ & 4 & BRM 1 & IIIIc & $8 D-5$ & Thin uniface & \\
\hline $\mathrm{E} 20 / \mathrm{S} 90$ & 5 & BRM 1 & IIIC & $8 \mathrm{E}-3$ & Biface fragment & \\
\hline E20/S90 & 5 & BRM 1 & IIIIc & $8 \mathrm{E}-1$ & Biface Stage 3 & r \\
\hline E20/S90 & 5 & BRM 1 & IIIC & & Debitage & 206 \\
\hline E20/S90 & 5 & BRM 1 & IIIIc & $8 \mathrm{E}-7$ & Denticulated flake & \\
\hline $\mathrm{E} 20 / \mathrm{S} 90$ & 5 & BRM 1 & IIIIc & $8 \mathrm{E}-2$ & Edge modified flake & \\
\hline $\mathrm{E} 20 / \mathrm{S} 90$ & 5 & BRM 1 & IIIc & $8 \mathrm{E}-6$ & Edge modified flake & \\
\hline $\mathrm{E} 20 / \mathrm{S} 90$ & 5 & BRM 1 & IIIC & $8 \mathrm{E}-4$ & Notched flake & 1 \\
\hline $\mathrm{E} 20 / \mathrm{S} 90$ & 5 & BRM 1 & IIIc & $8 \mathrm{E}-5$ & Notched flake & \\
\hline $\mathrm{E} 20 / \mathrm{S} 90$ & 6 & BRM 1 & IIIc & $8 \mathrm{~F}-2$ & Biface Stage 2 & \\
\hline $\mathrm{E} 20 / \mathrm{S} 90$ & 6 & BRM 1 & IIIIc & $8 \mathrm{~F}-1$ & Biface Stage 2 & \\
\hline $\mathrm{E} 20 / \mathrm{S} 90$ & 6 & BRM 1 & IIII & $8 \mathrm{~F}-4$ & Biface Stage 3 & 1 \\
\hline E20/S90 & 6 & BRM 1 & IIIc & & Debitage & 158 \\
\hline E20/S90 & 6 & BRM 1 & IIIIC & $8 \mathrm{~F}-6$ & Edge modified flake & \\
\hline $\mathrm{E} 20 / \mathrm{S} 90$ & 6 & BRM 1 & IIIIc & $8 \mathrm{~F}-9$ & Edge modified flake & \\
\hline $\mathrm{E} 20 / \mathrm{S} 90$ & 6 & BRM 1 & IIIIc & $8 \mathrm{~F}-5$ & Edge modified flake & \\
\hline $\mathrm{E} 20 / \mathrm{S} 90$ & 6 & BRM 1 & IIIIc & $8 \mathrm{~F}-7$ & Microspur/microdenticulate & \\
\hline $\mathrm{E} 20 / \mathrm{S} 90$ & 6 & BRM 1 & IIIC & $8 \mathrm{~F}-3$ & Projectile point, Travis & \\
\hline $\mathrm{E} 20 / \mathrm{S} 90$ & 6 & BRM 1 & IIIc & $8 \mathrm{~F}-8$ & Thin uniface & \\
\hline $\mathrm{E} 20 / \mathrm{S} 90$ & 7 & BRM 1 & IIIIc & & Debitage & 253 \\
\hline $\mathrm{E} 20 / \mathrm{S} 90$ & 7 & BRM 1 & IIIc & $8 \mathrm{G}-3$ & Edge modified flake & \\
\hline $\mathrm{E} 20 / \mathrm{S} 90$ & 7 & BRM 1 & IIIc & $8 \mathrm{G}-4$ & Edge modified flake & \\
\hline E20/S90 & 7 & BRM 1 & IIIIc & $8 \mathrm{G}-2$ & Notched flake & \\
\hline E20/S90 & 8 & BRM 1 & IIIIc & $8 \mathrm{H}-2$ & Biface fragment & \\
\hline E20/S90 & 8 & BRM 1 & IIIc & $8 \mathrm{H}-1$ & Burin & \\
\hline E20/S90 & 8 & BRM 1 & IIIc & & Debitage & 170 \\
\hline E20/S90 & 8 & BRM 1 & IIIIc & $8 \mathrm{H}-3$ & Projectile point, miscellaneous bifurcate & \\
\hline $\mathrm{E} 20 / \mathrm{S} 90$ & 9 & & Y/IIIc & $8-\mathrm{I}-4$ & Bifacial tool Form A & \\
\hline $\mathrm{E} 20 / \mathrm{S} 90$ & 9 & BRM 1 & Y/IIIc & $8 \mathrm{I}-7$ & Biface fragment & \\
\hline $\mathrm{E} 20 / \mathrm{S} 90$ & 9 & BRM 1 & Y/IIIc & $8 \mathrm{I}-8$ & Biface Stage 2 & \\
\hline $\mathrm{E} 20 / \mathrm{S} 90$ & 9 & BRM 1 & Y/IIIc & $8 \mathrm{I}-6$ & Biface Stage 3 & \\
\hline $\mathrm{E} 20 / \mathrm{S} 90$ & 9 & BRM 1 & Y/IIIc & $8 \mathrm{I}-4$ & Bifacial tool Form A & \\
\hline $\mathrm{E} 20 / \mathrm{S} 90$ & 9 & BRM 1 & Y/IIIc & & Debitage & 324 \\
\hline E20/S90 & 9 & BRM 1 & Y/IIIc & $8 \mathrm{I}-14$ & Edge modified flake & \\
\hline $\mathrm{E} 20 / \mathrm{S} 90$ & 9 & BRM 1 & Y/IIIc & $8 \mathrm{I}-13$ & Edge modified flake & \\
\hline $\mathrm{E} 20 / \mathrm{S} 90$ & 9 & BRM 1 & $\mathrm{Y} / \mathrm{IIIC}$ & $8 \mathrm{I}-12$ & Edge modified flake & \\
\hline E20/S90 & 9 & BRM 1 & $\mathrm{Y} / \mathrm{IIIC}$ & $8 \mathrm{I}-10$ & Edge modified flake & \\
\hline E20/S90 & 9 & BRM 1 & Y/IIIc & $8 \mathrm{I}-9$ & Edge modified flake & \\
\hline $\mathrm{E} 20 / \mathrm{S} 90$ & 9 & BRM 1 & Y/IIIc & $8 \mathrm{I}-16$ & Perforator Group 7 & \\
\hline $\mathrm{E} 20 / \mathrm{S} 90$ & 9 & BRM 1 & Y/IIIc & $8 \mathrm{I}-1$ & Projectile point, bifurcate stem fragment & \\
\hline $\mathrm{E} 20 / \mathrm{S} 90$ & 9 & BRM 1 & Y/IIIc & $8 \mathrm{I}-2$ & Projectile point, Martindale A & \\
\hline $\mathrm{E} 20 / \mathrm{S} 90$ & 9 & BRM 1 & Y/IIIc & $8 \mathrm{I}-17$ & Small core hammerstone & \\
\hline E20/S90 & 9 & BRM 1 & Y/IIIc & $8 \mathrm{I}-11$ & Thin uniface fragment & \\
\hline $\mathrm{E} 20 / \mathrm{S} 90$ & 10 & BRM 1 & Y/IIIc & $8 \mathbf{J}-7$ & Biface Stage 2 & \\
\hline $\mathrm{E} 20 / \mathrm{S} 90$ & 10 & BRM 1 & Y/IIIc & $8 \mathbf{J}-11$ & Bifacial tool Form A & \\
\hline $\mathrm{E} 20 / \mathrm{S} 90$ & 10 & BRM 1 & Y/IIIc & $8 \mathbf{J}-9$ & Bifacial tool Form E & \\
\hline $\mathrm{E} 20 / \mathrm{S} 90$ & 10 & BRM 1 & Y/IIIc & & Debitage & 486 \\
\hline $\mathrm{E} 20 / \mathrm{S} 90$ & 10 & BRM 1 & Y/IIIc & $8 \mathbf{J}-5$ & Edge modified flake & \\
\hline E20/S90 & 10 & BRM 1 & Y/IIIc & $8 \mathbf{J}-10$ & Edge modified flake & \\
\hline E20/S90 & 10 & BRM 1 & Y/IIIc & $8 \mathbf{J}-6$ & Edge modified flake & \\
\hline $\mathrm{E} 20 / \mathrm{S} 90$ & 10 & BRM 1 & $\mathrm{Y} / \mathrm{IIIc}$ & $8 \mathrm{~J}-3$ & Projectile point, bifurcate stem fragment & \\
\hline $\mathrm{E} 20 / \mathrm{S} 90$ & 10 & BRM 1 & Y/IIIc & $8 \mathbf{J}-2$ & Projectile point, expanding concave D & \\
\hline $\mathrm{E} 20 / \mathrm{S} 90$ & 10 & BRM 1 & Y/IIIc & $8 \mathbf{J}-4$ & Projectile point, Gower/Uvalde & \\
\hline $\mathrm{E} 20 / \mathrm{S} 90$ & 10 & BRM 1 & Y/IIIc & $8 \mathrm{~J}-1$ & Projectile point, Marcos & \\
\hline E20/S90 & 10 & BRM 1 & Y/IIIc & $8 \mathrm{~J}-8$ & Projectile point, miscellaneous expanding sten & \\
\hline $\mathrm{E} 20 / \mathrm{S} 90$ & 11 & & $\mathrm{Y}$ & $8 \mathrm{~K}-4$ & Biface fragment & \\
\hline $\mathrm{E} 20 / \mathrm{S} 90$ & 11 & & Y & $8 \mathrm{~K}-10$ & Biface fragment & \\
\hline E20/S90 & 11 & & $\mathrm{Y}$ & $8 \mathrm{~K}-11$ & Biface fragment & \\
\hline $\mathrm{E} 20 / \mathrm{S} 90$ & 11 & & Y & $8 \mathrm{~K}-5$ & Biface Stage 1 & 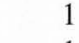 \\
\hline $\mathrm{E} 20 / \mathrm{S} 90$ & 11 & & Y & $8 \mathrm{~K}-3$ & Biface Stage 2 & \\
\hline
\end{tabular}




\begin{tabular}{|c|c|c|c|c|c|c|}
\hline Square & Level & Feature & Strata & Item & Analyst Identification & Count \\
\hline E20/S90 & 11 & & $\mathrm{Y}$ & $8 \mathrm{~K}-6$ & Biface Stage 2 & 1 \\
\hline $\mathrm{E} 20 / \mathrm{S} 90$ & 11 & & Y & $8 \mathrm{~K}-14$ & Burin & 1 \\
\hline $\mathrm{E} 20 / \mathrm{S} 90$ & 11 & & Y & $8 \mathrm{~K}-9$ & Burin spall & 1 \\
\hline $\mathrm{E} 20 / \mathrm{S} 90$ & 11 & & Y & $8 \mathrm{~K}-18$ & Burin spall & 1 \\
\hline $\mathrm{E} 20 / \mathrm{S} 90$ & 11 & & Y & & Debitage & 568 \\
\hline $\mathrm{E} 20 / \mathrm{S} 90$ & 11 & & Y & $8 \mathrm{~K}-16$ & Edge modified flake & 1 \\
\hline $\mathrm{E} 20 / \mathrm{S} 90$ & 11 & & Y & $8 \mathrm{~K}-17$ & Edge modified flake & 1 \\
\hline $\mathrm{E} 20 / \mathrm{S} 90$ & 11 & & Y & $8 \mathrm{~K}-12$ & Edge modified flake & 1 \\
\hline $\mathrm{E} 20 / \mathrm{S} 90$ & 11 & & $\mathrm{Y}$ & $8 \mathrm{~K}-7$ & Piece esquillee & 1 \\
\hline $\mathrm{E} 20 / \mathrm{S} 90$ & 11 & & $\mathrm{Y}$ & $8 \mathrm{~K}-8$ & Projectile point fragment & 1 \\
\hline $\mathrm{E} 20 / \mathrm{S} 90$ & 11 & & $\mathrm{Y}$ & $8 \mathrm{~K}-2$ & Projectile point, Martindale A & 1 \\
\hline E20/S90 & 11 & . & $\mathrm{Y}$ & $8 \mathrm{~K}-1$ & Projectile point, Thrall & 1 \\
\hline E20/S90 & 11 & & Y & $8 \mathrm{~K}-13$ & Thin uniface & 1 \\
\hline $\mathrm{E} 20 / \mathrm{S} 90$ & 12 & & $\mathrm{X} / \mathrm{Y}$ & $8 \mathrm{~L}-1$ & Biface fragment & 1 \\
\hline $\mathrm{E} 20 / \mathrm{S} 90$ & 12 & & $\mathrm{X} / \mathrm{Y}$ & & Debitage & 149 \\
\hline $\mathrm{E} 20 / \mathrm{S} 90$ & 12 & & $\mathrm{X} / \mathrm{Y}$ & $8 \mathrm{~L}-2$ & Edge modified flake & 1 \\
\hline E20/S90 & 12 & Feature 8 & $\mathrm{X} / \mathrm{Y}$ & & Debitage & 199 \\
\hline E20/S90 & 12 & Feature 8 & $\mathrm{X} / \mathrm{Y}$ & $8 \mathrm{~L}-7$ & Edge modified flake & 1 \\
\hline $\mathrm{E} 20 / \mathrm{S} 90$ & 12 & Feature 8 & $\mathrm{X} / \mathrm{Y}$ & $8 \mathrm{~L}-6$ & Microspur/microdenticulate & 1 \\
\hline E20/S90 & 12 & Feature 8 & $\mathrm{X} / \mathrm{Y}$ & $8 \mathrm{~L}-3$ & Projectile point fragment & 1 \\
\hline $\mathrm{E} 20 / \mathrm{S} 90$ & 12 & Feature 8 & $\mathrm{X} / \mathrm{Y}$ & $8 \mathrm{~L}-5$ & Spurred flake & 1 \\
\hline $\mathrm{E} 20 / \mathrm{S} 90$ & 12 & Feature 8 & $\mathrm{X} / \mathrm{Y}$ & $8 \mathrm{~L}-4$ & Thin uniface fragment & 1 \\
\hline $\mathrm{E} 20 / \mathrm{S} 90$ & 12 & Feature 8 & $\mathrm{X} / \mathrm{Y}$ & $8 \mathrm{~L}-8$ & Unifacial multiple tool & 1 \\
\hline E20/S90 & 13 & & $\mathrm{X} / \mathrm{Y}$ & $8 \mathrm{M}-2$ & Biface fragment & 1 \\
\hline $\mathrm{E} 20 / \mathrm{S} 90$ & 13 & & $\mathrm{X} / \mathrm{Y}$ & $8 \mathrm{M}-3$ & Burin spall & 1 \\
\hline $\mathrm{E} 20 / \mathrm{S} 90$ & 13 & & $\mathrm{X} / \mathrm{Y}$ & & Debitage & 711 \\
\hline E20/S90 & 13 & & $X / Y$ & $8 M-6$ & Edge modified flake & 1 \\
\hline $\mathrm{E} 20 / \mathrm{S} 90$ & 13 & & $\mathrm{X} / \mathrm{Y}$ & $8 \mathrm{M}-10$ & Edge modified flake & 1 \\
\hline E20/S90 & 13 & & $\mathrm{X} / \mathrm{Y}$ & $8 \mathrm{M}-8$ & Edge modified flake & 1 \\
\hline $\mathrm{E} 20 / \mathrm{S} 90$ & 13 & & $\mathrm{X} / \mathrm{Y}$ & $8 \mathrm{M}-15$ & Edge modified flake & 1 \\
\hline $\mathrm{E} 20 / \mathrm{S} 90$ & 13 & & $\mathrm{X} / \mathrm{Y}$ & $8 \mathrm{M}-14$ & Edge modified flake & 1 \\
\hline $\mathrm{E} 20 / \mathrm{S} 90$ & 13 & & $\mathrm{X} / \mathrm{Y}$ & $8 \mathrm{M}-13$ & Edge modified flake & 1 \\
\hline E20/S90 & 13 & & $\mathrm{X} / \mathrm{Y}$ & $8 \mathrm{M}-11$ & Edge modified flake & 1 \\
\hline E20/S90 & 13 & & $X / Y$ & $8 \mathrm{M}-12$ & Edge modified flake & 1 \\
\hline $\mathrm{E} 20 / \mathrm{S} 90$ & 13 & & $\mathrm{X} / \mathrm{Y}$ & $8 \mathrm{M}-5$ & Projectile point, bifurcate stem fragment & 1 \\
\hline $\mathrm{E} 20 / \mathrm{S} 90$ & 13 & & $\mathrm{X} / \mathrm{Y}$ & $8 \mathrm{M}-1$ & Projectile point, expanding concave $\mathrm{B}$ & 1 \\
\hline $\mathrm{E} 20 / \mathrm{S} 90$ & 13 & & $\mathrm{X} / \mathrm{Y}$ & $8 \mathrm{M}-4$ & Projectile point, expanding stem C & 1 \\
\hline $\mathrm{E} 20 / \mathrm{S} 90$ & 14 & & $\mathrm{X}$ & & Debitage & 520 \\
\hline E20/S90 & 14 & & $\mathrm{X}$ & $8 \mathrm{~N}-2$ & Edge modified flake & 1 \\
\hline $\mathrm{E} 20 / \mathrm{S} 90$ & 14 & & $X$ & $8 \mathrm{~N}-1$ & Projectile point, Jetta & 1 \\
\hline E20/S90 & 14 & & $\mathrm{X}$ & $8 \mathrm{~N}-3$ & Thin uniface & 1 \\
\hline $\mathrm{E} 20 / \mathrm{S} 90$ & 15 & & $X$ & $80-2$ & Biface Stage 2 & 1 \\
\hline $\mathrm{E} 20 / \mathrm{S} 90$ & 15 & & $X$ & & Debitage & 670 \\
\hline $\mathrm{E} 20 / \mathrm{S} 90$ & 15 & & $\mathrm{X}$ & $80-5$ & Edge modified flake & 1 \\
\hline $\mathrm{E} 20 / \mathrm{S} 90$ & 15 & & $X$ & $80-3$ & Micro-core, intermediate & 1 \\
\hline E20/S90 & 15 & & $\mathrm{X}$ & $80-1$ & Projectile point, Jetta & 1 \\
\hline $\mathrm{E} 20 / \mathrm{S} 90$ & 15 & & $\mathrm{X}$ & $80-6$ & Thin uniface & 1 \\
\hline $\mathrm{E} 20 / \mathrm{S} 90$ & 15 & & $X$ & $80-4$ & Thin uniface & 1 \\
\hline $\mathrm{E} 20 / \mathrm{S} 90$ & 15 & Feature 19/104 & $\mathrm{X}$ & & Debitage & 87 \\
\hline $\mathrm{E} 20 / \mathrm{S} 90$ & 15 & Feature 19/104 & $\mathrm{X}$ & $80-9$ & Thin uniface & 1 \\
\hline E20/S90 & 16 & Feature 17 & $\mathrm{X}$ & $8 \mathrm{P}-2$ & Burin & 1 \\
\hline $\mathrm{E} 20 / \mathrm{S} 90$ & 16 & Feature 17 & $\mathrm{X}$ & & Debitage & 547 \\
\hline E20/S90 & 16 & Feature 17 & $\mathrm{X}$ & $8 \mathrm{P}-4$ & Edge modified flake & 1 \\
\hline E20/S90 & 16 & Feature 17 & $\mathrm{X}$ & $8 \mathrm{P}-3$ & Edge modified flake & 1 \\
\hline E20/S90 & 16 & Feature 17 & $\mathrm{X}$ & $8 \mathrm{P}-1$ & Projectile point, Thrall & 1 \\
\hline $\mathrm{E} 20 / \mathrm{S} 90$ & 17 & & $X$ & 8Q-1 & Biface Stage 3 & 1 \\
\hline $\mathrm{E} 20 / \mathrm{S} 90$ & 17 & & $\mathrm{X}$ & $8 Q-2$ & Burin spall & 1 \\
\hline E20/S90 & 17 & & $X$ & $8 Q-3$ & Burin spall & 1 \\
\hline $\mathrm{E} 20 / \mathrm{S} 90$ & 17 & & $\mathrm{X}$ & & Debitage & 406 \\
\hline $\mathrm{E} 20 / \mathrm{S} 90$ & 18 & & $\mathrm{X}$ & $8 \mathrm{R}-3$ & Biface Stage 1 & 1 \\
\hline E20/S90 & 18 & & $X$ & $8 \mathrm{R}-1$ & Biface Stage 2 & 1 \\
\hline $\mathrm{E} 20 / \mathrm{S} 90$ & 18 & & $\mathrm{X}$ & $8 \mathrm{R}-4$ & Burin spall & 1 \\
\hline $\mathrm{E} 20 / \mathrm{S} 90$ & 18 & & $\mathrm{X}$ & $8 \mathrm{R}-2$ & Core tool, type 4 & 1 \\
\hline $\mathrm{E} 20 / \mathrm{S} 90$ & 18 & & $\mathrm{X}$ & & Debitage & 306 \\
\hline E20/S90 & 18 & & $\mathrm{X}$ & $8 \mathrm{R}-5$ & Thin uniface & 1 \\
\hline $\mathrm{E} 20 / \mathrm{S} 90$ & 19 & & $\mathrm{X}$ & & Debitage & 155 \\
\hline E20/S92 & 1 & & IIIc (pot) & $7 \mathrm{~A}-3$ & Arrow point, Scallorn & 1 \\
\hline $\mathrm{E} 20 / \mathrm{S} 92$ & 1 & & IIIc (pot) & $7 \mathrm{~A}-2$ & Arrow point, Scallorn & 1 \\
\hline E20/S92 & 1 & & IIIc (pot) & $7 \mathrm{~A}-5$ & Arrow point, Scallorn & 1 \\
\hline $\mathrm{E} 20 / \mathrm{S} 92$ & 1 & & IIIc (pot) & $7 A-6$ & Arrow point, stemmed & 1 \\
\hline E20/S92 & 1 & & IIIc (pot) & $7 \mathrm{~A}-1$ & Arrow point, stemmed & 1 \\
\hline E20/S92 & 1 & & IIIc (pot) & $7 \mathrm{~A}-7$ & Arrow point, tip & 1 \\
\hline E20/S92 & 1 & & IIIc (pot) & $7 \mathrm{~A}-15$ & Biface fragment & 1 \\
\hline E20/S92 & 1 & & IIIc (pot) & $7 A-18$ & Biface fragment & 1 \\
\hline
\end{tabular}




\begin{tabular}{|c|c|c|c|c|c|c|}
\hline Square & Level & Feature & Strata & Item & Analyst Identification & Count \\
\hline $\mathrm{E} 20 / \mathrm{S} 92$ & 1 & & IIIc (pot) & $7 \mathrm{~A}-17$ & Biface Stage 1 & 1 \\
\hline $\mathrm{E} 20 / \mathrm{S} 92$ & 1 & & IIIc (pot) & $7 \mathrm{~A}-14$ & Biface Stage 2 & 1 \\
\hline $\mathrm{E} 20 / \mathrm{S} 92$ & 1 & & IIIc (pot) & $7 \mathrm{~A}-13$ & Biface Stage 2 & 1 \\
\hline E20/S92 & 1 & & IIIc (pot) & $7 \mathrm{~A}-16$ & Biface Stage 2 & 1 \\
\hline $\mathrm{E} 20 / \mathrm{S} 92$ & 1 & & IIIc (pot) & & Debitage & 868 \\
\hline $\mathrm{E} 20 / \mathrm{S} 92$ & 1 & & IIIc (pot) & $7 \mathrm{~A}-19$ & Large core hammerstone & 1 \\
\hline $\mathrm{E} 20 / \mathrm{S} 92$ & 1 & & IIIc (pot) & $7 \mathrm{~A}-9$ & Projectile point fragment & \\
\hline $\mathrm{E} 20 / \mathrm{S} 92$ & 1 & & IIIc (pot) & $7 A-4$ & Projectile point fragment & 1 \\
\hline E20/S92 & 1 & & IIIc (pot) & $7 \mathrm{~A}-8$ & Projectile point fragment & 1 \\
\hline $\mathrm{E} 20 / \mathrm{S} 92$ & 1 & & IIIc (pot) & $7 \mathrm{~A}-12$ & Projectile point, Darl & 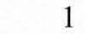 \\
\hline $\mathrm{E} 20 / \mathrm{S} 92$ & 1 & & IIIc (pot) & $7 \mathrm{~A}-11$ & Projectile point, Ensor & 1 \\
\hline $\mathrm{E} 20 / \mathrm{S} 92$ & 1 & & IIIc (pot) & $7 \mathrm{~A}-10$ & Projectile point, Ensor/Fairland & 1 \\
\hline $\mathrm{E} 20 / \mathrm{S} 92$ & 1 & & IIIc (pot) & $7 \mathrm{~A}-21$ & Thin uniface & 1 \\
\hline E20/S92 & 1 & & IIIc (pot) & $7 \mathrm{~A}-23$ & Thin uniface & 1 \\
\hline E20/S92 & 1 & & IIIc (pot) & $7 \mathrm{~A}-22$ & Thin uniface & 1 \\
\hline $\mathrm{E} 20 / \mathrm{S} 92$ & 1 & & IIIc (pot) & $7 \mathrm{~A}-20$ & Thin uniface & 1 \\
\hline E20/S92 & 2 & BRM 1 & IIIc (pot) & $7 B-3$ & Biface Stage 2 & 1 \\
\hline $\mathrm{E} 20 / \mathrm{S} 92$ & 2 & BRM 1 & IIIc (pot) & $7 B-6$ & Biface Stage 2 & 1 \\
\hline E20/S92 & 2 & BRM 1 & IIIc (pot) & 7B-1 & Biface Stage 2 & 1 \\
\hline $\mathrm{E} 20 / \mathrm{S} 92$ & 2 & BRM 1 & IIIc (pot) & $7 \mathrm{~B}-2$ & Biface Stage 2 & 1 \\
\hline $\mathrm{E} 20 / \mathrm{S} 92$ & 2 & BRM 1 & IIIc (pot) & & Debitage & 278 \\
\hline $\mathrm{E} 20 / \mathrm{S} 92$ & 2 & BRM 1 & IIIc (pot) & 7B-12 & Edge modified flake & 1 \\
\hline E20/S92 & 2 & BRM 1 & IIIc (pot) & $7 \mathrm{~B}-15$ & Edge modified flake & 1 \\
\hline E20/S92 & 2 & BRM 1 & IIIc (pot) & $7 \mathrm{~B}-10$ & Edge modified flake & 1 \\
\hline E20/S92 & 2 & BRM 1 & IIIc (pot) & $7 B-13$ & Edge modified flake & 1 \\
\hline E20/S92 & 2 & BRM 1 & IIIc (pot) & 7B-14 & Edge modified flake & 1 \\
\hline $\mathrm{E} 20 / \mathrm{S} 92$ & 2 & BRM 1 & IIIc (pot) & $7 B-4$ & Edge modified flake & 1 \\
\hline $\mathrm{E} 20 / \mathrm{S} 92$ & 2 & BRM 1 & IIIc (pot) & $7 B-7$ & Edge modified flake & 1 \\
\hline $\mathrm{E} 20 / \mathrm{S} 92$ & 2 & BRM 1 & IIIc (pot) & $7 B-11$ & Edge modified flake & 1 \\
\hline E20/S92 & 2 & BRM 1 & IIIc (pot) & $7 B-5$ & Thin uniface & 1 \\
\hline $\mathrm{E} 20 / \mathrm{S} 92$ & 2 & BRM 1 & IIIc (pot) & $7 B-8$ & Unifacial multiple tool & 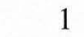 \\
\hline $\mathrm{E} 20 / \mathrm{S} 92$ & 2 & BRM 1 & IIIc (pot) & 7B-9 & Unifacial multiple tool & 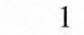 \\
\hline $\mathrm{E} 20 / \mathrm{S} 92$ & 3 & BRM 1 & IIIc (pot) & $7 C-2$ & Biface Stage 2 & 1 \\
\hline $\mathrm{E} 20 / \mathrm{S} 92$ & 3 & BRM 1 & IIIc (pot) & $7 \mathrm{C}-3$ & Biface Stage 3 & 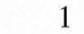 \\
\hline $\mathrm{E} 20 / \mathrm{S} 92$ & 3 & BRM 1 & IIIc (pot) & $7 C-4$ & Bifacial tool Form A & 1 \\
\hline $\mathrm{E} 20 / \mathrm{S} 92$ & 3 & BRM 1 & IIIc (pot) & & Debitage & 188 \\
\hline $\mathrm{E} 20 / \mathrm{S} 92$ & 3 & BRM 1 & IIIc (pot) & $7 C-6$ & Edge modified flake & . \\
\hline $\mathrm{E} 20 / \mathrm{S} 92$ & 3 & BRM 1 & IIIc (pot) & $7 \mathrm{C}-1$ & Metate fragment & 1 \\
\hline E20/S92 & 3 & BRM 1 & IIIc (pot) & $7 \mathrm{C}-7$ & Projectile point fragment & 1 \\
\hline $\mathrm{E} 20 / \mathrm{S} 92$ & 3 & BRM 1 & IIIc (pot) & $7 \mathrm{C}-5$ & Projectile point, miscellaneous expanding stem & $\mathrm{m}$ \\
\hline $\mathrm{E} 20 / \mathrm{S} 92$ & 4 & BRM 1 & IIIc (pot) & & Debitage & 56 \\
\hline $\mathrm{E} 20 / \mathrm{S} 92$ & 4 & BRM 1 & IIIc (pot) & $7 \mathrm{D}-2$ & Edge modified flake & 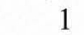 \\
\hline E20/S92 & 4 & BRM 1 & IIIc (pot) & 7D-1 & Thin uniface & 1 \\
\hline $\mathrm{E} 20 / \mathrm{S} 92$ & 5 & BRM 1 & IIIc (pot) & & Debitage & 24 \\
\hline $\mathrm{E} 20 / \mathrm{S} 92$ & 5 & BRM 1 & IIIc (pot) & $7 \mathrm{E}-1$ & Uniface, unanalyzed & 1 \\
\hline $\mathrm{E} 20 / \mathrm{S} 92$ & 6 & BRM 1 & IIIc (pot) & 7F-9 & Biface Stage 2 & 1 \\
\hline E20/S92 & 6 & BRM 1 & IIIc (pot) & $7 F-8$ & Burin spall & 1 \\
\hline $\mathrm{E} 20 / \mathrm{S} 92$ & 6 & BRM 1 & IIIc (pot) & $7 F-2$ & Clear Fork uniface & 1 \\
\hline E20/S92 & 6 & BRM 1 & IIIc (pot) & & Debitage & 57 \\
\hline E20/S92 & 6 & BRM 1 & IIIc (pot) & $7 F-7$ & Edge modified flake & 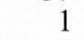 \\
\hline $\mathrm{E} 20 / \mathrm{S} 92$ & 6 & BRM 1 & IIIc (pot) & $7 \mathrm{~F}-1$ & Projectile point, expanding concave B & 1 \\
\hline $\mathrm{E} 20 / \mathrm{S} 92$ & 6 & BRM 1 & IIIc (pot) & $7 F-11$ & Thin uniface & 1 \\
\hline $\mathrm{E} 20 / \mathrm{S} 92$ & 6 & BRM 1 & IIIc (pot) & $7 F-6$ & Thin uniface fragment & 1 \\
\hline E20/S92 & 6 & Burial 1 & IIIc (pot) & $7 F-5$ & Metate fragment & 1 \\
\hline $\mathrm{E} 20 / \mathrm{S} 92$ & 7 & BRM 1 & IIIc & & Debitage & 82 \\
\hline $\mathrm{E} 20 / \mathrm{S} 92$ & 7 & BRM 1 & IIIc & $7 \mathrm{G}-4$ & Edge modified flake & 1 \\
\hline $\mathrm{E} 20 / \mathrm{S} 92$ & 7 & BRM 1 & IIIc & $7 \mathrm{G}-3$ & Edge modified flake & 1 \\
\hline $\mathrm{E} 20 / \mathrm{S} 92$ & 7 & BRM 1 & IIIc & $7 \mathrm{G}-1$ & Projectile point fragment & 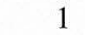 \\
\hline E20/S92 & 7 & BRM 1 & IIIc & $7 \mathrm{G}-2$ & Projectile point, expanding concave $\mathrm{C}$ & 1 \\
\hline E20/S92 & 8 & BRM 1 & IIIc & $7 \mathrm{H}-3$ & Biface Stage 2 & 1 \\
\hline E20/S92 & 8 & BRM 1 & IIIc & $7 \mathrm{H}-5$ & Biface Stage 3 & 1 \\
\hline $\mathrm{E} 20 / \mathrm{S} 92$ & 8 & BRM 1 & IIIC & $7 \mathrm{H}-4$ & Bifacial tool Form B & 1 \\
\hline E20/S92 & 8 & BRM 1 & IIIc & & Debitage & 158 \\
\hline E20/S92 & 8 & BRM 1 & IIIc & $7 \mathrm{H}-14$ & Edge modified flake & 1 \\
\hline E20/S92 & 8 & BRM 1 & IIIc & $7 \mathrm{H}-16$ & Edge modified flake & 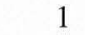 \\
\hline $\mathrm{E} 20 / \mathrm{S} 92$ & 8 & BRM 1 & IIIc & $7 \mathrm{H}-10$ & Edge modified flake & 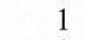 \\
\hline E20/S92 & 8 & BRM 1 & IIII & $7 \mathrm{H}-7$ & Edge modified flake & \\
\hline $\mathrm{E} 20 / \mathrm{S} 92$ & 8 & BRM 1 & IIIc & $7 \mathrm{H}-8$ & Edge modified flake & 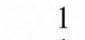 \\
\hline $\mathrm{E} 20 / \mathrm{S} 92$ & 8 & BRM 1 & IIIc & $7 \mathrm{H}-9$ & Edge modified flake & 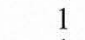 \\
\hline $\mathrm{E} 20 / \mathrm{S} 92$ & 8 & BRM 1 & IIIc & $7 \mathbf{H}-13$ & Edge modified flake & 1 \\
\hline $\mathrm{E} 20 / \mathrm{S} 92$ & 8 & BRM 1 & IIIc & $7 \mathrm{H}-1$ & Projectile point, Marshall & 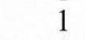 \\
\hline E20/S92 & 8 & BRM 1 & IIIc & $7 \mathrm{H}-2$ & Projectile point, Uvalde-like & \\
\hline E20/S92 & 8 & BRM 1 & IIIc & $7 \mathrm{H}-6$ & Thin uniface fragment & \\
\hline $\mathrm{E} 20 / \mathrm{S} 92$ & 9 & & Y/IIIc & $7 \mathrm{I}-2$ & Biface Stage 2 & 1 \\
\hline
\end{tabular}




\begin{tabular}{|c|c|c|c|c|}
\hline $\begin{array}{l}\text { Square } \\
\text { E20/S92 }\end{array}$ & Level & Feature & Strata & $\begin{array}{l}\text { Item } \\
\text { 7I-3 }\end{array}$ \\
\hline $\begin{array}{l}\text { E20/S92 } \\
\text { E20/S92 }\end{array}$ & $\begin{array}{l}9 \\
9\end{array}$ & & $\begin{array}{l}\text { Y/IIIc } \\
\text { Y/IIIc }\end{array}$ & $\begin{array}{l}71-3 \\
7 \mathrm{I}-4\end{array}$ \\
\hline $\mathrm{E} 20 / \mathrm{S} 92$ & 9 & & Y/IIII & \\
\hline $\mathrm{E} 20 / \mathrm{S} 92$ & 9 & & Y/IIII & 7I-1 \\
\hline $\mathrm{E} 20 / \mathrm{S} 92$ & 9 & & $\mathrm{Y} / \mathrm{IIII}$ & $7 \mathrm{I}-5$ \\
\hline $\mathrm{E} 20 / \mathrm{S} 92$ & 10 & & Y/IIIc & $7 \mathbf{J}-3$ \\
\hline $\mathrm{E} 20 / \mathrm{S} 92$ & 10 & & $\mathrm{Y} / \mathrm{IIIC}$ & $7 \mathrm{~J}-5$ \\
\hline E20/S92 & 10 & & Y/IIIc & $7 \mathrm{~J}-4$ \\
\hline $\mathrm{E} 20 / \mathrm{S} 92$ & 10 & & Y/IIII & \\
\hline $\mathrm{E} 20 / \mathrm{S} 92$ & 10 & & $\mathrm{Y} / \mathrm{IIIc}$ & $7 \mathrm{~J}-1$ \\
\hline E20/S92 & 10 & & $\mathrm{Y} / \mathrm{III} \mathrm{c}$ & $7 \mathrm{~J}-2$ \\
\hline $\mathrm{E} 20 / \mathrm{S} 92$ & 10 & & Y/IIIC & $7 \mathrm{~J}-7$ \\
\hline $\mathrm{E} 20 / \mathrm{S} 92$ & 11 & & $\mathrm{Y}$ & $7 \mathrm{~K}-3$ \\
\hline $\mathrm{E} 20 / \mathrm{S} 92$ & 11 & & Y & $7 \mathrm{~K}-1$ \\
\hline $\mathrm{E} 20 / \mathrm{S} 92$ & 11 & & $\mathrm{Y}$ & $7 \mathrm{~K}-2$ \\
\hline E20/S92 & 11 & & Y & \\
\hline E20/S92 & 12 & & $\mathrm{Y}$ & \\
\hline $\mathrm{E} 20 / \mathrm{S} 92$ & 12 & & Y & $7 \mathrm{~L}-2$ \\
\hline $\mathrm{E} 20 / \mathrm{S} 92$ & 12 & & Y & $7 \mathrm{~L}-1$ \\
\hline E20/S92 & 13 & & $\mathrm{Y}$ & $7 \mathrm{M}-5$ \\
\hline $\mathrm{E} 20 / \mathrm{S} 92$ & 13 & & $\mathrm{Y}$ & $7 \mathrm{M}-3$ \\
\hline E20/S92 & 13 & & $\mathrm{Y}$ & $7 \mathrm{M}-2$ \\
\hline $\mathrm{E} 20 / \mathrm{S} 92$ & 13 & & $\mathrm{Y}$ & $7 \mathrm{M}-4$ \\
\hline E20/S92 & 13 & & Y & \\
\hline E20/S92 & 13 & & Y & $7 \mathrm{M}-7$ \\
\hline $\mathrm{E} 20 / \mathrm{S} 92$ & 13 & & Y & $7 \mathrm{M}-8$ \\
\hline $\mathrm{E} 20 / \mathrm{S} 92$ & 14 & & $\mathrm{X} / \mathrm{Y}$ & $7 \mathrm{~N}-2$ \\
\hline $\mathrm{E} 20 / \mathrm{S} 92$ & 14 & & $\mathrm{X} / \mathrm{Y}$ & \\
\hline E20/S92 & 14 & & $\mathrm{X} / \mathrm{Y}$ & $7 N-9$ \\
\hline $\mathrm{E} 20 / \mathrm{S} 92$ & 14 & & $\mathrm{X} / \mathrm{Y}$ & $7 \mathrm{~N}-10$ \\
\hline E20/S92 & 14 & & $\mathrm{X} / \mathrm{Y}$ & $7 \mathrm{~N}-6$ \\
\hline $\mathrm{E} 20 / \mathrm{S} 92$ & 14 & & $\mathrm{X} / \mathrm{Y}$ & $7 \mathrm{~N}-11$ \\
\hline $\mathrm{E} 20 / \mathrm{S} 92$ & 14 & & $\mathrm{X} / \mathrm{Y}$ & $7 \mathrm{~N}-3$ \\
\hline E20/S92 & 14 & & $\mathrm{X} / \mathrm{Y}$ & $7 \mathrm{~N}-1$ \\
\hline E20/S92 & 14 & & $\mathrm{X} / \mathrm{Y}$ & $7 \mathrm{~N}-8$ \\
\hline $\mathrm{E} 20 / \mathrm{S} 92$ & 14 & & $\mathrm{X} / \mathrm{Y}$ & $7 \mathrm{~N}-4$ \\
\hline $\mathrm{E} 20 / \mathrm{S} 92$ & 15 & & $\mathrm{X}$ & $70-2$ \\
\hline $\mathrm{E} 20 / \mathrm{S} 92$ & 15 & & $\mathrm{X}$ & \\
\hline $\mathrm{E} 20 / \mathrm{S} 92$ & 15 & & $\mathrm{X}$ & $70-4$ \\
\hline $\mathrm{E} 20 / \mathrm{S} 92$ & 15 & & $\mathrm{X}$ & $70-6$ \\
\hline $\mathrm{E} 20 / \mathrm{S} 92$ & 15 & & $\mathrm{X}$ & $70-1$ \\
\hline $\mathrm{E} 20 / \mathrm{S} 92$ & 16 & & $\mathrm{X}$ & \\
\hline $\mathrm{E} 20 / \mathrm{S} 92$ & 16 & & $\mathrm{X}$ & $7 P-3$ \\
\hline $\mathrm{E} 20 / \mathrm{S} 92$ & 16 & & $\mathrm{X}$ & $7 \mathrm{P}-2$ \\
\hline $\mathrm{E} 20 / \mathrm{S} 92$ & 17 & & $\mathrm{X}$ & \\
\hline $\mathrm{E} 20 / \mathrm{S} 92$ & 17 & & $\mathrm{X}$ & $7 \mathrm{Q}-2$ \\
\hline $\mathrm{E} 20 / \mathrm{S} 92$ & 17 & & $\mathrm{X}$ & $7 \mathrm{Q}-1$ \\
\hline $\mathrm{E} 20 / \mathrm{S} 92$ & 18 & & $\mathrm{X}$ & \\
\hline E20/S94 & 1 & & IIIc (pot) & $6 \mathrm{~A}-1$ \\
\hline $\mathrm{E} 20 / \mathrm{S} 94$ & 1 & & IIIc (pot) & $6 \mathrm{~A}-2$ \\
\hline E20/S94 & 1 & & IIIc (pot) & $6 \mathrm{~A}-10$ \\
\hline $\mathrm{E} 20 / \mathrm{S} 94$ & 1 & & IIIc (pot) & $6 \mathrm{~A}-7$ \\
\hline E20/S94 & 1 & & IIIc (pot) & $6 \mathrm{~A}-11$ \\
\hline $\mathrm{E} 20 / \mathrm{S} 94$ & 1 & & IIIc (pot) & $6 \mathrm{~A}-8$ \\
\hline E20/S94 & 1 & & IIIc (pot) & $6 \mathrm{~A}-6$ \\
\hline E20/S94 & 1 & & IIIc (pot) & $6 \mathrm{~A}-9$ \\
\hline E20/S94 & 1 & & IIIc (pot) & $6 \mathrm{~A}-15$ \\
\hline $\mathrm{E} 20 / \mathrm{S} 94$ & 1 & & IIIc (pot) & $6 \mathrm{~A}-16$ \\
\hline $\mathrm{E} 20 / \mathrm{S} 94$ & 1 & & IIIc (pot) & $6 \mathrm{~A}-18$ \\
\hline $\mathrm{E} 20 / \mathrm{S} 94$ & 1 & & IIIc (pot) & $6 \mathrm{~A}-5$ \\
\hline E20/S94 & 1 & & IIIc (pot) & $6 \mathrm{~A}-3$ \\
\hline E20/S94 & 1 & & IIIc (pot) & $6 \mathrm{~A}-4$ \\
\hline $\mathrm{E} 20 / \mathrm{S} 94$ & 1 & & IIIc (pot) & $6 \mathrm{~A}-17$ \\
\hline $\mathrm{E} 20 / \mathrm{S} 94$ & 1 & & IIIc (pot) & 6A-33 \\
\hline $\mathrm{E} 20 / \mathrm{S} 94$ & 1 & & IIIc (pot) & $6 \mathrm{~A}-20$ \\
\hline $\mathrm{E} 20 / \mathrm{S} 94$ & 1 & & IIIc (pot) & \\
\hline E20/S94 & 1 & & IIIc (pot) & $6 \mathrm{~A}-3$ \\
\hline E20/S94 & 1 & & IIIc (pot) & $6 \mathrm{~A}-2$ \\
\hline $\mathrm{E} 20 / \mathrm{S} 94$ & 1 & & IIIc (pot) & $6 \mathrm{~A}-29$ \\
\hline $\mathrm{E} 20 / \mathrm{S} 94$ & 1 & & IIIc (pot) & $6 \mathrm{~A}-21$ \\
\hline $\mathrm{E} 20 / \mathrm{S} 94$ & 1 & & IIIc (pot) & $6 \mathrm{~A}-2$ \\
\hline E20/S94 & 1 & & IIIc (pot) & $6 \mathrm{~A}-24$ \\
\hline E20/S94 & 1 & & IIIc (pot) & $6 \mathrm{~A}-27$ \\
\hline E20/S94 & 1 & & IIIc (pot) & $6 \mathrm{~A}-26$ \\
\hline
\end{tabular}

Analyst Identification

Count

Stage 2

Debitage

Projectile point, miscellaneous bifurcate

Thin uniface

Biface Stage 2

Clear Fork biface

Core fragment

Debitage

Projectile point, expanding stem C

Projectile point, Uvalde

Thin uniface

Biface fragment

Biface fragment

Biface fragment

Debitage

Debitage

Edge modified flake

Projectile point, bifurcate stem fragment

Biface fragment

Biface Stage 2

Burin

Burin spall

Debitage

Thin uniface fragment

Unifacial multiple tool

Core, thermal

Debitage

Edge modified flake

Edge modified flake

Microspur/microdenticulate

Notched flake

Perforator Group 6

Projectile point, Thrall

Thin uniface

Unifacial multiple tool

Burin

Debitage

Edge modified flake

Microspur/microdenticulate

Projectile point, Angostura

Debitage

Edge modified flake

Microspur/microdenticulate

Debitage

Edge modified flake

Projectile point, St. Mary's Hall

Debitage

Arrow point, preform

Arrow point, preform

Arrow point, Scallorn

Arrow point, Scallorn

Arrow point, Scallorn

Arrow point, Scallorn

Arrow point, stemmed

Arrow point, stemmed

Biface Stage 2

Biface Stage 2

Biface Stage 2

Biface Stage 2

Biface Stage 2

Biface Stage 2

Biface Stage 3

Bifacial tool Form B

Burin

Debitage

Denticulated flake

Edge modified flake

Edge modified flake

Edge modified flake

Edge modified flake

Edge modified flake

Edge modified flake

Edge modified flake 


\begin{tabular}{|c|c|c|c|c|c|c|}
\hline Square & Level & Feature & Strata & Item & Analyst Identification & Count \\
\hline $\mathrm{E} 20 / \mathrm{S} 94$ & 1 & & IIIc (pot) & $6 \mathrm{~A}-19$ & Perforator Group 7 & 1 \\
\hline $\mathrm{E} 20 / \mathrm{S} 94$ & 1 & & IIIc (pot) & $6 \mathrm{~A}-14$ & Projectile point fragment & 1 \\
\hline E20/S94 & 1 & & IIIc (pot) & $6 \mathrm{~A}-13$ & Projectile point, Darl & 1 \\
\hline E20/S94 & 1 & & IIIc (pot) & $6 \mathrm{~A}-12$ & Projectile point, Frio & 1 \\
\hline $\mathrm{E} 20 / \mathrm{S} 94$ & 1 & & IIIc (pot) & $6 \mathrm{~A}-31$ & Thin uniface & 1 \\
\hline E20/S94 & 1 & & IIIc (pot) & $6 \mathrm{~A}-23$ & Thin uniface & 1 \\
\hline E20/S94 & 1 & & IIIc (pot) & $6 \mathrm{~A}-22$ & Thin uniface & 1 \\
\hline $\mathrm{E} 20 / \mathrm{S} 94$ & 1 & & IIIc (pot) & $6 \mathrm{~A}-30$ & Unifacial multiple tool & 1 \\
\hline $\mathrm{E} 20 / \mathrm{S} 94$ & 2 & BRM 1 & IIIc (pot) & $6 \mathrm{~B}-2$ & Biface fragment & 1 \\
\hline E20/S94 & 2 & BRM 1 & IIIc (pot) & $6 B-5$ & Biface Stage 2 & 1 \\
\hline E20/S94 & 2 & BRM 1 & IIIC (pot) & $6 \mathrm{~B}-7$ & Biface Stage 2 & 1 \\
\hline E20/S94 & 2 & BRM 1 & IIIc (pot) & $6 \mathrm{~B}-3$ & Biface Stage 2 & 1 \\
\hline E20/S94 & 2 & BRM 1 & IIIc (pot) & $6 \mathrm{~B}-4$ & Biface Stage 2 & 1 \\
\hline E20/S94 & 2 & BRM 1 & IIIc (pot) & $6 B-6$ & Biface Stage 3 & 1 \\
\hline E20/S94 & 2 & BRM 1 & IIIc (pot) & $6 \mathrm{~B}-1$ & Biface Stage 3 & 1 \\
\hline E20/S94 & 2 & BRM 1 & IIIc (pot) & & Debitage & 276 \\
\hline E20/S94 & 2 & BRM 1 & IIIc (pot) & $6 \mathrm{~B}-14$ & Edge modified flake & 1 \\
\hline $\mathrm{E} 20 / \mathrm{S} 94$ & 2 & BRM 1 & IIIc (pot) & $6 \mathrm{~B}-11$ & Edge modified flake & 1 \\
\hline $\mathrm{E} 20 / \mathrm{S} 94$ & 2 & BRM 1 & IIIc (pot) & $6 \mathrm{~B}-9$ & Projectile point, Nolan & 1 \\
\hline $\mathrm{E} 20 / \mathrm{S} 94$ & 2 & BRM 1 & IIIc (pot) & $6 \mathrm{~B}-16$ & Spurred flake & 1 \\
\hline E20/S94 & 2 & BRM 1 & IIIc (pot) & $6 \mathrm{~B}-10$ & Thin uniface & 1 \\
\hline E20/S94 & 2 & BRM 1 & IIIc (pot) & $6 \mathrm{~B}-12$ & Thin uniface & 1 \\
\hline E20/S94 & 2 & BRM 1 & IIIc (pot) & $6 \mathrm{~B}-13$ & Thin uniface & 1 \\
\hline E20/S94 & 2 & BRM 1 & IIIc (pot) & $6 \mathrm{~B}-15$ & Unifacial multiple tool & 1 \\
\hline E20/S94 & 2 & BRM 1 & IIIc (pot) & $6 \mathrm{~B}-8$ & Unifacial multiple tool & 1 \\
\hline E20/S94 & 3 & BRM 1 & IIIc (pot) & $6 C-2$ & Arrow point, Scallorn & 1 \\
\hline E20/S94 & 3 & BRM 1 & IIIc (pot) & & Debitage & 231 \\
\hline E20/S94 & 3 & BRM 1 & IIIc (pot) & $6 \mathrm{C}-4$ & Edge modified flake & 1 \\
\hline E20/S94 & 3 & BRM 1 & IIIc (pot) & $6 \mathrm{C}-7$ & Edge modified flake & 1 \\
\hline $\mathrm{E} 20 / \mathrm{S} 94$ & 3 & BRM 1 & IIIc (pot) & $6 C-8$ & Edge modified flake & 1 \\
\hline E20/S94 & 3 & BRM 1 & IIIc (pot) & $6 \mathrm{C}-10$ & Edge modified flake & 1 \\
\hline E20/S94 & 3 & BRM 1 & IIIc (pot) & $6 \mathrm{C}-3$ & Edge modified flake & 1 \\
\hline E20/S94 & 3 & BRM 1 & IIIC (pot) & $6 \mathrm{C}-5$ & Edge modified flake & 1 \\
\hline E20/S94 & 3 & BRM 1 & IIIc (pot) & $6 \mathrm{C}-1$ & Projectile point fragment & 1 \\
\hline E20/S94 & 3 & BRM 1 & IIIc (pot) & $6 C-12$ & Retouched blade & 1 \\
\hline E20/S94 & 3 & BRM 1 & IIIc (pot) & $6 \mathrm{C}-9$ & Thin uniface & 1 \\
\hline E20/S94 & 4 & BRM 1 & IIIc (pot) & $6 \mathrm{D}-1$ & Biface fragment & 1 \\
\hline E20/S94 & 4 & BRM 1 & IIIc (pot) & $6 \mathrm{D}-2$ & Biface Stage 2 & 1 \\
\hline E20/S94 & 4 & BRM 1 & IIIc (pot) & & Debitage & 147 \\
\hline E20/S94 & 4 & BRM 1 & IIIc (pot) & $6 \mathrm{D}-3$ & Edge modified flake & 1 \\
\hline E20/S94 & 4 & BRM 1 & IIIc (pot) & $6 \mathrm{D}-4$ & Thin uniface & 1 \\
\hline E20/S94 & 5 & BRM 1 & IIIc & $6 \mathrm{E}-1$ & Bifacial tool Form A & 1 \\
\hline E20/S94 & 5 & BRM 1 & IIIIc & $6 \mathrm{E}-2$ & Burin spall & 1 \\
\hline E20/S94 & 5 & BRM 1 & IIIc & & Debitage & 94 \\
\hline E20/S94 & 5 & BRM 1 & IIIC & $6 \mathrm{E}-5$ & Denticulated flake & 1 \\
\hline E20/S94 & 5 & BRM 1 & IIIc & $6 \mathrm{E}-6$ & Edge modified flake & 1 \\
\hline E20/S94 & 5 & BRM 1 & IIIc & $6 \mathrm{E}-3$ & Edge modified flake & 1 \\
\hline E20/S94 & 5 & BRM 1 & IIIc & $6 \mathrm{E}-7$ & Microspur/microdenticulate & 1 \\
\hline E20/S94 & 5 & BRM 1 & IIIc & $6 \mathrm{E}-4$ & Perforator Group 7 & 1 \\
\hline E20/S94 & 6 & BRM 1 & IIIc & $6 \mathrm{~F}-3$ & Burin & 1 \\
\hline E20/S94 & 6 & BRM 1 & IIIC & & Debitage & 145 \\
\hline E20/S94 & 6 & BRM 1 & IIIc & $6 \mathrm{~F}-2$ & Denticulated flake & 1 \\
\hline $\mathrm{E} 20 / \mathrm{S} 94$ & 6 & BRM 1 & IIIc & $6 \mathrm{~F}-4$ & Edge modified flake & 1 \\
\hline E20/S94 & 6 & BRM 1 & IIIc & $6 \mathrm{~F}-1$ & Projectile point, Martindale A & 1 \\
\hline E20/S94 & 6 & BRM 1 & IIIc & $6 \mathrm{~F}-5$ & Retouched blade & 1 \\
\hline E20/S94 & 6 & BRM 1 & IIII & $6 \mathrm{~F}-6$ & Thin uniface & 1 \\
\hline E20/S94 & 7 & & IIIc & & Debitage & 86 \\
\hline E20/S94 & 7 & & IIIc & $6 \mathrm{G}-3$ & Edge modified flake & 1 \\
\hline E20/S94 & 7 & & IIIc & $6 \mathrm{G}-4$ & Edge modified flake & 1 \\
\hline E20/S94 & 7 & & IIIc & $6 \mathrm{G}-6$ & Perforator Group 6 & 1 \\
\hline E20/S94 & 7 & & IIII & $6 \mathrm{G}-1$ & Projectile point, Hoxie/Gower & 1 \\
\hline E20/S94 & 7 & & IIIC & $6 \mathrm{G}-2$ & Projectile point, Uvalde & 1 \\
\hline E20/S94 & 7 & & IIIC & $6 \mathrm{G}-7$ & Retouched blade & 1 \\
\hline E20/S94 & 7 & & IIIc & $6 \mathrm{G}-5$ & Thin uniface & 1 \\
\hline E20/S94 & 8 & & Y/IIIc & $6 \mathrm{H}-3$ & Biface fragment & 1 \\
\hline E20/S94 & 8 & & Y/IIIc & $6 \mathrm{H}-2$ & Biface Stage 3 & \\
\hline E20/S94 & 8 & & Y/IIIc & $6 \mathrm{H}-15$ & Burin spall & 1 \\
\hline E20/S94 & 8 & & $\mathrm{Y} / \mathrm{III} \mathrm{c}$ & & Debitage & 347 \\
\hline E20/S94 & 8 & & Y/IIIc & $6 \mathrm{H}-12$ & Edge modified flake & 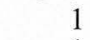 \\
\hline E20/S94 & 8 & & $\mathrm{Y} / \mathrm{III} \mathrm{c}$ & $6 \mathrm{H}-16$ & Edge modified flake & 1 \\
\hline E20/S94 & 8 & & $\mathrm{Y} / \mathrm{III} \mathrm{c}$ & $6 \mathrm{H}-4$ & Edge modified flake & 1 \\
\hline E20/S94 & 8 & & Y/IIIc & $6 \mathrm{H}-19$ & Edge modified flake & 1 \\
\hline E20/S94 & 8 & & Y/IIIc & $6 \mathrm{H}-18$ & Edge modified flake & 1 \\
\hline E20/S94 & 8 & & Y/IIIc & $6 \mathrm{H}-7$ & Edge modified flake & 1 \\
\hline
\end{tabular}




\begin{tabular}{|c|c|c|c|c|c|c|}
\hline Square & Level & Feature & Strata & Item & Analyst Identification & Count \\
\hline E20/S94 & 8 & & Y/IIIc & $6 \mathrm{H}-14$ & Edge modified flake & 1 \\
\hline E20/S94 & 8 & & Y/IIIc & $6 \mathrm{H}-13$ & Edge modified flake & 1 \\
\hline $\mathrm{E} 20 / \mathrm{S} 94$ & 8 & & Y/IIIc & $6 \mathrm{H}-1$ & Projectile point, miscellaneous bifurcate & 1 \\
\hline E20/S94 & 8 & & Y/IIIc & $6 \mathrm{H}-21$ & Thin uniface & 1 \\
\hline E20/S94 & 8 & & Y/IIIc & $6 \mathrm{H}-17$ & Thin uniface & 1 \\
\hline $\mathrm{E} 20 / \mathrm{S} 94$ & 8 & & Y/IIIc & $6 \mathrm{H}-20$ & Thin uniface & 1 \\
\hline E20/S94 & 9 & & Y/IIIc & & Debitage & 310 \\
\hline E20/S94 & 9 & & Y/IIIc & $6 \mathrm{I}-2$ & Thin uniface & 1 \\
\hline $\mathrm{E} 20 / \mathrm{S} 94$ & 9 & & Y/IIIc & $6 \mathrm{I}-3$ & Unifacial multiple tool & 1 \\
\hline $\mathrm{E} 20 / \mathrm{S} 94$ & 10 & & Y & & Debitage & 313 \\
\hline E20/S94 & 11 & & Y & $6 \mathrm{~K}-6$ & Biface fragment & 8 \\
\hline E20/S94 & 11 & & $\mathrm{Y}$ & $6 \mathrm{~K}-5$ & Biface Stage 1 & 1 \\
\hline E20/S94 & 11 & & $\hat{Y}$ & $6 \mathrm{~K}-2$ & Biface Stage 2 & 1 \\
\hline $\mathrm{E} 20 / \mathrm{S} 94$ & 11 & & $\mathrm{Y}$ & $6 \mathrm{~K}-1$ & Biface Stage 3 & 1 \\
\hline $\mathrm{E} 20 / \mathrm{S} 94$ & 11 & & $\mathrm{Y}$ & $6 \mathrm{~K}-3$ & Burin spall & 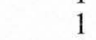 \\
\hline E20/S94 & 11 & & $\mathrm{Y}$ & $6 \mathrm{~K}-4$ & Burin spall & 1 \\
\hline E20/S94 & 11 & & $\mathrm{Y}$ & & Debitage & 486 \\
\hline E20/S94 & 11 & & $\mathrm{Y}$ & $6 \mathrm{~K}-8$ & Edge modified flake & \\
\hline $\mathrm{E} 20 / \mathrm{S} 94$ & 11 & & $\mathrm{Y}$ & $6 \mathrm{~K}-9$ & Edge modified flake & 1 \\
\hline E20/S94 & 11 & Feature 4 & $\mathrm{Y}$ & & Debitage & 69 \\
\hline $\mathrm{E} 20 / \mathrm{S} 94$ & 11 & Feature 4 & Y & $6 \mathrm{~K}-10$ & Projectile point, bifurcate stem fragment & 1 \\
\hline $\mathrm{E} 20 / \mathrm{S} 94$ & 11 & Feature 4 & Y & $6 \mathrm{~K}-11$ & Thin uniface & 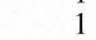 \\
\hline $\mathrm{E} 20 / \mathrm{S} 94$ & 12 & Feature 4 & $\mathrm{X} / \mathrm{Y}$ & & Debitage & 88 \\
\hline $\mathrm{E} 20 / \mathrm{S} 94$ & 12 & Feature 4 & $X / Y$ & $6 \mathrm{~L}-2$ & Edge modified flake & 00 \\
\hline E20/S94 & 12 & Feature 4 & $\mathrm{X} / \mathrm{Y}$ & $6 \mathrm{~L}-1$ & Unifacial multiple tool & 1 \\
\hline E20/S94 & 13 & & $\mathrm{X} / \mathrm{Y}$ & & Debitage & 365 \\
\hline E20/S94 & 13 & Feature 6 & X/Y & $6 \mathrm{M}-1$ & Thin uniface & 1 \\
\hline $\mathrm{E} 20 / \mathrm{S} 94$ & 14 & & $\mathrm{X} / \mathrm{Y}$ & $6 \mathrm{~N}-3$ & Biface fragment & 1 \\
\hline $\mathrm{E} 20 / \mathrm{S} 94$ & 14 & & $\mathrm{X} / \mathrm{Y}$ & $6 \mathrm{~N}-2$ & Bifacial tool Form E & \\
\hline E20/S94 & 14 & & $X / Y$ & $6 \mathrm{~N}-1$ & Core tool, type 1 & 1 \\
\hline E20/S94 & 14 & & $\mathrm{X} / \mathrm{Y}$ & & Debitage & 231 \\
\hline $\mathrm{E} 20 / \mathrm{S} 94$ & 15 & & $\mathrm{X}$ & $60-1$ & Burin & 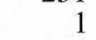 \\
\hline $\mathrm{E} 20 / \mathrm{S} 94$ & 15 & & $\mathrm{X}$ & $60-4$ & Core fragment & 1 \\
\hline E20/S94 & 15 & & $\mathrm{X}$ & $60-2$ & Core tool, type 5 & 1 \\
\hline E20/S94 & 15 & & $\mathrm{X}$ & & Debitage & 374 \\
\hline E20/S94 & 15 & & $\mathrm{X}$ & $60-8$ & Edge modified flake & . \\
\hline E20/S94 & 15 & & $\mathrm{X}$ & $60-3$ & Micro-core, large & 1 \\
\hline E20/S94 & 15 & & $\mathrm{X}$ & $60-7$ & Notched flake & 1 \\
\hline E20/S94 & 15 & & $X$ & $60-6$ & Thick uniface & 1 \\
\hline E20/S94 & 15 & & $X$ & $60-5$ & Thin uniface & 1 \\
\hline E20/S94 & 16 & & $\mathrm{X}$ & $6 \mathrm{P}-2$ & Biface fragment & 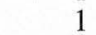 \\
\hline E20/S94 & 16 & & $\mathrm{X}$ & $6 \mathrm{P}-1$ & Burin & 1 \\
\hline E20/S94 & 16 & & $\mathrm{X}$ & $6 \mathrm{P}-5$ & Burin spall & 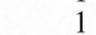 \\
\hline E20/S94 & 16 & & $\mathrm{X}$ & $6 \mathrm{P}-3$ & Core fragment & 1 \\
\hline E20/S94 & 16 & & $\mathrm{X}$ & & Debitage & 207 \\
\hline E20/S94 & 16 & & $\mathrm{X}$ & $6 \mathrm{P}-4$ & Edge modified flake & 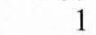 \\
\hline E20/S94 & 16 & & $X$ & $6 P-6$ & Edge modified flake & \\
\hline E20/S94 & 16 & & $\mathrm{X}$ & $6 P-7$ & Edge modified flake & 1 \\
\hline $\mathrm{E} 20 / \mathrm{S} 94$ & 16 & & $\mathrm{X}$ & $6 \mathrm{P}-10$ & Thin uniface & 1 \\
\hline E20/S94 & 16 & & $\mathrm{X}$ & $6 \mathrm{P}-12$ & Thin uniface fragment & 1 \\
\hline E20/S94 & 16 & & $\mathrm{X}$ & $6 \mathrm{P}-8$ & Uniface, unanalyzed & \\
\hline $\mathrm{E} 20 / \mathrm{S} 94$ & 17 & & $\mathrm{X}$ & $6 Q-1$ & Burin spall & 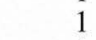 \\
\hline E20/S94 & 17 & & $\mathrm{X}$ & $6 \mathrm{Q}-2$ & Burin spall & 1 \\
\hline E20/S94 & 17 & & $\mathrm{X}$ & & Debitage & 306 \\
\hline E20/S94 & 18 & & $\mathrm{X}$ & & Debitage & 76 \\
\hline E20/S94 & 18 & & $\mathrm{X}$ & $6 \mathbf{R}-2$ & Edge modified flake & \\
\hline E20/S96 & 1 & & IIIc (pot) & $5 \mathrm{~A}-1$ & Arrow point, Scallorn & 1 \\
\hline E20/S96 & 1 & & IIIc (pot) & $5 \mathrm{~A}-2$ & Arrow point, stemmed & \\
\hline E20/S96 & 1 & & IIIc (pot) & $5 \mathrm{~A}-23$ & Arrow point, tip & 1 \\
\hline E20/S96 & 1 & & IIIc (pot) & $5 \mathrm{~A}-11$ & Biface fragment & \\
\hline E20/S96 & 1 & & IIIc (pot) & $5 A-16$ & Biface Stage 2 & \\
\hline $\mathrm{E} 20 / \mathrm{S} 96$ & 1 & & IIIc (pot) & $5 \mathrm{~A}-9$ & Biface Stage 2 & \\
\hline $\mathrm{E} 20 / \mathrm{S} 96$ & 1 & & IIIc (pot) & $5 \mathrm{~A}-19$ & Biface Stage 3 & 1 \\
\hline $\mathrm{E} 20 / \mathrm{S} 96$ & 1 & & IIIc (pot) & $5 \mathrm{~A}-15$ & Biface Stage 3 & 1 \\
\hline E20/S96 & 1 & & IIIc (pot) & $5 \mathrm{~A}-5$ & Biface Stage 3 & \\
\hline E20/S96 & 1 & & IIIc (pot) & $5 \mathrm{~A}-34$ & Biface Stage 3 & \\
\hline E20/S96 & 1 & & IIIc (pot) & $5 A-6$ & Biface Stage 3 & 1 \\
\hline E20/S96 & 1 & & IIIc (pot) & $5 \mathrm{~A}-10$ & Bifacial tool Form A & 1 \\
\hline $\mathrm{E} 20 / \mathrm{S} 96$ & 1 & & IIIc (pot) & $5 \mathrm{~A}-7$ & Bifacial tool Form B & \\
\hline E20/S96 & 1 & & IIIc (pot) & $5 \mathrm{~A}-12$ & Burin spall & \\
\hline E20/S96 & 1 & & IIIc (pot) & & Debitage & 1442 \\
\hline E20/S96 & 1 & & IIIc (pot) & $5 \mathrm{~A}-20$ & Edge modified flake & \\
\hline E20/S96 & 1 & & IIIc (pot) & $5 \mathrm{~A}-27$ & Edge modified flake & \\
\hline E20/S96 & 1 & & IIIc (pot) & $5 \mathrm{~A}-30$ & Edge modified flake & \\
\hline
\end{tabular}




\begin{tabular}{|c|c|c|c|c|c|c|}
\hline Square & Level & Feature & Strata & Item & Analyst Identification & Count \\
\hline E20/S96 & 1 & & IIIc $(\mathrm{pot})$ & $5 A-29$ & Microspur/microdenticulate & 1 \\
\hline $\mathrm{E} 20 / \mathrm{S} 96$ & 1 & & IIIc (pot) & $5 A-32$ & Microspur/microdenticulate & 1 \\
\hline E20/S96 & 1 & & IIIc (pot) & $5 \mathrm{~A}-31$ & Notched flake & 1 \\
\hline E20/S96 & 1 & & IIIc (pot) & $5 \mathrm{~A}-24$ & Perforator Group 7 & 1 \\
\hline E20/S96 & 1 & & IIIc (pot) & $5 \mathrm{~A}-14$ & Projectile point fragment & 1 \\
\hline E20/S96 & 1 & & IIIc (pot) & $5 \mathrm{~A}-22$ & Projectile point fragment & 1 \\
\hline E20/S96 & 1 & & IIIc (pot) & $5 \mathrm{~A}-17$ & Projectile point fragment & 1 \\
\hline E20/S96 & 1 & & IIIc (pot) & $5 \mathrm{~A}-3$ & Projectile point, Fairland & 1 \\
\hline E20/S96 & 1 & & IIIc (pot) & $5 \mathrm{~A}-4$ & Projectile point, Marshall & 1 \\
\hline E20/S96 & 1 & & IIIc (pot) & $5 \mathrm{~A}-13$ & Projectile point, Nolan & 1 \\
\hline E20/S96 & 1 & & IIIc (pot) & $5 A-25$ & Thin uniface & 1 \\
\hline E20/S96 & 1 & & IIIc (pot) & $5 \mathrm{~A}-8$ & Unifacial multiple tool & 1 \\
\hline E20/S96 & 1 & & IIIc (pot) & $5 \mathrm{~A}-26$ & Unifacial multiple tool & 1 \\
\hline E20/S96 & 2 & BRM 1 & IIIc (pot) & $5 B-7$ & Biface Stage 2 & 1 \\
\hline E20/S96 & 2 & BRM 1 & IIIc (pot) & $5 B-6$ & Biface Stage 2 & 1 \\
\hline $\mathrm{E} 20 / \mathrm{S} 96$ & 2 & BRM 1 & IIIc (pot) & $5 B-8$ & Clear Fork uniface & 1 \\
\hline E20/S96 & 2 & BRM 1 & IIIc (pot) & $5 B-4$ & Core fragment & 1 \\
\hline $\mathrm{E} 20 / \mathrm{S} 96$ & 2 & BRM 1 & IIIc (pot) & & Debitage & 603 \\
\hline E20/S96 & 2 & BRM 1 & IIIc (pot) & $5 B-5$ & Edge modified flake & 1 \\
\hline E20/S96 & 2 & BRM 1 & IIIc (pot) & $5 \mathrm{~B}-1$ & Projectile point, Darl & 1 \\
\hline E20/S96 & 2 & BRM 1 & IIIc (pot) & $5 B-2$ & Projectile point, Ensor & 1 \\
\hline E20/S96 & 2 & BRM 1 & IIIc (pot) & $5 B-3$ & Projectile point, miscellaneous bifurcate & 1 \\
\hline E20/S96 & 2 & BRM 1 & IIIc (pot) & $5 B-9$ & Thin uniface & 1 \\
\hline E20/S96 & 3 & BRM 1 & IIIc (pot) & $5 \mathrm{C}-3$ & Biface fragment & 1 \\
\hline E20/S96 & 3 & BRM 1 & IIIc (pot) & $5 \mathrm{C}-4$ & Biface Stage 2 & 1 \\
\hline $\mathrm{E} 20 / \mathrm{S} 96$ & 3 & BRM 1 & IIIc (pot) & $5 \mathrm{C}-8$ & Core, thermal & 1 \\
\hline E20/S96 & 3 & BRM 1 & IIIc (pot) & & Debitage & 86 \\
\hline E20/S96 & 3 & BRM 1 & IIIc (pot) & $5 \mathrm{C}-2$ & Projectile point fragment & 1 \\
\hline E20/S96 & 3 & BRM 1 & IIIc (pot) & $5 \mathrm{C}-1$ & Projectile point, Ensor & 1 \\
\hline E20/S96 & 3 & BRM 1 & IIIc (pot) & $5 C-6$ & Thin uniface & 1 \\
\hline E20/S96 & 4 & BRM 1 & IIIc (pot) & & Debitage & 132 \\
\hline E20/S96 & 4 & BRM 1 & IIIc (pot) & $5 \mathrm{D}-5$ & Edge modified flake & 1 \\
\hline E20/S96 & 4 & BRM 1 & IIIc (pot) & $5 \mathrm{D}-6$ & Edge modified flake & 1 \\
\hline E20/S96 & 4 & BRM 1 & IIIc (pot) & $5 \mathrm{D}-2$ & Projectile point, Ensor & 1 \\
\hline E20/S96 & 4 & BRM 1 & IIIc (pot) & $5 \mathrm{D}-1$ & Projectile point, Wells & 1 \\
\hline E20/S96 & 4 & BRM 1 & IIIc (pot) & $5 \mathrm{D}-3$ & Unifacial multiple tool & 1 \\
\hline E20/S96 & 5 & BRM 1 & IIIc (pot) & & Debitage & 57 \\
\hline E20/S96 & 5 & BRM 1 & IIIc (pot) & $5 \mathrm{E}-3$ & Edge modified flake & 1 \\
\hline E20/S96 & 5 & BRM 1 & IIIc (pot) & $5 \mathrm{E}-4$ & Edge modified flake & 1 \\
\hline E20/S96 & 5 & BRM 1 & IIIc (pot) & $5 \mathrm{E}-2$ & Projectile point, expanding stem B & 1 \\
\hline E20/S96 & 5 & BRM 1 & IIIc (pot) & $5 \mathrm{E}-1$ & Thin uniface & 1 \\
\hline E20/S96 & 5 & BRM 1 & IIIc (pot) & $5 \mathrm{E}-5$ & Thin uniface fragment & 1 \\
\hline E20/S96 & 6 & & IIIc (pot) & $5 F-5$ & Biface Stage 2 & 1 \\
\hline E20/S96 & 6 & & IIIc (pot) & $5 \mathrm{~F}-2$ & Biface Stage 2 & 1 \\
\hline $\mathrm{E} 20 / \mathrm{S} 96$ & 6 & & IIIc (pot) & $5 \mathrm{~F}-3$ & Biface Stage 2 & 1 \\
\hline E20/S96 & 6 & & IIIc (pot) & $5 \mathrm{~F}-4$ & Biface Stage 2 & 1 \\
\hline E20/S96 & 6 & & IIIc (pot) & & Debitage & 101 \\
\hline $\mathrm{E} 20 / \mathrm{S} 96$ & 6 & & IIIc (pot) & $5 F-10$ & Edge modified flake & 1 \\
\hline $\mathrm{E} 20 / \mathrm{S} 96$ & 6 & & IIIc (pot) & $5 \mathrm{~F}-7$ & Edge modified flake & 1 \\
\hline $\mathrm{E} 20 / \mathrm{S} 96$ & 6 & & IIIc (pot) & $5 \mathrm{~F}-8$ & Edge modified flake & 1 \\
\hline E20/S96 & 6 & & IIIc (pot) & $5 \mathrm{~F}-9$ & Edge modified flake & 1 \\
\hline E20/S96 & 6 & & IIIc (pot) & $5 \mathrm{~F}-1$ & Possible ground stone & 1 \\
\hline E20/S96 & 6 & & IIIc (pot) & $5 F-11$ & Thin uniface & 1 \\
\hline E20/S96 & 7 & & IIIc & $5 \mathrm{G}-3$ & Biface Stage 2 & 1 \\
\hline E20/S96 & 7 & & IIIC & $5 \mathrm{G}-4$ & Biface Stage 2 & 1 \\
\hline E20/S96 & 7 & & IIIc & $5 \mathrm{G}-8$ & Biface Stage 2 & 1 \\
\hline $\mathrm{E} 20 / \mathrm{S} 96$ & 7 & & IIIc & $5 G-5$ & Burin & 1 \\
\hline $\mathrm{E} 20 / \mathrm{S} 96$ & 7 & & IIIc & & Debitage & 197 \\
\hline E20/S96 & 7 & & IIIc & $5 \mathrm{G}-9$ & Edge modified flake & 1 \\
\hline E20/S96 & 7 & & IIIC & $5 \mathrm{G}-6$ & Edge modified flake & 1 \\
\hline E20/S96 & 7 & & IIIc & $5 \mathrm{G}-1$ & Projectile point, Lange & 1 \\
\hline E20/S96 & 7 & & IIIc & $5 \mathrm{G}-7$ & Thin uniface & 1 \\
\hline E20/S96 & 8 & & $\mathrm{Y} / \mathrm{IIIc}$ & $5 \mathrm{H}-4$ & Biface fragment & 1 \\
\hline E20/S96 & 8 & - & $\mathrm{Y} / \mathrm{IIIc}$ & $5 \mathrm{H}-3$ & Biface Stage 2 & 1 \\
\hline E20/S96 & 8 & & $\mathrm{Y} / \mathrm{III} \mathrm{c}$ & & Debitage & 217 \\
\hline E20/S96 & 8 & & Y/IIIc & $5 \mathrm{H}-2$ & Denticulated flake & 1 \\
\hline E20/S96 & 8 & & $\mathrm{Y} / \mathrm{IIII}$ & $5 \mathrm{H}-1$ & Projectile point, Bandy & 1 \\
\hline E20/S96 & 8 & & $\mathrm{Y} / \mathrm{IIIc}$ & $5 \mathrm{H}-5$ & Thin uniface & 1 \\
\hline E20/S96 & 9 & & $\mathrm{Y} / \mathrm{III} \mathrm{c}$ & & Debitage & 265 \\
\hline E20/S96 & 9 & & Y/IIIc & $5 \mathrm{I}-4$ & Edge modified flake & 1 \\
\hline E20/S96 & 9 & & $\mathrm{Y} / \mathrm{III} \mathrm{c}$ & $5 \mathrm{I}-2$ & Projectile point fragment & 1 \\
\hline E20/S96 & 9 & & $\mathrm{Y} / \mathrm{III} \mathrm{c}$ & $5 \mathrm{I}-1$ & Projectile point, indeterminate & 1 \\
\hline E20/S96 & 9 & & $\mathrm{Y} / \mathrm{IIIc}$ & $5 \mathrm{I}-3$ & Thin uniface & 1 \\
\hline E20/S96 & 10 & & $\mathrm{Y}$ & $5 \mathrm{~J}-5$ & Biface Stage 3 & 1 \\
\hline
\end{tabular}




\begin{tabular}{|c|c|c|c|c|c|c|}
\hline Square & Level & Feature & Strata & Item & Analyst Identification & Count \\
\hline E20/S96 & 10 & & $\mathrm{Y}$ & & Debitage & 348 \\
\hline E20/S96 & 10 & & $\mathrm{Y}$ & $5 \mathrm{~J}-7$ & Edge modified flake & 1 \\
\hline E20/S96 & 10 & & Y & $5 \mathrm{~J}-1$ & Projectile point, Jetta & 1 \\
\hline E20/S96 & 10 & & Y & $5 \mathrm{~J}-3$ & Projectile point, miscellaneous lanceolate & 1 \\
\hline E20/S96 & 10 & & Y & $5 \mathrm{~J}-4$ & Projectile point, Thrall & \\
\hline E20/S96 & 10 & & Y & $5 \mathrm{~J}-2$ & Projectile point, Uvalde & 1 \\
\hline E20/S96 & 10 & & Y & $5 \mathrm{~J}-8$ & Thin uniface & 1 \\
\hline E20/S96 & 11 & & $\mathrm{Y}$ & $5 \mathrm{~K}-1$ & Burin & 1 \\
\hline E20/S96 & 11 & & Y & & Debitage & 234 \\
\hline E20/S96 & 12 & & $\mathrm{X} / \mathrm{Y}$ & $5 \mathrm{~L}-3$ & Biface fragment & 20 \\
\hline E20/S96 & 12 & & $\mathrm{X} / \mathrm{Y}$ & $5 \mathrm{~L}-1$ & Biface Stage 1 & 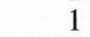 \\
\hline E20/S96 & 12 & & $\mathrm{X} / \mathrm{Y}$ & & Debitage & 299 \\
\hline E20/S96 & 12 & & $\mathrm{X} / \mathrm{Y}$ & $5 \mathrm{~L}-4$ & Edge modified flake & 1 \\
\hline $\mathrm{E} 20 / \mathrm{S} 96$ & 12 & & $\mathrm{X} / \mathrm{Y}$ & $5 \mathrm{~L}-5$ & Edge modified flake & 1 \\
\hline E20/S96 & 12 & & $X / Y$ & $5 \mathrm{~L}-6$ & Edge modified flake & 1 \\
\hline E20/S96 & 12 & & $\mathrm{X} / \mathrm{Y}$ & $5 \mathrm{~L}-7$ & Microspur/microdenticulate & 1 \\
\hline E20/S96 & 12 & & $\mathrm{X} / \mathrm{Y}$ & $5 \mathrm{~L}-2$ & Perforator Group 7 & 1 \\
\hline $\mathrm{E} 20 / \mathrm{S} 96$ & 13 & & $\mathrm{X} / \mathrm{Y}$ & & Debitage & 295 \\
\hline $\mathrm{E} 20 / \mathrm{S} 96$ & 14 & & $\mathrm{X}$ & & Debitage & 222 \\
\hline E20/S96 & 14 & & $\mathrm{X}$ & $5 \mathrm{~N}-1$ & Projectile point, bifurcate stem fragment & 1 \\
\hline E20/S96 & 14 & & $\mathrm{X}$ & $5 \mathrm{~N}-2$ & Projectile point, expanding concave B & 1 \\
\hline E20/S96 & 14 & & $\mathrm{X}$ & $5 \mathrm{~N}-3$ & Spurred flake & 1 \\
\hline E20/S96 & 15 & & $\mathrm{X}$ & $50-1$ & Burin spall & 1 \\
\hline E20/S96 & 15 & & $\mathrm{X}$ & & Debitage & 225 \\
\hline E20/S96 & 16 & & $\mathrm{X}$ & $5 \mathrm{P}-7$ & Biface Stage 2 & 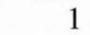 \\
\hline E20/S96 & 16 & & $\mathrm{X}$ & $5 \mathrm{P}-4$ & Core, thermal & 1 \\
\hline E20/S96 & 16 & & $\mathrm{X}$ & & Debitage & 116 \\
\hline E20/S96 & 17 & & $\mathrm{X}$ & $5 Q-1$ & Burin & \\
\hline E20/S96 & 17 & & $\mathrm{X}$ & & Debitage & 12 \\
\hline E20/S98 & & & & $3^{*}-1$ & Burin spall & 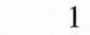 \\
\hline E20/S98 & 1 & & IIIc & $3 \mathrm{~A}-1$ & Arrow point, Scallorn & 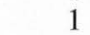 \\
\hline E20/S98 & 1 & & IIIc & $3 \mathrm{~A}-2$ & Arrow point, Scallorn & \\
\hline E20/S98 & 1 & & IIIC & $3 \mathrm{~A}-24$ & Biface fragment & \\
\hline E20/S98 & 1 & & IIIc & $3 \mathrm{~A}-4$ & Biface Stage 2 & 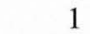 \\
\hline E20/S98 & 1 & & IIIc & $3 \mathrm{~A}-12$ & Biface Stage 3 & 1 \\
\hline E20/S98 & 1 & & IIIc & $3 \mathrm{~A}-8$ & Burin spall & 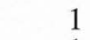 \\
\hline $\mathrm{E} 20 / \mathrm{S} 98$ & 1 & & IIIc & $3 \mathrm{~A}-31$ & Burin spall & \\
\hline E20/S98 & 1 & & IIIc & $3 \mathrm{~A}-18$ & Chert cobble, chunk & 1 \\
\hline E20/S98 & 1 & & IIIC & $3 \mathrm{~A}-11$ & Core tool, type 2 & 1 \\
\hline E20/S98 & 1 & & IIIc & $3 \mathrm{~A}-10$ & Core, multidirectional & 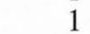 \\
\hline $\mathrm{E} 20 / \mathrm{S} 98$ & 1 & & IIIc & & Debitage & 593 \\
\hline E20/S98 & 1 & & IIIIc & $3 \mathrm{~A}-25$ & Denticulated flake & \\
\hline E20/S98 & 1 & & IIIC & $3 \mathrm{~A}-20$ & Edge modified flake & 1 \\
\hline E20/S98 & 1 & & IIIc & $3 \mathrm{~A}-27$ & Edge modified flake & 1 \\
\hline E20/S98 & 1 & & IIIc & $3 \mathrm{~A}-26$ & Edge modified flake & 1 \\
\hline E20/S98 & 1 & & IIIC & $3 \mathrm{~A}-29$ & Edge modified flake & \\
\hline $\mathrm{E} 20 / \mathrm{S} 98$ & 1 & & IIIc & $3 \mathrm{~A}-5$ & Edge modified flake & \\
\hline E20/S98 & 1 & & IIIIc & $3 \mathrm{~A}-7$ & Edge modified flake & 1 \\
\hline E20/S98 & 1 & & IIIc & $3 \mathrm{~A}-22$ & Edge modified flake & 1 \\
\hline E20/S98 & 1 & & IIIc & $3 \mathrm{~A}-6$ & Micro-core, large & 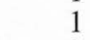 \\
\hline E20/S98 & 1 & & IIIC & $3 \mathrm{~A}-17$ & Microspur/microdenticulate & 1 \\
\hline E20/S98 & 1 & & IIIc & $3 \mathrm{~A}-16$ & Notched flake & 1 \\
\hline $\mathrm{E} 20 / \mathrm{S} 98$ & 1 & & IIIc & $3 \mathrm{~A}-3$ & Notched flake & 1 \\
\hline E20/S98 & 1 & & IIIc & $3 \mathrm{~A}-19$ & Notched flake & \\
\hline $\mathrm{E} 20 / \mathrm{S} 98$ & 1 & & IIIc & $3 \mathrm{~A}-14$ & Projectile point fragment & \\
\hline E20/S98 & 1 & & IIIc & $3 \mathrm{~A}-13$ & Projectile point fragment & \\
\hline E20/S98 & 1 & & IIIc & $3 \mathrm{~A}-15$ & Projectile point, Nolan & 1 \\
\hline E20/S98 & 1 & & IIIIc & $3 \mathrm{~A}-30$ & Spurred flake & 1 \\
\hline E20/S98 & 1 & & IIIc & $3 \mathrm{~A}-28$ & Thin uniface fragment & \\
\hline $\mathrm{E} 20 / \mathrm{S} 98$ & 1 & & IIIc & $3 \mathrm{~A}-23$ & Unifacial multiple tool & \\
\hline $\mathrm{E} 20 / \mathrm{S} 98$ & 2 & & IIIc & $3 B-4$ & Arrow point, medial & \\
\hline E20/S98 & 2 & & IIIc & $3 B-2$ & Arrow point, Scallorn & \\
\hline E20/S98 & 2 & & IIIC & 3B-1 & Arrow point, Scallorn & 1 \\
\hline E20/S98 & 2 & & IIIC & $3 B-6$ & Chert cobble, unmodified/tested & \\
\hline E20/S98 & 2 & & IIIc & $3 \mathrm{~B}-5$ & Core, multidirectional & \\
\hline $\mathrm{E} 20 / \mathrm{S} 98$ & 2 & & IIIc & & Debitage & 498 \\
\hline E20/S98 & 2 & & IIIC & 3B-7 & Perforator Group 1 & \\
\hline E20/S98 & 2 & & IIIc & $3 \mathrm{~B}-3$ & Projectile point, bifurcate stem fragment & 1 \\
\hline $\mathrm{E} 20 / \mathrm{S} 98$ & 2 & & IIIc & $3 B-9$ & Projectile point, rectangular stem (eccentric) & \\
\hline $\mathrm{E} 20 / \mathrm{S} 98$ & 2 & & IIIc & $3 \mathrm{~B}-8$ & Thin uniface & \\
\hline E20/S98 & 3 & BRM 1 & IIIc & $3 \mathrm{C}-2$ & Biface fragment & 1 \\
\hline E20/S98 & 3 & BRM 1 & IIIc & $3 C-3$ & Biface Stage 2 & 1 \\
\hline E20/S98 & 3 & BRM 1 & IIIC & $3 \mathrm{C}-1$ & Bifacial tool & 1 \\
\hline E20/S98 & 3 & BRM 1 & IIIC & & Debitage & 152 \\
\hline
\end{tabular}




\begin{tabular}{|c|c|c|c|c|c|c|}
\hline Square & Level & Feature & Strata & Item & Analyst Identification & Count \\
\hline E20/S98 & 3 & BRM 1 & IIIc & $3 C-5$ & Edge modified flake & 1 \\
\hline E20/S98 & 3 & BRM 1 & IIIC & $3 \mathrm{C}-4$ & Projectile point, beveled narrow stemmed & 1 \\
\hline $\mathrm{E} 20 / \mathrm{S} 98$ & 4 & BRM 1 & IIII & $3 \mathrm{D}-6$ & Biface fragment & 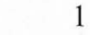 \\
\hline E20/S98 & 4 & BRM 1 & IIIIc & $3 \mathrm{D}-2$ & Biface Stage 2 & 1 \\
\hline E20/S98 & 4 & BRM 1 & IIIC & $3 \mathrm{D}-7$ & Clear Fork uniface & 1 \\
\hline E20/S98 & 4 & BRM 1 & IIIC & & Debitage & 106 \\
\hline E20/S98 & 4 & BRM 1 & IIIC & $3 \mathrm{D}-3$ & Edge modified flake & \\
\hline E20/S98 & 4 & BRM 1 & IIIc & $3 \mathrm{D}-5$ & Edge modified flake & 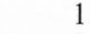 \\
\hline E20/S98 & 4 & BRM 1 & IIIC & 3D-1 & Thin uniface & \\
\hline E20/S98 & 4 & BRM 1 & IIIIc & 3D-4 & Unifacial multiple tool & \\
\hline E20/S98 & 5 & BRM 1 & IIIc & $3 \mathrm{E}-5$ & Bifacial tool Form A & \\
\hline E20/S98 & 5 & BRM 1 & IIIIc & $3 \mathrm{E}-4$ & Bifacial tool Form D & \\
\hline E20/S98 & 5 & BRM 1 & IIIc & $3 \mathrm{E}-10$ & Burin spall & \\
\hline E20/S98 & 5 & BRM 1 & IIIC & & Debitage & 94 \\
\hline E20/S98 & 5 & BRM 1 & IIIC & $3 \mathrm{E}-8$ & Edge modified flake & \\
\hline E20/S98 & 5 & BRM 1 & IIIC & $3 \mathrm{E}-7$ & Projectile point fragment & \\
\hline E20/S98 & 5 & BRM 1 & IIIc & $3 \mathrm{E}-6$ & Projectile point fragment & \\
\hline E20/S98 & 5 & BRM 1 & IIIc & $3 \mathrm{E}-2$ & Projectile point, Darl & \\
\hline E20/S98 & 5 & BRM 1 & IIIIc & $3 \mathrm{E}-1$ & Projectile point, Darl & \\
\hline E20/S98 & 5 & BRM 1 & IIIC & $3 \mathrm{E}-3$ & Projectile point, Nolan & \\
\hline E20/S98 & 5 & BRM 1 & IIIc & $3 \mathrm{E}-9$ & Unifacial multiple tool & \\
\hline E20/S98 & 6 & & Y/IIIc & $3 F-2$ & Biface Stage 1 & \\
\hline E20/S98 & 6 & & Y/IIIc & $3 \mathrm{~F}-1$ & Biface Stage 2 & \\
\hline E20/S98 & 6 & & Y/IIIc & & Debitage & 132 \\
\hline E20/S98 & 6 & & Y/IIIc & $3 F-3$ & Edge modified flake & \\
\hline E20/S98 & 6 & & Y/IIIc & $3 \mathrm{~F}-4$ & Edge modified flake & \\
\hline E20/S98 & 7 & & Y/IIIc & $3 \mathrm{G}-3$ & Biface Stage 2 & \\
\hline E20/S98 & 7 & & Y/IIIc & $3 \mathrm{G}-2$ & Burin & \\
\hline E20/S98 & 7 & & Y/IIIc & & Debitage & 199 \\
\hline E20/S98 & 7 & & Y/IIIc & $3 G-4$ & Thin uniface & \\
\hline E20/S98 & 8 & & Y/IIIc & $3 \mathrm{H}-4$ & Biface Stage 2 & \\
\hline E20/S98 & 8 & & Y/IIIc & $3 \mathrm{H}-3$ & Bifacial tool Form A & \\
\hline E20/S98 & 8 & & Y/IIIc & & Debitage & 114 \\
\hline E20/S98 & 8 & & Y/IIIc & $3 \mathrm{H}-5$ & Edge modified flake & \\
\hline E20/S98 & 8 & & Y/IIIc & $3 \mathrm{H}-1$ & Projectile point, bifurcate stem fragment & \\
\hline E20/S98 & 8 & & Y/IIIc & $3 \mathrm{H}-2$ & Projectile point, Uvalde & \\
\hline E20/S98 & 8 & & Y/IIIc & $3 \mathrm{H}-6$ & Thin uniface fragment & \\
\hline E20/S98 & 9 & & $\mathrm{Y}$ & $3 \mathrm{I}-2$ & Biface Stage 1 & \\
\hline E20/S98 & 9 & & $\mathrm{Y}$ & $3 \mathrm{I}-1$ & Burin & \\
\hline E20/S98 & 9 & & $\mathrm{Y}$ & & Debitage & 91 \\
\hline E20/S98 & 9 & & $\mathrm{Y}$ & $3 \mathrm{I}-3$ & Edge modified flake & \\
\hline E20/S98 & 9 & & $\mathrm{Y}$ & $3 \mathrm{I}-5$ & Edge modified flake & \\
\hline E20/S98 & 9 & & $\mathrm{Y}$ & $3 \mathrm{I}-4$ & Notched flake & \\
\hline E20/S98 & 10 & & $\mathrm{Y}$ & $3 \mathrm{~J}-4$ & Biface fragment & \\
\hline E20/S98 & 10 & & $\mathrm{Y}$ & $3 \mathrm{~J}-7$ & Chert cobble, chunk & \\
\hline E20/S98 & 10 & & $\mathrm{Y}$ & $3 \mathrm{~J}-6$ & Chert cobble, chunk & \\
\hline E20/S98 & 10 & & $\mathrm{Y}$ & $3 \mathrm{~J}-8$ & Core tool, type 1 & \\
\hline E20/S98 & 10 & & $\mathrm{Y}$ & & Debitage & 471 \\
\hline E20/S98 & 10 & & $\mathrm{Y}$ & $3 \mathrm{~J}-10$ & Denticulated flake & \\
\hline E20/S98 & 10 & & $\mathrm{Y}$ & $3 \mathrm{~J}-3$ & Mano fragment & \\
\hline E20/S98 & 10 & & $\mathrm{Y}$ & $3 \mathrm{~J}-11$ & Microspur/microdenticulate & \\
\hline E20/S98 & 10 & & $\mathrm{Y}$ & $3 \mathrm{~J}-2$ & Perforator Group 3 & \\
\hline E20/S98 & 10 & & $\mathrm{Y}$ & $3 \mathrm{~J}-1$ & Projectile point, Gower/Uvalde & \\
\hline E20/S98 & 10 & & $\mathrm{Y}$ & $3 \mathrm{~J}-9$ & Projectile point, Hoxie A & \\
\hline E20/S98 & 10 & & $\mathrm{Y}$ & $3 \mathrm{~J}-5$ & Small core hammerstone & \\
\hline E20/S98 & 11 & & $\mathrm{X} / \mathrm{Y}$ & $3 \mathrm{~K}-2$ & Biface Stage 2 & \\
\hline E20/S98 & 11 & & $\mathrm{X} / \mathrm{Y}$ & $3 \mathrm{~K}-3$ & Bifacial tool Form A & \\
\hline E20/S98 & 11 & & $\mathrm{X} / \mathrm{Y}$ & & Debitage & 265 \\
\hline E20/S98 & 11 & & $\mathrm{X} / \mathrm{Y}$ & $3 \mathrm{~K}-5$ & Edge modified flake & \\
\hline E20/S98 & 11 & & $\mathrm{X} / \mathrm{Y}$ & $3 \mathrm{~K}-1$ & Projectile point, Hoxie & \\
\hline E20/S98 & 12 & & $\mathrm{X} / \mathrm{Y}$ & & Debitage & 290 \\
\hline E20/S98 & $12^{\circ}$ & & $\mathrm{X} / \mathrm{Y}$ & $3 \mathrm{~L}-4$ & Edge modified flake & \\
\hline E20/S98 & 12 & & $\mathrm{X} / \mathrm{Y}$ & $3 \mathrm{~L}-2$ & Microspur/microdenticulate & \\
\hline E20/S98 & 12 & & $\mathrm{X} / \mathrm{Y}$ & $3 \mathrm{~L}-1$ & Projectile point, miscellaneous lanceolate & \\
\hline E20/S98 & 12 & & $\mathrm{X} / \mathrm{Y}$ & $3 \mathrm{~L}-3$ & Thick uniface & \\
\hline E20/S98 & 13 & & $\mathrm{X}$ & $3 \mathrm{M}-3$ & Burin spall & \\
\hline E20/S98 & 13 & & $\mathrm{X}$ & $3 \mathrm{M}-4$ & Burin spall & \\
\hline E20/S98 & 13 & & $\mathrm{X}$ & & Debitage & 29 \\
\hline E20/S98 & 13 & & $\mathrm{X}$ & $3 M-8$ & Edge modified flake & \\
\hline E20/S98 & 13 & & $\mathrm{X}$ & $3 M-9$ & Edge modified flake & \\
\hline E20/S98 & 13 & & $\mathrm{X}$ & $3 \mathrm{M}-7$ & Microspur/microdenticulate & \\
\hline E20/S98 & 13 & & $\mathrm{X}$ & $3 \mathrm{M}-11$ & Notched flake & \\
\hline E20/S98 & 13 & & $\mathrm{X}$ & $3 \mathrm{M}-1$ & Projectile point, Angostura & \\
\hline E20/S98 & 13 & & $\mathrm{X}$ & $3 \mathrm{M}-2$ & Projectile point, Jetta & \\
\hline
\end{tabular}




\begin{tabular}{|c|c|c|c|c|}
\hline Square & Level & Feature & Strata & Item \\
\hline E20/S98 & 13 & & $\mathrm{X}$ & $3 M-5$ \\
\hline E20/S98 & 13 & & $\mathrm{X}$ & $3 \mathrm{M}-12$ \\
\hline E20/S98 & 13 & & X & $3 M-10$ \\
\hline E20/S98 & 14 & & $\mathrm{X}$ & $3 \mathrm{~N}-1$ \\
\hline E20/S98 & 14 & & $\mathrm{X}$ & $3 N-3$ \\
\hline E20/S98 & 14 & & $\mathrm{X}$ & $3 N-2$ \\
\hline E20/S98 & 14 & & $\mathrm{X}$ & \\
\hline E20/S98 & 14 & & $\mathrm{X}$ & $3 N-4$ \\
\hline E20/S98 & 14 & & $\mathrm{X}$ & $3 N-5$ \\
\hline $\mathrm{E} 20 / \mathrm{S} 98$ & 15 & & $\mathrm{X}$ & $30-2$ \\
\hline E20/S98 & 15 & & $\mathrm{X}$ & $30-1$ \\
\hline E20/S98 & 15 & & $X$ & \\
\hline E20/S98 & 15 & & $\mathrm{X}$ & $30-3$ \\
\hline E20/S100 & 1 & & IIII & $1 \mathrm{~A}-3$ \\
\hline E20/S100 & 1 & & IIIc & $1 \mathrm{~A}-7$ \\
\hline $\mathrm{E} 20 / \mathrm{S} 100$ & 1 & & IIIc & $1 \mathrm{~A}-20$ \\
\hline $\mathrm{E} 20 / \mathrm{S} 100$ & 1 & & IIIc & $1 \mathrm{~A}-8$ \\
\hline $\mathrm{E} 20 / \mathrm{S} 100$ & 1 & & IIIc & $1 \mathrm{~A}-15$ \\
\hline $\mathrm{E} 20 / \mathrm{S} 100$ & 1 & & IIIc & $1 \mathrm{~A}-4$ \\
\hline E20/S100 & 1 & & IIIC & $1 \mathrm{~A}-5$ \\
\hline E20/S100 & 1 & & IIIc & $1 \mathrm{~A}-6$ \\
\hline $\mathrm{E} 20 / \mathrm{S} 100$ & 1 & & IIIc & $1 \mathrm{~A}-10$ \\
\hline $\mathrm{E} 20 / \mathrm{S} 100$ & 1 & & IIIc & \\
\hline E20/S100 & 1 & & IIIc & $1 \mathrm{~A}-16$ \\
\hline E20/S100 & 1 & & IIIc & $1 \mathrm{~A}-21$ \\
\hline $\mathrm{E} 20 / \mathrm{S} 100$ & 1 & & IIIc & $1 \mathrm{~A}-19$ \\
\hline E20/S100 & 1 & & IIIc & $1 \mathrm{~A}-11$ \\
\hline E20/S100 & 1 & & IIIc & $1 \mathrm{~A}-17$ \\
\hline $\mathrm{E} 20 / \mathrm{S} 100$ & 1 & & IIIC & $1 \mathrm{~A}-14$ \\
\hline $\mathrm{E} 20 / \mathrm{S} 100$ & 1 & & IIIc & $1 \mathrm{~A}-18$ \\
\hline E20/S100 & 1 & & IIIc & $1 \mathrm{~A}-12$ \\
\hline E20/S100 & 1 & & IIIC & $1 \mathrm{~A}-13$ \\
\hline $\mathrm{E} 20 / \mathrm{S} 100$ & 1 & & IIIc & $1 \mathrm{~A}-1$ \\
\hline E20/S100 & 1 & & IIIc & $1 \mathrm{~A}-2$ \\
\hline E20/S100 & 1 & & IIIc & $1 \mathrm{~A}-9$ \\
\hline E20/S100 & 2 & & IIIC & 1B-1 \\
\hline E20/S100 & 2 & & IIIc & $1 \mathrm{~B}-43$ \\
\hline $\mathrm{E} 20 / \mathrm{S} 100$ & 2 & & IIIc & \\
\hline E20/S100 & 2 & & IIIc & 1B-6 \\
\hline E20/S100 & 2 & & IIIc & 1B-3 \\
\hline E20/S100 & 2 & & IIII & $1 \mathrm{~B}-5$ \\
\hline E20/S100 & 2 & & IIIC & 1B-2 \\
\hline E20/S100 & 3 & & IIIC & $1 \mathrm{C}-4$ \\
\hline E20/S100 & 3 & & IIIc & \\
\hline E20/S100 & 3 & & IIII & $1 \mathrm{C}-6$ \\
\hline E20/S100 & 3 & & IIIC & $1 \mathrm{C}-1$ \\
\hline E20/S100 & 3 & & IIIc & $1 \mathrm{C}-3$ \\
\hline $\mathrm{E} 20 / \mathrm{S} 100$ & 3 & & IIIc & $1 \mathrm{C}-2$ \\
\hline E20/S100 & 3 & & IIIc & $1 \mathrm{C}-7$ \\
\hline E20/S100 & 3 & & IIIC & $1 C-5$ \\
\hline $\mathrm{E} 20 / \mathrm{S} 100$ & 3 & & IIIc & $1 \mathrm{C}-9$ \\
\hline E20/S100 & 4 & & IIIc & $1 D-3$ \\
\hline E20/S100 & 4 & & IIIC & 1D- 1 \\
\hline E20/S100 & 4 & & IIIc & 1D-2 \\
\hline E20/S100 & 4 & & IIIIc & \\
\hline E20/S100 & 4 & & IIIc & $1 \mathrm{D}-4$ \\
\hline E20/S100 & 5 & & IIIc & $1 \mathrm{E}-5$ \\
\hline $\mathrm{E} 20 / \mathrm{S} 100$ & 5 & & IIIC & $1 \mathrm{E}-7$ \\
\hline E20/S100 & 5 & & IIIc & $1 \mathrm{E}-4$ \\
\hline E20/S100 & 5 & & IIIc & $1 \mathrm{E}-3$ \\
\hline E20/S100 & 5 & & IIIc & \\
\hline E20/S100 & 5 & & IIIc & $1 \mathrm{E}-2$ \\
\hline $\mathrm{E} 20 / \mathrm{S} 100$ & 5 & & IIIc & $1 \mathrm{E}-1$ \\
\hline E20/S100 & 5 & & IIIc & $1 \mathrm{E}-6$ \\
\hline $\mathrm{E} 20 / \mathrm{S} 100$ & 6 & & $\mathrm{Y} / \mathrm{III}$ & $1 \mathrm{~F}-7$ \\
\hline E20/S100 & 6 & & $\mathrm{Y} / \mathrm{III} \mathrm{c}$ & $1 F-9$ \\
\hline E20/S100 & 6 & & $\mathrm{Y} / \mathrm{III} \mathrm{c}$ & $1 F-3$ \\
\hline E20/S100 & 6 & & Y/IIIc & $1 \mathrm{~F}-8$ \\
\hline E20/S100 & 6 & & Y/IIIc & $1 \mathrm{~F}-1$ \\
\hline E20/S100 & 6 & & Y/IIIc & \\
\hline E20/S100 & 6 & & $\mathrm{Y} / \mathrm{IIIC}$ & $1 F-6$ \\
\hline E20/S100 & 6 & & Y/IIIc & $1 F-5$ \\
\hline E20/S100 & 6 & & Y/IIIc & $1 \mathrm{~F}-4$ \\
\hline E20/S100 & 7 & & $\mathrm{Y}$ & $1 \mathrm{G}-7$ \\
\hline
\end{tabular}

Analyst Identification

Thin uniface

Unifacial multiple tool

Unifacial multiple tool

Biface fragment

Biface Stage 2

Biface Stage 2

Debitage

Projectile point, early bifurcate stem preform

Projectile point, miscellaneous lanceolate

Biface Stage 1

Biface Stage 2

Debitage

Thin uniface

Arrow point, preform

Biface fragment

Biface fragment

Biface fragment

Biface fragment

Biface Stage 2

Biface Stage 2

Biface Stage 2

Burin spall

Debitage

Denticulated flake

Edge modified flake

Edge modified flake

Large core hammerstone

Microspur/microdenticulate

Notched flake

Notched flake

Projectile point fragment

Projectile point fragment

Projectile point, Darl

Projectile point, miscellaneous bifurcate

Uniface, unanalyzed

Biface fragment

Biface Stage 1

Debitage

Edge modified flake

Edge modified flake

Edge modified flake

Notched flake

Biface Stage 1

Debitage

Edge modified flake

Projectile point, Ensor

Projectile point, Montell

Projectile point, Montell

Unifacial multiple tool

Unifacial multiple tool

Worked hematite

Battered cobble

Biface Stage 2

Biface Stage 2

Debitage

Edge modified flake

Biface Stage 2

Biface Stage 2

Biface Stage 2

Biface Stage 3

Debitage

Metate fragment

Projectile point, Pedernales

Unifacial multiple tool

Biface Stage 1

Biface Stage 1

Biface Stage 3

Bifacial tool Form J

Clear Fork biface

Debitage

Edge modified flake

Projectile point fragment

Projectile point, bifurcate stem fragment

Biface fragment 


\begin{tabular}{|c|c|}
\hline Square & Level \\
\hline E20/S100 & 7 \\
\hline E20/S100 & 7 \\
\hline E20/S100 & 7 \\
\hline E20/S100 & 7 \\
\hline E20/S100 & 7 \\
\hline E20/S100 & 7 \\
\hline E20/S100 & 7 \\
\hline E20/S100 & 7 \\
\hline E20/S100 & 7 \\
\hline E20/S100 & 7 \\
\hline E20/S100 & 7 \\
\hline E20/S100 & 7 \\
\hline E20/S100 & 7 \\
\hline E20/S100 & 7 \\
\hline E20/S100 & 7 \\
\hline E20/S100 & 7 \\
\hline E20/S100 & 7 \\
\hline $\mathrm{E} 20 / \mathrm{S} 100$ & 7 \\
\hline E20/S100 & 7 \\
\hline E20/S100 & 7 \\
\hline E20/S100 & 8 \\
\hline E20/S100 & 8 \\
\hline $\mathrm{E} 20 / \mathrm{S} 100$ & 8 \\
\hline $\mathrm{E} 20 / \mathrm{S} 100$ & 8 \\
\hline E20/S100 & 8 \\
\hline E20/S100 & 8 \\
\hline E20/S100 & 8 \\
\hline E20/S100 & 9 \\
\hline E20/S100 & 9 \\
\hline E20/S100 & 9 \\
\hline $\mathrm{E} 20 / \mathrm{S} 100$ & 9 \\
\hline E20/S100 & 9 \\
\hline E20/S100 & 9 \\
\hline E20/S100 & 9 \\
\hline E20/S100 & 9 \\
\hline E20/S100 & 9 \\
\hline $\mathrm{E} 20 / \mathrm{S} 100$ & 10 \\
\hline $\mathrm{E} 20 / \mathrm{S} 100$ & 10 \\
\hline E20/S100 & 11 \\
\hline $\mathrm{E} 22 / \mathrm{S} 72$ & 15 \\
\hline E22/S72 & 15 \\
\hline $\mathrm{E} 22 / \mathrm{S} 72$ & 15 \\
\hline $\mathrm{E} 22 / \mathrm{S} 72$ & 15 \\
\hline $\mathrm{E} 22 / \mathrm{S} 72$ & 15 \\
\hline $\mathrm{E} 22 / \mathrm{S} 72$ & 15 \\
\hline $\mathrm{E} 22 / \mathrm{S} 72$ & 15 \\
\hline E22/S72 & 15 \\
\hline $\mathrm{E} 22 / \mathrm{S} 72$ & 15 \\
\hline $\mathrm{E} 22 / \mathrm{S} 72$ & 15 \\
\hline $\mathrm{E} 22 / \mathrm{S} 72$ & 15 \\
\hline E22/S72 & 15 \\
\hline E22/S72 & 15 \\
\hline $\mathrm{E} 22 / \mathrm{S} 72$ & 15 \\
\hline E22/S72 & 15 \\
\hline E22/S72 & 15 \\
\hline E22/S72 & 15 \\
\hline $\mathrm{E} 22 / \mathrm{S} 72$ & 15 \\
\hline E22/S72 & 15 \\
\hline E22/S72 & 15 \\
\hline E22/S72 & 15 \\
\hline E22/S72 & 15 \\
\hline $\mathrm{E} 22 / \mathrm{S} 72$ & 15 \\
\hline E22/S72 & 15 \\
\hline $\mathrm{E} 22 / \mathrm{S} 72$ & $16 \mathrm{~A}$ \\
\hline E22/S72 & $16 \mathrm{~A}$ \\
\hline $\mathrm{E} 22 / \mathrm{S} 72$ & $16 \mathrm{~A}$ \\
\hline $\mathrm{E} 22 / \mathrm{S} 72$ & $16 \mathrm{~B}$ \\
\hline E22/S72 & $16 \mathrm{~B}$ \\
\hline E22/S72 & $16 \mathrm{~B}$ \\
\hline $\mathrm{E} 22 / \mathrm{S} 72$ & $17 \mathrm{~A}$ \\
\hline $\mathrm{E} 22 / \mathrm{S} 72$ & $17 \mathrm{~A}$ \\
\hline $\mathrm{E} 22 / \mathrm{S} 72$ & $17 \mathrm{~A}$ \\
\hline E22/S72 & $17 \mathrm{~A}$ \\
\hline E22/S72 & $17 \mathrm{~A}$ \\
\hline
\end{tabular}

\begin{tabular}{|c|c|}
\hline Strata & Item \\
\hline $\mathrm{Y}$ & $1 \mathrm{G}-3$ \\
\hline $\mathrm{Y}$ & $1 \mathrm{G}-9$ \\
\hline Y & $1 \mathrm{G}-6$ \\
\hline Y & $1 \mathrm{G}-4$ \\
\hline Y & $1 G-8$ \\
\hline Y & \\
\hline Y & $1 \mathrm{G}-11$ \\
\hline Y & $1 \mathrm{G}-12$ \\
\hline Y & $1 \mathrm{G}-13$ \\
\hline Y & 1G-15 \\
\hline Y & 1G-18 \\
\hline Y & $1 \mathrm{G}-20$ \\
\hline Y & $1 \mathrm{G}-17$ \\
\hline Y & $1 G-5$ \\
\hline Y & 1G-1 \\
\hline Y & $1 \mathrm{G}-2$ \\
\hline Y & $1 \mathrm{G}-14$ \\
\hline $\mathrm{Y}$ & $1 \mathrm{G}-19$ \\
\hline Y & 1G-21 \\
\hline Y & $1 \mathrm{G}-10$ \\
\hline$Y$ & $1 \mathrm{H}-1$ \\
\hline Y & \\
\hline Y & $1 \mathrm{H}-4$ \\
\hline Y & $1 \mathrm{H}-3$ \\
\hline Y & $1 \mathrm{H}-2$ \\
\hline Y & $1 \mathrm{H}-5$ \\
\hline Y & $1 \mathrm{H}-6$ \\
\hline Y & $1 \mathrm{I}-2$ \\
\hline Y & 1I-1 \\
\hline Y & \\
\hline Y & $1 \mathrm{I}-5$ \\
\hline Y & $1 \mathrm{I}-6$ \\
\hline Y & $1 \mathrm{I}-7$ \\
\hline Y & $1 \mathrm{I}-3$ \\
\hline Y & $1 \mathrm{I}-9$ \\
\hline $\mathrm{Y}$ & $1 \mathrm{I}-4$ \\
\hline Y & \\
\hline Y & $1 \mathrm{~J}-2$ \\
\hline $\mathrm{X} / \mathrm{Y}$ & \\
\hline IIIa/b & $270-6$ \\
\hline $\mathrm{IIIa} / \mathrm{b}$ & $270-9$ \\
\hline IIIa/b & $270-7$ \\
\hline IIIa/b & $270-8$ \\
\hline $\mathrm{IIIa} / \mathrm{b}$ & $270-1$ \\
\hline $\mathrm{III} / \mathrm{b}$ & $27 \mathrm{O}-3$ \\
\hline IIIa/b & $270-4$ \\
\hline IIIa/b & $270-10$ \\
\hline $\mathrm{IIIa} / \mathrm{b}$ & $270-11$ \\
\hline IIIa/b & \\
\hline IIIa/b & $270-18$ \\
\hline IIIa/b & $270-25$ \\
\hline IIIa/b & $270-20$ \\
\hline $\mathrm{IIIa} / \mathrm{b}$ & $270-21$ \\
\hline IIIa/b & $270-16$ \\
\hline $\mathrm{IIIa} / \mathrm{b}$ & $270-17$ \\
\hline IIIa/b & 27O-19 \\
\hline $\mathrm{III} / \mathrm{b}$ & $270-15$ \\
\hline $\mathrm{IIIa} / \mathrm{b}$ & $270-14$ \\
\hline IIIa/b & $270-2$ \\
\hline $\mathrm{IIIa} / \mathrm{b}$ & $270-12$ \\
\hline IIIa/b & $270-5$ \\
\hline $\mathrm{IIIa} / \mathrm{b}$ & $270-22$ \\
\hline IIIa/b & $270-26$ \\
\hline IIIa/b & $27 \mathrm{P} 1-1$ \\
\hline IIIa/b & \\
\hline $\mathrm{III} / \mathrm{b}$ & $27 \mathrm{P} 1-2$ \\
\hline IIIIa & $27 \mathrm{P} 2-2$ \\
\hline IIIa & $27 \mathrm{P} 2-1$ \\
\hline IIIa & \\
\hline IIIa & \\
\hline IIIIa & 27Q1-4 \\
\hline IIIa & $27 \mathrm{Q} 1-5$ \\
\hline IIIa & 27Q1-1 \\
\hline IIIa & 27Q1-3 \\
\hline
\end{tabular}

Analyst Identification

Biface fragment

Biface fragment, unanalyzed

Biface Stage 2

Biface Stage 2

Burin spall

Debitage

Edge modified flake

Edge modified flake

Edge modified flake

Edge modified flake

Edge modified flake

Edge modified flake

Notched flake

Piece esquillee

Projectile point, bifurcate stem fragment

Projectile point, expanding concave B

Thin uniface

Thin uniface

Thin uniface

Thin uniface

Biface Stage 1

Debitage

Perforator Group 5

Projectile point fragment

Projectile point fragment

Thin uniface

Thin uniface

Biface Stage 2

Biface Stage 2

Debitage

Edge modified flake

Edge modified flake

Edge modified flake

Perforator Group 7

Projectile point fragment

Thin uniface

Debitage

Microspur/microdenticulate

Debitage

Biface fragment

Biface fragment

Biface Stage 2

Biface Stage 2

Bifacial tool Form A

Bifacial tool Form E

Bifacial tool Form E

Burin spall

Burin spall

Debitage

Denticulated flake

Edge modified flake

Edge modified flake

Edge modified flake

Microspur/microdenticulate

Microspur/microdenticulate

Microspur/microdenticulate

Microspur/microdenticulate

Microspur/microdenticulate

Projectile point fragment

Projectile point fragment

Thin uniface fragment

Thin uniface fragment

Worked hematite

Biface Stage 3

Debitage

Microspur/microdenticulate

Bifacial tool Form A

Core fragment

Debitage

Debitage

Edge modified flake

Edge modified flake

Projectile point, bifurcate stem fragment

Uniface, unanalyzed 


\begin{tabular}{|c|c|c|c|c|c|c|}
\hline Square & Level & Feature & Strata & Item & Analyst Identification & Count \\
\hline $\mathrm{E} 22 / \mathrm{S} 72$ & $17 \mathrm{~A}$ & & IIIa & 27Q1-2 & Unifacial multiple tool & - \\
\hline E22/S72 & $17 \mathrm{~B}$ & & IIIa & 27Q2-1 & Biface fragment & 2 \\
\hline $\mathrm{E} 22 / \mathrm{S} 72$ & $17 \mathrm{~B}$ & & IIIa & $27 Q 2-4$ & Biface Stage 2 & 2 \\
\hline $\mathrm{E} 22 / \mathrm{S} 72$ & $17 \mathrm{~B}$ & & IIIa & & Debitage & 209 \\
\hline $\mathrm{E} 22 / \mathrm{S} 72$ & $17 \mathrm{~B}$ & & IIIa & 27Q2-5 & Edge modified flake & \\
\hline $\mathrm{E} 22 / \mathrm{S} 72$ & $17 \mathrm{~B}$ & & IIIa & $27 Q 2-3$ & Unifacial multiple tool & 1 \\
\hline $\mathrm{E} 22 / \mathrm{S} 72$ & $18 \mathrm{~A}$ & & IIIa & $27 R 1-3$ & Biface fragment & \\
\hline $\mathrm{E} 22 / \mathrm{S} 72$ & $18 \mathrm{~A}$ & & IIIa & $27 \mathrm{R} 1-7$ & Biface fragment & \\
\hline $\mathrm{E} 22 / \mathrm{S} 72$ & $18 \mathrm{~A}$ & & IIIa & $27 R 1-4$ & Biface Stage 2 & \\
\hline $\mathrm{E} 22 / \mathrm{S} 72$ & $18 \mathrm{~A}$ & & IIIa & $27 R 1-5$ & Biface Stage 2 & \\
\hline E22/S72 & $18 \mathrm{~A}$ & & IIIa & 27R1-2 & Burin spall & 1 \\
\hline $\mathrm{E} 22 / \mathrm{S} 72$ & $18 \mathrm{~A}$ & & IIIa & $27 R 1-6$ & Burin spall & \\
\hline $\mathrm{E} 22 / \mathrm{S} 72$ & $18 \mathrm{~A}$ & & IIIa & & Debitage & 440 \\
\hline $\mathrm{E} 22 / \mathrm{S} 72$ & $18 \mathrm{~A}$ & & IIIa & 27R1-1 & Projectile point, Hoxie A & \\
\hline $\mathrm{E} 22 / \mathrm{S} 72$ & $18 \mathrm{~B}$ & & IIIa & 27R2-2 & Biface fragment & \\
\hline $\mathrm{E} 22 / \mathrm{S} 72$ & $18 \mathrm{~B}$ & & IIIa & $27 R 2-4$ & Biface Stage 1 & \\
\hline $\mathrm{E} 22 / \mathrm{S} 72$ & $18 \mathrm{~B}$ & & IIIa & 27R2-1 & Bifacial tool & \\
\hline $\mathrm{E} 22 / \mathrm{S} 72$ & $18 \mathrm{~B}$ & & IIIa & & Debitage & 579 \\
\hline $\mathrm{E} 22 / \mathrm{S} 72$ & $18 \mathrm{~B}$ & & IIIa & $27 \mathrm{R} 2-3$ & Projectile point fragment & צ \\
\hline $\mathrm{E} 22 / \mathrm{S} 72$ & $18 \mathrm{~B}$ & & IIIa & $27 \mathrm{R} 2-5$ & Worked hematite & 1 \\
\hline $\mathrm{E} 22 / \mathrm{S} 72$ & $18 \mathrm{~B}$ & & IIIa & 27R2-7 & Worked hematite & \\
\hline $\mathrm{E} 22 / \mathrm{S} 72$ & $18 \mathrm{~B}$ & & IIIa & $27 R 2-6$ & Worked hematite & \\
\hline $\mathrm{E} 22 / \mathrm{S} 72$ & $19 \mathrm{~A}$ & & IIIa & $27 \mathrm{~S} 1-4$ & Biface Stage 1 & \\
\hline $\mathrm{E} 22 / \mathrm{S} 72$ & $19 \mathrm{~A}$ & & IIIa & $27 \mathrm{~S} 1-3$ & Biface Stage 2 & 1 \\
\hline $\mathrm{E} 22 / \mathrm{S} 72$ & $19 \mathrm{~A}$ & & IIIa & $27 \mathrm{~S} 1-2$ & Biface Stage 2 & \\
\hline $\mathrm{E} 22 / \mathrm{S} 72$ & $19 \mathrm{~A}$ & & IIIa & $27 \mathrm{~S} 1-1$ & Biface Stage 2 & \\
\hline $\mathrm{E} 22 / \mathrm{S} 72$ & $19 \mathrm{~A}$ & & IIIa & $27 S 1-5$ & Core, thermal & \\
\hline $\mathrm{E} 22 / \mathrm{S} 72$ & $19 \mathrm{~A}$ & & IIIa & & Debitage & 587 \\
\hline $\mathrm{E} 22 / \mathrm{S} 72$ & $19 \mathrm{~A}$ & & IIIa & $27 S 1-6$ & Denticulated flake & \\
\hline $\mathrm{E} 22 / \mathrm{S} 72$ & $19 \mathrm{~A}$ & & IIIa & $27 \mathrm{~S} 1-10$ & Edge modified flake & \\
\hline $\mathrm{E} 22 / \mathrm{S} 72$ & $19 \mathrm{~A}$ & & IIIa & $27 \mathrm{~S} 1-13$ & Edge modified flake & \\
\hline $\mathrm{E} 22 / \mathrm{S} 72$ & $19 \mathrm{~A}$ & & IIIIa & $27 \mathrm{~S} 1-12$ & Edge modified flake & \\
\hline E22/S72 & $19 \mathrm{~A}$ & & IIIa & 27S1-8 & Notched flake & 1 \\
\hline $\mathrm{E} 22 / \mathrm{S} 72$ & $19 \mathrm{~A}$ & & IIIa & $27 \mathrm{~S} 1-9$ & Notched flake & 1 \\
\hline $\mathrm{E} 22 / \mathrm{S} 72$ & $19 \mathrm{~A}$ & Feature 139 & IIIa & $27 \mathrm{~S} 1-7$ & Biface Stage 3 & \\
\hline $\mathrm{E} 22 / \mathrm{S} 72$ & $19 \mathrm{~B}$ & & IIIa & $27 S 2 B-4$ & Biface Stage 2 & \\
\hline $\mathrm{E} 22 / \mathrm{S} 72$ & $19 \mathrm{~B}$ & & IIIa & $27 S 2-2$ & Biface Stage 3 & \\
\hline E22/S72 & $19 \mathrm{~B}$ & & IIIa & & Debitage & 360 \\
\hline $\mathrm{E} 22 / \mathrm{S} 72$ & $19 B$ & & IIIa & 27S2-1 & Thin uniface & \\
\hline $\mathrm{E} 22 / \mathrm{S} 72$ & $19 B$ & & IIIIa & $27 \mathrm{~S} 2 \mathrm{C}-5$ & Uniface, unanalyzed & \\
\hline E22/S72 & $20 \mathrm{~A}$ & & II/IIIa & $27 \mathrm{~T} 1-1$ & Biface Stage 2 & \\
\hline $\mathrm{E} 22 / \mathrm{S} 72$ & $20 \mathrm{~A}$ & & II/IIIa & $27 \mathrm{~T} 1 \mathrm{~A}-8$ & Bifacial tool & 1 \\
\hline $\mathrm{E} 22 / \mathrm{S} 72$ & $20 \mathrm{~A}$ & & II/IIIa & 27T1D-13 & Chert cobble, chunk & 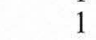 \\
\hline $\mathrm{E} 22 / \mathrm{S} 72$ & $20 \mathrm{~A}$ & & II/IIIa & $27 \mathrm{~T} 1-2$ & Core fragment & \\
\hline $\mathrm{E} 22 / \mathrm{S} 72$ & $20 \mathrm{~A}$ & & II/IIIa & & Debitage & 349 \\
\hline $\mathrm{E} 22 / \mathrm{S} 72$ & $20 \mathrm{~A}$ & & II/IIIa & $27 \mathrm{~T} 1-5$ & Edge modified flake & \\
\hline $\mathrm{E} 22 / \mathrm{S} 72$ & $20 \mathrm{~A}$ & & II/IIIa & $27 \mathrm{~T} 1-4$ & Edge modified flake & 1 \\
\hline $\mathrm{E} 22 / \mathrm{S} 72$ & $20 \mathrm{~A}$ & & II/IIIa & $27 \mathrm{~T} 1 \mathrm{~B}-9$ & Edge modified flake & $x$ \\
\hline $\mathrm{E} 22 / \mathrm{S} 72$ & $20 \mathrm{~A}$ & & II/IIIa & 27T1B-10 & Edge modified flake & \\
\hline E22/S72 & $20 \mathrm{~A}$ & & II/IIIa & $27 \mathrm{~T} 1-3$ & Micro-core, small & \\
\hline E22/S72 & $20 \mathrm{~A}$ & & II/IIIa & $27 \mathrm{~T} 1-6$ & Microspur/microdenticulate & 1 \\
\hline E22/S72 & $20 \mathrm{~A}$ & & II/IIIa & 27T1B-11 & Thin uniface fragment & 1 \\
\hline $\mathrm{E} 22 / \mathrm{S} 72$ & $20 \mathrm{~A}$ & & II/IIIa & 27T1D-12 & Thin uniface fragment & 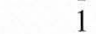 \\
\hline $\mathrm{E} 22 / \mathrm{S} 72$ & $20 \mathrm{~B}$ & & II/IIIIa & $27 \mathrm{~T} 2 \mathrm{D}-7$ & Bifacial tool Form B & \\
\hline $\mathrm{E} 22 / \mathrm{S} 72$ & $20 \mathrm{~B}$ & & II/IIIa & $27 \mathrm{~T} 2 \mathrm{C}-3$ & Core, thermal & \\
\hline $\mathrm{E} 22 / \mathrm{S} 72$ & $20 \mathrm{~B}$ & & II/IIIa & & Debitage & 281 \\
\hline $\mathrm{E} 22 / \mathrm{S} 72$ & $20 \mathrm{~B}$ & & II/IIIa & $27 \mathrm{~T} 2 \mathrm{D}-5$ & Edge modified flake & \\
\hline $\mathrm{E} 22 / \mathrm{S} 72$ & $20 \mathrm{~B}$ & & II/IIIa & $27 \mathrm{~T} 2 \mathrm{~B}-1$ & Microspur/microdenticulate & \\
\hline $\mathrm{E} 22 / \mathrm{S} 72$ & $20 \mathrm{~B}$ & & II/IIIa & $27 \mathrm{~T} 2 \mathrm{~B}-2$ & Unifacial multiple tool & \\
\hline $\mathrm{E} 22 / \mathrm{S} 72$ & $21 \mathrm{~A}$ & & II/IIIa & & Debitage & 219 \\
\hline E22/S72 & $21 \mathrm{~A}$ & & II/IIIa & 27U1B-2 & Edge modified flake & \\
\hline $\mathrm{E} 22 / \mathrm{S} 72$ & $21 \mathrm{~A}$ & Feature 153 & II/IIIa & $27 \mathrm{U} 1-1$ & Mano fragment & 1 \\
\hline $\mathrm{E} 22 / \mathrm{S} 72$ & $21 \mathrm{~B}$ & & II & $27 \mathrm{U} 2 \mathrm{~B}-1$ & Burin spall & \\
\hline $\mathrm{E} 22 / \mathrm{S} 72$ & $21 \mathrm{~B}$ & & II & & Debitage & 190 \\
\hline $\mathrm{E} 22 / \mathrm{S} 72$ & $22 \mathrm{~A}$ & & II & & Debitage & 173 \\
\hline $\mathrm{E} 22 / \mathrm{S} 72$ & $22 \mathrm{~A}$ & & II & $27 \mathrm{~V} 1 \mathrm{C}-7$ & Edge modified flake & \\
\hline $\mathrm{E} 22 / \mathrm{S} 72$ & $22 \mathrm{~A}$ & & II & $27 \mathrm{~V} 1 \mathrm{~B}-3$ & Edge modified flake & \\
\hline $\mathrm{E} 22 / \mathrm{S} 72$ & $22 \mathrm{~A}$ & & II & $27 \mathrm{~V} 1 \mathrm{~A}-1$ & Thick uniface & \\
\hline $\mathrm{E} 22 / \mathrm{S} 72$ & $22 B$ & & II & & Debitage & 133 \\
\hline $\mathrm{E} 22 / \mathrm{S} 72$ & $22 \mathrm{~B}$ & & II & 27V2B-1 & Uniface, unanalyzed & \\
\hline $\mathrm{E} 22 / \mathrm{S} 72$ & $22 \mathrm{~B}$ & Feature 158 & II & $27 \mathrm{~V} 2 \mathrm{C}-2$ & Thin uniface & 1 \\
\hline E22/S72 & $23 \mathrm{~A}$ & & II & & Debitage & 76 \\
\hline $\mathrm{E} 22 / \mathrm{S} 72$ & $23 \mathrm{~A}$ & & II & 27W1D-4 & Edge modified flake & \\
\hline $\mathrm{E} 22 / \mathrm{S} 72$ & $23 \mathrm{~B}$ & & II & $27 \mathrm{~W} 2 \mathrm{~B}-1$ & Burin spall & \\
\hline
\end{tabular}




\begin{tabular}{|c|c|c|c|c|c|c|}
\hline Square & Level & Feature & Strata & Item & Analyst Identification & $\begin{array}{r}\text { Count } \\
76\end{array}$ \\
\hline $\mathrm{E} 22 / \mathrm{S} 72$ & $23 \mathrm{~B}$ & & II & & Debitage & $\begin{array}{r}76 \\
1\end{array}$ \\
\hline E22/S72 & $23 \mathrm{~B}$ & & II & $27 \mathrm{~W} 2 \mathrm{~B}-3$ & Thin uniface & 1 \\
\hline $\mathrm{E} 22 / \mathrm{S} 72$ & $24 \mathrm{~A}$ & & II & $27 X 1 A-1$ & Burin spall & 1 \\
\hline $\mathrm{E} 22 / \mathrm{S} 72$ & $24 \mathrm{~A}$ & & II & & Debitage & 101 \\
\hline E22/S72 & $24 \mathrm{~A}$ & & II & $27 \times 1 D-4$ & Edge modified flake & 1 \\
\hline E22/S72 & $24 B$ & & II & $27 \times 2 C-3$ & Biface fragment & 1 \\
\hline E22/S72 & $24 B$ & & II & $27 \mathrm{X} 2 \mathrm{~B}-2$ & Biface fragment & 1 \\
\hline E22/S72 & $24 B$ & & II & & Debitage & 110 \\
\hline E22/S72 & $24 \mathrm{~B}$ & & II & $27 \mathrm{X} 2 \mathrm{~A}-1$ & Edge modified flake & 1 \\
\hline E22/S72 & $25 \mathrm{~A}$ & & II & $27 \mathrm{Y} 1 \mathrm{~A}-3$ & Biface Stage 2 & 1 \\
\hline $\mathrm{E} 22 / \mathrm{S} 72$ & $25 \mathrm{~A}$ & & II & & Debitage & 87 \\
\hline $\mathrm{E} 22 / \mathrm{S} 72$ & $25 \mathrm{~A}$ & & II & $27 Y 1 B-4$ & Edge modified flake & 1 \\
\hline $\mathrm{E} 22 / \mathrm{S} 72$ & $25 \mathrm{~B}$ & & II & & Debitage & 50 \\
\hline $\mathrm{E} 22 / \mathrm{S} 72$ & $26 \mathrm{~A}$ & & II & & Debitage & 32 \\
\hline E22/S72 & $26 \mathrm{~A}$ & & II & 27Z1A-1 & Edge modified flake & 1 \\
\hline $\mathrm{E} 22 / \mathrm{S} 72$ & $26 \mathrm{~B}$ & & II & & Debitage & 23 \\
\hline $\mathrm{E} 22 / \mathrm{S} 72$ & $27 \mathrm{~A}$ & & II & & Debitage & 43 \\
\hline $\mathrm{E} 22 / \mathrm{S} 72$ & $27 \mathrm{~B}$ & & II & & Debitage & 33 \\
\hline $\mathrm{E} 22 / \mathrm{S} 72$ & $27 \mathrm{~B}$ & & II & 27AA2B-1 & Edge modified flake & 1 \\
\hline E22/S72 & $28 \mathrm{~A}$ & & Isi-c/II & & Debitage & 46 \\
\hline $\mathrm{E} 22 / \mathrm{S} 72$ & $28 \mathrm{~B}$ & & Isi-c & & Debitage & 37 \\
\hline $\mathrm{E} 22 / \mathrm{S} 72$ & $29 \mathrm{~A}$ & & Isi-c & & Debitage & 41 \\
\hline E22/S72 & $29 B$ & & Isi-c & & Debitage & 34 \\
\hline $\mathrm{E} 22 / \mathrm{S} 72$ & $30 \mathrm{~A}$ & & Isi-c & & Debitage & 30 \\
\hline E22/S72 & $30 \mathrm{~B}$ & & Isi-c & & Debitage & 18 \\
\hline $\mathrm{E} 22 / \mathrm{S} 72$ & $31 \mathrm{~A}$ & & Isi-c & & Debitage & 16 \\
\hline $\mathrm{E} 22 / \mathrm{S} 72$ & $31 \mathrm{~B}$ & & Icl/Isi-c & & Debitage & 16 \\
\hline E22/S72 & $32 \mathrm{~A}$ & & Icl/Isi-c & & Debitage & 11 \\
\hline $\mathrm{E} 22 / \mathrm{S} 72$ & $32 \mathrm{~B}$ & & Icl/Isi-c & & Debitage & 0 \\
\hline $\mathrm{E} 22 / \mathrm{S} 72$ & $33 \mathrm{~A}$ & & Icl/Isi-c & & Debitage & 10 \\
\hline $\mathrm{E} 22 / \mathrm{S} 72$ & $33 \mathrm{~A}$ & & $\mathrm{Icl} / \mathrm{Isi}-\mathrm{c}$ & 27GG1C-1 & Unifacial multiple tool & 1 \\
\hline $\mathrm{E} 22 / \mathrm{S} 72$ & $33 \mathrm{~B}$ & & Icl & & Debitage & 18 \\
\hline E22/S72 & $33 \mathrm{~B}$ & & Icl & $27 \mathrm{GG} 2 \mathrm{~A}-1$ & Thin uniface & \\
\hline $\mathrm{E} 22 / \mathrm{S} 72$ & $34 \mathrm{~A}$ & & Icl & & Debitage & 31 \\
\hline $\mathrm{E} 22 / \mathrm{S} 72$ & $34 \mathrm{~A}$ & & Icl & 27HH1B-1 & Thin uniface & 2 \\
\hline $\mathrm{E} 22 / \mathrm{S} 72$ & $34 \mathrm{~B}$ & & Icl & & Debitage & 10 \\
\hline $\mathrm{E} 22 / \mathrm{S} 72$ & $35 \mathrm{~A}$ & & Isi/Icl & & Debitage & 20 \\
\hline $\mathrm{E} 22 / \mathrm{S} 72$ & $35 \mathrm{~A}$ & & Isi/Icl & 27IIID-1 & Face battered stone & 1 \\
\hline $\mathrm{E} 22 / \mathrm{S} 72$ & $35 \mathrm{~B}$ & & Isi/Icl & & Debitage & 13 \\
\hline E22/S72 & $35 \mathrm{~B}$ & & Isi/Icl & 27II2B-1 & Unifacial multiple tool & 1 \\
\hline E22/S72 & $36 \mathrm{~A}$ & & Isi/Icl & & Debitage & 13 \\
\hline $\mathrm{E} 22 / \mathrm{S} 72$ & $36 \mathrm{~B}$ & & Isi/Icl & & Debitage & 9 \\
\hline $\mathrm{E} 22 / \mathrm{S} 72$ & $37 \mathrm{~A}$ & & Isi & & Debitage & 18 \\
\hline $\mathrm{E} 22 / \mathrm{S} 72$ & 37B & & Igl/Isi & & Debitage & 13 \\
\hline $\mathrm{E} 22 / \mathrm{S} 72$ & $38 \mathrm{~A}$ & & $\mathrm{Igl} / \mathrm{Isi}$ & & Debitage & 16 \\
\hline $\mathrm{E} 22 / \mathrm{S} 72$ & $38 \mathrm{~B}$ & & $\mathrm{Igl} / \mathrm{Isi}$ & & Debitage & 7 \\
\hline $\mathrm{E} 22 / \mathrm{S} 72$ & $39 \mathrm{~A}$ & & $\mathrm{Igl} / \mathrm{Isi}$ & & Debitage & 4 \\
\hline $\mathrm{E} 22 / \mathrm{S} 72$ & $39 \mathrm{~A}$ & & $\mathrm{Igl} / \mathrm{Isi}$ & 27MM1A-1 & Edge modified flake & 1 \\
\hline E22/S74 & 15 & & IIIa/b & $26 \mathrm{O}-3$ & Burin spall & 1 \\
\hline E22/S74 & 15 & & $\mathrm{IIIa} / \mathrm{b}$ & $260-5$ & Burin spall & 1 \\
\hline E22/S74 & 15 & & $\mathrm{IIIa} / \mathrm{b}$ & $260-4$ & Burin spall & 1 \\
\hline E22/S74 & 15 & & $\mathrm{IIIa} / \mathrm{b}$ & & Debitage & 656 \\
\hline E22/S74 & 15 & & $\mathrm{IIIa} / \mathrm{b}$ & $260-13$ & Edge modified flake & 1 \\
\hline E22/S74 & 15 & & $\mathrm{IIIa} / \mathrm{b}$ & $260-14$ & Edge modified flake & 1 \\
\hline E22/S74 & 15 & & $\mathrm{IIIa} / \mathrm{b}$ & $260-16$ & Edge modified flake & 1 \\
\hline E22/S74 & 15 & & $\mathrm{IIIa} / \mathrm{b}$ & $260-9$ & Edge modified flake & 1 \\
\hline E22/S74 & 15 & & IIIa/b & $26 \mathrm{O}-15$ & Edge modified flake & 1 \\
\hline E22/S74 & 15 & & $\mathrm{IIIa} / \mathrm{b}$ & $260-20$ & Notched flake & 1 \\
\hline E22/S74 & 15 & & $\mathrm{III} a / \mathrm{b}$ & $260-6$ & Projectile point fragment & 1 \\
\hline $\mathrm{E} 22 / \mathrm{S} 74$ & 15 & & $\mathrm{IIIa} / \mathrm{b}$ & $260-2$ & Projectile point fragment & 1 \\
\hline $\mathrm{E} 22 / \mathrm{S} 74$ & 15 & & $\mathrm{IIIa} / \mathrm{b}$ & $260-17$ & Thin uniface & 1 \\
\hline E22/S74 & 15 & & IIIa/b & $260-22$ & Thin uniface & 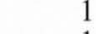 \\
\hline E22/S74 & 15 & & $\mathrm{IIIa} / \mathrm{b}$ & $260-21$ & Thin uniface fragment & 1 \\
\hline E22/S74 & $16 \mathrm{~A}$ & & IIIa & $26 \mathrm{P} 1-3$ & Biface Stage 1 & \\
\hline E22/S74 & $16 \mathrm{~A}$ & & IIIa & $26 \mathrm{P} 1-4$ & Biface Stage 1 & 1 \\
\hline E22/S74 & $16 \mathrm{~A}$ & & IIIa & 26P1-8 & Biface Stage 2 & 1 \\
\hline E22/S74 & $16 \mathrm{~A}$ & & IIIa & $26 \mathrm{P} 1-5$ & Biface Stage 2 & 1 \\
\hline E22/S74 & $16 \mathrm{~A}$ & & IIIa & & Debitage & 446 \\
\hline E22/S74 & $16 \mathrm{~A}$ & & IIIa & $26 \mathrm{P} 1-6$ & Edge modified flake & \\
\hline $\mathrm{E} 22 / \mathrm{S} 74$ & $16 \mathrm{~A}$ & & IIIa & $26 \mathrm{P} 1-1$ & Projectile point, Hoxie A & 1 \\
\hline E22/S74 & $16 \mathrm{~A}$ & & IIIa & $26 \mathrm{P} 1-7$ & Unifacial multiple tool & \\
\hline E22/S74 & $16 \mathrm{~A}$ & Feature 126 & IIIa & $26 \mathrm{P} 1-2$ & Projectile point, St. Mary's Hall & 1 \\
\hline E22/S74 & $16 \mathrm{~B}$ & & IIIa & $26 \mathrm{P} 2-2$ & Biface fragment & 1 \\
\hline E22/S74 & $16 \mathrm{~B}$ & & IIIa & $26 \mathrm{P} 2-4$ & Biface Stage 2 & 1 \\
\hline
\end{tabular}




\begin{tabular}{|c|c|c|c|c|c|c|}
\hline Square & $\begin{array}{l}\text { Level } \\
16 \mathrm{~B}\end{array}$ & Feature & Strata & Item & Analyst Identification & $\begin{array}{r}\text { Count } \\
234\end{array}$ \\
\hline $\mathrm{E} 22 / \mathrm{S} 74$ & $16 \mathrm{~B}$ & & IIIa & $26 \mathrm{P} 2-6$ & Edge modified flake & 1 \\
\hline $\mathrm{E} 22 / \mathrm{S} 74$ & $16 \mathrm{~B}$ & & IIIa & $26 \mathrm{P} 2-1$ & Projectile point, Hoxie/Gower & 1 \\
\hline E22/S74 & $16 \mathrm{~B}$ & & IIIa & $26 \mathrm{P} 2-3$ & Projectile point, miscellaneous lanceolate & 1 \\
\hline $\mathrm{E} 22 / \mathrm{S} 74$ & $16 \mathrm{~B}$ & & IIIa & $26 \mathrm{P} 2-5$ & Unifacial multiple tool & 1 \\
\hline E22/S74 & $16 \mathrm{~B}$ & & IIIa & 26P2-7 & Unifacial multiple tool & 1 \\
\hline $\mathrm{E} 22 / \mathrm{S} 74$ & $16 \mathrm{~B}$ & & IIIIa & $26 \mathrm{P} 2-8$ & Worked hematite & 1 \\
\hline $\mathrm{E} 22 / \mathrm{S} 74$ & $17 \mathrm{~A}$ & & IIIa & 26Q1-2 & Biface Stage 2 & 1 \\
\hline $\mathrm{E} 22 / \mathrm{S} 74$ & $17 \mathrm{~A}$ & & IIIIa & & Debitage & 324 \\
\hline $\mathrm{E} 22 / \mathrm{S} 74$ & $17 \mathrm{~A}$ & & IIIa & 26Q1-4 & Perforator Group 7 & 1 \\
\hline $\mathrm{E} 22 / \mathrm{S} 74$ & $17 \mathrm{~A}$ & & IIIa & $2601-1$ & Projectile point fragment & 1 \\
\hline $\mathrm{E} 22 / \mathrm{S} 74$ & $17 \mathrm{~A}$ & & IIIa & $26 Q 1-3$ & Uniface, unanalyzed & 1 \\
\hline $\mathrm{E} 22 / \mathrm{S} 74$ & $17 \mathrm{~A}$ & & IIIa & $2601-5$ & Unifacial multiple tool & 1 \\
\hline $\mathrm{E} 22 / \mathrm{S} 74$ & $17 \mathrm{~A}$ & & IIIa & $26 Q 1-6$ & Unifacial multiple tool & 1 \\
\hline E22/S74 & $17 \mathrm{~B}$ & & IIIa & 26Q2-2 & Bifacial tool Form E & 1 \\
\hline E22/S74 & $17 \mathrm{~B}$ & & IIIa & 26Q2-1 & Burin spall & 1 \\
\hline E22/S74 & $17 \mathrm{~B}$ & & IIIa & $26 Q 2-4$ & Core fragment & 1 \\
\hline $\mathrm{E} 22 / \mathrm{S} 74$ & $17 \mathrm{~B}$ & & IIIa & & Debitage & 548 \\
\hline $\mathrm{E} 22 / \mathrm{S} 74$ & $18 \mathrm{~A}$ & & IIIIa & $26 \mathrm{RI}-9$ & Biface fragment & 1 \\
\hline $\mathrm{E} 22 / \mathrm{S} 74$ & $18 \mathrm{~A}$ & & IIIa & $26 \mathrm{R} 1-16$ & Biface fragment & 1 \\
\hline E22/S74 & $18 \mathrm{~A}$ & & IIIIa & $26 \mathrm{R} 1-2$ & Biface Stage 2 & 1 \\
\hline $\mathrm{E} 22 / \mathrm{S} 74$ & $18 \mathrm{~A}$ & & IIIa & & Debitage & 429 \\
\hline $\mathrm{E} 22 / \mathrm{S} 74$ & $18 \mathrm{~A}$ & & IIIa & $26 \mathrm{R} 1-10$ & Edge modified flake & 1 \\
\hline $\mathrm{E} 22 / \mathrm{S} 74$ & $18 \mathrm{~A}$ & & IIIa & $26 \mathrm{R} 1-12$ & Edge modified flake & 1 \\
\hline $\mathrm{E} 22 / \mathrm{S} 74$ & $18 \mathrm{~A}$ & & IIIa & $26 \mathrm{R} 1-13$ & Edge modified flake & 1 \\
\hline $\mathrm{E} 22 / \mathrm{S} 74$ & $18 \mathrm{~A}$ & & IIIa & $26 \mathrm{R} 1-17$ & Edge modified flake & 1 \\
\hline $\mathrm{E} 22 / \mathrm{S} 74$ & $18 \mathrm{~A}$ & & IIIa & $26 R 1-6$ & Edge modified flake & 1 \\
\hline $\mathrm{E} 22 / \mathrm{S} 74$ & $18 \mathrm{~A}$ & & IIIIa & $26 \mathrm{R} 1-15$ & Notched flake & 1 \\
\hline $\mathrm{E} 22 / \mathrm{S} 74$ & $18 \mathrm{~A}$ & & IIIa & $26 \mathrm{R} 1-4$ & Perforator Group 1 & 1 \\
\hline $\mathrm{E} 22 / \mathrm{S} 74$ & $18 \mathrm{~A}$ & & IIIa & 26R $1-1$ & Projectile point, Golondrina-Barber & 1 \\
\hline $\mathrm{E} 22 / \mathrm{S} 74$ & $18 \mathrm{~A}$ & & IIIa & $26 \mathrm{R} 1-14$ & Uniface, unanalyzed & 1 \\
\hline $\mathrm{E} 22 / \mathrm{S} 74$ & $18 \mathrm{~A}$ & & IIIIa & $26 \mathrm{R} 1-11$ & Unifacial multiple tool & 1 \\
\hline $\mathrm{E} 22 / \mathrm{S} 74$ & $18 \mathrm{~A}$ & & IIIIa & 26R $1-19$ & Waco sinker & 1 \\
\hline $\mathrm{E} 22 / \mathrm{S} 74$ & $18 \mathrm{~B}$ & & IIIa & & Debitage & 440 \\
\hline E22/S74 & $18 \mathrm{~B}$ & & IIIa & 26R2-1 & Denticulated flake & 1 \\
\hline $\mathrm{E} 22 / \mathrm{S} 74$ & $18 \mathrm{~B}$ & & IIIa & $26 \mathrm{R} 2-2$ & Edge modified flake & 1 \\
\hline $\mathrm{E} 22 / \mathrm{S} 74$ & $19 \mathrm{~A}$ & & II/IIIa & & Debitage & 219 \\
\hline E22/S74 & 19A & & II/IIIa & $26 \mathrm{~S} 1-2$ & Thin uniface & 1 \\
\hline $\mathrm{E} 22 / \mathrm{S} 74$ & $19 \mathrm{~A}$ & & $\mathrm{II} / \mathrm{IIIa}$ & $26 \mathrm{~S} 1-3$ & Worked hematite & 1 \\
\hline $\mathrm{E} 22 / \mathrm{S} 74$ & 19B & & II/IIIa & & Debitage & 269 \\
\hline $\mathrm{E} 22 / \mathrm{S} 74$ & $19 \mathrm{~B}$ & & II/IIIa & $26 \mathrm{~S} 2 \mathrm{C}-6$ & Edge modified flake & 1 \\
\hline E22/S74 & 19B & & II/IIIa & $26 \mathrm{~S} 2 \mathrm{C}-5$ & Edge modified flake & 1 \\
\hline $\mathrm{E} 22 / \mathrm{S} 74$ & $19 \mathrm{~B}$ & & II/IIIa & 26S2D-10 & Edge modified flake & 1 \\
\hline $\mathrm{E} 22 / \mathrm{S} 74$ & 19B & & II/IIIa & $26 \mathrm{~S} 2 \mathrm{D}-9$ & Edge modified flake & 1 \\
\hline $\mathrm{E} 22 / \mathrm{S} 74$ & 19B & & II/IIIa & $26 \mathrm{~S} 2 \mathrm{~A}-4$ & Notched flake & 1 \\
\hline $\mathrm{E} 22 / \mathrm{S} 74$ & $19 \mathrm{~B}$ & & II/IIIa & $26 \mathrm{~S} 2-2$ & Projectile point, miscellaneous lanceolate & 1 \\
\hline $\mathrm{E} 22 / \mathrm{S} 74$ & 19B & & II/IIIa & $26 \mathrm{~S} 2 \mathrm{C}-8$ & Unifacial multiple tool & 1 \\
\hline $\mathrm{E} 22 / \mathrm{S} 74$ & $19 \mathrm{~B}$ & Feature 139 & II/IIIa & $26 \mathrm{~S} 2-1$ & Biface Stage 2 & 1 \\
\hline $\mathrm{E} 22 / \mathrm{S} 74$ & $20 \mathrm{~A}$ & & II/IIIa & 26T1-1 & Biface Stage 2 & 1 \\
\hline $\mathrm{E} 22 / \mathrm{S} 74$ & $20 \mathrm{~A}$ & & II/IIIa & & Debitage & 202 \\
\hline $\mathrm{E} 22 / \mathrm{S} 74$ & $20 \mathrm{~A}$ & & II/IIIa & 26T1D-4 & Edge modified flake & 1 \\
\hline E22/S74 & $20 \mathrm{~A}$ & & II/IIIa & $26 \mathrm{~T} 1 \mathrm{~B}-2$ & Edge modified flake & 1 \\
\hline $\mathrm{E} 22 / \mathrm{S} 74$ & $20 \mathrm{~A}$ & & II/IIIa & 26T1D-3 & Notched flake & 1 \\
\hline $\mathrm{E} 22 / \mathrm{S} 74$ & $20 \mathrm{~B}$ & & II & 26T2D-5 & Biface fragment & 1 \\
\hline $\mathrm{E} 22 / \mathrm{S} 74$ & $20 \mathrm{~B}$ & & II & & Debitage & 172 \\
\hline $\mathrm{E} 22 / \mathrm{S} 74$ & $20 \mathrm{~B}$ & & II & $26 \mathrm{~T} 2 \mathrm{~B}-4$ & Edge modified flake & 1 \\
\hline $\mathrm{E} 22 / \mathrm{S} 74$ & $20 \mathrm{~B}$ & & II & $26 \mathrm{~T} 2 \mathrm{~B}-3$ & Edge modified flake & 1 \\
\hline $\mathrm{E} 22 / \mathrm{S} 74$ & $20 \mathrm{~B}$ & & II & 26T2D-7 & Thick uniface & 1 \\
\hline $\mathrm{E} 22 / \mathrm{S} 74$ & $20 \mathrm{~B}$ & & II & 26T2B-2 & Unifacial multiple tool & 1 \\
\hline $\mathrm{E} 22 / \mathrm{S} 74$ & $20 \mathrm{~B}$ & & II & $26 \mathrm{~T} 2 \mathrm{C}-6$ & Unifacial multiple tool & 1 \\
\hline $\mathrm{E} 22 / \mathrm{S} 74$ & $21 \mathrm{~A}$ & & II & & Debitage & 141 \\
\hline $\mathrm{E} 22 / \mathrm{S} 74$ & $21 \mathrm{~A}$ & & II & 26U1A-1 & Edge modified flake & 1 \\
\hline $\mathrm{E} 22 / \mathrm{S} 74$ & $21 \mathrm{~A}$ & & II & $26 \mathrm{U} 1 \mathrm{~B}-3$ & Perforator Group 4 & 1 \\
\hline $\mathrm{E} 22 / \mathrm{S} 74$ & 21B & & II & $26 \mathrm{U} 2 \mathrm{C}-4$ & Biface Stage 2 & 1 \\
\hline $\mathrm{E} 22 / \mathrm{S} 74$ & $21 \mathrm{~B}$ & & II & $26 \mathrm{U} 2-1$ & Biface Stage 3 & 1 \\
\hline E22/S74 & $21 \mathrm{~B}$ & & II & & Debitage & 148 \\
\hline $\mathrm{E} 22 / \mathrm{S} 74$ & $21 \mathrm{~B}$ & & II & $26 \mathrm{U} 2-2$ & Projectile point, miscellaneous lanceolate & 1 \\
\hline $\mathrm{E} 22 / \mathrm{S} 74$ & $21 \mathrm{~B}$ & & II & $26 \mathrm{U} 2 \mathrm{D}-5$ & Thin uniface fragment & 1 \\
\hline $\mathrm{E} 22 / \mathrm{S} 74$ & $22 \mathrm{~A}$ & & II & & Debitage & 118 \\
\hline $\mathrm{E} 22 / \mathrm{S} 74$ & $22 \mathrm{~A}$ & & II & 26V1C-1 & Edge modified flake & 1 \\
\hline E22/S74 & $22 \mathrm{~B}$ & & II & $26 \mathrm{~V} 2 \mathrm{C}-4$ & Biface Stage 3 & 1 \\
\hline $\mathrm{E} 22 / \mathrm{S} 74$ & $22 \mathrm{~B}$ & & II & & Debitage & 97 \\
\hline $\mathrm{E} 22 / \mathrm{S} 74$ & $22 \mathrm{~B}$ & & II & $26 \mathrm{~V} 2 \mathrm{~A}-1$ & Edge modified flake & 1 \\
\hline $\mathrm{E} 22 / \mathrm{S} 74$ & $22 \mathrm{~B}$ & & II & $26 \mathrm{~V} 2 \mathrm{~B}-2$ & Projectile point, Scottsbluff & 1 \\
\hline
\end{tabular}




\begin{tabular}{|c|c|c|c|c|c|c|}
\hline Square & Level & Feature & Strata & Item & Analyst Identification & Count \\
\hline $\mathrm{E} 22 / \mathrm{S} 74$ & $22 \mathrm{~B}$ & & II & $26 \mathrm{~V} 2 \mathrm{C}-3$ & Thin uniface fragment & 1 \\
\hline $\mathrm{E} 22 / \mathrm{S} 74$ & $22 \mathrm{~B}$ & & II & $26 \mathrm{~V} 2 \mathrm{D}-5$ & Unifacial multiple tool & 1 \\
\hline $\mathrm{E} 22 / \mathrm{S} 74$ & $23 \mathrm{~A}$ & & II & & Debitage & 41 \\
\hline E22/S74 & $23 \mathrm{~B}$ & & II & & Debitage & 91 \\
\hline $\mathrm{E} 22 / \mathrm{S} 74$ & $23 \mathrm{~B}$ & & II & 26W2A-1 & Projectile point, expanding concave A & 1 \\
\hline $\mathrm{E} 22 / \mathrm{S} 74$ & $23 \mathrm{~B}$ & & II & $26 \mathrm{~W} 2 \mathrm{C}-3$ & Thin uniface fragment & 1 \\
\hline $\mathrm{E} 22 / \mathrm{S} 74$ & $23 \mathrm{~B}$ & & II & $26 \mathrm{~W} 2 \mathrm{~A}-2$ & Thin uniface fragment & 1 \\
\hline $\mathrm{E} 22 / \mathrm{S} 74$ & $24 \mathrm{~A}$ & & II & & Debitage & 90 \\
\hline $\mathrm{E} 22 / \mathrm{S} 74$ & $24 \mathrm{~A}$ & & II & $26 \times 1 B-1$ & Thick uniface & 1 \\
\hline $\mathrm{E} 22 / \mathrm{S} 74$ & $24 \mathrm{~B}$ & & II & & Debitage & 108 \\
\hline $\mathrm{E} 22 / \mathrm{S} 74$ & $24 \mathrm{~B}$ & & II & $26 \times 2 A-1$ & Projectile point, parallel side & \\
\hline $\mathrm{E} 22 / \mathrm{S} 74$ & 24B & & II & $26 \times 2 D-3$ & Thin uniface & 1 \\
\hline E22/S74 & $25 \mathrm{~A}$ & & II & & Debitage & 86 \\
\hline E22/S74 & $25 \mathrm{~A}$ & & II & $26 Y 1 C-2$ & Perforator Group 1 & 1 \\
\hline $\mathrm{E} 22 / \mathrm{S} 74$ & $25 \mathrm{~A}$ & & II & $26 Y 1 C-1$ & Thin uniface & 1 \\
\hline $\mathrm{E} 22 / \mathrm{S} 74$ & $25 \mathrm{~B}$ & & $\mathrm{Id} / \mathrm{II}$ & & Debitage & 45 \\
\hline E22/S74 & $25 \mathrm{~B}$ & & Id/II & $26 \mathrm{Y} 2 \mathrm{~A}-2$ & Edge modified flake & 1 \\
\hline $\mathrm{E} 22 / \mathrm{S} 74$ & $25 \mathrm{~B}$ & & $\mathrm{Id} / \mathrm{II}$ & $26 Y 2 C-1$ & Projectile point, Golondrina-Barber & \\
\hline E22/S74 & $25 \mathrm{~B}$ & & $\mathrm{Id} / \mathrm{II}$ & $26 Y 2 C-3$ & Projectile point, Midland & \\
\hline E22/S74 & $26 \mathrm{~A}$ & & $\mathrm{Id} / \mathrm{II}$ & & Debitage & 34 \\
\hline $\mathrm{E} 22 / \mathrm{S} 74$ & $26 \mathrm{~A}$ & & $\mathrm{Id} / \mathrm{II}$ & 26Z1B-1 & Thin uniface fragment & 1 \\
\hline $\mathrm{E} 22 / \mathrm{S} 74$ & 26B & & Isi-c/Id/II & $26 \mathrm{Z} 2 \mathrm{C}-1$ & Biface Stage 2 & 1 \\
\hline $\mathrm{E} 22 / \mathrm{S} 74$ & $26 \mathrm{~B}$ & & Isi-c/Id/II & & Debitage & 34 \\
\hline E22/S74 & $27 \mathrm{~A}$ & & Isi-c/II & & Debitage & 49 \\
\hline E22/S74 & $27 \mathrm{~A}$ & & Isi-c/II & 26AA1C-2 & Projectile point, miscellaneous lanceolate & 1 \\
\hline E22/S74 & $27 \mathrm{~A}$ & & Isi-c/II & 26AA1B-1 & Thin uniface & 1 \\
\hline E22/S74 & $27 \mathrm{~B}$ & & Isi-c/II & 26AA2B-1 & Biface Stage 2 & \\
\hline $\mathrm{E} 22 / \mathrm{S} 74$ & $27 \mathrm{~B}$ & & Isi-c/II & & Debitage & 31 \\
\hline E22/S74 & $28 \mathrm{~A}$ & & Isi-c & & Debitage & 27 \\
\hline E22/S74 & $28 \mathrm{~A}$ & & Isi-c & 26BB1A-1 & Edge modified flake & 1 \\
\hline E22/S74 & $28 \mathrm{~B}$ & & Isi-c & 26BB2B-1 & Biface Stage 2 & \\
\hline E22/S74 & $28 \mathrm{~B}$ & & Isi-c & & Debitage & 31 \\
\hline E22/S74 & $29 \mathrm{~A}$ & & Isi-c & & Debitage & 37 \\
\hline $\mathrm{E} 22 / \mathrm{S} 74$ & $29 B$ & & Isi-c & $26 \mathrm{CC} 2 \mathrm{D}-2$ & Biface Stage 2 & 1 \\
\hline $\mathrm{E} 22 / \mathrm{S} 74$ & $29 B$ & & Isi-c & & Debitage & 45 \\
\hline E22/S74 & $29 B$ & & Isi-c & $26 \mathrm{CC} 2 \mathrm{C}-1$ & Thin uniface & 1 \\
\hline $\mathrm{E} 22 / \mathrm{S} 74$ & $30 \mathrm{~A}$ & & Isi-c & & Debitage & 27 \\
\hline E22/S74 & $30 \mathrm{~B}$ & & Isi-c & & Debitage & 27 \\
\hline E22/S74 & $31 \mathrm{~A}$ & & Icl/Isi-c & & Debitage & 27 \\
\hline E22/S74 & $31 \mathrm{~B}$ & & Icl/Isi-c & & Debitage & 17 \\
\hline $\mathrm{E} 22 / \mathrm{S} 74$ & $32 \mathrm{~A}$ & & Icl/Isi-c & & Debitage & 18 \\
\hline E22/S74 & $32 \mathrm{~B}$ & & Icl/Isi-c & & Debitage & 15 \\
\hline E22/S74 & $33 \mathrm{~A}$ & & Isi/Icl & & Debitage & 19 \\
\hline $\mathrm{E} 22 / \mathrm{S} 74$ & $33 \mathrm{~B}$ & & Isi/Icl & & Debitage & 7 \\
\hline $\mathrm{E} 22 / \mathrm{S} 74$ & $33 \mathrm{~B}$ & & Isi/Icl & 26GG2D-1 & Edge modified flake & 1 \\
\hline E22/S74 & $34 \mathrm{~A}$ & & $\mathrm{Isi} / \mathrm{Icl}$ & & Debitage & 29 \\
\hline $\mathrm{E} 22 / \mathrm{S} 74$ & $34 \mathrm{~B}$ & & Isi/Icl & $26 \mathrm{HH} 2 \mathrm{C}-1$ & Biface Stage 2 & 1 \\
\hline $\mathrm{E} 22 / \mathrm{S} 74$ & $34 \mathrm{~B}$ & & Isi/Icl & & Debitage & 21 \\
\hline E22/S74 & $35 \mathrm{~A}$ & & Isi/Icl & & Debitage & 11 \\
\hline $\mathrm{E} 22 / \mathrm{S} 74$ & $35 \mathrm{~B}$ & & $\mathrm{Isi} / \mathrm{Icl}$ & & Debitage & 10 \\
\hline $\mathrm{E} 22 / \mathrm{S} 74$ & $36 \mathrm{~A}$ & & Isi/Icl & & Debitage & 10 \\
\hline E22/S74 & $36 \mathrm{~B}$ & & $\mathrm{Igl} / \mathrm{Isi}$ & & Debitage & 24 \\
\hline E22/S74 & $36 \mathrm{~B}$ & & Igl/Isi & 26JJ2D-1 & Edge modified flake & 1 \\
\hline E22/S74 & $36 \mathrm{~B}$ & & $\mathrm{Igl} / \mathrm{Isi}$ & 26JJ2D-2 & Edge modified flake & 1 \\
\hline E22/S74 & $37 \mathrm{~A}$ & & $\mathrm{Igl} / \mathrm{Isi}$ & & Debitage & 10 \\
\hline E22/S74 & $37 \mathrm{~B}$ & & $\mathrm{Igl} / \mathrm{Isi}$ & & Debitage & 17 \\
\hline E22/S74 & $37 \mathrm{~B}$ & & $\mathrm{Igl} / \mathrm{Isi}$ & $26 \mathrm{KK} 2 \mathrm{~A}-1$ & Thin uniface & 1 \\
\hline E22/S74 & $38 \mathrm{~A}$ & & Igl/Isi & & Debitage & 13 \\
\hline $\mathrm{E} 22 / \mathrm{S} 74$ & $38 \mathrm{~A}$ & & $\mathrm{Igl} / \mathrm{Isi}$ & 26LL1C-2 & Edge modified flake & 1 \\
\hline E22/S74 & $38 \mathrm{~B}$ & & $\mathrm{Igl} / \mathrm{Isi}$ & & Debitage & 4 \\
\hline E22/S76 & $2 ?$ & & Unknown & $25 \mathrm{~B}-8$ & Biface fragment, unanalyzed & 1 \\
\hline E22/S76 & 15 & & IIIa/b & $250-2$ & Biface Stage 2 & 1 \\
\hline $\mathrm{E} 22 / \mathrm{S} 76$ & 15 & & $\mathrm{IIIa} / \mathrm{b}$ & & Debitage & 108 \\
\hline E22/S76 & 15 & & IIIa/b & $250-3$ & Edge modified flake & 1 \\
\hline E22/S76 & 15 & & IIIa/b & $250-1$ & Perforator Group 3 & 1 \\
\hline $\mathrm{E} 22 / \mathrm{S} 76$ & 15 & & IIIa/b & $250-5$ & Projectile point fragment & \\
\hline $\mathrm{E} 22 / \mathrm{S} 76$ & 15 & & IIIa/b & $250-4$ & Projectile point, contracting stem, concave ba & ase \\
\hline $\mathrm{E} 22 / \mathrm{S} 76$ & $16 \mathrm{~A}$ & & IIIa & $25 \mathrm{P} 1-6$ & Biface fragment & 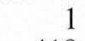 \\
\hline $\mathrm{E} 22 / \mathrm{S} 76$ & $16 \mathrm{~A}$ & & IIIa & & Debitage & 418 \\
\hline E22/S76 & $16 \mathrm{~A}$ & & IIIIa & $25 \mathrm{P} 1-5$ & Edge modified flake & 1 \\
\hline E22/S76 & $16 \mathrm{~A}$ & & IIIa & 25P1-4 & Edge modified flake & 1 \\
\hline $\mathrm{E} 22 / \mathrm{S} 76$ & $16 \mathrm{~A}$ & & IIIa & $25 \mathrm{P} 1-3$ & Microspur/microdenticulate & 1 \\
\hline $\mathrm{E} 22 / \mathrm{S} 76$ & $16 \mathrm{~A}$ & & IIIa & $25 \mathrm{P} 1-1$ & Microspur/microdenticulate & \\
\hline $\mathrm{E} 22 / \mathrm{S} 76$ & $16 \mathrm{~A}$ & & IIIa & $25 \mathrm{P} 1-2$ & Microspur/microdenticulate & 1 \\
\hline
\end{tabular}




\begin{tabular}{|c|c|c|c|c|c|c|}
\hline $\begin{array}{l}\text { Square } \\
\text { E22/S76 }\end{array}$ & $\begin{array}{l}\text { Level } \\
16 \mathrm{~A}\end{array}$ & Feature & $\begin{array}{l}\text { Strata } \\
\text { IIa }\end{array}$ & Item & Analyst Identification & $\begin{array}{r}\text { Count } \\
1\end{array}$ \\
\hline E22/S76 & $16 \mathrm{~A}$ & & IIIIa & $\begin{array}{l}25 \mathrm{P} 1-7 \\
25 \mathrm{P} 1-8\end{array}$ & $\begin{array}{l}\text { Thin uniface } \\
\text { Thin uniface }\end{array}$ & 1 \\
\hline E22/S76 & $16 \mathrm{~B}$ & & IIIIa & $25 \mathrm{P} 2-6$ & Biface fragment & 1 \\
\hline $\mathrm{E} 22 / \mathrm{S} 76$ & $16 \mathrm{~B}$ & & IIIa & $25 \mathrm{P} 2-1$ & Burin & 1 \\
\hline $\mathrm{E} 22 / \mathrm{S} 76$ & $16 \mathrm{~B}$ & & IIIa & $25 \mathrm{P} 2-5$ & Burin spall & 1 \\
\hline E22/S76 & $16 \mathrm{~B}$ & & IIIIa & $25 \mathrm{P} 2-2$ & Burin spall & 1 \\
\hline E22/S76 & 16B & & IIIIa & & Debitage & 554 \\
\hline $\mathrm{E} 22 / \mathrm{S} 76$ & $16 \mathrm{~B}$ & & IIIa & $25 \mathrm{P} 2-3$ & Edge modified flake & \\
\hline E22/S76 & $16 \mathrm{~B}$ & & IIIa & $25 \mathrm{P} 2-4$ & Uniface, unanalyzed & 1 \\
\hline E22/S76 & 16B & Feature 128 & IIIIa & $25 \mathrm{P} 2-7$ & Core, thermal & 1 \\
\hline $\mathrm{E} 22 / \mathrm{S} 76$ & $16 \mathrm{~B}$ & Feature 128 & IIIIa & & Debitage & 1 \\
\hline E22/S76 & $17 \mathrm{~A}$ & & IIIIa & $25 \mathrm{Q} 1-3$ & Biface fragment & 1 \\
\hline E22/S76 & $17 \mathrm{~A}$ & & IIIa & $25 \mathrm{Q} 1-2$ & Bifacial tool Form A & 1 \\
\hline $\mathrm{E} 22 / \mathrm{S} 76$ & $17 \mathrm{~A}$ & & IIIIa & $25 \mathrm{Q} 1-5$ & Bifacial tool Form B & 1 \\
\hline E22/S76 & $17 \mathrm{~A}$ & & IIIIa & $25 Q 1-4$ & Bifacial tool Form E & 1 \\
\hline E22/S76 & $17 \mathrm{~A}$ & & IIIa & $25 \mathrm{Q} 1-7$ & $\begin{array}{l}\text { Burin spall } \\
\text { But }\end{array}$ & 1 \\
\hline $\mathrm{E} 22 / \mathrm{S} 76$ & $17 \mathrm{~A}$ & & IIIa & $25 \mathrm{Q} 1-6$ & Burin spall & 1 \\
\hline $\mathrm{E} 22 / \mathrm{S} 76$ & $17 \mathrm{~A}$ & & IIIa & & Debitage & 593 \\
\hline E22/S76 & $17 \mathrm{~A}$ & & IIIIa & 25Q1-10 & Edge modified flake & 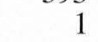 \\
\hline E22/S76 & $17 \mathrm{~A}$ & & IIIa & $25 \mathrm{Q} 1-9$ & Edge modified flake & 1 \\
\hline $\mathrm{E} 22 / \mathrm{S} 76$ & $17 \mathrm{~A}$ & & IIIa & $25 \mathrm{Q} 1-8$ & Edge modified flake & 1 \\
\hline E22/S76 & $17 \mathrm{~A}$ & & IIIa & $25 \mathrm{Q} 1-13$ & Edge modified flake & 1 \\
\hline E22/S76 & $17 \mathrm{~A}$ & & IIIa & $25 \mathrm{Q} 1-12$ & Edge modified flake & 1 \\
\hline E22/S76 & $17 \mathrm{~A}$ & & IIIIa & $25 \mathrm{Q} 1-1$ & Projectile point, Angostura & 1 \\
\hline E22/S76 & $17 \mathrm{~A}$ & & IIIIa & 25Q1-14 & Spurred flake & 1 \\
\hline E22/S76 & $17 \mathrm{~A}$ & & IIIa & $25 \mathrm{Q} 1-11$ & Uniface, unanalyzed & 1 \\
\hline E22/S76 & 17B & & IIIa & $25 \mathrm{Q} 2-17$ & Biface fragment & 1 \\
\hline $\mathrm{E} 22 / \mathrm{S} 76$ & $17 \mathrm{~B}$ & & IIIa & $25 \mathrm{Q} 2-21$ & Biface Stage 3 & 1 \\
\hline E22/S76 & 17B & & IIIIa & $25 \mathrm{Q} 2-3$ & Bifacial tool & 1 \\
\hline E22/S76 & 17B & & IIIa & $25 \mathrm{Q} 2-2$ & Bifacial tool & 1 \\
\hline E22/S76 & 17B & & IIIIa & $25 \mathrm{Q} 2-7$ & Bifacial tool Form C & 1 \\
\hline $\mathrm{E} 22 / \mathrm{S} 76$ & $17 \mathrm{~B}$ & & IIIa & $25 \mathrm{Q} 2-12$ & Burin spall & 1 \\
\hline E22/S76 & 17B & & IIIIa & $25 \mathrm{Q} 2-4$ & Burin spall, unanalyzed & 1 \\
\hline E22/S76 & $17 \mathrm{~B}$ & & IIIa & $25 \mathrm{Q} 2-22$ & Chert cobble, unmodified/tested & 1 \\
\hline E22/S76 & 17B & & IIITa & $25 \mathrm{Q} 2-1$ & Clear Fork biface & 1 \\
\hline E22/S76 & 17B & & IIIIa & & Debitage & 661 \\
\hline E22/S76 & 17B & & IIIIa & $25 \mathrm{Q} 2-10$ & Edge modified flake & . \\
\hline E22/S76 & $17 \mathrm{~B}$ & & IIIa & $25 \mathrm{Q} 2-14$ & Edge modified flake & 1 \\
\hline E22/S76 & 17B & & IIIa & $25 \mathrm{Q} 2-13$ & Edge modified flake & 1 \\
\hline $\mathrm{E} 22 / \mathrm{S} 76$ & $17 \mathrm{~B}$ & & IIIa & $25 \mathrm{Q} 2-15$ & Edge modified flake & 1 \\
\hline E22/S76 & 17B & & IIIIa & $25 \mathrm{Q} 2-8$ & Edge modified flake & 1 \\
\hline E22/S76 & $17 \mathrm{~B}$ & & IIIa & 25Q2-9 & Notched flake & 1 \\
\hline $\mathrm{E} 22 / \mathrm{S} 76$ & $17 \mathrm{~B}$ & & IIIa & $25 \mathrm{Q} 2-5$ & Perforator Group 7 & 1 \\
\hline $\mathrm{E} 22 / \mathrm{S} 76$ & $17 \mathrm{~B}$ & & IIIa & $25 \mathrm{Q} 2-18$ & Projectile point fragment & 1 \\
\hline $\mathrm{E} 22 / \mathrm{S} 76$ & $17 \mathrm{~B}$ & & IIIa & $25 \mathrm{Q} 2-11$ & Uniface, unanalyzed & 1 \\
\hline E22/S76 & $17 \mathrm{~B}$ & & IIIa & $25 \mathrm{Q} 2-6$ & Uniface, unanalyzed & 1 \\
\hline E22/S76 & $18 \mathrm{~A}$ & & IIIa & & Debitage & 540 \\
\hline E22/S76 & $18 \mathrm{~A}$ & & IIIa & 25R1-19 & Edge modified flake & \\
\hline $\mathrm{E} 22 / \mathrm{S} 76$ & $18 \mathrm{~A}$ & & IIIa & 25R1-11 & Edge modified flake & 1 \\
\hline E22/S76 & $18 \mathrm{~A}$ & & IIIa & $25 \mathrm{R} 1-16$ & Edge modified flake & 1 \\
\hline E22/S76 & $18 \mathrm{~A}$ & & IIIa & $25 \mathrm{R} 1-7$ & Edge modified flake & 1 \\
\hline $\mathrm{E} 22 / \mathrm{S} 76$ & $18 \mathrm{~A}$ & & IIIa & 25R $1-14$ & Edge modified flake & 1 \\
\hline E22/S76 & $18 \mathrm{~A}$ & & IIIa & $25 \mathrm{R} 1-10$ & Edge modified flake & 1 \\
\hline $\mathrm{E} 22 / \mathrm{S} 76$ & $18 \mathrm{~A}$ & & IIIa & $25 \mathrm{R} 1-6$ & Edge modified flake & 1 \\
\hline E22/S76 & $18 \mathrm{~A}$ & & IIIa & 25R1-13 & Microspur/microdenticulate & 1 \\
\hline $\mathrm{E} 22 / \mathrm{S} 76$ & $18 \mathrm{~A}$ & & IIIa & $25 \mathrm{R} 1-18$ & Notched flake & 1 \\
\hline $\mathrm{E} 22 / \mathrm{S} 76$ & $18 \mathrm{~A}$ & & IIIa & $25 \mathrm{R} 1-5$ & Projectile point fragment & 1 \\
\hline $\mathrm{E} 22 / \mathrm{S} 76$ & $18 \mathrm{~A}$ & & IIIa & $25 R 1-4$ & Projectile point fragment & 1 \\
\hline $\mathrm{E} 22 / \mathrm{S} 76$ & $18 \mathrm{~A}$ & & IIIIa & $25 \mathrm{R} 1-1$ & Projectile point, Angostura & 1 \\
\hline $\mathrm{E} 22 / \mathrm{S} 76$ & $18 \mathrm{~A}$ & & IIIa & $25 \mathrm{R} 1-3$ & Projectile point, Angostura & \\
\hline E22/S76 & $18 \mathrm{~A}$ & & IIIa & $25 \mathrm{R} 1-2$ & Projectile point, Thrall & 1 \\
\hline $\mathrm{E} 22 / \mathrm{S} 76$ & $18 \mathrm{~A}$ & & IIIa & $25 \mathrm{R} 1-17$ & Uniface, unanalyzed & 1 \\
\hline $\mathrm{E} 22 / \mathrm{S} 76$ & $18 \mathrm{~A}$ & & IIIa & $25 \mathrm{R} 1-8$ & Uniface, unanalyzed & 1 \\
\hline E22/S76 & $18 \mathrm{~B}$ & & IIIa & $25 \mathrm{R} 2-1$ & Biface fragment & 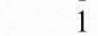 \\
\hline $\mathrm{E} 22 / \mathrm{S} 76$ & $18 \mathrm{~B}$ & & IIIa & & Debitage & 501 \\
\hline $\mathrm{E} 22 / \mathrm{S} 76$ & $18 \mathrm{~B}$ & & IIIa & $25 \mathrm{R} 2-3$ & Edge modified flake & \\
\hline E22/S76 & $19 \mathrm{~A}$ & & I//IIIa & $25 \mathrm{~S} 1-1$ & Biface Stage 1 & 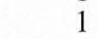 \\
\hline $\mathrm{E} 22 / \mathrm{S} 76$ & $19 \mathrm{~A}$ & & I/IIIIa & & Debitage & 424 \\
\hline E22/S76 & $19 \mathrm{~A}$ & & II/IIIa & $25 S 1-6$ & Denticulated flake & \\
\hline E22/S76 & $19 \mathrm{~A}$ & & ІІ/IIIa & $25 S 1-3$ & Edge modified flake & \\
\hline $\mathrm{E} 22 / \mathrm{S} 76$ & $19 \mathrm{~A}$ & & II/IIIa & $25 \mathrm{~S} 1-7$ & Edge modified flake & 1 \\
\hline $\mathrm{E} 22 / \mathrm{S} 76$ & $19 \mathrm{~A}$ & & I//IIIa & $25 \mathrm{~S} 1-5$ & Micro-core, small & \\
\hline E22/S76 & $19 \mathrm{~A}$ & & II/IIIIa & $25 \mathrm{~S} 1-4$ & Microspur/microdenticulate & \\
\hline E22/S76 & $19 \mathrm{~A}$ & & II/IIIa & $25 \mathrm{~S} 1-2$ & Uniface, unanalyzed & \\
\hline
\end{tabular}




\begin{tabular}{|c|c|c|c|c|c|c|}
\hline Square & Level & Feature & Strata & Item & Analyst Identification & Count \\
\hline E22/S76 & 19B & & II/IIIa & $25 \mathrm{~S} 2-1$ & Bifacial tool & \\
\hline E22/S76 & 19B & & II/IIIa & $25 \mathrm{~S} 2-2$ & Burin & $?$ \\
\hline E22/S76 & 19B & & II/IIIa & & Debitage & 318 \\
\hline $\mathrm{E} 22 / \mathrm{S} 76$ & 19B & & II/IIIa & $25 \mathrm{~S} 2-4$ & Notched flake & \\
\hline $\mathrm{E} 22 / \mathrm{S} 76$ & $19 \mathrm{~B}$ & & II/IIIa & $25 \mathrm{~S} 2 \mathrm{C}-7$ & Notched flake & \\
\hline $\mathrm{E} 22 / \mathrm{S} 76$ & 19B & & II/IIIa & $25 S 2-3$ & Piece esquillee & \\
\hline E22/S76 & $20 \mathrm{~A}$ & & II/IIIa & 25T1A-1 & Biface Stage 1 & \\
\hline E22/S76 & $20 \mathrm{~A}$ & & II/IIIa & $25 \mathrm{~T} 1 \mathrm{C}-3$ & Burin spall & \\
\hline E22/S76 & $20 \mathrm{~A}$ & & II/IIIa & $25 \mathrm{~T} 1 \mathrm{~B}-2$ & Core, thermal & \\
\hline E22/S76 & $20 \mathrm{~A}$ & & II/IIIa & & Debitage & 292 \\
\hline E22/S76 & $20 \mathrm{~B}$ & & II & & Debitage & 235 \\
\hline E22/S76 & $20 \mathrm{~B}$ & & II & 25T2D-4 & Edge modified flake & \\
\hline E22/S76 & $20 \mathrm{~B}$ & & II & 25T2B-2 & Edge modified flake & \\
\hline E22/S76 & $20 \mathrm{~B}$ & & II & $25 \mathrm{~T} 2 \mathrm{C}-3$ & Edge modified flake & \\
\hline $\mathrm{E} 22 / \mathrm{S} 76$ & $20 \mathrm{~B}$ & & II & $25 \mathrm{~T} 2 \mathrm{~A}-1$ & Spurred flake & \\
\hline $\mathrm{E} 22 / \mathrm{S} 76$ & $20 \mathrm{~B}$ & & II & $25 \mathrm{~T} 2 \mathrm{D}-5$ & Uniface, unanalyzed & \\
\hline E22/S76 & $20 \mathrm{~B}$ & & II & $25 \mathrm{~T} 2 \mathrm{~A}-7$ & Worked hematite & \\
\hline E22/S76 & $21 \mathrm{~A}$ & & II & $25 \mathrm{U} 1 \mathrm{C}-4$ & Biface fragment & \\
\hline E22/S76 & $21 \mathrm{~A}$ & & II & 25U1B-2 & Bifacial tool Form A & 1 \\
\hline $\mathrm{E} 22 / \mathrm{S} 76$ & $21 \mathrm{~A}$ & & II & & Debitage & 209 \\
\hline E22/S76 & $21 \mathrm{~A}$ & & II & $25 \mathrm{U} 1 \mathrm{~B}-1$ & Edge modified flake & \\
\hline E22/S76 & $21 \mathrm{~A}$ & & II & $25 \mathrm{U} 1 \mathrm{C}-3$ & Uniface, unanalyzed & \\
\hline E22/S76 & $21 \mathrm{~B}$ & & II & $25 \mathrm{U} 2-3$ & Biface fragment & \\
\hline E22/S76 & $21 \mathrm{~B}$ & & II & & Debitage & 123 \\
\hline E22/S76 & $21 \mathrm{~B}$ & & II & $25 \mathrm{U} 2-4$ & Edge modified flake & \\
\hline $\mathrm{E} 22 / \mathrm{S} 76$ & $21 \mathrm{~B}$ & & II & $25 \mathrm{U} 2-2$ & Edge modified flake & \\
\hline E22/S76 & $21 \mathrm{~B}$ & & II & $25 \mathrm{U} 2-1$ & Projectile point, St. Mary's Hall & \\
\hline E22/S76 & $22 \mathrm{~A}$ & & II & & Debitage & 100 \\
\hline E22/S76 & $22 \mathrm{~A}$ & & II & $25 \mathrm{~V} 1 \mathrm{C}-1$ & Projectile point, parallel side & \\
\hline E22/S76 & $22 \mathrm{~B}$ & & II & $25 \mathrm{~V} 2 \mathrm{~B}-1$ & Biface fragment & \\
\hline E22/S76 & $22 \mathrm{~B}$ & & II & $25 \mathrm{~V} 2 \mathrm{D}-3$ & Biface Stage 2 & \\
\hline E22/S76 & $22 \mathrm{~B}$ & & II & & Debitage & 106 \\
\hline E22/S76 & $22 \mathrm{~B}$ & & II & $25 \mathrm{~V} 2 \mathrm{D}-4$ & Edge modified flake & \\
\hline E22/S76 & $22 \mathrm{~B}$ & & II & $25 \mathrm{~V} 2 \mathrm{C}-2$ & Uniface, unanalyzed & \\
\hline $\mathrm{E} 22 / \mathrm{S} 76$ & $23 \mathrm{~A}$ & & II & & Debitage & 104 \\
\hline E22/S76 & $23 \mathrm{~B}$ & & II & & Debitage & 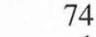 \\
\hline E22/S76 & $23 \mathrm{~B}$ & & II & $25 \mathrm{~W} 2 \mathrm{~A}-1$ & Uniface, unanalyzed & \\
\hline E22/S76 & $24 \mathrm{~A}$ & & II & & Debitage & 7 \\
\hline E22/S76 & $24 \mathrm{~A}$ & & II & $25 \times 1 D-2$ & Edge modified flake & \\
\hline E22/S76 & $24 \mathrm{~A}$ & & II & $25 \times 1 C-1$ & Edge modified flake & \\
\hline E22/S76 & $24 \mathrm{~A}$ & & II & $25 \times 1 D-3$ & Uniface, unanalyzed & \\
\hline E22/S76 & $24 B$ & & $\mathrm{Id} / \mathrm{II}$ & & Debitage & 72 \\
\hline E22/S76 & $25 \mathrm{~A}$ & & $\mathrm{Id} / \mathrm{II}$ & 25Y1D-3 & Biface Stage 1 & \\
\hline E22/S76 & $25 \mathrm{~A}$ & & $\mathrm{Id} / \mathrm{II}$ & $25 \mathrm{Y} 1 \mathrm{C}-2$ & Biface Stage 3 & \\
\hline E22/S76 & $25 \mathrm{~A}$ & & $\mathrm{Id} / \mathrm{II}$ & & Debitage & 65 \\
\hline E22/S76 & $25 \mathrm{~A}$ & & $\mathrm{Id} / \mathrm{II}$ & 25Y1A-1 & Edge modified flake & \\
\hline E22/S76 & $25 \mathrm{~B}$ & & $\mathrm{Id} / \mathrm{II}$ & & Debitage & 58 \\
\hline E22/S76 & $26 \mathrm{~A}$ & & $\mathrm{Id} / \mathrm{II}$ & & Debitage & 51 \\
\hline E22/S76 & $26 \mathrm{~A}$ & & $\mathrm{Id} / \mathrm{II}$ & $25 Z 1 C-1$ & Projectile point, Golondrina-Barber & \\
\hline $\mathrm{E} 22 / \mathrm{S} 76$ & $26 \mathrm{~B}$ & & Isi-c/Id/II & & Debitage & 32 \\
\hline E22/S76 & $27 \mathrm{~A}$ & & Isi-c & 25AA1A-1 & Biface fragment & \\
\hline $\mathrm{E} 22 / \mathrm{S} 76$ & $27 \mathrm{~A}$ & & Isi-c & & Debitage & 47 \\
\hline E22/S76 & $27 \mathrm{~A}$ & & Isi-c & 25AA1B-2 & Thin uniface fragment & \\
\hline E22/S76 & 27B & & Isi-c & & Debitage & 2 \\
\hline E22/S76 & $27 \mathrm{~B}$ & & Isi-c & $25 \mathrm{AA} 2 \mathrm{C}-4$ & Projectile point, miscellaneous lanceolate & \\
\hline $\mathrm{E} 22 / \mathrm{S} 76$ & $27 \mathrm{~B}$ & & Isi-c & $25 \mathrm{AA} 2 \mathrm{C}-5$ & Thick uniface & \\
\hline E22/S76 & 27B & & Isi-c & 25AA2A-1 & Thick uniface & \\
\hline E22/S76 & $27 \mathrm{~B}$ & & Isi-c & $25 \mathrm{AA} 2 \mathrm{~A}-2$ & Thin uniface & \\
\hline E22/S76 & $27 \mathrm{~B}$ & & Isi-c & $25 \mathrm{AA} 2 \mathrm{~B}-3$ & Thin uniface & \\
\hline E22/S76 & $28 \mathrm{~A}$ & & Isi-c & & Debitage & 49 \\
\hline E22/S76 & $28 \mathrm{~A}$ & & Isi-c & 25BB 1B-1 & Edge modified flake & \\
\hline $\mathrm{E} 22 / \mathrm{S} 76$ & $28 \mathrm{~B}$ & & Isi-c & 25BB2D-1 & Clear Fork biface & \\
\hline E22/S76 & $28 \mathrm{~B}$ & & Isi-c & & Debitage & 39 \\
\hline E22/S76 & $29 \mathrm{~A}$ & & Isi-c & $25 \mathrm{CC} 1 \mathrm{C}-2$ & Core fragment & \\
\hline E22/S76 & $29 \mathrm{~A}$ & & Isi-c & & Debitage & 2 \\
\hline E22/S76 & $29 \mathrm{~A}$ & & Isi-c & $25 \mathrm{CC} 1 \mathrm{~A}-1$ & Perforator Group 1 & \\
\hline E22/S76 & $29 \mathrm{~A}$ & & Isi-c & 25CC1D-3 & Thick uniface & \\
\hline E22/S76 & $29 \mathrm{~B}$ & & Isi-c & & Debitage & 21 \\
\hline E22/S76 & $29 \mathrm{~B}$ & & Isi-c & $25 \mathrm{CC} 2 \mathrm{D}-1$ & Notched flake & \\
\hline E22/S76 & $30 \mathrm{~A}$ & & Isi-c & & Debitage & 3 \\
\hline E22/S76 & $30 \mathrm{~A}$ & & Isi-c & 25DD1B-1 & Thin uniface fragment & \\
\hline E22/S76 & $30 \mathrm{~B}$ & & Isi-c & 25DD2C-3 & Biface fragment & \\
\hline E22/S76 & $30 \mathrm{~B}$ & & Isi-c & & Debitage & 11 \\
\hline E22/S76 & $30 \mathrm{~B}$ & & Isi-c & $25 \mathrm{DD} 2 \mathrm{~A}-1$ & Projectile point, Golondrina-Barber & \\
\hline
\end{tabular}




\begin{tabular}{|c|c|c|c|c|c|c|}
\hline Square & Level & Feature & Strata & Item & Analyst Identification & Count \\
\hline E22/S76 & $30 \mathrm{~B}$ & & Isi-c & 25DD2B-2 & Projectile point, miscellaneous lanceolate & \\
\hline $\mathrm{E} 22 / \mathrm{S} 76$ & $31 \mathrm{~A}$ & & Isi/Icl/Isi-c & & Debitage & 27 \\
\hline E22/S76 & $31 \mathrm{~A}$ & & Isi/Icl/Isi-c & 25EE1B-1 & Edge modified flake & 1 \\
\hline $\mathrm{E} 22 / \mathrm{S} 76$ & $31 \mathrm{~B}$ & & Isi/Icl/Isi-c & 25EE2C-2 & Chert cobble, chunk & 1 \\
\hline $\mathrm{E} 22 / \mathrm{S} 76$ & $31 \mathrm{~B}$ & & Isi/Icl/Isi-c & & Debitage & 22 \\
\hline $\mathrm{E} 22 / \mathrm{S} 76$ & $31 \mathrm{~B}$ & & Isi/Icl/Isi-c & 25EE2B-1 & Projectile point, miscellaneous lanceolate & \\
\hline E22/S76 & $32 \mathrm{~A}$ & & $\mathrm{Isi} / \mathrm{Icl} / \mathrm{Isi}-\mathrm{c}$ & & Debitage & 20 \\
\hline E22/S76 & $32 \mathrm{~B}$ & & Isi/Icl/Isi-c & & Debitage & 30 \\
\hline E22/S76 & $32 \mathrm{~B}$ & & Isi/Icl/Isi-c & 25FF2D-1 & Edge modified flake & \\
\hline $\mathrm{E} 22 / \mathrm{S} 76$ & $33 \mathrm{~A}$ & & Isi/Icl/Isi-c & & Debitage & 43 \\
\hline $\mathrm{E} 22 / \mathrm{S} 76$ & $33 \mathrm{~A}$ & & Isi/Icl/Isi-c & 25GG1D-1 & Edge modified flake & \\
\hline $\mathrm{E} 22 / \mathrm{S} 76$ & $33 \mathrm{~B}$ & & Isi/Icl & & Debitage & 45 \\
\hline E22/S76 & $34 \mathrm{~A}$ & & Isi/Icl & & Debitage & 42 \\
\hline E22/S76 & $34 \mathrm{~B}$ & & Isi/Icl & & Debitage & 35 \\
\hline $\mathrm{E} 22 / \mathrm{S} 76$ & $35 \mathrm{~A}$ & & Isi/Icl & & Debitage & 44 \\
\hline E22/S76 & $35 \mathrm{~A}$ & & Isi/Icl & 25II1C-2 & Edge modified flake & \\
\hline $\mathrm{E} 22 / \mathrm{S} 76$ & $35 \mathrm{~A}$ & & Isi/Icl & 25IIIC-1 & Edge modified flake & 1 \\
\hline $\mathrm{E} 22 / \mathrm{S} 76$ & $35 \mathrm{~B}$. & & Isi & & Debitage & 43 \\
\hline $\mathrm{E} 22 / \mathrm{S} 76$ & $36 \mathrm{~A}$ & & Isi/D? & $25 \mathrm{JJ} 1 \mathrm{C}-2$ & Biface fragment & \\
\hline $\mathrm{E} 22 / \mathrm{S} 76$ & $36 \mathrm{~A}$ & & Isi/D? & & Debitage & 10 \\
\hline E22/S76 & $36 \mathrm{~A}$ & & Isi/D? & $25 \mathrm{JJ} 1 \mathrm{~B}-1$ & Unifacial multiple tool & 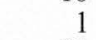 \\
\hline E22/S76 & $36 \mathrm{~B}$ & & Isi/D? & & Debitage & 11 \\
\hline E22/S76 & $36 \mathrm{~B}$ & & Isi/D? & 25JJ2B-1 & Edge modified flake & \\
\hline $\mathrm{E} 22 / \mathrm{S} 76$ & $36 \mathrm{~B}$ & & Isi/D? & $25 \mathrm{JJ} 2 \mathrm{D}-2$ & Thin uniface & \\
\hline $\mathrm{E} 22 / \mathrm{S} 76$ & $37 \mathrm{~A}$ & & Isi & & Debitage & $r$ \\
\hline E22/S76 & $37 \mathrm{~A}$ & & Isi & $25 \mathrm{KK} 1 \mathrm{~A}-1$ & Edge modified flake & 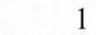 \\
\hline E22/S76 & 37B & & Isi & & Debitage & 1 \\
\hline $\mathrm{E} 22 / \mathrm{S} 76$ & $38 \mathrm{~A}$ & & Isi & & Debitage & 1 \\
\hline $\mathrm{E} 22 / \mathrm{S} 78$ & 2 & & IIIc & $24 \mathrm{~B}$ & Projectile point, Montell & 1 \\
\hline E22/S78 & 4 & & IIIc & 24D & Core tool, type 4 & 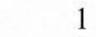 \\
\hline E22/S78 & 15 & & $\mathrm{IIIa/b}$ & $240-1$ & Biface Stage 2 & 1 \\
\hline E22/S78 & 15 & & IIIa/b & $240-2$ & Biface Stage 2 & 1 \\
\hline $\mathrm{E} 22 / \mathrm{S} 78$ & 15 & & $\mathrm{IIIa} / \mathrm{b}$ & & Debitage & 1173 \\
\hline $\mathrm{E} 22 / \mathrm{S} 78$ & 15 & & IIIa/b & $240-7$ & Edge modified flake & \\
\hline $\mathrm{E} 22 / \mathrm{S} 78$ & 15 & & $\mathrm{IIIa} / \mathrm{b}$ & $240-14$ & Edge modified flake & 1 \\
\hline E22/S78 & 15 & & $\mathrm{IIIa} / \mathrm{b}$ & $240-10$ & Edge modified flake & 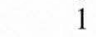 \\
\hline E22/S78 & 15 & & IIIa/b & $240-6$ & Edge modified flake & 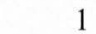 \\
\hline $\mathrm{E} 22 / \mathrm{S} 78$ & 15 & & $\mathrm{IIIa} / \mathrm{b}$ & $24 \mathrm{O}-13$ & Microspur/microdenticulate & \\
\hline E22/S78 & 15 & & $\mathrm{IIIa} / \mathrm{b}$ & $240-3$ & Projectile point fragment & $i$ \\
\hline $\mathrm{E} 22 / \mathrm{S} 78$ & 15 & & IIIa/b & $240-4$ & Retouched blade & 1 \\
\hline $\mathrm{E} 22 / \mathrm{S} 78$ & 15 & & $\mathrm{IIIa} / \mathrm{b}$ & $240-9$ & Unifacial multiple tool & 1 \\
\hline $\mathrm{E} 22 / \mathrm{S} 78$ & $16 \mathrm{~A}$ & & IIIa & $24 \mathrm{P} 1-3$ & Biface Stage 2 & 1 \\
\hline $\mathrm{E} 22 / \mathrm{S} 78$ & $16 \mathrm{~A}$ & & IIIa & 24P1-1 & Bifacial tool Form B & 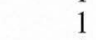 \\
\hline E22/S78 & $16 \mathrm{~A}$ & & IIIa & $24 \mathrm{P} 1-4$ & Core, multidirectional & 1 \\
\hline $\mathrm{E} 22 / \mathrm{S} 78$ & $16 \mathrm{~A}$ & & IIIIa & & Debitage & 219 \\
\hline $\mathrm{E} 22 / \mathrm{S} 78$ & $16 \mathrm{~A}$ & & IIIa & 24P1-5 & Edge modified flake & 1 \\
\hline $\mathrm{E} 22 / \mathrm{S} 78$ & $16 \mathrm{~A}$ & & IIIa & $24 \mathrm{P} 1-6$ & Unifacial multiple tool & 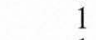 \\
\hline $\mathrm{E} 22 / \mathrm{S} 78$ & $16 \mathrm{~A}$ & Feature 123 & IIIa & $24 \mathrm{P} 1-2$ & Biface Stage 2 & \\
\hline $\mathrm{E} 22 / \mathrm{S} 78$ & $16 \mathrm{~A}$ & Feature 123 & IIIa & & Debitage & 129 \\
\hline $\mathrm{E} 22 / \mathrm{S} 78$ & $16 \mathrm{~B}$ & & IIIa & 24P2-1 & Burin & \\
\hline E22/S78 & $16 \mathrm{~B}$ & & IIIa & & Debitage & 536 \\
\hline $\mathrm{E} 22 / \mathrm{S} 78$ & $16 \mathrm{~B}$ & & IIIa & $24 \mathrm{P} 2-2$ & Edge modified flake & \\
\hline E22/S78 & $16 \mathrm{~B}$ & Feature 123 & IIIa & $24 \mathrm{P} 2-3$ & Projectile point, Gower & 1 \\
\hline $\mathrm{E} 22 / \mathrm{S} 78$ & $17 \mathrm{~A}$ & & IIIa & 24Q1-2 & Biface Stage 1 & 1 \\
\hline E22/S78 & $17 \mathrm{~A}$ & & IIIa & 24Q1-1 & Bifacial tool Form A & 1 \\
\hline E22/S78 & $17 \mathrm{~A}$ & & IIIa & & Debitage & 710 \\
\hline $\mathrm{E} 22 / \mathrm{S} 78$ & $17 \mathrm{~A}$ & & IIIa & 24Q1-7 & Edge modified flake & \\
\hline $\mathrm{E} 22 / \mathrm{S} 78$ & $17 \mathrm{~A}$ & & IIIa & $24 Q 1-5$ & Microspur/microdenticulate & \\
\hline E22/S78 & $17 \mathrm{~A}$ & & IIIIa & 24Q1-4 & Microspur/microdenticulate & 1 \\
\hline E22/S78 & $17 \mathrm{~A}$ & & IIIIa & 24Q1-3 & Spurred flake & 1 \\
\hline $\mathrm{E} 22 / \mathrm{S} 78$ & $17 \mathrm{~A}$ & & IIIa & 24Q1-6 & Uniface, unanalyzed & \\
\hline $\mathrm{E} 22 / \mathrm{S} 78$ & 17B & & IIIa & $24 Q 2-3$ & Biface Stage 3 & \\
\hline E22/S78 & $17 \mathrm{~B}$ & & IIIa & $24 Q 2-2$ & Burin spall & \\
\hline $\mathrm{E} 22 / \mathrm{S} 78$ & $17 \mathrm{~B}$ & & IIIa & $24 Q 2-1$ & Core, multidirectional & \\
\hline E22/S78 & 17B & & IIIIa & & Debitage & 617 \\
\hline E22/S78 & $18 \mathrm{~A}$ & & IIIa & & Debitage & 554 \\
\hline E22/S78 & $18 \mathrm{~A}$ & & IIIa & 24R1-1 & Projectile point, miscellaneous lanceolate & \\
\hline $\mathrm{E} 22 / \mathrm{S} 78$ & $18 \mathrm{~A}$ & & IIIa & 24R1-2 & Worked hematite & 1 \\
\hline E22/S78 & 18B & & II/IIIa & 24R2-1 & Biface fragment & 1 \\
\hline E22/S78 & $18 \mathrm{~B}$ & & II/IIIa & $24 \mathrm{R} 2-5$ & Burin & \\
\hline $\mathrm{E} 22 / \mathrm{S} 78$ & $18 \mathrm{~B}$ & & II/IIIa & $24 \mathrm{R} 2-4$ & Burin spall & \\
\hline $\mathrm{E} 22 / \mathrm{S} 78$ & $18 \mathrm{~B}$ & & II/IIIa & 24R2-11 & Burin spall & \\
\hline $\mathrm{E} 22 / \mathrm{S} 78$ & $18 \mathrm{~B}$ & & II/IIIa & $24 R 2-3$ & Clear Fork biface & \\
\hline E22/S78 & $18 \mathrm{~B}$ & & II/IIIa & 24R2-2 & Core fragment & \\
\hline
\end{tabular}




\begin{tabular}{|c|c|c|c|c|c|c|}
\hline Square & Level & Feature & Strata & Item & Analyst Identification & $\begin{array}{r}\text { Count } \\
335\end{array}$ \\
\hline $\mathrm{E} 22 / \mathrm{S} 78$ & $18 \mathrm{~B}$ & & II/IIIa & & Debitage & 335 \\
\hline E22/S78 & 18B & & II/IIIa & 24R2-6 & Edge modified flake & 1 \\
\hline $\mathrm{E} 22 / \mathrm{S} 78$ & $18 \mathrm{~B}$ & & II/IIIa & 24R2-7 & Thin uniface & 1 \\
\hline E22/S78 & $19 \mathrm{~A}$ & & II/IIIa & & Debitage & 287 \\
\hline $\mathrm{E} 22 / \mathrm{S} 78$ & $19 \mathrm{~A}$ & & II/IIIa & $24 \mathrm{~S} 1-2$ & Edge modified flake & \\
\hline $\mathrm{E} 22 / \mathrm{S} 78$ & $19 \mathrm{~A}$ & & II/IIIa & $24 S 1-6$ & Projectile point fragment & \\
\hline $\mathrm{E} 22 / \mathrm{S} 78$ & $19 \mathrm{~A}$ & & II/IIIa & $24 S 1-5$ & Small core hammerstone & \\
\hline $\mathrm{E} 22 / \mathrm{S} 78$ & $19 \mathrm{~A}$ & & II/IIIa & $24 \mathrm{~S} 1-4$ & Spurred flake & \\
\hline E22/S78 & $19 \mathrm{~A}$ & & II/IIIa & 24S1-1 & Uniface, unanalyzed & \\
\hline $\mathrm{E} 22 / \mathrm{S} 78$ & $19 \mathrm{~A}$ & & II/IIIa & $24 S 1-3$ & Uniface, unanalyzed & \\
\hline E22/S78 & 19B & & II/IIIa & $24 \mathrm{~S} 2 \mathrm{~A}-2$ & Biface fragment & \\
\hline $\mathrm{E} 22 / \mathrm{S} 78$ & $19 \mathrm{~B}$ & & II/IIIa & $24 \mathrm{~S} 2 \mathrm{~A}-4$ & Chert cobble, chunk & 1 \\
\hline E22/S78 & $19 \mathrm{~B}$ & & II/IIIa & & Debitage & 267 \\
\hline E22/S78 & $19 \mathrm{~B}$ & & II/IIIa & $24 \mathrm{~S} 2 \mathrm{~A}-3$ & Edge modified flake & \\
\hline $\mathrm{E} 22 / \mathrm{S} 78$ & $19 \mathrm{~B}$ & & II/IIIa & $24 \mathrm{~S} 2 \mathrm{C}-6$ & Edge modified flake & \\
\hline $\mathrm{E} 22 / \mathrm{S} 78$ & $19 \mathrm{~B}$ & & II/IIIa & 24 S2D-8 & Edge modified flake & \\
\hline $\mathrm{E} 22 / \mathrm{S} 78$ & $19 \mathrm{~B}$ & & II/IIIa & $24 \mathrm{~S} 2 \mathrm{~B}-5$ & Uniface, unanalyzed & \\
\hline E22/S78 & 19B & & II/IIIa & 24S2-1 & Unifacial multiple tool & \\
\hline $\mathrm{E} 22 / \mathrm{S} 78$ & $20 \mathrm{~A}$ & & II & $24 \mathrm{~T} 1 \mathrm{C}-3$ & Biface fragment & \\
\hline $\mathrm{E} 22 / \mathrm{S} 78$ & $20 \mathrm{~A}$ & & II & 24T1D-5 & Biface Stage 1 & \\
\hline E22/S78 & $20 \mathrm{~A}$ & & II & 24T1D-6 & Biface Stage 2 & \\
\hline $\mathrm{E} 22 / \mathrm{S} 78$ & $20 \mathrm{~A}$ & & II & & Debitage & 252 \\
\hline $\mathrm{E} 22 / \mathrm{S} 78$ & $20 \mathrm{~A}$ & & II & 24T1C-4 & Edge modified flake & \\
\hline $\mathrm{E} 22 / \mathrm{S} 78$ & $20 \mathrm{~A}$ & & II & 24T1A-1 & Edge modified flake & \\
\hline E22/S78 & $20 \mathrm{~A}$ & & II & 24T1D-9 & Edge modified flake & \\
\hline $\mathrm{E} 22 / \mathrm{S} 78$ & $20 \mathrm{~A}$ & & II & 24T1D-7 & Projectile point fragment & \\
\hline E22/S78 & $20 \mathrm{~A}$ & & II & 24T1D-8 & Uniface, unanalyzed & \\
\hline $\mathrm{E} 22 / \mathrm{S} 78$ & $20 \mathrm{~A}$ & & II & 24T1B-2 & Uniface, unanalyzed & \\
\hline $\mathrm{E} 22 / \mathrm{S} 78$ & $20 \mathrm{~B}$ & & II & & Debitage & 253 \\
\hline E22/S78 & $21 \mathrm{~A}$ & & II & 24U1A-3 & Core, thermal & \\
\hline $\mathrm{E} 22 / \mathrm{S} 78$ & $21 \mathrm{~A}$ & & II & 24U1B-4 & Core, thermal & 1 \\
\hline E22/S78 & $21 \mathrm{~A}$ & & II & & Debitage & 190 \\
\hline $\mathrm{E} 22 / \mathrm{S} 78$ & $21 \mathrm{~A}$ & & II & $24 \mathrm{U} 1 \mathrm{C}-5$ & Notched flake & \\
\hline $\mathrm{E} 22 / \mathrm{S} 78$ & $21 \mathrm{~A}$ & & II & 24U1A-2 & Projectile point fragment & \\
\hline E22/S78 & $21 \mathrm{~A}$ & & II & 24U1-1 & Projectile point, Big Sandy & \\
\hline $\mathrm{E} 22 / \mathrm{S} 78$ & $21 \mathrm{~B}$ & & II & $24 U 2 C-4$ & Biface Stage 2 & \\
\hline E22/S78 & 21B & & II & 24U2-1 & Biface Stage 3 & \\
\hline $\mathrm{E} 22 / \mathrm{S} 78$ & 21B & & II & 24U2-2 & Burin & 1 \\
\hline E22/S78 & 21B & & II & & Debitage & 113 \\
\hline $\mathrm{E} 22 / \mathrm{S} 78$ & $21 \mathrm{~B}$ & & II & $24 U 2-4$ & Microspur/microdenticulate & \\
\hline $\mathrm{E} 22 / \mathrm{S} 78$ & $21 \mathrm{~B}$ & & II & $24 U 2-3$ & Uniface, unanalyzed & \\
\hline $\mathrm{E} 22 / \mathrm{S} 78$ & $22 \mathrm{~A}$ & & II & 24V1D-2 & Burin & 1 \\
\hline E22/S78 & $22 \mathrm{~A}$ & & II & & Debitage & 76 \\
\hline $\mathrm{E} 22 / \mathrm{S} 78$ & 22B & & II & & Debitage & 122 \\
\hline E22/S78 & $22 \mathrm{~B}$ & & II & $24 \mathrm{~V} 2 \mathrm{C}-1$ & Projectile point fragment & \\
\hline E22/S78 & $22 \mathrm{~B}$ & & II & $24 \mathrm{~V} 2 \mathrm{C}-2$ & Thin uniface & \\
\hline $\mathrm{E} 22 / \mathrm{S} 78$ & $23 \mathrm{~A}$ & & II & & Debitage & 163 \\
\hline E22/S78 & $23 \mathrm{~A}$ & & II & 24W1B-2 & Edge modified flake & \\
\hline E22/S78 & $23 \mathrm{~A}$ & & II & 24W1B-1 & Uniface, unanalyzed & \\
\hline E22/S78 & $23 \mathrm{~B}$ & & $\mathrm{Id} / \mathrm{II}$ & & Debitage & 108 \\
\hline $\mathrm{E} 22 / \mathrm{S} 78$ & $23 \mathrm{~B}$ & & $\mathrm{Id} / \mathrm{II}$ & $24 \mathrm{~W} 2 \mathrm{~A}-1$ & Edge modified flake & \\
\hline E22/S78 & $23 \mathrm{~B}$ & & Id/II & 24W2D-2 & Thin uniface & 1 \\
\hline E22/S78 & $24 \mathrm{~A}$ & & $\mathrm{Id} / \mathrm{II}$ & & Debitage & 83 \\
\hline E22/S78 & $24 \mathrm{~A}$ & & $\mathrm{Id} / \mathrm{II}$ & 24X1D-1 & Thick uniface & \\
\hline $\mathrm{E} 22 / \mathrm{S} 78$ & $24 \mathrm{~B}$ & & $\mathrm{Id} / \mathrm{II}$ & & Debitage & 6 \\
\hline $\mathrm{E} 22 / \mathrm{S} 78$ & 24B & & Id/II & 24X2B-2 & Thin uniface fragment & \\
\hline E22/S78 & $24 B$ & & Id/II & $24 \mathrm{X} 2 \mathrm{~A}-1$ & Uniface, unanalyzed & \\
\hline $\mathrm{E} 22 / \mathrm{S} 78$ & $24 \mathrm{~B}$ & & $\mathrm{Id} / \mathrm{II}$ & $24 \mathrm{X} 2 \mathrm{C}-4$ & Unifacial multiple tool & \\
\hline E22/S78 & $25 \mathrm{~A}$ & & $\mathrm{Id} / \mathrm{II}$ & & Debitage & 67 \\
\hline $\mathrm{E} 22 / \mathrm{S} 78$ & $25 \mathrm{~A}$ & & $\mathrm{Id} / \mathrm{II}$ & 24Y1B-1 & Edge modified flake & \\
\hline E22/S78 & $25 \mathrm{~A}$ & & Id/II & 24Y1B-2 & Edge modified flake & \\
\hline E22/S78 & $25 \mathrm{~B}$ & & Isi-c/Id & & Debitage & 55 \\
\hline $\mathrm{E} 22 / \mathrm{S} 78$ & $25 \mathrm{~B}$ & & Isi-c/Id & $24 Y 2 C-3$ & Micro-core, small & \\
\hline E22/S78 & $25 \mathrm{~B}$ & & Isi-c/Id & 24Y2B-2 & Thin uniface & \\
\hline $\mathrm{E} 22 / \mathrm{S} 78$ & $26 \mathrm{~A}$ & Feature 163 & Isi-c/Id & $24 \mathrm{Z} 1 \mathrm{C}-1$ & Biface Stage 2 & \\
\hline E22/S78 & $26 \mathrm{~A}$ & Feature 163 & Isi-c/Id & & Debitage & 34 \\
\hline E22/S78 & $26 \mathrm{~A}$ & Feature 163 & Isi-c/Id & 24Z1D-3 & Thin uniface & \\
\hline $\mathrm{E} 22 / \mathrm{S} 78$ & $26 \mathrm{~B}$ & & Isi-c/Id & 24Z2D-1 & Core tool, type 4 & \\
\hline E22/S78 & $26 \mathrm{~B}$ & & Isi-c/Id & & Debitage & 39 \\
\hline $\mathrm{E} 22 / \mathrm{S} 78$ & $27 \mathrm{~A}$ & & Isi-c & & Debitage & 2 \\
\hline E22/S78 & $27 \mathrm{~B}$ & & Isi-c & 24AA2B-2 & Core fragment & \\
\hline $\mathrm{E} 22 / \mathrm{S} 78$ & 27B & & Isi-c & $24 \mathrm{AA} 2 \mathrm{C}-4$ & Core, thermal & \\
\hline $\mathrm{E} 22 / \mathrm{S} 78$ & 27B & & Isi-c & & Debitage & 32 \\
\hline E22/S78 & $27 \mathrm{~B}$ & & Isi-c & $24 \mathrm{AA} 2 \mathrm{C}-3$ & Edge modified flake & \\
\hline
\end{tabular}




\begin{tabular}{|c|c|c|c|c|c|c|}
\hline Square & Level & Feature & Strata & Item & Analyst Identification & Count \\
\hline $\mathrm{E} 22 / \mathrm{S} 78$ & $27 \mathrm{~B}$ & & Isi-c & 24AA2B-1 & Edge modified flake & \\
\hline $\mathrm{E} 22 / \mathrm{S} 78$ & $28 \mathrm{~A}$ & & Isi-c & & Debitage & 28 \\
\hline $\mathrm{E} 22 / \mathrm{S} 78$ & $28 \mathrm{~A}$ & & Isi-c & 24BB1D-1 & Possible ground stone & 1 \\
\hline $\mathrm{E} 22 / \mathrm{S} 78$ & $28 \mathrm{~B}$ & & Isi/Isi-c & & Debitage & 31 \\
\hline $\mathrm{E} 22 / \mathrm{S} 78$ & $29 \mathrm{~A}$ & & Isi/Isi-c & & Debitage & \\
\hline $\mathrm{E} 22 / \mathrm{S} 78$ & $29 \mathrm{~A}$ & & Isi/Isi-c & $24 \mathrm{CC} 1 \mathrm{~B}-1$ & Edge modified flake & \\
\hline $\mathrm{E} 22 / \mathrm{S} 78$ & $29 B$ & & Isi/Isi-c & & Debitage & 39 \\
\hline $\mathrm{E} 22 / \mathrm{S} 78$ & $29 \mathrm{~B}$ & & Isi/Isi-c & $24 \mathrm{CC} 2 \mathrm{C}-1$ & Edge modified flake & 1 \\
\hline $\mathrm{E} 22 / \mathrm{S} 78$ & $30 \mathrm{~A}$ & & Isi/Isi-c & & Debitage & \\
\hline $\mathrm{E} 22 / \mathrm{S} 78$ & $30 \mathrm{~A}$ & & Isi/Isi-c & 24DD1C-1 & Uniface, unanalyzed & \\
\hline $\mathrm{E} 22 / \mathrm{S} 78$ & $30 \mathrm{~A}$ & & Isi/Isi-c & $24 \mathrm{DD} 1 \mathrm{C}-2$ & Uniface, unanalyzed & 1 \\
\hline $\mathrm{E} 22 / \mathrm{S} 78$ & $30 \mathrm{~B}$ & & Isi/Isi-c & & Debitage & 54 \\
\hline E22/S78 & $31 \mathrm{~A}$ & & Isi/Isi-c & 24EE1B-1 & Biface Stage 2 & 1 \\
\hline $\mathrm{E} 22 / \mathrm{S} 78$ & $31 \mathrm{~A}$ & & Isi/Isi-c & & Debitage & 60 \\
\hline $\mathrm{E} 22 / \mathrm{S} 78$ & $31 \mathrm{~B}$ & & Isi/Icl/Isi-c & 24EE2A-1 & Core, thermal & \\
\hline $\mathrm{E} 22 / \mathrm{S} 78$ & $31 \mathrm{~B}$ & & $\mathrm{Isi} / \mathrm{Icl} / \mathrm{Isi}-\mathrm{c}$ & & Debitage & 17 \\
\hline $\mathrm{E} 22 / \mathrm{S} 78$ & $32 \mathrm{~A}$ & & Isi/Icl/Isi-c & & Debitage & 52 \\
\hline $\mathrm{E} 22 / \mathrm{S} 78$ & $32 \mathrm{~B}$ & & Isi/Icl/Isi-c & & Debitage & 37 \\
\hline $\mathrm{E} 22 / \mathrm{S} 78$ & $32 \mathrm{~B}$ & & Isi/Icl/Isi-c & 24FF2B-1 & Large core hammerstone & 1 \\
\hline $\mathrm{E} 22 / \mathrm{S} 78$ & $33 \mathrm{~A}$ & & Isi/Icl & & Debitage & 28 \\
\hline $\mathrm{E} 22 / \mathrm{S} 78$ & $33 \mathrm{~A}$ & & Isi/Icl & 24GG1B & Uniface, unanalyzed & 1 \\
\hline $\mathrm{E} 22 / \mathrm{S} 78$ & $33 \mathrm{~B}$ & & Isi & & Debitage & 15 \\
\hline $\mathrm{E} 22 / \mathrm{S} 78$ & $34 \mathrm{~A}$ & & Isi & & Debitage & \\
\hline $\mathrm{E} 22 / \mathrm{S} 78$ & $34 \mathrm{~B}$ & & Isi & & Debitage & \\
\hline $\mathrm{E} 22 / \mathrm{S} 78$ & $35 \mathrm{~A}$ & & Isi & & Debitage & \\
\hline $\mathrm{E} 22 / \mathrm{S} 78$ & $35 \mathrm{~B}$ & & Isi & & Debitage & \\
\hline $\mathrm{E} 22 / \mathrm{S} 78$ & $36 \mathrm{~A}$ & & Isi & & Debitage & 6 \\
\hline $\mathrm{E} 22 / \mathrm{S} 78$ & $36 \mathrm{~B}$ & & Isi & & Debitage & \\
\hline $\mathrm{E} 22 / \mathrm{S} 78$ & $37 \mathrm{~A}$ & & Isi & & Debitage & \\
\hline $\mathrm{E} 22 / \mathrm{S} 78$ & $37 \mathrm{~B}$ & & Isi & & Debitage & 1 \\
\hline $\mathrm{E} 22 / \mathrm{S} 80$ & 6 & & IIIc & $23 \mathrm{~F}-8$ & Biface fragment & \\
\hline $\mathrm{E} 22 / \mathrm{S} 80$ & 6 & & IIIc & $23 \mathrm{~F}-7$ & Biface Stage 2 & \\
\hline $\mathrm{E} 22 / \mathrm{S} 80$ & 6 & & IIIc & $23 \mathrm{~F}-6$ & Biface Stage 3 & \\
\hline $\mathrm{E} 22 / \mathrm{S} 80$ & 6 & & IIIc & & Debitage & 612 \\
\hline $\mathrm{E} 22 / \mathrm{S} 80$ & 6 & & IIIc & $23 \mathrm{~F}-5$ & Perforator Group 7 & \\
\hline $\mathrm{E} 22 / \mathrm{S} 80$ & 6 & & IIIc & $23 \mathrm{~F}-1$ & Projectile point, Marcos & \\
\hline $\mathrm{E} 22 / \mathrm{S} 80$ & 6 & & IIIc & $23 \mathrm{~F}-2$ & Projectile point, miscellaneous expanding stem & \\
\hline $\mathrm{E} 22 / \mathrm{S} 80$ & 6 & & IIIc & $23 \mathrm{~F}-4$ & Projectile point, square stem & \\
\hline $\mathrm{E} 22 / \mathrm{S} 80$ & 6 & Feature 78 & IIIc & $23 \mathrm{~F}-3$ & Biface Stage 3 & 1 \\
\hline $\mathrm{E} 22 / \mathrm{S} 80$ & 7 & & $\mathrm{IIIb} / \mathrm{c}$ & $23 \mathrm{G}-5$ & Biface fragment & \\
\hline $\mathrm{E} 22 / \mathrm{S} 80$ & 7 & & $\mathrm{IIIb} / \mathrm{c}$ & $23 \mathrm{G}-4$ & Biface Stage 2 & \\
\hline $\mathrm{E} 22 / \mathrm{S} 80$ & 7 & & $\mathrm{IIIb} / \mathrm{c}$ & $23 \mathrm{G}-7$ & Chert cobble, chunk & \\
\hline $\mathrm{E} 22 / \mathrm{S} 80$ & 7 & & $\mathrm{IIIb} / \mathrm{c}$ & & Debitage & 65 \\
\hline $\mathrm{E} 22 / \mathrm{S} 80$ & 7 & & $\mathrm{IIIb} / \mathrm{c}$ & $23 \mathrm{G}-10$ & Edge modified flake & \\
\hline $\mathrm{E} 22 / \mathrm{S} 80$ & 7 & & $\mathrm{IIIb} / \mathrm{c}$ & $23 \mathrm{G}-11$ & Edge modified flake & \\
\hline $\mathrm{E} 22 / \mathrm{S} 80$ & 7 & & $\mathrm{IIIb} / \mathrm{c}$ & $23 \mathrm{G}-9$ & Edge modified flake & \\
\hline $\mathrm{E} 22 / \mathrm{S} 80$ & 7 & & $\mathrm{IIIb} / \mathrm{c}$ & $23 \mathrm{G}-8$ & Edge modified flake & \\
\hline $\mathrm{E} 22 / \mathrm{S} 80$ & 7 & & $\mathrm{IIIb} / \mathrm{c}$ & $23 \mathrm{G}-6$ & Edge modified flake & \\
\hline $\mathrm{E} 22 / \mathrm{S} 80$ & 7 & & $\mathrm{IIIb} / \mathrm{c}$ & $23 \mathrm{G}-12$ & Notched flake & \\
\hline $\mathrm{E} 22 / \mathrm{S} 80$ & 7 & & $\mathrm{IIIb} / \mathrm{c}$ & $23 \mathrm{G}-3$ & Projectile point, bifurcate stem fragment & \\
\hline $\mathrm{E} 22 / \mathrm{S} 80$ & 7 & & $\mathrm{IIIb} / \mathrm{c}$ & $23 \mathrm{G}-1$ & Projectile point, expanding concave D & \\
\hline $\mathrm{E} 22 / \mathrm{S} 80$ & 7 & & $\mathrm{IIIb} / \mathrm{c}$ & $23 \mathrm{G}-2$ & Projectile point, rectangular stem B & \\
\hline $\mathrm{E} 22 / \mathrm{S} 80$ & 8 & & $\mathrm{IIIb} / \mathrm{c}$ & $23 \mathrm{H}-6$ & Biface fragment & \\
\hline $\mathrm{E} 22 / \mathrm{S} 80$ & 8 & & $\mathrm{IIIb} / \mathrm{c}$ & $23 \mathrm{H}-14$ & Biface fragment & \\
\hline E22/S80 & 8 & & $\mathrm{IIIb} / \mathrm{c}$ & $23 \mathrm{H}-7$ & Biface Stage 2 & \\
\hline $\mathrm{E} 22 / \mathrm{S} 80$ & 8 & & $\mathrm{IIIb} / \mathrm{c}$ & $23 \mathrm{H}-5$ & Biface Stage 2 & \\
\hline $\mathrm{E} 22 / \mathrm{S} 80$ & 8 & & $\mathrm{IIIb} / \mathrm{c}$ & $23 \mathrm{H}-8$ & Biface Stage 2 & \\
\hline $\mathrm{E} 22 / \mathrm{S} 80$ & 8 & & $\mathrm{IIIb} / \mathrm{c}$ & $23 \mathrm{H}-9$ & Biface Stage 3 & \\
\hline $\mathrm{E} 22 / \mathrm{S} 80$ & 8 & & $\mathrm{IIIb} / \mathrm{c}$ & $23 \mathrm{H}-3$ & Bifacial tool Form B & \\
\hline $\mathrm{E} 22 / \mathrm{S} 80$ & 8 & & $\mathrm{IIIb} / \mathrm{c}$ & & Debitage & 62 \\
\hline $\mathrm{E} 22 / \mathrm{S} 80$ & 8 & & $\mathrm{IIIb} / \mathrm{c}$ & $23 \mathrm{H}-15$ & Edge modified flake & \\
\hline $\mathrm{E} 22 / \mathrm{S} 80$ & 8 & & $\mathrm{IIIb} / \mathrm{c}$ & $23 \mathrm{H}-16$ & Edge modified flake & \\
\hline $\mathrm{E} 22 / \mathrm{S} 80$ & 8 & & $\mathrm{III} \mathrm{b} / \mathrm{c}$ & $23 \mathrm{H}-2$ & Metate fragment & \\
\hline $\mathrm{E} 22 / \mathrm{S} 80$ & 8 & & $\mathrm{IIIb} / \mathrm{c}$ & $23 \mathrm{H}-19$ & Notched flake & \\
\hline $\mathrm{E} 22 / \mathrm{S} 80$ & 8 & & $\mathrm{IIIb} / \mathrm{c}$ & $23 \mathrm{H}-12$ & Perforator Group 2 & \\
\hline $\mathrm{E} 22 / \mathrm{S} 80$ & 8 & & $\mathrm{IIIb} / \mathrm{c}$ & $23 \mathrm{H}-4$ & Projectile point fragment & \\
\hline $\mathrm{E} 22 / \mathrm{S} 80$ & 8 & & $\mathrm{IIIb} / \mathrm{c}$ & $23 \mathrm{H}-13$ & Projectile point fragment & \\
\hline $\mathrm{E} 22 / \mathrm{S} 80$ & 8 & & $\mathrm{IIIb} / \mathrm{c}$ & $23 \mathrm{H}-10$ & Projectile point, rectangular stem A & \\
\hline $\mathrm{E} 22 / \mathrm{S} 80$ & 8 & & $\mathrm{IIIb} / \mathrm{c}$ & $23 \mathrm{H}-11$ & Projectile point, Travis & \\
\hline $\mathrm{E} 22 / \mathrm{S} 80$ & 8 & & $\mathrm{IIIb} / \mathrm{c}$ & $23 \mathrm{H}-18$ & Thin uniface fragment & \\
\hline $\mathrm{E} 22 / \mathrm{S} 80$ & 9 & & $\mathrm{IIIb}$ & $23 I-5$ & Biface fragment & \\
\hline $\mathrm{E} 22 / \mathrm{S} 80$ & 9 & & IIIb & $23 I-4$ & Biface Stage 2 & \\
\hline $\mathrm{E} 22 / \mathrm{S} 80$ & 9 & & IIIb & & Debitage & \\
\hline $\mathrm{E} 22 / \mathrm{S} 80$ & 9 & & $\mathrm{IIIb}$ & $23 I-8$ & Denticulated flake & \\
\hline
\end{tabular}




\begin{tabular}{|c|c|c|c|c|c|c|}
\hline Square & Level & Feature & Strata & Item & Analyst Identification & Count \\
\hline $\mathrm{E} 22 / \mathrm{S} 80$ & 9 & & IIIb & $23 I-3$ & Edge modified flake & 1 \\
\hline $\mathrm{E} 22 / \mathrm{S} 80$ & 9 & & $\mathrm{IIIb}$ & $23 \mathrm{I}-10$ & Edge modified flake & 1 \\
\hline $\mathrm{E} 22 / \mathrm{S} 80$ & 9 & & IIIb & $23 I-7$ & Projectile point fragment & 1 \\
\hline $\mathrm{E} 22 / \mathrm{S} 80$ & 9 & & IIIb & $23 I-6$ & Projectile point fragment & 1 \\
\hline $\mathrm{E} 22 / \mathrm{S} 80$ & 9 & & IIIb & $23 I-1$ & Projectile point, expanding stem $\mathrm{C}$ & 1 \\
\hline $\mathrm{E} 22 / \mathrm{S} 80$ & 9 & & IIIb & $23 I-2$ & Projectile point, Travis & \\
\hline $\mathrm{E} 22 / \mathrm{S} 80$ & 9 & & IIIb & $23 I-9$ & Thin uniface & \\
\hline $\mathrm{E} 22 / \mathrm{S} 80$ & 9 & & IIIb & $23 \mathrm{I}-11$ & Thin uniface fragment & 1 \\
\hline $\mathrm{E} 22 / \mathrm{S} 80$ & 10 & & IIIb & $23 \mathrm{~J}-5$ & Biface fragment & 1 \\
\hline $\mathrm{E} 22 / \mathrm{S} 80$ & 10 & & IIIb & $23 \mathrm{~J}-1$ & Biface Stage 2 & \\
\hline $\mathrm{E} 22 / \mathrm{S} 80$ & 10 & & $\mathrm{IIIb}$ & $23 \mathrm{~J}-2$ & Biface Stage 2 & \\
\hline $\mathrm{E} 22 / \mathrm{S} 80$ & 10 & & IIIb & $23 \mathrm{~J}-4$ & BIface Stage 2 & 1 \\
\hline $\mathrm{E} 22 / \mathrm{S} 80$ & 10 & & IIIb & $23 \mathrm{~J}-3$ & Bifacial tool & 1 \\
\hline $\mathrm{E} 22 / \mathrm{S} 80$ & 10 & & IIIb & $23 \mathrm{~J}-6$ & Core tool, type 1 & 1 \\
\hline $\mathrm{E} 22 / \mathrm{S} 80$ & 10 & & IIIb & & Debitage & 529 \\
\hline $\mathrm{E} 22 / \mathrm{S} 80$ & 10 & & IIIb & $23 \mathrm{~J}-11$ & Edge modified flake & \\
\hline $\mathrm{E} 22 / \mathrm{S} 80$ & 10 & & IIIb & $23 \mathrm{~J}-17$ & Edge modified flake & \\
\hline $\mathrm{E} 22 / \mathrm{S} 80$ & 10 & & IIIb & $23 \mathrm{~J}-18$ & Edge modified flake & \\
\hline $\mathrm{E} 22 / \mathrm{S} 80$ & 10 & & IIIb & $23 \mathrm{~J}-12$ & Edge modified flake & \\
\hline $\mathrm{E} 22 / \mathrm{S} 80$ & 10 & & $\mathrm{IIIb}$ & $23 \mathrm{~J}-14$ & Edge modified flake & \\
\hline $\mathrm{E} 22 / \mathrm{S} 80$ & 10 & & IIIb & $23 \mathrm{~J}-8$ & Edge modified flake & 1 \\
\hline $\mathrm{E} 22 / \mathrm{S} 80$ & 10 & & IIIb & $23 \mathrm{~J}-19$ & Edge modified flake & 1 \\
\hline $\mathrm{E} 22 / \mathrm{S} 80$ & 10 & & IIIb & $23 \mathrm{~J}-13$ & Thick uniface & 1 \\
\hline $\mathrm{E} 22 / \mathrm{S} 80$ & 10 & & IIIb & $23 \mathrm{~J}-21$ & Thin uniface fragment & \\
\hline $\mathrm{E} 22 / \mathrm{S} 80$ & 10 & & IIIb & $23 \mathrm{~J}-16$ & Uniface, unanalyzed & \\
\hline $\mathrm{E} 22 / \mathrm{S} 80$ & 10 & & IIIb & $23 \mathrm{~J}-9$ & Uniface, unanalyzed & 1 \\
\hline $\mathrm{E} 22 / \mathrm{S} 80$ & 10 & & IIIb & $23 \mathrm{~J}-15$ & Unifacial multiple tool & 1 \\
\hline $\mathrm{E} 22 / \mathrm{S} 80$ & 10 & & IIIb & $23 \mathrm{~J}-7$ & Unifacial multiple tool & \\
\hline $\mathrm{E} 22 / \mathrm{S} 80$ & 11 & & IIIb & & Debitage & 498 \\
\hline $\mathrm{E} 22 / \mathrm{S} 80$ & 11 & & IIIb & $23 \mathrm{~K}-3$ & Microspur/microdenticulate & 1 \\
\hline $\mathrm{E} 22 / \mathrm{S} 80$ & 11 & & IIIb & $23 \mathrm{~K}-1$ & Projectile point, expanding concave D & 1 \\
\hline $\mathrm{E} 22 / \mathrm{S} 80$ & 11 & & IIIb & $23 \mathrm{~K}-2$ & Thin uniface & 1 \\
\hline $\mathrm{E} 22 / \mathrm{S} 80$ & 11 & & IIIb & $23 \mathrm{~K}-4$ & Unifacial multiple tool & 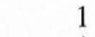 \\
\hline $\mathrm{E} 22 / \mathrm{S} 80$ & 12 & & IIIb & 23L-13 & Biface fragment & 1 \\
\hline $\mathrm{E} 22 / \mathrm{S} 80$ & 12 & & IIIb & $23 \mathrm{~L}-1$ & Biface fragment & 1 \\
\hline $\mathrm{E} 22 / \mathrm{S} 80$ & 12 & & IIIb & $23 \mathrm{~L}-10$ & Biface fragment & 1 \\
\hline $\mathrm{E} 22 / \mathrm{S} 80$ & 12 & & IIIb & $23 \mathrm{~L}-2$ & Biface Stage 2 & 1 \\
\hline $\mathrm{E} 22 / \mathrm{S} 80$ & 12 & & $\mathrm{IIIb}$ & $23 \mathrm{~L}-21$ & Biface Stage 2 & 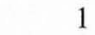 \\
\hline $\mathrm{E} 22 / \mathrm{S} 80$ & 12 & & IIIb & $23 \mathrm{~L}-5$ & Chert cobble, chunk & 1 \\
\hline $\mathrm{E} 22 / \mathrm{S} 80$ & 12 & & $\mathrm{IIIb}$ & $23 \mathrm{~L}-4$ & Core fragment & 1 \\
\hline $\mathrm{E} 22 / \mathrm{S} 80$ & 12 & & IIIb & $23 \mathrm{~L}-3$ & Core tool, type 2 & \\
\hline $\mathrm{E} 22 / \mathrm{S} 80$ & 12 & & IIIb & & Debitage & 910 \\
\hline $\mathrm{E} 22 / \mathrm{S} 80$ & 12 & & IIIb & $23 \mathrm{~L}-16$ & Denticulated flake & 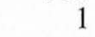 \\
\hline $\mathrm{E} 22 / \mathrm{S} 80$ & 12 & & IIIb & $23 \mathrm{~L}-11$ & Edge modified flake & 1 \\
\hline $\mathrm{E} 22 / \mathrm{S} 80$ & 12 & & IIIb & 23L-15 & Edge modified flake & 1 \\
\hline $\mathrm{E} 22 / \mathrm{S} 80$ & 12 & & IIIb & $23 \mathrm{~L}-20$ & Edge modified flake & \\
\hline $\mathrm{E} 22 / \mathrm{S} 80$ & 12 & & IIIb & 23L-12 & Edge modified flake & 1 \\
\hline $\mathrm{E} 22 / \mathrm{S} 80$ & 12 & & IIIb & 23L-23 & Edge modified flake & 1 \\
\hline $\mathrm{E} 22 / \mathrm{S} 80$ & 12 & & IIIb & $23 \mathrm{~L}-8$ & Microspur/microdenticulate & 1 \\
\hline $\mathrm{E} 22 / \mathrm{S} 80$ & 12 & & IIIb & $23 \mathrm{~L}-6$ & Projectile point, miscellaneous lanceolate & \\
\hline $\mathrm{E} 22 / \mathrm{S} 80$ & 12 & & IIIb & $23 \mathrm{~L}-7$ & Projectile point, rectangular stem C & \\
\hline $\mathrm{E} 22 / \mathrm{S} 80$ & 12 & & IIIb & 23L-9 & Thin uniface & 1 \\
\hline $\mathrm{E} 22 / \mathrm{S} 80$ & 12 & & IIIb & $23 \mathrm{~L}-24$ & Thin uniface & 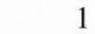 \\
\hline $\mathrm{E} 22 / \mathrm{S} 80$ & 12 & & IIIb & 23L-22 & Thin uniface fragment & 1 \\
\hline $\mathrm{E} 22 / \mathrm{S} 80$ & 12 & & IIIb & $23 \mathrm{~L}-17$ & Uniface, unanalyzed & \\
\hline $\mathrm{E} 22 / \mathrm{S} 80$ & 13 & & $\mathrm{IIIa} / \mathrm{b}$ & $23 \mathrm{M}-5$ & Biface fragment & 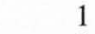 \\
\hline $\mathrm{E} 22 / \mathrm{S} 80$ & 13 & & $\mathrm{IIIa} / \mathrm{b}$ & $23 \mathrm{M}-8$ & Biface Stage 2 & \\
\hline $\mathrm{E} 22 / \mathrm{S} 80$ & 13 & & $\mathrm{IIIa} / \mathrm{b}$ & $23 \mathrm{M}-19$ & Biface Stage 2 & 1 \\
\hline $\mathrm{E} 22 / \mathrm{S} 80$ & 13 & & $\mathrm{IIIa} / \mathrm{b}$ & $23 \mathrm{M}-7$ & Biface Stage 3 & 1 \\
\hline $\mathrm{E} 22 / \mathrm{S} 80$ & 13 & & $\mathrm{IIIa} / \mathrm{b}$ & $23 \mathrm{M}-18$ & Bifacial tool Form B & 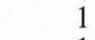 \\
\hline $\mathrm{E} 22 / \mathrm{S} 80$ & 13 & & IIIa/b & $23 \mathrm{M}-13$ & Burin & \\
\hline $\mathrm{E} 22 / \mathrm{S} 80$ & 13 & & $\mathrm{III} / \mathrm{b}$ & & Debitage & 1687 \\
\hline $\mathrm{E} 22 / \mathrm{S} 80$ & 13 & & $\mathrm{IIIa} / \mathrm{b}$ & $23 M-16$ & Edge modified flake & \\
\hline $\mathrm{E} 22 / \mathrm{S} 80$ & 13 & & $\mathrm{IIIa} / \mathrm{b}$ & $23 \mathrm{M}-11$ & Edge modified flake & \\
\hline $\mathrm{E} 22 / \mathrm{S} 80$ & 13 & & $\mathrm{III} / \mathrm{b}$ & $23 \mathrm{M}-12$ & Edge modified flake & \\
\hline $\mathrm{E} 22 / \mathrm{S} 80$ & 13 & & $\mathrm{III} / \mathrm{b}$ & $23 \mathrm{M}-14$ & Edge modified flake & \\
\hline $\mathrm{E} 22 / \mathrm{S} 80$ & 13 & & $\mathrm{IIIa} / \mathrm{b}$ & $23 \mathrm{M}-22$ & Edge modified flake & \\
\hline $\mathrm{E} 22 / \mathrm{S} 80$ & 13 & & $\mathrm{IIIa} / \mathrm{b}$ & $23 \mathrm{M}-4$ & Edge modified flake & \\
\hline $\mathrm{E} 22 / \mathrm{S} 80$ & 13 & & $\mathrm{IIIa} / \mathrm{b}$ & $23 \mathrm{M}-21$ & Edge modified flake & 1 \\
\hline $\mathrm{E} 22 / \mathrm{S} 80$ & 13 & & $\mathrm{III} / \mathrm{b}$ & $23 \mathrm{M}-20$ & Edge modified flake & \\
\hline $\mathrm{E} 22 / \mathrm{S} 80$ & 13 & & IIIa/b & $23 \mathrm{M}-23$ & Edge modified flake & \\
\hline $\mathrm{E} 22 / \mathrm{S} 80$ & 13 & & $\mathrm{IIIa} / \mathrm{b}$ & $23 \mathrm{M}-17$ & Edge modified flake & \\
\hline $\mathrm{E} 22 / \mathrm{S} 80$ & 13 & & $\mathrm{IIIa} / \mathrm{b}$ & $23 \mathrm{M}-15$ & Notched flake & \\
\hline $\mathrm{E} 22 / \mathrm{S} 80$ & 13 & & IIIa/b & $23 \mathrm{M}-6$ & Perforator Group 7 & 1 \\
\hline
\end{tabular}




\begin{tabular}{|c|c|c|c|c|c|c|}
\hline Square & Level & Feature & Strata & Item & Analyst Identification & Count \\
\hline E22/S80 & 13 & & $\mathrm{IIIa} / \mathrm{b}$ & $23 \mathrm{M}-9$ & Projectile point fragment & 1 \\
\hline E22/S80 & 13 & & $\mathrm{III} / \mathrm{b}$ & $23 \mathrm{M}-3$ & Projectile point fragment & 1 \\
\hline E22/S80 & 13 & & IIIa/b & $23 \mathrm{M}-1$ & Projectile point, Bandy & 1 \\
\hline E22/S80 & 13 & & $\mathrm{III} / \mathrm{b}$ & $23 \mathrm{M}-2$ & Projectile point, Gower & 1 \\
\hline $\mathrm{E} 22 / \mathrm{S} 80$ & 13 & & $\mathrm{IIIa} / \mathrm{b}$ & $23 \mathrm{M}-25$ & Thin uniface & 1 \\
\hline E22/S80 & 13 & & $\mathrm{III} / \mathrm{b}$ & $23 \mathrm{M}-10$ & Thin uniface & 1 \\
\hline E22/S80 & 13 & & IIIa/b & $23 \mathrm{M}-24$ & Unifacial multiple tool & 1 \\
\hline E22/S80 & 15 & & IIIa & $230-2$ & Biface fragment & 1 \\
\hline E22/S80 & 15 & & IIIa & $230-21$ & Biface fragment & 1 \\
\hline $\mathrm{E} 22 / \mathrm{S} 80$ & 15 & & IIIa & $230-7$ & Biface Stage 1 & 1 \\
\hline E22/S80 & 15 & & IIIa & $230-4$ & Biface Stage 1 & 1 \\
\hline E22/S80 & 15 & & IIIa & $230-5$ & Biface Stage 2 & 1 \\
\hline E22/S80 & 15 & & IIIa & $230-1$ & Biface Stage 3 & 1 \\
\hline $\mathrm{E} 22 / \mathrm{S} 80$ & 15 & & IIIa & $23 \mathrm{O}-17$ & Burin spall & 1 \\
\hline E22/S80 & 15 & & IIIa & & Debitage & 1180 \\
\hline E22/S80 & 15 & & IIIa & $23 \mathrm{O}-14$ & Edge modified flake & 1 \\
\hline $\mathrm{E} 22 / \mathrm{S} 80$ & 15 & & IIIa & $230-19$ & Edge modified flake & 1 \\
\hline E22/S80 & 15 & & IIIa & $230-20$ & Edge modified flake & 1 \\
\hline E22/S80 & 15 & & IIIa & $230-18$ & Notched flake & 1 \\
\hline E22/S80 & 15 & & IIIa & $230-16$ & Notched flake & 1 \\
\hline E22/S80 & 15 & & IIIa & $230-3$ & Perforator Group 1 & 1 \\
\hline $\mathrm{E} 22 / \mathrm{S} 80$ & 15 & & IIIa & $230-8$ & Projectile point fragment & 1 \\
\hline $\mathrm{E} 22 / \mathrm{S} 80$ & 15 & & IIIa & $230-9$ & Projectile point, Gower/Jetta & 1 \\
\hline $\mathrm{E} 22 / \mathrm{S} 80$ & 15 & & IIIa & $230-13$ & Thick uniface & 1 \\
\hline $\mathrm{E} 22 / \mathrm{S} 80$ & 15 & & IIIa & $23 \mathrm{O}-12$ & Thick uniface & 1 \\
\hline $\mathrm{E} 22 / \mathrm{S} 80$ & 15 & & IIIa & $23 \mathrm{O}-15$ & Thin uniface & 1 \\
\hline E22/S80 & 15 & & IIIa & $230-10$ & Thin uniface & 1 \\
\hline $\mathrm{E} 22 / \mathrm{S} 80$ & 15 & & IIIa & $230-11$ & Unifacial multiple tool & 1 \\
\hline $\mathrm{E} 22 / \mathrm{S} 80$ & 16 & & IIIa & $23 \mathrm{P}-4$ & Biface fragment & 1 \\
\hline $\mathrm{E} 22 / \mathrm{S} 80$ & 16 & & IIIa & $23 \mathrm{P}-14$ & Biface fragment & 1 \\
\hline $\mathrm{E} 22 / \mathrm{S} 80$ & 16 & & IIIa & $23 \mathrm{P}-6$ & Biface Stage 2 & 1 \\
\hline $\mathrm{E} 22 / \mathrm{S} 80$ & 16 & & IIIa & $23 \mathrm{P}-5$ & Biface Stage 2 & 1 \\
\hline $\mathrm{E} 22 / \mathrm{S} 80$ & 16 & & IIIIa & $23 \mathrm{P}-12$ & Burin spall & 1 \\
\hline $\mathrm{E} 22 / \mathrm{S} 80$ & 16 & & IIIa & & Debitage & 954 \\
\hline $\mathrm{E} 22 / \mathrm{S} 80$ & 16 & & IIIa & $23 \mathrm{P}-3$ & Edge modified flake & 1 \\
\hline $\mathrm{E} 22 / \mathrm{S} 80$ & 16 & & IIII & $23 \mathrm{P}-16$ & Edge modified flake & 1 \\
\hline $\mathrm{E} 22 / \mathrm{S} 80$ & 16 & & IIIa & $23 \mathrm{P}-13$ & Edge modified flake & 1 \\
\hline $\mathrm{E} 22 / \mathrm{S} 80$ & 16 & & IIIa & $23 \mathrm{P}-11$ & Edge modified flake & 1 \\
\hline $\mathrm{E} 22 / \mathrm{S} 80$ & 16 & & IIIa & $23 \mathrm{P}-2$ & Mano & 1 \\
\hline $\mathrm{E} 22 / \mathrm{S} 80$ & 16 & & IIIa & $23 \mathrm{P}-15$ & Micro-core, small & 1 \\
\hline $\mathrm{E} 22 / \mathrm{S} 80$ & 16 & & IIIa & $23 \mathrm{P}-7$ & Microspur/microdenticulate & 1 \\
\hline $\mathrm{E} 22 / \mathrm{S} 80$ & 16 & & IIIa & $23 \mathrm{P}-1$ & Projectile point, Angostura & 1 \\
\hline $\mathrm{E} 22 / \mathrm{S} 80$ & 16 & & III & 23P-17 & Thin uniface & 1 \\
\hline $\mathrm{E} 22 / \mathrm{S} 80$ & 16 & & IIIa & $23 \mathrm{P}-8$ & Unifacial multiple tool & 1 \\
\hline $\mathrm{E} 22 / \mathrm{S} 80$ & 17 & & II/IIIa & $23 Q-13$ & Burin spall & 1 \\
\hline $\mathrm{E} 22 / \mathrm{S} 80$ & 17 & & II/IIIa & $23 Q-6$ & Core fragment & 1 \\
\hline $\mathrm{E} 22 / \mathrm{S} 80$ & 17 & & II/IIIa & $23 \mathrm{Q}-2$ & Core tool, type 2 & 1 \\
\hline $\mathrm{E} 22 / \mathrm{S} 80$ & 17 & & II/IIIa & & Debitage & 1156 \\
\hline $\mathrm{E} 22 / \mathrm{S} 80$ & 17 & & II/IIIa & 23Q-11 & Edge modified flake & 1 \\
\hline $\mathrm{E} 22 / \mathrm{S} 80$ & 17 & & II/IIIa & $23 \mathrm{Q}-10$ & Edge modified flake & 1 \\
\hline $\mathrm{E} 22 / \mathrm{S} 80$ & 17 & & II/IIIa & 23Q-9 & Edge modified flake & 1 \\
\hline $\mathrm{E} 22 / \mathrm{S} 80$ & 17 & & II/IIIa & $23 \mathrm{Q}-7$ & Microspur/microdenticulate & 1 \\
\hline $\mathrm{E} 22 / \mathrm{S} 80$ & 17 & & II/III & $23 \mathrm{Q}-4$ & Projectile point fragment & 1 \\
\hline $\mathrm{E} 22 / \mathrm{S} 80$ & 17 & & II/IIIa & $23 \mathrm{Q}-1$ & Projectile point, Golondrina-Barber & 1 \\
\hline $\mathrm{E} 22 / \mathrm{S} 80$ & 17 & & II/IIa & $23 Q-8$ & Projectile point, miscellaneous lanceolate & 1 \\
\hline $\mathrm{E} 22 / \mathrm{S} 80$ & 17 & & II/IIIa & $23 \mathrm{Q}-3$ & Thick uniface & 1 \\
\hline $\mathrm{E} 22 / \mathrm{S} 80$ & 17 & & II/IIIa & $23 \mathrm{Q}-12$ & Uniface, unanalyzed & 1 \\
\hline E22/S80 & 17 & & II/III & $23 \mathrm{Q}-5$ & Unifacial multiple tool & 1 \\
\hline $\mathrm{E} 22 / \mathrm{S} 80$ & 17 & & II/IIIa & $23 Q-14$ & Worked hematite & 1 \\
\hline $\mathrm{E} 22 / \mathrm{S} 80$ & 18 & & II & & Debitage & 742 \\
\hline E22/S80 & 18 & & II & 23R-9 & Edge modified flake & 1 \\
\hline $\mathrm{E} 22 / \mathrm{S} 80$ & 18 & & II & $23 \mathrm{R}-8$ & Edge modified flake & 1 \\
\hline $\mathrm{E} 22 / \mathrm{S} 80$ & 18 & & II & 23R-10 & Edge modified flake & 1 \\
\hline $\mathrm{E} 22 / \mathrm{S} 80$ & 18 & & II & $23 \mathrm{R}-3$ & Edge modified flake & 1 \\
\hline $\mathrm{E} 22 / \mathrm{S} 80$ & 18 & & II & $23 \mathrm{R}-2$ & Edge modified flake & 1 \\
\hline $\mathrm{E} 22 / \mathrm{S} 80$ & 18 & & II & $23 R-7$ & Thin uniface & 1 \\
\hline $\mathrm{E} 22 / \mathrm{S} 80$ & 18 & & II & $23 \mathrm{R}-6$ & Uniface, unanalyzed & 1 \\
\hline $\mathrm{E} 22 / \mathrm{S} 80$ & 19 & & II & $23 \mathrm{~S}-1$ & Biface Stage 2 & 1 \\
\hline $\mathrm{E} 22 / \mathrm{S} 80$ & 19 & & II & $23 \mathrm{~S}-3$ & Burin spall & 1 \\
\hline $\mathrm{E} 22 / \mathrm{S} 80$ & 19 & & II & & Debitage & 717 \\
\hline $\mathrm{E} 22 / \mathrm{S} 80$ & 19 & & II & $23 \mathrm{~S}-4$ & Edge modified flake & 1 \\
\hline E22/S80 & 19 & & II & $23 \mathrm{~S}-8$ & Edge modified flake & 1 \\
\hline $\mathrm{E} 22 / \mathrm{S} 80$ & 19 & & II & $23 \mathrm{~S}-7$ & Notched flake & 1 \\
\hline $\mathrm{E} 22 / \mathrm{S} 80$ & 19 & & II & $23 \mathrm{~S}-2$ & Projectile point, miscellaneous lanceolate & 1 \\
\hline
\end{tabular}




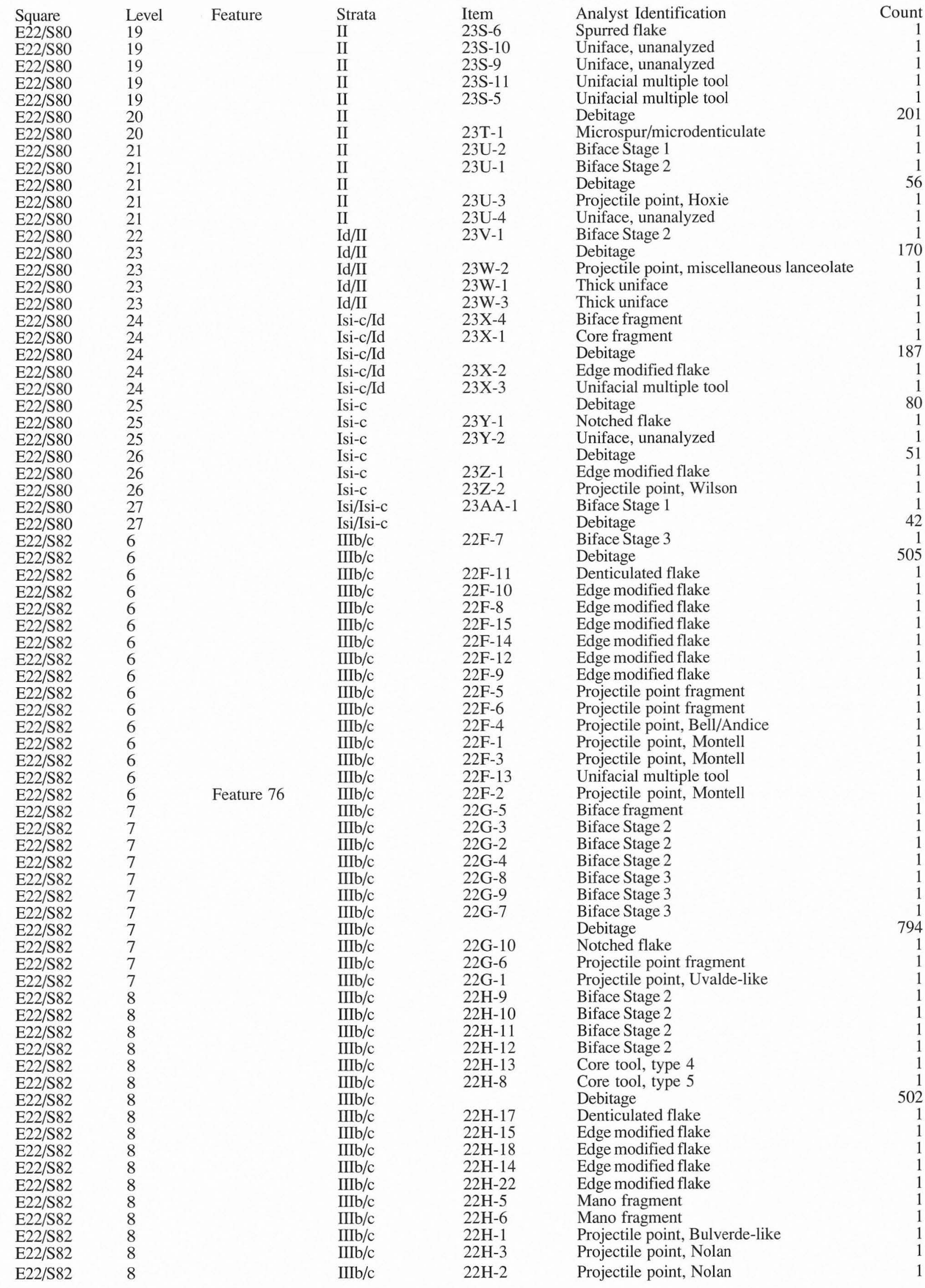




\begin{tabular}{|c|c|c|c|c|c|c|}
\hline $\begin{array}{l}\text { Square } \\
\text { E22/S82 }\end{array}$ & $\begin{array}{l}\text { Level } \\
8\end{array}$ & Feature & Strata & Item & Analyst Identification & $\begin{array}{r}\text { Count } \\
1\end{array}$ \\
\hline $\begin{array}{l}\mathrm{E} 22 / \mathrm{S} 82 \\
\mathrm{E} 22 / \mathrm{S} 82\end{array}$ & $\begin{array}{l}8 \\
8\end{array}$ & & $\begin{array}{l}\mathrm{IIII} / \mathrm{c} \\
\mathrm{IIIb} / \mathrm{c}\end{array}$ & $\begin{array}{l}22 \mathrm{H}-4 \\
22 \mathrm{H}-23\end{array}$ & $\begin{array}{l}\text { Projectile point, rectangular stem A } \\
\text { Thin uniface }\end{array}$ & $\begin{array}{l}1 \\
1\end{array}$ \\
\hline $\mathrm{E} 22 / \mathrm{S} 82$ & 8 & & $\mathrm{IIIJ} / \mathrm{c}$ & $22 \mathrm{H}-16$ & Uniface, unanalyzed & 1 \\
\hline E22/S82 & 8 & & $\mathrm{IIIb} / \mathrm{c}$ & $22 \mathrm{H}-19$ & Uniface, unanalyzed & 1 \\
\hline $\mathrm{E} 22 / \mathrm{S} 82$ & 8 & & $\mathrm{IIIb} / \mathrm{c}$ & $22 \mathrm{H}-20$ & Uniface, unanalyzed & 1 \\
\hline $\mathrm{E} 22 / \mathrm{S} 82$ & 8 & & $\mathrm{IIIb} / \mathrm{c}$ & $22 \mathrm{H}-21$ & Uniface, unanalyzed & 1 \\
\hline $\mathrm{E} 22 / \mathrm{S} 82$ & 9 & & IIIb & $22 \mathrm{I}-3$ & Biface Stage 1 & 1 \\
\hline $\mathrm{E} 22 / \mathrm{S} 82$ & 9 & & IIIb & $22 \mathrm{I}-5$ & Biface Stage 2 & 1 \\
\hline $\mathrm{E} 22 / \mathrm{S} 82$ & 9 & & IIIb & $22 \mathrm{I}-4$ & Biface Stage 2 & 1 \\
\hline $\mathrm{E} 22 / \mathrm{S} 82$ & 9 & & IIIIb & $22 \mathrm{I}-6$ & Bifacial tool Form $\mathrm{F}$ & 1 \\
\hline $\mathrm{E} 22 / \mathrm{S} 82$ & 9 & & IIIb & & Debitage & 685 \\
\hline E22/S82 & 9 & & IIIb & $22 \mathrm{I}-17$ & Edge modified flake & 1 \\
\hline $\mathrm{E} 22 / \mathrm{S} 82$ & 9 & & IIIb & $22 \mathrm{I}-18$ & Edge modified flake & 1 \\
\hline $\mathrm{E} 22 / \mathrm{S} 82$ & 9 & & IIIb & $22 \mathrm{I}-16$ & Edge modified flake & 1 \\
\hline $\mathrm{E} 22 / \mathrm{S} 82$ & 9 & & IIIb & $22 \mathrm{I}-15$ & Edge modified flake & 1 \\
\hline $\mathrm{E} 22 / \mathrm{S} 82$ & 9 & & IIIIb & $22 \mathrm{I}-1$ & Metate fragment & 1 \\
\hline E22/S82 & 9 & & IIIb & $22 \mathrm{I}-7$ & Notched flake & 1 \\
\hline $\mathrm{E} 22 / \mathrm{S} 82$ & 9 & & $\mathrm{IIIb}$ & $22 \mathrm{I}-2$ & Projectile point, miscellaneous lanceolate & 1 \\
\hline $\mathrm{E} 22 / \mathrm{S} 82$ & 9 & & IIIb & $22 \mathrm{I}-14$ & Thin uniface & 1 \\
\hline $\mathrm{E} 22 / \mathrm{S} 82$ & 9 & & IIIb & $22 \mathrm{I}-13$ & Thin uniface & 1 \\
\hline $\mathrm{E} 22 / \mathrm{S} 82$ & 9 & & IIIb & $22 \mathrm{I}-8 \mathrm{~B}$ & Thin uniface fragment & 1 \\
\hline $\mathrm{E} 22 / \mathrm{S} 82$ & 9 & & IIIb & $22 \mathrm{I}-11$ & Uniface, unanalyzed & 1 \\
\hline $\mathrm{E} 22 / \mathrm{S} 82$ & 9 & & IIIb & $22 \mathrm{I}-12$ & Uniface, unanalyzed & 1 \\
\hline $\mathrm{E} 22 / \mathrm{S} 82$ & 9 & & IIIb & $22 \mathrm{I}-9$ & Uniface, unanalyzed & 1 \\
\hline $\mathrm{E} 22 / \mathrm{S} 82$ & 9 & & IIIb & $22 \mathrm{I}-10$ & Uniface, unanalyzed & 1 \\
\hline $\mathrm{E} 22 / \mathrm{S} 82$ & 9 & & IIIb & $22 \mathrm{I}-8 \mathrm{~A}$ & Unifacial multiple tool & 1 \\
\hline $\mathrm{E} 22 / \mathrm{S} 82$ & 10 & & IIIb & $22 \mathrm{~J}-2$ & Biface Stage 1 & 1 \\
\hline $\mathrm{E} 22 / \mathrm{S} 82$ & 10 & & IIIb & $22 \mathrm{~J}-1$ & Biface Stage 2 & 1 \\
\hline $\mathrm{E} 22 / \mathrm{S} 82$ & 10 & & IIIb & $22 \mathrm{~J}-6$ & Biface Stage 2 & 1 \\
\hline $\mathrm{E} 22 / \mathrm{S} 82$ & 10 & & IIIb & $22 \mathrm{~J}-5$ & Biface Stage 2 & 1 \\
\hline $\mathrm{E} 22 / \mathrm{S} 82$ & 10 & & IIIb & 22J-4 & Biface Stage 2 & 1 \\
\hline $\mathrm{E} 22 / \mathrm{S} 82$ & 10 & & $\mathrm{IIIb}$ & $22 \mathrm{~J}-3$ & Bifacial tool Form $\mathrm{H}$ & 1 \\
\hline $\mathrm{E} 22 / \mathrm{S} 82$ & 10 & & IIIb & $22 \mathrm{~J}-7$ & Burin & 1 \\
\hline $\mathrm{E} 22 / \mathrm{S} 82$ & 10 & & IIIb & & Debitage & 664 \\
\hline $\mathrm{E} 22 / \mathrm{S} 82$ & 10 & & IIIIb & $22 \mathrm{~J}-9$ & Denticulated flake & 1 \\
\hline $\mathrm{E} 22 / \mathrm{S} 82$ & 10 & & IIIb & $22 \mathrm{~J}-12$ & Edge modified flake & 1 \\
\hline $\mathrm{E} 22 / \mathrm{S} 82$ & 10 & & IIII & $22 \mathrm{~J}-11$ & Edge modified flake & 1 \\
\hline $\mathrm{E} 22 / \mathrm{S} 82$ & 10 & & IIIb & $22 \mathrm{~J}-10$ & Uniface, unanalyzed & 1 \\
\hline $\mathrm{E} 22 / \mathrm{S} 82$ & 10 & & IIIb & $22 \mathrm{~J}-8$ & Unifacial multiple tool & 1 \\
\hline $\mathrm{E} 22 / \mathrm{S} 82$ & 11 & & IIIb & $22 \mathrm{~K}-2$ & Biface Stage 2 & 1 \\
\hline $\mathrm{E} 22 / \mathrm{S} 82$ & 11 & & IIIb & $22 \mathrm{~K}-3$ & Biface Stage 2 & 1 \\
\hline $\mathrm{E} 22 / \mathrm{S} 82$ & 11 & & IIIb & $22 \mathrm{~K}-4$ & Burin spall & 1 \\
\hline $\mathrm{E} 22 / \mathrm{S} 82$ & 11 & & IIIb & & Debitage & 429 \\
\hline E22/S82 & 11 & & IIIb & $22 \mathrm{~K}-5$ & Microspur/microdenticulate & 1 \\
\hline $\mathrm{E} 22 / \mathrm{S} 82$ & 11 & & IIIb & $22 \mathrm{~K}-6$ & Piece esquillee & 1 \\
\hline E22/S82 & 11 & & IIIb & $22 \mathrm{~K}-1$ & Projectile point, indeterminate & 1 \\
\hline $\mathrm{E} 22 / \mathrm{S} 82$ & 12 & & IIIb & $22 \mathrm{~L}-4$ & Biface fragment & 1 \\
\hline $\mathrm{E} 22 / \mathrm{S} 82$ & 12 & & IIIb & $22 \mathrm{~L}-10$ & Biface Stage 1 & 1 \\
\hline $\mathrm{E} 22 / \mathrm{S} 82$ & 12 & & IIIb & $22 \mathrm{~L}-2$ & Biface Stage 2 & 1 \\
\hline $\mathrm{E} 22 / \mathrm{S} 82$ & 12 & & IIIb & $22 \mathrm{~L}-16$ & Biface Stage 2 & 1 \\
\hline $\mathrm{E} 22 / \mathrm{S} 82$ & 12 & & IIIb & $22 \mathrm{~L}-3$ & Biface Stage 2 & 1 \\
\hline $\mathrm{E} 22 / \mathrm{S} 82$ & 12 & & IIIlb & $22 \mathrm{~L}-9$ & Biface Stage 2 & 1 \\
\hline $\mathrm{E} 22 / \mathrm{S} 82$ & 12 & & IIIb & $22 \mathrm{~L}-7$ & Burin spall & 1 \\
\hline $\mathrm{E} 22 / \mathrm{S} 82$ & 12 & & IIIb & $22 \mathrm{~L}-8$ & Burin spall & 1 \\
\hline $\mathrm{E} 22 / \mathrm{S} 82$ & 12 & & IIIb & & Debitage & 1695 \\
\hline E22/S82 & 12 & & IIIb & $22 \mathrm{~L}-18$ & Edge modified flake & 1 \\
\hline $\mathrm{E} 22 / \mathrm{S} 82$ & 12 & & IIIb & $22 \mathrm{~L}-19$ & Edge modified flake & 1 \\
\hline $\mathrm{E} 22 / \mathrm{S} 82$ & 12 & & IIIb & $22 \mathrm{~L}-12$ & Edge modified flake & 1 \\
\hline $\mathrm{E} 22 / \mathrm{S} 82$ & 12 & & IIIb & $22 \mathrm{~L}-14$ & Edge modified flake & 1 \\
\hline $\mathrm{E} 22 / \mathrm{S} 82$ & 12 & & IIIb & $22 \mathrm{~L}-6$ & Projectile point fragment & 1 \\
\hline $\mathrm{E} 22 / \mathrm{S} 82$ & 12 & & IIIb & $22 \mathrm{~L}-5$ & Projectile point fragment & 1 \\
\hline $\mathrm{E} 22 / \mathrm{S} 82$ & 12 & & IIIb & $22 \mathrm{~L}-1$ & Projectile point, bifurcate stem fragment & 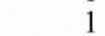 \\
\hline $\mathrm{E} 22 / \mathrm{S} 82$ & 12 & & IIIb & $22 \mathrm{~L}-17$ & Thin uniface & 1 \\
\hline E22/S82 & 12 & & IIIb & $22 \mathrm{~L}-15$ & Thin uniface fragment & 1 \\
\hline E22/S82 & 13 & & $\mathrm{III} / \mathrm{b}$ & $22 \mathrm{M}-29$ & Biface fragment & 1 \\
\hline $\mathrm{E} 22 / \mathrm{S} 82$ & 13 & & $\mathrm{IIIa} / \mathrm{b}$ & $22 \mathrm{M}-5$ & Biface fragment & 1 \\
\hline $\mathrm{E} 22 / \mathrm{S} 82$ & 13 & & IIIIa/b & $22 \mathrm{M}-4$ & Biface Stage 2 & 1 \\
\hline $\mathrm{E} 22 / \mathrm{S} 82$ & 13 & & $\mathrm{IIIa} / \mathrm{b}$ & $22 \mathrm{M}-10$ & Biface Stage 2 & 1 \\
\hline $\mathrm{E} 22 / \mathrm{S} 82$ & 13 & & IIIIa/b & $22 \mathrm{M}-6$ & Burin spall & 1 \\
\hline $\mathrm{E} 22 / \mathrm{S} 82$ & 13 & & $\mathrm{IIIa} / \mathrm{b}$ & $22 \mathrm{M}-7$ & Burin spall & 1 \\
\hline $\mathrm{E} 22 / \mathrm{S} 82$ & 13 & & IIIIa/b & & Debitage & 1148 \\
\hline $\mathrm{E} 22 / \mathrm{S} 82$ & 13 & & IIIa/b & $22 \mathrm{M}-8$ & Denticulated flake & 1 \\
\hline E22/S82 & 13 & & IIIa/b & $22 \mathrm{M}-20$ & Edge modified flake & 1 \\
\hline $\mathrm{E} 22 / \mathrm{S} 82$ & 13 & & IIIa/b & $22 \mathrm{M}-11$ & Edge modified flake & 1 \\
\hline
\end{tabular}




\begin{tabular}{|c|c|c|c|c|c|c|}
\hline Square & Level & Feature & Strata & Item & Analyst Identification & Count \\
\hline $\mathrm{E} 22 / \mathrm{S} 82$ & 13 & & $\mathrm{IIIa} / \mathrm{b}$ & $22 M-36$ & Edge modified flake & \\
\hline $\mathrm{E} 22 / \mathrm{S} 82$ & 13 & & $\mathrm{IIIa} / \mathrm{b}$ & $22 \mathrm{M}-9$ & Edge modified flake & \\
\hline $\mathrm{E} 22 / \mathrm{S} 82$ & 13 & & $\mathrm{III} / \mathrm{b}$ & $22 \mathrm{M}-18$ & Edge modified flake & \\
\hline $\mathrm{E} 22 / \mathrm{S} 82$ & 13 & & $\mathrm{IIIa} / \mathrm{b}$ & $22 \mathrm{M}-21$ & Edge modified flake & \\
\hline $\mathrm{E} 22 / \mathrm{S} 82$ & 13 & & $\mathrm{IIIa} / \mathrm{b}$ & $22 \mathrm{M}-28$ & Edge modified flake & \\
\hline $\mathrm{E} 22 / \mathrm{S} 82$ & 13 & & $\mathrm{IIIa} / \mathrm{b}$ & $22 \mathrm{M}-24$ & Edge modified flake & \\
\hline $\mathrm{E} 22 / \mathrm{S} 82$ & 13 & & $\mathrm{IIIa} / \mathrm{b}$ & $22 \mathrm{M}-22$ & Edge modified flake & \\
\hline $\mathrm{E} 22 / \mathrm{S} 82$ & 13 & & $\mathrm{IIIa} / \mathrm{b}$ & $22 \mathrm{M}-34$ & Edge modified flake & \\
\hline $\mathrm{E} 22 / \mathrm{S} 82$ & 13 & & IIIa/b & $22 \mathrm{M}-33$ & Edge modified flake & \\
\hline $\mathrm{E} 22 / \mathrm{S} 82$ & 13 & & $\mathrm{IIIa} / \mathrm{b}$ & $22 \mathrm{M}-31$ & Edge modified flake & \\
\hline $\mathrm{E} 22 / \mathrm{S} 82$ & 13 & & $\mathrm{III} / \mathrm{b}$ & $22 \mathrm{M}-19$ & Edge modified flake & \\
\hline $\mathrm{E} 22 / \mathrm{S} 82$ & 13 & & $\mathrm{IIIa} / \mathrm{b}$ & $22 \mathrm{M}-14$ & Notched flake & \\
\hline E22/S82 & 13 & & $\mathrm{IIIa} / \mathrm{b}$ & $22 \mathrm{M}-2$ & Projectile point, Hoxie & \\
\hline $\mathrm{E} 22 / \mathrm{S} 82$ & 13 & & IIIa/b & $22 \mathrm{M}-1$ & Projectile point, Hoxie C & \\
\hline $\mathrm{E} 22 / \mathrm{S} 82$ & 13 & & $\mathrm{IIIa} / \mathrm{b}$ & $22 \mathrm{M}-3$ & Projectile point, indeterminate & \\
\hline $\mathrm{E} 22 / \mathrm{S} 82$ & 13 & & $\mathrm{IIIa} / \mathrm{b}$ & $22 \mathrm{M}-17$ & Uniface, unanalyzed & \\
\hline $\mathrm{E} 22 / \mathrm{S} 82$ & 13 & & $\mathrm{IIIa} / \mathrm{b}$ & $22 \mathrm{M}-15$ & Uniface, unanalyzed & \\
\hline $\mathrm{E} 22 / \mathrm{S} 82$ & 13 & & IIIa/b & $22 \mathrm{M}-13$ & Uniface, unanalyzed & \\
\hline $\mathrm{E} 22 / \mathrm{S} 82$ & 13 & & $\mathrm{III} / \mathrm{b}$ & $22 \mathrm{M}-12$ & Uniface, unanalyzed & \\
\hline $\mathrm{E} 22 / \mathrm{S} 82$ & 13 & & $\mathrm{IIIa} / \mathrm{b}$ & $22 \mathrm{M}-27$ & Uniface, unanalyzed & \\
\hline $\mathrm{E} 22 / \mathrm{S} 82$ & 13 & & $\mathrm{IIIa} / \mathrm{b}$ & $22 \mathrm{M}-25$ & Uniface, unanalyzed & \\
\hline $\mathrm{E} 22 / \mathrm{S} 82$ & 13 & & $\mathrm{IIIa} / \mathrm{b}$ & $22 M-26$ & Unifacial multiple tool & \\
\hline $\mathrm{E} 22 / \mathrm{S} 82$ & 14 & & IIIa & $22 \mathrm{~N}-4$ & Biface fragment & \\
\hline $\mathrm{E} 22 / \mathrm{S} 82$ & 14 & & IIIa & $22 \mathrm{~N}-5$ & Biface fragment & \\
\hline $\mathrm{E} 22 / \mathrm{S} 82$ & 14 & & IIIa & $22 \mathrm{~N}-11$ & Biface fragment & \\
\hline $\mathrm{E} 22 / \mathrm{S} 82$ & 14 & & IIIa & $22 \mathrm{~N}-2$ & Biface Stage 1 & \\
\hline $\mathrm{E} 22 / \mathrm{S} 82$ & 14 & & IIIa & $22 \mathrm{~N}-3$ & Biface Stage 3 & \\
\hline $\mathrm{E} 22 / \mathrm{S} 82$ & 14 & & IIIa & & Debitage & 1091 \\
\hline $\mathrm{E} 22 / \mathrm{S} 82$ & 14 & & IIIa & $22 \mathrm{~N}-7$ & Edge modified flake & \\
\hline $\mathrm{E} 22 / \mathrm{S} 82$ & 14 & & IIIa & $22 \mathrm{~N}-8$ & Edge modified flake & \\
\hline $\mathrm{E} 22 / \mathrm{S} 82$ & 14 & & IIIa & $22 \mathrm{~N}-10$ & Edge modified flake & \\
\hline $\mathrm{E} 22 / \mathrm{S} 82$ & 14 & & IIIa & $22 \mathrm{~N}-9$ & Edge modified flake & \\
\hline $\mathrm{E} 22 / \mathrm{S} 82$ & 14 & & IIIa & $22 \mathrm{~N}-6$ & Thin uniface & \\
\hline $\mathrm{E} 22 / \mathrm{S} 82$ & 15 & & IIIa & $22 \mathrm{O}-3$ & Biface fragment & \\
\hline $\mathrm{E} 22 / \mathrm{S} 82$ & 15 & & IIIa & $220-7$ & Biface fragment & \\
\hline $\mathrm{E} 22 / \mathrm{S} 82$ & 15 & & IIIa & $22 \mathrm{O}-1$ & Biface fragment & \\
\hline E22/S82 & 15 & & IIIa & $220-8$ & Biface Stage 1 & \\
\hline $\mathrm{E} 22 / \mathrm{S} 82$ & 15 & & IIIa & $22 \mathrm{O}-4$ & Biface Stage 2 & \\
\hline $\mathrm{E} 22 / \mathrm{S} 82$ & 15 & & IIIa & $220-5$ & Biface Stage 2 & \\
\hline $\mathrm{E} 22 / \mathrm{S} 82$ & 15 & & IIIa & & Debitage & 1209 \\
\hline $\mathrm{E} 22 / \mathrm{S} 82$ & 15 & & IIIa & $220-19$ & Edge modified flake & \\
\hline $\mathrm{E} 22 / \mathrm{S} 82$ & 15 & & IIIa & $220-16$ & Edge modified flake & \\
\hline $\mathrm{E} 22 / \mathrm{S} 82$ & 15 & & IIIa & $22 \mathrm{O}-17$ & Edge modified flake & \\
\hline $\mathrm{E} 22 / \mathrm{S} 82$ & 15 & & IIIa & $22 \mathrm{O}-23$ & Edge modified flake & \\
\hline $\mathrm{E} 22 / \mathrm{S} 82$ & 15 & & IIIa & $220-21$ & Edge modified flake & \\
\hline $\mathrm{E} 22 / \mathrm{S} 82$ & 15 & & IIIa & $220-9$ & Micro-core, intermediate & \\
\hline $\mathrm{E} 22 / \mathrm{S} 82$ & 15 & & IIIa & $22 \mathrm{O}-12$ & Perforator Group 7 & \\
\hline $\mathrm{E} 22 / \mathrm{S} 82$ & 15 & & IIIa & $220-11$ & Perforator Group 7 & \\
\hline $\mathrm{E} 22 / \mathrm{S} 82$ & 15 & & IIIa & $22 \mathrm{O}-2$ & Projectile point, Hoxie & \\
\hline $\mathrm{E} 22 / \mathrm{S} 82$ & 15 & & IIIa & $220-10$ & Projectile point, Thrall & \\
\hline $\mathrm{E} 22 / \mathrm{S} 82$ & 15 & & IIIa & $220-15$ & Unifacial multiple tool & \\
\hline $\mathrm{E} 22 / \mathrm{S} 82$ & 15 & & IIIa & $220-6$ & Unifacial multiple tool & \\
\hline $\mathrm{E} 22 / \mathrm{S} 82$ & 16 & & II/IIIa & $22 \mathrm{P}-6$ & Biface fragment & \\
\hline $\mathrm{E} 22 / \mathrm{S} 82$ & 16 & & II/IIIa & $22 \mathrm{P}-7$ & Biface fragment & \\
\hline $\mathrm{E} 22 / \mathrm{S} 82$ & 16 & & II/IIIa & $22 \mathrm{P}-8$ & Biface fragment & \\
\hline $\mathrm{E} 22 / \mathrm{S} 82$ & 16 & & $\mathrm{II} / \mathrm{IIIa}$ & $22 \mathrm{P}-35$ & Biface fragment & \\
\hline $\mathrm{E} 22 / \mathrm{S} 82$ & 16 & & II/IIIa & $22 \mathrm{P}-16$ & Biface fragment, unanalyzed & \\
\hline $\mathrm{E} 22 / \mathrm{S} 82$ & 16 & & II/IIIa & $22 \mathrm{P}-10$ & Biface fragment, unanalyzed & \\
\hline $\mathrm{E} 22 / \mathrm{S} 82$ & 16 & & II/IIIa & $22 \mathrm{P}-12$ & Biface Stage 2 & \\
\hline E22/S82 & 16 & & II/IIIa & $22 \mathrm{P}-9$ & Bifacial tool Form E & \\
\hline $\mathrm{E} 22 / \mathrm{S} 82$ & 16 & & II/IIIa & $22 \mathrm{P}-17$ & Burin spall & \\
\hline $\mathrm{E} 22 / \mathrm{S} 82$ & 16 & & II/IIIa & $22 \mathrm{P}-18$ & Burin spall & \\
\hline $\mathrm{E} 22 / \mathrm{S} 82$ & 16 & & II/IIIa & $22 \mathrm{P}-13$ & Burin spall & \\
\hline $\mathrm{E} 22 / \mathrm{S} 82$ & 16 & & II/IIIa & $22 \mathrm{P}-20$ & Burin spall, unanalyzed & \\
\hline $\mathrm{E} 22 / \mathrm{S} 82$ & 16 & & II/IIIa & $22 \mathrm{P}-4$ & Clear Fork biface & \\
\hline $\mathrm{E} 22 / \mathrm{S} 82$ & 16 & & II/IIIa & $22 \mathrm{P}-23$ & Clear Fork biface, proximal & \\
\hline $\mathrm{E} 22 / \mathrm{S} 82$ & 16 & & II/IIIa & & Debitage & 1468 \\
\hline $\mathrm{E} 22 / \mathrm{S} 82$ & 16 & & II/IIIa & $22 \mathrm{P}-25$ & Denticulated flake & \\
\hline $\mathrm{E} 22 / \mathrm{S} 82$ & 16 & & II/IIIa & $22 \mathrm{P}-29$ & Denticulated flake & \\
\hline $\mathrm{E} 22 / \mathrm{S} 82$ & 16 & & II/IIIa & $22 \mathrm{P}-34$ & Edge modified flake & \\
\hline $\mathrm{E} 22 / \mathrm{S} 82$ & 16 & & II/IIIa & $22 \mathrm{P}-27$ & Edge modified flake & \\
\hline $\mathrm{E} 22 / \mathrm{S} 82$ & 16 & & II/IIIa & $22 \mathrm{P}-24$ & Microspur/microdenticulate & \\
\hline $\mathrm{E} 22 / \mathrm{S} 82$ & 16 & & II/IIIa & $22 \mathrm{P}-33$ & Perforator Unifacial & \\
\hline $\mathrm{E} 22 / \mathrm{S} 82$ & 16 & & II/IIIa & $22 \mathrm{P}-11$ & Projectile point fragment & \\
\hline
\end{tabular}




\begin{tabular}{|c|c|c|c|c|c|c|}
\hline Square & Level & Feature & Strata & Item & Analyst Identification & Count \\
\hline $\mathrm{E} 22 / \mathrm{S} 82$ & 16 & & II/IIIa & $22 \mathrm{P}-3$ & Projectile point, Hoxie A & 1 \\
\hline $\mathrm{E} 22 / \mathrm{S} 82$ & 16 & & II/IIIa & $22 \mathrm{P}-2$ & Projectile point, miscellaneous expanding ster & $\mathrm{m}$ \\
\hline $\mathrm{E} 22 / \mathrm{S} 82$ & 16 & & II/IIIa & $22 \mathrm{P}-1$ & Projectile point, Thrall & 1 \\
\hline $\mathrm{E} 22 / \mathrm{S} 82$ & 16 & & II/IIIa & $22 \mathrm{P}-38$ & Thin uniface & 1 \\
\hline $\mathrm{E} 22 / \mathrm{S} 82$ & 16 & & II/IIIa & $22 \mathrm{P}-36$ & Thin uniface & 1 \\
\hline $\mathrm{E} 22 / \mathrm{S} 82$ & 16 & & II/IIIa & $22 \mathrm{P}-32$ & Thin uniface & 1 \\
\hline $\mathrm{E} 22 / \mathrm{S} 82$ & 16 & & II/IIIa & $22 \mathrm{P}-30$ & Thin uniface & 1 \\
\hline $\mathrm{E} 22 / \mathrm{S} 82$ & 16 & & II/IIIa & $22 \mathrm{P}-39$ & Thin uniface fragment & 1 \\
\hline $\mathrm{E} 22 / \mathrm{S} 82$ & 16 & & II/IIIa & $22 \mathrm{P}-26$ & Uniface, unanalyzed & 1 \\
\hline $\mathrm{E} 22 / \mathrm{S} 82$ & 16 & & II/IIIa & $22 \mathrm{P}-28$ & Unifacial multiple tool & 1 \\
\hline $\mathrm{E} 22 / \mathrm{S} 82$ & 16 & Feature 107 & II/IIIa & $22 \mathrm{P}-5$ & Pestle & 1 \\
\hline $\mathrm{E} 22 / \mathrm{S} 82$ & 17 & & II & $22 \mathrm{Q}-10$ & Biface fragment & 1 \\
\hline $\mathrm{E} 22 / \mathrm{S} 82$ & 17 & & II & $22 \mathrm{Q}-11$ & Biface fragment & 1 \\
\hline $\mathrm{E} 22 / \mathrm{S} 82$ & 17 & & II & $22 \mathrm{Q}-7$ & Biface Stage 2 & 1 \\
\hline $\mathrm{E} 22 / \mathrm{S} 82$ & 17 & & II & $22 \mathrm{Q}-9$ & Biface Stage 2 & 1 \\
\hline $\mathrm{E} 22 / \mathrm{S} 82$ & 17 & & II & $22 Q-27$ & Biface Stage 2 & 1 \\
\hline $\mathrm{E} 22 / \mathrm{S} 82$ & 17 & & II & $22 \mathrm{Q}-12$ & Bifacial tool Form E & 1 \\
\hline $\mathrm{E} 22 / \mathrm{S} 82$ & 17 & & II & $22 \mathrm{Q}-8$ & Bifacial tool Form $\mathrm{H}$ & 1 \\
\hline $\mathrm{E} 22 / \mathrm{S} 82$ & 17 & & II & $22 \mathrm{Q}-2$ & Clear Fork biface & 1 \\
\hline E22/S82 & 17 & & II & $22 \mathrm{Q}-3$ & Clear Fork biface & 1 \\
\hline E22/S82 & 17 & & II & $22 \mathrm{Q}-6$ & Core, multidirectional & 1 \\
\hline E22/S82 & 17 & & II & & Debitage & 1164 \\
\hline $\mathrm{E} 22 / \mathrm{S} 82$ & 17 & & II & $22 Q-18$ & Edge modified flake & 1 \\
\hline $\mathrm{E} 22 / \mathrm{S} 82$ & 17 & & II & $22 Q-24$ & Edge modified flake & 1 \\
\hline $\mathrm{E} 22 / \mathrm{S} 82$ & 17 & & II & $22 \mathrm{Q}-22$ & Edge modified flake & 1 \\
\hline $\mathrm{E} 22 / \mathrm{S} 82$ & 17 & & II & $22 \mathrm{Q}-21$ & Edge modified flake & 1 \\
\hline $\mathrm{E} 22 / \mathrm{S} 82$ & 17 & & II & $22 \mathrm{Q}-20$ & Edge modified flake & 1 \\
\hline $\mathrm{E} 22 / \mathrm{S} 82$ & 17 & & II & $22 \mathrm{Q}-15$ & Large core hammerstone & 1 \\
\hline $\mathrm{E} 22 / \mathrm{S} 82$ & 17 & & II & $22 \mathrm{Q}-25$ & Microspur/microdenticulate & 1 \\
\hline $\mathrm{E} 22 / \mathrm{S} 82$ & 17 & & II & $22 Q-26$ & Microspur/microdenticulate & 1 \\
\hline $\mathrm{E} 22 / \mathrm{S} 82$ & 17 & & II & $22 \mathrm{Q}-17$ & Microspur/microdenticulate & 1 \\
\hline $\mathrm{E} 22 / \mathrm{S} 82$ & 17 & & II & $22 \mathrm{Q}-13$ & Projectile point fragment & 1 \\
\hline $\mathrm{E} 22 / \mathrm{S} 82$ & 17 & & II & $22 \mathrm{Q}-14$ & Projectile point fragment & 1 \\
\hline $\mathrm{E} 22 / \mathrm{S} 82$ & 17 & & II & $22 \mathrm{Q}-1$ & Projectile point, Hoxie & 1 \\
\hline $\mathrm{E} 22 / \mathrm{S} 82$ & 17 & & II & $22 \mathrm{Q}-16$ & Thick uniface & 1 \\
\hline $\mathrm{E} 22 / \mathrm{S} 82$ & 17 & & II & $22 \mathrm{Q}-28$ & Unifacial multiple tool & 1 \\
\hline $\mathrm{E} 22 / \mathrm{S} 82$ & 17 & & II & $22 \mathrm{Q}-4$ & Waco sinker & 1 \\
\hline E22/S82 & 17 & & II & $22 \mathrm{Q}-5$ & Waco sinker & 1 \\
\hline $\mathrm{E} 22 / \mathrm{S} 82$ & 18 & & II & $22 \mathrm{R}-2$ & Biface Stage 2 & 1 \\
\hline $\mathrm{E} 22 / \mathrm{S} 82$ & 18 & & II & $22 \mathrm{R}-1$ & Biface Stage 2 & 1 \\
\hline $\mathrm{E} 22 / \mathrm{S} 82$ & 18 & & II & $22 \mathrm{R}-4$ & Biface Stage 3 & 1 \\
\hline $\mathrm{E} 22 / \mathrm{S} 82$ & 18 & & II & $22 \mathrm{R}-3$ & Core, thermal & 1 \\
\hline $\mathrm{E} 22 / \mathrm{S} 82$ & 18 & & II & & Debitage & 560 \\
\hline E22/S82 & 18 & & II & $22 \mathrm{R}-6$ & Edge modified flake & 1 \\
\hline E22/S82 & 18 & & II & $22 \mathrm{R}-7$ & Uniface, unanalyzed & 1 \\
\hline $\mathrm{E} 22 / \mathrm{S} 82$ & 18 & & II & $22 \mathrm{R}-5$ & Unifacial multiple tool & 1 \\
\hline $\mathrm{E} 22 / \mathrm{S} 82$ & 19 & & II & $22 \mathrm{~S}-1$ & Biface fragment & 1 \\
\hline $\mathrm{E} 22 / \mathrm{S} 82$ & 19 & & II & $22 \mathrm{~S}-3$ & Biface fragment & 1 \\
\hline E22/S82 & 19 & & II & $22 \mathrm{~S}-2$ & Biface Stage 2 & 1 \\
\hline E22/S82 & 19 & & II & & Debitage & 441 \\
\hline $\mathrm{E} 22 / \mathrm{S} 82$ & 19 & & II & $22 \mathrm{~S}-10$ & Edge modified flake & 1 \\
\hline $\mathrm{E} 22 / \mathrm{S} 82$ & 19 & & II & $22 \mathrm{~S}-11$ & Edge modified flake & 1 \\
\hline $\mathrm{E} 22 / \mathrm{S} 82$ & 19 & & II & $22 \mathrm{~S}-8$ & Notched flake & 1 \\
\hline E22/S82 & 19 & & II & $22 \mathrm{~S}-4$ & Thick uniface & 1 \\
\hline E22/S82 & 20 & & II & $22 \mathrm{~T}-8$ & Biface fragment & 1 \\
\hline $\mathrm{E} 22 / \mathrm{S} 82$ & 20 & & II & $22 \mathrm{~T}-2$ & Biface Stage 3 & 1 \\
\hline E22/S82 & 20 & & II & $22 \mathrm{~T}-3$ & Bifacial tool Form A & 1 \\
\hline $\mathrm{E} 22 / \mathrm{S} 82$ & 20 & & II & $22 \mathrm{~T}-5$ & Burin & 1 \\
\hline $\mathrm{E} 22 / \mathrm{S} 82$ & 20 & & II & & Debitage & 232 \\
\hline $\mathrm{E} 22 / \mathrm{S} 82$ & 20 & & II & $22 \mathrm{~T}-6$ & Edge modified flake & 1 \\
\hline $\mathrm{E} 22 / \mathrm{S} 82$ & 20 & & II & $22 \mathrm{~T}-4$ & Edge modified flake & 1 \\
\hline $\mathrm{E} 22 / \mathrm{S} 82$ & 20 & & II & $22 \mathrm{~T}-9$ & Edge modified flake & 1 \\
\hline $\mathrm{E} 22 / \mathrm{S} 82$ & 20 & & II & $22 \mathrm{~T}-1$ & Projectile point, parallel side & 1 \\
\hline $\mathrm{E} 22 / \mathrm{S} 82$ & 20 & & II & $22 \mathrm{~T}-7$ & Uniface, unanalyzed & 1 \\
\hline $\mathrm{E} 22 / \mathrm{S} 82$ & 22 & & II & $22 \mathrm{~V}-1$ & Biface fragment & 1 \\
\hline $\mathrm{E} 22 / \mathrm{S} 82$ & 22 & & II & & Debitage & 114 \\
\hline $\mathrm{E} 22 / \mathrm{S} 82$ & 22 & & II & $22 \mathrm{~V}-2$ & Unifacial multiple tool & 1 \\
\hline E22/S82 & 23 & & $\mathrm{Id} / \mathrm{II}$ & $22 \mathrm{~W}-2$ & Biface Stage 2 & 1 \\
\hline $\mathrm{E} 22 / \mathrm{S} 82$ & 23 & & $\mathrm{Id} / \mathrm{II}$ & $22 \mathrm{~W}-1$ & Biface Stage 3 & 1 \\
\hline $\mathrm{E} 22 / \mathrm{S} 82$ & 23 & & $\mathrm{Id} / \mathrm{II}$ & & Debitage & 251 \\
\hline $\mathrm{E} 22 / \mathrm{S} 82$ & 24 & & Isi-c/Id & $22 X-3$ & Biface Stage 2 & 1 \\
\hline $\mathrm{E} 22 / \mathrm{S} 82$ & 24 & & Isi-c/Id & $22 \mathrm{X}-1$ & Biface Stage 2 & 1 \\
\hline $\mathrm{E} 22 / \mathrm{S} 82$ & 24 & & Isi-c/Id & $22 X-2$ & Biface Stage 2 & 1 \\
\hline $\mathrm{E} 22 / \mathrm{S} 82$ & 24 & & Isi-c/Id & $22 X-4$ & Core tool, type 4 & 1 \\
\hline
\end{tabular}




\begin{tabular}{|c|c|c|c|c|c|c|}
\hline ] Square & Level & Feature & Strata & Item & Analyst Identification & Count \\
\hline E22/S82 & 24 & & Isi-c/Id & & Debitage & \\
\hline $\mathrm{E} 22 / \mathrm{S} 82$ & 25 & & $\mathrm{X} / \mathrm{Isi}$ & $22 \mathrm{Y}-2$ & Chert cobble, unmodified/tested & \\
\hline $\mathrm{E} 22 / \mathrm{S} 82$ & 25 & & $\mathrm{X} / \mathrm{Isi}$ & $22 \mathrm{Y}-1$ & Core tool, type 4 & \\
\hline $\mathrm{E} 22 / \mathrm{S} 82$ & 25 & & $\mathrm{X} / \mathrm{Isi}$ & & Debitage & 88 \\
\hline $\mathrm{E} 22 / \mathrm{S} 82$ & 26 & & $\mathrm{X} / \mathrm{Isi}$ & & Debitage & 42 \\
\hline $\mathrm{E} 22 / \mathrm{S} 82$ & 27 & & $\mathrm{X} / \mathrm{Isi}$ & & Debitage & 1 \\
\hline $\mathrm{E} 22 / \mathrm{S} 84$ & 6 & & IIIc & $21 \mathrm{~F}-18$ & Biface fragment & \\
\hline E22/S84 & 6 & & IIIc & $21 \mathrm{~F}-3$ & Biface Stage 2 & \\
\hline E22/S84 & 6 & & IIIc & $21 \mathrm{~F}-7$ & Core tool, type 5 & \\
\hline $\mathrm{E} 22 / \mathrm{S} 84$ & 6 & & IIIc & & Debitage & 624 \\
\hline $\mathrm{E} 22 / \mathrm{S} 84$ & 6 & & IIIc & $21 \mathrm{~F}-14$ & Denticulated flake & \\
\hline $\mathrm{E} 22 / \mathrm{S} 84$ & 6 & & IIIc & $21 \mathrm{~F}-15$ & Edge modified flake & \\
\hline $\mathrm{E} 22 / \mathrm{S} 84$ & 6 & & IIIc & $21 \mathrm{~F}-10$ & Edge modified flake & \\
\hline $\mathrm{E} 22 / \mathrm{S} 84$ & 6 & & IIIc & $21 \mathrm{~F}-8$ & Edge modified flake & \\
\hline E22/S84 & 6 & & IIIC & $21 \mathrm{~F}-13$ & Edge modified flake & \\
\hline E22/S84 & 6 & & IIIc & $21 \mathrm{~F}-6$ & Projectile point fragment & \\
\hline $\mathrm{E} 22 / \mathrm{S} 84$ & 6 & & IIIc & $21 \mathrm{~F}-4$ & Projectile point fragment & \\
\hline $\mathrm{E} 22 / \mathrm{S} 84$ & 6 & & IIIc & $21 \mathrm{~F}-1$ & Projectile point, Angostura & \\
\hline $\mathrm{E} 22 / \mathrm{S} 84$ & 6 & & IIIc & $21 \mathrm{~F}-2$ & Projectile point, Marcos & \\
\hline E22/S84 & 6 & & IIIc & $21 \mathrm{~F}-5$ & Projectile point, Nolan & \\
\hline $\mathrm{E} 22 / \mathrm{S} 84$ & 6 & & IIIC & $21 \mathrm{~F}-16$ & Thick uniface & \\
\hline $\mathrm{E} 22 / \mathrm{S} 84$ & 6 & & IIIc & $21 \mathrm{~F}-11$ & Thin uniface & \\
\hline E22/S84 & 6 & & IIIc & $21 \mathrm{~F}-9$ & Uniface, unanalyzed & \\
\hline $\mathrm{E} 22 / \mathrm{S} 84$ & 6 & & IIIc & $21 \mathrm{~F}-12$ & Uniface, unanalyzed & \\
\hline E22/S84 & 7 & & $\mathrm{IIIb} / \mathrm{c}$ & $21 \mathrm{G}-21$ & Biface fragment & \\
\hline E22/S84 & 7 & & $\mathrm{IIIlb} / \mathrm{c}$ & $21 \mathrm{G}-3$ & Biface fragment, unanalyzed & \\
\hline $\mathrm{E} 22 / \mathrm{S} 84$ & 7 & & $\mathrm{IIIb} / \mathrm{c}$ & $21 \mathrm{G}-6$ & Biface Stage 2 & \\
\hline $\mathrm{E} 22 / \mathrm{S} 84$ & 7 & & $\mathrm{IIIb} / \mathrm{c}$ & $21 \mathrm{G}-4$ & Biface Stage 2 & \\
\hline $\mathrm{E} 22 / \mathrm{S} 84$ & 7 & & $\mathrm{IIIb} / \mathrm{c}$ & $21 \mathrm{G}-7$ & Biface Stage 2 & \\
\hline $\mathrm{E} 22 / \mathrm{S} 84$ & 7 & & $\mathrm{IIIb} / \mathrm{c}$ & $21 \mathrm{G}-5$ & Biface Stage 3 & \\
\hline $\mathrm{E} 22 / \mathrm{S} 84$ & 7 & & $\mathrm{IIIb} / \mathrm{c}$ & & Debitage & 687 \\
\hline E22/S84 & 7 & & $\mathrm{IIIb} / \mathrm{c}$ & $21 \mathrm{G}-22$ & Edge modified flake & \\
\hline $\mathrm{E} 22 / \mathrm{S} 84$ & 7 & & $\mathrm{IIIb} / \mathrm{c}$ & $21 \mathrm{G}-13$ & Edge modified flake & \\
\hline $\mathrm{E} 22 / \mathrm{S} 84$ & 7 & & $\mathrm{IIIb} / \mathrm{c}$ & $21 \mathrm{G}-20$ & Edge modified flake & \\
\hline E22/S84 & 7 & & $\mathrm{IIIb} / \mathrm{c}$ & $21 \mathrm{G}-18$ & Edge modified flake & \\
\hline $\mathrm{E} 22 / \mathrm{S} 84$ & 7 & & $\mathrm{IIIb} / \mathrm{c}$ & $21 \mathrm{G}-15$ & Edge modified flake & \\
\hline E22/S84 & 7 & & $\mathrm{IIIb} / \mathrm{c}$ & $21 \mathrm{G}-23$ & Edge modified flake & \\
\hline E22/S84 & 7 & & $\mathrm{IIIb} / \mathrm{c}$ & $21 \mathrm{G}-16$ & Microspur/microdenticulate & \\
\hline $\mathrm{E} 22 / \mathrm{S} 84$ & 7 & & $\mathrm{IIIb} / \mathrm{c}$ & $21 \mathrm{G}-10$ & Projectile point fragment & \\
\hline $\mathrm{E} 22 / \mathrm{S} 84$ & 7 & & $\mathrm{IIIb} / \mathrm{c}$ & $21 \mathrm{G}-9$ & Projectile point, Nolan & \\
\hline E22/S84 & 7 & & $\mathrm{IIIb} / \mathrm{c}$ & 21G-1 & Projectile point, Nolan & \\
\hline $\mathrm{E} 22 / \mathrm{S} 84$ & 7 & & $\mathrm{IIIb} / \mathrm{c}$ & $21 \mathrm{G}-8$ & Projectile point, Pedernales & \\
\hline $\mathrm{E} 22 / \mathrm{S} 84$ & 7 & & $\mathrm{IIIb} / \mathrm{c}$ & $21 \mathrm{G}-2$ & Projectile point, Travis & \\
\hline E22/S84 & 7 & & $\mathrm{IIIb} / \mathrm{c}$ & $21 \mathrm{G}-11$ & Thick uniface & \\
\hline E22/S84 & 7 & & $\mathrm{IIIb} / \mathrm{c}$ & $21 \mathrm{G}-14$ & Thick uniface & \\
\hline $\mathrm{E} 22 / \mathrm{S} 84$ & 7 & & $\mathrm{IIIb} / \mathrm{c}$ & $21 \mathrm{G}-19$ & Thin uniface & \\
\hline $\mathrm{E} 22 / \mathrm{S} 84$ & 7 & & $\mathrm{IIIb} / \mathrm{c}$ & 21G-17 & Uniface, unanalyzed & \\
\hline $\mathrm{E} 22 / \mathrm{S} 84$ & 8 & & $\mathrm{IIIb} / \mathrm{c}$ & $21 \mathrm{H}-6$ & Biface Stage 2 & \\
\hline E22/S84 & 8 & & $\mathrm{IIIb} / \mathrm{c}$ & $21 \mathrm{H}-5$ & Biface Stage 2 & \\
\hline $\mathrm{E} 22 / \mathrm{S} 84$ & 8 & & $\mathrm{IIIb} / \mathrm{c}$ & $21 \mathrm{H}-17$ & Biface Stage 2 & \\
\hline $\mathrm{E} 22 / \mathrm{S} 84$ & 8 & & $\mathrm{IIIb} / \mathrm{c}$ & $21 \mathrm{H}-8$ & Biface Stage 2 & \\
\hline $\mathrm{E} 22 / \mathrm{S} 84$ & 8 & & $\mathrm{IIIb} / \mathrm{c}$ & $21 \mathrm{H}-7$ & Bifacial tool Form D & \\
\hline $\mathrm{E} 22 / \mathrm{S} 84$ & 8 & & $\mathrm{IIIb} / \mathrm{c}$ & $21 \mathrm{H}-10$ & Burin spall & \\
\hline E22/S84 & 8 & & $\mathrm{IIIb} / \mathrm{c}$ & & Debitage & 583 \\
\hline E22/S84 & 8 & & $\mathrm{IIIb} / \mathrm{c}$ & $21 \mathrm{H}-19$ & Edge modified flake & \\
\hline $\mathrm{E} 22 / \mathrm{S} 84$ & 8 & & $\mathrm{IIIb} / \mathrm{c}$ & $21 \mathrm{H}-21$ & Edge modified flake & \\
\hline $\mathrm{E} 22 / \mathrm{S} 84$ & 8 & & $\mathrm{IIIb} / \mathrm{c}$ & $21 \mathrm{H}-20$ & Edge modified flake & \\
\hline E22/S84 & 8 & & $\mathrm{IIIb} / \mathrm{c}$ & $21 \mathrm{H}-14$ & Edge modified flake & \\
\hline E22/S84 & 8 & & $\mathrm{IIIb} / \mathrm{c}$ & $21 \mathrm{H}-15$ & Edge modified flake & \\
\hline $\mathrm{E} 22 / \mathrm{S} 84$ & 8 & & $\mathrm{IIIb} / \mathrm{c}$ & $21 \mathrm{H}-16$ & Edge modified flake & \\
\hline $\mathrm{E} 22 / \mathrm{S} 84$ & 8 & & $\mathrm{IIIb} / \mathrm{c}$ & $21 \mathrm{H}-18$ & Edge modified flake & \\
\hline E22/S84 & 8 & & $\mathrm{IIIb} / \mathrm{c}$ & $21 \mathrm{H}-2$ & Projectile point, expanding concave $\mathrm{C}$ & \\
\hline E22/S84 & 8 & & $\mathrm{IIIb} / \mathrm{c}$ & $21 \mathrm{H}-3$ & Projectile point, expanding concave $\mathrm{C}$ & \\
\hline $\mathrm{E} 22 / \mathrm{S} 84$ & 8 & & $\mathrm{IIIb} / \mathrm{c}$ & $21 \mathrm{H}-1$ & Projectile point, Marcos & \\
\hline E22/S84 & 8 & & $\mathrm{IIIb} / \mathrm{c}$ & $21 \mathrm{H}-11$ & Projectile point, rectangular stem B & \\
\hline $\mathrm{E} 22 / \mathrm{S} 84$ & 8 & & $\mathrm{IIIb} / \mathrm{c}$ & $21 \mathrm{H}-22$ & Uniface, unanalyzed & \\
\hline $\mathrm{E} 22 / \mathrm{S} 84$ & 8 & & $\mathrm{IIIb} / \mathrm{c}$ & $21 \mathrm{H}-13$ & Uniface, unanalyzed & \\
\hline E22/S84 & 8 & & $\mathrm{IIIb} / \mathrm{c}$ & $21 \mathrm{H}-9$ & Uniface, unanalyzed & \\
\hline E22/S84 & 8 & & $\mathrm{IIIb} / \mathrm{c}$ & $21 \mathrm{H}-23$ & Unifacial multiple tool & \\
\hline E22/S84 & 8 & & $\mathrm{IIIb} / \mathrm{c}$ & $21 \mathrm{H}-12$ & Unifacial multiple tool & \\
\hline E22/S84 & 9 & & $\mathrm{IIIb} / \mathrm{c}$ & $21 \mathrm{I}-8$ & Biface fragment & \\
\hline $\mathrm{E} 22 / \mathrm{S} 84$ & 9 & & $\mathrm{IIIb} / \mathrm{c}$ & $21 \mathrm{I}-20$ & Biface fragment & \\
\hline $\mathrm{E} 22 / \mathrm{S} 84$ & 9 & & $\mathrm{IIIb} / \mathrm{c}$ & $21 \mathrm{I}-2$ & Biface Stage 2 & \\
\hline E22/S84 & 9 & & $\mathrm{IIIb} / \mathrm{c}$ & $21 \mathrm{I}-1$ & Biface Stage 2 & \\
\hline
\end{tabular}




\begin{tabular}{|c|c|c|c|c|c|c|}
\hline Square & Level & Feature & Strata & Item & Analyst Identification & Count \\
\hline $\mathrm{E} 22 / \mathrm{S} 84$ & 9 & & $\mathrm{IIIb} / \mathrm{c}$ & $21 \mathrm{I}-4$ & Biface Stage 2 & \\
\hline $\mathrm{E} 22 / \mathrm{S} 84$ & 9 & & $\mathrm{IIIb} / \mathrm{c}$ & $21 \mathrm{I}-3$ & Biface Stage 3 & \\
\hline $\mathrm{E} 22 / \mathrm{S} 84$ & 9 & & $\mathrm{IIIb} / \mathrm{c}$ & $21 \mathrm{I}-5$ & Core fragment & 1 \\
\hline $\mathrm{E} 22 / \mathrm{S} 84$ & 9 & & $\mathrm{IIIb} / \mathrm{c}$ & & Debitage & 591 \\
\hline $\mathrm{E} 22 / \mathrm{S} 84$ & 9 & & $\mathrm{IIIb} / \mathrm{c}$ & $21 \mathrm{I}-18$ & Edge modified flake & \\
\hline $\mathrm{E} 22 / \mathrm{S} 84$ & 9 & & $\mathrm{IIIb} / \mathrm{c}$ & $21 \mathrm{I}-19$ & Edge modified flake & \\
\hline $\mathrm{E} 22 / \mathrm{S} 84$ & 9 & & $\mathrm{IIIb} / \mathrm{c}$ & $21 \mathrm{I}-17$ & Edge modified flake & \\
\hline $\mathrm{E} 22 / \mathrm{S} 84$ & 9 & & $\mathrm{IIIb} / \mathrm{c}$ & $21 \mathrm{I}-13$ & Edge modified flake & \\
\hline $\mathrm{E} 22 / \mathrm{S} 84$ & 9 & & $\mathrm{IIIb} / \mathrm{c}$ & $21 \mathrm{I}-7$ & Notched flake & \\
\hline $\mathrm{E} 22 / \mathrm{S} 84$ & 9 & & $\mathrm{IIIJ} / \mathrm{c}$ & $21 \mathrm{I}-14$ & Perforator Unifacial & \\
\hline $\mathrm{E} 22 / \mathrm{S} 84$ & 9 & & $\mathrm{IIIb} / \mathrm{c}$ & $21 \mathrm{I}-6$ & Projectile point fragment & \\
\hline $\mathrm{E} 22 / \mathrm{S} 84$ & 9 & & $\mathrm{IIIb} / \mathrm{c}$ & $21 \mathrm{I}-11$ & Retouched blade & \\
\hline $\mathrm{E} 22 / \mathrm{S} 84$ & 9 & & $\mathrm{IIIb} / \mathrm{c}$ & $21 \mathrm{I}-12$ & Thin uniface & \\
\hline $\mathrm{E} 22 / \mathrm{S} 84$ & 9 & & $\mathrm{IIIb} / \mathrm{c}$ & $21 \mathrm{I}-21$ & Uniface, unanalyzed & \\
\hline $\mathrm{E} 22 / \mathrm{S} 84$ & 9 & & $\mathrm{IIIb} / \mathrm{c}$ & $21 \mathrm{I}-16$ & Uniface, unanalyzed & \\
\hline $\mathrm{E} 22 / \mathrm{S} 84$ & 9 & & $\mathrm{IIIb} / \mathrm{c}$ & $21 \mathrm{I}-10$ & Uniface, unanalyzed & \\
\hline $\mathrm{E} 22 / \mathrm{S} 84$ & 9 & & $\mathrm{IIIb} / \mathrm{c}$ & $21 \mathrm{I}-15$ & Unifacial multiple tool & \\
\hline $\mathrm{E} 22 / \mathrm{S} 84$ & 10 & & $\mathrm{IIIb}$ & $21 \mathrm{~J}-10$ & Biface Stage 1 & \\
\hline $\mathrm{E} 22 / \mathrm{S} 84$ & 10 & & IIIb & $21 \mathrm{~J}-4$ & Biface Stage 2 & \\
\hline E22/S84 & 10 & & IIIb & $21 \mathrm{~J}-3$ & Biface Stage 2 & \\
\hline $\mathrm{E} 22 / \mathrm{S} 84$ & 10 & & IIIb & $21 \mathrm{~J}-5$ & Biface Stage 2 & \\
\hline $\mathrm{E} 22 / \mathrm{S} 84$ & 10 & & IIIb & $21 J-6$ & Biface Stage 3 & \\
\hline $\mathrm{E} 22 / \mathrm{S} 84$ & 10 & & IIIb & $21 \mathrm{~J}-7$ & Burin & \\
\hline $\mathrm{E} 22 / \mathrm{S} 84$ & 10 & & IIIb & $21 \mathrm{~J}-16$ & Burin spall & \\
\hline $\mathrm{E} 22 / \mathrm{S} 84$ & 10 & & IIIb & & Debitage & 501 \\
\hline $\mathrm{E} 22 / \mathrm{S} 84$ & 10 & & IIIb & 21J-14 & Edge modified flake & \\
\hline $\mathrm{E} 22 / \mathrm{S} 84$ & 10 & & IIIb & $21 \mathrm{~J}-8$ & Edge modified flake & \\
\hline $\mathrm{E} 22 / \mathrm{S} 84$ & 10 & & IIIb & $21 \mathrm{~J}-19$ & Edge modified flake & \\
\hline $\mathrm{E} 22 / \mathrm{S} 84$ & 10 & & IIIb & $21 \mathrm{~J}-20$ & Edge modified flake & \\
\hline $\mathrm{E} 22 / \mathrm{S} 84$ & 10 & & IIIb & $21 \mathrm{~J}-1$ & Projectile point, Martindale A & \\
\hline $\mathrm{E} 22 / \mathrm{S} 84$ & 10 & & IIIb & $21 \mathrm{~J}-12$ & Retouched blade & \\
\hline $\mathrm{E} 22 / \mathrm{S} 84$ & 10 & & IIIb & $21 \mathrm{~J}-9$ & Uniface, unanalyzed & \\
\hline $\mathrm{E} 22 / \mathrm{S} 84$ & 10 & & IIIb & $21 \mathrm{~J}-13$ & Uniface, unanalyzed & \\
\hline $\mathrm{E} 22 / \mathrm{S} 84$ & 10 & & IIIb & $21 \mathrm{~J}-11$ & Uniface, unanalyzed & \\
\hline $\mathrm{E} 22 / \mathrm{S} 84$ & 10 & & IIIb & $21 \mathrm{~J}-17$ & Uniface, unanalyzed & \\
\hline $\mathrm{E} 22 / \mathrm{S} 84$ & 10 & Feature 82 & IIIb & $21 \mathrm{~J}-2$ & Metate fragment & \\
\hline $\mathrm{E} 22 / \mathrm{S} 84$ & 11 & & IIIb & $21 \mathrm{~K}-6$ & Biface fragment & \\
\hline $\mathrm{E} 22 / \mathrm{S} 84$ & 11 & & IIIb & $21 \mathrm{~K}-7$ & Biface Stage 1 & \\
\hline $\mathrm{E} 22 / \mathrm{S} 84$ & 11 & & IIIb & $21 \mathrm{~K}-3$ & Biface Stage 1 & \\
\hline E22/S84 & 11 & & IIIb & $21 \mathrm{~K}-4$ & Biface Stage 2 & \\
\hline $\mathrm{E} 22 / \mathrm{S} 84$ & 11 & & IIIlb & & Debitage & 527 \\
\hline $\mathrm{E} 22 / \mathrm{S} 84$ & 11 & & IIIb & $21 \mathrm{~K}-8$ & Edge modified flake & \\
\hline $\mathrm{E} 22 / \mathrm{S} 84$ & 11 & & IIIb & $21 \mathrm{~K}-12$ & Edge modified flake & \\
\hline $\mathrm{E} 22 / \mathrm{S} 84$ & 11 & & IIIb & $21 \mathrm{~K}-2$ & Projectile point, Baker & \\
\hline $\mathrm{E} 22 / \mathrm{S} 84$ & 11 & & IIIb & $21 \mathrm{~K}-1$ & Projectile point, Bandy & \\
\hline $\mathrm{E} 22 / \mathrm{S} 84$ & 11 & & IIIb & $21 \mathrm{~K}-5$ & Projectile point, expanding concave A & \\
\hline $\mathrm{E} 22 / \mathrm{S} 84$ & 11 & & IIIb & $21 \mathrm{~K}-9$ & Uniface, unanalyzed & \\
\hline E22/S84 & 11 & & IIIb & $21 \mathrm{~K}-10$ & Uniface, unanalyzed & \\
\hline $\mathrm{E} 22 / \mathrm{S} 84$ & 11 & & IIIb & $21 \mathrm{~K}-11$ & Uniface, unanalyzed & \\
\hline $\mathrm{E} 22 / \mathrm{S} 84$ & 11 & & IIIb & $21 \mathrm{~K}-13$ & Uniface, unanalyzed & \\
\hline $\mathrm{E} 22 / \mathrm{S} 84$ & 11 & Feature 88 & IIIb & $21 \mathrm{~K}-14$ & Biface Stage 2 & \\
\hline $\mathrm{E} 22 / \mathrm{S} 84$ & 11 & Feature 88 & IIIb & $21 \mathrm{~K}-15$ & Thick uniface & \\
\hline $\mathrm{E} 22 / \mathrm{S} 84$ & 12 & & IIIb & $21 \mathrm{~L}-22$ & Biface fragment & \\
\hline $\mathrm{E} 22 / \mathrm{S} 84$ & 12 & & IIIb & $21 \mathrm{~L}-37$ & Biface fragment & \\
\hline $\mathrm{E} 22 / \mathrm{S} 84$ & 12 & & IIIb & $21 \mathrm{~L}-4$ & Biface Stage 1 & \\
\hline $\mathrm{E} 22 / \mathrm{S} 84$ & 12 & & IIIb & $21 \mathrm{~L}-7$ & Biface Stage 1 & \\
\hline $\mathrm{E} 22 / \mathrm{S} 84$ & 12 & & IIIb & $21 \mathrm{~L}-27$ & Biface Stage 2 & \\
\hline $\mathrm{E} 22 / \mathrm{S} 84$ & 12 & & IIIb & $21 \mathrm{~L}-8$ & Biface Stage 2 & \\
\hline $\mathrm{E} 22 / \mathrm{S} 84$ & 12 & & IIIb & $21 \mathrm{~L}-30$ & Biface Stage 2 & \\
\hline $\mathrm{E} 22 / \mathrm{S} 84$ & 12 & & IIIb & $21 \mathrm{~L}-9$ & Biface Stage 2 & \\
\hline $\mathrm{E} 22 / \mathrm{S} 84$ & 12 & & IIIb & $21 \mathrm{~L}-6$ & Biface Stage 2 & \\
\hline $\mathrm{E} 22 / \mathrm{S} 84$ & 12 & & IIIb & 21L-13 & Biface Stage 3 & \\
\hline $\mathrm{E} 22 / \mathrm{S} 84$ & 12 & & IIIb & $21 \mathrm{~L}-15$ & Biface Stage 3 & \\
\hline $\mathrm{E} 22 / \mathrm{S} 84$ & 12 & & IIIb & $21 \mathrm{~L}-28$ & Burin spall & \\
\hline $\mathrm{E} 22 / \mathrm{S} 84$ & 12 & & IIIb & $21 \mathrm{~L}-38$ & Clear Fork uniface & \\
\hline $\mathrm{E} 22 / \mathrm{S} 84$ & 12 & & IIIb & $21 \mathrm{~L}-11$ & Core, thermal & \\
\hline E22/S84 & 12 & & IIIb & & Debitage & \\
\hline $\mathrm{E} 22 / \mathrm{S} 84$ & 12 & & IIIb & $21 \mathrm{~L}-19$ & Edge modified flake & \\
\hline $\mathrm{E} 22 / \mathrm{S} 84$ & 12 & & IIIb & $21 \mathrm{~L}-18$ & Edge modified flake & \\
\hline $\mathrm{E} 22 / \mathrm{S} 84$ & 12 & & IIIb & $21 \mathrm{~L}-21$ & Edge modified flake & \\
\hline $\mathrm{E} 22 / \mathrm{S} 84$ & 12 & & IIIb & $21 \mathrm{~L}-26$ & Edge modified flake & \\
\hline $\mathrm{E} 22 / \mathrm{S} 84$ & 12 & & IIIb & 21L-29 & Edge modified flake & \\
\hline $\mathrm{E} 22 / \mathrm{S} 84$ & 12 & & IIIb & $21 \mathrm{~L}-20$ & Edge modified flake & \\
\hline E22/S84 & 12 & & IIIb & $21 \mathrm{~L}-17$ & Edge modified flake & \\
\hline
\end{tabular}




\begin{tabular}{|c|c|c|c|c|}
\hline Square & Level & Feature & Strata & Item \\
\hline E22/S84 & 12 & & IIIb & $21 \mathrm{~L}-31$ \\
\hline $\mathrm{E} 22 / \mathrm{S} 84$ & 12 & & IIIb & $21 \mathrm{~L}-35$ \\
\hline $\mathrm{E} 22 / \mathrm{S} 84$ & 12 & & IIIb & $21 \mathrm{~L}-23$ \\
\hline E22/S84 & 12 & & IIIb & $21 \mathrm{~L}-25$ \\
\hline $\mathrm{E} 22 / \mathrm{S} 84$ & 12 & & IIIb & $21 \mathrm{~L}-33$ \\
\hline $\mathrm{E} 22 / \mathrm{S} 84$ & 12 & & IIIb & $21 \mathrm{~L}-12$ \\
\hline E22/S84 & 12 & & IIIb & $21 \mathrm{~L}-16$ \\
\hline $\mathrm{E} 22 / \mathrm{S} 84$ & 12 & & IIIb & $21 \mathrm{~L}-5$ \\
\hline E22/S84 & 12 & & IIIb & $21 \mathrm{~L}-14$ \\
\hline E22/S84 & 12 & & IIIb & $21 \mathrm{~L}-1$ \\
\hline $\mathrm{E} 22 / \mathrm{S} 84$ & 12 & & IIIb & $21 \mathrm{~L}-2$ \\
\hline E22/S84 & 12 & & IIIb & $21 \mathrm{~L}-3$ \\
\hline $\mathrm{E} 22 / \mathrm{S} 84$ & 12 & & IIIb & $21 \mathrm{~L}-10$ \\
\hline E22/S84 & 12 & & IIIb & $21 \mathrm{~L}-36$ \\
\hline $\mathrm{E} 22 / \mathrm{S} 84$ & 12 & & IIIb & 21L-34 \\
\hline E22/S84 & 13 & & IIIb & $21 \mathrm{M}-5$ \\
\hline $\mathrm{E} 22 / \mathrm{S} 84$ & 13 & & IIIb & $21 \mathrm{M}-25$ \\
\hline E22/S84 & 13 & & IIIb & $21 \mathrm{M}-6$ \\
\hline $\mathrm{E} 22 / \mathrm{S} 84$ & 13 & & IIIb & $21 \mathrm{M}-19$ \\
\hline E22/S84 & 13 & & IIIb & $21 \mathrm{M}-10$ \\
\hline $\mathrm{E} 22 / \mathrm{S} 84$ & 13 & & IIIb & \\
\hline $\mathrm{E} 22 / \mathrm{S} 84$ & 13 & & IIIb & $21 \mathrm{M}-16$ \\
\hline $\mathrm{E} 22 / \mathrm{S} 84$ & 13 & & IIIb & $21 \mathrm{M}-9$ \\
\hline $\mathrm{E} 22 / \mathrm{S} 84$ & 13 & & IIIb & $21 \mathrm{M}-12$ \\
\hline E22/S84 & 13 & & IIIb & $21 \mathrm{M}-18$ \\
\hline $\mathrm{E} 22 / \mathrm{S} 84$ & 13 & & IIIb & $21 \mathrm{M}-11$ \\
\hline E22/S84 & 13 & & IIIb & $21 \mathrm{M}-20$ \\
\hline $\mathrm{E} 22 / \mathrm{S} 84$ & 13 & & IIIb & $21 \mathrm{M}-24$ \\
\hline E22/S84 & 13 & & IIIb & $21 \mathrm{H}-4$ \\
\hline $\mathrm{E} 22 / \mathrm{S} 84$ & 13 & & IIIb & $21 \mathrm{M}-1$ \\
\hline E22/S84 & 13 & & IIIb & $21 \mathrm{M}-7$ \\
\hline $\mathrm{E} 22 / \mathrm{S} 84$ & 13 & & IIIb & $21 \mathrm{M}-2$ \\
\hline $\mathrm{E} 22 / \mathrm{S} 84$ & 13 & & IIIb & $21 \mathrm{M}-3$ \\
\hline $\mathrm{E} 22 / \mathrm{S} 84$ & 13 & & IIIb & $21 \mathrm{M}-23$ \\
\hline E22/S84 & 13 & & IIIb & $21 \mathrm{M}-15$ \\
\hline $\mathrm{E} 22 / \mathrm{S} 84$ & 13 & & $\mathrm{IIIb}$ & $21 \mathrm{M}-13$ \\
\hline $\mathrm{E} 22 / \mathrm{S} 84$ & 13 & & IIIb & $21 \mathrm{M}-8$ \\
\hline $\mathrm{E} 22 / \mathrm{S} 84$ & 13 & & IIIb & $21 \mathrm{M}-17$ \\
\hline E22/S84 & 13 & & IIIb & $21 \mathrm{M}-22$ \\
\hline E22/S84 & 14 & & IIIa/b & $21 \mathrm{~N}-9$ \\
\hline $\mathrm{E} 22 / \mathrm{S} 84$ & 14 & & $\mathrm{III} a / \mathrm{b}$ & $21 \mathrm{~N}-4$ \\
\hline $\mathrm{E} 22 / \mathrm{S} 84$ & 14 & & $\mathrm{III} a / \mathrm{b}$ & $21 \mathrm{~N}-5$ \\
\hline $\mathrm{E} 22 / \mathrm{S} 84$ & 14 & & IIIa/b & \\
\hline $\mathrm{E} 22 / \mathrm{S} 84$ & 14 & & $\mathrm{IIIa} / \mathrm{b}$ & $21 \mathrm{~N}-6$ \\
\hline E22/S84 & 14 & & III $/ \mathrm{b}$ & $21 \mathrm{~N}-8$ \\
\hline $\mathrm{E} 22 / \mathrm{S} 84$ & 14 & & $\mathrm{IIIa} / \mathrm{b}$ & $21 \mathrm{~N}-13$ \\
\hline $\mathrm{E} 22 / \mathrm{S} 84$ & 14 & & $\mathrm{IIIa} / \mathrm{b}$ & $21 \mathrm{~N}-7$ \\
\hline $\mathrm{E} 22 / \mathrm{S} 84$ & 14 & & $\mathrm{IIIa} / \mathrm{b}$ & $21 \mathrm{~N}-3$ \\
\hline E22/S84 & 14 & & $\mathrm{III} / \mathrm{b}$ & $21 \mathrm{~N}-2$ \\
\hline E22/S84 & 14 & & IIIa/b & $21 \mathrm{~N}-1$ \\
\hline E22/S84 & 14 & & $\mathrm{IIIa} / \mathrm{b}$ & $21 \mathrm{~N}-14$ \\
\hline $\mathrm{E} 22 / \mathrm{S} 84$ & 14 & & IIIa/b & $21 \mathrm{~N}-11$ \\
\hline $\mathrm{E} 22 / \mathrm{S} 84$ & 14 & & $\mathrm{IIIa} / \mathrm{b}$ & $21 \mathrm{~N}-12$ \\
\hline $\mathrm{E} 22 / \mathrm{S} 84$ & 14 & & IIIa/b & $21 \mathrm{~N}-10$ \\
\hline $\mathrm{E} 22 / \mathrm{S} 84$ & 15 & & IIIa & $210-17$ \\
\hline E22/S84 & 15 & & IIIa & $210-3$ \\
\hline E22/S84 & 15 & & IIIa & $210-2$ \\
\hline $\mathrm{E} 22 / \mathrm{S} 84$ & 15 & & IIIa & $210-19$ \\
\hline E22/S84 & 15 & & IIIa & $210-1$ \\
\hline $\mathrm{E} 22 / \mathrm{S} 84$ & 15 & & IIIa & \\
\hline E22/S84 & 15 & & IIIa & $210-7$ \\
\hline E22/S84 & 15 & & IIIa & $210-10$ \\
\hline E22/S84 & 15 & & IIIa & $210-12$ \\
\hline E22/S84 & 15 & & IIIa & $210-23$ \\
\hline $\mathrm{E} 22 / \mathrm{S} 84$ & 15 & & IIIa & $210-8$ \\
\hline E22/S84 & 15 & & IIIa & $210-22$ \\
\hline $\mathrm{E} 22 / \mathrm{S} 84$ & 15 & & IIII & $210-20$ \\
\hline E22/S84 & 15 & & IIIa & $210-18$ \\
\hline E22/S84 & 15 & & IIIa & $210-15$ \\
\hline $\mathrm{E} 22 / \mathrm{S} 84$ & 15 & & IIIa & $210-5$ \\
\hline $\mathrm{E} 22 / \mathrm{S} 84$ & 15 & & IIIa & $210-13$ \\
\hline E22/S84 & 15 & & IIIa & $210-24$ \\
\hline E22/S84 & 15 & & IIIa & $210-4$ \\
\hline E22/S84 & 15 & & IIIa & $210-9$ \\
\hline
\end{tabular}

Analyst Identification

Edge modified flake

Edge modified flake

Edge modified flake

Notched flake

Notched flake

Perforator Group 1

Piece esquillee

Projectile point fragment

Projectile point fragment

Projectile point, Golondrina-Barber

Projectile point, Gower

Projectile point, Martindale B

Projectile point, miscellaneous lanceolate

Retouched blade

Uniface, unanalyzed

Biface fragment

Biface Stage 2

Biface Stage 2

Bifacial tool Form $\mathrm{H}$

Burin

Debitage

Denticulated flake

Denticulated flake

Edge modified flake

Edge modified flake

Edge modified flake

Edge modified flake

Microspur/microdenticulate

Perforator Group 3

Projectile point, Angostura

Projectile point, bifurcate stem fragment

Projectile point, contracting stem, concave base

Projectile point, Scottsbluff

Thick uniface fragment

Thin uniface

Thin uniface fragment

Thin uniface fragment

Uniface, unanalyzed

Unifacial multiple tool

Biface fragment

Biface Stage 2

Chert cobble, chunk

Debitage

Edge modified flake

Edge modified flake

Microspur/microdenticulate

Microspur/microdenticulate

Projectile point, Bandy

Projectile point, Hoxie C

Projectile point, Thrall

Thin uniface

Thin uniface fragment

Thin uniface fragment

Uniface, unanalyzed

Biface fragment

Biface fragment

Biface Stage 2

Burin

Clear Fork biface, proximal

Debitage

Edge modified flake

Edge modified flake

Edge modified flake

Edge modified flake

Edge modified flake

Edge modified flake

Edge modified flake

Microspur/microdenticulate

Microspur/microdenticulate

Notched flake

Notched flake

Perforator Group 1

Projectile point fragment

Uniface, unanalyzed 


\begin{tabular}{|c|c|c|c|c|c|c|}
\hline Square & Level & Feature & Strata & Item & Analyst Identification & Cour \\
\hline $\mathrm{E} 22 / \mathrm{S} 84$ & 15 & & IIIa & $210-16$ & Uniface, unanalyzed & \\
\hline E22/S84 & 15 & & IIIa & $210-6$ & Uniface, unanalyzed & \\
\hline $\mathrm{E} 22 / \mathrm{S} 84$ & 15 & & IIIa & $210-14$ & Uniface, unanalyzed & \\
\hline $\mathrm{E} 22 / \mathrm{S} 84$ & 15 & & IIIa & $210-21$ & Unifacial multiple tool & \\
\hline $\mathrm{E} 22 / \mathrm{S} 84$ & 16 & & IIIa & $21 \mathrm{P}-3$ & Biface fragment & \\
\hline E22/S84 & 16 & & IIIa & $21 \mathrm{P}-2$ & Biface Stage 2 & \\
\hline E22/S84 & 16 & & IIIa & & Debitage & \\
\hline E22/S84 & 16 & & IIIa & $21 \mathrm{P}-11$ & Edge modified flake & \\
\hline $\mathrm{E} 22 / \mathrm{S} 84$ & 16 & & IIIa & $21 \mathrm{P}-7$ & Edge modified flake & \\
\hline $\mathrm{E} 22 / \mathrm{S} 84$ & 16 & & IIIa & $21 \mathrm{P}-4$ & Edge modified flake & \\
\hline E22/S84 & 16 & & IIIa & $21 \mathrm{P}-6$ & Microspur/microdenticulate & \\
\hline E22/S84 & 16 & & IIIa & $21 \mathrm{P}-10$ & Piece esquillee & \\
\hline E22/S84 & 16 & & IIIIa & $21 \mathrm{P}-1$ & Projectile point, Hoxie & \\
\hline $\mathrm{E} 22 / \mathrm{S} 84$ & 16 & & IIIa & $21 \mathrm{P}-8$ & Uniface, unanalyzed & \\
\hline $\mathrm{E} 22 / \mathrm{S} 84$ & 17 & & II/IIIa & $21 Q-4$ & Biface Stage 2 & \\
\hline $\mathrm{E} 22 / \mathrm{S} 84$ & 17 & & II/IIIa & 21Q-3 & Biface Stage 2 & \\
\hline E22/S84 & 17 & & II/IIIa & & Debitage & 10 \\
\hline E22/S84 & 17 & & II/IIIa & 21Q-9 & Edge modified flake & \\
\hline $\mathrm{E} 22 / \mathrm{S} 84$ & 17 & & II/IIIa & $21 Q-8$ & Edge modified flake & \\
\hline $\mathrm{E} 22 / \mathrm{S} 84$ & 17 & & II/IIIa & $21 \mathrm{Q}-10$ & Edge modified flake & \\
\hline $\mathrm{E} 22 / \mathrm{S} 84$ & 17 & & II/IIIa & 21Q-11 & Edge modified flake & \\
\hline E22/S84 & 17 & & II/IIIa & 21Q-7 & Edge modified flake & \\
\hline $\mathrm{E} 22 / \mathrm{S} 84$ & 17 & & II/IIIa & 21Q-6 & Edge modified flake & \\
\hline E22/S84 & 17 & & II/IIIa & $21 Q-5$ & Micro-core, intermediate & \\
\hline E22/S84 & 17 & & II/IIIa & 21Q-2 & Projectile point, miscellaneous lanceolate & \\
\hline E22/S84 & 17 & & II/IIIa & 21Q-1 & Projectile point, St. Mary's Hall & \\
\hline $\mathrm{E} 22 / \mathrm{S} 84$ & 17 & & II/IIIa & $21 \mathrm{Q}-12$ & Uniface, unanalyzed & \\
\hline $\mathrm{E} 22 / \mathrm{S} 84$ & 18 & & II & $21 \mathrm{R}-3$ & Biface Stage 1 & \\
\hline $\mathrm{E} 22 / \mathrm{S} 84$ & 18 & & II & 21R-9 & Bifacial tool & \\
\hline E22/S84 & 18 & & II & $21 \mathrm{R}-5$ & Core fragment & \\
\hline E22/S84 & 18 & & II & & Debitage & 132 \\
\hline $\mathrm{E} 22 / \mathrm{S} 84$ & 18 & & II & $21 \mathrm{R}-4$ & Large core hammerstone & \\
\hline E22/S84 & 18 & & II & $21 \mathrm{R}-6$ & Piece esquillee & \\
\hline E22/S84 & 18 & & II & $21 \mathrm{R}-7$ & Projectile point fragment & \\
\hline $\mathrm{E} 22 / \mathrm{S} 84$ & 18 & & II & 21R-1 & Projectile point fragment & \\
\hline $\mathrm{E} 22 / \mathrm{S} 84$ & 18 & & II & $21 \mathrm{R}-8$ & Projectile point, expanding concave A & \\
\hline $\mathrm{E} 22 / \mathrm{S} 84$ & 18 & & II & $21 \mathrm{R}-2$ & Projectile point, miscellaneous lanceolate & \\
\hline $\mathrm{E} 22 / \mathrm{S} 84$ & 18 & & II & $21 \mathrm{R}-10$ & Thick uniface & \\
\hline $\mathrm{E} 22 / \mathrm{S} 84$ & 18 & & II & 21R-11 & Thick uniface & \\
\hline E22/S84 & 18 & & II & $21 \mathrm{R}-12$ & Thin uniface & \\
\hline E22/S84 & 20 & & $\mathrm{X} / \mathrm{II}$ & $21 \mathrm{~T}-1$ & Biface Stage 1 & \\
\hline $\mathrm{E} 22 / \mathrm{S} 84$ & 20 & & $\mathrm{X} / \mathrm{II}$ & $21 \mathrm{~T}-2$ & Bifacial tool Form E & \\
\hline E22/S84 & 20 & & $\mathrm{X} / \mathrm{II}$ & $21 \mathrm{~T}-4$ & Burin spall & \\
\hline $\mathrm{E} 22 / \mathrm{S} 84$ & 20 & & $\mathrm{X} / \mathrm{II}$ & $21 \mathrm{~T}-3$ & Core tool, type 4 & \\
\hline E22/S84 & 20 & & $\mathrm{X} / \mathrm{II}$ & & Debitage & \\
\hline E22/S84 & 20 & & $\mathrm{X} / \mathrm{II}$ & $21 \mathrm{~T}-6$ & Thin uniface & \\
\hline E22/S84 & 20 & & $\mathrm{X} / \mathrm{II}$ & $21 \mathrm{~T}-7$ & Uniface, unanalyzed & \\
\hline $\mathrm{E} 22 / \mathrm{S} 84$ & 22 & & $\mathrm{X} / \mathrm{II}$ & $21 \mathrm{~V}-1$ & Biface Stage 2 & \\
\hline $\mathrm{E} 22 / \mathrm{S} 84$ & 22 & & $\mathrm{X} / \mathrm{II}$ & & Debitage & \\
\hline $\mathrm{E} 22 / \mathrm{S} 84$ & 23 & & $\mathrm{X} / \mathrm{II}$ & & Debitage & \\
\hline $\mathrm{E} 22 / \mathrm{S} 84$ & 23 & & $\mathrm{X} / \mathrm{II}$ & $21 \mathrm{~W}-1$ & Thick uniface & \\
\hline $\mathrm{E} 22 / \mathrm{S} 84$ & 24 & & $\mathrm{X} / \mathrm{Isi}-\mathrm{c} / \mathrm{Id} / \mathrm{II}$ & $21 X-1$ & Biface Stage 2 & \\
\hline $\mathrm{E} 22 / \mathrm{S} 84$ & 24 & & $\mathrm{X} / \mathrm{Isi}-\mathrm{c} / \mathrm{Id} / \mathrm{II}$ & $21 X-6$ & Blade & \\
\hline $\mathrm{E} 22 / \mathrm{S} 84$ & 24 & & $\mathrm{X} / \mathrm{Isi}-\mathrm{c} / \mathrm{Id} / \mathrm{II}$ & & Debitage & \\
\hline E22/S84 & 24 & & $\mathrm{X} / \mathrm{Isi}-\mathrm{c} / \mathrm{Id} / \mathrm{II}$ & $21 X-8$ & Edge modified flake & \\
\hline $\mathrm{E} 22 / \mathrm{S} 84$ & 24 & & $\mathrm{X} / \mathrm{Isi}-\mathrm{c} / \mathrm{Id} / \mathrm{II}$ & $21 X-7$ & Edge modified flake & \\
\hline E22/S84 & 24 & & $\mathrm{X} / \mathrm{Isi}-\mathrm{c} / \mathrm{Id} / \mathrm{II}$ & $21 X-3$ & Edge modified flake & \\
\hline $\mathrm{E} 22 / \mathrm{S} 84$ & 24 & & X/Isi-c/Id/II & $21 X-2$ & Uniface, unanalyzed & \\
\hline E22/S84 & 25 & & $\mathrm{X} / \mathrm{Isi}-\mathrm{c} / \mathrm{Id}$ & & Debitage & \\
\hline E22/S86 & 6 & BRM 1 & IIIc & $20 \mathrm{~F}-1$ & Battered cobble & \\
\hline $\mathrm{E} 22 / \mathrm{S} 86$ & 6 & BRM 1 & IIIc & $20 \mathrm{~F}-18$ & Biface Stage 1 & \\
\hline E22/S86 & 6 & BRM 1 & IIIIc & $20 \mathrm{~F}-3$ & Biface Stage 1 & \\
\hline $\mathrm{E} 22 / \mathrm{S} 86$ & 6 & BRM 1 & IIIc & & Debitage & \\
\hline E22/S86 & 6 & BRM 1 & IIIc & $20 \mathrm{~F}-17$ & Edge modified flake & \\
\hline E22/S86 & 6 & BRM 1 & IIIc & $20 \mathrm{~F}-10$ & Edge modified flake & \\
\hline E22/S86 & 6 & BRM 1 & IIIc & $20 \mathrm{~F}-14$ & Edge modified flake & \\
\hline E22/S86 & 6 & BRM 1 & IIIc & $20 \mathrm{~F}-16$ & Edge modified flake & \\
\hline $\mathrm{E} 22 / \mathrm{S} 86$ & 6 & BRM 1 & IIIc & $20 \mathrm{~F}-15$ & Edge modified flake & \\
\hline E22/S86 & 6 & BRM 1 & IIIIc & $20 \mathrm{~F}-13$ & Edge modified flake & \\
\hline E22/S86 & 6 & BRM 1 & IIIc & $20 \mathrm{~F}-5$ & Edge modified flake & \\
\hline E22/S86 & 6 & BRM 1 & IIIc & $20 \mathrm{~F}-8$ & Edge modified flake & \\
\hline E22/S86 & 6 & BRM 1 & IIIc & $20 \mathrm{~F}-11$ & Edge modified flake & \\
\hline $\mathrm{E} 22 / \mathrm{S} 86$ & 6 & BRM 1 & IIIc & $20 \mathrm{~F}-7$ & Edge modified flake & \\
\hline E22/S86 & 6 & BRM 1 & IIIc & $20 \mathrm{~F}-4$ & Edge modified flake & \\
\hline
\end{tabular}




\begin{tabular}{|c|c|c|c|c|}
\hline Square & Level & Feature & Strata & Item \\
\hline $\mathrm{E} 22 / \mathrm{S} 86$ & 6 & BRM 1 & IIIc & $20 \mathrm{~F}-2$ \\
\hline $\mathrm{E} 22 / \mathrm{S} 86$ & 6 & BRM 1 & IIIc & $20 \mathrm{~F}-6$ \\
\hline E22/S86 & 6 & BRM 1 & IIIc & $20 \mathrm{~F}-9$ \\
\hline E22/S86 & 7 & BRM 1 & IIIc & 20G-5 \\
\hline $\mathrm{E} 22 / \mathrm{S} 86$ & 7 & BRM 1 & IIIc & $20 \mathrm{G}-7$ \\
\hline $\mathrm{E} 22 / \mathrm{S} 86$ & 7 & BRM 1 & IIIc & $20 \mathrm{G}-6$ \\
\hline $\mathrm{E} 22 / \mathrm{S} 86$ & 7 & BRM 1 & IIIc & $20 \mathrm{G}-4$ \\
\hline E22/S86 & 7 & BRM 1 & IIIc & 20G-8 \\
\hline E22/S86 & 7 & BRM 1 & IIIc & \\
\hline E22/S86 & 7 & BRM 1 & IIIc & $20 \mathrm{G}-22$ \\
\hline $\mathrm{E} 22 / \mathrm{S} 86$ & 7 & BRM 1 & IIIc & 20G-11 \\
\hline E22/S86 & 7 & BRM 1 & IIIc & 20G-12 \\
\hline E22/S86 & 7 & BRM 1 & IIIc & $20 \mathrm{G}-13$ \\
\hline $\mathrm{E} 22 / \mathrm{S} 86$ & 7 & BRM 1 & IIIc & 20G-20 \\
\hline E22/S86 & 7 & BRM 1 & IIIc & 20G-16 \\
\hline $\mathrm{E} 22 / \mathrm{S} 86$ & 7 & BRM 1 & IIIc & 20G-23 \\
\hline $\mathrm{E} 22 / \mathrm{S} 86$ & 7 & BRM 1 & IIIc & 20G-24 \\
\hline E22/S86 & 7 & BRM 1 & IIIc & $20 \mathrm{G}-21$ \\
\hline E22/S86 & 7 & BRM 1 & IIIc & 20G-15 \\
\hline $\mathrm{E} 22 / \mathrm{S} 86$ & 7 & BRM 1 & IIIc & 20G-17 \\
\hline $\mathrm{E} 22 / \mathrm{S} 86$ & 7 & BRM 1 & IIIc & 20G-10 \\
\hline E22/S86 & 7 & BRM 1 & IIIc & 20G-9 \\
\hline $\mathrm{E} 22 / \mathrm{S} 86$ & 7 & BRM 1 & IIIc & 20G-1 \\
\hline E22/S86 & 7 & BRM 1 & IIIc & 20G-2 \\
\hline $\mathrm{E} 22 / \mathrm{S} 86$ & 7 & BRM 1 & IIIc & 20G-19 \\
\hline E22/S86 & 8 & BRM 1 & $\mathrm{IIIb} / \mathrm{c}$ & $20 \mathrm{H}-9$ \\
\hline $\mathrm{E} 22 / \mathrm{S} 86$ & 8 & BRM 1 & $\mathrm{IIIb} / \mathrm{c}$ & $20 \mathrm{H}-5$ \\
\hline E22/S86 & 8 & BRM 1 & $\mathrm{IIIb} / \mathrm{c}$ & $20 \mathrm{H}-4$ \\
\hline $\mathrm{E} 22 / \mathrm{S} 86$ & 8 & BRM 1 & $\mathrm{IIIb} / \mathrm{c}$ & \\
\hline E22/S86 & 8 & BRM 1 & $\mathrm{IIIb} / \mathrm{c}$ & $20 \mathrm{H}-6$ \\
\hline E22/S86 & 8 & BRM 1 & $\mathrm{IIIb} / \mathrm{c}$ & $20 \mathrm{H}-18$ \\
\hline $\mathrm{E} 22 / \mathrm{S} 86$ & 8 & BRM 1 & $\mathrm{IIIb} / \mathrm{c}$ & $20 \mathrm{H}-12$ \\
\hline $\mathrm{E} 22 / \mathrm{S} 86$ & 8 & BRM 1 & $\mathrm{IIIb} / \mathrm{c}$ & $20 \mathrm{H}-14$ \\
\hline $\mathrm{E} 22 / \mathrm{S} 86$ & 8 & BRM 1 & $\mathrm{IIIb} / \mathrm{c}$ & $20 \mathrm{H}-10$ \\
\hline E22/S86 & 8 & BRM 1 & $\mathrm{IIIb} / \mathrm{c}$ & $20 \mathrm{H}-16$ \\
\hline $\mathrm{E} 22 / \mathrm{S} 86$ & 8 & BRM 1 & $\mathrm{IIIb} / \mathrm{c}$ & $20 \mathrm{H}-19$ \\
\hline E22/S86 & 8 & BRM 1 & $\mathrm{IIIb} / \mathrm{c}$ & $20 \mathrm{H}-22$ \\
\hline $\mathrm{E} 22 / \mathrm{S} 86$ & 8 & BRM 1 & $\mathrm{IIIb} / \mathrm{c}$ & 20H-8 \\
\hline E22/S86 & 8 & BRM 1 & $\mathrm{IIIb} / \mathrm{c}$ & $20 \mathrm{H}-20$ \\
\hline $\mathrm{E} 22 / \mathrm{S} 86$ & 8 & BRM 1 & $\mathrm{IIIb} / \mathrm{c}$ & $20 \mathrm{H}-11$ \\
\hline E22/S86 & 8 & BRM 1 & $\mathrm{IIIb} / \mathrm{c}$ & $20 \mathrm{H}-3$ \\
\hline $\mathrm{E} 22 / \mathrm{S} 86$ & 8 & BRM 1 & $\mathrm{IIIb} / \mathrm{c}$ & $20 \mathrm{H}-2$ \\
\hline E22/S86 & 8 & BRM 1 & $\mathrm{IIIb} / \mathrm{c}$ & $20 \mathrm{H}-1$ \\
\hline E22/S86 & 8 & BRM 1 & $\mathrm{IIIb} / \mathrm{c}$ & $20 \mathrm{H}-7$ \\
\hline $\mathrm{E} 22 / \mathrm{S} 86$ & 8 & BRM 1 & $\mathrm{IIIb} / \mathrm{c}$ & $20 \mathrm{H}-17$ \\
\hline $\mathrm{E} 22 / \mathrm{S} 86$ & 8 & BRM 1 & $\mathrm{IIIb} / \mathrm{c}$ & $20 \mathrm{H}-15$ \\
\hline E22/S86 & 9 & BRM 1 & $\mathrm{IIIb} / \mathrm{c}$ & $20 \mathrm{I}-2$ \\
\hline E22/S86 & 9 & BRM 1 & $\mathrm{IIIb} / \mathrm{c}$ & 20I-3 \\
\hline $\mathrm{E} 22 / \mathrm{S} 86$ & 9 & BRM 1 & $\mathrm{IIIb} / \mathrm{c}$ & $20 I-1$ \\
\hline E22/S86 & 9 & BRM 1 & $\mathrm{IIIb} / \mathrm{c}$ & $20 \mathrm{I}-4$ \\
\hline $\mathrm{E} 22 / \mathrm{S} 86$ & 9 & BRM 1 & $\mathrm{IIIb} / \mathrm{c}$ & \\
\hline E22/S86 & 9 & BRM 1 & $\mathrm{IIIb} / \mathrm{c}$ & $20 I-9$ \\
\hline E22/S86 & 9 & BRM 1 & $\mathrm{IIIb} / \mathrm{c}$ & $20 \mathrm{I}-8$ \\
\hline E22/S86 & 9 & BRM 1 & $\mathrm{IIIb} / \mathrm{c}$ & $20 \mathrm{I}-7$ \\
\hline E22/S86 & 9 & BRM 1 & $\mathrm{IIIb} / \mathrm{c}$ & $20 \mathrm{I}-5$ \\
\hline E22/S86 & 9 & BRM 1 & $\mathrm{IIIb} / \mathrm{c}$ & $20 I-6$ \\
\hline E22/S86 & 9 & BRM 1 & $\mathrm{IIIb} / \mathrm{c}$ & 20I-11 \\
\hline E22/S86 & 9 & BRM 1 & $\mathrm{IIIb} / \mathrm{c}$ & $20 \mathrm{I}-10$ \\
\hline $\mathrm{E} 22 / \mathrm{S} 86$ & 10 & BRM 1 & $\mathrm{IIIb} / \mathrm{c}$ & $20 \mathrm{~J}-3$ \\
\hline E22/S86 & 10 & BRM 1 & $\mathrm{IIIb} / \mathrm{c}$ & $20 \mathrm{~J}-4$ \\
\hline E22/S86 & 10 & BRM 1 & $\mathrm{IIIb} / \mathrm{c}$ & $20 \mathrm{~J}-1$ \\
\hline E22/S86 & 10 & BRM 1 & $\mathrm{IIIb} / \mathrm{c}$ & $20 \mathrm{~J}-5$ \\
\hline E22/S86 & 10 & BRM 1 & $\mathrm{IIIb} / \mathrm{c}$ & $20 \mathrm{~J}-6$ \\
\hline E22/S86 & 10 & BRM 1 & $\mathrm{IIIb} / \mathrm{c}$ & \\
\hline E22/S86 & 10 & BRM 1 & $\mathrm{IIIb} / \mathrm{c}$ & $20 \mathrm{~J}-8$ \\
\hline E22/S86 & 10 & BRM 1 & $\mathrm{IIIb} / \mathrm{c}$ & $20 \mathrm{~J}-2$ \\
\hline E22/S86 & 10 & BRM 1 & $\mathrm{IIIb} / \mathrm{c}$ & $20 \mathrm{~J}-7$ \\
\hline E22/S86 & 11 & & IIIb & $20 \mathrm{~K}-2$ \\
\hline E22/S 86 & 11 & & IIIb & $20 \mathrm{~K}-3$ \\
\hline E22/S86 & 11 & & IIIb & \\
\hline E22/S86 & 11 & & IIIb & $20 \mathrm{~K}-6$ \\
\hline E22/S86 & 11 & & IIIb & $20 \mathrm{~K}-5$ \\
\hline E22/S86 & 11 & & IIIb & $20 \mathrm{~K}-1$ \\
\hline E22/S86 & 11 & & IIIb & $20 \mathrm{~K}-4$ \\
\hline
\end{tabular}

Analyst Identification

Projectile point fragment

Unifacial multiple tool

Unifacial multiple tool

Biface fragment

Biface Stage 2

Biface Stage 2

Bifacial tool Form $\mathrm{H}$

Core tool, type 3

Debitage

Edge modified flake

Edge modified flake

Edge modified flake

Edge modified flake

Edge modified flake

Edge modified flake

Edge modified flake

Edge modified flake

Edge modified flake

Edge modified flake

Edge modified flake

Projectile point fragment

Projectile point, expanding concave B

Projectile point, Hoxie

Projectile point, Nolan

Thin uniface

Burin

Burin

Core fragment

Debitage

Denticulated flake

Edge modified flake

Edge modified flake

Edge modified flake

Edge modified flake

Edge modified flake

Edge modified flake

Edge modified flake

Edge modified flake

Edge modified flake

Edge modified flake

Projectile point fragment

Projectile point, Baker

Projectile point, Bulverde-like

Uniface, unanalyzed

Unifacial multiple tool

Unifacial multiple tool

Biface Stage 2

Biface Stage 2

Burin spall

Clear Fork uniface

Debitage

Denticulated flake

Edge modified flake

Edge modified flake

Edge modified flake

Notched flake

Thick uniface

Thin uniface

Biface fragment

Biface Stage 2

Biface Stage 3

Burin

Core, multidirectional

Debitage

Microspur/microdenticulate

Projectile point fragment

Uniface, unanalyzed

Biface fragment

Biface Stage 2

Debitage

Edge modified flake

Edge modified flake

Mano

Projectile point fragment
Coun

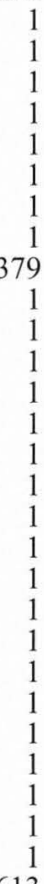

613 


\begin{tabular}{|c|c|c|c|c|c|c|}
\hline Square & Level & Feature & Strata & Item & Analyst Identification & Count \\
\hline $\mathrm{E} 22 / \mathrm{S} 86$ & 11 & & IIIb & $20 \mathrm{~K}-7$ & Thin uniface fragment & \\
\hline E22/S86 & 11 & Feature 88 & IIIb & $20 \mathrm{~K}-9$ & Projectile point, expanding concave $\mathrm{B}$ & \\
\hline $\mathrm{E} 22 / \mathrm{S} 86$ & 11 & Feature 88 & $\mathrm{IIIb}$ & $20 \mathrm{~K}-8$ & Projectile point, Gower/Uvalde & \\
\hline $\mathrm{E} 22 / \mathrm{S} 86$ & 12 & & $\mathrm{IIIb}$ & $20 \mathrm{~L}-5$ & Biface fragment & \\
\hline $\mathrm{E} 22 / \mathrm{S} 86$ & 12 & & IIIb & $20 \mathrm{~L}-3$ & Biface fragment & \\
\hline $\mathrm{E} 22 / \mathrm{S} 86$ & 12 & & IIIb & 20L-9 & Biface Stage 1 & \\
\hline E22/S86 & 12 & & IIIb & $20 \mathrm{~L}-2$ & Biface Stage 2 & \\
\hline $\mathrm{E} 22 / \mathrm{S} 86$ & 12 & & IIIb & $20 \mathrm{~L}-6$ & Burin & \\
\hline $\mathrm{E} 22 / \mathrm{S} 86$ & 12 & & $\mathrm{IIIb}$ & 20L-7 & Burin spall & \\
\hline $\mathrm{E} 22 / \mathrm{S} 86$ & 12 & & IIIb & $20 \mathrm{~L}-12$ & Burin spall & \\
\hline $\mathrm{E} 22 / \mathrm{S} 86$ & 12 & & IIIb & $20 \mathrm{~L}-11$ & Clear Fork biface & \\
\hline $\mathrm{E} 22 / \mathrm{S} 86$ & 12 & & IIIb & & Debitage & 106( \\
\hline $\mathrm{E} 22 / \mathrm{S} 86$ & 12 & & IIIb & $20 \mathrm{~L}-13$ & Microspur/microdenticulate & \\
\hline $\mathrm{E} 22 / \mathrm{S} 86$ & 12 & & $\mathrm{IIIb}$ & $20 \mathrm{~L}-4$ & Piece esquillee & \\
\hline $\mathrm{E} 22 / \mathrm{S} 86$ & 12 & & IIIb & $20 \mathrm{~L}-1$ & Projectile point fragment & \\
\hline $\mathrm{E} 22 / \mathrm{S} 86$ & 12 & & IIIb & $20 \mathrm{~L}-14$ & Retouched blade & \\
\hline $\mathrm{E} 22 / \mathrm{S} 86$ & 12 & & IIIb & $20 \mathrm{~L}-17$ & Unifacial multiple tool & \\
\hline $\mathrm{E} 22 / \mathrm{S} 86$ & 13 & & $\mathrm{X} / \mathrm{IIIb}$ & $20 \mathrm{M}-3$ & Biface Stage 2 & \\
\hline $\mathrm{E} 22 / \mathrm{S} 86$ & 13 & & $\mathrm{X} / \mathrm{IIIb}$ & $20 \mathrm{M}-4$ & Biface Stage 2 & \\
\hline E22/S86 & 13 & & $\mathrm{X} / \mathrm{IIIb}$ & $20 \mathrm{M}-2$ & Biface Stage 3 & \\
\hline $\mathrm{E} 22 / \mathrm{S} 86$ & 13 & & $\mathrm{X} / \mathrm{IIIb}$ & 20M-9 & Bifacial tool Form B & \\
\hline E22/S86 & 13 & & $\mathrm{X} / \mathrm{IIIb}$ & $20 \mathrm{M}-12$ & Bifacial tool Form C & \\
\hline $\mathrm{E} 22 / \mathrm{S} 86$ & 13 & & $\mathrm{X} / \mathrm{IIIb}$ & $20 \mathrm{M}-5$ & Burin spall & \\
\hline $\mathrm{E} 22 / \mathrm{S} 86$ & 13 & & $\mathrm{X} / \mathrm{IIIb}$ & & Debitage & 837 \\
\hline $\mathrm{E} 22 / \mathrm{S} 86$ & 13 & & $\mathrm{X} / \mathrm{IIIb}$ & $20 \mathrm{M}-8$ & Edge modified flake & \\
\hline E22/S86 & 13 & & $\mathrm{X} / \mathrm{IIIb}$ & $20 \mathrm{M}-19$ & Edge modified flake & \\
\hline $\mathrm{E} 22 / \mathrm{S} 86$ & 13 & & $\mathrm{X} / \mathrm{IIIb}$ & $20 \mathrm{M}-15$ & Edge modified flake & \\
\hline $\mathrm{E} 22 / \mathrm{S} 86$ & 13 & & $\mathrm{X} / \mathrm{IIIb}$ & $20 M-6$ & Projectile point fragment & \\
\hline $\mathrm{E} 22 / \mathrm{S} 86$ & 13 & & $\mathrm{X} / \mathrm{IIIb}$ & $20 \mathrm{M}-7$ & Projectile point fragment & \\
\hline $\mathrm{E} 22 / \mathrm{S} 86$ & 13 & & $\mathrm{X} / \mathrm{IIIb}$ & $20 \mathrm{M}-1$ & Projectile point, miscellaneous bifurcate & 1 \\
\hline $\mathrm{E} 22 / \mathrm{S} 86$ & 13 & & $\mathrm{X} / \mathrm{IIIb}$ & $20 \mathrm{M}-13$ & Retouched blade & \\
\hline $\mathrm{E} 22 / \mathrm{S} 86$ & 13 & & $\mathrm{X} / \mathrm{IIIb}$ & $20 \mathrm{M}-10$ & Thin uniface & \\
\hline $\mathrm{E} 22 / \mathrm{S} 86$ & 13 & & $\mathrm{X} / \mathrm{IIIb}$ & $20 \mathrm{M}-16$ & Thin uniface & \\
\hline $\mathrm{E} 22 / \mathrm{S} 86$ & 13 & & $\mathrm{X} / \mathrm{IIIb}$ & $20 \mathrm{M}-14$ & Uniface, unanalyzed & \\
\hline $\mathrm{E} 22 / \mathrm{S} 86$ & 13 & & $\mathrm{X} / \mathrm{IIIb}$ & $20 \mathrm{M}-17$ & Uniface, unanalyzed & \\
\hline $\mathrm{E} 22 / \mathrm{S} 86$ & 13 & & $\mathrm{X} / \mathrm{IIIb}$ & $20 \mathrm{M}-18$ & Unifacial multiple tool & \\
\hline $\mathrm{E} 22 / \mathrm{S} 86$ & 13 & & $\mathrm{X} / \mathrm{IIIb}$ & $20 \mathrm{M}-11$ & Unifacial multiple tool & \\
\hline $\mathrm{E} 22 / \mathrm{S} 86$ & 14 & & $\mathrm{X} / \mathrm{IIIa} / \mathrm{b}$ & $20 \mathrm{~N}-3$ & Biface fragment & \\
\hline $\mathrm{E} 22 / \mathrm{S} 86$ & 14 & & $\mathrm{X} / \mathrm{IIIa} / \mathrm{b}$ & & Debitage & 1023 \\
\hline $\mathrm{E} 22 / \mathrm{S} 86$ & 14 & & $\mathrm{X} / \mathrm{IIIa} / \mathrm{b}$ & $20 N-5$ & Edge modified flake & \\
\hline $\mathrm{E} 22 / \mathrm{S} 86$ & 14 & & $\mathrm{X} / \mathrm{III} / \mathrm{b}$ & $20 \mathrm{~N}-1$ & Projectile point, expanding concave D & \\
\hline $\mathrm{E} 22 / \mathrm{S} 86$ & 14 & & $\mathrm{X} / \mathrm{III} / \mathrm{b}$ & $20 \mathrm{~N}-2$ & Projectile point, Hoxie & \\
\hline $\mathrm{E} 22 / \mathrm{S} 86$ & 14 & & $\mathrm{X} / \mathrm{IIIa} / \mathrm{b}$ & $20 \mathrm{~N}-4$ & Uniface, unanalyzed & \\
\hline $\mathrm{E} 22 / \mathrm{S} 86$ & 15 & & X/IIIa & $200-19$ & Biface fragment & \\
\hline $\mathrm{E} 22 / \mathrm{S} 86$ & 15 & & $\mathrm{X} / \mathrm{IIIa}$ & $200-6$ & Biface Stage 1 & \\
\hline $\mathrm{E} 22 / \mathrm{S} 86$ & 15 & & $\mathrm{X} / \mathrm{IIIa}$ & $200-5$ & Biface Stage 2 & \\
\hline $\mathrm{E} 22 / \mathrm{S} 86$ & 15 & & $\mathrm{X} / \mathrm{IIIa}$ & $200-3$ & Biface Stage 2 & \\
\hline $\mathrm{E} 22 / \mathrm{S} 86$ & 15 & & $\mathrm{X} / \mathrm{III}$ & $200-25$ & Bifacial tool Form D & \\
\hline $\mathrm{E} 22 / \mathrm{S} 86$ & 15 & & $\mathrm{X} / \mathrm{IIIa}$ & $200-27$ & Bifacial tool Form $\mathrm{F}$ & \\
\hline $\mathrm{E} 22 / \mathrm{S} 86$ & 15 & & $\mathrm{X} / \mathrm{IIIa}$ & $200-20$ & Burin spall & \\
\hline $\mathrm{E} 22 / \mathrm{S} 86$ & 15 & & $\mathrm{X} / \mathrm{IIIa}$ & $200-26$ & Burin spall & \\
\hline $\mathrm{E} 22 / \mathrm{S} 86$ & 15 & & $\mathrm{X} / \mathrm{II}$ & & Debitage & 101 \\
\hline $\mathrm{E} 22 / \mathrm{S} 86$ & 15 & & $\mathrm{X} / \mathrm{IIIa}$ & $200-12$ & Edge modified flake & \\
\hline $\mathrm{E} 22 / \mathrm{S} 86$ & 15 & & $\mathrm{X} / \mathrm{III}$ & $200-10$ & Edge modified flake & \\
\hline $\mathrm{E} 22 / \mathrm{S} 86$ & 15 & & $\mathrm{X} / \mathrm{IIIa}$ & $200-13$ & Edge modified flake & \\
\hline $\mathrm{E} 22 / \mathrm{S} 86$ & 15 & & $\mathrm{X} / \mathrm{IIIa}$ & $200-14$ & Edge modified flake & \\
\hline $\mathrm{E} 22 / \mathrm{S} 86$ & 15 & & $\mathrm{X} / \mathrm{IIIa}$ & $200-9$ & Edge modified flake & \\
\hline $\mathrm{E} 22 / \mathrm{S} 86$ & 15 & & X/IIIa & $200-21$ & Edge modified flake & \\
\hline $\mathrm{E} 22 / \mathrm{S} 86$ & 15 & & $\mathrm{X} / \mathrm{IIIa}$ & $200-15$ & Edge modified flake & \\
\hline $\mathrm{E} 22 / \mathrm{S} 86$ & 15 & & $\mathrm{X} / \mathrm{III}$ & $200-29$ & Edge modified flake & \\
\hline $\mathrm{E} 22 / \mathrm{S} 86$ & 15 & & $\mathrm{X} / \mathrm{III}$ & $200-16$ & Notched flake & \\
\hline $\mathrm{E} 22 / \mathrm{S} 86$ & 15 & & $\mathrm{X} / \mathrm{IIIa}$ & $200-1$ & Projectile point fragment & \\
\hline $\mathrm{E} 22 / \mathrm{S} 86$ & 15 & & $\mathrm{X} / \mathrm{III}$ & $200-2$ & Projectile point, Uvalde-like & \\
\hline $\mathrm{E} 22 / \mathrm{S} 86$ & 15 & & $\mathrm{X} / \mathrm{IIIa}$ & $200-4$ & Small core hammerstone & \\
\hline $\mathrm{E} 22 / \mathrm{S} 86$ & 15 & & X/IIIa & $200-24$ & Thin uniface & \\
\hline E22/S86 & 15 & & $\mathrm{X} / \mathrm{IIIa}$ & $200-28$ & Thin uniface & \\
\hline $\mathrm{E} 22 / \mathrm{S} 86$ & 15 & & $\mathrm{X} / \mathrm{IIIa}$ & $200-23$ & Uniface, unanalyzed & \\
\hline $\mathrm{E} 22 / \mathrm{S} 86$ & 15 & & $\mathrm{X} / \mathrm{IIIa}$ & $200-22$ & Uniface, unanalyzed & \\
\hline $\mathrm{E} 22 / \mathrm{S} 86$ & 16 & & $\mathrm{X} / \mathrm{II} / \mathrm{IIIa}$ & $20 P-18$ & Biface fragment & \\
\hline $\mathrm{E} 22 / \mathrm{S} 86$ & 16 & & $\mathrm{X} / \mathrm{II} / \mathrm{IIIa}$ & $20 \mathrm{P}-3$ & Biface fragment & \\
\hline $\mathrm{E} 22 / \mathrm{S} 86$ & 16 & & X/II/IIIa & $20 \mathrm{P}-2$ & Biface fragment & \\
\hline $\mathrm{E} 22 / \mathrm{S} 86$ & 16 & & $\mathrm{X} / \mathrm{II} / \mathrm{IIIa}$ & $20 P-15$ & Biface Stage 1 & \\
\hline $\mathrm{E} 22 / \mathrm{S} 86$ & 16 & & X/II/IIIa & $20 \mathrm{P}-8$ & Biface Stage 2 & \\
\hline $\mathrm{E} 22 / \mathrm{S} 86$ & 16 & & X/II/IIIa & $20 P-6$ & Biface Stage 2 & \\
\hline
\end{tabular}




\begin{tabular}{|c|c|c|c|c|c|c|}
\hline Square & Level & Feature & Strata & Item & Analyst Identification & Count \\
\hline $\mathrm{E} 22 / \mathrm{S} 86$ & 16 & & $\mathrm{X} / \mathrm{II} / \mathrm{III} \mathrm{Ia}$ & $20 \mathrm{P}-7$ & Biface Stage 3 & 1 \\
\hline $\mathrm{E} 22 / \mathrm{S} 86$ & 16 & & X/II/IIIa & $20 P-5$ & Burin spall & 1 \\
\hline $\mathrm{E} 22 / \mathrm{S} 86$ & 16 & & $\mathrm{X} / \mathrm{II} / \mathrm{IIIa}$ & $20 \mathrm{P}-4$ & Clear Fork biface & 1 \\
\hline $\mathrm{E} 22 / \mathrm{S} 86$ & 16 & & X/II/IIIa & & Debitage & 1070 \\
\hline $\mathrm{E} 22 / \mathrm{S} 86$ & 16 & & $\mathrm{X} / \mathrm{II} / \mathrm{IIIa}$ & $20 P-9$ & Edge modified flake & 1 \\
\hline $\mathrm{E} 22 / \mathrm{S} 86$ & 16 & & $\mathrm{X} / \mathrm{II} / \mathrm{IIIa}$ & $20 \mathrm{P}-17$ & Edge modified flake & 1 \\
\hline $\mathrm{E} 22 / \mathrm{S} 86$ & 16 & & $\mathrm{X} / \mathrm{II} / \mathrm{IIIa}$ & $20 \mathrm{P}-13$ & Edge modified flake & 1 \\
\hline $\mathrm{E} 22 / \mathrm{S} 86$ & 16 & & $\mathrm{X} / \mathrm{II} / \mathrm{IIIa}$ & $20 \mathrm{P}-12$ & Edge modified flake & 1 \\
\hline E22/S86 & 16 & & $\mathrm{X} / \mathrm{II} / \mathrm{IIIa}$ & $20 \mathrm{P}-10$ & Edge modified flake & \\
\hline $\mathrm{E} 22 / \mathrm{S} 86$ & 16 & & $\mathrm{X} / \mathrm{II} / \mathrm{IIIa}$ & $20 \mathrm{P}-19$ & Edge modified flake & \\
\hline $\mathrm{E} 22 / \mathrm{S} 86$ & 16 & & $\mathrm{X} / \mathrm{II} / \mathrm{IIIa}$ & $20 \mathrm{P}-11$ & Microspur/microdenticulate & \\
\hline $\mathrm{E} 22 / \mathrm{S} 86$ & 16 & & $\mathrm{X} / \mathrm{II} / \mathrm{IIIa}$ & $20 \mathrm{P}-1$ & Projectile point, Angostura & 1 \\
\hline $\mathrm{E} 22 / \mathrm{S} 86$ & 16 & & $\mathrm{X} / \mathrm{II} / \mathrm{IIIa}$ & 20P-16 & Thick uniface & \\
\hline $\mathrm{E} 22 / \mathrm{S} 86$ & 16 & & $\mathrm{X} / \mathrm{II} / \mathrm{IIIa}$ & $20 \mathrm{P}-14$ & Uniface, unanalyzed & \\
\hline $\mathrm{E} 22 / \mathrm{S} 86$ & 17 & & X/II/IIIa & 20Q-8 & Biface fragment & \\
\hline $\mathrm{E} 22 / \mathrm{S} 86$ & 17 & & $\mathrm{X} / \mathrm{II} / \mathrm{IIIa}$ & 20Q-7 & Biface Stage 2 & 1 \\
\hline E22/S86 & 17 & & $\mathrm{X} / \mathrm{II} / \mathrm{IIIa}$ & $20 Q-5$ & Bifacial tool & \\
\hline $\mathrm{E} 22 / \mathrm{S} 86$ & 17 & & $\mathrm{X} / \mathrm{II} / \mathrm{IIIa}$ & $20 \mathrm{Q}-13$ & Bifacial tool Form A & \\
\hline $\mathrm{E} 22 / \mathrm{S} 86$ & 17 & & X/II/IIIa & $20 \mathrm{Q}-9$ & Burin & \\
\hline $\mathrm{E} 22 / \mathrm{S} 86$ & 17 & & X/II/IIIa & 20Q-10 & Burin spall & \\
\hline $\mathrm{E} 22 / \mathrm{S} 86$ & 17 & & $\mathrm{X} / \mathrm{II} / \mathrm{IIIa}$ & 20Q-11 & Burin spall & 1 \\
\hline $\mathrm{E} 22 / \mathrm{S} 86$ & 17 & & $\mathrm{X} / \mathrm{II} / \mathrm{IIIa}$ & & Debitage & 931 \\
\hline E22/S86 & 17 & & $\mathrm{X} / \mathrm{II} / \mathrm{IIIa}$ & $20 Q-3$ & Metate fragment & \\
\hline $\mathrm{E} 22 / \mathrm{S} 86$ & 17 & & $\mathrm{X} / \mathrm{II} / \mathrm{IIIa}$ & 20Q-4 & Possible ground stone & \\
\hline $\mathrm{E} 22 / \mathrm{S} 86$ & 17 & & $\mathrm{X} / \mathrm{II} / \mathrm{IIIa}$ & $20 \mathrm{Q}-12$ & Projectile point fragment & 1 \\
\hline $\mathrm{E} 22 / \mathrm{S} 86$ & 17 & & $\mathrm{X} / \mathrm{II} / \mathrm{IIIa}$ & $20 \mathrm{Q}-2$ & Projectile point, bifurcate stem fragment & \\
\hline $\mathrm{E} 22 / \mathrm{S} 86$ & 17 & & $\mathrm{X} / \mathrm{II} / \mathrm{IIIa}$ & $20 \mathrm{Q}-1$ & Projectile point, Thrall & \\
\hline $\mathrm{E} 22 / \mathrm{S} 86$ & 17 & & X/II/IIIa & $20 \mathrm{Q}-16$ & Thin uniface & \\
\hline $\mathrm{E} 22 / \mathrm{S} 86$ & 17 & & X/II/IIIa & $20 \mathrm{Q}-14$ & Thin uniface fragment & \\
\hline E22/S86 & 17 & & $\mathrm{X} / \mathrm{II} / \mathrm{IIIa}$ & $20 \mathrm{Q}-18$ & Unifacial multiple tool & \\
\hline $\mathrm{E} 22 / \mathrm{S} 86$ & 17 & & $\mathrm{X} / \mathrm{II} / \mathrm{IIIa}$ & $20 \mathrm{Q}-17$ & Unifacial multiple tool & \\
\hline $\mathrm{E} 22 / \mathrm{S} 86$ & 17 & & $\mathrm{X} / \mathrm{II} / \mathrm{IIIa}$ & $20 \mathrm{Q}-15$ & Unifacial multiple tool & 1 \\
\hline $\mathrm{E} 22 / \mathrm{S} 86$ & 17 & Feature 110 & X/II/IIIa & $20 \& 21 Q-20$ & Biface Stage 2 & 1 \\
\hline $\mathrm{E} 22 / \mathrm{S} 86$ & 17 & Feature 110 & $\mathrm{X} / \mathrm{II} / \mathrm{IIIa}$ & $20 \& 21 Q-21$ & Biface Stage 2 & 1 \\
\hline E22/S86 & 17 & Feature 110 & $\mathrm{X} / \mathrm{II} / \mathrm{IIIa}$ & $20 \& 21 Q-23$ & Biface Stage 2 & \\
\hline $\mathrm{E} 22 / \mathrm{S} 86$ & 17 & Feature 110 & X/II/IIIa & $20 \& 21 \mathrm{Q}-22$ & Core, multidirectional & 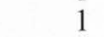 \\
\hline $\mathrm{E} 22 / \mathrm{S} 86$ & 17 & Feature 110 & $\mathrm{X} / \mathrm{II} / \mathrm{IIIa}$ & $20 \& 21 Q-19$ & Projectile point, miscellaneous lanceolate & 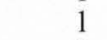 \\
\hline $\mathrm{E} 22 / \mathrm{S} 86$ & 18 & & $\mathrm{X} / \mathrm{II}$ & $20 \mathrm{R}-9$ & Biface fragment & - \\
\hline $\mathrm{E} 22 / \mathrm{S} 86$ & 18 & & $\mathrm{X} / \mathrm{II}$ & 20R-19 & Biface fragment & 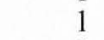 \\
\hline $\mathrm{E} 22 / \mathrm{S} 86$ & 18 & & $\mathrm{X} / \mathrm{II}$ & 20R-24 & Biface fragment & 1 \\
\hline $\mathrm{E} 22 / \mathrm{S} 86$ & 18 & & $\mathrm{X} / \mathrm{II}$ & $20 \mathrm{R}-22$ & Biface fragment & \\
\hline $\mathrm{E} 22 / \mathrm{S} 86$ & 18 & & $\mathrm{X} / \mathrm{II}$ & $20 \mathrm{R}-4$ & Biface Stage 1 & 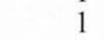 \\
\hline $\mathrm{E} 22 / \mathrm{S} 86$ & 18 & & $\mathrm{X} / \mathrm{II}$ & $20 \mathrm{R}-7$ & Biface Stage 1 & \\
\hline $\mathrm{E} 22 / \mathrm{S} 86$ & 18 & & $\mathrm{X} / \mathrm{II}$ & 20R-8 & Biface Stage 2 & \\
\hline $\mathrm{E} 22 / \mathrm{S} 86$ & 18 & & $\mathrm{X} / \mathrm{II}$ & 20R-11 & Burin spall & 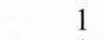 \\
\hline $\mathrm{E} 22 / \mathrm{S} 86$ & 18 & & $\mathrm{X} / \mathrm{II}$ & $20 \mathrm{R}-10$ & Clear Fork biface, proximal & 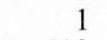 \\
\hline $\mathrm{E} 22 / \mathrm{S} 86$ & 18 & & $\mathrm{X} / \mathrm{II}$ & & Debitage & 693 \\
\hline $\mathrm{E} 22 / \mathrm{S} 86$ & 18 & & $\mathrm{X} / \mathrm{II}$ & $20 \mathrm{R}-26$ & Denticulated flake & \\
\hline $\mathrm{E} 22 / \mathrm{S} 86$ & 18 & & $\mathrm{X} / \mathrm{II}$ & 20R-14 & Edge modified flake & \\
\hline $\mathrm{E} 22 / \mathrm{S} 86$ & 18 & & $\mathrm{X} / \mathrm{II}$ & $20 \mathrm{R}-16$ & Edge modified flake & \\
\hline $\mathrm{E} 22 / \mathrm{S} 86$ & 18 & & $\mathrm{X} / \mathrm{II}$ & 20R-18 & Edge modified flake & \\
\hline $\mathrm{E} 22 / \mathrm{S} 86$ & 18 & & $\mathrm{X} / \mathrm{II}$ & $20 \mathrm{R}-20$ & Edge modified flake & \\
\hline $\mathrm{E} 22 / \mathrm{S} 86$ & 18 & & $\mathrm{X} / \mathrm{II}$ & $20 \mathrm{R}-21$ & Edge modified flake & \\
\hline $\mathrm{E} 22 / \mathrm{S} 86$ & 18 & & $\mathrm{X} / \mathrm{II}$ & $20 \mathrm{R}-23$ & Edge modified flake & \\
\hline $\mathrm{E} 22 / \mathrm{S} 86$ & 18 & & $\mathrm{X} / \mathrm{II}$ & $20 \mathrm{R}-25$ & Edge modified flake & \\
\hline $\mathrm{E} 22 / \mathrm{S} 86$ & 18 & & $\mathrm{X} / \mathrm{II}$ & 20R-15 & Edge modified flake & \\
\hline $\mathrm{E} 22 / \mathrm{S} 86$ & 18 & & $\mathrm{X} / \mathrm{II}$ & $20 \mathrm{R}-5$ & Micro-core, intermediate & \\
\hline $\mathrm{E} 22 / \mathrm{S} 86$ & 18 & & $\mathrm{X} / \mathrm{II}$ & $20 \mathrm{R}-17$ & Microspur/microdenticulate & \\
\hline $\mathrm{E} 22 / \mathrm{S} 86$ & 18 & & $\mathrm{X} / \mathrm{II}$ & $20 \mathrm{R}-3$ & Possible ground stone & \\
\hline E22/S86 & 18 & & $\mathrm{X} / \mathrm{II}$ & 20R-2 & Projectile point, bifurcate stem fragment & \\
\hline $\mathrm{E} 22 / \mathrm{S} 86$ & 18 & & $\mathrm{X} / \mathrm{II}$ & 20R-1 & Projectile point, square stem & \\
\hline $\mathrm{E} 22 / \mathrm{S} 86$ & 18 & & $\mathrm{X} / \mathrm{II}$ & 20R-6 & Thin uniface & \\
\hline $\mathrm{E} 22 / \mathrm{S} 86$ & 18 & & $\mathrm{X} / \mathrm{II}$ & 20R-12 & Thin uniface fragment & \\
\hline $\mathrm{E} 22 / \mathrm{S} 86$ & 18 & & $\mathrm{X} / \mathrm{II}$ & $20 \mathrm{R}-27$ & Thin uniface fragment & \\
\hline E22/S86 & 18 & & $\mathrm{X} / \mathrm{II}$ & $20 \mathrm{R}-13$ & Unifacial multiple tool & \\
\hline $\mathrm{E} 22 / \mathrm{S} 86$ & 19 & & $\mathrm{X} / \mathrm{II}$ & $20 \mathrm{~S}-2$ & Biface fragment & \\
\hline $\mathrm{E} 22 / \mathrm{S} 86$ & 19 & & $\mathrm{X} / \mathrm{II}$ & $20 \mathrm{~S}-3$ & Biface Stage 2 & \\
\hline E22/S86 & 19 & & $\mathrm{X} / \mathrm{II}$ & 20S-1 & Clear Fork biface & \\
\hline E22/S86 & 19 & & $\mathrm{X} / \mathrm{II}$ & 20 S-6 & Core, multidirectional & \\
\hline $\mathrm{E} 22 / \mathrm{S} 86$ & 19 & & $\mathrm{X} / \mathrm{II}$ & & Debitage & 566 \\
\hline $\mathrm{E} 22 / \mathrm{S} 86$ & 19 & & $\mathrm{X} / \mathrm{II}$ & 20S-11 & Edge modified flake & \\
\hline $\mathrm{E} 22 / \mathrm{S} 86$ & 19 & & $\mathrm{X} / \mathrm{II}$ & $20 \mathrm{~S}-12$ & Edge modified flake & \\
\hline $\mathrm{E} 22 / \mathrm{S} 86$ & 19 & & $\mathrm{X} / \mathrm{II}$ & $20 \mathrm{~S}-7$ & Perforator Group 5 & \\
\hline E22/S86 & 19 & & $\mathrm{X} / \mathrm{II}$ & $20 \mathrm{~S}-8$ & Perforator Group 7 & \\
\hline
\end{tabular}




\begin{tabular}{|c|c|c|c|c|c|c|}
\hline Square & Level & Feature & Strata & Item & Analyst Identification & Count \\
\hline E22/S86 & 19 & & $\mathrm{X} / \mathrm{II}$ & $20 \mathrm{~S}-10$ & Projectile point, miscellaneous lanceolate & 1 \\
\hline E22/S86 & 19 & & $\mathrm{X} / \mathrm{II}$ & $20 \mathrm{~S}-13$ & Thick uniface & 1 \\
\hline $\mathrm{E} 22 / \mathrm{S} 86$ & 19 & & $\mathrm{X} / \mathrm{II}$ & $20 \mathrm{~S}-5$ & Uniface, unanalyzed & 1 \\
\hline $\mathrm{E} 22 / \mathrm{S} 86$ & 20 & & $\mathrm{X} / \mathrm{II}$ & $20 \mathrm{~T}-1$ & Biface fragment & 1 \\
\hline $\mathrm{E} 22 / \mathrm{S} 86$ & 20 & & $\mathrm{X} / \mathrm{II}$ & & Debitage & 375 \\
\hline $\mathrm{E} 22 / \mathrm{S} 86$ & 20 & & $\mathrm{X} / \mathrm{II}$ & $20 \mathrm{~T}-2$ & Edge modified flake & 1 \\
\hline $\mathrm{E} 22 / \mathrm{S} 86$ & 20 & & $\mathrm{X} / \mathrm{II}$ & $20 \mathrm{~T}-4$ & Thick uniface & 1 \\
\hline $\mathrm{E} 22 / \mathrm{S} 86$ & 20 & & $\mathrm{X} / \mathrm{II}$ & $20 \mathrm{~T}-6$ & Thin uniface & 1 \\
\hline E22/S86 & 22 & & $\mathrm{X}$ & & Debitage & 256 \\
\hline E22/S86 & 22 & & $\mathrm{X}$ & $20 \mathrm{~V}-1$ & Microspur/microdenticulate & 1 \\
\hline E22/S86 & 22 & & $X$ & $20 \mathrm{~V}-2$ & Unifacial multiple tool & 1 \\
\hline $\mathrm{E} 22 / \mathrm{S} 86$ & 23 & & $\mathrm{X}$ & $20 \mathrm{~W}-3$ & Biface Stage 3 & 1 \\
\hline $\mathrm{E} 22 / \mathrm{S} 86$ & 23 & & $\mathrm{X}$ & $20 \mathrm{~W}-2$ & Brushy Creek biface & 1 \\
\hline E22/S86 & 23 & & $X$ & & Debitage & 101 \\
\hline E22/S86 & 23 & & $\mathrm{X}$ & $20 \mathrm{~W}-4$ & Edge modified flake & 1 \\
\hline E22/S86 & 23 & Feature 118 & $\mathrm{X}$ & $20 \mathrm{~W}-1$ & Projectile point, St. Mary's Hall & 1 \\
\hline $\mathrm{E} 22 / \mathrm{S} 86$ & 24 & & $X$ & $20 X-3$ & Biface Stage 2 & 1 \\
\hline $\mathrm{E} 22 / \mathrm{S} 86$ & 24 & & $\mathrm{X}$ & $20 X-2$ & Biface Stage 3 & 1 \\
\hline $\mathrm{E} 22 / \mathrm{S} 86$ & 24 & & $\mathrm{X}$ & $20 X-4$ & Bifacial tool Form $\mathrm{H}$ & 1 \\
\hline $\mathrm{E} 22 / \mathrm{S} 86$ & 24 & & $\mathrm{X}$ & & Debitage & 120 \\
\hline $\mathrm{E} 22 / \mathrm{S} 86$ & 24 & & $\mathrm{X}$ & $20 X-5$ & Micro-core, small & 1 \\
\hline E22/S86 & 24 & & $\mathrm{X}$ & $20 X-8$ & Notched flake & 1 \\
\hline E22/S86 & 24 & & $\mathrm{X}$ & $20 \mathrm{X}-1$ & Projectile point, Wilson & 1 \\
\hline E22/S86 & 24 & & $\mathrm{X}$ & $20 X-6$ & Uniface, unanalyzed & 1 \\
\hline $\mathrm{E} 22 / \mathrm{S} 86$ & $27 \mathrm{~B}$ & & $X$ & & Debitage & 12 \\
\hline E22/S88 & 2 & BRM 1 & IIIc & & Debitage & 3 \\
\hline E22/S88 & 6 & BRM 1 & IIIc & $19 \mathrm{~F}-5$ & Biface Stage 2 & 1 \\
\hline E22/S88 & 6 & BRM 1 & IIIIc & $19 \mathrm{~F}-3$ & Biface Stage 2 & 1 \\
\hline $\mathrm{E} 22 / \mathrm{S} 88$ & 6 & BRM 1 & IIIc & $19 \mathrm{~F}-2$ & Biface Stage 2 & 1 \\
\hline E22/S88 & 6 & BRM 1 & IIIc & $19 \mathrm{~F}-4$ & Biface Stage 2 & 1 \\
\hline $\mathrm{E} 22 / \mathrm{S} 88$ & 6 & BRM 1 & IIIc & & Debitage & 476 \\
\hline E22/S88 & 6 & BRM 1 & IIIc & $19 \mathrm{~F}-15$ & Denticulated flake & 1 \\
\hline $\mathrm{E} 22 / \mathrm{S} 88$ & 6 & BRM 1 & IIIc & $19 \mathrm{~F}-17$ & Edge modified flake & 1 \\
\hline E22/S88 & 6 & BRM 1 & IIIc & $19 \mathrm{~F}-8$ & Edge modified flake & 1 \\
\hline E22/S88 & 6 & BRM 1 & IIIc & $19 \mathrm{~F}-9$ & Edge modified flake & 1 \\
\hline E22/S88 & 6 & BRM 1 & IIIc & $19 \mathrm{~F}-16$ & Edge modified flake & 1 \\
\hline $\mathrm{E} 22 / \mathrm{S} 88$ & 6 & BRM 1 & IIIC & $19 \mathrm{~F}-14$ & Edge modified flake & 1 \\
\hline $\mathrm{E} 22 / \mathrm{S} 88$ & 6 & BRM 1 & IIIc & $19 \mathrm{~F}-1$ & Metate fragment & 1 \\
\hline $\mathrm{E} 22 / \mathrm{S} 88$ & 6 & BRM 1 & IIIc & $19 \mathrm{~F}-7$ & Microspur/microdenticulate & 1 \\
\hline E22/S88 & 6 & BRM 1 & IIIc & $19 \mathrm{~F}-12$ & Thin uniface & 1 \\
\hline E22/S88 & 6 & BRM 1 & IIIIc & $19 F-11$ & Thin uniface & 1 \\
\hline E22/S88 & 6 & BRM 1 & IIIIc & $19 F-13$ & Thin uniface & 1 \\
\hline E22/S88 & 6 & BRM 1 & IIIc & $19 F-6$ & Uniface, unanalyzed & 1 \\
\hline E22/S88 & 7 & BRM 1 & IIIc & 19G-3 & Biface Stage 2 & 1 \\
\hline $\mathrm{E} 22 / \mathrm{S} 88$ & 7 & BRM 1 & IIIc & & Debitage & 438 \\
\hline $\mathrm{E} 22 / \mathrm{S} 88$ & 7 & BRM 1 & IIIc & 19G-9 & Edge modified flake & 1 \\
\hline E22/S88 & 7 & BRM 1 & IIIIC & 19G-10 & Edge modified flake & 1 \\
\hline E22/S88 & 7 & BRM 1 & IIIc & $19 \mathrm{G}-8$ & Edge modified flake & 1 \\
\hline $\mathrm{E} 22 / \mathrm{S} 88$ & 7 & BRM 1 & IIIc & 19G-7 & Edge modified flake & 1 \\
\hline E22/S88 & 7 & BRM 1 & IIIc & 19G-5 & Edge modified flake & 1 \\
\hline E22/S88 & 7 & BRM 1 & IIIc & 19G-1 & Mano & 1 \\
\hline $\mathrm{E} 22 / \mathrm{S} 88$ & 7 & BRM 1 & IIIC & 19G-2 & Metate fragment & 1 \\
\hline E22/S88 & 7 & BRM 1 & IIIc & $19 \mathrm{G}-11$ & Notched flake & 1 \\
\hline E22/S88 & 7 & BRM 1 & IIIc & 19G-4 & Perforator Group 2 & 1 \\
\hline E22/S88 & 7 & BRM 1 & IIIc & 19G-12 & Thin uniface fragment & 1 \\
\hline E22/S88 & 8 & BRM 1 & IIIIc & 19H-1 & Biface Stage 2 & 1 \\
\hline E22/S88 & 8 & BRM 1 & IIIc & & Debitage & 435 \\
\hline E22/S88 & 8 & BRM 1 & IIIc & $19 \mathrm{H}-2$ & Edge modified flake & 1 \\
\hline E22/S88 & 8 & BRM 1 & IIIc & $19 \mathrm{H}-3$ & Edge modified flake & 1 \\
\hline E22/S88 & 8 & BRM 1 & IIIc & $19 \mathrm{H}-4$ & Edge modified flake & 1 \\
\hline E22/S88 & 8 & BRM 1 & IIIIc & $19 \mathrm{H}-5$ & Edge modified flake & 1 \\
\hline $\mathrm{E} 22 / \mathrm{S} 88$ & 8 & BRM 1 & IIIC & $19 \mathrm{H}-6$ & Edge modified flake & 1 \\
\hline $\mathrm{E} 22 / \mathrm{S} 88$ & 9 & BRM 1 & Y/IIIc & $19 \mathrm{I}-3$ & Biface Stage 2 & 1 \\
\hline E22/S88 & 9 & BRM 1 & Y/IIIc & $19 \mathrm{I}-5$ & Bifacial tool Form A & 1 \\
\hline E22/S88 & 9 & BRM 1 & Y/IIIc & 19I-4 & Bifacial tool Form B & 1 \\
\hline E22/S88 & 9 & BRM 1 & Y/IIIc & $19 I-6$ & Bifacial tool Form J & 1 \\
\hline $\mathrm{E} 22 / \mathrm{S} 88$ & 9 & BRM 1 & Y/IIIc & $19 I-8$ & Core, thermal & 1 \\
\hline $\mathrm{E} 22 / \mathrm{S} 88$ & 9 & BRM 1 & Y/IIIc & $19 \mathrm{I}-7$ & Core, thermal & 1 \\
\hline E22/S88 & 9 & BRM 1 & Y/IIIc & & Debitage & 702 \\
\hline E22/S88 & 9 & BRM 1 & Y/IIIc & 19I-10 & Denticulated flake & 1 \\
\hline $\mathrm{E} 22 / \mathrm{S} 88$ & 9 & BRM 1 & Y/IIIc & 19I-13 & Edge modified flake & 1 \\
\hline E22/S88 & 9 & BRM 1 & Y/IIIc & 19I-18 & Edge modified flake & 1 \\
\hline E22/S88 & 9 & BRM 1 & Y/IIIc & 19I-12 & Edge modified flake & 1 \\
\hline E22/S88 & 9 & BRM 1 & Y/IIIc & 19I-21 & Edge modified flake & 1 \\
\hline
\end{tabular}




\begin{tabular}{|c|c|}
\hline Square & Level \\
\hline $\mathrm{E} 22 / \mathrm{S} 88$ & 9 \\
\hline E22/S88 & 9 \\
\hline $\mathrm{E} 22 / \mathrm{S} 88$ & 9 \\
\hline $\mathrm{E} 22 / \mathrm{S} 88$ & 9 \\
\hline E22/S88 & 9 \\
\hline $\mathrm{E} 22 / \mathrm{S} 88$ & 9 \\
\hline $\mathrm{E} 22 / \mathrm{S} 88$ & 9 \\
\hline E22/S88 & 9 \\
\hline E22/S88 & 9 \\
\hline $\mathrm{E} 22 / \mathrm{S} 88$ & 10 \\
\hline E22/S88 & 10 \\
\hline $\mathrm{E} 22 / \mathrm{S} 88$ & 10 \\
\hline $\mathrm{E} 22 / \mathrm{S} 88$ & 10 \\
\hline $\mathrm{E} 22 / \mathrm{S} 88$ & 10 \\
\hline E22/S88 & 10 \\
\hline E22/S88 & 10 \\
\hline E22/S88 & 10 \\
\hline E22/S88 & 10 \\
\hline $\mathrm{E} 22 / \mathrm{S} 88$ & 10 \\
\hline E22/S88 & 11 \\
\hline $\mathrm{E} 22 / \mathrm{S} 88$ & 11 \\
\hline E22/S88 & 11 \\
\hline $\mathrm{E} 22 / \mathrm{S} 88$ & 11 \\
\hline $\mathrm{E} 22 / \mathrm{S} 88$ & 11 \\
\hline $\mathrm{E} 22 / \mathrm{S} 88$ & 11 \\
\hline E22/S88 & 11 \\
\hline E22/S88 & 11 \\
\hline E22/S88 & 11 \\
\hline $\mathrm{E} 22 / \mathrm{S} 88$ & 11 \\
\hline $\mathrm{E} 22 / \mathrm{S} 88$ & 12 \\
\hline $\mathrm{E} 22 / \mathrm{S} 88$ & 12 \\
\hline $\mathrm{E} 22 / \mathrm{S} 88$ & 12 \\
\hline E22/S88 & 12 \\
\hline $\mathrm{E} 22 / \mathrm{S} 88$ & 12 \\
\hline $\mathrm{E} 22 / \mathrm{S} 88$ & 12 \\
\hline $\mathrm{E} 22 / \mathrm{S} 88$ & 12 \\
\hline $\mathrm{E} 22 / \mathrm{S} 88$ & 12 \\
\hline $\mathrm{E} 22 / \mathrm{S} 88$ & 12 \\
\hline E22/S88 & 12 \\
\hline E22/S88 & 12 \\
\hline $\mathrm{E} 22 / \mathrm{S} 88$ & 12 \\
\hline $\mathrm{E} 22 / \mathrm{S} 88$ & 12 \\
\hline E22/S88 & 12 \\
\hline $\mathrm{E} 22 / \mathrm{S} 88$ & 12 \\
\hline E22/S88 & 12 \\
\hline E22/S88 & 12 \\
\hline $\mathrm{E} 22 / \mathrm{S} 88$ & 12 \\
\hline $\mathrm{E} 22 / \mathrm{S} 88$ & 12 \\
\hline $\mathrm{E} 22 / \mathrm{S} 88$ & 13 \\
\hline E22/S88 & 13 \\
\hline $\mathrm{E} 22 / \mathrm{S} 88$ & 13 \\
\hline E22/S88 & 13 \\
\hline $\mathrm{E} 22 / \mathrm{S} 88$ & 13 \\
\hline E22/S88 & 13 \\
\hline $\mathrm{E} 22 / \mathrm{S} 88$ & 13 \\
\hline $\mathrm{E} 22 / \mathrm{S} 88$ & 13 \\
\hline $\mathrm{E} 22 / \mathrm{S} 88$ & 13 \\
\hline $\mathrm{E} 22 / \mathrm{S} 88$ & 14 \\
\hline $\mathrm{E} 22 / \mathrm{S} 88$ & 14 \\
\hline $\mathrm{E} 22 / \mathrm{S} 88$ & 14 \\
\hline E22/S88 & 14 \\
\hline E22/S88 & 14 \\
\hline E22/S88 & 14 \\
\hline $\mathrm{E} 22 / \mathrm{S} 88$ & 14 \\
\hline $\mathrm{E} 22 / \mathrm{S} 88$ & 14 \\
\hline $\mathrm{E} 22 / \mathrm{S} 88$ & 14 \\
\hline $\mathrm{E} 22 / \mathrm{S} 88$ & 14 \\
\hline $\mathrm{E} 22 / \mathrm{S} 88$ & 14 \\
\hline $\mathrm{E} 22 / \mathrm{S} 88$ & 14 \\
\hline E22/S88 & 14 \\
\hline E22/S88 & 15 \\
\hline $\mathrm{E} 22 / \mathrm{S} 88$ & 15 \\
\hline E22/S88 & 15 \\
\hline E22/S88 & 15 \\
\hline
\end{tabular}

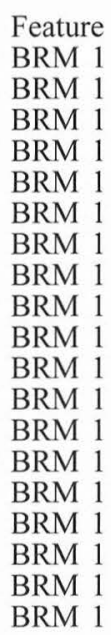

Strata

Y/IIIc

Y/IIIc

Y/IIIc

Y/IIIc

Y/IIIc

Y/IIIc

Y/IIIc

Y/IIIc

$\mathrm{Y} / \mathrm{IIIb} / \mathrm{c}$

$\mathrm{Y} / \mathrm{IIIb} / \mathrm{c}$

$\mathrm{Y} / \mathrm{IIIb} / \mathrm{c}$

$\mathrm{Y} / \mathrm{IIIb} / \mathrm{c}$

$\mathrm{Y} / \mathrm{IIIb} / \mathrm{c}$

$\mathrm{Y} / \mathrm{IIIb} / \mathrm{c}$

$\mathrm{Y} / \mathrm{IIIb} / \mathrm{c}$

$\mathrm{Y} / \mathrm{IIIb} / \mathrm{c}$

$\mathrm{Y} / \mathrm{IIIb} / \mathrm{c}$

$\mathrm{Y} / \mathrm{IIIb} / \mathrm{c}$

Y/IIIb

Y/IIIb

Y/IIIIb

$\mathrm{Y} / \mathrm{IIIb}$

Y/IIIb

$\mathrm{Y} / \mathrm{IIIb}$

$\mathrm{Y} / \mathrm{IIIb}$

$\mathrm{Y} / \mathrm{IIIb}$

Y/IIIb

$\mathrm{X} / \mathrm{Y} / \mathrm{IIIb}$

$\mathrm{X} / \mathrm{Y} / \mathrm{IIIb}$

$\mathrm{X} / \mathrm{Y} / \mathrm{IIIb}$

$\mathrm{X} / \mathrm{Y} / \mathrm{IIIb}$

$\mathrm{X} / \mathrm{Y} / \mathrm{IIIb}$

$\mathrm{X} / \mathrm{Y} / \mathrm{IIIb}$

$\mathrm{X} / \mathrm{Y} / \mathrm{IIIb}$

$\mathrm{X} / \mathrm{Y} / \mathrm{IIIb}$

$\mathrm{X} / \mathrm{Y} / \mathrm{IIIb}$

$\mathrm{X} / \mathrm{Y} / \mathrm{IIIb}$

$\mathrm{X} / \mathrm{Y} / \mathrm{IIIb}$

$\mathrm{X} / \mathrm{Y} / \mathrm{IIIb}$

$\mathrm{X} / \mathrm{Y} / \mathrm{IIIb}$

$\mathrm{X} / \mathrm{Y} / \mathrm{IIIb}$

$\mathrm{X} / \mathrm{Y} / \mathrm{IIIb}$

$\mathrm{X} / \mathrm{Y} / \mathrm{IIIb}$

$\mathrm{X} / \mathrm{Y} / \mathrm{IIIb}$

$\mathrm{X} / \mathrm{Y} / \mathrm{IIIb}$

$\mathrm{X} / \mathrm{Y} / \mathrm{IIIb}$

$\mathrm{X} / \mathrm{IIIb}$

$\mathrm{X} / \mathrm{IIIb}$

$\mathrm{X} / \mathrm{IIIb}$

$\mathrm{X} / \mathrm{IIIb}$

X/IIIb

$\mathrm{X} / \mathrm{IIIb}$

X/IIIb

$\mathrm{X} / \mathrm{IIIb}$

$\mathrm{X} / \mathrm{IIIb}$

$\mathrm{X} / \mathrm{IIIb}$

$\mathrm{X} / \mathrm{IIIb}$

$\mathrm{X} / \mathrm{IIIb}$

$\mathrm{X} / \mathrm{IIIb}$

$\mathrm{X} / \mathrm{IIIb}$

$\mathrm{X} / \mathrm{IIIb}$

$\mathrm{X} / \mathrm{IIIb}$

$\mathrm{X} / \mathrm{IIIb}$

$\mathrm{X} / \mathrm{IIIb}$

$\mathrm{X} / \mathrm{IIIb}$

$\mathrm{X} / \mathrm{IIIb}$

$\mathrm{X} / \mathrm{IIIb}$

$\mathrm{X} / \mathrm{IIIb}$

$\mathrm{X}$

$\mathrm{X}$

X
Item

19I-11

19I-14

19I-16

19I-15

19I-1

19I-2

19I-19

19I-20

19I-9

19J-9

19J-2

$19 \mathrm{~J}-3$

19J-6

19J-8

19J-4

19J-1

19J-7

$19 \mathrm{~J}-5$

$19 \mathrm{~K}-3$

$19 \mathrm{~K}-5$

19K-6

$19 \mathrm{~K}-4$

19K-9

$19 \mathrm{~K}-1$

$19 \mathrm{~K}-2$

$19 \mathrm{~K}-8$

19K-7

19L-7

19L-5

19L-8

19L-10

19L-9

19L-18

19L-16

19L-14

19L-15

19L-11

19L-2

19L-4

19L-3

19L-1

19L-6

19L-17

19L-13

19L-12

$19 \mathrm{M}-2$

$19 \mathrm{M}-1$

$19 \mathrm{M}-3$

19M-4

19M-8

$19 \mathrm{M}-7$

19M-5

19M-6

$19 \mathrm{~N}-12$

$19 \mathrm{~N}-5$

$19 \mathrm{~N}-7$

$19 \mathrm{~N}-8$

$19 \mathrm{~N}-6$

$19 \mathrm{~N}-2$

$19 \mathrm{~N}-4$

$19 \mathrm{~N}-1$

$19 \mathrm{~N}-3$

$19 \mathrm{~N}-11$

$19 \mathrm{~N}-9$

$19 \mathrm{~N}-10$

190-2

190-5

190-4

190-8
Analyst Identification

Edge modified flake

Microspur/microdenticulate

Notched flake

Projectile point, Bell/Andice

Projectile point, Gower/Uvalde

Projectile point, Uvalde-like

Thick uniface

Thin uniface fragment

Unifacial multiple tool

Biface fragment

Biface Stage 2

Biface Stage 2

Biface Stage 2

Debitage

Edge modified flake

Notched flake

Projectile point, bifurcate stem fragment

Thin uniface

Thin uniface

Biface Stage 2

Burin

Debitage

Edge modified flake

Edge modified flake

Projectile point, expanding concave B

Projectile point, expanding concave D

Thin uniface

Thin uniface

Unifacial multiple tool

Bifacial tool Form A

Burin spall

Burin spall

Core tool, type 1

Core tool, type 5

Debitage

Edge modified flake

Edge modified flake

Edge modified flake

Edge modified flake

Microspur/microdenticulate

Projectile point fragment

Projectile point, expanding concave B

Projectile point, miscellaneous side-notched

Projectile point, Thrall

Projectile point, Wells

Thin uniface fragment

Unifacial multiple tool

Unifacial multiple tool

Biface Stage 1

Biface Stage 2

Biface Stage 2

Burin spall

Debitage

Denticulated flake

Edge modified flake

Perforator Group 7

Uniface, unanalyzed

Biface Stage 1

Biface Stage 2

Biface Stage 2

Debitage

Edge modified flake

Projectile point fragment

Projectile point, bifurcate stem fragment

Projectile point, expanding concave $\mathrm{B}$

Projectile point, Thrall

Projectile point, Uvalde

Thin uniface fragment

Unifacial multiple tool

Unifacial multiple tool

Battered cobble

Biface fragment

Biface Stage 2

Biface Stage 2
Count

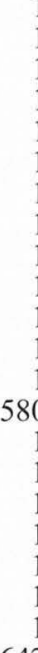

642
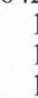

1 


\begin{tabular}{|c|c|c|c|c|c|c|}
\hline Square & Level & Feature & Strata & Item & Analyst Identification & Count \\
\hline $\mathrm{E} 22 / \mathrm{S} 88$ & 15 & & $\mathrm{X}$ & $190-15$ & Burin & 1 \\
\hline $\mathrm{E} 22 / \mathrm{S} 88$ & 15 & & $\mathrm{X}$ & $190-6$ & Core fragment & 1 \\
\hline $\mathrm{E} 22 / \mathrm{S} 88$ & 15 & & $\mathrm{X}$ & & Debitage & 685 \\
\hline $\mathrm{E} 22 / \mathrm{S} 88$ & 15 & & $\mathrm{X}$ & $190-14$ & Edge modified flake & 1 \\
\hline $\mathrm{E} 22 / \mathrm{S} 88$ & 15 & & $\mathrm{X}$ & $190-16$ & Edge modified flake & 1 \\
\hline $\mathrm{E} 22 / \mathrm{S} 88$ & 15 & & $\mathrm{X}$ & $190-10$ & Edge modified flake & 1 \\
\hline $\mathrm{E} 22 / \mathrm{S} 88$ & 15 & & $\mathrm{X}$ & $190-13$ & Edge modified flake & 1 \\
\hline $\mathrm{E} 22 / \mathrm{S} 88$ & 15 & & $\mathrm{X}$ & $190-9$ & Edge modified flake & 1 \\
\hline $\mathrm{E} 22 / \mathrm{S} 88$ & 15 & & $\mathrm{X}$ & $190-11$ & Edge modified flake & 1 \\
\hline $\mathrm{E} 22 / \mathrm{S} 88$ & 15 & & $\mathrm{X}$ & 190-7 & Projectile point, bifurcate stem fragment & 1 \\
\hline $\mathrm{E} 22 / \mathrm{S} 88$ & 15 & & $\mathrm{X}$ & $190-1$ & Projectile point, expanding concave D & 1 \\
\hline $\mathrm{E} 22 / \mathrm{S} 88$ & 15 & & $\mathrm{X}$ & $190-12$ & Uniface, unanalyzed & 1 \\
\hline $\mathrm{E} 22 / \mathrm{S} 88$ & 15 & Feature 103 & $\mathrm{X}$ & $190-17$ & Clear Fork biface & 1 \\
\hline $\mathrm{E} 22 / \mathrm{S} 88$ & 16 & & $\mathrm{X}$ & $19 \mathrm{P}-10$ & Biface fragment & 1 \\
\hline $\mathrm{E} 22 / \mathrm{S} 88$ & 16 & & $\mathrm{X}$ & 19P-2 & Biface Stage 2 & 1 \\
\hline $\mathrm{E} 22 / \mathrm{S} 88$ & 16 & & $\mathrm{X}$ & $19 \mathrm{P}-4$ & Biface Stage 2 & 1 \\
\hline E22/S88 & 16 & & $X$ & 19P-1 & Biface Stage 2 & 1 \\
\hline $\mathrm{E} 22 / \mathrm{S} 88$ & 16 & & $\mathrm{X}$ & $19 \mathrm{P}-3$ & Burin & 1 \\
\hline $\mathrm{E} 22 / \mathrm{S} 88$ & 16 & & $\mathrm{X}$ & 19P-15 & Core, thermal & 1 \\
\hline $\mathrm{E} 22 / \mathrm{S} 88$ & 16 & & $\mathrm{X}$ & $19 \mathrm{P}-16$ & Core, thermal & 1 \\
\hline $\mathrm{E} 22 / \mathrm{S} 88$ & 16 & & $\mathrm{X}$ & & Debitage & 895 \\
\hline E22/S88 & 16 & & $X$ & 19P-9 & Edge modified flake & 1 \\
\hline $\mathrm{E} 22 / \mathrm{S} 88$ & 16 & & $\mathrm{X}$ & 19P-12 & Edge modified flake & 1 \\
\hline $\mathrm{E} 22 / \mathrm{S} 88$ & 16 & & $\mathrm{X}$ & 19P-13 & Edge modified flake & 1 \\
\hline $\mathrm{E} 22 / \mathrm{S} 88$ & 16 & & $\mathrm{X}$ & $19 \mathrm{P}-8$ & Edge modified flake & 1 \\
\hline $\mathrm{E} 22 / \mathrm{S} 88$ & 16 & & $\mathrm{X}$ & $19 \mathrm{P}-5$ & Edge modified flake & 1 \\
\hline E22/S88 & 16 & & $X$ & $19 \mathrm{P}-6$ & Edge modified flake & 1 \\
\hline E22/S88 & 16 & & $\mathrm{X}$ & 19P-11 & Microspur/microdenticulate & 1 \\
\hline $\mathrm{E} 22 / \mathrm{S} 88$ & 16 & & $\mathrm{X}$ & $19 \mathrm{P}-14$ & Thin uniface & 1 \\
\hline $\mathrm{E} 22 / \mathrm{S} 88$ & 16 & & $\mathrm{X}$ & $19 \mathrm{P}-7$ & Uniface, unanalyzed & 1 \\
\hline $\mathrm{E} 22 / \mathrm{S} 88$ & 16 & & $X$ & 19P-17 & Worked hematite & 1 \\
\hline E22/S88 & 16 & & $X$ & 19P-18 & Worked hematite & 1 \\
\hline E22/S88 & 17 & & $X$ & 19Q-1 & Burin spall & 1 \\
\hline $\mathrm{E} 22 / \mathrm{S} 88$ & 17 & & $\mathrm{X}$ & & Debitage & 714 \\
\hline $\mathrm{E} 22 / \mathrm{S} 88$ & 17 & & $\mathrm{X}$ & $19 Q-4$ & Edge modified flake & 1 \\
\hline E22/S88 & 17 & & $X$ & $19 Q-2$ & Perforator Group 7 & 1 \\
\hline $\mathrm{E} 22 / \mathrm{S} 88$ & 17 & & $\mathrm{X}$ & 19Q-3 & Unifacial multiple tool & 1 \\
\hline $\mathrm{E} 22 / \mathrm{S} 88$ & 18 & & $\mathrm{X}$ & $19 \mathrm{R}-1$ & Clear Fork biface, proximal & 1 \\
\hline $\mathrm{E} 22 / \mathrm{S} 88$ & 18 & & $X$ & & Debitage & 219 \\
\hline E22/S88 & 18 & & $\mathrm{X}$ & $19 \mathrm{R}-2$ & Denticulated flake & 1 \\
\hline $\mathrm{E} 22 / \mathrm{S} 88$ & 19 & & $\mathrm{X}$ & $19 \mathrm{~S}-5$ & Biface Stage 1 & 1 \\
\hline $\mathrm{E} 22 / \mathrm{S} 88$ & 19 & & $X$ & $19 \mathrm{~S}-8$ & Burin & 1 \\
\hline $\mathrm{E} 22 / \mathrm{S} 88$ & 19 & & $\mathrm{X}$ & $19 \mathrm{~S}-3$ & Core fragment & 1 \\
\hline $\mathrm{E} 22 / \mathrm{S} 88$ & 19 & & $\mathrm{X}$ & & Debitage & 387 \\
\hline E22/S88 & 19 & & $X$ & 19S-10 & Edge modified flake & 1 \\
\hline $\mathrm{E} 22 / \mathrm{S} 88$ & 19 & & $\mathrm{X}$ & $19 \mathrm{~S}-7$ & Edge modified flake & 1 \\
\hline $\mathrm{E} 22 / \mathrm{S} 88$ & 19 & & $\mathrm{X}$ & $19 \mathrm{~S}-4$ & Edge modified flake & 1 \\
\hline $\mathrm{E} 22 / \mathrm{S} 88$ & 19 & & $\mathrm{X}$ & $19 \mathrm{~S}-12$ & Edge modified flake & 1 \\
\hline $\mathrm{E} 22 / \mathrm{S} 88$ & 19 & & $\mathrm{X}$ & $19 \mathrm{~S}-11$ & Edge modified flake & 1 \\
\hline $\mathrm{E} 22 / \mathrm{S} 88$ & 19 & & $\mathrm{X}$ & $19 \mathrm{~S}-2$ & Perforator Group 1 & 1 \\
\hline E22/S88 & 19 & & $\mathrm{X}$ & 19S-9 & Perforator Group 7 & 1 \\
\hline E22/S88 & 19 & & $X$ & 19S-1 & Projectile point, Hoxie? & 1 \\
\hline $\mathrm{E} 22 / \mathrm{S} 88$ & 19 & & $\mathrm{X}$ & $19 \mathrm{~S}-6$ & Thin uniface fragment & 1 \\
\hline $\mathrm{E} 22 / \mathrm{S} 88$ & 20 & & $\mathrm{X}$ & $19 \mathrm{~T}-1$ & Biface fragment & 1 \\
\hline E22/S88 & 20 & & $\mathrm{X}$ & $19 \mathrm{~T}-2$ & Biface fragment & 1 \\
\hline $\mathrm{E} 22 / \mathrm{S} 88$ & 20 & & $\mathrm{X}$ & $19 \mathrm{~T}-3$ & Clear Fork biface, proximal & 1 \\
\hline $\mathrm{E} 22 / \mathrm{S} 88$ & 20 & & $\mathrm{X}$ & & Debitage & 382 \\
\hline $\mathrm{E} 22 / \mathrm{S} 88$ & 22 & & $\mathrm{X}$ & $19 \mathrm{~V}-1$ & Burin spall & 1 \\
\hline $\mathrm{E} 22 / \mathrm{S} 88$ & 22 & & $X$ & & Debitage & 209 \\
\hline E22/S88 & 22 & & $X$ & $19 \mathrm{~V}-2$ & Thin uniface fragment & 1 \\
\hline $\mathrm{E} 22 / \mathrm{S} 88$ & 23 & & $\mathrm{X}$ & & Debitage & 91 \\
\hline $\mathrm{E} 22 / \mathrm{S} 88$ & 23 & Feature 115 & $\mathrm{X}$ & & Debitage & 2 \\
\hline $\mathrm{E} 22 / \mathrm{S} 88$ & 23 & Feature 115 & $\mathrm{X}$ & 19W-1 & Mano fragment & 1 \\
\hline $\mathrm{E} 22 / \mathrm{S} 88$ & 25 & & $\mathrm{X}$ & $19 \mathrm{Y}-1$ & Biface Stage 2 & 1 \\
\hline E22/S88 & 25 & & $\mathrm{X}$ & & Debitage & 74 \\
\hline E22/S88 & 26 & & $\mathrm{X}$ & & Debitage & 70 \\
\hline $\mathrm{E} 22 / \mathrm{S} 90$ & 6 & BRM 1 & IIIc & $18 \mathrm{~F}-2$ & Biface Stage 1 & 1 \\
\hline $\mathrm{E} 22 / \mathrm{S} 90$ & 6 & BRM 1 & IIIc & $18 \mathrm{~F}-1$ & Biface Stage 2 & 1 \\
\hline $\mathrm{E} 22 / \mathrm{S} 90$ & 6 & BRM 1 & IIIc & $18 \mathrm{~F}-7$ & Clear Fork uniface & 1 \\
\hline $\mathrm{E} 22 / \mathrm{S} 90$ & 6 & BRM 1 & IIIc & & Debitage & 346 \\
\hline $\mathrm{E} 22 / \mathrm{S} 90$ & 6 & BRM 1 & IIIc & $18 \mathrm{~F}-8$ & Edge modified flake & 1 \\
\hline $\mathrm{E} 22 / \mathrm{S} 90$ & 6 & BRM 1 & IIIc & $18 \mathrm{~F}-6$ & Edge modified flake & 1 \\
\hline $\mathrm{E} 22 / \mathrm{S} 90$ & 6 & BRM 1 & IIIc & $18 \mathrm{~F}-4$ & Projectile point fragment & 1 \\
\hline $\mathrm{E} 22 / \mathrm{S} 90$ & 6 & BRM 1 & IIIC & $18 \mathrm{~F}-3$ & Projectile point fragment & 1 \\
\hline
\end{tabular}




\begin{tabular}{|c|c|c|c|c|c|c|}
\hline Square & Level & Feature & Strata & Item & Analyst Identification & Count \\
\hline $\mathrm{E} 22 / \mathrm{S} 90$ & 6 & BRM 1 & IIIc & $18 \mathrm{~F}-5$ & Unifacial multiple tool & \\
\hline $\mathrm{E} 22 / \mathrm{S} 90$ & 7 & BRM 1 & IIIc & $18 \mathrm{G}-6$ & Biface fragment & \\
\hline $\mathrm{E} 22 / \mathrm{S} 90$ & 7 & BRM 1 & IIIc & 18G-1 & Biface Stage 2 & \\
\hline $\mathrm{E} 22 / \mathrm{S} 90$ & 7 & BRM 1 & IIIc & $18 \mathrm{G}-5$ & Biface Stage 2 & \\
\hline $\mathrm{E} 22 / \mathrm{S} 90$ & 7 & BRM 1 & IIIc & $18 \mathrm{G}-3$ & Biface Stage 2 & \\
\hline $\mathrm{E} 22 / \mathrm{S} 90$ & 7 & BRM 1 & IIIc & $18 \mathrm{G}-2$ & Biface Stage 3 & \\
\hline $\mathrm{E} 22 / \mathrm{S} 90$ & 7 & BRM 1 & IIIc & $18 \mathrm{G}-4$ & Biface Stage 3 & \\
\hline $\mathrm{E} 22 / \mathrm{S} 90$ & 7 & BRM 1 & IIIc & $18 \mathrm{G}-7$ & Burin spall & \\
\hline $\mathrm{E} 22 / \mathrm{S} 90$ & 7 & BRM 1 & IIIc & & Debitage & 461 \\
\hline $\mathrm{E} 22 / \mathrm{S} 90$ & 7 & BRM 1 & IIIc & $18 \mathrm{G}-17$ & Edge modified flake & \\
\hline $\mathrm{E} 22 / \mathrm{S} 90$ & 7 & BRM 1 & IIIc & $18 \mathrm{G}-10$ & Edge modified flake & \\
\hline $\mathrm{E} 22 / \mathrm{S} 90$ & 7 & BRM 1 & IIIC & $18 \mathrm{G}-12$ & Edge modified flake & \\
\hline $\mathrm{E} 22 / \mathrm{S} 90$ & 7 & BRM 1 & IIIc & $18 \mathrm{G}-15$ & Edge modified flake & \\
\hline $\mathrm{E} 22 / \mathrm{S} 90$ & 7 & BRM 1 & IIIc & $18 \mathrm{G}-18$ & Edge modified flake & \\
\hline $\mathrm{E} 22 / \mathrm{S} 90$ & 7 & BRM 1 & IIIc & $18 \mathrm{G}-9$ & Edge modified flake & \\
\hline $\mathrm{E} 22 / \mathrm{S} 90$ & 7 & BRM 1 & IIIc & $18 \mathrm{G}-13$ & Edge modified flake & \\
\hline $\mathrm{E} 22 / \mathrm{S} 90$ & 7 & BRM 1 & IIIc & $18 \mathrm{G}-14$ & Notched flake & \\
\hline $\mathrm{E} 22 / \mathrm{S} 90$ & 7 & BRM 1 & IIIc & $18 \mathrm{G}-8$ & Projectile point, Bulverde-like & \\
\hline $\mathrm{E} 22 / \mathrm{S} 90$ & 7 & BRM 1 & IIIc & 18G-11 & Unifacial multiple tool & \\
\hline $\mathrm{E} 22 / \mathrm{S} 90$ & 8 & BRM 1 & Y/IIIc & $18 \mathrm{H}-3$ & Biface fragment & \\
\hline $\mathrm{E} 22 / \mathrm{S} 90$ & 8 & BRM 1 & Y/IIIc & $18 \mathrm{H}-4$ & Biface Stage 2 & \\
\hline $\mathrm{E} 22 / \mathrm{S} 90$ & 8 & BRM 1 & Y/IIIc & $18 \mathrm{H}-2$ & Biface Stage 2 & \\
\hline $\mathrm{E} 22 / \mathrm{S} 90$ & 8 & BRM 1 & Y/IIIc & $18 \mathrm{H}-6$ & Burin & \\
\hline $\mathrm{E} 22 / \mathrm{S} 90$ & 8 & BRM 1 & Y/IIIc & & Debitage & 351 \\
\hline $\mathrm{E} 22 / \mathrm{S} 90$ & 8 & BRM 1 & Y/IIIc & $18 \mathrm{H}-1$ & Projectile point, Bulverde-like & \\
\hline $\mathrm{E} 22 / \mathrm{S} 90$ & 8 & BRM 1 & Y/IIIc & $18 \mathrm{H}-8$ & Thin uniface & \\
\hline $\mathrm{E} 22 / \mathrm{S} 90$ & 8 & BRM 1 & Y/IIIc & $18 \mathrm{H}-7$ & Thin uniface fragment & \\
\hline $\mathrm{E} 22 / \mathrm{S} 90$ & 8 & BRM 1 & Y/IIIc & $18 \mathrm{H}-5$ & Uniface, unanalyzed & \\
\hline $\mathrm{E} 22 / \mathrm{S} 90$ & 9 & BRM 1 & Y/IIIc & & Debitage & 404 \\
\hline $\mathrm{E} 22 / \mathrm{S} 90$ & 9 & BRM 1 & Y/IIIc & $18 \mathrm{I}-1$ & Projectile point, expanding concave A & \\
\hline $\mathrm{E} 22 / \mathrm{S} 90$ & 10 & BRM 1 & Y/IIIc & $18 \mathrm{~J}-7$ & Biface fragment & \\
\hline $\mathrm{E} 22 / \mathrm{S} 90$ & 10 & BRM 1 & Y/IIIc & $18 \mathrm{~J}-8$ & Biface Stage 1 & \\
\hline $\mathrm{E} 22 / \mathrm{S} 90$ & 10 & BRM 1 & Y/IIIc & $18 \mathrm{~J}-4$ & Biface Stage 2 & \\
\hline $\mathrm{E} 22 / \mathrm{S} 90$ & 10 & BRM 1 & Y/IIIc & $18 \mathrm{~J}-3$ & Biface Stage 2 & \\
\hline $\mathrm{E} 22 / \mathrm{S} 90$ & 10 & BRM 1 & Y/IIIc & $18 \mathrm{~J}-2$ & Biface Stage 2 & \\
\hline $\mathrm{E} 22 / \mathrm{S} 90$ & 10 & BRM 1 & Y/IIIc & $18 \mathrm{~J}-10$ & Clear Fork biface & \\
\hline $\mathrm{E} 22 / \mathrm{S} 90$ & 10 & BRM 1 & Y/IIIc & & Debitage & 1011 \\
\hline $\mathrm{E} 22 / \mathrm{S} 90$ & 10 & BRM 1 & Y/IIIc & $18 \mathrm{~J}-17$ & Edge modified flake & \\
\hline $\mathrm{E} 22 / \mathrm{S} 90$ & 10 & BRM 1 & Y/IIIc & $18 \mathrm{~J}-12$ & Edge modified flake & \\
\hline $\mathrm{E} 22 / \mathrm{S} 90$ & 10 & BRM 1 & Y/IIIc & $18 \mathrm{~J}-16$ & Edge modified flake & \\
\hline $\mathrm{E} 22 / \mathrm{S} 90$ & 10 & BRM 1 & Y/IIIc & $18 \mathrm{~J}-19$ & Edge modified flake & \\
\hline $\mathrm{E} 22 / \mathrm{S} 90$ & 10 & BRM 1 & Y/IIIc & $18 \mathrm{~J}-21$ & Edge modified flake & \\
\hline $\mathrm{E} 22 / \mathrm{S} 90$ & 10 & BRM 1 & Y/IIIc & $18 \mathrm{~J}-5$ & Micro-core, small & \\
\hline $\mathrm{E} 22 / \mathrm{S} 90$ & 10 & BRM 1 & Y/IIIc & $18 \mathrm{~J}-14$ & Microspur/microdenticulate & \\
\hline $\mathrm{E} 22 / \mathrm{S} 90$ & 10 & BRM 1 & Y/IIIc & $18 \mathrm{~J}-18$ & Notched flake & \\
\hline $\mathrm{E} 22 / \mathrm{S} 90$ & 10 & BRM 1 & Y/IIIc & $18 \mathrm{~J}-11$ & Perforator Unifacial & \\
\hline $\mathrm{E} 22 / \mathrm{S} 90$ & 10 & BRM 1 & Y/IIIc & $18 \mathrm{~J}-1$ & Projectile point, Uvalde & \\
\hline $\mathrm{E} 22 / \mathrm{S} 90$ & 10 & BRM 1 & Y/IIIc & $18 \mathrm{~J}-13$ & Thin uniface fragment & \\
\hline $\mathrm{E} 22 / \mathrm{S} 90$ & 10 & BRM 1 & Y/IIIc & $18 \mathrm{~J}-15$ & Uniface, unanalyzed & \\
\hline E22/S90 & 10 & BRM 1 & Y/IIIc & $18 \mathrm{~J}-6$ & Uniface, unanalyzed & \\
\hline $\mathrm{E} 22 / \mathrm{S} 90$ & 10 & BRM 1 & Y/IIIc & $18 \mathrm{~J}-20$ & Unifacial multiple tool & \\
\hline $\mathrm{E} 22 / \mathrm{S} 90$ & 12 & & $\mathrm{X} / \mathrm{Y}$ & $18 \mathrm{~L}-2$ & Biface Stage 1 & \\
\hline $\mathrm{E} 22 / \mathrm{S} 90$ & 12 & & $\mathrm{X} / \mathrm{Y}$ & $18 \mathrm{~L}-3$ & Biface Stage 1 & \\
\hline $\mathrm{E} 22 / \mathrm{S} 90$ & 12 & & $\mathrm{X} / \mathrm{Y}$ & $18 \mathrm{~L}-6$ & Bifacial tool Form B & \\
\hline $\mathrm{E} 22 / \mathrm{S} 90$ & 12 & & $\mathrm{X} / \mathrm{Y}$ & $18 \mathrm{~L}-4$ & Burin spall & \\
\hline $\mathrm{E} 22 / \mathrm{S} 90$ & 12 & & $\mathrm{X} / \mathrm{Y}$ & $18 \mathrm{~L}-5$ & Core fragment & \\
\hline $\mathrm{E} 22 / \mathrm{S} 90$ & 12 & & $\mathrm{X} / \mathrm{Y}$ & & Debitage & 707 \\
\hline E22/S90 & 12 & & $\mathrm{X} / \mathrm{Y}$ & $18 \mathrm{~L}-9$ & Edge modified flake & \\
\hline $\mathrm{E} 22 / \mathrm{S} 90$ & 12 & & $\mathrm{X} / \mathrm{Y}$ & $18 \mathrm{~L}-7$ & Edge modified flake & \\
\hline $\mathrm{E} 22 / \mathrm{S} 90$ & 12 & & $\mathrm{X} / \mathrm{Y}$ & $18 \mathrm{~L}-1$ & Projectile point, St. Mary's Hall-atypic & \\
\hline $\mathrm{E} 22 / \mathrm{S} 90$ & 12 & & $\mathrm{X} / \mathrm{Y}$ & $18 \mathrm{~L}-12$ & Thin uniface & \\
\hline E22/S90 & 12 & & $\mathrm{X} / \mathrm{Y}$ & $18 \mathrm{~L}-10$ & Uniface, unanalyzed & \\
\hline E22/S90 & 12 & & $\mathrm{X} / \mathrm{Y}$ & $18 \mathrm{~L}-8$ & Uniface, unanalyzed & \\
\hline E22/S90 & 12 & & $\mathrm{X} / \mathrm{Y}$ & 18L-11 & Unifacial multiple tool & \\
\hline $\mathrm{E} 22 / \mathrm{S} 90$ & 13 & & $\mathrm{X} / \mathrm{Y}$ & $18 \mathrm{M}-3$ & Biface Stage 1 & \\
\hline $\mathrm{E} 22 / \mathrm{S} 90$ & 13 & & $\mathrm{X} / \mathrm{Y}$ & $18 \mathrm{M}-2$ & Biface Stage 2 & \\
\hline E22/S90 & 13 & & $\mathrm{X} / \mathrm{Y}$ & $18 \mathrm{M}-4$ & Biface Stage 3 & \\
\hline $\mathrm{E} 22 / \mathrm{S} 90$ & 13 & & $\mathrm{X} / \mathrm{Y}$ & $18 \mathrm{M}-7$ & Burin spall & \\
\hline $\mathrm{E} 22 / \mathrm{S} 90$ & 13 & & $\mathrm{X} / \mathrm{Y}$ & & Debitage & 41 \\
\hline $\mathrm{E} 22 / \mathrm{S} 90$ & 13 & & $\mathrm{X} / \mathrm{Y}$ & $18 \mathrm{M}-5$ & Microspur/microdenticulate & \\
\hline E22/S90 & 13 & & $\mathrm{X} / \mathrm{Y}$ & $18 \mathrm{M}-1$ & Projectile point, Uvalde-like & \\
\hline $\mathrm{E} 22 / \mathrm{S} 90$ & 13 & & $\mathrm{X} / \mathrm{Y}$ & $18 \mathrm{M}-6$ & Thin uniface fragment & \\
\hline $\mathrm{E} 22 / \mathrm{S} 90$ & 14 & & $\mathrm{X}$ & $18 \mathrm{~N}-5$ & Biface Stage 2 & \\
\hline $\mathrm{E} 22 / \mathrm{S} 90$ & 14 & & $X$ & $18 \mathrm{~N}-4$ & Biface Stage 2 & \\
\hline
\end{tabular}




\begin{tabular}{|c|c|c|c|c|c|c|}
\hline Square & Level & Feature & Strata & Item & Analyst Identification & Count \\
\hline $\mathrm{E} 22 / \mathrm{S} 90$ & 14 & & $\mathrm{X}$ & $18 \mathrm{~N}-12$ & Bifacial tool Form B & \\
\hline $\mathrm{E} 22 / \mathrm{S} 90$ & 14 & & $\mathrm{X}$ & $18 \mathrm{~N}-8$ & Burin & 1 \\
\hline $\mathrm{E} 22 / \mathrm{S} 90$ & 14 & & $X$ & $18 \mathrm{~N}-7$ & Burin spall & 1 \\
\hline $\mathrm{E} 22 / \mathrm{S} 90$ & 14 & & $\mathrm{X}$ & $18 \mathrm{~N}-6$ & Core tool, type 3 & \\
\hline $\mathrm{E} 22 / \mathrm{S} 90$ & 14 & & $X$ & $18 \mathrm{~N}-9$ & Core tool, type 5 & \\
\hline $\mathrm{E} 22 / \mathrm{S} 90$ & 14 & & $X$ & & Debitage & 419 \\
\hline $\mathrm{E} 22 / \mathrm{S} 90$ & 14 & & $\mathrm{X}$ & $18 \mathrm{~N}-14$ & Edge modified flake & 1 \\
\hline $\mathrm{E} 22 / \mathrm{S} 90$ & 14 & & $\mathrm{X}$ & $18 \mathrm{~N}-13$ & Microspur/microdenticulate & 1 \\
\hline $\mathrm{E} 22 / \mathrm{S} 90$ & 14 & & $\mathrm{X}$ & $18 \mathrm{~N}-10$ & Perforator Group 4 & \\
\hline E22/S90 & 14 & & $X$ & $18 \mathrm{~N}-11$ & Projectile point fragment & \\
\hline $\mathrm{E} 22 / \mathrm{S} 90$ & 14 & & $X$ & $18 \mathrm{~N}-1$ & Projectile point, Gower/Uvalde & 1 \\
\hline $\mathrm{E} 22 / \mathrm{S} 90$ & 14 & & $\mathrm{X}$ & $18 \mathrm{~N}-2$ & Projectile point, Hoxie/Gower & 1 \\
\hline $\mathrm{E} 22 / \mathrm{S} 90$ & 14 & & $\mathrm{X}$ & $18 \mathrm{~N}-3$ & Small core hammerstone & 1 \\
\hline $\mathrm{E} 22 / \mathrm{S} 90$ & $\begin{array}{l}14 \\
14\end{array}$ & & $\begin{array}{l}X \\
Y\end{array}$ & $18 \mathrm{~N}-15$ & Thin uniface fragment & \\
\hline $\mathrm{E} 22 / \mathrm{S} 90$ & $\begin{array}{l}14 \\
15\end{array}$ & & $\mathrm{X}$ & $18 \mathrm{~N}-16$ & & \\
\hline $\mathrm{E} 22 / \mathrm{S} 90$ & $\begin{array}{l}15 \\
15\end{array}$ & $\begin{array}{l}\text { Feature 19/104 } \\
\text { Feature 19/104 }\end{array}$ & $\mathrm{X}$ & $180-13$ & Biface fragment & \\
\hline $\begin{array}{l}\mathrm{E} 22 / \mathrm{S} 90 \\
\mathrm{E} 22 / \mathrm{S} 90\end{array}$ & $\begin{array}{l}15 \\
15\end{array}$ & $\begin{array}{l}\text { Feature } 19 / 104 \\
\text { Feature } 19 / 104\end{array}$ & $\begin{array}{l}X \\
X\end{array}$ & $\begin{array}{l}18 \mathrm{O}-2 \\
18 \mathrm{O}-3\end{array}$ & $\begin{array}{l}\text { Biface Stage } 1 \\
\text { Biface Stage } 2\end{array}$ & \\
\hline $\begin{array}{l}\mathrm{E} 22 / \mathrm{S} 90 \\
\mathrm{E} 22 / \mathrm{S} 90\end{array}$ & 15 & Feature 19/104 & $\begin{array}{l}\lambda \\
X\end{array}$ & $\begin{array}{l}180-3 \\
180-5\end{array}$ & Biface Stage 2 & \\
\hline $\mathrm{E} 22 / \mathrm{S} 90$ & 15 & Feature 19/104 & $\mathrm{X}$ & $180-17$ & Burin & \\
\hline $\mathrm{E} 22 / \mathrm{S} 90$ & 15 & Feature 19/104 & $\mathrm{X}$ & $18 \mathrm{O}-4$ & Core fragment & \\
\hline $\mathrm{E} 22 / \mathrm{S} 90$ & 15 & Feature 19/104 & $\mathrm{X}$ & & Debitage & 629 \\
\hline $\mathrm{E} 22 / \mathrm{S} 90$ & 15 & Feature 19/104 & $\mathrm{X}$ & $180-7$ & Edge modified flake & \\
\hline $\mathrm{E} 22 / \mathrm{S} 90$ & 15 & Feature 19/104 & $X$ & $180-18$ & Edge modified flake & 1 \\
\hline $\mathrm{E} 22 / \mathrm{S} 90$ & 15 & Feature 19/104 & $X$ & $180-15$ & Edge modified flake & 1 \\
\hline $\mathrm{E} 22 / \mathrm{S} 90$ & 15 & Feature 19/104 & $X$ & $180-10$ & Edge modified flake & 1 \\
\hline E22/S90 & 15 & Feature 19/104 & $\mathrm{X}$ & $180-11$ & Microspur/microdenticulate & 1 \\
\hline E22/S90 & 15 & Feature 19/104 & $\mathrm{X}$ & $180-14$ & Microspur/microdenticulate & 1 \\
\hline $\begin{array}{l}\mathrm{E} 22 / \mathrm{S} 90 \\
\mathrm{E} 22 / \mathrm{S} 90\end{array}$ & $\begin{array}{l}15 \\
15\end{array}$ & $\begin{array}{l}\text { Feature } 19 / 104 \\
\text { Feature } 19 / 104\end{array}$ & $\begin{array}{l}\mathrm{X} \\
\mathrm{X}\end{array}$ & $180-1$ & Projectile point, Baker & 1 \\
\hline $\mathrm{E} 22 / \mathrm{S} 90$ & 15 & Feature 19/104 & $\begin{array}{l}X \\
X\end{array}$ & $\begin{array}{l}180-16 \\
180-6\end{array}$ & $\begin{array}{l}\text { Thin uniface fragment } \\
\text { Uniface, unanalyzed }\end{array}$ & 1 \\
\hline $\mathrm{E} 22 / \mathrm{S} 90$ & 15 & Feature 19/104 & $\mathrm{X}$ & $180-8$ & Uniface, unanalyzed & \\
\hline $\mathrm{E} 22 / \mathrm{S} 90$ & 15 & Feature 19/104 & $X$ & $180-9$ & Uniface, unanalyzed & \\
\hline $\mathrm{E} 22 / \mathrm{S} 90$ & $15-18$ & Feature 104 & $\mathrm{X}$ & & Debitage & 298 \\
\hline E22/S90 & 16 & Feature 19/104 & $\mathrm{X}$ & $18 \mathrm{P}-2$ & Burin spall & 1 \\
\hline $\mathrm{E} 22 / \mathrm{S} 90$ & 16 & Feature 19/104 & $\mathrm{X}$ & & Debitage & 343 \\
\hline E22/S90 & 16 & Feature 19/104 & $\mathrm{X}$ & $18 \mathrm{P}-1$ & Projectile point, Thrall & \\
\hline $\mathrm{E} 22 / \mathrm{S} 90$ & 17 & Feature 104 & $\mathrm{X}$ & & Debitage & 97 \\
\hline E22/S90 & 18 & & $\mathrm{X}$ & 18RC-11 & Bifacial tool & 1 \\
\hline E22/S90 & 18 & Feature 104 & $\mathrm{X}$ & 18R-2 & Biface Stage 2 & 1 \\
\hline E22/S90 & 18 & Feature 104 & $X$ & 18R-1 & Biface Stage 2 & 1 \\
\hline E22/S90 & 18 & Feature 104 & $\mathrm{X}$ & 18RA-8 & Burin & \\
\hline $\mathrm{E} 22 / \mathrm{S} 90$ & 18 & Feature 104 & $\mathrm{X}$ & 18RC-13 & Burin spall & 1 \\
\hline $\mathrm{E} 22 / \mathrm{S} 90$ & 18 & Feature 104 & $\mathrm{X}$ & & Debitage & 456 \\
\hline E22/S90 & 18 & Feature 104 & $\mathrm{X}$ & 18RD-16 & Edge modified flake & 1 \\
\hline $\mathrm{E} 22 / \mathrm{S} 90$ & 18 & Feature 104 & $\begin{array}{l}\mathrm{X} \\
\mathrm{y}\end{array}$ & 18R-3 & Edge modified flake & 1 \\
\hline E22/S90 & 18 & Feature 104 & $\mathrm{X}$ & 18RC-14 & Edge modified flake & \\
\hline $\mathrm{E} 22 / \mathrm{S} 90$ & 18 & Feature 104 & $\mathrm{X}$ & 18RB-9 & Edge modified flake & 1 \\
\hline $\mathrm{E} 22 / \mathrm{S} 90$ & 18 & Feature 104 & $\begin{array}{l}\mathrm{X} \\
\mathrm{Y}\end{array}$ & 18RA-6 & Edge modified flake & 1 \\
\hline E22/S90 & $\begin{array}{l}18 \\
18\end{array}$ & Feature 104 & $\begin{array}{l}X \\
X\end{array}$ & 18RB-10 & Thin uniface & 1 \\
\hline $\begin{array}{l}\mathrm{E} 22 / \mathrm{S} 90 \\
\mathrm{E} 22 / \mathrm{S} 90\end{array}$ & $\begin{array}{l}18 \\
19\end{array}$ & Feature 104 & $\begin{array}{l}X \\
X\end{array}$ & 18RD-15 & Uniface, unanalyzed & 187 \\
\hline $\mathrm{E} 22 / \mathrm{S} 90$ & 19 & & $\begin{array}{l}X \\
X\end{array}$ & 18QD-6 & $\begin{array}{l}\text { Debitage } \\
\text { Edge modified flake }\end{array}$ & 187 \\
\hline $\mathrm{E} 22 / \mathrm{S} 90$ & 19 & & $\mathrm{X}$ & $18 Q C-3$ & Edge modified flake & \\
\hline $\mathrm{E} 22 / \mathrm{S} 90$ & 19 & & $\mathrm{X}$ & 18QA-1 & Projectile point fragment & 1 \\
\hline $\mathrm{E} 22 / \mathrm{S} 90$ & 19 & & $\mathrm{X}$ & $18 \mathrm{Q}-4$ & Thick uniface & \\
\hline $\mathrm{E} 22 / \mathrm{S} 90$ & 19 & Feature 192 & $X$ & 18QD-5 & Edge modified flake & 1 \\
\hline $\mathrm{E} 22 / \mathrm{S} 90$ & 19 & Feature 192 & $\mathrm{X}$ & 18QB-2 & Perforator Group 6 & \\
\hline $\mathrm{E} 22 / \mathrm{S} 90$ & 20 & & $\mathrm{X}$ & & Debitage & 110 \\
\hline E22/S90 & 21 & & $\mathrm{X}$ & $18 \mathrm{SC}-3$ & Biface fragment & \\
\hline $\mathrm{E} 22 / \mathrm{S} 90$ & 21 & & $\mathrm{X}$ & & Debitage & 122 \\
\hline $\mathrm{E} 22 / \mathrm{S} 90$ & 21 & & $X$ & $18 \mathrm{SB}-2$ & Projectile point, Golondrina-Barber & 1 \\
\hline $\mathrm{E} 22 / \mathrm{S} 90$ & 22 & & $\mathrm{X}$ & & Debitage & 93 \\
\hline $\mathrm{E} 22 / \mathrm{S} 90$ & 22 & & $\mathrm{X}$ & 18TB-2 & Perforator Group 7 & 1 \\
\hline E22/S90 & 22 & & $\mathrm{X}$ & 18TB-1 & Projectile point fragment & \\
\hline $\mathrm{E} 22 / \mathrm{S} 90$ & 23 & & $\mathrm{X}$ & 18UC-1 & Burin spall & \\
\hline E22/S90 & 23 & & $\mathrm{X}$ & & Debitage & 31 \\
\hline $\mathrm{E} 22 / \mathrm{S} 90$ & 24 & & $\mathrm{X}$ & & Debitage & 28 \\
\hline $\mathrm{E} 22 / \mathrm{S} 90$ & Unknown & Feature 104 & & & Debitage & \\
\hline E22/S98 & 1 & & IIIc & $4 \mathrm{~A}-3$ & Arrow point, preform & \\
\hline E22/S98 & 1 & & IIIIc & $4 \mathrm{~A}-1$ & Arrow point, Scallorn & \\
\hline $\mathrm{E} 22 / \mathrm{S} 98$ & 1 & & IIIc & $4 \mathrm{~A}-7$ & Biface Stage 2 & \\
\hline $\mathrm{E} 22 / \mathrm{S} 98$ & 1 & & IIIc & $4 \mathrm{~A}-9$ & Biface Stage 2 & \\
\hline E22/S98 & 1 & & IIIc & $4 \mathrm{~A}-10$ & Biface Stage 2 & \\
\hline
\end{tabular}




\begin{tabular}{|c|c|c|c|c|c|c|}
\hline Square & Level & Feature & Strata & Item & Analyst Identification & Count \\
\hline $\mathrm{E} 22 / \mathrm{S} 98$ & 1 & & IIIc & $4 A-8$ & Biface Stage 2 & 1 \\
\hline E22/S98 & 1 & & IIIc & $4 A-6$ & Bifacial tool Form A & 1 \\
\hline $\mathrm{E} 22 / \mathrm{S} 98$ & 1 & & IIIc & & Debitage & 675 \\
\hline E22/S98 & 1 & & IIIc & $4 \mathrm{~A}-2$ & Mano fragment & 1 \\
\hline E22/S98 & 1 & & IIIc & $4 \mathrm{~A}-14$ & Microspur/microdenticulate & 1 \\
\hline $\mathrm{E} 22 / \mathrm{S} 98$ & 1 & & IIIc & $4 \mathrm{~A}-13$ & Projectile point fragment & 1 \\
\hline $\mathrm{E} 22 / \mathrm{S} 98$ & 1 & & IIIc & $4 \mathrm{~A}-12$ & Projectile point fragment & 1 \\
\hline E22/S98 & 1 & & IIIc & $4 \mathrm{~A}-11$ & Projectile point fragment & 1 \\
\hline $\mathrm{E} 22 / \mathrm{S} 98$ & 2 & & IIIC & $4 \mathrm{~B}-9$ & Biface fragment & 1 \\
\hline $\mathrm{E} 22 / \mathrm{S} 98$ & 2 & & IIIc & $4 \mathrm{~B}-3$ & Biface Stage 2 & 1 \\
\hline $\mathrm{E} 22 / \mathrm{S} 98$ & 2 & & IIIc & $4 B-6$ & Biface Stage 2 & 1 \\
\hline $\mathrm{E} 22 / \mathrm{S} 98$ & 2 & & IIIc & & Debitage & 278 \\
\hline $\mathrm{E} 22 / \mathrm{S} 98$ & 2 & & IIIc & 4B-7 & Edge modified flake & 1 \\
\hline $\mathrm{E} 22 / \mathrm{S} 98$ & 2 & & IIIc & $4 \mathrm{~B}-10$ & Perforator Unifacial & 1 \\
\hline $\mathrm{E} 22 / \mathrm{S} 98$ & 2 & & IIIc & $4 \mathrm{~B}-11$ & Projectile point fragment & 1 \\
\hline $\mathrm{E} 22 / \mathrm{S} 98$ & 2 & & IIIc & $4 \mathrm{~B}-1$ & Projectile point, Darl & 1 \\
\hline $\mathrm{E} 22 / \mathrm{S} 98$ & 2 & & IIIc & $4 B-5$ & Projectile point, Ensor & 1 \\
\hline $\mathrm{E} 22 / \mathrm{S} 98$ & 2 & & IIIc & $4 \mathrm{~B}-2$ & Projectile point, Gower & 1 \\
\hline E22/S98 & 2 & & IIIc & $4 \mathrm{~B}-4$ & Thin uniface fragment & 1 \\
\hline E22/S98 & 2 & & IIIc & $4 B-8$ & Unifacial multiple tool & 1 \\
\hline $\mathrm{E} 22 / \mathrm{S} 98$ & 2 & & IIIc & $4 \mathrm{~B}-13$ & Unifacial multiple tool & 1 \\
\hline $\mathrm{E} 22 / \mathrm{S} 98$ & 3 & BRM 1 & IIIc & & Debitage & 70 \\
\hline $\mathrm{E} 22 / \mathrm{S} 98$ & 4 & BRM 1 & IIIc & $4 \mathrm{D}-2$ & Biface Stage 2 & 1 \\
\hline $\mathrm{E} 22 / \mathrm{S} 98$ & 4 & BRM 1 & IIIc & $4 \mathrm{D}-4$ & Biface Stage 2 & 1 \\
\hline $\mathrm{E} 22 / \mathrm{S} 98$ & 4 & BRM 1 & IIIc & $4 D-3$ & Biface Stage 3 & 1 \\
\hline $\mathrm{E} 22 / \mathrm{S} 98$ & 4 & BRM 1 & IIIc & & Debitage & 94 \\
\hline $\mathrm{E} 22 / \mathrm{S} 98$ & 4 & BRM 1 & IIIc & $4 \mathrm{D}-1$ & Projectile point, expanding stem D & 1 \\
\hline $\mathrm{E} 22 / \mathrm{S} 98$ & 4 & BRM 1 & IIIc & $4 D-6$ & Thin uniface & 1 \\
\hline $\mathrm{E} 22 / \mathrm{S} 98$ & 4 & BRM 1 & IIIc & $4 \mathrm{D}-5$ & Thin uniface fragment & 1 \\
\hline $\mathrm{E} 22 / \mathrm{S} 98$ & 5 & BRM 1 & IIIC & $4 \mathrm{E}-3$ & Biface Stage 1 & 1 \\
\hline $\mathrm{E} 22 / \mathrm{S} 98$ & 5 & BRM 1 & IIIc & $4 \mathrm{E}-2$ & Biface Stage 2 & 1 \\
\hline $\mathrm{E} 22 / \mathrm{S} 98$ & 5 & BRM 1 & IIIc & & Debitage & 149 \\
\hline $\mathrm{E} 22 / \mathrm{S} 98$ & 5 & BRM 1 & IIIc & $4 \mathrm{E}-1$ & Projectile point, Jetta & 1 \\
\hline $\mathrm{E} 22 / \mathrm{S} 98$ & 7 & & Y/IIIc & $4 \mathrm{G}-2$ & Battered cobble & 1 \\
\hline $\mathrm{E} 22 / \mathrm{S} 98$ & 7 & & $\mathrm{Y} / \mathrm{III} \mathrm{c}$ & $4 \mathrm{G}-1$ & Battered cobble & 1 \\
\hline $\mathrm{E} 22 / \mathrm{S} 98$ & 7 & & Y/IIIc & & Debitage & 66 \\
\hline $\mathrm{E} 22 / \mathrm{S} 98$ & 8 & & $\mathrm{Y} / \mathrm{IIIc}$ & $4 \mathrm{H}-1$ & Biface fragment & 1 \\
\hline $\mathrm{E} 22 / \mathrm{S} 98$ & 8 & & Y/IIIc & $4 \mathrm{H}-2$ & Biface Stage 1 & 1 \\
\hline $\mathrm{E} 22 / \mathrm{S} 98$ & 8 & & $\mathrm{Y} / \mathrm{III} \mathrm{c}$ & & Debitage & 134 \\
\hline E22/S98 & 8 & & Y/IIIc & $4 \mathrm{H}-4$ & Edge modified flake & 1 \\
\hline $\mathrm{E} 22 / \mathrm{S} 98$ & 8 & & Y/IIIc & $4 \mathrm{H}-3$ & Unifacial multiple tool & 1 \\
\hline $\mathrm{E} 22 / \mathrm{S} 98$ & 9 & & $\mathrm{Y}$ & $4 \mathrm{I}-4$ & Biface fragment & 1 \\
\hline $\mathrm{E} 22 / \mathrm{S} 98$ & 9 & & $\mathrm{Y}$ & $4 \mathrm{I}-9$ & Biface fragment & 1 \\
\hline $\mathrm{E} 22 / \mathrm{S} 98$ & 9 & & $\mathrm{Y}$ & $4 \mathrm{I}-7$ & Biface Stage 2 & 1 \\
\hline $\mathrm{E} 22 / \mathrm{S} 98$ & 9 & & $\mathrm{Y}$ & & Debitage & 113 \\
\hline $\mathrm{E} 22 / \mathrm{S} 98$ & 9 & & $\mathrm{Y}$ & $4 \mathrm{I}-6$ & Edge modified flake & 1 \\
\hline $\mathrm{E} 22 / \mathrm{S} 98$ & 9 & & $\mathrm{Y}$ & $4 \mathrm{I}-5$ & Edge modified flake & 1 \\
\hline $\mathrm{E} 22 / \mathrm{S} 98$ & 9 & & $\mathrm{Y}$ & $4 \mathrm{I}-8$ & Microspur/microdenticulate & 1 \\
\hline $\mathrm{E} 22 / \mathrm{S} 98$ & 9 & & Y & $4 \mathrm{I}-2$ & Piece esquillee & 1 \\
\hline $\mathrm{E} 22 / \mathrm{S} 98$ & 9 & & $\mathrm{Y}$ & $4 \mathrm{I}-1$ & Projectile point, Uvalde & 1 \\
\hline $\mathrm{E} 22 / \mathrm{S} 98$ & 10 & & $\mathrm{Y}$ & $4 \mathrm{~J}-2$ & Biface Stage 2 & 1 \\
\hline $\mathrm{E} 22 / \mathrm{S} 98$ & 10 & & $\mathrm{Y}$ & & Debitage & 496 \\
\hline $\mathrm{E} 22 / \mathrm{S} 98$ & 10 & & Y & $4 \mathrm{~J}-1$ & Projectile point, Hoxie/Gower & 1 \\
\hline $\mathrm{E} 22 / \mathrm{S} 98$ & 11 & & $\mathrm{X} / \mathrm{Y}$ & $4 K-4$ & Biface fragment & 1 \\
\hline $\mathrm{E} 22 / \mathrm{S} 98$ & 11 & & $\mathrm{X} / \mathrm{Y}$ & & Debitage & 125 \\
\hline $\mathrm{E} 22 / \mathrm{S} 98$ & 11 & & $\mathrm{X} / \mathrm{Y}$ & $4 \mathrm{~K}-5$ & Edge modified flake & 1 \\
\hline E22/S98 & 11 & & $\mathrm{X} / \mathrm{Y}$ & $4 \mathrm{~K}-3$ & Edge modified flake & 1 \\
\hline $\mathrm{E} 22 / \mathrm{S} 98$ & 11 & & $\mathrm{X} / \mathrm{Y}$ & $4 \mathrm{~K}-1$ & Projectile point, Baker & 1 \\
\hline $\mathrm{E} 22 / \mathrm{S} 98$ & 11 & & $\mathrm{X} / \mathrm{Y}$ & $4 \mathrm{~K}-2$ & Unifacial multiple tool & 1 \\
\hline $\mathrm{E} 22 / \mathrm{S} 98$ & 12 & & $\mathrm{X} / \mathrm{Y}$ & $4 \mathrm{~L}-1$ & Biface Stage 3 & 1 \\
\hline $\mathrm{E} 22 / \mathrm{S} 98$ & 12 & & $\mathrm{X} / \mathrm{Y}$ & $4 \mathrm{~L}-2$ & Burin spall & 1 \\
\hline $\mathrm{E} 22 / \mathrm{S} 98$ & 12 & & $\mathrm{X} / \mathrm{Y}$ & & Debitage & 106 \\
\hline $\mathrm{E} 22 / \mathrm{S} 98$ & 13 & & $\mathrm{X}$ & $4 M-2$ & Biface fragment & 1 \\
\hline $\mathrm{E} 22 / \mathrm{S} 98$ & 13 & & $\mathrm{X}$ & $4 \mathrm{M}-1$ & Biface Stage 3 & 1 \\
\hline $\mathrm{E} 22 / \mathrm{S} 98$ & 13 & & $\mathrm{X}$ & & Debitage & 54 \\
\hline E22/S98 & 13 & & $\mathrm{X}$ & $4 \mathrm{M}-3$ & Microspur/microdenticulate & 1 \\
\hline E22/S98 & 14 & & $\mathrm{X}$ & & Debitage & 54 \\
\hline $\mathrm{E} 22 / \mathrm{S} 98$ & 14 & & $\mathrm{X}$ & $4 \mathrm{~N}-1$ & Denticulated flake & 1 \\
\hline E22/S98 & 15 & & $\mathrm{X}$ & & Debitage & 18 \\
\hline $\mathrm{E} 22 / \mathrm{S} 100$ & 1 & & IIIc & $2 \mathrm{~A}-1$ & Arrow point, Alba & 1 \\
\hline $\mathrm{E} 22 / \mathrm{S} 100$ & 1 & & IIIC & $2 A-6$ & Biface fragment & 1 \\
\hline $\mathrm{E} 22 / \mathrm{S} 100$ & 1 & & IIIc & $2 \mathrm{~A}-10$ & Biface fragment & 1 \\
\hline $\mathrm{E} 22 / \mathrm{S} 100$ & 1 & & IIIC & $2 \mathrm{~A}-11$ & Biface Stage 2 & 1 \\
\hline $\mathrm{E} 22 / \mathrm{S} 100$ & 1 & & IIIc & $2 \mathrm{~A}-5$ & Biface Stage 2 & 1 \\
\hline
\end{tabular}




\begin{tabular}{|c|c|c|c|c|c|c|}
\hline $\begin{array}{l}\text { Square } \\
\text { E22/S100 }\end{array}$ & $\begin{array}{l}\text { Level } \\
1\end{array}$ & Feature & $\begin{array}{l}\text { Strata } \\
\text { IIIc }\end{array}$ & $\begin{array}{l}\text { Item } \\
2 \mathrm{~A}-9\end{array}$ & $\begin{array}{l}\text { Analyst Identification } \\
\text { Biface Stage } 2\end{array}$ & Count \\
\hline $\mathrm{E} 22 / \mathrm{S} 100$ & 1 & & IIIc & $2 \mathrm{~A}-3$ & $\begin{array}{l}\text { Blface Stage } 2 \\
\text { Biface Stage } 3\end{array}$ & 1 \\
\hline E22/S100 & 1 & & IIIC & $2 \mathrm{~A}-4$ & Biface Stage 3 & 1 \\
\hline $\mathrm{E} 22 / \mathrm{S} 100$ & 1 & & IIIc & & Debitage & 480 \\
\hline $\mathrm{E} 22 / \mathrm{S} 100$ & 1 & & IIIc & $2 \mathrm{~A}-20$ & Edge modified flake & 1 \\
\hline $\mathrm{E} 22 / \mathrm{S} 100$ & 1 & & IIIc & $2 \mathrm{~A}-12$ & Edge modified flake & 1 \\
\hline $\mathrm{E} 22 / \mathrm{S} 100$ & 1 & & IIII & $2 \mathrm{~A}-16$ & Microspur/microdenticulate & 1 \\
\hline $\mathrm{E} 22 / \mathrm{S} 100$ & 1 & & IIIc & $2 \mathrm{~A}-18$ & Microspur/microdenticulate & 1 \\
\hline $\mathrm{E} 22 / \mathrm{S} 100$ & 1 & & IIIc & $2 \mathrm{~A}-2$ & Projectile point, Ensor & 1 \\
\hline $\mathrm{E} 22 / \mathrm{S} 100$ & 1 & & IIIc & $2 \mathrm{~A}-19$ & Unifacial multiple tool & 1 \\
\hline $\mathrm{E} 22 / \mathrm{S} 100$ & 2 & & IIIc & $2 \mathrm{~B}-1$ & Arrow point, Scallorn & 1 \\
\hline E22/S100 & 2 & & IIIc & $2 \mathrm{~B}-4$ & Biface Stage 1 & 1 \\
\hline $\mathrm{E} 22 / \mathrm{S} 100$ & 2 & & IIIc & $2 \mathrm{~B}-5$ & Biface Stage 2 & 1 \\
\hline $\mathrm{E} 22 / \mathrm{S} 100$ & 2 & & IIIIc & $2 \mathrm{~B}-10$ & Burin spall & 1 \\
\hline $\mathrm{E} 22 / \mathrm{S} 100$ & 2 & & IIIIc & $2 \mathrm{~B}-12$ & Burin spall & 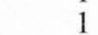 \\
\hline $\mathrm{E} 22 / \mathrm{S} 100$ & 2 & & IIIc & 2B-8 & Core fragment & 1 \\
\hline $\mathrm{E} 22 / \mathrm{S} 100$ & 2 & & IIIc & $2 \mathrm{~B}-6$ & Core, thermal & 1 \\
\hline $\mathrm{E} 22 / \mathrm{S} 100$ & 2 & & IIIc & & Debitage & 256 \\
\hline $\mathrm{E} 22 / \mathrm{S} 100$ & 2 & & IIIc & $2 \mathrm{~B}-11$ & Edge modified flake & 1 \\
\hline $\mathrm{E} 22 / \mathrm{S} 100$ & 2 & & IIIc & $2 \mathrm{~B}-3$ & Projectile point, Castroville & 1 \\
\hline E22/S100 & 2 & & IIII & $2 \mathrm{~B}-2$ & Projectile point, Ensor & 1 \\
\hline E22/S100 & 2 & & IIIc & 2B-9 & Unifacial multiple tool & 1 \\
\hline $\mathrm{E} 22 / \mathrm{S} 100$ & 3 & & IIIc & $2 \mathrm{C}-1$ & Biface fragment & 1 \\
\hline $\mathrm{E} 22 / \mathrm{S} 100$ & 3 & & IIIc & & Debitage & 31 \\
\hline $\mathrm{E} 22 / \mathrm{S} 100$ & 3 & & IIIc & $2 \mathrm{C}-2$ & Retouched blade & 1 \\
\hline $\mathrm{E} 22 / \mathrm{S} 100$ & 4 & & IIIC & & Debitage & 69 \\
\hline E22/S100 & 4 & & IIIc & $2 \mathrm{D}-2$ & Projectile point fragment & 1 \\
\hline $\mathrm{E} 22 / \mathrm{S} 100$ & 4 & & IIIc & $2 \mathrm{D}-1$ & Projectile point, beveled narrow stemmed & 1 \\
\hline $\mathrm{E} 22 / \mathrm{S} 100$ & 5 & & IIIc & & Debitage & 48 \\
\hline $\mathrm{E} 22 / \mathrm{S} 100$ & 5 & & IIIc & $2 \mathrm{E}-3$ & Metate fragment & 1 \\
\hline $\mathrm{E} 22 / \mathrm{S} 100$ & 5 & & IIIIc & $2 \mathrm{E}-1$ & Projectile point, Bulverde & 1 \\
\hline $\mathrm{E} 22 / \mathrm{S} 100$ & 5 & & IIIC & $2 \mathrm{E}-2$ & Projectile point, Fairland & 1 \\
\hline $\mathrm{E} 22 / \mathrm{S} 100$ & 6 & & Y/IIIc & $2 \mathrm{~F}-2$ & Biface Stage 2 & 1 \\
\hline $\mathrm{E} 22 / \mathrm{S} 100$ & 6 & & Y/IIIC & $2 \mathrm{~F}-4$ & Biface Stage 2 & 1 \\
\hline $\mathrm{E} 22 / \mathrm{S} 100$ & 6 & & Y/IIIc & $2 \mathrm{~F}-3$ & Biface Stage 2 & 1 \\
\hline $\mathrm{E} 22 / \mathrm{S} 100$ & 6 & & Y/IIIc & $2 \mathrm{~F}-1$ & Biface Stage 2 & 1 \\
\hline $\mathrm{E} 22 / \mathrm{S} 100$ & 6 & & Y/IIIc & & Debitage & 139 \\
\hline $\mathrm{E} 22 / \mathrm{S} 100$ & 6 & & Y/IIIc & $2 \mathrm{~F}-5$ & Thin uniface & 1 \\
\hline E22/S100 & 8 & & Y & $2 \mathrm{H}-3$ & Biface Stage 2 & 1 \\
\hline $\mathrm{E} 22 / \mathrm{S} 100$ & 8 & & $\mathrm{Y}$ & $2 \mathrm{H}-2$ & Biface Stage 2 & 1 \\
\hline $\mathrm{E} 22 / \mathrm{S} 100$ & 8 & & Y & $2 \mathrm{H}-1$ & Biface Stage 2 & 1 \\
\hline $\mathrm{E} 22 / \mathrm{S} 100$ & 8 & & Y & & Debitage & 139 \\
\hline $\mathrm{E} 22 / \mathrm{S} 100$ & 8 & & $\mathrm{Y}$ & $2 \mathrm{H}-4$ & Thin uniface & 1 \\
\hline $\mathrm{E} 22 / \mathrm{S} 100$ & 9 & & $\mathrm{Y}$ & $2 \mathrm{I}-2$ & Biface Stage 1 & 1 \\
\hline E22/S100 & 9 & & $\mathrm{Y}$ & $2 \mathrm{~K}-1$ & Biface Stage 2 & 1 \\
\hline $\mathrm{E} 22 / \mathrm{S} 100$ & 9 & & Y & & Debitage & 18 \\
\hline $\mathrm{E} 22 / \mathrm{S} 100$ & 9 & & Y & $2 \mathrm{I}-1$ & Projectile point, Hoxie B & 1 \\
\hline $\mathrm{E} 22 / \mathrm{S} 100$ & 11 & & $\mathrm{X} / \mathrm{Y}$ & $2 \mathrm{~K}-2$ & Biface Stage 2 & 1 \\
\hline E22/S100 & 11 & & $\mathrm{X} / \mathrm{Y}$ & $2 \mathrm{~K}-3$ & Burin & 1 \\
\hline $\mathrm{E} 22 / \mathrm{S} 100$ & 11 & & $\mathrm{X} / \mathrm{Y}$ & $2 \mathrm{~K}-4$ & Burin spall & 1 \\
\hline $\mathrm{E} 22 / \mathrm{S} 100$ & 11 & & $\mathrm{X} / \mathrm{Y}$ & & Debitage & 127 \\
\hline $\mathrm{E} 22 / \mathrm{S} 100$ & 12 & & $X / Y$ & $2 \mathrm{~L}-1$ & Biface Stage 2 & 1 \\
\hline E22/S100 & 12 & & $\mathrm{X} / \mathrm{Y}$ & & Debitage & 76 \\
\hline $\mathrm{E} 22 / \mathrm{S} 100$ & 12 & & $\mathrm{X} / \mathrm{Y}$ & $2 \mathrm{~L}-2$ & Microspur/microdenticulate & 1 \\
\hline $\mathrm{E} 22 / \mathrm{S} 100$ & 13 & & $\mathrm{X}$ & $2 \mathrm{M}-2$ & Bifacial tool & 1 \\
\hline $\mathrm{E} 22 / \mathrm{S} 100$ & 13 & & $\mathrm{x}$ & & Debitage & 190 \\
\hline $\mathrm{E} 22 / \mathrm{S} 100$ & 13 & & $\mathrm{X}$ & $2 \mathrm{M}-4$ & Edge modified flake & 1 \\
\hline $\mathrm{E} 22 / \mathrm{S} 100$ & 13 & & $\mathrm{X}$ & $2 \mathrm{M}-5$ & Edge modified flake & 1 \\
\hline $\mathrm{E} 22 / \mathrm{S} 100$ & 13 & & $\mathrm{X}$ & $2 \mathrm{M}-3$ & Edge modified flake & 1 \\
\hline $\mathrm{E} 22 / \mathrm{S} 100$ & 13 & & $\mathrm{x}$ & $2 \mathrm{M}-1$ & Projectile point, expanding concave E & 1 \\
\hline $\mathrm{E} 22 / \mathrm{S} 100$ & 14 & & $\mathrm{X}$ & & Debitage & 31 \\
\hline $\mathrm{E} 22 / \mathrm{S} 100$ & 14 & & $\mathrm{X}$ & $2 \mathrm{~N}-2$ & Edge modified flake & 1 \\
\hline $\mathrm{E} 22 / \mathrm{S} 100$ & 14 & & $\mathrm{X}$ & $2 \mathrm{~N}-3$ & Thin uniface & 1 \\
\hline E24/S60 & Unknown & & & $54 *-1$ & Metate & 1 \\
\hline E24/S64 & 13 & & III & & Debitage & 60 \\
\hline $\mathrm{E} 24 / \mathrm{S} 64$ & 14 & & III & & Debitage & 176 \\
\hline $\mathrm{E} 24 / \mathrm{S} 64$ & 14 & & III & $52 \mathrm{NC}-3$ & Mano fragment & 1 \\
\hline E24/S64 & 14 & & III & $52 \mathrm{NA}-1$ & Microspur/microdenticulate & 1 \\
\hline E24/S64 & 14 & & III & $52 \mathrm{ND}-4$ & Uniface, unanalyzed & 1 \\
\hline $\mathrm{E} 24 / \mathrm{S} 64$ & 14 & & III & $52 \mathrm{ND}-6$ & Uniface, unanalyzed & 1 \\
\hline E24/S64 & 14 & & III & 52ND-5 & Uniface, unanalyzed & 1 \\
\hline E24/S64 & 14 & & III & $52 \mathrm{NA}-2$ & Uniface, unanalyzed & 1 \\
\hline E24/S64 & 15 & & III & $52 \mathrm{OA}-1$ & Burin spall & 1 \\
\hline $\mathrm{E} 24 / \mathrm{S} 64$ & 15 & & III & $52 \mathrm{OC}-7$ & Core, thermal & 1 \\
\hline
\end{tabular}




\begin{tabular}{|c|c|c|c|c|c|c|}
\hline Square & Level & Feature & Strata & Item & Analyst Identification & Count \\
\hline E24/S64 & 15 & & III & & Debitage & 353 \\
\hline E24/S64 & 15 & & III & $52 \mathrm{OC}-5$ & Microspur/microdenticulate & 1 \\
\hline E24/S64 & 15 & & III & $52 \mathrm{OC}-3$ & Projectile point, bifurcate stem fragment & 1 \\
\hline E24/S64 & 15 & & III & $52 \mathrm{OC}-8$ & Thin uniface fragment & 1 \\
\hline E24/S64 & 15 & & III & $52 \mathrm{OC}-6$ & Uniface, unanalyzed & 1 \\
\hline E24/S64 & 15 & & III & $52 \mathrm{OA}-2$ & Uniface, unanalyzed & 1 \\
\hline E24/S64 & 15 & & III & $52 \mathrm{OD}-9$ & Uniface, unanalyzed & 1 \\
\hline E24/S64 & 15 & & III & $52 \mathrm{OC}-4$ & Unifacial multiple tool & 1 \\
\hline E24/S64 & 16 & & III & 52PA-1 & Biface fragment & 1 \\
\hline E24/S64 & 16 & & III & $52 \mathrm{~PB}-10$ & Biface Stage 2 & 1 \\
\hline E24/S64 & 16 & & III & $52 \mathrm{PA}-2$ & Burin & 1 \\
\hline E24/S64 & 16 & & III & & Debitage & 306 \\
\hline E24/S64 & 16 & & III & $52 \mathrm{~PB}-6$ & Edge modified flake & 1 \\
\hline E24/S64 & 16 & & III & $52 \mathrm{PC}-12$ & Microspur/microdenticulate & 1 \\
\hline E24/S64 & 16 & & III & $52 \mathrm{PD}-16$ & Microspur/microdenticulate & 1 \\
\hline E24/S64 & 16 & & III & $52 \mathrm{PA}-3$ & Microspur/microdenticulate & 1 \\
\hline E24/S64 & 16 & & III & $52 \mathrm{PC}-11$ & Perforator Group 7 & 1 \\
\hline E24/S64 & 16 & & III & $52 \mathrm{PC}-13$ & Uniface, unanalyzed & 1 \\
\hline E24/S64 & 16 & & III & $52 \mathrm{~PB}-8$ & Uniface, unanalyzed & 1 \\
\hline E24/S64 & 16 & & III & $52 \mathrm{~PB}-7$ & Uniface, unanalyzed & 1 \\
\hline E24/S64 & 16 & & III & $52 \mathrm{PA}-4$ & Uniface, unanalyzed & 1 \\
\hline $\mathrm{E} 24 / \mathrm{S} 64$ & 16 & & III & $52 \mathrm{~PB}-9$ & Uniface, unanalyzed & 1 \\
\hline E24/S64 & 16 & & III & $52 \mathrm{PD}-15$ & Uniface, unanalyzed & 1 \\
\hline E24/S64 & 16 & & III & $52 \mathrm{PD}-17$ & Unifacial multiple tool & 1 \\
\hline $\mathrm{E} 24 / \mathrm{S} 72$ & 15 & & $\mathrm{IIIa} / \mathrm{b}$ & $310-4$ & Bifacial tool & 1 \\
\hline $\mathrm{E} 24 / \mathrm{S} 72$ & 15 & & $\mathrm{IIIa} / \mathrm{b}$ & $310-7$ & Core tool, type 5 & 1 \\
\hline $\mathrm{E} 24 / \mathrm{S} 72$ & 15 & & $\mathrm{IIIa} / \mathrm{b}$ & & Debitage & 701 \\
\hline E24/S72 & 15 & & IIIa/b & $310-10$ & Denticulated flake & 1 \\
\hline $\mathrm{E} 24 / \mathrm{S} 72$ & 15 & & $\mathrm{IIIa} / \mathrm{b}$ & $310-6$ & Edge modified flake & 1 \\
\hline $\mathrm{E} 24 / \mathrm{S} 72$ & 15 & & $\mathrm{IIIa} / \mathrm{b}$ & $310-11$ & Micro-core, small & 1 \\
\hline $\mathrm{E} 24 / \mathrm{S} 72$ & 15 & & $\mathrm{IIIa} / \mathrm{b}$ & $310-2$ & Projectile point, Gower & 1 \\
\hline $\mathrm{E} 24 / \mathrm{S} 72$ & 15 & & $\mathrm{III} a / b$ & $310-1$ & Projectile point, Hoxie B & 1 \\
\hline E24/S72 & 15 & & $\mathrm{IIIa} / \mathrm{b}$ & $310-3$ & Uniface, unanalyzed & 1 \\
\hline $\mathrm{E} 24 / \mathrm{S} 72$ & 15 & & IIIa/b & $310-9$ & Unifacial multiple tool & 1 \\
\hline $\mathrm{E} 24 / \mathrm{S} 72$ & 16 & & IIIa & & Debitage & 321 \\
\hline E24/S72 & $16 \mathrm{~A}$ & & IIIa & 31P1-3 & Biface Stage 1 & 1 \\
\hline E24/S72 & $16 \mathrm{~A}$ & & IIIa & $31 P 1-6$ & Burin & 1 \\
\hline E24/S72 & $16 \mathrm{~A}$ & & IIIa & $31 P 1-5$ & Chert cobble, chunk & 1 \\
\hline E24/S72 & $16 \mathrm{~A}$ & & IIIa & & Debitage & 249 \\
\hline E24/S72 & $16 \mathrm{~A}$ & & IIIa & $31 \mathrm{P} 1-9$ & Microspur/microdenticulate & 1 \\
\hline $\mathrm{E} 24 / \mathrm{S} 72$ & $16 \mathrm{~A}$ & & IIIa & $31 \mathrm{P} 1-13$ & Microspur/microdenticulate & 1 \\
\hline E24/S72 & $16 \mathrm{~A}$ & & IIIa & $31 \mathrm{P} 1-2$ & Perforator Group 4 & 1 \\
\hline $\mathrm{E} 24 / \mathrm{S} 72$ & $16 \mathrm{~A}$ & & IIIa & 31P1-1 & Projectile point, Thrall & 1 \\
\hline E24/S72 & $16 \mathrm{~A}$ & & IIIa & $31 P 1-4$ & Spurred flake & 1 \\
\hline $\mathrm{E} 24 / \mathrm{S} 72$ & $16 \mathrm{~A}$ & & IIIa & $31 \mathrm{P} 1-7$ & Thin uniface fragment & 1 \\
\hline E24/S72 & $16 \mathrm{~A}$ & & IIIa & 31P1-11 & Uniface, unanalyzed & 1 \\
\hline E24/S72 & $16 \mathrm{~B}$ & & IIIa & $31 \mathrm{P} 2-1$ & Biface fragment, unanalyzed & 1 \\
\hline $\mathrm{E} 24 / \mathrm{S} 72$ & $16 \mathrm{~B}$ & & IIIa & & Debitage & 670 \\
\hline $\mathrm{E} 24 / \mathrm{S} 72$. & $16 \mathrm{~B}$ & & IIIa & $31 \mathrm{P} 2-2$ & Microspur/microdenticulate & 1 \\
\hline E24/S72 & $16 \mathrm{~B}$ & & IIIa & $31 \mathrm{P} 2-4$ & Thin uniface & 1 \\
\hline E24/S72 & $16 \mathrm{~B}$ & & IIIa & $31 \mathrm{P} 2-3$ & Uniface, unanalyzed & \\
\hline $\mathrm{E} 24 / \mathrm{S} 72$ & 17 & & IIIa & & Debitage & 321 \\
\hline $\mathrm{E} 24 / \mathrm{S} 72$ & $17 \mathrm{~A}$ & & IIIa & 31Q1-1 & Biface Stage 2 & \\
\hline $\mathrm{E} 24 / \mathrm{S} 72$ & $17 \mathrm{~A}$ & & IIIa & & Debitage & 420 \\
\hline E24/S72 & $17 \mathrm{~A}$ & & IIIa & 31Q1-3 & Thin uniface fragment & 1 \\
\hline E24/S72 & $17 \mathrm{~A}$ & & IIIa & $31 \mathrm{Q} 1-2$ & Uniface, unanalyzed & 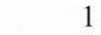 \\
\hline E24/S72 & $17 \mathrm{~B}$ & & IIIa & $31 \mathrm{Q} 2-1$ & Bifacial tool Form B & 1 \\
\hline $\mathrm{E} 24 / \mathrm{S} 72$ & $17 \mathrm{~B}$ & & IIIa & 31Q2-11 & Burin spall & 1 \\
\hline $\mathrm{E} 24 / \mathrm{S} 72$ & $17 \mathrm{~B}$ & & IIIa & & Debitage & 631 \\
\hline E24/S72 & $17 \mathrm{~B}$ & & IIIa & $31 \mathrm{Q} 2-5$ & Edge modified flake & 1 \\
\hline $\mathrm{E} 24 / \mathrm{S} 72$ & $17 \mathrm{~B}$ & & IIIa & $31 Q 2-2$ & Micro-core, intermediate & 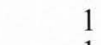 \\
\hline $\mathrm{E} 24 / \mathrm{S} 72$ & 17B & & IIIa & $31 \mathrm{Q} 2-6$ & Microspur/microdenticulate & 1 \\
\hline E24/S72 & $17 \mathrm{~B}$ & & IIIa & 31Q2-13 & Spurred flake & 1 \\
\hline $\mathrm{E} 24 / \mathrm{S} 72$ & $17 \mathrm{~B}$ & & IIIa & $31 \mathrm{Q} 2-8$ & Uniface, unanalyzed & 1 \\
\hline $\mathrm{E} 24 / \mathrm{S} 72$ & $17 \mathrm{~B}$ & & IIIa & $31 \mathrm{Q} 2-15$ & Uniface, unanalyzed & 1 \\
\hline E24/S72 & $17 \mathrm{~B}$ & & IIIa & $31 \mathrm{Q} 2-14$ & Uniface, unanalyzed & 1 \\
\hline $\mathrm{E} 24 / \mathrm{S} 72$ & $17 \mathrm{~B}$ & & IIIa & $31 \mathrm{Q} 2-10$ & Uniface, unanalyzed & 1 \\
\hline $\mathrm{E} 24 / \mathrm{S} 72$ & 17B & & IIIa & 31Q2-4 & Unifacial multiple tool & 1 \\
\hline E24/S72 & 17B & & IIIa & $31 \mathrm{Q} 2-3$ & Unifacial multiple tool & 1 \\
\hline $\mathrm{E} 24 / \mathrm{S} 72$ & $17 \mathrm{~B}$ & & IIIa & $31 \mathrm{Q} 2-7$ & Unifacial multiple tool & 1 \\
\hline E24/S72 & $18 \mathrm{~A}$ & & IIIa & $31 \mathrm{R} 1-8$ & Biface fragment & 1 \\
\hline E24/S72 & $18 \mathrm{~A}$ & & IIIa & $31 \mathrm{R} 1-4$ & Burin & 1 \\
\hline E24/S72 & $18 \mathrm{~A}$ & & IIIa & $31 \mathrm{R} 1-2$ & Clear Fork biface, proximal & 1 \\
\hline $\mathrm{E} 24 / \mathrm{S} 72$ & $18 \mathrm{~A}$ & & IIIa & & Debitage & 558 \\
\hline
\end{tabular}




\begin{tabular}{|c|c|c|c|c|c|c|}
\hline Square & Level & Feature & Strata & Item & Analyst Identification & Count \\
\hline $\mathrm{E} 24 / \mathrm{S} 72$ & $18 \mathrm{~A}$ & & IIIa & $31 \mathrm{R} 1-9$ & Edge modified flake & 1 \\
\hline E24/S72 & $18 \mathrm{~A}$ & & IIIa & $31 \mathrm{R} 1-12$ & Microspur/microdenticulate & 1 \\
\hline E24/S72 & $18 \mathrm{~A}$ & & IIIa & $31 \mathrm{R} 1-6$ & Perforator Group 7 & 1 \\
\hline E24/S72 & $18 \mathrm{~A}$ & & IIIa & 31R1-11 & Perforator Unifacial & 1 \\
\hline $\mathrm{E} 24 / \mathrm{S} 72$ & $18 \mathrm{~A}$ & & IIIa & $31 \mathrm{R} 1-7$ & Projectile point fragment & 1 \\
\hline E24/S72 & $18 \mathrm{~A}$ & & IIIa & 31R1-1 & Projectile point, Thrall & 1 \\
\hline E24/S72 & $18 \mathrm{~A}$ & & IIIa & $31 \mathrm{R} 1-10$ & Uniface, unanalyzed & 1 \\
\hline E24/S72 & $18 \mathrm{~A}$ & & IIIa & $31 \mathrm{R} 1-5$ & Uniface, unanalyzed & 1 \\
\hline $\mathrm{E} 24 / \mathrm{S} 72$ & $18 \mathrm{~B}$ & & IIIa & & Debitage & 566 \\
\hline $\mathrm{E} 24 / \mathrm{S} 72$ & $18 \mathrm{~B}$ & & IIIa & $31 \mathrm{R} 2-6$ & Denticulated flake & 1 \\
\hline E24/S72 & $18 \mathrm{~B}$ & & IIIa & $31 R 2-4$ & Microspur/microdenticulate & 1 \\
\hline E24/S72 & $18 \mathrm{~B}$ & & IIIa & $31 \mathrm{R} 2-3$ & Microspur/microdenticulate & 1 \\
\hline $\mathrm{E} 24 / \mathrm{S} 72$ & $18 \mathrm{~B}$ & & IIIa & 31R2-1 & Projectile point, Gower & 1 \\
\hline $\mathrm{E} 24 / \mathrm{S} 72$ & $18 \mathrm{~B}$ & & IIIa & $31 \mathrm{R} 2-2$ & Projectile point, Hoxie & 1 \\
\hline E24/S72 & $18 \mathrm{~B}$ & & IIIa & $31 \mathrm{R} 2-7$ & Uniface, unanalyzed & 1 \\
\hline E24/S72 & $18 \mathrm{~B}$ & & IIIIa & $31 R 2-5$ & Uniface, unanalyzed & 1 \\
\hline E24/S72 & $18 \mathrm{~B}$ & & IIIa & $31 \mathrm{R} 2-8$ & Uniface, unanalyzed & 1 \\
\hline E24/S72 & $19 \mathrm{~A}$ & & IIIa & $31 \mathrm{~S} 1-9$ & Biface fragment & 1 \\
\hline $\mathrm{E} 24 / \mathrm{S} 72$ & $19 \mathrm{~A}$ & & IIIa & $31 \mathrm{~S} 1-8$ & Biface Stage 3 & 1 \\
\hline E24/S72 & $19 \mathrm{~A}$ & & IIIa & $31 \mathrm{~S} 1-3$ & Bifacial tool Form E & 1 \\
\hline E24/S72 & $19 \mathrm{~A}$ & & IIIIa & $31 \mathrm{~S} 1-5$ & Chert cobble, unmodified/tested & 1 \\
\hline E24/S72 & $19 \mathrm{~A}$ & & IIIa & & Debitage & 457 \\
\hline $\mathrm{E} 24 / \mathrm{S} 72$ & $19 \mathrm{~A}$ & & IIIa & $31 \mathrm{~S} 1-11$ & Edge modified flake & 1 \\
\hline $\mathrm{E} 24 / \mathrm{S} 72$ & $19 \mathrm{~A}$ & & IIIa & $31 \mathrm{~S} 1-6$ & Micro-core, intermediate & 1 \\
\hline E24/S72 & $19 \mathrm{~A}$ & & IIIa & 31S1-1 & Projectile point, Hoxie & 1 \\
\hline E24/S72 & $19 \mathrm{~A}$ & & IIIa & $31 \mathrm{~S} 1-7$ & Thin uniface & 1 \\
\hline E24/S72 & $19 \mathrm{~A}$ & & IIIa & $31 \mathrm{~S} 1-10$ & Uniface, unanalyzed & 1 \\
\hline E24/S72 & $19 \mathrm{~A}$ & & IIIa & $31 \mathrm{~S} 1-4$ & Uniface, unanalyzed & 1 \\
\hline E24/S72 & 19B & & II/IIIa & & Debitage & 232 \\
\hline E24/S72 & 19B & & II/IIIa & 31S2D-5 & Microspur/microdenticulate & 1 \\
\hline E24/S72 & 19B & & II/IIIa & $31 \mathrm{~S} 2 \mathrm{D}-4$ & Thin uniface fragment & 1 \\
\hline $\mathrm{E} 24 / \mathrm{S} 72$ & $19 B$ & & II/IIIa & $31 \mathrm{~S} 2 \mathrm{C}-3$ & Uniface, unanalyzed & 1 \\
\hline $\mathrm{E} 24 / \mathrm{S} 72$ & $20 \mathrm{~A}$ & & II/IIIa & $31 \mathrm{~T} 1 \mathrm{~A}-2$ & Biface Stage 2 & 1 \\
\hline E24/S72 & $20 \mathrm{~A}$ & & II/IIIa & & Debitage & 226 \\
\hline E24/S72 & $20 \mathrm{~A}$ & & II/IIIa & $31 \mathrm{~T} 1-1$ & Notched flake & 1 \\
\hline E24/S72 & $20 \mathrm{~A}$ & & II/IIIa & $31 \mathrm{~T} 1 \mathrm{D}-6$ & Thin uniface fragment & 1 \\
\hline $\mathrm{E} 24 / \mathrm{S} 72$ & $20 \mathrm{~A}$ & & II/IIIa & $31 \mathrm{~T} 1 \mathrm{C}-3$ & Uniface, unanalyzed & 1 \\
\hline $\mathrm{E} 24 / \mathrm{S} 72$ & $20 \mathrm{~A}$ & & II/IIIa & $31 \mathrm{~T} 1 \mathrm{C}-4$ & Uniface, unanalyzed & 1 \\
\hline E24/S72 & $20 \mathrm{~A}$ & & $\mathrm{II} / \mathrm{IIIa}$ & $31 \mathrm{~T} 1 \mathrm{C}-5$ & Uniface, unanalyzed & 1 \\
\hline E24/S72 & $20 \mathrm{~B}$ & & II/IIIa & $31 \mathrm{~T} 2 \mathrm{~A}-1$ & Burin spall & 1 \\
\hline E24/S72 & $20 \mathrm{~B}$ & & II/IIIa & $31 \mathrm{~T} 2 \mathrm{C}-3$ & Burin spall & 1 \\
\hline E24/S72 & $20 \mathrm{~B}$ & & II/IIIa & & Debitage & 179 \\
\hline $\mathrm{E} 24 / \mathrm{S} 72$ & $20 \mathrm{~B}$ & & II/IIIa & $31 \mathrm{~T} 2 \mathrm{C}-4$ & Thin uniface & 1 \\
\hline E24/S72 & 20B & & II/IIIa & $31 \mathrm{~T} 2 \mathrm{D}-5$ & Uniface, unanalyzed & 1 \\
\hline E24/S72 & $21 \mathrm{~A}$ & & II/IIIa & 31U1B-1 & Biface Stage 2 & 1 \\
\hline $\mathrm{E} 24 / \mathrm{S} 72$ & $21 \mathrm{~A}$ & & II/IIIa & & Debitage & 162 \\
\hline $\mathrm{E} 24 / \mathrm{S} 72$ & $21 \mathrm{~A}$ & & II/IIIa & $31 \mathrm{U} 1 \mathrm{C}-2$ & Projectile point, Angostura & 1 \\
\hline E24/S72 & 21B & & II & & Debitage & 86 \\
\hline E24/S72 & $22 \mathrm{~A}$ & & II & & Debitage & 101 \\
\hline E24/S72 & $22 \mathrm{~A}$ & & II & 31V1D-2 & Small core hammerstone & 1 \\
\hline $\mathrm{E} 24 / \mathrm{S} 72$ & $22 \mathrm{~A}$ & & II & 31V1B-1 & Thin uniface fragment & 1 \\
\hline $\mathrm{E} 24 / \mathrm{S} 72$ & 22B & & II & $31 \mathrm{~V} 2 \mathrm{~B}-6$ & Biface Stage 2 & 1 \\
\hline E24/S72 & $22 \mathrm{~B}$ & & II & & Debitage & 69 \\
\hline E24/S72 & $22 \mathrm{~B}$ & & II & 31V2B-5 & Thin uniface & 1 \\
\hline E24/S72 & $22 \mathrm{~B}$ & & II & 31V2B-4 & Uniface, unanalyzed & 1 \\
\hline $\mathrm{E} 24 / \mathrm{S} 72$ & $23 \mathrm{~A}$ & & II & & Debitage & 79 \\
\hline $\mathrm{E} 24 / \mathrm{S} 72$ & $23 \mathrm{~A}$ & & II & $31 \mathrm{~W} 1 \mathrm{C}-2$ & Uniface, unanalyzed & 1 \\
\hline E24/S72 & $23 \mathrm{~B}$ & & II & & Debitage & 59 \\
\hline E24/S72 & $24 \mathrm{~A}$ & & II & $31 X 1 B-1$ & Biface fragment & 1 \\
\hline E24/S72 & $24 \mathrm{~A}$ & & II & & Debitage & 80 \\
\hline $\mathrm{E} 24 / \mathrm{S} 72$ & $24 \mathrm{~B}$ & & II & $31 \mathrm{X} 2 \mathrm{~B}-2$ & Biface Stage 2 & 1 \\
\hline $\mathrm{E} 24 / \mathrm{S} 72$ & $24 \mathrm{~B}$ & & II & $31 \times 2 D-3$ & Biface Stage 2 & 1 \\
\hline E24/S72 & $24 \mathrm{~B}$ & & II & & Debitage & 72 \\
\hline E24/S72 & $24 B$ & & II & $31 \mathrm{X} 2 \mathrm{~B}-1$ & Uniface, unanalyzed & 1 \\
\hline E24/S72 & $25 \mathrm{~A}$ & & II & 31Y1B-2 & Biface Stage 2 & 1 \\
\hline E24/S72 & $25 \mathrm{~A}$ & & II & & Debitage & 78 \\
\hline E24/S72 & $25 \mathrm{~A}$ & & II & $31 Y 1 A-1$ & Uniface, unanalyzed & 1 \\
\hline E24/S72 & $25 \mathrm{~B}$ & & II & & Debitage & 63 \\
\hline $\mathrm{E} 24 / \mathrm{S} 72$ & $25 B$ & & II & $31 Y 2 A-1$ & Uniface, unanalyzed & 1 \\
\hline $\mathrm{E} 24 / \mathrm{S} 72$ & $26 \mathrm{~A}$ & & II & & Debitage & 39 \\
\hline E24/S72 & $26 \mathrm{~A}$ & & II & 31Z1D-1 & Uniface, unanalyzed & 1 \\
\hline $\mathrm{E} 24 / \mathrm{S} 72$ & $26 \mathrm{~B}$ & & II & $31 \mathrm{Z} 2 \mathrm{C}-1$ & Core, thermal & 1 \\
\hline E24/S72 & $26 B$ & & II & & Debitage & 34 \\
\hline E24/S72 & $27 \mathrm{~A}$ & & II & & Debitage & 42 \\
\hline
\end{tabular}




\begin{tabular}{|c|c|c|c|c|c|c|}
\hline Square & Level & Feature & Strata & Item & Analyst Identification & Count \\
\hline E24/S72 & $27 \mathrm{~A}$ & & II & $31 \mathrm{AA} 1 \mathrm{C}-1$ & Thick uniface fragment & 1 \\
\hline E24/S72 & $27 \mathrm{~B}$ & & II & & Debitage & 31 \\
\hline $\mathrm{E} 24 / \mathrm{S} 72$ & $28 \mathrm{~A}$ & & Isi-c/II & & Debitage & 42 \\
\hline E24/S72 & $28 \mathrm{~B}$ & & Isi-c/II & & Debitage & 22 \\
\hline E24/S72 & $29 \mathrm{~A}$ & & Isi-c & & Debitage & 23 \\
\hline E24/S72 & $29 \mathrm{~A}$ & & Isi-c & $31 \mathrm{CC} 1 \mathrm{~A}-1$ & Thin uniface fragment & 1 \\
\hline $\mathrm{E} 24 / \mathrm{S} 72$ & $29 \mathrm{~B}$ & & Isi-c & & Debitage & 35 \\
\hline E24/S72 & $30 \mathrm{~A}$ & & Isi-c & & Debitage & 10 \\
\hline E24/S72 & $30 \mathrm{~B}$ & & Isi-c & & Debitage & 12 \\
\hline E24/S72 & $31 \mathrm{~A}$ & & Isi-c & & Debitage & 18 \\
\hline E24/S72 & $31 \mathrm{~B}$ & & Isi-c & & Debitage & 13 \\
\hline E24/S72 & $32 \mathrm{~A}$ & & Icl/Isi-c & & Debitage & \& \\
\hline $\mathrm{E} 24 / \mathrm{S} 72$ & $32 \mathrm{~A}$ & & Icl/Isi-c & 31FF1B-2 & Edge modified flake & 1 \\
\hline E24/S72 & $32 \mathrm{~B}$ & & Icl/Isi-c & & Debitage & 12 \\
\hline $\mathrm{E} 24 / \mathrm{S} 72$ & $33 \mathrm{~A}$ & & $\mathrm{Icl} / \mathrm{Isi}-\mathrm{c}$ & $31 \mathrm{GG} 1 \mathrm{C}-1$ & Core fragment & 1 \\
\hline $\mathrm{E} 24 / \mathrm{S} 72$ & $33 \mathrm{~A}$ & & Icl/Isi-c & & Debitage & 10 \\
\hline E24/S72 & $33 \mathrm{~B}$ & & Icl/Isi-c & & Debitage & 6 \\
\hline E24/S72 & $34 \mathrm{~A}$ & & Icl/Isi-c & & Debitage & 8 \\
\hline E24/S72 & $34 \mathrm{~B}$ & & Icl & & Debitage & 7 \\
\hline $\mathrm{E} 24 / \mathrm{S} 72$ & $35 \mathrm{~A}$ & & Icl & & Debitage & 9 \\
\hline E24/S72 & $35 \mathrm{~B}$ & & Icl & & Debitage & 10 \\
\hline E24/S72 & $36 \mathrm{~A}$ & & Isi/Icl & & Debitage & 5 \\
\hline E24/S72 & $36 \mathrm{~B}$ & & $\mathrm{Isi} / \mathrm{Icl}$ & & Debitage & 11 \\
\hline E24/S72 & $37 \mathrm{~A}$ & & Isi/Icl & & Debitage & 17 \\
\hline $\mathrm{E} 24 / \mathrm{S} 72$ & $37 \mathrm{~A}$ & & $\mathrm{Isi} / \mathrm{Icl}$ & $31 \mathrm{KK} 1 \mathrm{~A}-1$ & Face battered stone & 1 \\
\hline E24/S72 & $37 \mathrm{~B}$ & & Isi/Icl & & Debitage & 6 \\
\hline E24/S72 & $37 \mathrm{~B}$ & & Isi/Icl & $31 \mathrm{KK} 2 \mathrm{~B}-1$ & Uniface, unanalyzed & 1 \\
\hline E24/S72 & $37 \mathrm{~B}$ & Feature 178 & Isi/Icl & & Debitage & 1 \\
\hline $\mathrm{E} 24 / \mathrm{S} 72$ & $38 \mathrm{~A}$ & & Isi/Icl & & Debitage & 5 \\
\hline E24/S72 & $38 \mathrm{~B}$ & & $\mathrm{Igl} / \mathrm{Isi}$ & & Debitage & 10 \\
\hline E24/S72 & $39 \mathrm{~A}$ & & Igl/Isi & & Debitage & 5 \\
\hline $\mathrm{E} 24 / \mathrm{S} 72$ & $39 \mathrm{~B}$ & & $\mathrm{Igl} / \mathrm{Isi}$ & $31 \mathrm{MM} 2 \mathrm{~A}-2$ & Biface Stage 2 & 1 \\
\hline $\mathrm{E} 24 / \mathrm{S} 72$ & $39 \mathrm{~B}$ & & $\mathrm{Igl} / \mathrm{Isi}$ & & Debitage & 13 \\
\hline E24/S72 & $39 \mathrm{~B}$ & & Igl/Isi & $31 \mathrm{MM} 2 \mathrm{~B}-4$ & Edge modified flake & 1 \\
\hline E24/S72 & 39B & & Igl/Isi & 31MM2B-3 & Edge modified flake & 1 \\
\hline E24/S72 & $40 \mathrm{~A}$ & & Igl/Isi & $31 \mathrm{NN} 1 \mathrm{~A}-1$ & Core, multidirectional & 1 \\
\hline $\mathrm{E} 24 / \mathrm{S} 72$ & $40 \mathrm{~A}$ & & $\mathrm{Igl} / \mathrm{Isi}$ & & Debitage & 10 \\
\hline $\mathrm{E} 24 / \mathrm{S} 72$ & $40 \mathrm{~A}$ & & $\mathrm{Igl} / \mathrm{Isi}$ & $31 \mathrm{NN} 1 \mathrm{~A}-2$ & Uniface, unanalyzed & \\
\hline E24/S72 & $40 \mathrm{~B}$ & & $\operatorname{Igl} / / \mathrm{Isi}$ & & Debitage & 15 \\
\hline E24/S72 & $41 \mathrm{~A}$ & & $\mathrm{Igl} / \mathrm{Isi}$ & & Debitage & 2 \\
\hline E24/S74 & 15 & & IIIIa/b & $300-27$ & Biface fragment & 1 \\
\hline E24/S74 & 15 & & $\mathrm{IIIa} / \mathrm{b}$ & $300-18$ & Biface fragment & 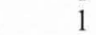 \\
\hline E24/S74 & 15 & & IIIa/b & $300-11$ & Biface fragment & 1 \\
\hline E24/S74 & 15 & & $\mathrm{IIIa} / \mathrm{b}$ & 30014 & Biface fragment & 1 \\
\hline E24/S74 & 15 & & IIIa/b & $300-25$ & Biface fragment & 1 \\
\hline E24/S74 & 15 & & IIIa/b & $300-3$ & Biface Stage 2 & 1 \\
\hline E24/S74 & 15 & & $\mathrm{IIIa} / \mathrm{b}$ & $300-8$ & Biface Stage 3 & 1 \\
\hline E24/S74 & 15 & & $\mathrm{IIIa} / \mathrm{b}$ & $300-2$ & Burin & 1 \\
\hline E24/S74 & 15 & & $\mathrm{III} a / \mathrm{b}$ & $300-16$ & Burin spall & 1 \\
\hline E24/S74 & 15 & & $\mathrm{IIIa} / \mathrm{b}$ & $300-20$ & Burin spall & 1 \\
\hline E24/S74 & 15 & & $\mathrm{III} a / \mathrm{b}$ & $300-28$ & Burin spall & 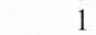 \\
\hline E24/S74 & 15 & & $\mathrm{IIIa} / \mathrm{b}$ & $300-6$ & Core, multidirectional & 1 \\
\hline E24/S74 & 15 & & $\mathrm{IIIa} / \mathrm{b}$ & & Debitage & 1068 \\
\hline E24/S74 & 15 & & $\mathrm{IIIa} / \mathrm{b}$ & $300-21$ & Microspur/microdenticulate & 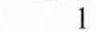 \\
\hline E24/S74 & 15 & & IIIa/b & $300-1$ & Projectile point, Angostura & 1 \\
\hline E24/S74 & 15 & & $\mathrm{III} a / \mathrm{b}$ & $300-7$ & Projectile point, expanding concave $\mathrm{B}$ & 1 \\
\hline E24/S74 & 15 & & $\mathrm{IIIa} / \mathrm{b}$ & $300-5$ & Retouched blade & 1 \\
\hline E24/S74 & 15 & & $\mathrm{III} a / \mathrm{b}$ & $300-24$ & Spurred flake & 1 \\
\hline E24/S74 & 15 & & $\mathrm{IIIa} / \mathrm{b}$ & $300-10$ & Thin uniface & 1 \\
\hline $\mathrm{E} 24 / \mathrm{S} 74$ & 15 & & $\mathrm{IIIa} / \mathrm{b}$ & $300-23$ & Uniface, unanalyzed & 1 \\
\hline E24/S74 & 15 & & $\mathrm{IIIa} / \mathrm{b}$ & $300-26$ & Uniface, unanalyzed & 1 \\
\hline E24/S74 & 15 & & $\mathrm{IIIa} / \mathrm{b}$ & $300-22$ & Uniface, unanalyzed & 1 \\
\hline E24/S74 & 15 & & $\mathrm{III} a / \mathrm{b}$ & $300-19$ & Uniface, unanalyzed & 1 \\
\hline $\mathrm{E} 24 / \mathrm{S} 74$ & 15 & & $\mathrm{IIIa} / \mathrm{b}$ & $300-17$ & Uniface, unanalyzed & 1 \\
\hline $\mathrm{E} 24 / \mathrm{S} 74$ & 15 & & $\mathrm{IIIa} / \mathrm{b}$ & $300-15$ & Uniface, unanalyzed & 1 \\
\hline E24/S74 & 15 & & $\mathrm{IIIa} / \mathrm{b}$ & $300-9$ & Uniface, unanalyzed & 1 \\
\hline E24/S74 & 15 & & $\mathrm{IIIa} / \mathrm{b}$ & $300-12$ & Uniface, unanalyzed & 1 \\
\hline E24/S74 & $16 \mathrm{~A}$ & & IIIa & $30 \mathrm{P} 1-3$ & Biface Stage 1 & 1 \\
\hline E24/S74 & $16 \mathrm{~A}$ & & IIIa & $30 \mathrm{P} 1-2$ & Biface Stage 2 & 1 \\
\hline $\mathrm{E} 24 / \mathrm{S} 74$ & $16 \mathrm{~A}$ & & IIIa & 30P1-1 & Biface Stage 2 & 1 \\
\hline E24/S74 & $16 \mathrm{~A}$ & & IIIa & & Debitage & 392 \\
\hline E24/S74 & $16 \mathrm{~A}$ & & IIIa & $30 \mathrm{P} 1-4$ & Uniface, unanalyzed & 1 \\
\hline E24/S74 & $16 \mathrm{~B}$ & & IIIa & $30 \mathrm{P} 2-1$ & Biface Stage 2 & \\
\hline $\mathrm{E} 24 / \mathrm{S} 74$ & $16 \mathrm{~B}$ & & IIIa & & Debitage & 509 \\
\hline
\end{tabular}




\begin{tabular}{|c|c|c|c|c|c|}
\hline Square & Level & Feature & Strata & Item & Analyst Identification \\
\hline $\mathrm{E} 24 / \mathrm{S} 74$ & $16 \mathrm{~B}$ & & IIIa & $30 \mathrm{P} 2-2$ & Micro-core, intermediate \\
\hline $\mathrm{E} 24 / \mathrm{S} 74$ & $17 \mathrm{~A}$ & & IIIa & $30 Q 1-2$ & Biface fragment \\
\hline E24/S74 & $17 \mathrm{~A}$ & & IIIa & $30 Q 1-3$ & Biface Stage 2 \\
\hline $\mathrm{E} 24 / \mathrm{S} 74$ & $17 \mathrm{~A}$ & & IIIa & & Debitage \\
\hline E24/S74 & $17 \mathrm{~A}$ & & IIIa & 30Q1-1 & Grooved stone \\
\hline E24/S74 & $17 \mathrm{~B}$ & & IIIa & $30 Q 2-2$ & Biface Stage 2 \\
\hline E24/S74 & 17B & & IIIa & $30 Q 2-3$ & Biface Stage 3 \\
\hline E24/S74 & $17 \mathrm{~B}$ & & IIIa & $30 Q 2-4$ & Burin spall \\
\hline E24/S74 & $17 \mathrm{~B}$ & & IIIa & $30 Q 2-1$ & Clear Fork biface \\
\hline E24/S74 & 17B & & IIIa & & Debitage \\
\hline E24/S74 & $17 \mathrm{~B}$ & & IIIa & $30 Q 2-5$ & Uniface, unanalyzed \\
\hline E24/S74 & $17 \mathrm{~B}$ & Feature 130 & IIIa & $30 Q 2-6$ & Chert cobble, unmodified/tested \\
\hline E24/S74 & $18 \mathrm{~A}$ & & IIIa & & Debitage \\
\hline E24/S74 & $18 \mathrm{~A}$ & & IIIa & 30R1-1 & Thin uniface \\
\hline $\mathrm{E} 24 / \mathrm{S} 74$ & $18 \mathrm{~A}$ & Feature 130 & IIIa & 30R $1-3$ & Uniface, unanalyzed \\
\hline E24/S74 & $18 \mathrm{~B}$ & & IIIa & $30 \mathrm{R} 2-8$ & Biface fragment \\
\hline $\mathrm{E} 24 / \mathrm{S} 74$ & $18 \mathrm{~B}$ & & IIIa & $30 \mathrm{R} 2-7$ & Biface Stage 1 \\
\hline E24/S74 & $18 \mathrm{~B}$ & & IIIa & $30 \mathrm{R} 2-2$ & Biface Stage 2 \\
\hline E24/S74 & $18 \mathrm{~B}$ & & IIIa & $30 \mathrm{R} 2-5$ & Bifacial tool Form J \\
\hline E24/S74 & $18 \mathrm{~B}$ & & IIIa & 30R2-3 & Burin \\
\hline $\mathrm{E} 24 / \mathrm{S} 74$ & $18 \mathrm{~B}$ & & IIIa & $30 \mathrm{R} 2-13$ & Burin \\
\hline $\mathrm{E} 24 / \mathrm{S} 74$ & $18 \mathrm{~B}$ & & IIIa & $30 \mathrm{R} 2-12$ & Core, thermal \\
\hline E24/S74 & $18 \mathrm{~B}$ & & IIIa & & Debitage \\
\hline $\mathrm{E} 24 / \mathrm{S} 74$ & $18 \mathrm{~B}$ & & IIIa & $30 \mathrm{R} 2-20$ & Large core hammerstone \\
\hline E24/S74 & $18 \mathrm{~B}$ & & IIIa & $30 \mathrm{R} 2-4$ & Micro-core, intermediate \\
\hline $\mathrm{E} 24 / \mathrm{S} 74$ & $18 \mathrm{~B}$ & & IIIa & $30 \mathrm{R} 2-6$ & Microspur/microdenticulate \\
\hline $\mathrm{E} 24 / \mathrm{S} 74$ & $18 \mathrm{~B}$ & & IIIa & $30 \mathrm{R} 2-22$ & Microspur/microdenticulate \\
\hline $\mathrm{E} 24 / \mathrm{S} 74$ & $18 \mathrm{~B}$ & & IIIa & 30R2-1 & Thick uniface \\
\hline $\mathrm{E} 24 / \mathrm{S} 74$ & $18 \mathrm{~B}$ & & IIIa & $30 \mathrm{R} 2-21$ & Thin uniface \\
\hline $\mathrm{E} 24 / \mathrm{S} 74$ & $18 \mathrm{~B}$ & & IIIa & $30 \mathrm{R} 2-17$ & Uniface, unanalyzed \\
\hline $\mathrm{E} 24 / \mathrm{S} 74$ & $18 \mathrm{~B}$ & & IIIa & $30 \mathrm{R} 2-10$ & Uniface, unanalyzed \\
\hline E24/S74 & $18 \mathrm{~B}$ & & IIIa & $30 R 2-9$ & Uniface, unanalyzed \\
\hline E24/S74 & $18 \mathrm{~B}$ & & IIIa & 30R2-11 & Uniface, unanalyzed \\
\hline E24/S74 & $18 \mathrm{~B}$ & & IIIa & $30 \mathrm{R} 2-15$ & Uniface, unanalyzed \\
\hline $\mathrm{E} 24 / \mathrm{S} 74$ & $18 \mathrm{~B}$ & & IIIa & $30 \mathrm{R} 2-19$ & Uniface, unanalyzed \\
\hline $\mathrm{E} 24 / \mathrm{S} 74$ & $18 \mathrm{~B}$ & & IIIa & $30 \mathrm{R} 2-16$ & Uniface, unanalyzed \\
\hline E24/S74 & $19 \mathrm{~A}$ & & IIIa & $30 \mathrm{~S} 1-1$ & Burin spall \\
\hline $\mathrm{E} 24 / \mathrm{S} 74$ & $19 \mathrm{~A}$ & & IIIa & & Debitage \\
\hline E24/S74 & $19 \mathrm{~A}$ & & IIIa & $30 \mathrm{~S} 1-6$ & Thin uniface fragment \\
\hline $\mathrm{E} 24 / \mathrm{S} 74$ & $19 \mathrm{~A}$ & & IIIa & 30 S1-5 & Uniface, unanalyzed \\
\hline $\mathrm{E} 24 / \mathrm{S} 74$ & $19 \mathrm{~A}$ & & IIIa & $30 \mathrm{~S} 1-3$ & Uniface, unanalyzed \\
\hline E24/S74 & $19 \mathrm{~A}$ & & IIIa & $30 \mathrm{~S} 1-4$ & Uniface, unanalyzed \\
\hline E24/S74 & $19 \mathrm{~A}$ & & IIIa & $30 \mathrm{~S} 1-2$ & Unifacial multiple tool \\
\hline $\mathrm{E} 24 / \mathrm{S} 74$ & $19 \mathrm{~A}$ & Feature 139 & IIIa & $30 S 1-7$ & Possible ground stone \\
\hline E24/S74 & $19 \mathrm{~B}$ & & IIIa & 30 S2D-6 & Burin spall \\
\hline $\mathrm{E} 24 / \mathrm{S} 74$ & $19 \mathrm{~B}$ & & IIIa & & Debitage \\
\hline $\mathrm{E} 24 / \mathrm{S} 74$ & $19 \mathrm{~B}$ & & IIIa & $30 \mathrm{~S} 2 \mathrm{~A}-2$ & Thin uniface \\
\hline E24/S74 & $19 \mathrm{~B}$ & & IIIa & $30 \mathrm{~S} 2 \mathrm{C}-5$ & Uniface, unanalyzed \\
\hline $\mathrm{E} 24 / \mathrm{S} 74$ & $19 \mathrm{~B}$ & & IIIa & $30 \mathrm{~S} 2 \mathrm{C}-3$ & Uniface, unanalyzed \\
\hline $\mathrm{E} 24 / \mathrm{S} 74$ & $19 \mathrm{~B}$ & & IIIa & $30 \mathrm{~S} 2 \mathrm{C}-4$ & Uniface, unanalyzed \\
\hline E24/S74 & $20 \mathrm{~A}$ & & II/IIIa & $30 \mathrm{~T} 1 \mathrm{C}-3$ & Clear Fork biface \\
\hline E24/S74 & $20 \mathrm{~A}$ & & II/IIIa & & Debitage \\
\hline E24/S74 & $20 \mathrm{~A}$ & & II/IIIa & $30 \mathrm{~T} 1 \mathrm{C}-1$ & Perforator Unifacial \\
\hline $\mathrm{E} 24 / \mathrm{S} 74$ & $20 \mathrm{~A}$ & & II/IIIa & 30T1D-5 & Projectile point, miscellaneous lanceolate \\
\hline $\mathrm{E} 24 / \mathrm{S} 74$ & $20 \mathrm{~A}$ & & II/IIIa & $30 \mathrm{~T} 1 \mathrm{C}-4$ & Thin uniface \\
\hline E24/S74 & $20 \mathrm{~A}$ & & II/IIIa & $30 \mathrm{~T} 1 \mathrm{C}-2$ & Thin uniface \\
\hline E24/S74 & $20 \mathrm{~B}$ & & II/IIIa & $30 \mathrm{~T} 2 \mathrm{D}-4$ & Core thermal \\
\hline $\mathrm{E} 24 / \mathrm{S} 74$ & $20 \mathrm{~B}$ & & II/IIIa & & Debitage \\
\hline $\mathrm{E} 24 / \mathrm{S} 74$ & $20 \mathrm{~B}$ & & II/IIIa & $30 \mathrm{~T} 2 \mathrm{~B}-2$ & Microspur/microdenticulate \\
\hline $\mathrm{E} 24 / \mathrm{S} 74$ & $20 \mathrm{~B}$ & & II/IIIa & $30 \mathrm{~T} 2 \mathrm{~A}-1$ & Notched flake \\
\hline E24/S74 & $20 \mathrm{~B}$ & & II/IIIa & $30 \mathrm{~T} 2 \mathrm{C}-3$ & Uniface, unanalyzed \\
\hline E24/S74 & $21 \mathrm{~A}$ & & II & 30 U1B-1 & Biface fragment \\
\hline $\mathrm{E} 24 / \mathrm{S} 74$ & $21 \mathrm{~A}$ & & II & & Debitage \\
\hline E24/S74 & $21 \mathrm{~A}$ & & II & 30U1B-2 & Thin uniface \\
\hline E24/S74 & $21 \mathrm{~A}$ & & II & $30 \mathrm{U} 1 \mathrm{C}-3$ & Uniface, unanalyzed \\
\hline $\mathrm{E} 24 / \mathrm{S} 74$ & $21 \mathrm{~A}$ & & II & $30 \mathrm{U} 1 \mathrm{C}-4$ & Uniface, unanalyzed \\
\hline E24/S74 & $21 \mathrm{~B}$ & & II & $30 \mathrm{U} 2 \mathrm{D}-3$ & Core, thermal \\
\hline $\mathrm{E} 24 / \mathrm{S} 74$ & $21 \mathrm{~B}$ & & II & & Debitage \\
\hline E24/S74 & $21 \mathrm{~B}$ & & II & $30 \mathrm{U} 2 \mathrm{C}-2$ & Edge modified flake \\
\hline E24/S74 & $21 \mathrm{~B}$ & & II & $30 \mathrm{U} 2 \mathrm{D}-4$ & Uniface, unanalyzed \\
\hline E24/S74 & $21 \mathrm{~B}$ & & II & $30 \mathrm{U} 2 \mathrm{~A}-1$ & Uniface, unanalyzed \\
\hline $\mathrm{E} 24 / \mathrm{S} 74$ & $21 \mathrm{~B}$ & Feature 150 & II & & Debitage \\
\hline E24/S74 & $22 \mathrm{~A}$ & & II & $30 \mathrm{~V} 1 \mathrm{D}-5$ & Biface Stage 1 \\
\hline E24/S74 & $22 \mathrm{~A}$ & & II & & Debitage \\
\hline
\end{tabular}

Count

366

626

1

638

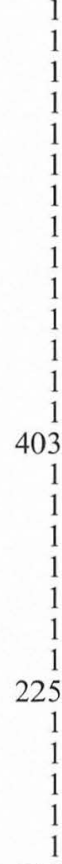

232

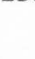

1

1

190

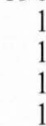

191

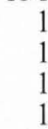

137

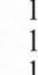

45

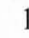

117 


\begin{tabular}{|c|c|c|c|c|c|c|}
\hline Square & Level & Feature & Strata & Item & Analyst Identification & Count \\
\hline $\mathrm{E} 24 / \mathrm{S} 74$ & $22 \mathrm{~A}$ & & II & 30V1D-4 & Thin uniface & \\
\hline $\mathrm{E} 24 / \mathrm{S} 74$ & $22 \mathrm{~A}$ & & II & $30 \mathrm{~V} 1 \mathrm{~B}-2$ & Uniface, unanalyzed & \\
\hline $\mathrm{E} 24 / \mathrm{S} 74$ & $22 \mathrm{~A}$ & & II & $30 \mathrm{~V} 1 \mathrm{C}-3$ & Uniface, unanalyzed & \\
\hline $\mathrm{E} 24 / \mathrm{S} 74$ & $22 \mathrm{~A}$ & & II & $30 \mathrm{~V} 1 \mathrm{D}-6$ & Uniface, unanalyzed & 00 \\
\hline $\mathrm{E} 24 / \mathrm{S} 74$ & $22 \mathrm{~B}$ & & II & & Debitage & 92 \\
\hline E24/S74 & 22B & & II & $30 \mathrm{~V} 2 \mathrm{C}-1$ & Notched flake & \\
\hline $\mathrm{E} 24 / \mathrm{S} 74$ & $22 \mathrm{~B}$ & & II & $30 \mathrm{~V} 2 \mathrm{D}-2$ & Projectile point, miscellaneous lanceolate & \\
\hline $\mathrm{E} 24 / \mathrm{S} 74$ & $23 \mathrm{~A}$ & & II & & Debitage & 87 \\
\hline $\mathrm{E} 24 / \mathrm{S} 74$ & $23 \mathrm{~B}$ & & II & & Debitage & 73 \\
\hline E24/S74 & $23 \mathrm{~B}$ & & II & $30 \mathrm{~W} 2 \mathrm{C}-1$ & Uniface, unanalyzed & \\
\hline $\mathrm{E} 24 / \mathrm{S} 74$ & $24 \mathrm{~A}$ & & II & & Debitage & 79 \\
\hline E24/S74 & $24 \mathrm{~A}$ & & II & $30 \times 1 D-3$ & Thin uniface fragment & \\
\hline E24/S74 & $24 \mathrm{~A}$ & & II & $30 \times 1 B-1$ & Uniface, unanalyzed & 1 \\
\hline E24/S74 & $24 \mathrm{~B}$ & & II & & Debitage & 106 \\
\hline E24/S74 & 24B & & II & $30 \times 2 B-1$ & Uniface, unanalyzed & 1 \\
\hline $\mathrm{E} 24 / \mathrm{S} 74$ & $25 \mathrm{~A}$ & & II & & Debitage & 99 \\
\hline E24/S74 & $25 \mathrm{~A}$ & & II & $30 Y 1 C-1$ & Thick uniface & \\
\hline E24/S74 & $25 \mathrm{~A}$ & & II & 30Y1D-2 & Thin uniface & \\
\hline E24/S74 & $25 \mathrm{~B}$ & & II & $30 \mathrm{Y} 2 \mathrm{C}-2$ & Biface Stage 2 & \\
\hline E24/S74 & $25 \mathrm{~B}$ & & II & & Debitage & 65 \\
\hline $\mathrm{E} 24 / \mathrm{S} 74$ & $25 \mathrm{~B}$ & & II & $30 Y 2 A-1$ & Thin uniface & 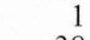 \\
\hline E24/S74 & $26 \mathrm{~A}$ & & II & & Debitage & 3 \\
\hline $\mathrm{E} 24 / \mathrm{S} 74$ & $26 \mathrm{~A}$ & & II & $30 \mathrm{Z} 1 \mathrm{D}-2$ & Uniface, unanalyzed & \\
\hline E24/S74 & $26 \mathrm{~A}$ & & II & $30 \mathrm{Z} 1 \mathrm{~A}-1$ & Unifacial multiple tool & 1 \\
\hline E24/S74 & $26 \mathrm{~B}$ & & II & & Debitage & 42 \\
\hline E24/S74 & $27 \mathrm{~A}$ & & II & & Debitage & 51 \\
\hline $\mathrm{E} 24 / \mathrm{S} 74$ & $27 \mathrm{~B}$ & & Isi-c/II & & Debitage & 4 \\
\hline E24/S74 & $27 \mathrm{~B}$ & & Isi-c/II & 30AA2B-1 & Uniface, unanalyzed & \\
\hline E24/S74 & $28 \mathrm{~A}$ & & Isi-c/II & & Debitage & 31 \\
\hline E24/S74 & $28 \mathrm{~B}$ & & Isi-c & $30 \mathrm{BB} 2 \mathrm{~A}-1$ & Core tool, type 2 & 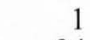 \\
\hline E24/S74 & $28 \mathrm{~B}$ & & Isi-c & & Debitage & 2 \\
\hline $\mathrm{E} 24 / \mathrm{S} 74$ & $28 \mathrm{~B}$ & & Isi-c & 30BB2D-2 & Uniface, unanalyzed & \\
\hline E24/S74 & $29 \mathrm{~A}$ & & Isi-c & & Debitage & 20 \\
\hline E24/S74 & $29 \mathrm{~A}$ & & Isi-c & $30 \mathrm{CC} 1 \mathrm{D}-1$ & Uniface, unanalyzed & 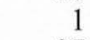 \\
\hline E24/S74 & $29 \mathrm{~B}$ & & Isi-c & & Debitage & 27 \\
\hline E24/S74 & $29 B$ & & Isi-c & $30 \mathrm{CC} 2 \mathrm{~A}-1$ & Projectile point, Wilson & \\
\hline E24/S74 & $29 B$ & & Isi-c & $30 \mathrm{CC} 2 \mathrm{D}-2$ & Thin uniface fragment & \\
\hline E24/S74 & $30 \mathrm{~A}$ & & Isi-c & & Debitage & 24 \\
\hline E24/S74 & $30 \mathrm{~A}$ & & Isi-c & 30DD1A-2 & Micro-core, large & 1 \\
\hline $\mathrm{E} 24 / \mathrm{S} 74$ & $30 \mathrm{~A}$ & & Isi-c & 30DD1A-1 & Uniface, unanalyzed & 1 \\
\hline E24/S74 & $30 \mathrm{~B}$ & & Isi-c & & Debitage & 16 \\
\hline E24/S74 & $30 \mathrm{~B}$ & & Isi-c & 30DD2B-1 & Uniface, unanalyzed & 1 \\
\hline E24/S74 & $31 \mathrm{~A}$ & & Isi-c & & Debitage & 23 \\
\hline E24/S74 & $31 \mathrm{~B}$ & & Icl/Isi-c & & Debitage & - \\
\hline E24/S74 & $32 \mathrm{~A}$ & & Icl/Isi-c & 30FF1D-1 & Core, thermal & \\
\hline E24/S74 & $32 \mathrm{~A}$ & & $\mathrm{Icl} / \mathrm{Isi}-\mathrm{c}$ & & Debitage & 12 \\
\hline E24/S74 & $32 \mathrm{~B}$ & & Ic1/Isi-c & & Debitage & 11 \\
\hline E24/S74 & $33 \mathrm{~A}$ & & Icl/Isi-c & & Debitage & 16 \\
\hline E24/S74 & $33 \mathrm{~B}$ & & Icl/Isi-c & & Debitage & 20 \\
\hline E24/S74 & $34 \mathrm{~A}$ & & Icl & & Debitage & 2 \\
\hline E24/S74 & $34 \mathrm{~B}$ & & Icl & $30 \mathrm{HH} 2 \mathrm{C}-1$ & Biface Stage 2 & 1 \\
\hline E24/S74 & $34 \mathrm{~B}$ & & Icl & & Debitage & 31 \\
\hline E24/S74 & $35 \mathrm{~A}$ & & Isi/Icl & & Debitage & 1 \\
\hline E24/S74 & $35 \mathrm{~B}$ & & Isi/Icl & & Debitage & 1 \\
\hline E24/S74 & $36 \mathrm{~A}$ & & $\mathrm{Isi} / \mathrm{Icl}$ & & Debitage & 2 \\
\hline E24/S74 & $36 \mathrm{~B}$ & & Isi/Icl & & Debitage & 18 \\
\hline $\mathrm{E} 24 / \mathrm{S} 74$ & $37 \mathrm{~A}$ & & Isi/Icl & & Debitage & 10 \\
\hline E24/S74 & $37 \mathrm{~B}$ & & Isi/Icl & & Debitage & \\
\hline E24/S74 & $38 \mathrm{~A}$ & & Isi/Icl & & Debitage & \\
\hline E24/S74 & $38 \mathrm{~A}$ & & $\mathrm{Isi} / \mathrm{Icl}$ & 30LL1C-1 & Thin uniface & \\
\hline E24/S74 & $38 \mathrm{~B}$ & & $\mathrm{Ig} / / \mathrm{Isi}$ & & Debitage & \\
\hline E24/S74 & $39 \mathrm{~A}$ & & Igl/Isi & & Debitage & \\
\hline $\mathrm{E} 24 / \mathrm{S} 74$ & Unknown & & & 30 & Unifacial multiple tool & \\
\hline $\mathrm{E} 24 / \mathrm{S} 76$ & 15 & & $\mathrm{III} \mathrm{a} / \mathrm{b}$ & $290-3$ & Biface Stage 2 & \\
\hline $\mathrm{E} 24 / \mathrm{S} 76$ & 15 & & $\mathrm{IIIa} / \mathrm{b}$ & $290-4$ & Biface Stage 2 & \\
\hline E24/S76 & 15 & & IIIa/b & $290-6$ & Burin spall & 1 \\
\hline E24/S76 & 15 & & $\mathrm{III} a / \mathrm{b}$ & $290-7$ & Burin spall & \\
\hline E24/S76 & 15 & & $\mathrm{IIIa} / \mathrm{b}$ & & Debitage & 94 \\
\hline E24/S76 & 15 & & IIIa/b & $290-11$ & Microspur/microdenticulate & \\
\hline E24/S76 & 15 & & $\mathrm{IIIa} / \mathrm{b}$ & $290-12$ & Microspur/microdenticulate & \\
\hline E24/S76 & 15 & & IIIa/b & $290-10$ & Perforator Group 1 & \\
\hline E24/S76 & 15 & & $\mathrm{III} a / b$ & $290-8$ & Projectile point, expanding stem D & \\
\hline E24/S76 & 15 & & $\mathrm{IIIa} / \mathrm{b}$ & $290-13$ & Projectile point, Jetta & \\
\hline E24/S76 & 15 & & $\mathrm{IIIa} / \mathrm{b}$ & $290-9$ & Projectile point, square stem & \\
\hline
\end{tabular}




\begin{tabular}{|c|c|c|c|c|c|c|}
\hline $\begin{array}{l}\text { Square } \\
\text { F24/S76 }\end{array}$ & $\begin{array}{l}\text { Level } \\
15\end{array}$ & Feature & Strata & Item & Analyst Identification & Count \\
\hline $\mathrm{E} 24 / \mathrm{S} 76$ & 15 & & III $/ \mathrm{b}$ & $\begin{array}{l}290-16 \\
290-14\end{array}$ & $\begin{array}{l}\text { Thin uniface fragment } \\
\text { Uniface, unanalyzed }\end{array}$ & 1 \\
\hline $\mathrm{E} 24 / \mathrm{S} 76$ & 15 & & $\mathrm{III} / \mathrm{b}$ & $290-15$ & Unifacial multiple tool & 1 \\
\hline $\mathrm{E} 24 / \mathrm{S} 76$ & 15 & & IIIa/b & $290-2$ & Unifacial multiple tool & 1 \\
\hline $\mathrm{E} 24 / \mathrm{S} 76$ & $16 \mathrm{~A}$ & & IIIa & & Debitage & 547 \\
\hline E24/S76 & $16 \mathrm{~A}$ & & IIIa & $29 \mathrm{P} 1-3$ & Perforator Group 7 & 1 \\
\hline E24/S76 & $16 \mathrm{~A}$ & & IIIa & $29 \mathrm{P} 1-4$ & Projectile point, Angostura & 1 \\
\hline $\mathrm{E} 24 / \mathrm{S} 76$ & $16 \mathrm{~A}$ & & IIIa & $29 \mathrm{P} 1-1$ & Projectile point, Hoxie & 1 \\
\hline $\mathrm{E} 24 / \mathrm{S} 76$ & $16 \mathrm{~A}$ & & IIIa & $29 \mathrm{P} 1-2$ & Projectile point, Hoxie & 1 \\
\hline E24/S 76 & $16 \mathrm{~B}$ & & IIIa & $29 \mathrm{P} 2-1$ & Bifacial tool & 1 \\
\hline E24/S76 & $16 \mathrm{~B}$ & & IIIa & & Debitage & 456 \\
\hline $\mathrm{E} 24 / \mathrm{S} 76$ & 16B & & IIIa & $29 \mathrm{P} 2-4$ & Edge modified flake & 1 \\
\hline E24/S76 & $16 \mathrm{~B}$ & & IIIa & $29 \mathrm{P} 2-5$ & Uniface, unanalyzed & 1 \\
\hline $\mathrm{E} 24 / \mathrm{S} 76$ & $17 \mathrm{~A}$ & & IIIa & 29Q1-6 & Biface Stage 2 & \\
\hline E24/S76 & $17 \mathrm{~A}$ & & IIIa & & Debitage & 665 \\
\hline $\mathrm{E} 24 / \mathrm{S} 76$ & $17 \mathrm{~A}$ & & IIIa & 29Q1-4 & Edge modified flake & 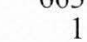 \\
\hline E24/S76 & $17 \mathrm{~A}$ & & IIIa & $2901-1$ & Small core hammerstone & 1 \\
\hline E24/S76 & $17 \mathrm{~A}$ & & IIIa & $29 \mathrm{Q} 1-5$ & Thin uniface & \\
\hline E24/S76 & $17 \mathrm{~A}$ & & IIIa & $2901-3$ & Uniface, unanalyzed & \\
\hline E24/S76 & $17 \mathrm{~A}$ & & IIIa & $29 Q 1-2$ & Unifacial multiple tool & \\
\hline E24/S76 & $17 \mathrm{~B}$ & & IIIa & $29 Q 2-4$ & Biface fragment & \\
\hline E24/S76 & 17B & & IIIa & $29 \mathrm{Q} 2-1$ & Biface fragment & \\
\hline E24/S76 & 17B & & IIIa & $29 \mathrm{Q} 2-2$ & Biface Stage 1 & \\
\hline E24/S76 & 17B & & IIIa & & Debitage & 461 \\
\hline E24/S76 & 17B & & IIIIa & 29Q2-7 & Microspur/microdenticulate & \\
\hline E24/S76 & $17 \mathrm{~B}$ & & IIIa & $29 Q 2-3$ & Projectile point fragment & 1 \\
\hline E24/S76 & 17B & & IIIa & $29 \mathrm{Q} 2-5$ & Uniface, unanalyzed & 1 \\
\hline E24/S76 & $17 \mathrm{~B}$ & & IIIa & $29 Q 2-6$ & Uniface, unanalyzed & 1 \\
\hline E24/S76 & 17B & & IIIa & $29 \mathrm{Q} 2-8$ & Uniface, unanalyzed & 1 \\
\hline $\mathrm{E} 24 / \mathrm{S} 76$ & $17 \mathrm{~B}$ & & IIIa & $29 Q 2-9$ & Uniface, unanalyzed & \\
\hline E24/S76 & $18 \mathrm{~A}$ & & IIIa & $29 \mathrm{R} 1-1$ & Core fragment & 1 \\
\hline E24/S76 & $18 \mathrm{~A}$ & & IIIa & & Debitage & 701 \\
\hline E24/S76 & $18 \mathrm{~A}$ & & IIIa & $29 \mathrm{R} 1-2$ & Microspur/microdenticulate & 1 \\
\hline $\mathrm{E} 24 / \mathrm{S} 76$ & $18 \mathrm{~A}$ & & IIIa & $29 \mathrm{R} 1-6$ & Thin uniface & 1 \\
\hline $\mathrm{E} 24 / \mathrm{S} 76$ & $18 \mathrm{~A}$ & & IIIIa & $29 \mathrm{R} 1-3$ & Uniface, unanalyzed & 1 \\
\hline E24/S76 & $18 \mathrm{~A}$ & & IIIa & $29 \mathrm{R} 1-4$ & Uniface, unanalyzed & 1 \\
\hline $\mathrm{E} 24 / \mathrm{S} 76$ & $18 \mathrm{~A}$ & Feature 124 & IIIa & $29 \mathrm{R} 1-7$ & Mano & 1 \\
\hline $\mathrm{E} 24 / \mathrm{S} 76$ & $18 \mathrm{~B}$ & & IIIa & $29 \mathrm{R} 2-1$ & Biface fragment & \\
\hline E24/S76 & $18 \mathrm{~B}$ & & IIIa & $29 \mathrm{R} 2-2$ & Biface fragment & 1 \\
\hline $\mathrm{E} 24 / \mathrm{S} 76$ & $18 \mathrm{~B}$ & & IIIa & $29 \mathrm{R} 2-3$ & Burin & 1 \\
\hline $\mathrm{E} 24 / \mathrm{S} 76$ & 18B & & IIIa & & Debitage & 718 \\
\hline $\mathrm{E} 24 / \mathrm{S} 76$ & $18 \mathrm{~B}$ & & IIIa & $29 \mathrm{R} 2-15$ & Edge modified flake & 1 \\
\hline $\mathrm{E} 24 / \mathrm{S} 76$ & $18 \mathrm{~B}$ & & IIIa & $29 \mathrm{R} 2-8$ & Edge modified flake & 1 \\
\hline $\mathrm{E} 24 / \mathrm{S} 76$ & $18 \mathrm{~B}$ & & IIIa & $29 \mathrm{R} 2-6$ & Projectile point, St. Mary’s Hall-atypic & 1 \\
\hline $\mathrm{E} 24 / \mathrm{S} 76$ & $18 \mathrm{~B}$ & & IIIa & $29 \mathrm{R} 2-4$ & Small core hammerstone & 1 \\
\hline $\mathrm{E} 24 / \mathrm{S} 76$ & $18 \mathrm{~B}$ & & IIIa & $29 R 2-13$ & Thin uniface & 1 \\
\hline $\mathrm{E} 24 / \mathrm{S} 76$ & 18B & & IIIa & $29 \mathrm{R} 2-7$ & Uniface, unanalyzed & 1 \\
\hline $\mathrm{E} 24 / \mathrm{S} 76$ & $18 \mathrm{~B}$ & & IIIa & $29 \mathrm{R} 2-14$ & Uniface, unanalyzed & 1 \\
\hline $\mathrm{E} 24 / \mathrm{S} 76$ & $18 \mathrm{~B}$ & & IIIa & $29 \mathrm{R} 2-9$ & Uniface, unanalyzed & 1 \\
\hline $\mathrm{E} 24 / \mathrm{S} 76$ & $19 \mathrm{~A}$ & & IIIa & & Debitage & 529 \\
\hline $\mathrm{E} 24 / \mathrm{S} 76$ & $19 \mathrm{~A}$ & & IIIa & 29S1-1 & Denticulated flake & 1 \\
\hline $\mathrm{E} 24 / \mathrm{S} 76$ & $19 \mathrm{~A}$ & & IIIa & $29 \mathrm{~S} 1-5$ & Projectile point, Hoxie B & 1 \\
\hline $\mathrm{E} 24 / \mathrm{S} 76$ & $19 \mathrm{~A}$ & & IIIa & $29 \mathrm{~S} 1-4$ & Projectile point, miscellaneous lanceolate & \\
\hline $\mathrm{E} 24 / \mathrm{S} 76$ & $19 \mathrm{~A}$ & & IIIa & 29S1-10 & Thick uniface & 1 \\
\hline $\mathrm{E} 24 / \mathrm{S} 76$ & $19 \mathrm{~A}$ & & IIIIa & $29 \mathrm{~S} 1-9$ & Uniface, unanalyzed & 1 \\
\hline $\mathrm{E} 24 / \mathrm{S} 76$ & $19 \mathrm{~A}$ & & IIIa & $29 \mathrm{~S} 1-6$ & Uniface, unanalyzed & 1 \\
\hline $\mathrm{E} 24 / \mathrm{S} 76$ & 19B & & II/IIIa & $29 \mathrm{~S} 2-11$ & Biface fragment & \\
\hline $\mathrm{E} 24 / \mathrm{S} 76$ & 19B & & II/IIIa & $29 \mathrm{~S} 2-1$ & Biface fragment & 1 \\
\hline $\mathrm{E} 24 / \mathrm{S} 76$ & $19 \mathrm{~B}$ & & II/IIIIa & $29 \mathrm{~S} 2 \mathrm{~A}-4$ & Biface fragment & 1 \\
\hline $\mathrm{E} 24 / \mathrm{S} 76$ & 19B & & II/IIIa & $29 \mathrm{~S} 2-3$ & Biface Stage 2 & 1 \\
\hline $\mathrm{E} 24 / \mathrm{S} 76$ & 19B & & II/IIIa & & Debitage & 298 \\
\hline $\mathrm{E} 24 / \mathrm{S} 76$ & 19B & & II/IIIa & $29 \mathrm{~S} 2-2$ & Edge modified flake & 1 \\
\hline E24/S76 & 19B & & II/IIIa & $29 \mathrm{~S} 2 \mathrm{~B}-7$ & Edge modified flake & 1 \\
\hline E24/S76 & 19B & & II/IIIa & $29 \mathrm{~S} 2 \mathrm{~A}-5$ & Projectile point fragment & \\
\hline E24/S76 & $19 \mathrm{~B}$ & & II/IIIa & 29S2D-10 & Projectile point, Clovis base & \\
\hline E24/S76 & 19B & & II/IIIa & $29 \mathrm{~S} 2 \mathrm{C}-9$ & Uniface, unanalyzed & \\
\hline E24/S76 & $19 \mathrm{~B}$ & & II/IIIIa & $29 \mathrm{~S} 2 \mathrm{C}-8$ & Uniface, unanalyzed & 1 \\
\hline E24/S76 & 19B & & II/IIIa & $29 \mathrm{~S} 2 \mathrm{~A}-6$ & Uniface, unanalyzed & \\
\hline E24/S76 & $20 \mathrm{~A}$ & & II/IIIa & $29 \mathrm{~T} 1 \mathrm{C}-4$ & Biface Stage 2 & 1 \\
\hline $\mathrm{E} 24 / \mathrm{S} 76$ & $20 \mathrm{~A}$ & & II/IIIa & & Debitage & 246 \\
\hline $\mathrm{E} 24 / \mathrm{S} 76$ & $20 \mathrm{~A}$ & & II/IIIa & $29 \mathrm{~T} 1 \mathrm{C}-1$ & Projectile point, Angostura & 1 \\
\hline $\mathrm{E} 24 / \mathrm{S} 76$ & $20 \mathrm{~A}$ & & II/IIIa & $29 \mathrm{~T} 1 \mathrm{D}-7$ & Uniface, unanalyzed & \\
\hline E24/S76 & $20 \mathrm{~B}$ & & II/IIIIa & 29T2B-4 & Biface fragment & 1 \\
\hline $\mathrm{E} 24 / \mathrm{S} 76$ & $20 \mathrm{~B}$ & & II/IIIa & & Debitage & 263 \\
\hline
\end{tabular}




\begin{tabular}{|c|c|c|c|c|c|}
\hline Square & Level & Feature & Strata & Item & Analyst Identification \\
\hline E24/S76 & $20 \mathrm{~B}$ & & II/IIIa & 29T2C-9 & Edge modified flake \\
\hline $\mathrm{E} 24 / \mathrm{S} 76$ & $20 \mathrm{~B}$ & & II/IIIa & 29T2A-2 & Projectile point fragment \\
\hline $\mathrm{E} 24 / \mathrm{S} 76$ & $20 \mathrm{~B}$ & & II/IIIa & $29 \mathrm{~T} 2 \mathrm{~A}-3$ & Thin uniface fragment \\
\hline $\mathrm{E} 24 / \mathrm{S} 76$ & $20 \mathrm{~B}$ & & II/IIIa & 29T2A-1 & Uniface, unanalyzed \\
\hline E24/S76 & $20 \mathrm{~B}$ & & II/IIIa & $29 \mathrm{~T} 2 \mathrm{D}-10$ & Unifacial multiple tool \\
\hline E24/S76 & $21 \mathrm{~A}$ & & II & 29 U1B-3 & Biface fragment \\
\hline $\mathrm{E} 24 / \mathrm{S} 76$ & $21 \mathrm{~A}$ & & II & $29 \mathrm{U} 1 \mathrm{C}-12$ & Brushy Creek biface \\
\hline $\mathrm{E} 24 / \mathrm{S} 76$ & $21 \mathrm{~A}$ & & II & 29U1C-8 & Core fragment \\
\hline $\mathrm{E} 24 / \mathrm{S} 76$ & $21 \mathrm{~A}$ & & II & & Debitage \\
\hline E24/S76 & $21 \mathrm{~A}$ & & II & 29U1D-13 & Edge modified flake \\
\hline $\mathrm{E} 24 / \mathrm{S} 76$ & $21 \mathrm{~A}$ & & II & 29U1A-2 & Notched flake \\
\hline E24/S76 & $21 \mathrm{~A}$ & & II & $29 \mathrm{U} 1 \mathrm{C}-7$ & Projectile point, miscellaneous lanceolate \\
\hline $\mathrm{E} 24 / \mathrm{S} 76$ & $21 \mathrm{~A}$ & & II & 29U1B-6 & Thin uniface \\
\hline E24/S76 & $21 \mathrm{~A}$ & & II & 29U1C-11 & Thin uniface \\
\hline E24/S76 & $21 \mathrm{~A}$ & & II & $29 \mathrm{U} 1 \mathrm{C}-10$ & Uniface, unanalyzed \\
\hline $\mathrm{E} 24 / \mathrm{S} 76$ & 21B & & II & 29U2A-2 & Biface Stage 2 \\
\hline $\mathrm{E} 24 / \mathrm{S} 76$ & $21 \mathrm{~B}$ & & II & & Debitage \\
\hline $\mathrm{E} 24 / \mathrm{S} 76$ & $22 \mathrm{~A}$ & & II & 29V1D-6 & Biface Stage 2 \\
\hline E24/S76 & $22 \mathrm{~A}$ & & II & 29V1A-1 & Burin spall \\
\hline $\mathrm{E} 24 / \mathrm{S} 76$ & $22 \mathrm{~A}$ & & II & & Debitage \\
\hline $\mathrm{E} 24 / \mathrm{S} 76$ & $22 \mathrm{~A}$ & Feature 155 & II & 29V1B-3 & Core fragment \\
\hline $\mathrm{E} 24 / \mathrm{S} 76$ & $22 \mathrm{~A}-\mathrm{B}$ & Feature 155 & II & & Debitage \\
\hline E24/S76 & $22 \mathrm{~B}$ & & II & & Debitage \\
\hline $\mathrm{E} 24 / \mathrm{S} 76$ & $22 \mathrm{~B}$ & & II & 29V2A-2 & Notched flake \\
\hline $\mathrm{E} 24 / \mathrm{S} 76$ & $22 \mathrm{~B}$ & & II & $29 \mathrm{~V} 2 \mathrm{~A}-3$ & Thin uniface \\
\hline $\mathrm{E} 24 / \mathrm{S} 76$ & $22 \mathrm{~B}$ & & II & $29 \mathrm{~V} 2 \mathrm{~B}-5$ & Uniface, unanalyzed \\
\hline E24/S76 & $22 \mathrm{~B}$ & Feature 155 & II & $29 \mathrm{~V} 2 \mathrm{~A}-4$ & Projectile point fragment \\
\hline $\mathrm{E} 24 / \mathrm{S} 76$ & $23 \mathrm{~A}$ & & II & & Debitage \\
\hline $\mathrm{E} 24 / \mathrm{S} 76$ & $23 \mathrm{~A}$ & & II & $29 \mathrm{~W} 1 \mathrm{C}-3$ & Notched flake \\
\hline $\mathrm{E} 24 / \mathrm{S} 76$ & $23 \mathrm{~A}$ & & II & $29 \mathrm{~W} 1 \mathrm{C}-2$ & Uniface, unanalyzed \\
\hline $\mathrm{E} 24 / \mathrm{S} 76$ & $23 \mathrm{~A}$ & & II & 29W1B-1 & Uniface, unanalyzed \\
\hline E24/S76 & $23 \mathrm{~B}$ & & II & & Debitage \\
\hline $\mathrm{E} 24 / \mathrm{S} 76$ & $23 \mathrm{~B}$ & & II & 29W2A-1 & Edge modified flake \\
\hline $\mathrm{E} 24 / \mathrm{S} 76$ & $24 \mathrm{~A}$ & & II & & Debitage \\
\hline $\mathrm{E} 24 / \mathrm{S} 76$ & $24 \mathrm{~A}$ & & II & 29X1A-2 & Projectile point fragment \\
\hline E24/S76 & $24 \mathrm{~A}$ & & II & $29 \times 1-1$ & Projectile point, Wilson \\
\hline E24/S76 & $24 B$ & & II & $29 \times 2 A-2$ & Biface fragment \\
\hline E24/S76 & $24 B$ & & II & $29 \times 2 A-1$ & Burin spall \\
\hline E24/S76 & $24 \mathrm{~B}$ & & II & & Debitage \\
\hline E24/S76 & $24 B$ & & II & $29 \times 2 C-7$ & Projectile point, Golondrina-Barber \\
\hline E24/S76 & $24 B$ & & II & $29 \times 2 A-3$ & Uniface, unanalyzed \\
\hline E24/S76 & $25 \mathrm{~A}$ & & II & & Debitage \\
\hline E24/S76 & $25 \mathrm{~A}$ & & II & 29Y1A-1 & Projectile point, San Patrice? \\
\hline E24/S76 & $25 \mathrm{~B}$ & & $\mathrm{Id} / \mathrm{II}$ & & Debitage \\
\hline $\mathrm{E} 24 / \mathrm{S} 76$ & $25 \mathrm{~B}$ & & $\mathrm{Id} / \mathrm{II}$ & 29Y2A-1 & Edge modified flake \\
\hline $\mathrm{E} 24 / \mathrm{S} 76$ & $26 \mathrm{~A}$ & & $\mathrm{Id} / \mathrm{II}$ & & Debitage \\
\hline $\mathrm{E} 24 / \mathrm{S} 76$ & $26 \mathrm{~A}$ & & $\mathrm{Id} / \mathrm{II}$ & 29Z1D-1 & Uniface, unanalyzed \\
\hline E24/S76 & $26 \mathrm{~B}$ & & Isi-c/Id/II & & Debitage \\
\hline $\mathrm{E} 24 / \mathrm{S} 76$ & $26 \mathrm{~B}$ & & Isi-c/Id/II & $29 \mathrm{Z} 2 \mathrm{C}-1$ & Uniface, unanalyzed \\
\hline $\mathrm{E} 24 / \mathrm{S} 76$ & $27 \mathrm{~A}$ & & Isi-c/Id/II & & Debitage \\
\hline $\mathrm{E} 24 / \mathrm{S} 76$ & $27 \mathrm{~A}$ & & Isi-c/Id/II & 29AA1B-3 & Uniface, unanalyzed \\
\hline $\mathrm{E} 24 / \mathrm{S} 76$ & 27B & & Isi-c/Id & & Debitage \\
\hline $\mathrm{E} 24 / \mathrm{S} 76$ & $27 \mathrm{~B}$ & & Isi-c/Id & 29AA2C-3 & Uniface, unanalyzed \\
\hline E24/S76 & $28 \mathrm{~A}$ & & Isi-c & & Debitage \\
\hline E24/S76 & $28 \mathrm{~A}$ & & Isi-c & 29BB1B-1 & Worked hematite \\
\hline $\mathrm{E} 24 / \mathrm{S} 76$ & $28 \mathrm{~B}$ & & Isi-c & & Debitage \\
\hline E24/S76 & $28 \mathrm{~B}$ & & Isi-c & 29BB2D-2 & Thin uniface fragment \\
\hline $\mathrm{E} 24 / \mathrm{S} 76$ & $29 \mathrm{~A}$ & & Isi-c & & Debitage \\
\hline $\mathrm{E} 24 / \mathrm{S} 76$ & $29 \mathrm{~A}$ & & Isi-c & $29 \mathrm{CC} 1 \mathrm{C}-2$ & Edge modified flake \\
\hline $\mathrm{E} 24 / \mathrm{S} 76$ & $29 \mathrm{~A}$ & & Isi-c & $29 \mathrm{CC} 1 \mathrm{~A}-3$ & Worked hematite \\
\hline $\mathrm{E} 24 / \mathrm{S} 76$ & 29B & & Isi-c & & Debitage \\
\hline E24/S76 & $29 B$ & & Isi-c & 29CC2B-3 & Uniface, unanalyzed \\
\hline $\mathrm{E} 24 / \mathrm{S} 76$ & $29 B$ & & Isi-c & $29 \mathrm{CC} 2 \mathrm{~A}-2$ & Uniface, unanalyzed \\
\hline $\mathrm{E} 24 / \mathrm{S} 76$ & $30 \mathrm{~A}$ & & Isi-c & 29DD1C-3 & Biface Stage 1 \\
\hline $\mathrm{E} 24 / \mathrm{S} 76$ & $30 \mathrm{~A}$ & & Isi-c & 29DD1C-4 & Core, thermal \\
\hline E24/S76 & $30 \mathrm{~A}$ & & Isi-c & & Debitage \\
\hline $\mathrm{E} 24 / \mathrm{S} 76$ & $30 \mathrm{~A}$ & & Isi-c & 29DD1B-1 & Thin uniface \\
\hline $\mathrm{E} 24 / \mathrm{S} 76$ & $30 \mathrm{~B}$ & & Isi-c & & Debitage \\
\hline E24/S76 & $31 \mathrm{~A}$ & & Isi-c & & Debitage \\
\hline $\mathrm{E} 24 / \mathrm{S} 76$ & $31 \mathrm{~A}$ & & Isi-c & 29EE1A-1 & Spurred flake \\
\hline E24/S76 & $31 \mathrm{~B}$ & & Isi-c & & Debitage \\
\hline $\mathrm{E} 24 / \mathrm{S} 76$ & $32 \mathrm{~A}$ & & $\mathrm{Icl} / \mathrm{Isi}-\mathrm{c}$ & 29FF1B-1 & Core fragment \\
\hline $\mathrm{E} 24 / \mathrm{S} 76$ & $32 \mathrm{~A}$ & & $\mathrm{Icl} / \mathrm{Isi}-\mathrm{c}$ & & Debitage \\
\hline E24/S76 & $32 \mathrm{~B}$ & & Icl/Isi-c & & Debitage \\
\hline
\end{tabular}

Count

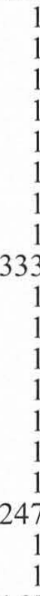

165 


\begin{tabular}{|c|c|c|c|c|c|c|}
\hline Square & Level & Feature & Strata & Item & Analyst Identification & $\begin{array}{r}\text { Count } \\
39\end{array}$ \\
\hline $\begin{array}{l}\text { E24/S76 } \\
\text { E24/S76 }\end{array}$ & $\begin{array}{l}33 \mathrm{~A} \\
33 \mathrm{~A}\end{array}$ & & $\begin{array}{l}\text { Icl/Isi-c } \\
\text { Jcl/Isi-c }\end{array}$ & $29 \mathrm{GG} 1 \mathrm{C}-2$ & Debitage & $\begin{array}{r}39 \\
1\end{array}$ \\
\hline E24/S76 & $33 \mathrm{~B}$ & & $\mathrm{Isi} / \mathrm{Icl} / \mathrm{Isi}-\mathrm{c}$ & $29001 \mathrm{C}-2$ & Debitage & 38 \\
\hline E24/S76 & $34 \mathrm{~A}$ & & Isi/Icl & & Debitage & 44 \\
\hline E24/S76 & $34 \mathrm{~B}$ & & Isi/Icl & & Debitage & 28 \\
\hline E24/S76 & $34 \mathrm{~B}$ & & Isi/Icl & 29HH2D-2 & Notched flake & 1 \\
\hline E24/S76 & $34 \mathrm{~B}$ & & Isi/Icl & $29 \mathrm{HH} 2 \mathrm{~A}-1$ & Thin uniface & 1 \\
\hline E24/S76 & $35 \mathrm{~A}$ & & Isi/Icl & & Debitage & 37 \\
\hline E24/S76 & $35 \mathrm{~B}$ & & Isi/Icl & 29II2C-2 & Biface fragment & \\
\hline E24/S76 & $35 \mathrm{~B}$ & & Isi/Icl & 29II2B-1 & Biface Stage 2 & 1 \\
\hline E24/S76 & $35 \mathrm{~B}$ & & Isi/Icl & & Debitage & 47 \\
\hline E24/S76 & $36 \mathrm{~A}$ & & Isi/Icl/D & 29JJ1D-1 & Biface Stage 3 & 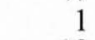 \\
\hline E24/S76 & $36 \mathrm{~A}$ & & Isi/Icl & & Debitage & 18 \\
\hline E24/S76 & $36 \mathrm{~A}$ & & Isi/Icl/D & & Debitage & 58 \\
\hline E24/S76 & $36 \mathrm{~A}$ & & Isi/Icl/D & 29JJ1C-4 & Edge modified flake & \\
\hline E24/S76 & $36 \mathrm{~A}$ & & Isi/Icl/D & 29JJ1C-3 & Edge modified flake & 1 \\
\hline E24/S76 & $36 \mathrm{~B}$ & & Isi/Icl & & Debitage & 16 \\
\hline E24/S76 & $36 \mathrm{~B}$ & & Isi/Icl/D & & Debitage & 18 \\
\hline E24/S76 & $37 \mathrm{~A}$ & & Isi/Icl & & Debitage & \\
\hline E24/S76 & $37 \mathrm{~A}$ & & Isi/Icl/D & & Debitage & 39 \\
\hline E24/S76 & $37 \mathrm{~B}$ & & Isi/Icl & & Debitage & 34 \\
\hline E24/S76 & $38 \mathrm{~A}$ & & Isi/Icl & & Debitage & 28 \\
\hline E24/S76 & $38 \mathrm{~A}$ & & Isi/Icl & 29LL1C-1 & Face battered stone & \\
\hline E24/S76 & $38 \mathrm{~B}$ & & Igl/Isi & & Debitage & 39 \\
\hline E24/S76 & $39 \mathrm{~A}$ & & Isi & & Debitage & 53 \\
\hline E24/S76 & $39 \mathrm{~B}$ & & $\mathrm{Ig} 1 / \mathrm{Isi}$ & & Debitage & 27 \\
\hline E24/S76 & $40 \mathrm{~A}$ & & Igl/Isi & & Debitage & 2 \\
\hline E24/S78 & 11 & & IIIIa/b & $28 \mathrm{~K}-1$ & Biface Stage 2 & 1 \\
\hline E24/S78 & 15 & & IIIa/b & $280-4$ & Biface Stage 2 & \\
\hline E24/S78 & 15 & & $\mathrm{IIIa} / \mathrm{b}$ & $280-5$ & Biface Stage 2 & 1 \\
\hline E24/S78 & 15 & & IIIa/b & & Debitage & 1060 \\
\hline E24/S78 & 15 & & IIIa/b & $280-9$ & Microspur/microdenticulate & 1 \\
\hline $\mathrm{E} 24 / \mathrm{S} 78$ & 15 & & $\mathrm{IIIa} / \mathrm{b}$ & $280-8$ & Projectile point fragment & 1 \\
\hline $\mathrm{E} 24 / \mathrm{S} 78$ & 15 & & $\mathrm{IIIa} / \mathrm{b}$ & $280-7$ & Projectile point, Gower & \\
\hline E24/S78 & 15 & & $\mathrm{IIIa} / \mathrm{b}$ & $280-2$ & Projectile point, Gower & 1 \\
\hline E24/S78 & 15 & & $\mathrm{III} / \mathrm{a}$ & $280-3$ & Projectile point, Gower & 1 \\
\hline E24/S78 & 15 & & $\mathrm{IIIa} / \mathrm{b}$ & $280-1$ & Projectile point, Wilson? & 1 \\
\hline E24/S78 & 15 & & $\mathrm{IIIa} / \mathrm{b}$ & $280-13$ & Uniface, unanalyzed & \\
\hline E24/S78 & 15 & & IIIa/b & $280-12$ & Uniface, unanalyzed & 1 \\
\hline $\mathrm{E} 24 / \mathrm{S} 78$ & 15 & & $\mathrm{IIIa} / \mathrm{b}$ & $280-14$ & Unifacial multiple tool & 1 \\
\hline E24/S78 & $16 \mathrm{~A}$ & & IIIa & 28P1-3 & Biface Stage 3 & 1 \\
\hline $\mathrm{E} 24 / \mathrm{S} 78$ & $16 \mathrm{~A}$ & & IIIa & $28 \mathrm{P} 1-2$ & Core fragment & a \\
\hline E24/S78 & $16 \mathrm{~A}$ & & IIIa & & Debitage & 808 \\
\hline E24/S78 & $16 \mathrm{~A}$ & & IIIa & $28 \mathrm{P} 1-5$ & Edge modified flake & \\
\hline E24/S78 & $16 \mathrm{~A}$ & & IIIa & 28P1-1 & Projectile point, rectangular stem A & 1 \\
\hline $\mathrm{E} 24 / \mathrm{S} 78$ & $16 \mathrm{~A}$ & & IIIa & 28P1-6 & Uniface, unanalyzed & 1 \\
\hline $\mathrm{E} 24 / \mathrm{S} 78$ & $16 \mathrm{~A}$ & & IIIa & 28P1-7 & Uniface, unanalyzed & $x$ \\
\hline $\mathrm{E} 24 / \mathrm{S} 78$ & $16 \mathrm{~A}$ & & IIIa & $28 \mathrm{P} 1-8$ & Uniface, unanalyzed & 1 \\
\hline E24/S78 & $16 \mathrm{~A}$ & & IIIa & 28P1-4 & Unifacial multiple tool & 1 \\
\hline E24/S78 & $16 \mathrm{~B}$ & & IIIIa & 28P2-2 & Biface fragment & 1 \\
\hline E24/S78 & $16 \mathrm{~B}$ & & IIIa & $28 \mathrm{P} 2-6$ & Bifacial tool Form C & 1 \\
\hline E24/S78 & $16 \mathrm{~B}$ & & IIIa & $28 \mathrm{P} 2-4$ & Burin spall & \\
\hline E24/S78 & $16 \mathrm{~B}$ & & IIIa & $28 \mathrm{P} 2-3$ & Clear Fork biface, proximal & \\
\hline E24/S78 & $16 \mathrm{~B}$ & & IIIa & & Debitage & 789 \\
\hline E24/S78 & $16 \mathrm{~B}$ & & IIIa & 28P2-5 & Micro-core, large & 1 \\
\hline E24/S78 & $16 \mathrm{~B}$ & & IIIa & 28P2-7 & Microspur/microdenticulate & \\
\hline $\mathrm{E} 24 / \mathrm{S} 78$ & $16 \mathrm{~B}$ & & IIIa & 28P2-8 & Perforator Unifacial & \\
\hline E24/S78 & $16 \mathrm{~B}$ & & IIIa & 28P2-1 & Projectile point fragment & \\
\hline E24/S78 & $17 \mathrm{~A}$ & & IIIa & & Debitage & 298 \\
\hline $\mathrm{E} 24 / \mathrm{S} 78$ & $17 \mathrm{~A}$ & & IIIa & 28Q1-1 & Uniface, unanalyzed & \\
\hline E24/S78 & 17B & & IIIa & $28 Q 2-4$ & Biface fragment & \\
\hline E24/S78 & 17B & & IIIa & 28Q2-3 & Burin spall & \\
\hline E24/S78 & $17 \mathrm{~B}$ & & IIIa & 28Q2-2 & Burin spall & \\
\hline E24/S78 & 17B & & IIIa & & Debitage & 623 \\
\hline E24/S78 & 17B & & IIIIa & 28Q2-8 & Microspur/microdenticulate & \\
\hline E24/S78 & 17B & & IIIa & 28Q2-10 & Perforator Unifacial & \\
\hline E24/S78 & 17B & & IIIa & $28 \mathrm{Q} 2-13$ & Spurred flake & \\
\hline $\mathrm{E} 24 / \mathrm{S} 78$ & 17B & & IIIa & 28Q2-11 & Thin uniface fragment & \\
\hline E24/S78 & $17 \mathrm{~B}$ & & IIIa & 28Q2-14 & Uniface, unanalyzed & 1 \\
\hline E24/S78 & 17B & & IIIa & 28Q2-15 & Uniface, unanalyzed & 1 \\
\hline $\mathrm{E} 24 / \mathrm{S} 78$ & $17 \mathrm{~B}$ & & IIIa & 28Q2-12 & Uniface, unanalyzed & \\
\hline $\mathrm{E} 24 / \mathrm{S} 78$ & 17B & & IIIa & 28Q2-6 & Uniface, unanalyzed & \\
\hline $\mathrm{E} 24 / \mathrm{S} 78$ & $17 \mathrm{~B}$ & & IIIa & $28 Q 2-9$ & Uniface, unanalyzed & \\
\hline E24/S78 & 17B & & IIIa & 28Q2-7 & Uniface, unanalyzed & \\
\hline
\end{tabular}




\begin{tabular}{|c|c|c|c|c|c|c|}
\hline Square & Level & Feature & Strata & Item & Analyst Identification & Count \\
\hline $\mathrm{E} 24 / \mathrm{S} 78$ & $17 \mathrm{~B}$ & & IIIa & $28 Q 2-5$ & Unifacial multiple tool & \\
\hline E24/S78 & $18 \mathrm{~A}$ & & IIIa & 28R1-1 & Biface fragment & \\
\hline $\mathrm{E} 24 / \mathrm{S} 78$ & $18 \mathrm{~A}$ & & IIIa & 28R1-6 & Biface Stage 1 & \\
\hline $\mathrm{E} 24 / \mathrm{S} 78$ & $18 \mathrm{~A}$ & & IIIa & 28R1-7 & Biface Stage 1 & \\
\hline $\mathrm{E} 24 / \mathrm{S} 78$ & $18 \mathrm{~A}$ & & IIIa & 28R1-2 & Bifacial tool Form F & \\
\hline $\mathrm{E} 24 / \mathrm{S} 78$ & $18 \mathrm{~A}$ & & IIIa & & Debitage & 428 \\
\hline E24/S78 & $18 \mathrm{~A}$ & & IIIa & 28R $1-4$ & Perforator Group 7 & \\
\hline $\mathrm{E} 24 / \mathrm{S} 78$ & $18 \mathrm{~A}$ & & IIIa & $28 \mathrm{R} 1-5$ & Perforator Group 7 & \\
\hline $\mathrm{E} 24 / \mathrm{S} 78$ & $18 \mathrm{~A}$ & & IIIa & $28 \mathrm{R} 1-3$ & Projectile point, miscellaneous lanceolate & \\
\hline $\mathrm{E} 24 / \mathrm{S} 78$ & $18 \mathrm{~A}$ & Feature 131 & IIIa & & Debitage & 2 \\
\hline E24/S78 & $18 \mathrm{~A}$ & Feature 131 & IIIa & 28R $1-10$ & Edge modified flake & \\
\hline $\mathrm{E} 24 / \mathrm{S} 78$ & $18 \mathrm{~A}$ & Feature 131 & IIIa & $28 \mathrm{R} 1-9$ & Uniface, unanalyzed & \\
\hline E24/S78 & $18 \mathrm{~B}$ & & IIIa & 28R2-3 & Biface fragment & \\
\hline E24/S78 & $18 \mathrm{~B}$ & & IIIa & 28R2-6 & Biface fragment & \\
\hline E24/S78 & $18 \mathrm{~B}$ & & IIIa & 28R2-7 & Biface Stage 1 & \\
\hline E24/S78 & $18 \mathrm{~B}$ & & IIIa & 28R2-8 & Biface Stage 2 & \\
\hline E24/S78 & $18 \mathrm{~B}$ & & IIIa & 28R2-1 & Biface Stage 3 & \\
\hline E24/S78 & $18 \mathrm{~B}$ & & IIIa & $28 R 2-2$ & Bifacial tool Form A & \\
\hline $\mathrm{E} 24 / \mathrm{S} 78$ & $18 \mathrm{~B}$ & & IIIa & $28 \mathrm{R} 2-5$ & Burin spall & \\
\hline E24/S78 & $18 \mathrm{~B}$ & & IIIa & & Debitage & 39 \\
\hline E24/S78 & $18 \mathrm{~B}$ & & IIIa & 28R2-4 & Microspur/microdenticulate & \\
\hline E24/S78 & $19 \mathrm{~A}$ & & II/IIIa & $28 \mathrm{~S} 1-3$ & Burin spall & \\
\hline E24/S78 & $19 \mathrm{~A}$ & & II/IIIa & $28 \mathrm{~S} 1-8$ & Core, multidirectional & \\
\hline $\mathrm{E} 24 / \mathrm{S} 78$ & $19 \mathrm{~A}$ & & II/IIIa & & Debitage & 412 \\
\hline E24/S78 & $19 \mathrm{~A}$ & & II/IIIa & $28 \mathrm{~S} 1-2$ & Notched flake & \\
\hline E24/S78 & $19 \mathrm{~A}$ & & II/IIIa & 28S1-1 & Projectile point, Hoxie B & \\
\hline E24/S78 & $19 \mathrm{~A}$ & & II/IIIa & $28 \mathrm{~S} 1-7$ & Thin uniface & \\
\hline E24/S78 & $19 \mathrm{~A}$ & & II/IIIa & $28 \mathrm{~S} 1-4$ & Uniface, unanalyzed & \\
\hline E24/S78 & $19 \mathrm{~A}$ & & $\mathrm{II} / \mathrm{IIIa}$ & $28 \mathrm{~S} 1-5$ & Uniface, unanalyzed & \\
\hline E24/S78 & $19 \mathrm{~A}$ & & II/IIIa & $28 \mathrm{~S} 1-6$ & Unifacial multiple tool & \\
\hline E24/S78 & 19B & & II/IIIa & $28 \mathrm{~S} 2 \mathrm{~A}-1$ & Biface Stage 1 & \\
\hline E24/S78 & $19 \mathrm{~B}$ & & II/IIIa & & Debitage & 216 \\
\hline E24/S78 & 19B & & II/IIIa & $28 \mathrm{~S} 2 \mathrm{C}-4$ & Notched flake & \\
\hline E24/S78 & $19 \mathrm{~B}$ & & II/IIIa & $28 \mathrm{~S} 2 \mathrm{C}-3$ & Thin uniface fragment & \\
\hline E24/S78 & 19B & & II/IIIa & 28S2D-6 & Uniface, unanalyzed & \\
\hline E24/S78 & $19 \mathrm{~B}$ & & II/IIIa & $28 \mathrm{~S} 2 \mathrm{~A}-2$ & Uniface, unanalyzed & \\
\hline E24/S78 & 19B & & II/IIIa & 28S2D-7 & Uniface, unanalyzed & \\
\hline E24/S78 & $19 \mathrm{~B}$ & & II/IIIa & $28 \mathrm{~S} 2 \mathrm{C}-5$ & Uniface, unanalyzed & \\
\hline E24/S78 & $20 \mathrm{~A}$ & & II & 28T1A-1 & Core tool, type 2 & \\
\hline $\mathrm{E} 24 / \mathrm{S} 78$ & $20 \mathrm{~A}$ & & II & & Debitage & 189 \\
\hline E24/S78 & $20 \mathrm{~A}$ & & II & 28T1C-5 & Uniface, unanalyzed & \\
\hline E24/S78 & $20 \mathrm{~A}$ & & II & $28 \mathrm{~T} 1 \mathrm{C}-4$ & Uniface, unanalyzed & \\
\hline $\mathrm{E} 24 / \mathrm{S} 78$ & $20 \mathrm{~A}$ & & II & 28T1A-2 & Uniface, unanalyzed & \\
\hline E24/S78 & $20 \mathrm{~B}$ & & II & & Debitage & 203 \\
\hline E24/S78 & $20 \mathrm{~B}$ & & II & 28T2B-4 & Edge modified flake & \\
\hline E24/S78 & $20 \mathrm{~B}$ & & II & 28T2D-7 & Microspur/microdenticulate & \\
\hline $\mathrm{E} 24 / \mathrm{S} 78$ & $20 \mathrm{~B}$ & & II & 28T2B-1 & Projectile point, Golondrina-Barber & \\
\hline E24/S78 & $20 \mathrm{~B}$ & & II & 28T2B-2 & Projectile point, miscellaneous lanceolate & \\
\hline E24/S78 & $20 \mathrm{~B}$ & & II & $28 \mathrm{~T} 2 \mathrm{~B}-6$ & Spurred flake & \\
\hline E24/S78 & $20 \mathrm{~B}$ & & II & 28T2B-5 & Uniface, unanalyzed & \\
\hline E24/S78 & $20 \mathrm{~B}$ & & II & 28T2B-3 & Uniface, unanalyzed & \\
\hline E24/S78 & $21 \mathrm{~A}$ & & II & 28U1C-2 & Bifacial tool Form C & \\
\hline E24/S78 & $21 \mathrm{~A}$ & & II & & Debitage & 163 \\
\hline $\mathrm{E} 24 / \mathrm{S} 78$ & $21 \mathrm{~A}$ & & II & 28U1D-3 & Uniface, unanalyzed & \\
\hline $\mathrm{E} 24 / \mathrm{S} 78$ & $21 \mathrm{~A}$ & & II & 28U1D-4 & Uniface, unanalyzed & \\
\hline $\mathrm{E} 24 / \mathrm{S} 78$ & $21 \mathrm{~B}$ & & II & 28U2-1 & Core fragment & \\
\hline E24/S78 & $21 \mathrm{~B}$ & & II & & Debitage & 85 \\
\hline E24/S78 & 21B & & II & 28U2B-3 & Thick uniface & \\
\hline E24/S78 & $21 \mathrm{~B}$ & & II & $28 \mathrm{U} 2 \mathrm{~A}-2$ & Uniface, unanalyzed & \\
\hline $\mathrm{E} 24 / \mathrm{S} 78$ & $22 \mathrm{~A}$ & & II & 28V1B-2 & Biface fragment & \\
\hline $\mathrm{E} 24 / \mathrm{S} 78$ & $22 \mathrm{~A}$ & & II & 28VID-3 & Biface fragment & \\
\hline E24/S78 & $22 \mathrm{~A}$ & & II & 28V1D-3 & Biface fragment & \\
\hline $\mathrm{E} 24 / \mathrm{S} 78$ & $22 \mathrm{~A}$ & & II & & Debitage & 112 \\
\hline E24/S78 & $22 \mathrm{~A}$ & & II & 28V1A-1 & Uniface, unanalyzed & \\
\hline $\mathrm{E} 24 / \mathrm{S} 78$ & $22 \mathrm{~B}$ & & II & $28 \mathrm{~V} 2 \mathrm{~A}-1$ & Biface fragment & \\
\hline E24/S78 & $22 \mathrm{~B}$ & & II & $28 \mathrm{~V} 2 \mathrm{~A}-2$ & Clear Fork biface, proximal & \\
\hline E24/S78 & $22 \mathrm{~B}$ & & II & & Debitage & 9 \\
\hline E24/S78 & $22 \mathrm{~B}$ & & II & $28 \mathrm{~V} 2 \mathrm{C}-4$ & Thin uniface & \\
\hline $\mathrm{E} 24 / \mathrm{S} 78$ & $22 \mathrm{~B}$ & & II & $28 \mathrm{~V} 2 \mathrm{~A}-3$ & Thin uniface fragment & \\
\hline $\mathrm{E} 24 / \mathrm{S} 78$ & $22 \mathrm{~B}$ & & II & $28 \mathrm{~V} 2 \mathrm{D}-5$ & Uniface, unanalyzed & \\
\hline E24/S78 & $23 \mathrm{~A}$ & & II & $28 \mathrm{~W} 1 \mathrm{~A}-2$ & Biface fragment & \\
\hline E24/S78 & $23 \mathrm{~A}$ & & II & & Debitage & 102 \\
\hline $\mathrm{E} 24 / \mathrm{S} 78$ & $23 \mathrm{~A}$ & & II & 28W1B-4 & Microspur/microdenticulate & \\
\hline $\mathrm{E} 24 / \mathrm{S} 78$ & $23 \mathrm{~A}$ & & II & 28W1B-3 & Perforator Group 7 & \\
\hline
\end{tabular}




\begin{tabular}{|c|c|c|c|c|c|c|}
\hline $\begin{array}{l}\text { Square } \\
\text { E24/S78 }\end{array}$ & $\begin{array}{l}\text { Level } \\
23 \mathrm{~A}\end{array}$ & Feature & $\begin{array}{l}\text { Strata } \\
\text { II }\end{array}$ & $\begin{array}{l}\text { Item } \\
28 \mathrm{~W} 1-1\end{array}$ & $\begin{array}{l}\text { Analyst Identification } \\
\text { Projectile point, Wilson?-Atypic }\end{array}$ & Count \\
\hline $\mathrm{E} 24 / \mathrm{S} 78$ & $23 \mathrm{~B}$ & & II & & Debitage & 222 \\
\hline $\mathrm{E} 24 / \mathrm{S} 78$ & $23 \mathrm{~B}$ & & II & $28 \mathrm{~W} 2 \mathrm{C}-1$ & Projectile point, St. Mary's Hall & 1 \\
\hline E24/S78 & $23 \mathrm{~B}$ & & II & $28 \mathrm{~W} 2 \mathrm{~B}-6$ & Uniface, unanalyzed & 1 \\
\hline $\mathrm{E} 24 / \mathrm{S} 78$ & $23 \mathrm{~B}$ & & II & $28 \mathrm{~W} 2 \mathrm{~A}-4$ & Uniface, unanalyzed & \\
\hline $\mathrm{E} 24 / \mathrm{S} 78$ & 23B & & II & $28 \mathrm{~W} 2 \mathrm{~A}-3$ & Unifacial multiple tool & \\
\hline E24/S78 & $24 \mathrm{~A}$ & & $\mathrm{Id} / \mathrm{II}$ & $28 \times 1 \mathrm{~A}-1$ & Core tool, type 5 & 1 \\
\hline $\mathrm{E} 24 / \mathrm{S} 78$ & $24 \mathrm{~A}$ & & $\mathrm{Id} / \mathrm{II}$ & & Debitage & 282 \\
\hline E24/S78 & $24 \mathrm{~A}$ & & $\mathrm{Id} / \mathrm{II}$ & $28 \times 1 C-3$ & Edge modified flake & \\
\hline $\mathrm{E} 24 / \mathrm{S} 78$ & $24 \mathrm{~A}$ & & $\mathrm{Id} / \mathrm{II}$ & $28 \times 1 C-4$ & Projectile point, parallel side (potlid) & \\
\hline $\mathrm{E} 24 / \mathrm{S} 78$ & $24 \mathrm{~A}$ & & $\mathrm{Id} / \mathrm{II}$ & $28 \mathrm{X} 1 \mathrm{C}-2$ & Uniface, unanalyzed & \\
\hline E24/S78 & $24 \mathrm{~A}$ & Feature 161 & $\mathrm{Id} / \mathrm{II}$ & & Debitage & 37 \\
\hline E24/S78 & 24B & & $\mathrm{Id} / \mathrm{II}$ & $28 \times 2 A-1$ & Burin spall & . \\
\hline E24/S78 & 24B & & $\mathrm{Id} / \mathrm{II}$ & & Debitage & 149 \\
\hline $\mathrm{E} 24 / \mathrm{S} 78$ & 24B & & $\mathrm{Id} / \mathrm{II}$ & $28 \times 2 A-2$ & Projectile point fragment & \\
\hline E24/S78 & $25 \mathrm{~A}$ & & $\mathrm{Id} / \mathrm{II}$ & & Debitage & 97 \\
\hline E24/S78 & $25 \mathrm{~A}$ & & $\mathrm{Id} / \mathrm{II}$ & 28Y1D-1 & Uniface, unanalyzed & 1 \\
\hline $\mathrm{E} 24 / \mathrm{S} 78$ & $25 \mathrm{~B}$ & & $\mathrm{Id} / \mathrm{II}$ & & Debitage & 79 \\
\hline E24/S78 & $25 \mathrm{~B}$ & & $\mathrm{Id} / \mathrm{II}$ & $28 \mathrm{Y} 2 \mathrm{C}-1$ & Projectile point, Wilson & \\
\hline $\mathrm{E} 24 / \mathrm{S} 78$ & $25 \mathrm{~B}$ & & $\mathrm{Id} / \mathrm{II}$ & $28 \mathrm{Y} 2 \mathrm{D}-2$ & Projectile point, Wilson & \\
\hline E24/S78 & $26 \mathrm{~A}$ & & Isi-c/Id/II & $28 \mathrm{Z} 1 \mathrm{~A}-1$ & Biface Stage 2 & \\
\hline $\mathrm{E} 24 / \mathrm{S} 78$ & $26 \mathrm{~A}$ & & Isi-c/Id/II & & Debitage & 42 \\
\hline $\mathrm{E} 24 / \mathrm{S} 78$ & $26 \mathrm{~B}$ & & Isi-c/Id & & Debitage & 49 \\
\hline $\mathrm{E} 24 / \mathrm{S} 78$ & $27 \mathrm{~A}$ & & Isi-c/Id & & Debitage & 39 \\
\hline E24/S78 & $27 \mathrm{~A}$ & & Isi-c/Id & 28AA1D-1 & Uniface, unanalyzed & 1 \\
\hline $\mathrm{E} 24 / \mathrm{S} 78$ & $27 \mathrm{~B}$ & & Isi-c/Id & 28AA2D-1 & Core, thermal & \\
\hline $\mathrm{E} 24 / \mathrm{S} 78$ & $27 \mathrm{~B}$ & & Isi-c/Id & & Debitage & 31 \\
\hline E24/S78 & $28 \mathrm{~A}$ & & Isi-c/Id & & Debitage & 41 \\
\hline $\mathrm{E} 24 / \mathrm{S} 78$ & $28 \mathrm{~A}$ & & Isi-c/Id & 28BB1B-1 & Thin uniface & 1 \\
\hline $\mathrm{E} 24 / \mathrm{S} 78$ & $28 \mathrm{~B}$ & & Isi-c & & Debitage & 31 \\
\hline $\mathrm{E} 24 / \mathrm{S} 78$ & $28 \mathrm{~B}$ & & Isi-c & 28BB2A-1 & Large core hammerstone & \\
\hline $\mathrm{E} 24 / \mathrm{S} 78$ & $28 \mathrm{~B}$ & & Isi-c & 28BB2D-2 & Thin uniface & \\
\hline E24/S78 & $29 \mathrm{~A}$ & & Isi-c & & Debitage & 43 \\
\hline $\mathrm{E} 24 / \mathrm{S} 78$ & $29 \mathrm{~B}$ & & Isi-c & $28 \mathrm{CC} 2 \mathrm{C}-1$ & Biface fragment & 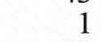 \\
\hline $\mathrm{E} 24 / \mathrm{S} 78$ & $29 \mathrm{~B}$ & & Isi-c & & Debitage & 31 \\
\hline $\mathrm{E} 24 / \mathrm{S} 78$ & $30 \mathrm{~A}$ & & Isi/Isi-c & & Debitage & 28 \\
\hline $\mathrm{E} 24 / \mathrm{S} 78$ & $30 \mathrm{~B}$ & & Isi/Isi-c & 28DD2D-2 & Biface Stage 2 & \\
\hline $\mathrm{E} 24 / \mathrm{S} 78$ & $30 \mathrm{~B}$ & & Isi/Isi-c & 28DD2D-1 & Core, thermal & \\
\hline E24/S78 & $30 \mathrm{~B}$ & & Isi/Isi-c & & Debitage & 37 \\
\hline $\mathrm{E} 24 / \mathrm{S} 78$ & $31 \mathrm{~A}$ & & Isi/Isi-c & & Debitage & 31 \\
\hline $\mathrm{E} 24 / \mathrm{S} 78$ & $31 \mathrm{~B}$ & & Isi/Isi-c & & Debitage & 47 \\
\hline $\mathrm{E} 24 / \mathrm{S} 78$ & $31 \mathrm{~B}$ & & Isi/Isi-c & 28EE2D-2 & Edge modified flake & \\
\hline $\mathrm{E} 24 / \mathrm{S} 78$ & $31 \mathrm{~B}$ & & Isi/Isi-c & 28EE2B-1 & Uniface, unanalyzed & \\
\hline $\mathrm{E} 24 / \mathrm{S} 78$ & $32 \mathrm{~A}$ & & $\mathrm{Isi} / \mathrm{Icl} / \mathrm{Isi}-\mathrm{c}$ & $28 \mathrm{FF} 1 \mathrm{~B}-1$ & Core, thermal & \\
\hline $\mathrm{E} 24 / \mathrm{S} 78$ & $32 \mathrm{~A}$ & & $\mathrm{Isi} / \mathrm{Icl} / \mathrm{Isi}-\mathrm{c}$ & & Debitage & 37 \\
\hline E24/S78 & $32 \mathrm{~B}$ & & $\mathrm{Isi} / \mathrm{Icl} / \mathrm{Isi}-\mathrm{c}$ & & Debitage & 35 \\
\hline $\mathrm{E} 24 / \mathrm{S} 78$ & $32 \mathrm{~B}$ & & Isi/Icl/Isi-c & $28 \mathrm{FF} 2 \mathrm{~A}-1$ & Thin uniface & \\
\hline $\mathrm{E} 24 / \mathrm{S} 78$ & $32 \mathrm{~B}$ & Feature 171 & $\mathrm{Isi} / \mathrm{Icl} / \mathrm{Isi}-\mathrm{c}$ & $28 \mathrm{FF} 2 \mathrm{~A}-2$ & Biface Stage 2 & 1 \\
\hline $\mathrm{E} 24 / \mathrm{S} 78$ & $33 \mathrm{~A}$ & & $\mathrm{Isi} / \mathrm{Icl} / \mathrm{Isi}-\mathrm{c}$ & & Debitage & 35 \\
\hline E24/S78 & 33B & & $\mathrm{Isi} / / \mathrm{cl}$ & 28GG2A-1 & Biface Stage 1 & \\
\hline E24/S78 & $33 \mathrm{~B}$ & & $\mathrm{Isi} / \mathrm{Icl}$ & $28 \mathrm{GG} 2 \mathrm{C}-2$ & Biface Stage 2 & \\
\hline E24/S78 & 33B & & $\mathrm{Isi} / \mathrm{Icl}$ & & Debitage & 4 \\
\hline E24/S78 & $33 \mathrm{~B}$ & & $\mathrm{Isi} / \mathrm{Icl}$ & $28 \mathrm{GG} 2 \mathrm{~B}-3$ & Uniface, unanalyzed & \\
\hline E24/S78 & $34 \mathrm{~A}$ & & Isi//Icl & & Debitage & 6 \\
\hline $\mathrm{E} 24 / \mathrm{S} 78$ & $34 \mathrm{~A}$ & & $\mathrm{Isi} / \mathrm{Icl}$ & 28HH1B-1 & Uniface, unanalyzed & \\
\hline E24/S78 & $34 \mathrm{~B}$ & & $\mathrm{Isi} / / \mathrm{Icl}$ & & Debitage & 43 \\
\hline $\mathrm{E} 24 / \mathrm{S} 78$ & $34 \mathrm{~B}$ & & $\mathrm{Isi} / \mathrm{Icl}$ & $28 \mathrm{HH} 2 \mathrm{~B}-1$ & Edge modified flake & \\
\hline $\mathrm{E} 24 / \mathrm{S} 78$ & $35 \mathrm{~A}$ & & $\mathrm{Isi} / \mathrm{Icl}$ & & Debitage & 74 \\
\hline $\mathrm{E} 24 / \mathrm{S} 78$ & $35 \mathrm{~A}$ & & Isi/Icl & 28II1B-1 & Thin uniface & \\
\hline E24/S78 & $35 \mathrm{~B}$ & & Isi//Icl & & Debitage & 3 \\
\hline $\mathrm{E} 24 / \mathrm{S} 78$ & $36 \mathrm{~A}$ & & Isi & & Debitage & \\
\hline $\mathrm{E} 24 / \mathrm{S} 78$ & $36 \mathrm{~A}$ & & Isi/D & & Debitage & 24 \\
\hline $\mathrm{E} 24 / \mathrm{S} 78$ & $36 \mathrm{~A}$ & & Isi/D & $28 \mathrm{JJ} 1 \mathrm{~B}-1$ & Unifacial multiple tool & \\
\hline E24/S78 & $36 \mathrm{~B}$ & & Isi & & Debitage & \\
\hline $\mathrm{E} 24 / \mathrm{S} 78$ & $36 \mathrm{~B}$ & & Isi/D & & Debitage & \\
\hline E24/S78 & $37 \mathrm{~A}$ & & Isi & & Debitage & \\
\hline $\mathrm{E} 24 / \mathrm{S} 78$ & $37 \mathrm{~A}$ & & Isi/D & & Debitage & \\
\hline E24/S78 & $37 \mathrm{~A}$ & & Isi & $28 \mathrm{KK} 1 \mathrm{~B}-2$ & Uniface, unanalyzed & \\
\hline $\mathrm{E} 24 / \mathrm{S} 78$ & $37 \mathrm{~B}$ & & Isi & & Debitage & 0 \\
\hline E24/S78 & $38 \mathrm{~A}$ & & Isi & & Debitage & \\
\hline $\mathrm{E} 24 / \mathrm{S} 78$ & $38 \mathrm{~A}$ & & Isi & 28LL1A-2 & Edge modified flake & \\
\hline E24/S78 & $38 \mathrm{~A}$ & & Isi & 28LL1A-1 & Micro-core, large & \\
\hline $\mathrm{E} 24 / \mathrm{S} 78$ & $38 \mathrm{~B}$ & & Isi & & Debitage & \\
\hline E24/S78 & $39 \mathrm{~A}$ & & Isi & & Debitage & \\
\hline
\end{tabular}




\begin{tabular}{|c|c|c|c|c|c|c|}
\hline Square & Level & Feature & Strata & Item & Analyst Identification & Count \\
\hline E26/S72 & Surface & & & $35-1$ & Mano & \\
\hline $\mathrm{E} 26 / \mathrm{S} 72$ & 11 & & III & $35 \mathrm{~K}$ & Projectile point, Nolan & 1 \\
\hline $\mathrm{E} 26 / \mathrm{S} 72$ & $16 \mathrm{~A}$ & & IIIa & $35 \mathrm{P} 1-1$ & Biface fragment & 1 \\
\hline $\mathrm{E} 26 / \mathrm{S} 72$ & $16 \mathrm{~A}$ & & IIIa & & Debitage & 247 \\
\hline $\mathrm{E} 26 / \mathrm{S} 72$ & $16 \mathrm{~A}$ & & IIIa & $35 \mathrm{P} 1-2$ & Edge modified flake & \\
\hline $\mathrm{E} 26 / \mathrm{S} 72$ & $17 \mathrm{~A}$ & & IIIa & $35 \mathrm{Q} 1-3$ & Biface fragment & 1 \\
\hline $\mathrm{E} 26 / \mathrm{S} 72$ & $17 \mathrm{~A}$ & & IIIa & $35 \mathrm{Q} 1-4$ & Biface fragment & \\
\hline $\mathrm{E} 26 / \mathrm{S} 72$ & $17 \mathrm{~A}$ & & IIIa & 35Q1-1 & Biface Stage 2 & \\
\hline $\mathrm{E} 26 / \mathrm{S} 72$ & $17 \mathrm{~A}$ & & IIIa & & Debitage & 401 \\
\hline $\mathrm{E} 26 / \mathrm{S} 72$ & $17 \mathrm{~A}$ & & IIIa & $35 \mathrm{Q} 1-8$ & Denticulated flake & \\
\hline $\mathrm{E} 26 / \mathrm{S} 72$ & $17 \mathrm{~A}$ & & IIIa & 35Q1-10 & Edge modified flake & \\
\hline $\mathrm{E} 26 / \mathrm{S} 72$ & $17 \mathrm{~A}$ & & IIIa & $35 Q 1-9$ & Notched flake & \\
\hline $\mathrm{E} 26 / \mathrm{S} 72$ & $17 \mathrm{~A}$ & & IIIa & $35 Q 1-2$ & Perforator Group 2 & \\
\hline $\mathrm{E} 26 / \mathrm{S} 72$ & $17 \mathrm{~A}$ & & IIIa & $35 \mathrm{Q} 1-7$ & Thin uniface fragment & \\
\hline E26/S72 & $17 \mathrm{~A}$ & & IIIa & $35 Q 1-5$ & Uniface, unanalyzed & \\
\hline $\mathrm{E} 26 / \mathrm{S} 72$ & $17 \mathrm{~A}$ & & IIIa & $35 \mathrm{Q} 1-6$ & Uniface, unanalyzed & \\
\hline $\mathrm{E} 26 / \mathrm{S} 72$ & 17B & & IIIa & $35 Q 2-3$ & Biface fragment & \\
\hline $\mathrm{E} 26 / \mathrm{S} 72$ & $17 \mathrm{~B}$ & & IIIIa & 35Q2-1 & Biface Stage 1 & \\
\hline $\mathrm{E} 26 / \mathrm{S} 72$ & $17 \mathrm{~B}$ & & IIIa & $35 Q 2-4$ & Burin spall & \\
\hline $\mathrm{E} 26 / \mathrm{S} 72$ & $17 \mathrm{~B}$ & & IIIa & & Debitage & 671 \\
\hline E26/S72 & $17 \mathrm{~B}$ & & IIIa & 35Q2-2 & Perforator Unifacial & \\
\hline E26/S72 & $17 \mathrm{~B}$ & & IIIa & $35 Q 2-6$ & Thin uniface & \\
\hline E26/S72 & $17 \mathrm{~B}$ & & IIIa & $35 Q^{2}-5$ & Uniface, unanalyzed & \\
\hline E26/S72 & $18 \mathrm{~A}$ & & IIIa & $35 \mathrm{R} 1-7$ & Bifacial tool Form A & \\
\hline E26/S72 & $18 \mathrm{~A}$ & & IIIa & $35 \mathrm{R} 1-2$ & Core fragment & \\
\hline $\mathrm{E} 26 / \mathrm{S} 72$ & $18 \mathrm{~A}$ & & IIIa & $35 \mathrm{R} 1-3$ & Core fragment & \\
\hline E26/S72 & $18 \mathrm{~A}$ & & IIIa & $35 \mathrm{R} 1-5$ & Core, thermal & \\
\hline $\mathrm{E} 26 / \mathrm{S} 72$ & $18 \mathrm{~A}$ & & IIIa & & Debitage & 606 \\
\hline $\mathrm{E} 26 / \mathrm{S} 72$ & $18 \mathrm{~A}$ & & IIIa & $35 \mathrm{R} 1-9$ & Denticulated flake & \\
\hline $\mathrm{E} 26 / \mathrm{S} 72$ & $18 \mathrm{~A}$ & & IIIa & 35R1-1 & Small core hammerstone & \\
\hline $\mathrm{E} 26 / \mathrm{S} 72$ & $18 \mathrm{~A}$ & & IIIa & $35 \mathrm{R} 1-10$ & Uniface, unanalyzed & \\
\hline $\mathrm{E} 26 / \mathrm{S} 72$ & $18 \mathrm{~A}$ & & IIIa & $35 \mathrm{R} 1-6$ & Uniface, unanalyzed & \\
\hline $\mathrm{E} 26 / \mathrm{S} 72$ & $18 \mathrm{~A}$ & & IIIa & $35 \mathrm{R} 1-8$ & Uniface, unanalyzed & \\
\hline $\mathrm{E} 26 / \mathrm{S} 72$ & $18 \mathrm{~A}$ & Feature 133 & IIIa & 35R1-13 & Unifacial multiple tool & \\
\hline $\mathrm{E} 26 / \mathrm{S} 72$ & $18 \mathrm{~B}$ & & IIIa & $35 \mathrm{R} 2-1$ & Biface fragment & \\
\hline $\mathrm{E} 26 / \mathrm{S} 72$ & $18 \mathrm{~B}$ & & IIIa & $35 R 2-3$ & Biface fragment, unanalyzed & \\
\hline $\mathrm{E} 26 / \mathrm{S} 72$ & $18 \mathrm{~B}$ & & IIIa & $35 \mathrm{R} 2-4$ & Biface Stage 2 & \\
\hline E26/S72 & $18 \mathrm{~B}$ & & IIIa & $35 \mathrm{R} 2-10$ & Burin spall & \\
\hline $\mathrm{E} 26 / \mathrm{S} 72$ & $18 \mathrm{~B}$ & & IIIa & $35 \mathrm{R} 2-30$ & Core tool, type 2 & 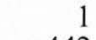 \\
\hline $\mathrm{E} 26 / \mathrm{S} 72$ & $18 \mathrm{~B}$ & & IIIa & & Debitage & 442 \\
\hline $\mathrm{E} 26 / \mathrm{S} 72$ & $18 \mathrm{~B}$ & & IIIa & $35 \mathrm{R} 2-28$ & Perforator Group 7 & \\
\hline E26/S72 & $18 \mathrm{~B}$ & & IIIa & $35 R 2-5$ & Thin uniface & \\
\hline E26/S72 & $18 \mathrm{~B}$ & & IIIa & $35 \mathrm{R} 2-13$ & Thin uniface & \\
\hline $\mathrm{E} 26 / \mathrm{S} 72$ & $18 \mathrm{~B}$ & & IIIa & $35 \mathrm{R} 2-29$ & Thin uniface fragment & \\
\hline E26/S72 & $18 \mathrm{~B}$ & & IIIa & $35 \mathrm{R} 2-22$ & Uniface, unanalyzed & \\
\hline $\mathrm{E} 26 / \mathrm{S} 72$ & $18 \mathrm{~B}$ & & IIIa & $35 \mathrm{R} 2-15$ & Uniface, unanalyzed & \\
\hline $\mathrm{E} 26 / \mathrm{S} 72$ & $18 \mathrm{~B}$ & & IIIa & $35 R 2-12$ & Uniface, unanalyzed & \\
\hline E26/S72 & $18 \mathrm{~B}$ & & IIIa & $35 \mathrm{R} 2-14$ & Uniface, unanalyzed & \\
\hline E26/S72 & $18 \mathrm{~B}$ & & IIIa & $35 \mathrm{R} 2-19$ & Uniface, unanalyzed & \\
\hline $\mathrm{E} 26 / \mathrm{S} 72$ & $18 \mathrm{~B}$ & & IIIa & $35 \mathrm{R} 2-25$ & Uniface, unanalyzed & \\
\hline $\mathrm{E} 26 / \mathrm{S} 72$ & $18 \mathrm{~B}$ & & IIIa & $35 R 2-23$ & Uniface, unanalyzed & \\
\hline $\mathrm{E} 26 / \mathrm{S} 72$ & $18 \mathrm{~B}$ & & IIIa & $35 \mathrm{R} 2-24$ & Uniface, unanalyzed & \\
\hline $\mathrm{E} 26 / \mathrm{S} 72$ & $18 \mathrm{~B}$ & & IIIa & $35 R 2-26$ & Uniface, unanalyzed & \\
\hline $\mathrm{E} 26 / \mathrm{S} 72$ & $18 \mathrm{~B}$ & & IIIa & $35 \mathrm{R} 2-9$ & Uniface, unanalyzed & \\
\hline E26/S72 & $18 \mathrm{~B}$ & & IIIa & $35 \mathrm{R} 2-21$ & Uniface, unanalyzed & \\
\hline E26/S72 & $18 \mathrm{~B}$ & & IIIa & $35 \mathrm{R} 2-20$ & Uniface, unanalyzed & \\
\hline E26/S72 & $19 \mathrm{~A}$ & & IIIa & $35 \mathrm{~S} 1-1$ & Bifacial tool Form B & \\
\hline E26/S72 & $19 \mathrm{~A}$ & & IIIa & & Debitage & 221 \\
\hline $\mathrm{E} 26 / \mathrm{S} 72$ & $19 \mathrm{~B}$ & & II/IIIa & $35 \mathrm{~S} 2-1$ & Biface Stage 1 & \\
\hline E26/S72 & $19 \mathrm{~B}$ & & II/IIIa & $35 \mathrm{~S} 2-2$ & Biface Stage 2 & \\
\hline $\mathrm{E} 26 / \mathrm{S} 72$ & $19 \mathrm{~B}$ & & II/IIIa & & Debitage & 186 \\
\hline E26/S72 & $19 \mathrm{~B}$ & & II/IIIa & $35 \mathrm{~S} 2 \mathrm{~B}-3$ & Projectile point, bifurcate stem fragment & \\
\hline $\mathrm{E} 26 / \mathrm{S} 72$ & $20 \mathrm{~A}$ & & II/IIIa & $35 \mathrm{~T} 1 \mathrm{~B}-3$ & Core tool, type 2 & \\
\hline $\mathrm{E} 26 / \mathrm{S} 72$ & $20 \mathrm{~A}$ & & II/IIIa & & Debitage & 199 \\
\hline E26/S72 & $20 \mathrm{~A}$ & & II/IIIa & $35 \mathrm{~T} 1 \mathrm{~A}-2$ & Edge modified flake & \\
\hline $\mathrm{E} 26 / \mathrm{S} 72$ & $20 \mathrm{~A}$ & & II/IIIa & $35 \mathrm{~T} 1 \mathrm{D}-5$ & Notched flake & \\
\hline $\mathrm{E} 26 / \mathrm{S} 72$ & $20 \mathrm{~A}$ & & II/IIIa & $35 \mathrm{~T} 1 \mathrm{~A}-1$ & Projectile point, miscellaneous lanceolate & \\
\hline E26/S72 & $20 \mathrm{~A}$ & & II/IIIa & $35 \mathrm{~T} 1 \mathrm{C}-4$ & Thin uniface & \\
\hline $\mathrm{E} 26 / \mathrm{S} 72$ & $20 \mathrm{~B}$ & & II/IIIa & $35 \mathrm{~T} 2 \mathrm{~B}-2$ & Burin spall & \\
\hline E26/S72 & $20 \mathrm{~B}$ & & II/IIIa & & Debitage & 198 \\
\hline $\mathrm{E} 26 / \mathrm{S} 72$ & $20 \mathrm{~B}$ & & II/IIIa & $35 \mathrm{~T} 2 \mathrm{~A}-1$ & Uniface, unanalyzed & \\
\hline $\mathrm{E} 26 / \mathrm{S} 72$ & $20 \mathrm{~B}$ & & II/IIIa & $35 \mathrm{~T} 2 \mathrm{~B}-3$ & Uniface, unanalyzed & \\
\hline $\mathrm{E} 26 / \mathrm{S} 72$ & $20 \mathrm{~B}$ & & II/IIIa & $35 \mathrm{~T} 2 \mathrm{~B}-4$ & Uniface, unanalyzed & \\
\hline $\mathrm{E} 26 / \mathrm{S} 72$ & $21 \mathrm{~A}$ & & II & 35 U1D-3 & Biface fragment & \\
\hline
\end{tabular}




\begin{tabular}{|c|c|c|c|c|c|c|}
\hline Square & Level & Feature & Strata & Item & Analyst Identification & Count \\
\hline $\begin{array}{l}\mathrm{E} 26 / \mathrm{S} 72 \\
\mathrm{E} 26 / \mathrm{S} 72\end{array}$ & $\begin{array}{l}21 \mathrm{~A} \\
21 \mathrm{~A}\end{array}$ & & II & $35 \mathrm{U} 1 \mathrm{C}-2$ & Brushy Creek biface & $\begin{array}{r}1 \\
220\end{array}$ \\
\hline $\mathrm{E} 26 / \mathrm{S} 72$ & $21 \mathrm{~A}$ & & II & $35 \mathrm{U} 1 \mathrm{C}-4$ & Thin uniface fragment & 1 \\
\hline E26/S72 & $21 \mathrm{~A}$ & Feature 146 & II & & Debitage & 11 \\
\hline $\mathrm{E} 26 / \mathrm{S} 72$ & $21 \mathrm{~B}$ & & II & & Debitage & 135 \\
\hline E26/S72 & $21 \mathrm{~B}$ & & II & $35 \mathrm{U} 2 \mathrm{~B}-5$ & Edge modified flake & 1 \\
\hline E26/S72 & $21 \mathrm{~B}$ & & II & $35 \mathrm{U} 2 \mathrm{~B}-4$ & Edge modified flake & 1 \\
\hline E26/S72 & 21B & & II & $35 \mathrm{U} 2 \mathrm{C}-6$ & Notched flake & 1 \\
\hline E26/S72 & $21 \mathrm{~B}$ & & II & $35 \mathrm{U} 2 \mathrm{D}-7$ & Uniface, unanalyzed & 1 \\
\hline $\mathrm{E} 26 / \mathrm{S} 72$ & 21B & & II & $35 \mathrm{U} 2 \mathrm{~A}-3$ & Uniface, unanalyzed & 1 \\
\hline E26/S72 & $21 \mathrm{~B}$ & & II & $35 \mathrm{U} 2 \mathrm{~A}-2$ & Uniface, unanalyzed & 1 \\
\hline $\mathrm{E} 26 / \mathrm{S} 72$ & $21 \mathrm{~B}$ & & II & $35 \mathrm{U} 2 \mathrm{~A}-1$ & Uniface, unanalyzed & 1 \\
\hline E26/S72 & $22 \mathrm{~A}$ & & II & & Debitage & 53 \\
\hline $\mathrm{E} 26 / \mathrm{S} 72$ & $22 \mathrm{~A}$ & Feature 157 & II & & Debitage & 56 \\
\hline $\mathrm{E} 26 / \mathrm{S} 72$ & $22 \mathrm{~A}-\mathrm{B}$ & Feature 157 & II & $35 \mathrm{~V} 1 \& 2-1$ & Core, multidirectional & 1 \\
\hline E26/S72 & $22 \mathrm{~A}-\mathrm{B}$ & Feature 157 & II & & Debitage & 10 \\
\hline $\mathrm{E} 26 / \mathrm{S} 72$ & $22 \mathrm{~A}-\mathrm{B}$ & Feature 157 & II & $35 \mathrm{~V} 1 \& 2-3$ & Uniface, unanalyzed & 1 \\
\hline E26/S72 & $22 B$ & Feature 157 & II & & Debitage & 76 \\
\hline E26/S72 & $23 \mathrm{~A}$ & & II & & Debitage & 77 \\
\hline $\mathrm{E} 26 / \mathrm{S} 72$ & $23 \mathrm{~A}$ & & II & $35 \mathrm{~W} 1 \mathrm{~A}-1$ & Uniface, unanalyzed & ? \\
\hline E26/S72 & $23 \mathrm{~B}$ & & II & $35 \mathrm{~W} 2 \mathrm{~A}-1$ & Burin spall & 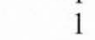 \\
\hline $\mathrm{E} 26 / \mathrm{S} 72$ & $23 \mathrm{~B}$ & & II & & Debitage & 62 \\
\hline E26/S72 & $23 \mathrm{~B}$ & & II & $35 \mathrm{~W} 2 \mathrm{~B}-2$ & Uniface, unanalyzed & 1 \\
\hline E26/S72 & $24 \mathrm{~A}$ & & II & $35 \times 1 A-1$ & Core tool, type 5 & 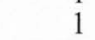 \\
\hline E26/S72 & $24 \mathrm{~A}$ & & II & & Debitage & 63 \\
\hline E26/S72 & $24 B$ & & II & $35 \times 2 A-2$ & Biface fragment & 1 \\
\hline E26/S72 & $24 \mathrm{~B}$ & & II & & Debitage & 56 \\
\hline $\mathrm{E} 26 / \mathrm{S} 72$ & 24B & & II & $35 \times 2 A-1$ & Edge modified flake & \\
\hline $\mathrm{E} 26 / \mathrm{S} 72$ & $25 \mathrm{~A}$ & & II & & Debitage & 64 \\
\hline $\mathrm{E} 26 / \mathrm{S} 72$ & $25 \mathrm{~B}$ & & II & & Debitage & 62 \\
\hline $\mathrm{E} 26 / \mathrm{S} 72$ & $26 \mathrm{~A}$ & & II & & Debitage & 43 \\
\hline $\mathrm{E} 26 / \mathrm{S} 72$ & $26 \mathrm{~B}$ & & II & & Debitage & 16 \\
\hline $\mathrm{E} 26 / \mathrm{S} 72$ & $26 \mathrm{~B}$ & & II & $35 Z 2 D-1$ & Uniface, unanalyzed & 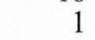 \\
\hline $\mathrm{E} 26 / \mathrm{S} 72$ & $26 \mathrm{~B}$ & Feature 165 & II & & Debitage & 10 \\
\hline E26/S72 & $27 \mathrm{~A}$ & & II & 35AA1D-1 & Burin spall & . \\
\hline E26/S72 & $27 \mathrm{~A}$ & & II & & Debitage & 9 \\
\hline E26/S72 & $27 \mathrm{~A}$ & Feature 165 & II & & Debitage & 9 \\
\hline $\mathrm{E} 26 / \mathrm{S} 72$ & $27 \mathrm{~B}$ & & II & & Debitage & 18 \\
\hline E26/S72 & $27 \mathrm{~B}$ & Feature 165 & II & & Debitage & 0 \\
\hline E26/S72 & $27 \mathrm{~B}$ & Feature 165 & II & 35AA2A-1 & Edge modified flake & 1 \\
\hline E26/S72 & $28 \mathrm{~A}$ & & II & & Debitage & 26 \\
\hline $\mathrm{E} 26 / \mathrm{S} 72$ & $28 \mathrm{~A}$ & Feature 165 & II & & Debitage & 10 \\
\hline E26/S72 & $28 \mathrm{~B}$ & & Isi-c/II & & Debitage & 14 \\
\hline E26/S72 & $29 \mathrm{~A}$ & & Isi-c/II & $35 \mathrm{CC} 1 \mathrm{~A}-1$ & Biface Stage 2 & 1 \\
\hline E26/S72 & $29 \mathrm{~A}$ & & Isi-c/II & & Debitage & $F$ \\
\hline $\mathrm{E} 26 / \mathrm{S} 72$ & $29 \mathrm{~A}$ & & Isi-c/II & $35 \mathrm{CC} 1 \mathrm{C}-3$ & Edge modified flake & 1 \\
\hline E26/S72 & $29 \mathrm{~A}$ & & Isi-c/II & $35 \mathrm{CC} 1 \mathrm{~B}-2$ & Uniface, unanalyzed & 1 \\
\hline E26/S72 & $29 \mathrm{~B}$ & & Isi-c & $35 \mathrm{CC} 2 \mathrm{D}-1$ & Biface Stage 2 & 1 \\
\hline E26/S72 & $29 B$ & & Isi-c & & Debitage & 15 \\
\hline E26/S72 & $30 \mathrm{~A}$ & & Isi-c & & Debitage & 6 \\
\hline $\mathrm{E} 26 / \mathrm{S} 72$ & $30 \mathrm{~A}$ & & Isi-c & 35DD1B-1 & Thin uniface & 1 \\
\hline E26/S72 & $30 \mathrm{~B}$ & & Isi-c & & Debitage & 8 \\
\hline E26/S72 & $31 \mathrm{~A}$ & & Isi-c & & Debitage & 7 \\
\hline E26/S72 & $31 \mathrm{~A}$ & & Isi-c & 35EE1A-1 & Projectile point, Wilson & 1 \\
\hline E26/S72 & $31 \mathrm{~B}$ & & Isi-c & & Debitage & 11 \\
\hline E26/S72 & $32 \mathrm{~A}$ & & Isi-c & & Debitage & 5 \\
\hline $\mathrm{E} 26 / \mathrm{S} 72$ & $33 \mathrm{~A}$ & & $\mathrm{Icl} / \mathrm{Isi}-\mathrm{c}$ & & Debitage & 5 \\
\hline E26/S72 & $33 \mathrm{~B}$ & & Icl/Isi-c & & Debitage & 3 \\
\hline E26/S72 & $34 \mathrm{~A}$ & & Icl/Isi-c & & Debitage & 9 \\
\hline E26/S72 & $34 \mathrm{~B}$ & & Icl/Isi-c & & Debitage & 2 \\
\hline $\mathrm{E} 26 / \mathrm{S} 72$ & $35 \mathrm{~A}$ & & Icl & & Debitage & 4 \\
\hline E26/S72 & $35 \mathrm{~A}$ & & Icl & 35II1D-1 & Thin uniface fragment & 1 \\
\hline $\mathrm{E} 26 / \mathrm{S} 72$ & $35 \mathrm{~B}$ & & $\mathrm{Icl}$ & & Debitage & 6 \\
\hline E26/S72 & $35 \mathrm{~B}$ & & Icl & $35 \mathrm{II} 2 \mathrm{~A}-1$ & Uniface, unanalyzed & 1 \\
\hline E26/S72 & $36 \mathrm{~A}$ & & Icl & & Debitage & 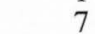 \\
\hline $\mathrm{E} 26 / \mathrm{S} 72$ & $36 \mathrm{~B}$ & & Icl & & Debitage & 8 \\
\hline E26/S72 & $36 \mathrm{~B}$ & & Icl & $35 \mathrm{JJ} 2 \mathrm{~B}-1$ & Worked hematite & 1 \\
\hline $\mathrm{E} 26 / \mathrm{S} 72$ & $37 \mathrm{~A}$ & & Icl & & Debitage & 4 \\
\hline $\mathrm{E} 26 / \mathrm{S} 72$ & $37 \mathrm{~B}$ & & Isi/Icl & & Debitage & 7 \\
\hline E26/S72 & $37 \mathrm{~B}$ & & $\mathrm{Isi} / \mathrm{Icl}$ & $35 \mathrm{KK} 2 \mathrm{~A}-2$ & Face battered stone & 1 \\
\hline E26/S72 & $37 \mathrm{~B}$ & & Isi/Icl & $35 \mathrm{KK} 2 \mathrm{C}-3$ & Thick uniface & 1 \\
\hline E26/S72 & $37 \mathrm{~B}$ & & Isi/Icl & $35 \mathrm{KK} 2 \mathrm{~A}-1$ & Uniface, unanalyzed & 1 \\
\hline E26/S72 & $38 \mathrm{~A}$ & & Isi/Icl & & Debitage & 7 \\
\hline E26/S72 & $38 \mathrm{~B}-39 \mathrm{~A}$ & & Isi/Icl & & Debitage & 19 \\
\hline
\end{tabular}




\begin{tabular}{|c|c|c|c|c|c|}
\hline Square & Level & Feature & Strata & Item & Analyst Identification \\
\hline $\mathrm{E} 26 / \mathrm{S} 72$ & $39 \mathrm{~B}$ & & Isi/Icl & & Debitage \\
\hline E26/S72 & $40 \mathrm{~A}-\mathrm{B}$ & & Isi/Icl & $35 \mathrm{NN} 1 \& 2 \mathrm{~B}-3$ & Biface Stage 2 \\
\hline E26/S72 & $40 \mathrm{~A}-\mathrm{B}$ & & Isi/Icl & $35 \mathrm{NN} 1 \& 2 \mathrm{D}-4$ & Core tool, type 4 \\
\hline E26/S72 & $40 \mathrm{~A}-\mathrm{B}$ & & Isi/Icl & & Debitage \\
\hline $\mathrm{E} 26 / \mathrm{S} 72$ & $40 \mathrm{~A}-\mathrm{B}$ & & Isi/Icl & $35 \mathrm{NN} 1 \& 2 \mathrm{~A}-1$ & Thin uniface fragment \\
\hline $\mathrm{E} 26 / \mathrm{S} 72$ & $41 \mathrm{~A}$ & & Igl/Isi & & Debitage \\
\hline E26/S72 & $41 \mathrm{~A}$ & & Igl//si & $35001 B-2$ & Thin uniface \\
\hline $\mathrm{E} 26 / \mathrm{S} 72$ & $41 \mathrm{~A}$ & & $\mathrm{Igl} / \mathrm{Isi}$ & 35001B-1 & Uniface, unanalyzed \\
\hline $\mathrm{E} 26 / \mathrm{S} 72$ & $41 \mathrm{~A}$ & & Igl/Isi & $35001 D-3$ & Worked hematite \\
\hline E26/S72 & $41 \mathrm{~B}$ & & Igl/Isi & & Debitage \\
\hline $\mathrm{E} 26 / \mathrm{S} 72$ & $42 \mathrm{~A}$ & & $\mathrm{Igl} / \mathrm{Isi}$ & & Debitage \\
\hline E26/S74 & 15 & & IIIa/b & $340-8$ & Biface fragment \\
\hline E26/S74 & 15 & & IIIa/b & $340-21$ & Biface fragment \\
\hline E26/S74 & 15 & & IIIa/b & $340-4$ & Biface fragment \\
\hline E26/S74 & 15 & & $\mathrm{IIIa} / \mathrm{b}$ & $340-3$ & Biface Stage 2 \\
\hline $\mathrm{E} 26 / \mathrm{S} 74$ & 15 & & $\mathrm{IIIa} / \mathrm{b}$ & $340-1$ & Biface Stage 2 \\
\hline $\mathrm{E} 26 / \mathrm{S} 74$ & 15 & & $\mathrm{IIIa} / \mathrm{b}$ & $340-2$ & Biface Stage 2 \\
\hline E26/S74 & 15 & & $\mathrm{IIIa} / \mathrm{b}$ & $340-5$ & Burin spall \\
\hline E26/S74 & 15 & & $\mathrm{IIIa} / \mathrm{b}$ & $340-7$ & Burin spall \\
\hline E26/S74 & 15 & & IIIa/b & & Debitage \\
\hline E26/S74 & 15 & & IIIa/b & $340-18$ & Edge modified flake \\
\hline $\mathrm{E} 26 / \mathrm{S} 74$ & 15 & & $\mathrm{IIIa} / \mathrm{b}$ & $340-9$ & Projectile point, San Patrice? \\
\hline E26/S74 & 15 & & IIIa/b & $340-16$ & Thin uniface fragment \\
\hline E26/S74 & 15 & & $\mathrm{IIIa} / \mathrm{b}$ & $340-10$ & Uniface, unanalyzed \\
\hline E26/S74 & 15 & & $\mathrm{IIIa} / \mathrm{b}$ & $340-19$ & Uniface, unanalyzed \\
\hline $\mathrm{E} 26 / \mathrm{S} 74$ & 15 & & IIIa/b & $340-22$ & Uniface, unanalyzed \\
\hline E26/S74 & 15 & & IIIa/b & $340-15$ & Uniface, unanalyzed \\
\hline E26/S74 & 15 & & $\mathrm{IIIa} / \mathrm{b}$ & $340-12$ & Uniface, unanalyzed \\
\hline E26/S74 & 15 & & $\mathrm{IIIa} / \mathrm{b}$ & $340-20$ & Uniface, unanalyzed \\
\hline $\mathrm{E} 26 / \mathrm{S} 74$ & 15 & & IIIa/b & $340-11$ & Uniface, unanalyzed \\
\hline E26/S74 & 15 & & IIIa/b & $340-14$ & Uniface, unanalyzed \\
\hline E26/S74 & 15 & & $\mathrm{IIIa} / \mathrm{b}$ & $340-23$ & Unifacial multiple tool \\
\hline $\mathrm{E} 26 / \mathrm{S} 74$ & $16 \mathrm{~A}$ & & IIIa & $34 \mathrm{P} 1-1$ & Biface Stage 2 \\
\hline $\mathrm{E} 26 / \mathrm{S} 74$ & $16 \mathrm{~A}$ & & IIIa & $34 \mathrm{P} 1-7$ & Burin spall \\
\hline E26/S74 & $16 \mathrm{~A}$ & & IIIa & & Debitage \\
\hline E26/S74 & $16 \mathrm{~A}$ & & IIIa & $34 \mathrm{P} 1-3$ & Microspur/microdenticulate \\
\hline E26/S74 & $16 \mathrm{~A}$ & & IIIa & $34 \mathrm{P} 1-5$ & Notched flake \\
\hline E26/S74 & $16 \mathrm{~A}$ & & IIIa & $34 \mathrm{P} 1-2$ & Thin uniface \\
\hline E26/S74 & $16 \mathrm{~A}$ & & IIIa & $34 \mathrm{P} 1-6$ & Uniface, unanalyzed \\
\hline E26/S74 & $16 \mathrm{~A}$ & & IIIa & $34 \mathrm{P} 1-9$ & Uniface, unanalyzed \\
\hline E26/S74 & $16 \mathrm{~A}$ & & IIIa & $34 \mathrm{P} 1-4$ & Uniface, unanalyzed \\
\hline E26/S74 & $16 \mathrm{~B}$ & & IIIa & & Debitage \\
\hline E26/S74 & $16 \mathrm{~B}$ & & IIIa & $34 \mathrm{P} 2-14$ & Edge modified flake \\
\hline E26/S74 & $16 \mathrm{~B}$ & & IIIa & $34 \mathrm{P} 2-15$ & Microspur/microdenticulate \\
\hline $\mathrm{E} 26 / \mathrm{S} 74$ & $16 \mathrm{~B}$ & & IIIa & $34 \mathrm{P} 2-18$ & Notched flake \\
\hline E26/S74 & $16 \mathrm{~B}$ & & IIIa & $34 \mathrm{P} 2-23$ & Spurred flake \\
\hline $\mathrm{E} 26 / \mathrm{S} 74$ & $16 \mathrm{~B}$ & & IIIa & $34 \mathrm{P} 2-17$ & Uniface, unanalyzed \\
\hline E26/S74 & $16 \mathrm{~B}$ & & IIIa & $34 \mathrm{P} 2-12$ & Uniface, unanalyzed \\
\hline $\mathrm{E} 26 / \mathrm{S} 74$ & $16 \mathrm{~B}$ & & IIIa & $34 \mathrm{P} 2-13$ & Uniface, unanalyzed \\
\hline E26/S74 & $16 \mathrm{~B}$ & & IIIa & $34 \mathrm{P} 2-11$ & Uniface, unanalyzed \\
\hline $\mathrm{E} 26 / \mathrm{S} 74$ & $16 \mathrm{~B}$ & & IIIa & $34 \mathrm{P} 2-1$ & Uniface, unanalyzed \\
\hline E26/S74 & $16 \mathrm{~B}$ & & IIIa & $34 \mathrm{P} 2-20$ & Uniface, unanalyzed \\
\hline E26/S74 & $16 \mathrm{~B}$ & & IIIa & $34 \mathrm{P} 2-21$ & Uniface, unanalyzed \\
\hline E26/S74 & $16 \mathrm{~B}$ & & IIIa & $34 \mathrm{P} 2-3$ & Uniface, unanalyzed \\
\hline E26/S74 & $17 \mathrm{~A}$ & & IIIa & 34Q1-1 & Biface Stage 2 \\
\hline E26/S74 & $17 \mathrm{~A}$ & & IIIa & & Debitage \\
\hline E26/S74 & $17 \mathrm{~A}$ & & IIIa & 34Q1-2 & Projectile point fragment \\
\hline $\mathrm{E} 26 / \mathrm{S} 74$ & $17 \mathrm{~A}$ & & IIIa & $34 Q 1-4$ & Projectile point fragment \\
\hline E26/S74 & $17 \mathrm{~A}$ & & IIIa & $34 Q 1-3$ & Projectile point, miscellaneous lanceolate \\
\hline E26/S74 & 17B & & IIIa & $34 Q 2-1$ & Biface Stage 2 \\
\hline $\mathrm{E} 26 / \mathrm{S} 74$ & $17 \mathrm{~B}$ & & IIIa & $34 Q 2-6$ & Clear Fork biface \\
\hline E26/S74 & 17B & & IIIa & $34 Q 2-4$ & Core, thermal \\
\hline E26/S74 & $17 \mathrm{~B}$ & & IIIa & & Debitage \\
\hline E26/S74 & $17 \mathrm{~B}$ & & IIIa & 34Q2-9 & Denticulated flake \\
\hline E26/S74 & $17 \mathrm{~B}$ & & IIIa & $34 Q 2-5$ & Small core hammerstone \\
\hline E26/S74 & $17 \mathrm{~B}$ & & IIIa & $34 Q 2-8$ & Thin uniface \\
\hline $\mathrm{E} 26 / \mathrm{S} 74$ & $17 \mathrm{~B}$ & & IIIa & $34 Q 2-3$ & Uniface, unanalyzed \\
\hline E26/S74 & $18 \mathrm{~A}$ & & IIIa & $34 \mathrm{R} 1-8$ & Biface Stage 2 \\
\hline E26/S74 & $18 \mathrm{~A}$ & & IIIa & 34R1-9 & Bifacial tool Form $\mathrm{H}$ \\
\hline E26/S74 & $18 \mathrm{~A}$ & & IIIa & & Debitage \\
\hline E26/S74 & $18 \mathrm{~A}$ & & IIIa & 34R1-1 & Thin uniface \\
\hline $\mathrm{E} 26 / \mathrm{S} 74$ & $18 \mathrm{~A}$ & & IIIa & $34 \mathrm{R} 1-4$ & Uniface, unanalyzed \\
\hline E26/S74 & $18 \mathrm{~A}$ & & IIIa & $34 \mathrm{R} 1-5$ & Uniface, unanalyzed \\
\hline E26/S74 & $18 \mathrm{~A}$ & & IIIa & $34 \mathrm{R} 1-3$ & Uniface, unanalyzed \\
\hline
\end{tabular}

Count

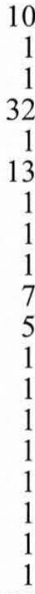

1209
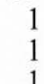

1 


\begin{tabular}{|c|c|c|c|c|c|}
\hline Square & Level & Feature & Strata & Item & Analyst Identification \\
\hline $\mathrm{E} 26 / \mathrm{S} 74$ & $18 \mathrm{~A}$ & & IIIa & $34 \mathrm{R} 1-7$ & Uniface, unanalyzed \\
\hline E26/S74 & $18 \mathrm{~A}$ & & IIIa & $34 \mathrm{R} 1-2$ & Unifacial multiple tool \\
\hline $\mathrm{E} 26 / \mathrm{S} 74$ & $18 \mathrm{~B}$ & & IIIa & 34R2-1 & Biface Stage 2 \\
\hline $\mathrm{E} 26 / \mathrm{S} 74$ & $18 \mathrm{~B}$ & & IIIa & $34 \mathrm{R} 2-3$ & Biface Stage 2 \\
\hline E26/S74 & $18 \mathrm{~B}$ & & IIIa & $34 \mathrm{R} 2-6$ & Biface Stage 2 \\
\hline E26/S74 & $18 \mathrm{~B}$ & & IIIa & $34 \mathrm{R} 2-7$ & Biface Stage 2 \\
\hline $\mathrm{E} 26 / \mathrm{S} 74$ & $18 \mathrm{~B}$ & & IIIa & & Debitage \\
\hline E26/S74 & $18 \mathrm{~B}$ & & IIIa & $34 \mathrm{R} 2-8$ & Perforator Group 2 \\
\hline E26/S74 & $18 \mathrm{~B}$ & & IIIa & $34 R 2-2$ & Thin uniface \\
\hline E26/S74 & $18 \mathrm{~B}$ & & IIIa & $34 \mathrm{R} 2-5$ & Thin uniface fragment \\
\hline E26/S74 & $18 \mathrm{~B}$ & & IIIa & $34 \mathrm{R} 2-4$ & Uniface, unanalyzed \\
\hline $\mathrm{E} 26 / \mathrm{S} 74$ & $19 \mathrm{~A}$ & & IIIa & & Debitage \\
\hline E26/S74 & $19 \mathrm{~A}$ & & IIIa & $34 \mathrm{~S} 1-1$ & Microspur/microdenticulate \\
\hline E26/S74 & 19B & & IIIa & & Debitage \\
\hline E26/S74 & $19 \mathrm{~B}$ & & IIIa & $34 \mathrm{~S} 2 \mathrm{C}-2$ & Microspur/microdenticulate \\
\hline $\mathrm{E} 26 / \mathrm{S} 74$ & 19B & & IIIa & $34 \mathrm{~S} 2 \mathrm{D}-7$ & Thin uniface \\
\hline $\mathrm{E} 26 / \mathrm{S} 74$ & $19 \mathrm{~B}$ & & IIIa & 34S2B-1 & Uniface, unanalyzed \\
\hline E26/S74 & $19 \mathrm{~B}$ & & IIIa & $34 \mathrm{~S} 2 \mathrm{C}-3$ & Uniface, unanalyzed \\
\hline $\mathrm{E} 26 / \mathrm{S} 74$ & 19B & & IIIa & $34 \mathrm{~S} 2 \mathrm{C}-5$ & Uniface, unanalyzed \\
\hline $\mathrm{E} 26 / \mathrm{S} 74$ & $20 \mathrm{~A}$ & & II/IIIa & $34 \mathrm{TIC}-4$ & Burin spall \\
\hline E26/S74 & $20 \mathrm{~A}$ & & II/IIIa & & Debitage \\
\hline E26/S74 & $20 \mathrm{~A}$ & & II/IIIa & $34 \mathrm{~T} 1 \mathrm{D}-9$ & Uniface, unanalyzed \\
\hline $\mathrm{E} 26 / \mathrm{S} 74$ & $20 \mathrm{~A}$ & & $\mathrm{II} / \mathrm{IIIa}$ & $34 \mathrm{~T} 1 \mathrm{D}-7$ & Uniface, unanalyzed \\
\hline $\mathrm{E} 26 / \mathrm{S} 74$ & $20 \mathrm{~A}$ & & II/IIIa & $34 \mathrm{~T} 1 \mathrm{D}-6$ & Uniface, unanalyzed \\
\hline E26/S74 & $20 \mathrm{~A}$ & & $\mathrm{II} / \mathrm{IIIa}$ & $34 \mathrm{~T} 1 \mathrm{D}-5$ & Uniface, unanalyzed \\
\hline $\mathrm{E} 26 / \mathrm{S} 74$ & $20 \mathrm{~A}$ & & II/IIIa & $34 \mathrm{~T} 1 \mathrm{C}-3$ & Uniface, unanalyzed \\
\hline $\mathrm{E} 26 / \mathrm{S} 74$ & $20 \mathrm{~A}$ & Feature 146 & II/IIIa & & Debitage \\
\hline E26/S74 & $20 \mathrm{~A}$ & Feature 146 & II/IIIa & $34 \mathrm{~T} 1 \mathrm{~A}-2$ & Uniface, unanalyzed \\
\hline $\mathrm{E} 26 / \mathrm{S} 74$ & $20 \mathrm{~A}$ & Feature 146 & II/IIIa & $34 \mathrm{~T} 1 \mathrm{~A}-1$ & Uniface, unanalyzed \\
\hline $\mathrm{E} 26 / \mathrm{S} 74$ & $20 \mathrm{~B}$ & & II/IIIa & & Debitage \\
\hline $\mathrm{E} 26 / \mathrm{S} 74$ & $20 \mathrm{~B}$ & & II/IIIa & $34 \mathrm{~T} 2 \mathrm{C}-1$ & Uniface, unanalyzed \\
\hline $\mathrm{E} 26 / \mathrm{S} 74$ & $20 \mathrm{~B}$ & Feature 146 & II/IIIa & & Debitage \\
\hline $\mathrm{E} 26 / \mathrm{S} 74$ & $20 \mathrm{~B}$ & Feature 150 & II/IIIa & & Debitage \\
\hline E26/S74 & $21 \mathrm{~A}$ & & II/IIIa & & Debitage \\
\hline $\mathrm{E} 26 / \mathrm{S} 74$ & $21 \mathrm{~A}$ & & II/IIIa & 34U1B-1 & Projectile point, St. Mary's Hall \\
\hline E26/S74 & $21 \mathrm{~A}$ & & $\mathrm{II} / \mathrm{IIIa}$ & $34 \mathrm{U} 1 \mathrm{D}-2$ & Uniface, unanalyzed \\
\hline $\mathrm{E} 26 / \mathrm{S} 74$ & $21 \mathrm{~A}$ & & II/IIIa & $34 U 1 D-3$ & Unifacial multiple tool \\
\hline $\mathrm{E} 26 / \mathrm{S} 74$ & $21 \mathrm{~B}$ & & II & $34 U 2 D-5$ & Biface Stage 1 \\
\hline E26/S74 & $21 \mathrm{~B}$ & & II & $34 \mathrm{U} 2 \mathrm{D}-6$ & Biface Stage 2 \\
\hline $\mathrm{E} 26 / \mathrm{S} 74$ & $21 \mathrm{~B}$ & & II & $34 \mathrm{U} 2 \mathrm{~A}-1$ & Burin spall \\
\hline E26/S74 & $21 \mathrm{~B}$ & & II & & Debitage \\
\hline E26/S74 & 21B & & II & $34 \mathrm{U} 2 \mathrm{C}-3$ & Thin uniface \\
\hline E26/S74 & $22 \mathrm{~A}$ & & II & $34 \mathrm{~V} 1 \mathrm{C}-4$ & Biface fragment \\
\hline $\mathrm{E} 26 / \mathrm{S} 74$ & $22 \mathrm{~A}$ & & II & $34 \mathrm{~V} 1 \mathrm{D}-6$ & Biface Stage 2 \\
\hline E26/S74 & $22 \mathrm{~A}$ & & II & $34 \mathrm{~V} 1 \mathrm{~B}-3$ & Burin spall \\
\hline E26/S74 & $22 \mathrm{~A}$ & & II & & Debitage \\
\hline $\mathrm{E} 26 / \mathrm{S} 74$ & $22 \mathrm{~A}$ & & II & 34V1B-1 & Grooved stone \\
\hline E26/S74 & $22 \mathrm{~A}$ & & II & $34 \mathrm{~V} 1 \mathrm{D}-7$ & Notched flake \\
\hline $\mathrm{E} 26 / \mathrm{S} 74$ & $22 \mathrm{~A}$ & & II & $34 \mathrm{~V} 1 \mathrm{~B}-2$ & Uniface, unanalyzed \\
\hline $\mathrm{E} 26 / \mathrm{S} 74$ & $22 \mathrm{~A}$ & & II & $34 \mathrm{~V} 1 \mathrm{C}-5$ & Uniface, unanalyzed \\
\hline E26/S74 & $22 \mathrm{~A}$ & Feature 146 & II & & Debitage \\
\hline E26/S74 & $22 \mathrm{~B}$ & & II & & Debitage \\
\hline E26/S74 & $23 \mathrm{~A}$ & & II & $34 \mathrm{~W} 1 \mathrm{~B}-3$ & Battered cobble \\
\hline $\mathrm{E} 26 / \mathrm{S} 74$ & $23 \mathrm{~A}$ & & II & $34 \mathrm{~W} 1 \mathrm{C}-5$ & Burin \\
\hline E26/S74 & $23 \mathrm{~A}$ & & II & & Debitage \\
\hline E26/S74 & $23 \mathrm{~A}$ & & II & $34 \mathrm{~W} 1 \mathrm{D}-6$ & Edge modified flake \\
\hline E26/S74 & $23 \mathrm{~A}$ & & II & $34 \mathrm{~W} 1 \mathrm{~A}-1$ & Thin uniface \\
\hline E26/S74 & $23 \mathrm{~A}$ & & II & $34 \mathrm{~W} 1 \mathrm{~B}-2$ & Uniface, unanalyzed \\
\hline $\mathrm{E} 26 / \mathrm{S} 74$ & $23 \mathrm{~A}$ & & II & $34 \mathrm{~W} 1 \mathrm{C}-4$ & Uniface, unanalyzed \\
\hline E26/S74 & $23 \mathrm{~B}$ & & II & & Debitage \\
\hline E26/S74 & $23 \mathrm{~B}$ & & II & $34 \mathrm{~W} 2 \mathrm{~A}-1$ & Uniface, unanalyzed \\
\hline E26/S74 & $24 \mathrm{~A}$ & & II & $34 \times 1 D-5$ & Biface Stage 2 \\
\hline $\mathrm{E} 26 / \mathrm{S} 74$ & $24 \mathrm{~A}$ & & II & $34 X 1 D-6$ & Biface Stage 2 \\
\hline $\mathrm{E} 26 / \mathrm{S} 74$ & $24 \mathrm{~A}$ & & II & & Debitage \\
\hline E26/S74 & $24 \mathrm{~A}$ & & II & $34 \times 1 B-2$ & Uniface, unanalyzed \\
\hline $\mathrm{E} 26 / \mathrm{S} 74$ & $24 \mathrm{~A}$ & & II & $34 \times 1 \mathrm{~A}-1$ & Uniface, unanalyzed \\
\hline E26/S74 & $24 \mathrm{~A}$ & & II & $34 \times 1 B-3$ & Uniface, unanalyzed \\
\hline E26/S74 & $24 \mathrm{~A}$ & & II & $34 \times 1 D-7$ & Uniface, unanalyzed \\
\hline E26/S74 & $24 \mathrm{~B}$ & & II & $34 \mathrm{X} 2 \mathrm{D}-3$ & Biface fragment, unanalyzed \\
\hline E26/S74 & 24B & & II & $34 \times 2 A-1$ & Brushy Creek biface \\
\hline $\mathrm{E} 26 / \mathrm{S} 74$ & $24 \mathrm{~B}$ & & II & & Debitage \\
\hline E26/S74 & $24 \mathrm{~B}$ & & II & $34 \times 2 B-2$ & Unifacial multiple tool \\
\hline E26/S74 & $25 \mathrm{~A}$ & & II & $34 Y 1 D-6$ & Biface Stage 3 \\
\hline $\mathrm{E} 26 / \mathrm{S} 74$ & $25 \mathrm{~A}$ & & II & & Debitage \\
\hline
\end{tabular}

Coun

1
1
1
1

662

1

1

439

364

1

1

1

1

265

1

1

1 


\begin{tabular}{|c|c|c|c|c|c|}
\hline Square & Level & Feature & Strata & Item & Analyst Identification \\
\hline E26/S74 & $25 \mathrm{~A}$ & & II & 34Y1D-7 & Microspur/microdenticulate \\
\hline E26/S74 & $25 \mathrm{~A}$ & & II & $34 Y 1 D-1$ & Projectile point, Wilson \\
\hline E26/S74 & $25 \mathrm{~A}$ & & II & $34 Y 1 A-2$ & Uniface, unanalyzed \\
\hline $\mathrm{E} 26 / \mathrm{S} 74$ & $25 \mathrm{~A}$ & & II & 34Y1D-8 & Uniface, unanalyzed \\
\hline $\mathrm{E} 26 / \mathrm{S} 74$ & $25 \mathrm{~B}$ & & II & $34 \mathrm{Y} 2 \mathrm{C}-3$ & Biface Stage 1 \\
\hline $\mathrm{E} 26 / \mathrm{S} 74$ & $25 \mathrm{~B}$ & & II & & Debitage \\
\hline E26/S74 & $25 \mathrm{~B}$ & & II & $34 Y 2 D-4$ & Thin uniface \\
\hline E26/S74 & $25 \mathrm{~B}$ & & II & $34 Y 2 B-1$ & Uniface, unanalyzed \\
\hline $\mathrm{E} 26 / \mathrm{S} 74$ & $26 \mathrm{~A}$ & & II & & Debitage \\
\hline $\mathrm{E} 26 / \mathrm{S} 74$ & $26 \mathrm{~A}$ & & II & $34 \mathrm{Z1AB}-1$ & Thick uniface fragment \\
\hline E26/S74 & $26 \mathrm{~A}$ & & II & $34 \mathrm{Z1AB}-2$ & Uniface, unanalyzed \\
\hline $\mathrm{E} 26 / \mathrm{S} 74$ & $26 \mathrm{~B}$ & & II & & Debitage \\
\hline $\mathrm{E} 26 / \mathrm{S} 74$ & $26 \mathrm{~B}$ & & II & 34Z2B-1 & Uniface, unanalyzed \\
\hline $\mathrm{E} 26 / \mathrm{S} 74$ & $27 \mathrm{~A}$ & & II & & Debitage \\
\hline $\mathrm{E} 26 / \mathrm{S} 74$ & $27 \mathrm{~A}$ & & II & 34AA1D-2 & Uniface, unanalyzed \\
\hline E26/S74 & $27 \mathrm{~A}$ & & II & 34AA1D-1 & Uniface, unanalyzed \\
\hline $\mathrm{E} 26 / \mathrm{S} 74$ & $27 \mathrm{~B}$ & & Isi-c/II & $34 \mathrm{AA} 2 \mathrm{C}-2$ & Biface fragment \\
\hline $\mathrm{E} 26 / \mathrm{S} 74$ & $27 \mathrm{~B}$ & & Isi-c/II & & Debitage \\
\hline E26/S74 & $27 \mathrm{~B}$ & & Isi-c/II & 34AA2B-1 & Edge modified flake \\
\hline E26/S74 & $27 \mathrm{~B}$ & & Isi-c/II & $34 \mathrm{AA} 2 \mathrm{C}-3$ & Uniface, unanalyzed \\
\hline E26/S74 & $28 \mathrm{~A}$ & & Isi-c/II & & Debitage \\
\hline E26/S74 & $28 \mathrm{~B}$ & & Isi-c/II & & Debitage \\
\hline $\mathrm{E} 26 / \mathrm{S} 74$ & $28 \mathrm{~B}$ & & Isi-c/II & 34BB2B-1 & Edge modified flake \\
\hline E26/S74 & $28 \mathrm{~B}$ & & Isi-c/II & 34BB2D-3 & Edge modified flake \\
\hline E26/S74 & $28 \mathrm{~B}$ & & Isi-c/II & 34BB2B-2 & Uniface, unanalyzed \\
\hline E26/S74 & $29 \mathrm{~A}$ & & Isi-c & & Debitage \\
\hline $\mathrm{E} 26 / \mathrm{S} 74$ & $29 \mathrm{~A}$ & & Isi-c & $34 \mathrm{CC} 1 \mathrm{D}-1$ & Thin uniface fragment \\
\hline E26/S74 & 29B & & Isi-c & & Debitage \\
\hline E26/S74 & 29B & & Isi-c & $34 \mathrm{CC} 2 \mathrm{D}-2$ & Mano \\
\hline E26/S74 & $29 B$ & & Isi-c & $34 \mathrm{CC} 2 \mathrm{C}-1$ & Uniface, unanalyzed \\
\hline E26/S74 & $30 \mathrm{~A}$ & & Isi-c & & Debitage \\
\hline E26/S74 & $30 \mathrm{~A}$ & & Isi-c & 34DD1C-1 & Micro-core, small \\
\hline E26/S74 & $30 \mathrm{~B}$ & & Isi-c & & Debitage \\
\hline E26/S74 & $30 \mathrm{~B}$ & & Isi-c & 34DD2C-2 & Notched flake \\
\hline $\mathrm{E} 26 / \mathrm{S} 74$ & $30 \mathrm{~B}$ & & Isi-c & $34 \mathrm{DD} 2 \mathrm{~B}-1$ & Uniface, unanalyzed \\
\hline E26/S74 & $31 \mathrm{~A}$ & & Isi-c & & Debitage \\
\hline $\mathrm{E} 26 / \mathrm{S} 74$ & $31 \mathrm{~A}$ & & Isi-c & 34EE1B-1 & Projectile point, Wilson \\
\hline E26/S74 & $31 \mathrm{~A}$ & & Isi-c & 34EE1C-2 & Thin uniface \\
\hline E26/S74 & $31 \mathrm{~B}$ & & Isi-c & & Debitage \\
\hline E26/S74 & $32 \mathrm{~A}$ & & Isi-c & & Debitage \\
\hline E26/S74 & $32 \mathrm{~A}$ & & Isi-c & 34FF1D-1 & Uniface, unanalyzed \\
\hline E26/S74 & $32 \mathrm{~B}$ & & Isi-c & & Debitage \\
\hline E26/S74 & $33 \mathrm{~A}$ & & Icl/Isi-c & & Debitage \\
\hline E26/S74 & $33 \mathrm{~B}$ & & Icl/Isi-c & & Debitage \\
\hline E26/S74 & $34 \mathrm{~A}$ & & Icl/Isi-c & & Debitage \\
\hline E26/S74 & $34 \mathrm{~B}$ & & Icl & & Debitage \\
\hline E26/S74 & $34 \mathrm{~B}$ & & Icl & $34 \mathrm{HH} 2 \mathrm{D}-3$ & Edge modified flake \\
\hline $\mathrm{E} 26 / \mathrm{S} 74$ & $34 \mathrm{~B}$ & & Icl & $34 \mathrm{HH} 2 \mathrm{D}-2$ & Uniface, unanalyzed \\
\hline E26/S74 & $35 \mathrm{~A}$ & & Icl & & Debitage \\
\hline E26/S74 & $35 \mathrm{~A}$ & & Icl & 34II1B-1 & Uniface, unanalyzed \\
\hline E26/S74 & $35 \mathrm{~B}$ & & Icl & 34 II $2 \mathrm{C}-1$ & Biface Stage 2 \\
\hline E26/S74 & $35 \mathrm{~B}$ & & Icl & & Debitage \\
\hline E26/S74 & $36 \mathrm{~A}$ & & Icl & & Debitage \\
\hline E26/S74 & $36 \mathrm{~B}$ & & Icl & & Debitage \\
\hline E26/S74 & $37 \mathrm{~A}$ & & Icl & & Debitage \\
\hline E26/S74 & $37 \mathrm{~B}$ & & Icl & & Debitage \\
\hline E26/S74 & $37 \mathrm{~B}$ & & Icl & $34 \mathrm{KK} 2 \mathrm{D}-2$ & Edge modified flake \\
\hline E26/S74 & $37 \mathrm{~B}$ & & Icl & $34 \mathrm{KK} 2 \mathrm{C}-1$ & Thin uniface \\
\hline $\mathrm{E} 26 / \mathrm{S} 74$ & $38 \mathrm{~A}$ & & Isi/Icl & & Debitage \\
\hline E26/S74 & $38 \mathrm{~B}-39 \mathrm{~A}$ & & Isi/Icl & & Debitage \\
\hline E26/S74 & 38B-39A & & Isi/Icl & 34LL2MM1D-1 & Edge modified flake \\
\hline E26/S74 & $40 \mathrm{~A}$ & & Isi/Icl & & Debitage \\
\hline E26/S74 & $40 \mathrm{~A}$ & & Isi/Icl & $34 \mathrm{NN} 1 \mathrm{~B}-2$ & Face battered stone \\
\hline $\mathrm{E} 26 / \mathrm{S} 74$ & $40 \mathrm{~A}$ & & Isi/Icl & 34 NN1D-1 & Mano/hammerstone \\
\hline $\mathrm{E} 26 / \mathrm{S} 74$ & $40 \mathrm{~A}-\mathrm{B}$ & & Isi/Icl & $34 \mathrm{NN} 1 \& 2 \mathrm{~A}$ & Core tool, type 2 \\
\hline $\mathrm{E} 26 / \mathrm{S} 74$ & $40 \mathrm{~B}$ & & Isi & & Debitage \\
\hline $\mathrm{E} 26 / \mathrm{S} 74$ & $41 \mathrm{~B}$ & & Ig1/Isi & & Debitage \\
\hline $\mathrm{E} 26 / \mathrm{S} 76$ & 15 & & IIIa/b & $330-1$ & Biface fragment \\
\hline E26/S76 & 15 & & $\mathrm{IIIa} / \mathrm{b}$ & $330-4$ & Biface Stage 2 \\
\hline E26/S76 & 15 & & $\mathrm{IIIa} / \mathrm{b}$ & & Debitage \\
\hline E26/S76 & 15 & & $\mathrm{IIIa} / \mathrm{b}$ & $330-3$ & Perforator Group 4 \\
\hline E26/S76 & 15 & & $\mathrm{IIIa} / \mathrm{b}$ & $330-6$ & Thin uniface fragment \\
\hline $\mathrm{E} 26 / \mathrm{S} 76$ & 15 & & $\mathrm{IIIa} / \mathrm{b}$ & $330-7$ & Uniface, unanalyzed \\
\hline E26/S76 & 15 & & IIIa/b & $330-8$ & Unifacial multiple tool \\
\hline
\end{tabular}

Count

Microspur/microdenticulate

Biface Stage

Debitage

nanalyzed

34Z1AB-1 Thick uniface fragment

Uniface, unanalyzed

34AA1D-2 Uniface, unanalyzed

34AA2C-2 $\quad$ Biface fragment

34AA2B-1 Edge modified flake

Uniface, unanalyzed

位age

Edge modified flake

Edge modified flake

Debitage

Debitage

Debitage

Notched flak

Debitage

Uniface, unanalyzed

Debitage

Debitage

34HH2D-3 Edge modified flake

Uniface, unanalyzed

Biface Stage 2

Debitage

Edge modified flake

Debitage

Isi/Icl

Isi/Icl

Isi/Icl

Isi/Icl

Isi

IIIa/b

IIIa/b

$\mathrm{III} / \mathrm{b}$

IIIa/b

$\mathrm{IIIa} / \mathrm{b}$ 


\begin{tabular}{|c|c|c|c|c|c|c|}
\hline Square & Level & Feature & Strata & Item & Analyst Identification & Coun \\
\hline E26/S76 & 15 & & $\mathrm{IIIa} / \mathrm{b}$ & $330-10$ & Unifacial multiple tool & \\
\hline E26/S76 & $16 \mathrm{~A}$ & & IIIa & $33 \mathrm{P} 1-5$ & Biface fragment & \\
\hline E26/S76 & $16 \mathrm{~A}$ & & IIIa & $33 \mathrm{P} 1-2$ & Biface fragment & \\
\hline E26/S76 & $16 \mathrm{~A}$ & & IIIa & $33 P 1-6$ & Biface Stage 1 & \\
\hline E26/S76 & $16 \mathrm{~A}$ & & IIIa & $33 P 1-1$ & Burin spall & \\
\hline E26/S76 & $16 \mathrm{~A}$ & & IIIa & & Debitage & 46 \\
\hline $\mathrm{E} 26 / \mathrm{S} 76$ & $16 \mathrm{~A}$ & & IIIa & $33 \mathrm{P} 1-3$ & Microspur/microdenticulate & \\
\hline $\mathrm{E} 26 / \mathrm{S} 76$ & $16 \mathrm{~A}$ & & IIIa & $33 \mathrm{P} 1-4$ & Microspur/microdenticulate & \\
\hline E26/S76 & $16 \mathrm{~B}$ & & IIIa & $33 \mathrm{P} 2-1$ & Biface fragment & \\
\hline E26/S76 & $16 \mathrm{~B}$ & & IIIa & $33 \mathrm{P} 2-2$ & Biface Stage 2 & \\
\hline $\mathrm{E} 26 / \mathrm{S} 76$ & $16 \mathrm{~B}$ & & IIIa & & Debitage & 31 \\
\hline E26/S76 & $16 \mathrm{~B}$ & & IIIa & $33 \mathrm{P} 2-3$ & Microspur/microdenticulate & \\
\hline $\mathrm{E} 26 / \mathrm{S} 76$ & $16 \mathrm{~B}$ & & IIIa & $33 \mathrm{P} 2-4$ & Uniface, unanalyzed & \\
\hline E26/S76 & $16 \mathrm{~B}$ & & IIIa & $33 P 2-5$ & Uniface, unanalyzed & \\
\hline E26/S76 & $16 \mathrm{~B}$ & & IIIa & $33 \mathrm{P} 2-6$ & Uniface, unanalyzed & \\
\hline E26/S76 & $16 \mathrm{~B}$ & Feature 124 & IIIa & $33 \mathrm{P} 2-7$ & Biface Stage 2 & \\
\hline E26/S76 & $16 \mathrm{~B}$ & Feature 124 & IIIa & $33 \& 32 \mathrm{P} 2-8$ & Burin spall & \\
\hline E26/S76 & $16 \mathrm{~B}$ & Feature 124 & IIIa & & Debitage & \\
\hline $\mathrm{E} 26 / \mathrm{S} 76$ & $17 \mathrm{~A}$ & & IIIa & 33Q1-2 & Biface Stage 2 & \\
\hline E26/S76 & $17 \mathrm{~A}$ & & IIIa & $33 Q 1-1$ & Biface Stage 2 & \\
\hline $\mathrm{E} 26 / \mathrm{S} 76$ & $17 \mathrm{~A}$ & & IIIa & & Debitage & 62 \\
\hline $\mathrm{E} 26 / \mathrm{S} 76$ & $17 \mathrm{~A}$ & & IIIa & $33 \mathrm{Q} 1-5$ & Projectile point, bifurcate stem fragment & \\
\hline E26/S76 & $17 \mathrm{~A}$ & & IIIa & $33 \mathrm{Q} 1-3$ & Uniface, unanalyzed & \\
\hline $\mathrm{E} 26 / \mathrm{S} 76$ & 17B & & IIIa & $33 Q 2-2$ & Biface fragment & \\
\hline E26/S76 & $17 \mathrm{~B}$ & & IIIIa & $33 \mathrm{Q} 2-1$ & Biface Stage 2 & \\
\hline $\mathrm{E} 26 / \mathrm{S} 76$ & $17 \mathrm{~B}$ & & IIIa & $33 \mathrm{Q} 2-3$ & Biface Stage 2 & \\
\hline E26/S76 & 17B & & IIIa & $33 \mathrm{Q} 2-5$ & Clear Fork biface & \\
\hline $\mathrm{E} 26 / \mathrm{S} 76$ & 17B & & IIIa & $33 Q 2-4$ & Core, thermal & \\
\hline E26/S76 & $17 \mathrm{~B}$ & & IIIa & & Debitage & 60 \\
\hline E26/S76 & $17 \mathrm{~B}$ & & IIIIa & $33 \mathrm{Q} 2-13$ & Edge modified flake & \\
\hline $\mathrm{E} 26 / \mathrm{S} 76$ & 17B & & IIIa & $33 \mathrm{Q} 2-15$ & Thin uniface & \\
\hline E26/S76 & 17B & & IIIa & $33 \mathrm{Q} 2-17$ & Thin uniface fragment & \\
\hline E26/S76 & $17 \mathrm{~B}$ & & IIIa & $33 \mathrm{Q} 2-7$ & Uniface, unanalyzed & \\
\hline E26/S76 & $17 \mathrm{~B}$ & & IIIa & $33 Q 2-9$ & Uniface, unanalyzed & \\
\hline $\mathrm{E} 26 / \mathrm{S} 76$ & $17 \mathrm{~B}$ & & IIIa & $33 Q 2-11$ & Uniface, unanalyzed & \\
\hline $\mathrm{E} 26 / \mathrm{S} 76$ & $17 \mathrm{~B}$ & & IIIa & $33 \mathrm{Q} 2-10$ & Uniface, unanalyzed & \\
\hline E26/S76 & 17B & & IIIa & $33 \mathrm{Q} 2-6$ & Uniface, unanalyzed & \\
\hline E26/S76 & $17 \mathrm{~B}$ & & IIIa & $33 Q 2-16$ & Unifacial multiple tool & \\
\hline E26/S76 & $17 \mathrm{~B}$ & & IIIIa & $33 Q 2-14$ & Unifacial multiple tool & \\
\hline E26/S76 & $17 \mathrm{~B}$ & Feature 124 & IIIa & $33 \mathrm{Q} 2-18$ & Biface fragment & \\
\hline E26/S76 & $17 \mathrm{~B}$ & Feature 124 & IIIa & $33 \& 32 Q 2-22$ & Biface Stage 2 & \\
\hline E26/S76 & $17 \mathrm{~B}$ & Feature 124 & IIIa & $33 \& 32 \mathrm{Q} 2-23$ & Biface Stage 2 & \\
\hline E26/S76 & $17 \mathrm{~B}$ & Feature 124 & IIIa & $33 \mathrm{Q} 2-19$ & Core, thermal & \\
\hline $\mathrm{E} 26 / \mathrm{S} 76$ & $17 \mathrm{~B}$ & Feature 124 & IIIa & $33 Q 2-20$ & Thin uniface & \\
\hline $\mathrm{E} 26 / \mathrm{S} 76$ & $18 \mathrm{~A}$ & & IIIa & $33 \mathrm{R} 1-1$ & Biface Stage 1 & \\
\hline E26/S76 & $18 \mathrm{~A}$ & & IIIa & & Debitage & \\
\hline E26/S76 & $18 \mathrm{~A}$ & & IIIa & $33 R 1-6$ & Edge modified flake & \\
\hline E26/S76 & $18 \mathrm{~A}$ & & IIIa & 33R1-2 & Perforator Group 7 & \\
\hline $\mathrm{E} 26 / \mathrm{S} 76$ & $18 \mathrm{~A}$ & & IIIa & $33 \mathrm{R} 1-8$ & Projectile point, miscellaneous lanceolate & \\
\hline $\mathrm{E} 26 / \mathrm{S} 76$ & $18 \mathrm{~A}$ & & IIIa & $33 \mathrm{R} 1-7$ & Retouched blade & \\
\hline $\mathrm{E} 26 / \mathrm{S} 76$ & $18 \mathrm{~A}$ & & IIIa & $33 \mathrm{R} 1-3$ & Small core hammerstone & \\
\hline E26/S76 & $18 \mathrm{~A}$ & & IIIa & $33 R 1-5$ & Uniface, unanalyzed & \\
\hline E26/S76 & $18 \mathrm{~B}$ & & IIIa & 33R2-1 & Biface fragment & \\
\hline $\mathrm{E} 26 / \mathrm{S} 76$ & $18 \mathrm{~B}$ & & IIIa & $33 R 2-7$ & Biface Stage 1 & \\
\hline $\mathrm{E} 26 / \mathrm{S} 76$ & $18 \mathrm{~B}$ & & IIIa & $33 \mathrm{R} 2-9$ & Clear Fork biface & \\
\hline E26/S76 & $18 \mathrm{~B}$ & & IIIa & & Debitage & \\
\hline $\mathrm{E} 26 / \mathrm{S} 76$ & $18 \mathrm{~B}$ & & IIIa & $33 R 2-5$ & Edge modified flake & \\
\hline $\mathrm{E} 26 / \mathrm{S} 76$ & $18 \mathrm{~B}$ & & IIIa & $33 \mathrm{R} 2-10$ & Edge modified flake & \\
\hline $\mathrm{E} 26 / \mathrm{S} 76$ & $18 \mathrm{~B}$ & & IIIa & $33 R 2-2$ & Perforator Group 7 & \\
\hline E26/S76 & $18 \mathrm{~B}$ & & IIIa & 33R2-12 & Projectile point, bifurcate stem fragment & \\
\hline E26/S76 & $18 \mathrm{~B}$ & & IIIa & $33 R 2-6$ & Uniface, unanalyzed & \\
\hline E26/S76 & $18 \mathrm{~B}$ & & IIIa & 33R2-11 & Uniface, unanalyzed & \\
\hline E26/S76 & $18 \mathrm{~B}$ & Feature 141 & IIIa & $33 R 2-8$ & Clear Fork biface, proximal & \\
\hline $\mathrm{E} 26 / \mathrm{S} 76$ & $19 \mathrm{~A}$ & & II/IIIa & & Debitage & 30 \\
\hline E26/S76 & $19 \mathrm{~A}$ & & II/IIIa & $33 S 1-3$ & Denticulated flake & \\
\hline E26/S76 & $19 \mathrm{~A}$ & & II/IIIa & $33 \mathrm{~S} 1-6$ & Thick uniface & \\
\hline E26/S76 & $19 \mathrm{~A}$ & & II/IIIa & $33 \mathrm{~S} 1-1$ & Thin uniface fragment & \\
\hline E26/S76 & $19 \mathrm{~A}$ & & II/IIIa & $33 \mathrm{~S} 1-2$ & Uniface, unanalyzed & \\
\hline E26/S76 & $19 \mathrm{~A}$ & & II/IIIa & $33 \mathrm{~S} 1-5$ & Uniface, unanalyzed & \\
\hline $\mathrm{E} 26 / \mathrm{S} 76$ & $19 \mathrm{~A}$ & & II/IIIa & $33 \mathrm{~S} 1-7$ & Unifacial multiple tool & \\
\hline E26/S76 & $19 \mathrm{~B}$ & & II/IIIa & $33 \mathrm{~S} 2-1$ & Biface fragment & \\
\hline E26/S76 & 19B & & II/IIIa & $33 \mathrm{~S} 2 \mathrm{~A}-3$ & Burin spall & \\
\hline E26/S76 & $19 \mathrm{~B}$ & & II/IIIa & $33 \mathrm{~S} 2 \mathrm{~B}-4$ & Burin spall & \\
\hline E26/S76 & $19 \mathrm{~B}$ & & II/IIIa & & Debitage & 308 \\
\hline
\end{tabular}




\begin{tabular}{|c|c|c|c|c|c|}
\hline Square & Level & Feature & Strata & Item & Analyst Identification \\
\hline E26/S76 & $19 \mathrm{~B}$ & & II/IIIa & $33 \mathrm{~S} 2-2$ & Perforator Group 2 \\
\hline E26/S76 & 19B & & II/IIIa & $33 \mathrm{~S} 2 \mathrm{C}-8 \mathrm{~B}$ & Thin uniface \\
\hline E26/S76 & $19 \mathrm{~B}$ & & II/IIIa & $33 \mathrm{~S} 2 \mathrm{~B}-6$ & Uniface, unanalyzed \\
\hline E26/S76 & $19 \mathrm{~B}$ & & II/IIIa & 33 S2D-9 & Uniface, unanalyzed \\
\hline E26/S76 & $19 \mathrm{~B}$ & & II/IIIa & $33 \mathrm{~S} 2 \mathrm{C}-8 \mathrm{~A}$ & Unifacial multiple tool \\
\hline $\mathrm{E} 26 / \mathrm{S} 76$ & $20 \mathrm{~A}$ & & II/IIIa & $33 \mathrm{~T} 1 \mathrm{~B}-8$ & Battered cobble \\
\hline $\mathrm{E} 26 / \mathrm{S} 76$ & $20 \mathrm{~A}$ & & II/IIIa & 33 TIB-5 & Burin spall \\
\hline E26/S76 & $20 \mathrm{~A}$ & & II/IIIa & & Debitage \\
\hline E26/S76 & $20 \mathrm{~A}$ & & II/IIIa & $33 \mathrm{~T} 1 \mathrm{C}-12$ & Notched flake \\
\hline $\mathrm{E} 26 / \mathrm{S} 76$ & $20 \mathrm{~A}$ & & II/IIIa & $33 \mathrm{~T} 1 \mathrm{~B}-4$ & Notched flake \\
\hline E26/S76 & $20 \mathrm{~A}$ & & II/IIIa & 33T1D-13 & Projectile point fragment \\
\hline E26/S76 & $20 \mathrm{~A}$ & & II/IIIa & $33 \mathrm{~T} 1 \mathrm{~B}-9$ & Small core hammerstone \\
\hline E26/S76 & $20 \mathrm{~A}$ & & II/IIIa & $33 \mathrm{~T} 1 \mathrm{~A}-2$ & Uniface, unanalyzed \\
\hline E26/S76 & $20 \mathrm{~A}$ & & II/IIIa & $33 \mathrm{~T} 1 \mathrm{C}-11$ & Uniface, unanalyzed \\
\hline $\mathrm{E} 26 / \mathrm{S} 76$ & $20 \mathrm{~A}$ & & II/IIIa & $33 \mathrm{~T} 1 \mathrm{C}-10$ & Uniface, unanalyzed \\
\hline $\mathrm{E} 26 / \mathrm{S} 76$ & $20 \mathrm{~A}$ & & II/IIIa & 33T1B-3 & Uniface, unanalyzed \\
\hline E26/S76 & $20 \mathrm{~A}$ & & II/IIIa & 33T1A-1 & Uniface, unanalyzed \\
\hline E26/S76 & $20 \mathrm{~A}$ & & II/IIIa & 33T1D-14 & Uniface, unanalyzed \\
\hline E26/S76 & $20 \mathrm{~A}$ & & II/IIIa & $33 \mathrm{~T} 1 \mathrm{~B}-6$ & Uniface, unanalyzed \\
\hline $\mathrm{E} 26 / \mathrm{S} 76$ & $20 \mathrm{~A}$ & Feature 145 & II/IIIa & & Debitage \\
\hline E26/S76 & $20 \mathrm{~B}$ & & II/IIIa & & Debitage \\
\hline E26/S76 & $20 \mathrm{~B}$ & & II/IIIa & $33 \mathrm{~T} 2 \mathrm{~A}-2$ & Uniface, unanalyzed \\
\hline E26/S76 & $20 \mathrm{~B}$ & & II/IIIa & $33 \mathrm{~T} 2 \mathrm{C}-3$ & Uniface, unanalyzed \\
\hline $\mathrm{E} 26 / \mathrm{S} 76$ & $20 \mathrm{~B}$ & & II/IIIa & $33 \mathrm{~T} 2 \mathrm{C}-4$ & Uniface, unanalyzed \\
\hline E26/S76 & $20 \mathrm{~B}$ & & II/IIIa & $33 \mathrm{~T} 2 \mathrm{D}-5$ & Uniface, unanalyzed \\
\hline E26/S76 & $20 \mathrm{~B}$ & & II/IIIa & $33 \mathrm{~T} 2 \mathrm{~A}-1$ & Uniface, unanalyzed \\
\hline E26/S76 & $21 \mathrm{~A}$ & & II/IIIa & & Debitage \\
\hline E26/S76 & $21 \mathrm{~A}$ & & II/IIIa & $33 \mathrm{U} 1 \mathrm{C}-2$ & Notched flake \\
\hline $\mathrm{E} 26 / \mathrm{S} 76$ & $21 \mathrm{~A}$ & & II/IIIa & 33 U1D-4 & Uniface, unanalyzed \\
\hline E26/S76 & $21 \mathrm{~A}$ & & II/IIIa & 33U1A-1 & Uniface, unanalyzed \\
\hline E26/S76 & $21 \mathrm{~A}$ & & II/IIIa & $33 \mathrm{U} 1 \mathrm{C}-3$ & Uniface, unanalyzed \\
\hline $\mathrm{E} 26 / \mathrm{S} 76$ & $21 \mathrm{~A}$ & & II/IIIa & 33 U1D-6 & Unifacial multiple tool \\
\hline $\mathrm{E} 26 / \mathrm{S} 76$ & $21 \mathrm{~B}$ & & II & & Debitage \\
\hline E26/S76 & $21 \mathrm{~B}$ & & II & $33 \mathrm{U} 2 \mathrm{D}-3$ & Thick uniface \\
\hline E26/S76 & $21 \mathrm{~B}$ & & II & $33 \mathrm{U} 2 \mathrm{D}-1$ & Uniface, unanalyzed \\
\hline $\mathrm{E} 26 / \mathrm{S} 76$ & $21 \mathrm{~B}$ & & II & $33 \mathrm{U} 2 \mathrm{D}-2$ & Uniface, unanalyzed \\
\hline E26/S76 & $22 \mathrm{~A}$ & & II & 33V1D-2 & Biface Stage 2 \\
\hline $\mathrm{E} 26 / \mathrm{S} 76$ & $22 \mathrm{~A}$ & & II & $33 \mathrm{~V} 1 \mathrm{D}-3$ & Biface Stage 3 \\
\hline $\mathrm{E} 26 / \mathrm{S} 76$ & $22 \mathrm{~A}$ & & II & & Debitage \\
\hline E26/S76 & $22 \mathrm{~A}$ & & II & $33 \mathrm{~V} 1 \mathrm{~A}-1$ & Uniface, unanalyzed \\
\hline E26/S76 & $22 \mathrm{~B}$ & & II & $33 \mathrm{~V} 2 \mathrm{D}-2$ & Biface Stage 2 \\
\hline E26/S76 & $22 \mathrm{~B}$ & & II & & Debitage \\
\hline $\mathrm{E} 26 / \mathrm{S} 76$ & $22 \mathrm{~B}$ & & II & $33 \mathrm{~V} 2 \mathrm{~B}-1$ & Uniface, unanalyzed \\
\hline E26/S76 & $23 \mathrm{~A}$ & & II & $33 \mathrm{~W} 1 \mathrm{C}-2$ & Biface Stage 2 \\
\hline E26/S76 & $23 \mathrm{~A}$ & & II & & Debitage \\
\hline E26/S76 & $23 \mathrm{~A}$ & & II & $33 \mathrm{~W} 1 \mathrm{~B}-1$ & Uniface, unanalyzed \\
\hline E26/S76 & $23 \mathrm{~B}$ & & II & & Debitage \\
\hline $\mathrm{E} 26 / \mathrm{S} 76$ & $23 \mathrm{~B}$ & & II & $33 \mathrm{~W} 2 \mathrm{~B}-1$ & Uniface, unanalyzed \\
\hline E26/S76 & $24 \mathrm{~A}$ & & II & & Debitage \\
\hline E26/S76 & $24 \mathrm{~A}$ & & II & $33 \mathrm{X} 1 \mathrm{~A}-4$ & Projectile point, miscellaneous lanceolate \\
\hline E26/S76 & $24 \mathrm{~B}$ & & II & $33 \times 2 B-4$ & Core fragment \\
\hline $\mathrm{E} 26 / \mathrm{S} 76$ & $24 \mathrm{~B}$ & & II & & Debitage \\
\hline E26/S76 & $24 \mathrm{~B}$ & & II & $33 \times 2 \mathrm{C}-1$ & Projectile point, Golondrina-Barber \\
\hline E26/S76 & $24 \mathrm{~B}$ & & II & $33 \times 2 C-2$ & Uniface, unanalyzed \\
\hline E26/S76 & $24 B$ & & II & $33 \times 2 D-3$ & Uniface, unanalyzed \\
\hline E26/S76 & $25 \mathrm{~A}$ & & II & 33Y1B-1 & Biface Stage 1 \\
\hline E26/S76 & $25 \mathrm{~A}$ & & II & & Debitage \\
\hline E26/S76 & $25 \mathrm{~A}$ & & II & 33 Y1D-2 & Possible ground stone \\
\hline $\mathrm{E} 26 / \mathrm{S} 76$ & $25 \mathrm{~B}$ & & II & $33 Y 2 A-1$ & Biface Stage 2 \\
\hline $\mathrm{E} 26 / \mathrm{S} 76$ & $25 \mathrm{~B}$ & & II & & Debitage \\
\hline E26/S76 & $25 \mathrm{~B}$ & & II & $33 \mathrm{Y} 2 \mathrm{C}-3$ & Thin uniface fragment \\
\hline E26/S76 & $25 \mathrm{~B}$ & & II & $33 \mathrm{Y} 2 \mathrm{D}-4$ & Uniface, unanalyzed \\
\hline E26/S76 & $25 \mathrm{~B}$ & & II & 33Y2B-2 & Uniface, unanalyzed \\
\hline E26/S76 & $26 \mathrm{~A}$ & & II & & Debitage \\
\hline $\mathrm{E} 26 / \mathrm{S} 76$ & $26 \mathrm{~B}$ & & II & & Debitage \\
\hline E26/S76 & $26 \mathrm{~B}$ & Feature 164 & II & & Debitage \\
\hline E26/S76 & $27 \mathrm{~A}$ & & $\mathrm{Id} / \mathrm{II}$ & 33AA1B-1 & Biface Stage 2 \\
\hline E26/S76 & $27 \mathrm{~A}$ & & $\mathrm{Id} / \mathrm{II}$ & & Debitage \\
\hline E26/S76 & $27 \mathrm{~B}$ & & Isi-c/Id/II & & Debitage \\
\hline $\mathrm{E} 26 / \mathrm{S} 76$ & $28 \mathrm{~A}$ & & Isi-c/Id/II & & Debitage \\
\hline E26/S76 & $28 \mathrm{~A}$ & & Isi-c/Id/II & 33BB1B-1 & Denticulated flake \\
\hline $\mathrm{E} 26 / \mathrm{S} 76$ & $28 \mathrm{~B}$ & & Isi-c/Id & & Debitage \\
\hline $\mathrm{E} 26 / \mathrm{S} 76$ & $29 \mathrm{~A}$ & & Isi-c/Id & & Debitage \\
\hline $\mathrm{E} 26 / \mathrm{S} 76$ & $29 \mathrm{~A}$ & & Isi-c/Id & $33 \mathrm{CC} 1 \mathrm{C}-1$ & Edge modified flake \\
\hline
\end{tabular}

Count

1

33S2B-6 Uniface, unanalyzed

$33 \mathrm{~S} 2 \mathrm{C}-8 \mathrm{~A}$

33T1B-8

33 TIB-5

33 T1B-9

33T1A-2

$331 \mathrm{C}-1$

33T1B-3

33T1A-1

33T1D-14

$33 \mathrm{~T} 2 \mathrm{~A}-2$

33T2A-1

$33 \mathrm{U} 1 \mathrm{C}-2$

$33 \mathrm{U} 1 \mathrm{D}-4$

33U1D-6

$33 \mathrm{U} 2 \mathrm{D}-3$

3

33V1D-2

33V1D-3

33V1A-1

$33 \mathrm{~W} 1 \mathrm{C}-2$

33W1B-

33W2B-1

$33 \times 1 A-4$

$33 \times 2 B-4$

33Y1D-2

$33 \mathrm{Y} 2 \mathrm{C}-3$

33Y2D-4

33 Y $2 B-2$

33AA1B-

Debitage

Denticulated flake

Debitage

Isi-c/Id

$33 \mathrm{CC} 1 \mathrm{C}-1$

Edge modified flake 


\begin{tabular}{|c|c|c|c|c|c|c|}
\hline Square & Level & Feature & Strata & Item & Analyst Identification & $\begin{array}{r}\text { Count } \\
27\end{array}$ \\
\hline $\begin{array}{l}\text { E26/S76 } \\
\text { E26/S76 }\end{array}$ & $\begin{array}{l}29 \mathrm{~B} \\
29 \mathrm{~B}\end{array}$ & & $\begin{array}{l}\text { Isi-c } \\
\text { Isi-c }\end{array}$ & $33 \mathrm{CC} 2 \mathrm{~A}-1$ & $\begin{array}{l}\text { Debitage } \\
\text { Edge modified flake }\end{array}$ & 27 \\
\hline $\mathrm{E} 26 / \mathrm{S} 76$ & $30 \mathrm{~A}$ & & Isi-c & & Debitage & 2 \\
\hline E26/S76 & $30 \mathrm{~B}$ & & Isi-c & & Debitage & 2 \\
\hline E26/S76 & $31 \mathrm{~A}$ & & Isi-c & & Debitage & \\
\hline $\mathrm{E} 26 / \mathrm{S} 76$ & $31 \mathrm{~A}$ & & Isi-c & 33EE1C-1 & Projectile point, Wilson & \\
\hline E26/S76 & $31 \mathrm{~B}$ & & Isi-c & & Debitage & \\
\hline E26/S76 & $32 \mathrm{~A}$ & & Isi-c & & Debitage & 2 \\
\hline E26/S76 & $32 \mathrm{~A}$ & & Isi-c & 33FF1D-2 & Edge modified flake & \\
\hline E26/S76 & $32 \mathrm{~A}$ & & Isi-c & $33 \mathrm{FF} 1 \mathrm{C}-1$ & Unifacial multiple tool & \\
\hline E26/S76 & $32 \mathrm{~B}$ & & Icl/Isi-c & & Debitage & \\
\hline E26/S76 & $32 \mathrm{~B}$ & & Icl/Isi-c & 33FF2B-1 & Thin uniface & \\
\hline E26/S76 & $33 \mathrm{~A}$ & & Icl/Isi-c & 33GG1C-1 & Burin spall & \\
\hline $\mathrm{E} 26 / \mathrm{S} 76$ & $33 \mathrm{~A}$ & & Icl/Isi-c & & Debitage & 1 \\
\hline E26/S76 & 33B & & $\mathrm{Icl} / \mathrm{Isi}-\mathrm{c}$ & & Debitage & \\
\hline E26/S76 & $33 \mathrm{~B}$ & & Icl/Isi-c & $33 \mathrm{GG} 2 \mathrm{~A}-1$ & Edge modified flake & \\
\hline $\mathrm{E} 26 / \mathrm{S} 76$ & $34 \mathrm{~A}$ & & Icl/Isi-c & & Debitage & 10 \\
\hline E26/S76 & $34 \mathrm{~A}$ & & Icl/Isi-c & 33HH1D-1 & Edge modified flake & \\
\hline E26/S76 & $34 \mathrm{~B}$ & & Icl & & Debitage & 1 \\
\hline E26/S76 & $35 \mathrm{~A}$ & & Icl & & Debitage & 2 \\
\hline E26/S76 & $35 \mathrm{~B}$ & & Icl & & Debitage & 3 \\
\hline E26/S76 & $36 \mathrm{~A}$ & & Icl & 33JJ1A-1 & Blade & \\
\hline $\mathrm{E} 26 / \mathrm{S} 76$ & $36 \mathrm{~A}$ & & $\mathrm{Icl} / \mathrm{D}$ & & Debitage & 1 \\
\hline $\mathrm{E} 26 / \mathrm{S} 76$ & $36 \mathrm{~A}$ & & Icl & & Debitage & 3 \\
\hline E26/S76 & $36 \mathrm{~B}$ & & Icl & & Debitage & 17 \\
\hline E26/S76 & $36 \mathrm{~B}$ & & $\mathrm{Icl} / \mathrm{D}$ & & Debitage & \\
\hline $\mathrm{E} 26 / \mathrm{S} 76$ & $37 \mathrm{~A}$ & & Icl & & Debitage & 3 \\
\hline $\mathrm{E} 26 / \mathrm{S} 76$ & $37 \mathrm{~A}$ & & $\mathrm{Icl} / \mathrm{D}$ & & Debitage & \\
\hline E26/S76 & $37 \mathrm{~A}$ & & Icl & $33 \mathrm{KK} 1 \mathrm{~B}-1$ & Thin uniface fragment & \\
\hline E26/S76 & $37 \mathrm{~A}-38 \mathrm{~A}$ & Feature 175 & $\mathrm{Icl} / \mathrm{D}$ & & Debitage & \\
\hline E26/S76 & $37 \mathrm{~B}$ & & $\mathrm{Icl} / \mathrm{D}$ & & Debitage & 10 \\
\hline $\mathrm{E} 26 / \mathrm{S} 76$ & $37 \mathrm{~B}$ & & Icl & & Debitage & \\
\hline $\mathrm{E} 26 / \mathrm{S} 76$ & $37 \mathrm{~B}$ & & Icl & $33 \mathrm{KK} 2 \mathrm{~B}-1$ & Spurred flake & \\
\hline $\mathrm{E} 26 / \mathrm{S} 76$ & $37 \mathrm{~B}$ & & Icl & $33 \mathrm{KK} 2 \mathrm{C}-3$ & Uniface, unanalyzed & \\
\hline E26/S76 & $38 \mathrm{~A}$ & & Isi/Icl & & Debitage & 22 \\
\hline E26/S76 & $38 \mathrm{~A}$ & & Isi/Icl & 33LL1A-1 & Spurred flake & \\
\hline E26/S76 & 38B & & Isi/Icl & & Debitage & 1 \\
\hline E26/S76 & $39 \mathrm{~A}$ & & Isi/Icl & & Debitage & 2 \\
\hline E26/S76 & $39 \mathrm{~A}$ & & Isi/Icl & $33 \mathrm{MM} 1 \mathrm{~A}-1$ & Uniface, unanalyzed & \\
\hline E26/S76 & $39 \mathrm{~B}$ & & Isi/Icl & 33MM2D-2 & Biface Stage 1 & \\
\hline E26/S76 & 39B & & Isi/Icl & & Debitage & 2 \\
\hline E26/S76 & $39 B$ & & Isi/Icl & 33MM2D-1 & Large core hammerstone & \\
\hline E26/S76 & 39B & & Isi/Icl & 33MM2D & Uniface, unanalyzed & \\
\hline $\mathrm{E} 26 / \mathrm{S} 76$ & $40 \mathrm{~A}$ & & Isi/Icl & 33NN1D-1 & Core fragment & \\
\hline E26/S76 & $40 \mathrm{~A}$ & & Isi/Icl & & Debitage & 48 \\
\hline $\mathrm{E} 26 / \mathrm{S} 76$ & $40 \mathrm{~A}$ & & Isi/Icl & 33NN1D-2 & Uniface, unanalyzed & \\
\hline E26/S76 & $40 \mathrm{~B}$ & & Isi/Icl & & Debitage & \\
\hline $\mathrm{E} 26 / \mathrm{S} 76$ & $40 \mathrm{~B}$ & & Isi/Icl & $33 \mathrm{NN} 2 \mathrm{~A}-1$ & Uniface, unanalyzed & \\
\hline $\mathrm{E} 26 / \mathrm{S} 76$ & $41 \mathrm{~A}$ & & Isi/Icl & & Debitage & 1 \\
\hline E26/S76 & $41 \mathrm{~B}$ & & Isi/Icl & & Debitage & \\
\hline $\mathrm{E} 26 / \mathrm{S} 76$ & $42 \mathrm{~A}$ & & $\mathrm{Igl} / \mathrm{Isi} / \mathrm{Icl}$ & & Debitage & \\
\hline $\mathrm{E} 26 / \mathrm{S} 78$ & 13 & & IIIIa/b & $32 \mathrm{M}-1$ & Projectile point, miscellaneous lanceolate & \\
\hline E26/S78 & 15 & & $\mathrm{IIIa} / \mathrm{b}$ & $32 \mathrm{O}-8$ & Biface Stage 2 & \\
\hline E26/S78 & 15 & & $\mathrm{IIIa} / \mathrm{b}$ & $320-5$ & Biface Stage 2 & \\
\hline $\mathrm{E} 26 / \mathrm{S} 78$ & 15 & & IIIa/b & $320-10$ & Burin & \\
\hline E26/S78 & 15 & & $\mathrm{IIIa} / \mathrm{b}$ & & Debitage & 1621 \\
\hline $\mathrm{E} 26 / \mathrm{S} 78$ & 15 & & $\mathrm{IIIa} / \mathrm{b}$ & $32 \mathrm{O}-12$ & Micro-core, intermediate & \\
\hline E26/S78 & 15 & & $\mathrm{IIIa} / \mathrm{b}$ & $320-9$ & Projectile point fragment & \\
\hline E26/S78 & 15 & & IIIa/b & $320-11$ & Projectile point fragment & \\
\hline $\mathrm{E} 26 / \mathrm{S} 78$ & 15 & & $\mathrm{IIIa} / \mathrm{b}$ & $32 \mathrm{O}-4$ & Projectile point fragment & \\
\hline $\mathrm{E} 26 / \mathrm{S} 78$ & 15 & & $\mathrm{IIIa} / \mathrm{b}$ & $32 \mathrm{O}-6$ & Projectile point, bifurcate stem fragment & \\
\hline E26/S78 & 15 & & IIIa/b & $32 \mathrm{O}-1$ & Projectile point, expanding concave $\mathrm{B}$ & \\
\hline E26/S78 & 15 & & $\mathrm{III} / \mathrm{b}$ & $320-2$ & Projectile point, indeterminate & \\
\hline E26/S78 & 15 & & IIIa/b & $320-14$ & Spurred flake & \\
\hline E26/S78 & 15 & & $\mathrm{IIIa} / \mathrm{b}$ & $32 \mathrm{O}-13$ & Thin uniface & \\
\hline $\mathrm{E} 26 / \mathrm{S} 78$ & 15 & & $\mathrm{IIIa} / \mathrm{b}$ & $32 \mathrm{O}-16$ & Uniface, unanalyzed & \\
\hline E26/S78 & 15 & & $\mathrm{IIIa} / \mathrm{b}$ & $32 \mathrm{O}-17$ & Uniface, unanalyzed & \\
\hline E26/S78 & 15 & & $\mathrm{IIIa} / \mathrm{b}$ & $320-15$ & Uniface, unanalyzed & \\
\hline E26/S78 & $16 \mathrm{~A}$ & Feature 124 & IIIa & $32 \mathrm{P} 1-1$ & Burin spall & \\
\hline E26/S78 & $16 \mathrm{~A}$ & Feature 124 & IIIa & & Debitage & \\
\hline E26/S78 & $16 \mathrm{~A}$ & Feature 124 & IIIa & $32 \mathrm{P} 1-3$ & Perforator Group 7 & \\
\hline E26/S78 & $16 \mathrm{~A}$ & Feature 124 & IIIa & $32 P 1-6$ & Thin uniface & \\
\hline $\mathrm{E} 26 / \mathrm{S} 78$ & $16 \mathrm{~A}$ & Feature 124 & IIIa & $32 \mathrm{P} 1-4$ & Uniface, unanalyzed & \\
\hline E26/S78 & $16 \mathrm{~A}$ & Feature 124 & IIIa & $32 \mathrm{P} 1-5$ & Uniface, unanalyzed & \\
\hline
\end{tabular}




\begin{tabular}{|c|c|c|c|c|c|}
\hline Square & Level & Feature & Strata & Item & Analyst Identification \\
\hline $\mathrm{E} 26 / \mathrm{S} 78$ & $16 \mathrm{~B}$ & & IIIa & $32 \mathrm{P} 2-5$ & Biface fragment \\
\hline $\mathrm{E} 26 / \mathrm{S} 78$ & $16 \mathrm{~B}$ & & IIIa & $32 \mathrm{P} 2-7$ & Burin spall \\
\hline $\mathrm{E} 26 / \mathrm{S} 78$ & $16 \mathrm{~B}$ & & IIIa & & Debitage \\
\hline $\mathrm{E} 26 / \mathrm{S} 78$ & $16 \mathrm{~B}$ & & IIIa & $32 \mathrm{P} 2-6$ & Edge modified flake \\
\hline $\mathrm{E} 26 / \mathrm{S} 78$ & $16 \mathrm{~B}$ & & IIIa & $32 \mathrm{P} 2-1$ & Perforator Group 7 \\
\hline $\mathrm{E} 26 / \mathrm{S} 78$ & $16 \mathrm{~B}$ & & IIIa & $32 \mathrm{P} 2-3$ & Uniface, unanalyzed \\
\hline E26/S78 & $16 \mathrm{~B}$ & & IIIa & $32 \mathrm{P} 2-4$ & Uniface, unanalyzed \\
\hline $\mathrm{E} 26 / \mathrm{S} 78$ & $16 \mathrm{~B}$ & & IIIa & $32 \mathrm{P} 2-2$ & Uniface, unanalyzed \\
\hline $\mathrm{E} 26 / \mathrm{S} 78$ & $16 \mathrm{~B}$ & Feature 124 & IIIa & $32 \mathrm{P} 2-15$ & Biface Stage 2 \\
\hline $\mathrm{E} 26 / \mathrm{S} 78$ & $16 \mathrm{~B}$ & Feature 124 & IIIa & $32 \mathrm{P} 2-14$ & Biface Stage 2 \\
\hline $\mathrm{E} 26 / \mathrm{S} 78$ & $16 \mathrm{~B}$ & Feature 124 & IIIa & $32 \mathrm{P} 2-13$ & Biface Stage 2 \\
\hline E26/S78 & $16 \mathrm{~B}$ & Feature 124 & IIIa & $32 \mathrm{P} 2-17$ & Denticulated flake \\
\hline $\mathrm{E} 26 / \mathrm{S} 78$ & $16 \mathrm{~B}$ & Feature 124 & IIIa & $32 \mathrm{P} 2-11$ & Mano \\
\hline $\mathrm{E} 26 / \mathrm{S} 78$ & $16 \mathrm{~B}$ & Feature 124 & IIIa & $32 \mathrm{P} 2-12$ & Projectile point, Hoxie C \\
\hline $\mathrm{E} 26 / \mathrm{S} 78$ & $16 \mathrm{~B}$ & Feature 124 & IIIa & $32 \mathrm{P} 2-18$ & Thin uniface \\
\hline E26/S78 & $17 \mathrm{~A}$ & & IIIa & & Debitage \\
\hline $\mathrm{E} 26 / \mathrm{S} 78$ & $17 \mathrm{~A}$ & & IIIa & 32Q1-1 & Projectile point, bifurcate stem fragment \\
\hline E26/S78 & $17 \mathrm{~A}$ & & IIIa & $32 \mathrm{Q} 1-2$ & Uniface, unanalyzed \\
\hline E26/S78 & $17 \mathrm{~A}$ & & IIIa & $32 Q 1-6$ & Uniface, unanalyzed \\
\hline E26/S78 & $17 \mathrm{~A}$ & & IIIa & $32 \mathrm{Q} 1-5$ & Uniface, unanalyzed \\
\hline $\mathrm{E} 26 / \mathrm{S} 78$ & $17 \mathrm{~A}$ & & IIIa & $32 \mathrm{Q} 1-3$ & Uniface, unanalyzed \\
\hline $\mathrm{E} 26 / \mathrm{S} 78$ & $17 \mathrm{~A}$ & & IIIa & $32 \mathrm{Q} 1-4$ & Uniface, unanalyzed \\
\hline $\mathrm{E} 26 / \mathrm{S} 78$ & $17 \mathrm{~A}$ & Feature 124 & IIIa & $32 \mathrm{Q} 1-7$ & Thick uniface \\
\hline $\mathrm{E} 26 / \mathrm{S} 78$ & $17 \mathrm{~B}$ & & IIIa & $32 \mathrm{Q} 2-2$ & Biface fragment \\
\hline $\mathrm{E} 26 / \mathrm{S} 78$ & $17 \mathrm{~B}$ & & IIIa & $32 \mathrm{Q} 2-4$ & Core fragment \\
\hline $\mathrm{E} 26 / \mathrm{S} 78$ & $17 \mathrm{~B}$ & & IIIa & & Debitage \\
\hline $\mathrm{E} 26 / \mathrm{S} 78$ & $17 \mathrm{~B}$ & & IIIa & $32 \mathrm{Q} 2-1$ & Mano fragment \\
\hline E26/S78 & 17B & & IIIa & $32 Q 2-3$ & Notched flake \\
\hline $\mathrm{E} 26 / \mathrm{S} 78$ & $17 \mathrm{~B}$ & & IIIa & $32 \mathrm{Q} 2-8$ & Thin uniface \\
\hline E26/S78 & $17 \mathrm{~B}$ & & IIIa & $32 \mathrm{Q} 2-9$ & Thin uniface \\
\hline E26/S78 & $17 \mathrm{~B}$ & & IIIa & $32 \mathrm{Q} 2-7$ & Thin uniface fragment \\
\hline E26/S78 & $17 \mathrm{~B}$ & & IIIa & $32 Q 2-5$ & Uniface, unanalyzed \\
\hline $\mathrm{E} 26 / \mathrm{S} 78$ & $18 \mathrm{~A}$ & & IIIa & $32 \mathrm{R} 1-9$ & Biface fragment \\
\hline $\mathrm{E} 26 / \mathrm{S} 78$ & $18 \mathrm{~A}$ & & IIIa & $32 \mathrm{R} 1-1$ & Biface Stage 1 \\
\hline $\mathrm{E} 26 / \mathrm{S} 78$ & $18 \mathrm{~A}$ & & IIIa & $32 \mathrm{R} 1-12$ & Biface Stage 1 \\
\hline $\mathrm{E} 26 / \mathrm{S} 78$ & $18 \mathrm{~A}$ & & IIIa & & Debitage \\
\hline $\mathrm{E} 26 / \mathrm{S} 78$ & $18 \mathrm{~A}$ & & IIIa & $32 \mathrm{R} 1-8$ & Denticulated flake \\
\hline $\mathrm{E} 26 / \mathrm{S} 78$ & $18 \mathrm{~A}$ & & IIIa & $32 \mathrm{R} 1-6$ & Microspur/microdenticulate \\
\hline $\mathrm{E} 26 / \mathrm{S} 78$ & $18 \mathrm{~A}$ & & IIIa & $32 \mathrm{R} 1-2$ & Projectile point, bifurcate stem fragment \\
\hline $\mathrm{E} 26 / \mathrm{S} 78$ & $18 \mathrm{~A}$ & & IIIa & $32 \mathrm{R} 1-13$ & Thin uniface \\
\hline $\mathrm{E} 26 / \mathrm{S} 78$ & $18 \mathrm{~A}$ & & IIIa & $32 \mathrm{R} 1-7$ & Uniface, unanalyzed \\
\hline $\mathrm{E} 26 / \mathrm{S} 78$ & $18 \mathrm{~A}$ & & IIIa & $32 \mathrm{R} 1-3$ & Uniface, unanalyzed \\
\hline $\mathrm{E} 26 / \mathrm{S} 78$ & $18 \mathrm{~A}$ & & IIIa & $32 \mathrm{R} 1-4$ & Uniface, unanalyzed \\
\hline $\mathrm{E} 26 / \mathrm{S} 78$ & $18 \mathrm{~A}$ & & IIIa & $32 \mathrm{R} 1-10$ & Uniface, unanalyzed \\
\hline $\mathrm{E} 26 / \mathrm{S} 78$ & $18 \mathrm{~A}$ & & IIIa & 32R1-11 & Uniface, unanalyzed \\
\hline $\mathrm{E} 26 / \mathrm{S} 78$ & $18 \mathrm{~B}$ & & IIIa & $32 \mathrm{R} 2-2$ & Burin spall \\
\hline $\mathrm{E} 26 / \mathrm{S} 78$ & $18 \mathrm{~B}$ & & IIIa & & Debitage \\
\hline $\mathrm{E} 26 / \mathrm{S} 78$ & $18 \mathrm{~B}$ & & IIIa & $32 \mathrm{R} 2-1$ & Projectile point fragment \\
\hline $\mathrm{E} 26 / \mathrm{S} 78$ & $18 \mathrm{~B}$ & & IIIa & $32 \mathrm{R} 2-6$ & Thin uniface fragment \\
\hline E26/S78 & $18 \mathrm{~B}$ & & IIIa & $32 \mathrm{R} 2-4$ & Uniface, unanalyzed \\
\hline $\mathrm{E} 26 / \mathrm{S} 78$ & $18 \mathrm{~B}$ & & IIIa & $32 \mathrm{R} 2-5$ & Uniface, unanalyzed \\
\hline E26/S78 & $18 \mathrm{~B}$ & & IIIa & $32 \mathrm{R} 2-3$ & Unifacial multiple tool \\
\hline E26/S78 & $19 \mathrm{~A}$ & & II/IIIa & $32 \mathrm{~S} 1-2$ & Biface Stage 2 \\
\hline E26/S78 & $19 \mathrm{~A}$ & & II/IIIa & $32 \mathrm{~S} 1-4$ & Chert cobble, unmodified/tested \\
\hline $\mathrm{E} 26 / \mathrm{S} 78$ & $19 \mathrm{~A}$ & & II/IIIa & $32 \mathrm{~S} 1-5$ & Core, thermal \\
\hline E26/S78 & $19 \mathrm{~A}$ & & II/IIIa & & Debitage \\
\hline $\mathrm{E} 26 / \mathrm{S} 78$ & $19 \mathrm{~A}$ & & II/IIIa & $32 S 1-6$ & Micro-core, intermediate \\
\hline E26/S78 & $19 \mathrm{~A}$ & & II/IIIa & $32 \mathrm{~S} 1-1$ & Notched flake \\
\hline $\mathrm{E} 26 / \mathrm{S} 78$ & $19 \mathrm{~A}$ & & II/IIIa & $32 \mathrm{~S} 1-3$ & Uniface, unanalyzed \\
\hline E26/S78 & $19 \mathrm{~B}$ & & II/IIIa & $32 \mathrm{~S} 2 \mathrm{~B}-5$ & Biface fragment \\
\hline $\mathrm{E} 26 / \mathrm{S} 78$ & $19 \mathrm{~B}$ & & II/IIIa & $32 \mathrm{~S} 2-1$ & Biface Stage 3 \\
\hline E26/S78 & $19 B$ & & II/IIIa & & Debitage \\
\hline $\mathrm{E} 26 / \mathrm{S} 78$ & 19B & & II/IIIa & $32 \mathrm{~S} 2-3$ & Thick uniface \\
\hline $\mathrm{E} 26 / \mathrm{S} 78$ & $19 B$ & & II/IIIa & $32 \mathrm{~S} 2-2$ & Uniface, unanalyzed \\
\hline E26/S78 & $20 \mathrm{~A}$ & & II & & Debitage \\
\hline E26/S78 & $20 \mathrm{~A}$ & & II & $32 \mathrm{~T} 1 \mathrm{D}-4$ & Notched flake \\
\hline $\mathrm{E} 26 / \mathrm{S} 78$ & $20 \mathrm{~A}$ & & II & $32 \mathrm{~T} 1 \mathrm{~A}-1$ & Projectile point fragment \\
\hline $\mathrm{E} 26 / \mathrm{S} 78$ & $20 \mathrm{~A}$ & & II & $32 \mathrm{~T} 1 \mathrm{C}-3$ & Projectile point, Angostura \\
\hline $\mathrm{E} 26 / \mathrm{S} 78$ & $20 \mathrm{~A}$ & & II & $32 \mathrm{~T} 1 \mathrm{D}-5$ & Thin uniface \\
\hline $\mathrm{E} 26 / \mathrm{S} 78$ & $20 \mathrm{~A}$ & & II & $32 \mathrm{~T} 1 \mathrm{C}-2$ & Uniface, unanalyzed \\
\hline E26/S78 & $20 \mathrm{~B}$ & & II & & Debitage \\
\hline $\mathrm{E} 26 / \mathrm{S} 78$ & $21 \mathrm{~A}$ & & II & & Debitage \\
\hline $\mathrm{E} 26 / \mathrm{S} 78$ & $21 \mathrm{~A}$ & & II & $32 \mathrm{U} 1 \mathrm{C}-1$ & Projectile point fragment \\
\hline $\mathrm{E} 26 / \mathrm{S} 78$ & $21 \mathrm{~A}$ & & II & $32 \mathrm{U} 1 \mathrm{D}-3$ & Uniface, unanalyzed \\
\hline
\end{tabular}




\begin{tabular}{|c|c|c|c|c|c|c|}
\hline & Level & Feature & Strata & Item & Analyst Identification & Count \\
\hline $\begin{array}{l}\text { E26/S78 } \\
\text { E26/S78 }\end{array}$ & $\begin{array}{l}21 \mathrm{~A} \\
21 \mathrm{~B}\end{array}$ & & $\begin{array}{l}\text { II } \\
\text { II }\end{array}$ & 32U1D-2 & Uniface, unanalyzed & \\
\hline $\mathrm{E} 26 / \mathrm{S} 78$ & $21 \mathrm{~B}$ & & II & $32 \mathrm{U} 2 \mathrm{~B}-1$ & $\begin{array}{l}\text { Debitage } \\
\text { Projectile point fragment }\end{array}$ & \\
\hline $\mathrm{E} 26 / \mathrm{S} 78$ & 21B & & II & $32 \mathrm{U} 2 \mathrm{D}-2$ & Uniface, unanalyzed & \\
\hline $\mathrm{E} 26 / \mathrm{S} 78$ & 21B & & II & $32 \mathrm{U} 2 \mathrm{D}-3$ & Uniface, unanalyzed & \\
\hline $\mathrm{E} 26 / \mathrm{S} 78$ & $22 \mathrm{~A}$ & & II & $32 \mathrm{~V} 1-1$ & Biface Stage 2 & 1 \\
\hline E26/S78 & $22 \mathrm{~A}$ & & II & & Debitage & \\
\hline E26/S78 & $22 \mathrm{~A}$ & & II & $32 \mathrm{~V} 1 \mathrm{~A}-3$ & Small core hammerstone & \\
\hline E26/S78 & $22 \mathrm{~A}$ & & II & $32 \mathrm{~V} 1 \mathrm{C}-5$ & Uniface, unanalyzed & \\
\hline E26/S78 & $22 \mathrm{~A}$ & & II & $32 \mathrm{~V} 1 \mathrm{~B}-4$ & Uniface, unanalyzed & 1 \\
\hline $\mathrm{E} 26 / \mathrm{S} 78$ & 22B & & II & & Debitage & \\
\hline E26/S78 & 22B & & II & $32 \mathrm{~V} 2 \mathrm{~A}-1$ & Uniface, unanalyzed & \\
\hline E26/S78 & $23 \mathrm{~A}$ & & II & & Debitage & \\
\hline E26/S78 & $23 \mathrm{~A}$ & & II & $32 \mathrm{~W} 1 \mathrm{~B}-1$ & Perforator Group 2 & \\
\hline E26/S78 & $23 \mathrm{~A}$ & & II & $32 \mathrm{~W} 1 \mathrm{D}-3$ & Uniface, unanalyzed & \\
\hline E26/S78 & $23 \mathrm{~A}$ & & II & $32 \mathrm{~W} 1 \mathrm{C}-2$ & Unifacial multiple tool & \\
\hline E26/S78 & $23 \mathrm{~B}$ & & II & & Debitage & 79 \\
\hline E26/S78 & 23B & & II & $32 \mathrm{~W} 2 \mathrm{~A}-1$ & Uniface, unanalyzed & \\
\hline E26/S78 & $24 \mathrm{~A}$ & & II & & Debitage & 110 \\
\hline E26/S78 & $24 \mathrm{~A}$ & & II & $32 \times 1 D-4$ & Edge modified flake & \\
\hline E26/S78 & $24 \mathrm{~A}$ & & II & $32 \times 1 B-1$ & Edge modified flake & \\
\hline E26/S78 & $24 \mathrm{~A}$ & & II & $32 \times 1 B-2$ & Thin uniface & \\
\hline E26/S78 & $24 \mathrm{~A}$ & & II & $32 \times 1 D-3$ & Thin uniface & \\
\hline E26/S78 & $24 B$ & & II & $32 \times 2 B-4$ & Biface Stage 2 & \\
\hline E26/S78 & $24 B$ & & II & $32 \times 2 B-1$ & Burin spall & \\
\hline E26/S78 & $24 \mathrm{~B}$ & & II & $32 \times 2 C-6$ & Burin spall & \\
\hline E26/S78 & 24B & & II & & Debitage & 19 \\
\hline E26/S78 & 24B & & II & $32 \times 2 D-8$ & Thick uniface & \\
\hline E26/S78 & 24B & & II & $32 \mathrm{X} 2 \mathrm{~B}-5$ & Uniface, unanalyzed & \\
\hline E26/S78 & $24 B$ & & II & $32 \times 2 C-7$ & Uniface, unanalyzed & \\
\hline E26/S78 & 24B & & II & $32 \times 2 B-2$ & Unifacial multiple tool & \\
\hline E26/S78 & $25 \mathrm{~A}$ & & $\mathrm{Id} / \mathrm{II}$ & 32 Y1C-2 & Burin spall & \\
\hline E26/S78 & $25 \mathrm{~A}$ & & $\mathrm{Id} / \mathrm{II}$ & & Debitage & 16 \\
\hline $\mathrm{E} 26 / \mathrm{S} 78$ & $25 \mathrm{~A}$ & & $\mathrm{Id} / \mathrm{II}$ & $32 \mathrm{Y} 1 \mathrm{C}-3$ & Uniface, unanalyzed & \\
\hline E26/S78 & $25 \mathrm{~A}$ & & $\mathrm{Id} / \mathrm{II}$ & 32Y1B-1 & Uniface, unanalyzed & \\
\hline E26/S78 & $25 \mathrm{~B}$ & & $\mathrm{Id} / \mathrm{II}$ & 32 Y $2 B-2$ & Burin spall & \\
\hline E26/S78 & $25 \mathrm{~B}$ & & $\mathrm{Id} / \mathrm{II}$ & & Debitage & 9 \\
\hline E26/S78 & $25 \mathrm{~B}$ & & $\mathrm{Id} / \mathrm{II}$ & $32 \mathrm{Y} 2 \mathrm{C}-1$ & Projectile point, Wilson & \\
\hline E26/S78 & $25 \mathrm{~B}$ & & $\mathrm{Id} / \mathrm{II}$ & $32 \mathrm{Y} 2 \mathrm{~B}-3$ & Thin uniface & \\
\hline E26/S78 & $25 \mathrm{~B}$ & & $\mathrm{Id} / \mathrm{II}$ & $32 \mathrm{Y} 2 \mathrm{C}-4$ & Uniface, unanalyzed & \\
\hline E26/S78 & $26 \mathrm{~A}$ & & $\mathrm{Id} / \mathrm{II}$ & 32Z1B-3 & Biface Stage 2 & \\
\hline $\mathrm{E} 26 / \mathrm{S} 78$ & $26 \mathrm{~A}$ & & $\mathrm{Id} / \mathrm{II}$ & & Debitage & 122 \\
\hline E26/S78 & $26 \mathrm{~A}$ & & $\mathrm{Id} / \mathrm{II}$ & $32 Z 1-2$ & Projectile point, miscellaneous lanceolate & \\
\hline E26/S78 & $26 \mathrm{~A}$ & & $\mathrm{Id} / \mathrm{II}$ & $32 \mathrm{Z1}-1$ & Uniface, unanalyzed & \\
\hline E26/S78 & $26 \mathrm{~A}$ & & $\mathrm{Id} / \mathrm{II}$ & $32 \mathrm{Z1D}-4$ & Uniface, unanalyzed & \\
\hline E26/S78 & $26 \mathrm{~B}$ & & $\mathrm{Id} / \mathrm{II}$ & $32 \mathrm{Z} 2 \mathrm{D}-5$ & Biface Stage 2 & \\
\hline E26/S78 & $26 \mathrm{~B}$ & & $\mathrm{Id} / \mathrm{II}$ & & Debitage & \\
\hline E26/S78 & $26 \mathrm{~B}$ & & $\mathrm{Id} / \mathrm{II}$ & $32 \mathrm{Z} 2 \mathrm{C}-3$ & Edge modified flake & \\
\hline E26/S78 & $26 \mathrm{~B}$ & & $\mathrm{Id} / \mathrm{II}$ & $32 \mathrm{Z} 2 \mathrm{~A}-1$ & Uniface, unanalyzed & \\
\hline $\mathrm{E} 26 / \mathrm{S} 78$ & $26 \mathrm{~B}$ & & $\mathrm{Id} / \mathrm{II}$ & $32 \mathrm{Z} 2 \mathrm{~A}-2$ & Uniface, unanalyzed & \\
\hline $\mathrm{E} 26 / \mathrm{S} 78$ & 26B & & $\mathrm{Id} / \mathrm{II}$ & $32 \mathrm{Z} 2 \mathrm{D}-4$ & Uniface, unanalyzed & \\
\hline E26/S78 & $27 \mathrm{~A}$ & & Isi-c/Id/II & & Debitage & 3 \\
\hline E26/S78 & $27 \mathrm{~A}$ & & Isi-c/Id/II & 32AA1A-1 & Edge modified flake & \\
\hline E26/S78 & $27 \mathrm{~A}$ & & Isi-c/Id/II & $32 \mathrm{AA} 1 \mathrm{C}-3$ & Uniface, unanalyzed & \\
\hline E26/S78 & $27 \mathrm{~A}$ & & Isi-c/Id/II & 32AA1A-2 & Uniface, unanalyzed & \\
\hline E26/S78 & $27 \mathrm{~B}$ & & Isi-c/Id & & Debitage & \\
\hline E26/S78 & 27B & & Isi-c/Id & 32AA2D-1 & Uniface, unanalyzed & \\
\hline E26/S78 & $28 \mathrm{~A}$ & & Isi-c/Id & 32BB1D-1 & Biface Stage 2 & \\
\hline E26/S78 & $28 \mathrm{~A}$ & & Isi-c/Id & & Debitage & 5 \\
\hline E26/S78 & $28 \mathrm{~B}$ & & Isi-c/Id & & Debitage & 46 \\
\hline $\mathrm{E} 26 / \mathrm{S} 78$ & $28 \mathrm{~B}$ & & Isi-c/Id & 32BB2A-1 & Uniface, unanalyzed & \\
\hline E26/S78 & 28B & & Isi-c/Id & $32 \mathrm{BB} 2 \mathrm{~A}-2$ & Uniface, unanalyzed & \\
\hline E26/S78 & $29 \mathrm{~A}$ & & Isi-c/Id & & Debitage & \\
\hline E26/S78 & $29 \mathrm{~B}$ & & Isi-c & & Debitage & \\
\hline E26/S78 & 29B & & Isi-c & $32 \mathrm{CC} 2 \mathrm{~B}-1$ & Projectile point, Wilson & \\
\hline $\mathrm{E} 26 / \mathrm{S} 78$ & $29 B$ & & Isi-c & $32 \mathrm{CC} 2 \mathrm{C}-2$ & Projectile point, Wilson & \\
\hline E26/S78 & $30 \mathrm{~A}$ & & Isi-c & & Debitage & \\
\hline E26/S78 & $30 \mathrm{~A}$ & & Isi-c & 32DD1B-1 & Projectile point, Wilson & \\
\hline $\mathrm{E} 26 / \mathrm{S} 78$ & $30 \mathrm{~B}$ & & Isi-c & & Debitage & \\
\hline E26/S78 & $30 \mathrm{~B}$ & & Isi-c & 32DD2C-1 & Projectile point, Wilson & \\
\hline E26/S78 & $31 \mathrm{~A}$ & & Isi-c & & Debitage & \\
\hline $\mathrm{E} 26 / \mathrm{S} 78$ & $31 \mathrm{~B}$ & & Isi-c & & Debitage & 54 \\
\hline $\mathrm{E} 26 / \mathrm{S} 78$ & $31 \mathrm{~B}$ & & Isi-c & $32 \mathrm{EE} 2 \mathrm{~A}-1$ & Thin uniface & \\
\hline $\mathrm{E} 26 / \mathrm{S} 78$ & $32 \mathrm{~A}$ & & Isi-c & & Debitage & \\
\hline
\end{tabular}




\begin{tabular}{|c|c|c|c|c|c|c|}
\hline Square & Level & Feature & Strata & Item & Analyst Identification & Count \\
\hline E26/S78 & $32 \mathrm{~A}$ & & Isi-c & 32FF1B-3 & Uniface, unanalyzed & 1 \\
\hline $\mathrm{E} 26 / \mathrm{S} 78$ & $32 \mathrm{~A}$ & & Isi-c & 32FF1A-1 & Uniface, unanalyzed & 1 \\
\hline E26/S78 & $32 \mathrm{~B}$ & & Isi/Icl/Isi-c & & Debitage & 13 \\
\hline $\mathrm{E} 26 / \mathrm{S} 78$ & $32 \mathrm{~B}$ & Feature 171 & Isi/Icl/Isi-c & $32 \mathrm{FF} 2 \mathrm{~B}-1$ & Thin uniface & 1 \\
\hline E26/S78 & $33 \mathrm{~A}$ & & Isi/Icl/Isi-c & & Debitage & 35 \\
\hline E26/S78 & $33 \mathrm{~B}$ & & Isi/Icl/Isi-c & & Debitage & 24 \\
\hline E26/S78 & $33 \mathrm{~B}$ & & Isi/Icl/Isi-c & 32GG2B-1 & Thin uniface & \\
\hline $\mathrm{E} 26 / \mathrm{S} 78$ & $33 \mathrm{~B}$ & & Isi/Icl/Isi-c & $32 \mathrm{GG} 2 \mathrm{D}-2$ & Uniface, unanalyzed & 1 \\
\hline E26/S78 & $34 \mathrm{~A}$ & & $\mathrm{Isi} / \mathrm{Icl} / \mathrm{Isi}-\mathrm{c}$ & & Debitage & 52 \\
\hline E26/S78 & $34 \mathrm{~B}$ & & $\mathrm{Isi} / \mathrm{Icl}$ & & Debitage & \\
\hline E26/S78 & $34 \mathrm{~B}$ & & $\mathrm{Isi} / \mathrm{Icl}$ & $32 \mathrm{HH} 2 \mathrm{~A}-1$ & Spurred flake & 1 \\
\hline E26/S78 & $34 \mathrm{~B}$ & & $\mathrm{Isi} / \mathrm{Icl}$ & $32 \mathrm{HH} 2 \mathrm{~B}-2$ & Thin uniface & \\
\hline E26/S78 & $34 \mathrm{~B}$ & & $\mathrm{Isi} / \mathrm{Icl}$ & $32 \mathrm{HH} 2 \mathrm{D}-3$ & Uniface, unanalyzed & \\
\hline E26/S78 & $35 \mathrm{~A}$ & & Isi/Icl & 32 IIIA-1 & Biface Stage 2 & \\
\hline E26/S78 & $35 \mathrm{~A}$ & & Isi/Icl & 32IIIB-1 & Biface Stage 2 & . \\
\hline E26/S78 & $35 \mathrm{~A}$ & & Isi/Icl & & Debitage & 40 \\
\hline E26/S78 & $35 \mathrm{~B}$ & & Isi/Icl & 32II2A-1 & Biface Stage 2 & 1 \\
\hline E26/S78 & $35 \mathrm{~B}$ & & $\mathrm{Isi} / \mathrm{Icl}$ & & Debitage & 50 \\
\hline E26/S78 & $35 \mathrm{~B}$ & & Isi/Icl & $32 \mathrm{II} 2 \mathrm{C}-2$ & Uniface, unanalyzed & 1 \\
\hline E26/S78 & $36 \mathrm{~A}$ & & $\mathrm{Isi} / \mathrm{Icl}$ & & Debitage & 33 \\
\hline $\mathrm{E} 26 / \mathrm{S} 78$ & $36 \mathrm{~A}$ & & $\mathrm{Isi} / \mathrm{Icl} / \mathrm{D}$ & & Debitage & 8 \\
\hline E26/S78 & $36 \mathrm{~B}$ & & Isi/Icl & & Debitage & 26 \\
\hline E26/S78 & $36 \mathrm{~B}$ & & Isi/Icl/D & & Debitage & 11 \\
\hline E26/S78 & $36 \mathrm{~B}$ & & Isi/Icl & $32 \mathrm{JJ} 2 \mathrm{D}-1$ & Uniface, unanalyzed & 1 \\
\hline E26/S78 & $37-38 \mathrm{~A}$ & Feature 175 & Isi/Icl & & Debitage & 3 \\
\hline $\mathrm{E} 26 / \mathrm{S} 78$ & $37 \mathrm{~A}$ & & Isi/Icl & $32 \mathrm{KK} 1 \mathrm{C}-1$ & Core, multidirectional & 1 \\
\hline E26/S78 & $37 \mathrm{~A}$ & & $\mathrm{Isi} / \mathrm{Icl}$ & & Debitage & 29 \\
\hline E26/S78 & $37 \mathrm{~A}$ & & Isi/Icl/D & & Debitage & 20 \\
\hline E26/S78 & $37 \mathrm{~B}$ & & Isi/Icl/D & $32 \mathrm{KK} 2 \mathrm{~B}-2$ & Biface Stage 2 & \\
\hline E26/S78 & $37 \mathrm{~B}$ & & Isi/Icl & $32 \mathrm{KK} 2 \mathrm{~A}-1$ & Core tool, type 5 & \\
\hline $\mathrm{E} 26 / \mathrm{S} 78$ & $37 \mathrm{~B}$ & & Isi/Icl/D & & Debitage & 8 \\
\hline E26/S78 & $37 \mathrm{~B}$ & & Isi/Icl & & Debitage & 30 \\
\hline E26/S78 & $38 \mathrm{~A}$ & & $\mathrm{Isi} / \mathrm{Icl}$ & & Debitage & 23 \\
\hline E26/S78 & $38 \mathrm{~A}$ & & $\mathrm{Isi} / \mathrm{Icl}$ & 32LL1B-3 & Edge modified flake & \\
\hline E26/S78 & $38 \mathrm{~A}$ & & $\mathrm{Isi} / \mathrm{Icl}$ & $32 \mathrm{LL} 1 \mathrm{C}-4$ & Edge modified flake & \\
\hline E26/S78 & $38 \mathrm{~A}$ & & Isi/Icl & 32LL1A-2 & Thick uniface & \\
\hline E26/S78 & $38 \mathrm{~A}$ & & $\mathrm{Isi} / \mathrm{Icl}$ & 32LL1A-1 & Uniface, unanalyzed & 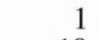 \\
\hline E26/S78 & $38 \mathrm{~B}$ & & Isi/Icl & & Debitage & 18 \\
\hline E26/S78 & $38 \mathrm{~B}$ & & $\mathrm{Isi} / \mathrm{Icl}$ & 32LL2A-1 & Uniface, unanalyzed & \\
\hline E26/S78 & $39 \mathrm{~A}$ & & Isi/Icl & 32MM1 A-1 & Biface Stage 2 & \\
\hline E26/S78 & $39 \mathrm{~A}$ & & $\mathrm{Isi} / \mathrm{Icl}$ & & Debitage & 34 \\
\hline E26/S78 & $39 \mathrm{~B}$ & & Isi/Icl & & Debitage & 1. \\
\hline E26/S78 & $40 \mathrm{~B}$ & & $\mathrm{Isi} / \mathrm{Icl}$ & & Debitage & 1 \\
\hline E26/S78 & $41 \mathrm{~A}$ & & Isi/Icl & & Debitage & \\
\hline E26/S78 & $41 \mathrm{~B}$ & & Isi/Icl & & Debitage & 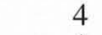 \\
\hline $\mathrm{E} 26 / \mathrm{S} 80$ & 13 & & IIIb & $55 \mathrm{M}$ & Projectile point, Bandy & \\
\hline E28/S78 & 1 & & IIII & $37 \mathrm{AD}-22$ & Arrow point, Scallorn & \\
\hline E28/S78 & 1 & & IIIc & $37 \mathrm{AC}-20$ & Biface fragment & \\
\hline E28/S78 & 1 & & IIII & $37 \mathrm{AC}-15$ & Biface fragment & \\
\hline $\mathrm{E} 28 / \mathrm{S} 78$ & 1 & & IIIc & $37 \mathrm{AC}-12$ & Biface Stage 2 & \\
\hline $\mathrm{E} 28 / \mathrm{S} 78$ & 1 & & IIIc & $37 \mathrm{AD}-23$ & Biface Stage 2 & \\
\hline E28/S78 & 1 & & IIIC & $37 \mathrm{AD}-24$ & Biface Stage 2 & \\
\hline E28/S78 & 1 & & IIIC & 37AA-5 & Biface Stage 3 & \\
\hline E28/S78 & 1 & & IIIc & & Debitage & 644 \\
\hline E28/S78 & 1 & & IIII & $37 \mathrm{AA}-4$ & Edge modified flake & \\
\hline E28/S78 & 1 & & IIIc & $37 \mathrm{AB}-7$ & Edge modified flake & \\
\hline E28/S78 & 1 & & IIIC & $37 \mathrm{AB}-6$ & Edge modified flake & \\
\hline E28/S78 & 1 & & IIIc & $37 \mathrm{AC}-18$ & Edge modified flake & \\
\hline $\mathrm{E} 28 / \mathrm{S} 78$ & 1 & & IIIc & $37 \mathrm{AA}-2$ & Edge modified flake & \\
\hline $\mathrm{E} 28 / \mathrm{S} 78$ & 1 & & IIIc & $37 \mathrm{AD}-27$ & Edge modified flake & \\
\hline E28/S78 & 1 & & IIIc & $37 \mathrm{AD}-31$ & Edge modified flake & \\
\hline $\mathrm{E} 28 / \mathrm{S} 78$ & 1 & & IIIc & $37 \mathrm{AD}-25$ & Edge modified flake & \\
\hline E28/S78 & 1 & & IIIc & $37 \mathrm{AD}-26$ & Edge modified flake & \\
\hline E28/S78 & 1 & & IIIc & $37 \mathrm{AC}-17$ & Edge modified flake & \\
\hline $\mathrm{E} 28 / \mathrm{S} 78$ & 1 & & IIIC & $37 \mathrm{AA}-1$ & Microspur/microdenticulate & \\
\hline E28/S78 & 1 & & IIIC & $37 \mathrm{AA}-3$ & Notched flake & \\
\hline E28/S78 & 1 & & IIIC & $37 \mathrm{AB}-33$ & Possible ground stone & \\
\hline E28/S78 & 1 & & IIIc & $37 \mathrm{AD}-32$ & Projectile point fragment & \\
\hline E28/S78 & 1 & & IIIc & $37 \mathrm{AC}-14$ & Projectile point fragment & \\
\hline $\mathrm{E} 28 / \mathrm{S} 78$ & 1 & & IIIc & $37 \mathrm{AC}-13$ & Projectile point fragment & \\
\hline $\mathrm{E} 28 / \mathrm{S} 78$ & 1 & & IIIC & $37 \mathrm{AD}-30$ & Projectile point fragment & \\
\hline E28/S78 & 1 & & IIII & $37 \mathrm{AC}-11$ & Projectile point, Ensor & \\
\hline E28/S78 & 1 & & IIIc & $37 \mathrm{AD}-21$ & Projectile point, Ensor & \\
\hline $\mathrm{E} 28 / \mathrm{S} 78$ & 1 & & IIIc & $37 \mathrm{AC}-16$ & Spurred flake & \\
\hline
\end{tabular}




\begin{tabular}{|c|c|c|c|c|c|c|}
\hline $\begin{array}{l}\text { Square } \\
\text { E28/S78 }\end{array}$ & $\begin{array}{l}\text { Level } \\
1\end{array}$ & Feature & $\begin{array}{l}\text { Strata } \\
\text { IIIc }\end{array}$ & Item & $\begin{array}{l}\text { Analyst Identification } \\
\text { Thin uniface }\end{array}$ & $\begin{array}{r}\text { Count } \\
1\end{array}$ \\
\hline $\begin{array}{l}\mathrm{E} 28 / \mathrm{S} 78 \\
\mathrm{E} 28 / \mathrm{S} 78\end{array}$ & 1 & & $\begin{array}{l}\text { IIIC } \\
\text { IIIC }\end{array}$ & $\begin{array}{l}37 \mathrm{AB}-10 \\
37 \mathrm{AD}-29\end{array}$ & $\begin{array}{l}\text { Thin uniface } \\
\text { Thin uniface fragment }\end{array}$ & \\
\hline E28/S78 & 1 & & IIIc & $37 \mathrm{AB}-9$ & Uniface, unanalyzed & 1 \\
\hline $\mathrm{E} 28 / \mathrm{S} 78$ & 2 & & IIIc & $37 \mathrm{BC}-12$ & Biface Stage 2 & 1 \\
\hline E28/S78 & 2 & & IIIC & $37 \mathrm{BD}-20$ & Biface Stage 2 & \\
\hline E28/S78 & 2 & & IIIc & 37BD-18 & Biface Stage 2 & 1 \\
\hline E28/S78 & 2 & & IIIc & $37 \mathrm{BD}-22$ & Burin spall & \\
\hline E28/S78 & 2 & & IIIC & $37 \mathrm{BD}-27$ & Core, thermal & 1 \\
\hline E28/S78 & 2 & & IIIc & $37 \mathrm{BD}-24$ & Core, thermal & \\
\hline $\mathrm{E} 28 / \mathrm{S} 78$ & 2 & & IIIc & & Debitage & 1166 \\
\hline $\mathrm{E} 28 / \mathrm{S} 78$ & 2 & & IIIC & 37BD-26 & Edge modified flake & \\
\hline E28/S78 & 2 & & IIIC & $37 \mathrm{BA}-2$ & Edge modified flake & 1 \\
\hline E28/S78 & 2 & & IIIc & 37BB-9 & Edge modified flake & \\
\hline E28/S78 & 2 & & IIIc & $37 \mathrm{BC}-17$ & Edge modified flake & \\
\hline E28/S78 & 2 & & IIIc & $37 \mathrm{BD}-29$ & Edge modified flake & 1 \\
\hline E28/S78 & 2 & & IIIc & $37 \mathrm{BB}-7$ & Edge modified flake & \\
\hline E28/S78 & 2 & & IIIc & $37 \mathrm{BB}-10$ & Edge modified flake & \\
\hline E28/S78 & 2 & & IIIC & 37BD-34 & Notched flake & \\
\hline E28/S78 & 2 & & IIIc & $37 \mathrm{BD}-19$ & Projectile point fragment & 1 \\
\hline E28/S78 & 2 & & IIIc & $37 \mathrm{BB}-35$ & Projectile point fragment & \\
\hline E28/S78 & 2 & & IIIc & $37 \mathrm{BB}-5$ & Projectile point fragment & 1 \\
\hline E28/S78 & 2 & & IIIIc & $37 \mathrm{BA}-1$ & Projectile point fragment & \\
\hline $\mathrm{E} 28 / \mathrm{S} 78$ & 2 & & IIIC & $37 \mathrm{BC}-13$ & Projectile point fragment & \\
\hline E28/S78 & 2 & & IIIc & 37BD-21 & Projectile point fragment & \\
\hline E28/S78 & 2 & & IIIc & $37 \mathrm{BD}-25$ & Projectile point, Montell & 1 \\
\hline E28/S78 & 2 & & IIIc & $37 \mathrm{BC}-14$ & Retouched blade & \\
\hline $\mathrm{E} 28 / \mathrm{S} 78$ & 2 & & IIIC & $37 \mathrm{BA}-4$ & Thick uniface & 1 \\
\hline E28/S78 & 2 & & IIIc & $37 \mathrm{BC}-16$ & Thin uniface & 1 \\
\hline E28/S78 & 2 & & IIIC & $37 \mathrm{BB}-11$ & Thin uniface & 1 \\
\hline E28/S78 & 2 & & IIIc & $37 \mathrm{BD}-28$ & Unifacial multiple tool & \\
\hline E28/S78 & 2 & & IIIc & $37 \mathrm{BD}-32$ & Unifacial multiple tool & 1 \\
\hline E28/S78 & 2 & & IIIc & $37 \mathrm{BB}-8$ & Unifacial multiple tool & \\
\hline $\mathrm{E} 28 / \mathrm{S} 78$ & 2 & & IIIc & 37BA-3 & Unifacial multiple tool & \\
\hline E28/S78 & 2 & & IIIc & $37 \mathrm{BC}-15$ & Unifacial multiple tool & 1 \\
\hline E28/S78 & 2 & & IIIc & $37 \mathrm{BD}-31$ & Unifacial multiple tool & . \\
\hline E28/S78 & 3 & & IIIc & $37 \mathrm{CD}-38$ & Biface fragment & 1 \\
\hline $\mathrm{E} 28 / \mathrm{S} 78$ & 3 & & IIIc & $37 \mathrm{CB}-29$ & Biface Stage 1 & 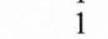 \\
\hline E28/S78 & 3 & & IIIc & $37 \mathrm{CC}-34$ & Burin & 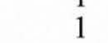 \\
\hline $\mathrm{E} 28 / \mathrm{S} 78$ & 3 & & IIIc & & Debitage & 1125 \\
\hline $\mathrm{E} 28 / \mathrm{S} 78$ & 3 & & IIIc & $37 \mathrm{CA}-7$ & Edge modified flake & 20 \\
\hline $\mathrm{E} 28 / \mathrm{S} 78$ & 3 & & IIIc & $37 \mathrm{CA}-9$ & Edge modified flake & 1 \\
\hline E28/S78 & 3 & & IIIc & $37 \mathrm{CB}-23$ & Edge modified flake & 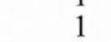 \\
\hline E28/S78 & 3 & & IIIc & $37 \mathrm{CA}-8$ & Edge modified flake & 1 \\
\hline $\mathrm{E} 28 / \mathrm{S} 78$ & 3 & & IIIIc & $37 \mathrm{CA}-4$ & Edge modified flake & 1 \\
\hline E28/S78 & 3 & & IIIc & $37 \mathrm{CA}-11$ & Edge modified flake & 1 \\
\hline E28/S78 & 3 & & IIIc & $37 \mathrm{CB}-24$ & Edge modified flake & 1 \\
\hline E28/S78 & 3 & & IIIc & $37 \mathrm{CB}-27$ & Edge modified flake & 1 \\
\hline E28/S78 & 3 & & IIIIc & $37 \mathrm{CB}-28$ & Edge modified flake & 1 \\
\hline E28/S78 & 3 & & IIIc & $37 \mathrm{CC}-35$ & Edge modified flake & 1 \\
\hline $\mathrm{E} 28 / \mathrm{S} 78$ & 3 & & IIIc & $37 \mathrm{CA}-5$ & Edge modified flake & 1 \\
\hline E28/S78 & 3 & & IIIc & $37 \mathrm{CC}-37$ & Edge modified flake & 1 \\
\hline E28/S78 & 3 & & IIIc & $37 \mathrm{CB}-15$ & Micro-core, small & 1 \\
\hline E28/S78 & 3 & & IIIc & $37 \mathrm{CA}-6$ & Notched flake & 1 \\
\hline E28/S78 & 3 & & IIIc & $37 \mathrm{CB}-22$ & Notched flake & 1 \\
\hline E28/S78 & 3 & & IIIc & $37 \mathrm{CB}-26$ & Notched flake & 1 \\
\hline E28/S78 & 3 & & IIIc & $37 \mathrm{CC}-31$ & Perforator Group 7 & 1 \\
\hline E28/S78 & 3 & & IIIc & $37 \mathrm{CA}-14$ & Projectile point fragment & 1 \\
\hline E28/S78 & 3 & & IIIc & $37 \mathrm{CB}-16$ & Projectile point fragment & 1 \\
\hline E28/S78 & 3 & & IIIc & $37 \mathrm{CB}-17$ & Projectile point, Edgewood & 1 \\
\hline E28/S78 & 3 & & IIIc & $37 \mathrm{CC}-33$ & Thin uniface fragment & 1 \\
\hline E28/S78 & 3 & & IIIc & $37 \mathrm{CA}-10$ & Uniface, unanalyzed & 1 \\
\hline E28/S78 & 4 & & IIIc & $37 \mathrm{DB}-12$ & Biface fragment & 1 \\
\hline E28/S78 & 4 & & IIIc & $37 \mathrm{DA}-6$ & Biface fragment & 1 \\
\hline E28/S78 & 4 & & IIIIc & 37DA-11 & Bifacial tool Form A & 1 \\
\hline E28/S78 & 4 & & IIIc & 37DD-32 & Burin & \\
\hline E28/S78 & 4 & & IIIc & 37DA-7 & Burin & \\
\hline E28/S78 & 4 & & IIIc & $37 \mathrm{DB}-16$ & Burin spall & 1 \\
\hline $\mathrm{E} 28 / \mathrm{S} 78$ & 4 & & IIIc & $37 \mathrm{DC}-21$ & Burin spall & 1 \\
\hline E28/S78 & 4 & & IIIc & $37 \mathrm{DA}-1$ & Chert cobble, unmodified/tested & \\
\hline E28/S78 & 4 & & IIIC & & 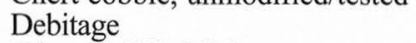 & 884 \\
\hline E28/S78 & 4 & & IIII & 37DD-35 & Edge modified flake & 1 \\
\hline E28/S78 & 4 & & IIIc & $37 \mathrm{DB}-14$ & Edge modified flake & 1 \\
\hline $\mathrm{E} 28 / \mathrm{S} 78$ & 4 & & IIIc & 37DD-38 & Edge modified flake & 1 \\
\hline $\mathrm{E} 28 / \mathrm{S} 78$ & 4 & & IIIc & 37DD-34 & Edge modified flake & \\
\hline
\end{tabular}




\begin{tabular}{|c|c|c|c|c|c|c|}
\hline Square & Level & Feature & Strata & Item & Analyst Identification & Count \\
\hline $\mathrm{E} 28 / \mathrm{S} 78$ & 4 & & IIIc & $37 \mathrm{DB}-18$ & Edge modified flake & 1 \\
\hline E28/S78 & 4 & & IIIc & 37DD-33 & Edge modified flake & 1 \\
\hline $\mathrm{E} 28 / \mathrm{S} 78$ & 4 & & IIIc & $37 \mathrm{DA}-5$ & Edge modified flake & 1 \\
\hline $\mathrm{E} 28 / \mathrm{S} 78$ & 4 & & IIIC & $37 \mathrm{DC}-24$ & Edge modified flake & 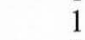 \\
\hline $\mathrm{E} 28 / \mathrm{S} 78$ & 4 & & IIIc & $37 \mathrm{DA}-4$ & Edge modified flake & 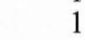 \\
\hline $\mathrm{E} 28 / \mathrm{S} 78$ & 4 & & IIIc & $37 \mathrm{DA}-3$ & Edge modified flake & 1 \\
\hline $\mathrm{E} 28 / \mathrm{S} 78$ & 4 & & IIIc & $37 \mathrm{DC}-28$ & Edge modified flake & 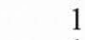 \\
\hline $\mathrm{E} 28 / \mathrm{S} 78$ & 4 & & IIIc & $37 \mathrm{DC}-27$ & Edge modified flake & \\
\hline E28/S78 & 4 & & IIIc & $37 \mathrm{DC}-31$ & Notched flake & \\
\hline $\mathrm{E} 28 / \mathrm{S} 78$ & 4 & & IIIc & $37 \mathrm{DA}-2$ & Projectile point fragment & 1 \\
\hline E28/S78 & 4 & & IIIc & $37 \mathrm{DA}-10$ & Projectile point fragment & 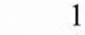 \\
\hline $\mathrm{E} 28 / \mathrm{S} 78$ & 4 & & IIIc & $37 \mathrm{DB}-17$ & Projectile point, Frio & 1 \\
\hline E28/S78 & 4 & & IIIc & $37 D C-23$ & Unifacial multiple tool & \\
\hline E28/S78 & 4 & Feature 173 & IIIc & $37 \mathrm{DD}-42$ & Mano fragment & \\
\hline E28/S78 & 5 & Feature 173 & IIIc & $37 \mathrm{EA}-7$ & Biface fragment & \\
\hline E28/S78 & 5 & Feature 173 & IIIc & $37 \mathrm{EC}-30$ & Biface fragment & 1 \\
\hline $\mathrm{E} 28 / \mathrm{S} 78$ & 5 & Feature 173 & IIIc & $37 \mathrm{EC}-37$ & Biface fragment & \\
\hline $\mathrm{E} 28 / \mathrm{S} 78$ & 5 & Feature 173 & IIII & $37 \mathrm{~EB}-11$ & Biface Stage 2 & \\
\hline E28/S78 & 5 & Feature 173 & IIIc & $37 \mathrm{~EB}-12$ & Biface Stage 3 & \\
\hline $\mathrm{E} 28 / \mathrm{S} 78$ & 5 & Feature 173 & IIIC & $37 \mathrm{ED}-48$ & Bifacial tool Form B & 1 \\
\hline $\mathrm{E} 28 / \mathrm{S} 78$ & 5 & Feature 173 & IIIc & & Debitage & 1618 \\
\hline E28/S78 & 5 & Feature 173 & IIIc & $37 \mathrm{EC}-24$ & Edge modified flake & \\
\hline E28/S78 & 5 & Feature 173 & IIIc & $37 \mathrm{EC}-34$ & Edge modified flake & \\
\hline E28/S78 & 5 & Feature 173 & IIIc & 37ED-43 & Edge modified flake & \\
\hline $\mathrm{E} 28 / \mathrm{S} 78$ & 5 & Feature 173 & IIIc & $37 \mathrm{ED}-45$ & Edge modified flake & 1 \\
\hline $\mathrm{E} 28 / \mathrm{S} 78$ & 5 & Feature 173 & IIIc & 37EB-21 & Edge modified flake & \\
\hline E28/S78 & 5 & Feature 173 & IIIc & $37 \mathrm{ED}-53$ & Edge modified flake & \\
\hline $\mathrm{E} 28 / \mathrm{S} 78$ & 5 & Feature 173 & IIIc & $37 \mathrm{ED}-54$ & Edge modified flake & 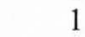 \\
\hline E28/S78 & 5 & Feature 173 & IIIC & 37EA-9 & Edge modified flake & 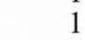 \\
\hline $\mathrm{E} 28 / \mathrm{S} 78$ & 5 & Feature 173 & IIIc & 37EA-4 & Edge modified flake & \\
\hline $\mathrm{E} 28 / \mathrm{S} 78$ & 5 & Feature 173 & IIIc & $37 \mathrm{EA}-8$ & Edge modified flake & 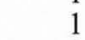 \\
\hline E28/S78 & 5 & Feature 173 & IIIc & $37 \mathrm{~EB}-15$ & Edge modified flake & 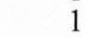 \\
\hline $\mathrm{E} 28 / \mathrm{S} 78$ & 5 & Feature 173 & IIIc & $37 \mathrm{~EB}-19$ & Edge modified flake & 1 \\
\hline $\mathrm{E} 28 / \mathrm{S} 78$ & 5 & Feature 173 & IIIc & $37 \mathrm{EC}-22$ & Edge modified flake & \\
\hline $\mathrm{E} 28 / \mathrm{S} 78$ & 5 & Feature 173 & IIIc & $37 \mathrm{~EB}-10$ & Mano fragment & \\
\hline $\mathrm{E} 28 / \mathrm{S} 78$ & 5 & Feature 173 & IIIc & $37 \mathrm{EA}-1$ & Micro-core, large & 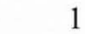 \\
\hline E28/S78 & 5 & Feature 173 & IIIc & 37ED-46 & Notched flake & \\
\hline E28/S78 & 5 & Feature 173 & IIIc & $37 \mathrm{EC}-25$ & Perforator Unifacial & \\
\hline $\mathrm{E} 28 / \mathrm{S} 78$ & 5 & Feature 173 & IIIc & $37 \mathrm{~EB}-13$ & Projectile point fragment & \\
\hline $\mathrm{E} 28 / \mathrm{S} 78$ & 5 & Feature 173 & IIIc & $37 \mathrm{EA}-2$ & Projectile point fragment & \\
\hline E28/S78 & 5 & Feature 173 & IIIc & 37EC-36 & Projectile point fragment & \\
\hline $\mathrm{E} 28 / \mathrm{S} 78$ & 5 & Feature 173 & IIIc & $37 \mathrm{EC}-40$ & Projectile point, Bulverde-like & \\
\hline E28/S78 & 5 & Feature 173 & IIIc & 37ED-56 & Projectile point, Castroville & \\
\hline E28/S78 & 5 & Feature 173 & IIIc & $37 \mathrm{EC}-39$ & Projectile point, Pedernales & \\
\hline E28/S78 & 5 & Feature 173 & IIIc & $37 \mathrm{EC}-38$ & Spurred flake & 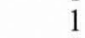 \\
\hline $\mathrm{E} 28 / \mathrm{S} 78$ & 5 & Feature 173 & IIIc & $37 \mathrm{~EB}-17$ & Thin uniface & \\
\hline $\mathrm{E} 28 / \mathrm{S} 78$ & 5 & Feature 173 & IIIC & $37 \mathrm{EC}-26$ & Thin uniface & \\
\hline $\mathrm{E} 28 / \mathrm{S} 78$ & 5 & Feature 173 & IIIc & 37ED-49 & Thin uniface & \\
\hline E28/S78 & 5 & Feature 173 & IIIc & $37 \mathrm{~EB}-16$ & Thin uniface fragment & 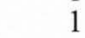 \\
\hline E28/S78 & 5 & Feature 173 & IIIc & 37EC-35 & Unifacial multiple tool & \\
\hline $\mathrm{E} 28 / \mathrm{S} 78$ & 5 & Feature 173 & IIIc & $37 \mathrm{~EB}-20$ & Unifacial multiple tool & \\
\hline E28/S78 & 6 & & IIIc & $37 \mathrm{FC}-16$ & Biface fragment & \\
\hline $\mathrm{E} 28 / \mathrm{S} 78$ & 6 & & IIIc & $37 \mathrm{FC}-8$ & Biface Stage 2 & 1 \\
\hline E28/S78 & 6 & & IIIc & $37 \mathrm{FC}-17$ & Biface Stage 3 & \\
\hline E28/S78 & 6 & & IIIc & $37 \mathrm{FB}-5$ & Burin & \\
\hline $\mathrm{E} 28 / \mathrm{S} 78$ & 6 & & IIIc & $37 F D-27$ & Core fragment & \\
\hline $\mathrm{E} 28 / \mathrm{S} 78$ & 6 & & IIIc & & Debitage & 977 \\
\hline E28/S78 & 6 & & IIIC & $37 \mathrm{FC}-10$ & Denticulated flake & \\
\hline $\mathrm{E} 28 / \mathrm{S} 78$ & 6 & & IIIc & $37 \mathrm{FC}-11$ & Edge modified flake & \\
\hline $\mathrm{E} 28 / \mathrm{S} 78$ & 6 & & IIIc & $37 \mathrm{FC}-24$ & Edge modified flake & \\
\hline $\mathrm{E} 28 / \mathrm{S} 78$ & 6 & & IIIc & $37 \mathrm{FA}-2$ & Edge modified flake & \\
\hline E28/S78 & 6 & & IIIc & $37 \mathrm{FD}-25$ & Edge modified flake & \\
\hline E28/S78 & 6 & & IIIc & $37 \mathrm{FC}-23$ & Edge modified flake & \\
\hline $\mathrm{E} 28 / \mathrm{S} 78$ & 6 & & IIIc & $37 F D-26$ & Edge modified flake & \\
\hline E28/S78 & 6 & & IIIc & $37 \mathrm{FC}-19$ & Edge modified flake & \\
\hline $\mathrm{E} 28 / \mathrm{S} 78$ & 6 & & IIIC & $37 \mathrm{FC}-20$ & Edge modified flake & \\
\hline E28/S78 & 6 & & IIIc & $37 \mathrm{FC}-18$ & Notched flake & \\
\hline $\mathrm{E} 28 / \mathrm{S} 78$ & 6 & & IIIc & 37FB-7 & Notched flake & \\
\hline E28/S78 & 6 & & IIIc & $37 \mathrm{FC}-9$ & Projectile point fragment & \\
\hline $\mathrm{E} 28 / \mathrm{S} 78$ & 6 & & IIIc & $37 \mathrm{FB}-6$ & Projectile point fragment & \\
\hline $\mathrm{E} 28 / \mathrm{S} 78$ & 6 & & IIIc & $37 \mathrm{FC}-13$ & Thin uniface & \\
\hline E28/S78 & 7 & & IIIc & $37 \mathrm{GA}-2$ & Biface fragment & \\
\hline E28/S78 & 7 & & $\mathrm{IIIb} / \mathrm{c}$ & $37 \mathrm{GD}-19$ & Biface Stage 1 & \\
\hline E28/S78 & 7 & & IIIc & $37 \mathrm{GA}-1$ & Biface Stage 2 & \\
\hline
\end{tabular}




\begin{tabular}{|c|c|c|c|c|c|c|}
\hline Square & Level & Feature & Strata & Item & Analyst Identification & Count \\
\hline $\mathrm{E} 28 / \mathrm{S} 78$ & 7 & & $\mathrm{IIIb} / \mathrm{c}$ & $37 \mathrm{GC}-10$ & Biface Stage 2 & 1 \\
\hline $\mathrm{E} 28 / \mathrm{S} 78$ & 7 & & $\mathrm{IIIb} / \mathrm{c}$ & $37 \mathrm{GD}-20$ & Biface Stage 2 & 1 \\
\hline E28/S78 & 7 & & IIIc & 37GB-9 & Brushy Creek biface & 1 \\
\hline E28/S78 & 7 & & $\mathrm{IIIb} / \mathrm{c}$ & & Debitage & 497 \\
\hline $\mathrm{E} 28 / \mathrm{S} 78$ & 7 & & IIIc & & Debitage & 346 \\
\hline E28/S78 & 7 & & $\mathrm{IIIb} / \mathrm{c}$ & $37 \mathrm{GD}-24$ & Edge modified flake & 1 \\
\hline E28/S78 & 7 & & IIIc & $37 \mathrm{~GB}-6$ & Edge modified flake & 1 \\
\hline E28/S78 & 7 & & IIIc & $37 \mathrm{~GB}-4$ & Edge modified flake & 1 \\
\hline E28/S78 & 7 & & $\mathrm{IIIb} / \mathrm{c}$ & $37 \mathrm{GC}-11$ & Edge modified flake & 1 \\
\hline E28/S78 & 7 & & $\mathrm{IIIb} / \mathrm{c}$ & $37 \mathrm{GC}-13$ & Edge modified flake & 1 \\
\hline $\mathrm{E} 28 / \mathrm{S} 78$ & 7 & & IIIc & $37 \mathrm{~GB}-7$ & Edge modified flake & 1 \\
\hline E28/S78 & 7 & & $\mathrm{IIIb} / \mathrm{c}$ & $37 \mathrm{GD}-22$ & Notched flake & 1 \\
\hline E28/S78 & 7 & & IIIC & $37 \mathrm{~GB}-3$ & Projectile point, Bulverde-like & 1 \\
\hline $\mathrm{E} 28 / \mathrm{S} 78$ & 7 & & $\mathrm{IIIb} / \mathrm{c}$ & 37GD-18 & Projectile point, Nolan eccentric & 1 \\
\hline $\mathrm{E} 28 / \mathrm{S} 78$ & 7 & & IIIc & $37 \mathrm{~GB}-8$ & Thin uniface fragment & 1 \\
\hline $\mathrm{E} 28 / \mathrm{S} 78$ & 7 & & $\mathrm{IIIb} / \mathrm{c}$ & $37 \mathrm{GC}-14$ & Thin uniface fragment & 1 \\
\hline $\mathrm{E} 28 / \mathrm{S} 78$ & 7 & & $\mathrm{IIIb} / \mathrm{c}$ & $37 \mathrm{GC}-12$ & Uniface, unanalyzed & 1 \\
\hline E28/S78 & 8 & & $\mathrm{IIIb} / \mathrm{c}$ & $37 \mathrm{HB}-7$ & Biface fragment & 1 \\
\hline E28/S78 & 8 & & $\mathrm{IIIb} / \mathrm{c}$ & $37 \mathrm{HC}-19$ & Biface Stage 1 & 1 \\
\hline $\mathrm{E} 28 / \mathrm{S} 78$ & 8 & & $\mathrm{IIIb} / \mathrm{c}$ & $37 \mathrm{HC}-13$ & Biface Stage 2 & 1 \\
\hline E28/S78 & 8 & & $\mathrm{IIIb} / \mathrm{c}$ & & Debitage & 914 \\
\hline E28/S78 & 8 & & $\mathrm{IIIb} / \mathrm{c}$ & $37 \mathrm{HC}-23$ & Denticulated flake & 1 \\
\hline E28/S78 & 8 & & $\mathrm{IIIb} / \mathrm{c}$ & $37 \mathrm{HC}-17$ & Edge modified flake & 1 \\
\hline E28/S78 & 8 & & $\mathrm{IIIb} / \mathrm{c}$ & $37 \mathrm{HA}-2$ & Edge modified flake & 1 \\
\hline $\mathrm{E} 28 / \mathrm{S} 78$ & 8 & & $\mathrm{IIIb} / \mathrm{c}$ & $37 \mathrm{HC}-20$ & Edge modified flake & 1 \\
\hline $\mathrm{E} 28 / \mathrm{S} 78$ & 8 & & $\mathrm{IIIb} / \mathrm{c}$ & $37 \mathrm{HB}-12$ & Edge modified flake & 1 \\
\hline E28/S78 & 8 & & $\mathrm{IIIb} / \mathrm{c}$ & 37HB-11 & Edge modified flake & 1 \\
\hline E28/S78 & 8 & & $\mathrm{IIIb} / \mathrm{c}$ & 37HB-10 & Edge modified flake & 1 \\
\hline E28/S78 & 8 & & $\mathrm{IIIb} / \mathrm{c}$ & $37 \mathrm{HA}-4$ & Edge modified flake & 1 \\
\hline E28/S78 & 8 & & $\mathrm{IIIb} / \mathrm{c}$ & $37 \mathrm{HA}-1$ & Edge modified flake & 1 \\
\hline E28/S78 & 8 & & $\mathrm{IIIb} / \mathrm{c}$ & $37 \mathrm{HC}-15$ & Edge modified flake & 1 \\
\hline $\mathrm{E} 28 / \mathrm{S} 78$ & 8 & & $\mathrm{IIIb} / \mathrm{c}$ & $37 \mathrm{HC}-22$ & Notched flake & 1 \\
\hline E28/S78 & 8 & & $\mathrm{IIIb} / \mathrm{c}$ & $37 \mathrm{HB}-9$ & Projectile point fragment & 1 \\
\hline $\mathrm{E} 28 / \mathrm{S} 78$ & 8 & & $\mathrm{IIIb} / \mathrm{c}$ & $37 \mathrm{HC}-14$ & Projectile point, square stem & 1 \\
\hline E28/S78 & 8 & & $\mathrm{IIIb} / \mathrm{c}$ & 37HD-24 & Unifacial multiple tool & 1 \\
\hline E28/S78 & 9 & & $\mathrm{IIIb} / \mathrm{c}$ & 37IB-3 & Biface fragment & 1 \\
\hline E28/S78 & 9 & & $\mathrm{IIIb} / \mathrm{c}$ & 37IA-1 & Biface Stage 1 & 1 \\
\hline E28/S78 & 9 & & $\mathrm{IIIb} / \mathrm{c}$ & $37 \mathrm{IC}-7$ & Biface Stage 2 & 1 \\
\hline E28/S78 & 9 & & $\mathrm{IIIb} / \mathrm{c}$ & $37 \mathrm{IC}-8$ & Burin spall & 1 \\
\hline $\mathrm{E} 28 / \mathrm{S} 78$ & 9 & & $\mathrm{IIIb} / \mathrm{c}$ & $37 \mathrm{ID}-17$ & Chert cobble, chunk & 1 \\
\hline E28/S78 & 9 & & $\mathrm{IIIb} / \mathrm{c}$ & & Debitage & 626 \\
\hline E28/S78 & 9 & & $\mathrm{IIIb} / \mathrm{c}$ & $37 \mathrm{IC}-15$ & Edge modified flake & 1 \\
\hline E28/S78 & 9 & & $\mathrm{IIIb} / \mathrm{c}$ & $37 \mathrm{IA}-2$ & Edge modified flake & 1 \\
\hline E28/S78 & 9 & & $\mathrm{IIIb} / \mathrm{c}$ & $37 \mathrm{IC}-12$ & Projectile point fragment & 1 \\
\hline E28/S78 & 9 & & $\mathrm{IIIb} / \mathrm{c}$ & 37IB-4 & Projectile point, bifurcate stem fragment & 1 \\
\hline E28/S78 & 9 & & $\mathrm{IIIb} / \mathrm{c}$ & $37 \mathrm{ID}-16$ & Projectile point, Bulverde-like & 1 \\
\hline E28/S78 & 9 & & $\mathrm{IIIb} / \mathrm{c}$ & 37IB-5 & Thin uniface fragment & 1 \\
\hline E28/S78 & 9 & & $\mathrm{IIIb} / \mathrm{c}$ & $37 \mathrm{IC}-14$ & Uniface, unanalyzed & 1 \\
\hline E28/S78 & 10 & & $\mathrm{IIIb} / \mathrm{c}$ & $37 \mathrm{JA}-5$ & Biface fragment & 1 \\
\hline E28/S78 & 10 & & $\mathrm{IIIb} / \mathrm{c}$ & 37JC-19 & Chert cobble, chunk & 1 \\
\hline E28/S78 & 10 & & $\mathrm{IIIb} / \mathrm{c}$ & & Debitage & 333 \\
\hline E28/S78 & 10 & & IIIb & & Debitage & 188 \\
\hline E28/S78 & 10 & & IIIb & $37 \mathrm{JB}-15$ & Edge modified flake & 1 \\
\hline $\mathrm{E} 28 / \mathrm{S} 78$ & 10 & & $\mathrm{IIIb} / \mathrm{c}$ & $37 \mathrm{JC}-21$ & Edge modified flake & 1 \\
\hline E28/S78 & 10 & & $\mathrm{IIIb} / \mathrm{c}$ & $37 \mathrm{JA}-4$ & Edge modified flake & 1 \\
\hline E28/S78 & 10 & & IIIb & $37 \mathrm{JD}-27$ & Edge modified flake & 1 \\
\hline E28/S78 & 10 & & $\mathrm{IIIb} / \mathrm{c}$ & $37 \mathrm{JA}-2$ & Projectile point fragment & 1 \\
\hline E28/S78 & 10 & & $\mathrm{IIIb} / \mathrm{c}$ & $37 \mathrm{JA}-1$ & Projectile point, miscellaneous lanceolate & 1 \\
\hline $\mathrm{E} 28 / \mathrm{S} 78$ & 10 & Feature 176 & $\mathrm{IIIb} / \mathrm{c}$ & & Debitage & 1 \\
\hline E28/S78 & 10 & Feature 176 & $\mathrm{IIIb} / \mathrm{c}$ & 37JA-11 & Unifacial multiple tool & 1 \\
\hline $\mathrm{E} 28 / \mathrm{S} 78$ & 10 & Feature 177 & $\mathrm{IIIb} / \mathrm{c}$ & & Debitage & 24 \\
\hline E28/S78 & 11 & & $\mathrm{IIIb}$ & $37 \mathrm{~KB}-1$ & Biface fragment & 1 \\
\hline E28/S78 & 11 & & $\mathrm{IIIb}$ & $37 \mathrm{KC}-5$ & Biface Stage 2 & 1 \\
\hline E28/S78 & 11 & & IIIb & & Debitage & 231 \\
\hline E28/S78 & 11 & & $\mathrm{IIIb} / \mathrm{c}$ & & Debitage & 92 \\
\hline E28/S78 & 11 & & IIIb & $37 \mathrm{KC}-6$ & Denticulated flake & 1 \\
\hline $\mathrm{E} 28 / \mathrm{S} 78$ & 11 & & IIIb & $37 \mathrm{KC}-7$ & Thick uniface & 1 \\
\hline E28/S78 & 11 & & $\mathrm{IIIb}$ & $37 \mathrm{~KB}-2$ & Unifacial multiple tool & 1 \\
\hline $\mathrm{E} 28 / \mathrm{S} 78$ & 11 & Feature 179 & $\mathrm{IIIb}$ & $37 \mathrm{KCD}-1$ & Core, thermal & 1 \\
\hline $\mathrm{E} 28 / \mathrm{S} 78$ & 11 & Feature 179 & $\mathrm{IIIb}$ & & Debitage & 18 \\
\hline E28/S78 & 12 & & IIIb & 37LB-14 & Biface Stage 1 & 1 \\
\hline E28/S78 & 12 & & IIIb & 37LB-9 & Biface Stage 1 & 1 \\
\hline $\mathrm{E} 28 / \mathrm{S} 78$ & 12 & & IIIb & 37LB-11 & Biface Stage 2 & 1 \\
\hline E28/S78 & 12 & & IIIb & 37LD-34 & Biface Stage 2 & 1 \\
\hline
\end{tabular}




\begin{tabular}{|c|c|c|c|c|c|c|}
\hline Square & Level & Feature & Strata & Item & Analyst Identification & Count \\
\hline $\mathrm{E} 28 / \mathrm{S} 78$ & 12 & & IIIb & $37 \mathrm{LD}-37$ & Biface Stage 2 & 1 \\
\hline $\mathrm{E} 28 / \mathrm{S} 78$ & 12 & & IIIb & $37 \mathrm{LA}-3$ & Bifacial tool Form C & 1 \\
\hline $\mathrm{E} 28 / \mathrm{S} 78$ & 12 & & IIIb & $37 \mathrm{LB}-15$ & Burin & 1 \\
\hline $\mathrm{E} 28 / \mathrm{S} 78$ & 12 & & IIIb & 37LB-12 & Burin & 1 \\
\hline E28/S78 & 12 & & IIIb & $37 \mathrm{LA}-1$ & Core, multidirectional & 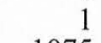 \\
\hline E28/S78 & 12 & & IIIb & & Debitage & 1075 \\
\hline E28/S78 & 12 & & IIIb & 37LD-38 & Edge modified flake & 1 \\
\hline $\mathrm{E} 28 / \mathrm{S} 78$ & 12 & & IIIb & $37 \mathrm{LC}-22$ & Edge modified flake & 1 \\
\hline $\mathrm{E} 28 / \mathrm{S} 78$ & 12 & & IIIb & 37LC-27 & Edge modified flake & 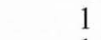 \\
\hline E28/S78 & 12 & & IIIb & $37 \mathrm{LC}-21$ & Edge modified flake & 1 \\
\hline $\mathrm{E} 28 / \mathrm{S} 78$ & 12 & & IIIb & 37LB-18 & Edge modified flake & 1 \\
\hline $\mathrm{E} 28 / \mathrm{S} 78$ & 12 & & IIIb & $37 \mathrm{LD}-36$ & Microspur/microdenticulate & 1 \\
\hline $\mathrm{E} 28 / \mathrm{S} 78$ & 12 & & IIIb & $37 \mathrm{LB}-16$ & Notched flake & \\
\hline $\mathrm{E} 28 / \mathrm{S} 78$ & 12 & & $\mathrm{IIIb}$ & 37LA-2 & Perforator Group 2 & \\
\hline E28/S78 & 12 & & IIIb & $37 \mathrm{LB}-10$ & Piece esquillee & \\
\hline $\mathrm{E} 28 / \mathrm{S} 78$ & 12 & & IIIb & 37LD-31 & Projectile point, Gower/Uvalde & 1 \\
\hline $\mathrm{E} 28 / \mathrm{S} 78$ & 12 & & IIIb & 37LC-19 & Projectile point, Uvalde & 1 \\
\hline $\mathrm{E} 28 / \mathrm{S} 78$ & 12 & & IIIb & 37LD-30 & Projectile point, Wilson? & 1 \\
\hline $\mathrm{E} 28 / \mathrm{S} 78$ & 12 & & IIIb & 37LD-35 & Spurred flake & 1 \\
\hline $\mathrm{E} 28 / \mathrm{S} 78$ & 12 & & IIIb & $37 \mathrm{LA}-4$ & Thin uniface & 1 \\
\hline E28/S78 & 12 & & IIIb & $37 \mathrm{LA}-5$ & Thin uniface & 1 \\
\hline $\mathrm{E} 28 / \mathrm{S} 78$ & 12 & & IIIb & $37 \mathrm{LC}-29$ & Thin uniface fragment & 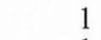 \\
\hline $\mathrm{E} 28 / \mathrm{S} 78$ & 12 & & IIIb & 37LB-17 & Thin uniface fragment & 1 \\
\hline $\mathrm{E} 28 / \mathrm{S} 78$ & 12 & & IIIb & 37LD-39 & Uniface, unanalyzed & 1 \\
\hline E28/S78 & 13 & & IIIb & $37 \mathrm{MA}-1$ & Biface fragment & 1 \\
\hline $\mathrm{E} 28 / \mathrm{S} 78$ & 13 & & IIIb & $37 \mathrm{MC}-27$ & Biface fragment & 1 \\
\hline $\mathrm{E} 28 / \mathrm{S} 78$ & 13 & & IIIb & $37 \mathrm{MC}-23$ & Biface fragment & i \\
\hline E28/S78 & 13 & & IIIb & $37 \mathrm{MC}-20$ & Biface fragment & 1 \\
\hline $\mathrm{E} 28 / \mathrm{S} 78$ & 13 & & IIIb & $37 \mathrm{MD}-29$ & Biface fragment, unanalyzed & 1 \\
\hline $\mathrm{E} 28 / \mathrm{S} 78$ & 13 & & IIIb & $37 \mathrm{MA}-2$ & Biface Stage 3 & 1 \\
\hline $\mathrm{E} 28 / \mathrm{S} 78$ & 13 & & IIIb & $37 \mathrm{MC}-14$ & Biface Stage 3 & 1 \\
\hline $\mathrm{E} 28 / \mathrm{S} 78$ & 13 & & IIIb & $37 \mathrm{MA}-10$ & Burin spall & 1 \\
\hline E28/S78 & 13 & & IIIb & & Debitage & 1204 \\
\hline $\mathrm{E} 28 / \mathrm{S} 78$ & 13 & & IIIb & $37 \mathrm{MC}-22$ & Edge modified flake & 列 \\
\hline $\mathrm{E} 28 / \mathrm{S} 78$ & 13 & & IIIb & $37 \mathrm{MA}-12$ & Edge modified flake & 1 \\
\hline $\mathrm{E} 28 / \mathrm{S} 78$ & 13 & & IIIb & $37 \mathrm{MD}-35$ & Edge modified flake & 1 \\
\hline E28/S78 & 13 & & IIIb & $37 \mathrm{MA}-7$ & Edge modified flake & 1 \\
\hline $\mathrm{E} 28 / \mathrm{S} 78$ & 13 & & IIIb & $37 \mathrm{MA}-8$ & Edge modified flake & 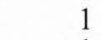 \\
\hline E28/S78 & 13 & & IIIb & $37 \mathrm{MC}-19$ & Edge modified flake & 1 \\
\hline $\mathrm{E} 28 / \mathrm{S} 78$ & 13 & & IIIb & $37 \mathrm{MC}-26$ & Edge modified flake & 1 \\
\hline E28/S78 & 13 & & IIIb & $37 \mathrm{MD}-30$ & Microspur/microdenticulate & 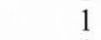 \\
\hline E28/S78 & 13 & & IIIb & $37 \mathrm{MD}-32$ & Notched flake & 1 \\
\hline $\mathrm{E} 28 / \mathrm{S} 78$ & 13 & & IIIb & $37 \mathrm{MA}-3$ & Projectile point fragment & it \\
\hline $\mathrm{E} 28 / \mathrm{S} 78$ & 13 & & IIIb & $37 \mathrm{MC}-16$ & Projectile point, expanding concave D & 1 \\
\hline $\mathrm{E} 28 / \mathrm{S} 78$ & 13 & & IIIb & $37 \mathrm{MC}-15$ & Projectile point, Hoxie & 1 \\
\hline E28/S78 & 13 & & IIIb & $37 \mathrm{MA}-4$ & Projectile point, Martindale A & 1 \\
\hline $\mathrm{E} 28 / \mathrm{S} 78$ & 13 & & IIIb & $37 \mathrm{MB}-13$ & Spurred flake & 1 \\
\hline $\mathrm{E} 28 / \mathrm{S} 78$ & 13 & & IIIb & $37 \mathrm{MC}-25$ & Unifacial multiple tool & 1 \\
\hline $\mathrm{E} 28 / \mathrm{S} 78$ & 13 & & IIIb & $37 \mathrm{MC}-17$ & Unifacial multiple tool & 1 \\
\hline E28/S78 & 14 & & $\mathrm{IIIa} / \mathrm{b}$ & $37 \mathrm{NC}-11$ & Biface Stage 2 & 1 \\
\hline $\mathrm{E} 28 / \mathrm{S} 78$ & 14 & & IIIa/b & $37 \mathrm{NC}-10$ & Burin spall & 1 \\
\hline $\mathrm{E} 28 / \mathrm{S} 78$ & 14 & & IIIb & & Debitage & 391 \\
\hline $\mathrm{E} 28 / \mathrm{S} 78$ & 14 & & $\mathrm{III} / \mathrm{b}$ & & Debitage & 296 \\
\hline E28/S78 & 14 & & $\mathrm{III} \mathrm{a} / \mathrm{b}$ & $37 N D-15$ & Edge modified flake & \\
\hline E28/S78 & 14 & & $\mathrm{III} a / \mathrm{b}$ & $37 N D-14$ & Edge modified flake & 1 \\
\hline $\mathrm{E} 28 / \mathrm{S} 78$ & 14 & & $\mathrm{IIIb}$ & $37 \mathrm{NB}-8$ & Edge modified flake & 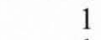 \\
\hline $\mathrm{E} 28 / \mathrm{S} 78$ & 14 & & IIIb & $37 \mathrm{NA}-1$ & Edge modified flake & 1 \\
\hline $\mathrm{E} 28 / \mathrm{S} 78$ & 14 & & $\mathrm{IIIa} / \mathrm{b}$ & $37 \mathrm{NC}-12$ & Edge modified flake & 1 \\
\hline E28/S78 & 14 & & IIIb & $37 \mathrm{NA}-4$ & Notched flake & 1 \\
\hline E28/S78 & 14 & & $\mathrm{IIIa} / \mathrm{b}$ & $37 N D-13$ & Projectile point fragment & 1 \\
\hline $\mathrm{E} 28 / \mathrm{S} 78$ & 14 & & IIIb & $37 \mathrm{NB}-7$ & Projectile point, expanding concave D & 1 \\
\hline $\mathrm{E} 28 / \mathrm{S} 78$ & $15 \mathrm{~A}$ & & $\mathrm{III} / \mathrm{b}$ & & Debitage & 284 \\
\hline $\mathrm{E} 28 / \mathrm{S} 78$ & $15 \mathrm{~A}$ & & $\mathrm{IIIb}$ & & Debitage & 123 \\
\hline E28/S78 & $15 \mathrm{~A}$ & & IIIa & & Debitage & 108 \\
\hline $\mathrm{E} 28 / \mathrm{S} 78$ & $15 \mathrm{~A}$ & & IIIa & $3701 \mathrm{D}-9$ & Edge modified flake & 1 \\
\hline $\mathrm{E} 28 / \mathrm{S} 78$ & $15 \mathrm{~A}$ & & IIIb & $3701 B-5$ & Edge modified flake & 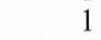 \\
\hline $\mathrm{E} 28 / \mathrm{S} 78$ & $15 \mathrm{~A}$ & & $\mathrm{IIIa} / \mathrm{b}$ & $3701 \mathrm{~A}-2$ & Microspur/microdenticulate & 1 \\
\hline $\mathrm{E} 28 / \mathrm{S} 78$ & $15 \mathrm{~A}$ & & $\mathrm{IIIb}$ & $3701 B-3$ & Thin uniface & 1 \\
\hline E28/S78 & $15 \mathrm{~A}$ & & IIIa & $3701 \mathrm{D}-10$ & Unifacial multiple tool & 1 \\
\hline $\mathrm{E} 28 / \mathrm{S} 78$ & $15 \mathrm{~A}$ & Feature 181 & $\mathrm{IIIa} / \mathrm{b}$ & $37 \mathrm{O} 1 \mathrm{C}-6$ & Biface Stage 2 & 1 \\
\hline $\mathrm{E} 28 / \mathrm{S} 78$ & $15 \mathrm{~A}$ & Feature 181 & IIIa & $3701 \mathrm{D}-8$ & Burin spall & 1 \\
\hline $\mathrm{E} 28 / \mathrm{S} 78$ & $15 \mathrm{~A}$ & Feature 181 & IIIa & $3701 D-1$ & Projectile point, Jetta & 1 \\
\hline $\mathrm{E} 28 / \mathrm{S} 78$ & $15 \mathrm{~B}$ & & $\mathrm{III} / \mathrm{b}$ & & Debitage & 134 \\
\hline E28/S78 & $15 \mathrm{~B}$ & & $\mathrm{IIIa} / \mathrm{b}$ & $37 \mathrm{O} 2 \mathrm{~A}-3$ & Edge modified flake & \\
\hline
\end{tabular}




\begin{tabular}{|c|c|c|c|c|c|c|}
\hline Square & Level & Feature & Strata & Item & Analyst Identification & Count \\
\hline E28/S78 & $15 \mathrm{~B}$ & & $\mathrm{IIIa} / \mathrm{b}$ & $3702 \mathrm{~A}-1$ & Notched flake & 1 \\
\hline E28/S78 & $15 \mathrm{~B}$ & & $\mathrm{IIIa} / \mathrm{b}$ & $37 \mathrm{O} 2 \mathrm{~A}-2$ & Spurred flake & 1 \\
\hline E28/S78 & $15 \mathrm{~B}$ & Feature 181 & IIIa & $37 \mathrm{O} 2 \mathrm{C}-11$ & Biface fragment & 1 \\
\hline E28/S78 & $15 \mathrm{~B}$ & Feature 181 & IIIa & $37 \mathrm{O} 2 \mathrm{C}-13$ & Biface Stage 2 & 1 \\
\hline $\mathrm{E} 28 / \mathrm{S} 78$ & $15 \mathrm{~B}$ & Feature 181 & IIIa & $37 \mathrm{O} 2 \mathrm{C}-10$ & Burin spall & 1 \\
\hline $\mathrm{E} 28 / \mathrm{S} 78$ & $15 \mathrm{~B}$ & Feature 181 & IIIa & & Debitage & 185 \\
\hline E28/S78 & $15 \mathrm{~B}$ & Feature 181 & $\mathrm{IIIa} / \mathrm{b}$ & & Debitage & 114 \\
\hline $\mathrm{E} 28 / \mathrm{S} 78$ & $15 \mathrm{~B}$ & Feature 181 & IIIa & $37 \mathrm{O} 2 \mathrm{C}-9$ & Projectile point fragment & 1 \\
\hline E28/S78 & $15 \mathrm{~B}$ & Feature 181 & $\mathrm{IIIa} / \mathrm{b}$ & $37 \mathrm{O} 2 \mathrm{~B}-7$ & Projectile point, Hoxie & 1 \\
\hline $\mathrm{E} 28 / \mathrm{S} 78$ & $15 \mathrm{~B}$ & Feature 181 & IIIa & $37 \mathrm{O} 2 \mathrm{C}-8$ & Projectile point, Hoxie & 1 \\
\hline E28/S78 & $15 \mathrm{~B}$ & Feature 181 & IIIa & $37 \mathrm{O} 2 \mathrm{C}-12$ & Thin uniface & 1 \\
\hline E28/S78 & $15 \mathrm{~B}$ & Feature 181 & $\mathrm{IIIa} / \mathrm{b}$ & $37 \mathrm{O} 2 \mathrm{~B}-4$ & Unifacial multiple tool & 1 \\
\hline E28/S78 & $16 \mathrm{~A}$ & Feature 181 & IIIa & 37P1D-6 & Biface fragment & 1 \\
\hline $\mathrm{E} 28 / \mathrm{S} 78$ & $16 \mathrm{~A}$ & Feature 181 & IIIa & 37P1D-5 & Biface fragment & 1 \\
\hline E28/S78 & $16 \mathrm{~A}$ & Feature 181 & IIIa & 37P1D-7 & Biface Stage 1 & 1 \\
\hline E28/S78 & $16 \mathrm{~A}$ & Feature 181 & IIIa & 37P1B-3 & Biface Stage 3 & 1 \\
\hline $\mathrm{E} 28 / \mathrm{S} 78$ & $16 \mathrm{~A}$ & Feature 181 & IIIa & 37P1D-8 & Burin spall & 1 \\
\hline E28/S78 & $16 \mathrm{~A}$ & Feature 181 & IIIa & & Debitage & 505 \\
\hline E28/S78 & $16 \mathrm{~A}$ & Feature 181 & IIIa & 37P1D-11 & Edge modified flake & 1 \\
\hline E28/S78 & $16 \mathrm{~A}$ & Feature 181 & IIIIa & $37 \mathrm{P} 1 \mathrm{~A}-1$ & Edge modified flake & 1 \\
\hline E28/S78 & $16 \mathrm{~A}$ & Feature 181 & IIIa & $37 \mathrm{P} 1 \mathrm{C}-4$ & Microspur/microdenticulate & 1 \\
\hline E28/S78 & $16 \mathrm{~A}$ & Feature 181 & IIIa & $37 \mathrm{P} 1 \mathrm{~A}-2$ & Perforator Group 7 & 1 \\
\hline $\mathrm{E} 28 / \mathrm{S} 78$ & $16 \mathrm{~A}$ & Feature 181 & IIIa & 37P1D-9 & Uniface, unanalyzed & 1 \\
\hline $\mathrm{E} 28 / \mathrm{S} 78$ & $16 \mathrm{~B}$ & & IIIa & & Debitage & 142 \\
\hline E28/S78 & $16 \mathrm{~B}$ & Feature 181 & IIIIa & $37 \mathrm{P} 2 \mathrm{C}-4$ & Burin spall & 1 \\
\hline E28/S78 & $16 \mathrm{~B}$ & Feature 181 & IIIa & & Debitage & 143 \\
\hline E28/S78 & $16 \mathrm{~B}$ & Feature 181 & IIIa & 37P2B-1 & Edge modified flake & 1 \\
\hline $\mathrm{E} 28 / \mathrm{S} 78$ & $16 \mathrm{~B}$ & Feature 181 & IIIa & $37 \mathrm{P} 2 \mathrm{~B}-3$ & Edge modified flake & 1 \\
\hline $\mathrm{E} 28 / \mathrm{S} 78$ & $16 \mathrm{~B}-18 \mathrm{~A}$ & Feature 181 & II/IIIa & & Debitage & 10 \\
\hline E28/S78 & $17 \mathrm{~A}$ & & IIIa & & Debitage & 366 \\
\hline E28/S78 & $17 \mathrm{~A}$ & & IIIa & $37 Q 1 C-5$ & Projectile point, miscellaneous lanceolate & 1 \\
\hline E28/S78 & $17 \mathrm{~A}$ & Feature 181 & IIIIa & $37 \mathrm{Q} 1 \mathrm{~A}-1$ & Bifacial tool Form A & 1 \\
\hline E28/S78 & $17 \mathrm{~A}$ & Feature 181 & IIIa & $37 Q 1 D-6$ & Burin spall & 1 \\
\hline $\mathrm{E} 28 / \mathrm{S} 78$ & $17 \mathrm{~A}$ & Feature 181 & IIIa & & Debitage & 316 \\
\hline E28/S78 & $17 \mathrm{~A}$ & Feature 181 & IIIa & 37Q1A-2 & Edge modified flake & 1 \\
\hline $\mathrm{E} 28 / \mathrm{S} 78$ & $17 \mathrm{~A}$ & Feature 181 & IIIa & $37 Q 1 D-8$ & Thin uniface & 1 \\
\hline $\mathrm{E} 28 / \mathrm{S} 78$ & $17 \mathrm{~A}$ & Feature 183 & IIIa & $37 \mathrm{Q} 1 \mathrm{D}-7$ & Perforator Group 7 & 1 \\
\hline E28/S78 & $17 \mathrm{~B}$ & & IIIa & $37 \mathrm{Q} 2 \mathrm{~B}-5$ & Burin spall & 1 \\
\hline E28/S78 & $17 \mathrm{~B}$ & & IIIa & & Debitage & 168 \\
\hline $\mathrm{E} 28 / \mathrm{S} 78$ & $17 \mathrm{~B}$ & & IIIa & 37Q2B-4 & Microspur/microdenticulate & 1 \\
\hline E28/S78 & 17B & & IIIa & $37 \mathrm{Q} 2 \mathrm{~B}-3$ & Spurred flake & 1 \\
\hline E28/S78 & $17 \mathrm{~B}$ & Feature 181 & IIIa & $37 \mathrm{Q} 2 \mathrm{~A}-1$ & Burin spall & 1 \\
\hline E28/S78 & 17B & Feature 181 & IIIIa & & Debitage & 324 \\
\hline E28/S78 & 17B & Feature 181 & IIIa & $37 Q 2 C-7$ & Edge modified flake & 1 \\
\hline $\mathrm{E} 28 / \mathrm{S} 78$ & $17 \mathrm{~B}$ & Feature 181 & IIIa & 37Q2D-12 & Notched flake & 1 \\
\hline E28/S78 & 17B & Feature 181 & IIIa & $37 \mathrm{Q} 2 \mathrm{D}-14$ & Uniface, unanalyzed & 1 \\
\hline $\mathrm{E} 28 / \mathrm{S} 78$ & $17 \mathrm{~B}$ & Feature 181 & IIIa & $37 \mathrm{Q} 2 \mathrm{C}-6$ & Unifacial multiple tool & 1 \\
\hline $\mathrm{E} 28 / \mathrm{S} 78$ & 17B & Feature 181 & IIIa & $37 \mathrm{Q} 2 \mathrm{D}-15$ & Unifacial multiple tool & 1 \\
\hline E28/S78 & $17 \mathrm{~B}$ & Feature 183 & IIIa & & Debitage & 1 \\
\hline E28/S78 & $18 \mathrm{~A}$ & & II/IIIa & $37 R 1 D-6$ & Biface Stage 2 & 1 \\
\hline E28/S78 & $18 \mathrm{~A}$ & & ІІ/IIIa & & Debitage & 137 \\
\hline $\mathrm{E} 28 / \mathrm{S} 78$ & $18 \mathrm{~A}$ & & IIIa & & Debitage & 200 \\
\hline $\mathrm{E} 28 / \mathrm{S} 78$ & $18 \mathrm{~A}$ & & II/IIIa & 37R1D-3 & Edge modified flake & 1 \\
\hline E28/S78 & $18 \mathrm{~A}$ & Feature 181 & IIIa & & Debitage & 64 \\
\hline $\mathrm{E} 28 / \mathrm{S} 78$ & $18 \mathrm{~A}$ & Feature 183 & IIIa & 37R1B-1 & Core tool, type 3 & 1 \\
\hline $\mathrm{E} 28 / \mathrm{S} 78$ & $18 \mathrm{~B}$ & & II & & Debitage & 46 \\
\hline E28/S78 & $18 \mathrm{~B}$ & & II/IIIa & & Debitage & 119 \\
\hline E28/S78 & 18B & Feature 181 & IIIa & & Debitage & 21 \\
\hline E28/S78 & $18 \mathrm{~B}$ & Feature 184 & II/IIIa & & Debitage & 1 \\
\hline $\mathrm{E} 28 / \mathrm{S} 78$ & $18 \mathrm{~B}$ & Feature 184 & II/IIIa & $37 \mathrm{R} 2 \mathrm{C}-1$ & Notched flake & 1 \\
\hline $\mathrm{E} 28 / \mathrm{S} 78$ & 19 & Feature 181 & II/IIIa & & Debitage & 13 \\
\hline E28/S78 & $19 \mathrm{~A}$ & & II/IIIa & $37 \mathrm{~S} 1 \mathrm{C}-7$ & Biface Stage 2 & 1 \\
\hline $\mathrm{E} 28 / \mathrm{S} 78$ & $19 \mathrm{~A}$ & & II & & Debitage & 100 \\
\hline E28/S78 & $19 \mathrm{~A}$ & & II/IIIa & & Debitage & 130 \\
\hline E28/S78 & $19 \mathrm{~A}$ & & II/IIIa & $37 \mathrm{~S} 1 \mathrm{C}-6$ & Edge modified flake & 1 \\
\hline $\mathrm{E} 28 / \mathrm{S} 78$ & $19 \mathrm{~A}$ & & II/IIIa & $37 \mathrm{~S} 1 \mathrm{C}-5$ & Edge modified flake & 1 \\
\hline $\mathrm{E} 28 / \mathrm{S} 78$ & $19 \mathrm{~A}$ & Feature 181 & IIIa & & Debitage & 58 \\
\hline $\mathrm{E} 28 / \mathrm{S} 78$ & $19 \mathrm{~A}$ & Feature 181 & IIIa & $37 \mathrm{~S} 1 \mathrm{~A}-1$ & Denticulated flake & 1 \\
\hline E28/S78 & $19 \mathrm{~A}$ & Feature 184 & II/IIIa & $37 \mathrm{~S} 1 \mathrm{C}-4$ & Burin & 1 \\
\hline E28/S78 & 19B & & II/IIIa & & Debitage & 38 \\
\hline $\mathrm{E} 28 / \mathrm{S} 78$ & $19 \mathrm{~B}$ & & II & & Debitage & 56 \\
\hline $\mathrm{E} 28 / \mathrm{S} 78$ & $19 B$ & & II & 37 S2B-1 & Microspur/microdenticulate & 1 \\
\hline E28/S78 & $19 \mathrm{~B}$ & Feature 181 & II/IIIa & & Debitage & 40 \\
\hline E28/S78 & 19B & Feature 184 & II/IIIa & & Debitage & 2 \\
\hline
\end{tabular}




\begin{tabular}{|c|c|c|c|c|c|}
\hline Square & Level & Feature & Strata & Item & Analyst Identification \\
\hline E28/S78 & $20 \mathrm{~A}$ & & II & 37T1D-4 & Burin spall \\
\hline E28/S78 & $20 \mathrm{~A}$ & & II & & Debitage \\
\hline $\mathrm{E} 28 / \mathrm{S} 78$ & $20 \mathrm{~A}$ & & II/IIIa & & Debitage \\
\hline $\mathrm{E} 28 / \mathrm{S} 78$ & $20 \mathrm{~A}$ & Feature 181 & II/IIIa & & Debitage \\
\hline $\mathrm{E} 28 / \mathrm{S} 78$ & $20 \mathrm{~A}$ & Feature 184 & II/IIIa & & Debitage \\
\hline E28/S78 & $20 \mathrm{~A}$ & Feature 185 & II & $37 \mathrm{~T} 1 \mathrm{~B}-1$ & Biface fragment \\
\hline $\mathrm{E} 28 / \mathrm{S} 78$ & $20 \mathrm{~A}$ & Feature 185 & II & $37 \mathrm{~T} 1 \mathrm{D}-3$ & Clear Fork biface \\
\hline $\mathrm{E} 28 / \mathrm{S} 78$ & $20 \mathrm{~B}$ & & II & & Debitage \\
\hline $\mathrm{E} 28 / \mathrm{S} 78$ & $20 \mathrm{~B}$ & & II & $37 \mathrm{~T} 2 \mathrm{~A}-2$ & Edge modified flake \\
\hline E28/S78 & $20 \mathrm{~B}$ & & II & $37 \mathrm{~T} 2 \mathrm{~B}-4$ & Edge modified flake \\
\hline $\mathrm{E} 28 / \mathrm{S} 78$ & $20 \mathrm{~B}$ & & II & $37 \mathrm{~T} 2 \mathrm{~B}-3$ & Projectile point, Golondrina-Barber \\
\hline $\mathrm{E} 28 / \mathrm{S} 78$ & $20 \mathrm{~B}$ & & II & $37 \mathrm{~T} 2 \mathrm{D}-8$ & Thick uniface \\
\hline E28/S78 & $20 \mathrm{~B}$ & & II & $37 \mathrm{~T} 2 \mathrm{~A}-1$ & Waco sinker \\
\hline E28/S78 & $20 \mathrm{~B}$ & Feature 181 & II & & Debitage \\
\hline E28/S78 & $20 \mathrm{~B}$ & Feature 184 & II & & Debitage \\
\hline E28/S78 & $20 \mathrm{~B}$ & Feature 184 & II & $37 \mathrm{~T} 2 \mathrm{C}-7$ & Micro-core, small \\
\hline E28/S78 & $20 \mathrm{~B}$ & Feature 184 & II & $37 \mathrm{~T} 2 \mathrm{C}-6$ & Uniface, unanalyzed \\
\hline $\mathrm{E} 28 / \mathrm{S} 78$ & $20 \mathrm{~B}$ & Feature 185 & II & & Debitage \\
\hline $\mathrm{E} 28 / \mathrm{S} 78$ & $21 \mathrm{~A}$ & & II & $37 \mathrm{U} 1 \mathrm{~A}-1$ & Burin spall \\
\hline $\mathrm{E} 28 / \mathrm{S} 78$ & $21 \mathrm{~A}$ & & II & $37 \mathrm{U} 1 \mathrm{~A}-4$ & Core tool, type 5 \\
\hline $\mathrm{E} 28 / \mathrm{S} 78$ & $21 \mathrm{~A}$ & & II & & Debitage \\
\hline $\mathrm{E} 28 / \mathrm{S} 78$ & $21 \mathrm{~A}$ & & II & $37 \mathrm{U} 1 \mathrm{~A}-2$ & Edge modified flake \\
\hline $\mathrm{E} 28 / \mathrm{S} 78$ & $21 \mathrm{~A}$ & & II & $37 \mathrm{U} 1 \mathrm{~B}-5$ & Edge modified flake \\
\hline $\mathrm{E} 28 / \mathrm{S} 78$ & $21 \mathrm{~A}$ & & II & $37 \mathrm{U} 1 \mathrm{~A}-3$ & Unifacial multiple tool \\
\hline $\mathrm{E} 28 / \mathrm{S} 78$ & $21 \mathrm{~B}$ & & II & & Debitage \\
\hline $\mathrm{E} 28 / \mathrm{S} 78$ & $21 \mathrm{~B}$ & & II & $37 \mathrm{U} 2 \mathrm{~A}-2$ & Edge modified flake \\
\hline $\mathrm{E} 28 / \mathrm{S} 78$ & $21 \mathrm{~B}$ & & II & $37 \mathrm{U} 2 \mathrm{~A}-1$ & Projectile point fragment \\
\hline E28/S78 & $22 \mathrm{~A}$ & & II & & Debitage \\
\hline $\mathrm{E} 28 / \mathrm{S} 78$ & $22 B$ & & II & & Debitage \\
\hline $\mathrm{E} 28 / \mathrm{S} 78$ & $22 \mathrm{~B}$ & & II & $37 \mathrm{~V} 2 \mathrm{D}-1$ & Edge modified flake \\
\hline E28/S78 & $23 \mathrm{~A}$ & & II & & Debitage \\
\hline E28/S78 & $23 \mathrm{~B}$ & & II & & Debitage \\
\hline $\mathrm{E} 28 / \mathrm{S} 78$ & $23 \mathrm{~B}$ & & II & $37 \mathrm{~W} 2 \mathrm{C}-2$ & Edge modified flake \\
\hline E28/S78 & $24 \mathrm{~A}$ & & II & $37 \times 1 A-1$ & Burin spall \\
\hline $\mathrm{E} 28 / \mathrm{S} 78$ & $24 \mathrm{~A}$ & & II & & Debitage \\
\hline $\mathrm{E} 28 / \mathrm{S} 78$ & $24 B$ & & II & $37 X 2 B-2$ & Burin spall \\
\hline E28/S78 & $24 \mathrm{~B}$ & & II & & Debitage \\
\hline $\mathrm{E} 28 / \mathrm{S} 78$ & $24 \mathrm{~B}$ & & $\mathrm{Id} / \mathrm{II}$ & & Debitage \\
\hline $\mathrm{E} 28 / \mathrm{S} 78$ & $24 \mathrm{~B}$ & & $\mathrm{Id} / \mathrm{II}$ & $37 X 2 D-5$ & Perforator Group 4 \\
\hline E28/S78 & $24 \mathrm{~B}$ & & II & $37 \times 2 C-3$ & Perforator Group 7 \\
\hline $\mathrm{E} 28 / \mathrm{S} 78$ & $24 \mathrm{~B}$ & & $\mathrm{Id} / \mathrm{II}$ & $37 \times 2 D-4$ & Projectile point, miscellaneous lanceolate \\
\hline $\mathrm{E} 28 / \mathrm{S} 78$ & $24 \mathrm{~B}$ & & II & $37 \mathrm{X} 2 \mathrm{~A}-1$ & Unifacial multiple tool \\
\hline E28/S78 & $25 \mathrm{~A}$ & & $\mathrm{Id} / \mathrm{II}$ & & Debitage \\
\hline E28/S78 & $25 \mathrm{~A}$ & & II & & Debitage \\
\hline $\mathrm{E} 28 / \mathrm{S} 78$ & $25 \mathrm{~A}$ & & $\mathrm{Id} / \mathrm{II}$ & $37 Y 1 D-3$ & Projectile point fragment \\
\hline $\mathrm{E} 28 / \mathrm{S} 78$ & $25 \mathrm{~A}$ & & $\mathrm{Id} / \mathrm{II}$ & $37 \mathrm{Y} 1 \mathrm{D}-2$ & Thin uniface fragment \\
\hline $\mathrm{E} 28 / \mathrm{S} 78$ & $25 \mathrm{~A}$ & & II & $37 \mathrm{Y} 1 \mathrm{~A}-1$ & Unifacial multiple tool \\
\hline $\mathrm{E} 28 / \mathrm{S} 78$ & $25 \mathrm{~B}$ & & II & & Debitage \\
\hline E28/S78 & $25 \mathrm{~B}$ & & $\mathrm{Id}$ & & Debitage \\
\hline $\mathrm{E} 28 / \mathrm{S} 78$ & $25 \mathrm{~B}$ & & $\mathrm{Id} / \mathrm{II}$ & & Debitage \\
\hline $\mathrm{E} 28 / \mathrm{S} 78$ & $26 \mathrm{~A}$ & & $\mathrm{Id} / \mathrm{II}$ & $37 Z 1 A-1$ & Biface Stage 2 \\
\hline $\mathrm{E} 28 / \mathrm{S} 78$ & $26 \mathrm{~A}$ & & Id & & Debitage \\
\hline E28/S78 & $26 \mathrm{~A}$ & & $\mathrm{Id} / \mathrm{II}$ & & Debitage \\
\hline E28/S78 & $26 \mathrm{~A}$ & & Id & 37Z1D-2 & Thin uniface \\
\hline $\mathrm{E} 28 / \mathrm{S} 78$ & $26 \mathrm{~B}$ & & Isi-c/Id & & Debitage \\
\hline $\mathrm{E} 28 / \mathrm{S} 78$ & $26 \mathrm{~B}$ & & Id & & Debitage \\
\hline $\mathrm{E} 28 / \mathrm{S} 78$ & $26 \mathrm{~B}$ & & $\mathrm{Id} / \mathrm{II}$ & & Debitage \\
\hline $\mathrm{E} 28 / \mathrm{S} 78$ & $27 \mathrm{~A}$ & & Id & & Debitage \\
\hline $\mathrm{E} 28 / \mathrm{S} 78$ & $27 \mathrm{~A}$ & & Isi-c/Id & & Debitage \\
\hline $\mathrm{E} 28 / \mathrm{S} 78$ & $27 \mathrm{~A}$ & & Id & 37AA1A-1 & Thin uniface fragment \\
\hline $\mathrm{E} 28 / \mathrm{S} 78$ & $27 \mathrm{~B}$ & & Id & & Debitage \\
\hline $\mathrm{E} 28 / \mathrm{S} 78$ & $27 \mathrm{~B}$ & & Isi-c/Id & & Debitage \\
\hline E28/S78 & $27 \mathrm{~B}$ & & Id & 37AA2B-1 & Micro-core, small \\
\hline $\mathrm{E} 28 / \mathrm{S} 78$ & $28 \mathrm{~A}$ & & Id & & Debitage \\
\hline $\mathrm{E} 28 / \mathrm{S} 78$ & $28 \mathrm{~A}$ & & Isi-c & & Debitage \\
\hline E28/S78 & $28 \mathrm{~A}$ & & Isi-c/Id & & Debitage \\
\hline $\mathrm{E} 28 / \mathrm{S} 78$ & $28 \mathrm{~A}$ & & Id & 37BB1A-1 & Edge modified flake \\
\hline $\mathrm{E} 28 / \mathrm{S} 78$ & $28 \mathrm{~B}$ & & Isi-c & & Debitage \\
\hline $\mathrm{E} 28 / \mathrm{S} 78$ & $28 \mathrm{~B}$ & & Isi-c/Id & & Debitage \\
\hline $\mathrm{E} 28 / \mathrm{S} 78$ & $28 \mathrm{~B}$ & & Isi-c/Id & 37BB2A-1 & Notched flake \\
\hline $\mathrm{E} 28 / \mathrm{S} 78$ & $29 \mathrm{~A}$ & & Isi-c/Id & $37 \mathrm{CC} 1 \mathrm{~B}-1$ & Biface Stage 2 \\
\hline $\mathrm{E} 28 / \mathrm{S} 78$ & $29 \mathrm{~A}$ & & Isi-c & & Debitage \\
\hline $\mathrm{E} 28 / \mathrm{S} 78$ & $29 \mathrm{~A}$ & & Isi-c/Id & & Debitage \\
\hline E28/S78 & $29 \mathrm{~A}$ & & Isi-c & 37CC1D-3 & Projectile point fragment \\
\hline
\end{tabular}

Count

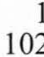

17

1
1

177

. 


\begin{tabular}{|c|c|c|c|c|c|c|}
\hline Square & Level & Feature & Strata & Item & Analyst Identification & Count \\
\hline E28/S78 & $29 \mathrm{~A}$ & & Isi-c & $37 \mathrm{CC} 1 \mathrm{D}-4$ & Thin uniface fragment & \\
\hline E28/S78 & $29 \mathrm{~A}$ & & Isi-c & $37 \mathrm{CC} 1 \mathrm{D}-5$ & Thin uniface fragment & \\
\hline E28/S78 & $29 B$ & & Isi-c & & Debitage & 20 \\
\hline E28/S78 & 30 & & Isi-c & & Debitage & 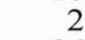 \\
\hline E28/S78 & $30 \mathrm{~A}$ & & Isi-c & & Debitage & 2 \\
\hline $\mathrm{E} 28 / \mathrm{S} 78$ & $30 \mathrm{~A}$ & & Isi-c & 37DD1C-1 & Unifacial multiple tool & \\
\hline E28/S78 & $30 \mathrm{~A}$ & Feature 193 & Isi-c & & Debitage & \\
\hline E28/S78 & $30 \mathrm{~B}$ & & Isi-c & & Debitage & \\
\hline E28/S78 & $31 \mathrm{~A}$ & & Isi-c & & Debitage & \\
\hline $\mathrm{E} 28 / \mathrm{S} 78$ & $31 \mathrm{~A}$ & & Isi-c & 37EE1C-1 & Thin uniface & \\
\hline $\mathrm{E} 28 / \mathrm{S} 78$ & 31B & & Isi-c & 37EE2B-1 & Chert cobble, unmodified/tested & \\
\hline $\mathrm{E} 28 / \mathrm{S} 78$ & $31 \mathrm{~B}$ & & Isi-c & & Debitage & 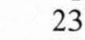 \\
\hline E28/S78 & $32 \mathrm{~A}$ & & Isi-c & & Debitage & 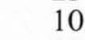 \\
\hline E28/S78 & $32 \mathrm{~A}$ & & $\mathrm{Icl} / \mathrm{Isi}-\mathrm{c}$ & & Debitage & \\
\hline $\mathrm{E} 28 / \mathrm{S} 78$ & $32 \mathrm{~B}$ & & $\mathrm{Icl} / \mathrm{Isi}-\mathrm{c}$ & & Debitage & \\
\hline E28/S78 & $32 \mathrm{~B}-33 \mathrm{~A}$ & Feature 187 & Icl/Isi-c & & Debitage & \\
\hline E28/S78 & $33 \mathrm{~A}$ & & Icl & & Debitage & 12 \\
\hline E28/S78 & $33 \mathrm{~A}$ & & Icl/Isi-c & & Debitage & \\
\hline E28/S78 & $33 \mathrm{~B}$ & & Icl/Isi-c & & Debitage & \\
\hline E28/S78 & $33 \mathrm{~B}$ & & Icl & & Debitage & 12 \\
\hline E28/S78 & $34 \mathrm{~A}$ & & Icl & & Debitage & 15 \\
\hline E28/S78 & $34 \mathrm{~A}$ & & Icl & 37HH1B-1 & Thick uniface & \\
\hline $\mathrm{E} 28 / \mathrm{S} 78$ & $34 \mathrm{~B}$ & & Icl & & Debitage & \\
\hline E28/S78 & $35 \mathrm{~A}$ & & Icl & & Debitage & \\
\hline $\mathrm{E} 28 / \mathrm{S} 78$ & $35 \mathrm{~B}$ & & Icl & & Debitage & 24 \\
\hline E28/S78 & $35 \mathrm{~B}$ & & Icl & 37II2D-1 & Denticulated flake & \\
\hline $\mathrm{E} 28 / \mathrm{S} 78$ & $35 \mathrm{~B}$ & & Icl & $37 \mathrm{II} 2 \mathrm{~A}-2$ & Edge modified flake & \\
\hline $\mathrm{E} 28 / \mathrm{S} 78$ & $36 \mathrm{~A}$ & & Icl & & Debitage & \\
\hline E28/S78 & $36 \mathrm{~B}$ & & Icl & & Debitage & \\
\hline $\mathrm{E} 28 / \mathrm{S} 78$ & $37 \mathrm{~A}$ & & Icl & $37 \mathrm{KK} 1 \mathrm{C}-2$ & Core, thermal & \\
\hline E28/S78 & $37 \mathrm{~A}$ & & Icl & & Debitage & \\
\hline $\mathrm{E} 28 / \mathrm{S} 78$ & $37 \mathrm{~A}$ & & Icl & 37KK1B-1 & Edge modified flake & \\
\hline $\mathrm{E} 28 / \mathrm{S} 78$ & $37 \mathrm{~A}$ & & Icl & $37 \mathrm{KK} 1 \mathrm{C}-3$ & Edge modified flake & \\
\hline E28/S78 & $37 \mathrm{~B}$ & & Icl & & Debitage & 12 \\
\hline E28/S78 & $37 \mathrm{~B}$ & & Isi/Icl & & Debitage & 1 \\
\hline E28/S78 & $38 \mathrm{~A}$ & & Icl & & Debitage & \\
\hline $\mathrm{E} 28 / \mathrm{S} 78$ & $38 \mathrm{~A}$ & & Isi/Icl & & Debitage & \\
\hline $\mathrm{E} 28 / \mathrm{S} 78$ & $38 \mathrm{~B}$ & & Isi/Icl & 37LL2C-2 & Biface Stage 1 & \\
\hline $\mathrm{E} 28 / \mathrm{S} 78$ & $38 \mathrm{~B}$ & & Icl & & Debitage & 2 \\
\hline E28/S78 & $38 \mathrm{~B}$ & & Isi/Icl & & Debitage & 11 \\
\hline E28/S78 & $39 \mathrm{~A}$ & & Isi/Icl & 37MM1C-1 & Biface Stage 2 & \\
\hline E28/S78 & $39 \mathrm{~A}$ & & Icl & & Debitage & \\
\hline E28/S78 & $39 \mathrm{~A}$ & & Isi & & Debitage & \\
\hline E28/S78 & $39 \mathrm{~A}$ & & Isi/Icl & & Debitage & \\
\hline E28/S78 & $39 \mathrm{~B}$ & & Icl & & Debitage & \\
\hline $\mathrm{E} 28 / \mathrm{S} 78$ & $39 \mathrm{~B}$ & & Isi & & Debitage & \\
\hline $\mathrm{E} 28 / \mathrm{S} 78$ & $39 \mathrm{~B}$ & & Isi/Icl & & Debitage & \\
\hline E28/S78 & $39 \mathrm{~B}$ & & $\mathrm{Isi} / \mathrm{Icl}$ & $37 \mathrm{MM} 2 \mathrm{~A}-1$ & Edge modified flake & \\
\hline E28/S78 & $40 \mathrm{~A}$ & & Icl & & Debitage & 10 \\
\hline E28/S78 & $40 \mathrm{~A}$ & & Isi & & Debitage & \\
\hline E28/S78 & $40 \mathrm{~A}$ & & Isi/Icl & & Debitage & \\
\hline E28/S78 & $40 \mathrm{~A}$ & & $\mathrm{Isi} / \mathrm{Icl}$ & $37 N N 1 C-3$ & Edge modified flake & \\
\hline $\mathrm{E} 28 / \mathrm{S} 78$ & $40 \mathrm{~A}$ & & Isi/Icl & $37 N N 1 A-2$ & Thin uniface & \\
\hline E28/S78 & $40 \mathrm{~A}$ & & Isi/Icl & $37 N N 1 A-1$ & Thin uniface fragment & \\
\hline E28/S78 & $40 \mathrm{~B}$ & & Isi/Icl & $37 N N 2 A-2$ & Biface Stage 2 & \\
\hline $\mathrm{E} 28 / \mathrm{S} 78$ & $40 \mathrm{~B}$ & & Icl & & Debitage & \\
\hline E28/S78 & $40 \mathrm{~B}$ & & Isi & & Debitage & \\
\hline $\mathrm{E} 28 / \mathrm{S} 78$ & $40 \mathrm{~B}$ & & Isi/Icl & & Debitage & \\
\hline E28/S78 & $40 \mathrm{~B}$ & & $\mathrm{Isi} / \mathrm{Icl}$ & 37NN2C-4 & Edge modified flake & \\
\hline $\mathrm{E} 28 / \mathrm{S} 78$ & $40 \mathrm{~B}$ & & Isi/Icl & 37NN2A-1 & Edge modified flake & \\
\hline $\mathrm{E} 28 / \mathrm{S} 78$ & $41 \mathrm{~A}$ & & Isi & & Debitage & \\
\hline E28/S78 & $41 \mathrm{~A}$ & & Isi/Icl & & Debitage & \\
\hline $\mathrm{E} 28 / \mathrm{S} 78$ & $41 \mathrm{~A}$ & & Isi/Icl & $37001 \mathrm{~A}-1$ & Face battered stone & \\
\hline E28/S78 & $41 \mathrm{~B}$ & & $\mathrm{Isi} / \mathrm{Icl}$ & $37002 B-4$ & Biface fragment & \\
\hline $\mathrm{E} 28 / \mathrm{S} 78$ & $41 \mathrm{~B}$ & & Isi/Icl & $37002 B-5$ & Burin spall & \\
\hline $\mathrm{E} 28 / \mathrm{S} 78$ & $41 \mathrm{~B}$ & & $\mathrm{Isi} / \mathrm{Icl}$ & & Debitage & \\
\hline E28/S78 & $41 \mathrm{~B}$ & & Isi & & Debitage & \\
\hline E28/S78 & $41 \mathrm{~B}$ & & Isi/Icl & 37OO2B-1 & Edge modified flake & \\
\hline $\mathrm{E} 28 / \mathrm{S} 78$ & $41 \mathrm{~B}$ & & $\mathrm{Isi} / \mathrm{Icl}$ & $37002 B-2$ & Thin uniface fragment & \\
\hline E28/S78 & $41 \mathrm{~B}$ & & Isi/Icl & $37002 B-3$ & Unifacial multiple tool & \\
\hline E28/S78 & $42 \mathrm{~A}$ & & Isi & & Debitage & \\
\hline E28/S78 & $42 \mathrm{~A}$ & & Isi/Icl & & Debitage & \\
\hline $\mathrm{E} 28 / \mathrm{S} 78$ & $42 \mathrm{~A}$ & & Isi/Icl & 37PP1A-1 & Edge modified flake & \\
\hline E28/S78 & $42 \mathrm{~B}$ & & $\mathrm{Isi} / \mathrm{Icl}$ & & Debitage & \\
\hline
\end{tabular}




\begin{tabular}{|c|c|c|c|c|c|c|}
\hline Square & Level & Feature & Strata & Item & Analyst Identification & Count \\
\hline $\mathrm{E} 28 / \mathrm{S} 78$ & $42 \mathrm{~B}$ & & Isi & & Debitage & 1 \\
\hline E28/S78 & $42 \mathrm{~B}$ & & Isi/Icl & 37PP2B-1 & Microspur/microdenticulate & 1 \\
\hline $\mathrm{E} 28 / \mathrm{S} 78$ & $43 \mathrm{~A}$ & & $\mathrm{Isi} / \mathrm{Icl}$ & & Debitage & 3 \\
\hline E28/S78 & $43 \mathrm{~A}$ & & Isi & & Debitage & 3 \\
\hline $\mathrm{E} 28 / \mathrm{S} 78$ & $43 \mathrm{~A}$ & & Isi & 37QQ1C-2 & Edge modified flake & 1 \\
\hline $\mathrm{E} 28 / \mathrm{S} 78$ & $43 \mathrm{~A}$ & & $\mathrm{Isi} / \mathrm{Icl}$ & 37QQ1A-1 & Thin uniface & 1 \\
\hline $\mathrm{E} 28 / \mathrm{S} 78$ & $43 \mathrm{~B}$ & & Isi & & Debitage & 5 \\
\hline E28/S78 & $44 \mathrm{~A}$ & & Isi & & Debitage & 6 \\
\hline E28/S78 & $44 \mathrm{~A}$ & Feature 188 & Isi & 37RR1A-2 & Battered cobble & 1 \\
\hline $\mathrm{E} 28 / \mathrm{S} 78$ & $44 \mathrm{~A}$ & Feature 188 & Isi & 37RR1A-1 & Chert cobble, tested & 1 \\
\hline E28/S78 & $44 \mathrm{~B}$ & & Isi & & Debitage & \\
\hline E28/S78 & $45 \mathrm{~A}$ & & Isi & & Debitage & \\
\hline $\mathrm{E} 28 / \mathrm{S} 78$ & $45 \mathrm{~B}$ & & Isi & & Debitage & 5 \\
\hline E28/S78 & Unknown & & & & Debitage & 1 \\
\hline $\mathrm{E} 40 / \mathrm{S} 70$ & 1 & & IIIc & & Debitage & 386 \\
\hline $\mathrm{E} 40 / \mathrm{S} 70$ & 1 & & IIIc & $36 \mathrm{~A}-1$ & Projectile point fragment & \\
\hline $\mathrm{E} 40 / \mathrm{S} 70$ & 2 & & IIIc & $36 \mathrm{~B}-10$ & Arrow point, stemmed & 1 \\
\hline $\mathrm{E} 40 / \mathrm{S} 70$ & 2 & & IIIc & $36 \mathrm{~B}-3$ & Biface fragment & 1 \\
\hline $\mathrm{E} 40 / \mathrm{S} 70$ & 2 & & IIIc & $36 \mathrm{~B}-21$ & Biface fragment & 1 \\
\hline $\mathrm{E} 40 / \mathrm{S} 70$ & 2 & & IIIc & $36 \mathrm{~B}-6$ & Biface fragment & \\
\hline $\mathrm{E} 40 / \mathrm{S} 70$ & 2 & & IIIc & $36 \mathrm{~B}-4$ & Biface Stage 2 & \\
\hline $\mathrm{E} 40 / \mathrm{S} 70$ & 2 & & IIIc & $36 \mathrm{~B}-1$ & Biface Stage 2 & 1 \\
\hline $\mathrm{E} 40 / \mathrm{S} 70$ & 2 & & IIIc & $36 \mathrm{~B}-30$ & Core, thermal & 1 \\
\hline $\mathrm{E} 40 / \mathrm{S} 70$ & 2 & & IIIc & & Debitage & 2563 \\
\hline $\mathrm{E} 40 / \mathrm{S} 70$ & 2 & & IIIc & 36B-19 & Edge modified flake & \\
\hline $\mathrm{E} 40 / \mathrm{S} 70$ & 2 & & IIIc & $36 \mathrm{~B}-34$ & Edge modified flake & 1 \\
\hline $\mathrm{E} 40 / \mathrm{S} 70$ & 2 & & IIIc & $36 \mathrm{~B}-7$ & Micro-core, intermediate & 1 \\
\hline $\mathrm{E} 40 / \mathrm{S} 70$ & 2 & & IIIc & $36 \mathrm{~B}-23$ & Notched flake & 1 \\
\hline $\mathrm{E} 40 / \mathrm{S} 70$ & 2 & & IIIc & $36 \mathrm{~B}-35$ & Notched flake & 1 \\
\hline $\mathrm{E} 40 / \mathrm{S} 70$ & 2 & & IIIc & $36 \mathrm{~B}-12$ & Projectile point fragment & 1 \\
\hline $\mathrm{E} 40 / \mathrm{S} 70$ & 2 & & IIIc & $36 \mathrm{~B}-2$ & Projectile point fragment & 1 \\
\hline $\mathrm{E} 40 / \mathrm{S} 70$ & 2 & & IIIc & $36 \mathrm{~B}-17$ & Projectile point fragment & 1 \\
\hline $\mathrm{E} 40 / \mathrm{S} 70$ & 2 & & IIIc & $36 \mathrm{~B}-16$ & Projectile point fragment & 1 \\
\hline $\mathrm{E} 40 / \mathrm{S} 70$ & 2 & & IIIc & $36 \mathrm{~B}-15$ & Projectile point fragment & 1 \\
\hline $\mathrm{E} 40 / \mathrm{S} 70$ & 2 & & IIIc & $36 \mathrm{~B}-14$ & Projectile point fragment & 1 \\
\hline $\mathrm{E} 40 / \mathrm{S} 70$ & 2 & & IIIc & 36B-13 & Projectile point fragment & 1 \\
\hline $\mathrm{E} 40 / \mathrm{S} 70$ & 2 & & IIIc & $36 B-5$ & Projectile point fragment & , \\
\hline $\mathrm{E} 40 / \mathrm{S} 70$ & 2 & & IIIC & 36B-37 & Projectile point fragment & 1 \\
\hline $\mathrm{E} 40 / \mathrm{S} 70$ & 2 & & IIIc & 36B-11 & Projectile point, Darl & 1 \\
\hline $\mathrm{E} 40 / \mathrm{S} 70$ & 2 & & IIIc & 36B-29 & Thin uniface & 1 \\
\hline $\mathrm{E} 40 / \mathrm{S} 70$ & 2 & & IIIc & $36 \mathrm{~B}-22$ & Thin uniface fragment & 1 \\
\hline $\mathrm{E} 40 / \mathrm{S} 70$ & 2 & & IIIc & $36 \mathrm{~B}-25$ & Thin uniface fragment & 1 \\
\hline $\mathrm{E} 40 / \mathrm{S} 70$ & 2 & & IIIc & 36B-9 & Uniface, unanalyzed & 1 \\
\hline $\mathrm{E} 40 / \mathrm{S} 70$ & 2 & & IIIc & $36 \mathrm{~B}-20$ & Uniface, unanalyzed & 1 \\
\hline $\mathrm{E} 40 / \mathrm{S} 70$ & 2 & & IIIc & $36 \mathrm{~B}-8$ & Uniface, unanalyzed & 1 \\
\hline $\mathrm{E} 40 / \mathrm{S} 70$ & 2 & & IIIc & $36 \mathrm{~B}-36$ & Uniface, unanalyzed & 1 \\
\hline $\mathrm{E} 40 / \mathrm{S} 70$ & 2 & & IIIc & $36 \mathrm{~B}-28$ & Uniface, unanalyzed & 1 \\
\hline $\mathrm{E} 40 / \mathrm{S} 70$ & 2 & & IIIc & $36 \mathrm{~B}-33$ & Uniface, unanalyzed & 1 \\
\hline $\mathrm{E} 40 / \mathrm{S} 70$ & 2 & & IIIc & $36 \mathrm{~B}-24$ & Uniface, unanalyzed & 1 \\
\hline $\mathrm{E} 40 / \mathrm{S} 70$ & 2 & & IIIc & $36 \mathrm{~B}-26$ & Uniface, unanalyzed & 1 \\
\hline $\mathrm{E} 40 / \mathrm{S} 70$ & 2 & & IIIc & $36 \mathrm{~B}-31$ & Uniface, unanalyzed & 1 \\
\hline $\mathrm{E} 40 / \mathrm{S} 70$ & 3 & & IIIc & $36 \mathrm{C}-3$ & Biface Stage 1 & 1 \\
\hline $\mathrm{E} 40 / \mathrm{S} 70$ & 3 & & IIIc & $36 \mathrm{C}-6$ & Biface Stage 2 & 1 \\
\hline $\mathrm{E} 40 / \mathrm{S} 70$ & 3 & & IIIc & $36 \mathrm{C}-5$ & Biface Stage 2 & 1 \\
\hline $\mathrm{E} 40 / \mathrm{S} 70$ & 3 & & IIIC & $36 \mathrm{C}-8$ & Biface Stage 3 & \\
\hline $\mathrm{E} 40 / \mathrm{S} 70$ & 3 & & IIIc & & Debitage & 1674 \\
\hline $\mathrm{E} 40 / \mathrm{S} 70$ & 3 & & IIIc & $36 \mathrm{C}-4$ & Projectile point fragment & 1 \\
\hline $\mathrm{E} 40 / \mathrm{S} 70$ & 3 & & IIIc & $36 \mathrm{C}-7$ & Projectile point fragment & 1 \\
\hline $\mathrm{E} 40 / \mathrm{S} 70$ & 3 & & IIIc & $36 \mathrm{C}-9$ & Projectile point fragment & \\
\hline $\mathrm{E} 40 / \mathrm{S} 70$ & 3 & & IIIc & $36 \mathrm{C}-2$ & Projectile point, Marcos & 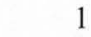 \\
\hline $\mathrm{E} 40 / \mathrm{S} 70$ & 3 & & IIIc & $36 \mathrm{C}-1$ & Projectile point, Pedernales & 1 \\
\hline $\mathrm{E} 40 / \mathrm{S} 70$ & 3 & & IIIc & $36 \mathrm{C}-10$ & Uniface, unanalyzed & \\
\hline $\mathrm{E} 40 / \mathrm{S} 70$ & 4 & & IIIc & $36 \mathrm{D}-4$ & Biface fragment & 1 \\
\hline $\mathrm{E} 40 / \mathrm{S} 70$ & 4 & & IIIc & $36 \mathrm{D}-3$ & Burin & \\
\hline $\mathrm{E} 40 / \mathrm{S} 70$ & 4 & & IIIc & & Debitage & 3287 \\
\hline $\mathrm{E} 40 / \mathrm{S} 70$ & 4 & & IIIc & $36 \mathrm{D}-8$ & Perforator Group 3 & \\
\hline $\mathrm{E} 40 / \mathrm{S} 70$ & 4 & & IIIc & $36 \mathrm{D}-11$ & Perforator Group 7 & \\
\hline $\mathrm{E} 40 / \mathrm{S} 70$ & 4 & & IIIc & $36 \mathrm{D}-7$ & Projectile point fragment & \\
\hline $\mathrm{E} 40 / \mathrm{S} 70$ & 4 & & IIIc & $36 \mathrm{D}-9$ & Projectile point fragment & \\
\hline $\mathrm{E} 40 / \mathrm{S} 70$ & 4 & & IIIc & $36 \mathrm{D}-1$ & Projectile point, Bulverde & \\
\hline $\mathrm{E} 40 / \mathrm{S} 70$ & 4 & & IIIc & $36 \mathrm{D}-2$ & Projectile point, Ensor & \\
\hline $\mathrm{E} 40 / \mathrm{S} 70$ & 4 & & IIIc & $36 \mathrm{D}-10$ & Uniface, unanalyzed & \\
\hline $\mathrm{E} 40 / \mathrm{S} 70$ & 4 & & IIIc & $36 \mathrm{D}-13$ & Uniface, unanalyzed & \\
\hline $\mathrm{E} 40 / \mathrm{S} 70$ & 4 & & IIIc & $36 \mathrm{D}-12$ & Uniface, unanalyzed & \\
\hline
\end{tabular}




\begin{tabular}{|c|c|c|c|c|c|c|}
\hline Square & Level & Feature & Strata & Item & Analyst Identification & Count \\
\hline $\mathrm{E} 40 / \mathrm{S} 70$ & 4 & & IIIc & $36 \mathrm{D}-14$ & Uniface, unanalyzed & \\
\hline $\mathrm{E} 40 / \mathrm{S} 70$ & 4 & Feature 120 & IIIc & $36 \mathrm{D}-26$ & Biface Stage 2 & 1 \\
\hline $\mathrm{E} 40 / \mathrm{S} 70$ & 4 & Feature 120 & IIIc & $36 \mathrm{D}-27$ & Biface Stage 2 & \\
\hline $\mathrm{E} 40 / \mathrm{S} 70$ & 4 & Feature 120 & IIIc & $36 \mathrm{D}-23$ & Bifacial tool Form $\mathrm{J}$ & \\
\hline $\mathrm{E} 40 / \mathrm{S} 70$ & 4 & Feature 120 & IIIc & $36 \mathrm{D}-28$ & Core tool, type 2 & \\
\hline $\mathrm{E} 40 / \mathrm{S} 70$ & 4 & Feature 120 & IIIc & & Debitage & 1 \\
\hline $\mathrm{E} 40 / \mathrm{S} 70$ & 4 & Feature 120 & IIIc & $36 \mathrm{D}-21$ & Mano & \\
\hline $\mathrm{E} 40 / \mathrm{S} 70$ & 4 & Feature 120 & IIIc & $36 \mathrm{D}-20$ & Mano & \\
\hline $\mathrm{E} 40 / \mathrm{S} 70$ & 4 & Feature 120 & IIIc & $36 \mathrm{D}-17$ & Projectile point, Bulverde & \\
\hline $\mathrm{E} 40 / \mathrm{S} 70$ & 4 & Feature 120 & IIIc & $36 \mathrm{D}-16$ & Projectile point, Bulverde & \\
\hline $\mathrm{E} 40 / \mathrm{S} 70$ & 4 & Feature 120 & IIIC & $36 \mathrm{D}-19$ & Projectile point, Castroville & \\
\hline $\mathrm{E} 40 / \mathrm{S} 70$ & 4 & Feature 120 & IIIc & $36 \mathrm{D}-18$ & Projectile point, Edgewood & \\
\hline $\mathrm{E} 40 / \mathrm{S} 70$ & 4 & Feature 120 & IIIc & $36 \mathrm{D}-22$ & Projectile point, indeterminate & \\
\hline $\mathrm{E} 40 / \mathrm{S} 70$ & 4 & Feature 120 & IIIc & $36 \mathrm{D}-29$ & Thin uniface fragment & \\
\hline $\mathrm{E} 40 / \mathrm{S} 70$ & 4 & Feature 120 & IIIc & $36 \mathrm{D}-24$ & Uniface, unanalyzed & \\
\hline $\mathrm{E} 40 / \mathrm{S} 70$ & 4 & Feature 120 & IIIc & $36 \mathrm{D}-15$ & Uniface, unanalyzed & \\
\hline $\mathrm{E} 40 / \mathrm{S} 70$ & 4 & Feature 120 & IIIc & $36 \mathrm{D}-30$ & Unifacial multiple tool & \\
\hline $\mathrm{E} 40 / \mathrm{S} 70$ & 5 & & IIIc & $36 \mathrm{E}-10$ & Biface fragment & \\
\hline $\mathrm{E} 40 / \mathrm{S} 70$ & 5 & & IIIc & $36 \mathrm{E}-15$ & Biface fragment & \\
\hline $\mathrm{E} 40 / \mathrm{S} 70$ & 5 & & IIIc & $36 \mathrm{E}-12$ & Biface Stage 1 & \\
\hline $\mathrm{E} 40 / \mathrm{S} 70$ & 5 & & IIIc & $36 \mathrm{E}-8$ & Biface Stage 2 & \\
\hline $\mathrm{E} 40 / \mathrm{S} 70$ & 5 & & IIIC & $36 \mathrm{E}-9$ & Burin & \\
\hline $\mathrm{E} 40 / \mathrm{S} 70$ & 5 & & IIIc & $36 \mathrm{E}-31$ & Burin spall & \\
\hline $\mathrm{E} 40 / \mathrm{S} 70$ & 5 & & IIIc & $36 \mathrm{E}-25$ & Core fragment & 1 \\
\hline $\mathrm{E} 40 / \mathrm{S} 70$ & 5 & & IIIc & & Debitage & 1942 \\
\hline $\mathrm{E} 40 / \mathrm{S} 70$ & 5 & & IIIc & $36 \mathrm{E}-7$ & Mano fragment & \\
\hline $\mathrm{E} 40 / \mathrm{S} 70$ & 5 & & IIIc & $36 \mathrm{E}-11$ & Perforator Group 1 & \\
\hline $\mathrm{E} 40 / \mathrm{S} 70$ & 5 & & IIIc & $36 \mathrm{E}-13$ & Projectile point fragment & \\
\hline $\mathrm{E} 40 / \mathrm{S} 70$ & 5 & & IIIc & $36 \mathrm{E}-14$ & Projectile point fragment & 1 \\
\hline $\mathrm{E} 40 / \mathrm{S} 70$ & 5 & & IIIc & $36 \mathrm{E}-16$ & Projectile point, Castroville & \\
\hline $\mathrm{E} 40 / \mathrm{S} 70$ & 5 & & IIIc & $36 \mathrm{E}-1$ & Projectile point, Darl & \\
\hline $\mathrm{E} 40 / \mathrm{S} 70$ & 5 & & IIIc & $36 \mathrm{E}-2$ & Projectile point, Marcos & \\
\hline $\mathrm{E} 40 / \mathrm{S} 70$ & 5 & & IIIc & $36 \mathrm{E}-5$ & Projectile point, Montell & 1 \\
\hline $\mathrm{E} 40 / \mathrm{S} 70$ & 5 & & IIIc & $36 \mathrm{E}-4$ & Projectile point, Montell & 1 \\
\hline $\mathrm{E} 40 / \mathrm{S} 70$ & 5 & & IIIc & $36 \mathrm{E}-3$ & Projectile point, Montell & \\
\hline $\mathrm{E} 40 / \mathrm{S} 70$ & 5 & & IIIc & $36 \mathrm{E}-6$ & Projectile point, Nolan & \\
\hline $\mathrm{E} 40 / \mathrm{S} 70$ & 5 & & IIIc & $36 \mathrm{E}-23$ & Thin uniface & \\
\hline $\mathrm{E} 40 / \mathrm{S} 70$ & 5 & & IIIc & $36 \mathrm{E}-20$ & Uniface, unanalyzed & \\
\hline $\mathrm{E} 40 / \mathrm{S} 70$ & 5 & & IIIc & $36 \mathrm{E}-32$ & Uniface, unanalyzed & \\
\hline $\mathrm{E} 40 / \mathrm{S} 70$ & 5 & & IIIc & $36 \mathrm{E}-30$ & Uniface, unanalyzed & \\
\hline $\mathrm{E} 40 / \mathrm{S} 70$ & 5 & & IIIc & $36 \mathrm{E}-29$ & Uniface, unanalyzed & \\
\hline $\mathrm{E} 40 / \mathrm{S} 70$ & 5 & & IIIc & $36 \mathrm{E}-28$ & Uniface, unanalyzed & \\
\hline $\mathrm{E} 40 / \mathrm{S} 70$ & 5 & & IIIc & $36 \mathrm{E}-27$ & Uniface, unanalyzed & 1 \\
\hline $\mathrm{E} 40 / \mathrm{S} 70$ & 5 & & IIIC & $36 \mathrm{E}-26$ & Uniface, unanalyzed & \\
\hline $\mathrm{E} 40 / \mathrm{S} 70$ & 5 & & IIIC & $36 \mathrm{E}-22$ & Uniface, unanalyzed & \\
\hline $\mathrm{E} 40 / \mathrm{S} 70$ & 5 & & IIIc & $36 \mathrm{E}-19$ & Uniface, unanalyzed & \\
\hline $\mathrm{E} 40 / \mathrm{S} 70$ & 5 & & IIIc & $36 \mathrm{E}-17$ & Unifacial multiple tool & \\
\hline $\mathrm{E} 40 / \mathrm{S} 70$ & 6 & & IIIc & $36 \mathrm{~F}-9$ & Biface fragment & \\
\hline $\mathrm{E} 40 / \mathrm{S} 70$ & 6 & & IIIc & $36 \mathrm{~F}-10$ & Biface Stage 1 & \\
\hline $\mathrm{E} 40 / \mathrm{S} 70$ & 6 & & IIIc & $36 \mathrm{~F}-8$ & Biface Stage 1 & \\
\hline $\mathrm{E} 40 / \mathrm{S} 70$ & 6 & & IIIc & $36 \mathrm{~F}-25$ & Biface Stage 2 & \\
\hline $\mathrm{E} 40 / \mathrm{S} 70$ & 6 & & IIIc & $36 \mathrm{~F}-7$ & Biface Stage 2 & \\
\hline $\mathrm{E} 40 / \mathrm{S} 70$ & 6 & & IIIc & $36 \mathrm{~F}-24$ & Bifacial tool Form $\mathrm{H}$ & \\
\hline $\mathrm{E} 40 / \mathrm{S} 70$ & 6 & & IIIC & & Debitage & 2239 \\
\hline $\mathrm{E} 40 / \mathrm{S} 70$ & 6 & & IIIc & $36 \mathrm{~F}-11$ & Projectile point fragment & \\
\hline $\mathrm{E} 40 / \mathrm{S} 70$ & 6 & & IIIc & $36 \mathrm{~F}-1$ & Projectile point, Bulverde & 1 \\
\hline $\mathrm{E} 40 / \mathrm{S} 70$ & 6 & & IIIc & $36 \mathrm{~F}-3$ & Projectile point, Marshall & 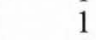 \\
\hline $\mathrm{E} 40 / \mathrm{S} 70$ & 6 & & IIIc & $36 \mathrm{~F}-2$ & Projectile point, Pedernales & \\
\hline $\mathrm{E} 40 / \mathrm{S} 70$ & 6 & & IIIC & $36 \mathrm{~F}-4$ & Projectile point, Pedernales & \\
\hline $\mathrm{E} 40 / \mathrm{S} 70$ & 6 & & IIIc & $36 \mathrm{~F}-13$ & Uniface, unanalyzed & \\
\hline $\mathrm{E} 40 / \mathrm{S} 70$ & 6 & & IIIc & $36 \mathrm{~F}-22$ & Uniface, unanalyzed & 1 \\
\hline $\mathrm{E} 40 / \mathrm{S} 70$ & 6 & & IIIc & $36 \mathrm{~F}-15$ & Uniface, unanalyzed & \\
\hline $\mathrm{E} 40 / \mathrm{S} 70$ & 6 & & IIIc & $36 \mathrm{~F}-20$ & Uniface, unanalyzed & \\
\hline $\mathrm{E} 40 / \mathrm{S} 70$ & 6 & & IIIC & $36 \mathrm{~F}-17$ & Uniface, unanalyzed & \\
\hline $\mathrm{E} 40 / \mathrm{S} 70$ & 6 & & IIIc & $36 \mathrm{~F}-12$ & Uniface, unanalyzed & \\
\hline $\mathrm{E} 40 / \mathrm{S} 70$ & 6 & & IIIc & $36 \mathrm{~F}-21$ & Uniface, unanalyzed & 1 \\
\hline $\mathrm{E} 40 / \mathrm{S} 70$ & 6 & & IIIc & $36 \mathrm{~F}-18$ & Unifacial multiple tool & 1 \\
\hline $\mathrm{E} 40 / \mathrm{S} 70$ & 6 & & IIIc & $36 \mathrm{~F}-19$ & Unifacial multiple tool & \\
\hline $\mathrm{E} 40 / \mathrm{S} 70$ & 6 & Feature 121 & IIIc & $36 \mathrm{~F}-5$ & Biface Stage 3 & \\
\hline $\mathrm{E} 40 / \mathrm{S} 70$ & 6 & Feature 121 & IIIC & $36 \mathrm{~F}-23$ & Mano/hammerstone & 1 \\
\hline $\mathrm{E} 40 / \mathrm{S} 70$ & 6 & Feature 121 & IIIc & $36 \mathrm{~F}-6$ & Projectile point fragment & 1 \\
\hline $\mathrm{E} 40 / \mathrm{S} 70$ & 7 & & $\mathrm{IIIb} / \mathrm{c}$ & $36 \mathrm{G}-4$ & Biface Stage 1 & 1 \\
\hline $\mathrm{E} 40 / \mathrm{S} 70$ & 7 & & $\mathrm{IIIb} / \mathrm{c}$ & $36 \mathrm{G}-5$ & Biface Stage 2 & 1 \\
\hline $\mathrm{E} 40 / \mathrm{S} 70$ & 7 & & $\mathrm{IIIb} / \mathrm{c}$ & $36 \mathrm{G}-3$ & Biface Stage 2 & \\
\hline
\end{tabular}




\begin{tabular}{|c|c|c|c|c|c|c|}
\hline Square & Level & Feature & Strata & Item & Analyst Identification & Count \\
\hline $\mathrm{E} 40 / \mathrm{S} 70$ & 7 & & $\mathrm{IIIb} / \mathrm{c}$ & $36 \mathrm{G}-2$ & Bifacial tool Form A & 1 \\
\hline $\mathrm{E} 40 / \mathrm{S} 70$ & 7 & & $\mathrm{IIIb} / \mathrm{c}$ & 36G-7 & Core, thermal & 1 \\
\hline $\mathrm{E} 40 / \mathrm{S} 70$ & 7 & & $\mathrm{IIIb} / \mathrm{c}$ & & Debitage & 1815 \\
\hline $\mathrm{E} 40 / \mathrm{S} 70$ & 7 & & $\mathrm{IIIb} / \mathrm{c}$ & $36 \mathrm{G}-10$ & Projectile point fragment & 1 \\
\hline $\mathrm{E} 40 / \mathrm{S} 70$ & 7 & & $\mathrm{IIIb} / \mathrm{c}$ & $36 \mathrm{G}-9$ & Projectile point fragment & 1 \\
\hline $\mathrm{E} 40 / \mathrm{S} 70$ & 7 & & $\mathrm{IIIb} / \mathrm{c}$ & $36 \mathrm{G}-1$ & Projectile point, Nolan & 1 \\
\hline $\mathrm{E} 40 / \mathrm{S} 70$ & 7 & & $\mathrm{IIIb} / \mathrm{c}$ & $36 \mathrm{G}-17$ & Thick uniface & 1 \\
\hline $\mathrm{E} 40 / \mathrm{S} 70$ & 7 & & $\mathrm{IIIb} / \mathrm{c}$ & $36 \mathrm{G}-18$ & Uniface, unanalyzed & 1 \\
\hline $\mathrm{E} 40 / \mathrm{S} 70$ & 7 & & $\mathrm{IIIb} / \mathrm{c}$ & $36 \mathrm{G}-21$ & Uniface, unanalyzed & 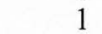 \\
\hline $\mathrm{E} 40 / \mathrm{S} 70$ & 7 & & $\mathrm{IIIb} / \mathrm{c}$ & $36 \mathrm{G}-19$ & Uniface, unanalyzed & 1 \\
\hline $\mathrm{E} 40 / \mathrm{S} 70$ & 7 & & $\mathrm{IIIb} / \mathrm{c}$ & $36 \mathrm{G}-15$ & Uniface, unanalyzed & 1 \\
\hline $\mathrm{E} 40 / \mathrm{S} 70$ & 7 & & $\mathrm{IIIb} / \mathrm{c}$ & $36 \mathrm{G}-14$ & Uniface, unanalyzed & 1 \\
\hline $\mathrm{E} 40 / \mathrm{S} 70$ & 7 & & $\mathrm{IIIb} / \mathrm{c}$ & $36 \mathrm{G}-12$ & Uniface, unanalyzed & 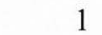 \\
\hline $\mathrm{E} 40 / \mathrm{S} 70$ & 7 & & $\mathrm{IIIb} / \mathrm{c}$ & $36 \mathrm{G}-16$ & Uniface, unanalyzed & 1 \\
\hline $\mathrm{E} 40 / \mathrm{S} 70$ & 7 & & $\mathrm{IIIb} / \mathrm{c}$ & $36 \mathrm{G}-20$ & Uniface, unanalyzed & 1 \\
\hline $\mathrm{E} 40 / \mathrm{S} 70$ & 7 & & $\mathrm{IIIb} / \mathrm{c}$ & 36G-11 & Unifacial multiple tool & 1 \\
\hline $\mathrm{E} 40 / \mathrm{S} 70$ & 7 & & $\mathrm{IIIb} / \mathrm{c}$ & $36 \mathrm{G}-6$ & Unifacial multiple tool & 1 \\
\hline $\mathrm{E} 40 / \mathrm{S} 70$ & 7 & & $\mathrm{IIIb} / \mathrm{c}$ & $36 \mathrm{G}-8$ & Unifacial multiple tool & 1 \\
\hline $\mathrm{E} 40 / \mathrm{S} 70$ & 8 & & $\mathrm{IIIb} / \mathrm{c}$ & $36 \mathrm{H}-4$ & Biface fragment & 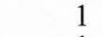 \\
\hline $\mathrm{E} 40 / \mathrm{S} 70$ & 8 & & $\mathrm{IIIb} / \mathrm{c}$ & $36 \mathrm{H}-2$ & Biface Stage 2 & 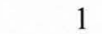 \\
\hline $\mathrm{E} 40 / \mathrm{S} 70$ & 8 & & $\mathrm{IIIb} / \mathrm{c}$ & $36 \mathrm{H}-3$ & Biface Stage 2 & 1 \\
\hline $\mathrm{E} 40 / \mathrm{S} 70$ & 8 & & $\mathrm{IIIb} / \mathrm{c}$ & & Debitage & 278 \\
\hline $\mathrm{E} 40 / \mathrm{S} 70$ & 8 & & $\mathrm{IIIb} / \mathrm{c}$ & $36 \mathrm{H}-6$ & Edge modified flake & - \\
\hline $\mathrm{E} 40 / \mathrm{S} 70$ & 8 & & $\mathrm{IIIb} / \mathrm{c}$ & $36 \mathrm{H}-5$ & Notched flake & 1 \\
\hline $\mathrm{E} 40 / \mathrm{S} 70$ & 8 & & $\mathrm{IIIb} / \mathrm{c}$ & $36 \mathrm{H}-8$ & Projectile point fragment & 1 \\
\hline $\mathrm{E} 40 / \mathrm{S} 70$ & 8 & & $\mathrm{IIIb} / \mathrm{c}$ & $36 \mathrm{H}-7$ & Projectile point, expanding stem A & 1 \\
\hline $\mathrm{E} 40 / \mathrm{S} 70$ & 8 & & $\mathrm{IIIb} / \mathrm{c}$ & $36 \mathrm{H}-1$ & Projectile point, Travis & 1 \\
\hline $\mathrm{E} 40 / \mathrm{S} 70$ & 8 & & $\mathrm{IIIb} / \mathrm{c}$ & $36 \mathrm{H}-12$ & Uniface, unanalyzed & 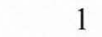 \\
\hline $\mathrm{E} 40 / \mathrm{S} 70$ & 8 & & $\mathrm{IIIb} / \mathrm{c}$ & $36 \mathrm{H}-9$ & Uniface, unanalyzed & 1 \\
\hline $\mathrm{E} 40 / \mathrm{S} 70$ & 9 & & $\mathrm{IIIb} / \mathrm{c}$ & $36 \mathrm{I}-3$ & Biface fragment & 1 \\
\hline $\mathrm{E} 40 / \mathrm{S} 70$ & 9 & & $\mathrm{IIIb} / \mathrm{c}$ & $36 \mathrm{I}-5$ & Biface Stage 1 & 1 \\
\hline $\mathrm{E} 40 / \mathrm{S} 70$ & 9 & & $\mathrm{IIIb} / \mathrm{c}$ & $36 \mathrm{I}-6$ & Bifacial tool Form A & 1 \\
\hline $\mathrm{E} 40 / \mathrm{S} 70$ & 9 & & $\mathrm{IIIb} / \mathrm{c}$ & & Debitage & 1143 \\
\hline $\mathrm{E} 40 / \mathrm{S} 70$ & 9 & & $\mathrm{IIIb} / \mathrm{c}$ & $36 \mathrm{I}-10$ & Perforator Group 5 & 1 \\
\hline $\mathrm{E} 40 / \mathrm{S} 70$ & 9 & & $\mathrm{IIIb} / \mathrm{c}$ & $36 \mathrm{I}-4$ & Piece esquillee & 1 \\
\hline $\mathrm{E} 40 / \mathrm{S} 70$ & 9 & & $\mathrm{IIIb} / \mathrm{c}$ & $36 \mathrm{I}-1$ & Projectile point fragment & 1 \\
\hline $\mathrm{E} 40 / \mathrm{S} 70$ & 9 & & $\mathrm{IIIb} / \mathrm{c}$ & $36 \mathrm{I}-2$ & Projectile point, expanding stem D & 1 \\
\hline $\mathrm{E} 40 / \mathrm{S} 70$ & 9 & & $\mathrm{IIIb} / \mathrm{c}$ & $36 \mathrm{I}-7$ & Uniface, unanalyzed & 1 \\
\hline $\mathrm{E} 40 / \mathrm{S} 70$ & 9 & & $\mathrm{IIIb} / \mathrm{c}$ & $36 \mathrm{I}-9$ & Unifacial multiple tool & 1 \\
\hline $\mathrm{E} 40 / \mathrm{S} 70$ & 10 & & IIIb & $36 \mathrm{~J}-3$ & Biface fragment & 1 \\
\hline $\mathrm{E} 40 / \mathrm{S} 70$ & 10 & & IIIb & $36 \mathrm{~J}-5$ & Biface fragment & 1 \\
\hline $\mathrm{E} 40 / \mathrm{S} 70$ & 10 & & IIIb & $36 \mathrm{~J}-4$ & Biface fragment & 1 \\
\hline $\mathrm{E} 40 / \mathrm{S} 70$ & 10 & & IIIb & $36 \mathrm{~J}-2$ & Biface Stage 3 & 1 \\
\hline $\mathrm{E} 40 / \mathrm{S} 70$ & 10 & & IIIb & & Debitage & 1387 \\
\hline $\mathrm{E} 40 / \mathrm{S} 70$ & 10 & & IIIb & $36 \mathrm{~J}-12$ & Microspur/microdenticulate & 1 \\
\hline $\mathrm{E} 40 / \mathrm{S} 70$ & 10 & & IIIb & $36 \mathrm{~J}-1$ & Projectile point, Martindale B & 1 \\
\hline $\mathrm{E} 40 / \mathrm{S} 70$ & 10 & & IIIb & $36 \mathrm{~J}-7$ & Thin uniface fragment & 1 \\
\hline $\mathrm{E} 40 / \mathrm{S} 70$ & 10 & & IIIb & $36 \mathrm{~J}-13$ & Uniface, unanalyzed & 1 \\
\hline $\mathrm{E} 40 / \mathrm{S} 70$ & 10 & & IIIb & $36 \mathrm{~J}-9$ & Uniface, unanalyzed & 1 \\
\hline $\mathrm{E} 40 / \mathrm{S} 70$ & 10 & & IIIb & $36 \mathrm{~J}-8$ & Uniface, unanalyzed & 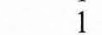 \\
\hline $\mathrm{E} 40 / \mathrm{S} 70$ & 10 & & IIIb & $36 \mathrm{~J}-10$ & Uniface, unanalyzed & 1 \\
\hline $\mathrm{E} 40 / \mathrm{S} 70$ & 10 & & IIIb & $36 \mathrm{~J}-11$ & Uniface, unanalyzed & 1 \\
\hline $\mathrm{E} 40 / \mathrm{S} 70$ & 10 & & IIIb & $36 \mathrm{~J}-14$ & Unifacial multiple tool & 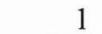 \\
\hline $\mathrm{E} 40 / \mathrm{S} 70$ & 11 & & IIIb & & Debitage & 646 \\
\hline $\mathrm{E} 40 / \mathrm{S} 70$ & 11 & & IIIb & $36 \mathrm{~K}-3$ & Uniface, unanalyzed & 1 \\
\hline $\mathrm{E} 40 / \mathrm{S} 70$ & 11 & & IIIb & $36 \mathrm{~K}-5$ & Uniface, unanalyzed & 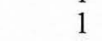 \\
\hline $\mathrm{E} 40 / \mathrm{S} 70$ & 12 & & $\mathrm{IIIa} / \mathrm{b}$ & $36 \mathrm{~L}-1$ & Biface fragment & 1 \\
\hline $\mathrm{E} 40 / \mathrm{S} 70$ & 12 & & $\mathrm{IIIa} / \mathrm{b}$ & $36 \mathrm{~L}-3$ & Biface fragment & 1 \\
\hline $\mathrm{E} 40 / \mathrm{S} 70$ & 12 & & $\mathrm{IIIa} / \mathrm{b}$ & $36 \mathrm{~L}-2$ & Biface fragment & 1 \\
\hline $\mathrm{E} 40 / \mathrm{S} 70$ & 12 & & $\mathrm{IIIa} / \mathrm{b}$ & & Debitage & 593 \\
\hline $\mathrm{E} 40 / \mathrm{S} 70$ & 12 & & $\mathrm{IIIa} / \mathrm{b}$ & $36 \mathrm{~L}-4$ & Perforator Unifacial & . \\
\hline $\mathrm{E} 40 / \mathrm{S} 70$ & 12 & & $\mathrm{IIIa} / \mathrm{b}$ & $36 \mathrm{~L}-10$ & Retouched blade & 1 \\
\hline $\mathrm{E} 40 / \mathrm{S} 70$ & 12 & & $\mathrm{IIIa} / \mathrm{b}$ & $36 \mathrm{~L}-5$ & Uniface, unanalyzed & 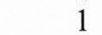 \\
\hline $\mathrm{E} 40 / \mathrm{S} 70$ & 12 & & $\mathrm{IIIa} / \mathrm{b}$ & $36 \mathrm{~L}-8$ & Uniface, unanalyzed & 1 \\
\hline $\mathrm{E} 40 / \mathrm{S} 70$ & 13 & & IIIa & $36 \mathrm{M}-5$ & Biface Stage 2 & 1 \\
\hline $\mathrm{E} 40 / \mathrm{S} 70$ & 13 & & IIIa & $36 \mathrm{M}-4$ & Biface Stage 3 & 1 \\
\hline $\mathrm{E} 40 / \mathrm{S} 70$ & 13 & & IIIa & & Debitage & 964 \\
\hline $\mathrm{E} 40 / \mathrm{S} 70$ & 13 & & IIIa & $36 \mathrm{M}-6$ & Edge modified flake & 1 \\
\hline $\mathrm{E} 40 / \mathrm{S} 70$ & 13 & & IIIa & $36 \mathrm{M}-8$ & Microspur/microdenticulate & 1 \\
\hline $\mathrm{E} 40 / \mathrm{S} 70$ & 13 & & IIIa & $36 \mathrm{M}-1$ & Projectile point, Angostura & 1 \\
\hline $\mathrm{E} 40 / \mathrm{S} 70$ & 13 & & IIIa & $36 \mathrm{M}-2$ & Projectile point, Baker & 1 \\
\hline $\mathrm{E} 40 / \mathrm{S} 70$ & 13 & & IIIa & $36 \mathrm{M}-3$ & Projectile point, Hoxie & 1 \\
\hline $\mathrm{E} 40 / \mathrm{S} 70$ & 13 & & IIIa & $36 \mathrm{M}-7$ & Uniface, unanalyzed & 1 \\
\hline $\mathrm{E} 40 / \mathrm{S} 70$ & 13 & & IIIa & $36 \mathrm{M}-9$ & Unifacial multiple tool & 1 \\
\hline
\end{tabular}




\begin{tabular}{|c|c|c|c|c|c|c|}
\hline Square & Level & Feature & Strata & Item & Analyst Identification & Count \\
\hline $\mathrm{E} 40 / \mathrm{S} 70$ & 13 & & IIIa & $36 \mathrm{M}-10$ & Worked hematite & \\
\hline $\mathrm{E} 40 / \mathrm{S} 70$ & 14 & & IIIa & $36 \mathrm{~N}-11$ & Biface fragment & \\
\hline $\mathrm{E} 40 / \mathrm{S} 70$ & 14 & & IIIa & $36 \mathrm{~N}-5$ & Biface Stage 2 & \\
\hline $\mathrm{E} 40 / \mathrm{S} 70$ & 14 & & IIIa & $36 \mathrm{~N}-6$ & Biface Stage 2 & \\
\hline $\mathrm{E} 40 / \mathrm{S} 70$ & 14 & & IIIa & $36 \mathrm{P}-5$ & Burin spall & \\
\hline $\mathrm{E} 40 / \mathrm{S} 70$ & 14 & & IIIa & $36 \mathrm{~N}-24$ & Burin spall & \\
\hline $\mathrm{E} 40 / \mathrm{S} 70$ & 14 & & IIIa & $36 \mathrm{~N}-17$ & Burin spall & \\
\hline $\mathrm{E} 40 / \mathrm{S} 70$ & 14 & & IIIa & & Debitage & 2115 \\
\hline $\mathrm{E} 40 / \mathrm{S} 70$ & 14 & & IIIa & $36 \mathrm{~N}-10$ & Edge modified flake & \\
\hline $\mathrm{E} 40 / \mathrm{S} 70$ & 14 & & IIIa & $36 \mathrm{~N}-27$ & Mano fragment & \\
\hline $\mathrm{E} 40 / \mathrm{S} 70$ & 14 & & IIIa & $36 \mathrm{~N}-18$ & Microspur/microdenticulate & \\
\hline $\mathrm{E} 40 / \mathrm{S} 70$ & 14 & & IIIa & $36 \mathrm{~N}-15$ & Microspur/microdenticulate & \\
\hline $\mathrm{E} 40 / \mathrm{S} 70$ & 14 & & IIIa & $36 \mathrm{~N}-21$ & Microspur/microdenticulate & \\
\hline $\mathrm{E} 40 / \mathrm{S} 70$ & 14 & & IIIa & $36 \mathrm{~N}-7$ & Perforator Group 1 & \\
\hline $\mathrm{E} 40 / \mathrm{S} 70$ & 14 & & IIIa & $36 \mathrm{~N}-26$ & Perforator Group 7 & \\
\hline $\mathrm{E} 40 / \mathrm{S} 70$ & 14 & & IIIa & $36 \mathrm{~N}-28$ & Possible ground stone & \\
\hline $\mathrm{E} 40 / \mathrm{S} 70$ & 14 & & IIIa & $36 \mathrm{~N}-1$ & Projectile point fragment & \\
\hline $\mathrm{E} 40 / \mathrm{S} 70$ & 14 & & IIIa & $36 \mathrm{~N}-4$ & Projectile point, bifurcate stem fragment & \\
\hline $\mathrm{E} 40 / \mathrm{S} 70$ & 14 & & IIIa & $36 \mathrm{~N}-2$ & Projectile point, miscellaneous lanceolate & \\
\hline $\mathrm{E} 40 / \mathrm{S} 70$ & 14 & & IIIa & $36 \mathrm{~N}-3$ & Projectile point, miscellaneous lanceolate & \\
\hline $\mathrm{E} 40 / \mathrm{S} 70$ & 14 & & IIIa & $36 \mathrm{~N}-9$ & Thin uniface & \\
\hline $\mathrm{E} 40 / \mathrm{S} 70$ & 14 & & IIIa & $36 \mathrm{~N}-23$ & Thin uniface & \\
\hline $\mathrm{E} 40 / \mathrm{S} 70$ & 14 & & IIIa & $36 \mathrm{~N}-20$ & Thin uniface fragment & \\
\hline $\mathrm{E} 40 / \mathrm{S} 70$ & 14 & & IIIa & $36 \mathrm{~N}-19$ & Thin uniface fragment & \\
\hline $\mathrm{E} 40 / \mathrm{S} 70$ & 14 & & IIIa & $36 \mathrm{~N}-12$ & Uniface, unanalyzed & \\
\hline $\mathrm{E} 40 / \mathrm{S} 70$ & 14 & & IIIa & $36 \mathrm{~N}-16$ & Uniface, unanalyzed & \\
\hline $\mathrm{E} 40 / \mathrm{S} 70$ & 14 & & IIIa & $36 \mathrm{~N}-13$ & Uniface, unanalyzed & \\
\hline $\mathrm{E} 40 / \mathrm{S} 70$ & 14 & & IIIa & $36 \mathrm{~N}-22$ & Uniface, unanalyzed & \\
\hline $\mathrm{E} 40 / \mathrm{S} 70$ & 14 & & IIIa & $36 \mathrm{~N}-29$ & Worked hematite & \\
\hline $\mathrm{E} 40 / \mathrm{S} 70$ & 15 & & IIIa & $360-9$ & Biface fragment & \\
\hline $\mathrm{E} 40 / \mathrm{S} 70$ & 15 & & IIIa & $36 \mathrm{O}-4$ & Biface Stage 2 & \\
\hline $\mathrm{E} 40 / \mathrm{S} 70$ & 15 & & IIIIa & $360-3$ & Biface Stage 2 & \\
\hline $\mathrm{E} 40 / \mathrm{S} 70$ & 15 & & IIIa & $360-6$ & Burin spall & \\
\hline $\mathrm{E} 40 / \mathrm{S} 70$ & 15 & & IIIa & $360-7$ & Burin spall & \\
\hline $\mathrm{E} 40 / \mathrm{S} 70$ & 15 & & IIIa & $360-11$ & Clear Fork biface & \\
\hline $\mathrm{E} 40 / \mathrm{S} 70$ & 15 & & IIIa & $360-10$ & Core tool, type 1 & \\
\hline $\mathrm{E} 40 / \mathrm{S} 70$ & 15 & & IIIa & & Debitage & 1727 \\
\hline $\mathrm{E} 40 / \mathrm{S} 70$ & 15 & & IIIa & $360-16$ & Edge modified flake & \\
\hline $\mathrm{E} 40 / \mathrm{S} 70$ & 15 & & IIIa & $360-15$ & Edge modified flake & \\
\hline $\mathrm{E} 40 / \mathrm{S} 70$ & 15 & & IIIa & $360-12$ & Edge modified flake & \\
\hline $\mathrm{E} 40 / \mathrm{S} 70$ & 15 & & IIIa & $360-13$ & Perforator Unifacial & \\
\hline $\mathrm{E} 40 / \mathrm{S} 70$ & 15 & & IIIa & $360-5$ & Projectile point fragment & \\
\hline $\mathrm{E} 40 / \mathrm{S} 70$ & 15 & & IIIa & $360-1$ & Projectile point, Hoxie B & \\
\hline $\mathrm{E} 40 / \mathrm{S} 70$ & 15 & & IIIa & $360-8$ & Thin uniface fragment & \\
\hline $\mathrm{E} 40 / \mathrm{S} 70$ & 15 & & IIIIa & $360-18$ & Uniface, unanalyzed & \\
\hline $\mathrm{E} 40 / \mathrm{S} 70$ & 15 & & IIIa & $360-14$ & Uniface, unanalyzed & \\
\hline $\mathrm{E} 40 / \mathrm{S} 70$ & 15 & & IIIa & $360-21$ & Unifacial multiple tool & \\
\hline $\mathrm{E} 40 / \mathrm{S} 70$ & 16 & & IIIa & $36 \mathrm{P}-11$ & Biface fragment & \\
\hline $\mathrm{E} 40 / \mathrm{S} 70$ & 16 & & IIIa & $36 \mathrm{P}-12$ & Biface fragment & \\
\hline $\mathrm{E} 40 / \mathrm{S} 70$ & 16 & & IIIa & $36 \mathrm{P}-6$ & Burin spall & \\
\hline $\mathrm{E} 40 / \mathrm{S} 70$ & 16 & & IIIa & $36 \mathrm{P}-7$ & Clear Fork biface & \\
\hline $\mathrm{E} 40 / \mathrm{S} 70$ & 16 & & IIIa & & Debitage & 654 \\
\hline $\mathrm{E} 40 / \mathrm{S} 70$ & 16 & & IIIa & $36 \mathrm{P}-1$ & Projectile point, miscellaneous lanceolate & \\
\hline $\mathrm{E} 40 / \mathrm{S} 70$ & 16 & & IIIa & $36 \mathrm{P}-13$ & Thin uniface fragment & \\
\hline $\mathrm{E} 40 / \mathrm{S} 70$ & 16 & & IIIIa & $36 \mathrm{P}-8$ & Uniface, unanalyzed & \\
\hline $\mathrm{E} 40 / \mathrm{S} 70$ & 16 & & IIIa & $36 \mathrm{P}-9$ & Uniface, unanalyzed & \\
\hline $\mathrm{E} 40 / \mathrm{S} 70$ & 16 & & IIIa & $36 \mathrm{P}-10$ & Uniface, unanalyzed & \\
\hline $\mathrm{E} 40 / \mathrm{S} 70$ & 16 & & IIIa & $36 \mathrm{P}-2$ & Waco sinker & \\
\hline $\mathrm{E} 40 / \mathrm{S} 70$ & 17 & & IIIa & $36 Q-7$ & Biface fragment & \\
\hline $\mathrm{E} 40 / \mathrm{S} 70$ & 17 & & IIIa & $36 Q-4$ & Biface Stage 1 & \\
\hline $\mathrm{E} 40 / \mathrm{S} 70$ & 17 & & IIIa & $36 \mathrm{Q}-6$ & Core fragment & \\
\hline $\mathrm{E} 40 / \mathrm{S} 70$ & 17 & & IIIa & & Debitage & 487 \\
\hline $\mathrm{E} 40 / \mathrm{S} 70$ & 17 & & IIIa & $36 Q-9$ & Microspur/microdenticulate & \\
\hline $\mathrm{E} 40 / \mathrm{S} 70$ & 17 & & IIIa & $36 \mathrm{Q}-1$ & Microspur/microdenticulate & \\
\hline $\mathrm{E} 40 / \mathrm{S} 70$ & 17 & & IIIa & $36 \mathrm{Q}-10$ & Thin uniface fragment & \\
\hline $\mathrm{E} 40 / \mathrm{S} 70$ & 17 & & IIIa & $36 \mathrm{Q}-2$ & Uniface, unanalyzed & \\
\hline $\mathrm{E} 40 / \mathrm{S} 70$ & 17 & & IIIa & $36 \mathrm{Q}-3$ & Uniface, unanalyzed & \\
\hline $\mathrm{E} 40 / \mathrm{S} 70$ & 17 & & IIIa & $36 Q-5$ & Uniface, unanalyzed & \\
\hline $\mathrm{E} 40 / \mathrm{S} 70$ & 18 & & II/IIIa & $36 \mathrm{R}-4$ & Biface fragment & \\
\hline $\mathrm{E} 40 / \mathrm{S} 70$ & 18 & & II/IIIa & $36 \mathrm{R}-5$ & Biface fragment & \\
\hline $\mathrm{E} 40 / \mathrm{S} 70$ & 18 & & II/IIIa & $36 \mathrm{R}-2$ & Biface Stage 2 & \\
\hline $\mathrm{E} 40 / \mathrm{S} 70$ & 18 & & II/IIIa & $36 \mathrm{R}-3$ & Biface Stage 3 & \\
\hline $\mathrm{E} 40 / \mathrm{S} 70$ & 18 & & II/IIIa & & Debitage & 476 \\
\hline $\mathrm{E} 40 / \mathrm{S} 70$ & 18 & & II/IIIa & $36 \mathrm{R}-11$ & Denticulated flake & \\
\hline
\end{tabular}




\begin{tabular}{|c|c|c|c|c|c|c|}
\hline Square & Level & Feature & Strata & Item & Analyst Identification & Count \\
\hline $\mathrm{E} 40 / \mathrm{S} 70$ & 18 & & II/IIIa & $36 \mathrm{R}-9$ & Projectile point, miscellaneous lanceolate & 1 \\
\hline $\mathrm{E} 40 / \mathrm{S} 70$ & 18 & & II/IIIa & 36R-1 & Projectile point, St. Mary’s Hall & 1 \\
\hline $\mathrm{E} 40 / \mathrm{S} 70$ & 18 & & II/IIIa & $36 \mathrm{R}-8$ & Uniface, unanalyzed & 1 \\
\hline $\mathrm{E} 40 / \mathrm{S} 70$ & 18 & & II/IIIa & $36 \mathrm{R}-6$ & Uniface, unanalyzed & 1 \\
\hline $\mathrm{E} 40 / \mathrm{S} 70$ & 18 & & II/IIIa & $36 \mathrm{R}-7$ & Uniface, unanalyzed & 1 \\
\hline $\mathrm{E} 40 / \mathrm{S} 70$ & 18 & & II/IIIa & $36 \mathrm{R}-12$ & Unifacial multiple tool & 1 \\
\hline $\mathrm{E} 40 / \mathrm{S} 70$ & 19 & & II/IIIa & $36 \mathrm{~S}-1$ & Biface Stage 2 & 1 \\
\hline $\mathrm{E} 40 / \mathrm{S} 70$ & 19 & & II/IIIa & $36 \mathrm{~S}-2$ & Biface Stage 2 & 1 \\
\hline $\mathrm{E} 40 / \mathrm{S} 70$ & 19 & & II/IIIa & & Debitage & 230 \\
\hline $\mathrm{E} 40 / \mathrm{S} 70$ & 19 & & II/IIIa & $36 \mathrm{~S}-3$ & Perforator Group 4 & 1 \\
\hline $\mathrm{E} 40 / \mathrm{S} 70$ & 19 & & II/IIIa & $36 \mathrm{~S}-4$ & Thin uniface & 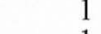 \\
\hline $\mathrm{E} 40 / \mathrm{S} 70$ & 19 & & II/IIIa & $36 \mathrm{~S}-8$ & Uniface, unanalyzed & 1 \\
\hline $\mathrm{E} 40 / \mathrm{S} 70$ & 19 & & II/IIIa & $36 \mathrm{~S}-5$ & Uniface, unanalyzed & 1 \\
\hline $\mathrm{E} 40 / \mathrm{S} 70$ & 20 & & II/IIIa & & Debitage & 147 \\
\hline $\mathrm{E} 40 / \mathrm{S} 70$ & 20 & & II/IIIa & $36 \mathrm{~T}-5$ & Thin uniface & 1 \\
\hline $\mathrm{E} 40 / \mathrm{S} 70$ & 20 & & II/IIIa & $36 \mathrm{~T}-3$ & Uniface, unanalyzed & 1 \\
\hline $\mathrm{E} 40 / \mathrm{S} 70$ & 20 & & II/IIIa & $36 \mathrm{~T}-1$ & Uniface, unanalyzed & 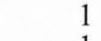 \\
\hline $\mathrm{E} 40 / \mathrm{S} 70$ & 20 & & II/IIIa & $36 \mathrm{~T}-2$ & Unifacial multiple tool & 1 \\
\hline $\mathrm{E} 40 / \mathrm{S} 70$ & 21 & & II & & Debitage & 93 \\
\hline $\mathrm{E} 40 / \mathrm{S} 70$ & 22 & & $\mathrm{I} / \mathrm{II}$ & & Debitage & 58 \\
\hline $\mathrm{E} 40 / \mathrm{S} 70$ & 22 & & $\mathrm{I} / \mathrm{II}$ & $36 \mathrm{~V}-1$ & Thin uniface & 1 \\
\hline $\mathrm{E} 40 / \mathrm{S} 70$ & 23 & & I & & Debitage & 27 \\
\hline $\mathrm{E} 40 / \mathrm{S} 70$ & 23 & & I & $36 \mathrm{~W}-1$ & Mano & 1 \\
\hline $\mathrm{E} 40 / \mathrm{S} 70$ & 23 & Feature 154 & I & & Debitage & 3 \\
\hline E40/S70 & 24 & & I & & Debitage & 17 \\
\hline E40/S70 & 24 & & I & $36 \mathrm{X}-1$ & Uniface, unanalyzed & 1 \\
\hline $\mathrm{E} 40 / \mathrm{S} 70$ & 24 & Feature 154 & I & & Debitage & 11 \\
\hline $\mathrm{E} 40 / \mathrm{S} 70$ & 25 & & I & & Debitage & 11 \\
\hline $\mathrm{E} 40 / \mathrm{S} 70$ & 25 & Feature 154 & I & & Debitage & \\
\hline $\mathrm{E} 40 / \mathrm{S} 70$ & 26 & & I & & Debitage & 5 \\
\hline $\mathrm{E} 40 / \mathrm{S} 70$ & 26 & Feature 154 & I & & Debitage & 1 \\
\hline $\mathrm{E} 40 / \mathrm{S} 70$ & 27 & & I & & Debitage & 1 \\
\hline $\mathrm{E} 40 / \mathrm{S} 70$ & 28 & & I & $36 \mathrm{BBD}-1$ & Biface Stage 1 & 1 \\
\hline $\mathrm{E} 40 / \mathrm{S} 70$ & 28 & & I & & Debitage & 12 \\
\hline $\mathrm{E} 40 / \mathrm{S} 70$ & 29 & & I & & Debitage & 7 \\
\hline $\mathrm{E} 40 / \mathrm{S} 70$ & $30 \mathrm{~A}-\mathrm{B}$ & & I & & Debitage & 2 \\
\hline $\mathrm{E} 40 / \mathrm{S} 70$ & 31A-B & & I & & Debitage & $?$ \\
\hline $\mathrm{E} 40 / \mathrm{S} 70$ & $31 \mathrm{~A}-\mathrm{B}$ & & I & $36 \mathrm{EE} 1 \& 2 \mathrm{D}-1$ & Uniface, unanalyzed & 1 \\
\hline $\mathrm{E} 40 / \mathrm{S} 70$ & 34 & & I & & Debitage & 3 \\
\hline $\mathrm{E} 40 / \mathrm{S} 70$ & 38 & & I & & Debitage & 3 \\
\hline $\mathrm{E} 40 / \mathrm{S} 70$ & 39 & & I & & Debitage & $?$ \\
\hline $\mathrm{E} 40 / \mathrm{S} 70$ & Unknown & & & $36 *-15$ & Biface fragment & 1 \\
\hline $\mathrm{E} 40 / \mathrm{S} 70$ & Unknown & & & $36 *-7$ & Biface fragment & 1 \\
\hline $\mathrm{E} 40 / \mathrm{S} 70$ & Unknown & & & $36^{*}-6$ & Biface fragment & 1 \\
\hline $\mathrm{E} 40 / \mathrm{S} 70$ & Unknown & & & $36 *-10$ & Biface Stage 1 & 1 \\
\hline $\mathrm{E} 40 / \mathrm{S} 70$ & Unknown & & & $36 *-4$ & Biface Stage 2 & 1 \\
\hline $\mathrm{E} 40 / \mathrm{S} 70$ & Unknown & & & $36^{*}-5$ & Biface Stage 2 & 1 \\
\hline $\mathrm{E} 40 / \mathrm{S} 70$ & Unknown & & & $36^{*}-9$ & Biface Stage 2 & 1 \\
\hline $\mathrm{E} 40 / \mathrm{S} 70$ & Unknown & & & $36^{*}-3$ & Biface Stage 3 & 1 \\
\hline $\mathrm{E} 40 / \mathrm{S} 70$ & Unknown & & & $36 *-11$ & Burin spall & 1 \\
\hline $\mathrm{E} 40 / \mathrm{S} 70$ & Unknown & & & $36^{*}-1$ & Mano & 1 \\
\hline $\mathrm{E} 40 / \mathrm{S} 70$ & Unknown & & & $36^{*}-2$ & Mano fragment & 1 \\
\hline E40/S70 & Unknown & & & $36^{*}-12$ & Projectile point fragment & 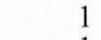 \\
\hline $\mathrm{E} 40 / \mathrm{S} 70$ & Unknown & & & $36^{*}-17$ & Projectile point, Bulverde & 1 \\
\hline $\mathrm{E} 40 / \mathrm{S} 70$ & Unknown & & & $36 *-18$ & Projectile point, Marcos & 1 \\
\hline $\mathrm{E} 40 / \mathrm{S} 70$ & Unknown & & & $36 *-19$ & Projectile point, Marcos & 1 \\
\hline $\mathrm{E} 40 / \mathrm{S} 70$ & Unknown & & & $36^{*}-23$ & Projectile point, Montell & 1 \\
\hline $\mathrm{E} 40 / \mathrm{S} 70$ & Unknown & & & $36^{*}-20$ & Projectile point, Nolan & 1 \\
\hline $\mathrm{E} 40 / \mathrm{S} 70$ & Unknown & & & $36^{*}-21$ & Projectile point, Pedernales & 1 \\
\hline $\mathrm{E} 40 / \mathrm{S} 70$ & Unknown & & & $36 *-14$ & Uniface, unanalyzed & 1 \\
\hline $\mathrm{E} 40 / \mathrm{S} 70$ & Unknown & & & $36^{*}-13$ & Uniface, unanalyzed & 1 \\
\hline $\mathrm{E} 40 / \mathrm{S} 70$ & Unknown & & & $36 *-16$ & Uniface, unanalyzed & 1 \\
\hline $\mathrm{E} 40 / \mathrm{S} 70$ & Unknown & & & $36^{*}-8$ & Unifacial multiple tool & 1 \\
\hline Test Pit 1 & 1 & & Unknown & TP1A-5 & Biface fragment & 1 \\
\hline Test Pit 1 & 1 & & Unknown & TP1A-1 & Biface fragment & 1 \\
\hline Test Pit 1 & 1 & & Unknown & & Debitage & 328 \\
\hline Test Pit 1 & 1 & & Unknown & TP1A-4 & Edge modified flake & \\
\hline Test Pit 1 & 1 & & Unknown & TP1A-2 & Edge modified flake & 1 \\
\hline Test Pit 1 & 1 & & Unknown & TP1A-3 & Edge modified flake & 1 \\
\hline Test Pit 1 & 2 & & Unknown & & Debitage & 79 \\
\hline Test Pit 1 & 3 & & Unknown & & Debitage & 16 \\
\hline Test Pit 1 & 5 & & Unknown & & Debitage & 17 \\
\hline Test Pit 1 & 6 & & Unknown & & Debitage & 10 \\
\hline Test Pit 1 & 6 & & Unknown & TP1F-1 & Edge modified flake & \\
\hline
\end{tabular}




\begin{tabular}{|c|c|c|c|c|c|c|}
\hline Square & Level & Feature & Strata & Item & Analyst Identification & Count \\
\hline Test Pit 1 & 7 & & Unknown & & Debitage & 44 \\
\hline Test Pit 1 & 7 & & Unknown & TP1G-1 & Edge modified flake & \\
\hline Test Pit 1 & 9 & & Unknown & & Debitage & 48 \\
\hline Test Pit 1 & 10 & & Unknown & & Debitage & 23 \\
\hline Test Pit 2 & 1 & & Unknown & & Debitage & 141 \\
\hline Test Pit 2 & 2 & & Unknown & TP2B-1 & Biface fragment & \\
\hline Test Pit 2 & 2 & & Unknown & & Debitage & 99 \\
\hline Test Pit 2 & 2 & & Unknown & TP2B-4 & Edge modified flake & 1 \\
\hline Test Pit 2 & 3 & & Unknown & & Debitage & 104 \\
\hline Test Pit 2 & 4 & & Unknown & & Debitage & 106 \\
\hline Test Pit 2 & 5 & & Unknown & & Debitage & 37 \\
\hline Test Pit 2 & 6 & & Unknown & & Debitage & 2 \\
\hline Test Pit 3 & 1 & & Unknown & & Debitage & 20 \\
\hline Test Pit 3 & 1 & & Unknown & TP3A-1 & Edge modified flake & \\
\hline Test Pit 3 & 2 & & Unknown & ТP3B-5 & Biface fragment & \\
\hline Test Pit 3 & 2 & & Unknown & TP3B-2 & Biface Stage 3 & 1 \\
\hline Test Pit 3 & 2 & & Unknown & & Debitage & 187 \\
\hline Test Pit 3 & 2 & & Unknown & ТР3В-3 & Edge modified flake & \\
\hline Test Pit 3 & 2 & & Unknown & TP3B-6 & Edge modified flake & \\
\hline Test Pit 3 & 2 & & Unknown & TP3B-1 & Projectile point, Ensor & \\
\hline Test Pit 3 & 3 & & Unknown & ТР $3 \mathrm{C}-9$ & Biface Stage 2 & 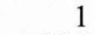 \\
\hline Test Pit 3 & 3 & & Unknown & & Debitage & 295 \\
\hline Test Pit 3 & 3 & & Unknown & TP3C-4 & Edge modified flake & \\
\hline Test Pit 3 & 3 & & Unknown & TP3C-2 & Edge modified flake & \\
\hline Test Pit 3 & 3 & & Unknown & TP3C-3 & Edge modified flake & 1 \\
\hline Test Pit 3 & 3 & & Unknown & TP3C-6 & Projectile point fragment & 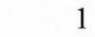 \\
\hline Test Pit 3 & 3 & & Unknown & TP3C-7 & Projectile point fragment & \\
\hline Test Pit 3 & 3 & & Unknown & TP3C-8 & Projectile point, Ensor/Fairland & \\
\hline Test Pit 3 & 4 & & Unknown & TP3D-4 & Biface Stage 2 & \\
\hline Test Pit 3 & 4 & & Unknown & & Debitage & 251 \\
\hline Test Pit 3 & 4 & & Unknown & TP3D-5 & Edge modified flake & \\
\hline Test Pit 3 & 4 & & Unknown & TP3D-3 & Projectile point fragment & \\
\hline Test Pit 3 & 4 & & Unknown & TP3D-1 & Projectile point, Ensor & \\
\hline Test Pit 3 & 4 & & Unknown & TP3D-2 & Projectile point, Fairland & 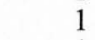 \\
\hline Test Pit 3 & 5 & & Unknown & TP3E-3 & Biface Stage 2 & , \\
\hline Test Pit 3 & 5 & & Unknown & TP3E-2 & Biface Stage 2 & 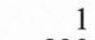 \\
\hline Test Pit 3 & 5 & & Unknown & & Debitage & 220 \\
\hline Test Pit 3 & 5 & & Unknown & TP3E-4 & Edge modified flake & 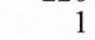 \\
\hline Test Pit 3 & 5 & & Unknown & TP3C-1 & Edge modified flake & 1 \\
\hline Test Pit 3 & 5 & & Unknown & TP3E-5 & Edge modified flake & \\
\hline Test Pit 3 & 5 & & Unknown & TP3E-7 & Mano & \\
\hline Test Pit 3 & 5 & & Unknown & TP3E-1 & Projectile point, Fairland & \\
\hline Test Pit 3 & 5 & & Unknown & TP3E-6 & Unifacial multiple tool & 1 \\
\hline Test Pit 3 & 6 & & Unknown & TP3F-2 & Biface Stage 3 & \\
\hline Test Pit 3 & 6 & & Unknown & & Debitage & 141 \\
\hline Test Pit 3 & 6 & & Unknown & TP3F-1 & Projectile point fragment & \\
\hline Test Pit 3 & 7 & & Unknown & & Debitage & 144 \\
\hline Test Pit 3 & 7 & & Unknown & TP3G-3 & Edge modified flake & \\
\hline Test Pit 3 & 7 & & Unknown & TP3G-2 & Edge modified flake & 1 \\
\hline Test Pit 3 & 7 & & Unknown & TP3G-4 & Edge modified flake & \\
\hline Test Pit 3 & 7 & & Unknown & TP3G-1 & Projectile point, indeterminate & \\
\hline Test Pit 3 & 8 & & Unknown & & Debitage & $5 \hat{5}$ \\
\hline Test Pit 3 & 8 & & Unknown & ТР3H-1 & Edge modified flake & \\
\hline Test Pit 3 & 9 & & Unknown & & Debitage & 2 \\
\hline Trench 1 & & & & TR1-127 & Projectile point, Nolan & \\
\hline Trench 2 & & Feature 172 & & TR2-62 & Projectile point, beveled narrow stemmed & \\
\hline Unknown & & & & $0-244$ & Perforator Group 7 & \\
\hline Unknown & & & & $0-143$ & Projectile point, Gower/Uvalde & \\
\hline Unknown & & & & $0-245$ & Worked hematite & \\
\hline Unknown & & Feature 104 & & & Debitage & 145 \\
\hline Unknown & & Feature 104 & & $0-164$ & Edge modified flake & \\
\hline
\end{tabular}


ISBN 1-887072-27-6 (Volume III)

ISBN 1-887072-24-1 (5 Volume Set) 